Bibliothek der Brandenburgischen und Preußischen Geschichte

Klaus Neitmann (Hrsg.)

\title{
Landesherr, Adel und Städte in der mittelalterlichen und frühneuzeitlichen Neumark
}
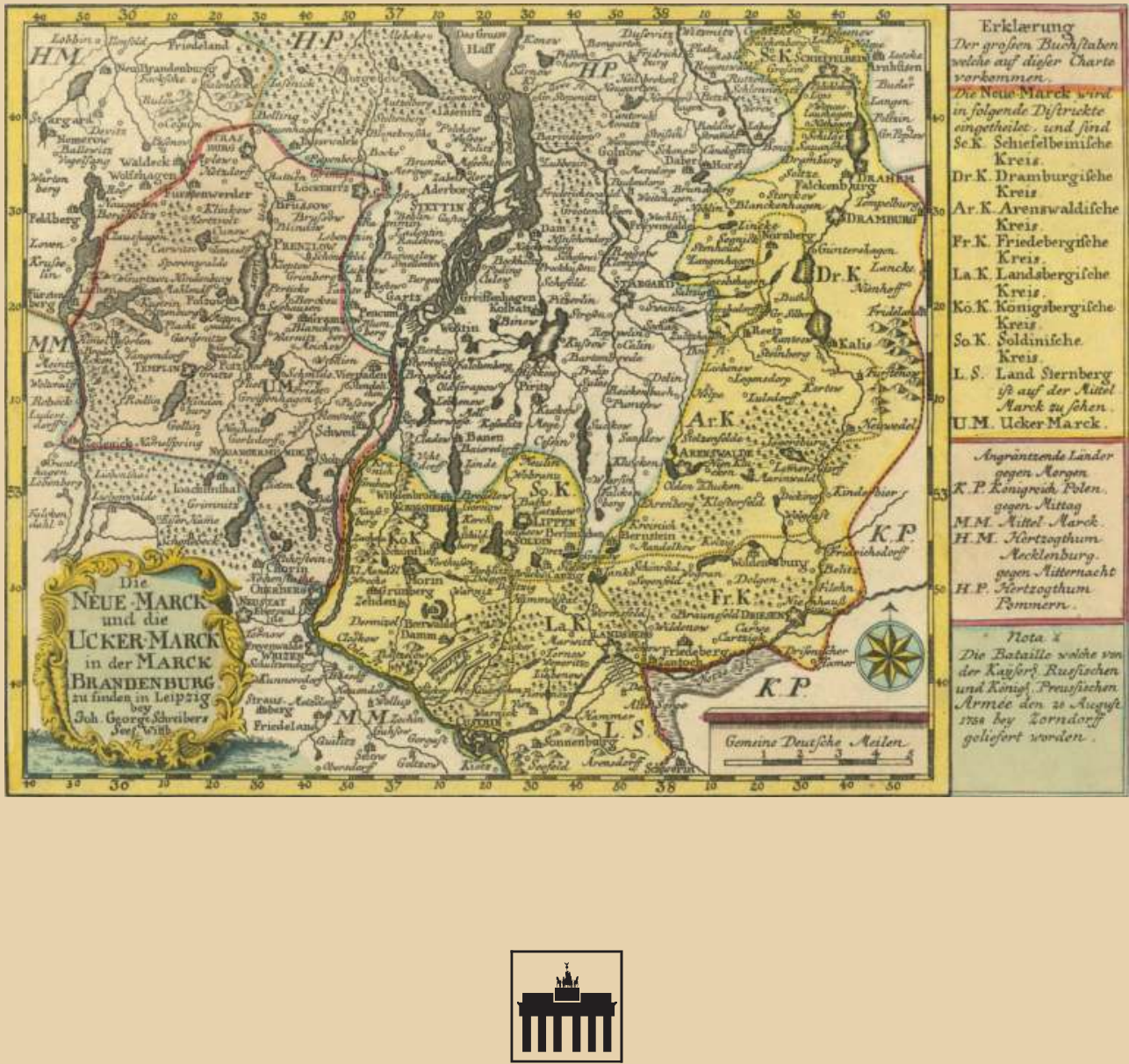

Klaus Neitmann (Hrsg.)

Landesherr, Adel und Städte

in der mittelalterlichen und frühneuzeitlichen Neumark 


\title{
BIBLIOTHEK DER BRANDENBURGISCHEN UND PREUSSISCHEN GESCHICHTE
}

\author{
Herausgegeben \\ im Auftrag des Brandenburgischen Landeshauptarchivs \\ und der Historischen Kommission zu Berlin \\ von Klaus Neitmann und Michael Wildt
}

Band 14 
Klaus Neitmann (Hrsg.)

\section{Landesherr, Adel und Städte in der mittelalterlichen und frühneuzeitlichen Neumark}

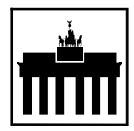

BWV • BERLINER WISSENSCHAFTS-VERLAG 


\section{Umschlagabbildung:}

Karte „Die Neue=Marck und die Ucker=Mark in der Marck Brandenburg“, verlegt bei Johann Georg Schreibers Witwe, Leipzig, nach 1758

(Brandenburgisches Landeshauptarchiv, Allgemeine Kartensammlung, Nr. 844 C).

Bibliografische Informationen der Deutschen Nationalbibliothek

Die Deutsche Nationalbibliothek verzeichnet diese Publikation in der Deutschen

Nationalbibliografie; detaillierte bibliografische Daten sind im Internet über http://dnb.d-nb.de abrufbar.

ISBN 978-3-8305-3029-9

(C) 2015

BWV・BERLINER WISSENSCHAFTS-VERLAG GmbH

Markgrafenstraße 12-14, 10969 Berlin

E-Mail: bwv@bwv-verlag.de, Internet: http://www.bwv-verlag.de

Printed in Germany. Alle Rechte, auch die des Nachdrucks von Auszügen, der fotomechanischen

Wiedergabe und der Übersetzung, vorbehalten. 


\section{Inhalt}

Vorwort

Klaus Neitmann

Zur Einführung: der ständische Regionalismus

der brandenburgischen Neumark

KLAUS NeITMANN

Die mittelalterliche Besiedlung der unteren Wartheregion

(in der ehemaligen Neumark bzw. der heutigen Wojewodschaft

Zachodnio-Pomorskie, Lubuskie und Wielkopolskie).

Eine deutsch-polnische Fallstudie anhand archäologischer Forschungen

ARMin VOLKMANN

bei der Beurteilung der

Peter Neumeister

Zur Herkunft und Zusammensetzung des neumärkischen Adels

bis zur Mitte des 14. Jahrhunderts

Christian Gahlbeck

Von Frankfurt an der Oder nach Landsberg an der Warthe.

Die Anfänge der markgräflichen Städtegründungen in der Neumark

unter Johann I. und Otto III.

WINFRIED SCHICH

Die Stadt Königsberg (Neumark) als agrarisches Zentrum

im späten Mittelalter

FeLIX EsCHER

Ein Ritterwappen auf dem Stadtsiegel oder über die Anfänge

von Bernstein (Pelczyce) und Bärwalde (Mieszkowice)

Ewa SysKa 
Die Städte und der Deutsche Orden in der Neumark und in Preußen

Roman Czaja

Huldigung und Privilegienbestätigung.

Die Ausbildung der landständischen Verfassung der Neumark

unter der Herrschaft des Deutschen Ordens und der frühen Hohenzollern

Klaus NeitmanN

Die Vögte des Deutschen Ordens in der Neumark

und ihr Verhältnis zu Preußen

BERNHART JÄHNIG

Festungsbau und Herrschaftspraxis.

Die Umstrukturierung des neumärkischen Territoriums

durch Markgraf Johann von Küstrin im 16. Jahrhundert

Ralf Gebuhr

Zwischen Resistenz und Anpassung: Die neumärkische Adelsgesellschaft von der Mitte des 16. bis zum frühen 18. Jahrhundert

FRANK GöSE

Handel und Gewerbe der Neumark in friderizianischer Zeit.

Entwicklungsprozesse, Standorte, soziale Träger

Rolf Straubel

Inschriften in der Neumark

JOACHIM ZDRENKA

Das Haus Brandenburg. Geschichte und Wirksamkeit

Werner Vogel 


\section{Vorwort}

Die brandenburgische Neumark hat immer im Windschatten der Geschichte gestanden. So ist der Historiker geneigt zu denken, wenn er einen Blick auf sie wirft, und er meint damit Doppeltes: Das Land und seine Menschen haben nie den großen Gang der brandenburgischen und deutschen Geschichte entscheidend beeinflußt oder gar bestimmt, und von der Historiographie sind sie in deren Erinnerungs- und Forschungsarbeit recht stiefmütterlich behandelt worden. Die moderne brandenburgische Landesgeschichtsschreibung hat ihnen seit dem frühen 19. Jahrhundert infolge ihrer Konzentration auf die Mark Brandenburg im Ganzen und deren Dynastien wenig Aufmerksamkeit gewidmet und sie in ihren Untersuchungen nur sporadisch berücksichtigt, nur einzelne Forscher haben sich ihnen eindringlich mit umfassenden Studien zugewandt. Besonders wertvolle Leistungen sind vom Verein für Geschichte der Neumark, von seinen Mitgliedern und von seinem Umfeld in der Zeit zwischen seiner Gründung 1890 und seinem Untergang 1945 in seiner Zeitschrift und in seinen Schriftenreihen erbracht worden, die in der Dichte ihrer Darstellungen und in der Kenntnis der Quellen und des Stoffes unübertroffen geblieben sind. Die Vertreibung der ansässigen Deutschen aus ihrer Heimat 1945 beraubte die neumärkische Geschichtsforschung der wichtigsten Grundlage, der gerade eine Landeshistoriographie bedarf, der Verankerung im Lande selber durch die dort lebenden und in seinen Institutionen und Gesellschaften wirkenden Forscher. Die neumärkische Geschichtsschreibung ist mit dem Tode ihrer letzten noch im Lande selbst geborenen und aufgewachsenen Vertreter nach dem Ende der Nachkriegszeit weitgehend zum Erliegen gekommen, und seitdem gibt es nur noch wenige brandenburgische Landeshistoriker, die sich ihrem Banner verschrieben haben oder die sie auch nur gelegentlich streifen. Die polnische Geschichtswissenschaft ist in den vergangenen 70 Jahren in die dadurch entstandene Lücke nur teilweise eingetreten, da es auch in der neuen polnischen Wissenschaftsorganisation an akademischen Einrichtungen mit Konzentration auf die historische Neumark weitgehend fehlt und zudem lange Zeit die Ideologie von den „wiedergewonnenen“ polnischen Westgebieten ihre unbefangene Untersuchung verstellte. In der jüngeren Vergangenheit hat das Interesse an der deutschen Vergangenheit des heutigen Lebuser Landes spürbar zugenommen und etwa in einem vom Staatsarchiv in Gorzów Wielkopolski (Landsberg/ Warthe) herausgegebenen regionalgeschichtlichen Jahrbuch seinen Ausdruck gefunden.

Auf deutscher Seite ist im letzten Vierteljahrhundert die Beschäftigung mit den einzelnen brandenburgischen Landschaften deutlich intensiviert worden und hat neben der Breite der verschiedenartigen Ansätze in den bedeutenden Landschaftsgeschichten der Uckermark, der Prignitz und der Altmark aus der Feder von Dr. Lieselott Enders ihre bisherigen Höhepunkte gefunden. Es lag daher für den Unterzeichnenden nahe, im Rahmen der Bemühungen des Brandenburgischen Landeshauptarchivs um die überkommenen historischen Bestandteile Brandenburgs die Neumark in seine Absichten einzubeziehen und sie zum Gegenstand eines größeren Tagungsvorhabens zu machen. Er fand für seine 
Erwägungen aufgeschlossene und geneigte Partner in der Historischen Kommission zu Berlin, die gemäß ihrer Aufgabe zur Erforschung und Darstellung der Geschichte Berlins, Brandenburgs und Preußens die Regionen Brandenburgs in ihr Arbeitsprogramm aufnahm, und im Haus Brandenburg der Stiftung Brandenburg in Fürstenwalde, das sich der kulturellen und wissenschaftlichen Pflege der einst ostbrandenburgischen Gebiete östlich von Oder und Neiße angenommen hat. Der Unterzeichnende erfreute sich dabei insbesondere der tatkräftigen Unterstützung des Institutes für Geschichtswissenschaft der Humboldt-Universität zu Berlin und seines Lehrstuhlinhabers für Landesgeschichte Prof. Dr. Winfried Schich, mit dem zusammen das Tagungsprogramm vorbereitet wurde. Der Kreis der Veranstalter wurde mit der Landesgeschichtlichen Vereinigung für die Mark Brandenburg e.V. abgerundet, die seit jeher in ihren Veranstaltungen, Exkursionen und Veröffentlichungen die Neumark ausgiebig berücksichtigt hat. Die genannten Partner führten die von ihnen verabredete Tagung „Adel, Städte und Landesherr in der Neumark in Mittelalter und Früher Neuzeit" in zwei Teilen am 3./4. Oktober 2003 und am 7./8. Mai 2004 in Fürstenwalde durch und verbanden die Vorträge der gewonnenen Referenten und deren Diskussion mit zwei Exkursionen in die Neumark, um Eindrücken von ausgewählten historische Stätten ebenso wie von der gegenwärtigen Lage der Region zu gewinnen.

Die von vornherein geplante Veröffentlichung der Tagungsergebnisse hat sich in der Folge sehr viel mehr verzögert, als es der verantwortliche Herausgeber vorgesehen und beabsichtigt hatte. Obwohl die meisten Manuskripte ihm seit längerem vorlagen, ist er immer wieder durch andere Verpflichtungen von den erforderlichen redaktionellen und organisatorischen Arbeiten abgehalten worden und hat sie nicht mit dem gebührenden Nachdruck vorantreiben können. Auf Grund dieses und anderer Umstände haben nicht alle damaligen Referenten ihm ihre Texte zur Verfügung stellen können. Andererseits haben andere Autoren ihre Vortragsfassung für den Druck erheblich erweitert, waren dadurch aber auch zuweilen an einer schnelleren Fertigstellung gehindert. Am Ende einer langen Wegstrecke fühlt sich der Herausgeber zu besonderem Dank den Kolleginnen und Kollegen verpflichtet, die allen Verzögerungen zum Trotz geradezu unendliche Geduld bewahrt und schließlich noch einmal ihre Ausarbeitungen im Zusammenhang mit der Drucklegung überprüft und ggf. aktualisiert und ergänzt haben. Daß die Tagung zustande kam, ist vorrangig auf den Einsatz von Dietrich Handt, dem damaligen Kurator des Hauses Brandenburg in Fürstenwalde, und Prof. Dr. Winfried Schich in inhaltlichen und organisatorischen Angelegenheiten zurückzuführen. Es ist nur folgerichtig, daß das Haus Brandenburg mit seinem grundsätzlichen Anliegen und mit seiner vielfältigen Tätigkeit in diesem Band von Prof. Dr. Werner Vogel, dem Nachfolger Dietrichs Handts als Kurator, vorgestellt wird.

Obwohl die einzelnen Beiträge dieses Bandes in zeitlicher und sachlicher Hinsicht unterschiedliche Themen behandeln, lassen sie sich trotz aller Individualität mit Gewinn unter die Leitfrage nach einem neumärkischen „Regionalismus“ bringen, vermitteln sie jeweils aus ihrem besonderen Gegenstand heraus in größerem oder geringerem Maße Einsichten über die Entstehung und Ausprägung der Neumark als einer eigenständigen politischen und sozialen Einheit innerhalb der mittelalterlichen und frühneuzeitlichen Mark Brandenburg. Wie Landesherr, Adel und Städte in ihrem Miteinander und Gegen- 
einander unter wechselnden Bedingungen die Neumark als eine abgrenzbare Region mit eigenem Selbstbewußtsein ausgestaltet haben, steht immer wieder im Mittelpunkt der nachfolgenden Schilderungen. Tagung und Tagungsband waren und sind gedacht als Anstoß zur Weiterführung und Vertiefung der Forschungsarbeit über die neumärkische Landesgeschichte, zur erweiterten Erkenntnis des Eigengewichtes der Neumark, deren Bewohner sich jahrhundertelang, auch wenn sie nicht ein weithin wirkendes politisches Zentrum ausgebildet haben, ihre eigene Lebenswelt $\mathrm{zu}$ behaupten und auszugestalten vermocht haben. Zwei Vortragende der damaligen Tagung haben ihre vorgestellten neumärkischen Projekte jenseits dieses Tagungsbandes mit Unterstützung des Brandenburgischen Landeshauptarchivs intensiv weiterverfolgt, so daß ihre Initiativen zu wesentlichen neuen Ergebnissen geführt haben. In dieser vom Brandenburgischen Landeshauptarchiv und der Historischen Kommission zu Berlin gemeinsam herausgegebenen Schriftenreihe ist im Jahr 2012 die auf ausgedehnten Archivstudien beruhende Arbeit von PD Dr. Heinrich Kaak über die Agrarreformen auf den neumärkischen Gütern des Johanniterordens 1750-1811 erschienen. Der in diesem Band enthaltene Programmentwurf von Prof. Dr. Joachim Zdrenka über die neumärkischen Inschriften konnte glücklicherweise in den letzten Jahren bereits in ansehnlichen Teilen umgesetzt werden, so daß nunmehr mehrere Manuskripte über einzelne neumärkische Kreise vorliegen und zum Druck anstehen. Es bleibt zu hoffen, daß die Neumark auf deutscher ebenso wie auf polnischer Seite und in Kooperation beider Seiten die Aufmerksamkeit der Landeshistorikerschaft findet, die sie auf Grund ihrer bemerkenswerten Geschichte verdient.

Potsdam, im Februar 2015

Prof. Dr. Klaus Neitmann

Direktor des Brandenburgischen Landeshauptarchivs 



\title{
Zur Einführung: \\ der ständische Regionalismus der brandenburgischen Neumark
}

\author{
Von KLaus Neitmann
}

In einem unverändert lesenswerten, gedankentiefen, ja faszinierenden Aufsatz aus dem Jahr 1952 hat Dietrich Gerhard, gespeist aus den Erfahrungen seiner erzwungenen Emigration in die USA, in einem universalhistorischen, Amerika und Rußland im Vergleich einbeziehenden Ansatz „Regionalismus und ständisches Wesen als ein Grundthema europäischer Geschichte" behandelt. Ihn zogen in seinen Forschungen geradezu unwiderstehlich gegenüber den ungegliederten und beweglichen amerikanischen und russischen Gesellschaften die Dauerwirkung der ständischen Kräfte und ihre Verbindung mit landschaftlicher Sonderart, landschaftliche Zusammengehörigkeit und das Bewußtsein besonderer Standesüberlieferung als maßgebliche Komponenten europäischer Lebensform vom Hohen Mittelalter bis zum Einbruch der französischen und der industriellen Revolution an. In der europäischen Staatenwelt und innerhalb ihrer territorialen Flächenstaaten haben sich durch die Jahrhunderte autonome Lebenskreise in ihren Grundzügen zu behaupten vermocht. Eine reich gegliederte ständische Gesellschaft formte sich in starker lokaler oder regionaler korporativer Ordnung aus. Die vielfachen Zwischengewalten - die regionale Selbstverwaltung, die Städte, die Grundherrschaften - und ihr korporativer und landschaftlicher Gedanke traten dem nationalen Zentralismus der Krongewalt entgegen, und regionale und korporative Einflüsse verhinderten dabei sogar, daß deren wesentliches Werkzeug, das Beamtentum, durch den Kampf um die Besetzung der Beamtenstellen mit Einheimischen, das Indigenat, ausschließlich dem fürstlichen Willen diente. Korporative Zusammenschlüsse wirkten zugleich als regionales Bollwerk, das Ständetum bewahrte mit dem Gefühl ständischer Ordnung und Freiheiten auch das Landschaftsbewußtsein und den Stolz städtischen Wesens. Mit seinem abschließenden Urteil will Gerhard hervorheben, „daß Landschaftsbewußtsein und ständische Ordnung konstitutive Elemente des alten Europa gewesen sind ... um sich klar zu bleiben, daß, in welchen Formen auch immer, Vielfältigkeit und Stetigkeit zu den Grundlagen aller Kultur gehören“"1.

Wer sich als brandenburgischer Landeshistoriker in Gerhards hier mit einigen markanten Sätzen und Formulierungen angedeuteten Thesen vertieft, wird nicht umhinkommen, dafür als gewichtigstes märkisches Beispiel die Neumark anzuführen. Keine andere Landschaft innerhalb der mittelalterlichen und frühneuzeitlichen Mark Brandenburg hat, verglichen mit deren anderen markanten Regionen wie der Altmark, der Prignitz oder der

1 Dietrich Gerhard: Regionalismus und ständisches Wesen als ein Grundthema europäischer Geschichte, in: Historische Zeitschrift 174 (1952), S. 307-337; wiederholt in: Herrschaft und Staat im Mittelalter, hrsg. v. Hellmut Kämpf. Darmstadt 1956, S. 332-364, das Zitat S. 364 (=Wege der Forschung, 2). 
Uckermark, ihre Eigenart so scharf und deutlich ausgeprägt. Für diesen bedenkenswerten Umstand hat eine wesentliche Rolle gespielt, daß die Neumark auf Grund politischer Entscheidungen der Landesherren im letzten Viertel des 14. und in der ersten Hälfte des 15. Jahrhunderts etwa ein Dreivierteljahrhundert lang sowie in der Mitte des 16. Jahrhunderts fast vier Jahrzehnte lang von der übrigen Mark Brandenburg abgesondert war, sie dabei entweder einer anderen Herrschaft nur locker angegliedert oder gar ein selbständiges Reichsterritorium war und infolgedessen ihre Eigenständigkeit schon allein ihrer politischen Organisation umso mehr ausgestaltet und im Alltag erfahrbar war. Aber zur Erklärung von deren unübersehbarer Wirksamkeit bedarf es darüber hinaus des Blickes auf die ständischen Gruppen, die aus verschiedenen Gründen das Gefühl und die Überzeugung von der Einheit der Region entwickelten und sie im Einsatz für deren Belange bekräftigten und behaupteten. Die Markgrafen richteten ihr Augenmerk notwendigerweise auf ihr ganzes Territorium, auf die Summe seiner einzelnen politischen und administrativen Einheiten und waren um deren Erweiterung und Vermehrung im Rahmen ihrer zunehmend dynastisch orientierten Territorialpolitik bemüht, achteten dabei durchaus die überkommenen Rechte und Freiheiten der einzelnen Landschaften oder entwickelten sie in Verhandlungen mit den dortigen Führungskräften sogar weiter, aber allenfalls beförderten sie den Regionalismus unter äußerem Druck, weniger aus eigenem Antrieb. Dessen eigentlicher Träger waren die Stände - Geistlichkeit, Adel und Städte -, von ihnen und von ihrer Kraft und Initiative, von ihrem Geschick und Selbstbehauptungswillen hing es ab, inwieweit ihr abgegrenzter überschaubarer Lebensraum seine Eigentümlichkeiten entfaltete und allen unvermeidlichen (und notwendigen) zentralisierenden Bestrebungen zum Trotz in gleichbleibenden oder gewandelten Formen aufrechterhielt. Wer die folgenden Beiträge von Landesherr, Adel und Städten in der mittelalterlichen und frühneuzeitlichen Neumark aufmerksam liest, sollte den Gedanken an den neumärkischen Regionalismus nicht aus dem Kopf verlieren, auch wenn nicht jede Untersuchung den Begriff aufgreift oder den damit verbundenen Sachverhalt ausdrücklich erörtert. Aber immer drehen sich die Untersuchungen darum zu erhellen, wie die Neumark und die Neumärker im freundschaftlichen Zusammenwirken ebenso wie in kontroverser Auseinandersetzung mit der landesherrlichen Zentrale ihr eigenes Land, das über die Jahrhunderte hinweg keine gravierenden Grenzveränderungen erlebte und sein eigenes Verfassungsgefüge in Abgrenzung von dem der Nachbarn ausbildete, in politischer, sozialer und wirtschaftlicher Hinsicht auszugestalten trachteten. Die Zusammenfassung der nachfolgenden Aufsätze will zur besseren und leichteren Orientierung des geneigten Lesers versuchen, die für diese Problematik einschlägigen Gesichtspunkte besonders hervorzuheben, ohne dadurch die jeweilige individuelle Themenbreite zu verkürzen.

Die terra transoderana oder Nova Marchia ist im 13. und 14. Jahrhundert entstanden durch den hochmittelalterlichen Landesausbau, die deutschen Einwanderer und ihre Verschmelzung mit den vorgefundenen slawischen Bewohnern und die Territorialbildung im Kampf der verschiedenen Konkurrenten, vornehmlich der weltlichen und geistlichen Herrschaften in Pommern, Schlesien, Großpolen und Brandenburg, aus deren Ringen schließlich die brandenburgischen Markgrafen aus dem Fürstenhaus der Askanier in den drei Generationen etwa zwischen 1250 und 1320 als Sieger hervorgingen. Am Ende der 
askanischen Epoche zeichnete sich merklich spürbar mit den brandenburgischen Gebieten östlich der Oder und nördlich der Warthe ein eigenständiger Teil der Mark Brandenburg ab, der sich noch sehr viel deutlicher im 14. und 15. Jahrhundert von der übrigen Mark, der „Kurmark“ Brandenburg, absetzte, zeitweise sogar gänzlich von ihr losgelöst war. Aber die deutschen Zuwanderer kamen nicht in ein menschenleeres Land, und ihre Siedlungen wurden nicht in einem kulturlosen Gebiet angelegt, so daß es unverzichtbar ist, die Vor- und Frühgeschichte der Landstriche, die dann in die spätmittelalterliche und frühneuzeitliche Neumark eingegangen sind, in die Betrachtung einzubeziehen, eben als Grundlage, auf der die Neumark geschaffen wurde. In diesen Gegenstand führt Armin Volkmann ein, indem er vornehmlich die wechselvolle Besiedlung der unteren Wartheregion von der späten Völkerwanderungszeit bis zum 14. Jahrhundert mit Konzentration auf slawische Landnahme und Landnutzung, auf die allmählich zunehmender differenzierte Gesellschaft sowie auf den durch die deutsche Einwanderung einsetzenden und mit slawischer Beteiligung durchgeführten Landesausbau eingehend und eindringlich beschreibt. Grundlage der Untersuchung ist die erstmalige vollständige, auf die bisherigen deutschen und polnischen Forschungsergebnisse gestützte Aufnahme der archäologischen Fundstellen der späten Völkerwanderungszeit und des Mittelalters auf dem Gebiet der Neumark. Ausgewertet wurden die Archive des Märkischen Museums Berlin, des Museums für Vor- und Frühgeschichte Berlin und des Brandenburgischen Landesamtes für Denkmalpflege und Archäologischen Landesmuseums in Wünsdorf mit ihren Unterlagen der deutschen Bodendenkmalpflege bis 1945, während die Funde, die seit 1945 von der polnischen Bodendenkmalpflege erfaßt wurden, auf Grundlage einer umfassenden Literaturrecherche und einer Stichprobenaufnahme der 1978 begonnenen „Archeologiczne Zdjęcie Polski - AZP“ (Archäologische Geländeaufnahme Polens) im „Wojewódzki Urząd Ochrony Zabytków w Zielonej Górze Delegatura Gorzów Wlkp.“ (Wojewodschaftsamt für Denkmalschutz in Zielona Góra [Grünberg] Außenstelle Gorzów Wlkp. [Landsberg/Warthe]) erhoben wurden. Die Geschichte der archäologischen Forschung in der Neumark läßt sich bis in die 1840er Jahre verfolgen. Die zahlreichen, bis zum II. Weltkrieg gemachten Funde wurden auf mindestens 41 deutsche, polnische und russische Sammlungen verteilt und sind heute weitgehend verschollen. Eine Interpretation des Fundmaterials erfolgte durch die zahlreichen kleinen Einzelpublikationen und Archivmeldungen, die hier in Katalogform zusammengebracht und kritisch nach der Sichtweise der heutigen Forschung analysiert werden.

Aus der späten Völkerwanderungszeit (5.-6. Jahrhundert) liegen nur sehr wenige Einzel-, Grab- und Siedlungsfunde vor, es ist von einem weitgehenden Hiatus zwischen spätgermanischer und frühslawischer Besiedlung auszugehen. Die slawische Einwanderung setzte im Norden des Untersuchungsgebiets schon im frühen 7. Jahrhundert auf den fruchtbaren und leicht zu beackernden, schwarzerdeähnlichen Böden um die Soldiner Seenplatte ein, während das Gebiet südlich der Warthe mit unfruchtbaren Sandböden erst gegen Ende des 7. Jahrhunderts wiederbesiedelt wurde; die seltenen frühslawischen Siedlungsbefunde deuten auf eine geringe Siedlungsdichte im vorherrschenden Waldland hin. Allerdings sind im Süden, im Sternberger und östlichen Lebuser Land, die ältesten Burganlagen schon in der Mitte des 8. Jahrhunderts, wahrscheinlich auf offenen Vorgän- 
gersiedlungen, errichtet worden. Die nördlichen Burgwälle datieren erst in die mittelslawische Zeit ab dem 9. Jahrhundert. Die nachgewiesenen acht altslawischen Burgen sind bis auf zwei Höhenburgen Burgwälle in feuchten Niederungsgebieten. Der erhebliche Anstieg der Fundstellen spricht für eine starke Aufsiedlung in mittelslawischer Zeit durch Burgwälle und offene Siedlungen. Die Bewohner nutzten je nach Standort ihrer Siedlung optimal die natürlichen Ressourcen der fruchtbaren Böden für Ackerbau, der feuchten Weiden für Viehzucht, der offenen Gewässer für Fischfang, der Wälder für Holzschlag, Sammelwirtschaft und Wildjagd aus. Der kontinuierlichere Acker- und Feldbau brachte höhere Erträge, einerseits durch dessen Intensivierung auf bestehenden und andererseits durch die verstärkte Erschließung neuer Wirtschaftsflächen. Das Untersuchungsgebiet ist in zwei räumliche Großeinheiten nördlich und südlich der Warthe zu unterteilen, die im Verlauf des Mittelalters immer wieder unterschiedliche kulturgeschichtliche Entwicklungen etwa in Bezug auf Siedlungsdichte und Siedlungsverteilung mit Kontinuitäten oder Diskontinuitäten zeigten. Die stark mäandrierende Warthe bildete eine natürliche Barriere, die nur an zwei (Zantoch und Landsberg) bzw. drei Furten (Küstrin als Pass über Warthe und Oder) zu überwinden war. So war das südlicher gelegene Land Sternberg und das östliche Lebuser Land von Pommern her schlecht zugänglich. Die Oder war hingegen keine Kulturbarriere, sondern es lassen sich in ihrem Unterlauf ganz im Gegensatz zur Warthe die Gemeinsamkeiten der westslawischen Kulturgenese westlich und östlich des Flusses gut erkennen. In der Nähe der Furten (z. B. an der Oderfurt bei Zehden) wurden größere Handelssiedlungen an und in Burgwallanlagen angelegt, in denen händlerische und herrschaftliche Aktivitäten konzentriert waren. Politisch gehörte der dünner besiedelte Süden ab dem Ende des 10. Jahrhunderts zum piastischen Großpolen. Der Norden mit einer hohen Siedlungsdichte wurde hingegen nur temporär in das vorfeudale Piastenreich eingegliedert und entwickelte sich innerhalb Pommerns weitgehend unabhängig.

Schon im 9./10. Jahrhundert wurde das ganze Gebiet flächenhaft durch die Anlage zahlreicher Burgwälle und offener Siedlungen erschlossen. Im 11./12. Jahrhundert wurden einzelne Regionen inselartig intensiver aufgesiedelt, wobei von einem starken Bevölkerungswachstum auszugehen ist. Nur ca. 25\% der Burgwälle und offenen Siedlungen weisen eine echte Kontinuität seit mittelslawischer Zeit auf. In spätslawischer Zeit entstanden innerhalb dieses weitgehend neuen Siedlungsmusters durch bedeutend größere Burgwälle geschützte Handelsorte mit Märkten, umfangreichem Warenangebot und in einheitsnormierten, lokal hergestelltem Silbergeld spürbaren monetären Strukturen. Aber hauptsächlich wurden weiterhin zahlreiche ungeschützte Kleinsiedlungen angelegt, die oft nach einer Nutzung von nur 25 bis 50 Jahren aufgegeben und in unmittelbarer Nachbarschaft innerhalb des Siedlungsgefildes neu errichtet wurden. Die Zentralörtlichkeitsfunktion der Burgwallanlagen wurde dadurch verstärkt, daß mehr offene Siedlungen als zuvor in den Machtbereich der dortigen lokalen „Fürsten“ eingebunden wurden. In den Siedlungen gab es Bauten in Blockhaus- und Pfosten-Ständerkonstruktion mit einem rechteckigen Grundriss sowie Hauswände aus Flechtwerk mit Lehmverputz. Am Ende der spätslawischen Zeit bildeten sich in den natürlich durch beste Böden und offene Gewässer begünstigten Räumen fünf bis sechs eindeutige Siedlungs-Ballungszentren (im Gebiet des späteren Soldin, Landsberg/Warthe, Arnswalde, Reppen und Kö- 
nigsberg/Neumark bis zum Oderbruch) an gut zu überschauenden und zu verteidigenden Plätzen mit vorzüglicher infrastruktureller Anbindung über die Fließe und Landhandelswege. Die Bevölkerung differenzierte sich sozial zunehmend: Neben der wohl ackerbaulich orientierten breiten Masse werden Handwerker für rohe Eisenverarbeitung (Funde von Schmelztiegeln und geschmiedeten Zangen und Scheren), wohlhabende Personen (Schmuckfunde) und ,adlige“ Krieger (Funde von Schwertern, Lanzen- und Pfeilspitzen) sichtbar.

Im Zuge des hochmittelalterlichen Landesausbaus, der in Anfängen ab ca. 1230 und verstärkt ab ca. 1250 einsetzte und eine deutsch-slawische Mischgesellschaft zur Folge hatte, entstand das noch heute weitgehend vorhandene Siedlungsmuster. Rund $90 \%$ der „,neuen“ Städte wurden in unmittelbarer Nähe zu oder sogar auf spätslawischen Burgwallanlagen angelegt, diese Handelsorte also zumeist weiter genutzt, die Haupthandelswege allerdings teilweise verlagert, etwa durch andere Flußfurten geführt. Die Anzahl der dörflichen Siedlungen nahm stark zu, von ca. 77 offenen Siedlungen in spätslawischer Zeit auf 239 planvoll angelegte Dörfer; in ihnen lebten die aus dem Reich eingewanderten Deutschen und die Slawen gemeinsam, möglicherweise in räumlicher Separation, oder es wurden zwei nebeneinander liegende Siedlungen mit Zusatzbezeichnungen wie „Deutsch“ und „Wendisch“/,Groß“ und „Klein“ geschaffen. Die Dörfer entstanden oft in der Nähe zu spätslawischen offenen Siedlungen oder wurden sogar in diesen errichtet. Gleichzeitig wurden aber auch zuvor unerschlossene Regionen durch Dorfneugründungen in stereotypen Formen (hauptsächlich Angerdörfer und Straßendörfer) systematisch aufgesiedelt. In der ersten Hälfte des 14. Jahrhunderts fielen, bedingt durch die unruhigen politischen Verhältnisse, viele Ortschaften wüst, wobei sie teilweise wegen ihrer Lage auf schlechten Böden nicht mehr wiedererrichtet wurden, teilweise wegen der wirtschaftlich lohnenden Erschließung von besseren Böden im 16. Jahrhundert wieder erstanden.

Eine gegliederte ständische Ordnung erwuchs erst aus der deutschen Zuwanderung und durch die damit verbundene Differenzierung von unterschiedlichen sozialen Gruppen nach den jeweils für sie geltenden Rechten und Privilegien, entsprechend ihrer unterschiedlichen wirtschaftlichen Betätigung und gemäß ihrer verschiedenartigen herrschaftlichen Unterordnung. Die grundlegende Einteilung der Gesellschaft in Geistlichkeit, Adel und Bürgertum (und das politisch irrelevante Bauerntum) wurde aus dem Westen durch die Einwanderer gemäß den ihnen vertrauten Vorstellungen in die entstehende Neumark eingeführt. Für ihre Untersuchung ist zu berücksichtigen, daß im 13. und 14. Jahrhundert nicht bloß wie im Altsiedelland ein bestehendes differenziertes Gesellschaftsgefüge fortentwickelt und umgewandelt, sondern daß ein solches überhaupt erst einmal im Rahmen des Landesausbaues mit den dazugehörigen Rechts- und Lebensformen geschaffen werden mußte. Die neumärkische Geistlichkeit bleibt in den Aufsätzen dieses Bandes ausgeschlossen, aus äußeren Gründen und wegen ihrer für den ständischen Regionalismus nachrangigen Bedeutung, im Mittelpunkt stehen Adel und Bürgertum in Land und Stadt, die freilich ohne den Landesherrn und dessen Absichten und Maßnahmen in ihren Existenzbedingungen nicht zu denken sind und die immer in ihrem Zusammenwirken mit ihm zu betrachten sind. Wir wenden uns in der Folge der Artikel zunächst dem Adel zu. 
Da die Adelsforschung bislang nicht zu den Domänen der brandenburgischen Landesgeschichtsforschung gehört hat, konzentriert sich einleitend Peter Neumeister darauf, für die notwendigen, aber bislang weitgehend fehlenden Untersuchungen Leitfragen zur Auswertung des Quellenstoffs aufzuwerfen. Auszugehen ist von wesentlichen Strukturunterschieden des Adels diesseits und jenseits von Elbe und Saale, zwischen Alt- und Neusiedelland, denn der einzelne Adlige hatte zuerst überhaupt in das Kolonisationsgebiet zu gelangen und sich dann darin auf Dauer zu behaupten, so daß er schließlich kraft seiner Verbundenheit mit anderen Adligen zu einer regionalen Adelsgesellschaft zusammenwuchs. Wie migrierten Adlige in die Neumark und ließen sich hier nieder? Als erste Anlaufstellen dienten wohl die landesherrlichen Höfe, die fürstlichen der Markgrafen von Brandenburg und Meißen, der Herzöge von Schlesien und Pommern, der Könige von Polen sowie die geistlichen der Bischöfe von Brandenburg, Breslau, Kammin und Lebus. An ihnen konnte der Adlige am ehesten auf Verleihung von Lehen auf Grund seiner geleisteten Dienste oder auf den Ankauf von Gütern wegen der landesherrlichen Geldknappheit hoffen. Die größte Zahl von Immigranten ist in der Neumark zwischen 1250 und 1320, dem Aussterben der Askanier, gekommen (wie die von Wedel, von Behr, von der Osten, von Kerkow, von Lossow usw.), aber auch danach kam der Zuzug nicht zum Erliegen (wie die von Lochen, von Waldow, von Rohr unter den Wittelsbachern oder die von Kittlitz unter den Luxemburgern). Das neumärkische Landbuch von 1337 nennt ca. 150 Namen von adligen und adliglebenden (bürgerlichen) Familien, wobei die große Aufspaltung der einzelnen Familien und die enge Verwandtschaft vieler Familien zu berücksichtigen ist. - Wie etablierten sich die Adligen auf Dauer in ihrem neuen Wirkungsraum? Die Erlangung von Lehen und Alloden wurde als Grundstock für eigenständige Herrschaften genutzt. Besonders gewichtig war die von der fürstlichen Finanznot ausgelöste Inbesitznahme einer markgräflichen Burg durch Kauf oder Verpfändung, aus der die hochrangigen schloßgesessenen Familien hervorgingen. Die Ausübung von landesherrlichen Ämtern (wie Vogt, Kastellan, Rat, Hofamt) über mehrere Generationen hinweg sicherte die langfristige Existenz ebenso wie die aus eigener Initiative entsprungene Mitwirkung am Landesausbau und der Anwendung seiner Instrumentarien wie Burgenbau und bäuerliche und städtische Ansiedlung zu deutschem Recht. Kinderreichtum ermöglichte die Anbindung an alteingesessene Familien und gewährleistete den Bestand der Sippe. Alle Behauptungskriterien wie Lehen, Burgenbesitz, Verwandtschaft, Anlehnung an einen Fürsten sind aber nur als Chancen zu begreifen, da etwa der Wandel politischer Konstellationen günstige Ausgangsbedingungen rasch zunichte machte und eine Familie schnell wieder verschwinden ließ (z. B. von Lochen). - Gab es eine neumärkische Adelsgesellschaft eigener Ausprägung? Für die Ausbildung einer eigenen Identität sind ein- oder mehrdeutige herrschaftliche Orientierungen, Lehnsabhängigkeiten, Memoria, Namenvergabe, Heiratsverhalten innerhalb und außerhalb der Neumark, Gründung geistlicher Institutionen als geistige Zentren des Adels, Adelsversammlungen, Adelsbündnisse zu erforschen, überhaupt die materiellen und geistigen Zeugnisse des neumärkischen Adels aufzuarbeiten. Nach vorsichtiger Einschätzung wird man für das 15. Jahrhundert von einer eigenständigen neumärkischen Adelsgesellschaft und Adelskultur sprechen dürfen. 
Die grundsätzlichen Überlegungen Peter Neumeisters werden von Christian Gahlbeck weitergeführt und auf der Grundlage der ausgiebig herangezogenen und ausgewerteten gedruckten und ungedruckten Quellen mit eigenen, aus umfassender Materialkenntnis gespeisten Akzentsetzungen am konkreten Objekt erprobt und umgesetzt. Eine adlige Führungsschicht bildete sich in der Neumark zwischen 1270 und 1350 heraus, wie auch sich ein alle Stände umfassendes Bewußtsein regionaler Einheit in der ersten Hälfte des 14. Jahrhunderts herauskristallisierte. Die familiären Verbindungen des neumärkischen Adels reichten im ausgehenden 13. und im 14. Jahrhundert vor allem nach Pommern und in die Uckermark, in erheblich geringerem Maße in die westliche Oderregion mit dem Land Lebus und dem Oberbarnim sowie in das südlich der Warthe gelegene Land Sternberg, was aus seiner vornehmlichen Herkunft aus Pommern und der Uckermark folgte. Aus den über 250 adligen Geschlechtern der Neumark sind $54=$ ca. 20\% der Führungsgruppe zuzuordnen, legt man für deren Bestimmung die folgenden Kriterien zugrunde: Besitz von Burgen oder Schlössern - die späteren schloßgesessenen Adelsfamilien, ein sehr kleiner Kreis (1612 elf Geschlechter) -, Bekleidung von Vogteien oder Hofämtern in der Neumark, anderswo in der Mark Brandenburg oder auch in Pommern (verbunden mit Güterbesitz in der Neumark), Lokatorentätigkeit, Einsatz als vermögende Bürgen oder Kreditgeber, Teilnahme an Ständeverhandlungen bzw. Landtagen und Einsatz als Vermittler in schiedsgerichtlichen Verfahren zwischen Fürst und Adligen oder innerhalb des Adels. Dieser Oberschicht entstammten die Inhaber von Hof- und Verwaltungsämtern in der Neumark. Der fragliche Kreis wandelte sich allerdings im Laufe des Mittelalters in seiner Zusammensetzung und blieb nicht unverändert: Einige Familien stiegen erst um oder nach 1350 in die Oberschicht auf, andere starben aus, sanken bis zur Bedeutungslosigkeit herab oder gaben ihre neumärkischen Besitzungen auf. Die statistische Auswertung der in den Urkundenregistern der wittelsbachischen Markgrafen von 1333 bis 1373 enthaltenen Namen neumärkischer Adelsgeschlechter bestätigt die herausragende Position von fünf Familien: der Herren von Wedel (mit einer absoluten Ausnahmestellung: 105 der insgesamt ca. 725 Registereinträge), gefolgt mit weitem Abstand von den Mörner und von der Osten (43 bzw. 38 Erwähnungen), diese wiederum mit einigem Abstand von den von Brederlow und von Güntersberg (23 bzw. 20 Erwähnungen). Darunter sind noch acht Adelsgeschlechter mit fünf bis acht Erwähnungen anzuführen.

Die ausführliche Untersuchung des Wirkens der aus diesem Kreis ausgewählten neun Familien in und für die Neumark - der von Brederlow, Güntersberg, Liebenthal, Schöning, Liebenow, Wedel, Uchtenhagen, Jagow und (von) Mörner - ergibt, daß ihr Weg in die Neumark in fast allen Fällen über Pommern führte oder dort begann. Spürt man ihre Herkunft in älteren Zeiten auf, so läßt sie sich in die Grafschaft Stormarn (SchleswigHolstein), den Braunschweiger Raum, in das mitteldeutsche Gebiet um Merseburg und in die Altmark zurückverfolgen. Aus dem Havelland, dem Teltow, dem Land Lebus oder der Niederlausitz sind hingegen keine später führenden Geschlechter gekommen, und es gibt keinerlei Hinweise auf eine Herkunft aus autochthonen slawischen Adelsgeschlechtern oder überhaupt Anhaltspunkte dafür, daß es in den slawisch besiedelten Gebieten zwischen Oder und Drage, Warthe und Pommern unmittelbar vor dem Einsetzen des hochmittelalterlichen Landesausbaus eine adlige slawische Führungsschicht gab. Unter den 
betrachteten Familien lassen sich zwei verschiedene Gruppen ausmachen: Bereits in voraskanischer Zeit gelangten die von Wedel, Liebenow, Brederlow und Schöning und wahrscheinlich auch die von Liebenthal als Burgmannen und Siedlungsunternehmer unmittelbar von Pommern aus, als Vasallen Herzog Barnims I. oder der Bischöfe von Kammin, in die Neumark, während die von Uchtenhagen, Jagow und Mörner als landesherrliche Lokatoren in der Neumark eingesetzt und an älteren pommerschen Burgorten angesiedelt wurden, wo sie an die Stelle der früheren pommerschen Burgmannen (ohne deren Funktion und Rang) traten. Lieselott Enders hat für die Besiedlung der Uckermark drei unterschiedliche Typen von Ortsgründern gefunden: ranghöhere Ritter, die als Unternehmer im landesherrlichen Auftrag den Landesausbau überhaupt organisierten und dabei für sich selbst weitgehend unabhängige Herrschaften schufen; rangniedrigere Ministerialen, die im direkten landesherrlichen oder über den Siedlungsunternehmer vermittelten Auftrag ein oder mehrere Dörfer praktisch ,anrichteten“; Niederadlige und Bauern, die als Lokatoren im wörtlichen Sinne wirkten, indem sie das ihnen vom Grundherrn übertragene Land an die Nutzer verpachteten. Nach diesem Schema lassen sich die von Wedel, von Liebenow, von Brederlow, von Schöning und von Liebenthal eher dem ersten und die von Uchtenhagen, Jagow und Mörner eher dem zweiten Typus zuordnen. Allerdings reichte die Unabhängigkeit der ersten Gruppe weder in der Mark noch in Pommern so weit, daß die Adligen von der Landesherrschaft unabhängige Herrschaften einrichten konnten, vielmehr unterlagen auch sie dem Lehnrecht und waren ebenso wie die Vertreter der zweiten Gruppe Vasallen ihrer Landesherren. Während die Mitglieder der ersten Gruppe als Fremde an den pommerschen Hof kamen und die Bedingungen, unter denen sie als Ritter und Siedlungsunternehmer in den Dienst des Herzogs oder des Bischofs traten, mehr oder minder frei aushandelten, stand die zweite Gruppe, als die Askanier die südliche Uckermark übernahmen, vor der Entscheidung, sich entweder mit ihrem uckerländischen Besitz in deren Lehnsabhängigkeit zu begeben oder ihre Freiheit zu dem Preis zu behalten, ihre gerade erst gewonnenen Güter sowie ihre kostenträchtigen Investitionen in die von ihnen aufgesiedelte terra ersatzlos zu verlieren, um an anderer Stelle von vorne anzufangen. Diejenigen, die sich für das Vasallitätsverhältnis unter den Askaniern entschieden, waren als landsässig Gewordene an diese erheblich stärker gebunden als die aus der Fremde Gekommenen. Da sie aus der ersten Gruppe hervorgegangen waren, kamen sie aber immer noch als Unternehmer für größere Siedlungs- und Ausbauprojekte in Betracht, z. B. für die Anlage einer ganzen deutschrechtlichen Stadt oder für die Einrichtung des gesamten mit einer solchen Stadt verbundenen Weichbilds. Auch konnten sie ebenso wie die Vertreter des ersten Typus als Burghauptleute für die Landessicherung des askanischen Herrschaftsgebiets sorgen. Von ihnen sind diejenigen Adligen zu unterscheiden, die je nach Vermögen von den adligen Siedlungs-Großunternehmern als Kleinunternehmer zur Aufsiedlung einzelner oder mehrerer Dörfer angeworben wurden und im übrigen auch militärisch zur Gefolgschaft, zu den socii oder Mithelfern der Ritter-Unternehmer zählten, die ihre Hauptleute waren.

Um sich längerfristig im führenden Kreis des neumärkischen Adels bis $1350 \mathrm{zu}$ etablieren, war ein Engagement als Burgmann (oder: Burghauptmann) in einer landesherrlichen Burg in Pommern (unter Einschluß des Uckerlandes) die Schlüsselposition, schuf es 
doch die Voraussetzung für die Übertragung größerer Aufgaben in der Landessicherung und im Landesausbau durch die Askanier. Wer sich in diesen Funktionen bewährt hatte, kam alsbald auch für höhere Aufgaben im Landesdienst in Frage. Daher läßt sich bei den meisten der behandelten Familien ein Aufstieg beobachten, bei dem die Generation der Söhne schon in jungen Jahren als Vögte einer terra tätig waren und entweder selbst in höherem Alter zu Oberhauptleuten wurden oder höhere Hofämter wie die des Marschalls, des Truchsess, des Mundschenks, des Küchen- oder Kammermeisters oder des Hofrichters oder (als höchstes Amt) das des Hofmeisters erhielten. Diese Ämter erforderten zum einen wie bereits das Engagement als Siedlungsunternehmer erhebliche finanzielle Mittel, zum andern erbrachten sie bedeutende Erträge, die es den Adligen irgendwann im Laufe der Zeit ermöglichten, größere Besitzkomplexe zu erwerben und schließlich zu Schloßgesessenen zu werden. Für die Siedlungsgeschichte ergeben sich aus der Betrachtung der Herkunft der untersuchten Adelsfamilien und ihrer Wirkungsgebiete in der Neumark neue Aspekte. Die pommerschen Regionen, aus denen sie kamen, waren das Uckerland um Prenzlau, das anschließende Gebiet um das Dreieck Penkun-Gartz-Stettin, der Pyritzer Weizacker, der ehemals zur terra Zehden zählende Raum Bärwalde-Königsberg und das Land Stargard, also die Gebiete, die einem Zehntvertrag von 1240 zufolge seit langem wüst lagen und deren Dörfer neu ausgebaut werden sollten. Innerhalb der Neumark spielte für die adlige Siedlung das von der terra Pyritz abgetrennte Land Lippehne, das nach Norden bis vor Pyritz, nach Süden bis vor Soldin reichte, eine Schlüsselrolle. Der Raum zwischen Lippehne und Soldin, dessen westlicher und östlicher Rand bis nach Schildberg, Berlinchen und Bernstein reichte, war, abgesehen von den Landschaften des Oder-, Warthe- und Netzebruchs, die in vorkolonialer Zeit am dichtesten besiedelte Landschaft der Neumark. Dieser Raum wurde zwischen 1248 und 1276 hauptsächlich im Auftrag der Kamminer Bischöfe besiedelt, die daher wohl dafür verantwortlich sein dürften, daß die von Brederlow, Schöning und Liebenthal sich als ihre Burgmannen in und um Lippehne ansiedelten.

Mit den folgenden Artikeln verlassen wir den Adelsstand und wenden uns dem Bürgerstand bzw. seinen Städten zu und erörtern für diesen die gleich oder ähnlich gearteten Probleme seiner „Etablierung“ in der Neumark. Wie die Markgrafen von Brandenburg im 13. Jahrhundert die Gründung von Städten als ein wesentliches Mittel zur Ausweitung und Festigung ihrer Territorialherrschaft im Land Lebus und in der terra transoderana nutzten, wird von Winfried Schich unter Konzentration auf die beiden frühesten und bedeutendsten Stadtgründungen, Frankfurt an der Oder und Landsberg an der Warthe, unter sorgsamer Abwägung der urkundlichen Zeugnisse, der archäologischen Grabungsfunde und der Stadtgrundrisse eingängig erläutert. Die Askanier knüpften an die ältere Entwicklung unter polnischer, pommerscher und schlesischer Hoheit an. Das Land Lebus besaß seit dem 12. Jahrhundert in dem gleichnamigen Ort durch die dortige Verbindung von Burg, Bischofssitz und städtischer Siedlung ein politisches, kirchliches und wirtschaftliches Zentrum. Während der schlesischen Vorherrschaft in den ersten Jahrzehnten des 13. Jahrhunderts wurden zudem in Küstrin und Drossen neuartige Marktorte bzw. Städte geschaffen, die, aus dem polnischen Herzogsrecht herausgelöst, ein besonderes lokales Recht wie in den deutschen Städten erhielten, die wirtschaftlich auf den Markt ausgerich- 
tet und kommunal verfaßt waren. Als die Markgrafen von Brandenburg 1252 einen Teil des Lebuser Landes erworben hatten, stellte Johann I. im Juli 1253 eine Urkunde für die zu bauende bzw. auszubauende civitas Frankfurt aus, damit durch die kommunal verfaßte Marktstadt sein Territorium beiderseits der Oder ein neues Zentrum erhielt, über das der Fernhandelsverkehr sowohl in west-östlicher als auch auf der Oder in Nord-Süd-Richtung verlaufen sollte. Die Bürger erhielten Zollfreiheit im Herrschaftsbereich des Stadtherrn, siebenjährige Steuerfreiheit für die Zeit des Neuaufbaues, danach fiel ein Drittel der Zinsen von Hausgrundstücken, Hufen und Verkaufsstätten wie von den Gerichtsgefällen an den Lokator bzw. Schultheißen, zwei Drittel verblieben dem Markgrafen. Frankfurt erhielt Berliner Recht (mit der Vorrangstellung der Kaufleute vor den Handwerkern). Der Bau einer Oderbrücke und einer Schwesterstadt auf dem Platz Zliwitz (Słubice) jenseits der Oder waren vorgesehen. Der Grundriß zeigt eine planvolle Form mit einem Kaufhaus auf dem Markt und einer Wassermühle nördlich der Stadt. Frankfurt wurde anfänglich mit 124 Hufen ausgestattet, die dann noch um die für die unrealisierte Stadt „Słubice“ angesetzten 60 Hufen erweitert wurden.

Während für Frankfurt offensichtlich kapitalkräftige Bürger zum Aufbau der Stadt bereitstanden, fehlten sie in ausreichendem Maße für die Gründung von Landsberg an der Warthe. Markgraf Johann beauftragte im Juli 1257 seinen Getreuen Albert von Luge, seine freie Stadt Landisberch Novam zu errichten, überließ ihm dafür ein Drittel der Zinsen von Hausstätten, Hufen und Verkaufsständen auf dem Markt sowie von den Gerichtsgefällen und den innerhalb des Stadtgebietes zu errichtenden Mühlen und überließ ihm zudem 64 Hufen außerhalb der Stadtgrenzen zur Anlage eines Kirchdorfes. Die Stadt wurde mit 104 Ackerhufen und 50 Hufen Weideland, ihre Bürger mit Brandenburger Recht ausgestattet (da Brandenburg an der Havel als oberster Stadtrechtsvorort in der Mark galt). Der Zins war nach zehn Freijahren zu entrichten. Der Markgraf versprach, innerhalb von vier Monaten die Siedlung selbst zu befestigen. Mit der um den Ackerbau erweiterten Basis war es möglich, die Stadt mit einer größeren Zahl von wirtschaftlich aktiven Bewohnern zu füllen und mit Ackerbauern und ihren Fuhrwerken zusätzliche Kräfte für Bau und Unterhalt der Befestigung zu gewinnen. Mit der Stadtgründung war gleichzeitig die Umstrukturierung der vorhandenen Siedlungen im ländlichen Bereich durch die Vermessung der - üblicherweise 64 - dörflichen Hufen verknüpft, daraus erwuchs die terra Landsberg. Der Bau von Wassermühlen diente der Verarbeitung des wichtigsten agrarischen Produktes, des Getreides. Die entscheidende Neuerung bestand 1257 darin, daß der Markgraf anstelle der alten Herrschaftszentren, der Burgen, den hinsichtlich der Verkehrslage besser ausgestatteten Platz in dem Gebiet mit fruchtbaren Ackerböden zum neuen Landeszentrum in der Form der kommunal verfaßten und gut befestigten Markstadt ausbauen ließ. Zur Füllung der Großburg sollten die bürgerlichen Kräfte herangezogen werden, die sich im Handel, im Handwerk und im Ackerbau betätigten. Markt und Burg wurden in einem neuartigen Siedlungskörper vereinigt. Während in Frankfurt genügend an der Ausweiterung ihrer Handelsaktivitäten, insbesondere des Getreidehandels interessierte Kaufleute bereitstanden, wurde in Landsberg ein landesherrlicher Stützpunkt auf einer anfangs schwächeren stadtwirtschaftlichen Grundlage errichtet. Die Landsberger Stadtanlage mit Richtstraße, Nebenrichtstraße, Marktplatz und großer Pfarrkirche im 
Zentrum wurde in späteren Stadtgründungen in der Neumark wie etwa Berlinchen und Soldin vielfältig modifiziert. 1261 brachten die Markgrafen durch einen Besitztausch mit den Templern das oppidum Küstrin, das sich aus herrschaftlicher Burg und kommunalem Städtchen zusammensetzte, und fünf Dörfer an der Straße von Küstrin nach Landsberg in ihre Hand. Die Erfassung der Neumark über die Städte, also die Zusammenfassung von Handel und Gewerbe in den privilegierten Marktstädten und der dazugehörige Ausbau der benachbarten ländlichen Siedlungen und einer auf den Getreideanbau ausgerichteten Agrarlandschaft mündete wirtschaftlich im 14. Jahrhundert in den von ihren Kaufleuten durchgeführten umfangreichen Getreideexporten auf dem Wasserweg nach Stettin.

Die Erforschung der Anfänge des neumärkischen Städtewesens in der zweiten Hälfte des 13. Jahrhundert führt Felix Escher fort, indem er eine der wirtschaftlich führenden Städte des Landes, das agrarische Handelszentrum Königsberg, schildert, unter Konzentration auf die Umstände, die dessen Blüte im späten 13. und im 14. Jahrhundert bezeugen. Der 1270 erstmals als civitas genannte Ort, also eine schon in ihrem damaligen Übergang von der bischöflich zur markgräflich brandenburgischen Herrschaft deutschrechtlich organisierte Stadt, war der Mittelpunkt der terra Königsberg, die 133730 Dörfer umfaßte und damit, gemessen an der Zahl der Siedlungen, die zweitgrößte neumärkische Vogtei war. Die Erwähnung einer Neustadt im frühen 14. Jahrhundert deutet auf eine zumindest zweistufige Entwicklung des Stadtraumes, und den Rang der Stadt belegen zudem das ursprüngliche Nebeneinander von Marien- und Nikolaipfarren, Augustinerstift, St. Georg-Spital und Münzprägestätte. Königsberg lag in einer der ertragreichsten Gegenden der Neumark, der Kreis Königsberg wurde noch im 18. Jahrhundert für seine gute Viehzucht und fruchtbaren Äcker gerühmt. Die große städtische Feldmark wurde schrittweise durch die Aneignung von Bruch- und Heideland, von Seen und Dörfern gewonnen, dortige stadtfremde Rechte wurden abgelöst. Königsberger Bürger nutzten ihren Reichtum zur lehnrechtlichen Erwerbung von agrarischen Nutzflächen und Abgaben im Umland, die Stadt vermochte dort ganze Dörfer in ihren Besitz zu bringen. Der Landesherr räumte ihrem Rat das Recht zur Errichtung eigener (Korn-)Mühlen in der Stadt und ihrer Gemarkung ein, die Emanzipation vom Stadtherrn wurde schließlich durch die Erwerbung des Schulzenamtes und der Gerichtsrechte sowie die Zerstörung der landesherrlichen Burg vollendet. Die Lebensader Königsbergs war das Flüßchen Rörike, es ermöglichte den Kaufleuten den Transport agrarischer Produkte auf dem Schiffswege nach Stettin und in den Ostseeraum. Markgräfliche Privilegien förderten ihren Handel durch die Zusicherung ungehinderter Schifffahrt auf der Rörike und der Oder nach Stettin, durch die Befreiung von Zoll und anderen Abgaben auf Handelswaren auf Oder, Havel und Elbe und an dort gelegenen Orten. Als der Rat um 1350 die in Königsberg lebenden Juden wegen ihrer unliebsamen Handelskonkurrenz ermorden ließ, stand er auf dem Höhepunkt seiner Macht. Die im 15. Jahrhundert in Wüstungen sichtbare Krise verschärfte sich entscheidend dadurch, daß die Hohenzollern den adligen Agrarproduzenten die Versendung ihres Getreides direkt an die Ostseehafenstädte gestattete, so daß im frühen 16. Jahrhundert nur noch der Königsberger Rat, aber nicht mehr der einzelne Kaufmann mit dem Stettiner Handelshaus der Loitz Geschäfte abschloß, bis die kurfürstliche Genehmigung der adligen Kornausfuhr endgültig Königsberg in die Bedeutungslosigkeit verstieß. 
In ihrem kleinen methodisch instruktiven Beitrag verdeutlicht Ewa Syska, wie die vorsichtige Deutung von städtischen Siegelbildern zu Erkenntnissen über die Stadtgründer führen kann. Sie erörtert die ältesten bekannten Siegel der beiden neumärkischen Städte Bernstein und Bärwalde. Der Name „Bernstein“ bzw. dessen ursprüngliche Fassung $B e$ rensteyn leitet sich von der aus Westfalen stammenden Familie Behr ab, die Spuren ihrer Siedlungstätigkeit im 13. Jahrhundert im Raum von Greifswald bis Stolp hinterlassen hat. Die Zeichnungen eines unpublizierten Stadtsiegels von Bernstein aus dem Jahr 1315 zeigen auf beiden Seiten einer kleinen Erhebung zwei steigende Bären, über ihnen ein Adler; die Bären symbolisieren den Besitzer des wohl um 1275 zur Stadt erhobenen Ortes, die Gützkower Linie der Familie von Behr, und spielen auf das Wappen des sich nach Bernstein titulierenden Lippold II. von Behr (erwähnt 1237-1294/98) an. Der Adler, der auf die Oberhoheit der Markgrafen von Brandenburg verweist, kann an dem Siegelstempel erst nach 1279/80 angebracht worden sein, als die Stadt von den Askaniern erworben worden war; dafür spricht auch, daß sich der Adler am Rande des Siegelbildes, auf der Linie der Umschrift, befindet, als ob er erst später einem schon früher bestehenden Ganzen hinzugefügt worden sei. Das große Wappensiegel und das Sekretsiegel von Bärwalde enthalten ebenfalls zwei steigende Bären, dazwischen eine Eiche, über den Baumästen einen Adler. Das Siegelbild bietet also deutliche Analogien zu diesem Bernsteiner Siegel, so daß vermutlich Bärwalde ebenfalls von der Familie von Behr gegründet wurde, zumal in den 1320er Jahren ihr vorübergehender Besitz der Stadt urkundlich nachweisbar ist.

Standen in den beiden bisherigen das neumärkische Städtewesen betreffenden Aufsätzen vornehmlich die Städte selbst und ihr Bürgertum im Mittelpunkt der Betrachtung und ist dabei ihr Zusammenwirken mit den Markgrafen notwendigerweise einbezogen worden, so stellt der folgende Beitrag gänzlich die allgemeinen und konkreten Sichtweisen und Ziele des Landesherrn im 15. Jahrhundert in den Vordergrund. In dem halben Jahrhundert seiner Herrschaft über die Neumark betrieb der Deutsche Orden, wie Roman Czaja darlegt, keine einheitliche Städtepolitik, sondern verfolgte in mehreren aufeinanderfolgenden Phasen unterschiedliche Absichten. Nach der Erwerbung des Landes 1402 suchte er seine finanziellen Grundlagen zu verbreitern, indem er in der vorangegangenen wittelsbachischen und luxemburgischen Zeit in den Städten verlorengegangene Einnahmen aus Regalien wie Mühlen, Zöllen und Orbeden sowie aus dem Grundbesitz zurückzugewinnen trachtete. Der Marienburger Treßler gab zur Wiederauslösung verpfändeter Rechte hohe Summen aus, so ca. 5100 mr. in den Jahren 1403/04 für den Rückkauf von Mühlenrechten. Nach der Tannenberger Niederlage von 1410 fehlten die erforderlichen Mittel zur Fortsetzung dieser Linie, so daß die Einwirkungsmöglichkeiten der Vögte geschwächt wurden und sich die Städte auf den ständischen Versammlungen stärker als die Ritterschaft den Forderungen des Ordens widersetzten. Die mangelhafte Abwehr des hussitischen Einfalls 1433 zwang den Landesherrn allerdings dazu, unter dem Druck der Ritterschaft den Wiederaufbau zerstörter Städte zu unterstützen. Hochmeister Konrad von Erlichshausen (1441-1449) suchte durch den Ausbau von Schlössern in einzelnen Städten, durch Eingriffe in Grundbesitz und Gerichtsbarkeit der Städte und die Einschränkung ihrer verfassungsrechtlichen Selbständigkeit seinen Einfluß wieder zu verstärken, aber trotz der gelegentlich harten Bestrafung von oppositionellen Räten erreichte er kei- 
nen überzeugenden Erfolg, so daß der letzte Ordensvogt in der Neumark etwa durch die Rückgabe der Niedergerichtsbarkeit erneut um einen Ausgleich bemüht war. Während nach 1440 die Konflikte zwischen dem Orden und den Städten in der Neumark aus seinen Bestrebungen zur Befestigung seiner Stadtherrschaft resultierten, suchten umgekehrt die preußischen Großstädte an den inneren und äußeren Angelegenheiten des Landes maßgeblich beteiligt zu werden und strebten nach vollständiger Unabhängigkeit. Dabei wurden sie in ihrer Haltung vom Adel unterstützt, während in der Neumark eine engere Zusammenarbeit zwischen den Städten und dem Adel nicht zustande kam.

Die Neumark, verstanden als das „Land über Oder“ (terra transoderana), die „,eigentliche“ Neumark östlich der Oder, nördlich der Warthe bis nach Schivelbein und östlich bis zur Drage (ohne die später sog. inkorporierten Lande der östlichen Mark Brandenburg, nämlich das Land Sternberg und das Fürstentum Crossen), entstand als eine neue politische und soziale Einheit etwa in dem Jahrhundert zwischen 1250 und 1350, wie sich aus der Summe der ersten Aufsätze ergibt. Die Herrschafts- und Siedlungsstrukturen wurden gegenüber den Verhältnissen der früheren slawischen Jahrhunderte so grundlegend umgestaltet und neu geformt, daß die Elemente der Diskontinuität die der Kontinuität bei weitem überwiegen. Hatte das Gebiet zuvor ohne eine eigene politische Organisation zwischen den gewichtigen politischen Herrschaften im Norden und Süden, zwischen Pommern und dem piastischen (Groß)Polen gestanden, wurde es jetzt auf Grund des erfolgreichen, vom Westen ausgehenden Ausgriffs der Askanier über die Oder in die Mark Brandenburg eingefügt, in Grenzen, die diese in ihren Auseinandersetzungen mit den pommerschen und polnischen Nachbarmächten erreichten und die für die folgenden Jahrhunderte, sieht man einmal von eher geringfügigen Verlusten und Verschiebungen ab, unverändert blieben. In diese brandenburgisch gewordene Landschaft zogen - vor und nach der brandenburgischen Erwerbung - vornehmlich von Pommern aus deutsche Zuwanderer ein und vermischten sich mit den vorgefundenen Slawen im Zuge des gemeinsam betriebenen Landesausbaues. Es wandelte sich aber nicht nur die Zusammensetzung der Bevölkerung, sondern die Deutschen brachten auch aus ihrer bisherigen westlichen Heimat die ihnen vertrauten Rechts- und Sozialformen des Alltagslebens mit sich und prägten mit ihnen fortan ihre neue östliche Heimat. Die neue deutsch-slawische Gesellschaft war ständisch gegliedert, sie bestand aus Städten und Dörfern bzw. aus dem städtischen Bürgertum und dem ländlichen Adel mit ihren jeweils eigenen privilegierten Lebensordnungen in den kommunal verfaßten, auf Handel und Gewerbe beruhenden Marktstädten und in den Grundherrschaften des ritterlichen bzw. adligen Kriegerstandes mit abhängigen Bauern und ihren Wirtschaftshöfen. Wie sich an den aufkommenden Landschaftsnamen „Land über Oder“ bzw. „Neumark“ ablesen läßt, zählten schon die Zeitgenossen des 14. Jahrhunderts die Neumark zu den Ländern, aus denen sich die Mark Brandenburg zusammensetzte, und einzelne Handlungen und Verfügungen sowohl der Markgrafen als auch der beiden neumärkischen Stände zeugen von der Eigenständigkeit der Neumark innerhalb der gesamten Mark Brandenburg. Eine neue Phase oder ein höheres Niveau des ständischen Regionalismus war freilich erst dann erreicht, wenn Adel und Städte der Neumark nicht nur gelegentlich jeweils für sich auftraten, sondern wenn sie sich dauerhaft fester gegenüber dem Landesherrn zusammenschlossen und sich schließlich zu einer ein- 
zigen ständischen Korporation vereinigten. Unter welchen äußeren Umständen und inneren Antrieben ihr Zusammenhalt allen innerständischen Differenzen zum Trotz absichtlich oder unabsichtlich gestärkt wurde, wird im nächsten Beitrag dieses Bandes deutlich.

Das verfassungsrechtliche Verhältnis des Adels und der Städte zur Landesherrschaft und die Ausbildung einer landständischen Verfassung verfolgt Klaus Neitmann für das 15. Jahrhundert, also für die - auf Grund einer günstigen Quellenüberlieferung vorrangig behandelte - Zeit der Deutschordensherrschaft zwischen 1402 und 1454/55 und die anschließende Regierung der ersten drei Hohenzollern bis 1499, indem er die beiden zusammengehörigen Rechtsakte der Huldigung und Privilegienbestätigung, die im Falle eines Herrschafts- bzw. Herrscherwechsels anstanden, analysiert. Die landesherrliche Privilegienbestätigung setzte die ständische Huldigung voraus - wie auch umgekehrt: Die Huldigung bedingte die Privilegienbestätigung. Beide Seiten waren jedenfalls davon überzeugt, daß der stufenweise Übergang vom alten auf den neuen Herrn rechtlich erst vollendet war, wenn sowohl die Stände gehuldigt als auch der Landesfürst ihre Privilegien erneuert hatte. Eine Einigung über den künftigen ständisch-landesherrlichen modus vivendi anläßlich eines Herrschaftswechsels wurde schließlich in allen betrachteten Fällen gefunden. Die ständische Inanspruchnahme des Widerstandsrechtes und die Aufkündigung des ständischen Gehorsams wie in Preußen 1454 ist als ganz außergewöhnlicher Fall einzustufen. Die Formel des Huldigungseides rief in der Neumark weder in der Ordens- noch in der Hohenzollernzeit nennenswerte Debatten hervor: Sie beinhaltete die Treueerklärung des einzelnen Untertanen gegenüber dem Hochmeister, gegenüber seinem Bevollmächtigten im Land, dem Vogt, und gegenüber dem ganzen Orden, was die Neumärker als unproblematisch empfanden, weil sie alle drei immer als Einheit erlebt hatten. Die preußischen Stände hingegen suchten sich 1441 und 1450 immer stärker mit ihrem Eid nur noch dem Hochmeister, der als Fürst verstanden wurde, zu verpflichten und nicht mehr der Ordensgemeinschaft, weil sie hatten erfahren müssen, daß sie aus der in sich zerstrittenen Korporation zu entgegengesetzten Treuebekundungen aufgefordert worden waren. Die eigentlichen Kontroversen wurden in der Neumark über den Inhalt der Privilegienbestätigung ausgefochten. In der Dispositio wurde zunächst ausschließlich oder vorrangig festgehalten, daß der Landesherr sich zur Beachtung der ständischen Rechte und Gewohnheiten verstand, ohne diese präzise und konkret darzustellen. Allerdings legten es politische Erfahrungen und politische Ziele nahe, auf der Aufnahme von besonderen Rechten oder Pflichten zu bestehen, in Punkten, auf die die eine oder beide Seiten größten Nachdruck legten oder die unter ihnen umstritten waren.

Huldigungen und Privilegienbestätigungen wurden immer ausgelöst durch einen Herrschaftswechsel, durch einen noch bevorstehenden ebenso wie durch einen schon vollzogenen Herrschaftswechsel. Von den drei in der Praxis auftretenden verschiedenartigen Fällen bestand der erste Fall darin, daß im Territorium nach dem Tode oder dem Rücktritt des bisherigen Herrschers kraft Erb- oder Wahlrechts sein Nachfolger die Herrschaft antrat. Der Vorgang beruhte auf der Voraussetzung, daß der Treueid der Untertanen immer einer bestimmten Person, dem regierenden Herrn oder Fürsten, galt und mit dessen Tod oder Rücktritt erlosch; er war nicht auf einen abstrakten Staat bezogen. Ein wenig komplexer gestaltete sich die Lage, wenn die Landschaft die territoriale Zugehö- 
rigkeit tauschte, wenn mithin die Neumark zwischen der Mark Brandenburg und dem Deutschen Orden hin und her geschoben, einem anderen Fürsten und seinem Territorium eingeschränkt oder uneingeschränkt zugewiesen wurde. Dann waren zunächst die Untergebenen von ihrem bisherigen Herrn des ihm geleisteten Treueides zu entbinden und von ihm an den neuen Herrn zu verweisen, die zwingende Bedingung dafür, daß dieser von ihnen für sich einen neuen Treueid verlangte und dabei ihnen ihre Rechte bekräftigte. Den dritten Fall, die Änderung der verfassungsrechtlichen Grundlage der Herrschaft, also die Ersetzung einer zeitlich befristeten und sachlich beschränkten Pfandherrschaft durch eine zeitlich und sachlich unbegrenzte Erbherrschaft, anders formuliert aus ständischer Sicht: die Ersetzung einer Pfandhuldigung durch eine Erbhuldigung, aus landesherrlicher Sicht: der endgültige Ausschluß einer Rückerwerbung des vormaligen Besitzers, nutzten die Neumärker 1430 dazu, die bislang schwebenden prinzipiellen Probleme ihres Rechteund Pflichtenkanons gegenüber ihrem Landesherrn nachdrücklich aufzugreifen und durch eine neue Privilegierung mit zusätzlichen schriftlichen Vereinbarungen zu lösen.

Für das in der Geschichtswissenschaft kontrovers diskutierte Thema des sog. dualistischen Ständestaates ist an Hand der neumärkischen Ereignisse einerseits nicht zu verkennen, daß Herrschaft und Stände sich auf einer gemeinsamen Rechtsgrundlage gegenüberstanden, daß sie auf dieser wie zwei selbständige Parteien miteinander verhandelten und dabei von gleich zu gleich um einen Ausgleich miteinander rangen. Andererseits verfehlt die Vorstellung eines starren Gegensatzes zweier Seiten die historische Wirklichkeit in erheblichem Maße. Die neumärkischen Stände waren kein einheitlicher Block, es setzten sich Angehörige der Mannschaft bzw. Ritterschaft sowie der Städte mit den Vertretern der Landesherrschaft auseinander. Die politische vorrangige Frage lautete immer wieder, ob Mannschaft und Städte sich auf eine übereinstimmende Linie gegenüber der Herrschaft verständigten oder ob eine der beiden Seiten dieser mehr zuneigte und eher zu einem Übereinkommen bereit war, so daß man von einer Dreieckskonstellation zu sprechen geneigt ist. Das hochmeisterliche Privileg von 1430, die wichtigste Privilegienbestätigung des 15. Jahrhunderts, verdankte seine Entstehung und seinen Inhalt der Konstellation, daß die Mannschaft wegen der ausreichenden Berücksichtigung ihrer Interessen das Privilegienangebot des Ordens annahm und sich damit von den Städten trennte. Dabei offenbaren gerade die Verhandlungen von 1430, daß zwischen der Herrschaft und den beiden ständischen Gruppen ein Gremium stand, das nicht eindeutig einer Seite zuzuordnen war, eben weil es seinem Wesen nach zur Vermittlung bestimmt war: der Rat des neumärkischen Vogtes. Die Räte dienten dem Landesherrn, waren von ihm ausgewählt und waren ihm verpflichtet, aber sie entstammten dem neumärkischen Adel, zählten zu seinen sehr angesehenen und begüterten Angehörigen, und waren daher durch ihre soziale Herkunft und durch ihr amtliches Vertrauensverhältnis in die Lage versetzt, in einem Konflikt zwischen Ständen und Herrschaft auszugleichen. Im Falle der dramatischen Zuspitzung drohten sie zwar zwischen beiden Seiten zerrieben zu werden, wie sie 1430 so schön ausdrückten, aber sie brachten letztlich den damaligen Kompromiß zustande. In vergleichender Betrachtung ist es aufschlußreich, daß dieses Modell, das 1430 in der Neumark seine Bewährungsprobe bestand, in Preußen nicht funktionierte: Die dortigen großen Städte und die Ritterschaften lehnten es ab, weil sie befürchten mußten, daß da- 
durch ihre eigenen Mitspracherechte beschnitten und die letzte Entscheidung in ein unter maßgeblich hochmeisterlichem Einfluß stehendes, weniger an den Ständen orientiertes Organ verlagert würde.

Unter den Gegenständen, die in die neumärkischen Verhandlungen zwischen Herrschaft und Ständen eingebracht wurden und die deren Ergebnis in Gestalt der Privilegien bestimmten, ragte in der Ordenszeit mit langer Nachwirkung in der frühen Hohenzollernzeit konkurrenzlos der Militärdienst hervor, also die Frage nach Art und Ausmaß der ständischen Heeresfolge und der dazugehörigen landesherrlichen Leistungen. Es bestand für ein ständisches Aufgebot ein Unterschied zwischen einem Einsatz innerhalb oder außerhalb der Neumark, ähnlich wie etwa in Preußen für die kulmerländische Ritterschaft auf Grund der Kulmer Handfeste von 1233, nach der sie zum Landwehrdienst nur innerhalb der Grenzen der Kulmerlandes verpflichtet war und gegen ihren Willen nicht zum Kriegseinsatz an anderen Orten entboten werden durfte. Die Behandlung der neumärkischen Städte orientierte sich 1430 am Einsatz ihres Aufgebotes diesseits oder jenseits der Landesgrenzen: Innerhalb der Neumark waren die Städte zu seiner Unterhaltung auf eigene Kosten verpflichtet, außerhalb der Neumark durften sie für einen Teil, für die berittene Truppe, Versorgung beanspruchen. Der Mannschaft waren hingegen inner- wie außerhalb des eigenen Landes Verpflegung ihrer Einheiten und Schadenersatz für die von ihnen erlittenen Verluste, vornehmlich die Ersetzung der verletzten oder getöteten Pferde und die Lösung aus der Kriegsgefangenschaft, zugesichert. Die Hochmeister billigten mit ihrer Privilegierung die traditionellen Ansprüche des Adels, gegenüber denjenigen der Städte verstanden sie sich nur zu deren teilweiser Berücksichtigung, womit sie indirekt zum Ausdruck brachten, daß sie die militärischen Dienste des Adels für höherwertig als die der Städte erachteten. Während die allgemeinen Überblicksdarstellungen zum spätmittelalterlichen Ständestaat in dem Verlangen des Landesherrn nach Steuererhebungen den wesentlichen Ansatz zum Ausbau der ständischen Mitsprache betonen, ist der Vorrang des Militärdienstes aus der außenpolitischen Lage der Neumark fast über das ganze Jahrhundert hinweg zu erklären, aus den zahlreichen kleineren und größeren Fehden und Kriegen, die nahezu von allen Nachbarn drohten, vornehmlich von Polen und von Pommern. Unter solchen Gegebenheiten war der Orden mit seinem schwachen Personalbestand in der Neumark unausweichlich auf die militärische Unterstützung der Stände angewiesen, in erster Linie auf die offenkundig als leistungsfähiger eingeschätzte der Ritterschaft, wenn er die Fehden eindämmen, die Feinde überwinden und den Landfrieden sichern wollte. Für Kämpfe und Schlachten wurden vorrangig „Reisige“, berittene Kämpfer, benötigt, und sie entstammten in erster Linie dem Adel, weniger dem Bürgertum.

Von 1402 bis 1454 war die Neumark, war sie auch de iure der preußischen Ordensherrschaft angegliedert, de facto wegen ihrer von Preußen gänzlich abweichenden, eigenständigen Verfassungsordnung ein eigenes Territorium. Auch wenn die neumärkischen Ritter und Städte vereinzelt schon im 14. Jahrhundert von den wittelsbachischen Markgrafen von Brandenburg gesondert und gruppenweise privilegiert worden waren, führte doch erst ihre völlige Abtrennung von Alt- und Mittelmark und deren Ständen dazu, daß sie sich insgesamt oder zumindest jede Gruppe für sich um die Regulierung ihres Verhältnisses zu dem neuen Landesherrn bemühen mußte. Auf Landtagen kamen die ständischen 
Vertreter zur Erörterung der brennenden politischen Angelegenheiten mit dem Vogt und sonstigen Vertretern des Ordens zusammen. Nach 1410 stellte sich rasch heraus, daß die Berufung auf die althergebrachten Rechte und Gewohnheiten auf Grund ihrer mangelnden schriftlichen Fixierung unter den außenpolitischen Gefährdungen nicht ausreichten, den ständischen Wünschen im vorrangigen Bereich des militärischen Aufgebotes gebührenden Nachdruck zu verleihen. Die Herrschaftswechsel gaben dann den äußeren Anstoß dazu, daß die Stände in ihrer Gesamtheit oder ihre beiden maßgeblichen Zweige, Ritterschaft und Städte, allgemeine, also sie alle betreffende und begünstigende Privilegierungen verlangten, wenn sie sich alle zur angemahnten Huldigung bereiterklären sollten. Dabei bezeugen die Urkunden, daß einzelne Adlige und einzelne Städte namens der gesamten Ritterschaft und der gesamten Städtegruppe und somit verbindlich für sie handelten, was einen ausreichenden Grad an politischer Selbstorganisation verrät. Wenn 1470 vielleicht nur ein Viertel des neumärkischen Adels zum angesetzten Landtag mit dem Markgrafen zur Erörterung und Festlegung der Modalitäten von Huldigung und Privilegienbestätigung erschien, gab den Ausschlag, daß die Anwesenden von allen Seiten, von ihren Standesgenossen ebenso wie von der Landesherrschaft, als handlungs- und abschlußberechtigt angesehen wurden und daß die dort getroffenen Absprachen auch alle Abwesenden einbezogen. Die Auseinandersetzungen um die auf das Militärwesen konzentrierten Inhalte einer landesherrlichen Privilegierung der Stände, die auf ihren Höhepunkten wegen bevorstehender Huldigungen geführt wurden, schufen im neumärkischen 15. Jahrhundert die ersten wesentlichen Elemente einer fixierten landständischen Verfassung.

Wir richten dann nochmals unser Augenmerk unter einem anderen Blickwinkel ausschließlich auf den Landesherrn zwischen 1402 und 1454/55, den Deutschen Orden. Während dieses Zeitraumes war die Neumark gewissermaßen ein hinzugewonnenes „Nebenland" des Deutschordensstaates Preußen, und es bedurfte ebenso wie zuvor eines als Vertreter und im Auftrage des Landesherrn tätigen Leitungspersonals, aber innerhalb einer andersartigen, nämlich geistlichen Landesherrschaft. Ihm wendet sich Bernhart Jähnig zu, indem er den Ordensvogt der Neumark in die personelle und organisatorische Struktur Preußens einordnet. Der Deutsche Orden gliederte seine dortige Landesherrschaft im 13. und im frühen 14. Jahrhundert in Komtureien, deren Verwaltung einem Komtur und dessen größerem oder kleinerem Konvent oblag. In späteren Zeiten wurden jedoch keine neuen Komtureien mehr eingerichtet oder gar bestehende Komtureien in Vogteien, die nur mit einem Vogt, einem Ritter- und einem Priesterbruder besetzt waren, umgewandelt, da nicht mehr unbegrenzt Ritterbrüder zur Verfügung standen, um neue Konvente personell angemessen auszustatten, und da die Verwaltung des Ordenslandes zentralisiert wurde, daher die Vogteien im Gegensatz zu den Komtureien in die dem Hochmeister unterstehende Treßlerkasse zinsten. In den Neuerwerbungen um 1400 wurden von vornherein nur Vogteien geschaffen, so 1384 die Vogtei Schivelbein und 1402 die räumlich anschließende Vogtei Neumark, die dann während der Deutschordensherrschaft die längste Zeit über von demselben Vogt verwaltet wurden; erst nach 1441 wurde die Vogtei Schivelbein wieder verselbständigt und diente zwei Gebietigern als Alterssitz. Von 1402 bis 1455 hatten 15 Ritterbrüder das Amt des neumärkischen Vogtes inne. Sie entstammten alle soweit nachweisbar entsprechend den damaligen sozialen Verhältnissen 
innerhalb der Ritterbruderschaft des Ordens niederadeligen Familien. Sie kamen zu je einem Drittel aus oberdeutschen und mitteldeutschen Landschaften, drei von ihnen waren Niederdeutsche, so daß, verglichen mit der geographischen Herkunft der preußischen Ordensgebietiger, der oberdeutsche Anteil niedriger, der niederdeutsche Anteil höher ausfiel. Die durchschnittliche Amtszeit betrug 3 1/2 Jahre. Die wesentlich kürzeren Amtszeiten während des Großen Krieges 1409-1411 und in den nachfolgenden Jahren folgten aus dem Verlust an qualifizierten Kandidaten auf Grund der zahlreichen Todesfälle in der Schlacht bei Tannenberg. Betrachtet man die Ämterlaufbahnen der einzelnen Vögte, so zeigt sich, daß in mehr als zwei Dritteln der Fälle der Weg nach der Neumark in der Folge in die Ränge von Komturen oder sogar Großgebietigern führte. Die neumärkische Vogtei war also, auch wenn das Land keine Komturei werden konnte, ein kaum weniger bedeutendes Amt, die Vogtei war in der Regel eine Station für aufsteigende Ordensgebietiger. Die große geopolitische Bedeutung der Neumark für den Orden in Preußen spiegelte sich somit auch in der Personalpolitik der Ordensleitung wider.

Daß die Neumark zwischen 1378 und 1455 von der übrigen Mark Brandenburg abgetrennt war und in andere innen- und außenpolitische Kraftfelder eingefügt wurde, beförderte die Ausbildung ihrer Eigenständigkeit erheblich, wie beispielhaft die landesherrlichen Privilegienbestätigungen des 15. Jahrhunderts mit ihren von den kurmärkischen Parallelurkunden so abweichenden Schwerpunktsetzungen verdeutlicht haben. Im 16. Jahrhundert erhielt die neumärkische Eigenart durch die dynastischen Entscheidungen der Hohenzollern einen nochmaligen zusätzlichen Schub. Als die Mark Brandenburg 1535 gemäß dem Testament des Kurfürsten Joachim I. zwischen seinen beiden Söhnen Joachim [II.] und Johann (Hans) geteilt wurde, wählte letzterer in seinem Territorium, zu dem die Neumark, das Land Sternberg und das Fürstentum Crossen mit Züllichau und Sommerfeld sowie die Herrschaft Cottbus und Peitz in der Niederlausitz gehörten, das bis dahin unbedeutende Städtchen Küstrin am Einfluß der Warthe in die Oder - unmittelbar an der Grenze zur kurmärkischen Herrschaft seines älteren Bruders - zu seiner Residenz aus. Ein eigenes Territorium mit einem eigenen Fürsten an der Spitze verlangte geradezu gebieterisch nach einem fürstlichen Mittelpunkt, nach einem dauernden Aufenthaltsort des Fürsten, seines Hofes und seiner Behörden, in der Sprache der damaligen Zeit, nach einem „Hoflager“. Für die Neumark entstand dadurch eine neue Situation, denn ein derartiges auf einen Fürsten konzentriertes Zentrum hatte bis dahin mangels eines eigenen Landesherrn nicht eingerichtet zu werden brauchen. Ralf Gebuhr geht den Motiven und Folgen der überraschenden Entscheidung für Küstrin nach, denn der Markgraf setzte sich mit seinem raumplanerischen Impuls über die vorgefundenen zentralörtlichen Strukturen der Neumark hinweg. Stadt und Umfeld Küstrins wurden weitgehend neu gestaltet: Mit der Verlegung der Oderbrücke wurde die Verkehrsanbindung der Stadt grundlegend geändert, die Dienstsiedlung der Burg, der Kietz, eine rechtlich eigenständige Siedlung, wurde auf eine der Stadt gegenüberliegende Oderinsel verlegt. Der Bau der mit modernen pentagonalen Bastionen ausgestatteten Festung verlangte ansehnliche wassertechnische Einrichtungen, für Festungsgräben und Mühlen wurden eine Stauanlage und ein Mühlgraben angelegt. Küstrin hatte bis dahin auf Grund seiner schwachen wirtschaftlichen Leistungskraft zu den unbedeutendsten Städten der Neumark gehört. 
Wie ältere Zusammenstellungen des Leistungsvermögens ihrer Städte belegen, durfte vor 1535 Soldin mit Fug und Recht die Spitzenstellung unter ihnen für sich beanspruchen, auf Grund seiner kirchlichen Funktionen und seiner wirtschaftlichen Kraft. Soldin verfügte über das einzige Kollegiatstift und die einzige Dominikanerniederlassung in der Neumark, nach dem Landbuch Kaiser Karls IV. von 1375 entrichtete es dem Landesherrn mit 73 Mark Silber die höchste städtische Abgabe mit deutlichem Abstand vor Königsberg und Arnswalde, und mit seinem militärischen Aufgebot gehörte es 1529 zur obersten Gruppe. Privilegien des wittelsbachischen Markgrafen aus der Mitte des 14. Jahrhunderts hatten den Weg des Fernverkehrs über Soldin befördert und die städtische Autonomie durch den Verzicht auf eine landesherrliche Burg und die eigenmächtige Einsetzung des landesherrlichen Vogtes gesichert. Die Stadt war stark befestigt, besaß einen markgräflichen Wohnhof innerhalb ihrer Mauern und diente den Landständen als Versammlungsort. Obwohl in Soldin somit wichtige Voraussetzungen für den Aufbau einer fürstlichen Residenz gegeben waren und obwohl Markgraf Johann die dortige Wirtschaft zu fördern trachtete, beschloß er mit Küstrin die zentralörtliche Neustrukturierung des Landes. Aus seiner Sicht sprachen für die Oderstadt ihre Lage an der zu schützenden Grenze, eine schwache Bürgerschaft ohne Neigung zur Konfrontation mit dem Fürsten und vor allem die Stellung im Verkehrsnetz am Zusammenfluß zweier wichtiger schiffbarer Flüsse: Der damals stark zunehmende Ochsenhandel von Osten her in Richtung der westlichen Umschlagplätze regte, wenn er über große und leicht zu kontrollierende Straßen geführt wurde, dazu an, ihn mit Zöllen abzuschöpfen, so daß folgerichtig in Küstrin ein neues Brückengeld für Rindvieh, Schafe und Schweine erhoben wurde.

Inzwischen in der Frühen Neuzeit angekommen, greifen wir für diese Epoche die von Peter Neumeister und Christian Gahlbeck erörterten Fragen nach der Eigenart des neumärkischen Adels wieder auf und stoßen dabei trotz gewandelter Herrschaftsstrukturen auf dieselben Grundprobleme, zu denen insbesondere die von Christian Gahlbeck berührte Herkunft des landesherrlichen Führungspersonals, der Zwist um seine Auswahl aus den Reihen des neumärkischen Adels oder aus „landfremden“, d.h. nicht-neumärkischen Vertrauensleuten des Markgrafen und Kurfürsten, gehört. Zwischen den beiden entgegengesetzten Polen der Resistenz, also der Behauptung der regionalen Eigenständigkeit innerhalb des brandenburg-preußischen Gesamtstaates, und der Anpassung, also der Orientierung an den monarchischen Ansprüchen auf adlige Dienste, verortet Frank Göse die neumärkische Adelsgesellschaft in den zwei Jahrhunderten zwischen Markgraf Hans von Küstrin (1535-1571) und König Friedrich Wilhelm I. (1713-1740). Sie blieb in diesem Zeitraum in unterschiedlichem Ausmaß durch Abgeschiedenheit und Residenzferne geprägt. Markgraf Hans fügte den Adel seines selbständigen Territoriums in seine Herrschaft ein, indem er einzelne Adlige mit säkularisiertem Klostergut bedachte, den gewünschten Fortbestand sächsischer Rechtstraditionen garantierte und seine Amtsträgerschaft (Landes- und Amtshauptleute) unter Anerkennung des Indigenats vielfach aus Angehörigen besonders einflußreicher Familien rekrutierte, so daß diese wie ein Bindeglied zwischen Regierung und Adel wirkten. Auf den ständischen Versammlungen repräsentierten vornehmlich Mitglieder der begütertsten Familien ihre Kreise, und gerade sie bewahrten zugleich etwa durch ihre Kreditgewährungen ihre Nähe zur Landesherrschaft. 
Hans vermied so die Einberufung von Plenarlandtagen und verhandelte stattdessen lieber mit Repräsentanten einzelner Kreise bzw. mit einem Ausschuß der Ritterschaft. Auf die im Lehnswesen verankerte Gestellungspflicht der Ritterschaft legte er großen Wert und sorgte durch regelmäßige Musterungen dafür, daß deren Kriegstüchtigkeit gewahrt blieb, wenn auch Meinungsverschiedenheiten über die vasallitische Verpflichtung zum Kriegsdienst außerhalb des eigenen Landes auftraten. Nach der Wiedervereinigung der Neumark mit der Kurmark 1571 waren die Neumärkischen Stände bestrebt, wegen ihrer abgelegenen Lage die eingetretenen administrativen Strukturen zu bewahren oder noch durch zusätzliche Regionalbehörden wie etwa ein neumärkisches Konsistorium zu ergänzen. Die Erfahrung einer ein längeres Herrscherleben andauernden Separierung führte zugleich zu einer distanzierten Haltung gegenüber den kurmärkischen Standesgenossen; die auf Eigenständigkeit bedachte Position der Neumärker verhinderte ihre vorbehaltlose Integration in einen gesamtständischen Corpus, in dem sie gerne aus taktischen Gründen bei gesamtständischen Beschlußfassungen ,als geringster Teil der Lande“ den Kurmärkern den Vortritt ließen, und beraubte sie zugleich ihrer Karriereoptionen am Berlin-Cöllner Hof, nur wenige bauten eine engere, dauerhaftere Bindung zum Kurfürsten auf. Die Heiratsverbindungen blieben meistenteils auf die neumärkischen Adelsfamilien beschränkt.

Nach dem 30jährigen Krieg stand der neumärkische Adel wegen demographischer Einbrüche und der schwierigen wirtschaftlichen Selbstbehauptung unter enormem Anpassungsdruck. Es galt, die Grundlagen der Gutswirtschaft dadurch zu sichern, daß die Abhängigkeitsverhältnisse der bäuerlichen Hintersassen verstärkt, die Frondienste erhöht und Bauernlande eingezogen sowie auf Kosten der Städte Handelsvorteile wie etwa die zollfreie Ausfuhr des auf eigenem ritterschaftlichen und bäuerlichen Besitz geernteten Getreides errungen wurden. Trotzdem blieb die wirtschaftliche Lage der meistens nur auf 10-20.000 Rtl. geschätzten neumärkischen Rittergüter prekär (zum Vergleich: Durchschnitt der kurmärkischen Rittergüter zwischen 20000 und 50000 Rtl.). Seit dem frühen 17. Jahrhundert ging der relative Anteil des brandenburgischen Adels innerhalb der Berlin-Potsdamer Residenzgesellschaft unter dem Großen Kurfürsten zurück, besonders aber der der aus der Neumark stammenden Amtsträger (nur 15 Neumärker innerhalb von 121 Brandenburgern bei insgesamt 343 Amtsträgern), ein Zeichen für die unzureichende Integration der Neumärker in den größeren Gesamtstaat. Auch wenn die Gestellungspflicht der Lehnsvasallen ihren militärischen Wert verloren hatte und durch Gelder abgelöst worden war, achteten die Kurfürsten sorgsam auf die Einhaltung der vasallitischen Pflichten etwa bei der Huldigung oder den Lehngeldzahlungen. Die neumärkische Ritterschaft widerstrebte anfänglich der von Friedrich Wilhelm I. verfügten Lehnsallodifikation, weil dadurch der Zusammenhalt innerhalb des Geschlechterverbandes geschwächt werde und umso weniger Erbteilungen und Besitzverschleuderung entgegengetreten werden könne. Der König kam ihr immerhin insofern entgegen, als er ihr die Führung des für die Taxierungen und Kreditbelastungen der Rittergüter eingerichteten Landbuches überließ. Die neumärkischen Stände vermochten sich dem gesamtstaatlichen Integrationsprozeß zwar nicht zu entziehen, aber sie bewahrten sich durch den von ihnen aufgebauten Gegendruck ein gewisses Maß an Eigenarten. Am ehesten wurden sie in den ersten Jahrzehnten des 18. Jahrhunderts durch den Militärdienst in die Monarchie eingebunden, der Anteil der 
dort tätigen Rittergutsbesitzer stieg von 1718 bis 1751 von $36 \%$ auf $46 \%$ an, sie wurden größtenteils in Garnisonen außerhalb der eigenen Landschaft eingesetzt, gingen auch Heiratsverbindungen zu anderen preußischen Territorien ein. Andererseits verstanden sich die in übergroßer Mehrheit aus dem einheimischen Adel stammenden Amtsträger wie Beamte der Küstriner Regierung, Kreiskommissare und Landräte noch lange Zeit primär als Interessenvertreter ihrer Mitstände und nicht vorrangig als Sachwalter der Landesherrschaft. Typologisch betrachtet, ist die Neumark eine Adelslandschaft, die Residenzferne und Bewahrung ihrer regionalen Eigenständigkeit mit einem nicht gering zu veranschlagenden Anpassungspotential zu verbinden wußte.

Zum Abschluß unseres Durchganges durch die Epochen der mittelalterlichen und frühneuzeitlichen neumärkischen Geschichte wenden wir uns noch einmal den Städten zu, genauer gesagt, ihrem Wirtschaftsbürgertum in den letzten Jahrzehnten der altpreuBischen Monarchie, als es dank der Wirtschaftspolitik des Königs und seiner Zentralbehörden zu außergewöhnlichen Erfolgen gelangte. Die erstaunliche wirtschaftliche Potenz der preußischen Provinz Neumark, zu der damals auch das niederlausitzische Gebiet um Cottbus und Peitz gehörte, untersucht Rolf Straubel vornehmlich für die Zeit zwischen dem Siebenjährigen Krieg und den Napoleonischen Kriegen. Im Gegensatz zur Kurmark, die im Handelsverkehr mit dem Ausland ein starkes Defizit aufwies, trug die Neumark, deren Gewerbeerzeugnisse zu mehr als $80 \%$ ins Ausland gingen, zusammen mit Schlesien maßgeblich zum Aufstieg Preußens in den Kreis der großen europäischen Gewerbebzw. Wirtschaftsstaaten bei. Dabei nahmen ihr Handel und ihr Handelsüberschuß sowohl mit den anderen Provinzen der Monarchie wie mit dem Ausland in der zweiten Hälfte des 18. Jahrhunderts kontinuierlich zu. Unter den ausgeführten Produkten ragten einerseits Wollwaren und Leinwand, die vornehmlich nach Frankfurt/Oder und in die Residenzstädte Berlin und Potsdam geliefert wurden, andererseits Getreide, Vieh und Holz, die hauptsächlich ins Ausland verkauft wurden, mit einem annähernden Gleichgewicht untereinander hervor. Die Blüte der Neumark wurde durch die Nähe zu Polen befördert, bezog sie doch von dort billiges Korn, Schlachtvieh, Wolle und Rohleder und stärkte dadurch die Konkurrenzfähigkeit der neumärkischen Textilfabrikanten auf den Außenmärkten und setzte zugleich dort preußische Gewerbeerzeugnisse ab. Indikatoren eines anhaltenden Wachstums waren die Zunahme der verarbeiteten Wollmenge wie der Produktionsausstoß. In den überregionalen Warenverkehr waren vor allem Klein- und Mittelstädte wie Landsberg/Warthe, Callies, Reppen, Driesen, Zielenzig, Züllichau und Cottbus eingebunden, in denen Tuche und Leinwand für den Export hergestellt wurden. Dabei lag der Tuchhandel in den Händen weniger Kaufleute, teilweise Aufsteiger der ersten oder zweiten Generation aus dem Handwerk, die neue Geschäftsbeziehungen mit dem In- und Ausland anknüpften und neue Absatzmärkte erschlossen und auf Grund ihres Erfolges aus dem Kreise der Steuerzahler herausragten, während die Masse der Tuchmacher verarmt war und von Händlern verlegt wurde. Zu den Faktoren, die die Lage der Bevölkerung beeinflußten, gehörten die Betriebsformen im exportorientierten Gewerbe, die Marktorientierung, die verkehrsgeographische Lage, die handwerklich-kommerziellen Traditionen und die nebengewerbliche Tätigkeit. 
Unter den namhaften neumärkischen Kaufleuten nach 1763 ist zuerst der aus Posen stammende Treppmacher mit seiner Großhandlung in Driesen zu erwähnen. Seine polnischen Handelsverbindungen, eine mehrjährige Akzise- und Zollfreiheit sowie die Einräumung von Vergünstigungen der Stettiner Kaufleute mit zollpolitischen Vorteilen in der seewärtigen Ein- und Ausfuhr verschafften ihm fast zwei Jahrzehnte lang ansehnliche Erfolge im Ausfuhrhandel mit polnischem Holz und Einfuhrhandel mit Kolonialwaren, vornehmlich Wein, bis er den wirtschaftspolitischen Bestrebungen der Regie zum Opfer fiel, die zwecks besserer Kontrolle der Warenströme den Zwischenhandel über Stettin, Breslau und Elbing zum Nachteil von Driesen und Bromberg lenken wollte. Außerhalb der großen Handelszentren wurde Kapitalbildung in erster Linie durch die Verbindung von Fabrikation und Warenvertrieb ermöglicht. Daß Züllichau, ein in den überregionalen Handel eingebundenes Textilgewerbezentrum, 1813 eine höhere Anleihe für die Vorfinanzierung der Landwehrausrüstung aufbrachte als das bevölkerungsstärkere Landsberg, eine Beamtenstadt mit Nahmarktfunktion, war in der Existenz einer Handvoll begüterter Kaufleute und Meister-Verleger begründet, die aus der Arbeit abhängiger „Fabrikanten“ und aus dem Tuchhandel großen Nutzen zogen. Dabei war in Züllichau in der zweiten Hälfte des 18. Jahrhunderts die Zahl der Meister im Zuge einer innergewerblichen Differenzierung um nahezu die Hälfte zurückgegangen, während sich die der Gesellen und der Produktionsausstoß erhöht hatten. Aber auf Grund der Entwicklung in Zielenzig, Callies, Drossen, Reppen und Cottbus wuchs das neumärkische Textilgewerbe nach dem Siebenjährigen Krieg erheblich an. Von den Kontributionssummen, die die neumärkischen Städte 1813 aufzubringen hatten, stammten zusammen ein Drittel aus den Städten Züllichau, Landsberg und Crossen, hinter denen die anderen Kommunen merklich zurückblieben. Zur damaligen Zwangsanleihe wurden vornehmlich die finanzkräftigen Kaufleuten in den größeren und überregionalen Handelsplätzen wie in den Textilgewerbezentren herangezogen.

Am Ende unseres Weges durch die Beiträge dieses Bandes angekommen, dürfen wir wohl im Rückblick das Fazit ziehen, daß die Konzentration auf den neumärkischen Regionalismus, auf seine Ausprägung und seine Behauptung, auf seine Eigenarten, die Umstände und Bedingungen ihrer Entfaltung ebenso wie ihrer Anpassung an allgemeine, übergeordnete Entwicklungen Brandenburg-Preußens reichen Ertrag vermittelt hat. Getragen wurde er vornehmlich von den Ständen, von Adel und Städten des Landes, die aus ihrer generationenlangen und jahrhundertealten gemeinsamen Erfahrung seiner (relativen) Eigen- und Selbständigkeit Willen und Kraft zu deren Bewahrung schöpften. Obwohl die Neumark von der zweiten Hälfte des 13. Jahrhunderts bis 1945 fast immer ein Teil Brandenburgs gewesen ist, wichen ihre politischen Geschicke wiederholt und merklich von denen der größeren und bedeutenderen Kurmark und ihrer Zentrallandschaft um Berlin ab, so daß sie sich in ihrer Eigenexistenz bestätigt fühlen konnte. Für die künftige landesgeschichtliche Forschung wird es erfolgversprechend sein, ihrer Entwicklung zwischen den Polen von „Resistenz“ und „Anpassung“ (Frank Göse) an Hand maßgeblicher Phänomene, von denen im Vorstehenden einige eingehend erörtert worden sind, weiterhin nachzugehen und Ursachen, Wirkungen und Kraft des ständischen Regionalismus in seinem Zusammenspiel und Widerspiel mit der Landesherrschaft intensiv zu erhellen. 


\title{
Die mittelalterliche Besiedlung der unteren Wartheregion (in der ehemaligen Neumark bzw. in den heutigen Wojewodschaften Zachodnio-Pomorskie, Lubuskie und Wielkopolskie) Eine deutsch-polnische Fallstudie anhand archäologischer Forschungen ${ }^{1}$
}

\author{
Von ARmin VolKMANN
}

Das Gebiet der ehemaligen Neumark ist seit über 100 Jahren als archäologisch fundreiche Region bekannt ${ }^{2}$, wie zahlreiche, auch außergewöhnliche Funde eindrucksvoll belegen. Die archäologischen Hinterlassenschaften vergangener Kulturen weisen auf unterschiedliche Einflüsse aus verschiedenen benachbarten Regionen hin. Die Neumark ist nicht eine in sich geschlossene Region, sondern es sind aus Ost und West sowie Nord und Süd unterschiedliche kulturelle Merkmale im archäologischen Fundgut auszumachen. Diese komplexen Zusammenhänge näher zu beleuchten, soll eine Aufgabe dieser Studie sein. Dabei geht es besonders um die Entwicklung der Kulturlandschaft, deren heutiges Erscheinungsbild stark durch die mittelalterlichen Vorgänge geprägt wurde. Besiedlungsvorgänge können nicht die gesamte Kulturlandschaftsgenese aufzeigen. Aber sie können, sofern sie mit archäologischen Mitteln fassbar sind, die Erschließung einer Landschaft durch die räumliche Verteilung der Artefakte aus verschiedenen archäologischen Kulturstufen im zeitlichen Verlauf gut erhellen.

Die mittelalterlichen Erschließungsprozesse sind keineswegs linear von der weitgehend ,natürlichen“ Landschaft hin zur Kulturlandschaft zu sehen ${ }^{3}$, sondern sie unterlagen starken epochalen Schwankungen von verstärkter oder verminderter Tätigkeit der Menschen. Sie sollen u.a. mit siedlungsarchäologischen Mitteln ${ }^{4}$ genauer untersucht werden. Dabei ist die Kartierung der Fundstellen aus den einzelnen Epochen, also die Projizierung der Fundstellen auf thematische Karten wie z.B. auf boden-geologische Karten und die

1 Die vorliegende Abhandlung basiert auf einer Magisterarbeit am Lehrstuhl für Ur- und Frühgeschichte der Humboldt-Universität zu Berlin und ist auf Initiative von Herrn Prof. Dr. A. Leube und unter Betreuung von Herrn Prof. Dr. E. Gringmuth-Dallmer entstanden, denen ich aufgrund ihrer konstruktiven Unterstützung zu Dank verpflichtet bin.

2 A. Götze: Die Vorgeschichte der Neumark. Würzburg 1897 (= Schriften des Vereins für Geschichte der Neumark, 5).

3 H. Ellenberg: Die Vegetation Mitteleuropas mit den Alpen. Stuttgart 1996.

4 H. Jankuhn: Einführung in die Siedlungsarchäologie. Berlin/New York 1977; - E. Gringmuth-Dallmer: Siedlungsmodelle für Überlagerungsprozesse am Beispiel der mittelalterlichen deutschen Ostsiedlung. Ländliche Siedlungen zwischen Spätantike und Mittelalter, in: Archäologie und Museum 33 (1995), S. 11-118. 
Kartierung der Fundstellen nach unterschiedlichen Fundarten, ein wichtiges graphisches Hilfsmittel, um räumliche Veränderungen der Siedlungsmuster zu erfassen (Abb. 1) $)^{5}$.

Grundlage dieser Untersuchung bildet der Fundstellenkatalog mit 500 Fundstellen der späten Völkerwanderungszeit und des Mittelalters auf dem Gebiet der ehemaligen Neumark. Zur exakten Fundstellenaufnahme wurden in den Archiven der Prähistorischen Abteilung des Märkischen Museums Berlin, des Museums für Vor- und Frühgeschichte Berlin sowie des Brandenburgischen Landesamts für Denkmalpflege die Akten der brandenburgischen Kreise (bis 1945) Königsberg/Nm., Landsberg/W., Soldin, Friedeberg, Arnswalde, West- und Oststernberg gesichtet und ausgewertet (Abb. 2) ${ }^{6}$. Diese sieben Kreise stellen die Neumark in den politischen Grenzen um 1900 dar. Die räumliche Eingrenzung war notwendig, um eine Gebietseinheit zu schaffen, denn die Grenzen der Neumark unterlagen im Verlauf der Jahrhunderte zahlreichen administrativen Veränderungen.

Eine zeitliche Zäsur stellt das Jahr 1945 dar, denn die brandenburgischen, östlich der Oder und Neiße liegenden Kreise gehörten nur bis zu diesem Zeitpunkt zu Deutschland. Nach 1945 wurden hier, nun von der polnischen Archäologie, selbstverständlich weiterhin Funde gemacht. Eine mit Kommilitonen des Lehrstuhls für Ur- und Frühgeschichte organisierte Exkursion in die heutigen Wojewodschaften Zachodnio-Pomorskie, Lubuskie und Wielkopolskie, die mit Teilen ihres Gebietes die einstige Neumark abdeckten, zeigte bei Besuchen der Regionalmuseen von Myślibórz (Soldin), Gorzów Wlkp. (Landsberg), Drezdenko (Driesen) und Barlinik (Berlinchen) zahlreiche Neufunde ${ }^{7}$. Es konnte eine Kontaktaufnahme zur polnischen Bodendenkmalpflege erreicht werden, die ein starkes Interesse an der Lage und Art der Altfundstellen bis 1945 bekundete.

$5 \quad$ Von besonderem Interesse war im Zuge einer Fundstellenkartierung die systematische Auswertung des in Berlin umfangreich vorhandenen historischen Kartenmaterials, wodurch die Rekonstruktion des ursprünglichen Landschaftsbildes ohne die massiven Veränderungen der jüngsten Vergangenheit erst möglich wird: Schmettausche Karten (1767-1784), Geognostische Kartenblätter der Provinz Brandenburg (1880-1920) und Urmesstischblätter Preußens (1826-44) in der Kartensammlung der Staatsbibliothek zu Berlin Preußischer Kulturbesitz; Luftbildaufnahmen der Alliierten (1941-45) in der Dokumentesammlung des Herder-Instituts e.V. in Marburg; thematischen Kartenwerke in dem von der Historischen Kommission zu Berlin veröffentlichten „Historischen Handatlas von Brandenburg und Berlin“. Berlin/New York 1980. - Herrn Prof. Dr. W. Schich vom ehemaligen Lehrstuhl für Landesgeschichte der Humboldt-Universität zu Berlin ist für die freundliche Ausleihe der thematischen Karten zu danken.

6 Hier gilt es besonders Herrn Dr. H. Junker vom Archiv sowie Frau A. Hoffmann vom Magazin des Museums für Vor- und Frühgeschichte der Stiftung Preußischer Kulturbesitz in Berlin sowie Frau G. Musch und Herrn Dr. D. Buck vom Ortsaktenarchiv des Brandenburgischen Landesamts für Denkmalpflege und Archäologischen Landesmuseums in Wünsdorf zu danken. Als echte Schätze erwiesen sich die gläsernen Bildplatten im Fundortarchiv der Prähistorischen Abteilung des Märkischen Museums aus der Zeit vor 1945. In meist gestochen scharfen Schwarz-Weiß-Aufnahmen sind viele der unwiederbringlich verlorenen Funde für die Forschernachwelt konserviert. Für die freigiebige Zurverfügungstellung der meist unpublizierten Bildplatten und Zeichnungen sowie des umfangreichen Aktenmaterials danke ich ganz besonders Herrn Dr. H. Seyer und Herrn Dr. E. Kirsch als auch Herrn B. Fischer vom Märkischen Museum der Stiftung Stadtmuseum Berlin.

7 Hier sei M. Gauza vom Stadtmuseum in Barlinek (Berlinchen), M. Kosciukiewicz und R. Jobke vom Plasticznej i Historiczne in Myślibórz (Soldin) sowie K. Zarębska vom Muzeum Puszczy Drawskiej i Noteckiej in Drezdenko (Driesen) für die Unterstützung und Hilfe vor Ort gedankt. 
Um wissenschaftlich fundierte Aussagen zu erreichen, stützt sich die Untersuchung nicht nur auf die Altfundstellen, sondern auf der Grundlage einer umfangreichen Literaturrecherche wurden die publizierten polnischen Fundstellen des Untersuchungsgebietes einbezogen. Die „Archäologischen Geländeaufnahmen Polens (AZP)“ wurden für das Gebiet um Gorzów Wlkp. (Landsberg a.d. Warthe) ausgewertet ${ }^{8}$. Allein hieraus konnten 142 meist unpublizierte Fundstellen nach 1945 untersucht werden. Es erwies sich, dass viele Altfundstellen der polnischen Bodendenkmalpflege unbekannt waren. Eine weiterführende epochenübergreifende Dissertation befindet sich in Arbeit. Ein Ziel dieses Projektes soll die Zusammenführung und Bereitstellung aller bekannten Fundstellen für polnische und deutsche Forscher sein. Die vorliegende Publikation ist ein Schritt in diese Richtung.

Bis heute steht eine umfassende und aktuelle archäologische Auswertung der zahlreichen Funde der Neumark aus. A. Götzes schmales Heftchen „Die Vorgeschichte der Neumark" von 1896 ist bis heute die einzige regionale, epochenübergreifende Auswertung der damals bekannten Funde. Der Forschungsstand für die Neumark steht weit hinter dem anderer Teile Polens zurück. Zum Beispiel ist das südöstlich angrenzende Großpolen (Wielkopolska), das „Kernland der Piasten“, gerade für das Mittelalter gut erforscht ${ }^{9}$. „Das überaus reiche Fundmaterial deutscher Museen aus der Zeit bis 1945 ist bis heute“ [jedoch nahezu] ,unpubliziert“10. Nach 1945 wurde Westpolen zur Randregion, die weitgehend ihren ländlichen Charakter behielt. Durch die geringere Bautätigkeit wurden auch weniger Artefakte geborgen. Seit der politischen Wende in Polen und in der DDR wurden Teile des Untersuchungsgebietes wieder verstärkt zum Transitland zwischen Ost und West. Dadurch kam es zu einem Wandel der Infrastruktur, der mit einer verstärkten Bautätigkeit verbunden ist und eine höhere Anzahl von archäologischen Funden zur Folge hat. Trotzdem blieb das Fundverteilungsbild ausschnitthaft mit Zufallscharakter, da viele Altfunde in Polen unbekannt sind und bis heute unbearbeitet in deutschen Archiven und Museen schlummern.

Das Untersuchungsgebiet ist für Vergleiche mit den westlich anschließenden Gebieten durch die Lage an der Oder ebenso wie mit dem südöstlich anschließenden Großpolen besonders interessant. Aufgrund des naturräumlichen Potentials sind die Regionen beiderseits der Oder miteinander vergleichbar, denn sie haben eine ähnliche naturräumliche Genese. Deutsche und polnische Untersuchungen des Projektes „Mensch und Umwelt

$8 \quad$ Mein Dank gilt Frau Małgorzata Pytlak vom Muzeum Lubuskie in Gorzów Wlkp. (Landsberg a.d. W.) und Frau Teresa Tybiszewska vom Wojewódzki Urząd Ochrony Zabytków w Zielonej Górze Delegatura Gorzów Wlkp., die mir die Auswertung des Fundstellenarchivs der polnischen Funde der „Archeologiczne Zdjęcie Polski - AZP“ (Archäologische Geländeaufnahme Polens) nach 1945 ermöglichten.

9 Z. Kurnatowska/A. Łosińska: Weryfikacja grodzisk wielkopolskich na półmetku, in: Fontes Archaeologici Posnanienses (FAP) 32 (1983), S. 25-62; - dies.: Sprawozdanie z weryfikacji grodzisk wielkopolskich w latach 1983-1984, in: Fontes Archaeologici Posnanienses (FAP) 34 (1985), S. 77-85.

10 A. Leube: Zur Ur- und Frühgeschichtsforschung im Odergebiet, in: E. Gringmuth-Dallmer/L. Leciejewicz (Hrsg.): Forschungen zu Mensch und Umwelt im Odergebiet in ur- und frühgeschichtlicher Zeit, 1-5. Mainz 2002. 
im mittleren und unteren Odergebiet" am Deutschen Archäologischen Institut (DAI) in Berlin unter Leitung von E. Gringmuth-Dallmer und L. Leciejewicz in der Zeit von 1992 bis 1998 verdeutlichten, dass die Oder in ur- und frühgeschichtlicher Zeit keine archäologisch-kulturelle Grenze war, sondern nachweislich schon ab dem Jungpaläolitikum einen Kulturtransfer erlaubte, der sich im ähnlichen archäologischen Fundmaterial beiderseits des Flusses bemerkbar macht ${ }^{11}$. Der richtungweisende Aufsatz von J. Strzelczyk ${ }^{12}$ über die „Probleme der Geschichte der Neumark im Mittelalter aus polnischer Sicht“ (mit einer umfassenden Bibliographie polnischer Arbeiten über das mittelalterliche Brandenburg) belegt die Notwendigkeit einer deutsch-polnischen Zusammenarbeit zur objektiven Aufarbeitung der Geschichte. Besonders im Hinblick auf das zusammenwachsende Europa mit Polen als neuem Mitglied der Europäischen Union sind Untersuchungen der Oder-Neiße-Warthe-Region besonders geeignet, vorhandene Gemeinsamkeiten in der (vor)geschichtlichen Kulturgenese aufzuzeigen.

\section{Spuren der späten Völkerwanderungszeit}

Aus den Grabbefunden der spätvölkerwanderungszeitlichen bis früh-/altslawischen Fundstellen des Untersuchungsgebietes konnten Fragen zur Kontinuität oder Diskontinuität sowie zu möglichen Kontakten der germanischen Restbevölkerung mit den slawischen Einwandern nicht eingehend beleuchtet werden. Es fällt allerdings auf, dass sich im Kreis Landsberg spätvölkerwanderungszeitliche Grabbefunde und Einzelfunde häufen. Erste eindeutig frühslawische Grabbefunde sind nur außerhalb des Untersuchungsgebietes, z.B. nördlich davon in Pommern, bekannt ${ }^{13}$. Auch südlich davon, in Schlesien ${ }^{14}$, und in dem westlich benachbarten Spree-Havelgebiet ${ }^{15}$ sind einige wenige frühslawische Fundstellen entdeckt worden, ausschließlich Brandbestattungen aus Gräberfeldern mit Flach- und Hügelgräbern (Abb. 3). Es könnte sich hier um Bestattungen handeln, die aus spirituellen bzw. rituellen Gründen (,Fluss-See-Gottheiten“) in der Nähe der zahlreichen, weiträumigen Fließe des Warthebruches angelegt wurden. Des weiteren ist zu bedenken, dass zur späten Völkerwanderungszeit der Grundwasserspiegel ca. $1 \mathrm{~m}$ tiefer lag als heute und

11 L. Leciejewicz/E.Gringmuth-Dallmer (Hrsg.): Człowiek a Środowisko w Środkowyn i Dolnym Nadodrzu. Mensch und Umwelt im mittleren und unteren Odergebiet. Beiträge zur ur- und frühgeschichtlichen Besiedlung. Wrocław 1996; - Gringmuth-Dallmer/Leciejewicz (Hrsg.): Forschungen (wie Anm. 10).

12 J. Strzelczyk: Probleme der Geschichte der Neumark im Mittelalter aus polnischer Sicht, in: L. Enders/K. Neitmann (Hrsg.): Brandenburgische Landesgeschichte heute. Potsdam 1999, S. $103-144$.

13 P. Swiątkiewicz: Próba periodyzacji roswoju obrządku pogrzebowego na wczesnośredniowiecznym Pomorzu, in: Materialy Zachodnio Pomorskie (MZP) 10 (1980), S. 145-158.

14 M. Parczewski: Początki Kultury Wczesnostowiańskiej w Polsce. Wrocław 1988; - ders.: Die Anfänge der Frühslawischen Kultur in Polen. Wien 1993, S. 94, Abb. 69.

15 S. Bracher: Archäologie der westlichen Slawen, in: H. Beck u. a. (Hrsg.): Ergänzungsband zum Reallexikon der Germanischen Altertumskunde, Bd. 30. Berlin/New York 2001. 
weite Teile des Warthe- und Netze-Bruchs trocken waren ${ }^{16}$. Aufgrund ihrer fruchtbaren Auenböden kamen sie durchaus als Ackerland und Siedlungsstandort in Frage. So liegen einige völkerwanderungszeitliche Siedlungen, die damals an den Gewässerrändern lagen, heute unter der Gewässeroberfläche. Dies zeigt sich im Oderbruch zwischen Lebus und Frankfurt an der kaiserzeitlichen bis völkerwanderungszeitlichen Siedlung Wüste Kunersdorf unter einer teilweise bis zu $70 \mathrm{~cm}$ mächtigen Auensediment-Schwemmschicht, die heute im jährlichen Hochwasserbereich liegt ${ }^{17}$.

Die im Kreis Landsberg gehäuften spätvölkerwanderungszeitlichen bis möglicherweise frühslawischen Grabbefunde sind zurückzuführen auf die im Vergleich zu anderen neumärkischen Regionen häufigen und systematischen Oberflächenbegehungen des Leiters des Landsberger Stadt- und Landmuseums, Fritz Buchholz, in den Jahren von 1922 bis $1944^{18}$. Dessen Fokus lag auf der Untersuchung von „,vorzeitlichen Gräberfeldern“. Auf seine Arbeit ist die Kenntnis von ca. 70-80\% aller Gräber und Einzelfunde aus unterschiedlichen Zeiten im Kreis Landsberg bis 1945 zurückzuführen.

\section{Siedlungen aus frühslawischer Zeit}

„Die älteste slawische Siedlung vom Typ Dziedzice [Deetz] in Westpommern scheint nicht viel jünger zu sein als die jüngsten Kulturkomplexe jener Region aus der Zeit der späten Völkerwanderung“", schreibt A. Porzeziński ${ }^{19}$. Kontakte von spätgermanischer und frühslawischer Bevölkerung ${ }^{20}$, in welcher Form auch immer, deuten sich in Łobzany (Fst. 1) in Westpommern $a^{21}$. Sie sind aber aufgrund der schwierigen Feindatierung bzw. Unterscheidung des spärlichen spätgermanischen oder frühslawischen Fundmaterials (oft

16 F. Brose: Ein Beitrag zur Entwicklungsgeschichte und der jüngeren Entwicklung des Flußsystems der unteren Oder, in: E. Gringmuth-Dallmer (Hrsg.): Beiträge zum Oderprojekt 2 (1997).

17 R. Laser: Die Ergebnisse der Archäologischen Ausgrabung der Wüste Kunersdorf, Kr. Seelow, in: Veröffentlichungen des Museums für Ur- und Frühgeschichte Potsdam 4 (1968), S. $23-98$.

18 Fitz Buchholz versuchte, wie einige andere „Forscher“ bis 1945 auch, aufgrund der archäologischen Hinterlassenschaften ein „lineares Deutschtum“ östlich der Oder nachzuweisen, in dem er retrospektiv die germanischen (vorslawischen) Funde einem „,deutschen Ethnikum“ gleichsetzte und somit, methodisch völlig falsch, das "Warthe-Netzeland“" als ,urdeutsches Siedlungsgebiet" bezeichnete. F. Buchholz: Aus der Vorgeschichte des Kreises Soldin. 4. Die Völkerwanderungszeit, Wendenzeit und die Zeit der Wiedereindeutschung, in: Heimatkalender des Kreises Soldin/Nm. 10 (1931), S. 45-83. - Zur Person von F. Buchholz siehe: E. Dahms: Fritz Buchholz und das Heimatmuseum, in: H. Beske und E. Handke (Hrsg.): Landsberg an der Warthe 1257-1945-1976. Stadt und Land im Umbruch der Zeiten. Schriftenreihe der Bundesarbeitsgemeinschaft Landsberg/W., Band II: Aus Kultur und Gesellschaft im Spiegel der Jahrhunderte. Bielefeld 1978, S. 30 ff.

19 M. Parczewski: Z badań nad problematyką osadnictwa najstarrszej fazy wczesnego średniowiecza na Pomorzu Zachodnim, in: Materialy Zachodnio Pomorskie (MZP) 26 (1980), S. 115-144.

20 Zur ethnischen Deutung von archäologischem Fundmaterial als „spätgermanisch“ oder ,frühslawisch“ siehe: S. Brather: „Germanische“, „slawische“ und „,deutsche“ Sachkultur des Mittelalters - Probleme ethnischer Interpretation, in: Ethnographisch Archäologische Zeitschrift (EAZ) 37 (1996), S. 177-216.

21 W. Łosiński: Osadnictwo plemienne Pomorza VI-X wiek. Warszawa/Wrocław/Kraków/Gdańsk/ Łódź 1982. 
nur recht undifferenzierte, grob gearbeitete Kümpfe) im Untersuchungsgebiet längst nicht verifiziert. Westlich der Oder, in der Gemarkung Waltersdorf (südlich von Berlin), zeichnet sich in der intensiv untersuchten Siedlungskammer ein wahrscheinlicher Hiatus von maximal 100 Jahren zwischen spätgermanischer und frühslawischer Besiedlung ab. Die jüngsten germanischen Siedlungen wurden ab der Mitte des 5. bis ins ausgehende 6. Jahrhundert nicht mehr genutzt ${ }^{22}$. Aufgrund neuer Dendrodaten wird westlich der Oder die slawische Einwanderung nicht vor das Ende des 7. oder gar in das beginnende 8. Jahrhundert angesetzt ${ }^{23}$. Die Wahl von teilweise denselben Standorten für die Siedlungen ist

22 A. Leube: Germanische Völkerwanderungen und ihr Fundniederschlag. Bemerkungen zu den germanisch-slawischen Kontakten, in: Ethnographisch Archäologische Zeitschrift (EAZ) 36/2 (1995), S. 259-298.

23 Bis zum Anfang der neunziger Jahre ging man von einem lückenlosen Übergang bzw. von Kontakten spätgermanischer und frühslawischer Siedler aus. Einige brandenburgische Landschafts-, Fluss- und Gewässernamen, z.B. Havel, Spree, Nuthe u.a., scheinen germanischen Ursprungs zu sein (siehe R. E. Fischer/G. Schlimpert: Vorslawische Namen in Brandenburg, in: Zeitschrift für Slawistik 5, S. 661-697). Sie verweisen damit auf Kontakte, in welcher Form auch immer, von Slawen und Germanen. Denkbar sind auch von umherreisenden Händlern vermittelte germanische Namen, die so den Slawen bereits vor deren Einwanderung bekannt gewesen sein könnten. Auch die pollenanalytischen und dendrochronologischen Analysen aus den beginnenden siebziger und achtziger Jahren (siehe P. Donat und E. Lange: Botanische Quellen und Probleme der Landwirtschaftsentwicklung im ersten Jahrtausend, in: Zeitschrift für Archäologie 17 [1983], S. 223-248) schienen einen germanisch-slawischen Kontakt zu belegen oder zumindest wahrscheinlich zu machen. Das vielzitierte dendrochronologische Material - z.B. die spätgermanischen und frühslawischen Brunnenhölzer aus Berlin-Marzahn (B. Fischer/E. Kirsch: Die frühslawische Besiedlung Berlin-Marzahn, in: Veröffentlichungen des Museums für Ur- und Frühgeschichte Potsdam 17 [1983], S. 147-164) enthielt in insgesamt vier Proben nur jeweils 25 bis maximal 50 erhaltene Jahrringe, so dass eine gesicherte Gleichläufigkeit mit der standardisierten Jahrringkurve von Haithabu prinzipiell nicht erreicht werden konnte. Es gelang auch nicht, die zahlreichen Pollenprofile aus Mecklenburg und der Niederlausitz exakt, absolut chronologisch, zu kalibrieren. Somit existiert bis heute in Deutschland und Polen (siehe M. Mączyńska: Die Endphase der Przeworsk-Kultur, in: Ethnographisch Archäologische Zeitschrift [EAZ] 39 [1998] S. 65-99) kein naturwissenschaftlicher oder archäologischer Beweis für spätgermanisch-frühslawische Kontakte, die aber, wenn auch in sehr geringem Umfang und archäologisch kaum fassbar, durchaus vom späten 5. bis 7. Jh. bestanden haben könnten. Bereits K. Grebe (Zur frühslawischen Besiedlung des Havelgebietes, in: Veröffentlichungen des Museums für Ur- und Frühgeschichte Potsdam 10 [1976], S. 167-204) konnte für das Havelland aufgrund stratigraphisch-typologischer Überlegungen verdeutlichen, dass die slawische Einwanderung nicht vor das 7. Jh. zu stellen ist. Die ältesten, als gesichert geltenden frühslawischen Dendrodaten datieren in die erste Hälfte des 8. Jhs. Sie stammen aus Bauhölzern von frühslawischen Brunnen wie die des Brunnens von Berlin-Marzahn, der nun nach Aufbau einer regionalen, brandenburgischen Jahrringkurve um 739 datiert wird (J. Henning/K. U. Heußner: Zur Burgengeschichte im 10. Jahrhundert. Neue archäologische und dendrochronologische Daten zu Anlagen vom Typ Tornow, in: Ausgrabungen und Funde 37 [1992], S. 314-324); dabei wird durch die Regionalität der Jahrringkurve eine größere Gleichläufigkeit und damit Genauigkeit von Proben auch mit nur wenigen Jahrringen erzielt. Ein weiterer frühslawischer Holzkasten-Brunnenbefund aus Brandenburg-Schmerzke (F. Biermann/S. Dalitz/K.U. Heußner: Der Brunnen von Schmerzke, Stadt Brandenburg a.d. Havel und die absolute Chronologie der frühslawischen Besiedlung im nordostdeutschen Raum, in: Prähistorische Zeitschrift 74 [1999], S. 219-234) datiert ebenfalls in das frühe 8. Jh., mit Fälldatum der Bauhölzer im Frühjahr bis Frühsommer 736, und gibt so gleichzeitig eine absolute Zeitmarke als terminus post quem für die Begleitfunde der frühslawischen Keramik vom Sukower Typ. A. Leube : Germanische Völkerwanderungen und ihr archäologischer 
wohl eher in einer ähnlichen Bewirtschaftung der Nutzflächen zu suchen, als dass sich durch die räumliche Übereinstimmung zwangsläufig zeitliche Überschneidungen oder gar echte Kontakte ergeben müssten. Inwieweit sich diese Ergebnisse auf das östlich der Oder gelegene Untersuchungsgebiet übertragen lassen, ist fraglich, da sich die slawische Einwanderung aufgrund der Wanderungsbewegungen von der Ostsee und von Kleinpolen her schon früher, d.h. im Nordteil der Neumark schon ab dem frühen bis mittleren 7. Jahrhundert, vollzog ${ }^{24}$. Großflächige Untersuchungen stehen jedoch für Westpolen noch aus. Die zeitlich versetzte, erst ab dem späten 7. Jahrhundert erkennbare, von Süden bzw. Südosten gerichtete frühslawische Einwanderung in den Süden der Neumark scheint sich durch früher zu datierende Siedlungsbefunde, die südlich des Untersuchungsgebietes, bei Jazów (pow. Gubin), gemacht wurden, zu bestätigen ${ }^{25}$.

Die frühslawische Landnahme erfolgte sporadisch und nicht flächendeckend, wobei einzelne siedlungsungünstige Gebiete nur durchstreift und nicht erschlossen wurden. Die Gebiete der ältesten belegbaren Landnahme liegen an der südöstlichen Ostseeküste (siehe Anmerkung 119). Das unmittelbare Hinterland Westpommerns, besonders das Gebiet des „Pyritzer Weißackers“ um Pyritz (Pyrzyce) mit fruchtbaren schwarzerdeähnlichen Böden und zahlreichen Seen und Fließen, weist einige der ältesten frühslawischen Fundstellen des frühen bis mittleren 7. Jahrhunderts auf. Die südlich anschließende Neumark wurde wahrscheinlich während der Einwanderung von Norden her in weiten Teilen durchzogen.

Fundniederschlag. Das 5. u. 6. Jh. östlich der Elbe, in: Ethnographisch Archäologische Zeitschrift 36/1 (1995), S. 3-84, verweist auf die bekannte Trockenperiode des 5.-7. Jhs. (J. Hermann/K. U. Heußner: Dendrochronologie, Archäologie und Frühgeschichte vom 6. bis 12. Jh. in den Gebieten zwischen Saale, Elbe und Oder, in: Ausgrabungen und Funde 36/6 [1991], S. 255-290), aus der, klimatisch bedingt, kaum Bauhölzer überliefert sind. Trotz dieser möglichen Forschungslücke, aufgrund der schlechten Erhaltungsbedingungen für Bauhölzer als auch wegen der typologisch schwer unterscheidbaren Keramik geht er von einem Hiatus zwischen spätgermanischer und frühslawischer Besiedlung von 100-150 Jahren im westlichen Odergebiet aus. Selbst wenn dies zutreffen mag, ist das Vorhandensein von Dendrodaten erst ab dem frühen 8. Jh. im westlich der Oder gelegenen slawischen Siedlungsbereich kein zwingender Beweis für eine slawische Landnahme des unteren Oder-Warthegebiets erst ab dem ausgehenden 7. oder beginnenden 8. Jh. Leider gibt es aus dem Untersuchungsgebiet kein Dendrodatum aus der Zeit vor der 2. Hälfte des 10. Jhs., so dass auch im Zuge dieser Untersuchung der absolute Zeitpunkt der slawischen Einwanderung offen bleiben muss.

24 Die schriftlichen Quellen der Historiae VI 2, 12-14 des Theophylos Simocattes (um 590) nennen die Slawen schon um 590 als an der Ostsee ansässig (,,am äußersten Ende des westlichen Ozeans“, Leube: Germanische Völkerwanderungen [wie Anm. 22]), so dass eine wenn auch sporadische und äußerst dünne Besiedlung des südlich anschließenden Binnenlands Westpommerns, nördlich des Untersuchungsgebiets, ab dem Ende des 6. Jhs. wahrscheinlich erscheint. Im Untersuchungsgebiet ist das bis zu $8 \mathrm{~km}$ breite, sumpfige Warthedelta keine „Leitlinie der frühslawischen Einwanderung“, wie es das untere Odertal war, sondern eine Barriere. Die frühslawische Landnahme des nördlichen Untersuchungsgebiets erfolgte wahrscheinlich zuerst, von der Ostseeküste ausgehend, in südlicher Richtung über das fruchtbare Binnenland des Pyritzer Weißackers bis zur Warthe schon im frühen bis mittleren 7. Jh. Das Gebiet südlich der Warthe wurde wesentlich später, erst ab dem Ende des 7. Jhs., wahrscheinlich aus südöstlicher Richtung vom frühslawischen Fundzentrum in Kleinpolen (siehe Anm. 11) her erschlossen.

25 F. Biermann: Slawische Besiedlung zwischen Elbe, Neiße und Lubsza. Archäologische Studien zum Siedlungswesen und zur Sachkultur des frühen Mittelalters. Bonn 2000. 
Erschlossen wurden nur besonders attraktive Siedlungsstandorte mit hohem wirtschaftlichem Potential. Die Aufsiedlung des südlich der Warthe (Warta) gelegenen, in weiten Teilen für den Ackerbau recht unfruchtbaren Gebiets wurde erst aufgrund von ersten infrastrukturellen Erschließungen eines Verkehrswegenetzes, gewissermaßen als Transitland zwischen Zentralpolen (dem Gebiet um Posen [Poznań]) und dem mittleren Odergebiet (um Lebus), zum Ende des 7. Jahrhunderts notwendig ${ }^{26}$.

In dem frühslawischen rechteckigen Grubenhausbefund mit Pfosten- und Dachkonstruktionsspuren von Jazów (pow. Gubin) ist ausschließlich handgemachte, dickwandige und unverzierte Keramik gefunden worden, die eindeutig dem typologisch älteren frühslawischen Prager Keramiktyp zuzuordnen ist. Sie kann daher ins frühe 7. Jahrhundert datiert werden. Im äußersten Nordosten des Untersuchungsgebietes in Słutowo (Kreis Arnswalde) wurde der einzige Siedlungsbefund der späten Völkerwanderungszeit des 5./6. Jahrhunderts entdeckt. Trotzdem zeichnet sich ein weitgehender Siedlungshiatus zwischen spätgermanischer und frühslawischer Zeit ab, wenn auch eine äußerst geringe, archäologisch kaum fassbare, spätgermanische Restbevölkerung durchaus bis in slawische Zeit hinein Gebiete mit sehr guten Böden, die auch in dieser Trockenphase Getreideanbau als wirtschaftliche Grundlage ermöglichten, bewohnt haben könnte. Zweifelsohne waren aber (fast) alle spätgermanischen Siedlungen spätestens ab dem Ende des 6. Jahrhunderts aufgegeben worden, und die Bevölkerung war nach Südwesten abgewandert. So ist davon auszugehen, dass die von Germanen genutzten Wirtschaftsflächen, Äcker, Weiden und Eisenverhüttungsplätze über ein Jahrhundert später bei Ankunft der Slawen wieder bewaldet waren. Zumindest müssen die ehemaligen Wirtschaftsflächen mit PionierHolzgewächsen (wie Holunder, Kiefer und Birke usw.) stark verbuscht oder mit einem lichten Parkwald bedeckt gewesen sein. Insgesamt gesehen war das Untersuchungsgebiet weitgehend siedlungsleer, was auch von pollenanalytischen und bodenkundlichen Unter-

26 Ähnliche Landnahmeprozesse zeigen sich, wenn auch später, in der Niederlausitz, wo die Spreewaldniederung mit ihren fruchtbaren Böden schon in frühslawischer Zeit erschlossen wurde. Der südöstlich anschließende Lausitzer Landrücken mit seinen trockenen und recht unfruchtbaren Böden wurde hingegen in spätslawischer Zeit aufgesiedelt, wie einige Regionaluntersuchungen zeigen (siehe z.B. A. Volkmann: Alte Sellessener und Neu Haidemühler. Spätgermanische Kulturlandschaft. Untersuchungen am Umsiedlungsstandort Sellessen, Lkr. Spree-Neiße, in: Ausgrabungen im Niederlausitzer Braunkohlenrevier 2004, S. 108-124 [=Arbeitsberichte der Bodendenkmalpflege in Brandenburg 14. Calau 2005]). Die Wahl dieser wirtschaftlich relativ schlechten Siedlungsstandorte wurde erst durch einen steigenden Bevölkerungsdruck, nach einer starken Bevölkerungszunahme (E. Gringmuth-Dallmer: Bevölkerungsexplosion um die Jahrtausendwende? Zur Umgestaltung der slawischen Siedlungslandschaft in Nordostdeutschland, in: H. Küster/A. Lang/P. Schauer [Hrsg.]: Archäologische Forschungen in urgeschichtlichen Siedlungslandschaften. Festschrift für G. Kossack zum 75. Geburtstag. Regensburg/Bonn 1998, S. 577-601) notwendig. Wahrscheinlich spielten auch klimatische Bedingungen eine Rolle, denn erst mit einem allmählichen Anstieg der Niederschläge ab mittelslawischer Zeit (Hermann/Heußner: Dendrochronologie [wie Anm. 23]) konnten die stellenweise von niedrigen Grundwasserständen geprägten Böden und damit besonders die von Niederschlag abhängigen Grundmoränenplatten und Endmoränenzüge als Wirtschaftsland flächig erschlossen werden. 
suchungen aus dem unteren Odergebiet bestätigt wird ${ }^{27}$. H.-U. Voss konnte eine Diskontinuität der jüngsten spätgermanischen und ältesten frühslawischen Siedlungen im Gebiet zwischen Elbe/Saale und Oder/Neiße aufzeigen ${ }^{28}$. Die ersten frühslawischen Siedlungen wurden zwar in der Nähe spätgermanischer Siedlungen errichtet, aber meist nicht genau am selben Platz, sondern nur innerhalb der stellenweise recht offenen, nicht flächig dicht bewaldeten Altsiedellandschaft, da sich die slawischen Neusiedler durch ähnliche Wirtschaftsweisen auszeichneten wie die germanischen Altsiedler und somit ähnliche Ansprüche an den Siedlungsstandort stellten ${ }^{29}$.

Die frühslawischen Siedlungen des Untersuchungsgebietes, Deetz (Dziedzice) und Dertzow (Derczewo), liegen beide im Norden des Kreises Soldin innerhalb des frischen (wenig entkalkten) Grundmoränengebietes um die Soldiner-Seenplatte, etwas südlich des Pyritzer Weizackers, mit fruchtbaren Schwarzerden. Das feingliedrige Bodenmosaik aus basenreichen lehmig-sandigen Braunerden für Ackerbau und humusreichen Niederungstorfen für Viehweidewirtschaft bietet gute naturräumliche Voraussetzungen für die Landwirtschaft. Bewaldete Flächen, die das benötigte Bauholz lieferten, waren jedoch bei weitem die vorherrschende Vegetationsform ${ }^{30}$.

In Deetz ebenso wie in Dertzow weisen die erkannten Gruben ganz ähnliche Maße auf. In Deetz sind sie in der überwiegenden Mehrzahl auf eine Achse ausgerichtet ${ }^{31}$. Dies lässt auf eine planvolle oder zumindest koordinierte Anlage der Siedlung schließen (Abb. 4). Die langovalen Gruben dieser unbefestigten Siedlung finden eine eindeutige Parallele mit analogen Befunden in den frühslawischen Siedlungsgruben von TornowLütjenberg in der Niederlausitz. Insgesamt entdeckte man in Deetz ca. 120 frühslawische Gruben, wovon ca. 46 als Halbgrubenhäuser mit einer oberirdischen Blockbebauung zu interpretieren sind, da sich keine Pfostenlöcher oder andere archäologische Indizien für eine andere obertägige Bebauung fanden. In zwei Gruben konnte durch ein Gussformund Schmelzschlackenfragment Eisenverarbeitung nachgewiesen werden. Die Siedlung konnte leider nicht komplett ausgegraben werden. Fraglich ist auch, wie viele Häuser gleichzeitig bestanden haben. Damit ist kein Anhaltspunkt für eine Hochrechnung der Bevölkerungszahl der Siedlung oder gar Region gegeben.

In Tornow-Lütjenberg wurden neben spätgermanischen auch völkerwanderungszeitliche sowie frühslawische Gruben entdeckt. Neben dem Hauptanteil von Sukower Keramik

27 T. Schatz: Untersuchungen zur holozänen Landschaftsentwicklung Nordostdeutschlands. Zalf-Bericht 41. Müncheberg 2000.

28 H.-U. Voss: Kontinuität und Diskontinuität von der spätvölkerwanderungszeitlichen germanischen zur frühslawischen Besiedlung zwischen Elbe/Saale und Oder/Neiße, in: Archäologie und Heimatgeschichte 1 (1989), S. 58-65.

29 E. Gringmuth-Dallmer: Siedlungsmodelle (wie Anm. 4).

30 Z. Kurnatowski: Die Wirtschaft, Besiedlung und Siedlungslandschaft der Westslawen zwischen Oder und Weichsel, in: A. Wieczorek/H.-M. Hinz (Hrsg.): Europas Mitte um 1000, Band 1. Stuttgart 2000, S. 92-96.

31 Parczewski: Z badań (wie Anm. 19); - R. Köhler: Frühe slawische Siedlungen in Pommern unter besonderer Berücksichtigung der neuen Grabungen in Dziedzice/Deetz, in: Offa 37 (1980), S. $177-183$. 
in den früh- bis mittelslawischen (=altslawischen) Gruben wurde frühslawische Keramik des Prager-Typs und des mittelslawischen Menkendorfer-Typs gefunden. F. Biermann stellt die dominante Sukower Keramik der Siedlung ins 8. Jahrhundert und setzt ihren Anfang, d. h. die slawische Einwanderung in die Niederlausitz, ins späte 7. oder erst ins 8. Jahrhundert ${ }^{32}$. Die Keramik vom Typ Deetz, die typologisch weitgehend der Sukower Keramik entspricht, kann aber durchaus in Westpommmern etwas früher angesetzt werden. Die Einwanderung erfolgte wie oben erwähnt nicht flächendeckend, d.h. mit einer kompletten Erschließung der Gebiete von Südwesten her, sondern sukzessive. Es wurden zuerst die Flächen, die wirtschaftlich etwa durch sehr gute Böden wie um Deetz am interessantesten waren, besiedelt und erschlossen. Diese „schwarzerdeähnlichen“ Böden sind in der Niederlausitz nicht zu finden. Möglicherweise kannten die slawischen „Neusiedler", die nicht als geschlossene „Stammesverbände“, sondern eher in mehreren „Kleingruppenschüben“ einwanderten ${ }^{33}$, aus ihrem mutmaßlichen Ursprungsgebiet, dem Karpatenraum, Balkan, Donaugebiet und/oder der Südukraine, das hohe Potential von Schwarzerden noch, denn diese sind dort weit verbreitet und ermöglichen bei leichter Bearbeitbarkeit ertragreiche Ernten. Hinzu kommt noch, dass die natürliche, potentielle Vegetation auf ihnen Buschwald ist, und somit sind die Schwarzerdeflächen einfach zu roden. Es spricht also einiges dafür, die slawische Einwanderung im Norden der Neumark bereits in die Mitte des 7. Jahrhunderts zu rücken. Wenn die Einwanderer den Hauptflusslinien gefolgt sind, entlang den „hydrologischen Leitlinien“, wie vielfach behauptet, wäre das Gebiet um Deetz über die Oder, der Mietzel (Myśla) folgend, zudem leicht erreichbar (Abb. 5).

Insgesamt sind frühslawische Siedlungsbefunde im Untersuchungsgebiet sehr selten ( 2 von 500 Fundstellen), ebenso in der Niederlausitz mit 7 von 620 Fundstellen $^{34}$. Die frühslawische Besiedlung war daher wohl nur sporadisch, in der Niederlausitz wie in der Neumark herrschte eine geringe Siedlungsdichte im vorherrschenden Waldland. Es wurden anfangs wahrscheinlich nur die allerbesten Standorte besiedelt. 17 Fundstellen des Katalogs mit insgesamt 500 Fundstellen (bzw. 646, wenn man die unterschiedlichen Eigenschaften und mehrfachen Zeitstellungen der einzelnen Fundstellen beachtet) sind in die späte Völkerwanderungszeit bis früh- bzw. altslawische Zeit einzuordnen. Dies sind gerade einmal 3,4\% (bzw. 2,7\% bei beachteter Mehrphasigkeit der Fundstellen) der Gesamtfundstellenanzahl.

\section{Erste altslawische Burgen}

Nördlich der Warthe (Warta) war nur ein altslawischer Burgwall, in Reetz (Recz, Kr. Arnswalde), auszumachen, der wohl aufgrund des Fundmaterials erst in mittelslawische Zeit datiert. Südlich der Warthe aber, im Sternberger und im östlichen Lebuser Land,

32 Biermann: Slawische Besiedlung (wie Anm. 25), S. 40 u. 281.

33 Brather: Sachkultur (wie Anm. 20), S. 195.

34 Biermann: Slawische Besiedlung (wie Anm. 25), Katalog. 
sind insgesamt sechs früh- bzw. altslawische Burgen nachzuweisen, die als die ältesten slawischen Burgwälle Polens angesehen werden ${ }^{35}$. Ähnlich alte Burgwallanlagen liegen im südöstlich benachbarten Großpolen. Interessant ist auch, dass in den anschließenden Gebieten Pommerns und der Niederlausitz keine Burgen aus jener Zeit zu erkennen sind. Es muss im südlichen Oder-Warthegebiet daher schon früh zu hoch organisierten Gesellschaften gekommen sein, die für den Burgenbau mit seinem immensen Aufwand an Arbeit und Organisation vorauszusetzen sind. Wahrscheinlich ist dies auch im Zusammenhang mit der Nachbarschaft zu den aufstrebenden Piasten zu sehen, aus deren Bestrebungen bis zum Ende des 10. Jahrhunderts die polnische Staatsbildung hervorging ${ }^{36}$.

Die acht altslawischen Burgen des Untersuchungsgebietes (Abb. 6) sind bis auf zwei Ausnahmen von Höhenburgen Burgwälle in feuchten Niederungen (Niederungsburgen). Eine Höhenburg von ca. 100 x 150 m Größe liegt bei Göritz (Gorzyca) und datiert in altslawische Zeit, wohl ins 8./9. Jahrhundert. Es handelt sich um eine Spornbefestigung eines Hochplateaus in exponierter Lage über der im südlichen Teil des Untersuchungsgebiets einzigen Oderfurt, mit weiter Sicht über das anschließende Umland. An dieser Stelle wurde später die Göritzer Kathedrale mit dem Bischofssitz des Lebuser Landes von 1276 bis 1325 errichtet $^{37}$. Hier konnte auch ein spätkaiserzeitliches Gräberfeld aufgedeckt werden. Die beiden Oststernberger Burgwälle, Alt Limmeritz (Limierzyce) und Gleißen (Glisno), datieren beide in die Phasen B-C (8./9. Jh.). Alt Limmeritz wurde bis D (ca. 10. Jh.), möglicherweise mit einer kurzfristigen Unterbrechung in $\mathrm{C}$, weiter genutzt. Beide sind somit früh- bis mittelslawisch bzw., allgemein gesagt, altslawisch. Der Befund von Gleißen zeigt ebenfalls wie der von Alt Limmeritz einen zweifachen Ringwall in der Niederung an einem See. Mit einem Durchmesser von ca. 150 m bzw. 100 x 200 m sind sie mehr als doppelt so groß wie der zweifache Ringwall von Göbitsch (Garbicz), der einen Durchmesser von nur ca. $60 \mathrm{~m}$ aufweist, auf einem Sporn liegt, in die Phasen B bis F (mit überbauter hochmittelalterlicher Motte) datiert und auch eine früheisenzeitliche Vornutzung aufweist. Ein Burgwall von gleicher Zeitstellung und mit ähnlichen Ausmaßen, von ebenfalls ca. $60 \mathrm{~m}$ im Durchmesser, ist in Groß Gandern (Gádkow Wielki) zu finden, liegt jedoch in der Niederung unweit der Pleiske (Pliszka) zwischen zwei Seen auf einer künstlichen Aufschüttung. Die Burganlage ist von Sumpf umgeben und an der einzig zugänglichen Seite noch durch einen Abschnittswall gesichert. Nördlich des Burgwallgeländes wurde ein Hügelgräberfeld entdeckt, das sich im heutigen Wald in unmittelbarer Nähe

35 Z. Kurnatowska/A. Łosińska: Perspektywy badań nad wczesnym średniowieczem Ziemi Lubuskiej. Perspektiven der Forschung zum Mittelalter im Lebuser Land, in: Leciejewicz/Gringmuth-Dallmer (Hrsg.): Człowiek (wie Anm. 11), S. 161-176.

36 Z. Kurnatowska: Territorial Structures in West Poland prior to the founding of the State organization of Mieszko I., in: P. Urbańczyk (Hrsg.): Origins of Central Europe. Warsaw 1997, S. 125-135; dies.: Forschungen zu frühmittelalterlichen Burgen in Großpolen; in: J. Hennning/T. Ruttkay (Hrsg.): Frühmittelalterlicher Burgenbau in Mittel- und Osteuropa. Bonn 1998, S. 31-36; - dies.: Herrschaftszentren und Herrschaftsorganisation, in: Wieczorek/Hinz (Hrsg.): Europas Mitte (wie Anm. 30), S. 458-463.

37 U. Fiedler: Das Land Lebus in piastischer Zeit, in: S. Moździoch (Hrsg.): Centrum i zaplecze we wczesnoşredniowiecznej Europie środkowej. Wrocław 1999, S. 218. 
zum Seeufer befindet. Wahrscheinlich stammt es aus der gleichen früh- bis mittelslawischen Zeit oder ist noch älter (früheisenzeitliches „Lausitzer“ Gräberfeld mit slawischen Nachbestattungen?). Im Hochmittelalter, also in der Phase E-F (ca. 1150 bis 1350), wurden im Sternberger Land über fünf der insgesamt acht einstigen Burgwallanlagen in Form einer Motte zur Kennzeichnung der neuen Machtverhältnisse überbaut.

Die Chronologie der Burgwälle des Untersuchungsgebietes ist aufgrund fehlender Dendrodaten noch nicht ausreichend verifiziert und kann nur relativchronologisch ,eingehängt" werden. Jedoch ist das östlich anschließende Gebiet Großpolens (Wielkopolska) durch eine Vielzahl von dendrochronologischen Untersuchungen umfassend absolutchronologisch datiert ${ }^{38}$. Ebenso können auch analoge Befunde und Funde der benachbarten Neumark datiert werden. In Zantoch (Santok), aus dem einzig dendrochronologisches Material des Untersuchungsgebietes (Eichenholz aus dem Ringwall, dem Siedlungshorizont 4, Phase D, $967+2 /-9$ A.D. ${ }^{39}$ ) vorliegt, wurde retrospektiv, bei einer angenommenen Besiedlungsdauer von durchschnittlich 50 Jahren je Horizont, der Siedlungsbeginn in das Ende des 7. Jahrhunderts gesetzt. Die Phase B (Phase A ist im Untersuchungsgebiet in keinem Burgwall nachweisbar) umfasste demnach die Zeit vom Ende des 7. bis in die Mitte des 8. Jahrhunderts. Der Beginn der ältesten Burgwälle im Sternberger Land liegt daher wohl in der Mitte des 7. Jahrhunderts. Dies deckt sich aufgrund des Fundmaterials auch mit den neuen Keramikchronologien, die durch Dendrodaten und Silbermünzfunde (terminus post quem) aus dem gesamten westslawischen Gebiet verifiziert wurden ${ }^{40}$. Anders als bei den offenen frühslawischen Siedlungen kann den Burgwällen eindeutig ein wehrhafter Charakter zugesprochen werden. Bei der Burgplatzwahl wurde immer die Topographie des Reliefs ausgenutzt und ein Standort gewählt, der möglichst nur von einer Seite, als Eingang und Ausgang, leicht zugänglich war.

Die frühslawischen Burgwälle waren zuerst nur eingezäunte Siedlungen, wie in Zantoch (Santok) belegt ist. Hier waren die Häuser der frühslawischen Siedlungshorizonte mit Flechtwerkwänden mit Lehmputz ausgestattet und mit einem Holzplankenzaun eingezäunt. Ein Burgwall war zu diesem Zeitpunkt noch nicht vorhanden ${ }^{41}$. Auch im Vergleich mit der Niederlausitz zeigt sich unter dem Burgwall von Tornow „Bochelt“, der sogar in mittelslawische Zeit datiert, zuunterst eine offene Siedlung, die erst um 900 umgebaut und mit einem umschließenden Wall befestigt wurde ${ }^{42}$. Von Interesse ist auch, dass bereits vor der Tornower Siedlung „Bochelt“ ein zweite offene Siedlung „Lütjenberg“ in unmittelbarer Nähe bestand. Wahrscheinlich ging aus der ältesten frühslawischen Siedlung eine Tochtersiedlung hervor. Beide bestanden wahrscheinlich fast ein Jahrhundert (oder etwas

38 M. Kapiec: Dendrochronological dating of early fortified settlements in Poland, in: Henning/Ruttkay (Hrsg.): Frühmittelalterlicher Burgenbau (wie Anm. 36), S. 257-266.

39 Kurnatowska: Forschungen (wie Anm. 36).

40 Brather: Sachkultur (wie Anm. 20), S. 183.

41 U. Dymaczewska: Frühmittelalterliche Keramik aus Santok, Kreis Gorzów Wielkopolski, in: Archaeologia Polonica 13 (1972), S. 165-192.

42 Hermann/Heußner: Dendrochronologie (wie Anm. 23), Abb. 4. 
weniger) parallel, bis die Tochtersiedlung noch in frühslawischer Zeit zum neuen Zentrum aufstieg und die alte Siedlung aufgelassen wurde und wüst fiel.

\section{Fundverteilung der mittelslawischen Zeit}

Aus der mittelslawischen Zeit liegen Einzelfunde nur im westlichen Untersuchungsgebiet vor. Hier war die Bodendenkmalpflege besonders intensiv, so dass auch solche gemeldet wurden. Da es sich um besonders viele Lanzenspitzen, zwei Bartäxte und Pfeilspitzen handelt, die ausschließlich im äußersten Westen des Kreises Königsberg zu finden waren, wurden hier höchst wahrscheinlich Opfergaben in den offenen Gewässern des Odergebietes Fluss- oder Seegottheiten dargebracht. Eine zweite Gattung der mittelslawischen Einzelfunde sind jene, die als Teilfunde einer nicht erkannten Siedlung anzusehen sind.

Ein Überblick aller mittelslawischen offenen Siedlungen auf der geologischen Karte (Abb. 8) zeigt, dass sie meist nur an den Grundmoränenrändern in der Nähe zu einem Fließgewässer lagen. Die mittelslawische Phase wird in der älteren Literatur auch als Burgwallphase bezeichnet ${ }^{43}$, was sowohl für das Untersuchungsgebiet als auch für die Niederlausitz ${ }^{44}$ nicht unzutreffend ist. Unter den 94 Befunden sind immerhin 34 Burgwälle. Erst an zweiter Stelle in der Häufigkeit kommen 33 (offene) Siedlungen, 12 Grabbzw. Gräberfeldbefunde, 7 Horte und 8 Einzelfunde. Die Burgwälle sind somit anscheinend die dominante Siedlungsform, zumindest in den durch die Archäologie erhobenen Befunden. Wahrscheinlich haben einstmals bei weitem mehr offene Kleinsiedlungen existiert als entdeckt wurden, wie die systematisch untersuchte Siedlungskammer von Zehden (Cedynia) zeigt, wo auf einen Burgwall mindestens 5 offene Kleinsiedlungen kommen ${ }^{45}$. Diese Kleinsiedlungen sind jedoch nicht so leicht wie die im Relief markanten Burgwälle zu entdecken, und das ,reale“ Fundbild ist daher wahrscheinlich zuungunsten der offenen Siedlungen verschoben.

\section{Kleine, meist runde mittelslawische Burgwälle}

Südlich der Warthe bestanden die Burgwälle wie zuvor geschildert wahrscheinlich schon seit frühslawischer Zeit. Aufgrund des Fundmaterials fallen sie meist allgemein als altslawisch in die früh- bis mittelslawische Zeit. Einige von ihnen (z.B. in Göritz [Gorzyca], Zantoch [Santok] und in Alt Limmeritz [Limierzyce]) wurden kontinuierlich auch unter Aus- und Umbau der Anlagen sowie Verstärkung oder Erneuerung der Befestigungen (Wälle) weiter genutzt. Es waren fast ausnahmslos Höhenburgen, auch auf künstlichen, von Menschen geschaffenen, anthropogen aufgeschütteten „Wohnhügeln“, die einen im-

43 Z.B. H.U. Knorr: Die slawische Keramik zwischen Elbe und Oder. Leipzig 1937 (= Mannus Bücherei, 58).

44 Biermann: Slawische Besiedlung (wie Anm. 25), S. 47.

45 Łosiński (wie Anm. 21), S. $201 \mathrm{f}$. 
mensen, gemeinschaftlich koordinierten und gelenkten Arbeitsaufwand voraussetzen. In Zantoch konnte ab der mittelslawischer Zeit bis zum 10. Jahrhundert ein bedeutender Ausbau der Burganlage durch die Anlage eines bis zu 240 m im Durchmesser großen Ringwalls mit Vorburg (doppelter Ringwall) erschlossen werden (Abb. 9). Es zeigten sich Blockbaubefunde und Hinweise auf Knochen- und Hornverarbeitung.

Etwas anders gestaltete sich die Anlage der Burgwälle im Norden des Untersuchungsgebietes, wo, abgesehen von der Ausnahme des altslawischen Burgwalls von Reetz (Recz), nur ab mittelslawischer Zeit Burgwälle in das Licht der archäologischen Forschung treten. Es handelt sich, wie an ihrer Lage erkennbar, hauptsächlich um Niederungsburgen in Form eines einfachen oder doppelten Rundwalls (Verhältnis Niederungs- zu Höhenburg: ca. 2 zu 1). Es wurden aber auch Höhenburgen auf natürlichen Spornen angelegt, die meist eine früheisenzeitliche Vorgängerburgwallanlage aufweisen. Die Burgwälle waren die herrschaftlichen, Handels-, Verteidigungs- und Kommunikationszentren, denen vielfach einige zeitgleiche offene Siedlungen (wie in der Siedlungskammer um Zehden [Cedynia] und Pyritz [Pyrzyce] erwiesen) angegliedert waren ${ }^{46}$. Anders als in der benachbarten Niederlausitz, in der keine regionale Gliederung nach unterschiedlichen Burgwalltypen erkennbar ist ${ }^{47}$, ist im Untersuchungsgebiet eindeutig ein regionaler Unterschied in der Häufigkeit der Spornburgen in mittelslawischer Zeit zu erkennen. Wahrscheinlich waren im Süden, im Sternberger Land, wo auch im Gegensatz zu Pommern im Norden eine Vielzahl von Fundstellen der Lausitzer Kultur bekannt ist, noch einige Spornburganlagen mit Abschnittswällen der jüngeren Bronze- bis frühen Eisenzeit als solche für die mittelslawischen „Neuburgenbauer“ zu erkennen und boten sich bei der Anlage der mittelslawischen Burgen an, wodurch es zur verstärkten Wiederbesiedlung dieser alten Burgstellen kam.

Im Vergleich zur frühslawischen Zeit kam es in mittelslawischer Zeit zu einer starken Aufsiedlung des Untersuchungsgebietes (Anstieg von 2 auf 8 Einzelfundstellen, von 2 auf 33 Siedlungsfundstellen sowie von 7 auf 34 Burgfundstellen). Dabei ist jedoch zu beachten, dass nicht alle 34 Burgwälle und 33 offenen Siedlungen gleichzeitig parallel, sondern unterschiedlich lang bestanden, manchmal nur weniger als 50 Jahre, aber auch weitgehend kontinuierlich bis in spätslawische Zeit bzw. gar bis ins Hochmittelalter. Alle offenen Siedlungen wurden neu angelegt, es bestand mithin keine Siedlung von frühslawischer bis mittelslawischer Zeit kontinuierlich, was jedoch differenziert werden muss. Im Falle der frühslawischen Siedlung von Dertzow (Derczewo) kam es in kurzer räumlicher Distanz von nur wenigen Kilometern auf der anderen, östlichen Seite des „Großen Sees“ zu einer Neuanlage der mittelslawischen Siedlung von Brügge (Lawy). Das Siedlungsgefilde wurde somit kontinuierlich weiter genutzt, denn es wurde nur der Siedlungsplatz verlagert. Anders sieht es im Falle der frühslawischen Siedlung von Deetz (Dziedzice) aus. Hier ist in unmittelbarer Nachbarschaft keine mittelslawische Neusiedlung auszumachen, somit brach hier wohl die Nutzung des Siedlungsgefildes ab. Da es sich aus früh-

46 Łosiński (wie Anm. 21), S. 303.

47 Biermann: Slawische Besiedlung (wie Anm. 25), S. 50, Abb. 11. 
slawischer Zeit nur um zwei (erkannte) Siedlungen handelt, kann man ausschließlich der beschriebenen Ausnahme von einer weitgehenden Neuerschließung der Siedlungsgefilde mit der Neuanlage von offenen Siedlungen im weitem Umfang erst in mittelslawischer Zeit ausgehen.

Die nördlich benachbarte Region um Pyritz (Pyrzyce) wurde vom 9. bis zum 10. Jahrhundert stark aufgesiedelt. Die zahlreichen offenen Siedlungen der mittelslawischen Zeit bestanden meist kontinuierlich, oft über ein bis zwei Jahrhunderte. Seltener wurden sie nach einer oder zwei Generationen (ca. 20-50 Jahren) nicht mehr genutzt und meist in unmittelbarer Nähe neu angelegt. Eine frühslawische offene Siedlung wurde auch noch in mittelslawischer Zeit weiter genutzt. Aus zwei frühslawischen offenen Siedlungen entwickelten sich zwei mittelslawische Burgwälle, da sie wohl auf den günstigsten Standorten lagen, die sich in Konkurrenz zu anderen Siedlungen als am geeignetsten erwiesen hatten. Die meisten Siedlungsgefilde wurden neu erschlossen, und es konnte eine planmäßige Neuanlage von Burgwällen aufgezeigt werden. Lediglich 2 Burgwallanlagen wurden in bereits bestehenden Siedlungsgefilden zur Aufsiedlung des Gebiets errichtet. Im Durchschnitt entfielen auf einen Burgwall 4 bis 5 offene Siedlungen, die einen Abstand von 5 bis $10 \mathrm{~km}$ zueinander hatten ${ }^{48}$.

\section{Siedlungskammer von Zehden (Cedynia) im 10.-15. Jahrhundert}

Die ersten zwei offenen mittelslawischen Siedlungen wurden in der Siedlungskammer um Zehden (Cedynia) im 9. Jahrhundert in unmittelbarer Nähe zur Oderbruchkante angelegt (Abb. 10). Bereits in der ersten Hälfte des 10. Jahrhunderts wurden sie in die östlich oberhalb liegenden Mittelhänge der relativ steil aufsteigenden Endmoränenzüge verlegt. Wahrscheinlich wurden die alten Siedlungen durch ein Oderhochwasser überspült, so dass bei der Neuanlage die höhergelegenen, hochwassersicheren Mittelhänge als Standorte ausgewählt wurden. Ohne Verlagerung bestand ca. 1,5 km nordnordöstlich von Zehden eine offene Siedlung, die auch oberhalb der Oderbruchkante, ebenfalls in den Mittelhängen und am Südmündungspunkt des steilen Parchnitztals, kontinuierlich vom 9. bis zum 12. Jahrhundert bestand. Möglicherweise ist sie schon als „Tochtersiedlung“ des „Zentralen Orts“49 im heutigen Stadtgebiet Zehdens anzusehen. Am Oberhang und auf der plateauartigen Kuppe wurde ein Gräberfeld angelegt, das ebenfalls kontinuierlich von der zweiten Hälfte des 10. Jahrhunderts bis in spätslawische Zeit und noch im Hoch- und

Spätmittelalter (bis ins 15. Jahrhundert) als Friedhof genutzt wurde.

48 Łosiński (wie Anm. 21), S. 70-72 und 175-176, Ryc. 16-17 und 55-56.

49 L. Leciejewicz: Zur Entwicklung von Frühstädten an der südlichen Ostseeküste, in: Zeitschrift für Archäologie 3 (1969), S. 182-210. 


\section{Ländliche Siedlungen der mittelslawischen Zeit (8.-10. Jahrhundert)}

Im Untersuchungsgebiet sind aus mittelslawischer Zeit 12 Gräberfelder bekannt. Sehr oft, in der Hälfte der Fälle (5), wurden die mittelslawischen Gräberfelder auf Hügelgräberfeldern der jungbronzezeitlichen Lausitzer Kultur oder der früheisenzeitlichen Göritzer Gruppe angelegt. Die alten Hügelgräberfelder waren wohl in mittelslawischer Zeit noch nicht (ab)erodiert und als „Gräber-Kultstätte“ noch zu erkennen, so dass der Standort der Gräber bewusst auf den erkennbaren vorzeitlichen Grabstätten gewählt wurde. Die Gräberfelder häufen sich um Landsberg (Gorzów Wlkp.) und zwischen Königsberg (Chojna) und Bad Freienwalde (Abb. 3). In beiden Regionen kommt wohl abermals die verstärkte bodendenkmalpflegerische Tätigkeit einzelner Personen (wie Fritz Buchholz) zum Ausdruck.

In den Siedlungen Wollin (Wolin) 4 und Kolberg (Kołobrzeg) 1 in Pommern, aus denen in spätslawischer Zeit Siedlungen mit frühstädtischem Charakter bzw. Handels- und Kommunikationszentren hervorgingen, ist ab der Mitte des 9. Jahrhunderts Glas-, Bernstein-, Horn- und Eisenverarbeitung belegt ${ }^{50}$. Diese Produktions- und Verarbeitungsprozesse nahmen bis zum Ende des 10. Jahrhunderts stark zu, wie besonders die Zunahme der aufgefundenen Produktionsabfälle verdeutlicht. In den unterschiedlichen Siedlungen sind verschiedene Schwerpunkte der verarbeiteten Materialien erkennbar, was wiederum auf eine handwerkliche Spezialisierung und damit eine recht hohe händlerische Organisationsform schließen lässt, die weitab einer einfach organisierten Subsistenzwirtschaft liegt.

Archäozoologische Funde bei Soldin (Myślybórz) zeigen, dass zahlreiche Wildtiere wie Hirsch, Reh, Biber, Fuchs, Bär und Wildschwein gejagt und verzehrt wurden. Domestiziert war das Schwein, die „Torfkuh“ und kleinwüchsige Pferde, die alle auch verspeist wurden (verkohlte und mit Schnittmarken versehene Knochen) ${ }^{51}$. Unüblicherweise wurden hier keine Knochen von Schafen und Ziegen gefunden. Insgesamt wurden in alt- und mittelslawischer Zeit im Havelland, Mecklenburg und Pommern am häufigsten Schweineknochen (zwischen 47 und 64\% je nach Siedlungstyp und Regionen) gefunden. An zweiter Stelle folgen Rinderknochen (22-32\%), und die dritthäufigsten tierischen Knochen waren die von Schafen und Ziegen (17-12\%). Außerdem sind meist viele Knochen von wohl nicht domestiziertem Geflügel zu finden ${ }^{52}$. Das Pferd diente als Pack- und Reittier und wurde neben der Kuh und dem Ochsen als Zugtier auch in mittelslawischer Zeit genutzt, wie in Dabergotz (Kreis Neuruppin) mit einen C14-Datum von $733+/-80$ nachweisbar ist ${ }^{53}$. Der Fund von Soldin mit einer Getreidereibe zeigt, dass ne-

$50 \quad$ Leciejewicz (wie Anm. 50), S. 192-193, Abb. 4 und 5.

51 v. Kamienski: Über den Pfahlbau der Möwen-Insel im Soldiner See, in: Zeitschrift für Ethnologie 5 (1873), S. $108-110$.

52 N. Benecke: Archäozoologische Studien zur Entwicklung der Haustierhaltung in Mitteleuropa und Südskandinavien von den Anfängen bis zum Mittelalter. Berlin 1994.

53 U. Bentzien: Haken und Pflug. Eine volkskundliche Untersuchung zur Geschichte der Produktionsinstrumente im Gebiet zwischen unterer Elbe und Oder. Berlin 1969. 
ben der Wildjagd auch Ackerbau, wohl als Hauptquelle der Ernährung, betrieben wurde. Daneben wurden Früchte aus Wald und Flur (z.B. Haselnüsse) gesammelt. Ein weiterer wichtiger Wirtschaftszweig war der Fischfang, der besonders in Siedlungen, die direkt an Gewässern lagen, neben Ackerbau, Viehzucht, Wildjagd und Sammelwirtschaft die dominante Wirtschaftsform war (belegt durch eine sehr hohe Anzahl von Fischgräten verschiedener Arten).

Die slawischen Siedler nutzten je nach Standort ihrer Siedlung optimal die natürlichen Ressourcen der fruchtbaren Böden für Ackerbau, der feuchten Weiden für Viehzucht, der offenen Gewässer für Fischfang, der Wälder für Holzschlag, Sammelwirtschaft und Wildjagd aus. Die Anteile der einzelnen Wirtschaftsformen sind daher von Siedlung zu Siedlung stark unterschiedlich, und eine Siedlungsstruktur lässt sich nicht ohne weiteres auf andere Siedlungen der gleichen Zeit, auch wenn sie in unmittelbarer Nachbarschaft zueinander liegen, übertragen. Von Nöten ist also eine differenzierte Betrachtungsweise mit einem genauen Studium der Siedlungsbefunde und der Befundlage mit pollenanalytischen ${ }^{54}$,

54 E. Lange: Pollenanalytische Untersuchungen von Burggrabensedimenten aus der nordwestlichen Niederlausitz. Ein Beitrag zu methodischen Fragen der Auswertung von Pollendiagrammen und der slawischen Landschaft, in: K.-E. Behre (Hrsg.): Anthropogenetic Indicators in Pollen Diagrams. Rotterdam/Boston 1986, S. 153-166, betrieb diesbezügliche Forschungen westlich der Oder auf dem Gebiet der ehemaligen DDR. - Von M. Klichowska: Wczesnośredniowieczne szczątki roślinne odkryte w Wolinie na stanowisku wykopaliskowym 4 w latach 1953-1955, in: Materialy Zachodnio Pomorskie 7 (1961), S. 457-462, wurden die Pflanzenreste aus Wollin St.4 (Westpommern) aus Schichten vom Ende des 12. bis zum 14. Jh. untersucht. - W. Niewiarowski/B. Noryśkiewicz/ W. Piotrowski/M. Sinkiewicz: An outline of natural and anthropogenic changes of geographical environment in the Biskupin area during the last 7000 years, in: Quaternary Studies in Poland 13 (1995), S. 77-88, untersuchten die Pollenablagerungen im See des Biskupiner Burgwalls in Großpolen, mit Material von 7000 bis 200 B.P. - E. Lange (wie zitiert) rekonstruierte Wirtschaftsflächen aufgrund von pollenanalytischen Untersuchungen der slawischen Siedlungen und Burgwälle in der Niederlausitz. Diese Überlegungen und Modelle können aber nicht einfach für das Untersuchungsgebiet übernommen werden, da aus diesem nicht eine vollständig, flächenhaft ausgegrabene Siedlung mit Pollenanalyse (und Bodenanalyse) für repräsentative Vergleiche vorliegt und die naturräumlichen Gegebenheiten (u. a. andere Böden) mit etwas anderen Pflanzengemeinschaften (im Mikrobereich) anders gestaltet sind. - Untersuchungen von C. Herking (Eurasien Abteilung des Deutschen Archäologischen Instituts in Berlin) hatten im Zuge des Oder-Projektes Pollenprofile des Oder-Warthegebiets zum Forschungsgegenstand. Im Verlauf ihrer Dissertation (Pollenanalytische Untersuchungen zur holozänen Vegetationsgeschichte entlang des östlichen Odertals und südlichen unteren Wartatals in Nordwestpolen. Göttingen 2004) wurden auch 3 Pollenprofile des Untersuchungsgebietes aus der Zeit des gesamten Holozäns auswertet. Als ein Ergebnis der Bohrstockaufnahmen aus Feuchtböden oder Seen und Flüssen von Pyritz (Pyrcyce), der Drage (Drawa) (beide nördlich der Warthe) sowie Lagow (Lagow, südlich der Warthe) konnte für die Völkerwanderungszeit eine starke Zunahme der Hainbuche (Carpinus betulus aus der Familie der wärmeliebenden Haselnussgewächse - Corylaceae) nachgewiesen werden. Dadurch erschließt Herking eine starke Zunahme der klimatischen Kontinentalität mit kalten Wintern und heißen, trockenen Sommern. Selbst bei heutigem milden, eher atlantisch geprägtem Klima liegen zahlreiche Äcker an der wirtschaftlichen Ertragsgrenze, d.h. es kommt bei nur geringer Verschlechterung des Klimas (Zunahme der Kälte und weniger Niederschläge) zu einer drastischen Verkürzung der Vegetationsperiode, die zu hohen Ernteausfällen führt. Den völkerwanderungszeitlichen Bauern war es demnach kaum möglich, eine größere Bevölkerungsgruppe zu ernähren, was wiederum neben anderen Gründen wie der Sogwirkung des zerfallenden Römischen Reiches eine starke Abwanderung zur Folge hatte. 
archäozoologischen ${ }^{55}$ und bodenkundlichen ${ }^{56}$ Untersuchungen, die so die Wirtschaftsweise der Siedlungen erschließen können. Insgesamt lassen sich jedoch folgende Aussagen treffen.

Im Vergleich zur frühslawischen Siedlung von Dertzow (Derczewo), die unter den domestizierten Tieren einen Schweineknochenanteil von fast 58\% neben 38\% Rinderknochen aufweist, wurden in der mittel- bis spätslawischen Siedlung von Zehden (Cedynia) über $67 \%$ Schweineknochen und nur $28 \%$ Rinderknochen gefunden. Die Nutzung des Rindes verlor somit an Bedeutung von früh- zur spätslawischen Zeit. Wichtiger wurden die Schweine- und die Geflügelhaltung (bis ca. 2\% der Knochen). Die Haltung von Pferden blieb im slawischen Frühmittelalter gleichbleibend gering, wie 2-5\% Anteil an tierischen Fundknochen zeigt $t^{57}$. Dieser Trend wurde auch durch vergleichende überregionale Untersuchungen bestätigt ${ }^{58}$. In vielen untersuchten frühmittelalterlichen Siedlungen war die Jagd für die Ernährung besonders wichtig, wie ein Anteil von bis zu 50\% der gefundenen tierischen Knochen in dörflichen Siedlungen belegt. In den Burganlagen sind oft noch höhere Anteile von Wildtierknochen zu finden, die in der jüngsten Literatur oft mit verstärkter adliger, herrschaftlicher Jagd in Zusammenhang gebracht werden ${ }^{59}$. Hier darf nicht vergessen werden, dass die Wirtschaftsweise der Dörfer und Burgen recht unterschiedlich war. Die ländlichen Siedlungen lebten hauptsächlich von Ackerbau und Viehzucht sowie gelegentlicher (saisonaler) Jagd, während sicher auch im unmittelbaren Umfeld der Burgen Landwirtschaft, jedoch in einem geringeren Umfang, auch Jagd sowie zunehmend Handel betrieben wurden. In den Burgorten kam es durch Handel mit wertvollen Wildgeweihen, -fellen und -knochen (und vielleicht auch durch Abgaben) zu einer Häufung der Wildtierknochen. Frühfeudale Strukturen mit einem funktionierenden Abgabensystem kamen im Untersuchungsgebiet aber erst um 1000 oder noch später im 11. Jahrhundert auf. Erste derartige Anzeichen sind durch zahlreiche Schwertfunde frühestens ab dem 10. Jahrhundert belegt.

W. Niewiarowski u.a. ${ }^{60}$ konnten für die mittelslawische im Vergleich zur frühslawischen Zeit außerhalb des Untersuchungsgebietes, im Gebiet um Biskupin (ca. 50 km östlich von Landsberg [Górzow Wielkopolski]), weniger Pflanzenpollen der „Ruderalgesellschaften“" nachweisen. Es waren also weniger Brachflächen vorhanden. Die Waldpollenanzahl blieb lange Zeit konstant, und erst in der Schicht aus dem 10. Jahrhundert

55 Benecke (wie Anm. 53).

56 R. Schmidt/U. Fischer-Zujkov: Substratgenese und Bodenentwicklung im Bereich der Grabung Neuenhagen, in: E. Gringmuth-Dallmer (Hrsg.): Beiträge zum Oder-Projekt 4 (1998); - U. Fischer-Zujkov: Die Schwarzerden Nordostdeutschlands. Ihre Stellung und Entwicklung im holozänen Landschaftswandel. Online publizierte Dissertation am Geographischen Institut der Humboldt Universität zu Berlin (Berlin 2000): http:/www.edoc.hu-berlin.de/dissertationen/fischer-zujkovute-2000-12-05/PDF/Fischer-zujkov.pdf.

57 Siehe für Zehden (Cedynia): M. Kubasiewicz/J. Gawlikowski: Szczątki zwierzęce z wczesnośredniowiecznego grogziska w Cedyni, pow. Chojna, in: Materialy Zachodnio Pomorskie 7 (1961), S. 435-456.

58 Benecke (wie Anm. 53), S. 217.

59 Kurnatowska: Herrschaftszentren (wie Anm. 36).

60 Niewiarowski u.a. (wie Anm. 55). 
fiel ihre Anzahl, und die Anzahl der „Ackerzeigergesellschaften“ (die Pollen der Getreide und Ackerunkräuter) stieg stark an. Dies bedeutet, dass zunehmend der Wald gerodet wurde und das Land anschließend als Acker genutzt wurde. Gleichzeitig ist bis um 1000 auch ein starker Anstieg der „Frisch-Wiesengesellschaften“ zu verzeichnen. Somit erfuhr neben dem Ackerbau auch die Weidewirtschaft einen starken Auftrieb, beide waren sichere Grundlagen für den starken Bevölkerungsanstieg, der auch anderorts nachweisbar ist ${ }^{61}$. Indirekt konnte durch die Zunahme der Hangabtragung und die dadurch verstärkte Bildung von Schwemmböden in der Zeit zwischen 790+/-60 und 1160+/-90 in Biskupin ein Nachweis für die Zunahme des Ackerbaus erbracht werden. In den Bodenprofilen des Biskupiner Sees erhöhte sich nach der Trockenperiode der späten Völkerwanderungszeit und frühslawischen Phase der Seespiegel von ca. 800 bis 1000 um ca. $1 \mathrm{~m}$ von ca. 78 auf $79 \mathrm{~m}$ ü.NN. Gleichzeitig konnte in der mittelslawischen Phase ein Zunahme der Niederschläge nachgewiesen werden (durch Lessivierungen [Tonverlagerungen] im Oberboden), die jedoch um 1000 wieder abnahmen. Um (800?) 850-900, ungefähr mit dem Einsetzen der mittelslawischen Periode, begann die „mittelalterliche Warmzeit ${ }^{662}$. Die weitreichenden neuen Innovationen, z.B. die neue Feldberger Keramik ab der zweiten Hälfte des 8. Jahrhunderts ${ }^{63}$, setzten schon etwas früher ein. Aber das für den Menschen angenehmere Klima begünstigte, wenn auch etwas zeitversetzt, einen starken Aufschwung der slawischen Kultur, der sich qualitativ und vor allem quantitativ im archäologischen Fundgut erkennen lässt.

Im Gebiet um dem Parsteiner See, Eberswalde, Bad Freienwalde und im unteren Odertal erhöhte sich die durchschnittliche Temperatur von 850 bis um 1050 um ca. $1,5^{\circ} \mathrm{C}^{64}$ gegenüber der völkerwanderungszeitlichen Kaltphase, die bis ins 8. Jahrhundert und einer anschließenden kurzen Übergangsphase anhielt. Zusammen mit den insgesamt erhöhten Niederschlägen entwickelte sich das mittelalterliche Klimaoptimum ${ }^{65}$, welches bis ca. 1200 anhielt. Zwischen 900 und 1000 lagen die Sommertemperaturen ca. $1^{\circ} \mathrm{C}$ und die Wintertemperaturen durchschnittlich fast $2^{\circ} \mathrm{C}$ höher als heute ${ }^{66}$. Diese relative Frostmilde und eine nicht zu große Hitze bei hauptsächlich antizyklonalem Wetter mit geringeren Niederschlägen im Hochsommer brachte optimale Bedingungen für den Getreide- und Hülsenfruchtanbau ${ }^{67}$. Es ist wohl von einem Wechsel der vorherigen stark extensiven Feld-Graswirtschaft mit weiten, langjährigen Brachflächen hin zu einer intensiveren Fruchtfolgewirtschaft mit nahezu dauernd bestellten Feldern mit Vier- oder

61 Westlich der Oder: Gringmuth-Dallmer: Bevölkerungsexplosion (wie Anm. 26), S. 596.

62 Niewiarowski u.a. (wie Anm. 55), Fig. 4.

63 Brather: Sachkultur (wie Anm. 20), S. 202.

64 J.H. Schröder (Hrsg.): Führer zur Geologie von Berlin und Brandenburg, Nr.2: Bad FreienwaldeParsteinsee. Berlin 1994.

65 L. Schönwiese: Klimaänderungen. Daten, Analysen, Prognosen. Berlin 1995.

66 M. Hendel: Allgemeine Klimageographie, in: M. Hendel/H. Liedtke (Hrsg.): Lehrbuch der Allgemeinen Physischen Geographie. Gotha 2002, S. 335-336.

67 Siehe zu Umweltbedingungen Großpolens um 1000: T. Kazimierz: Die natürliche Umwelt Mittelgroßpolens zur Zeit des Aktes von Gnesen, in: Wieczorek/Hinz: Europas Mitte (wie Anm. 30), S. 85-89. 
Dreijahreszyklus und den Fruchtfolgen von Weizen/Gerste, Roggen, Hirse, Brache oder Weizen/Gerste, Hirse/Roggen, Weizen/Gerste und anschließender drei- oder mehrjähriger Brache ${ }^{68}$ auszugehen. Daneben wurden schon seit altslawischer Zeit nachweislich die Hülsenfrüchte Linse (Lens culinaris M.), Erbse (Pisum sativum L.) und Ackerbohne (Vica faba L.) angebaut ${ }^{69}$. Auch der Haferanbau konnte nachgewiesen werden, wohl in Bezug auf die Pferdehaltung von besonderem Interesse. Geerntet wurde hauptsächlich mit eisernen Sicheln und Kurzstielsensen, die aus zahlreichen Funden westlich der Oder bekannt $\operatorname{sind}^{70}$. Aber auch Flintsteinsicheln und -messerchen (Flintklingen) waren wie in Soldin (Myślibórz) weiterhin in Gebrauch und alltäglich, da die Anzahl der Eisenfunde auch in mittelslawischer Zeit im Verhältnis zur an sich erhöhten Fundstellenzahl im Untersuchungsgebiet nicht zunahm.

Der kontinuierlichere Acker- und Feldbau brachte höhere Erträge, einerseits durch dessen Intensivierung auf bestehenden und andererseits durch die verstärkte Erschließung neuer Wirtschaftsflächen, wiederum eine der Voraussetzungen für einen starken Bevölkerungsanstieg schon am Ende der mittelslawischen Zeit. Inwieweit die Erhöhung der Bevölkerungszahlen durch eine zusätzliche Zuwanderung potenziert wurde, ist noch unklar. Die im archäologischen Fundgut nachgewiesene neue Keramik des Feldberger Typs ist wohl autark im nördlichen, westslawischen Siedlungsgebiet entstanden ${ }^{71}$ und gibt keinen Hinweis auf verstärkte Einwanderung von Neusiedlern, die dieses Kulturgut eingeführt haben könnten. Die demographische Entwicklung des Untersuchungsgebietes, in der der Mensch weiterhin nach der neolithischen Revolution hauptsächlich mehr oder weniger als Teil der Natur mit einem natürlichen Bevölkerungswachstum ${ }^{72}$ als positive Differenz zwischen der hohen Geburtenrate und der hohen Anzahl der Sterbefälle anzusehen ist, kann sich allein aufgrund optimaler klimatischer Verhältnisse innerhalb von nur einer Generation (siehe Anmerkung 124), wie ethnographische Vergleiche zeigen, fast verdoppeln. Diese Bevölkerungsrate ist jedoch keineswegs stark linear ansteigend zu verstehen, sondern unterlag erheblichen regionalen Schwankungen. Insgesamt weist sie jedoch eine stark positive Tendenz auf und beruhte wohl auf den geschilderten inneren und natürlichen Prozessen, die weitgehend unabhängig von äußerem Zuzug waren.

\section{Aufkommen der Silberhorte ab dem 9./10. Jahrhundert}

Unter den Silberhorten, die ab ca. 800 in Pommern (Pomorze) und erstmalig um 960/70 im Untersuchungsgebiet zu finden sind, befinden sich größtenteils arabische Dirham (Abb. 11). Daneben wurden wenige böhmische, dänische, englische und deutsche Sil-

68 Gringmuth-Dallmer: Bevölkerungsexplosion (wie Anm. 26), S. 588.

69 E. Lange: Botanische Beiträge zur mitteleuropäischen Siedlungsgeschichte. Berlin 1971, Karten 18-20 (= Schriften zur Ur- und Frühgeschichte, 27).

70 Gringmuth-Dallmer: Bevölkerungsexplosion (wie Anm. 26), S. 588.

71 Brather: Sachkultur (wie Anm. 20), S. 149-153.

72 J. Leib/G. Mertens: Bevölkerungsgeographie. Das geographische Seminar. Braunschweig 1986. 
bermünzen entdeckt. Die Horte des Untersuchungsgebietes fügen sich in das überregional bekannte Fundbild ${ }^{73}$ und auch in die regional erarbeiteten Studien für die Neumark und Posen ${ }^{74}$ sowie für Großpolen und Pommern ${ }^{75}$ ein. Die ältesten Silberhorte aus dem 9. Jahrhundert sind nur an der Ostsee, im unmittelbar angrenzenden Raum Pommerns, in Südskandinavien, Gotland, Bornholm, Falster, Rügen, im Baltikum und im Mündungsgebiet der Weichsel gefunden worden. In der ersten Hälfte des 10. Jahrhunderts besteht dieses Fundbild weitgehend fort, jedoch sind nun wesentlich mehr Funde im Ostseehinterland und an den größeren Flussläufen, an Oder, Weichsel, Warthe, Rega, Stolpe (Sułpia) und Ucker, auszumachen. In der zweiten Hälfte des 10. Jahrhunderts steigen die Silberhortfundstellen im gesamten nördlichen Raum der westslawischen Kultur zwischen Elbe und Weichsel extrem an, sind aber immer noch hauptsächlich an die großen Fließgewässer gebunden ${ }^{76}$. Erstmals sind 6 Silberhorte im Untersuchungsgebiet thesauriert worden, und zwar an der Oder, Netze, Mietzel (Myśla) und am Seeufer des „Clara-Sees“ bei Nowogróde Pomorski. All diese Horte lassen durch ihre Fundlage ausschließlich an schiffbaren, miteinander verbundenen Gewässern und durch ihre Zusammensetzung auf Handelsaktivitäten schließen. Die Funde bestehen zu einem großen Teil aus den erwähnten zentralasiatischen arabischen Dirham und anderen mitteleuropäischen Silbermünzen, Silberschmuck, der unterschiedliche Fundhäufungen der analogen Silberschmuckstücke vom südskandinavischen bis baltischen Raum hat, sowie Silberrohgussprodukte wie Gusskuchen und Barren. Möglicherweise sind schon die am Ende des 10. Jahrhunderts aus dem Tempelhofer Hort (Swiatki) bekannten Ohrringe vom Tempelhofer Typ, die auch Hinweise auf den neuen christlichen Glauben innerhalb des Synkretismus geben, als Machtsymbol einer aufstrebenden Elite anzusehen (Abb. 12). In dieser Zeit bildet sich südöstlich des Untersuchungsgebietes, im Kerngebiet der Piasten, Großpolen ${ }^{77}$, der polnische Staat heraus ${ }^{78}$.

In allen untersuchten Silberhorten ist wie auch bei den Silberhorten, die aus der Literatur bekannt sind, das Fundgut meist zu 60-90\% zerhackt, was die These nahelegt, dass der Wert dieses Hacksilbers nur nach dem Gewicht bemessen wurde. Es konnte aber auch nachgewiesen werden, dass besonders schöne Schmuckstücke nicht zerhackt wurden und wohl einen gewissen Wert selbst besaßen. Es ist nicht von einer monetären Wirtschafts-

73 S. Brather: Frühmittelalterliche Dirham-Schatzfunde in Europa. Probleme ihrer wirtschaftlichen Interpretation aus archäologischer Perspektive, in: Zeitschrift Archäologie im Mittelalter 23/24 (1995/96), S. 73-153.

74 T.H.A. Knorr: Die Hacksilberfunde Hinterpommerns, der Grenzmark und der Neumark, in: Mannus 28 (1936), S. 160-229.

75 W. Łosiński: Zur Frage der Entwicklung der frühmittelalterlichen Ware-Geld-Wirtschaft in polnischen Gebieten im Kontext der Geschichte des Geldumsatzes in der Ostseezone, Teil 2, in: Archeologia Polski Tom XXXVI, Zeszyt 1-2 (1991), S. 235-263.

76 Leciejewicz: Entwicklung (wie Anm. 50), Abb. 2.

77 J. Strzelczyk: Polen im 10. Jahrhundert, in: Wieczorek/Hinz (Hrsg.): Europas Mitte (wie Anm. 30), S. $446-457$.

78 Ders.: Die Piasten und Polen, in: ebd., S. 531-535; - J. Górecki: Waffen und Reiterausrüstungen von Ostrów Lednicki. Zur Geschichte des frühen polnischen Staats und seines Heeres, in: Zeitschrift für Archäologie des Mittelalters 29 (2001), S. 41-86. 
weise aller Gesellschaftsschichten auszugehen. Die in den schriftlichen Quellen genannten herrschaftlichen, händlerischen und wirtschaftlichen Schulden wurden in Form von abgewägtem Silber bezahlt, Geld war auf eine kleine Gesellschaftsschicht beschränkt. Diese prämonetäre Struktur, d.h. eine im Ansatz begriffene Geldwirtschaft, ist nicht auf die allgemeine Bevölkerung zu übertragen, die im ländlichen Bereich bis in das Hochmittelalter hinein hauptsächlich in Tauschwirtschaft lebte. Die überaus seltenen Münzfunde in slawischen Siedlungen sind ein Indiz dafür, dass kaum Münzgeld bzw. Hacksilber in Umlauf war.

Auch das hohe Gewicht der Silberhorte von 1,250 kg in Tempelhof und bis zu $3 \mathrm{~kg}$ Silber z.B. in Gralow (Jenin, Kr. Landsberg), zeigt, dass sie nicht als „Wertanhäufungsschatz“ eines Wohlhabenden, sondern als „Händlerschatz“ anzusehen sind. 3 kg Silber hatten damals etwa den Gegenwert von 10-20 Pferden, 24-60 Ochsen, 30-38 Kühen oder 100 bis 300 Schweinen $^{79}$. Eine solche Wertanhäufung hätte eine große Siedlung oder einen Burgwall zur Wertschaffung vorausgesetzt. Solche Siedlungen sind aber in keinem Fall in unmittelbarer Nähe der Horte zu finden. Lediglich einige Kilometer vom Burgwall von Raduhn (Radun) entfernt fand sich ein Silberschatz unbekannter Größe. Die Horte wurden ausschließlich im dicht besiedelten Gebiet thesauriert, was nicht verblüfft, denn durch eine erhöhte Siedlungsdichte kam es allgemein zum Anstieg des Handels. Nachweise von Schmuckherstellung wurden nicht gefunden. Da gerade einmal 4 sichere (oder 6, einschließlich 2 fraglicher) mittelslawische Silberhorte auszumachen sind, konnten aufgrund dieser geringen Anzahl keine Handelsrouten oder Ähnliches herausgearbeitet werden. Wahrscheinlich folgten die Händler, die die Silberhorte mutmaßlich thesauriert haben ${ }^{80}$, dem natürlichen Verlauf der Gewässer, an denen die Silberhorte des Untersuchungsgebietes zu finden sind. Von einem echten Routensystem über Land und/oder über die größeren Fließe mit festen Wegen und festgelegten Handelsorten mit Märkten ist in mittelslawischer Zeit nicht auszugehen.

\section{„Adel“ der spätslawischen Zeit vom 10. bis Anfang des 13. Jahrhunderts}

Es sind im Untersuchungsgebiet insgesamt 9 Eisenschwerter aus der Zeit von der zweiten Hälfte des 10. bis ins 12. Jahrhundert gefunden worden, 4 von ihnen in oder in der Nähe von ehemaligen offenen Gewässern, oft in heute verlandeten Torfen, zudem in unmittelbarer Nähe zu 3 Niederungsburgwällen; davon stammen allein 3 Schwerter von 2 Burgwällen in der Gegend von Lippehne (Lipiany), ein Schwert wurde beim Burgwall von Soldin (Myślybórz) entdeckt. 2 Schwerter des Augusthofs bei Lippehne sind aus einem spätslawischen Gräberfeld mit Brandbestattungen (Leichenbrand und Asche in Urnen) in nächster Nähe zu einem mehrphasigen Burgwall geborgen worden. Somit sind

79 H. Seyer: Slawische Silberschatzfunde des Mittelalters. Berlin 1997, S. 16, nach J. Herrmann: Siedlung, Wirtschaft und gesellschaftliche Verhältnisse der slawischen Stämme zwischen Oder/Neisse und Elbe. Berlin 1968, $131 \mathrm{ff}$.

80 Brather: Frühmittelalterliche Dirham-Schatzfunde (wie Anm. 74), S. 80 f. 
insgesamt 6 Schwerter in nur wenigen hundert Metern Entfernung zum nächsten spätslawischen Burgwall entdeckt worden. Aus dem Süden des Untersuchungsgebietes ist kein frühmittelalterlicher Schwertfund bekannt. 6 Schwerter sind im äußersten Norden, im Gebiet zu Pommern, zum Vorschein gekommen, wobei der Fundschwerpunkt zwischen Lippehne und Soldin liegt. 2 Schwerter aus Lippehne und Soldin sind dem Typ S nach Petersen (1919) ${ }^{81}$ zuzuordnen und weisen stark auf eine (süd-)skandinavische Werkstatt als Herstellungsort hin. Ein weiteres Schwert von Typ X nach Petersen (1919) ${ }^{82}$, ein „Ulfberht-Schwert", welches aufwendig mit einer stark stilisierten Inschrift auf der Schwertschneide, quasi als Qualitätssiegel, verziert wurde, ist in Landsberg (Gorzów Wlkp.) gefunden worden (Abb. 13). Die „Ulfberth-Inschrift“" weist mangelnde orthographische Kenntnisse auf, die davon zeugen könnten, dass es sich hier um ein Markenplagiat handelt, das nicht aus der ursprünglichen, wohl im Niederrhein angesiedelten „UlfberthWerkstatt" kommt ${ }^{83}$. Direkt an der Oder fand man in Nieder Kränig (Krajmik Dolny, Kr. Königsberg) ein weiteres, aber unbeschriftetes Eisenschwert vom Typ X, dem häufigsten Schwerttyp der beginnenden spätslawischen Zeit ${ }^{84}$. In einem Gräberfeld nahe der piastischen Burg von Zantoch (Santok, Kr. Landsberg) mit überwiegend Körperbestattungen in gestreckter Rückenlage und wenigen Brandbestattungen mit Urnen, Beigefäßen und Steinsetzungen fand man 2 aufwendig tauschierte Eisenschwerter des 12./13. Jahrhunderts, wovon eines eingravierte Ritterdarstellungen aufweist. 5 Schwerter stammen aus Niederungen der Gewässer und sind als Opfergaben an Fluss-See-Gottheiten zu verstehen. Weitere 4 Schwerter wurden in Gräbern gefunden und können als rituelle Grabbeigabe, als Statussymbol für das Jenseits interpretiert werden.

Die Schwerter, die in den westslawischen Raum gelangten, wurden über skandinavische Händler dorthin gebracht, denn im Deutschen Reich, in dem Schwerter laut schriftlichen Quellen hergestellt wurden, bestand ein Exportverbot von Waffen an die Slawen (,arma et brunias“ in der Verordnung von Thionville des 9. Jahrhunderts ${ }^{85}$ ). Wahrscheinlich haben Handwerker der skandinavischen Wikinger die Schwerter in ihren eigenen Werkstätten kopiert. Der definitive Beweis in Form einer skandinavischen (aber auch niederrheinischen) Schwertschmiede steht jedoch noch aus ${ }^{86}$. Dass die Schwertfunde zu einem hohen Prozentsatz aus heute noch offenen, großen Fließen und Seen stammen, legt die These nahe, dass sie durch rituelle Handlungen den „,heiligen Gewässern“ übergeben wurden und so erhalten blieben ${ }^{87}$. Ihre hohe Anzahl widerspricht einem rein zufälligen

81 J. Petersen: De norske vikingesverd. En typologisk-kronologisk studie over vikingetidens vaaben. Videnskapsselskapets Skr. II. Hist. - Filos. Kl. Nr. 1. Kristiania 1919.

82 Petersen (wie Anm. 82).

83 J.-P. Schmidt: Ein Ulfberth-Schwert aus Alt Galow, Gem. Schöneberg, Kr. Uckermark, in: Veröffentlichungen des Brandenburgischen Landesmuseums für Ur- und Frühgeschichte 28 (1994), S. $223-229$.

84 J. Herrmann (Hrsg.): Die Slawen in Deutschland. Geschichte und Kultur der slawischen Stämme westlich der Oder und Neiße vom 6.-12. Jh. Berlin 1985, S. 294-295, Abb. 142.

85 Knorr (wie Anm. 75), S. 215.

86 Schmidt (wie Anm. 84), S. 226.

87 M. Haan: Die Flußfunde der Oder, Ucker und Randow als Hinweise auf Kult, Schifffahrt und Handel, in: Deutsches Archäologisches Institut/Römisch-Germanische Kommission (Hrsg.): Beiträge 
Fundcharakter. Sie wären auch, wenn sie unbeabsichtigt verloren gegangen wären, aufgrund ihres hohen Gegenwertes von ca. 125g Silber (je nach Ausstattung und Region), welcher ungefähr dem Kaufpreis eines Ochsen entsprach ${ }^{88}$, wahrscheinlich auch aus tiefem Wasser mit Netzen oder ähnlichem geborgen worden. Dies geschah jedoch nicht, denn sie sollten absichtlich den Menschen unzugänglich bleiben, und daher sind sie als Gabe an die Götter zu sehen. Dass die Hälfte der Schwertfunde des Untersuchungsgebiets aus Gräberfeldern stammt, verdeutlicht den rituellen Kontext der wertvollen Schwertdeponierungen.

Die Schwerter sind neben anderen im Untersuchungsgebiet gefundenen, neu auftretenden Artefakten wie Eisenäxten, pyramidenförmigen Reitersporen mit Tauschierarbeiten und langen Prunklanzenspitzen sowie aufwendigem Silberschmuck als Insignien herrschaftlicher Macht und Würde anzusehen. Denkbar sind zwei Interpretationsvarianten: 1. Eine aufstrebende Machtelite, die durch die florierende Wirtschaft zu Wohlstand und Reichtum gelangte, glich langsam, aber stetig ihre Lebensweise an die der Eliten im deutschen Reich im Westen und die im polnischen Reich im Osten an und trug nun zur Anerkennung eigener Herrschaft und Würde die kodierten Insignien der benachbarten Herrscher. Demnach wäre die alte Machtelite im nördlichen Teil des Untersuchungsgebietes bei dessen Eingliederung in das piastische Reich ab ca. 970 weitgehend erhalten geblieben $^{89}$, was sicher die etablierten Wirtschaftsverhältnisse stützte. -2 . Bei der Eingliederung des Gebietes wurde eine neue Herrschaft installiert, die aus Großpolen kam und von dort die Schwerter einführte, um, abgesehen von ihrem symbolischen Wert, mit ihnen gegen auftretenden Widerstand ihre Interessen durchzusetzen.

\section{Handel und Handwerk des fortgeschrittenen Frühmittelalters}

Weitere wichtige Einzelfunde sind bronzene Wägstücke, die in Rosenthal (Rózańsko [Kr. Soldin]) und Warnitz (Warnice [Kr. Königsberg]) gemacht wurden ${ }^{90}$. Es sind insgesamt drei metallene Wägstücke in Form beidseitig abgeflachter Bronzekugeln bekannt. Das Stück aus Rosenthal ist ein mit runenähnlichen Symbolen versehenes Waaggewicht aus Bronze, das in der Feldmark des Dorfes gefunden wurde (Abb. 14). Vergleichbare Funde liegen aus dem Gräberfeld von Sowinki (Kr. Posen [Poznań]) vor, und zwar dort mit einer Klappwaage und einem Gewichtssatz aus unterschiedlichen Gewichten (aus Eisen, Silber, Bronze, Blei und Stein), die jeweils alle mit einer Prüfmarke versehen und von unterschiedlichem Gewicht sind ${ }^{91}$. Die zwei Wägstücke aus Warnitz wurden in einem auf Handwerk und Handel spezialisierten Werk- und Siedlungsplatz gefunden. Solche Wägstücke belegen verstärkte Handelsaktivitäten, die auf den Handel mit einem wägbaren

zum Oderprojekt 3, 1997, S. 65-161.

88 Herrmann (Hrsg.): Die Slawen (wie Anm. 85), S. 135.

89 Kurnatowska: Herrschaftszentren (wie Anm. 60), S. 459.

90 Knorr (wie Anm. 75), S. 229.

91 A. Wieczorek/H.-M. Hinz (Hrsg.): Europas Mitte um 1000, Band 2. Stuttgart 2000, Katalog, S. 124. 
Wertäquivalent, wohl Silber, schließen lassen, und sind als spätslawisch (Ende des 10. bis erste Hälfte des 11. Jahrhunderts) zu datieren.

Im nahen Sumpf bei Warnitz wurden tierische Schädel, Knochen und Geweihe von Hirschen, Rehen, Füchsen, Rindern, Schweinen und von bereits aus mittelslawischer Zeit bekannten kleinen Pferden freigelegt. Die Pferde der spätslawischen Siedler waren den heute wieder in Nordostpolen in der Masurischen Seenplatte wild lebenden Tarpanen ähnlich, wie Knochenfunde aus Warnitz zeigen ${ }^{92}$. Als Nutztiere und als Nahrungstiere diente also weiterhin neben den domestizierten Tieren eine Vielzahl von Wildtieren. Das tierische Nahrungsmittelangebot wurde nicht wesentlich verändert, wobei aber von Siedlung zu Siedlung starke Unterschiede im Spektrum der gefundenen tierischen Knochen auszumachen sind. Insgesamt kam es zu einem Anstieg der Schweineknochen und zu einem Rückgang der Rinderknochen, was bis zum Hochmittelalter zu verfolgen ist ${ }^{93}$. Schon seit der Römischen Kaiserzeit vollzog sich der Wechsel vom wichtigsten (mit der höchsten Anzahl der gefundenen Knochen) domestizierten Tier, dem Rind, zur überwiegenden Schweinehaltung.

In spätslawischer Zeit wurde wohl, da kaum Nachweise auf Eisenverhüttung auszumachen waren (nur in Lippehne [Lipiany, Kr. Soldin]), aus dem benachbarten Pommern, wo einige Verhüttungsplätze bekannt $\operatorname{sind}^{94}$ und die Hauptlagerstätten des zur Verhüttung dienenden Raseneisenerzes liegen ${ }^{95}$, Roheisen ins Untersuchungsgebiet importiert. Aus mittelslawischer Zeit ist Eisenverhüttung im Burgwall von Königsberg (Chojna) durch den Fund von Arseneisenschlacke, welche keine Schmiedeschlacke ist, wahrscheinlich. Aus altslawischer Zeit liegt eine kleines Gusseisenfragment oder angeschmolzenes Eisenfragment der altslawischen Siedlung des 7./8. Jahrhunderts von Dertzow (Derczewo [Kr. Soldin]) vor, wobei es sich aber nicht um einen Eisenverhüttungsbefund handeln muss. In Königswalde (Lubniewice [Kr. Oststernberg]) wurden einige Eisenmeiler zur Eisenverhüttung durch große Mengen von Eisenschlacke nachgewiesen. Wahrscheinlich gehören sie in die jüngste spätslawische Phase (erste Hälfte des 13. Jahrhunderts), könnten aber auch hochmittelalterlich oder sogar frühneuzeitlich sein. Außerdem wurde noch ein Eisenofen bei Guscht (Guszczano [Kr. Friedeberg]) entdeckt, der an einem durch die Geomorphologie des Reliefs bedingten alten Handelsweg lag. Dieser Befund konnte jedoch nicht eindeutig datiert werden, so dass sein Alter zwischen der frühen Eisenzeit und der Neuzeit liegen $\operatorname{mag}^{96}$.

92 R. Virchow: Über alte Ansiedlungen bei Warnitz in der Nähe von Königsberg i.d.N., in: Zeitschrift für Ethnologie 3 (1871), S. 118-119.

93 Knorr (wie Anm. 53), S. 217.

94 Herrmann (Hrsg.): Die Slawen (wie Anm. 85), S. 33, 104.

95 J. Schneeweiss: Die ur- und frühgeschichtliche Eisenverhüttung und -verarbeitung im westlichen Odergebiet, in: Ethnographisch Archäologische Zeitschrift 37 (1996), S. 335-363.

96 Państwowe Muzeum Archeologiczne Warszawa u. a. (Hrsg.): Eisenverhüttung vor 2000 Jahren. Archäologische Forschungen in der VR Polen. Berlin 1977. 


\section{Besiedlungsmuster des spätslawischen Mittelalters}

Insgesamt ist von der mittel- zur spätslawischen Zeit nochmals ein vehementer Anstieg der Fundplätze festzustellen. Die Anzahl der entdeckten offenen Siedlungen steigt von 33 in mittelslawischer auf 77 in spätslawischer Zeit an (Abb. 15). Es ist von einem starken Anstieg der Bevölkerung auszugehen, der auch durch den Anstieg der Einzelfundanzahlen (von 8 auf 23) verdeutlicht wird, hinter denen sich oft Siedlungen und Gräberfelder verbergen, sowie durch einen ebenfalls starken Anstieg der entdecken Burgwälle (von 34 auf 41), die große Bevölkerungszahlen an sich banden. Die Gräberfeldfundanzahl stagniert jedoch bei 12 erkannten Gräberfeldern, was sich zum einen durch die nachweislich größeren Gräberfelder begründen lässt, auf denen in spätslawischer Zeit mehr Verstorbene bestattet wurden, zum andern ursächlich auf einen Forschungshiatus zurückzuführen ist, denn die spätestslawischen Bestattungsriten, die des 12. bis 13. Jahrhunderts, weisen nur wenige und kaum spezifische Grabbeigaben auf, die eine exakte Datierung zulassen ${ }^{97}$.

Die großräumige Fundstellenanzahl unterliegt starken regionalen Schwankungen, wie sich in dem von mittelslawischer Zeit bis zum Hochmittelalter kontinuierlich bestehenden Siedlungsgefilde um Zehden (Cedynia [Kr. Königsberg)) zeigt. Hier ist eine Stagnation der Fundstellenanzahl zu erkennen. Es wurden 4 von 5 Fundplätzen von mittelslawischer zu spätslawischer Zeit weiterhin genutzt. Außerdem wurden 5 mittelslawische Fundplätze aufgegeben und genauso viele in der folgenden Epoche wieder angelegt. Durch die erschlossenen archäologischen Befunde ist ersichtlich, dass die Siedlungsstrukturen, d.h. Form, Größe und Standortwahl, ähnlich blieben. Es handelte sich um Kleinsiedlungen, die öfter verlagert wurden und alle an Westhängen auf Lehmsandböden, oberhalb des Auenfeuchtbodenbereiches, errichtet wurden. Aufgrund des archäologischen Fundmaterials hatten sie wohl nur ein bis zwei Generationen (20-50 Jahre) Bestand. Diese Struktur zeigt sich auch in der Siedlungskammer um Rosenthal (Rózańsko [Kr. Soldin]), wo eine Bootsanlegestelle an einem heute verlandeten See nachgewiesen und von wo aus wahrscheinlich mit Getreide überregional gehandelt wurde.

Rechnerisch kommen auf eine Altsiedlung mit Kontinuität über 4 Neusiedlungen, die nur als spätslawisch zu datieren sind. Von den 34 mittelslawischen Siedlungen wurde ca. die Hälfte (18) in spätslawischer Zeit aufgegeben. Alles in allem kam es aber in spätslawischer Zeit zu einer intensiven Aufsiedlung der Landschaft. Dabei entstand ein Siedlungsverteilungsmuster, das sich noch heute in der räumlichen Verteilung der Ortschaften zeigt. Das Warthesumpfgebiet mit einer Breite von bis zu 10 Kilometern war in der Mitte des Untersuchungsgebietes eine nahezu unüberwindbare Barriere, die sicher nur an zwei Stellen, bei Zantoch (Santok) und Königsberg (Chojna), möglicherweise noch bei Landsberg (Gorzów Wlkp.), passierbar war und nur dort einen umfangreichen Kulturtransfer mit Handel und Gütertausch erlaubte. So war das südlicher gelegene Land Sternberg und das östliche mittelalterliche Land Lebus von Pommern her schlecht zu-

97 H. Malinowska-Łazarczyk: Cmentarzysko średniowieczne w Cedyni, Tom I-II. Szczecin 1982, S. $222 \mathrm{f}$. 
gänglich. Westlich begrenzte die schwer zu überwindende Oder das Gebiet, wobei es nur bei Göritz (Gorzyca) eine Furt gab, die das Ostlebuser und Sternberger Land von Westen her erschloss. Von Süden her war es ebenso vom Umland abgeschnitten, denn hier liegen die unfruchtbaren Sanderflächen, die auch noch heute weitgehend bewaldet sind $\left(\right.$ Grenzwald $\left.^{98}\right)$. Am besten zugänglich war es vom piastischen Großpolen, d.h. von Osten bzw. Südosten, aus, was sich auch im archäologischen Fundgut widerspiegelt. Beispielsweise setzte hier schon analog zu Großpolen in altslawischer Zeit der Burgenbau ein, welcher im Norden des Untersuchungsgebietes erst in mittelslawischer Zeit begann. Auch die spätslawische Besiedlung und Landeserschließung ist eng mit den Ereignissen der aufstrebenden Dynastie der Piasten verknüpft, und so wurde wahrscheinlich schon um 950 das südliche Untersuchungsgebiet in den Gnesener Staat eingegliedert ${ }^{99}$. Kulturell ist der Norden der Neumark stark an Pommern orientiert. Es besteht also eine Art „Kulturbarriere“ zwischen dem Norden mit einer hohen und dem Süden mit einer geringen Siedlungsdichte. Hinzu kommt, dass im Sternberger Land die Böden durchschnittlich von schlechterer Güte sind als die nördlich der Warthe. Insgesamt macht sich dies in der weit geringeren Anzahl der Siedlungen stark bemerkbar. Landschaften mit guten Böden als landwirtschaftlicher Grundlage oder mit anderem naturräumlich wirtschaftlichen Potential (z.B. Seen mit Fischfang) und guter Erreichbarkeit über die großen und kleinen Fließe bzw. gute Anbindung an die überregionalen Landwege wurden besonders intensiv erschlossen.

\section{Ländliche Kleinsiedlungen in spätslawischer Zeit}

Hinweise für die als typisch slawisch angesehene Hausform, das Blockhaus, konnten neben zahlreichen Pfostenbefunden von Häusern oder Bauten in Pfosten-Stabbauweise in Küstrin „Klößnitz“ (Kostrzyn [Kr. Königsberg]) aus spätslawischer Zeit erkannt werden (Abb. 16). Die Pfostenbauten dieser Siedlung stammen zum Teil von einer frühkaiserzeitlichen Vorgängersiedlung des 2. Jahrhunderts sowie von einer hochmittelalterlichen Folgesiedlung. Die Ausgrabung von A. Kiekebusch ${ }^{100}$ hat einen stark ausschnitthaften Charakter und wurde nie umfassend aufgearbeitet. Erst durch eine genaue chronologische Teilung und graphische Markierung der Befunde konnte ein regelmäßiges Bebauungssystem erkannt werden. Es zeigten sich der Grundriss eines frühkaiserzeitlichen, eines oder vielleicht zweier slawischer sowie eines zeitlich unbestimmten Pfostenhauses als auch drei oder vier spätslawische Grubenhäuser mit je einer Feuerstelle. Die möglichen konstruierten Pfostenhäuser der slawischen und spätslawischen Zeit weisen eine einheitliche Ausrichtung von Nordwesten nach Südosten auf. In spätslawischer Zeit sind hier also Pfosten und Blockhäuser angelegt worden. Jedoch muss einschränkend hervorgeho-

98 W. Schich: Die „Grenze“ im östlichen Mitteleuropa im hohen Mittelalter, in: Siedlungsforschung. Archäologie-Geschichte-Geographie 9 (1991), S. 135-146.

99 Kurnatowska: Herrschaftszentren (wie Anm. 36), S. 458.

100 Das wendische Dorf Clössnitz bei Cüstrin, in: Zeitschrift für Ethnologie (1914), S. 880-902. 
ben werden, dass durch die kleine Ausgrabungsfläche die Pfostenhausbefunde nicht im Ganzen erfasst werden konnten und somit nicht eindeutig belegt sind. Die Grubenhäuser müssen nicht zwangsläufig mit Blockbauten überbaut worden sein, sondern können auch nicht erkannte Pfostenhauskonstruktionen aufweisen. Zahlreiche kleinere Brandstellen mit hohem Anteil an tierischem Knochenmaterial und jeweils einer Steinsetzung bezeugen Herdstellen in den gruben- und ebenerdigen Pfostenbauten.

„Klößnitz“ ist der einzige mittel- bis spätslawische Fundplatz des Untersuchungsgebietes, in dem auch Pfostenbauweise (Ständer-Stabkonstruktionen) nachgewiesen wurde. Durch die ähnlichen archäologischen Befunde der Gruben ist in der gesamten slawischen Zeit im Untersuchungsgebiet von einer andauernd ähnlichen Hausbauweise in obertägiger Blockbauweise mit untertägigen „Wohnkellergruben“ auszugehen. Einige Gruben dienten wohl auch der Vorratshaltung, wie Anhäufungen von Getreide und Fischschuppen zeigen. Im Burgwall von Zantoch (Santok [Kr. Landsberg]) konnten Blockbauten mit Schwellbalkenkonstruktion (ohne untertägige Grube) teilweise auf (Eck-)Steinfundamenten aus behauenen Steinen von mittel- bis spätslawischer Zeit nachgewiesen werden ${ }^{101}$. Weiterhin konnten auch Flechtwerkwände und Lehmputz erkannt werden. Stark gebrannter Lehm gab Hinweise auf eine Ofenkonstruktion, die wahrscheinlich als Kuppelofen angelegt war ${ }^{102}$.

E. Gringmuth-Dallmer ${ }^{103}$ geht von einer regelrechten Bevölkerungsexplosion um das Jahre 1000 aus, die mit einer extensiven Ausweitung der Produktion mittels Vergrößerung der landwirtschaftlichen Nutzflächen einherging. Es ist von einem immensen inneren Landesausbau mit einer Erschließung von neuen Siedlungs- und Wirtschaftsflächen innerhalb der bestehenden Siedlungsgefilde und einem äußeren Landesausbau mit einer Erschließung neuer Siedlungs- und Wirtschaftsflächen außerhalb der bestehenden Siedlungsgefilde auszugehen. Die Gründe dafür waren aber wahrscheinlich nicht die steigenden Bevölkerungszahlen. Schon zu Beginn der spätslawischen Zeit wurden im Zuge des herrschaftlich gelenkten, planmäßigen Landesausbaus neue Siedlungsflächen angelegt und damit Siedlungsraum für Neusiedler aus den prosperierenden alten Siedlungsgefilden erschlossen, der so gelenkt aufgesiedelt werden konnte. Dies war eine wichtige Voraussetzung für ein Bevölkerungswachstum, und so bewirkte ursächlich der gelenkte Landesausbau neben anderen Gründen wie dem mittelalterliche Klimaoptimum und der Konsolidierung der Machtverhältnisse und Handelsstrukturen erst den starken Anstieg der Bevölkerungszahlen. Für das Gebiet westlich der Oder wurde fast eine Verdreifachung $(1: 2,8)$ der spätslawischen Fundstellen (laut der Fundstellenzahlen des Corpus ${ }^{104}$ ) nachgewiesen ${ }^{105}$, wobei die unterschiedliche Länge der Perioden (mittelslawisch ca. 180

101 U. Dymaczewska: Frühmittelalterliche Keramik aus Santok, Kreis Gorzów Wielkopolski, in: Archaeologia Polona 13 (1972), S. 165-192.

102 E. Kirsch: Mittelalterliche Keramik in Berlin und Brandenburg. Die Keramik vom 13. bis zum Anfang des 16. Jahrhunderts in Berlin/Brandenburg. Berlin 1994, Abb. 8-9.

103 Gringmuth-Dallmer: Bevölkerungsexplosion (wie Anm. 26), S. 596 f.

104 J. Herrmann/P. Donat (Hrsg.): Corpus archäologischer Quellen zur Frühgeschichte auf dem Gebiet der Deutschen Demokratischen Republik (7.-12. Jahrhundert), 1.-4. Lieferung. Berlin 1973-1985.

105 Gringmuth-Dallmer: Bevölkerungsexplosion (wie Anm. 26), S. 578 f., Abb. 1. 
Jahre und spätslawisch 220 Jahre) und die sich daraus ergebende unterschiedliche Gewichtung beim Vergleich eingerechnet worden ist.

\section{Erste ,frühstädtische Zentren“ um das Jahr 1000}

Im Gegensatz zu den Kleinsiedlungen weisen die nach ausschnitthaften Teiluntersuchungen mutmaßlichen größeren Siedlungen meist eine Kontinuität seit mittelslawischer Zeit auf. 18 der 77 spätslawischen offenen Siedlungen bestanden schon zu mittelslawischer Zeit. Sie liegen alle in den Zentren der in spätslawischer Zeit herausgebildeten eindeutigen drei Hauptsiedlungsgebiete um Klein Mantel (Mętno Małe [Kr. Königsberg]) im Nordwesten, um Lippehne (Lipiany [Kr. Soldin]) im mittleren Norden und um Landsberg (Gorzów Wielkopolski) im mittleren Osten des Untersuchungsgebietes. In dessen äußerstem Nordosten, Ost-Nordosten und Süden deuten sich drei weitere Siedlungskammern an, die aber wegen fehlender kontinuierlich besiedelter ,zentraler Orte ${ }^{6106}$ nicht so klar auszumachen sind. Diese Orte konnten nicht eindeutig als „,frühstädtische Siedlungen“107 erkannt werden, da umfassende Ausgrabungen bei den meisten Siedlungen bis heute nicht umgesetzt wurden und so ein Desiderat der archäologischen Forschung bleiben. Aufgrund der einzigen flächenhaft groß angelegten Ausgrabungskampagne von Teilflächen der Großsiedlung in und an den Burgwallanlagen von Zantoch (Santok [Kr. Landsberg]) machen sich erste frühstädtische Tendenzen (mit einer herrschaftlichen und wirtschaftlichen Zentralfunktion) bemerkbar. Die schriftlichen Quellen ${ }^{108}$ belegen „Santok“ („Santokh“ 1097, „Santhoc“ 1181, „Santog“ 1208) wahrscheinlich schon um 990 (im Jahr der Eroberung durch Mieszko I. und der anschließenden Anlage der riesigen Burgwallanlage von $240 \mathrm{~m}$ im Durchmesser) und bezeugen die außergewöhnliche Funktion der Anlage, die hauptsächlich strategisch und politisch, aber auch händlerisch begründet ist. Die handwerkliche Produktion ist jedoch gering, im Vergleich mit anderen zentralen, frühstädtischen Orten wie Wollin oder Kolberg (Kołobrzeg) in Pommern ${ }^{109}$, in denen ein weitgefächertes Spektrum an handwerklichen Produktionen wie Glas-, Bernstein-, Horn-

106 Als zentraler Ort ist hier nicht ein ,zentraler Ort“ im siedlungsgeographischen Sinn zu verstehen, der eine Funktion als herrschaftliches, administratives und wirtschaftliches (Ober-)Zentrum aufweist, denn diese eindeutige ,frühstädtische Struktur“ lässt sich im Untersuchungsgebiet in keinem Ort zweifelsfrei nachweisen. Als ,zentraler Ort“ soll hier eine räumliche Ballung von herrschaftlichen, handwerklichen und händlerischen Aktivitäten innerhalb eines archäologischen Siedlungsbefundes angesehen werden, welcher tendenziell im Zentrum einer Siedlungskammer oder eines Siedlungsgefildes räumlich angeordnet ist und so von einigen umgebenden (Klein-)Siedlungen begleitet wird. Siehe zu „zentralen Orten“, „frühen Zentren“ und „Vorformen der Stadtentwicklung“: E. Gringmuth-Dallmer: Methodische Überlegungen zur Erforschung zentraler Orte in ur- und frühgeschichtlicher Zeit, in: S. Moździoch (Hrsg.): Centrum i zaplecze we wczesnoşredniowiecznej Europie środkowej. Wrocław 1999, S. 9-20.

107 Leciejewicz: Zur Entwicklung (wie Anm. 50), Abb. 2, 3, 6.

108 Vgl. G. Heinrich (Hrsg.): Handbuch der historischen Stätten Deutschlands, Band 10: Berlin und Brandenburg. Stuttgart 1995, S. $418 \mathrm{ff}$.

109 Leciejewicz: Zur Entwicklung (wie Anm. 50), Abb. 4, 5. 
und Eisenverarbeitung als Teilaspekt nachgewiesen ist. Zum Beispiel fehlt in Zantoch der Nachweis für eine umfassende handwerkliche Metallverarbeitung und -herstellung. Auf eine Dreilagenkammproduktion auch mit überregionalem Handel deuten die vielen Kammfunde und ein Waagbalkenfund hin.

In Zehden (Cedynia) könnte eine frühstädtische Siedlung schon ab dem 10. Jahrhundert bestanden haben, da die schriftlichen Quellen den Ort („Cidini“ 972) als bedeutend ausweisen (unter anderem wahrscheinlicher Schauplatz der kriegerischen Auseinandersetzungen der slawischen Pomoranen mit deutschen Heeren im Jahr 972). Es konnten jedoch trotz der zahlreichen archäologischen Befunde keine außergewöhnlichen Handelsaktivitäten nachgewiesen werden. Sie sind aber wahrscheinlich, denn bei Zehden lag der einzige Oderübergang im Nordteil des Untersuchungsgebietes, und er war bedeutend für Handel und Kommunikation des östlichen Binnenlandes nördlich der Warthe mit den westlich anschließenden Gebieten ${ }^{110}$.

\section{Bestattungsformen im späten Frühmittelalter}

In spätslawischer Zeit sind im Untersuchungsgebiet, wie sich an über 10 eindeutigen Gräberfundstellen zeigt, birituelle Bestattungszeremonien angewandt worden. Neben den hauptsächlichen ost-west-orientierten Skelettbestattungen fand man auch nord-südorientierte Gräber und Brandbestattungen, besonders im Norden des Untersuchungsgebietes, in Pommern, bis ins 12. Jahrhundert hinein, die dort nicht unüblich waren ${ }^{111}$. Eine umfassende Christianisierung ist erst in die Anschlusszeit zu datieren, aus der nur noch beigabenlose Skelettbestattungen bekannt sind. Im Untersuchungsgebiet konnten nur Flachgräber erkannt werden. Möglicherweise waren einige von ihnen ursprüngliche Hügelgräber, die durch das Fehlen einer Steinsetzung wohl schnell (ab)erodiert waren. Im nördlich anschließenden Pommern sind Hügelgräber mit Körperbestattungen mindestens bis um 1200 nachgewiesen, während die Brandbestattungen in Flachgräbern schon um 1100 und die Brandbestattungen in Hügelgräbern um 1150 aufhören (Abb. 3).

Das Gräberfeld von Zehden (Cedynia [Kr. Königsberg]) liefert umfassendes Fundmaterial von ca. 770 Skelettgräbern (Körperbestattungen) des 11.-14. Jahrhunderts

110 Eine weitere Oderfurt lag bei Küstrin (Kostrzyn) in der Mitte des Untersuchungsgebiets, an der Einmündung der Warthe. Südlich der Warthe war die Oder bei Lebus und Göritz (Górzyca) passierbar (G. Heinrich: Handelsstraßen des Mittelalters 1300-1375-1600. Veröffentlichungen der Historischen Kommission zu Berlin. Historischer Handatlas von Brandenburg und Berlin, Heft 5. Berlin/ New York 1980, Karte). Die insgesamt drei Oderübergänge (Zehden, Küstrin und Göritz) sind alle von mittelslawischer Zeit bis in das Hochmittelalter genutzt worden. Der in spätslawischer Zeit bedeutende Oderübergang von Lebus verlor im Hochmittelalter ab der Verlegung des seit 1124/33 bestehenden Bischofssitzes von Lebus im Jahr 1276 auf die östliche Seite der Oder nach Göritz, auch über das Jahr 1325 hinaus, als er wieder nach Lebus zurückverlegt wurde (U. Fiedler: Das Land Lebus in piastischer Zeit, in: Moździoch [Hrsg.]: Centrum [wie Anm. 107], S. 207-226), stark an Bedeutung.

111 P. Swiątkiewicz: Próba periodyzacji roswoju obrządku pogrzebowego na wczesnośredniowiecznym Pomorzu, in: Materialy Zachodnio Pomorskie (MZP) 10 (1980), S. 156, Tab. 7.IV. 
(Abb. 17). Eine genaue Analyse des Fundinventars ${ }^{112}$ zeigt eine im Vergleich zur mittelslawischen Zeit zunehmende soziale Differenzierung der Gesellschaft in verschiedene Schichten. Dabei wurde eine verstärkte Militarisierung durch die Zunahme von Waffenfunden (ein Schwert, Lanzen- und Pfeilspitzen) deutlich, ebenso eine Schicht von wohlhabenden Personen durch reiche Schmuckfunde. Es wurden Handwerker für rohe Eisenverarbeitung identifiziert (Funde von Schmelztiegeln und geschmiedeten Zangen und Scheren). Vielen Verstorbenen aus der wohl ackerbaulich orientierten breiten Masse waren nur wenige Grabbeigaben, einzelne Scherben, Steine oder nicht erhalten gebliebene organische Behältnisse aus Holz und Leder mit Speisen und Pflanzen mitgeben worden. Die rituelle Mitgabe einer Münze, des „Totenobulus“, ist durch alle Schichten hinweg erkennbar. Umfangreiche anthropologische Untersuchungen belegen ein durchschnittliches Sterbealter der Individuen, sowohl der männlichen als auch der weiblichen, von ca. 25-30 Jahren ${ }^{113}$. Die Hälfte der Bevölkerung verstarb bereits, bevor sie um die 20 Jahre alt war. Die Kindersterblichkeit lag bei fast $21 \%$, die Säuglingssterblichkeit um einiges höher. Frauen starben oft durch die unmittelbaren Auswirkungen einer Kindsgeburt, wie eindeutige Geburtstraumata an den Beckenknochen ohne nachgewachsene Knochenhaut belegen. Im Vergleich zu anderen westslawischen Siedlungen der gleichen Zeit und Region ist die Kinder- und Müttersterblichkeit aber nicht außergewöhnlich hoch. Es wurden morphologische Veränderungen im Verlauf des 11. bis 14. Jahrhunderts festgestellt, die durch „natürliche Selektion“, aber auch Einwanderungen erklärt wurden. Durch Hochrechnungen kommt man durchschnittlich auf ca. 175 Einwohner Zehdens, die das Gräberfeld gleichzeitig zur Bestattung ihrer Verstorbenen nutzten. Diese Zahl erscheint als realistisch und passt auch zu den zuvor angestellten Überlegungen zur Größe spätslawischer Kleinsiedlungen (in diesem Fall mit 10 bis 15 gleichzeitig genutzten Häusern), wobei die Kleinsiedlungen meist nach ein bis zwei Generationen (ca. 20-50 Jahre) ${ }^{114}$ verlagert wurden, da die unmittelbar am Boden errichteten Holzbauten dann weitgehende Schäden aufwiesen, auch wenn sie schon zum Teil auf ,schwellbalkenartigen“, meist nicht durchgehend gesetzten Feststeinfundamenten (,Feldsteinunterleger") gelagert waren.

112 Malinowska-Lazarczyk (wie Anm. 98), Tafeln 1-38.

113 J. Pinontek/E. Mucha: Cmentarzysko średniowiecezne w Cedyni. Analiza antropologiszna, in: Materiały Zachodniopomorskie (MZP) 29 (1983), S. 75-144.

114 Eine Generation (20-25 Jahre) ist hier als durchschnittliche Zeitspanne zwischen dem Alter der Eltern und Kinder aus den Daten des Gräberfeldes von Zehden (Cedynia [Kr. Königsberg]) definiert (Państwowe Muzeum Archeologiczne Warszawa [wie Anm. 97], S. 220). Für heutige demographische Entwicklungen in der Bevölkerungsgeographie Deutschlands wird meist die durchschnittliche Dauer einer Generation auf 33 Jahre angesetzt (H. Leser/H. D. Haas/T. Mosimann/R. Paesler: Wörterbuch der Allgemeinen Geographie, Band 1. München 1995). 


\section{Große Burgwallanlagen vom 11. bis in die erste Hälfte des 13. Jahrhunderts}

In Zantoch (Santok [Kr. Landsberg]) fand man unter den Feldsteinfundamenten des polanisch-piastischen und späteren frühdeutschen Burgwards (Motte) der Templer auf dem Schloßberg ein darunter liegendes pommersches Skelettgräberfeld des 9./10. Jahrhunderts. Auf der gegenüber, am südlichen Wartheufer liegenden Schanze konnte man die Anlage der riesigen Burgwälle (bis $240 \mathrm{~m}$ im Durchmesser) der slawisch-polanischen Phase (D) zuweisen und damit ans Ende des 10. bis 12. Jahrhunderts datieren. Hier kam es in spätslawischer Zeit zur Anlage von Blockbauten, deren Ecken auf behauenen Feldsteinfundamenten trocken, wohl frei stehend, errichtet wurden. Dadurch wurde die Nutzbarkeit der Blockbauten von vormals ca. 50 auf bis zu 150 Jahre verlängert. Gleichzeitig kam es zur Errichtung erster repräsentativer Bauten, einer Kirche und einer kleinen Motte, die zumindest in den erhaltenen Grundrissen und Fundamenten aus Steinen bestanden ${ }^{115}$. Der Handel zwischen Großpolen und Pommern ging zunächst hauptsächlich über Zantoch, das für die Piasten das „,Tor zur Eroberung“, aber auch die Hauptachse zur händlerischen Erschließung Pommerns war. Dies löste auch weiter westlich, an der Warthe, die eine Haupttransportroute war, eine Vielzahl von Burgneugründungen aus, die von den stark zugenommenen Handelsaktivitäten profitieren wollten ${ }^{116}$.

Insgesamt wählten die spätslawischen Burgenbauer ähnliche Standorte für ihre Burgen wie in mittelslawischer Zeit. Es gab in spätslawischer Zeit ungefähr gleich viele Höhen-Spornburgen mit teilweise eisenzeitlicher und mittelslawischer Nutzungsphase wie auch Niederungsburgen, die ebenfalls teilweise schon in mittelslawischer Zeit angelegt worden waren. Über drei Viertel der Burgwälle im Nordteil des Untersuchungsgebietes weisen eine kontinuierliche Nutzung von der mittel- bis in die spätslawische Zeit auf. Südlich der Warthe wurden fast alle spätslawischen Burgen, bis auf eine Ausnahme bei Limmritz (Lemierzyce [Kr. Oststernberg]), neu angelegt, wobei ein neues Burgenverteilungsmuster in Diskontinuität zu den vorher genutzten mittelslawischen Burgen entstand. Dies ist wohl mit der planmäßigen Erschließung des südlichen Untersuchungsgebietes durch die Piasten ab ca. 970 in Verbindung zu bringen. Alle spätslawischen Burgen waren als ringförmige Wälle oder Abschnittswälle in Holzerdekonstruktionen errichtet und somit gesichert. Die gesamte Anzahl der Burgwälle im Untersuchungsgebiet stieg von 34 in mittel- auf 41 in spätslawischer Zeit an (Abb. 7). In mittelslawischer Zeit kam auf einen meist runden Burgwall rechnerisch eine offene Siedlung, wobei es sich hier auch um einen Forschungshiatus, bedingt durch die unerkannten offenen Kleinsiedlungen, handeln könnte (siehe das gut untersuchte Fallbeispiel von Zehden mit einem mittelslawischen Burgwall und fünf offenen zeitgleichen Kleinsiedlungen). In spätslawischer Zeit hat sich

115 Zum Hausbau: P. Donat: Haus, Hof und Dorf in den deutschen Gebieten. Die Anfänge der Ständerbauweise, in: N. Benecke/P. Donat/E. Gringmuth-Dallmer/U. Willerding: Frühgeschichte der Landwirtschaft in Deutschland. Langenweißbach 2003, S. 263-266.

116 U. Dymaczewska: Z badań nad zapleczem osdniczym wczesnośredniowiecznego Santoka, in: Slavia Antiqua 10 (1963), S. 292 f., Mapa 2, 3. 
dieses Verhältnis stark verändert, denn nun kommen auf einen Burgwall fast zwei offene Kleinsiedlungen, die meist in unmittelbarer Nähe zu dem im Vergleich zur mittelslawischen Zeit bedeutend größeren Burgwallanlagen angelegt wurden (Abb. 18).

Trotz des rechnerischen Anstiegs der offenen Kleinsiedlungen im Verhältnis zu den Burgwallanlagen kam es in spätslawischer Zeit zu einem räumlichen Konzentrationsbzw. Zentralisationsprozess um die nun bedeutend größeren Burgwallanlagen. Deren Zentralörtlichkeitsfunktion mit Sitz der Herrschaft und des Handels nahm zu, denn es waren mehr offene Siedlungen als zuvor an die jeweiligen Burgwälle durch ihre räumliche Nähe im Machtbereich eines lokalen „Fürsten“ gebunden. Dabei ist durchaus eine Tendenz zur Anlage von größeren Burgwallanlagen als vorher zu erkennen. Jedoch muss beachtet werden, dass die in mittelslawischer Zeit üblichen kleineren Ringwallanlagen mit einem Durchmesser von nur 30-60 m auch weiterhin angelegt worden sind (z.B. in Bottschow [Boczów, Kr. Weststernberg]). Aber schon in mittelslawischer Zeit kam es zur Anlage großer Burgen wie z.B. in Alt Limmeritz (Lemierzyce [Kr. Oststernberg]), dessen länglicher Burgwall mit Ausmaßen von ca. 200x100 m in Phase B-D (Großpolen) datiert und somit sogar schon in altslawischer Zeit, ab dem 8. Jahrhundert, angelegt worden sein könnte ${ }^{117}$ und in spätslawischer Zeit kontinuierlich weiter genutzt wurde. Zumindest weist er eine Kontinuität von mittel- zu spätslawischer Zeit auf.

Ungefähr die Hälfte (21) der insgesamt 41 spätslawischen Burgwälle des gesamten Untersuchungsgebietes weisen eine scheinbare Kontinuität auf. Jedoch verbirgt sich dahinter oft nur die Schwierigkeit einer feinchronologischen Datierung, wobei manche Burgwälle nur allgemein in mittel- bis spätslawische Zeit zu stellen sind, was die Kontinuität noch nicht beweist. Schaut man sich das Fundmaterial genauer an, so konnte gerade einmal in ca. 10 Burgwällen durch eindeutig mittel- und spätslawisches Fundmaterial eine Zwei- oder gar Mehrphasigkeit bestätigt werden. Diese kontinuierlich genutzten Burgwallanlagen liegen fast alle mehr oder weniger in den Zentren der vier oder fünf Hauptsiedlungsgebiete im Norden des Untersuchungsgebietes, in der kulturell zu Pommern gehörenden, nördlich der Warthe liegenden Region (Abb. 5). Es sind oft jene Burganlagen, die auch schon in der frühen Eisenzeit besiedelt waren und auf denen im Hochmittelalter eine Folgesiedlung oder Burgmotte errichtet wurde. Diese Zentralörtlichkeiten sind alle in den natürlich begünstigten Gebieten mit besten Böden und offenen Gewässern zu finden, an gut zu überschauenden und zu verteidigenden Plätzen mit bester infrastruktureller Anbindung über die Fließe und Landhandelswege.

Im Sternberger Land findet sich kein von der mittel- bis in die spätslawische Zeit kontinuierlich genutzter Burgwall. Einzig der Burgwall von Zantoch (Santok) am Nordrand des piastischen Interessengebietes an einer passierbaren Furt der Warthe wurde von mittel- bis spätslawischer Zeit (wie auch im Hochmittelalter) genutzt. In der alt- bis mittelslawischen Zeit war dies noch ganz anders. Damals wies ca. die Hälfte der südlich der Warthe gelegenen Burganlagen eine Platzkontinuität auf. Von besonderem Interesse ist dabei, dass teilweise diese altslawischen Burganlagen (Göbitsch [Garbicz] und Groß Gandern

117 Fiedler: Das Land Lebus (wie Anm. 37), S. 221. 
[Gądków Wielki]) im Hochmittelalter wieder als Standorte für Motten dienten und so die alten, seit der frühen Eisenzeit temporär besiedelten, topographisch vorteilhaften Burgstandorte wieder genutzt wurden. Diese Burgen weisen einen Hiatus in der kontinuierlichen Nutzung in der gesamten spätslawische Zeit auf. Sie wurden ab dem Ende der mittelslawischen Zeit, um 970, als die Region im Süden von den Piasten erobert wurde, nicht mehr benötigt, und es wurden neue Burganlagen errichtet. Wahrscheinlich war dafür die starke Einbindung in das piastische Großpolen verantwortlich, in dessen Zuge es auch zu einer umfassenden Umgestaltung der Siedlungs- und Burgenlandschaft kam. Im Gegensatz dazu wurde der Norden des Untersuchungsgebietes, das Hinterland von Pommern, das nur von ca. 970/80 bis 1033 und nochmals von $1121-1181^{118}$, d.h. gerade einmal für ca. 50 und dann nochmals 60 Jahre, zum polnischen Reich gehörte, nie umfassend in das piastische Interessengebiet eingegliedert. Dadurch blieben hier die alten Siedlungs- und Burgenverteilungsmuster weitgehend über die mittel- und spätslawische Zeit erhalten. Die Burgen wurden, wenn das wirtschaftliche Potential des Standortes sich im Verlauf der Zeit als günstig erwiesen hatte, an ihrem Platz beibehalten.

\section{Letzte große Silberhorte des 11. Jahrhunderts}

Die Gründe für die Thesaurierung von Silberhorten haben sich am Anfang der spätslawischen Zeit, zu Beginn des 11. Jahrhunderts, im Vergleich zum vorherigen Jahrhundert erst einmal nicht geändert. Die Silberhorte sind anfangs weiterhin hauptsächlich als durch Handel erwirtschaftete Wertüberschüsse anzusehen, für die zunächst noch kein Markt in Form von echten monetären Strukturen bestand. Das Wertäquivalent Silber wurde angehäuft und gehortet, denn durch die mangelnden Marktstrukturen mit geringem Warenangebot konnte es nicht wieder schnell in eine andere reale, nicht abstrakte Ware umgetauscht werden. Im ländlichen Bereich, in den Dörfern, herrschte noch bis in das Hochmittelalter die Tauschwirtschaft vor. Erste größere regionale Marktplätze entstanden an den Burgwallanlagen. Hier wurden ab dem 10./11. Jahrhundert auch schon mit überregional wandernden Händlern Geschäfte in Form von abgewägtem Silber als Wertäquivalent getätigt, wie zahlreiche Waag- und normierte Waaggewichtsfunde verdeutlichen (Abb. 14). Auf der Ebene der Herrschenden wurden schon seit dem 9. Jahrhundert Geschäfte getätigt, deren Gegenwert in Silbergewichtseinheiten bemessen wurde, wie aus den schriftlichen Quellen, z.B. den Reiseberichten der arabischen Händler Ibn Fadlans und Ibrahim ibn Jacub, bekannt ist ${ }^{119}$. Neben Silber als Warenäquivalent waren im 10. bis 12. Jahrhundert Leinentuch und eiserne Schüsselbarren beliebte Wertmaßstäbe ${ }^{120}$. Erst im Verlauf des 12. Jahrhunderts ist von einer Durchsetzung echter monetärer Strukturen mit

118 G. Rhode: Kleine Geschichte Polens. Darmstadt 1965, S. 13 ff.

119 Leib/Mertens (wie Anm. 73), S. 79-81.

120 Herrmann (Hrsg.): Die Slawen (wie Anm. 85), S. 127-137. 
Abbildungen 



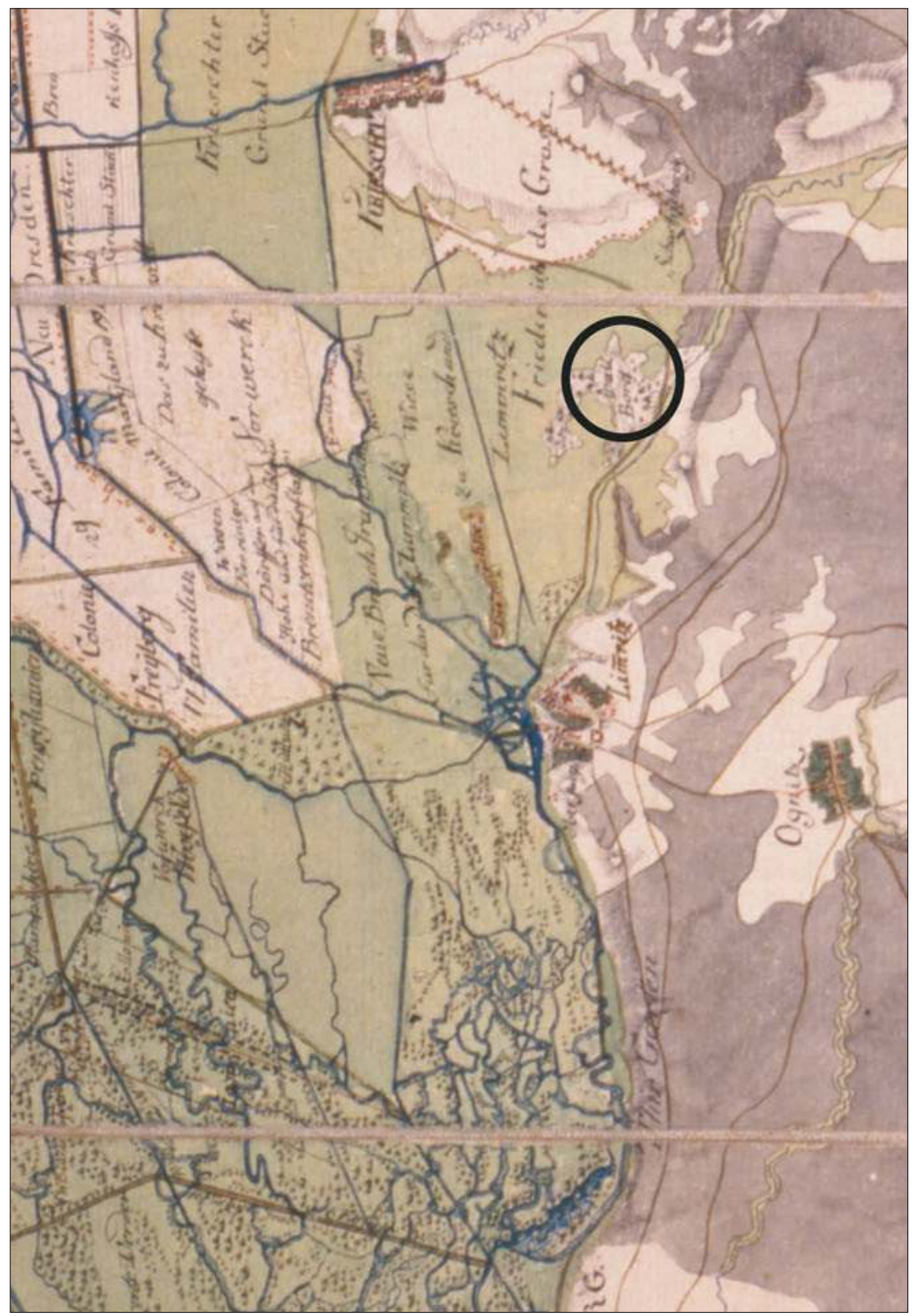

Abb. 1: Heute weitgehend zerstörter Burgwall von Alt Limmritz (Limierrzyce) auf Schmettauscher Karte 1767-1784 im Bestand der Kartenabteilung der Staatsbibliothek zu Berlin Preußischer Kulturbesitz 


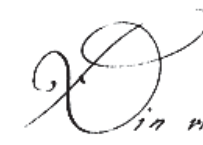

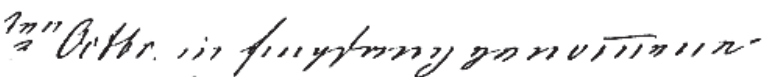

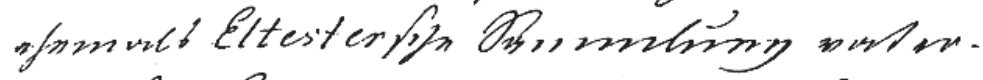

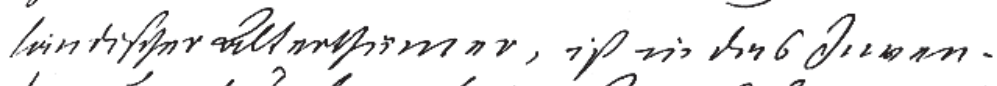

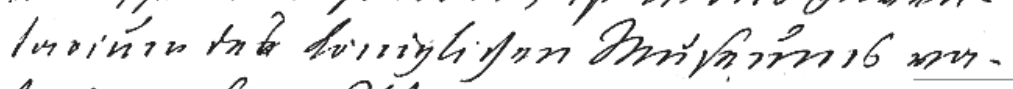

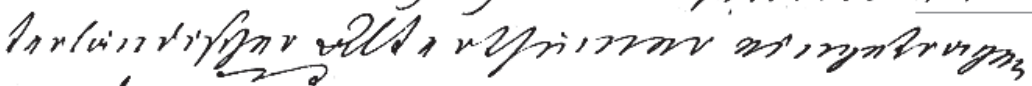
nuwhn गयने 3arnd

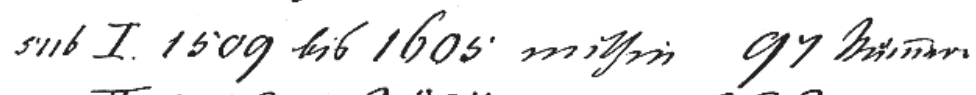

- II. $3273-2504-233=$

- III. $94-163$ 그 $=$

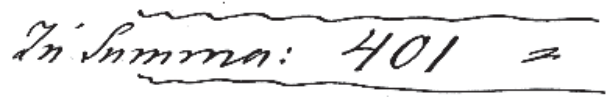

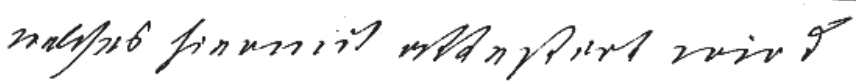

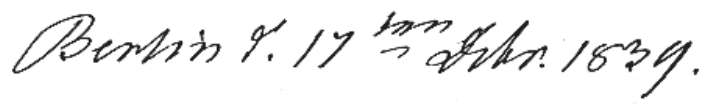

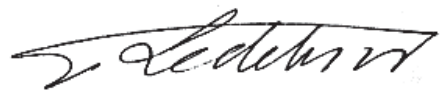

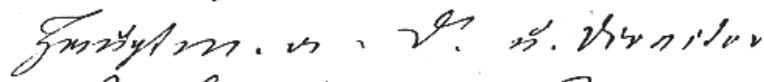

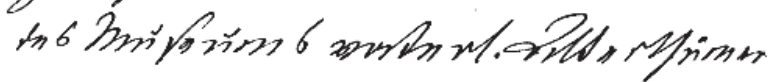

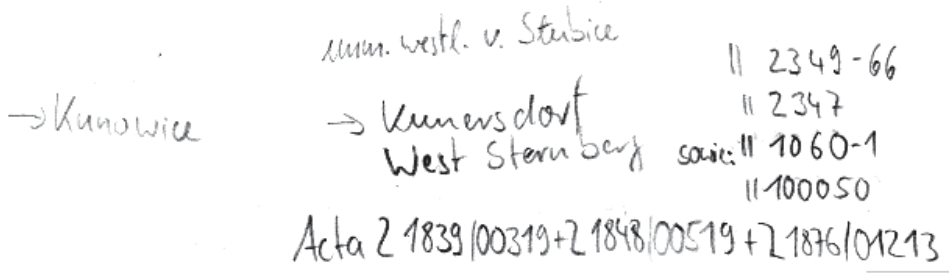

Abb. 2: Ortsakte mit Auflistung u.a. neumärkischer Fundorte von Leopold Freiherr von Ledebur, dem Vorsteher des „,Königlichen Museums Vaterländischer Alterthümer" im Schloß Monbijou, im Archiv des Museums für Vor- und Frühgeschichte der Stiftung Preußischer Kulturbesitz. 


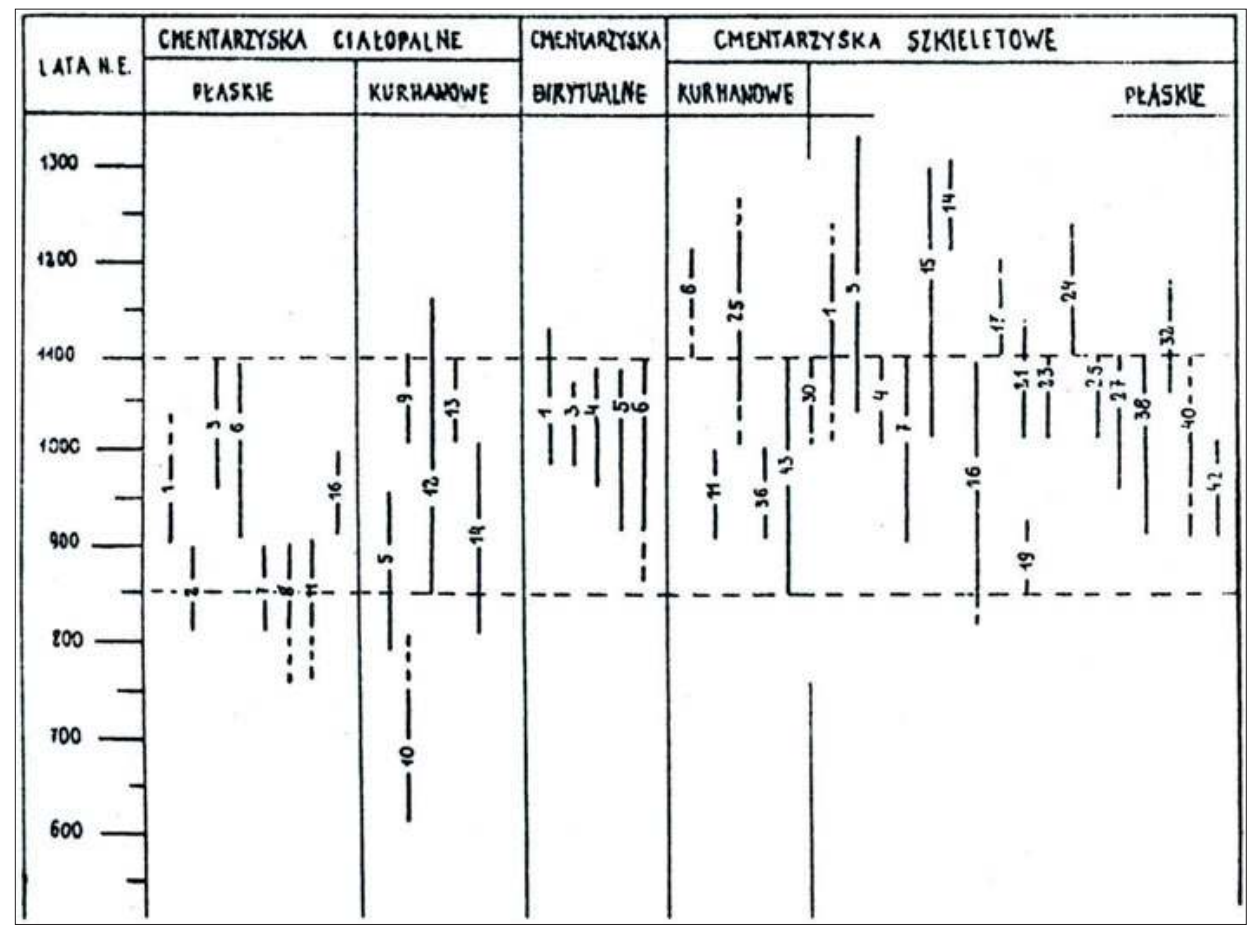

Abb. 3: Chronologie der unterschiedlichen Bestattungsriten im frühmittelalterlichen Pommern (Pomorze). Aufgelistet sind mit einer Nummer die einzelnen Gräberfelder, die in drei Hauptkassen unterteilt werden, welche sich nochmals in je zwei Unterklassen aufteilen (von links nach rechts): 1. Spalte - Gräberfelder mit Brandbestattungen und Flachgräbern; 2. Spalte - Gräberfelder mit Brandbestattungen und Hügelgräbern; 3. Spalte - Gräberfeld biritual; 4. Spalte - Gräberfeld mit Skelettbestattungen und Hügelgräbern; 5. Spalte - Gräberfeld mit Skelettbestattungen und Flachgräbern (nach Swiatkiewicz [wie Anm. 14], Tabela 7.IV). 


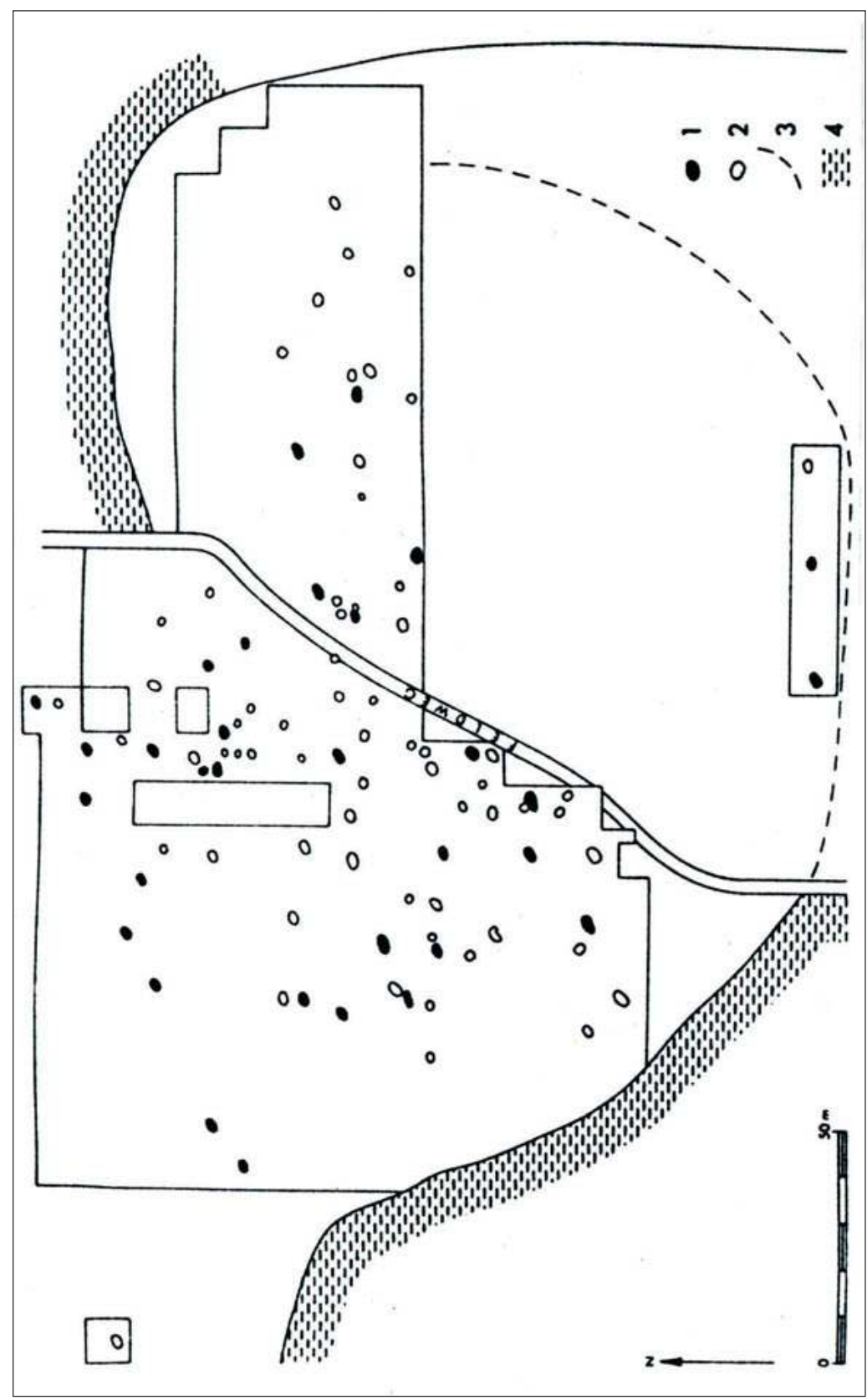

Abb. 4: Plan der Siedlung Deetz (Dziedzice) Station 4: 1: Wohnobjekte = Halberdgruben; 2: übrige Objekte; 3: angenommener Bereich der Siedlung; 4: feuchte Wiesen. Umgezeichnet nach A. Porzeziński, in: Slavia Antiqua 22 (1975), S. 53 (nach R. Köhler [wie Anm. 31], S. 178). 


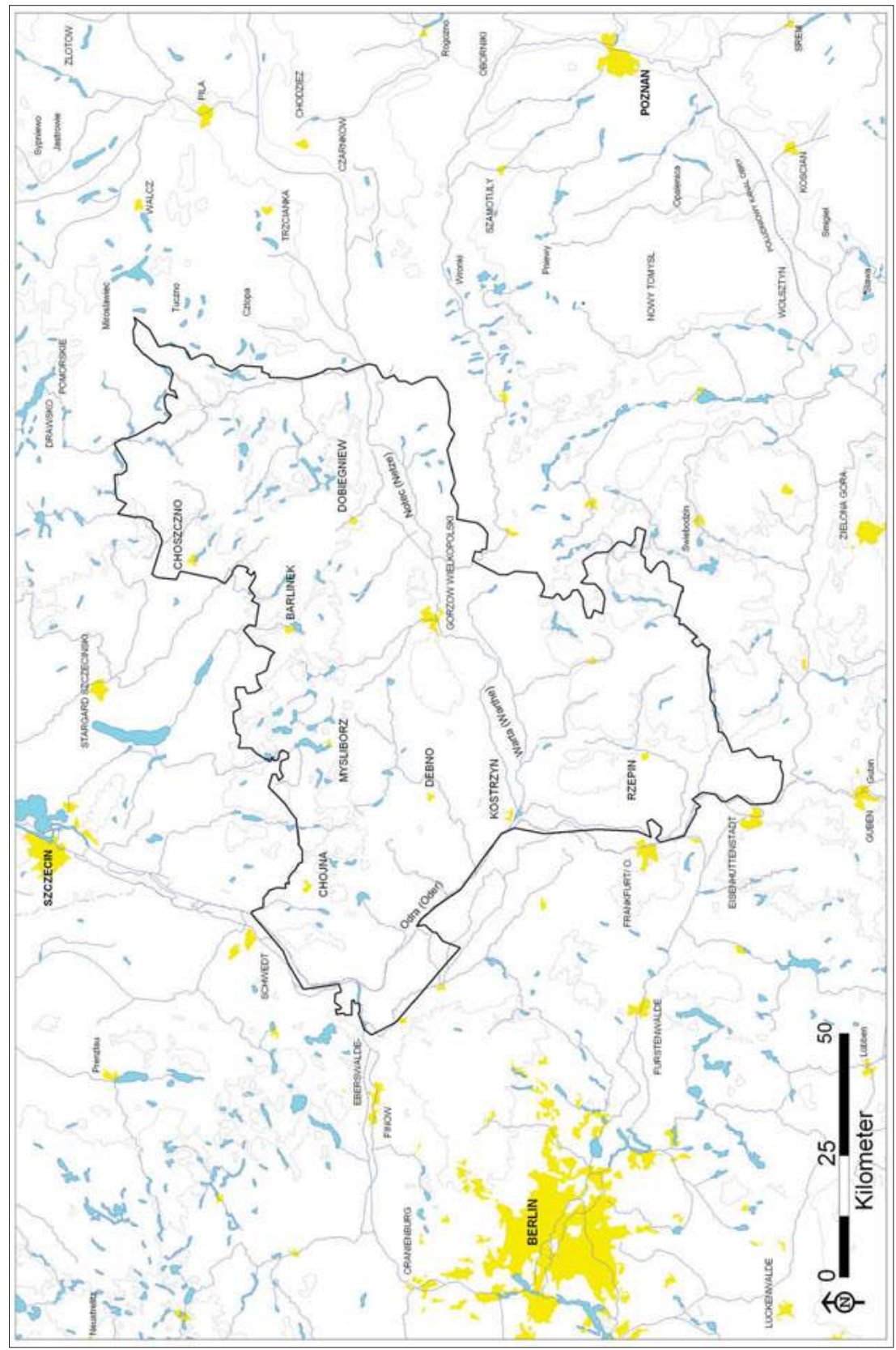

Abb. 5: Lage der Neumark im gedachten Dreieck zwischen Berlin, Stettin (Szcecin) und Posen (Posnań) mit den wichtigsten Gewässern (A. Volkmann). 


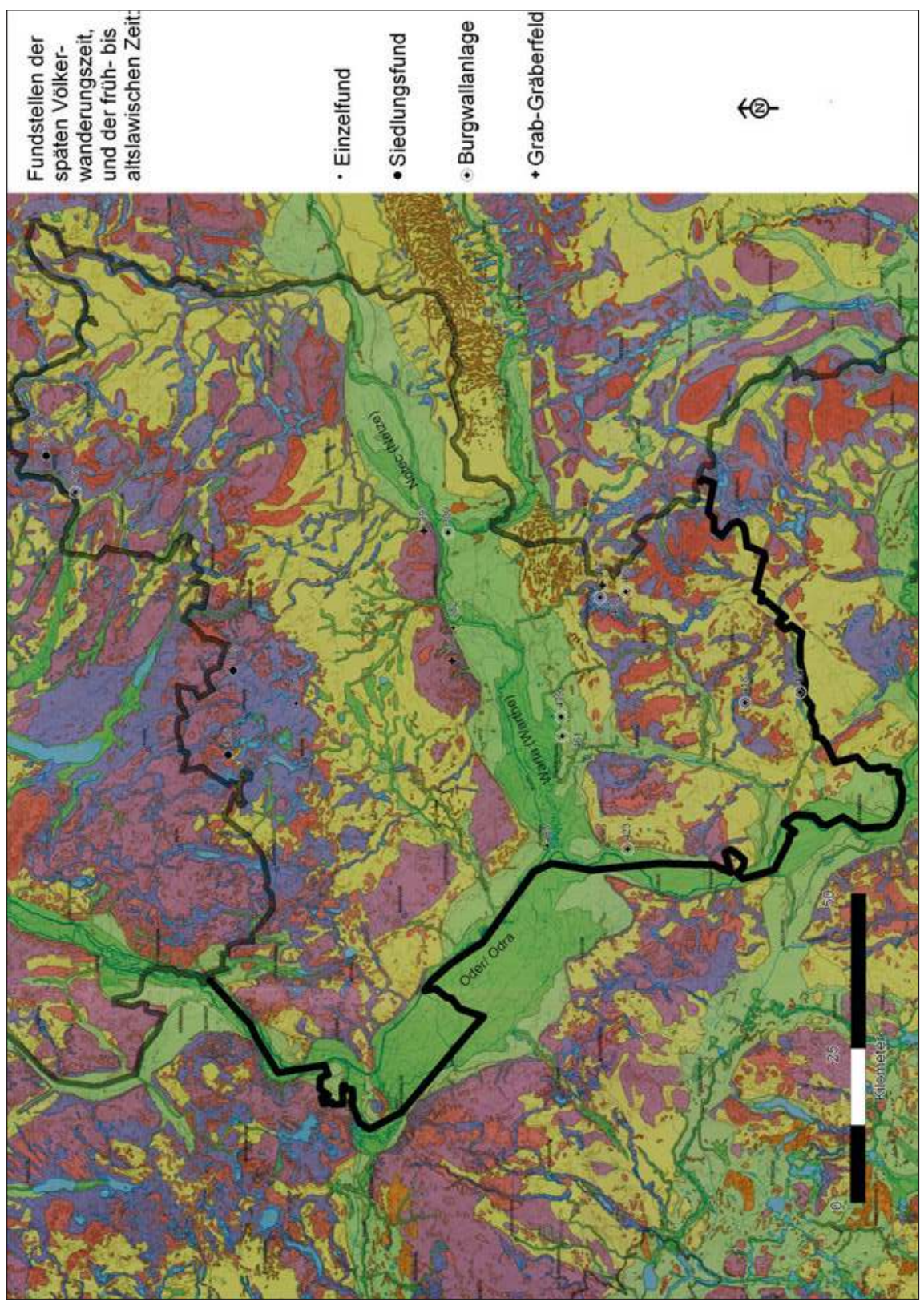

Abb. 6: Übersichtskarte der spätvölkerwanderungszeitlichen bis altslawischen

Fundstellen (Kartengrundlage: P. Ergenzinger/J. Hövermann/G. Jannsen:

Geomorphologie. Veröffentlichungen der Historischen Kommission zu Berlin.

Historischer Handatlas von Brandenburg und Berlin. Berlin/New York 1980). 


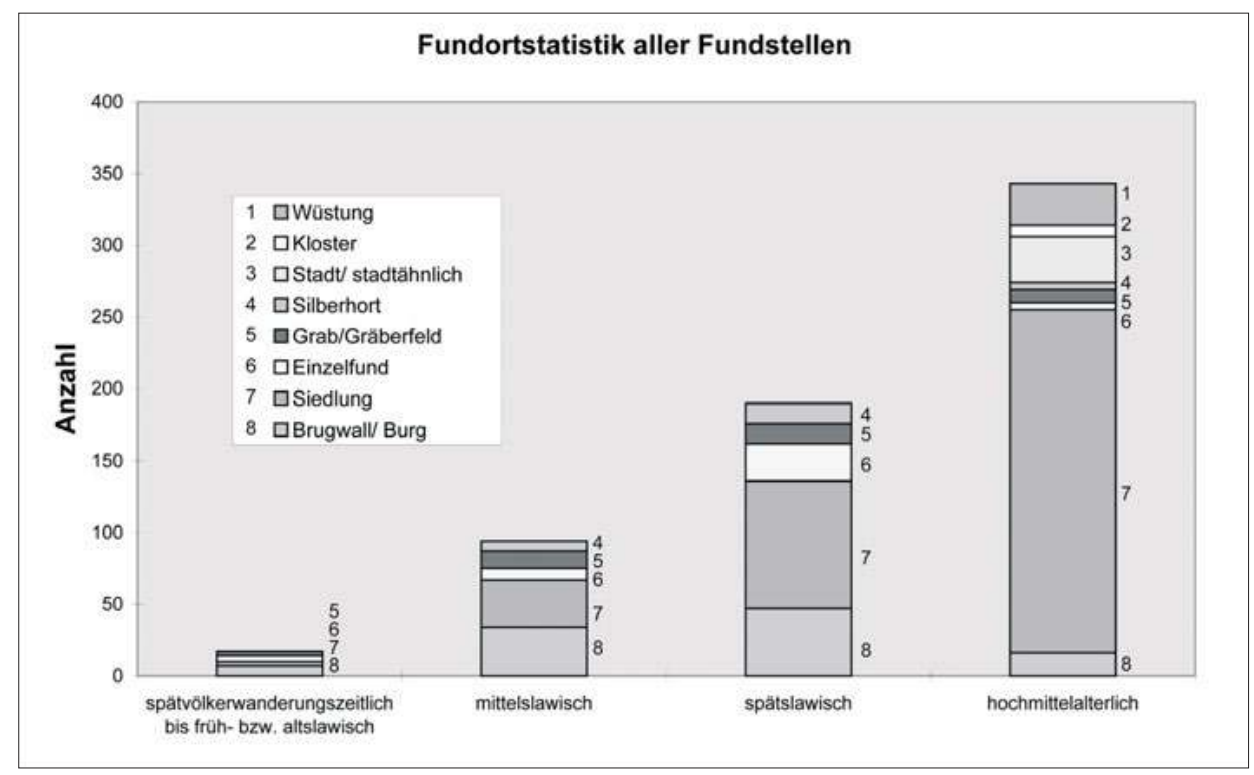

Abb. 7: Die Statistik der Fundstellen des Untersuchungsgebietes ist geordnet nach Fundarten der betreffenden Zeitstellung in einer akkumulierenden Darstellung. Aus den 500 Fundstellen des Katalogs geht durch Mehrphasigkeit und mehrfache Eigenschaften (Fundarten) einiger Fundstellen eine reale Fundstellenanzahl von ca. 646 hervor. Zu beachten ist hier, dass die miteinander verglichenen Perioden unterschiedliche Zeiträume darstellen: spätvölkerwanderungszeitlich bis früh- bzw. altslawisch 5.-8. Jh. $=400$ Jahre, mittelslawisch 9. -10. Jh. $=200$ Jahre, spätslawisch 11.-12. Jh. und 1. Drittel des 13. Jhs. $=230$ Jahre und hoch- und spätmittelalterlich 2. Drittel 13.-ca. Mitte 15. Jh. =ca. 200 Jahre. Geeicht auf eine gleiche Dauer der einzelnen Perioden und mit einer so gegebenen Vergleichbarkeit, verschiebt sich das Fundbild etwas, wobei ein reelleres Fundbild aufgezeigt wird. Die Haupttendenzen dieses Diagramms verändern sich jedoch nicht wesentlich, und es behält seine grundlegende Aussagekraft zu einer Gesamtübersicht der Funde in den unterschiedlichen Perioden. ${ }^{1}$

1 Die Anzahl der hochmittelalterlichen Fundstellen basiert nicht nur auf dem archäologischen Fundmaterial, sondern auch auf der Auswertung der schriftlichen Quellen: A.F. Riedel (Hrsg.): Codex diplomaticus Brandenburgensis, Hauptteil I, Bd. 18/19. Berlin 1859; - J. Schultze (Hrsg.): Das Landbuch der Mark Brandenburg von 1375. Berlin 1940 (= Brandenburgische Landbücher, 2); L. Gollmert (Hrsg.): Das Neumärkische Landbuch Markgraf Ludwigs des Älteren vom Jahre 1337, in: Mitteilungen des Historischen Vereins zu Frankfurt a.d. O. 2 (1862); - K. Kletke (Hrsg.): Regesta historiae Neomarchicae. Die Urkunden zur Geschichte der Neumark und des Landes Sternberg, 3 Teile, in: Märkische Forschungen 10, 12, 13 (1867-1876); - Kodeks Diplomatyczny Wielkopolski. Codex Diplomaticus Majoris Poloniae, Band 1-5. Poznań 1877-1908; Band 6-10. Warszawa/Poznań $1982 \mathrm{ff}$. 


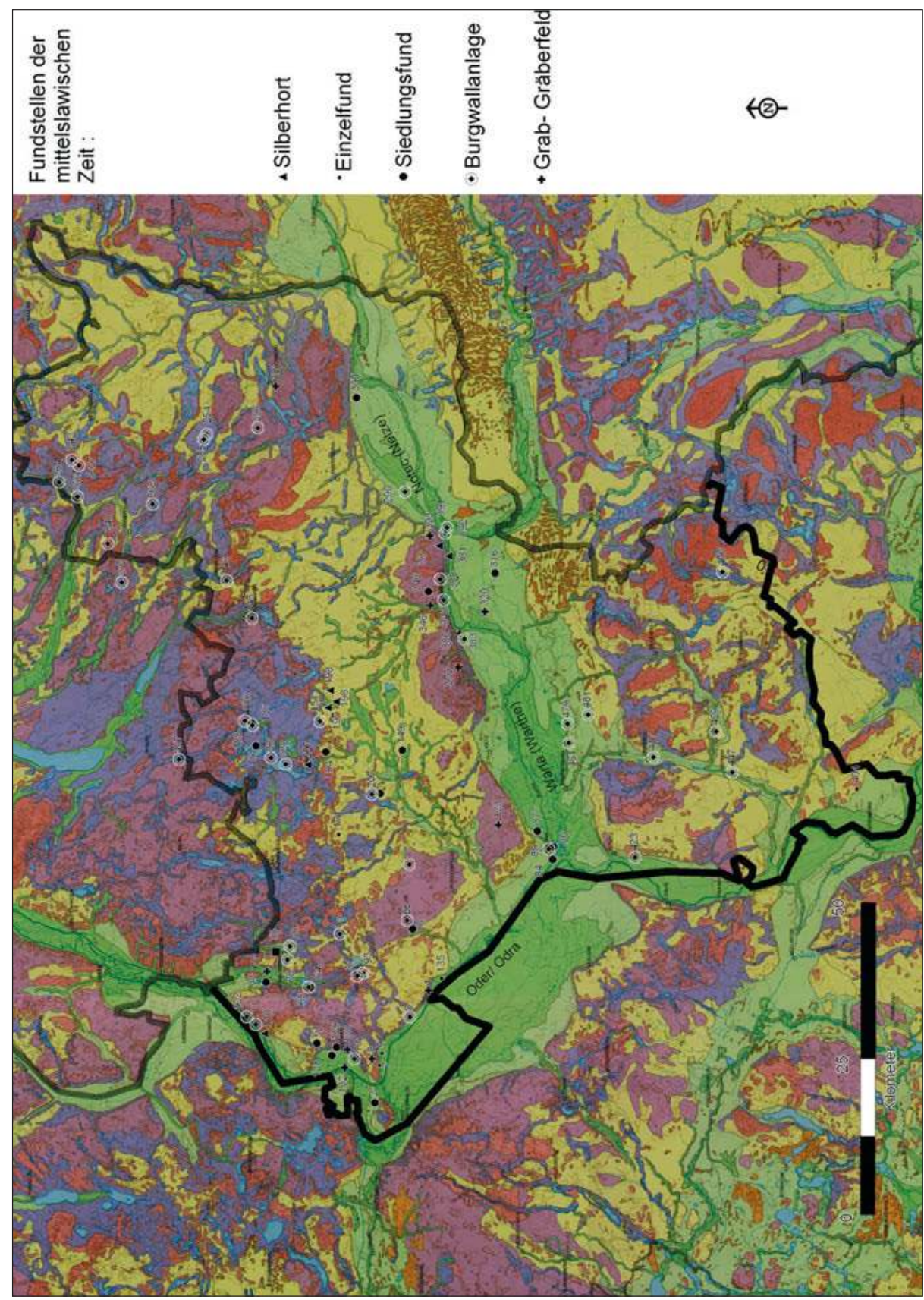

Abb. 8: Übersichtskarte der mittelslawischen Fundstellen (Kartengrundlage: Ergenzinger u.a. [wie Abb. 6]). 


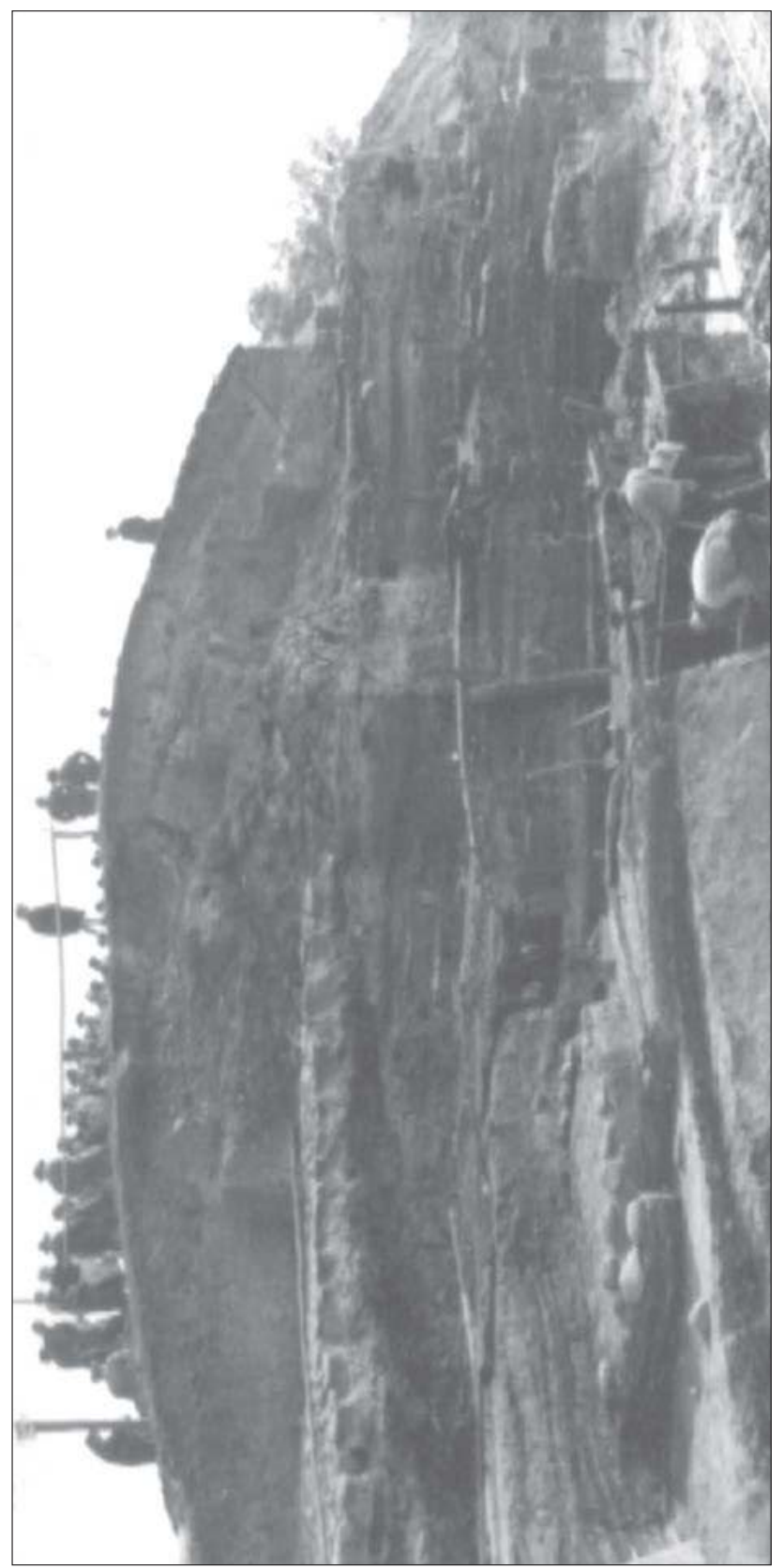

Abb. 9: Burgwall von Zantoch während der Ausgrabungen 1932-35 (aus dem Nachlass von W. Unverzagt im Archiv des Museums für Vor- und Frühgeschichte Berlin der Stiftung Preußischer Kulturbesitz). 


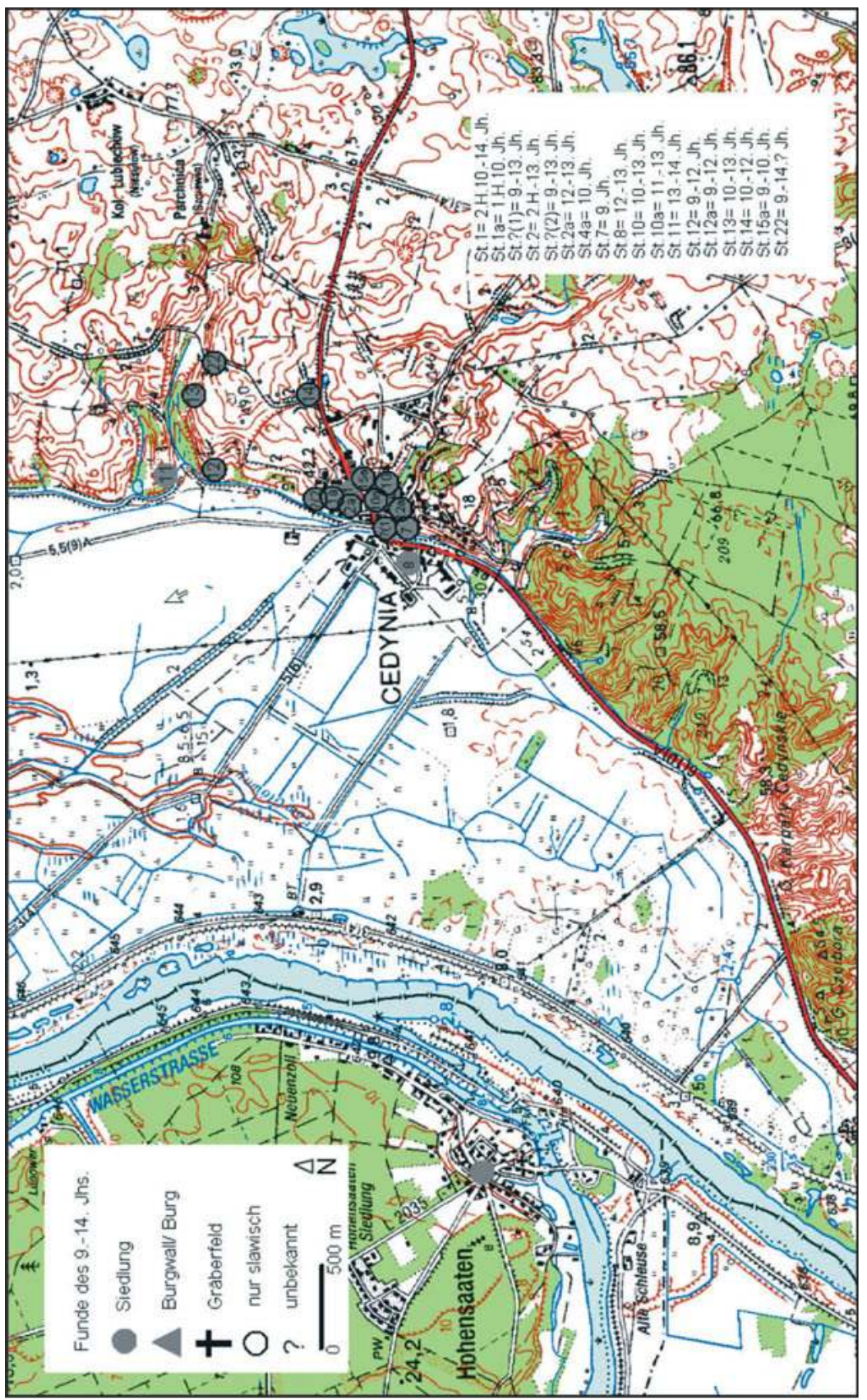

Abb. 10: Mittelslawische bis Spätmittelalterliche Siedlungskammer um Zehden (Cedynia) (Kartengrundlage: Topographische Karte TK 50 des Landesvermessungsamts Potsdam). 


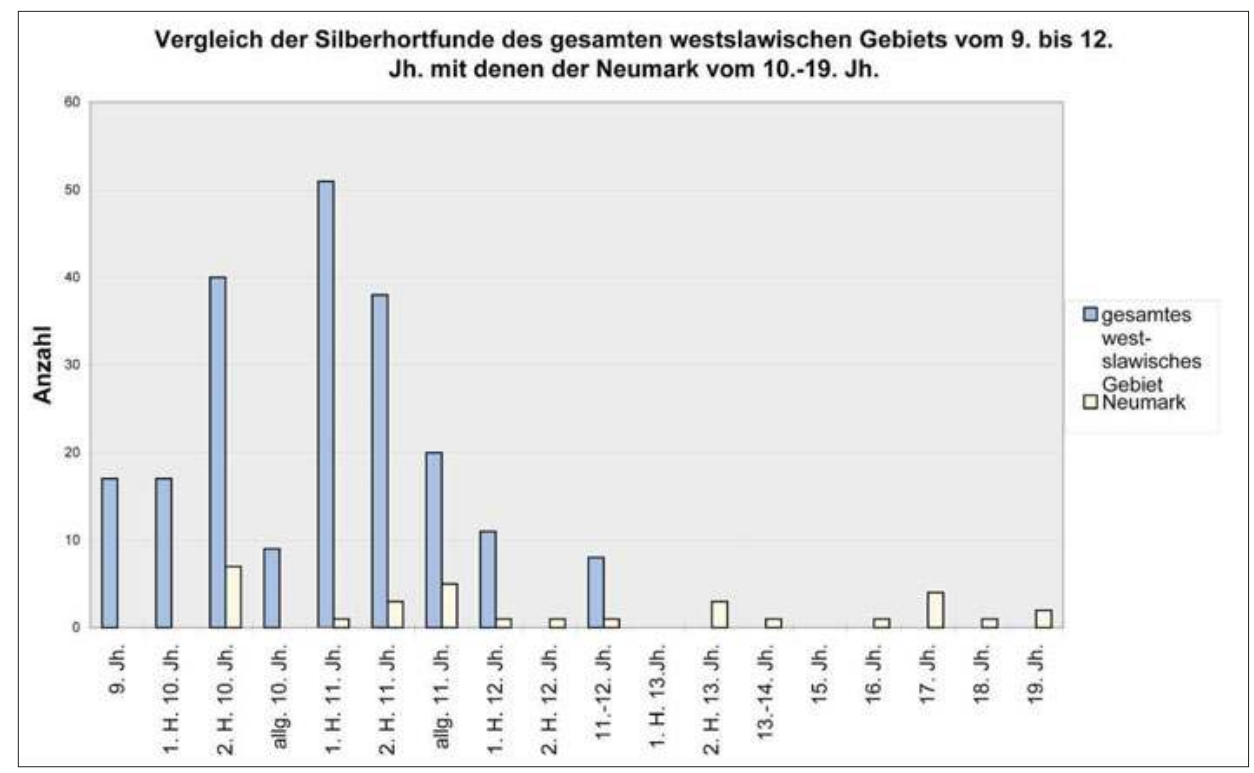

Abb. 11: Graphische Darstellung der Silberhortfunde des Untersuchungsgebietes sowie des gesamten westslawischen Raumes. 


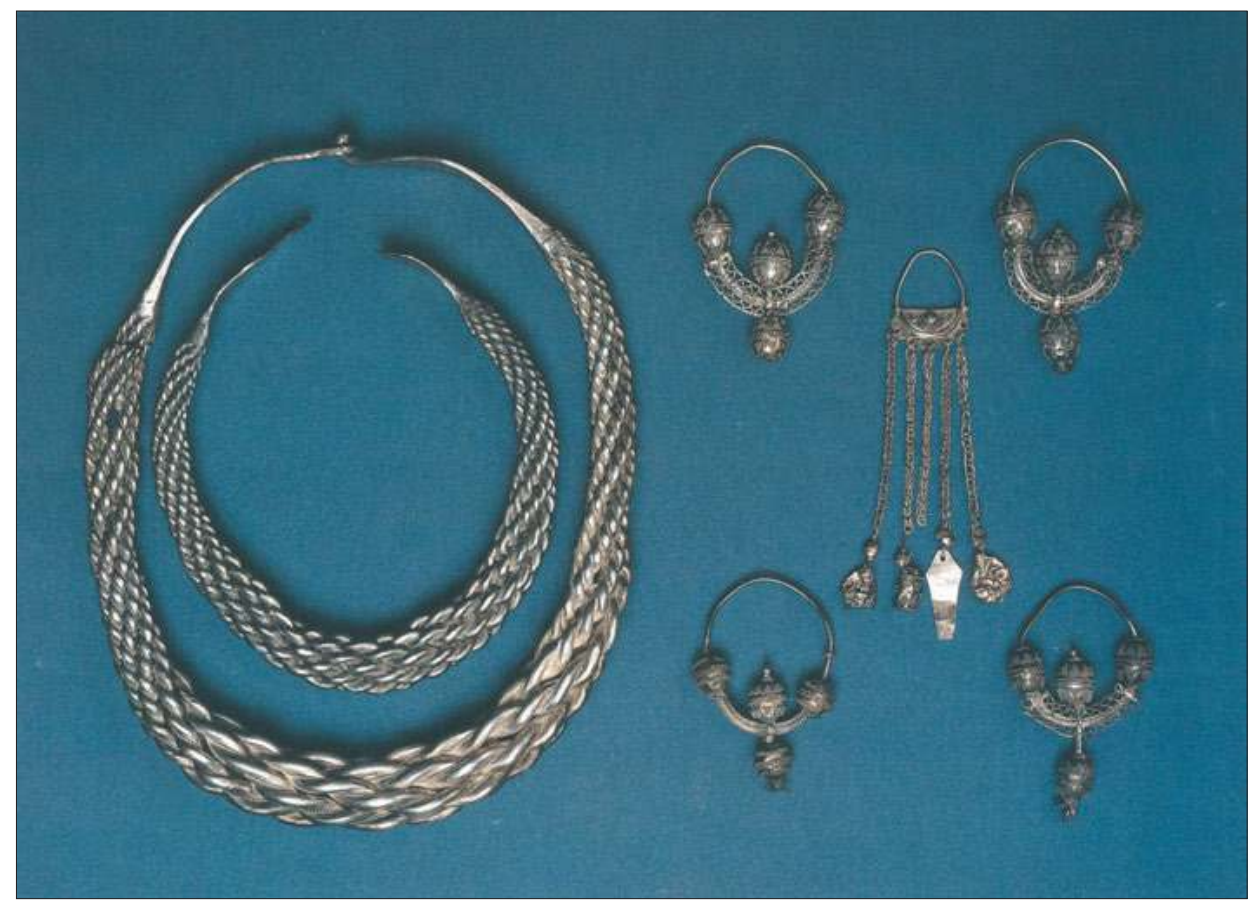

Abb. 12: Hortfund von Tempelhof (Swiatki) mit den markanten Ohrringen von Tempelhofer Typ mit einem Gesamtgewicht von 1,25 kg (nach H. Seyer: Slawische Silberschatzfunde des Mittelalters. Berlin 1997, S. 59). 


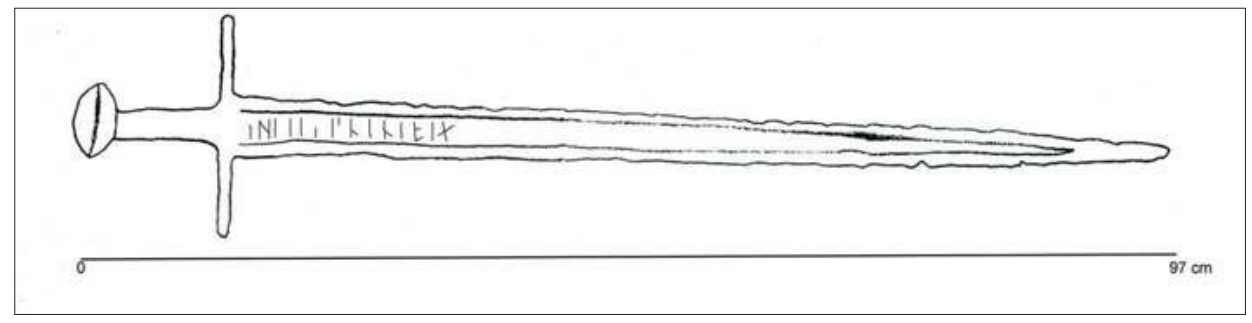

Abb.13: Eisen-Ulfberht-Schwert des Typs X aus der zweiten Hälfte des

10. Jahrhunderts aus Landsberg a.d.W. (Gorzów Wlkp.) (im Magazin des Museums für Vor- und Frühgeschichte Berlin der Stiftung Preußischer Kulturbesitz).

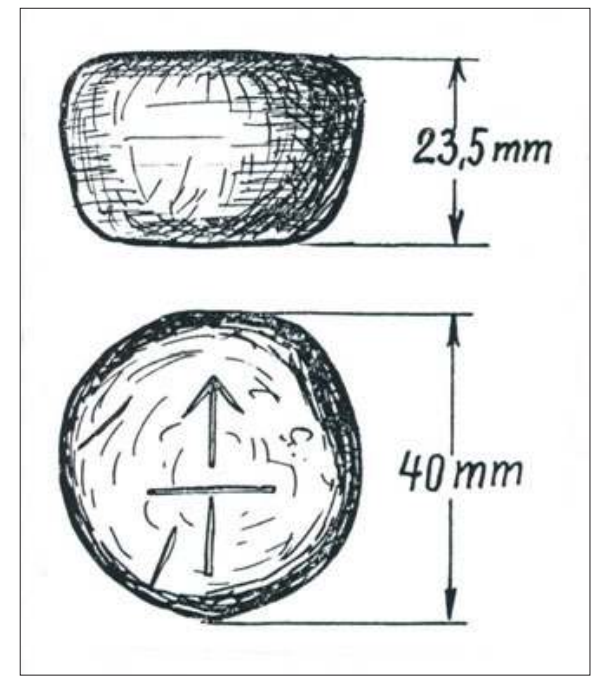

Abb. 14: spätslawische (11./12. Jh.) gewichtsnormierte Feinwaagengewichte aus Bronze (F. Buchholz: Aus der Vorgeschichte des Kreises Soldin. 4. Die Völkerwanderungszeit, Wendenzeit und die Zeit der Wiedereindeutschung, in: Heimatkalender des Kreises Soldin/Nm. 10 [1931], Abb. 11). 


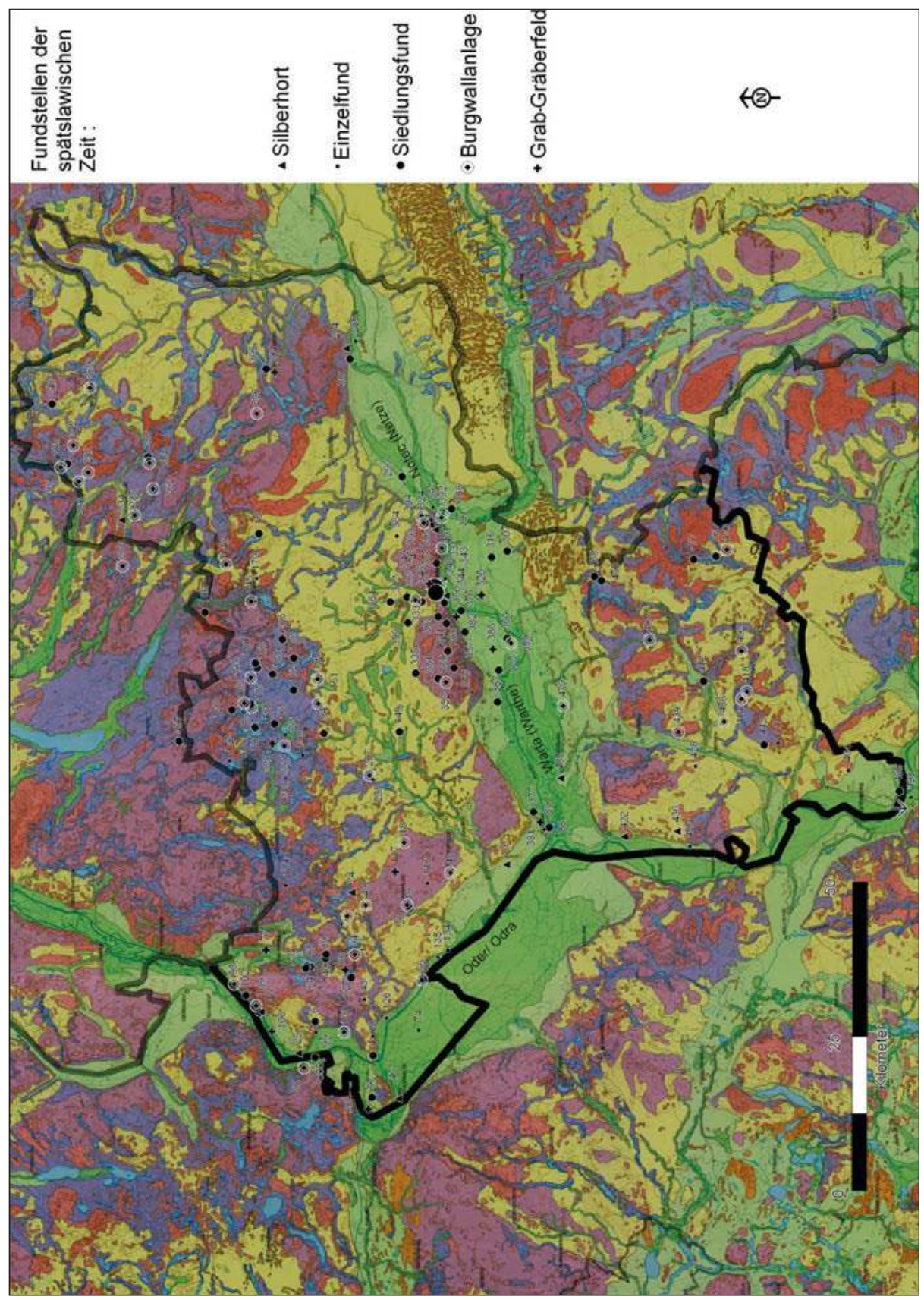

Abb. 15: Übersichtskarte der spätslawischen Fundstellen (Kartengrundlage: Ergenzinger u.a. [wie Abb. 6]). 


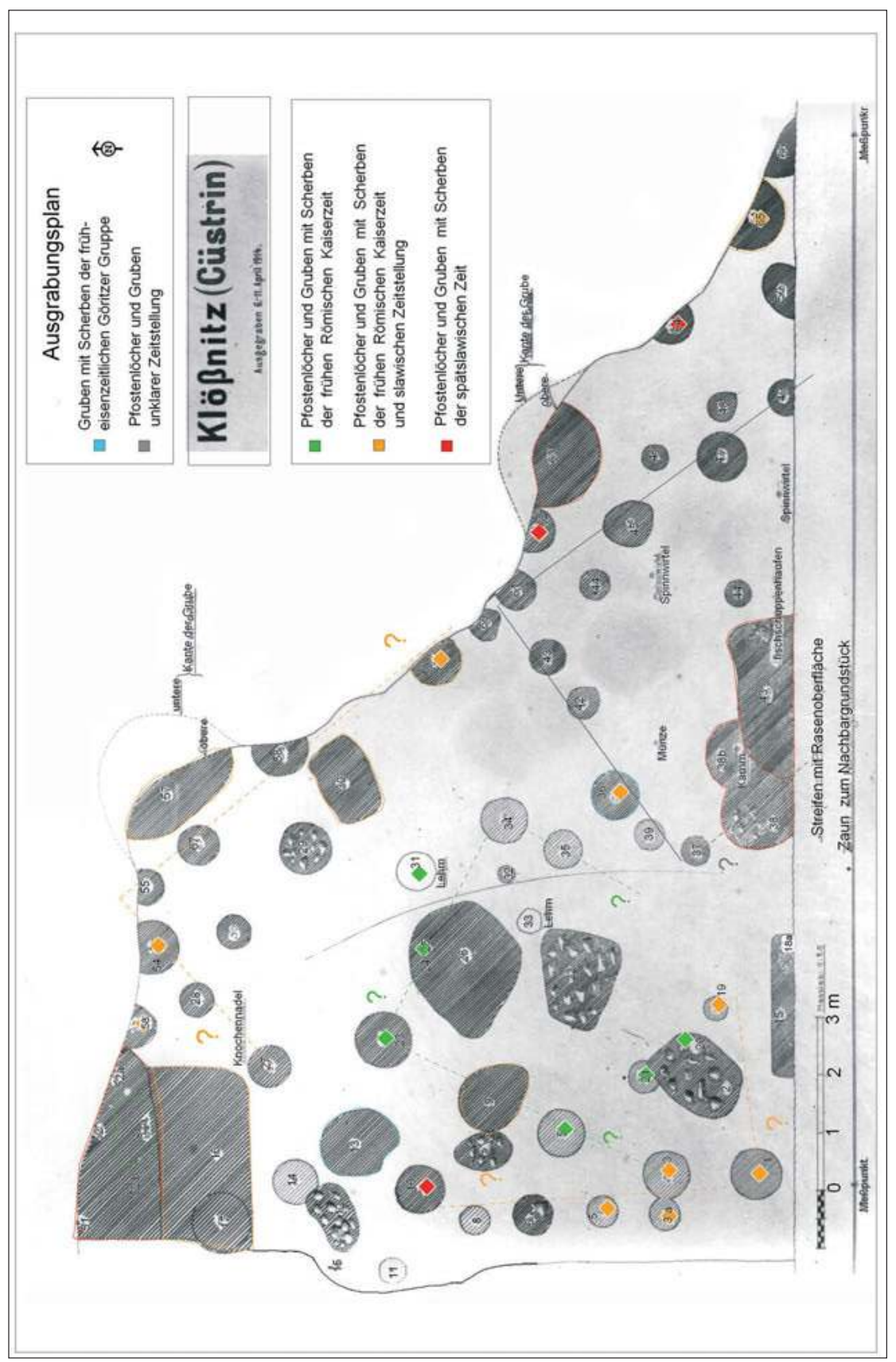

Abb. 16: Mehrperiodiger Siedlungsplatz von Küstrin-Klößnitz (Kostrzyn) (nach einer Bildplatte im Archiv der Prähistorischen Abteilung des Märkischen Museums der Stiftung Stadtmuseum Berlin). 


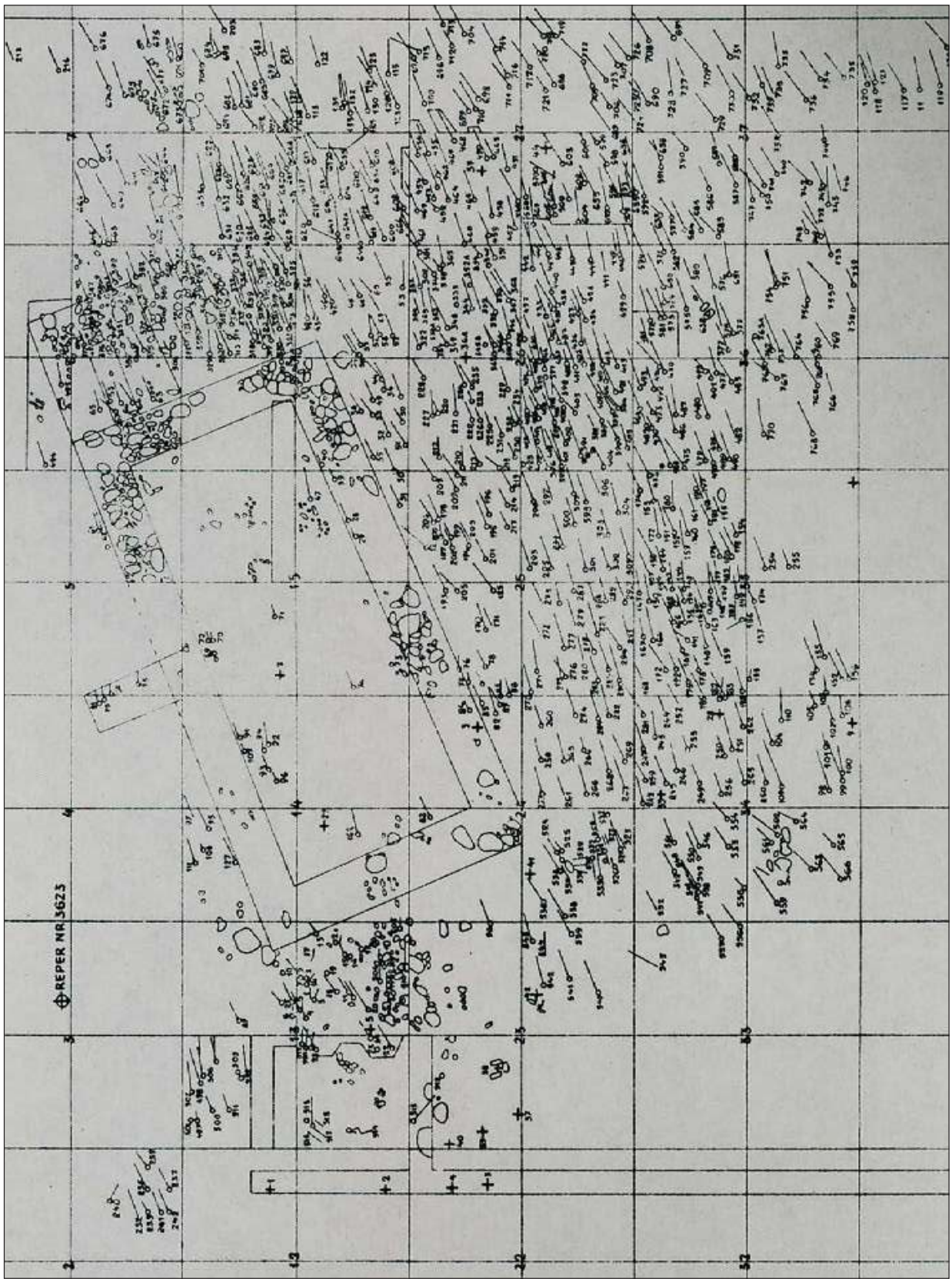

Abb. 17: Ausgrabungsplan des mittelslawisch bis spätmittelalterlichen Friedhofs von Zehden (Cedynia, Kr. Königsberg) (nach H. Malinowska-Lazarczyk: Cmentarzysko średniowieczne w Cedyni, Tom I-II. Szczecin 1982, Ryc. 5). 


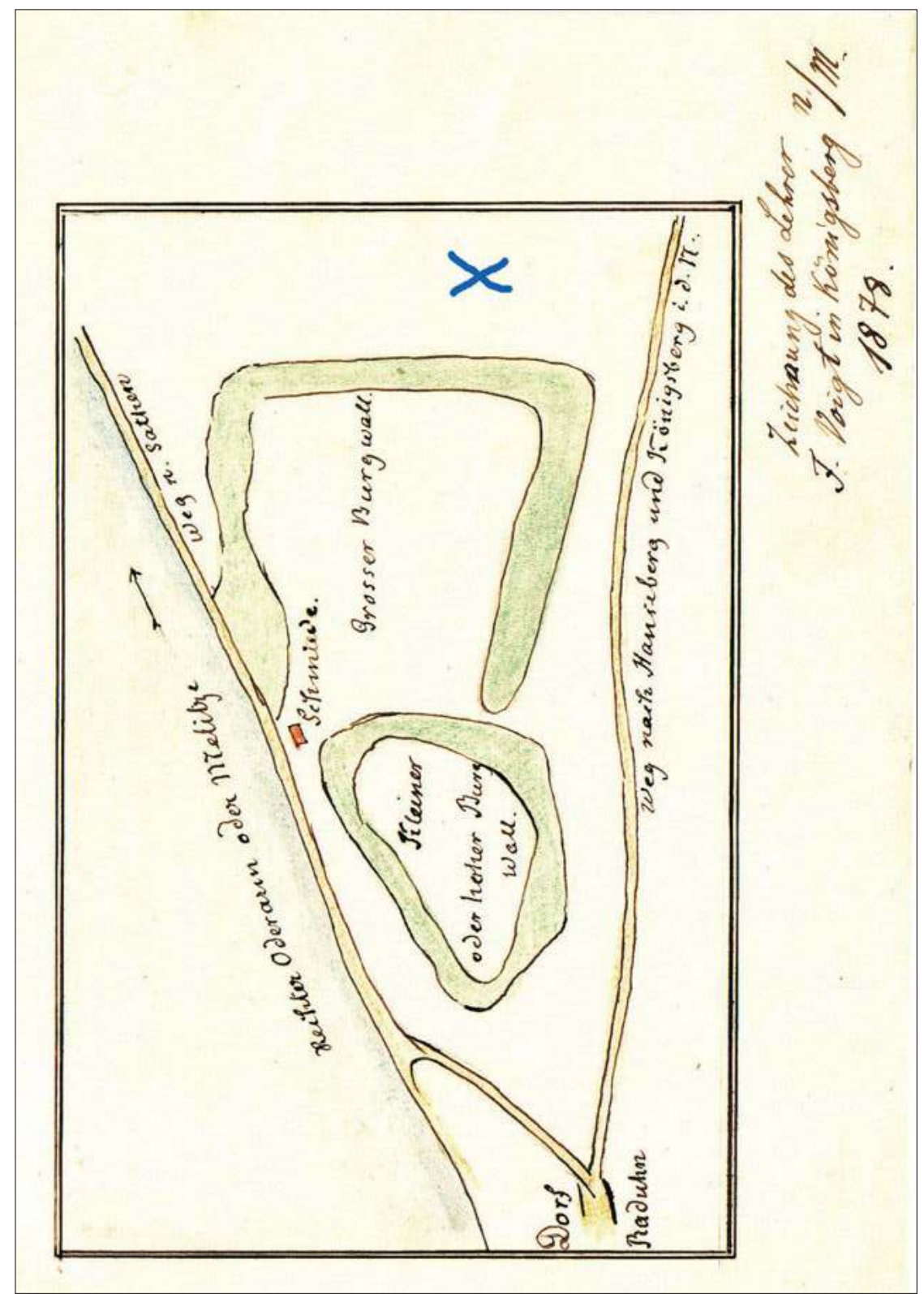

Abb. 18: Kleiner mittelslawischer runder Burgwall von 50-60 $\mathrm{m}$ im Durchmesser und große spätslawische Burganlage $(75 \times 85 \mathrm{~m})$ mit erweiterter Vorburganlage mit Gesamtgröße von $135 \times 85$ m. Das blaue Kreuz markiert die Lage der 1939 entdeckten spätslawischen bis hochmittelalterlichen Nekropole. Nach den Akten im Archiv der Prähistorischen Abteilung des Märkischen Museums Berlin (Stiftung Stadtmuseum Berlin). 


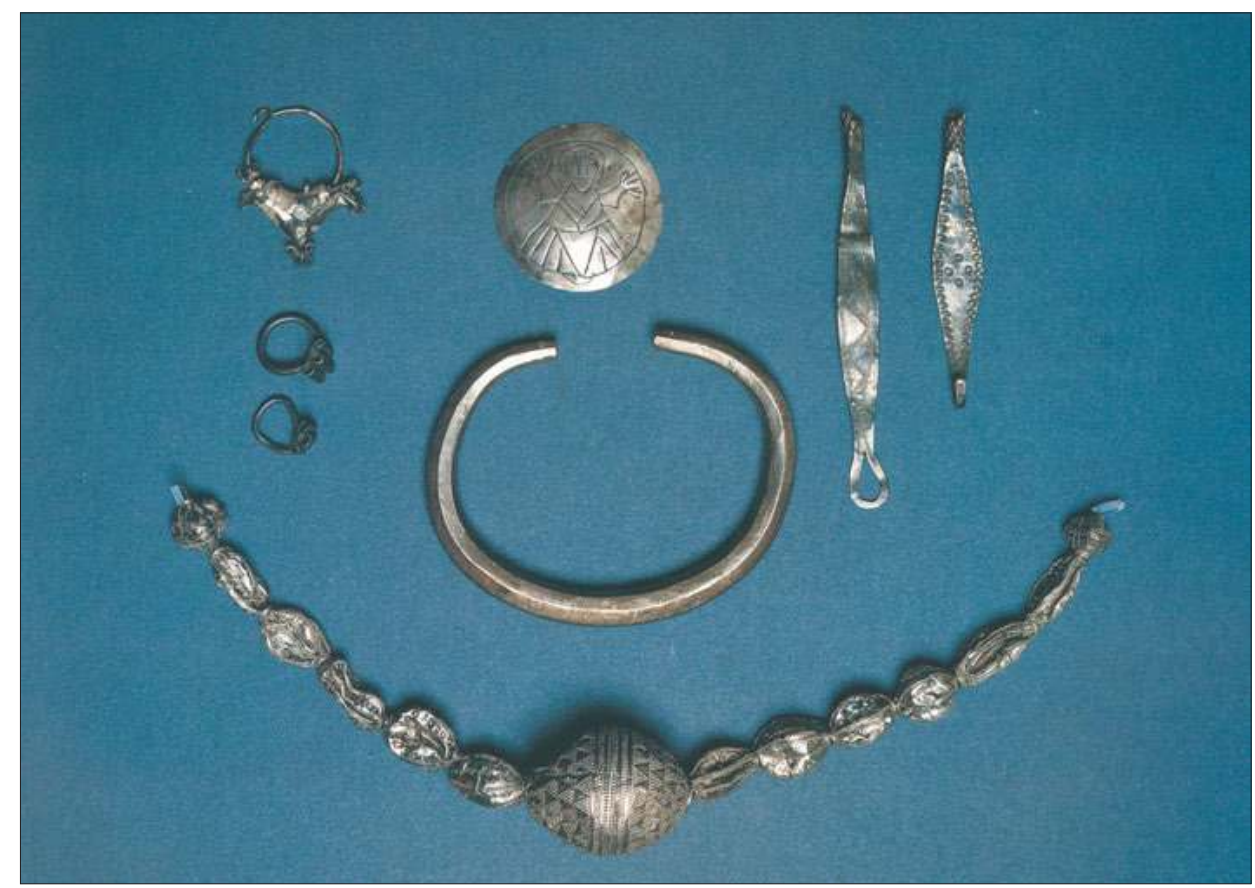

Abb. 19: Die schönsten Schmuckstücke des Hortfundes der Leißower Mühle (Lisówek) aus der Zeit nach 1015 (post quem) mit fast 10kg Gesamtgewicht (nach H. Seyer: Slawische Silberschatzfunde des Mittelalters. Berlin 1997, S. 52.). 


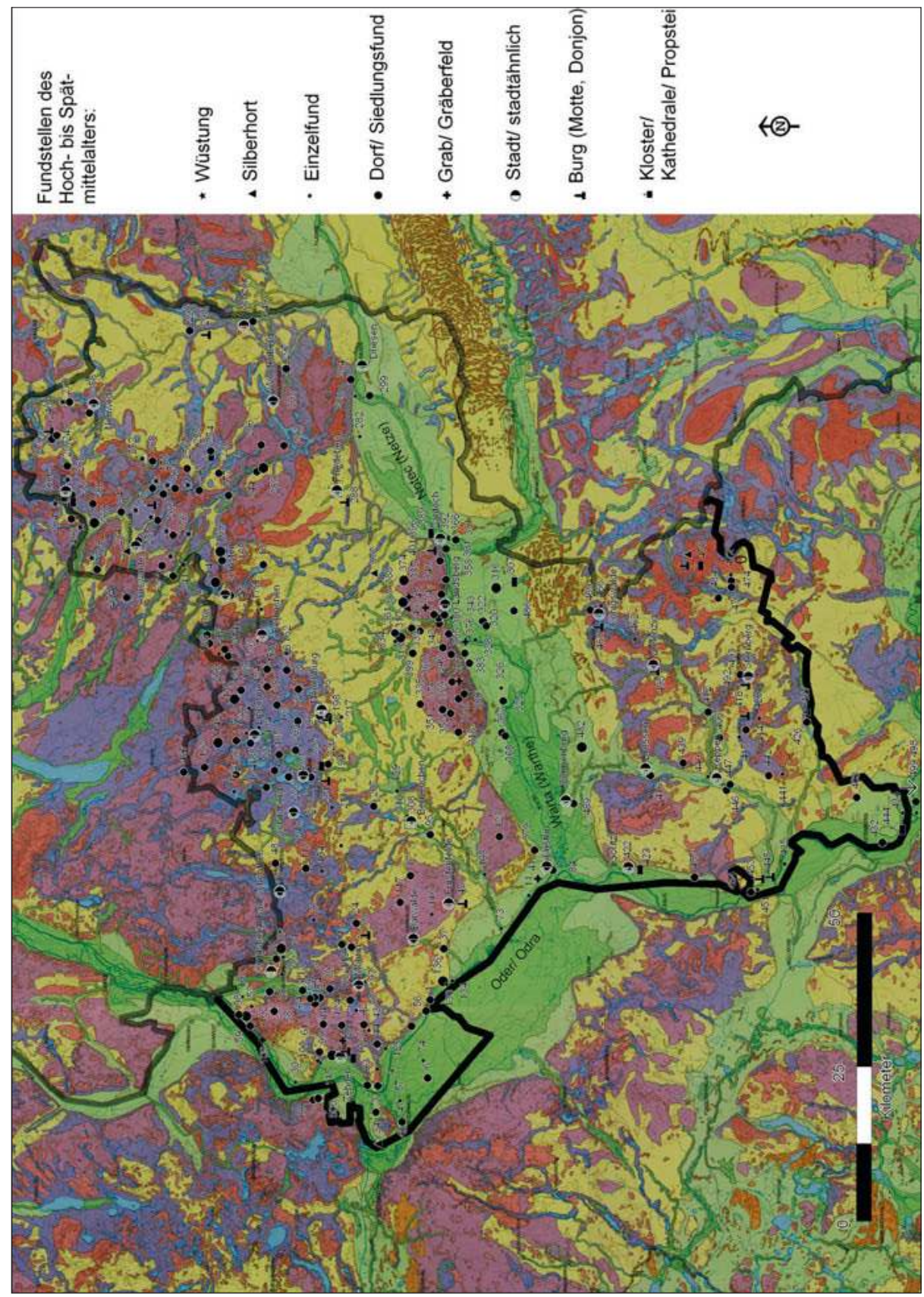

Abb. 20: Übersichtskarte der hochmittelalterlichen Fundstellen (Kartengrundlage: Ergenzinger u.a. [wie Abb. 6]). 


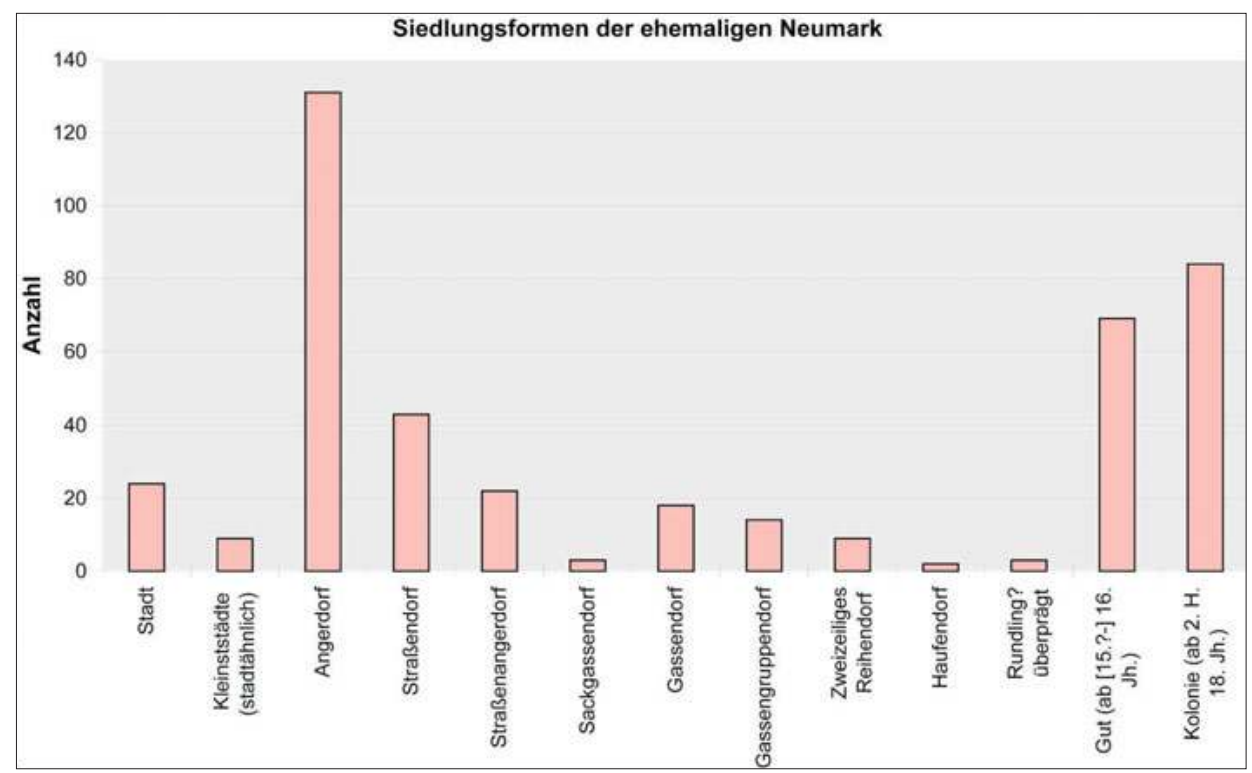

Abb. 21: Dorfformen der Neumark. Wie im übrigen Brandenburg dominieren in der Neumark die stereotypen Großdorfformen der Anger- und Straßendörfer (nach der Auswertung der Schmettauschen Karten sowie der Karten von A. Krenzlin: Die Siedlungsformen der Provinz Brandenburg. Erläuterungsheft. Veröffentlichungen der Historischen Kommission zu Berlin. Historischer Handatlas von Brandenburg und Berlin. Berlin 1983). 


\begin{tabular}{|c|c|c|c|c|c|c|c|c|}
\hline $\begin{array}{l}\text { Kata- } \\
\text { logar. }\end{array}$ & $\begin{array}{l}\text { polnischer } \\
\text { Ortsname }\end{array}$ & $\begin{array}{l}\text { hochmittel- } \\
\text { alterliche } \\
\text { Stadt }\end{array}$ & Altkreis & $\begin{array}{l}\text { älteste bekannte } \\
\text { urkundliche } \\
\text { Namensgebung }\end{array}$ & \begin{tabular}{|c|} 
schriftliche \\
Ersterwähnung \\
im Jahr
\end{tabular} & $\begin{array}{l}\text { spătslawische } \\
\text { Funde }\end{array}$ & $\begin{array}{l}\text { weitere Angabea hoch- bis } \\
\text { spãtmittelalterlicher Quellen }\end{array}$ & $\begin{array}{l}\text { geologischer } \\
\text { Untergrund }\end{array}$ \\
\hline 16 & $\begin{array}{l}\text { Trzińsko } \\
\text { Zdrój }\end{array}$ & Schönfließ & Königsberg & Sconenvlete & $1248 / 1281$ & Burgwall & Kirche St. Marien 1332 & $\begin{array}{l}\text { Sand, Lehm, } \\
\text { Mergel der } \\
\text { Grundmorăne } \\
\end{array}$ \\
\hline 19 & Miesckowice & Bärwalde & Königsberg & Berenwalde & 1298 & \begin{tabular}{|} 
Burgwall in der \\
Niederung \\
Hobenburg auf \\
Sporm sowic \\
dazwischen Siedlung
\end{tabular} & $\begin{array}{c}\text { Straubberg-Soldiner (Magdeburger-) } \\
\text { Stadtrecht }\end{array}$ & $\begin{array}{l}\text { Geschiebemergel } \\
\text { der Endmorlane }\end{array}$ \\
\hline 45 & Boleszkowice & Fürstenfelde & Königsberg & Forstenfelde & 1325 & Burgwall & $\begin{array}{c}\text { Straubberg-Soldiner (Magdeburger-) } \\
\text { Stadtrecht }\end{array}$ & $\begin{array}{c}\begin{array}{c}\text { Sand, Mergel am } \\
\text { Rand der } \\
\text { Endmoràne und } \\
\text { Sander }\end{array} \\
\end{array}$ \\
\hline 80 & Chojna & Kōnigsberg & Königsberg & Konigksberge & $1244 ? / 1267$ & Graber und Siedlung & $\begin{array}{c}\text { Sitz der schlesischen Piasten ab } 1102- \\
1138 ? \text { bis } 1236 ? \text {, bis } 1217 ?-1249 ? \\
\text { Pommemsitz, ab 1250-56 askanisch, } \\
\text { St. Marien } 1382\end{array}$ & $\begin{array}{l}\text { Talsand der } \\
\text { Grundmorăne }\end{array}$ \\
\hline 94 & Moryn & Mohrin & Königsberg & Moryn & 1306 & $\begin{array}{l}\text { Burgwall und } \\
\text { Siedlung }\end{array}$ & $\begin{array}{l}\text { bedeutender Burgsitz, pommersche } \\
\text { Burg 2. H. 13. Jh., frahdeutsch } \\
\text { Hügelburg im 13. Jh., um } 1363 \\
\text { Stolzenburg" }\end{array}$ & $\begin{array}{l}\text { Geschiebemergel } \\
\text { der Endmoräne }\end{array}$ \\
\hline 131 & Codynia & Zehden & Königsberg & Cidini & $9722 / 1187 / 1240$ & $\begin{array}{l}\text { Burgwall und } \\
\text { Siedlungen }\end{array}$ & $\begin{array}{c}\text {.kastellan de Zedin } 11187^{*} \text {, , ,oppidum } \\
\text { um } 1240 / 50^{\circ}, \text {, castum } 1400^{*} \text {, danach } \\
\text { ".Medialstadichen", bedeutende Lage } \\
\text { am einer Flussfurt }\end{array}$ & $\begin{array}{l}\text { Lehm, Sand der } \\
\text { Endmoraine }\end{array}$ \\
\hline 195 & $\begin{array}{c}\text { Nowogródek } \\
\text { Pomonski }\end{array}$ & Neuenburg & Soldin & Nienborch & $12982 / 1317$ & $\begin{array}{l}\text { Burgwall und } \\
\text { Siedlung }\end{array}$ & $\begin{array}{c}\text { Strautbery-Soldiner (Magdeburger-) } \\
\text { Stadtrecht 1276, schon } 1337 \text { wieder } \\
\text { Dorf }\end{array}$ & $\begin{array}{l}\text { Sand des Sanders } \\
\text { und Geschiebe- } \\
\text { mergel der } \\
\text { Ginundmoralne }\end{array}$ \\
\hline 215 & Golenice & Schildberg & Soldin & Schiltberghe & 1276 & $\begin{array}{c}\text { Siedlung (allgemein } \\
\text { slawisch) }\end{array}$ & $\begin{array}{l}\text { im 14. Jh. zum Oppidum geworden, } \\
\text { Burg }\end{array}$ & \begin{tabular}{|c|} 
Talsand und \\
Geschiebemergel \\
der Grundmorline
\end{tabular} \\
\hline 225 & Myslibórz & Soldin & Soldin & Soldin & $12602 / 1271$ & $\begin{array}{l}\text { Burgwall und } \\
\text { Siedlung }\end{array}$ & $\begin{array}{c}\text { bedeutende Lage an See, im und am } \\
\text { See spltslawisch Burgwalle, schon ab } \\
1234 \text { Templersitz, Topferei, Burg } \\
\text { ("Templer Hof") und Kloster, ab } 1296 \\
\text { Probstsitz (vergleiche Zantoch), } \\
\text { Stadtgründung durch ,branden- } \\
\text { burgischen Markgrafen um } 1270\end{array}$ & $\begin{array}{l}\text { Talsand und } \\
\text { Geschiebemergel } \\
\text { der Grundmorlne }\end{array}$ \\
\hline 143 & Barlinek & Berlinchen & Soldin & Berlyn & 1278 & Burgwall & $\begin{array}{l}\text { Grilindungsurkunde vorhanden } \\
\text { (Albrecht III u Otto V) }\end{array}$ & \begin{tabular}{|c|} 
Talsand und \\
Geschiebemergel \\
der Grundmorine \\
\end{tabular} \\
\hline 147 & Pelezyce & Bernstein & Soldin & Berensteyn & $12502 / 1290$ & $\begin{array}{l}\text { Burgwall, Motte, } \\
\text { Siedlung }\end{array}$ & $\begin{array}{c}\text { liegt gegenüber dem Kloster am See, } \\
\text { bedeutender Handelsweg. Motte } \\
\text { Schlossberg" ab der Mitte des } 13 \text {. } \\
\text { Jhs, auf alterem Burgwall, ,mils de } \\
\text { Bernensteyn } 1250^{\circ}, 1485 \text { zum } \\
\text { Oppidum geworden }\end{array}$ & $\begin{array}{l}\text { Talsand und } \\
\text { Geschiebemergel } \\
\text { der Grundmorane }\end{array}$ \\
\hline keine & Korytowo & Kairtow & Arnswalde & Choritowo & 1237 & Burgwall? & $\begin{array}{l}\text { polnischer Burgwart, ab } 1237 \\
\text { Johanniter Orden }\end{array}$ & $\begin{array}{l}\text { Geschiebemergel } \\
\text { der Grundmorăne }\end{array}$ \\
\hline
\end{tabular}

Abb. 22: Auszug aus der Arbeitsliste zur Analyse der 33 hochmittelalterlichen Stadtgründungen (nach Anm. 41 und 109) 

einheitsnormiertem, lokal hergestelltem Silbergeld auszugehen (siehe die Jaxa von Köpenick-Brakteaten von 1157 bis $1180^{121}$ aus Gabow [Kr. Königsberg]).

Die meisten Silberhorte des 11. Jahrhunderts weisen viel Schmuck und westeuropäische Münzen auf. Diese beiden Hauptanteile sind teilweise stark als Hacksilber fragmentiert. Der Gegenwert dieser Hacksilberhorte beruhte daher weiterhin auf dem Gewicht des Silbers, wobei es unerheblich war, ob ein schönes Silberschmuckstück komplett oder zerhackt war. Jedoch stieg der Anteil der kompletten Silberschmuckstücke im Vergleich zur mittelslawischen Zeit, denn die teilweise handwerklich aufwendig hergestellten Schmuckstücke wie die Ohrringe vom Tempelhofer Typ sind keineswegs nur als Silbergewichts-Wertäquivalent anzusehen, sondern hatten wohl einen weit höheren Wert durch ihre Repräsentativität.

Die Horte enthalten nun keine arabischen Dirham mehr. Der Zustrom arabischer Münzen nach Mitteleuropa hörte um 1000 auf. Die Gründe hierfür werden in der neuen Literatur in der zentralasiatischen Silberkrise gesucht, bei der es aufgrund geänderter politischer Verhältnisse zu einer Verminderung des Silberabbaus in den Minen und bei der Silbermünzenproduktion kam. Nach 943 verloren die samanidischen Herrscher die Kontrolle über die Münzprägung ${ }^{122}$. Die arabischen Münzen aus dieser Zeit weisen meist einen geringeren Silbergehalt auf, was wiederum die Händler dazu bewog, sich nicht auf Silber einer solch schlechten Qualität einzulassen, denn sonst hätten sie Schwierigkeiten bei dessen Absatz gehabt. Die aufstrebenden westeuropäischen Großmächte und deren Münzstätten übernahmen um 1000 die Versorgung des westslawischen Raumes mit Silbermünzen $^{123}$. Es wurden nicht mehr, wie noch zuvor im 10. und frühen 11. Jahrhundert üblich, bis $10 \mathrm{~kg}$ Hacksilbermünzen und -schmuck gehortet und verborgen (siehe „Leißower Mühle“, Abb. 19), sondern die Horte im Untersuchungsgebiet wurden kleiner, und ihre Fundanzahl stieg an. Gerade die Zunahme besonders von Silbermünzeneinzelfunden auch in Siedlungen (siehe „Klößnitz“) aus der zweiten Hälfte des 11. Jahrhunderts belegt eine Zunahme monetärer Strukturen, wobei auch Einzelmünzen umliefen. Die Silbermünzen blieben in größerem Umfang (Hacksilber, Schmuck und Münzen) im Umlauf, und so kam es zu einer verminderten Thesaurierungsaktivität. Dies ist zusammen mit den insgesamt verstärkten Aktivitäten des Handels zu betrachten: Es kam zur Schaffung eines großen Warenangebots, bei dem das Silber ebenfalls in Umlauf gehalten wurde und nur noch selten gehortet werden musste. Die Kontakte der Händler reichten, wie aufgrund von Analogien des Silberschmucks in den Horten des Untersuchungsgebietes anzunehmen ist, von (Süd-)Skandinavien über das Baltikum bis ins Gebiet der Kiever

121 G. und K. Friese: Münzfunde im Bezirk Frankfurt (Oder): 900 bis 1500, in: Kulturbund der DDR. Gesellschaft für Heimatgeschichte. Bezirksfachausschuß Numismatik Frankfurt (Oder) (Hrsg.): Numismatische Arbeiten aus dem Bezirk Frankfurt/ Oder, 1985, S. 5-68.

122 Leib/Mertens (wie Anm. 73), S. 106.

123 M. Müller-Wille: Opferkulte der Germanen und Slawen, in: Archäologie in Deutschland, Sonderband 1999. 
Russ $^{124}$. Besonders über die Münzen in den Horten sind aber auch intensive Kontakte zu den mitteleuropäischen Feudalstaaten des Deutschen Reiches und Großpolens erkennbar.

\section{Hochmittelalterlicher Landesausbau}

Weite Teile von Nordostbrandenburg wie die Uckermark, Pommern und ganz besonders die Neumark sind noch lange in die jung- bzw. spätslawische Zeit einzugliedern. Die umfassenden gesellschaftlichen Veränderungen, die mit der Feudalisierung begannen und mit der hochmittelalterlichen Ostsiedlung einhergingen, setzten hier erst ab ca. 1230 in Anfängen und $\mathrm{ab}$ ca. 1250 verstärkt ein ${ }^{125}$. Im vollen Umfang sind diese Prozesse mit einer starken zeitlichen Verzögerung umgesetzt worden, verglichen mit den Regionen West- und Südwestbrandenburgs, wo diese schon teilweise Jahrzehnte zuvor stattgefunden hatten.

Im Hochmittelalter ist abermals eine starke Zunahme an Siedlungen im Untersuchungsgebiet zu verzeichnen. Von ca. 77 offenen Siedlungen in spätslawischer Zeit stieg die Anzahl der ländlichen Siedlungen auf 239 an (Abb. 20) ${ }^{126}$. Im Zuge des Landesausbaus der askanischen Markgrafen von Brandenburg kam es zur planvollen Anlage von Dörfern und einem starken Zuzug von Neusiedlern aus dem deutschen Reich (Anhalt, Sachsen, Thüringen, Hessen/Franken und dem Rheinland), aus Flandern und den Niederlanden. Dabei ist nach Initiatoren und Trägern des Landesausbaus zu differenzieren. Aufgrund der systematischen, planmäßigen und überregionalen Landeserschließung sind wohl hauptsächlich das Königtum und die kirchlichen Bischöfe als Initiatoren zu nennen ${ }^{127}$. Die Träger waren der hohe und niedere Adel sowie maßgeblich die Klöster und wahrscheinlich auch freie Bauern, die in den schriftlichen Quellen aber kaum erwähnt werden. Die slawische Bevölkerung, d.h. die Altsiedler, wurden weitgehend in den Landesausbau integriert, denn ihre Arbeitskraft und ihr Abgabenaufkommen trug wesentlich zur Landeserschließung bei, und nur selten, meist aus „,religiösen Gründen“ oder wirtschaftlichen Interessenkonflikten, wurden sie zwangsweise umgesiedelt oder gar gewaltsam verfolgt ${ }^{128}$. Vor der planmäßigen Aufsiedlung machten sich sog. Exploratoren auf den Weg, um das mögliche Neusiedelland genauestens zu erkunden, Einheimische zu befra-

124 R. Jakimowicz: Über die Herkunft der Hacksilberfunde, in: Congressus Secundus Archäologorum Balticorum, Riga 1930, S. 251-274; - J. Herrmann: Neue Arbeiten über die altrussischen Wallund Wehranlagen, in: Prähistorische Zeitschrift 37 (1959), S. 227-241; - Stalsberg: The Scandinavian Viking Age finds in Rus, in: Bericht der Römisch Germanischen Kommission 69 (1988), S. $448-471$.

125 wie Anm. 101, S. 411-418 ff.

126 Die Siedlungszahlen des Hochmittelalters basieren nicht nur auf den archäologischen Funden, sondern es wurden zusätzlich noch die schriftlichen Quellen ausgewertet (siehe Anm. 40).

127 E. Gringmuth-Dallmer: Frühmittelalterlicher Landesausbau in Thüringen und Hessen, in: M. Gockel (Hrsg.): Aspekte thüringisch-hessischer Geschichte. Marburg 1992, S. 78 f.

128 W. Schich: Die Anlage des brandenburgischen Zisterzienserklosters Chorin in einem slawischen Siedlungsgebiet, in: Z. Kurnatowska (Hrsg.): Słowiańszczyzna w Europie Średniowiecznej 2. Wrocław 1996, S. 206 f. 
gen und dabei besonders auf bestehende Gebietsansprüche zu achten, die durch Grenzwälder, Steinwälle, Grabhügel und andere Grenzzeichen (,signa“) markiert waren. All dies ist schon aus den frühmittelalterlichen Berichten Eigils über die Aktivitäten Sturmis im Zuge der von Bonifatius beauftragten nordosthessischen Klostergründung von Fulda ersichtlich, wo mit einem „ferrum“, wahrscheinlich einem Sax oder einer Axt, in markante Bäume um das beanspruchte Gebiet Grenzmarkierungen eingeschnitten wurden. Diese Vorgänge sind wahrscheinlich mit ähnlichem Erscheinungsbild auf die späteren hochmittelalterlichen Erschließungsmaßnahmen in Brandenburg, Mecklenburg und Pommern zu übertragen ${ }^{129}$.

Ein schönes Beispiel für die mutmaßliche Herkunftsregion der Neusiedler gibt der Name „Hessendrop“ (Objezierze [Kr. Arnswalde]) im Neumärkischen Landbuch von 1337, die in diesem Fall wohl mehrheitlich aus Hessen kamen. Die geplanten Dörfer waren stereotype Anger-, Straßen- oder als Mischform Straßenangerdörfer. Sie bekamen eine Hufenverfassung mit einer festgelegten Anzahl von ackerbautreibenden Bauern. Die Ackerfluren wurden in Gewanne eingeteilt, die im Tonus der neu eingeführten Dreifelderwirtschaft abwechselnd mit unterschiedlichen Fruchtfolgen bestellt wurden. Die Einteilung der Wirtschaftsflächen in die Großgewannflur war auch bedingt durch den neuen Wendepflug, der zur rationellen Beackerung längere Äcker benötigte. Es wurde aber auch noch mit dem Hakenpflug gewirtschaftet (bis in das 19. Jahrhundert). Die Fluren, die mit dem Hakenpflug bearbeitet wurden, sind tendenziell eher in kleine Blockfluren eingeteilt worden.

Aufgrund der Flurform ist keine ethnische Interpretation des Ackerbautreibenden nach „slawisch oder deutsch“ möglich ${ }^{130}$. Da die Slawen stark in den Landesausbau integriert waren, wie zahlreiche ,deutsch-wendische“ Ortsnamenpaare oder „Wenddorf“- bzw. „Wendfeld“-Bezeichnungen belegen, ist es nicht möglich, nur aufgrund der Gewannflur mit dem wahrscheinlichen Einsatz des Wendepfluges oder der Blockflur mit dem wahrscheinlichen Einsatz des Hakenpfluges auf das den Acker bestellende Ethnikum zu schließen, wie etwa J. Henker in seiner Arbeit über die ,villa slawica - zum Verbleib der slawischen Bevölkerung in der Neumark“" an zahlreichen Beispielen wie Groß Mantel (Mętno) und Klein Mantel (Mętno Małe) verdeutlicht ${ }^{131}$. Es kam auch zur planvollen Anlage von Kleindörfern wie Gassen-, Zeilen-, Haufendörfern und systematisch angelegten Rundlingen, in denen oft umgesiedelte Slawen angesiedelt wurden und die alle meist kleine

129 M. Hardt: Siedlung als Integrationsfaktor. Zur Veränderung der Kulturlandschaft bei der Eingliederung des nördlichen Hessens in das Frankenreich - mit einem Ausblick auf die mittelalterliche Ostsiedlung, in: I. Baumgärtner/W. Schich (Hrsg.): Nordhessen im Mittelalter. Probleme von Identität und überregionaler Integration. Marburg 2001, S. 15-19.

$130 \mathrm{Zu}$ ethnischen Fragen, zur Deutung als „slawisch“ oder „deutsch“ aufgrund der materiellen Hinterlassenschaften innerhalb des archäologischen Befundes vgl. Brather: Sachkultur (wie Anm. 20). Zur Begegnung von „Slawen“ und „Deutschen“ vgl. W. Fritze: Die Begegnung von deutschen und slawischen Ethnikum im Bereich der hochmittelalterlichen deutschen Ostsiedlung, in: Siedlungsforschung. Archäologie-Geschichte-Geograpie 2 (1984), S. 187-219.

131 Unveröffentlichte Hauptseminararbeit am Seminar für Mittelalterliche Geschichte und Landesgeschichte des Instituts für Geschichtswissenschaften der Humboldt-Universität zu Berlin im WS. 2000/01. 
Blockfluren aufweisen (Abb. 21). Dies könnte ein Indiz dafür sein, dass hier hauptsächlich mit dem Hakenpflug gepflügt wurde, da diese meist nicht auf den schweren, fruchtbaren Lehmböden liegen, wo ein Wendepflug die Erdscholle optimal auflockert, sondern auf weniger fruchtbaren Sandböden, wo auch mit einem einfachen Hakenpflug der Boden aufgelockert werden kann. Die Kleindörfer können teilweise auch im Hochmittelalter als Siedlungen angesehen werden, in denen oft Slawen die Hauptbevölkerungsgruppe ausmachten, was sich auf der Grundlage onomastischer Überlegungen bei slawischen Ortsnamen und entsprechenden archäologischen Funden von spätslawischen Vorgängersiedlungen zu bestätigen scheint. In vielen geplanten Klein- und Großdörfern sind in unmittelbarer Nähe oder sogar im Dorf selbst spätslawische Funde auszumachen, die bis in die erste Hälfte des 13. Jahrhunderts reichen und mit den ersten kolonialzeitlichen Funden der „,blaugrauen Harten Grauware“ zeitgleich sein können. Innerhalb des Gassendorfes Eulam (Ulim), das mit regelmäßigen Kleingewannen innerhalb der Blockflur ausgestattet war, wurde „, frühdeutsche Harte Grauware“ und ,jüngste spätslawischer Gurtfurchenkeramik“ gefunden. Deutsche und Slawen lebten gemeinsam in Dörfern, möglicherweise mit einer räumlichen Separation, oder es wurden zwei nebeneinander liegende Siedlungen mit Zusatzbezeichnungen wie „Deutsch“ und „Wendisch“/,Groß“ und „Klein“ angelegt $^{132}$. Dieser Vorgang ist im Untersuchungsgebiet belegt z.B. durch ,dutschen Latzkowe" und „wenitelschen Latzkowe“, welche nur $3 \mathrm{~km}$ von einander entfernt sind und in der hochmittelalterlichen „terra Bernstein“ (Kr. Soldin) des Neumärkischen Landbuchs von 1337 genannt werden ${ }^{133}$, oder durch die Dörfer „Niewedele“ (Drawno) von 1338 und „Alten Wedel“ (Sicko) (Kr. Arnswalde) von 1333. Noch 1303 wird nur ein Dorf „Wedele“ erwähnt, in dem anscheinend damals Deutsche und Slawen noch zusammenlebten. Kurze Zeit später wurde in dessen Nähe eine dazugehörige Tochtersiedlung angelegt, und die vorherige mutmaßlich gemischte Dorfgemeinschaft wurde nach Ethnien separiert bzw. Slawen, welche aus einer anderen Ortschaft stammten, wurden dort angesiedelt. Ähnlich verhält es sich mit den Dörfern „Groß-““ und „Klein Latzkow“ (Laskowo) (Kr. Soldin). 1236 wird „Lascoue“, 1324 ,,wendischen Lascow“ und 1337 „mol. Latzkow“ (später wüstgefallener Mühlenort) schriftlich erwähnt ${ }^{134}$. Aus „Lascoue“ könnte das deutsche „Groß Latzkow“ und aus dem „wendischen Lascow“ könnte das slawische „Klein Latzkow“ entstanden sein. Hierbei ist jedoch nicht klar, ob sich in dem 1236 erwähnten „Lascoue“ überhaupt schon „deutsche Neusiedler“ im großen Umfang niedergelassen hatten. Es könnte sich anfangs um eine bestehende (hauptsächlich) slawische Siedlung handeln, die erst später als deutsche Siedlung ausgewiesen wurde. Die slawischen Altsiedler wären somit innerhalb dieser komplexen Ereignisse in die neue Tochtersiedlung verdrängt wor-

132 E. Gringmuth-Dallmer: Deutsch und Wendisch - Groß und Klein. Zur siedlungsgeographischen Aussage von Ortsnamen mit unterscheidenden Zusätzen in der Mark Brandenburg, in: Onomastika Slavogermanica 19 (1990), S. 77-89.

133 G.W. v. Raumer: Die Neumark Brandenburg im Jahre 1337 oder Markgraf Ludwig's des Älteren Neumärkisches Landbuch aus dieser Zeit. Berlin 1837, Karte.

134 C. Gahlbeck: Zisterzienser und Zisterzienserinnen in der Neumark. Berlin 2002, S. 1027, Tabelle 34 Nr. 282-283 (= Veröffentlichungen des Brandenburgischen Landeshauptarchivs, 47). 
den. Eindeutiger verhält es sich mit dem Siedlungspaar von „deutunita Dykow“ und „altera Dikow“ (Kr. Soldin, beide mit Ersterwähnung 1337). Hier wurde eine neue deutsche Siedlung neben einer bereits bestehenden älteren slawischen errichtet. Insgesamt gesehen wurden die bereits bestehenden spätslawischen Siedlungsgefilde durch den Landesausbau intensiv erschlossen, wobei, abgesehen von einigen spätmittelalterlichen Wüstungen im Nordosten des Untersuchungsgebiet, das bis heute bestehende Siedlungsmuster entstand.

\section{Die hochmittelalterlichen Städte}

Die Anlage von Städten im Hochmittelalter war ein weiterer wichtiger Schritt zur umfassenden Landeserschließung und Bekundung des brandenburgischen Herrschaftsanspruchs innerhalb des Untersuchungsgebietes (Abb. 22). Die Städte waren die zentralen Orte als Sitz der herrschenden weltlichen Fürsten und kirchlichen Bischöfe oder Äbte. Von ihnen ging ein bedeutender wirtschaftlicher Impuls aus, denn sie waren die Händler- und Handwerkszentren, in denen es zu einem umfassenden, auf monetären Strukturen basierenden Warenaustausch kam. Wie die Silberhorte aus der zweiten Hälfte des 13. Jahrhunderts im archäologischen Befund sowie zusätzlich die schriftlichen Quellen zeigen, wurden größere Geschäfte in monetären Einheiten wie „,Schock“ (60 Stück) und nicht mehr wie bis in das 12. Jahrhundert hinein üblich nach dem Silbergewicht als Wertäquivalent getätigt ${ }^{135}$. Bis in das 14. Jahrhundert werden jedoch in den schriftlichen Quellen aus Brandenburg bei Silberzahlungen nicht nur die Anzahl, sondern auch die Gewichtseinheit üblicherweise angegeben.

Die Mehrzahl der hochmittelalterlichen Städte entstand in unmittelbarer Nähe zu oder sogar auf spätslawischen Burganlagen. Die spätslawischen Handelsorte wurden also meist (mit der Ausnahme von Zantoch [Santok]) kontinuierlich weiter genutzt, wobei es aber zu einer teilweisen Verlagerung der Haupthandelswege, z.B. durch andere Flussfurten, kam. Anderseits ist zu erkennen, dass das hochmittelalterliche Wegenetz auf bereits bestehende slawische Strukturen zurückgriff. Die neue Wartheflussfurt für den Hauptwarentausch von Norden nach Süden war ab ca. 1250 in Landsberg (Gorzów Wlkp.), möglicherweise teilweise künstlich, angelegt worden, wo bereits in spätslawischer Zeit ein Burgwall bestand, der aber aufgrund seines spärlichen Fundmaterials nicht als überregional bedeutender Handelsort anzusehen ist. Der Oderübergang bei Lebus war in slawischer Zeit von großer Bedeutung, wie der mächtigen Burgwallanlage westlich der Oder ${ }^{136}$ und dem außergewöhnlich wertvollen, schweren Silberhortschatz (von 1015 post quem) von fast $10 \mathrm{~kg}$ Gewicht der „Leißower Mühle“ (Lisówek) auf der gegenüberliegenden

135 W. Ribbe: Wirtschaftsprozesse der Zisterzienser im Spätmittelalter, in: F. Beck/K. Neitmann (Hrsg.): Brandenburgische Landesgeschichte und Archivwissenschaft. Berlin 1997, S. 75 (= Veröffentlichungen des Brandenburgischen Landeshauptarchivs, 34).

136 U. Fiedler: Das Umfeld der Burg von Lebus in ur- und frühgeschichtlicher Zeit, in: E. GringmuthDallmer/L. Leciejewicz (Hrsg.): Forschungen zu Mensch und Umwelt im Odergebiet in ur- und frühgeschichtlicher Zeit, in: Römisch-Germanische Forschungen 60 (2002), S. 193-200. 
Seite der Oder abzulesen ist. Ab 1125 oder spätestens 1133 erlangte Lebus mit dem Sitz des Bischofs und dem Bau einer Kathedrale eine kirchliche Vorrangstellung in Ostbrandenburg. Der dortige Oderübergang verlor mit der Verlegung des Bischofssitzes auf die östliche Seite der Oder, nach Göritz (Gorzyca), im Jahr 1276 stark an Bedeutung ${ }^{137}$. Der neue Oderübergang mit Marktplatz bei Göritz etablierte sich und wurde auch nach der Rückverlegung des Bischofssitzes nach Lebus (1325) weiter genutzt, so dass die städtische Entwicklung von Lebus stagnierte. Jedoch kam auch Göritz kaum über die dörfliche Entwicklung hinaus und blieb eine „Stadt mit ländlichem Charakter“. Die Haupthandelswege verliefen nicht über Göritz, sondern südlich und nördlich über das prosperierende Frankfurt und Küstrin (Kostrzyn) ${ }^{138}$. In Küstrin konnte bislang kein slawischer Burgwall nachgewiesen werden. Die bedeutenden spätslawischen Siedlungsfunde von KüstrinKlößnitz (nordöstlich der Altstadt) und weitere Einzelfunde im Warthedelta, südlich der alten Odermündung auf der Talsandinsel im hochmittelalterlichen Stadtbereich, verdeutlichen die Nutzung des Oder- und Wartheübergangs seit slawischer Zeit. Der weiter nördlich gelegene Oderübergang bei Zehden (Cedinya), der seit mittelslawischer Zeit genutzt wurde, war zu Beginn der Hochmittelalters von großer Bedeutung für die askanische Erschließung des nördlichen Warthelands und verhalf dem spätslawischen Burgwall mit Handelsort schon früh (1187 Nennung als Burgsitz „,kastellan“ und vor 1250 Nennung als Städtchen bzw. „oppidum“139) zur wirtschaftlichen Blüte, die jedoch im Verlauf des Hochmittelalters zugunsten Küstrins stark abflaute.

\section{Die spätmittelalterlichen Wüstungen}

In der ersten Hälfte des 14. Jahrhunderts folgte eine umfassende Wüstungsphase, die beispielsweise im Dorfverzeichnis der „Terra transoderana“, das das für den wittelsbachischen Markgrafen Ludwig den Älteren erarbeitete Neumärkische Landbuch von 1337 enthält, belegt ist ${ }^{140}$. Die Ursachen für diesen kolonisatorischen Niedergang waren die politisch unruhigen Verhältnisse (Erbstreitigkeiten nach dem Tode der letzten Askanier 1319/20, verstärktes Raubrittertum, überregionale Querelen), die ein Ende des Landesausbaues bedingten. Die folgenden Wüstungsprozesse wurden in der Mitte des 14 . Jahrhunderts noch durch das Ausbrechen der Pest verstärkt. Dabei sind teilweise oder totale sowie temporäre oder andauernde Wüstungen zu unterscheiden ${ }^{141}$. Bei totalen Wüstungen wurden die Ortschaften bis heute nicht wieder errichtet; sie liegen meist in Gegenden mit relativ schlechten Böden. Die temporären Wüstungen waren meist nur vom

137 Kirsch: Mittelalterliche Keramik (wie Anm. 103).

138 Heinrich: Handelsstraßen (wie Anm. 111).

139 E. Keyser (Hrsg.): Deutsches Städtebuch. Handbuch städtischer Geschichte, Band 1: Nordostdeutschland. Stuttgart-Berlin 1939. - E. Engel u.a. [Hrsg.]: Neuauflage für Berlin und Brandenburg. Stuttgart 2000.

140 Gollmert (Hrsg.): Das Neumärkische Landbuch (wie Anm. 41).

141 E. Gringmuth-Dallmer: Landesausbau und Wüstungsgeschehen, in: H. Brachmann/H. und H.-J. Vogt (Hrsg.): Mensch und Umwelt. Berlin 1992, S. 209-217. 
14. bis 15. Jahrhundert wüst gefallen und wurden, abgesehen von der Wüstungsphase des 30jährigen Krieges, im 16. Jahrhundert wieder als Ortschaften mit einer Feldflur erschlossen $^{142}$. Sie liegen meist auf besseren Böden, auf denen sich die Wiedererschließung wirtschaftlich lohnte. Besonders stark machte sich der Wüstungsprozess in der ,terra Arnswolde“" am äußersten nordöstlichen Rand der Mark Brandenburg bemerkbar. Von 42 Dörfern, die dort 1337 im Neumärkischen Landbuch genannt sind, werden 18 als wüst (,ville deserte“) verzeichnet ${ }^{143}$. Die nicht wüst gefallenen Dörfer im späteren Kreis Arnswalde liegen fast ausnahmslos in dessen südwestlichen Teil und damit nicht in der damaligen Grenzzone zu Pommern und dem polnischen Staat. Zwischen dem vor 1337 fast zu 90\% wüstgefallenen Nordteil der „terra Arnswolde“ und dem weitgehend kontinuierlich besiedelten Südteil bestehen vom naturräumlichen Potential, d.h. hier von der Bodengüte her, keine großen Unterschiede. Wenn man sich die bodengeologischen Karten beider Gebiete anschaut, so sind im Südteil und besonders auch im Nordteil fruchtbare lehmige Böden auf den Grundmoränenplatten und Endmoränenzügen zu finden. Daher müssen hier wohl andere Faktoren für die spätmittelalterlichen Wüstungsprozesse verantwortlich sein. Es fällt auf, dass der Lauf des kleinen Flüsschens, der Rudnitza, eine Grenze ${ }^{144}$ zwischen der Siedlungs- und der Wüstungszone bildet. Es wurde also eine Grenze, die zwar einem natürlichen Fließlauf folgte, aber nicht natürlich bedingt war, zwischen den beiden Gebieten gezogen. Die Ursache dafür ist in den Unruhen der Zeit ab 1325 zu suchen. Ab jener Zeit kam es in der ,terra Arnswolde“ zu andauernden kriegerischen Auseinandersetzungen Brandenburgs mit Pommern, Polen und Litauern sowie zu Adelsfehden, Raubrittertum und internen brandenburgischen Herrschaftskämpfen, die innerhalb eines Jahrzehntes, ab den zwanziger Jahren des 14. Jahrhunderts, die weitgehende Entsiedlung des Gebietes bewirkten.

\section{Zusammenfassung}

Grundlage der Untersuchung ist eine vollständige Aufnahme der archäologischen Fundstellen des Mittelalters auf dem Gebiet der ehemaligen Neumark. Ausgewertet wurden die Archive des Märkischen Museums Berlin, des Museums für Vor- und Frühgeschichte Berlin und des Brandenburgischen Landesamtes für Denkmalpflege in Wünsdorf. Die Aufnahme der Funde, die seit 1945 von der polnischen Bodendenkmalpflege erfasst wurden, basiert auf einer umfassenden Literaturrecherche und Stichprobenaufnahme der 1978 begonnenen „Archeologiczne Zdjęcie Polski - AZP“ (Archäologische Geländeaufnahme Polens) im Wojewódzki Urząd Ochrony Zabytków w Zielonej Górze Delegatura Gorzów Wlkp. Die Geschichte der archäologischen Forschung in der Neumark lässt sich

142 A. Kuttner: Wüstungsprozesse in der Neumark. Unveröffentlichte Hauptseminararbeit am Seminar für Mittelalterliche Geschichte und Landesgeschichte des Instituts für Geschichtswissenschaften der Humboldt-Universität zu Berlin im WS 2000/01.

143 Ribbe (wie Anm. 136), S. 25.

144 Gringmuth-Dallmer: Bevölkerungsexplosion (wie Anm. 62), S. 596 f. 
bis in die vierziger Jahre des 19. Jahrhunderts zurückverfolgen. Die zahlreichen damaligen Funde wurden auf mindestens 41 verschiedene deutsche, polnische und russische Sammlungen verteilt und sind heute weitgehend verschollen. Eine Interpretation der Befunde und des Fundmaterials erfolgt hier meist durch die zahlreichen kleineren Einzelpublikationen und Archivmeldungen, die in Katalogform zusammengebracht und kritisch unter der Sichtweise des heutigen Forschungsstandes analysiert wurden.

Aus der späten Völkerwanderungszeit (5.-6. Jh.) liegen nur sehr wenige Einzel-, Grab- und Siedlungsfunde vor. Die slawische Einwanderung setzte im Norden des Untersuchungsgebiets schon im frühen 7. Jahrhundert auf den fruchtbaren und leicht zu beackernden schwarzerdeähnlichen Böden ein. Das Gebiet südlich der Warthe mit recht unfruchtbaren Sandböden wurde erst gegen Ende des 7. Jahrhunderts wiederbesiedelt. Im Süden wurden die ältesten Burganlagen schon in der Mitte des 8. Jahrhunderts wahrscheinlich auf offenen Vorgängersiedlungen errichtet. Die nördlichen Burgwallanlagen datieren erst in die mittelslawische Zeit ab dem 9. Jahrhundert. Vergleichend wurden zur Verifizierung der Ergebnisse siedlungsarchäologische Untersuchungen aus benachbarten Regionen mit ähnlichen naturräumlichen Potentialen wie in der Niederlausitz ${ }^{145}$ oder in Pommern $^{146}$ und Großpolen ${ }^{147}$ herangezogen.

Das Untersuchungsgebiet ist in zwei räumliche Großeinheiten nördlich und südlich der Warthe zu unterteilen, die im Verlauf des Mittelalters immer wieder unterschiedliche kulturgeschichtliche Entwicklungen, etwa in Bezug auf Siedlungsdichte und Siedlungsverteilung mit Kontinuitäten oder Diskontinuitäten, erkennen lassen. Die stark mäandrierende Warthe bildete eine natürliche Barriere, die nur an zwei (Zantoch [Santok] und Landsberg [Gorzów Wielkopolski]) bzw. drei Furten (Küstrin [Kostrzyn] als Pass über Warthe und Oder) zu überwinden war. Die Oder war hingegen keine Kulturbarriere, sondern es lassen sich, ganz im Gegensatz zur Warthe, in ihrem Unterlauf besonders die Gemeinsamkeiten der westslawischen Kulturgenese westlich und östlich des Flusses erkennen. In der Nähe der Furten wie etwa an der Oderfurt bei Zehden (Cedynia) wurden größere Handelssiedlungen an und in Burgwallanlagen angelegt. In ihnen konzentrierten sich händlerische und herrschaftliche Aktivitäten. Politisch gehörte der Süden ab dem Ende des 10. Jahrhunderts. zum piastischen Großpolen. Der Norden wurde nur temporär in das vorfeudale Piastenreich eingegliedert und entwickelte sich innerhalb Pommerns weitgehend unabhängig.

Bereits schon im 9./10. Jahrhundert wurde das ganze Gebiet flächenhaft durch die Anlage zahlreicher Burgwälle und offener Siedlungen erschlossen. Im 11./12. Jahrhundert wurden einzelne Regionen inselartig intensiver aufgesiedelt, wobei von einem starken Bevölkerungswachstum auszugehen ist. Nur ca. 25\% der Burgwälle und offenen Siedlungen weisen eine echte Kontinuität seit mittelslawischer Zeit auf. In spätslawischer Zeit entstanden innerhalb dieses weitgehend neuen Siedlungsmusters große, durch Burgwälle geschützte Handelsorte mit Märkten und umfangreichem Warenangebot sowie einset-

145 Biermann: Slawische Besiedlung (wie Anm. 25).

146 Łosiński (wie Anm. 21).

147 Kurnatowska/Losińska (wie Anm. 9). 
zenden monetären Strukturen. Weiterhin wurden hauptsächlich zahlreiche ungeschützte Kleinsiedlungen angelegt, die oft nach einer Nutzung von nur 25 bis 50 Jahren aufgegeben und in unmittelbarer Nachbarschaft innerhalb desselben Siedlungsgefildes neu errichtet wurden. Im Untersuchungsgebiet konnten in den Siedlungen Bauten in Blockhausund Pfosten-Ständerkonstruktion mit einem rechteckigen Grundriss sowie Hauswände aus Flechtwerk mit Lehmverputz nachgewiesen werden. Am Ende der spätslawischen Zeit entstanden in den naturräumlich begünstigten Bereichen fünf bis sechs eindeutige Siedlungs-Ballungszentren (im Gebiet des späteren Soldin [Myślibórz], Landsberg [Gorzów Wlkp.], Arnswalde [Choszczno], Reppen [Rzepin] und Königsberg [Chojna] bis zum Oderbruch), die im heutigen Siedlungsverteilungsmuster der Dörfer und Städte durchaus noch zu erkennen sind.

Im Zuge des hochmittelalterlichen Landesausbaus, der eine deutsch-slawische Mischgesellschaft zur Folge hatte, entstand das noch heute weitgehend vorhandene Siedlungsmuster, wobei rund $90 \%$ der städtischen Neugründungen auf spätslawische Burgwallanlagen zurückzuführen sind. Der intensive Landesausbau, der ab 1230 das gesamte Untersuchungsgebiet erfasste, ging mit der planvollen Anlage der heutigen Dörfer einher. Sie entstanden oft in der Nähe zu spätslawischen offenen Siedlungen oder wurden sogar in diesen errichtet. Gleichzeitig wurden zuvor unerschlossene Regionen durch Dorfneugründungen in stereotypen Formen (hauptsächlich Angerdörfer und Straßendörfer) systematisch aufgesiedelt. ${ }^{148}$

148 Dazu weiterführend vgl. die Dorfformkartierungen (Abb. 9-11 und 13-15) sowie die Kartierungen der Wüstungen des Spätmittelalters (Abb. 16-17) von A. Volkmann: Siedlungsgenetisch-archäologische Raumanalyse und Forschungen zum Verbleib der slawischen Bevölkerung in der mittelalterlichen provincia trans Oderam, in: Neitmann, K./Schopper, F. (Hrsg.): Wie die Mark entstand. 850 Jahre Mark Brandenburg. Tagung des Brandenburgischen Landesamts für Denkmalpflege und Brandenburgischen Landeshauptarchivs (Wünsdorf 2009), S. 225-248. 



\title{
Kommen - Behaupten - Zusammenwachsen Schwierigkeiten bei der Beurteilung der neumärkischen Adelsgesellschaft im späteren Mittelalter
}

\author{
Von Peter Neumeister
}

Adelsforschung - bezogen auf die Zeit des Mittelalters - ist nicht gerade eine Domäne der brandenburgischen Landesgeschichtsschreibung. An dieser Einschätzung ändert sich wenig, wenn man den bibliographischen Anhang betrachtet, der der Veröffentlichung von Peter-Michael Hahn, Struktur und Funktion des brandenburgischen Adels im 16. Jahrhundert, beigefügt ist und der etwa 65 Titel umfaßt ${ }^{1}$. Diese Liste ließe sich leicht verdoppeln, wenn sie durch weitere Arbeiten seit dem Erscheinungsdatum der Hahnschen Monographie (1979) ergänzt werden würde ${ }^{2}$. In diesem Zusammenhang sind in erster Linie auch die verdienstvollen polnischen Arbeiten von Antoni Czacharowski und Edward Rymar zu nennen ${ }^{3}$. Nicht zu vergessen sind die Forschungen, welche Teilaspekte der Adelsherrschaft wie Burgen und Herrschaft enthalten. Wir denken diesbezüglich an die große Arbeit von Wolfgang Podehl ${ }^{4}$. Trotzdem bleibt das Gesamtbild mosaikhaft mit zahlreichen Lücken. Denn bereits mit dem Aufsatz von Helga Cramer über die Herren von We-

1 Peter-Michael Hahn: Struktur und Funktion des brandenburgischen Adels im 16. Jahrhundert. Berlin 1979, S. 337-339 (= Historische und pädagogische Studien, 9). Siehe auch die Aufstellung bei Wolfgang Ribbe: Quellen und Historiographie zur mittelalterlichen Geschichte von Berlin-Brandenburg. Berlin 1977, S. 43, Anm. 146 (= Schriften des Vereins für die Geschichte Berlins, 61).

2 Siehe hierzu u.a.: Gerd Heinrich: Brandenburg-Preußen, in: Dahlmann/Waitz, Quellenkunde der deutschen Geschichte, Bd. 4. 10. Auflage Stuttgart 1987, Nrr. 134/1-1173; Brandenburgische Literatur der Gegenwart, Heft 13-19, Neuerscheinungen 1979-1990 mit Nachträgen aus früheren Jahren, bearb. v. Dorothee Geßner. Potsdam 1983-1990, ab Berichtsjahr 1990 (Folge 20) unter dem Titel Brandenburgische Bibliographie. Zu beachten auch die Literaturberichte in: Blätter für deutsche Landesgeschichte, u.a. 128 (1995), etc.

3 Antoni Czacharowski: Die Neumark - Gestaltung einer regionalen Einheit hinter der polnischen Nordgrenze im Mittelalter, in: ders.:, Bürgertum und Rittertum im Spätmittelalter. Festgabe zu seinem siebzigsten Geburtstag. Toruń 2001, S. 129-139; ders.: Der neumärkische Adel während der Auseinandersetzung zwischen Polen, Pommern und dem Deutschen Orden um die Wende vom 14. zum 15. Jahrhundert, in: ebenda, S. 141-161. Aus der langen Liste der Publikationen von Edward Rymar nenne ich: Studia i materiały z dziejów Nowej Marchii i Gorzowa. Szkice historyczne. Gorzów Wlkp. 1999. Weiterhin verweise ich u.a. auf: Grzegorz Jack Brzustowicz: Ród Hagenów (Indagine) w średniowieczu. Z heraldyki i genealogii rycerstwa Nowej Marchii i Pomorza Zachodniego, in: Nadwarciański Rocznik Historyczno-Archwalny 2 (1996), S. 58-77. Neuerdings zu beachten: Ewa Syska, Die Urkunden der Stadt Landsberg an der Warthe (Gorzów Wielkopolski) aus der Askanier- und Wittelsbacherzeit 1257-1373, in: Jahrbuch für die Geschichte Mittel- und Ostdeutschlands (im Folgenden zitiert: JGMOD) 48 (2002), S. 29-116.

4 Wolfgang Podehl: Burg und Herrschaft in der Mark Brandenburg. Untersuchungen zur mittelalterlichen Verfassungsgeschichte unter besonderer Berücksichtigung von Altmark, Neumark und Havelland, Köln, Wien 1975 (= Mitteldeutsche Forschungen, 75). 
del beginnen die Probleme ${ }^{5}$. Die Gleichung Wedel = neumärkischer Adel wird suggeriert, wobei dies bei genauerem Hinsehen so abwegig gar nicht ist. Die ohne Frage erwiesene Verwandtschaft der von Wedel mit dem großen Rest des neumärkischen Adels, zumindest im 14. und 15. Jahrhundert, scheint offenbar. Gleichwohl sollte man sich von Irrlichtern nicht den Weg weisen lassen.

Wir haben stattdessen zu Beginn festzustellen, was der brandenburgischen Adelsforschung, einschließlich des Blickes auf die Neumark, Wegweisendes fehlt. Es ist für die allgemeine Beurteilung der Thematik eine Studie wie die von Karl-Heinz Spiess über Familie und Verwandtschaft im deutschen Hochadel (gemeint ist im übrigen der südwestdeutsche Adel) des Spätmittelalters ${ }^{6}$. Die Frage nach der Existenz oder Nichtexistenz eines „Hochadels“ in Brandenburg wie in der Neumark scheint mir sehr berechtigt und bisher unbeantwortet zu sein. Es stellen sich übrigens Zweifel ein, daß in diesem Zusammenhang mit einem Negativurteil zu rechnen ist. Tangiert sind hier wichtige Strukturunterschiede des Adels diesseits und jenseits von Elbe und Saale. So ist zu fragen, ob die Ergebnisse von Spiess auch auf unseren Raum zu übertragen sind. Vielleicht ist eine Neudefinition von Adel bzw. „Hochadel“ in diesem Kontext notwendig und sinnvoll.

Es fehlen des weiteren Arbeiten wie die von Dieter Rübsamen ${ }^{7}$ über die kleinen Herrschaftsträger des Pleißenlandes oder die von Susanne Baudisch ${ }^{8}$ über den Adel Nordwestsachsens. Übrigens scheint mir diesbezüglich die Verwendung des Begriffs „,kleine Herrschaftsträger“ sinnvoller als die Benutzung des Begriffs „niederer Adel“. Der Begriff ,niederer Adel“" mag in der sozialgeschichtlich orientierten Adelsforschung bei der Beschreibung sozialer Mobilität eine gewisse Berechtigung haben, ob er für die Untersuchung geographischer Mobilität geeignet ist, muß sich erweisen . Bei Rübsamen und

$5 \quad$ Helga Cramer: Die Herren von Wedel im Lande über der Oder. Besitz- und Herrschaftsbildung bis 1402, in: JGMOD 18 (1969), S. 63-129.

6 Karl-Heinz Spiess: Familie und Verwandtschaft im Deutschen Hochadel des Spätmittelalters. 13. bis Anfang des 16. Jahrhunderts. Stuttgart 1993 (=Vierteljahrschrift für Sozial- und Wirtschaftsgeschichte, Beihefte, 111); vgl dazu meine Besprechung in: Zeitschrift für Geschichtswissenschaft 43 (1995), S. 858 f. Der Titel der Arbeit von Spiess ist etwas irreführend, weil er den ,mitteldeutschen“" und „ostdeutschen“ Adel außer Acht läßt.

7 Dieter Rübsamen: Kleine Herrschaftsträger im Pleißenland. Studien zur Geschichte des mitteldeutschen Adels im 13. Jahrhundert. Köln, Wien 1987 (= Mitteldeutsche Forschungen, 95).

8 Susanne Baudisch: Burgen und Herrensitze in Nordwestsachsen. Ausgang 11. Jahrhundert bis Mitte 14. Jahrhundert, Teil 1: Burgen und Herrensitze, Teil 2: Schriftquellen, Regis-Breitingen 1996; dies.: Lokaler Adel in Nordwestsachsen. Siedlungs- und Herrschaftsstrukturen vom späten 11. bis zum 14. Jahrhundert, Köln, Weimar, Wien 1999 (= Geschichte und Politik in Sachsen, 10).

9 Im Hinblick auf die Definition von Adel möchte ich aus der Vielzahl von Publikationen auf folgende verweisen: Otto Gerhard Oexle: Aspekte der Geschichte des Adels im Mittelalter und in der Frühen Neuzeit, in: Europäischer Adel 1750-1950, hg. v. Hans-Ulrich Wehler. Göttingen 1990, S. 19-56 (= Geschichte und Gesellschaft, Zeitschrift für Historische Sozialwissenschaft, Sonderheft 13); Karl-Heinz Spiess: Aufstieg in den Adel und Kriterien der Adelszugehörigkeit im Spätmittelalter, in: Zwischen Nicht-Adel und Adel, hg. v. Kurt Andermann u. Peter Johanek. Stuttgart 2001, S. 1-26 (= Vorträge und Forschungen, 53); Norbert Kersken: Der Kleinadel in Polen im 15. und 16. Jahrhundert, in: ebenda, S. 213-237. Daß der Mediävist auch vom Neuzeithistoriker in diesem Zusammenhang lernen kann, zeigt der Band: Stephan Malinowski, Vom König zum Führer. Deutscher Adel und Nationalsozialismus. Frankfurt am Main 2004, besonders S. 34-117, wo es um 
Baudisch handelt es sich um zielpunktgenaue Forschungen, die sich bemühen, die Spezifik einer ausgewählten Landschaft im Hinblick auf ihre adligen Herrschaftsträger zu ergründen. Die modernen methodischen Ansätze jener Arbeiten wurden bis heute nicht auf den Nordosten des deutschen Reichsgebietes im Mittelalter übertragen. Hans K. Schulze, Adelsherrschaft und Landesherrschaft (1963) versuchte so etwas ansatzweise für Brandenburg, jedoch nur für die Altmark ${ }^{10}$. Zugeschnitten auf mein Thema fehlt es auch an Untersuchungen über das Procedere, wie adlige Herrschaftsträger in die Neumark gelangten und sich dort auf verschiedene Weise etablierten. Als Vorbild kann hierbei die Monographie von Tomasz Jurek über das fremde Rittertum in Schlesien bis zur Mitte des 14. Jahrhunderts dienen ${ }^{11}$.

Am meisten zu beklagen ist jedoch das Fehlen von modernen, neuen Forschungsansätzen gerecht werdenden, Studien über die brandenburgischen Askanier und die Wittelsbacher und Luxemburger in der Mark. Wir wissen sehr wohl die neueren Arbeiten von Assing und Partenheimer über die Askanier zu schätzen, leider fehlen Gesamtdarstellungen jener bedeutenden Hochadelsgeschlechter für die Zeit des 12./13. und 14. Jahrhunderts in Brandenburg ${ }^{12}$. Ein wichtiger Orientierungsturm historischer Forschung bleibt da-

die Begrifflichkeit geht und der Versuch unternommen wird, Elemente des adligen Habitus zu analysieren.

10 Hans K. Schulze: Adelsherrschaft und Landesherrschaft. Studien zur Verfassungs- und Besitzgeschichte der Altmark, des ostsächsischen Raumes und des hannoverschen Wendlandes im hohen Mittelalter, Köln, Graz 1963 (= Mitteldeutsche Forschungen, 29).

11 Tomasz Jurek: Obce rycerstwo na Śląsku do Połowy XIV wieku. Poznań 1998 (= Poznańskie Towarzystwo Przyjaciół Nauk, Wydział Historii i Nauk społecznych prace Komisji Historycznej, Tom 54); derselbe, Fremde Ritter im mittelalterlichen Polen, in: quaestiones medii aevi novae 3 (1998), S. 19-49; Erik Fügedi, Janos M. Bak, Fremde Ritter im mittelalterlichen Ungarn, in: ebenda, S. 3-17.

12 Siehe u.a.: Helmut Assing: Brandenburg, Anhalt und Thüringen im Mittelalter. Askanier und Ludowinger beim Aufbau fürstlicher Territorialherrschaften. Zum 65. Geburtstag des Autors hg. v. Tilo Köhn, Lutz Partenheimer, Uwe Zielmann. Köln, Weimar, Wien 1997; ders.: Der Aufstieg der askanischen Markgrafen von Brandenburg in das Kurfürstenkolleg, in: Königliche Tochterstämme, Königswähler und Kurfürsten, hg. v. Armin Wolf. Frankfurt am Main 2002, S. 317-358 (= Studien zur europäischen Rechtsgeschichte, 152); Lutz Partenheimer, Albrecht der Bär, Gründer der Mark Brandenburg und des Fürstentums Anhalt. Köln, Weimar, Wien 2. Aufl. 2003, hier vor allem auch das Literaturverzeichnis. Nützlich bzw. unentbehrlich sind nach wie vor: Johannes Schultze: Die Mark Brandenburg. Unveränderter Nachdruck der 1. Auflage. Berlin 1989, mit wichtigen Informationen über die Zeit der Wittelsbacher und Luxemburger; Eberhard Schmidt: Die Mark Brandenburg unter den Askaniern (1134-1320). Köln, Wien 1973 (= Mitteldeutsche Forschungen, 71); Hermann Krabbo, Georg Winter (Hg.): Regesten der Markgrafen von Brandenburg aus askanischem Hause (im Folgenden zitiert: KW), 12 Lieferungen. München, Leipzig, Berlin 1910-1955 (= Veröffentlichungen des Vereins für Geschichte der Mark Brandenburg). Verdienstvoll: Die frühen Askanier. Protokoll der Wissenschaftlichen Konferenzen zur politischen und territorialen Herrschaftsgeschichte sowie den sozialen und kulturhistorischen Aspekten der frühen Askanier-Zeit am 19./20. Mai 2000 in Aschersleben/Ballenstedt und am 25.05.2002 in Bernburg, in: Beiträge zur Regionalund Landeskultur Sachsen-Anhalts, Heft 28, Halle 2003. Symptomatisch für den Forschungsstand über die Askanier ist die Tatsache, daß in der neuesten Studie von Tobias Weller: Die Heiratspolitik des deutschen Hochadels im 12. Jahrhundert. Köln, Weimar, Wien 2004 (= Rheinisches Archiv, 149) dieses Geschlecht keinen eigenen Abschnitt erhalten hat. Nicht ohne Grund darf man aber be- 
mit unbeleuchtet. Warum diese Desiderate zu beklagen sind, vermag ich nicht zu erklären. Gerade die Askanier als Kurfürsten, deutsche Thronkandidaten und als frühe Prototypen der Errichtung von Landesherrschaft im Brunnerschen Sinne müssen eine große Anziehungskraft im mittelalterlichen Reich ausgeübt haben und sollten deshalb das Interesse der modernen Geschichtsschreibung beanspruchen ${ }^{13}$. Dem askanischen Hof in Brandenburg kann sicherlich eine ebensolche Anziehungskraft zugeschrieben werden, wie sie Tomasz Jurek den Höfen der schlesischen Piasten zubilligte ${ }^{14}$. Beim Stichwort „Hof“ deutet sich eine weitere Lücke brandenburgischer Adelsforschung an. Verweise auf Hans Spangenberg, Eberhard Schmidt und Karl-Heinz Ahrens vermögen diese Lücke nur unvollständig zu schließen ${ }^{15}$. Wünschenswert wäre es zudem ohne Zweifel, um einmal die positive, optimistische Ausdrucksweise zu wählen, wenn wir über eine vergleichende Arbeit, die eine Adelsherrschaft im Altsiedelland und eine im Kolonisationsgebiet wie der Neumark behandelt, verfügen könnten.

Im Folgenden möchte ich nun einige Gedanken über die neumärkische Adelsgesellschaft äußern, die mir bei der Untersuchung meines Themas wichtig erscheinen. Vollständige oder allumfassende Aussagen werden nicht angestrebt, alle sind eingeladen zu ergänzen. Konzentrieren möchte ich mich auf drei Schwerpunkte: das Kommen, das Behaupten und das Zusammenwachsen von Adligen in einem überschaubaren Raum: in der Neumark.

\section{Das Kommen}

Wenn wir über das Kommen von adligen Herrschaftsträgern sprechen, interessiert uns vorrangig nicht die genealogische und soziale Herkunft der Zuziehenden, sondern vielmehr das Wie der Migration. Im siedlungsgeschichtlichen Kontext wurden zur Kolonisation vorrangig von bäuerlicher und städtischer Bevölkerung kompetente Aussagen erst kürzlich wieder von Winfried Schich getroffen ${ }^{16}$. Daß die Ergebnisse bedenkenlos auf

haupten, daß im 12. Jahrhundert die Askanier durchaus an die Seite der bei Weller behandelten Wettiner und Ludowinger zu stellen sind.

13 Siehe Otto Brunner: Land und Herrschaft, Grundfragen der territorialen Verfassungsgeschichte Österreichs im Mittelalter. 5. Auflage, Wien 1965 (Neudruck 1973); die Forschungen zum Thema Landesherrschaft hat jüngst kritisch zusammengefaßt Ernst Schubert: Fürstliche Herrschaft und Territorium im späten Mittelalter. München 1996 (=Enzyklopädie Deutscher Geschichte, 35); der Versuch einer Anwendung auf den nordostdeutschen Raum bei Peter Neumeister: „Landesherrschaft“ im südlichen Ostseeraum im 12. und 13. Jahrhundert, in: Architektur im weltlichen Kontext, hrsg. v. Dirk Schumann. Berlin 2001, S. 18-43 (= Studien zur Geschichte, Kunst und Kultur der Zisterzienser, 4).

14 Jurek: Śląsku (wie Anm. 11), S. 441-450 (deutsche Zusammenfassung).

15 Hans Spangenberg: Hof- und Zentralverwaltung der Mark Brandenburg im Mittelalter. Leipzig 1908; Schmidt (wie Anm. 12), S. 139-149 und S. 178-185; Karl-Heinz Ahrens: Residenz und Herrschaft. Studien zur Herrschaftsorganisation, Herrschaftspraxis und Residenzbildung der Markgrafen von Brandenburg im späten Mittelalter. Frankfurt am Main, Bern, New York, Paris 1990.

16 Winfried Schich: Die Gründung von deutschrechtlichen Marktorten und Städten östlich der Elbe im 12. und 13. Jahrhundert, in: Hausbau und Raumstruktur früher Städte in Ostmitteleuropa 
den Adel bezogen werden dürfen, wage ich zu bezweifeln. Zu bedenken ist nämlich, daß Ansprüche auf die neumärkischen Gebiete im 13. Jahrhundert nicht nur die Askanier und die Erzbischöfe von Magdeburg, die aus westlicher Richtung kamen, erhoben, sondern daß sie auch aus dem Norden (Pommern, Cammin), aus dem Osten und Süden (Posen, Polen, Schlesien und Meißen) zur Geltung kamen ${ }^{17}$. Die von Winfried Irgang 1987 herausgegebenen Urkunden und Regesten zur Geschichte des Templerordens im Bereich des Bistums Cammin und der Kirchenprovinz Gnesen veranschaulichen diesen Prozeß eindrucksvoll ${ }^{18}$. Zu vergessen sind in diesem Zusammenhang auch die adligen Kräfte nicht, die bereits im 13. Jh. in diesem Gebiet saßen. Stellvertretend nenne ich die von Kenstel, die slawischen Ursprungs gewesen sein sollen ${ }^{19}$. Außerdem kommt den Lebuser Bischöfen hier eine besondere Bedeutung zu, wenn man z.B. an die Urkunden denkt, die den Grafen Mrochko oder Mrotsek betreffen. Kam Mrochko wirklich aus Schlesien ${ }^{20}$ ? Er hatte jedenfalls in oder um Zielenzig Erbgüter, was darauf hindeutet, daß bereits die Vorfahren hier verankert waren. Die Probleme um die Begriffe proprietas und hereditas sind uns bewußt ${ }^{21}$. Hierher gehört auch der Graf Goslaus, der das Amt des Kastellans von Zantoch innehatte. Sowohl der Grafentitel als auch das Namengut der Herrschaftsträger

(= Památky Archeologické - Supplementum, 6), S. 7-16; ders.: Die pommersche Frühstadt im 11. und frühen 12. Jahrhundert am Beispiel von Kolberg (Kołobrzeg), in: Die Frühgeschichte der europäischen Stadt im 11. Jahrhundert, hg. v. Jörg Jarnut und Peter Johanek. Köln, Weimar, Wien 1998, S. 273-304; ders.: Es kamen disse von Suawen, eine vome Rine. Zur Herkunft der Zuwanderer in die Mark Brandenburg im 12. und 13. Jahrhundert, in: Die Herkunft der Brandenburger. Sozial- und mentalitätsgeschichtliche Beiträge zur Bevölkerung Brandenburgs vom hohen Mittelater bis zum 20. Jahrhundert, hg. v. Klaus Neitmann/Jürgen Theil. Potsdam 2001, S. 17-40 (= Brandenburgische Historische Studien, 9; Arbeiten des Uckermärkischen Geschichtsvereins zu Prenzlau e.V., 4), hier auch Bemerkungen zum Anteil des Adels an der Kolonisation; ders.: Die ostelbische Kulturlandschaft des 10. und 12. Jahrhunderts im Vergleich, Polen und Deutschland vor 1000 Jahren. Die Berliner Tagung über den „Akt von Gnesen“, hg. v. Michael Borgolte. Berlin 2002, S. 61-89. Siehe auch Jan Piskorski: Die deutsche Ostsiedlung des Mittelalters in der Entwicklung des östlichen Mitteleuropa. Zum Stand der Forschung aus polnischer Sicht, in: JGMOD 40 (1991), S. 27-86.

17 Paul von Nießen: Geschichte der Neumark im Zeitalter ihrer Entstehung und Besiedlung (Von den ältesten Zeiten bis zum Aussterben der Askanier.), Landsberg a. W. 1905 (= Schriften des Vereins für Geschichte der Neumark, Geschichte der Neumark in Einzeldarstellungen); Christian Gahlbeck: Der Oder-Drage-Raum in voraskanischer Zeit. Großpolen, Schlesien und Pommern im Wettstreit um den Besitz der späteren Neumark, in: JGMOD 45 (1999), S. 1-98.

18 Urkunden und Regesten zur Geschichte des Templerordens im Bereich des Bistums Cammin und der Kirchenprovinz Gnesen. Nach Vorlage von Helmut Lüpke neu bearbeitet von Winfried Irgang. Köln, Wien 1987; siehe auch Günther Wrede: Grenzen der Neumark 1319-1817. Diss. phil. Greifswald 1935.

19 Vgl. Nießen (wie Anm. 17), S. 313; Podehl (wie Anm. 4), S. 674.

20 Siehe Karl Kletke: Regesta Historiae Neomarchicae. Die Urkunden zur Neumark und des Landes Sternberg, in Auszügen mitgeteilt. Berlin 1867 (= Märkische Forschungen, X), S. 8 f. (zu 1241), S. 9 f. (zu 1244), Güter in und um Zielenzig betreffend; vgl. auch Irgang (wie Anm. 18), S. 30, Nr. 27; vgl. zu Mrochko auch Nießen (wie Anm. 17), S. 140 ff.; zum Namen vor allem Gerhard Schlimpert: Slawische Personennamen in mittelalterlichen Quellen Deutschlands. Berlin 1964 (= Deutsch-Slawische Forschungen zur Namenkunde und Siedlungsgeschichte, 17), S. 63 (unter unsichere Namen).

21 Johannes Schultze: Propietas und Hereditas östlich Elbe und Oder, in: Blätter für deutsche Landesgeschichte 104 (1968), S. 32-41. 
werfen zahlreiche Fragen auf. Der Grafentitel bezieht sich sicherlich auf das „Burggrafenamt". Aber die Problematik ist für diesen Raum kaum ausreichend untersucht, vor allem bei Berücksichtigung der neueren Arbeiten über das Burggrafenamt ${ }^{22}$. Im Hinblick auf das Namengut gilt es zu beachten, daß der slawische „Graf“ Mrochko einen Bruder namens Gerlach hatte, der im Lebuser Domkapitel eine gewisse Rolle spielte ${ }^{23}$. Über die Namen ethnische Zuordnungen zu treffen, ist aber auch in anderen geographischen Räumen wie z.B. dem Ostseegebiet mit Schwierigkeiten verbunden. Hinzu kommen nun noch weitere ,international“ agierende Gemeinschaften wie die Ritterorden, im besonderen in der Frühzeit die Templer und Johanniter, später im 15. Jahrhundert der Deutsche Orden.

Doch damit haben wir bereits etwas vorgegriffen. Zunächst gilt es zur Frage zurückzukehren, wie Adlige in die Neumark gelangen konnten und sich schließlich hier niederließen, um kleinere oder größere Herrschaften zu begründen. Was Jurek für Schlesien erkannt hat, dürfte vielleicht auch für die Neumark zutreffen. Zu untersuchen sind im 13. Jahrhundert im Gefolge der Bemühungen zur Unterwerfung der Neumark die Zusammensetzung der Höfe des Königs von Polen, der Herzöge von Schlesien und Pommern, der Markgrafen von Brandenburg und Meißen und der Bischöfe von Cammin, Posen, Lebus und Brandenburg sowie vielleicht der des Bischofs von Breslau ${ }^{24}$. Die Höfe waren

22 Zu Goslaus siehe Kletke (wie Anm. 20), S. 20 zu 1260; zur Problematik des Burggrafenamtes siehe immer noch Siegfried Rietschel: Das Burggrafenamt und die hohe Gerichtsbarkeit in den deutschen Bischofsstädten während des früheren Mittelalters. Leipzig 1905; methodisch wegweisend jetzt André Thieme: Die Burggrafschaft Altenburg. Studien zu Amt und Herrschaft im Übergang vom hohen zum späten Mittelalter. Leipzig 2001 (= Schriften zur Sächsischen Landesgeschichte, 2); zu Brandenburg wurde die Thematik angerissen von Ralf Gebuhr, in: Felix Biermann, Ralf Gebuhr, Helmut Erlenkeuser, Josef Riederer und Elisabeth Schnepp: Ein mittelalterlicher Töpferofen aus Belzig im Fläming, in: Zeitschrift für Archäologie des Mittelalters 29 (2001), S. 142-154.

23 Siegmund Wilhelm Wohlbrück: Geschichte des ehemaligen Bistums Lebus und des Landes dieses Namens. Erster Teil. Berlin 1829, S. 66-70 und S. 80-82; Oskar Breitenbach: Das Land Lebus unter den Piasten. Fürstenwalde/Spree 1890, S. 105-107; Fritz Funcke: Regesten der Bischöfe von Lebus bis zum Jahre 1418, in: Brandenburgia 24 (1916), S. 200, Nr. 42; S. 201, Nr. 48 und 49; ders.: Das Bistum bis zum Anfange der Hohenzollernherrschaft in der Mark Brandenburg, in: Jahrbuch für Kirchengeschichte 16 (1918), S. 4 f.; Adolph Friedrich Riedel (Hg.): Codex diplomaticus Brandenburgensis. Sammlung der Urkunden, Chroniken und sonstigen Geschichtsquellen für die Geschichte der Mark Brandenburg und ihrer Regenten. Erster Hauptteil, zwanzigster Band. Berlin 1861, S. 182, Nr. VIII (im Folgenden zitiert: Riedel A, S., Nr.); Irgang (wie Anm. 18), S. 30, Nr. 27 u. S. 31, Nr. 28.

24 Zur Definition von „Hof“" siehe Werner Rösener: Artikel „Hof“, in: Lexikon des Mittelalters, Bd. V. München 1991, Sp. 66 f.; zur Problematik weiterhin: Joachim Bumke: Höfische Kultur. Literatur und Gesellschaft im hohen Mittelalter, 2 Bde. 9. Auflage München 1999 (=dtv 4442), vor allem Bd. 1, S. 76 ff.; Alheydis Plassmann: Die Struktur des Hofes unter Friedrich I. Barbarossa nach den deutschen Zeugen seiner Urkunden. Hannover 1998 (= Monumenta Germaniae Historica, Studien und Texte, 20), siehe dazu meine Besprechung in: Neues Archiv für sächsische Geschichte 71 (2000), S. 305-307; siehe zudem: Christian Hillen: Curia regis. Untersuchungen zur Hofstruktur Heinrichs (VII.) 1220-1235 nach Zeugen seiner Urkunden. Frankfurt am Main, Berlin, Bern ... 1999 (= Europäische Hochschulschriften, Reihe III: Geschichte und ihre Hilfswissenschaften, 837). Die Untersuchungen über die Zusammensetzung der Höfe nach den Zeugenlisten ist mit zahlreichen methodischen Problemen verbunden und kann leicht in die Irre führen. Nur wenn Zeugen über 
aber wohl nur die ersten Anlaufstellen, und in der Folge militärischer Konflikte oder anderer Dienstleistungen konnte der Adlige hier am ehesten auf die Verleihung eines Lehens hoffen (v. Klepzig) ${ }^{25}$. Weiterhin bot die Geldknappheit vieler dieser Potentaten die Möglichkeit, sich Herrschaft zu erkaufen (Driesen, Wedel/Dänemark) ${ }^{26}$. Ein besonderes Augenmerk ist nach der Eroberung bzw. Inbesitznahme von Land auf die Neustrukturierung und Beherrschung des Gebietes zu legen, wobei die Vergabe von Ämtern (Vogt, Kastellan) ein Ausgangspunkt für Herrschaftsbildung im kleineren Maßstab sein kann. Kamen dabei die neuen Amtsinhaber aus dem einheimischen oder auswärtigen Adel? Bei den Kastellanen tauchen in der Frühzeit (13. Jahrhundert) m. E. mehr slawische als germanische bzw. christliche Namen auf. Wohl entgegengesetzt verhält es sich bei der Geistlichkeit $^{27}$. Des weiteren haben wir auch geistliche Würdenträger als Wegbereiter des Zuzugs zu berücksichtigen.

Ein besonderes Problem stellen die von Jurek benannten wandernden bzw. reisenden Ritter dar, die vor allem in der Literatur der Zeit gepriesen werden ${ }^{28}$. Versammelte sich in der Neumark der Adel aus dem Altsiedelland (Polen, Böhmen und Ungarn dürften im Hinblick auf die Ausprägung von Adelskultur nur wenige Unterschiede zum Adel des Westens aufweisen), der einen besonders hohen Mobilitätsgrad aufwies? Diese Frage kann nur im überregionalen Vergleich, die Ausgangsgebiete der Adligen einbeziehend, beantwortet werden.

Schwierig ist es weiterhin zu ermessen, wievieler Generationen es bedarf, um eine adlige Familie in der Neumark zu verankern. Die erste ergiebige Quelle, welche eine Vielzahl von Adligen verzeichnet, ist das sogenannte Landbuch der Neumark von 1337 (für

einen längeren Zeitraum und in ,regelmäßigen“ Abständen bei Hof festgestellt werden können, kann man wohl mit einigem Recht von einem Angehörigen des Hofes sprechen. Sicherheit über die Zusammensetzung des Hofes erreichen wir aber erst mit dem Ende der Reiseherrschaft und der Ausbildung von Residenzen. Zur Residenzenforschung siehe aus der Vielzahl der Publikationen: Höfe und Residenzen im spätmittelalterlichen Reich. Ein dynastisch-topographisches Handbuch, hg. von Werner Paravicini unter Bearbeitung von Jan Hirschbiegel/Jörg Wettlaufer. Stuttgart 2003 (= Residenzenforschung, 15/1).

25 Kletke (wie Anm. 20), S. 57 f., Nießen (wie Anm. 17), S. 190 ff., Podehl (wie Anm. 4), S. 371 ff. Vgl. zudem KW, S. 406, Nr. 1521; S. 415, Nr. 1555 minsterialis; S. 437, Nr. 1643 ein Klepzig unter den milites, S. 467, Nr, 1748 zu 1299 die Übertragung der Burg Lagow.

26 Kletke (wie Anm. 20), S. 23; Nießen (wie Anm. 17), S. 120, Cramer (wie Anm. 5), S. 69 ff. ; Podehl (wie 4), S. 666.

27 Kletke (wie Anm. 20), S. 9 zu 1243 Graf Volosto, S. 10 zu 1245 Kastellan von Zantoch namens Boleslaus, S. 20 zu 1260 Graf Goslaus, Kastellan zu Zantoch; vgl. auch die Zeugenlisten bei Irgang (wie Anm. 18), S. 12 f., Nr. 6, S. 13 f., Nr. 7, S. 28 f., Nr. 25, S. 30, Nr. 27 usw. Podehl wie Anm. 4), S. 289, Anm. 33 u.ö. Breitenbach (wie Anm. 23), S. 106 will mehr slawische Namen in der Anfangszeit erkennen; bei Gerhard Sappok: Die Anfänge des Bistums Posen und die Reihe seiner Bischöfe von 968-1498. Leipzig 1937, S. 71-140 lassen sich mehr germanische und christliche Namen der Bischöfe nachweisen.

28 Jurek: Śląsku (wie Anm. 11); Volker Honemann: Gesellschaftliche Mobilität in Dichtungen des deutschen Mittelalters, in: Zwischen Nicht-Adel und Adel (wie Anm. 9), S. 27-48; Bumke (wie Anm. 24); Werner Paravicini: Die Preußenreisen des europäischen Adels, Teil 1. Sigmaringen 1989 (= Beihefte der Francia, 17/1); 
die Zeit vorher sind natürlich die Zeugenlisten der Urkunden zu studieren) ${ }^{29}$. Die hier erscheinenden Adligen werden aber doch größtenteils bereits mehr als zwei Generationen in der Neumark gewesen sein. Zeugenlisten helfen uns nur bedingt weiter, wenn es um die Dauer des Zuzugsvorganges geht. Im Landbuch von 1337 ist die Verfestigung von Herrschaftsstrukturen bereits erkennbar. Sicher ist jedoch, daß im Zeitraum von 1250 bis zum Austerben der Askanier die größte Zahl von Immigranten, wie Jurek die Zuziehenden nennt, in der Neumark erschienen $\operatorname{sind}^{30}$. Zu diesen frühen Adelsfamilien sind neben den von Wedel die von Behr, die von der Osten, die von Kerkow, die von Klepzig, die von Lossow, die von Liebenthal (Gruthow?), die von Sonnenburg und die von Strehle zu zäh$\operatorname{len}^{31}$. Die späterhin weitverzweigten von Wedel gelangten möglicherweise im Schlepptau des dänischen Königs, im besonderen im Verbund des Drosten Nikolaus Olafson, und des pommerschen Herzogs nach 1250 in die Neumark ${ }^{32}$. Um 1320 mit dem Aussterben der brandenburgischen Askanier kam jedoch der Zuzug von Adligen keineswegs zum Erliegen. Auch in der Zeit der Wittelsbacher (von Lochen, von Waldow, von Rohr), der Luxemburger (v. Kittlitz) und vielleicht in der Zeit des Deutschen Ordens sowie der Hohenzollern wanderten noch adlige Familien bzw. Zweige derselben in die Neumark ${ }^{33}$. Ob die

29 Das Neumärkische Landbuch Markgraf Ludwig's des Älteren vom Jahre 1337. Nach einer neu aufgefundenen Handschrift des vierzehnten Jahrhunderts mitgeteilt von Ludwig Gollmert. Frankfurt a. O. 1862 (= Mitteilungen des Historischen Vereins zu Frankfurt a. O., Heft 2), S. 13-32; Zur Quelle vgl. jetzt: Christian Gahlbeck: Das sogenannte Neumärkische Landbuch Markgraf Ludwigs des Älteren von 1337. Studien zur territorialen Gliederung und zur Überlieferung, in: JbGMOD, Bd. 50 (2004), S. 1-48; siehe zudem die Zeugenlisten bei Kletke (wie Anm. 20), S. 31 ff. nach 1280 und im besonderen S. 36 zu 1284.

30 Jurek: Śląsku (wie Anm. 11).

$31 \mathrm{Zu}$ den von Behr vgl.: F.G.C. Lisch: Urkunden und Forschungen zur Geschichte des Geschlechtes Behr, Bd. 1-6, Schwerin 1861-1864. u. KW, S. 237 f., Nr. 964/965 zu 1269, S. 911, Nr. N1481 zu 1290; zu den von der Osten: Kletke (wie Anm. 20), S. 12 zu 1248; zu den von Kerkow: Kletke (wie Anm. 20), S. 27 f. zu 1276; zu den von Klepzig: KW, Nr. 948 zu 1267, Kletke (wie Anm. 20), S. 57 f. zu 1299; zu den von Lossow: KW, Nr. 1499 zu 1290, Nr. 1673 zu 1297; zu den von Liebenthal (Gruthow): Gahlbeck, Landbuch (wie Anm. 29), S. 32 ff., KW, Nr. 1137 zu 1278; zu den von Sonnenburg: KW, Nr. 1611 zu 1295; zu den von Strehle: KW, Nr. 954 zu 1268 (Lausitz), Nr. 1256 zu 1281 (Soldin); Kletke (wie Anm. 20), S. 61 f. zu 1300.

32 Cramer (wie Anm. 5), S. 118 ff.; Podehl (wie Anm. 4), S. 387 f., 692 f., 724-726; siehe vor allem: Pommersches Urkundenbuch (PUB), V. Bd. (1311-1320). Bearb. von Otto Heinemann. Stettin 1905 (Neudruck Aalen, Köln, Graz 1970), S. 36 f., Nr. 2706: dominus Ni(colaus) Olefson zu 1312; S. 187, Nr. 2911: domino Nicolao, Olavi filio, incliti principis domini E(rici) dei gracia regis Danorum capitaneo zu 1314; S. 213, Nr. 2940: beseglet Nicol(aus) Oluffsǿn, dapifer zu 1315; S. 343 f., Nr. 3265: Kauf von Schivelbein für 11000 Mark Brandenburgisch - unsen truwen mannen hern Nicolaus Olafson, die eteranne was droste tì Denemarke, unde sinen rechten erven unde hern Wedegen van Wedele zu 1319; S. 509 f., Nr. 3398: presentibus Nicolao, olim dapifero regis Dacie zu 1320; PUB, VII. Bd. (1326-1330). Bearb. von Hans Frederichs und Erich Sandow, Stettin 1934/40 (Fotomechanischer Nachdruck der 1. Auflage, Köln, Graz 1958), S. 26 f., Nr. 4182: Johannes Olafson zu 1326, die Urkunde wurde in Nyköping auf Falster ausgestellt.

33 Zu den von Lochen: Schultze: Die Mark Brandenburg (wie Anm. 12), S. 61, 65, 68, 71 u.ö., siehe auch Rudolf Schmidt (Hrsg.): Christian Samuel Ulrichs Beschreibung der Stadt Wriezen. Wriezen 1910, S. 115 und S. 195; zu den von Waldow: Willy Spatz/Willy Hoppe: Die Geschichte derer von Waldow. Berlin 1927, S. 19 ff.; zu den von Rohr: H. O. von Rohr: Die von Rohr. Ein mittelalterliches Geschlecht in Niedersachsen, Oberösterreich und der Mark Brandenburg, in: Verhandlungen 
von Podehl ermittelten 96 Burgen in der Neumark (einschließlich der Länder Lebus und Sternberg) und die von Nießen geschätzten etwa 300 Rittersitze als Orientierungspunkte für die qualitative Stärke des neumärkischen Adels dienen können, muß mit einem Fragezeichen versehen werden ${ }^{34}$. Das Landbuch von 1337 nennt ca. 150 Namen von adligen und adliglebenden (bürgerlichen) Familien ${ }^{35}$. Diese Zahlen sind aber aufgrund der großen Aufspaltung der einzelnen Familien und der engen Verwandtschaft vieler dieser Familien untereinander relativ wertlos. Spätere Ständeakten und Steuerregister sowie Matrikelverzeichnisse sind gegebenenfalls für die Frage der Herkunft hilfreich, bieten jedoch wenig zur Lösung der Frage nach dem Zuzug der Familien ${ }^{36}$.

\section{Das Behaupten}

Nach der Ankunft im neuen Betätigungsraum stand vor den Adligen das Problem der Etablierung. M.E. konnten diesbezüglich mehrere Handlungsmuster zur Anwendung kommen. Am wichtigsten erscheint mir die Erlangung von Lehen und Alloden, die als Grundstock für die Errichtung eigenständiger Herrschaften genutzt werden konnten. Ohne Frage kam dabei der Inbesitznahme einer landesfürstlichen Burg eine besondere Bedeutung zu. Daß die sogenannten schloßgesessenen Familien wie die von Wedel, von der Osten, von Uchtenhagen, von Mörner usw. einen Vorrang beanspruchten und mit diesen Burgen über ein brauchbares Behauptungspotential verfügten, ist offensichtlich ${ }^{37}$. Der Besitz einer landesfürstlichen Burg dokumentiert außerdem Nähe zum übergeordneten Herrschaftsträger. Darüber hinaus konnten diese Familien, die aber für den Vorgang des Behauptens nicht als pars pro toto stehen sollten, die permanente Finanznot der Fürsten ausnutzen, um durch Kauf oder Verpfändung die Nutzungsrechte über Grund und Boden sowie eben

des Historischen Vereins für Niederbayern 79 (1953), S. 47-104, im besonderen S. 92 ff. Diese Familie hat freilich nur indirekt mit der Neumark zu tun, gleichwohl läßt sich hier aufgrund der Quellenlage das Kommen einer Adelsfamilie in die Mark Brandenburg recht gut erkennen; zu den von Kittlitz: Podehl (wie Anm. 4), S. 426.

34 Podehl (wie Anm. 4), S. 658-719; Nießen (wie Anm. 17), S. 406 wo er annimmt, daß in den meisten Dörfern nur ein Rittersitz vorhanden wäre. S. 378 f. schätzt er die Anzahl der nördlich der Warthe vorhandenen Dörfer auf 279. Daraus könnte ein Zahl von etwa 300 Rittersitzen vermutet werden. Genaueres müßte ermittelt werden.

35 Gollmert: Das Neumärkische Landbuch (wie Anm. 29).

36 Zur Thematik vgl. Hahn (wie Anm. 1), S. 22 ff. u.ö. sowie zu den Matrikelverzeichnissen S. 288, Anm. 582; siehe auch Ribbe: Quellen (wie Anm. 1), S. 19 ff.

37 Zum Problem des schloßgesessenen Adels siehe: Adolph Friedrich Riedel: Von dem Unterschiede zwischen den beschlossenen und unbeschlossenen Geschlechtern der brandenburgischen Ritterschaft, in: Märkische Forschungen 1 (1841), S. 266-290; Hahn (wie Anm. 1), S. 5 ff.; Podehl (wie Anm. 4), S. 200-212.; zu den von Osten vgl. Podehl (wie Anm. 4), S. 381-387 u.ö.; zu den von Uchtenhagen siehe: Podehl (wie Anm. 4), S. 373-381 u.ö.; zu den von Mörner: Podehl (wie Anm. 4), S. 379, 384 u.ö., neuerdings auch: Herbert J. Langer und Jens E. Olesen (Hg.): Eine deutsch-schwedische Adelsfamilie im Ostseeraum. Das „Geschlechtsregister“ der Mörner (14681653), mit einem Vorwort von Magnus Mörner. Greifswald 2001, besonders S. 12 ff. mit weiteren Hinweisen auf deutsche und polnische Literatur. 
Burgen zu erlangen. Als Behauptungspotential darf des weiteren die Ausübung von landesfürstlichen Ämtern (Vogt, Kastellan, Rat, Hofamt) über mehrere Generationen hinweg angesehen werden. Im Zusammenhang mit dem Behaupten adliger Familien in der Neumark wäre nun auch ihr Anteil am Landesausbau, durch die Gründung von Städten oder besser Städtchen, Märkten, Dörfern, Mühlen, geistlichen Einrichtungen etc. zu erörtern. Mir scheint, daß wir uns allzu oft auf die ordnende und planende Hand des Landesfürsten verlassen und die kleineren adligen Herrschaftsträger nur als ausführende Organe betrachten. Wie steht es aber mit der Eigeninitiative dieser Adligen? Sorgten diese, weil sie vor allem die Kommunikation mit ihren Herkunftsgebieten aufrecht erhielten, dafür, daß bäuerliche und bürgerliche Siedler ins Land kamen? Der oft gebrauchte Begriff des „Lokationsadels“ scheint mir das Problem der Neustrukturierung eines in Herrschaft genommenen Raumes etwas einengend und unvollständig zu beleuchten. Die modernen Instrumentarien, die im 13. Jh. zur Herrschaftsbehauptung zur Verfügung standen, waren einerseits der Befestigungsbau, eben auch in Regie kleinerer Herrschaftsträger, und die bäuerliche sowie städtische Ansiedlung zu Deutschem Recht (ius Teutonicum) bzw. zu entsprechenden Stadtrechten ${ }^{38}$. Diese Instrumentarien wurden nicht nur von Deutschen benutzt. Die Benutzung des Computers ist ja ebenfalls nicht an ethnische Herkunft gebunden.

Zum Behauptungspotential einer adligen Familie gehörte aber andererseits auch die Möglichkeit, sich recht schnell an eine ,alteingesessene“ Familie anzubinden. Die Größe der Familie im Kolonisationsgebiet unterscheidet sich wohl grundlegend von der adligen Familie, die im Altsiedelland lebte. Galt im Altsiedelland Kinderreichtum als Armutsrisiko - wie ähneln sich doch die Zeiten -, so war sie im Kolonisationsgebiet eine Garantie für ein erfolgreiches Etablieren einer adligen Sippe ${ }^{39}$. Das Eheverhalten neumärkischer Adelsfamilien müßte allerdings, soweit ich sehe, noch flächendeckend untersucht werden. Hier ist auch zu klären, ob Gepflogenheiten aus Pommern, Polen oder etwa Schlesien im Heiratsverhalten in der Neumark übernommen wurden. Die weite Verzweigung der Familien dürfte auch der Anbindung an verschiedene größere Herrschaftsträger entgegengekommen sein. Das Behauptungsrisiko zu verteilen, sich mehrere potentielle Verbündete zu suchen, dies dürfte sinnvoll und nötig gewesen sein.

Diesbezüglich kann vielleicht aus mißglückten Versuchen des Zuzuges und des Behauptens etwas gelernt werden. Um 1287 zogen die Herren von Friesack - ihre alte Herrschaft aufgebend - im Verbund mit ihrem Verwandten Pribislaw III. von Belgard und vielleicht auf Druck des brandenburgischen Markgrafen ins Land Belgard, das Land Daber und das Land Welschenburg und nahmen diese Länder zur gemeinsamen Hand zu Lehen ${ }^{40}$.

38 Vgl. Schich (wie Anm. 17)

39 Vgl. Spiess (wie Anm. 6), S. 20-130, S. 398-493; Hahn (wie Anm. 1), S. 120-130.

40 Vgl. u.a. Walter Feske: Das Geschlecht der von Friesack, in: Märkische Heimat, Neuruppin, 4 (1931), S. 6; Johannes Schultze: Der Wendenkreuzzug 1147 und die Adelsherrschaften in Prignitz und Rhingebiet, in: JGMOD 2 (1953), S. 95-124; PUB, III. Bd. (1287-1300), bearb. von Rodgero Prümers. Stettin 1891 (Neudruck Aalen, Köln, Graz 1970), S. 15 f., Nr. 1431 zu 1287; KW, S. 378, Nr. 1426. 
Die Gründe für diese Aktion bleiben undurchsichtig ${ }^{41}$. Jedenfalls gehen Pribislaw und die Friesacker in den Wirren der Zeit, wohl besonders in den Kämpfen der Markgrafen gegen die Pommern, ihrer Lehen verlustig und entschwinden nach 1300 aus dem Blickfeld. Dabei scheinen die Friesacker nicht ohne Vorbereitung in die Neumark gezogen zu sein. Neben der Verwandtschaft zu Pribislaw bestanden familiäre Beziehungen zu den von Kerkow, die vor 1287 gar einen Bischof von Brandenburg stellten ${ }^{42}$.

Und trotzdem: Die wichtigen Behauptungskriterien wie Lehen, Burgenbesitz, Verwandtschaft, Anlehnung an einen mächtigen Fürsten, an die Markgrafen von Brandenburg etwa, waren lediglich als Chance zu begreifen. Ungünstige politische Konstellationen, die zu militärischen Auseinandersetzungen führten, ließen hoffnungsvolle Ausgangsbedingungen schnell zunichte werden. Eine gute Ausgangsbedingung war sicherlich die Anlehnung an einen Landesfürsten. Bei Herrschaftswechsel konnte sich jedoch diese brauchbare Konstellation ins Gegenteil verkehren. Friedrich von Lochen, der wohl mit den Wittelsbachern gekommen war und im Land Lebus eine ansehnliche Stellung erreichte, konnte keine langlebigen Behauptungsbedingungen schaffen. Mit dem Ende der Herrschaft der Wittelsbacher kehrte ein Teil der Familie an den Bodensee zurück ${ }^{43}$.

Wenn es also um das Behaupten von Herrschaft in kleinerem Rahmen geht, waren variable Überlebensstrategien verlangt. Diese Strategien sind genauer zu untersuchen, um unser Bild von Kolonisationsvorgängen auf adliger Seite zu vervollständigen.

\section{Das Zusammenwachsen}

Das Zusammenwachsen des neumärkischen Adels impliziert die Frage nach einer neumärkischen Adelsgesellschaft. Wir wollen also abschließend fragen: Gab es eine neumärkische Adelsgesellschaft eigener Ausprägung bzw. wenn ja, ab wann gab es diese? Nun, die Antwort könnte recht pragmatisch ausfallen. Etwa seit der Mitte des 14. Jahrhunderts gab es einen Landvogt für die Neumark ${ }^{44}$. Die oft gescholtenen landesfremden Wittelsbacher haben wohl für dieses überspannende Amt Sorge getragen. Gleichwohl, die verfassungsrechtliche Antwort mag nicht recht befriedigen. Ein gemeinsamer Richter sagt noch nichts über das Ausmaß einer gemeinsamen Identität aus.

Orientierte sich der neumärkische Adel von einer bestimmten Zeit an auf einen einzigen Herrschaftsträger? Die diesbezüglichen Schwierigkeiten wurden bereits angedeutet: Die Neumark lag im Schnittpunkt verschiedener Herrschaftsansprüche (Brandenburg,

41 Interessant ist die Parallelität von Gewässernamen, so des Flusses Daber in der Friesacker Umgebung und im Gebiet der Neumark.

42 Gustav Abb und Gottfried Wentz: Das Bistum Brandenburg, 1. Teil, in: Germania Sacra, 1. Abteilung: Die Bistümer der Kirchenprovinz Magdeburg, 1. Bd. Berlin, Leipzig 1929, S. 31.

$43 \mathrm{Zu}$ den von Lochen siehe Schultze: Die Mark Brandenburg (wie Anm. 12), S. 121, Anm. 24 mit Quellenangaben; siehe auch Riedel A XX, S. 216 ff., Nrr. LIV, LVI, LVII.

44 Martin Liebegott: Der brandenburgische Landvogt bis zum XVI. Jahrhundert. Halle a.S. 1906; vgl. auch Eberhard Bohm: Das Land Lebus und seine Vogteien westlich der Oder (13. bis 15. Jh.). Ein Beitrag zur Verfassungsgeschichte der Mark Brandenburg, in: JGMOD 25 (1976), S. 42-81. 
Pommern, Polen, Deutscher Orden). Hat dieser Tatbestand aber trotzdem zur Ausprägung einer eigenen Identität beigetragen oder nicht? Lehnabhängigkeiten, Memoria, Heiratsverhalten nach innerhalb und außerhalb der Neumark, Gründung geistlicher Institutionen als geistige Zentren des Adels, Adelsversammlungen, Adelsbündnisse und vieles mehr wären einzuordnen und zu bewerten. Qualifizierende Einschätzungen sind dabei frei von nationalen Aspekten zu treffen, denn Adel läßt sich nur bedingt in nationale Korsette pressen. Aber vielleicht sollte man sich nicht zu sehr in theoretische Modelle verstricken, sondern auf Altbewährtes zurückgreifen. Das alphabetische Register zum Codex diplomaticus Brandenburgensis von Heffter ${ }^{45}$ bietet zu den einzelnen neumärkischen Adelsfamilien zahlreiches Namenmaterial, und diesbezüglich läßt sich doch eine bemerkenswerte Entdeckung für unsere Fragestellung finden. Mit Überraschung ist nämlich festzustellen, daß die neumärkischen Adligen bei der Namenvergabe nur in geringem Maße auf die Namen ihrer Herren zurückgriffen ${ }^{46}$. Sicherlich, um die Modenamen Heinrich und Conrad sowie die diversen Kurzformen dieser Namen machten die Adligen keinen Bogen. Aber die Verwendung dieser Namen hielt sich in überschaubaren Grenzen. Der neumärkische Adel zeigte sich stattdessen bibelfest. Alt- und neutestamentarische Namen sowie Heiligennamen prägen bei einer ersten Durchsicht das Bild.

Als Beispiele nenne ich: Nicolaus und Jacob (Borke/Boytin/Güntersberg) ${ }^{47}$, Baltasar $(\text { Boytin/Marwitz) })^{48}$, Caspar (Boytin) ${ }^{49}$, Michael (de Albea, Elbe) ${ }^{50}$, Simon (Güntersberg) $)^{51}$,

45 Riedels Codex diplomaticus Brandenburgensis. Sammlung der Urkunden, Chroniken und sonstigen Geschichtsquellen. Geschichte der Mark Brandenburg und ihrer Regenten. Namenverzeichnis zu sämtlichen Bänden. Bearbeitet von M. W. Heffter, Bd. I-III. Berlin 1867/1868.

46 Zur Namenvergabepraxis vgl. Michael Mitterauer: Ahnen und Heilige. Namengebung in der europäischen Geschichte. München 1993; derselbe, „Senioris sui nomine“. Zur Verbreitung von Fürstennamen durch das Lehenswesen, in: Mitteilungen des Instituts für Österreichische Geschichtsforschung 96 (1988), S. 275-330.

47 Heffter (wie Anm. 45), Bd. 1, S. 146 und Bd. 2, S. 354 f.; im 15. Jh. statt Nikolaus häufig die Kurzform Klaus. Nikolaus wohl nach dem heiligen Bischof Nikolaus von Migra ( $†$ nach 345); Jacob entweder nach Jacob dem Älteren, Apostel und Märtyrer, oder seinem Bruder Jacob dem Jüngeren. Zu denken ist auch an eine der berühmtesten Pilgerstätten des Mittelalters, Santiago de Compostella, wo auch die Gebeine Jacob des Älteren ruhen sollen.

48 Heffter (wie Anm. 45), Bd. 1, S. 152 (Boytin) und Bd. 2, S. 354 f. Zu den von der Marwitz siehe: Hans Georg von Redern: Zur Geschichte der Familie von der Marwitz. Regesten, Stammtafeln und andere Materialien. Berlin 1879. Den Namen trug einer der Heiligen Drei Könige von denen Matthäus 2,1-12 berichtet. Außerdem mag man an den Aufbewahrungsort der Gebeine der Heiligen im Kölner Dom denken. Ob dies mit dem Herkunftsgebiet dieser Adelsfamilien zusammengehört, ist fraglich.

49 Heffter (wie Anm. 45), Bd. 1, S. 152 (Boytin). Caspar gilt ebenfalls als Namen eines der Heiligen Drei Könige.

50 Heffter (wie Anm. 45), Bd. 1, S. 402 (de Albea). Michael (der Erzengel) findet sich im Alten Testament bei Daniel und im Neuen Testament in der Apokalypse sowie im Judasbrief Erwähnung. Er war u. a. Patron der Ritter.

51 Heffter (wie Anm. 45), Bd. 1, S. 523 f. Zu denken wäre bei diesem Namen an Simon Stylite den Älteren († um 459) oder auch den Apostel und Märtyrer Simon Zelotes, der im Neuen Testament genannt ist. 
Johann und Melchior (Hagen/Güntersberg) ${ }^{52}$, Bartolomäus (Borke) ${ }^{53}$, Zacharias (Marwitz $)^{54}$. Die hier vorgestellten Namen finden sich freilich auch bei anderen neumärkischen Adelsfamilien.

An zweiter Stelle scheinen Namen aus literarischen Vorlagen, im besonderen der Ritterdichtung zu stehen. Als Beispiele sind auswahlweise zu nennen: Gunther (Borke/ Güntersberg) ${ }^{55}$, Walther (Güntersberg) ${ }^{56}$, Dietrich (Brederlow) ${ }^{57}$, Siegmund (Sack) $)^{58}$, Georg (Uchtenhagen) ${ }^{59}$, Wolf (Uchtenhagen) ${ }^{60}$, Witicho (Wedel, Osten) ${ }^{61}$, Kunigunde $(\text { Marwitz })^{62}$. Diese Namen sind wiederum auch in anderen Adelsfamilien der Neumark anzutreffen.

52 Heffter (wie Anm. 45), Bd. 1, S. 523 f. und Bd. 2, S. 3. Beim Namen Johann ist auch an die Variante Henning etwa bei den von Güntersberg zu denken. Ansonsten dürfte Johannes an Johannes den Täufer erinnern, aber auch an Johannes den Evangelisten († um 100) muß gedacht werden. Beim Namen Melchior handelt es sich um einen der Heiligen Drei Könige.

53 Heffter (wie Anm. 45), Bd. 1, S. 146. Als Namenvorbild dürfte der Apostel Bartholomäus gedient haben.

54 Heffter (wie Anm. 45), Bd. 2, S. 355. Zacharias wird sich auf den Vater Johannes des Täufers beziehen. Interessant wäre zu wissen, ob eine der Töchter derer von Marwitz den Namen Elisabeth trug. Elisabeth und Zacharias galten als die Eltern Johannes des Täufers.

55 Heffter (wie Anm. 45), Bd. 1, S. 146 und S. 523 f. Beim Namen Gunther dürfte das Nibelungenlied als Vorbild gedient haben. Im Folgenden ist zu diesem Sachverhalt zu nutzen: Die deutsche Literatur des Mittelalters. Verfasserlexikon. Begründet von Wolfgang Stammler, fortgeführt von Kurt Langosch. Zweite, völlig neu bearbeitete Auflage, hrsg. von Kurt Ruh u.a., Bd. 1-11. Berlin, New York 1978-2004.

56 Heffter (wie Anm. 45), Bd. 1, S. 523 f. Sollte Walter von der Vogelweide als Namensvorbild gedient haben? Für mittelalterliche Adelsfamilien muß man aber wohl vorrangig an das Walthariuslied (Walther mit der starken Hand) denken. In diesem Zusammenhang wäre auch auf den Frauennamen Hildegunde zu achten. Leider ist die frühe Überlieferung von Frauennamen in den neumärkischen Adelsfamilien nicht sehr gut.

57 Heffter (wie Anm. 45), Bd. 1, S. 272 f. Hier wird an Dietrich von Bern zu denken sein, der sich u.a. in der sogenannten Thidrekssaga findet.

58 Heffter (wie Anm. 45), Bd. 3, S. 110 f. Hier wäre an König Siegmund, den Vater des Siegfried, aus dem Nibelungenlied zu denken. Ein Zusammenhang könnte freilich zu dem heiligen Burgunderkönig Siegmund um 500 bestanden haben. Nach 1410/11 bietet sich der Römische König Sigismund als Namenvorbild an.

59 Heffter (wie Anm. 45), Bd. 3, S. 347 ff. Der heilige Georg von Kappadokien († um 303) drängt sich als Namenvorbild auf. Er galt als Symbol für Ritterlichkeit schlechthin und er war der Ursprung für eine vielfältige Legendenbildung.

60 Ebenda. Der Name Wolf kann neben der schriftlichen (Wolfdietrich) in der mündlichen Überlieferung eine Rolle gespielt haben. In den Pegauer Annalen wird einer der Vorfahren des Legenden umwobenen Wiprecht von Groitzsch mit dem Namen Wolf bezeichnet. Gerade im Grenzland zwischen deutschen und slawischen Ansprüchen bildete sich wohl ein bestimmter Typ kämpferischen Rittertums heraus. Dieser Typ Ritter mag Vorbildwirkung ausgestrahlt haben. Siehe zum „Wolfdietrich“ Verfasserlexikon (wie Anm. 55), Bd. 10, Sp. 1309-1322 und die Artikel „Wolf“ (Ch. Hünemörder/S. Schwenk) und „Wolfdietrich“ (J. Heinzle) in: Lexikon des Mittelalters, Bd. IX. München 1998, Sp. 302 f.

61 Heffter (wie Anm. 45), Bd. 3, S. 398 ff. und Bd. 2, S. 448 ff. Witicho kommt u.a. in der Thidrekssaga vor.

62 Heffter (wie Anm. 45), Bd. 2, S. 354 f. Kunigunde verbindet sich mit der heiligen Kunigunde, der Gattin Kaiser Heinrich II., und der gleichnamigen Ehefrau, der Stauferin Kunigunde, des böhmischen Königs Wenzel I. 
In späterer Zeit (15. Jh./16. Jh.) stellte sich humanistisches Namengut ein. Als Beispiele liegen vor: Liborius (Borke), Erasmus (Boytin), Scholastica, Hyppolyta, Calixtus (Marwitz), Dionysios (Osten) ${ }^{63}$.

Slawisches Namengut tritt nur vereinzelt auf wie zum Beispiel Dobergast etc. ${ }^{64}$. Ist diese Namenvergabepraxis ein Indiz für Ungebundenheit, für eine eigene Identität? Wir möchten das mit aller gebotenen Vorsicht bejahen. Ein interessanter Befund ist es allemal. Es zeigt vielleicht eine gewisse Abschottungstendenz gegenüber auswärtigen Mächten. Eine besondere Rolle kommt bei der Beantwortung unserer Frage auch der Zeit nach 1402 unter der Herrschaft des Deutschen Ordens zu. Der Deutsche Ordensstaat, selbst in seiner Zeit ein modernes „Staatswesen“, hat sicherlich auf die „Organisiertheit“ des neumärkischen Adels unbewußt Einfluß genommen. Zudem war die Neumark lange Zeit Durchzugsgebiet für die Preußenreisen des europäischen Adels und damit kommunikativ eingebunden in die Veränderungen adliger Kultur im 14./15. Jahrhundert ${ }^{65}$.

Wenn wir also zu unserem Ausgangspunkt zurückkommen, scheint das 15. Jahrhundert am ehesten geeignet, um von einer eigenständigen neumärkischen Adelsgesellschaft und Adelskultur zu sprechen. Dennoch bedarf es der weiteren Aufarbeitung der materiellen und geistigen Zeugnisse des neumärkischen Adels. Diesbezüglich verweise ich auf die Arbeiten von Eva Syska. Sie widmete sich in der letzten Zeit u.a. auch den Siegeln des neumärkischen Adels ${ }^{66}$.

Ein kurzes Fazit: Keine Wiederholung oder Komprimierung des bisher Gesagten soll jetzt erfolgen. Es geht abschließend um die Perspektive brandenburgischer Adelsforschung. Das zu beackernde Feld ist riesig. Aber es wird, wenn sich die jetzige Situation der brandenburgischen Landesgeschichtsforschung zum Dauerzustand verfestigt, bald ein wüstes Feld zu betrachten sein, aus dem in steter Regelmäßigkeit Unkraut in Form absurder Sichtweisen herauswuchert.

63 Der Name Liborius wird sich auf den heiligen Bischof von Le Mans ( $†$ um 397), den Freund des heiligen Martin von Tours, beziehen. Seine Reliquien befinden sich in Paderborn. Einer gewissen Beliebtheit dürfte sich der Name aber erst um 1500 erfreut haben. Von 1484-1486 war ein Liborius von Schlieben Bischof von Lebus. Vgl. Erwin Gatz (Hg.): Die Bischöfe des Heiligen Römischen Reiches 1448 bis 1648. Ein biographisches Lexikon, Berlin 1996, S. 64. Gleiches gilt für den Namen Erasmus, den Märtyrerbischof († um 303). In der Reformationszeit könnte der bekannteste Namenträger, Erasmus von Rotterdam, für eine weitere Verbreitung gesorgt haben. Ob bei den Frauennamen Scholastica (für Philosophie) und Hyppolyta die ursprüngliche griechische Bedeutung bekannt war und diesbezüglich auf ein bestimmtes Bildungsniveau geschlossen werden darf, bleibt fraglich. Die Namen Calixtus und Dionysius haben ebenfalls kirchengeschichtliche Bedeutung und erfreuten sich um 1500 einer gewissen Beliebtheit. Bei Dionysius können auch antike Vorbilder in Frage kommen.

64 Zum slawischen Personennamen Dobergast siehe Schlimpert (wie Anm. 20), S. 19.

65 Paravicini (wie Anm. 28); Hartmut Boockmann: Der Deutsche Orden. Zwölf Kapitel aus seiner Geschichte. 4. durchgesehene Aufl. München 1994.

66 Eva Syska in diesem Band und dieselbe: Rycerstwo Nowej Marchii do polowy XIV w. Poznan 2004 (Uniwersytet im. Adama Mickiewicza w Poznaniu). 


\title{
Zur Herkunft und Zusammensetzung des neumärkischen Adels bis zur Mitte des 14. Jahrhunderts
}

\author{
Von Christian Gahlbeck
}

\begin{abstract}
$I$
Am 25. Juli 1367 übertrug der wittelsbachische Markgraf Otto VIII. von Brandenburg die Vogtei im Lande über der Oder den Brüdern Gebhard d. Ä., Heinrich, Gebhard d.J. und Werner aus dem altmärkischen Geschlecht derer von Alvensleben. ${ }^{1}$ Im September 1368
\end{abstract}

$1 \quad$ Dieser Beitrag beruht wesentlich auf einer Auswertung der Register der wittelsbachischen Markgrafen von Brandenburg (Ludwig der Ältere, Ludwig der Römer und Otto VIII.) für die Jahre 1333 bis 1373, die 1414 vom damaligen Berliner Propst Johann von Waldow (dem späteren Lebuser Bischof Johann dem Älteren von Waldow) bzw. in dessen Auftrag für den Deutschen Orden kopiert und (zusammen mit einigen weiteren Teilen aus der Kanzlei der Luxemburger) zu einem Neumärkischen Landbuch zusammengestellt wurden. Der größte Teil dieser Register ist in zwei Folianten des Geheimen Staatsarchivs Preußischer Kulturbesitz in Berlin [künftig zit.: GStA PK Berlin] überliefert, bei denen es sich wahrscheinlich um zwei Ausfertigungen des Neumärkischen Landbuchs von 1414 handelt, nämlich GStA PK Berlin, I. HA, Rep. 78a Nr. 5 [Exemplar A], und Nr. 5a [Exemplar B]. In beiden Folianten, die vermutlich ursprünglich inhaltsgleich waren (Ihr Inhalt geht aus einem in einem Brief des Vogtes der Neumark an den Hochmeister des Deutschen Ordens von 1414 April 19 als Anlage übersandten Inhaltsverzeichnis hervor, vgl.: GStA PK Berlin, XX. HA, Ordensbriefarchiv [künftig zit.: OBA] 2177, Druck: Christian Gahlbeck: Das sogenannte Neumärkische Landbuch Markgraf Ludwigs des Älteren von 1337. Studien zur territorialen Gliederung und zur Überlieferung, in: Jahrbuch für die Geschichte Mittel- und Ostdeuschlands [künftig zit.: JGMOD] 50 [2004], S. 1-48, hier: S. 46-48; auch erschienen in: Nowa Marchia - prowincja zapomniana wspólne korzenie. Materlały z sesji naukowych organizowanych przez Wojewódzką i Miejską Bibliotekę Publiczną w Gorzowie Wlkp. czerwiec 2003 r., kwiecień - maj 2004 r. [Die Neumark eine vergessene Provinz - die gemeinsamen Wurzeln. Dokumentation der von der Wojewodschaftsund Stadtbibliothek in Gorzów Wlkp. vom Juni 2003 bis zum Mai 2004 veranstalteten Vortragsreihe]. Gorzów Wlkp. 2005, S. 97-138, hier: S. 136-138 u. hinter Umschlagseite [= Wojewódzka i Miejska Biblioteka Publiczna, Zeszyty naukowe, 2]; desgl. in polnischer Übersetzung unter dem Titel: Tak zwana Nowomarchijska Księga Ziemska margrabiego Ludwika Starszego z 1337 roku. Studia nad podziałem terytorialnym i przekazem historycznym, Übers. von Grzegorz Kowalski, ebd., S. 9-50, hier: S. 48-50), sind verschiedene Teile des Landbuchs von 1414 nicht mehr oder nur noch unvollständig enthalten; zum Teil ergänzen sich die beiden Bände gegenseitig. Es handelt sich im einzelnen um folgende Register: 1. Register Markgraf Ludwigs des Älteren der Vogtei Soldin; 1333-1348 , 2. Register Markgraf Ludwigs des Älteren der Vogtei Landsberg, 1333-1339; 3. Register Markgraf Ludwigs des Älteren der Vogtei Soldin 1348-1351, 4. Register Markgraf Ludwigs des Römers der Vogtei Soldin 1352-1356, 5. Register der neumärkischen Vogtei Markgraf Ludwigs des Römers, 1360-1364, 6. Register der neumärkischen Vogtei der Markgrafen Ludwig der Römer und Otto VIII., 1360, 1364-1373, und 7. das unter dem Namen „Das Neumärkische Landbuch Markgraf Ludwigs des Älteren von 1337“ bekannte Neumärkische Kataster aus dem Jahr 1337. Im folgenden werden diese Register jeweils mit „R“ und den Eckjahren ihrer Laufzeit sowie ihrer Überlieferung im Exemplar A bzw. B zitiert (z. B. das unter 3. genannte Register unter 
belehnte er sie mit dem Hof und Dorf Schwachenwalde (Chłopowo) im Kreis Arnswalde. ${ }^{2}$ Die von Alvensleben haben sich dieses Besitzes jedoch nicht lange erfreut. Wahrscheinlich hatten sie überhaupt nur wenig Freude daran, denn das Dorf war bereits im Jahr 1363 von Markgraf Ludwig dem Römer dem Zisterzienserkloster Marienwalde (Bierzwnik) übereignet worden ${ }^{3}$, und der dortige Adelsbesitz erstreckte sich damals offenbar nur über 20 Hufen, die um 1337 den von Mortzin gehört hatten. ${ }^{4}$ Noch bevor zwei Jahre verstrichen waren, gaben die Ritter aus der Altmark ihr Lehen an den Markgrafen zurück. Dieser verlieh es am 24. Mai 1370 an den neumärkischen Ritter Conrad von Lauchstädt und dessen Bruder Heinrich. ${ }^{5}$ Obwohl ihr Mandat von Otto VIII. am 1. August 1370 erneu-

„R 1348-51 A“). Abweichend hiervon werden zitiert: 1. die Nummern 1-111 des Registers der Vogtei Soldin von 1333-1348 unter ,R 1333-48“ nach dem bis Nr. 111 reichenden Originalregister auf Pergament, GStA PK Berlin, I. HA, Rep. 78a Nr. 1 (Teil 2), 2. das weder in A noch B überlieferte Register der Vogtei Landsberg 1333-1339 unter „R 1333-39 L“" nach dem Originalregister, Leipzig, Stadtbibliothek, Rep. II Nr. 128 (Kopiar der Vogteien Havelberg und Landsberg), S. 2326v, und 3. das Kataster von 1337 unter „K 1337 B“ bzw. nach der Edition von Louis Gollmert (Bearb.): Das Neumärkische Landbuch Markgraf Ludwig's des Aelteren vom Jahre 1337, nach einer neu aufgefundenen Handschrift des vierzehnten Jahrhunderts mitgetheilt, hg. vom Historisch-Statistischen Verein zu Frankfurt a.O. [künftig zit.: LB/Gollmert]. Frankfurt a.O. 1862 (Mitteilungen des Historischen Vereins für Heimatkunde zu Frankfurt/O., 2). Zu den Registern vgl. Hermann Bier: Das Urkundenwesen und die Kanzlei der Markgrafen von Brandenburg aus dem Hause Wittelsbach 1323-1373. 1. Teil: Die Register. Einleitung und Kapitel 1 (mehr nicht erschienen). Diss. Berlin 1907. - Als weitere Hauptquellen für die Adelsgeschichte der Neumark wurden herangezogen: 1. das Verzeichnis der Kosten des pommerschen Kriegszugs in die Mark Brandenburg von 1321, Druck: Pommersches Urkundenbuch, bearb. von Rodgero Prümers, Otto Heinemann u. a., hg. vom Königlichen Staats-Archiv zu Stettin bzw. von der Landesgeschichtlichen Forschungsstelle (Historische Kommission) für die Provinz Pommern, 11 Bde. Stettin 1868-1940 (ND Köln 1970); Köln 1975-90 [künftig zit.: PUB], hier: PUB 6, S. 81-85, Nr. 3560; 2. eine Liste der Adligen, die dem Deutschen Orden gehuldigt haben, von [1402 um und nach August 9], GStA PK Berlin, XX. HA, OBA 727 (ungedruckt), und 3. zwei Verzeichnisse der neumärkischen Mannen, die Kurfürst Friedrich II. gehuldigt haben, bzw. der Adligen und Vertreter der Städte und der Geistlichkeit, die zu den neumärkischen Landtagen zu laden sind, von 1454/55, GStA PK Berlin, I. HA, Rep. 78a, Nr. 10, fol. 52-53v, Druck: Adolph Friedrich Riedel (Hg.): Codex diplomaticus Brandenburgensis. Sammlung der Urkunden, Chroniken und sonstigen Geschichtsquellen für die Geschichte der Mark Brandenburg. I.-IV. Hauptteil, 41 Bde. Berlin 1838-69 [künftig zit: CDB], hier: CDB I 24, S. 161 f., Nr. 217. - Zur Urkunde von 1367 Juli 25 vgl. R 1360-73 A, fol. 138 f., Nr. 48; Druck: CDB I 24, S. 79 f., Nr. 132. - Zur Geschichte der von Alvensleben allgemein vgl. Peter-Michael Hahn: Fürstliche Territorialgewalt und lokale Adelsgewalt. Die herrschaftliche Durchdringung des ländlichen Raumes zwischen Elbe und Aller (1300-1700). Berlin, New York 1989 (=Veröffentlichungen der Historischen Kommission zu Berlin, 72).

2 Vgl. Urkunde von 1368 September 18, R 1360-73 A, fol. 143vf., Nr. 62; CDB I 18, S. 307, Nr. 49 u. CDB I 24, S. 81, Nr. 135.

3 Vgl. Urkunde von 1363 November 22, Ausfertigung: Staatsbibliothek zu Berlin Preußischer Kulturbesitz [künftig zit.: SBB PK Berlin], Wippelsche Sammlung, A 43; auch überliefert in: R 1360-64 B, fol. 164v., Nr. 61; Druck: CDB I 18, S. 29, Nr. 44. Dazu vgl. Christian Gahlbeck: Zisterzienser und Zisterzienserinnen in der Neumark. Berlin 2002, S. 339 mit Anm. 35 (= Veröffentlichungen des Brandenburgischen Landeshauptarchivs, 47).

4 Vgl. K 1337 B, fol. 116v; LB/Gollmert, S. 25.

5 Vgl. Urkunde von 1370 Mai 24, R 1360-73, fol. 150vf., Nr. 79; CDB I 24, S. 81, Nr. 136. 
ert und auf Gebhards d. Ä. Sohn Gebhard ausgedehnt wurde ${ }^{6}$, blieb auch die Landvogtei nicht viel länger in den Händen der von Alvensleben; schon vor dem 12. April 1371 war ihnen Hasso von Wedel-Uchtenhagen als Vogt des Landes östlich der Oder nachgefolgt. ${ }^{7}$ Heimisch wurden die von Alvensleben in der Neumark nicht; die Zeit ihrer dortigen Anwesenheit bildete in der Geschichte dieses Raumes nur eine kurze Episode, die nach noch nicht einmal vier Jahren beendet war. ${ }^{8}$

Sicherlich waren die Umstände, unter denen der Versuch einer Ansiedlung des altmärkischen Geschlechts im Land jenseits der Oder scheiterte, sehr ungünstig, zumal er Teil der Maßnahmen war, mit denen Markgraf Otto VIII. danach trachtete, die seit den Auseinandersetzungen mit dem falschen Woldemar gewonnene Macht des neumärkischen Adels wieder einzuschränken. Hierzu gehörte vor allem der Plan, die seit 1347/48 als Vögte in der Neumark tätigen einheimischen Ritter aus ihren Ämtern zu entfernen und sie durch nichtbrandenburgische oder zumindest durch nichtneumärkische Adlige zu ersetzen. Die Alvensleben-Episode zeigt jedoch, dass der wittelsbachische Markgraf um 1368 nicht mehr die Macht besaß, den neumärkischen Adel nachhaltig vom Vogteiamt östlich der Oder fernzuhalten. Die Neumärker schotteten sich gegenüber fremden Adligen (sofern diese nicht aus Pommern kamen) ab. Die von Alvensleben wurden als Altmärker ebenso als Landfremde wahrgenommen wie ihre seit 1364 ernannten Amtsvorgänger Nickel von Erdmannsdorf, Graf Heinrich von Schwarzburg und Friedrich von Schlieben, die nicht aus der Mark stammten. Wie diesen gelang es ihnen nicht, in der Neumark Fuß zu fassen; der dortige Adel nahm sie in seine Reihen nicht auf.

Eine adlige Führungsschicht bildete sich in der Neumark etwa in der Zeit zwischen 1270 und 1350 heraus. Um die Jahrhundertwende stellte sie, wie bereits Antoni Czacharowski betont hat, von ihrer Zusammensetzung her allerdings noch keine stabile Schicht dar. ${ }^{9}$ Aber bereits um 1319/20 hatte sich bei den Ständen ein erkennbares Regionalbewusstsein herauskristallisiert ${ }^{10}$, das sich bis zur Mitte des Jahrhunderts zu einem nicht nur

$6 \quad$ Vgl. Urkunde von 1370 August 1, R 1360-73, fol. 150 f., Nr. 78; CDB I 24, S. 82, Nr. 137.

7 In der Urkunde von 1371 April 12 wird Hasso von Wedel auf Uchtenhagen als (amtierender) Vogt erwähnt. Vgl. CDB I 19, S. 254, Nr. 130.

8 Zur Tätigkeit Werners von Alvensleben als Vogt im Land über der Oder vgl. die Urkunden von [zwischen 1367 Juli 25 und 1371 April 12], SBB PK Berlin, Wippelsche Sammlung, A 49, ungedruckt, und von 1369 Dezember 30, R 1360-73 A, fol. 147 f., Nr. 71; CDB I 18, S. 143, Nr. 74. Die beiden Brüder Gebhard und Gebhard von Alvensleben sind in neumärkischen Urkunden noch bis April 1371 nachweisbar. Vgl. Karl Kletke: Regesta Historiae Neomarchicae. Die Urkunden zur Geschichte der Neumark und des Landes Sternberg, in Auszügen mitgeteilt. 3 Bde. Berlin 1867-1876 (= Märkische Forschungen 10, 12, 13), hier: Bd. 1, S. 338 f. Dazu vgl. Gahlbeck: Zisterzienser (wie Anm. 3), S. 873 f. mit Anm. 44; Grzegorz Jacek Brzustowicz: Rycerstwo ziemi choszczeńskiej XIII-XVI wieku. Polityka - gospodarka - kultura - genealogia [Die Ritterschaft des Landes Arnswalde des 13.-16. Jahrhunderts. Politik - Wirtschaft - Kultur - Genealogie]. Warszawa 2004, S. $251 \mathrm{ff}$.

9 Vgl. Antoni Czacharowski: Die Neumark - Gestaltung einer regionalen Einheit hinter der polnischen Nordgrenze im Mittelalter, in: Ders. (Hg.): Nationale, ethnische Minderheiten und regionale Identitäten in Mittelalter und Neuzeit. Toruń 1994, S. 151-159, hier: S. 153.

10 Vgl. Christian Gahlbeck: Von der terra Transoderana bis zur Provinz Neumark. Zur Ausprägung eines ständischen Regionalismus im Land östlich der Oder zwischen 1300 und 1600, in: Lorenz 
die ritterlichen Oberschichten, sondern alle Stände umfassenden Bewusstsein regionaler Einheit entwickelte, für das das am 29. November 1348 abgeschlossene Stillhalteabkommen zwischen den zu den Wittelsbachern haltenden Mannen und Städten und den Rittern von Brederlow und den Städten Königsberg/Neumark (Chojna), Schönfließ (TrzcińskoZdrój), Lippehne (Lipiany) und Soldin (Myślibórz), die den falschen Woldemar unterstützten, kennzeichnend war. ${ }^{11}$ Folgt man der Beobachtung von Peter-Michael Hahn, der 1979 darauf hingewiesen hat, dass es im 16. Jahrhundert keine Heiraten zwischen kurund neumärkischen Adelsfamilien gab ${ }^{12}$, so könnte man für die Regierungszeit Markgraf Johanns von Küstrin (1535-1571) die Existenz einer zur Oder hin mehr oder minder geschlossenen Adelsgesellschaft in der Neumark annehmen. Allerdings steht eine genauere Untersuchung, die auch die familiären Beziehungen der neumärkischen Ritterschaft zu ihren Nachbarn in Pommern und Polen mit einschließt, noch aus. Auch lässt sich diese Beobachtung nicht ohne weiteres auf frühere Jahrhunderte übertragen. Soweit erkennbar, scheinen aber auch im ausgehenden 13. und im 14. Jahrhundert die familiären Bindungen der neumärkischen Adelsfamilien vor allem nach Pommern und in die Uckermark gereicht zu haben. Besonders nach Pommern hin waren sie stets ausgesprochen intensiv. Es existierten nur wenige bedeutende Adelsgeschlechter in der Neumark, die nicht auch einen pommerschen Familienzweig vorweisen konnten oder selbst in Pommern aktiv waren. ${ }^{13}$ In erheblich geringerem Maße lassen sich verwandtschaftliche Verbindungen in die westliche Oderregion mit dem Land Lebus und Teilen des Oberbarnim sowie in das Land Sternberg südlich der Warthe nachweisen. Einige, relativ wenige Beziehungen gab es auch zwischen neumärkischen und großpolnischen Rittern. Zum Adel der Altmark oder der westlichen und mittleren Mittelmark dagegen waren die familiären Kontakte offenbar gering.

Diese ungleiche Verteilung der Verwandtschaften dürfte vor allem eine Folge der Herkunft der neumärkischen Adelsfamilien sein, die ebenfalls hauptsächlich nach Pommern und in die Uckermark (und erst von dort aus in weiter entfernte Regionen) weist. Bereits Paul van Niessen hat in seiner „Geschichte der Neumark“ wiederholt auf den großen Anteil aufmerksam gemacht, den Herzog Barnim I. von Pommern und mehrere von Pommern in die Neumark überwechselnde herzogliche Vasallen an der Besiedlung der Neumark hatten. Nach seiner Ansicht fanden namentlich die ,deutschen“ Ritter von „Köthen, Bertikow, Kaul, Behr, Jagow, Uchtenhagen, Schwanebeck, Schmogerow, Bornstedt,

Friedrich Beck/Frank Göse (Hgg.): Brandenburg und seine Landschaften. Zentrum und Region vom Spätmittelalter bis 1800. Tagung der Landesgeschichtlichen Vereinigung für die Mark Brandenburg e.V. im Haus der Brandenburgisch-Preußischen Geschichte am 22. November 2008 unter der Schirmherrschaft des Präsidenten des Landtages Brandenburg. Berlin 2009, S. 131-155, hier: S. 139-144 (= Schriften der Landesgeschichtlichen Vereinigung für die Mark Brandenburg N.F., 1).

11 Vgl. Urkunde von 1348 November 29, CDB I 19, S. 213, Nr. 69 (nach der 1945 vernichteten Ausfertigung aus dem ehem. Stadtarchiv Königsberg/Nm). Dazu vgl. Gahlbeck: terra Transoderana (wie Anm. 10), S. 146-148.

12 Vgl. Peter-Michael Hahn: Struktur und Funktion des brandenburgischen Adels im 16. Jahrhundert. Berlin 1979, S. 323, Anm. 1164 (= Historische und Pädagogische Studien, 9).

13 Vgl. Gahlbeck: terra Transoderana (wie Anm. 10), S. 143. 
Schöningen, Altenfließ, v. d. Hagen, Blankenburg ${ }^{1466}$ sowie die von Wedel, Block, Holzbüttel, Falkenberg, Billerbeck, Haselow, von Güntersberg, von Liebenthal, Rosenthal, Brüsehaver, Blume und wohl auch die von Winningen, Sydow, Kerkow, von Buch und Wolf $^{15}$ ihren Weg in die Neumark unter Barnim I. Gleiches gelte für die Geschlechter „mit mehr oder weniger slawischen Namen [...] Garthow, Morzin, Mellenthin, Granzow, Kunow, Lettenin, Geil, Bentz, Vromold (von Wutzig), Liebenow, Gobelo, Romelo“, Retzin, Wusterwitz, Sanitz, Slamer, Stavenow und Brederlow, „ob sie nun von Hause aus deutsch waren oder nicht. "16 Zu den bedeutenderen Vertretern aus der Mittel- und Uckermark stammender Geschlechter zählten für ihn im Raum Landsberg/W. (Gorzów Wlkp.) die dort zuerst ansässig gewordenen Perwenitz und von der Marwitz, denen später die von Splinter, Belling, Osterburg, Paris und Dornstedt nachgefolgt seien ${ }^{17}$, ferner die aus bzw. über die Altmark gekommenen Familien Brunkow, von Schneidlingen, von Spennigen, vielleicht auch ,die Wulkow, deren Herkunft nicht zu ergründen ist“", und im Raum Schildberg (Golenice) die von der Goltz. ${ }^{18}$ Das Geschlecht der Witte (Albus) war nach Ansicht van Niessens eine ursprünglich autochthone slawische, im Raum Zehden (Cedynia) angesiedelte Familie, die mit dem 1187/89 urkundlich erwähnten Gozislaus de Zedin verwandt gewesen sei, deren Angehörige um 1200 als Burgmannen auf Zehden saßen und seit der Erwähnung des Pribislaw Albus im Jahr 1235 im Gefolge Herzog Barnims I. von Pommern standen. ${ }^{19}$ Die Besiedlung des Weichbilds von Friedeberg (Strzelce Krajeńskie) schließlich führt er gegen die Annahmen Carl Treus ${ }^{20}$ nicht auf Siedler aus dem Mansfeldischen, sondern zum überwiegenden Teil auf nachrückende Ritterfamilien zurück, die sich erst in askanischer Zeit dort niederließen und zum Teil aus der Prignitz, dem Barnim, dem Teltow und der Uckermark, zum größeren Teil aber aus innerneumärkischen Nachbarregionen hergekommen seien. ${ }^{21}$

Diese Beobachtungen sind, wenn sicherlich auch im Einzelfall korrekturbedürftig ${ }^{22}$, so doch in ihrer Tendenz wohl einigermaßen zutreffend. Eine individuelle Betrachtung

14 Paul van Niessen: Geschichte der Neumark im Zeitalter ihrer Entstehung und Besiedlung (Von den ältesten Zeiten bis zum Aussterben der Askanier). Landsberg a.W. 1905, S. 199 (= Geschichte der Neumark in Einzeldarstellungen; Schriften des Vereins für Geschichte der Neumark [künftig zit.: SVGN], o.Nr.).

15 Vgl. ebd., S. 200-207, 283.

16 Vgl. ebd., S. 200-207; Zitat ebd., S. 199.

17 Vgl. ebd., S. 176.

18 Vgl. ebd., S. 211-213; Zitat ebd., S. 182.

19 Vgl. ebd., S. 158.

20 Vgl. Carl Treu: Geschichte der Stadt Friedeberg in der Neumark und des Landes Friedeberg, der alten Terra Ffredeberghe. Friedeberg 1865, S. 20 f.

21 Vgl. van Niessen: Geschichte der Neumark (wie Anm. 14), S. 283 ff. Auch die „pommerschen“ Familien seien nicht unmittelbar aus Pommern, sondern mittelbar aus angrenzenden Bezirken der Neumark dorthin gezogen.

22 Nur kurz sei an dieser Stelle auf ein paar Irrtümer hingewiesen, die sich relativ schnell klären lassen. Die Familie des pommerschen Marschalls Gobelo hat sich in der Neumark nicht niedergelassen, die von Garthow südlich der Warthe im Land Sternberg. Eine Familie von Kunow ist in der Neumark in den Quellen bis 1350 nicht nachweisbar, hier liegt offenbar eine Verwechslung vor, entweder mit den von Kinow (Kynow) oder mit Kuno von Sack, der 1337 in Braunsfelde (Brono- 
aller aufgezählten Familien ist an dieser Stelle nicht möglich. Die Erforschung des Adels in der Neumark im Mittelalter ist, abgesehen von Abhandlungen zu einzelnen Geschlech$\operatorname{tern}^{23}$, seit den Zeiten van Niessens nur selten Gegenstand historischer Betrachtungen gewesen. In erster Linie sind hier die Arbeiten zweier polnischer Historiker zu nennen. Antoni Czacharowski hat sich vor allem mit der Führungsschicht innerhalb des neumärkischen Adels bis 1373 befasst. ${ }^{24}$ Die Ritterschaft des Landes Arnswalde (Choszczno) vom 13. bis 16. Jahrhundert hat Grzegorz Jacek Brzustowicz zum Gegenstand einer gröBeren Untersuchung gemacht. ${ }^{25}$ Auf deutscher Seite hat sich Wolfgang Podehl im Rahmen seiner Dissertation „Burg und Herrschaft in der Mark Brandenburg“ mit Adligen beschäftigt, die in der Neumark Burgen besaßen oder als Ministeriale landesherrliche Burgen innehatten. ${ }^{26}$ Eine Gesamtuntersuchung der mittelalterlichen Adelsgesellschaft im Lande über der Oder, zu der insgesamt über 250 Geschlechter gehörten, und ihrer inneren Entwicklungen vom 13. bis zum 16. Jahrhundert liegt bisher nicht vor. Angesichts dieser Forschungslage und des Umstands, dass insbesondere zum „niederen“ Adel kaum Untersuchungen vorliegen, konzentriert sich der vorliegende Beitrag auf die führenden Adelsgeschlechter der Neumark.

wice), Kr. Friedeberg 16 Hufen besaß. Vgl. K 1337 B, fol. 113, 115v; LB/Gollmert, S. 19, 24. Dazu vgl. Urkunde von 1333 August 11, R 1333-39 L, fol. 23v, Nr. 5; CDB I 24, S. 15, Nr. 24. Der Name Wusterwitz ist als Familienname in der Neumark nur für den 1312 erwähnten Königsberger Stadtpräfekten Heinrich Wusterwitz überliefert (vgl. CDB I 19, S. 180, Nr. 13), dessen Herkunft sich auf der Grundlage der bekannten Quellen wohl nicht klären lässt. Die Ortsnamen Wusterwitz im Kreis Soldin bzw. Dramburg (poln.: Ostrowiec bzw. Ostrowice) sind slawische Örtlichkeitsnamen autochthonen Ursprungs, die sich jeweils von einem benachbarten Wusterwitz-See mit einer Insel in seiner Mitte (slaw. ostrovz) herleitet. Vgl. Reinhold Trautmann: Die elb- und ostseeslavischen Ortsnamen, 2 Bde. Berlin 1948-1949 (= Abhandlungen der Deutschen Akademie der Wissenschaften zu Berlin. Philosoph.-hist. Klasse, 1947/4 bzw. 1947/7), hier: Bd. 2, S. 23.

23 Zur Literatur der an dieser Stelle behandelten Adelsfamilien vgl. die Abschnitte zu den einzelnen Namen weiter unten.

24 Vgl. Antoni Czacharowski: Społeczne i gospodarcze siły w walce o Nową Marchie w latach 13191373. Ze szczególnym uwzględnieniem roli możnowładstwa nowomarchijskiego [Soziale und politische Kräfte im Kampf um die Neumark in den Jahren 1319-1373. Mit besonderer Berücksichtigung des neumärkischen Hochadels]. Toruń 1968 (Roczniki towarzystwa naukiego w Toruniu, 73/2). - Ders.: Die Neumark (wie Anm. 9), S. 151-159. - Ders.: Die Entwicklung der Adelsherrschaft in der Neumark im Mittelalter. Unveröff. masch. Ms. Toruń, Berlin 1982/83. Dieses Manuskript sollte die Grundlage für einen geplanten Beitrag Czacharowskis über den neumärkischen Adel bilden, der im Neumark-Band der an der Freien Universität Berlin gegründeten Interdisziplinären Arbeitsgemeinschaft (IAG) „Germania Slavica“ erscheinen sollte. Da das Neumark-Projekt der IAG nicht abgeschlossen werden konnte und der Neumark-Band nicht zustande kam, ist das Manuskript bis heute unveröffentlicht geblieben; ein Exemplar befindet sich im Besitz des Referenten. Der Beitrag ist in mehrere Kapitel und Unterkapitel gegliedert, die im Manuskript jeweils eine eigene Seitenzählung aufweisen, daher wird bei Zitaten jeweils auf das Kapitel mitverwiesen.

25 Vgl. Brzustowicz: Rycerstwo ziemi choszczeńskiej (wie Anm. 8). Hingewiesen sei vor allem auf 35 von Brzustowicz erstellte Tafeln zur Genealogie einzelner neumärkischer Adelsgeschlechter, ebd. S. 424-448.

26 Vgl. Wolfgang Podehl: Burg und Herrschaft in der Mark Brandenburg. Untersuchungen zur mittelalterlichen Verfassungsgeschichte unter besonderer Berücksichtigung von Altmark, Neumark und Havelland. Köln-Wien 1975 (= Mitteldeutsche Forschungen, 76). 
Als Kriterien für eine führende Stellung innerhalb des neumärkischen Adels werden in der Literatur zum einen der für das 13. oder 14. Jahrhundert nachgewiesene Burgenbesitz gezählt, zum anderen die Erlangung landesherrlicher Hof-, Regierungs- und Verwaltungsämter, von Hauptmannschaften und Vogteien. In der Neumark lässt sich nur ein kleiner Kreis von Ritterfamilien feststellen, die Burgen oder Schlösser besaßen. Es handelte sich im wesentlichen um die Geschlechter, die später zu den schlossgesessenen Adelsfamilien gehörten, die, wie Podehl behauptet, schon im Mittellalter eine ,rechtlich-soziale Sonderstellung innerhalb der Schicht des landsässigen Adels“ innehatten. ${ }^{27}$ Im Verzeichnis Kaiser Karls IV. von 1373 werden nur die von Wedel, von Brederlow, von der Osten und von Wulkow als nobiles vasalli mit Burgenbesitz bezeichnet ${ }^{28}$; das Verzeichnis Kurfürst Friedrichs II. von 1455 führt nur die von Güntersberg, von Wedel und von Brederlow als Schlossgesessene (beschlossene manne) in der Neumark nördlich der Warthe auf. ${ }^{29} 1612$ umfasste dieser Kreis schließlich elf Geschlechter. ${ }^{30}$

Czacharowski nennt für die Wittelsbacherzeit von 1333 bis 1373 insgesamt sieben Familien: die von Brederlow, von Güntersberg, von Liebenthal, von Mörner, von der Osten, von Uchtenhagen und von Wedel. Alle sieben (vielleicht mit Ausnahme derer von Liebenthal) seien, so Czacharowski, Burgbesitzer in der Neumark gewesen, die, da sich der Besitz sämtlicher neumärkischer Adelsburgen praktisch auf sie allein verteilte, eine aktive Führungsschicht innerhalb des Adels im Raum östlich der Oder und nördlich der Warthe gebildet hätten. ${ }^{31}$ Brzustowicz erwähnt für das Land Arnswalde außer mehreren Burgen der von Wedel, von Güntersberg und von Brederlow ${ }^{32}$ auch eine Burg in Blocksdorp, die sich im Besitz des Dietrich Block befand, zuletzt 1328 erwähnt wurde und später wüst fiel $^{33}$, ferner eine Burg in Schwachenwalde, die die von Alvensleben und von Lauchstädt zwischen 1368 und 1372 innehatten $^{34}$, sowie im Land Friedeberg eine in der Askanierzeit

27 Ebd., S. 618. Worin diese Sonderstellung bestand, speziell in rechtlicher Hinsicht, wird bei Podehl, der nur allgemein von einem Mehr an Ansehen, Einfluss und Vermögen im Vergleich mit den hofgesessenen Geschlechtern spricht und die Schlossgesessenen als „bevorrechtigten“ Adel (ebd.) bezeichnet, nicht deutlich. Zur Bestimmung einer solchen Bevorrechtigung sind noch weitere Forschungen vonnöten. Auf die Frage, inwieweit der Begriff der "Schlossgesessenen“, der im allgemeinen erst in der Frühen Neuzeit eine größere Rolle spielte, auf das 13.-15. Jahrhundert übertragbar ist, kann an dieser Stelle nicht eingegangen werden.

28 Johannes Schultze (Hg.): Das Landbuch der Mark Brandenburg von 1375 [künftig zit.: LB 1375]. Berlin 1940, S. 5 (= Veröffentlichungen der Historischen Kommission für die Provinz Brandenburg und die Reichshauptstadt Berlin, VIII 2; Brandenburgische Landbücher 2).

29 Vgl. GStA PK Berlin, I. HA, Rep. 78a, Nr.10, fol. 53v; CDB I 24, S. 161 f., Nr. 217.

30 Vgl. Podehl: Burg und Herrschaft (wie Anm. 26), S. 395, 399 ff. Die Schlossgesessenen südlich der Warthe wurden hier nicht mitgezählt.

31 Vgl. Czacharowski: Die Neumark (wie Anm. 9), S. 153 f. Dazu vgl. ders.: Społeczne i gospodarcze siły (wie Anm. 24), S. 54-92. - Ders.: Adelsherrschaft (wie Anm. 24), Kap. II: Die Erwerbung und Entwicklung der Besitzungen der führenden Adelsfamilien, pass., u. Kap. III: Die Herrschaftsrechte des neumärkischen Adels, S. 5 f.

32 Vgl. Brzustowicz: Rycerstwo ziemi choszczeńskiej (wie Anm. 8), S. 198-205.

33 Vgl. ebd., S. $198 \mathrm{f}$.

34 Vgl. ebd., S. 199. 
erbaute Burg in Hermsdorf (Chomętowo). ${ }^{35}$ Podehl nennt unter insgesamt 69 neumärkischen Burgen (unter denen sich mit Oderberg und einigen pommerschen und polnischen Anlagen allerdings auch mehrere nichtneumärkische befinden) ${ }^{36} 64$ Adelsburgen, unter deren Inhabern außer den bereits genannten Namen die Familien von Behr (Bernstein [Pełczyce]), von Bertikow (Hochzeit [Stare Osieczno]), von Block (Blocksdorf), von Borcke (Becheler ${ }^{37}$; Alt Ritzerow [Rycerzewo] ${ }^{38}$ ), von dem Borne (Grassee [Studnica], Klanzig [Kłącko], Alt Ritzerow), von der Goltz (Becheler, Karsbaum [Karsibór], Machlin [Machliny]), von Jagow (Zantoch [Santok]), von Kremzow (Göhren [Górzno], Hermsdorf), von Ritzerow (Alt Ritzerow), von Schöning (Adamsdorf [Sulimierz]), von Wachholz (Becheler) von Wenden (Tankow [Danków]), von dem Wolde (Becheler) sowie Elsholt, Plötze und Güstebiese (die Stolzenburg bei bzw. heute in Mohrin [Moryń] ${ }^{39}$ ) genannt werden. ${ }^{40}$ Aus den Quellen ist hierzu zu ergänzen, dass die von der Goltz 1348 die Erlaubnis erhielten, die Burgen Welschenburg (Oleszno) und Janikow (Jankowo) bei Dramburg (Drawsko Pomorskie) zu befestigen ${ }^{41}$, und dass auch die von Block 1352 in der Neumark eine neue Burganlage erbauen durften. ${ }^{42}$ In voraskanischer Zeit hatten sehr wahrscheinlich die von Liebenow (vielleicht gemeinsam mit den von Wedel) die Burg in Reetz (Recz) inne. ${ }^{43}$ Schließlich dürften auch die von Schönebeck und von Witte (Albus), die 1337 die curia dicta Werder auf dem Burgwerder in Lippehne bzw. die curia Nienhoff in Neuenhagen (bei Oderberg) besaßen, zu den beschlossenen mannen der Neumark zählen. ${ }^{44}$ Ferner weist Podehl darauf hin, dass neben dem Burg- auch ein Stadtbesitz eine

35 Vgl. ebd. Der Besitzer der Burg Hermsdorf wird von Brzustowicz nicht erwähnt.

36 Vgl. Podehl: Burg und Herrschaft (wie Anm. 26), Anhang, S. 658-704. Podehl führt zudem auch ein paar mittelalterliche Burgen auf, die nur durch die Archäologie, nicht aber durch schriftliche Überlieferung bekannt sind.

37 Burgwall am Nordufer des Schliglang-Sees südlich von Dramburg, ca. 2 km südöstlich von Neu Lobitz (Nowy Łowicz). Mit der Burg Becheler belehnte 1365 Markgraf Otto VIII. Burkhard und Eckhard von dem Wolde und Rickowe von Warzholt (i.e.: von Wachholtz), die sie von ihren Vorbesitzern, den von Borcke und von der Goltz, gekauft hatten. Vgl. Urkunde von 1365 Januar 15, R 1360-73 A, fol. 134vf., Nr. 38; CDB I 24, S. 76 f., Nr. 128.

38 Bei Ritzerow ist unsicher, ob die von dem Borne, die von Borcke oder die von Ritzerow die Burg innehatten. Vgl. Podehl: Burg und Herrschaft (wie Anm. 26), S. 690.

39 Zusammen mit den von Mörner. Vgl. ebd., S. 695.

40 Vgl. ebd., S. 661 f., 671-675, 681, 690 ff., 695 f., 700-703.

41 Noverint etc., quod nos etc. strennuis viris Hinrico militi et Hermanno fratribus dictis de Golti[z], fidelibus nostris dilectis, nostrum consensum, benivolum et assensum firmandi et muniendi castra Welsenburg et Janekow, prout ipsis et heredibus ipsorum sine preiudicio nostro terrarumque nostrarum et incolarum melius et conveniencius videbitur expedire. Urkunde von 1348 September 27, R 1348-51 A, fol. 26vf., Nr. 6 (ungedruckt).

42 Anno domini $M^{\circ} C C C^{\circ} L I I^{\circ}$ in die Palmarum presente de Swarczborg data est litera Lúdekino, Anshelmo et Fred[erico] fratribus dictis Blok ad omnes civitates Transoderam, quod possunt edificare unum propungnaculum. Urkunde (Registereintrag) von 1352 April 1, R 1352-56 A, S. 75, Nr. 11 (ungedruckt); inhaltlich fehlerhaftes Regest in: Kletke: Regesta (wie Anm. 8), Bd. 1, S. 233.

43 Vgl. Christian Gahlbeck: Der Oder-Drage-Raum in voraskanischer Zeit. Großpolen, Schlesien und Pommern im Wettstreit um den Besitz der späteren Neumark, in: JGMOD 45 (1999), S. 1-97, hier: S. $1-7$.

44 Vgl. K 1337 B, fol. 109v, 113; LB/Gollmert, S. 13, 19. Auf dem Burgwerder zu Lippehne ist ein spätslawischer Burgwall aus dem Zeitraum von 950 bis 1250 archäologisch nachgewiesen. Vgl. 
Familie für die Aufnahme in den Kreis der Schlossgesessenen qualifizierte ${ }^{45}$ und dass der Stammsitz dieser Familien, wie z.B. im Fall der von Wedel auf Uchtenhagen (Krzywnica) und auf Freienwalde in Pommern (Chociwel), auch außerhalb der Neumark bzw. der Mark Brandenburg liegen konnte. ${ }^{46}$ Damit müsste man auch die von Stegelitz, die bis 1347 das Städtchen Berneuchen (Barnówko) besaßen ${ }^{47}$, und die von Jagow auch aufgrund ihres Besitzes von Zehden (1299) ${ }^{48}$ und Schildberg (Golenice; 1334) ${ }^{49} \mathrm{zu}$ den führenden Adligen der Neumark hinzurechnen.

Aber nicht alle der oben genannten Burgbewohner gehörten zur Führungsschicht innerhalb des neumärkischen Adels. Die von Behr wurden im Zuge der Eroberung von Bernstein durch die Askanier aus dem Gebiet der späteren Neumark vertrieben, und als sie 1353 wieder dort auftraten, spielten sie nur eine marginale Rolle. ${ }^{50}$ Auch bei den von Kremzow und von Wenden lässt sich, da sie in den Quellen der Wittelsbacherzeit nur sehr selten erwähnt werden, keine größere Bedeutung innerhalb des neumärkischen Adels feststellen. Die von Wachholz und von dem Wolde wurden in den Wittelsbacher-Registern nur anlässlich ihrer Belehnung mit dem Haus Becheler genannt ${ }^{51}$, im übrigen schweigen die Quellen. ${ }^{52}$ Die von Plötze und von Güstebiese, die 1368 mit den von Mörner und von Elsholt als Burgmannen auf der im Auftrag des Landesherrn neu erbauten Stolzenburg bei Mohrin saßen ${ }^{53}$, waren einfache Landadlige, die im 14. Jahrhundert nicht weiter auffielen. Die von Güstebiese sanken später zu Raubrittern herab, die von ihrem Sitz in Güstebiese (Gozdowice) aus die auf der Oder zu Schiff verkehrenden Kaufleute überfielen. ${ }^{54}$ Hans von Rakow - die Familie ist in dieser Zeit sonst nur als Bürgergeschlecht in mehreren neumärkischen Städten überliefert - erhielt am 8. Dezember 1368 huws

Eugeniusz Cnotliwy: Badania grodzisk słowiańskich w powiecie pyrzyckim w 1969 roku [Forschungen zu slawischen Burgwällen im Kreis Pyritz im Jahr 1969], in: Zeszyty pyrzyckie 4 (1971), S. 7-11; ders./Tadeusz Nawrolski/Ryszard Rogosz: Grodziska wczesnośredniowieczne na ziemi pyrzyckiej [Frühmittelalterliche Burgwälle im Land Pyritz[], in: Slavia Antiqua 26 (1979), S. 143 238, hier: S. 173-183. In Neuenhagen erbauten die von Uchtenhagen um 1475 anstelle der alten curia ein neues Schloss.

45 Vgl. Podehl: Burg und Herrschaft (wie Anm. 26), S. 399.

46 Vgl. ebd., S. 399 ff., 618.

47 Die Brüder Henning und Bertram von Stegelitz verkauften Berneuchen damals an Henning und Reinecke Mörner, die am 5. Oktober 1347 von Markgraf Ludwig mit dem Städtchen belehnt wurden. Vgl. R 1333-48 A, fol. 18, Nr. 116; CDB I 24, S. 41, Nr.74, mit falscher Datumsauflösung zu 1347 September 28.

48 Vgl. Urkunde von 1299 August 10, CDB I 19, S. 67 f., Nr. 6.

49 Vgl. Urkunde von 1334 März 5, R 1333-48, fol. 2, Nr. 9; CDB I 18, S. 105, Nr. 9. Der Vorbesitzer von Schildberg war Henning von Wedel Anesel („Ohneseel“).

50 Vgl. die Urkunden von 1353 April 12, R 1352-56 A, fol. 82v, Nr. 40 (ungedruckt), von $1353 \mathrm{Au}-$ gust 1, R 1352-56 A, fol. 94, Nr. 75; CDB I 24, S. 60 f., Nr. 110, und von 1367 Juni 11, Ausf. SBB PK Berlin, Urkunden, Sammlung Wippel, A 47 (ungedruckt).

51 Vgl. Urkunde von 1365 Januar 15, R 1360-73 A, fol. 134vf., Nr. 38; CDB I 24, S. 76 f., Nr. 128.

52 Die von Ritzerow werden, abgesehen vom Kataster von 1337, in den Quellen der Wittelsbacher von 1333 bis 1373 offenbar überhaupt nicht genannt. - Bei der Auswertung der Wittelsbacher-Register wurden die (dort häufig nur abgekürzt notierten) Zeugenlisten der Urkunden nicht berücksichtigt.

53 Vgl. Urkunde von 1368 April 21, R 1360-73 A, fol. 143 f., Nr. 60: CDB I 19, S. 84, Nr. 35.

54 Vgl. Gahlbeck: Zisterzienser (wie Anm. 3), S. 300-304. 
und stadt czu Retz nur für ein Jahr, und zwar zu dem Zweck, das her dieselbe feste und houbtmanschafft [...] innehaben und vorsteen sal czu unserm nutcze..$^{55}$ Die Burg Tankow wurde 1353 sogar dem Frankfurter Bürger Bruno Goldschmied anbefohlen. ${ }^{56}$ Diese Beispiele zeigen, dass der Burg- oder Schlossbesitz kein sicheres Kriterium zur Bestimmung einer Führungsschicht innerhalb des neumärkischen Adels darstellt. Obwohl als Voraussetzung notwendig, so führt Podehl hierzu aus, habe der Besitz einer Befestigungsanlage allein nicht ausgereicht, ,um eine landsässige Ritterfamilie zur Oberschicht innerhalb der markgräflichen Vasallität zu erheben; es mussten vielmehr wohl noch andere Momente, wie z.B. Alter, Ansehen und Bewährung einer Familie im Hof-, Landes- und Kriegsdienst hinzutreten. ${ }^{\text {"57 }}$

Nun lässt sich der neumärkische Adel im Mittelalter nicht lediglich in eine kleine Führungselite von Schlossgesessenen und den großen Rest einteilen. Vielmehr waren die Übergänge im sozialen Ansehen der Familien fließend, Auf- und Abstiege durchaus möglich. Auch war die Führungsschicht innerhalb des Adels insgesamt größer und lässt sich nicht auf die Schlossgesessenen beschränken, auch wenn diese sich z. T. noch einmal deutlich aus der Menge der bedeutenderen Geschlechter im Land über der Oder abhoben. So sind ebenso wie die in der Neumark begüterten Inhaber von Burgen in anderen Landesteilen der Mark auch die Familien zur Führungsschicht zu rechnen, die in der Askanierzeit anderswo in der Mark Vogteien innehatten oder Hofämter bekleideten. Gleiches gilt für die Zeit 1230-1320 auch für die Familien von hohen Amtsträgern in Pommern, die in der Neumark Güter besaßen, und die dort in dieser Zeit tätig gewordenen adligen Lokatoren. Schließlich sind auch die in der Neumark ansässig gewordenen Geschlechter zu berücksichtigen, deren Ansehen oder Finanzvermögen so hoch war, dass ihre Mitglieder wiederholt von den brandenburgischen Markgrafen oder den Herzögen von Pommern als Bürgen oder als Kreditgeber in Anspruch genommen wurden, als Repräsentanten des neumärkischen Adels auf Landtagen an Ständeverhandlungen teilnahmen oder in schiedsgerichtlichen Verfahren zwischen den Fürsten und den Adligen oder innerhalb des Adels zu Vermittlern, Schieds- und Obleuten gewählt wurden.

Unter Berücksichtigung dieser Kriterien setzt sich die Namensliste der bedeutenden bzw. führenden Adelsfamilien, die in der Neumark begütert waren ${ }^{58}$, aus folgenden 54 Familiennamen zusammen: Altenfließ (markgräflicher Marschall, Truchsess), Behr (bis 1280), Belling (mgfl. Vogt von Stolpe/Uckermark), Benz (mgfl. Vogt von Pasewalk), Ber-

55 Urkunde von 1368 Dezember 8, R 1360-73 A, fol. 144vf., Nr. 65; CDB I 18, S. 31, Nr. 48.

56 Vgl. Urkunde von 1353 März 14, R 1352-56 A, fol. 82 f., Nr. 39; CDB I 18, S. 297 f., Nr. 31 (zu 1352 April 2).

57 Podehl: Burg und Herrschaft (wie Anm. 26), S. 401.

58 Die von den Wittelsbachern eingesetzten Vögte aus auswärtigen Familien - die von Alvensleben, Schlabrendorff, Schlieben, Ertmannsdorf sowie der Vogt Albert von Wolffstein - wurden in der Liste nicht berücksichtigt, da sie in der Neumark entweder gar keinen oder nur geringen Landbesitz hatten, über den sie im Prinzip nur während ihrer Amtszeit verfügten. Aufgenommen dagegen wurden die von Behr, da sie in voraskanischer Zeit als Lokatoren maßgeblich an der Besiedlung der Länder Bärwalde und Bernstein beteiligt waren und zumindest im Land Bernstein auch in größerem Umfang Landgüter besaßen. 
tikow, Billerbeck (herzoglicher Vogt von Bernstein, 1444), Blankenburg (mgfl. Vogt in der Uckermark), Block, Borcke, von dem Borne (Bornim; Vögte von Spandau und unter dem Bischof von Kammin [Kamień Pom.]), Brederlow, Brewitz (mgfl. Mundschenk), Brunkow (mgfl. Vogt, Marschall), Buch (Truchsess, Hofrichter), Dosse (Vogt von Königsberg), Ellingen (mgfl. Schenk), Elsholt, Eylstedt (mgfl. Vogt, 1296), von der Goltz, Güntersberg (mit dem Familienzweig der Kenstel), Jagow, Kerkow (Herr von Schildberg [bis 1276], mgfl. Hofmeister), Köthen (mgfl. Hofschreiber), Liebenow, Liebenthal, Luge (Lokator von Landsberg), von der Marwitz (Gefolgschaft Albrechts III.), Meißner (Ständevertreter, 1280), Mellenthin (herzogl. Vogt), Mörner, Mortzin (pomm. Adelsvertreter), von der Osten, Osterburg (mgfl. Vogt, Truchsess, Ständevertreter), Pfuel (mgfl. Vogt), Pohlenz (kurfürstl. Landvogt, 15. Jh.), Rülicke (kurfürstl. Vogt, Marschall, 14861496), Sack (herzogl. Vogt 1321), Saganz (herzogl. Marschall), Schneidlingen (mgfl. Vögte von Spandau und Tangermünde), Schönebeck, Schöning, Spening (herzogl. Marschall), Stegelitz, Sydow (mgfl. Vogt, Marschall), Toyte (Lokator von Berlinchen [Barlinek]), Uchtenhagen, Wachholz, Waldow (mgfl. Vogt v. Drossen-Zielenzig), Wedel, Winningen (Ständevertreter), Witte (Albus), von dem Wolde, Wolf (mgfl. Hofrichter) und Wulkow. Damit umfasste die Oberschicht ca. 20\% der in der Neumark nachweisbaren Adelsgeschlechter. Aus ihr rekrutierten sich alle Inhaber landesherrlicher Verwaltungsämter im Lande über der Oder (mit Ausnahme der Heidereiter und -wächter, deren Ansehen offenbar erheblich geringer als das der Vögte war). Auch die aus der Neumark stammenden Inhaber von Hofämtern (Hofmeister, Hofrichter, Kämmerer, Marschall, Mundschenk, Truchsess) gingen aus dieser Oberschicht hervor. Allerdings hatten diese Geschlechter in der Geschichte der Neumark nicht gleichbleibende Bedeutung für das gesamte Mittelalter; vielmehr gelang es einigen Familien erst um oder nach 1350, durch Umzug aus anderen Regionen oder sozialen Aufstieg in den Kreis der führenden Geschlechter aufzusteigen, andere starben aus, sanken bis zur Bedeutungslosigkeit herab oder gaben ihre neumärkischen Besitzungen auf. Insgesamt lässt sich vor allem für das 14. Jahrhundert ein Konzentrationsprozess innerhalb der Adelsfamilien der Neumark beobachten. Während im Kataster von 1337 noch 150 verschiedene Familien namentlich aufgeführt werden $^{59}$, umfasst eine Liste der dem Deutschen Orden huldigenden Adligen von 1402 nur 62 Familiennamen $^{60}$, und in der Huldigungliste Kurfürst Friedrichs II. von 1454/55 und der etwa gleichzeitig entstandenen Liste der neumärkischen Landtagsteilnehmer werden insgesamt 52 Namen von Adelsfamilien genannt. ${ }^{61}$ Eine nähere Untersuchung der Geschichte aller 54 Familien kann an dieser Stelle nicht erfolgen. Eine gewisse Orientierung vermag die statistische Auswertung der in den Wittelsbacher-Registern von 1333-137362

59 Vgl. K 1337 B, pass.; LB/Gollmert, pass.

60 Vgl. Urkunde von [1402 um und nach August 9], GStA PK Berlin, XX. HA, OBA 727.

61 Vgl. GStA PK Berlin, I. HA, Rep. 78a, Nr.10, fol. 52-53v; CDB I 24, S. 161 f., Nr. 217.

62 Vgl. Anm. 1. Bei der Auswertung wurden nur die Namen der Urkundenempfänger, der Inhaber von Ämtern und Landgütern, der Empfänger von Vergünstigungen sowie die Namen der urkundlich erwähnten Vorbesitzer von Gütern, Amtsvorgänger oder sonst unmittelbar im inhaltlichen Kontext des jeweiligen urkundlichen Rechtsgehalts genannten Adligen mitgezählt; die Namen in den Zeugenlisten wurden nicht berücksichtigt, ebensowenig die Namen von Adligen in Urkunden für 
enthaltenen Namen neumärkischer Adelsgeschlechter zu vermitteln. Diese bestätigt vor allem die herausragende Position von fünf Adelsfamilien. Eine absolute Ausnahmestellung hatten die Herren von Wedel inne, die in 105 der insgesamt ca. 725 Registereinträge eine Rolle spielten. Mit weitem Abstand folgen dann die Mörner und von der Osten (43 bzw. 38 Erwähnungen), wiederum mit einigem Abstand schließlich die von Brederlow und von Güntersberg (23 bzw. 20 Erwähnungen). Die Zahl der Urkunden für alle übrigen neumärkischen Adelsgeschlechter bewegt sich unter 10. Darunter werden acht mindestens fünfmal erwähnt: die von Wulkow (8x), die von Liebenthal, Schöning und Witte (je $7 \mathrm{x}$ ), von der Marwitz (6x) sowie von Liebenow, Sydow und von Perwenitz (je 5x), die erste Familie, die nicht den oberen $20 \%$ der neumärkischen Adelsgeschlechter angehörte. Unter diesen 13 Familien habe ich sechs ausgewählt, auf die ich im folgenden ausführlicher eingehen werde: die von Brederlow, von Güntersberg, von Liebenthal, von Schöning, von Liebenow und von Wedel. Ergänzend wird außerdem, allerdings nur kurz, ein Blick auf die von Uchtenhagen, von Jagow und (von) Mörner geworfen, die eng miteinander zusammenhingen.

\section{II}

Über die Herkunft der Familie von Brederlow ${ }^{63}$ lässt sich aus den Quellen nichts Genaues in Erfahrung bringen. Ihr Stammsitz befand sich in Brederlow (Przydarłów), Kreis Pyritz, an der neumärkisch-pommerschen Grenze, einem Dorf, das 1337 zum Land Lippehne zählte. ${ }^{64}$ Der slawische Name dieses Ortes lässt sich nicht eindeutig bestimmen; möglicherweise, aber nicht sicher, leitet er sich vom slawischen Personennamen ${ }^{*} B e-$ drola ab. ${ }^{65}$ In Brederlow existierte auf dem Burgwerder ein slawischer Burgwall, dessen Funde jedoch nicht der spätslawischen Epoche, sondern dem 8.-10. Jahrhundert zugeordnet werden. ${ }^{66}$ Das Land Lippehne wurde wahrscheinlich in den fünfziger Jahren des 13. Jahrhunderts in den Landesausbau einbezogen; Initiator war hier der Kamminer Bischof Hermann von Gleichen. ${ }^{67} \mathrm{Im}$ Jahr 1259 einigte er sich mit Herzog Barnim I. darauf, die

die Länder Sternberg und Lebus sowie in Urkunden aus anderen Gebieten, die irrtümlich in die neumärkischen Register aufgenommen wurden.

63 Zu dieser Familie vgl. Czacharowski: Społeczne i gospodarcze siły (wie Anm. 24), S. 55-62; ders.: Adelsherrschaft (wie Anm. 24), Kap. II 1, S. 1-4; Brzustowicz: Rycerstwo ziemi choszczeńskiej (wie Anm. 8), S. $274-278$ u. S. 431 (Stammtafel 10).

64 Vgl. K 1337 B, fol. 112; LB/Gollmert, S. 17.

65 Vgl. Trautmann: Die elb- und ostseeslavischen Ortsnamen (wie Anm. 22), Bd. 1, S. 136; Friedrich Lorentz: Slawische Namen Hinterpommerns (Pomorze Zachodnie), bearb. von F. Hinze. Berlin 1964, S. 12 (= Deutsche Akademie der Wissenschaften zu Berlin. Veröffentlichungen des Instituts für Slavistik, 32).

66 Vgl. Cnotliwy/Nawrolski/Rogosz: Grodziska wczesnośredniowieczne (wie Anm. 44), S. 198-204.

67 Zur Entstehung und Besiedlung des Landes Lippehne vgl. Rudolf Benl: Untersuchungen zur Personen- und Besitzgeschichte des hoch- und spätmittelalterlichen Pommern, in: Baltische Studien [künftig zit.: B. St.] NF 71 (1985), S. 7-45, hier: S. 25-28; Gahlbeck: Zisterzienser (wie Anm. 3), S. 569-575; ders.: Oder-Drage-Raum (wie Anm. 43), S. 85 f. 
Grenze zwischen den Ländern Lippehne und Pyritz (Pyrzyce) durch ein Gremium von 12 Rittern und vier Klerikern bestimmen zu lassen. ${ }^{68}$ Dabei wurde die Feldmark von Brederlow dem Land Lippehne zugeschlagen. Es ist gut vorstellbar, dass bei dieser Grenzfestlegung bereits ein von Brederlow beteiligt war; allerdings sind die Namen der Kommissionsmitglieder nicht überliefert. Im August 1276 verkaufte der Bischof das Land Lippehne an die Markgrafen Johann II., Otto IV. und Konrad von Brandenburg. ${ }^{69}$ Ein halbes Jahr später wurde das Dorf Brederlow erstmals urkundlich erwähnt. ${ }^{70}$

Die ersten bekannten Angehörigen der von Brederlow waren die Brüder Henning, Ritter, und Dietrich, Knappe, die gemeinsam in einer Urkunde vom 3. Februar 1320 als Zeugen überliefert sind, in der Herzog Wartislaw IV. von Pommern in seiner Funktion als Vormund Markgraf Heinrichs von Brandenburg vor einem Großteil der Vertreter des neumärkischen Adels dem Augustinerinnenkloster Pyritz zur Gründung eines (allerdings nie errichteten) Tochterklosters mehrere Dörfer bei Dramburg überwies. ${ }^{71}$ Henning von Brederlow war bereits bei der Ausstellung der Wahlkapitulation Wartislaws IV. für die Stände des Landes Lebus am 29. September 1319 in Arnswalde als Zeuge zugegen gewesen. $^{72} 1321$ schuldeten ihm die Herzöge von Pommern 356 Mark Silber, für die ihm Wedego von Wedel im Auftrag der Herzöge die Beden der Dörfer Stresow (Strzeszów) und Thänsdorf (Grzybno) am Südrand des Landes Bahn (Banie) überwies. ${ }^{73}$ Aus den Aufzeichnungen der Kosten, die der Kriegszug verursachte, den die pommerschen Vasallen unter Beteiligung der gesamten Mannschaft der Neumark 1321 in die Mark unternahm, geht hervor, dass die von Brederlow innerhalb dieses pommersch-neumärkischen Heeres eine bedeutende Stellung innehatten. In der Summe für die in Prenzlau entstandenen Kosten werden an erster Stelle octo de Bredello genannt, von denen je vier mit Streitrössern (cum dextrariis) bzw. mit Arbeitspferden (cum caballis) unterwegs waren, wofür den pommerschen Herzöge Kosten in Höhe von 66 Brandenburgischen Talenten entstanden. Zudem geriet einer von ihnen, Hinceke, in Gefangenschaft und musste von Wedego von Wedel für 36 Mark Silber ausgelöst werden. ${ }^{74}$ Auch sonst waren die von Brederlow am pommerschen Hof gern gesehen; ein Dietrich von Brederlow war 1320 dort als Kaplan

68 Super limitibus vero Piriz et Lipene est condictum, quod duodecim milites et quatuor clerici [...] super limites conveniant ad distingwendum easdem. Urkunde von [1259] September 10, PUB 2, S. 59 f., Nr. 667.

69 Vgl. Urkunde von 1276 August 18, PUB 2, S. 331, Nr. 1042. Das Kamminer Domkapitel stimmte diesem Verkauf am 30. August 1276 zu; vgl. PUB 2, S. 331 f., Nr. 1043.

70 Die Markgrafen von Brandenburg bestätigten damals der Stadt Pyritz (Pyrzyce) den Besitz von 10 Hufen, die u. a. an Brederlow grenzten Vgl. Urkunde von [1277] Februar 14, PUB 2, S. 468 f., Nr. 1228 (zu 1282 Februar 14); Regest: Hermann Krabbo/Georg Winter (Hgg.): Regesten der Markgrafen von Brandenburg aus dem Hause der Askanier. Berlin 1910-55, S. 282 f., Nr. 1107 (= Veröffentlichungen des Vereins für die Geschichte der Mark Brandenburg, [8,1]) [künftig zit.: KW].

71 Vgl. Urkunde von 1320 Februar 3, PUB 5, S. 485, Nr. 3332.

72 Vgl. Urkunde von 1319 September 29, CDB I 20, S. 132 ff., Nr. 11. Dazu vgl. Gahlbeck: terra Transoderana (wie Anm. 10), S. $140 \mathrm{ff}$.

73 Vgl. PUB 6, S. 81-85, Nr. 3560, hier: S. 84.

74 Ebd., S. 82. 
Herzog Wartislaws IV. tätig. ${ }^{75}$ Die Brüder Henning, Ritter, und Dietrich, Knappe, besaßen damals das Schloss in Dertzow (Derczewo) in der terra Lippehne, mit dem sie sich 1326 vom noch unmündigen Markgrafen Ludwig dem Älteren gegen das Versprechen der Offenhaltung belehnen ließen ${ }^{76}$, sowie die 1337 im Neumärkischen Kataster im Land Lippehne erwähnte Soldinische Mühle und 19 Hufen in Naulin (Nowielin), die sie 1333 erwarben und für die Dietrich von Brederlow 1337 ein servicium innehatte. ${ }^{77}$ Ihre Vettern Nikolaus d.Ä., Nikolaus d.J., Heinrich und Kopke, die in Brederlow wohnten, verfügten über insgesamt 32 von 58 Hufen in Brederlow, für die sie 21/2 Rossdienste zu leisten hatten. ${ }^{78}$ Darüber hinaus besaßen Heinrich von Brederlow 7 Hufen in Grüneberg (Golice) im Land Bärwalde (Mieszkowice) und Kunekin von Brederlow 6 Hufen in Deetz (Dziedzice) und ein Achtel eines serviciums. ${ }^{79}$ In jenem Jahr 1337 hatte Dietrich von Brederlow, als officiatus bezeichnet, ein Amt innerhalb der neumärkischen Vogtei inne ${ }^{80}$, worüber der Knappe am 1. Januar 1340 gemeinsam mit Hasso d.Ä. von Wedel Rechnung ablegte. ${ }^{81}$ Es handelte sich dabei offenbar um eine Untervogtei, denn in einem in Spandau gefällten Urteil des Hofrichters Johann von Buch vom 10. Januar jenes Jahres wurde Dietrich als advocatus executor damit beauftragt, den Reiner von Goldbeck vor Ort in Blocksdorf in seine Güter einzuweisen. ${ }^{82}$ Ludeke von Brederlow war dagegen 1337 und 1339 in pommerschen Diensten tätig: Er schlichtete u.a. 1337 einen Streit zwischen den Herzögen Otto I. und Barnim III. von Pommern-Stettin und denen von Schwerin über die Bede im Land Groswin und war 1339 Zeuge in einer Urkunde Ottos I. für die Moritzkirche in Pyritz. ${ }^{83}$ Trotz seiner Dienste für Pommern erhielt auch er gemeinsam mit seinen

75 Vgl. Urkunde von 1320 August 16, PUB 5, S. 528, Nr. 3392.

76 Vgl. Urkunde von 1326 März 30, GStA PK Berlin, I. HA, Rep. 78a Nr. 1, T. 1, fol. 15 f., lit. y; CDB I 24, S. 13 f., Nr. 21. Diese Urkunde wurde von weiteren, nicht namentlich genannten Brüdern Hennings und Dietrichs von Brederlow mit ausgestellt. Wer diese Brüder waren, ist nicht bekannt. Henning von Brederlow nennt sich hier mit Vornamen Johannes; der Rufname Henning ist ebenso wie Hans und Jan aus Johannes hervorgegangen.

77 Vgl. Urkunde von 1333 Juli 21, R 1333-48, fol. 1, Nr. 2; PUB 8, S. 218, Nr. 5078; K 1337 B, fol. 113; LB/Gollmert, S. 19.

78 Vgl. K 1337 B, fol. 112; LB/Gollmert, S. 17.

79 Vgl. K 1337 B, fol. 109v, 112v; LB/Gollmert, S. 13, 19.

80 Vgl. Urkunde von 1337 März 19, R 1333-48, fol. 5, Nr. 18; CDB I 18, S. 76, Nr. 24.

81 Vgl. Urkunde von 1340 Januar 1, R 1333-48, fol. 15v, Nr. 63; CDB I 18, S. 115, Nr. 28.

82 Vgl. Urkunde von 1340 Januar 10, GStA PK Berlin, XX. HA, OF 328, S. 15, Nr. 25; ungedruckt. Regesten: Repertorium der im Kgl. Staatsarchive zu Königsberg i. Pr. befindlichen Urkunden zur Geschichte der Neumark, bearb. von Erich Joachim, gemeinsam hg. mit Paul van Niessen. Landsberg/W. 1895, S. 5 f., Nr. 23 (SVGN, 3) [künftig zit.: Rep. Kön.]; Urkundenbuch zur Geschichte des Schlossgesessenen Geschlechts der Grafen und Herren von Wedel, hg. von Heinrich Friedrich Paul von Wedel [künftig zit.: UB Wedel], 4 Bde. Leipzig 1885-1891 (Bde. 2 und 3 in 2 Teilbänden erschienen), hier: Bd. 2: Die Herren von Wedel im Märkischen Lande über der Oder, im Herzogthum Pommern und im Bisthum Camin. 1269-1348. Leipzig 1888, T. 1, S. 66, Nr. 97; Geschichte des Geschlechts v. d. Osten. Urkundenbuch. Im Auftrag des v. d. Ostenschen Familienverbandes bearbeitet von Otto Grotefend [künftig zit.: UB Osten], Bd. 1 (1200-1400). Leipzig 1914, S. 157, Nr. 502.

83 Vgl. Urkunden von 1337, PUB 10, fol. 227 f., Nr. 5570, 5571, und von 1339 Juni 11, PUB 10, S. 388 f., Nr. 5752 . 
Brüdern die gesamte Hand am Dorf Glasow (Głazów), Kr. Soldin, mit dem Dietrich und Henning von Brederlow 1339 von Markgraf Ludwig dem Älteren belehnt wurden. ${ }^{84} \mathrm{Im}$ märkisch-pommerschen Krieg von 1339 kämpften dann alle von Brederlow gemeinsam auf der märkischen Seite, wofür die Brüder in Brederlow 1340 das Dorf Sammenthin (Zamęcin), Kr. Arnswalde ${ }^{85}$, und die zu Dertzow im darauffolgenden Jahr 30 Hufen in Klemzow (Klępicz), Kr. Königsberg, erhielten. ${ }^{86}$ Für die Ausgaben, die Dietrich und Henning von Brederlow in diesem Krieg als Beamte des Markgrafen getätigt hatten, wurden sie mit Hebungen aus dem Hufenzins von Arnswalde, Dramburg und Reetz entschädigt. ${ }^{87}$

Im Februar 1347 wurde Dietrich erneut, diesmal zusammen mit seinem Sohn Henning, in das Vogteiamt im Lande über der Oder berufen, aus dem beide jedoch bereits im Herbst desselben Jahres wieder entlassen wurden. ${ }^{88}$ Bei der Abrechnung ihrer Einnahmen und Ausgaben in dieser Zeit kam es nach längerem Streit ${ }^{89}$ schließlich zum Zerwürfnis zwischen ihnen und dem Markgrafen, in dessen Folge sie die Seite wechselten und am 12. Oktober 1348 in den Dienst des Falschen Woldemar traten. ${ }^{90}$ Sie blieben dort allerdings nicht lange, denn es gelang den Rittern Betekin von der Osten und Claus Sack und den Knappen Henning von Uchtenhagen und Johann von Wedel sowie Vertretern der Städte Arnswalde, Friedeberg, Landsberg und Mohrin, einen Burgfrieden mit den zu Woldemar haltenden Städten zu vermitteln, der am 29. November 1348 geschlossen wurde $^{91}$, und diese Städte sowie auch die von Brederlow noch vor Ende 1348 zur Rückkehr zu den Wittelsbachern zu bewegen. ${ }^{92}$ Der Preis für diese Rückkehr war das Schloss Zantoch, auf

84 Vgl. Urkunde von 1339, R 1333-48, fol.15vf., Nr. 64; CDB I 24, S. 29, Nr. 51.

85 Vgl. Urkunde von 1340 Januar [7-13], R 1333-48, fol.16 f., Nr. 67; CDB I 24, S. 30, Nr. 54.

86 Vgl. Urkunde von 1341 September 13, R 1333-48, fol.21vf., Nr. 86; CDB I 24, S. 32, Nr. 58. Diese Hufen befanden sich bereits zuvor im Besitz der Familie; der konkrete Vorbesitzer war Georg von Brederlow. Die 10 Hufen, die Nikolaus von Brederlow in Klemzow besaß, waren offenbar nicht zu gesamter Hand verliehen worden. Markgraf Ludwig verlieh diese Hufen am 9. September 1341 an Heyne Wolgast. Vgl. R 1333-48, fol. 22, Nr. 87; CDB I 24, S. 31, Nr. 57.

87 Vgl. Urkunde von 1340 März 16, R 1333-48, fol.15vf., Nr. 70; CDB I 18, S. 116, Nr. 30; PUB 10, S. 461 f., Nr. 5832.

88 Vgl. die Bestallungsurkunde von 1347 Februar 24, R 1333-48 A, fol.16, Nr. 108, ungedruckt; Regest: Kletke: Regesta (wie Anm. 8), Bd. 1, S. 169, und die Urkunde über die Abrechnung mit den von Brederlow über die Ausgaben während ihrer Vogtei von 1347 Oktober 20, R 1333-48 A, fol.18vf., Nr. 120, Regest: Kletke: Regesta (wie Anm. 8), Bd. 1, S. 172.

89 Am 9. Dezember 1347 versprach der Markgraf, die Ansprüche, die die von Brederlow geltend gemacht hatten, gemäß dem Schiedsspruch, den eine von beiden Seiten paritätisch besetzte Schiedskommission fällen sollte, anzuerkennen und zu begleichen. Vgl. R 1333-48 A, fol.20v., Nr. 125; Regest: Kletke: Regesta (wie Anm. 8), Bd. 1, S. 173. Diese konnte sich in der Folgezeit über die Höhe der Ansprüche offenbar nicht einigen. Die von Brederlow sind aber noch bis April 1348 als Gefolgsleute der Wittelsbacher urkundlich bezeugt; am 30. März 1348 waren sie noch als Vögte tätig (vgl. CDB I 19, S. 210 f., Nr. 65), und am 30. April 1348 verpfändete ihnen Markgraf Ludwig die Bede und den Wagendienst zu Simonsdorf (Kruszwín). Vgl. R 1333-48 A, fol. 20v, Nr. 126; Regest: Kletke: Regesta (wie Anm. 8), Bd. 1, S. 168 (zu 1347 Februar 4).

90 Vgl. Urkunde von 1348 Oktober 12, CDB I 24, S. 44 f., Nr. 81.

91 Vgl. Urkunde von 1348 November 29, CDB I 19, S. 13, Nr. 69.

92 Bereits am 1. Januar 1349 testierte Dietrich von Brederlow wieder im Gefolge Markgraf Ludwigs des Älteren. Vgl. Urkunde von 1349 Januar 1, Ausfertigung: GStA PK Berlin, VII. HA (Urkunden), Abt. h (Märk. Ortschaften), Nelep, Nr. 1; R 1348-51 A, fol. 30v, Nr. 25; CDB I 18, S. 121, Nr. 39. 
das Henning und Arnold von Uchtenhagen damals verzichteten ${ }^{93}$ Die von Brederlow erwarben das Schloss für 712 Silbermark $^{94}$, wobei das Geld damals vermutlich gar nicht gezahlt, sondern von den ausstehenden Schulden des Landesherrn abgezogen wurde. Im März 1353 (nicht 1352) räumte Henning von Brederlow Markgraf Ludwig dem Römer das Schloss auf dessen Bitten hin ein, wofür die von Brederlow zu gesamter Hand mit dem Dorf Peetzig/Oder (Piasek) und der Hohen Heide (Krzymowskie Góry) belehnt wurden. ${ }^{95}$ Aber noch im Juni 1353 verhandelten die von Brederlow und ihre vrunde um die Vogtei. Sie verfolgten damals offenbar das Ziel, die Hohe Heide als ewiges Lehen übertragen zu bekommen. Wie aus dem Revers vom 20. Juni 1353 hervorgeht, rückte der Markgraf von seiner Position, die Heide jederzeit für den Kaufpreis für Zantoch zurückkaufen zu können, jedoch nicht ab. ${ }^{96}$ Der Besitz der von Brederlow wuchs seit 1350 noch weiter an: 1350 verlieh Markgraf Ludwig der Ältere Henning von Brederlow das Angefälle an den Gütern des Hincze Junge in Zollen (Czółnów; u.a. gehörte dazu eine Wassermühle), Wuthenow (Otanów) und Naulin (8 Hufen). ${ }^{97}$ Bis 1372 kamen dann noch das Dorf Gruse zwischen Lippehne und Dertzow (1360) ${ }^{98}$ sowie die Beden von Schmarfendorf (Gogolice; 1354), Stolzenfelde (Stołeczna), Wuthenow und Zollen (alle 1372) hinzu. ${ }^{99}$ Die Mühle, die die von Brederlow bei Lippehne besaßen, musste Henning von Brederlow allerdings 1363 an die Stadt Lippehne verkaufen. ${ }^{100}$

Unter den Luxemburgern hatte Henning von Brederlow außer Dertzow vorübergehend auch die Burgen in Hermsdorf und Klanzig sowie einen Anteil an der Burg Rützow

93 In einer nicht näher datierten Urkunde von 1348 (R 1348-51 A, fol. 28v, Nr. 14, ungedruckt; Regest: UB Osten, Bd. 1, S. 172, Nr. 553) belehnte Markgraf Ludwig der Ältere die Brüder Henning und Arnold von Uchtenhagen eo, quod ab impeticione castri Zantach sibi competente benivole cessaverint, mit den Dörfern Wrechow (Orzechów) und Eulam (Ulim).

$94[. .$.$] pro septuaginta marcis et XII marcis argenti puri, cum quibus pater meus bone memorie et ego$ emimus castrum Czantoch. Urkunde von 1353 August 14, R 1352-56 A, fol. 92 f., Nr. 71; CDB I 18, S. 398, Nr. 46.

95 Vgl. ebd. sowie Urkunde von 1353 März 3, R 1352-56 A, fol. 83vff., Nr. 45; CDB I 24, S. 56 f., Nr. 102 (zu 1352 März 18). Darüber hinaus erhielten die von Brederlow am selben Tag vom Markgrafen zu gesamter Hand die Beden von 13 Hufen in Dertzow mit dem kreczem daselbst sowie von 9 Hufen im benachbarten Mellenthin (Mielęcin). Vgl. Urkunde von [1353 März 3], R 1352-56 A, fol. 84v, Nr. 46.

96 Vgl. Urkunde von 1353 Juni 20, R 1352-56 A, fol. 89vf, Nr. 64, ungedruckt; Regest: Kletke: Regesta (wie Anm. 8), Bd. 1, S. 212 (zu 1352 Juni 12).

97 Vgl. Urkunde von 1350 Oktober 20, R 1348-51 A, fol. 55, Nr. 118; CDB I 24, S. 52, Nr. 95.

98 Vgl. Urkunde von 1360 September 27, R 1360-64 B, fol., Nr. 20; CDB I 24, S. 67, Nr. 120.

99 Vgl. Urkunden von 1354 Mai 29, R 1352-56 A, fol. 102v., Nr. 108; CDB I 24, S. 61, Nr. 111, und von 1372 September 22, R 1360-73 B, fol. 139v, Nr. 111; CDB I 24, S. 84, Nr. 141. Bei dem in der letzteren Urkunde genannten Stolzenfelde dürfte es sich wohl nicht um Stolzenfelde, Kr. Arnswalde (Stradzewo), handeln, wie von Czacharowski: Społeczne i gospodarcze siły (wie Anm. 24), S. 62; ders.: Adelsherrschaft (wie Anm. 24), Kap. II 1; Brzustowicz: Rycerstwo ziemi choszczeńskiej (wie Anm. 8), S. 276, behauptet wird, sondern um Stolzenfelde, Kr. Königsberg (Stołeczna), da dieses Dorf mehr oder minder am Rand des Brederlowschen Besitzkomplexes um Dertzow und in relativer Nähe zu den anderen beiden genannten Dörfern, Wuthenow und Zollen, liegt.

100 Vgl. Urkunde von 1363 Juni 20, R 1360-64 B, fol. 163vf., Nr. 56; CDB I 18, S. 84, Nr. 37. 
(Rydzewo), Kr. Dramburg, inne. ${ }^{101}$ Von den sechs Angehörigen dieser Familie, die 1402 dem Deutschen Orden huldigten, saßen je zwei auf Dertzow und Adamsdorf, Kr. Soldin. ${ }^{102}$ Aber auch in Pommern hatten die von Brederlow Besitzungen, vor allem oberhalb des Plönesees und an der Faulen Ihna. 1383 versprach Dietrich von Brederlow vier Hufen in Dobberphul (Dobropole Pyrzyckie), das Leibgedinge seiner Frau und seiner Tochter, einer Nonne im Kloster Bernstein, nach dem Tod dieser beiden dem Kloster Kolbatz $(\text { Kołbacz })^{103}$, und im 15. und 16. Jahrhundert war die Familie u.a. in Garz (Gardziec), Plönzig (Płońsko) und Warsin (Warszyn) begütert. ${ }^{104}$

Zusammenfassend lässt sich feststellen, dass die von Brederlow um 1337 in der Neumark über zwei Besitzkomplexe verfügten, nämlich einen im Land Lippehne um ihren Stammsitz, die Burg Dertzow, zu dem u. a. auch die Lippehnsche und die Soldiner Mühle gehörten, und einen zweiten, kleineren, zwischen Zehden und Mohrin in den Dörfern Grüneberg und Klemzow. ${ }^{105}$ Der Vogt Dietrich von Brederlow und sein Sohn Henning verfolgten vor allem den Plan, den Komplex um Dertzow zu erweitern und ihre Rechte in diesem Raum auszubauen. Mit nur wenigen Lücken umfasste ihr dortiger Besitz schließlich fast den ganzen Raum zwischen Pyritz, Soldin und Lippehne und umschloss, abgesehen vom Ostufer, das der Stadt Lippehne gehörte, den gesamten Kloppsee, den zweitgrößten See dieser Region. Der Komplex Grüneberg/Klemzow ging ihnen dagegen nach 1341 verloren. Die 1353 erworbene Hohe Heide bei Königsberg war ihnen nur auf Wiederkauf verliehen worden, so dass sie schließlich als Grundbesitzer aus diesem Gebiet gänzlich verschwanden. Stattdessen richtete sich ihr Interesse auf den Raum um Arnswalde, in dem sie 1340 Sammenthin erworben hatten. Der Ausbau ihres Besitzes zu einem größeren Komplex gelang ihnen allerdings erst im 15. Jahrhundert. ${ }^{106}$ Aufgrund ih-

101 Vgl. LB 1375, S. 5. Die Angaben zu Hermsdorf sind allerdings widersprüchlich, Ebd., S. 19, 66, wird die Burg zu den landesherrlichen Festen gezählt. Vgl. Podehl: Burg und Herrschaft (wie Anm. 26), S. 672, 675, 690; Brzustowicz: Rycerstwo ziemi choszczeńskiej (wie Anm. 8), S. 276. Die Anteile an Rützow traten die von Brederlow um 1375 an Kaiser Karl IV. ab. Anders, als von Brzustowicz, ebd., S. 364, Anm. 437, behauptet wird, hatten sie 1377 an Rützow keinen Anteil mehr. In der Urkunde vom 20. August 1377 traten Hans und Kune von Brederlow lediglich als Bürgen Kaiser Karls IV. auf, die Hasso von Wedel auf Schildberg garantierten, dass der Kaiser die beim Verkauf von Hassos Anteil an Retzow vereinbarten beiden Ratentermine für die Übergabe des Kaufgelds einhielt. Vgl. CDB I 19, S. 268 f., Nr. 147.

102 Vgl. Huldigungsliste von [1402 um und nach August 9], GStA PK Berlin, XX. HA, OBA 727. Für die beiden übrigen Familienangehörigen wird in der Liste kein Wohnort genannt.

103 Vgl. Urkunde von 1383 April 14, Landesarchiv Greifswald, Rep. 1, Kloster Kolbatz, Urkunden, Nr. U 22, ungedruckt.

104 Vgl. Brzustowicz: Rycerstwo ziemi choszczeńskiej (wie Anm. 8), S. 277.

105 Es ist m.E. bemerkenswert, dass sich zwischen beiden Gebietskomplexen auch bei den Ortsnamen ein Zusammenhang andeutet. So ist es sicherlich kein Zufall, dass sich in beiden Gebieten der Ortsname Grüneberg wiederfindet, einmal für Grüneberg, Kr. Königsberg (Golice) und einmal für Grüneberg, Kr. Soldin (Skrzynka). Ob die von Brederlow im letztgenannten Ort, der unmittelbar zwischen ihrem Güterkomplex um Dertzow und Lippehne lag, über Besitz verfügten, ist unbekannt. Das Dorf wird, außer im Kataster von 1337 (K 1337 B, fol. 112v; LB/Gollmert, S. 18), in dem lediglich ein filius Vridberni ansässig war, der für 12 Hufen dienstpflichtig war, in mittelalterlichen Quellen offenbar nicht erwähnt.

106 Vgl. Brzustowicz: Rycerstwo ziemi choszczeńskiej (wie Anm. 8), S. 276 f. 
rer zahlreichen Angehörigen in mehreren Familienzweigen waren sie zahlenmäßig im neumärkischen Adel stark vertreten; ihre militärischen Fähigkeiten waren offenbar sehr geschätzt. Ihre politische Bedeutung erreichte mit der Tätigkeit von Dietrich von Brederlow als Vogt in der Zeit zwischen 1337 und 1348 ihren Zenit. Ihr Abfall von den Wittelsbachern im Streit um die in dessen Amtszeit angefallenen Kosten der Vogtei und ihr Seitenwechsel zum Falschen Woldemar kostete sie allerdings ein erhebliches Maß an Reputation. Ein bedeutendes Amt konnten sie in der Neumark nicht mehr bekleiden, und ihre Bedeutung und ihr Einfluss innerhalb des neumärkischen Adels war seitdem im Sinken begriffen.

Interessanterweise gehörten zum Verwandtschaftskreis der von Brederlow u.a. auch Jacob Kenstel und Günter von Güntersberg. ${ }^{107}$ Diese Familie ist in der Forschung, zumindest was ihre Bedeutung in der Neumark in der ersten Hälfte des 14. Jahrhunderts anbelangt, bisher überschätzt worden, was vor allem daran liegt, dass sie mit den de Gruthow identifiziert wurde, die im neumärkischen Kataster von 1337 einen umfangreichen, zusammenhängenden Güterkomplex zwischen Märkisch Friedland (Mirosławiec), Kallies (Kalisz Pom.), Neuwedell (Drawno) und dem Großen Lübbesee besaßen. ${ }^{108} \mathrm{Ob}-$ wohl bereits seit 1862 bekannt ist, dass der Name tatsächlich als de Gruthow und nicht, wie in der Edition des Katasters von Georg Wilhelm von Raumer angegeben, de Bruthow oder gar de Butow lautete ${ }^{109}$, werden bis heute die von Güntersberg, die 1336 von Markgraf Ludwig die Erlaubnis zum Bau einer Burg in Butow (Bytowo Ińskie) anstelle des von brandenburgischen Mannen zerstörten Ravenstein (Wapnica) in Pommern erhiel-

107 Vgl. Urkunde von 1353 Juni 20, R 1352-56 A, fol. 89vf, Nr. 64, ungedruckt; Regest: Kletke: Regesta (wie Anm. 8), Bd. 1, S. 212 (zu 1352 Juni 12). - Zu den von Güntersberg vgl. Czacharowski: Społeczne i gospodarcze siły (wie Anm. 24), S. 62-64; ders.: Adelsherrschaft (wie Anm. 24), Kap. II 2; Edward Rymar: Güntersbergowie. Szczeciński rajca - mordercą polskiego króla? Początki kariery rodu [Die von Güntersberg. War ein Stettiner Rat der Mörder des polnischen Königs?. Die Anfänge vom Aufstieg des Geschlechts], in: Blażej Śliwiński (Hg.): Kopijnicy, szyprowie, tenutariusze [Lanzenritter, Schiffer, Pächter]. Gdańsk 2002, S. 99-126, mit Stammtafel, S. 125 (= Gdańskie Studia z Dziejów Średniowiecza, 8); Brzustowicz: Rycerstwo ziemi choszczeńskiej (wie Anm. 8), S. 283-289 u. Stammtafel (Auszug), S. 434.

108 Vgl. K 1337 B, fol. 119vf.; LB/Gollmert, S. 29 f..; Gahlbeck: Das sogenannte Neumärkische Landbuch (wie Anm. 1), S. 36-38.

109 Vgl. Georg Wilhelm von Raumer: Die Neumark Brandenburg im Jahre 1337 oder Markgraf Ludwig des Aelteren Neumärkisches Landbuch aus dieser Zeit. Berlin 1837, S. 47. Zur Namensform Gruthow vgl. dagegen: K 1337 B, fol. 119v; LB/Gollmert, S. 29. - In jüngster Zeit hat sich Edward Rymar, ohne die Handschrift gesehen zu haben, wieder für die falsche Schreibweise entschieden und zudem Louis Gollmert unterstellt, dieser habe seine Lesart Gruthow „ohne Grund“ mit Kürtow bei Arnswalde verbunden: „L. Gollmert, wydawca Landbuchu [...] bez podstaw kojarzył swą lekcję Gruthow z Kurtow (Korytowo) koło Choszczna“ (Rymar: Güntersbergowie [wie Anm. 107], S. 119, Anm. 64, Hervorhebung von C.G.). Hierzu ist festzustellen, dass Gollmert den Namen Kürtow in diesem Zusammenhang gar nicht erwähnt, so dass sich die Kritik Rymars offenbar gegen Gollmerts Lesart Gruthow richtet. Es muss daher an dieser Stelle ausdrücklich betont werden, dass die Transkription des Katasters von 1337 durch Gollmert den Text seiner Vorlage buchstabengetreu wiedergibt und in K 1337 B, fol. 119v, unzweifelhaft Gruthow und nicht Bruthow zu lesen ist. Zu den m.E. durchaus guten Gründen, Gruthow mit Kürtow zu identifizieren, vgl. Gahlbeck: Das sogenannte Neumärkische Landbuch (wie Anm. 1), S. 32-38. 
ten ${ }^{110}$, für die im Kataster genannten de Gruthow gehalten. ${ }^{11}$ Seit der Stettiner NeumarkHistoriker Edward Rymar 1983 den Versuch einer Identifizierung des Mörders des großpolnischen Herzogs Przemysław II. von 1296 unternommen hat und den pommerschen Knappen und vorigen Stettiner Ratsherrn Jakob von Güntersberg dieses Mordes bezichtigt $^{112}$, den nach Angaben der Kolbatzer Annalen ein Jacob Kassube begangen haben soll ${ }^{113}$, hat sich zu dieser Legende der angeblichen Identität dieses Adelsgeschlecht mit den von Gruthow noch eine zweite hinzugesellt, nämlich die einer Beteiligung der von Güntersberg am Mord an Przemysław II. Beide sind nicht haltbar.

Die von Güntersberg gehörten im 13. Jahrhundert zunächst dem Stadtbürgertum an. Der Name der Familie leitet sich wahrscheinlich vom uckermärkischen Dorf Günterberg (sic! 1306: Gunthersberghe) her. ${ }^{114}$ Von 1277 bis 1284 ist ein Jakob von Güntersberg als Stettiner Ratsherr bezeugt. ${ }^{115}$ Daneben ist dieser Name auch im Prenzlauer Stadtpatriziat

110 Vgl. Urkunde von 1336 Juli 24, R 1333-48, fol. 4v, Nr.16; CDB I 18, S. 107, Nr. 14.

111 Vgl. Heinrich Berghaus: Landbuch der Mark Brandenburg und des Markgrafthums Nieder-Lausitz in der Mitte des 19. Jahrhunderts; oder geographisch-historisch-statistische Beschreibung der Provinz Brandenburg. 3 Bde. Brandenburg 1856, hier: Bd. 3, S. 343, 356; Fr. Schultz: Das Deutsch Kroner Land im 14. Jahrhunderte, in: Zeitschrift des Westpreußischen Geschichtsvereins 39 (1899), S. 1-98, hier: S. 38; Czacharowski: Społeczne i gospodarcze siły (wie Anm. 24), S. 62 f.; ders.: Adelsherrschaft (wie Anm. 24), Kap. II 2; Edward Rymar: Przynależność polityczna wielkopolskich ziem zanoteckich między dolną Drawą i dolną Gwdą oraz Wielenia, Czarnkowa i Ujścia w latach 1296-1368 [Die politische Zugehörigkeit der großpolnischen Territorien an der Netze zwischen der unteren Drage und der unteren Gwda sowie von Wieleń [Filehne], Czarnków [Czarnikau] und Ujście [Usch] in den Jahren 1296-1368], in: Roczniki Historyczne 50 (1984), S. 39-84, hier: S. 74-77. Vgl. auch die folgende Anm.

112 Vgl. Edward Rymar: Próba identyfikacji Jakuba Kaszuby, zabójcy króla Przemysława II, w powiązaniu z ekspansją brandenburską na północne obszary Wielkopolski [Versuch der Identifizierung Jakub Kaszubas, des Mörders des Königs Przemysław II., im Zusammenhang mit der brandenburgischen Expansion in die nördlichen Bereiche Großpolens], in: Niemcy - Polska w średniowieczu. Materiały z konferencji naukowej zorganizowanej przez Instytut Historii UAM w dniach 14-16 XI 1983 roku, hg. von Jerzy Strzelczyk. Poznań 1986, S. 203-224, pass.; ders.: Güntersbergowie (wie Anm. 107), pass. - Ihm folgt Brzustowicz: Rycerstwo ziemi choszczeńskiej (wie Anm. 8), S. 284 f., allerdings ohne Übernahme der von Rymar behaupteten Identität von Gruthow mit Butow. - Insgesamt gilt Rymar, mit Recht, als der bedeutendste polnische Historiker auf dem Gebiet der neumärkischen und pommerschen Landesgeschichte des Mittelalters.

113 Occisus est Petrus rex Polonie a quodam marchionum milite dicto Jacob Kassube. SBB PK Berlin, Ms. theol. Lat. $2^{\circ} 149$, fol. 24; Druck: Annales et notae Colbazienses, hg. von Wilhelmus Arndt, in: Monumenta Germaniae Historica. Scriptores XIX, S. 710-720., hier: S. 716.

114 Urkunde von 1306 März 29, CDB I 13, S. 231 f., Nr. 49. - Der Name Güntersberg ist von der Stadt Güntersberge, Kr. Quedlinburg, im Ostharz in die Uckermark übertragen worden, zusammen mit mehreren anderen Ortsnamen aus jener Gegend. Es ist allerdings nicht nachweisbar, dass ein Angehöriger der Familie von Güntersberg für diese Ortsnamensübertragung verantwortlich ist. Da die von Güntersberg vor ihrer Aufnahme in den Adelsstand um 1284/85 Stadtbürger waren, ist es wahrscheinlicher, dass sich ihr Name von dem uckermärkischen Dorf herleitet, als dass sie dem Dorf ihren Namen gaben. Zu Günterberg vgl. Lieselott Enders (Bearb.): Historisches Ortslexikon für Brandenburg, Bd. 8: Uckermark, Weimar 1986, S. 385-387 (= Veröffentlichungen des Staatsarchivs Potsdam, 21); Sophie Wauer: Brandenburgisches Namenbuch, Bd. 9: Die Ortsnamen der Uckermark, Weimar 1996, S. 122, Nr. 272 (= Berliner Beiträge zur Namenforschung, 10).

115 Am 24. März 1277 stiftete Jakob von Güntersberg einen Altar in der Stettiner Marienkirche, der dem hl. Stephan geweiht war. Vgl. PUB 2, S. 443 f., Nr. 1194 (zu 1281 März 22; zur Datierung 
vertreten ${ }^{116}$; da die Prenzlauer von Güntersberg allerdings erst im 15. Jahrhundert erwähnt werden, ist nicht sicher, ob sie mit dem Stettiner Ratsherrn von 1280 verwandt waren. Im Winter 1284/85 wurde Jakob von Güntersberg in den Adelsstand aufgenommen und diente als Knappe unter Herzog Bogislaw IV., der ihn wahrscheinlich mit der Burg Ravenstein und dem benachbarten Dorf Güntersberg (Nosowo) im Kreis Saatzig (Szadzko, powiat Stargard Szcz.) belehnte. ${ }^{117}$ Seit Ende 1286 allerdings ist aus pommerschen Quellen für über 30 Jahre nichts über Angehörige der von Güntersberg zu erfahren. Aus dem Teilungsvertrag zwischen Bogislaw IV. und Otto I. von Pommern vom 12. Juli 1295, in dem die bona illorum de Rauensten dem zweiten Landesteil zugeschlagen wurden ${ }^{118}$, den Bogislaw behielt, scheint jedoch hervorzugehen, dass die von Güntersberg damals noch Vasallen der pommerschen Herzöge auf Ravenstein waren. ${ }^{119}$

Während die pommerschen Quellen schweigen, finden sich Belege in brandenburgischen Urkunden dafür, dass sich einige von Güntersberg in den Dienst der Askanier begeben hatten. Am 2. August 1299 bezeugte ein Günter von Ravenstein die Bestätigungsurkunde der Markgrafen Otto IV., Konrad, Heinrich und Johann IV. aus der johanneischen Linie der Askanier für das Zisterzienserinnenkloster Bernstein, und am 21. Dezember 1299 bestätigte Markgraf Albrecht III. aus der ottonischen Linie den Ankauf u. a. von einer Rente von 91/2 Scheffeln Roggen aus der Mühle Vogelsang von einem Johann von Ravenstein durch den Abt des Zisterzienserklosters Semmritz (Zemsko). ${ }^{120}$ Am 23. April

vgl. Hermann Hoogeweg: Die Stifter und Klöster der Provinz Pommern, 2 Bde. Stettin 19241925, hier: Bd. 2, S. 518). Vgl. ferner die Urkunden Herzog Bogislaws IV. von [nach 1278] Juli 16, PUB 2, S. 395 ff., Nr. 1124; von 1280 September 7, PUB 2, S. 435 f., Nr. 1178; von 1281 März 22, PUB 2, S. 443 f., Nr. 1194; von 1281 Dezember 3, PUB 2, S. 462, Nr. 1220, von 1283 September 1, PUB 2, S. 508 f., Nr. 1274, von 1284 März 25, PUB 2, S. 522 f., Nr. 1297, von 128[4] Juli 2, PUB 2, S. 503 f., Nr. 1268 (zu 1283 Juli 4; zur Datierung vgl. Hermann Hoogeweg: Die Grundbesitzerwerbung des Klosters Kolbatz, in: B.St. NF 19 (1916), S. 1-58, hier: S. 43), 1284 Juli 8, PUB 2, S. 531, Nr. 1308, und 1284 (ohne Tagesdatum), PUB 6, S. 364, Nr. 3997. Die erste der genannten herzoglichen Urkunden, ausgestellt für das Zisterzienserinnenkloster Stettin, weist im Ausstellungsdatum das Jahr 1276 auf, kann jedoch erst frühestens 1279 ausgestellt worden sein, da die Urkunde erst nach dem Tod Herzog Barnims I. im November 1278 entstanden sein kann. - Vgl. Gahlbeck: Zisterzienser (wie Anm. 3), S. 246 f.; Rymar: Güntersbergowie (wie Anm. 107), S. 100103; Brzustowicz: Rycerstwo ziemi choszczeńskiej (wie Anm. 8), S. 283 f.

116 Belege in: CDB Namensverzeichnis, Bd. 1, S. 524.

117 Vgl. Urkunden von 1285 März 15, PUB 2, S. 552 f., Nr. 1329, und von 1286 Mai 10, PUB 2, S. 591 f., Nr. 1375. Dazu vgl. Rymar: Güntersbergowie (wie Anm. 107), S. 102 f. Zu Ravenstein s. weiter unten.

118 Urkunde von 1295 Juli 12, PUB 3, S. 246 f., Nr. 1730.

119 Vgl. Rymar: Güntersbergowie (wie Anm. 107), S. 104. - Über die Identität der von Ravenstein mit den von Güntersberg besteht in der historischen Forschung Konsens.

120 Vgl. Urkunden von 1299 August 2, Abschrift (1746), Archiwum Państwowe w Szczecinie [künftig zit.: AP Szczecin], Zb. Loeper, Nr. 156 (XII-2-215): Friedrich Dreger, Abschriften von Privilegien und Urkunden Nonnenklosters Bernstein, S. 53 ff., Nr. 30; Druck (fehlerhaft): CDB I 18, S. 71, Nr. 16, und von 1299 Dezember 21, Ausfertigung: Deutschordens Zentralarchiv [künftig zit.: DOZA], Wien, Abt. Urkunden, 1299, XII.21; Druck: CDB I 18, S. 170 f., Nr. 2 und CDB II 1, S. 229, Nr. 295; Regesten: Ewa Syska: Die Urkunden der Stadt Landsberg an der Warthe (Gorzów Wielkopolski) aus der Askanier- und Wittelsbacherzeit 1257-1373, in: JGMOD 48 (2002), S. 29116, hier: S. 40 ff., Nr. 7; Udo Arnold (Hg.): Die Urkunden des Deutschordens-Zentralarchivs in 
1303 schließlich bezeugten (Ianussius/Jonas?) Kenstel, dessen Sohn Johann sowie Janeke von Güntersberg die Gründung der Stadt Deutsch Krone (Arnescrone; Wałcz) durch die Markgrafen Otto IV., Konrad, Johann IV. und Woldemar. ${ }^{121}$

Rymar hat nun aus dem Wechsel der von Güntersberg in den Dienst Brandenburgs geschlossen, dass diese Familie einen Verrat bzw. Treuebruch gegenüber Pommern begangen habe: „Als Schluss aus dem obigen Befund ergibt sich, dass es in den Jahren 1295-1297 zur Felonie der von Güntersberg kam. " ${ }^{\text {"122 }}$ Darüber hinaus nimmt Rymar an, dass Jakob von Güntersberg im Februar 1296 als Anführer eines bewaffneten brandenburgischen Kommandos („oddział“"123) eine mit polnischen Adligen aus den Geschlechtern der Zaremba und Nałęcz verabredete Aktion leitete, die das Ziel verfolgte, Przemysław II. von Großpolen, der sich kurz zuvor zum König von Polen ernannt hatte, zu entführen, und ihn tötete, nachdem der König bei der Ausführung dieser Aktion so schwer verletzt worden war, dass er nicht transportfähig war. ${ }^{124}$ Beide Annahmen treffen m. E. nicht zu. Wie bereits erwähnt, nennen die Kolbatzer Annalen einen Jacob Kassube als Mörder und nicht einen Jakob von Güntersberg. Nun deutet die Bezeichnung Kassube wohl tatsächlich auf einen in märkischen Diensten stehenden Ritter hin, der unter den Herzögen der Kassuben und Wenden, wie sich die pommerschen Greifenherzöge nannten, ansässig war oder von dort herkam. ${ }^{125}$ Da dieser Begriff jedoch in den Annales Kolbazienses, einer pommerschen Quelle, benutzt wurde und sich wohl ausschließen lässt, dass die Kolbatzer Mönche alle Ritter des Herzogtums Pommern-Stettin Kaschuben nannten, dürfte es ziemlich unwahrscheinlich sein, dass ausgerechnet ein Adliger deutscher Herkunft mit dieser ethnischen Bezeichnung umschrieben werden sollte. In Kolbatz waren die von Güntersberg gut bekannt; 1325 musste Herzog Otto I. einen Streit der Mönche mit Janeke von Güntersberg wegen der an diesen verliehenen oder verpfändeten Bede in Treben, das später in Dölitz (Dolice) aufging, schlichten, nachdem sich die dortigen Klosteruntertanen

Wien. Regesten, nach dem Manuskript von Martin Tumler hg. [künftig zit.: UDOZA], 3 Bde. Marburg 2006-2007, hier: Bd. 1, S. 361 f., Nr. 1140 (= Quellen und Studien zur Geschichte des Deutschen Ordens, 60/1-60/3; Veröffentlichungen der Internationalen Historischen Kommission zur Erforschung des Deutschen Ordens II/1-II/3).

121 Vgl. Urkunde von 1303 April 23, Ausfertigung: GStA PK Berlin, XX. HA, Urkunden, Schieblade 46, Nr. 1; Druck: CDB II 1, S. 248 ff., Nr. 318.

122 „Z powyższego wynika wniosek, iż w latach 1295-1297 doszło do felonii Güntersbergów ...“ Rymar: Próba identyfikacji (wie Anm. 112), S. 211. Vgl. auch ders.: Güntersbergowie (wie Anm. 107), S. 106, wo der Satz fast wörtlich wiederholt wird.

123 Der polnische Begriff oddziat ist in diesem Kontext nicht eindeutig übersetzbar, er umfasst eine Bandbreite, die von Gruppe über Kommando bis Abteilung oder Truppe reicht.

124 Vgl. Rymar: Güntersbergowie (wie Anm. 107), S. 105 f. Dabei, so Rymar (ebd., S. 105), sei es unerheblich gewesen, ob Jakob (von Güntersberg) den ersten Stoß gegen den König führte, ihm den Gnadenstoß gab oder lediglich das brandenburgische Kommando befehligte: ,i nieważne, czy ów Jakub zadał pierwszy cios, dobił krola, czy tylko dowodził oddziałem brandenburskim.“ - Zum Mord an Przemysław II. und seinen Hintergründen vgl. auch das Regest zu 1296 Februar 8 in: KW, S. 437 f., Nr. 1644.

125 Vgl. Rymar: Güntersbergowie (wie Anm. 107), S. 105 f. 
über die Geldforderungen und Einzugspraxis des Ritters beschwert hatten. ${ }^{126}$ Wäre der Königsmörder tatsächlich Jakob von Güntersberg gewesen, so gab es für Kolbatz keinen Grund, ihn nicht bei seinem richtigen Namen zu nennen. Die Annalen haben im Mittelalter die Kolbatzer Klostermauern höchstwahrscheinlich nie verlassen. Warum hätte also ihr Verfasser den Namen des Mörders verschleiern sollen? Daher kommt Jakob von Güntersberg als Mörder Przemysławs II. nicht in Frage. Mit großer Wahrscheinlichkeit hat man in Kolbatz den Täter deshalb einen Kaschuben genannt, weil er ein Angehöriger des Volksstamms dieses Namens war und man seinen Familiennamen nicht kannte. ${ }^{127}$

Im übrigen bedurfte es für den Übertritt der von Güntersberg zu den Askaniern weder dieses Mordes noch eines Aktes der Felonie. Allem Anschein nach wurde das Land Ravenstein, das die von Güntersberg innehatten, von 1295 oder 1296 bis 1299 von Herzog Bogislaw IV. an die Askanier verpfändet, so dass die von Güntersberg zumindest vorübergehend ganz ohne Verrat unter brandenburgische Lehnsoberhoheit gerieten. ${ }^{128}$ Zudem waren in der pommersch-neumärkischen Ritterschaft des 13. und 14. Jahrhunderts Vasallitätswechsel und vor allem Doppelvasallitäten weit verbreitet und wurden als rechtsgemäß und üblich betrachtet. ${ }^{129}$ Die Adligen konnten ihre Gefolgschaft auf friedlichem Wege und im gegenseitigen Einvernehmen aufkündigen. Nur wenn sie „zur Unzeit, etwa während eines Kampfes“, ihrem Lehnsherrn die Treue aufsagten, diesen rechtswidrig angriffen oder einen nahen Verwandten ihres Herrn töteten, begingen sie Felonie, woraufhin ihnen der Lehnsherr die Treue aufkündigen und ihre Lehen einziehen konnte. ${ }^{130}$ Dafür, dass es im Verhältnis der von Güntersberg zu den Herzögen Pommerns zur Felonie kam, gibt es in den Quellen keinen Hinweis. Die Familie besaß Ravenstein bis um 1330/35 durchgehend als herzogliches Lehen; dass Bogislaw IV. oder Otto I. die Burg zwischenzeitlich an andere verliehen, ist urkundlich nicht überliefert.

126 Vgl. Urkunde von 1325 Oktober 14, PUB 6, S. 297, Nr. 3882. - Zur Lage von Treben vgl. Gahlbeck: Zisterzienser (wie Anm. 3), S. 578 f.

127 Zum Volksstamm der Kaschuben und seiner Geschichte vgl.: Max Broesike: Deutsche, Polen, Masuren und Kaschuben in der Provinz Westpreußen. Berlin 1910; Friedrich Lorentz: Geschichte der Kaschuben. Berlin 1926; Aleksander Majkowski: Historia Kaszubów. Gdynia 1938 (ND: Gdańsk 1991), auch in dt. Übers. der Publikationsstelle des Geheimen Staatsarchivs in Berlin: Geschichte der Kaschuben. Berlin ca 1940 (masch.); Alfred Cammann: Die Kaschuben. Aus ihrer Welt, von ihrem Schicksal in Geschichte und Geschichten. Münster 2007 (= Quellen und Darstellungen zur Geschichte Westpreußens, 31).

128 In einer Urkunde vom 6. Januar 1299 erhielt Herzog Bogislaw IV. von der Stadt Treptow/Rega 1500 Mark slawischer Denare und 200 Silbermark, mit denen er seine Schulden begleichen und das (hierfür verpfändete) Land Ravenstein auslösen wollte. Vgl. PUB 3, S. 338 f., Nr. 1877. Dazu vgl. Rymar: Próba identyfikacji (wie Anm. 112), S. 211; ders.: Güntersbergowie (wie Anm. 107), S. $106 \mathrm{f}$.

129 Im märkisch-pommerschen Friedensvertrag vom 14. August 1338 wurde u. a. vereinbart: Swelhie belehent mann gemeinlichen von uns und den herzogen belehent sind, di sullen uns beiden dienen und gehorsam sin, als si von so̊lichen lehen ze recht und von gewonheit ti̊n süllen. Ausfertigung: GStA PK Berlin, VII. HA (Urkunden), Abt. k (Weltliche Reichsstände in Beziehung zur Mark), Pommern Nr. 12; Druck: PUB 10, S. 302-305, Nr. 5656 (Hervorhebung von CG). Vgl. auch die Gegenurkunde, PUB 10, S. 296-301, Nr. 5655.

130 Gerhard Theuerkauf: [Artikel] Felonie, in: Handwörterbuch zur deutschen Rechtsgeschichte, hg. von Adalbert Erler/Ekkehard Kaufmann, Bd. 1. Berlin 1971, Sp. 1098-1099. 
Bei seinem Versuch, den Mörder Przemysławs II. zu bestimmen, nimmt E. Rymar über die vermutete Identität des Jakob von Güntersberg mit Jacob Kassube hinaus an, dass der ehemalige Stettiner Ratsherr und spätere Knappe im Dienste Bogislaws IV. auch mit dem Ritter Jakob von Wolgast identisch gewesen sei, der 1297 in einer Urkunde für das Kloster Marienwalde als Zeuge überliefert ist ${ }^{131}$, der sich nach dem gleichnamigen Dorf Wolgast (Wołogoszcz) bei Woldenberg (Dobiegniew) genannt haben soll. Jakob von Wolgast sei zwischen 1280 und 1310 der einzige bekannte märkische Adlige östlich der Oder gewesen, der Jacob hieß, und müsse daher der Königsmörder gewesen sein. Das Geschlecht von Wolgast sei in der Neumark sonst unbekannt, und es habe damals die Praxis geherrscht, dass sich die Ritter vielfach, wenn sie sich an einem neuen Ort niederließen, nach diesem benannt hätten. ${ }^{132} \mathrm{Im}$ konkreten Fall wird es sich aber wohl eher umgekehrt verhalten haben: dass der Ort Wolgast seinen Namen durch Übertragung des Ortsnamens der pommerschen Stadt Wolgast erhalten hat, den ein Adliger aus dem Geschlecht der von Wolgast mitbrachte, als er sich in dem Dorf bei Woldenberg niederließ. ${ }^{133}$ Dieses Geschlecht ist im übrigen nicht völlig unbekannt. 1341 belehnte Markgraf Ludwig der Ältere den strennus vir Heyne Wolgast mit 10 Hufen in Klemzow, die durch den Tod des Nicolaus von Brederlow heimgefallen waren. ${ }^{134}$ Ein Besitz von Gütern in Wolgast durch die von Güntersberg ist nicht nachweisbar, nach dem Kataster von 1337 war dort mit den von dem Borne eine andere bedeutende neumärkische Adelsfamilie begütert. ${ }^{135}$ Daher ist eine Identität Jakobs von Güntersberg mit Jakob von Wolgast ziemlich unwahrscheinlich.

Offenbar starb Jakob von Güntersberg nicht erst zwischen 1297 und 1299, wie Rymar annimmt ${ }^{136}$, sondern bereits ca. zehn Jahre früher. Dies würde u.a. sein Verschwinden aus den Quellen um diese Zeit erklären. Die für 1299 bezeugten Günter und Johann (Janeke) von Ravenstein waren vermutlich seine Söhne und hatten mehrere Geschwister. Zumindest einer von Jakobs Nachkommen dürfte die Burg und das Dorf im pommerschen Ravenstein sowie Güntersberg von ihm geerbt haben. Günter und Johann von Ravenstein traten, nachdem sie volljährig geworden waren, in den Dienst der Markgrafen, Günter in den der ottonischen, Johann in den der johanneischen Linie. Günter wurde von den Askaniern nach ihrer Einnahme der terra Welschenburg und Gründung der Stadt Dramburg (im Jahr 1297) mit dem nach ihm benannten Dorf Güntershagen (Lubieszewo) am Nord-

131 Vgl. Urkunde von 1297 Dezember 12, SBB PK Berlin, Wippelsche Sammlung, A 7; CDB I 19, S. 446, Nr. 4.

132 Vgl. Rymar: Güntersbergowie (wie Anm. 107), S. 105-108.

133 Möglich ist allerdings auch eine autochthone Entstehung des Ortsnamens, der als primärer slawischer Siedlungsname von einem alten slawischen Personennamen (Volegošč oder Volgost) abgeleitet ist. Vgl. Trautmann: Die elb- und ostseeslavischen Ortsnamen (wie Anm. 22), Bd. 1, S. 46; Gerhard Schlimpert: Slawische Personennamen in mittelalterlichen Quellen zur deutschen Geschichte. Berlin 1978, S. 159 (= Deutsch-slawische Forschungen zur Namenkunde und Siedlungsgeschichte, 32).

134 Vgl. Urkunde von 1341 September 9, R 1333-1348, fol. 22, Nr. 87; CDB I 24, S. 31, Nr. 57. Ferner ist der Familienname auch für ein Bürgergeschlecht in Greifenhagen (Gryfino) überliefert. Vgl. Urkunde von 1348 Juni 22, CDB I 19, S. 211 f., Nr. 67.

135 Vgl. K 1337 B, fol. 115v; LB/Gollmert, S. 23.

136 Vgl. Rymar: Güntersbergowie (wie Anm. 107), S. 108. 
ufer des Großen Lübbesees östlich von Dramburg sowie den Nachbardörfern Schweinshausen (Świniary) und Stöwen (Stawno) belehnt. ${ }^{137}$ In Güntershagen, wo es bereits einen mittel- und spätslawischen Burgwall gegeben hatte, erbaute Günter von Güntersberg eine Burg, die zum zweiten Familiensitz der von Güntersberg in diesem Raum wurde. ${ }^{138}$ Über die Erwerbungen Johanns bzw. Janekes von Güntersberg ist aus den Quellen nichts Konkretes zu erfahren. Anscheinend jedoch knüpfte dieser Adlige Kontakte nach Polen, möglicherweise durch Heirat mit einer Tochter des polnischen Adligen Ianussius Kenstel. Dieser diente um 1290 dem großpolnischen Herzog (und späteren König) Przemysław II. und war von diesem mit einem Amt im Raum zwischen Drage und Küddow betraut worden, in dessen Ausübung er für den Templerorden ein Areal wüsten Landes (desertum) an der Drage und am Dratzigsee absteckte, in dem die Ordensritter bald darauf die Stadt Tempelburg (Czaplinek) gründeten. ${ }^{139}$ Die von Güntersberg und Kenstel wuchsen im Laufe des 14. Jahrhunderts zu einer Familie zusammen. ${ }^{140}$ Um 1303 hatte dieser Prozess schon eingesetzt, aber noch traten beide Zweige nebeneinander auf, wobei die Kenstel offenbar für bedeutender als Janeke von Güntersberg gehalten wurden, der in der Zeugenliste der Gründungsurkunde von Dt. Krone an letzter Stelle erwähnt wurde. ${ }^{141} \mathrm{Zu}$ diesem

137 Eine Belehnungsurkunde über Güntershagen hat sich nicht erhalten. Die von Güntersberg hatten die dortige Burg jedoch nachweislich 1375 unter Kaiser Karl IV. inne. Vgl. LB 1375, S. 5. Darüber hinaus setzt die Belehnung mit Schweinshausen und Stöwen die mit Güntershagen als Hauptbesitz voraus. - Schweinshausen, dessen Name auch auf die von Güntersberg zurückgehen dürfte, die in ihrem Wappen einen Eberkopf führten, fiel in der Zeit des märkischen Interregnums wüst und wurde 1340 der Stadt Dramburg überlassen. Vgl. die Urkunde von 1340 Dezember 30, R 1333-1348, fol. 18, Nr. 73; CDB I 18, S. 222, Nr. 15. Aus dieser Urkunde geht hervor, dass Günter von Güntersberg und seine Brüder das wüst gefallene Dorf als Lehen von den Askaniern (a predecessoribus nostris Brandenburgensibus marchionibus bone recordacionis) erhalten hatten. Vgl. Rymar: Güntersbergowie (wie Anm. 107), S. 109. - Das Dorf Stöwen verkauften die von Güntersberg 1355 an die von Anklam, die Markgraf Ludwig der Römer daraufhin mit diesem Dorf belehnte. Vgl. Urkunde von 1355 Oktober 6, R 1352-1356 A, fol. 120 f., Nr. 165, ungedruckt. Auch diesen Ort dürften die von Güntersberg von den Askaniern erhalten haben, vermutlich gemeinsam mit Güntershagen und Schweinshausen.

138 Zum Burgwall in Güntershagen vgl. Jerzy Olczak/Kazimierz Siuchniński: Żródła archeologiczne do studiów nad wczesnośredniowiecznym osadnictwem grodowym na terenie województwa koszalińskiego (Archäologische Quellen für Studien zur frühmittelalterlichen Burgsiedlung auf dem Gebiet der Wojewodschaft Köslin), 4 Bde. Poznań 1966-71, hier: Bd. 1, S. 37-44 (= UAM w Poznaniu. Prace wydziału filozoficzno-historycznego. Seria Archeologia, 1-4). - Zu Wappen und Siegel der von Güntersberg vgl. die Zeichnung des Siegels von Matzke von Güntersberg auf Ravenstein von Friedrich Dreger unter seiner 1746 gefertigten Abschrift der Urkunde dieses Ritters für das Kloster Reetz von 1426 November 11, AP Szczecin, Zb. Loeper Nr. 156 (XII-2-215), S. 66 ff., Nr. 39.

139 Vgl. Urkunde von 1286 November 19, Winfried Irgang (Hg.): Urkunden und Regesten zur Geschichte des Templerordens im Bereich des Bistums Cammin und der Kirchenprovinz Gnesen. Nach Vorlage von Helmut Lüpke neu bearb. Köln 1987, S. 60 f., Nr. 64 (= Veröffentlichungen der Historischen Kommission für Pommern: Reihe 4, Quellen zur pommerschen Geschichte, 10). Irgang zufolge ist die Urkunde, wofern nicht gefälscht, offenbar rückdatiert worden und kann nur 1290-91 ausgestellt worden sein. Vgl. auch Rymar: Güntersbergowie (wie Anm. 107), S. 108.

$140 \mathrm{Zu}$ diesem Prozess vgl. Rymar: Güntersbergowie (wie Anm. 107), S. 108 f.

141 Vgl. Urkunde von 1303 April 23 (wie Anm. 121). 
Zeitpunkt waren auch die Kenstel zu Vasallen der Askanier geworden. 1313 übereignete Markgraf Woldemar der Stadt Kallies eine Mühle, die einem Kenstel gehört hatte. ${ }^{142}$ Gegen Ende des Jahres 1316 nahmen die von Güntersberg (oder Kenstel) an einem brandenburgischen Kriegszug über die Drage hinaus teil, der gegen Wronke (Wronki) geführt wurde. Seit dieser Zeit besaßen sie das Schloss in der Netzestadt Usch (Ujście) sowie weitere Güter an der Netze und östlich der Küddow. ${ }^{143}$

Vermutlich auf eine Belehnung von seiten der Askanier geht auch der Güntersberger Hufenbesitz in Groß Sabin (Żabin) zurück. Nach dem Kataster von 1337 besaß Günter von Güntersberg dort sieben dienstpflichtige Hufen. ${ }^{144}$ Auch das im Kataster unmittelbar hinter Gr. Sabin erwähnte wüste Gun[t]ershagen, das mit dem gleichnamigen Ort am Großen Lübbesee nicht identisch ist ${ }^{145}$, sondern ein Nachbarort von Gr. Sabin war, an dessen Stelle die von Güntersberg am Ende des 15. Jahrhunderts oder im 16. Jahrhundert den Hof Neuhof (Będlino) errichteten, war wahrscheinlich ein von den Askaniern verliehenes Lehen dieser Familie. Offenbar lebten die von Güntersberg damals in relativ enger Gemeinschaft mit Hermann und Henning von Pressel, die in Gr. Sabin 10 bzw. 6 dienstpflichtige Hufen besaßen. ${ }^{146}$ Beide Familien hatten in der Marienkirche in Stettin (Szczecin) einen Heiligkreuz- und St.-Stephanus-Altar gestiftet, dessen Altaristenstelle 1327 der Dekan des Soldiner Domkapitels und Hofkaplan Herzog Ottos I. Dietrich Pressel innehatte, der zur besseren Ausstattung dieser Stelle fünf Hufen in Sabow (Żabów) ankaufte. Als der Herzog dem Altar diese Hufen übereignete, traten Janekin und Walter von Güntersberg ihr Patronats- und Präsentationsrecht einmalig für die erste Stellenbesetzung nach dem Tod Dietrich Pressels an Otto I. ab. ${ }^{147}$

In Pommern gelang den von Güntersberg zwischen ca. 1315 und 1335 ein rascher Aufstieg zu den führenden Adelsgeschlechtern des Landes. Diese Entwicklung verdank-

142 Vgl. Urkunde von 1313 September 29, CDB I 18, S. 102, Nr. 4.

143 Vgl. Rymar: Güntersbergowie (wie Anm. 107), S. 108-112. Rymar verweist in diesem Zusammenhang auf das Ausgabenverzeichnis Markgraf Woldemars von 1316/17, in dem zum 1. November 1316 die Übergabe eines Pferdes im Wert von 5 Talenten durch den markgräflichen Vogt an die von Güntersberg und der Kriegszug selbst als Ziel einer Truppe aus 26 Bewaffneten erwähnt wird, die am 19. November 1316 in Königsberg eintrafen. Vgl. Hans Spangenberg: Hof- und Zentralverwaltung der Mark Brandenburg im Mittelalter. Leipzig 1908, S. 522 (= Veröffentlichungen des Vereins für Geschichte der Mark Brandenburg).

144 Magna Gabin [!]: LXXVIII [mansos], [...] dictus Dünther [!] pro servicio VII [mansos]. K 1337 B, fol. 118v; LB/Gollmert, S. 29, Die offensichtlichen orthographischen Fehler im Ortsnamen von Gr. Sabin und im Personennamen Günter wurden durch Flüchtigkeit des mittelalterlichen Schreibers des Katasters verursacht. - In späterer Zeit bauten die von Güntersberg diesen Ort zu einem dritten Familiensitz im Oder-Drage-Raum aus.

145 Im Kataster von 1337, K 1337 B, fol. 118v; LB/Gollmert, S. 29, werden unter den bona illorum de Gruthow zwei Orte namens Güntershagen genannt, einmal unmittelbar hinter Gr. Sabin und einmal zwischen dem wüsten Spring (vgl. die Springmühle in der Feldmark von Güntershagen am Gr. Lübbesee) und Woltersdorf (Linowo), Kr. Dramburg. Der Name des letzteren Ortes ist durch ein Versehen (Ausrutschen der Feder?) des mittelalterlichen Kopisten zu Gunfershagen (mit einem nKürzel über dem $u$ ) entstellt worden.

146 Vgl. K 1337 B, fol. 118v; LB/Gollmert, S. 29. Ein viertes servicium in Gr. Sabin leistete damals ein Johannes Beke, der hierfür mit sechs Hufen belehnt worden war.

147 Vgl. Urkunde von 1327 Februar 9, PUB 7, S. 98 ff., Nr. 4272. 
ten sie vor allem zwei Söhnen Jakobs (I.). Janekin von Güntersberg, der in den Jahren 1319-1321 in pommerschen Quellen mehrfach genannt wird, war den Greifenherzögen damals offenbar sowohl als Angehöriger der pommerschen als auch der neumärkischen Ritterschaft verpflichtet, die Wartislaw IV. und Otto I. als kommissarische Herrscher bis zur Ernennung eines neuen Markgrafen von Brandenburg anerkannt hatte. Er bezeugte in dieser Zeit sowohl pommersche als auch neumärkische Angelegenheiten. ${ }^{148}$ An dem von Wedego von Wedel geleiteten Kriegszug in die Mark von 1321 nahm er teil, wobei er anscheinend weder größeren Schaden erlitt noch sich am Freikauf der in Gefangenschaft geratenen pommerschen und neumärkischen Vasallen beteiligte. ${ }^{149}$ Vermutlich hatte er damals ein Vogteiamt im Herzogtum inne. Hierfür spricht der Umstand, dass er 1325 über die Bede des Kolbatzer Klosterdorfs Treben verfügte. ${ }^{150}$ Da der Besitz der Bede eigentlich den Herzögen zustand, müssen diese sie an Janeke von Güntersberg entweder als Erblehen verliehen oder verpfändet haben. Derartige Belehnungen oder Verpfändungen erfolgten damals aber in aller Regel aufgrund von Schulden der Landesherrn gegenüber ihren Ministerialen, die sich durch Ausgaben und Aufwendungen dieser Amtsträger in Ausübung ihres Amtes im landesherrlichen Dienst angehäuft hatten. Unter den landesherrlichen Ämtern bildeten die Vogteien gewissermaßen die unterste Ebene, während die eigentlichen Hofämter (Küchenmeister, Truchsess, Mundschenk, Hofrichter, Kämmerer und Hofmeister) höheren Stufen auf der Karriereleiter entsprachen. Wenn Janeke von Güntersberg damals also die Bede eines ganzen Dorfes innehatte, spricht vieles dafür, dass er um 1325 als Vogt im Dienst der pommerschen Herzöge stand. Auch sein Bruder Walter übte Ämter an deren Hof aus. Seit 1327 war er Notar, seit 1334 Protonotar Herzog Barnims III. ${ }^{151}$ Walter von Güntersberg hatte eine Laufbahn als Geistlicher eingeschlagen, deren erste Station die städtische Pfarrei in Dramburg war, die er durch einen Vikar verwalten ließ. 1326 verlieh ihm Papst Johannes XXII. ein Kanonikat im Bistum Schwerin, 1329 in Kammin (Kamień Pom.). Von 1331 bis zu seinem Tod im Jahr 1339 hatte er als Kamminer Domherr das Archidiakonat (bzw. die Propstei) in Demmin inne. ${ }^{152}$ In die höchsten Hofämter gelangte schließlich Jakob (II.), ein Knappe aus der Enkelgeneration Jakobs I. von Güntersberg. Seit 1325 in den Quellen nachweisbar, bekleidete er seit 1327 das Amt des Küchenmeisters und stieg um 1334 zum herzoglichen Kammermeister auf. ${ }^{153}$ Damit gelang der Familie von Güntersberg der Aufstieg von ihrer Nobili-

148 Vgl. für erstere die Urkunden von 1320 August 23, PUB 5, S. 534 f., Nr. 3398, von 1321 Januar 25, PUB 6, S. 4 f., Nr. 3451, von 1321 März 24, PUB 6, S. 19, Nr. 3479, 1321 April 24, PUB 6, S. 24 f., Nr. 3486, und von 1321 Dezember 13, PUB 6, S. 76 f., Nr. 3552, für letztere die Urkunden von 1319 September 29, CDB I 20, S. 132 ff., Nr. 11, von 1319 Oktober 4, CDB II 1, S. 447 f., Nr. 537 und von 1320 Februar 3, CDB I 18, S. 219 f., Nr. 10; PUB 5, S. 485, Nr. 3332. - Vgl. Rymar: Güntersbergowie (wie Anm. 107), S. $112 \mathrm{f}$.

149 Vgl. Rymar: Güntersbergowie (wie Anm. 107), S. 112. - In den Verzeichnissen über die Kosten dieses Kriegszugs von 1321, PUB 6, S. 81-85, Nr. 3560, wird kein von Güntersberg erwähnt.

150 Vgl. Urkunde von 1325 Oktober 14, PUB 6, S. 297, Nr. 3882.

151 Vgl. Rymar: Güntersbergowie (wie Anm. 107), S. 114.

152 Zur Karriere des Walter von Güntersberg vgl. Rymar: Güntersbergowie (wie Anm. 107), S. 114 f.

153 Vgl. Urkunden von 1325 September 25, PUB 6, S. 293 ff., Nr. 3878, als Küchenmeister: Urkunden von 1327 Mai 12, PUB 7, S. 135 f., Nr. 4313; von 1327 Juni 1, PUB 7, S. 138, Nr. 4317; von 1337 
tierung über die niederen und mittleren Verwaltungsämter bis hin zu Hofämtern binnen dreier Generationen.

Aufgrund dieser Familienkarriere war es selbstverständlich, dass die von Güntersberg in den märkisch-pommerschen Auseinandersetzungen zwischen 1324 und 1334 auf der pommerschen Seite standen, obwohl sie als Lehnsbesitzer beiden Seiten verpflichtet waren. Wir wissen zwar nicht, ob sie damals aktiv in die Kriegshandlungen eingriffen - es ist durchaus denkbar, dass ihr Lehnsvertrag ihre Doppelvasallität berücksichtigte und sie daher zum Kampf gegen Brandenburg nicht (oder nur bei einer Verteidigung Pommerns) verpflichtet waren - , wegen ihrer Position am pommerschen Hof war es aber wohl unvermeidlich, dass ihre Burg in Ravenstein von brandenburgischen Truppen zerstört wurde. ${ }^{154}$ Da ihr märkisch-polnischer Zweig aufgrund polnischer Eroberungen etwa gleichzeitig auch Ujście und die östlich der Küddow gelegenen Güter verloren hatte ${ }^{155}$, verfügten sie 1336 offenbar nur noch über ihre Burgen in den beiden Güntershagen. Markgraf Ludwig dem Älteren gegenüber waren sie, wie aus der Urkunde vom 24. Juli 1336 hervorgeht, lediglich zu drei Manndiensten verpflichtet. ${ }^{156}$ Diese servicia lasteten nachweislich auf Groß Sabin sowie wahrscheinlich auf den beiden Güntershagen. ${ }^{157}$

November 8, PUB 7, S. 115 f., Nr. 4347; von 1328 Januar 30, PUB 7, S. 178 f., Nr. 4363; von 1328 April 11, PUB 7, S. 191 f., Nr. 4382; von 1328 Dezember 3, PUB 7, S. 234f, Nr. 4422; von 1329 Januar 21, PUB 7, S. 243, Nr. 4440; von 1329 April 15, PUB 7, S. 270 f., Nr. 4471; als Kammermeister: Urkunden von 1334 Mai 1, PUB 8, S. 313 f., Nr. 5159; von 1334 Dezember 22, PUB 8, S. 378 f., Nr. 5219, und von 1335 Januar 14, PUB 8, S. 394 f., Nr. 5240. Vgl. Rymar: Güntersbergowie (wie Anm. 107), S. $113 \mathrm{f}$.

154 Vgl. Urkunde von 1338 Oktober 12, R 1333-1348, fol. 13v, Nr. 53; PUB 10, S. 320, Nr. 5676. Dort bezeichnet Markgraf Ludwig der ältere Ravenstein als castrum Rabensteyn quondam per nos desolatum et destructum. - Rymar: Güntersbergowie (wie Anm. 107), S. 117 f., hält es für möglich, dass Ravenstein erst infolge des Lippehner Waffenstillstands vom 28. Juni 1333 (GStA PK. Berlin, I. HA, Rep. 78a Nr. 1, T. 1, fol. 25vff., lit. r'; CDB II 1, S. 74 f., Nr. 684) zerstört wurde, da der Vertrag den Abbruch sämtlicher seit dem Tod Markgraf Woldemars auf beiden Seiten erbauter Burgen sowie weiterer Burgen vorsah, deren Besitzer gegen den dreijährigen Waffenstillstand verstießen. Die Burg in Ravenstein dürfte jedoch bereits vor dem Übergang der Burg an die von Güntersberg im 13. Jahrhundert errichtet worden und damit von der Abbruchsklausel nicht betroffen gewesen sein. Ravenstein war schon seit dem 9.-11. Jahrhundert ein bewehrter Ort. Zunächst entstand im Ravensteiner See in Insellage ein Burgwall etwa $1 \mathrm{~km}$ südlich des Burgbergs, der dann zugunsten eines vom 11.-13. Jahrhundert bewohnten Burgwalls auf dem Burgberg abgelöst wurde, auf dem dann Raven von Brüsewitz, der dem Ort seinen Namen gab, schließlich die mittelalterliche Burg errichtete. Vgl. Kazimierz Siuchniński: Wapnica. Odkrycia. Powiat Stargard [Ravenstein. Funde, Kreis Stargard], in: Materiały Zachodniopomorskie 6 (1960), S. 709-710, pass.; Władysław Filipowiak: Stargard we wczesnym średniowieczu [Stargard im frühen Mittelalter], in: Bogdan Dopierała: Z dziejów ziemi stargardzkiej. Poznań 1969, S. 71-98, hier: S. 72, Kte. 27, Nr. 60 (= Instytut Zachodniopomorskie w Szczecinie. Monografie regionalne, 4); W. Łosiński: Osadnictwo plemienne Pomorza (VI-X wiek) [Die Siedlung der Stämme Pommerns (6.-10. Jh.)]. WrocławWarszawa-Kraków-Łódź-Gdańsk 1982, S. 229, Nr. S 750.

155 Vgl. Czacharowski: Społeczne i gospodarcze siły (wie Anm. 24), S. 120 f.; Rymar: Przynależność (wie Anm. 111), S. 59, 66; ders.: Güntersbergowie (wie Anm. 107), S. 118.

156 Vgl. Urkunde von 1336 Juli 24, R 1333-1348, fol. 4 f., Nr. 16; CDB I 18, S. 107, Nr. 14.

157 Vgl. K 1337 B, fol. 118v; LB/Gollmert, S. 29. 
Als nun Herzogin Elisabeth von Pommern, die Witwe Wartislaws IV., 1336 unter Bruch des mit Markgraf Ludwig am 8. Dezember 1334 geschlossenen Bündnisvertrags in die Uckermark einfiel ${ }^{158}$, scheinen die von Güntersberg ihr entsagt und sich dem Markgrafen angeschlossen zu haben, offenbar gemeinsam mit den Brüdern von Stegelitz auf Saatzig und dem Ritter Henning von Pansin auf Barskewitz (Barzkowice). Zur Familie zählten damals die Ritter Walter und Günter, der junge (luttike) Günter, Jonas [!], Hartwich, Matheus, Henning und Jakob (Koppekin), Söhne des Volzekin, sowie Henning Kenstel und sein Sohn Koppekin. Nicht dabei waren Jakob II. von Güntersberg und sein Sohn Martin, die zum Gefolge Herzog Ottos I. gehörten. Markgraf Ludwig belehnte die von Güntersberg am 24. Juli 1336 mit dem unmittelbar an der pommerschen Grenze gelegenen Dorf Butow und gestattete ihnen, dort als Ersatz für das verlorengegangene Ravenstein eine neue Burg zu bauen. Hierfür sollten sie ihm nunmehr mit fünf statt bisher drei Mannen dienen. ${ }^{159}$ Ihr Versuch, den Markgrafen dazu zu bewegen, die von ihnen angestrebte Wiedererlangung von Ujście zu unterstützen, hatte nur insofern Erfolg, als Ludwig versprach, sich auf dem Verhandlungsweg (mit degdingen) dafür einzusetzen. ${ }^{160}$ Die Baugenehmigung für die Burg in Butow richtete sich unmittelbar gegen Pommern, zumindest als Mittel der Abschreckung vor pommerschen Einfällen in die Neumark. Es war sicher kein Zufall, dass der Markgraf diese Erlaubnis keine vier Wochen nach Ablauf des dreijährigen Lippehner Waffenstillstands erteilte. Auch das markgräfliche Versprechen, die von Güntersberg gegen jedermann zu verteidigen, der ihnen widerrechtlich nach Leib und Gut trachtete ${ }^{161}$, war wohl hauptsächlich an Herzogin Elisabeth adressiert, die ihnen nach ihrem Seitenwechsel Ravenstein als Lehen entzogen hatte. In der Folgezeit beruhigte sich die Situation jedoch wieder, und die von Güntersberg konnten, nachdem die Herzogin ihnen signalisiert hatte, sie wieder mit Ravenstein zu belehnen, an den Ort ihrer alten Stammburg zurückkehren. Mit dieser Wiedereinsetzung, die am 30. November 1336 erfolgte, wurde der status quo ante an der neumärkisch-pommerschen Grenze schon damals wiederhergestellt. Dies spiegelt sich bereits im Kataster von 1337 wider,

158 Vgl. Urkunde von 1334 Dezember 3, CDB II 2, S. 94 f., Nr. 708; Rymar: Güntersbergowie (wie Anm. 107), S. $117 \mathrm{f}$.

159 [...] dat si und ere erfnamen uns [...] dienen scullen mit twiiger manne dinst boven drier manne dinst, der si uns von recht sculdich sint. Urkunde von 1336 Juli 24, R 1333-1348, fol. 4 f., Nr. 16; CDB I 18, S. 107, Nr. 14.

160 Eine gewaltsame Eroberung war ausgeschlossen, da die Wittelsbacher damals Verhandlungen mit König Kasimir von Polen führten, um eine Ehe zwischen Ludwigs Halbbruder, dem späteren Markgraf Ludwig dem Römer, und einer Tochter des Königs anzubahnen. Vgl. Rymar: Güntersbergowie (wie Anm. 107), S. 121. - Nach Abschluss des märkisch-pommerschen Friedensvertrags von 1338 wurde das markgräfliche Versprechen in der Urkunde vom 12. Oktober 1338 erneuert. Wie sehr Ludwig damals an friedlichen Verhältnissen mit Polen gelegen war, zeigt sich an einem Passus in dieser Urkunde, in dem er den von Güntersberg verbot, eigenmächtig in Polen einzufallen, um ihren Besitz von Ujście und der anderen Güter zurückzuerlangen: Non debebunt eciam ipsi Polonos quovismodo invadere, nisi de nostro consensus fuerit et beneplacito voluntatis. Urkunde von 1338 Oktober 12, R 1333-1348, fol. 13v, Nr. 53; PUB 10, S. 320, Nr. 5676.

161 [...] und scollen si ok vordedingen ers rechten wider aller malken, di si $i^{e}$ vor unrechten an wollen an live oder an gude. Urkunde von 1336 Juli 24, R 1333-1348, fol. 4 f., Nr. 16; CDB I 18, S. 107, Nr. 14. 
dem zufolge Butow, das (ohne die 4 Pfarrhufen) 60 Hufen umfasste, zu einem Drittel dem pommerschen Herzog gehörte und in dem die von Güntersberg und ihre beiden dort angesiedelten servicia nicht erwähnt sind. ${ }^{162}$ Offiziell besiegelt wurden die Verhältnisse zum einen durch den von Kaiser Ludwig vermittelten Friedensvertrag zwischen Markgraf Ludwig und den Herzögen Otto I. und Barnim III. von Pommern vom 14. August $1338^{163}$ und zum anderen durch die Urkunde Markgraf Ludwigs vom 12. Oktober 1338, mit der die persönlichen Folgen des Friedensvertrags für die von Güntersberg geregelt wurden: Hierzu gehörte, dass sie die neue Burg in Butow wieder abbrechen mussten, aber auch, dass ihre Rückkehr nach Ravenstein und der Wiederaufbau der dortigen Burganlage vom Markgrafen gebilligt wurde. Da ihr brandenburgisches Lehnsverhältnis fortbestand, ist anzunehmen, dass die zwei mit Butow verbundenen servicia damals auf Ravenstein übertragen wurden. ${ }^{164}$

Aus den geschilderten Verhältnissen geht eindeutig hervor, dass die von Güntersberg in der Zeit um 1336/38, als sie Butow innehatten, nicht die Herren von Gruthow gewesen sein können. Insbesondere steht die Zahl von lediglich fünf Manndiensten - und damit weniger, als die von Brederlow damals innehatten - , in krassem Widerspruch zu dem behaupteten Besitz eines großen Besitzkomplexes. Ich habe bereits an anderer Stelle den Nachweis geführt, dass nicht sie, sondern die Herren von Wedel auf Kürtow (Korytowo) und Neuwedell mit jenen Herren von Gruthow von 1337 identisch waren, wie nicht zuletzt aus dem Posener Zehntregister von 1349 hervorgeht, in dem alle Dörfer jenes Gebiets als von Wedelscher Besitz genannt werden. ${ }^{165}$ Der Name de Gruthow dürfte denn

162 Vgl. K 1337 B, fol. 116v; LB/Gollmert, S. 24.

163 Vgl. GStA PK Berlin, VII. HA (Urkunden), Abt. k (Weltliche Reichsstände in Beziehung zur Mark), Pommern Nr. 12; Druck: PUB 10, S. 302-305, Nr. 5656.

164 Vgl. Urkunde von 1338 Oktober 12, R 1333-1348, fol. 13v, Nr. 53; PUB 10, S. 320, Nr. 5676. Podehl: Burg und Herrschaft (wie Anm. 26), S. 688 f.; Rymar: Próba identyfikacji (wie Anm. 112), S. 212 f.; ders., Güntersbergowie (wie Anm. 107), S. 122; Brzustowicz: Rycerstwo ziemi choszczeńskiej (wie Anm. 8), S. 286, schließen aus dieser Urkunde, dass Markgraf Ludwig damals die Neumark über die Ihna hinaus bis nach Ravenstein ausgedehnt und dieses Dorf zu seinem Machtbereich gehört habe. Dies trifft m.E. nicht zu. Ravenstein wird an keiner Stelle der Urkunde als markgräflicher Besitz (z.B. durch ein nostrum) gekennzeichnet. Das Lehnsverhältnis bezog sich nur persönlich auf die von Güntersberg, nicht auf den Ort. Dies zeigt auch die Bestimmung, dass die von Güntersberg den Wittelsbachern mit allen gegenwärtigen und künftigen Schlössern dienen sollten, ob sie nun an der Netze oder woanders lagen. Markgraf Ludwig stellte es den von Güntersberg sogar frei, Ravenstein wieder aufzubauen oder nicht (dum voluerint). Auch unterlagen sie keinerlei Baubeschränkungen seitens des Markgrafen. Dieser erkannte, indem er die Söhne Herzog Wartislaws IV. von Pommern als Gegner, gegen die von Güntersberg mit ihm in den Krieg zu ziehen verpflichtet waren, ausnahm, an, dass die von Güntersberg damals in einem Doppelvasallitätsverhältnis standen.

165 Vgl. Gahlbeck: Das sogenannte Neumärkische Landbuch (wie Anm. 1), S. 32-38. Dazu vgl. jetzt auch: Brzustowicz: Rycerstwo ziemi choszczeńskiej (wie Anm. 8), S. 285 f.- Das Zehntregister des Posener Archiakons für das Drage-Netze-Gebiet in dessen Brief an seinen Bischof von 1349 Mai 30 ist gedruckt in: Kodeks Diplomatyczny Wielkopolski, obejmujący dokumenta tak już drukowane, jak dotąd nie ogłoszone, sięgający do roku 1400. Codex Diplomaticus Majoris Poloniae. Documenta, et jam typis descripta et adhuc inedita completens, annum 1400 attingentia [künftig zit.: 
auch wahrscheinlich eine verderbte Form des Ortsnamens Kürtow sein. ${ }^{166}$ Der Besitz, über den die von Güntersberg um 1337 tatsächlich in der Neumark verfügten, dürfte mit Güntershagen, Schweinshausen, Stöwen, Gr. Sabin und Güntershagen II (Neuhof) sowie (von 1336-38) Butow ungefähr umrissen sein; dies entsprach auch dem Umfang ihrer Manndienste.

An diesem Besitzstand änderte sich bis zur Jahrhundertmitte offenbar nicht viel. Erst um 1350, wohl nicht zufällig in der Folgezeit der Auseinandersetzungen mit dem Falschen Woldemar, traten die von Güntersberg als Angehörige des märkischen Adels deutlicher in Erscheinung. Ihre erste neue Erwerbung in dieser Zeit bestand aus einem Viertel der Güter, die der erbenlos verstorbene Ritter Otto von Liebenow in den Dörfern Liebenow (Lubieniów), Kratznick (Kraśnik) und Kölpin (Kiełpino; Kochin) in der terra Arnswalde sowie in einer Heide bei Königsberg besessen hatte. ${ }^{167}$ Dieser folgten nur zehn Tage später zehn frusta aus der Pfennigbede von Alt Klücken (Stary Klukom) bei Arnswalde und im Folgejahr als Pfandbesitz die Bedeeinkünfte aus Liebenow, Kratznick und

KDW]. Bd. 1-5. Poznań 1877-1908, Bd. 6-10 Warszawa-Poznań 1982 ff., hier: KDW 2, S. 615 f., Nr. 1284.

166 Vgl. Gahlbeck: Das sogenannte Neumärkische Landbuch (wie Anm. 1), S. 37. - In Gahlbeck: Zisterzienser (wie Anm. 3), S. 623 ff., bin ich zunächst, geprägt von der traditionellen Identifizierung mit Bruthow/Butow und, getragen von dem Gedanken, dass Neuwedell in Analogie zu Woldenberg, das in der Askanierzeit noch Dubegnewe hieß, vor seiner Gründung als Rechtsstadt durch die von Wedel einen slawischen Namen gehabt haben muss, davon ausgegangen, dass Gruthow dieser slawische Name für Neuwedell gewesen sei. Aus diesem Grund habe ich die eigentlich augenfällige Ähnlichkeit zwischen Gruthow und Kürtow (Cvritov, Urkunde von 1305 Juli 6, SBB PK Berlin, Wippelsche Sammlung, A 13; CDB I 19, S. 446 f., Nr. 5) nicht wahrgenommen. Inzwischen bin ich von der Identität von Gruthow und Kürtow überzeugt.

167 Vgl. Urkunde von 1350 September 23, R 1348-1351 A, fol. 54v, Nr. 117. Dieser Registereintrag, der selbst eine sorgfältige Schrift aufweist, ist offenbar nach einer sehr flüchtig geschriebenen und viele Flüchtigkeitsfehler enthaltenden Vorlage gefertigt worden, so dass z.B. aus dem vermutlich ursprünglich Kolpin genannten Ort ein entstelltes Kochin wurde. Bereits der Anfang weist eine grobe Entstellung auf, außerdem ist offenbar eine ganze Zeile der Vorlage nicht abgeschrieben worden: Noverint etc., quod nos Lud[ewicus] etc. strennuis viris Günthero de Wachorden [sic!] de Güntersberch ipsorumque veris et legitimis heredibus in refusionem fidelium serviciorum suorum nobis hactenus exhibitorum et in perpetuum fidelius exhibendum et ad usum seu utilitatem ipsorum [hier die Auslassung] strennuis viris Günthero militi, Henningo et Jacobo de Güntersberch contulimus [...]. Dabei steht das unverständliche de Wachorden offensichtlich für ursprünglich et Walthero, den Bruder Günters von Güntersberg. Der Ausstellungsort ist nur abgekürzt als Ber. angegeben. In R 1348-1351 B, fol. 105, Nr. 117, von dem auf dem Umweg über eine Abschrift des Freiherrn von Hackwitz die Druckfassung in CDB I 18, S. 123, Nr. 44, angefertigt wurde, wurde der Text weiter entstellt. So wurde aus Wachorden nunmehr Wachardo, und der Passus veris et legitimis heredibus wurde durch etc. ersetzt. Ein Lesefehler führte auch zur Änderung des Ausstellungsdatums von $f e$ ria quinta in feria quarta ante Michaelis. Offenbar durch Hackwitz sind dann weitere Fehler in den Text gekommen. Durch falsche Auflösung von Abkürzungen wurde z.B. aus principalem und principales (in R 1348-1351 A eindeutig lesbar) puerilem und pueriles, und durch Interpretation entstand aus der mehrdeutigen Abkürzung Ber. der Ausstellungsort (Noua) Berlin. Ich nehme an, dass hier nicht der Anteil Ottos an den Familiengütern der von Liebenow in vier Teile aufgeteilt wurde, sondern dass er ein Viertel des Familienbesitzes innehatte, das komplett an die von Güntersberg überging. Vgl. hierzu weiter unten. 
Kölpin. ${ }^{168}$ Markgraf Ludwig der Römer erneuerte 1352 die Verpfändung der Beden, erweiterte sie um die Bede von Kremlin (Krzemlin) bei Lippehne ${ }^{169}$ und überließ Günter und Walter von Güntersberg (unter Hintanstellung der Ansprüche der von Brederlow) 100 Mark [!] Finkenaugen aus der Bede von Sammenthin zum Erwerb eines Pferdes (ad comparandum unum caballum ad servicium nostrum) ${ }^{170} 1354$ fügte der Markgraf zu den verpfändeten Beden auch noch den Wagendienst in den genannten Dörfern hinzu, den er sich bis dahin vorbehalten hatte ${ }^{171}$. Im selben Jahr gestattete er ihnen, in Kratznick eine neue Burg zu errichten. ${ }^{172}$ Den von Güntersberg gelang es nunmehr auch in der Neumark, Hofämter zu bekleiden. Als erster Inhaber eines Amtes ist Günter von Güntersberg 1355 und 1362 als pincerna trans Oderam urkundlich bezeugt. ${ }^{173}$ Ihre bedeutendste Zeit im Lande über der Oder begann aber erst 1364, als sie anfingen, die Politik Kaiser Karls IV. zu unterstützen. Unter den Luxemburgern und dem Deutschen Orden stiegen sie schließlich, vor allem aufgrund ihrer hoch geschätzten diplomatischen Fähigkeiten, endgültig zu den führenden Geschlechtern im neumärkischen Adel auf.

Eine der Familien, die möglicherweise über den Barnim in die Neumark gekommen ist, war das Geschlecht der von Liebenthal. ${ }^{174}$ Im bis 1345 reichenden Pommerschen Urkundenbuch sind Angehörige dieser Familie nicht überliefert, und die erste Erwähnung des Dietrich von Liebenthal unter den Zeugen der Gründungsurkunde der Stadt Berlinchen von $1278^{175}$ könnte die These unterstützen, dass die von Liebenthal ein rein märkisches Adelsgeschlecht gewesen seien. Der Familienname weist auf das Dorf Liebenthal in der Schorfheide nordöstlich von Liebenwalde. ${ }^{176}$ Paul van Niessen jedoch, der an-

168 Vgl. Urkunden von 1350 Oktober 3, R 1348-1351 A, fol. 55v, Nr. 121; Regest: UB Osten, Bd. 1, S. 184, Nr. 607, und von 1351 September 30, R 1348-1351 A, fol. 65, Nr. 154.

169 Vgl. Urkunde von 1352 März 2, R 1352-1356 A, fol. 73, Nr. 3; CDB I 18, S. 128, Nr. 52.

170 Urkunde von 1352 Juli 15, R 1352-1356 A, fol. 77vf., Nr. 23; Regest: Kletke: Regesta (wie Anm. 8), Bd. 1, S. 239.

171 Vgl. Urkunde von 1354 Januar 7, R 1352-1356 A, fol. 96 f., Nr. 85; CDB I 18, S. 132, Nr. 58.

172 Vgl. Urkunde von 1354 März 31, R 1352-1356 A, fol. 104v, Nr. 117; CDB I 18, S. 132 f., Nr. 59.

173 Vgl. Urkunden von 1355 Oktober 16, R 1352-1356 A, fol. 122 f., Nr. 173/174, und von 1362 Februar 14, R 1360-1364, fol. 160 f., Nr. 37; CDB I 18, S. 28 f., Nr. 43.

$174 \mathrm{Zu}$ den von Liebenthal vgl. Czacharowski: Społeczne i gospodarcze siły (wie Anm. 24), S. 64-66; ders., Adelsherrschaft (wie Anm. 24), Kap. II 3, S. 1-3.

175 Vgl. Urkunde von 1278 Januar 25, Ausfertigung: DOZA Wien, Abt. Urkunden, 1278, 125; Foto: BLHA Potsdam, Rep. 8, Stadt Berlinchen, (U 1); Druck: CDB I 18, S. 63, Nr. 4; Regesten: KW, S. 289, Nr. 1137; UDOZA, Bd. 1, S. 261, Nr. 821.

$176 \mathrm{Zu}$ Liebenthal, Kr. Niederbarnim, das 1459 erstmals erwähnt wurde und damals eine wüste Feldmark war, vgl. Lieselott Enders (Bearb.) u.M.v. Margot Beck: Historisches Ortslexikon für Brandenburg, Bd. 6: Barnim [künftig zit.: HOL 6]. Weimar 1980, S. 327-329 (= Veröffentlichungen des Staatsarchivs Potsdam, 16); Gerhard Schlimpert: Brandenburgisches Namenbuch, Bd. 5: Die Ortsnamen des Barnim [künftig zit.: BNB 5]. Weimar 1984, S. 182, Nr. 201 (= Berliner Beiträge zur Namensforschung, 6). - Der Name des Ortes Liebenthal westlich von Wittstock/Dosse in der Prignitz ist dagegen eine Neubildung für eine auf zwei ehemaligen wüsten Feldmarken gegründete Kolonie des 18. Jahrhunderts. Vgl. Sophie Wauer: Brandenburgisches Namenbuch, Bd. 6: Die Ortsnamen der Prignitz. Weimar 1989, S. 160, Nr. 256 (= Berliner Beiträge zur Namensforschung, 7); Lieselott Enders (Bearb.): Historisches Ortslexikon für Brandenburg, Bd. 1: Prignitz, Weimar 1997², S. 512 f.; dies.: Die Prignitz. Geschichte einer kurmärkischen Landschaft vom 12. 
nimmt, dass die Familie ebenso wie die von Schöning offenbar aus dem Braunschweigischen stammte, vermutet, dass auch sie über Pommern in die Neumark eingewandert sei, nicht zuletzt wegen der Verwandtschaftsbeziehungen zwischen Herzog Barnim I. und dem braunschweigischen Herrscherhaus und der Herkunft des seit 1251 amtierenden Kamminer Bischofs Hermann von Gleichen aus demselben Gebiet. ${ }^{177}$ Im Jahr 1524 waren die von Liebenthal zusammen mit den von Elsholt im pommerschen Petershagen, $\mathrm{Kr}$. Randow, südöstlich von Penkun, begütert. ${ }^{178}$ Es ist m.E. nicht auszuschließen, dass dieser Besitz bereits erheblich früher dieser Familie gehört hat, allerdings liegt dieser zeitliche Beleg sehr spät, so dass die Möglichkeit, dass die Familie vielleicht über Petershagen in die Neumark gekommen sein könnte, sehr vage ist.

Dietrich und Rudolf von Liebenthal gehörten am Ende des 13. Jahrhunderts zur Gefolgschaft Markgraf Ottos V. (des „Langen“) bzw. Markgraf Albrechts III. von Brandenburg, in deren Urkunden sie bis 1298 mehrfach als Zeugen auftraten. ${ }^{179}$ Bereits um 1280 hatte Dietrich unter den Adligen der ottonischen Markgrafen eine prominente Stellung inne, da er zusammen mit Friedrich von Brunkow, Heinrich von Sydow und den Brüdern Otto und Konrad von Winningen als Vertreter der Ritterschaft der zum ottonischen Zweig der Askanier gehörenden Landesteile der Neumark 1280 an den Verhandlungen mit den Markgrafen über die Umwandlung der Beden in eine feste Steuer teilnahm. ${ }^{180}$ Rudolf von Liebenthal folgte den Askaniern 1296/97 bei ihren Eroberungszügen gegen Polen und wurde 1297 zusammen mit Johann von Lossow zum capitane[us] in Meseritz ex parte inclitorum principum domini Ottonis [V.] et domini Alberti [III.] bestellt. ${ }^{181}$ Im Jahr 1303 beteiligte er sich an der Gründung der terra und Stadt Arnscrone (später: Dt. Krone, heute: Wałcz), wofür er von den Askaniern 16 abgaben- und dienstfreie Jahre für sich und seine Untertanen im Dorf Groß Ehrenberg (Przekolno; ursprünglich: Herenberch) im Land Bernstein gewährt bekam. ${ }^{182}$ Dort hatte die Familie ihren ersten Stammsitz in der Neumark. ${ }^{183}$ Am 26. Dezember 1317 bezeugte Rudolf von Liebenthal als Vogt

bis zum 18. Jahrhundert. Potsdam 2000, S. 970 (Veröffentlichungen des Brandenburgischen Landeshauptarchivs, 38).

177 Vgl. van Niessen: Geschichte der Neumark (wie Anm. 14), S. 207 f. - Zu dem in einer Urkunde des schlesischen Klarissenklosters Strehlen (Strzelno) von 1302 erwähnten Puzch von Liebenthal (vgl. KW, S. 497 f., Nr. 1849) ist aus den Quellen keine verwandtschaftliche Beziehung feststellbar.

178 Vgl. Urkunde von 1524 August 24, CDB I 13, S. 506 f., Nr. 32.

179 Vgl. außer den im folgenden genannten die Urkunden von 1281 Juni 8, CDB I 18, S. 440 f., Nr. 7; von 1289 August 5, AP Szczecin, Zb. Loeper, Nr. 156 (XII-2-215), fol. 11vf., Nr. 18; CDB I 18, S. 64, Nr. 5; von 1293 Juni 27, AP Szczecin, Zb. Loeper, Nr. 156 (XII-2-215), fol. 52 f., Nr. 29, CDB I 18, S. 69, Nr. 12; und von 1298 Mai 15, 2 Ausfertigungen, BLHA Potsdam, Rep. 9B (Johanniterorden), U 39, U 40; CDB II 1, S. 217 ff., Nr. 283. Aus den Urkunden geht hervor, dass die von Liebenthal bereits damals in der Neumark ansässig waren.

180 Vgl. Urkunde von 1280 August 18, Ausf. BLHA Potsdam, Rep. 23 A (Kurmärkische Stände), U I/3; CDB III 1, S. 9 f., Nr. 8; KW, S. 312 f., Nr. 1223.

181 Urkunde von 1297 Mai 20, KDW 2, S. 134, Nr.764; KW, S. 446, Nr. 1672.

182 Vgl. Urkunde von 1303 April 23 (wie Anm. 121).

183 Da das Dorf in der terra Bernstein lag, die 1315 von Markgraf Woldemar an Herzog Otto I. von Pommern verkauft wurde, gehörte es in der Folgezeit überwiegend nicht zur Neumark, sondern zu Pommern und wurde vermutlich deshalb nicht im Kataster von 1337 aufgeführt. Zur wechselvollen 
Markgraf Woldemars dessen Urkunde für Soldin, in der der Markgraf den Städten Berlinchen, Landsberg, Küstrin (Kostrzyn), Zellin (Czelin), Bärwalde, Berneuchen und Neuenburg (Nowogródek Pomorski) gebot, die Rechtsbelehrung in allen strittigen Gerichtsfällen sich fortan von Soldin und nicht mehr von Strausberg zu holen. ${ }^{184}$ Bald darauf ist er offenbar gestorben: Er wird noch zweimal in Urkunden vom 22. und 25. Januar 1318 als Zeuge genannt und verschwindet dann aus den Quellen. ${ }^{185}$ Anscheinend hinterließ er vier Söhne, von denen zwei dem Kataster von 1337 zufolge im Land Lippehne und der dritte in der terra Bärwalde begütert waren: Arnold von Liebenthal verfügte in Alt Deetz (Stara Dziedzina) über 12 Hufen und 6 Hufen in Adamsdorf; er leistete von beiden Gütern insgesamt 1 1/2 Rossdienste. ${ }^{186}$ Außerdem war er bis Januar 1340 mit zwei Hufen in Neuenburg begütert. ${ }^{187}$ Hermann von Liebenthal hatte zusammen mit Peter Lettenin in Kraazen (Krasne) bei Lippehne 16 Hufen inne ${ }^{188}$, und Fritz von Liebenthal besaß gemeinsam mit Hermann von der Marwitz ein servicium und 15 Hufen in Bärfelde (Smolnica), Kr. Königsberg. ${ }^{189}$ Die Brüder Arnold und Heinrich wohnten 1346 einem vom neumärkischen Vogt Markgraf Ludwigs, Albert von Wolffstein, in Berlinchen geschlossenen Vergleich zwischen dem Kloster Kolbatz und den Brüdern Bernhard und Gerhard von Wulkow bei. ${ }^{190}$ Weiteres lässt sich über die zweite Generation der von Liebenthal aus den Quellen nicht erfahren.

Rudolf von Liebenthal, aufgrund des Diminutivs Ruleke (1352) vermutlich bereits ein Enkel des Vogtes von 1317, gehörte im Jahr 1348 zu den Anhängern des falschen Woldemar, kehrte aber wie die übrigen Neumärker schon nach relativ kurzer Zeit zu den Wittelsbachern zurück. ${ }^{191}$ Im Dezember 1352 übertrug ihm Markgraf Ludwig der Römer die voythie unsers landes und stete uff desseit der Odir, ane als vele die voythie, die unser lieber getruwer Betke von Ost von uns inne hat. Anscheinend sollte Ruleke diese Vogtei nicht allein, sondern mit Unterstützung mehrerer Helfer aus seinem Verwandtenkreis (den frunden) ausüben - genannt werden außer Rulo auch ein Betke von Liebenthal, Henning Wrechow sowie Klaus und Otto von Schöning - , denen der Markgraf, gewissermaßen zu gesamter Hand versprach, für die Kosten aufzukommen, die im Laufe ihrer Vogtei an-

Geschichte des Landes Bernstein im Mittelalter vgl. Gahlbeck: Zisterzienser (wie Anm. 3), S. 308318.

184 Vgl. Urkunde von 1317 Dezember 26, BLHA Potsdam, Rep. 8, Stadt Soldin, U 1; CDB I 18, S. 445, Nr. 6; KW, S. 757, Nr. 2617.

185 Vgl. Urkunden von 1318 Januar 22, CDB I 19, S. 70, Nr. 10 (zu 1317); KW, S. 759, Nr. 2619, und von 1318 Januar 25, SBB PK Berlin, Urkunden, Wippelsche Sammlung, A 17; CDB I 19, S. 456, Nr. 17; KW, S. 759, Nr. 2620.

186 Vgl. K 1337 B, fol. 112 f.; LB/Gollmert, S. 18.

187 Vgl. Urkunde von 1340 Januar 28, R 1333-1348, fol. 16v, Nr. 68; CDB I 18, S. 454, Nr. 18

188 Vgl. K 1337 B, fol. 113; LB/Gollmert, S. 18.

189 Vgl. K 1337 B, fol. 109v; LB/Gollmert, S. 12.

190 Vgl. Urkunde von 1346 Januar 12, CDB II 2, S. 177, Nr. 802. Für Heinrich von Liebenthal ist dies die einzige urkundliche Erwähnung, so dass nichts darüber ausgesagt werden kann, wo er begütert war.

191 Vgl. Urkunde von 1348 November 29, CDB I 19, S. 213, Nr. 69. 
fielen, und sie nicht abzusetzen, bis alle Schulden abgegolten waren. ${ }^{192}$ Konkret dürfte Rudolf von Liebenthal damals die Vogtei über die Länder Königsberg, Soldin, Bärwalde, Lippehne, Schönfließ (Trzcińsko-Zdrój) und Mohrin erhalten haben, während Betekin von der Osten damals die Vogtei Landsberg-Friedeberg und Hasso von Wedel-Uchtenhagen die Vogtei Arnswalde-Dramburg-Schivelbein innehatten. ${ }^{193}$ Mit dieser Stellenbesetzung setzte der seit Weihnachten 1351 regierende Markgraf erstmals eigene Akzente seiner Herrschaft. Er beabsichtigte offenbar, die große Macht der vier damals bedeutendsten Familien des Landes, der von Wedel, Uchtenhagen, Mörner und von der Osten, die als Gefolgsleute seines Halbbruders nach dem Krieg gegen den Falschen Woldemar die Verwaltung der Neumark praktisch unter sich aufgeteilt und die Herrschaft Ludwigs des Älteren unter die Aufsicht der neumärkischen Landstände gestellt hatten ${ }^{194}$, wieder zurückzuschneiden. Dass er sich dabei des noch jungen Ruleke von Liebenthal bediente, der zudem 1348 vorübergehend dem ehemaligen Kriegsgegner angehangen hatte, war ein deutlicher Affront gegen die seit 1348/49 mitregierende Seilschaft der genannten Familien, zu der die von Liebenthal nicht gehörten. Gegenüber den Ständen konnte Ludwig der Römer immerhin anführen, einen Angehörigen eines Geschlechts zum Vogt ernannt zu haben, dessen Großvater bereits unter Markgraf Woldemar dieses Amt besessen hatte und der - im Gegensatz zu dem am 7. April 1353 von ihm als Nachfolger Hassos von Wedel-Uchtenhagen und Betekins von der Osten zum Vogt ernannten Otto von Schlieben ${ }^{195}$ - immerhin ein Neumärker war. Hinzu kam, dass Rulo offenbar in der besonderen Gunst Ludwigs des Römers sowie seiner Gattin, der Markgräfin Kunigunde, einer Tochter König Kasimirs I. von Polen, stand. Am 5. März 1353 beauftragte ihn der Markgraf damit, für ihn und die Markgräfin Anschaffungen im Werte von 100 Pfund Brandenburgischer Pfennige zu tätigen, die Rulo durch Einbehalt der Einkünfte aus den Beden der ganzen Neumark gegenfinanzieren sollte. ${ }^{196}$ Zudem erhielt der Vogt am selben Tag die Zusicherung einer jährlichen Summe von 40 brandenburgischen Talenten, die er, solange er die

192 Dorczu gelobe wir dem vorgenanten Rulen und seynen rechten erben und czu erer hand den festen mannen Betken und Rulen von Lyuendal, Hennyng Wreich, Claws und Otten von Schynyngen, welchen reddelichen schaden sie nemen die czeit, als sie unsir voythie innehaben, is sey an gewynne, den sie uns thün, adir an andern sachen, den sie uns ouch reddelichen beweisen mögen, das wir sie von derselben unsir voythie nicht brengen noch entsetczen süllen, wir haben sie danne von allen schülden und schaden bracht. Urkunde von 1352 Dezember 2, R 1352-1356 A, fol. 84vf., Nr. 47. Aus dem Text ist nicht eindeutig zu erkennen, ob Rudolf (Rule) von Liebenthal hier zweimal genannt wird oder ob es damals zwei Personen dieses Namens gab.

193 Vgl. ebd. sowie Urkunde von 1353 April 7, R 1352-1356 A, fol. 82vf., Nr. 41; Czacharowski: Społeczne i gospodarcze siły (wie Anm. 24), S. 65; ders.: Adelsherrschaft (wie Anm. 24), Kap. II 3, S. 2.

194 Vgl. Gahlbeck: terra Transoderana (wie Anm. 10), S. 146-149.

195 Vgl. Urkunde von 1353 April 7, R 1352-1356 A, fol. 82vf., Nr. 41.

$196[$ [...] das her uffheben und innemen sal unser bete, die sey von pfennyngen, von korne adir von fleische, o̊bir al in unseme lande obir Oder, wo wir die haben, also lange, bis her do von uffgehebet und empfangen hat hundert pfundt Brandenburgesche pfennynge, die her uns und unsir lieben gemahelen, der marggrafynnen, an ko ste gewynnen sal. Urkunde von 1353 März 5, R 1352-1356 A, fol. 85 f., Nr. 48. Sofern die Auslagen die geplante Summe überstiegen, sicherte der Markgraf seinem Vogt zu, auch diesen Betrag auszugleichen und ihn so lange im Amt zu behalten. 
Vogtei innehatte, den markgräflichen Einkünften aus der Vogtei entnehmen durfte. Diese Summe war als Etat zur Bestreitung von Kosten für Dinge des täglichen Lebensbedarfs des Markgrafen gedacht und war offenbar großzügig kalkuliert, da vereinbart wurde, dass Ruleke im Falle, dass dieser Etat überschritten wurde, die Kosten nicht zusätzlich berechnen bzw. geltend machen durfte. ${ }^{197}$ Damit übte Rudolf von Liebenthal am Hof Ludwigs des Römers, sofern sich der Markgraf im Raum östlich der Oder aufhielt, faktisch ein Hofamt aus, das man wohl am ehesten als Kellermeisteramt bezeichnen kann, und verfügte über Kompetenzen, die über die eines neumärkischen Landvogts hinausreichten. Offensichtlich beabsichtigte Ludwig, den jungen Neumärker über eine längere Zeit im Amt zu belassen, musste sich aber schon nach kurzer Zeit dem Druck der vier genannten Magnatenfamilien beugen und seinen Vogt wieder absetzen. Am 13. Juni 1353 übernahm Rudolf von Liebenthal in seiner vorletzten Amtshandlung die Aufgabe, die Stadt Königsberg in den Besitz einer jährlichen Rente aus dem Hufenzins zu Schönfließ einzuweisen. ${ }^{198}$ Eine Woche später wurde er dann nach Ablegung seiner Halbjahresabrechnung als Vogt aus dem Amt entlassen und für die angefallenen Unkosten und Schulden in Höhe von 250 Mark leichter Pfennige mit dem Lehnsbesitz der Kleinen Heide bei Neuenburg abgefunden. ${ }^{199}$ Für die von ihm ausgelegten 187 Talente an leichten Pfennigen für die markgräfliche Haushaltung in der Neumark (nobis ac familie nostre in terris nostris trans Oderam) erhielt er als Pfandbesitz bis zur Tilgung der Schuldsumme die Beden des Dorfes Kl. Lindenbusch (Bylice) bei Lippehne. ${ }^{200}$

Daraufhin zog sich Rudolf von Liebenthal auf seine Familiengüter zurück und nahm nur noch vereinzelt Aufträge der Landesherrschaft an. Am Hofe weilte er anscheinend höchst selten, so dass aus der Zeit nach Juni 1353 kaum noch urkundliche Nachrichten über ihn zu finden sind. Etwa um 1360, in der zweiten Amtszeit des Johann von Wedel als Vogt in der Neumark, fungierte er als vom Markgrafen eingesetzter Richter in einem Streit zwischen der Dorfschaft und dem Schulzen des dem Zisterzienserkloster Marienwalde gehörenden Dorfes Klosterfelde (Klasztorne). ${ }^{201}$ Seine letzte Spur findet sich ca. 30 Jahre später in einer Urkunde des neumärkischen Landvogts Caspar von Donyn, als er in hohem Alter an der rechtlichen Beilegung eines Streites zwischen Friedrich und Claus Sack auf Steinwehr (Kamienny Jaz, in Pommern) und der Stadt Königsberg betei-

197 Noverint, quod nos Lud[ewicus] Romanus etc. dedimus, damus et presentibus deputamus strennuo viro Ruloni Lyuendal, advocato Transoderam, fideli nostro dilecto, XL talenta denariorum Brandenburgensium, que annis singulis, quamdiu nostram tenuerit advocaciam, pro satisfaccione nostrorum sumptuum et expensum tollere et pacifice debebit de omnibus proventibus advocacie nostre Transoderam prenotate, nichil nobis predictis suis expensis ultra summam predictam annuatim quolibet computando. Urkunde von 1353 März 5, R 1352-1356 A, fol. 88v, Nr. 61.

198 Vgl. Urkunde von 1353 Juni 13, R 1352-1356 A, fol. 91, Nr. 69; CDB I 19, S. 228 f., Nr. 92.

199 Vgl. Urkunde von 1353 Juni 20, R 1352-1356 A, fol. 98v, Nr. 95; CDB I 24, S. 59, Nr. 107. Den Honigzins dieser Heide behielt der Markgraf für den eigenen Bedarf zurück.

200 Vgl. Urkunde von 1353 Juni 26, R 1352-1356 A, fol. 93vf., Nr. 74; CDB I 24, S. 59, Nr. 108.

201 Vgl. undatierte Urkunde von [ca. 1360], SBB PK Berlin, Ms. Borussica $2^{\circ} 584$ (Sammlung des Küstriner Konsistorialrats Seyfert zur brandenburgischen bzw. neumärkischen Geschichte), S. 190. Zur ungefähren Datierung vgl. Gahlbeck: Zisterzienser (wie Anm. 3), S. 875, Anm. 48. 
ligt war. ${ }^{202}$ Auch der bereits 1353 bezeugte Verwandte Rudolfs, Betekin von Liebenthal, und dessen Brüder Arnd und Hermann traten während der Regierungszeit Ludwigs des Römers und Ottos VIII. nicht besonders hervor; 1362 belehnte sie Markgraf Ludwig mit sieben Hufen in Adamsdorf. ${ }^{203}$

Gemeinsam mit den von Liebenthal trat in der Neumark häufiger das Geschlecht der von Schöning ${ }^{204}$ auf, das aus der Umgebung der Stadt Schöningen südlich von Helmstedt im Braunschweigischen stammte und im ausgehenden 13. und beginnenden 14. Jahrhundert dort zu den Burgmannen der einige Kilometer östlich von Schöningen gelegenen Sommerschenburg zählten, die zum Herrschaftsgebiet der Erzbischöfe von Magdeburg gehörte. ${ }^{205}$ In Pommern ließen sich die von Schöning in verschiedenen Regionen nieder. Westlich der Oder gründeten sie im Kreis Randow das Dorf Schöning (Kamieniec) ${ }^{206}$ und besaßen Karow (Karwowo). ${ }^{207}$ Östlich der Oder siedelten sie sich, offenbar als Burgmannen von Pyritz, in Lübtow (Lubiatowo) an und verfügten über Besitz u. a. in Megow (Mechowo) und Brietzig (Brzesko) und über die Heiliggeistmühle in Pyritz. ${ }^{208}$ Die dritte Region, in der sie ansässig wurden, war das Land Lippehne, wohin sie offenbar ebenfalls als Burgmannen kamen. In dieser Funktion dürften sie wahrscheinlich schon damals ihre Gü-

202 Vgl. Urkunde von [ca. 1388-1396], CDB I 19, S. 274, Nr. 155. Diese Urkunde ist im CDB irrtümlich nach dem darin enthaltenen Insert, das als vorfolgende Urkunde ebd., S. 273, Nr. 154, nochmals separat abgedruckt ist, zu 1381 Februar 23 datiert worden. Markgraf Johann, Herzog von Görlitz, der Caspar von Donyn als seinen Vogt in der Neumark eingesetzt hatte, herrschte in der Neumark jedoch erst von 1388 bis zu seinem Tod im Jahr 1396. Daher kann diese Urkunde erst in dieser Zeit ausgestellt worden sein.

203 Vgl. Urkunde von 1362 Juni 14, R 1360-1364 B, fol. 162v, Nr. 50.

204 Zur Geschichte der von Schöning vgl. Hans von Schöning/Kurd von Schöning: Geschichtliche Nachrichten von dem Geschlechte von Schöning und dessen Gütern, 2 Bde. Berlin 1830, 1848; Heinrich Berghaus: Landbuch des Herzogthums Stettin, von Kamin und Hinterpommern; oder des Verwaltungs-Bezirks der Königl. Regierung zu Stettin, T. 3: Die Kreise Greifenhagen und Piritz. Anklam-Berlin 1868, S. 783-797.

205 Vgl. Berghaus: Landbuch Stettin, T. 3 (wie Anm. 204), S. 785. Daneben waren die von Schöning offenbar auch im Anhaltinischen begütert, worauf die Erwähnung von vier Familienmitgliedern unter den Zeugen einer Urkunde Markgraf Hermanns für das Servitenkloster bei Halle/Saale von 1304 hindeutet. Vgl. Urkunde von 1304 Januar 16, Regest KW, S. 511 f., Nr. 1896.

206 Das Dorf Schöningen wird erstmals in einer Urkunde für die Stadt Greifenhagen von 1330 April 14 erwähnt. Vgl. v. Schöning/v. Schöning: Geschichtliche Nachrichten (wie Anm. 204), Bd. 2, S. 22, Nr. 108; PUB 8, S. 344 f., Nr. 4563. Dazu vgl. Berghaus: Landbuch Stettin, T. 3 (wie Anm. 204), S. $788 \mathrm{f}$.

207 Vgl. Urkunden von 1320 November 11, PUB 5, S. 547 f., Nr. 3417, und von 1324, PUB 6, S. 245, Nr. 2807; v. Schöning/v. Schöning: Geschichtliche Nachrichten (wie Anm. 204), Bd. 1, S. 18, und Berghaus: Landbuch Stettin, T. 3 (wie Anm. 204), S. 787 - Unzutreffend ist die Behauptung von v. Schöning/v. Schöning: Geschichtliche Nachrichten, Bd. 2, S. 26, Nr. 141, und Berghaus: Landbuch Stettin, T. 3, S. 788, die von Schöning seien bis 1339 auch im Kamminer Stiftsgebiet in und um die Stadt Bublitz (Bobolice) ansässig gewesen. Diese Annahme ist die Folge eines Lese- oder Schreibfehlers bzw. einer Verwechslung, denn es waren nicht die von Schöning, sondern die von Spening, die dort mit den von Wedel gemeinsam wohnten. Vgl. PUB 10, S. 365 f., Nr. 5726.

208 Vgl. Berghaus: Landbuch Stettin, T. 3 (wie Anm. 204), S. 788; Urkunden von 1311 Mai 2, PUB 5, S. 7 f., Nr. 2658, von 1331 August 25, PUB 8, S. 56 f., Nr. 4901, und von 1341 November 19, PUB 11, S. 75, Nr. 5972. 
ter in Chursdorf (Mostkowo) erhalten haben; vielleicht war sogar der um 1250 erstmals bezeugte Konrad von Schöning der Gründer dieses Dorfes, das damals Conradestorp hieß. ${ }^{209}$ Schließlich lässt sich noch annehmen, dass auch ihr Besitz von sechs Hufen in Gralow (Gralewo), Kr. Landsberg/W., auf eine Ansiedlung in voraskanischer Zeit zurückgeht. Möglicherweise waren sie hier Burgmannen der von Herzog Barnim I. 1244 erbauten Burg Neu Zantoch, die von Gralow nur ca. 2 km entfernt lag. ${ }^{210}$

Etwa zwischen 1244 und 1250 dürften die von Schöning nach Pommern gekommen sein. Ihr erster namentlich bekannter Vertreter war Konrad von Schöning, der in zwei Urkunden Barnims I. als Zeuge genannt wird, in denen der Herzog der Stadt Stargard (Stargard Szczeciński) Magdeburger Recht verlieh ${ }^{211}$ bzw. mit der Überweisung der Stadtkirche zu Pyritz an das Kloster Wülfinghausen den ersten Schritt zur Gründung des Pyritzer Augustinerinnenklosters unternahm. ${ }^{212}$ Die in den Jahren 1277 bis 1311 erwähnten Heinrich, Hermann, Konrad, Bertram (Bertold) und Ulrich von Schöning waren vermutlich seine Söhne. Die Knappen Heinrich und Hermann bezeugten 1277 die Schenkung des Dorfes Pritzlow (Przecław) an das Zisterzienserinnenkloster Stettin. ${ }^{213}$ Beide wurden offenbar um 1285 zu Rittern geschlagen. Heinrich von Schöning schenkte 1286 seinen Anteil an der Kornpacht aus der Pyritzer Untermühle dem dortigen Frauenkloster, in dem damals eine Tochter von ihm Nonne war. ${ }^{214}$ In einer Urkunde von 1300 wird er dann mit mehreren anderen als officialis Herzog Ottos I. bezeichnet. ${ }^{215} 1302$ hielt er offenbar Abrechnung mit dem Herzog über seine Ausgaben in landesherrlichen Diensten. ${ }^{216}$ Heinrich pflegte noch Kontakte mit der Heimat seiner Vorfahren im Braunschweigischen, wo er mit seinem Bruder Konrad (II.) 1286 den Zehnten des Dorfes Werdesleben zugunsten des Zisterzienserklosters Marienthal bei Helmstedt aufließ. ${ }^{217}$ Hermann von Schöning, der sich auch nach seinem Wohnsitz Hermann von Karow nannte, bezeugte zwischen 1301 und 1306 Urkunden für die Städte Greifenhagen (Gryfino) und Pyritz und schenkte 1311 zusammen mit seinem Sohn Betekin dem Pyritzer Nonnenkloster die dortige Heiliggeist-

209 Chursdorf wird erstmals in der Gründungsurkunde des Klosters Reetz als Conradesdorff erwähnt. Vgl. Urkunde von 1296 Oktober 10, Abschrift einer dt. Übersetzung, BLHA Potsdam, Rep. 3B, Amt Reetz, Nr. 3751 (Kopie des Reetzer Erbregisters von 1590, Küstrin 1669/70), S. 135-138; CDB I 18, S. 6 f., in Nr. 6. Die Ausfertigung der Urkunde ist verloren und ihr lateinischer Text heute unbekannt.

210 Zum Besitz der von Schöning in Gralow vgl. K 1337 B, fol. 115; LB/Gollmert, S. 22, zu Neu Zantoch und zur Besiedlung des Raums um Landsberg/W. und Zantoch durch Adlige unter Herzog Barnim I. von Pommern vgl. Rocznik Wielkopolski (Rocznik kapituły Gneznieńskiej) 1192-1309, hg. v. A. Bielowski, in: Monumenta Poloniae Historica 3 (1878, ND: 1961), S. 4-42, hier: S. 11, 13; Gahlbeck: Oder-Drage-Raum (wie Anm. 43), S. 59 f., 69 f., 79 f.

211 Vgl. Urkunde von [1248-53], PUB 1², S. 684-687, Nr. 572. Zur Datierung dieser Urkunde vgl. die Ausführungen von K. Conrad ebd.

212 Vgl. Urkunde von 1250, PUB 12, S. 517, Nr. 519.

213 Vgl. Urkunde von 1277 April 4, PUB 2, S. 342, Nr. 1056.

214 Vgl. Urkunde von 1286 Mai 10, PUB 2, S. 592, Nr. 1376.

215 Vgl. Urkunde von 1300 November 29, PUB 3, S. 426, Nr. 1962.

216 Vgl. Regest zu 1302 September 17, PUB 3, S. 56, Nr. 2053.

217 Vgl. Urkunde von 1286 November 17, Regest KW, S. 374, Nr. 1413. Konrad II. von Schöning ist anscheinend nicht nach Pommern gezogen. 
mühle. ${ }^{218}$ Bertram von Schöning wählte eine Karriere als Geistlicher und gehörte mindestens von 1285 bis 1308 als Kanoniker dem Stettiner Marienstift an. ${ }^{219}$

Der fünfte Vertreter der zweiten Generation der von Schöning in diesem Raum war offenbar durch den Verkauf des Landes Lippehne durch den Bischof von Kammin an die Markgrafen von Brandenburg ${ }^{220}$ zum Neumärker geworden. Ulrich (I.) von Schöning blieb auch unter den Askaniern Burgmann in Lippehne und behielt sein Burggut in Chursdorf, das er noch 1303 innehatte, als er von den Markgrafen Otto IV. und Woldemar zusammen mit Rudolf von Liebenthal mit der Gründung der Stadt und terra Dt. Krone beauftragt wurde. Zur Erleichterung dieser Arbeit (ut fundatores minus terreat fundacionis labor) erhielt er ebenso wie sein Mitstreiter für dessen Besitz in Gr. Ehrenberg für seine Güter in Chursdorf eine Befreiung von allen seinen Diensten innerhalb der nächsten 16 Jahre, desgleichen die unter ihm ansässigen Bauern, denen auch die Bede für diese Zeit erlassen wurde. ${ }^{221}$ Ulrich sah sich jedoch schon vier Jahre später dazu gezwungen, das Unternehmen der Lokation von Stadt und Land Dt. Krone aufzugeben. Sich auf sein hohes Alter und seine Debilität berufend (jam senio confectus et debilitate pergamenti anutus), die ihn daran hinderte, den Landesausbau zu einem ordentlichen Abschluss zu bringen (eandem terram ad sui cultum commode nequeat edificare), verkaufte er seinen Anteil an Stadt und Land Arnscrone an Heinrich von Liebenow, der das Werk dann fortsetzte. ${ }^{222}$ Offenbar waren seine 1303 erwähnten Söhne 1307 entweder noch zu klein oder nicht mehr am Leben, so dass sie die Aufgabe nicht übernehmen konnten. Ulrich von Schöning scheint dann auch schon kurze Zeit später gestorben zu sein; in den Quellen wird er nicht mehr genannt. Seine Güter in Chursdorf gingen anscheinend an Hermann von Schöning bzw. dessen Sohn Betekin über, von dem sie wiederum nach seinem Tod um 1324 an seine Kinder vererbt wurden.

In der Generation der Enkel Konrads von Schöning tat sich besonders Heinrich II. hervor, der wohl ein Sohn Heinrichs I. von Schöning war. Er wurde spätestens 1319 zum Hofmarschall Herzog Ottos I. von Pommern und übte dieses Amt offenbar bis zu dessen Tod im Jahr 1344 aus. Er ist in zahlreichen Urkunden als Marschall bezeugt und stand offenbar ausschließlich im Dienst Ottos I. Seine Vettern Dietrich, Ulrich (II.), Ludolf und Henning, die Söhne Betekins von Schöning, waren dagegen Vasallen sowohl der Greifenherzöge als auch der Markgrafen von Brandenburg. Ulrich war in Pommern in Karow wie auch in Brietzig begütert. 1345 übte er unter Barnim III. das Amt eines Vogtes im östlich der Oder gelegenen Landesteil des Herzogtums Pommern-Stettin aus. ${ }^{223}$ In der Neumark

218 Vgl. Urkunde von 1311 Mai 2, PUB 5, S. 7 f., Nr. 2658.

219 Vgl. Urkunden von 1285 Februar 2, PUB 2, S. 545 f., Nr. 133, und von 1296 März 11, PUB 3, S. 282 f., Nr. 1775.

220 Vgl. Urkunden von 1276 August 18 und August 30, PUB 2, S. 331 f., Nr. 1042, 1043.

221 Urkunde von 1303 April 23 (wie Anm. 121). Über die in dieser Urkunde erwähnten, aber nicht namentlich genannten Söhne Ulrichs I. von Liebenthal lässt sich weder in der Urkunde von 1307 April 19 (s. folgende Anm.) noch in späteren Dokumenten irgendetwas erfahren.

222 Urkunde von 1307 April 19, GStA PK Berlin, XX. HA, OBA 115; Regest: KW, S. 347 f., Nr. 2013.

223 Vgl. Urkunden von 1320 November 11, PUB 5, S. 547 f., Nr. 3417, von 1324, PUB 6, S. 245, Nr. 2807, von 1341 November 19, PUB 11, S. 75, Nr. 5972, und von 1345 März 21, PUB 11, S. $452-456$, Nr. 6371. 
teilte er sich 1337 mit seinem Bruder Henning ein servicium in Chursdorf, für das die beiden dort 9 Hufen besaßen. Henning verfügte außerdem über ein halbes servicium und 6 Hufen in Deetz, Ludolf (Ludeke) über einen halben Manndienst und 5 Hufen in Adamsdorf, wo auch die von Liebenthal begütert waren. Schließlich hatten die von Schöning noch 2 Hufen in Herrendorf (Chłopowo) sowie 6 Hufen in Gralow bei Zantoch inne. ${ }^{224}$

Am 28. November 1350 wurde den Brüdern Nikolaus und Otto, den Söhnen Hennings von Schöning, für ihre Schäden, die sie in markgräflichen Diensten erlitten hatten, die Hochgerichtsbarkeit über Chursdorf übertragen. ${ }^{225}$ Drei Jahre später verpfändete Markgraf Ludwig der Römer ihnen und ihrem Vater bis zur Tilgung von 17 Silbermark die Beden von Chursdorf und Deetz, nachdem sie von Dezember 1352 bis Juni 1353 Ruleke von Liebenthal in seinem Vogteiamt in der Neumark unterstützt hatten. ${ }^{26}$ Unter Ludwig dem Römer und Otto VIII. unternahmen Nikolaus und Otto Anstrengungen, den Familienbesitz in und um Lippehne zu erweitern. 1360 erhielt Nikolaus zusammen mit Kune Blume das Angefälle eines Drittels des Schulzenamtes zu Lippehne. ${ }^{227}$ Drei Jahre später genehmigte ihm Markgraf Ludwig den Bau eines 36 Fuß hohen Bergfrieds in Adamsdorf. ${ }^{228}$ Im Jahr 1367 belehnte ihn Markgraf Otto mit einem Freihof in der Stadt Lippehne, der zuvor dem Markgrafen selbst gehört hatte. ${ }^{229}$ Den Besitz von fünf Hufen, den er zusammen mit seinem Bruder Otto in Naulin hatte, verkaufte Nikolaus von Schöning gleichzeitig an das Nonnenkloster in Pyritz. ${ }^{230} 1402$ huldigten insgesamt acht Mitglieder der Familie von Schöning dem Deutschen Orden, von denen zwei im Zehdenschen Winkel wohnten. ${ }^{231}$

$\mathrm{Zu}$ den bedeutenden Familien in der Neumark zählte ursprünglich auch das Geschlecht der von Liebenow. ${ }^{232} \mathrm{Ob}$ dieses Geschlecht, wie seit Leopold von Ledebur behauptet wird, aus Mitteldeutschland stammt und von Burgliebenau bei Merseburg aus in

224 Vgl. K 1337 B, fol. 111v, 112v, 115; LB/Gollmert, S. 16, 18, 22.

225 Vgl. Urkunde von 1350 November 28, R 1348-1351 A, fol. 54, Nr. 114; CDB I 18, S. 79 f., Nr. 29 (ohne Tagesdatum).

226 Vgl. Urkunde von [1353] Dezember 1, R 1352-1356 A, fol. 96v, Nr. 86; CDB I 18, S. 81, Nr. 32. Aufgrund des Überlieferungszusammenhangs in R 1352-1356 A ist davon auszugehen, dass das Dokument nicht erst 1354 ausgestellt wurde und bei der Jahreszahl ein Schreibfehler vorliegt. - Zur Vogtei Rulekes von Liebenthal und seiner Unterstützung durch Nikolaus und Otto von Schöning vgl. die Ausführungen weiter oben.

227 Vgl. Urkunde von 1360 Juli 23, R 1360-1364 B, fol. 155v, Nr. 2; CDB I 18, S. 85., Nr. 40 (ohne Datum).

228 [...] dat sy bynnen deme dorpe Adamstorp tho erer wonung buwen sullen unde mogen eyn berchfrede, sechs unde druttich vote houch, mit unser gunst unde willen. Urkunde von 1363 Juli 31, R 1360-1364 B, fol. 164, Nr. 58; CDB I 24, S. 68, Nr. 172.

229 Vgl. Urkunde von 1367 August 15, R 1360-1373 A, fol. 138vf., Nr. 51; CDB I 18, S. 86, Nr. 42.

230 Vgl. Urkunde von 1367 August 15, R 1360-1373 A, fol. 139 ff., Nr. 52.

231 Vgl. Urkunde von [1402 um und nach August 9], GStA PK Berlin, XX. HA, OBA 727.

232 Zur Familie von Liebenow vgl.: Leopold von Ledebur: Zur Adelsgeschichte des Landes Friedeberg. in: Archiv für deutsche Adelsgeschichte 1 (1863), S. 375-376; Georg Haag: Zur Geschichte der Stadt Pasewalk und der Klöster Grobe und Reetz, in: B. St. 33 (1883), S. 161-189, hier: S. 182 184; Paul van Niessen: Der Anteil der Familie v. Liebenow an der ältesten Geschichte der Neumark, in: SVGN 7 (1896), S. 192-201; Brzustowicz: Rycerstwo ziemi choszczeńskiej (wie Anm. 8), S. 208-300 u. S. 436, Stammtafel 18. 
die Neumark gekommen ist ${ }^{233}$ und ob sein Name deutscher oder, wie Paul van Niessen annimmt, slawischer Herkunft ist ${ }^{234}$, lässt sich nicht zweifelsfrei klären. Von den in brandenburgischen und pommerschen Quellen genannten Vertretern dieses Namens dürfte wohl nur der 1290/91 als Ritter im Dienst Herzog Ottos IV. von Brandenburg erwähnte Bartholomäus von Liebenow mit hoher Wahrscheinlichkeit mit der mitteldeutschen Familie unmittelbar verwandt gewesen sein. Aus dem Inhalt der beiden Urkunden, in denen er überliefert ist, ist anzunehmen, dass er auch in Mitteldeutschland wohnte; Beziehungen zu den in Pommern und der Neumark lebenden von Liebenow sind nicht bekannt. ${ }^{235}$ Bei der von ihm behaupteten slawischen Namensherkunft ist van Niessen von einer alten Namensform Lubno oder Lubanow ausgegangen, wobei er den Ort Liebenow (Lubno), Kr. Landsberg/W., mit dem 1241 in den Quellen erwähnten Templerdorf Lubno identifiziert und darüber hinaus annimmt, dass der in Pommern bezeugte Johann von Liebenow und der 1276 genannte polnische Kastellan von Bentschen (Zbążyń), Graf Albert von Liebenow (Albertus comes de Lubenow) ${ }^{236}$, Brüder gewesen seien. ${ }^{237}$ Nun trifft beides nicht zu. Auf die Nichtidentität von Lubno und Liebenow, Kr. Landsberg, habe ich bereits andernorts hingewiesen, ${ }^{238}$ und dass außer der Namensähnlichkeit bzw. -gleichheit allein der Umstand, dass Heinrich von Liebenow, der Sohn Johanns, bis 1296 auch von Herzog Przemysław II. von Großpolen Güter als Lehen innehatte, ein solches Verwandtschaftsverhältnis begründen soll ${ }^{239}$, ist als Erklärung äußerst dürftig. Jedoch haben unabhängig von van Niessen auch Trautmann, Lorentz und Schlimpert eine slawische Her-

233 Vgl. v. Ledebur: Adelsgeschichte Friedeberg (wie Anm. 232), S. 376. Ihm folgen: Haag: Pasewalk (wie Anm. 232), S. 183; Edward Rymar: Rycerstwo Nowej Marchii w czasach margrabiego Jana kostrzyńskiego [Die Ritterschaft der Neumark zu Zeiten Markgraf Johanns von Küstrin], in: Rocznik Lubuski 27 (2001), S. 13-55, hier: S. 34; Brzustowicz: Rycerstwo ziemi choszczeńskiej (wie Anm. 8), S. 298 f. Eine gewisse Wahrscheinlichkeit hierfür erkennt auch van Niessen: v. Liebenow (wie Anm. 232), S. 192, jedoch mit unverkennbarer Skepsis: „Der Beweis wird schwer werden.“

234 Vgl. van Niessen: v. Liebenow (wie Anm. 232), S. 193 f.

235 Vgl. Urkunden von 1290 Februar 11, KW, S. 394, Nr. 1475, und von 1291 November 14, KW, S. 407, Nr. 1526. In der ersten Urkunde lieh Otto IV. dem Pfalzgrafen Friedrich von Sachsen 1.400 Mark Freiberger Silbers bei gleichzeitiger Pfandnahme der Stadt Lockstede, in der zweiten verzichtete der Markgraf gemeinsam mit dem Landgrafen Albrecht von Thüringen zugunsten des Bischofs von Merseburg auf das Lehen der Stadt Leipzig. - Ebensowenig wie bei Bartholomäus lässt sich auch für den 1302 erwähnten Peter von Liebenow eine Verwandtschaft mit den von Liebenow in Pommern und der Neumark feststellen. Dieser Peter war offenbar in schlesischen Diensten. Markgraf Hermann von Brandenburg, der die Urkunde von 1302 Juli 9, in der er als Zeuge genannt ist, anfertigen ließ, handelte damals als tutor Silesie; die Urkunde wurde in Breslau ausgestellt.

236 Vgl. Urkunde von 1276 September 6, KDW 1, S. 404, Nr. 461. Es handelt sich um die Gründungsurkunde der Stadt Liebenau (Lubrza) im späteren Kreis Züllichau-Schwiebus.

237 Vgl. van Niessen: v. Liebenow (wie Anm. 232), S. $193 \mathrm{ff}$.

238 Vgl. Gahlbeck: Oder-Drage-Raum (wie Anm. 43), S. 48 f.

239 „Fragen wir, was unsern Heinrich v. L. nach Polen getrieben hat, so dürfen wir wohl annehmen, daß die Thatsache an sich für eine verwandtschaftliche Beziehung zu unserm oben erwähnten Grafen Albert und seinen polonisierten Verwandten spricht." van Niessen: v. Liebenow (wie Anm. 232), S. 195. - Obwohl in den Quellen eine Verwandtschaftsbeziehung zwischen Albert von Lubenow und Johann von Liebenow nicht nachgewiesen werden kann, hat auch Brzustowicz: Rycerstwo ziemi choszczeńskiej (wie Anm. 8), S. 436, die beiden in seiner Stammtafel als Brüder ausgewiesen. 
kunftserklärung für den Namen Liebenow gefunden. ${ }^{240}$ Wenn jedoch die Annahme einer Herkunft der Familie aus Burgliebenau bei Merseburg stimmt und die Ortsnamen Libnow bei Anklam und Liebenow (Lubanowo, Lubno, Lubieniów) in den Kreisen Greifenhagen, Landsberg/W. und Arnswalde alle übertragen sind, muss m. E. auch eine deutsche Herkunft des Namens parallel zu den in Brandenburg und Pommern verbreiteten Personen- und Ortsnamen Liebenthal, Liebenberg, Liebenwalde und Liebenfelde erwogen werden, zumal sich nicht ausschließen lässt, dass man die Herkunft der Familie weiter nach Westen, etwa nach Liebenau, Kr. Nienburg/Weser, oder Liebenau, Kr. Kassel-Land, verfolgen kann. ${ }^{241}$

In pommerschen Quellen sind die von Liebenow seit 1261 nachweisbar. Es ist jedoch anzunehmen, dass sie bereits etwa 30 Jahre früher nach Pommern kamen. Haag hat aufgezeigt, dass die Umbenennung des dem Prämonstratenserstift Grobe gehörenden Dorfes Ribeniz (1241 242 ) bei Anklam in Libnow (erster Beleg: Lubanowe, 1257243) wahrscheinlich auf die von Liebenow zurückgeht. ${ }^{244}$ Auch auf die drei in Pommern und der Neumark liegenden Dörfer Liebenow dürfte die Familie ihren Namen übertragen haben. Da Liebenow, Kr. Greifenhagen, im Land Bahn lag, das Herzog Barnim I. im Jahr 1234 den Templern überlie $\beta^{245}$, muss die Gründung dieses Ortes bereits zu Beginn der Regierungszeit Barnims I. 1233/34 erfolgt sein. Die von Liebenow gehörten damals einer Gruppe von Adligen an, die unter Federführung des Ritters Burkhard von Vehlefanz die Länder Fiddichow (Widuchowa) und Bahn in Pommern zu besiedeln begonnen hatten, dann wegen der Übergabe an die Templer ihre dortigen Güter aufgaben und mit dem Vorstoß Barnims auf Zantoch 1238 nach Süden zogen, wo sie sich im Raum Landsberg/W. niederließen. Die zahlreichen, gruppenartig in beiden Regionen auftretenden Ortsnamen zeigen an, dass hier damals dieselben Gründerfamilien tätig gewesen sein müssen. Zu ihnen zählten auch die von Liebenow. Bedingt durch das Vordringen der Askanier in den Landsberger Raum ab 1255, zogen sie sich in der Mitte des Jahrhunderts von dort zurück und wurden vom Herzog nunmehr, vermutlich zusammen mit den von Wedel, als Burgmannen in Reetz ansässig und erhielten als Burggut ein Nachbardorf dieser Stadt, das von ihnen den Namen Liebenow (Lubieniów) erhielt.

Der erste namentlich bekannte Vertreter der Familie war Johann von Liebenow. Er ist in zahlreichen Urkunden Herzog Barnims I. von Pommern von 1261 bis 1278 be-

240 Vgl. Trautmann: Die elb- und ostseeslavischen Ortsnamen (wie Anm. 22), Bd. 1, S. 25, 129; Lorentz: Slawische Namen Hinterpommerns (wie Anm. 65), S. 63; Schlimpert: Slawische Personennamen (wie Anm. 133), S. 78.

241 Eine derartige Untersuchung müsste allerdings noch geleistet werden.

242 Vgl. Urkunde von 1241 März 8, PUB 1², S. 463 f., Nr. 387.

243 Vgl. Urkunde von 1257 September 14, S. 46, Nr. 643.

244 Vgl. Haag: Pasewalk (wie Anm. 232), S. 182 f.

245 Vgl. Urkunde von 1234 Dezember 28, Irgang (Hg.): Urkunden und Regesten (wie Anm. 139), S. 17 f., Nr. 12. Liebenow ist für 1303 als Ordensdorf der Templer bezeugt. Vgl. Urkunde von 1303 April 21, ebd., S. 75 ff., Nr. 78. Zur Besiedlung der Länder Fiddichow, Bahn, Landsberg und Arnswalde vgl. Gahlbeck: Oder-Drage-Raum (wie Anm. 43), S.64-70, 89 f.; Gahlbeck, Das sogenannte Neumärkische Landbuch (wie Anm. 1), S. 14 f., 18 f., 24-26. 
zeugt ${ }^{246}$ und gehörte dem engsten Beraterkreis des Herzog an; van Niessen nennt ihn „Hauptberater“'. ${ }^{247}$ Welches Amt er jedoch am Herzogshof innehatte, ist nicht überliefert. Im Jahr 1269 wurde er gemeinsam mit Barnim I., dem Abt von Kolbatz und einer stattlichen Anzahl pommerscher Adliger, darunter Ludwig von Wedel, vom Dominikanermönch Albertus Magnus exkommuniziert und zwei Jahre später mit dem Interdikt belegt ${ }^{248}$, da der Herzog und die Adligen sich damals weigerten, die in einem Verfahren nach mittelalterlichem Pfandrecht von Albertus Magnus für den Johanniterorden bestimmten Pfandgüter diesem einzuräumen. Hauptsächlich bedroht war damals das Schloss Reetz, das als Pfandgut konkret genannt war. ${ }^{249}$ Anders als Ludwig von Wedel, der damals zu den Askaniern überwechselte, blieb Johann von Liebenow, wohl bedingt durch die enge Nähe zum Herzog, bei Barnim I.

Auch seine drei Söhne Johann (II.), Heinrich (II.) und Otto (I.) dienten vorerst in Pommern. ${ }^{250}$ Sie konnten jedoch keine ihrem Vater vergleichbare Stelle am Herzogshof erlangen. Bis 1296 wurden sie in Urkunden Herzog Bogislaws IV. nur höchstens einmal unter den Zeugen genannt. ${ }^{251}$ Heinrich lebte allerdings, wahrscheinlich nach 1278, in einem Doppelvasallitätsverhältnis, nachdem er sich von Herzog Przemysław II. von Großpolen mit Gütern hatte belehnen lassen, die entweder zwischen Drage und Döberitz oder noch weiter östlich lagen. Als Przemysław 1296 ermordet wurde, lief er zu den Askaniern über, die ihm 1297 dieselben Güter sowie 300 Hufen in der Heide Trepiz und 100 Hufen jenseits der Döberitz verliehen. ${ }^{252}$ Diese Belehnung fiel u.a. offenbar deshalb so großzügig aus, weil mit ihr die Aufgabe der Stellung als Burgmannen in Reetz für die von Liebenow verbunden war. Die Burg war spätestens bei den märkisch-pommerschen Auseinandersetzungen von 1295 zerstört worden und sollte nach den Plänen der Askanier nicht wieder aufgebaut werden. An ihrer Stelle, nämlich unmittelbar in den Ruinen der Burganlage, entstand damals das Zisterzienserinnenkloster Reetz. Heinrich von Liebenow war bei der offiziellen Ausstattung des bereits 1295 bestehenden Klosters im Oktober 1296 persön-

246 Erste Erwähnung: Urkunde von 1261 April 18, PUB 2, S. 78 f., Nr. 698, letzte Erwähnung unter Barnim I.: Urkunde von 1278 Februar 5, PUB 2, S. 363, Nr. 1084. Letztmalig testierte er unter Herzog Bogislaw in der Urkunde von 1278 Dezember 14, PUB 2, S. 391 f., Nr. 1118. Insgesamt finden sich in den Quellen des PUB 2 über 35 Belege.

247 van Niessen: v. Liebenow (wie Anm. 232), S. 193.

248 Vgl. Urkunden von 1269 August 12, BLHA Potsdam, Rep. 9 B: Johanniterorden, U 22; PUB 2, S. 218 f., Nr. 891, und von 1271 April 8, BLHA Potsdam, Rep. 9 B: Johanniterorden, U 27; PUB 2, S. 234, Nr. 914 (irrtümlich zu 1270 April 16). Mit Johann wurden auch seine Brüder Dietrich und Heinrich exkommuniziert, die allerdings nicht mehr 1271 mit dem Interdikt belegt wurden. Über beide Brüder wird in den Quellen sonst nichts berichtet.

249 Zum Hintergrund vgl. Hans Frederichs: Herzog Barnim I. im Streit mit dem Johanniterorden, in: B.St. NF 36 (1934), S. 256-267; Gahlbeck, Oder-Drage-Raum (wie Anm. 43), S. 1-9.

250 Sie werden erstmals 1271, als Söhne Johanns I. von Liebenow, erwähnt. Vgl. Urkunden von 1271 Juni 20, PUB 2, S. 252, Nr. 940, und von 1271, S. 256 f., Nr. 947.

251 Vgl. Urkunden von 1283 Mai 26, PUB 2, S. 493 f., Nr. 1261 (Johann II.), und von 1291 August 20, PUB 3, S. 120 f., Nr. 1567 (Heinrich II.). Ein urkundlicher Beleg für Otto von Liebenow fehlt in dieser Zeit.

252 Vgl. Urkunde von [1297] März 3, GStA PK Berlin, XX. HA, OBA 84; KW, S. 443, Nr. 1665, dort auch nähere Angaben zur Datierung. 
lich zugegen. ${ }^{253}$ Zur Ausstattung der Zisterze steuerten er und seine Familie aber anscheinend nichts bei. Auf die jährlichen Einkünfte in Höhe von 27 Scheffeln Roggen aus der Mühle an der Ihna am Weg von Reetz nach Altenwedel (Sicko) verzichteten die Brüder Heinrich und Otto von Liebenow 1303 nur widerwillig und nach einem Streit mit den Reetzer Nonnen. ${ }^{254} 1318$ musste Heinrich auf Befehl Markgraf Woldemars einige Güter, die er dem Kloster abgekauft hatte, diesem wieder zurückgeben. ${ }^{255}$ Insgesamt war Heinrich anscheinend ziemlich vermögend, denn er vermochte im Jahr 1307, als Ulrich von Schöning seine Beteiligung an der Gründung von Stadt und Land Dt. Krone aufgab, den Anteil dieses Ritters zu übernehmen. ${ }^{256}$ Im Juli 1313 wurde er als Besitzer dieses Landes und seiner übrigen Güter östlich von Drage und Döberitz von Graf Günter von Kevernberg angefordert, um ihm bei der Absteckung von 200 Hufen im Land Dt. Krone, die dem Bischof von Posen zugesprochen worden waren, zu helfen. ${ }^{257}$ Unklar ist, ob Heinrich mit jenem Heyno von Liebenow identisch war, der zwischen 1302 und 1304 in verschiedenen Urkunden Herzog Bogislaws IV. von Pommern als Zeuge auftrat, 1319 die Wahl der Pommernherzöge als Vormünder Markgraf Heinrichs bezeugte und im Jahr 1321 als Mitglied des herzoglichen Hofgerichts unter dem Vorsitz Herzog Ottos I. über einen Streit zwischen den von Witte und dem Kloster Bernstein entschied. ${ }^{258}$ Entweder wurde Heinrich über 65 Jahre alt, oder es handelte sich um einen Sohn Heinrichs, Johanns II. oder Ottos. Etwa das gleiche Alter erreichte auch Otto von Liebenow, der 1321 für seinen erlittenen Schaden und Aufwand beim Kriegszug in die Mark 31/2 Talente an Geld geltend machte. ${ }^{259}$

253 Vgl. Urkunde von 1296 Oktober 10 (wie Anm. 209). Zur Gründung des Klosters Reetz vgl. Gahlbeck: Zisterzienser (wie Anm. 3), S. 237-254; ders.: Die Gründung der Zisterzienserinnenklöster Zehden (Cedynia), Bernstein (Pełczyce) und Reetz (Recz) in der Neumark im Lichte brandenburgischer Klosterpolitik um 1300, in: Andrzej Marek Wyrwa/Antoni Kiełbasa/Jozef Swastek (Hgg.): Cysterki w dziejach i kulturze ziem polskich, dawnej Rzeczypospolitej i Europy Środkowej. Materiały z siódmej Międzynarodowej Konferenzji Cystersologów odbytej z okazji 800. rocznicy fundacji opactwa cysterek w Trzebnicy. Trzebnica 18-21 września 2002 r. [Zisterzienserinnen in der Geschichte und Kultur Polens, der früheren Republik und Mitteleuropas. Materialien zur 7. Konferenz der Zisterzienser-Wissenschaftler anlässlich des 800jährigen Jubiläums der Gründung der Zisterzienserinnen-Abtei in Trebnitz. Trebnitz, 18.-21. September 2002]. Poznań 2004, S. 773794, hier: S. 781-786.

254 [...] vigintiseptem modios siliginis singulis annis percipiendos, quos ipse domine percipient amplius annuatim, et hoc nullo impedimento inposterum a nobis et a nostris heredibus resistennte[!] Urkunde von 1303 Januar 6, SBB PK Berlin, Wippelsche Sammlung, A 10; Regest: van Niessen: Regesten zur Geschichte des Cistercienser-Nonnenklosters Reetz [künftig zit.: R Reetz], in: SVGN 11 (1901), S. 37-51, hier: S. 40, Nr. 11.

255 Vgl. R Reetz, S. 42, Nr. 19.

256 Vgl. Urkunde von 1307 April 19 (wie Anm. 222).

257 Vgl. Urkunden von 1311 Dezember 27 (nach Weihnachtsstil), KW, S. 694 f., Nr. 2281 (zu 1312 Dezember 27), und von 1313 Juli 27, KDW 2, S. 305, Nr. 960; PUB 5, S. 124, Nr. 2821.

258 Vgl. Urkunden von 1302 Mai 21, PUB 4, S. 44 f., Nr. 2027; von 1302 September 25, PUB 4, S. 56 f., Nr. 2044; von 1302 Dezember 12, PUB 4, S. 64 f., Nr. 2054; von 1304 Juli 15, PUB 4, S. 145 ff., Nr. 2170, 2171; von 1319 Oktober 4, PUB 5, S. 461 f., Nr. 329, und von 1321 Juni 12, PUB 6, S. 41 f., Nr. 3508.

259 Vgl. PUB 6, S. 81-85, Nr. 3560, hier: S. 82. 
Was nach 1320 aus den umfangreichen Gütern der von Liebenow östlich der Drage wurde, wird in den Quellen nicht berichtet. Allem Anschein nach konnte die Familie diesen Besitz ebensowenig behaupten wie ihre Stellung am pommerschen Herzogshof oder als Lokatoren. Es ist ziemlich wahrscheinlich, dass sie bei der Besiedlung ihrer Ländereien nur mäßigen Erfolg hatte, da die aus dem Westen erwarteten Siedler entweder ausblieben oder nach Preußen weiterzogen, so dass ein Großteil ihrer Investitionen in den Landesausbau vermutlich vergeblich war, weshalb sie mittelfristig im Konzert der bedeutenden Adelsfamilien des Oder-Drage-Raumes nicht mehr mitzuspielen vermochten. Gerhard, der Sohn Heinrichs von Liebenow, bezeugte am 26. Februar 1319 die Belehnung der von Hagen durch Markgraf Woldemar mit Radun (Raduń), Kr. Arnswalde. ${ }^{260}$ Nach dem Tod des Markgrafen schloss er sich Herzog Otto I. an, in dessen Gefolgschaft er sich bis 1330 urkundlich nachweisen lässt. ${ }^{261}$ Den umgekehrten Weg scheint Henning (Johann III.) von Liebenow, ein anderer Enkel Johanns von Liebenow, beschritten zu haben. Er wurde im Juli 1319 von Herzog Otto I. mit Linde (Lipke) bei Zachan (Suchan) belehnt. ${ }^{262} 1333$ erwarb er von Markgraf Ludwig dem Älteren für 200 Mark Silber - soviel hatte er damals immerhin zur Verfügung - 41 Hufen in Gossow (Goszków) im Kr. Königsberg. Dieser Besitz war allerding nicht unumstritten, denn der Markgraf versprach, ihn gegen fremde Ansprüche zu verteidigen. Offenbar gehörten die 41 Hufen eigentlich den von der Osten und waren über die Schwester Betekins von der Osten an dessen Schwager Dobrogost von Samter (Szamotuły) aus der polnischen Familie Nałęcz gekommen, der sie nunmehr Henning von Liebenow einräumen musste. ${ }^{263}$ Allerdings hatte sich der Markgraf beim Verkauf den Rückkauf vorbehalten, der spätestens 1338 erfolgte, denn im Oktober jenes Jahres erhielten Betekin von der Osten und sein Schwager die $41 \mathrm{Hu}-$ fen zurück. ${ }^{264}$ Henning von Liebenow gab damals anscheinend jegliche Ambitionen im Raum um Königsberg und Bärwalde auf. Den Kern der Besitzungen der Familie bildete um 1337 ihr ehemaliges Burggut, das Dorf Liebenow, Kr. Arnswalde, zu dem sie noch die Dörfer Kratznick, Nantikow (Nętkowo), Kölpin sowie Anteile an Rietzig (Rzecko), Kr. Arnswalde, besaßen. Diese Dörfer lagen damals größtenteils wüst, so dass das Kataster von 1337 die von Liebenow nur als Inhaber eines Rossdienstes in Liebenow aufführt. ${ }^{265}$

Das Wüstfallen ihrer Güter führte offenbar zur einer Verarmung der Familie, die Henning und die beiden ältesten seiner drei Kinder Albert und Henning dazu brachte, im Jahr

260 Vgl. Urkunde von 1319 Februar 26, KW, S. 783, Nr. 2683.

261 Vgl. Urkunden von 1319 Dezember 7, PUB 5, S. 475, Nr. 3314, von 1320 August 23, PUB 5, S. 534 f., Nr. 3398, von 1325 September 9, PUB 6, S. 289 ff., Nr. 3872 f., von 1326 nach März 30, PUB 7, S. 118 f., Nr. 4164, von 1328 März 5, PUB 7, S. 183, Nr. 4371. Zuletzt wird er erwähnt in zwei Urkunden vom 11. Februar 1330, PUB 7, S. 332 ff., Nr. 4347 und 4348.

262 Vgl. Urkunde von 1319 Juli 28, PUB 5, S. 448, Nr. 3279. Welcher der drei Söhne Johanns I. der Vater von Henning von Liebenow war, ist nicht ermittelbar. Dass er, wie Brzustowicz: Rycerstwo ziemi choszczeńskiej (wie Anm. 8), S. 436, in seiner Stammtafel verzeichnet, Sohn Heinrichs (II.) gewesen sein soll. ist urkundlich nicht zu belegen.

263 Vgl. Urkunde von 1333 Oktober 1, R 1333-1348, fol. 1 f., Nr. 5; CDB I 24, S. 15, Nr. 25.

264 Vgl. Urkunde von 1338 Oktober 12, R 1333-1348, fol. 12v, Nr. 50; CDB I 24, S. 27, Nr. 48. Dazu vgl. Brzustowicz: Rycerstwo ziemi choszczeńskiej (wie Anm. 8), S. 299.

265 Vgl. K 1337 B, fol. 116vf.; LB/Gollmert, S. 24 f. 
1340 vier Hufen in Rietzig an die von dem Borne zu verkaufen. ${ }^{266}$ Der Besitz in und um Liebenow gehörte damals anscheinend zu drei Vierteln Henning (Johann III.) und seinen Kindern und zu einem Viertel Otto von Liebenow, der entweder ein Bruder oder Vetter Hennings war. Henning von Liebenow übte damals, und zwar bis 1348, den Vorsitz des Vasallengerichts im Distrikt Arnswalde aus, der mit der Bede des Dorfes Schönfeld (Żeńsko) verbunden war. ${ }^{267}$ Um 1350 ist er dann ebenso wie Otto von Liebenow gestorben und vererbte seinen Anteil in und um Liebenow an seine Söhne Albert, Henning und Heinrich. Nur der vierte, bisher Otto gehörende Teil, gelangte 1350, da Otto keine Söhne hatte, an die von Güntersberg, vielleicht aufgrund einer Ehe einer Tochter Ottos von Liebenow mit Heinrich von Güntersberg. ${ }^{268}$ Entgegen der Annahme van Niessens, dass die von Liebenow in der Neumark damals mit Otto von Liebenow ausgestorben seien ${ }^{269}$, ist festzustellen, dass die Familie fortbestand und, auch wenn sie ein Viertel ihres Besitzes an die von Güntersberg abgeben mussten, doch drei Viertel behalten hat. Mit diesem Besitz war auch weiterhin ein Rossdienst verbunden, der offenbar ebenfalls in vier Teile geteilt und zu einem Viertel an die von Güntersberg übergegangen war. Im Jahr 1353 erließ Markgraf Ludwig der Römer Heinrich, dem jüngsten Sohn Hennings (Johanns III.) von Liebenow, diesen Viertel-Rossdienst auf vier Jahre. ${ }^{270}$ Liebenow, Kr. Arnswalde, blieb (zu drei Vierteln) während des ganzen restlichen Mittelalters im Besitz der Familie; noch 1516 ist ein Hans von Liebenow als erbsessen auf Liebenow bezeugt. ${ }^{271}$

Das Geschlecht der von Wedel hat aufgrund seiner bereits oben angedeuteten Sonderstellung innerhalb des neumärkischen Adels die Aufmerksamkeit der Forschung in besonderem Maße auf sich gezogen ${ }^{272}$; ich werde mich daher an dieser Stelle etwas kürzer

266 Vgl. R Reetz, S. 43, Nr. 25.

267 Markgraf Ludwig der Ältere übertrug im September 1348 dieses Gericht dem Arnswalder Bürger Henning von dem Graben, wobei er Henning von Liebenow als dessen Amtsvorgänger erwähnte. Vgl. Urkunde von 1349 September 24-26, R 1348-1351 A, fol. 27v, Nr. 9; ungedruckt.

268 Vgl. Urkunde von 1350 September 23, R 1348-1351 A, fol. 54v, Nr. 117. Dazu vgl. die Ausführungen weiter oben. - Dass die von Güntersberg dieses Viertel erwerben konnten, zeigt. dass den von Liebenow diese Güter nicht zur gesamten Hand verliehen worden waren.

269 Vgl. van Niessen: v. Liebenow (wie Anm. 232), S. 201,

270 Dominus dimisit liberum et solutum Heinricum filium quondam Hennynghi de Lyuenow de quarta parte servicii, quo domino est astrictus, per quatuor annos. Datum anno LIII ${ }^{\circ}$ in crastino beati Egidii. Registereintrag zu 1353 September 2, R 1352-1356 A, fol. 98 f., Nr. 93, ungedruckt. M.E. ist der Eintrag so zu verstehen, dass der Markgraf Heinrich von dem von ihm zu leistenden Viertel befreite, und nicht, dass er ihm den Rossdienst zu $25 \%$ erließ und die übrigen $75 \%$ weiterhin verlangte.

271 Zitat bei Brzustowicz: Rycerstwo ziemi choszczeńskiej (wie Anm. 8), S. 300.

272 Zur Geschichte der von Wedel vgl. UB Wedel, pass.; Heinrich Friedrich Paul von Wedel: Geschichte des Schlossgesessenen Geschlechtes der Grafen und Herren von Wedel 1212-1402, 2 Bde. Leipzig 1894; ders.: Hasso der Rothe von Wedel-Hochzeit und Ritter Hasso II. von Wedel-Falkenburg. Berlin 1897; ders.: Über die Herkunft, die politische Bedeutung und die Standesstellung des Geschlechts von Wedel von der Mitte des 12.bis zum Ausgang des 14. Jahrhunderts. Berlin 1915; Albert Lothert: Zur Geschichte der Familie von Wedell-Neuwedell (Vom Ende des 15. bis zum Ende des 16. Jahrhunderts), in: Die Neumark. Mitteilungen des Vereins für Geschichte der Neumark 13 (1936), S. 83-109; Czacharowski: Społeczne i gospodarcze siły (wie Anm. 24), S. 80-91; ders.: Adelsherrschaft (wie Anm. 24), Kap. II 7, S. 1-15; Helga Cramer: Die Herren von Wedel im 
fassen. Die von Wedel, deren Namen sich wahrscheinlich vom 1875 zur Stadt erhobenen Dorf Wedel an der Unterelbe westlich von Hamburg ableitet, sind als Adelsgeschlecht im frühen 13. Jahrhundert in Holstein bzw. in der Grafschaft Stormarn bezeugt. ${ }^{273}$ Zumeist wird angenommen, dass einer der beiden 1238 bezeugten Hasso et hasso castellani in Etzeho (Itzehoe) ${ }^{274}$ um oder nach 1240 nach Pommern einwanderte und dort starb, bevor seine Familie in pommerschen Urkunden Erwähnung fand. Möglicherweise erfolgte die Einwanderung bereits kurz nach 1240 in den Raum Stargard, der damals unter der Herrschaft der Bischöfe von Kammin stand, so dass der Stammvater der pommerschen von Wedel vielleicht zunächst bischöflicher Vasall war, ehe Bischof Wilhelm das Land 1248 Herzog Barnim I. von Pommern verlieh. ${ }^{275}$ Anscheinend wurden die von Wedel im Raum Stargard als Burgmannen von Stargard ansässig, die als Burggut das Dorf Kremzow (Krępcowo) erhielten, das sie sich mit den von Kremzow teilten. Kremzow war ihr erste Stammsitz, an dem die Familie eine eigene Burg errichtete und um den sie im Laufe des ausgehenden 13. und des 14. Jahrhunderts einen ansehnlichen Besitzkomplex erwarb, der aus Repplin (Rzeplino), Linde (1319), Brallentin (Brałęcin), Petznick, Kr. Pyritz (Piasecznik) und Suckow (Żuków) bestand. ${ }^{276}$ Als Burgmannen Herzog Barnims I. besetzten dann in der zweiten Hälfte des 13. Jahrhunderts die Söhne des aus Holstein gekommenen Einwanderers, Ludwig (I.) und seine fünf Brüder Siegfried, Hasso (I.), Heinrich (I.),

Lande über der Oder. Besitz- und Herrschaftsbildung bis 1402, in: JGMOD 18 (1969), S. 63-129; Hasso von Wedel: Die Wedel in Stormarn. Aumühle b. Hamburg 1978 (masch. Ms., Exemplar in der Bibliothek des GStA PK vorhanden); Edward Rymar: Udział rodu Wedłów w ekspansji margrabiów brandenburskich na Pomorze Srodkowe i Wschodnie w latach 1269-1313 [Die Beteiligung des Geschlechts von Wedel an der Expansion der Markgrafen von Brandenburg in das mittlere und östliche Pommern in den Jahren 1269-1313], in: Jerzy Hauziński (Hg.): Pomorze słowiańskie i jego sąsiedzi X-XV w. [Das slawische Pommern und seine Nachbarn im 10.-15. Jahrhundert). Tagungsband zur Tagung „Pomorze słowiańskie i jego sąsiedzi w średniowieczu“ vom 2.-4.12.1993. Gdańsk 1995 (= Pomerania Mediaevalis), S. 45-60; Brzustowicz: Rycerstwo ziemi choszczeńskiej (wie Anm. 8), S. 329-346; Gahlbeck: terra Transoderana (wie Anm. 10), S. 144 f. - Die Stammtafeln von Brzustowicz: Rycerstwo ziemi choszczeńskiej (wie Anm. 8), S. 443-448, Tafeln 30-35, sind unzuverlässig. Man vermisst den in der Mitte des 14. Jahrhundert in den Quellen bezeugten Hasso von Falkenburg; dafür taucht der 1354 verstorbene Hasso der Rote von Wedel doppelt auf, einmal auf Tafel 30 (S. 443) als Sohn eines Heinrichs von Wedel und einmal auf Tafel 34 (S. 447) als Sohn Ludwigs II. von Wedel.

273 Vgl. UB Wedel, Bd. 1, pass.; v. Wedel: Die Wedel in Stormarn (wie Anm. 272), pass. Belege aus der Zeit vor 1200 sind zweifelhaft. Vgl. Cramer: Die Herren von Wedel (wie Anm. 272), S. 70.

274 Urkunde von 1238 [Juli 21?], Paul Hasse (Hg.): Schleswig-holstein-lauenburgische Regesten und Urkunden. Im Auftrage der Gesellschaft für Schleswig-Holstein-Lauenburgische Geschichte bearbeitet [künftig zit.: SHRU]. Bd. 1-4. Hamburg-Leipzig 1886-1888, hier: Bd. 1, S. 256, Nr. 577.

275 Vgl. Rymar: Udział rodu Wedłów (wie Anm. 272), S. 45; Brzustowicz: Rycerstwo ziemi choszczeńskiej (wie Anm. 8), S. 329. Abweichend hiervon erwägt Cramer: Die Herren von Wedel (wie Anm. 272), S. 70 f., als Stammvater Lambrecht von Wedel, der 1255/56 seine holsteinischen Güter verkaufte und danach in den Quellen jenes Raumes nicht mehr genannt wird. - Zum Besitz des Landes Stargard vgl. die Urkunden von 1240 April 24, PUB 1², S. 451 ff., Nr. 377, und von 1248 Oktober 7, PUB 12, S. 557 ff., Nr. 475.

276 Später kamen noch Wulkow (Ulikowo), Kitzerow (Kiczarowo), Pegelow (Gogolewo), Dahlow (Dalewo) und Barskewitz (Barzkowice) hinzu. Vgl. Cramer: Die Herren von Wedel (wie Anm. 272), S. $72 \mathrm{ff}$. 
Zulis und Ludolf (I.), die Burgen in Reetz und Kürtow. Das Burggut der von Wedel auf Reetz war Altenwedel (Sicko), hinzu kamen noch die Dörfer Glambeck (Głębokie), Hassendorf (Źółwino), die wohl von Hasso (II.) von Wedel-Glambeck gegründet wurden, sowie Güter in Schlagenthin (Zlawęcin). ${ }^{277}$ Zum Kürtower Gebietskomplex - die Burg ging nach der Gründung von Arnswalde durch die Askanier in den Besitz der von Wedel über - zählten u.a. das nach Zulis von Wedel benannte Zühlsdorf (Suliszewo), das vielleicht das ursprüngliche Kürtower Burggut der von Wedel war, sowie Plagow (Pławno), Neu Plagow (Pławienko), Sellnow (Zielieniewo) mit dem Großen Prietzensee (jez. Przeczno), ferner Güter in Kranzin (Krzęcin), Radun und vermutlich in Alt Klücken (Stary Klukom). ${ }^{278}$

Als Herzog Barnim I., der beim Johanniterorden einen Kredit aufgenommen hatte und nicht zurückzahlen konnte, in einem Prozess nach mittelalterlichem Pfandrecht dazu verurteilt wurde, die Stadt Stargard, die Burgen in Reetz und Kürtow mit ihren Zubehörungen sowie mehrere zwischen diesen drei Orten gelegene Dörfer den Johannitern als Pfandbesitz einzuräumen, drohte den von Wedel der Verlust ihres gesamten Besitzes oder zumindest eines großen Teils ihrer Güter. Sie weigerten sich daher ebenso wie der Herzog, das Kloster Kolbatz und die übrigen betroffenen pommerschen Adligen, den Johannitern ihre Besitzungen zu überantworten, weshalb sie 1269 vom Dominikanermönch Albertus Magnus, der den Prozess gegen Barnim I. geführt hatte, exkommuniziert und 1271 mit dem Interdikt belegt wurden. ${ }^{279}$ In dieser Situation wechselten die von Wedel auf die Seite der Markgrafen von Brandenburg über. Konkret traten Ludwig und seine Brüder in den Dienst der Söhne der johanneischen Linie der Askanier und sind fortan überwiegend in Urkunden des Markgrafen Otto IV. (,mit dem Pfeil“) anzutreffen. Ihre soziale Stellung innerhalb des Adels sowie auch ihr militärischer Ruf war bereits damals beachtlich. Schon in kürzester Zeit hatten sie unter den Askaniern führende militärische Positionen inne. An der Eroberung von Danzig (Gdańsk) im Jahr 1271 waren sie maßgeblich beteiligt, ebenso am Koalitionskrieg mit Pommern 1272-75, in dem die Markgrafen u.a. den Landstrich zwischen den beiden Ihnaarmen westlich von Arnswalde einnahmen. ${ }^{280}$ Als

277 Vgl. ebd, S. $81 \mathrm{ff}$.

278 Vgl. ebd., S. 80-83. Alt Klücken gehörte zu den Dörfern, die in dem von Albertus Magnus geführten Pfändungsprozess der Johanniter gegen Herzog Barnim I. dem Orden als Pfandbesitz zugesprochen waren. Vgl. Urkunde von 1269 August 12 (wie Anm. 248).

279 Vgl. Urkunden von 1269 August 12 und 1271 April 8 (wie Anm. 248). Namentlich wurde damals nur Ludwig von Wedel exkommuniziert bzw. mit dem Interdikt belegt. Es ist aber anzunehmen, dass auch seine Brüder von der Exkommunikation und dem Interdikt betroffen waren. Die Urkunde vom 12. August 1269 ist der erste Quellenbeleg für die Anwesenheit der von Wedel im Oder-Drage-Raum. Vgl. Czacharowski: Społeczne i gospodarcze siły (wie Anm. 24), S. 80 f.; ders.: Adelsherrschaft (wie Anm. 24), Kap. II 7, S. 1; Cramer: Die Herren von Wedel (wie Anm. 272), S. 71 f. Wenn Rymar: Udział rodu Wedłów (wie Anm. 272), S. 45 f., und Brzustowicz: Rycerstwo ziemi choszczeńskiej (wie Anm. 8), S. 329, das Jahr 1267 als erstes Jahr angeben, in dem sich die Tätigkeit der von Wedel in diesem Raum nachweisen lasse, so liegt dem keine Urkunde von 1267 zugrunde, sondern es wird lediglich der Zeitraum von 1269 zurückgerechnet, den der im Dokument vom 12. August 1269 erwähnte Prozess in Anspruch nahm bzw. bereits zurücklag.

280 Vgl. Gahlbeck: Zisterzienser (wie Anm. 3), S. 113-115. - Die ersten Angehörigen der von Wedel (Ludwig und Heinrich) im Dienst der Askanier werden in den beiden Urkunden der Markgrafen 
die Askanier dieses Gebiet 1278 im Vertrag von Zweiraden an Barnim I. zurückgaben, indem sie ihn damit belehnten, war es Ludwig von Wedel, der ihn in das Lehen einwies. ${ }^{281}$ Selbst erhielten die von Wedel damals im Land Bernstein Besitzungen in Falkenberg (Brzezina), Kl. Latzkow (Laskówko) und Gottberg (Boguszyny). ${ }^{282}$ Außerdem traten sie anscheinend die Nachfolge der von Kerkow als Burgmannen auf der Burg Schildberg an, zu der als Burggut Kerkow (Kierzków) gehörte. ${ }^{283}$ Dort hatte offenbar Hasso I. seinen ersten Wohnsitz in der Neumark, der 1296 in einer in Schildberg ausgestellten Urkunde der Markgrafen unter dem Namen Hasso de Eylstede ${ }^{284}$ als Vogt der Askanier die Über-

Johann II., Otto IV. und Konrad für die Stadt Danzig von 1272 August 17, KW, S. 256 f., Nr. 1027 und 1028, unter den Zeugen erwähnt. Beide Urkunden wurden in Lübeck ausgestellt.

281 Nos ... Barnim dux Slavorum presentibus protestamur, quod ab illustri principe domino nostro dilecto Conrado, marchione Brandenburgensi, in pheodum recepimus ista bona ..., prout dominus Lodewicus de Wedele ex parte ipsius nos misit in possessionem corporalem. Urkunde von 1278 Juni 1 (Vertrag von Zweiraden), PUB 2, S. 371 f., Nr. 1096.

282 Vgl. Cramer: Die Herren von Wedel (wie Anm. 272), S. 80 f. - Ergänzend sei noch auf folgende Besitzungen hingewiesen: Im Jahr 1297 wollten Hasso und Ludolf von Wedel von Markgraf Albrecht III. mit den Dörfern Hohen Selchow und Kl. Schönfeld im vorpommerschen Kreis Randow belehnt werden, was der Markgraf mit dem Hinweis auf die Lage der Orte im Herzogtum Pommern-Stettin ablehnte. Vgl. Urkunde von 1297 April 24, KW, S. 445, Nr. 1671. Krabbo (KW, ebd.) hält die Urkunde für eine Fälschung. Man kann aber wohl dennoch davon ausgehen, dass die von Wedel Güter in den beiden Dörfern besaßen. Da diese dann pommersche Lehen gewesen sein müssen, lässt sich annehmen, dass es sich eventuell um Burggüter handelte, die ein Familienmitglied der von Wedel - die Familie war ja groß genug - als pommerscher Burgmann auf Gartz oder Penkun innehatte. Unklar bleibt, wann und wie die von Wedel in den Besitz des Hofes Wedell (Czartoryja) bei Königsberg/Nm. gelangten, den Christian von Wedel im Jahr 1386 besaß. Vgl. Urkunde von 1386 Januar 13, CDB I 19, S. 278 f., Nr. 163.

283 Am 10. August 1276 verzichteten die von Kerkow zugunsten der Askanier auf Schildberg und wurden zum Ausgleich dafür mit dem Schloss Boitzenburg in der Uckermark und zehn umliegenden Dörfern belehnt. Vgl. GStA PK Berlin, I. HA, Rep. 78a, Nr. 1, T. 1, fol. 60v, lit. i*; CDB I 13, S. 318, Nr. 13. Als nächster adliger Besitzer von Schildberg ist Heinrich von Wedel Anesel nachweisbar, der die Burg vor ihrer Verlehnung an die von Jagow durch Markgraf Ludwig den Älteren im Jahr 1334 innehatte. Vgl. Urkunde von 1334 März 5, GStA PK Berlin, I. HA, Rep. 78a, Nr. 1, T. 1, fol. 2, Nr. 9; CDB I 18, S. 105, Nr. 9. Dazu vgl. Cramer: Die Herren von Wedel (wie Anm. 272), S. 98.

284 Hasso von Eylstedt ist bereits von Edward Rymar: Nieco uwag o dziejach Nowei Marchii w okresie askańskim. Na marginesie książki Jerzego Walachowicza, Geneza i ustrój polityczny Nowej Marchii do początków XIV wieku. Warszawa-Poznań 1980 [Einige Bemerkungen zur Geschichte der Neumark in der Askanierzeit. Randbemerkungen zum Buch von Jerzy Walachowicz, Geneza i ustrój Nowej Marchii ...], in: Studia i materiały do dziejów Wielkopolski i Pomorza [Studien und Materialien zur Geschichte Großpolens und Pommerns] 29 (1983), S. 161-180, hier: S. 173 f., mit einem Mitglied der Familie von Wedel identifiziert worden, allerdings mit Hasso, einem Sohn Ludwigs (I.) von Wedel, der sich 1301 und 1308 Hasso von Glambeck nannte und auch als Hasso von Kremzow in den Quellen bezeichnet wird. Ihm folgt: Brzustowicz: Rycerstwo ziemi choszczeńskiej (wie Anm. 8), S. 332 f. Bei dieser Annahme bleibt jedoch unklar, in welcher verwandtschaftlichen Beziehung der 1337 im Kataster genannte Hasso von Eylstedt zu Hasso von Glambeck-Kremzow steht. Ich gehe daher davon aus, dass der 1296 genannte Hasso von Eylstedt mit Hasso I. von Wedel identisch war, wenn auch mit gewissen Bedenken wegen seiner separaten Nennung in der Zeugenliste, die allerdings in der Hervorhebung seines Vogteiamtes ihre Ursache haben kann. - Der Name Eylstede wird von Georg Winter (vgl. KW, Namensregister, S. 958) auf das Städtchen Eilenstedt (Kr. Oschersleben) nördlich von Halberstadt zurückgeführt. Dorthin gibt es jedoch keine familiäre 
eignung des von den von Wedel erworbenen Dorfes Neu Plagow an das Kloster Marienwalde bezeugte. ${ }^{285}$ Als Hasso um die Jahrhundertwende für die Askanier die polnische Kastellaneiburg Driesen (Drezdenko) erobert hatte und von ihnen dafür die Vogtei Driesen erhielt, das er bis zu seinem Tod besaß, nannte er sich fortan häufiger auch Hasso von Driesen. ${ }^{286} 1305$ stiftete er 10 Hufen in Regenthin (Radęcin) zur Ausstattung eines Altars im Kloster Marienwalde, in dem er später auf seinen Wunsch hin auch begraben wurde. ${ }^{287}$ Sein Sohn Hasso beteiligte sich 1321 an dem von Wedego von Wedel geleiteten Kriegszug in die Mark. ${ }^{288}$ Als Markgraf Woldemar nach dem Tod seines Vaters Driesen an die Ritter Heinrich und Borchard von der Osten verlieh ${ }^{289}$, nahm Hasso (III.) ${ }^{290}$ wieder den

Verbindung, auch nicht zu der in altmärkischen Quellen mehrfach genannten Familie von Eylstede (vgl. CDB, Namenverzeichnis, Bd. 1, S. 398 f.), in der der Name Hasso nicht bezeugt ist. Gegen diese Annahme hatte sich auch bereits Rymar: Nieco uwag (s.o.), S. 173, gewandt, ohne eine alternative Erklärungsmöglichkeit anzubieten: „Miejscowości Eylenstede nie daje się zidentyfikować Die Ortsnamen Eylenstede lassen sich nicht identifizieren.“ (Ebd.). M.E. geht der Name auf die wüst gefallene Siedlung Eidelstedt zurück, die dem heutigen Stadtteil im Westen Hamburgs ihren Namen gab. Der Name dieser Siedlung bzw. Wüstung, die in der unmittelbaren Nachbarschaft der Stadt Wedel liegt, ist urkundlich als Eylstede bzw. Eilenstede bezeugt. Vgl. SHRU 2, S. 45, Nr. 112; Hamburgisches Urkundenbuch, hg. von Johann Martin Lappenberg, Bd. 4. Hamburg 1967, S. 223, Nr. 271.

285 Urkunde von 1296 Februar 3, Transsumt von 1397 Juli 9, SBB PK Berlin, Urkunden, Wippelsche Sammlung, A 63. Aus diesem Transsumt geht eindeutig hervor, dass die Urkunde in Schildberg und nicht, wie in der Literatur bisher zumeist angegeben, in Falkenberg, Kr. Pyritz, ausgestellt wurde. Dieser Irrtum geht auf eine unvollständige und fehlerhafte Abschrift von ca. 1450 in GStA PK Berlin, XX. HA, OBA 94, zurück, die den Drucken in CDB I 18, S. 5 f., Nr. 5, und UB Wedel II 1, S. 25, Nr. 41, zugrunde liegt.

286 Hasso dictus de Wedele in castro Drysen residens. Urkunde von 1305 Juli 6 (wie Anm. 166). Hasso miles de Wedele, nunc dictus de Drysen. Urkunde von 1306 [vor November 11], SBB PK Berlin, Urkunden, Wippelsche Sammlung, A 15; CDB I 19, S. 449, Nr. 7.

287 [...] claustro, quod Marienwolt nominatur, in quo sepulturam elegimus. Urkunde von 1305 Juli 6 (wie Anm. 166). Trotz der großen Wahrscheinlichkeit ist es nicht völlig sicher, ob es sich bei dem in der Gruft unter dem Chor der Marienwalder Klosterkirche aufgefundenen Skelett mit dem höchsten Lebensalter um die Überreste des Ludwig von Wedel handelt. Insgesamt wurden die Skelette von drei Menschen gefunden, darunter von einem Kind im Alter von ca. 4-6 Jahren und von einem jungen Menschen im Alter von 23-25 Jahren. Das Geschlecht der in der Gruft bestatteten Menschen konnte anhand der Funde nicht bestimmt werden. Vgl. Elżbieta Alicja Puch/Jerzy Kozak: Materiały kostne z obrębu kościoła i cmentarza przykościełnego na terenie byłego opactwa cysterskiego w Bierzwniku [Knochenmaterial aus dem Bereich der Kirche und des an der Kirche gelegenen Friedhofs auf dem Gebiet der ehemaligen Zisterzienserabtei Marienwalde], in: Zeszyty bierzwinickie 4 (2002), S. 125-142; Christian Gahlbeck/Blandine Wittkopp: Marienwalde (Bierzwnik). Zisterzienser, in: Brandenburgisches Klosterbuch. Handbuch der Klöster, Stifte und Kommenden bis zur Mitte des 16. Jahrhunderts, hg. von Heinz-Dieter Heimann, Klaus Neitmann, Winfried Schich mit Martin Bauch, Ellen Franke, Christian Gahlbeck, Christian Popp und Peter Riedel [künftig zit.: BKB]. Berlin 2007, Bd. 2, S. 860-883, hier: S. 873 (= Brandenburgische Historische Studien, 14).

288 [...] Ludolfus die Craz et filius Hassonis de Dreezen XII talenta. Kriegskostenverzeichnisse von 1321, PUB 6, S. 81-85, Nr. 3560, hier: S. 83.

289 Vgl. Urkunde von 1317 Februar 2, CDB I 18, S. 282 f., Nr. 1.

290 Die Einordnung dieses Hasso von Wedel erfolgt hier unter Berücksichtigung des von Brzustowicz: Rycerstwo ziemi choszczeńskiej (wie Anm. 8), S. 443, Tafel 30 als Hasso II. bezeichneten Hasso von Glambeck, der lt. Brzustowicz ein Sohn Ludwigs (I.) und wahrscheinlich älter als der gleichnamige Sohn Hassos I. war. Wie bereits oben Anm. 272 bemerkt, bedürfen die Genealogie-Tafeln 
alten Herkunftsnamen von Eylstedt an, unter dem er als Inhaber von je 12 dienstpflichtigen Hufen in den Dörfern Rosenthal (Różańsko) und Zernickow (Czerników) im Kataster von 1337 notiert ist. ${ }^{291}$

Ludwig (I.) von Wedel, seine Brüder und ihre Nachkommen verfügten über eigene Vasallen und damit über eine eigene Streitmacht. Mit ihr unterstützten sie die Askanier nachhaltig bei ihren Vorstößen nach Osten und gegen Pommerellen und wurden von ihnen dafür mit ganzen Landschaften an der Drage belohnt, die sie als Lehnsbesitz erhielten. Nach dem Register von 1337 besaßen sie die terrae Falkenburg (Złocieniec), Kallies, Böthin (Bytyń), Tütz (Tuczno) und den Güterkomplex der Häuser Kürtow und Neuwedell (die bona illorum de Gruthow), der sich, rechnet man noch die Wedelsche Heide dazu, zu beiden Seiten der Drage vom Großen Lübbesee flussabwärts bis nach Hochzeit erstreckte. Sie saßen zudem noch auf Schivelbein (Świdwin) und gründeten mit Neuwedell, Märkisch Friedland und Falkenburg drei eigene Städte. ${ }^{292}$ Von den Brüdern Ludwigs (I.) gelangten zumindest Zulis und Ludolf I. von Wedel in hohe Ämter am Hofe der Askanier. Zulis von Wedel bekleidete 1282 das Amt des Hofmarschalls ${ }^{293}$, Ludolf I. zunächst 1302 das eines Vogtes im Lande über der Oder ${ }^{294}$, von 1305 bis 1308 war er dann Truchsess Markgraf Ottos IV. ${ }^{295}$ Auch die Söhne der Brüder erlangten z. T. bedeutende Ämter. Hasso, nach Brzustowicz Sohn Ludwigs I., der sich zwischen 1301 und 1308 Hasso von Glambeck und 1319/20 Hasso von Kremzow nannte, war etwa gleichzeitig mit seinem

von Brzustowicz zur Familie von Wedel, in denen der Zweig der von Eylstedt fehlt, grundsätzlich einer Überarbeitung.

291 Vgl. K 1337 B, fol. 111vf.; LB/Gollmert, S. 17. Von den 12 Hufen in Zernickow mussten 2 servicia geleistet werden.

292 Auf die hier genannten Erwerbungen und Entwicklungen kann an dieser Stelle nicht weiter eingegangen werden. Vgl. LB/Gollmert, S. 27-30; Helmut Wittlinger: Untersuchungen zur Entstehung und Frühgeschichte der neumärkischen Städte. Landsberg /W. 1932, S. 56 f., $63-65$ (= Die Neumark, Jahrbuch des Vereins für Geschichte der Neumark, 8); Czacharowski: Społeczne i gospodarcze siły (wie Anm. 24), S. 81-83; ders.: Adelsherrschaft (wie Anm. 24), Kap. II 7, S. 3; Cramer: Die Herren von Wedel (wie Anm. 272), S. 84 f., 90-97, 108-122; Rymar: Udział rodu Wedłów (wie Anm. 272), pass. - Die Gründung von Märkisch Friedland durch die von Wedel erfolgte am 2. Februar 1314, vgl. CDB I 18, S. 102 f., Nr. 5, die von Falkenburg am 13. Dezember 1333, vgl. PUB 8, S. 263-267, Nr. 5114. Die von Wedel übten im Raum Falkenburg aber schon 1313 Herrschaftsrechte aus, z.B. als sie am 16. April 1313 (vgl. PUB 5, S. 99, Nr. 2792) die von Elbe mit dem bei Falkenburg gelegenen Dorf Venzlaffshagen (Więcław) belehnten. Eine Gründungsurkunde für Neuwedell hat sich nicht erhalten; es ist aber anzunehmen, dass die Stadt ebenfalls im 2. Jahrzehnt des 14. Jahrhunderts entstand. Vgl. Wittlinger: Untersuchungen (s.o.), S. 56 f.; Gahlbeck: Das sogenannte Neumärkische Landbuch (wie Anm. 1), S. 36-38. - Durch die Häusergemeinschaft KürtowNeuwedell verlagerte sich der Wedelsche Besitz aus der Umgebung von Kürtow und Arnswalde nach Osten. Die Güter in Alt Klücken, Kranzin, Radun und Gottberg wurden im ersten Drittel des 14. Jahrhunderts von den von Wedel an andere neumärkische Adlige verkauft. Vgl. Cramer: Die Herren von Wedel (wie Anm. 272), S. 81.

293 Vgl. Urkunden von 1282 August 24, KW, S. 339 f., Nr. 1306, 1307.

294 Vgl. Urkunde von 1302 Februar 14, KW, S. 494 f., Nr. 1838.

295 Vgl. Urkunden von 1305 September 25, SBB PK Berlin, Urkunden, Wippelsche Sammlung, A 12, CDB I 19, S. 447 f., Nr. 6, von 1306 April 18, KW, S. 540, Nr. 1985, und von 1308 März 14, KW, S. 560, Nr. 2051. 
Onkel Ludolf (I.) Vogt in der Neumark, wenn auch in einem anderen Distrikt. ${ }^{296}$ Dessen Sohn Lambrecht diente als Vogt 1313 unter Herzog Otto I. von Pommern. ${ }^{297}$ Wedego (I.) von Wedel, Sohn Hassos (I.), der seit 1313 sowohl Vasall Markgraf Woldemars von Brandenburg als auch Herzog Ottos I. von Pommern war ${ }^{298}$, hatte von 1317 bis 1322 unter dem pommerschen Herzog das Amt des Marschalls inne. ${ }^{299}$ Darüber hinaus leitete er, nachdem die neumärkischen Stände nach dem Tod Woldemars Herzog Wartislaw IV. als ihren Herrn anerkannt hatten, den Kriegszug des pommersch-neumärkischen Heers in die Uckermark im Jahr 1321. Auf dieser Heerfahrt führte Wedego eigene Schreiber mit, für die die pommerschen Herzöge 10 Talente Brandenburgisch zahlen mussten. ${ }^{300}$ Auch hatte er seine Söhne Wedego (II.), der den Herzögen damals als Kammermeister diente, und Hasso (von Uchtenhagen) sowie mehrere Bediente in den Krieg mitgenommen. ${ }^{301}$ Wedego (I.) von Wedel wandte 1321 insgesamt über 750 Mark brandenburgischen Silbers sowie knapp 125 Mark reinen Silbers und 100 Mark Finkenaugen für die Auslösung von pommerschen und neumärkischen Kriegsgefangenen auf. Darüber hinaus schuldete ihm

296 Vgl. Urkunden von 1301 September 13, KW, S. 490, Nr. 1821 (als Vogt Hasso von Glambeck); von 1302 Februar 14, KW, S. 494 f., Nr. 1838, von 1303 April 23 (wie Anm. 121), von 1303 Mai 20, KW, S. 504, Nr. 1872; von 1303 September 14, KW, S. 507, Nr. 1881, von 1305 September 25 (wie Anm. 295), von 1306 Oktober 24, KW, S. 543, Nr. 1996, von 1306 November 4, KW, S. 544, Nr. 1999, von 1306 Dezember 4, SBB PK Berlin, Urkunden, Wippelsche Sammlung, A 14, Druck: Hermann Krabbo: Ungedruckte Urkunden der Markgrafen von Brandenburg aus dem Hause der Askanier, in: Forschungen zur Brandenburgisch-Preußischen Geschichte 25 (1912), S. 1-27, hier: S. 16 f., Nr. 14, von 1307 April 19 (wie Anm. 222), von 1307 Juni 15, KW, S. 550, Nr. 2023 (als Vogt), 1308 August 23, KW, S. 567, Nr. 2073 (als Hasso von Glambeck), von 1319 September 29, KW, S. 814 f., Nr. 2763, und von 1320 März 14, KW, S. 829, Nr. 2800 (als Hasso von Kremzow). Vgl. Brzustowicz: Rycerstwo ziemi choszczeńskiej (wie Anm. 8), S. 332 f. u. S. 443, Tafel 30.

297 Vgl. Urkunden von 1313 August 20 und 21, PUB 5, S. 151-153, Nr. 2857-2859.

298 Vgl. z.B. Urkunden von 1313 Januar 4, PUB 5, S. 83, Nr. 2768, und von 1313 Juni 30, PUB 5, S. 115, Nr. 2813.

299 Vgl. Urkunden von 1317 Mai 12, PUB 5, S. 299, Nr. 3058, und von 1322 Juni 2, PUB 6, S. 110 , Nr. 3600 (erster und letzter Beleg als Vogt). Zu weiteren Belegen vgl. die Orts- und Personenregister in PUB 5, S. 693, und PUB 6, S. 558, wo jedoch nicht alle Belegstellen für Wedego von Wedel auch seinen Titel als Marschall belegen.

300 Vgl. die Kriegskostenverzeichnisse von 1321, PUB 6, S. 81-85, Nr. 3560, hier: S. 83: item scriptoribus domini Wedegoni infra totam gwerram $X$ talenta.

301 Domino Wedegoni Kamermester VIII talenta. [...] Hassoni, filio domini Wedegonis, et [...] XII talenta, [...] familie domini Wedegonis XIIII talenta. Ebd. Ferner zogen noch Sifrid de Wedele (ebd., fehlt bei Brzustowicz) und Ludolf (II.) der Jüngere von Wedel, Sohn Ludolfs (I.) mit, letzterer offenbar in Begleitung von mehreren ihm dienenden Bogenschützen. (ebd., S. 84). - Die Stammtafel der von Wedel auf Schivelbein-Uchtenhagen-Reetz bei Brzustowicz: Rycerstwo ziemi choszczeńskiej (wie Anm. 8), S. 444, Tafel 31, ist fehlerhaft. Der von Brzustowicz als Hasso II. (der Jüngere) bezeichnete angebliche Sohn Wedegos II. ist, wie aus dem o.g. Zitat hervorgeht, ein Sohn Wedegos I. und damit Bruder Wedegos II. Dieser ist zudem nicht 1332 gestorben, sondern mit dessen angeblichem Sohn Wedego IV. (einen Wedego III. gibt es in den Tafeln von Brzustowicz nicht!) identisch, so dass die Angaben unter Wedego II. mit denen von Wedego IV. zusammenzuziehen sind und es sich bei der gesamten angeblichen Enkelgeneration Wedegos I. tatsächlich um die Kindergeneration handelt. Zu Ludolf II. vgl. die Stammtafel ebd., S. 445, Tafel 32. 
Herzog Wartislaw IV. noch 1.400 Mark Stettiner Geld, die er ihm 1320 in Stargard bzw. Greifswald zu zahlen versprochen, aber nicht tatsächlich gezahlt hatte..$^{302}$

1324 schlossen sich Wedego von Wedel und der überwiegende Teil der von Wedel dem wittelsbachischen Markgrafen Ludwig dem Älteren an. ${ }^{303}$ Mit ihnen - und sicherlich nicht zuletzt auf ihr Betreiben - traten die gesamten neumärkischen Stände auf die Seite Markgraf Ludwigs über. Von den von Wedel ist bekannt, dass sie damals zusammen mit den Grafen von Lindow-Ruppin den jungen Markgrafen stützten und förderten. Ludolf (II.) und Ludwig (II.) von Wedel, Söhne Ludolfs (I.), wurden in einer Urkunde Papst Johannes' XXII. als Hauptleute Markgraf Ludwigs genannt. ${ }^{304}$ Am 8. Juli 1333, zu Beginn seiner selbständigen Herrschaft nach Erklärung der Volljährigkeit, schworen die Söhne Ludolfs (I.), Heinrich (II.), Ludwig (II.), Ludolf (II.), Hasso (nach Brzustowicz: IV.), Johann (I.) und Lambrecht (II.), sowie Hasso von Eylstedt, der Sohn Hassos I., und die Söhne Wedegos (I.), Hasso von Uchtenhagen, Wedego (II.), Godeke, Henning und Friedrich, Markgraf Ludwig mit ihren Burgen (vesten) gegen jedermann Beistand und Hilfe zu leisten. ${ }^{305}$ Vier Jahre später schlossen sich ihnen auch Hasso der Rote und Henning von Wedel an, die ihm versprachen, ihre Burg und Stadt Polzin (Połczyn-Zdrój) offen zu halten außer gegen ihre Lehnsherrn, die Kinder des verstorbenen pommerschen Herzogs Wartislaw IV. Umgekehrt sicherte ihnen der Markgraf seinen Schutz gegen jedermann außer den pommerschen Herzögen zu und dehnte ihn auch auf weitere Burgen aus, die die beiden von Herzog Barnim III. (nach Erreichen von dessen Volljährigkeit) noch erhalten wollten. ${ }^{306}$ Ebenfalls 1337 gestattete Markgraf Ludwig dem Heinrich dicto Anesele von Wedel, bei Gabbert (Jaworze) an der Mündung des Trabunfließes in die Drage eine Burg zu errichten, die dieser ihm und seinen Hauptleuten gegen jedermann offenhalten sollte..$^{307}$ Vermutlich seit 1326 besaßen die von Wedel Burg, Stadt und Land Bernstein. Das Land hatte Markgraf Woldemar 1315 an Herzog Otto I. verkauft, und dieser hatte anscheinend

302 Vgl. PUB 6, S. 81-85, Nr. 3560, hier: S. 81 f., 84.

303 Wedego (I.) von Wedel wird in der Urkunde Markgraf Ludwigs für die Stadt Königsberg/Nm. von 1324 Oktober 9, CDB I 19, S. 186 f., Nr. 24, unter den Zeugen genannt. Er ist offenbar bald danach gestorben.

304 Ludolfus, Ludovicus et quidam alii dicti de Wedele, predictorum Ludovici et comitum capitanei. Urkunde von 1326 März 27, PUB 7, S. 16 ff., Nr. 4163.

305 Vgl. Urkunden von 1333 Juli 8, CDB I 18, S. 104 f., Nr. 7 und 8. - Dazu vgl. Czacharowski: Społeczne i gospodarcze siły (wie Anm. 24), S. 105-107; Gahlbeck: Zisterzienser (wie Anm. 3), S. 121-124; Brzustowicz: Rycerstwo ziemi choszczeńskiej (wie Anm. 8), S. 443-447, Tafeln 30, 31, 33, 34. - Beide Urkunden stimmen, abgesehen von den Namen, im Wortlaut miteinander überein. Eine gleichlautende Urkunde der Söhne Zulis’ I., Hasso (nach Brzustowicz, S. 446: III.), Betekin und Henning, die es höchstwahrscheinlich ebenfalls gegeben haben wird, ist nicht überliefert.

306 Vgl. die drei Urkunden von 1337 September 15, GStA PK Berlin, I. HA, Rep. 78a Nr. 1, T. 1, fol. 65 f., lit. g**, CDB I 18, S. 109, Nr. 18, sowie R 1333-1348, fol. 11, Nr. 40, 41; CDB I 18, S. 110, Nr. 19, 20.

307 Vgl. die Urkunden von 1337 März 17, R 1333-1348, fol. 4vf., Nr. 17; CDB I 18, S. 108, Nr. 16, und GStA PK Berlin, I. HA, Rep. 78a Nr. 1, T. 1, fol. 64vf., lit. f**, CDB I 18, S. 108 f., Nr. 17. 
eine neue Burg in der Stadt Bernstein errichten lassen. ${ }^{308}$ Die von Wedel hatten jedoch Ansprüche auf eine Entschädigung für ihre für die Pommernherzöge seit Markgraf Woldemars Tod geleisteten Dienste als Hauptleute geltend gemacht, die noch nicht beglichen waren, und, als sie mit Graf Ulrich von Lindow (als Vormund Markgraf Ludwigs) 1326 in Pommern einfielen, Burg, Stadt und Land Bernstein in ihren Besitz gebracht, mit dem sie sich dann spätestens 1328 vom Markgrafen hatten belehnen lassen. ${ }^{309}$ Bei den Friedensverhandlungen von 1338 wurde vereinbart, Bernstein an Herzog Otto zurückzugeben. Da man jedoch die Anrechte der von Wedel nicht übergehen konnte, wollte Markgraf Ludwig versuchen, sie um die Aufgabe von Bernstein zu bitten. Falls die Bitte erfolglos blieb, sollte der Streit um Bernstein von Kaiser Ludwig entschieden werden. ${ }^{310}$ Allerdings blieben die von Wedel noch ca. 12 Jahre im Besitz von Burg, Stadt und Land. Erst 1350, nach dem Tod Hennings (II.) von Wedel, der Bernstein innegehabt hatte, verzichtete dessen Sohn Henning auf Bernstein zugunsten der Belehnung mit der Stadt Kallies, dem Pfandbesitz von Nörenberg (Ińsko) und einer damals offenbar erreichbar erscheinenden Aussicht auf eine Belehnung mit Schloss, Stadt und Land Tempelburg, das um 1350 allerdings den Johannitern gehörte. ${ }^{311}$

Für das Jahr 1340 ist Hasso der Alte von Wedel als markgräflicher Ministerialer (officiatus) bezeugt, wahrscheinlich war er Hauptmann. ${ }^{312}$ Im September 1345 vertrat er gemeinsam mit Graf Ulrich von Lindow den Markgrafen auf dem Landtag zu Berlin, auf

308 Vgl. die beiden Urkunden von 1315 August 27, PUB 5, S. 232 f., Nr. 2967, 2968, sowie die Urkunde von 1315 November 18, PUB 5, S. 242, Nr. 2981. Zum Burgenbau in Bernstein und zum Besitz von Burg, Stadt und Land vgl. Podehl, Burg und Herrschaft (wie Anm. 26), S. 661.

309 Vgl. Urkunde von 1327 März 11, CDB II 2, S. 36 f., Nr. 638; Cramer: Die Herren von Wedel (wie Anm. 272), S. 96 f., Edward Rymar: Burzliwe dzieje ziemi pełczyckiej (do końca XVI wieku) [Die turbulente Geschichte des Landes Bernstein (bis zum Ende des 16. Jahrhunderts)], in: Zeszyty Pyrzyckie 5 (1972-73)'74, S. 139-176, hier: S. 156 f.; Gahlbeck: Zisterzienser (wie Anm. 3), S. 309312.

310 Vgl. die Urkunden von 1338 August 14, PUB 10, S. 296-305, Nr. 5655, 5656, hier besonders S. 299, 303.

311 Vgl. die beiden Urkunden von 1350 November 2, R 1348-1351 A, fol. 47vf., Nr. 89, 90; CDB I 18, S. 124 f., Nr. 45, 46. Es sei darauf hingewiesen, dass bereits zwei Jahre zuvor König Karl IV. die Herzogin Agnes von Stettin u. a. mit Bernstein beleibdingt hatte. Vgl. Urkunde von 1348 Juni 12, CDB I 18, S. 78 f., Nr. 26. - Im November 1350 standen die in den Weihnachtstagen desselben Jahres mit der Verleihung von Lagow (Łagów) abgeschlossenen Verhandlungen Markgraf Ludwigs mit dem Johanniterorden unmittelbar bevor. Offenbar verfolgte der Markgraf hier den Plan, die Johanniter durch entsprechende größere Zugeständnisse im Land Sternberg zu einem Verzicht auf Tempelburg bewegen zu können, das er ihnen am 10. September 1345 (vgl. R 1333-1348, fol. 25v, Nr. 103; CDB I 24, S. 37, Nr. 66) übertragen hatte. Allerdings hatte er damit keinen Erfolg; die Tempelburg-Frage fand in den Urkunden von 1350 Dezember 21-24, BLHA Potsdam, Rep. 9 B, Johanniterorden, U 112, U 113; R 1348-1351 A, fol. 50-51v, Nr. 100-103; CDB I 19, S. 133-138, Nr. 15-20, keinen Niederschlag. Zu Lagow vgl. Maciej Przybył: O zamku Joannitów w Łagowie/ Über die Johanniterburg in Łagów/The Castle of the Knights-Hospitalliers in Łagów. Dreisprachige Ausgabe. (Poznań) 2001, deutscher Text, übersetzt von Włodzimierz Zarzycki: S. 49-88; Christian Gahlbeck: Lagow (Łagów). Kommende des Johanniterordens, in: BKB, Bd. 2, S. 723-745; ders./ Dirk Schumann: Lagow/Lagów. Berlin 2009 (= Schlösser und Gärten der Neumark/Zamki i ogrody Nowej Marchii, 6).

312 Vgl. Urkunde von 1340 Januar 1, R 1333-1348, fol. 15v, Nr. 63; CDB I 18, S. 115, Nr. 128. 
dem sich die brandenburgischen Landstände gegen den Plan Markgraf Ludwigs, einen neuen Landschoss einzuführen, verbanden. ${ }^{313}$ Als 1348 der falsche Woldemar in Brandenburg auftauchte, sorgten die von Wedel, die Ludwig dem Älteren unbedingt treu blieben, für die Organisation der Landesverteidigung. Auch setzten sie sich mit Nachdruck dafür ein, dass die neumärkischen Adligen und Städte, die auf die Seite Woldemars gewechselt waren, mit der wittelsbachischen Seite einen Waffenstillstand schlossen, der die Neumark zu einer Insel des Friedens im damaligen Kriege werden ließ und um die Jahreswende 1348/49 dazu führte, dass die Anhänger des falschen Markgrafen auf die Seite Ludwigs des Älteren zurückkehrten. ${ }^{314}$ Dies honorierte der Markgraf u. a., indem er ihnen Distriktsvogteien in der Neumark überließ. Im Oktober bzw. November 1348 ernannte er Hasso den Alten, Hasso von Falkenburg, die beide bereits als Hauptleute für ihn kämpften, und einen weiteren Hasso von Wedel zu Vögten in den Distrikten Arnswalde, Reetz, Dramburg, Nörenberg und Kallies sowie Johann von Wedel (gemeinsam mit den Brüdern Henning und Arnold von Uchtenhagen und mit Heinrich, Otto und Reineke Mörner) in den Distrikten Königsberg, Soldin, Schönfließ, Lippehne, Bärwalde und Mohrin. ${ }^{315} \mathrm{Zu}$ Beginn des Jahres 1349 wurde dann Hasso von Falkenburg anstelle von Hasso dem Alten zum Vogt von Arnswalde, Reetz, Dramburg, Kallies und Nörenberg bestellt, und als er im Laufe des Jahres 1350 in Gefangenschaft geriet, nahm stellvertretend Johann von Wedel seine Stelle ein. ${ }^{316}$

Als Markgraf Ludwig der Römer die Mark Brandenburg von seinem Halbbruder übernahm, wollte er zunächst die Macht der neumärkischen Ministerialen und besonders die der von Wedel beschneiden. Zwar bestätigte er ihnen im Februar/März 1352 ihre Privilegien, gelobte, sie bei allen ihren Rechten und Gütern zu belassen, die sie ihm mit Urkunden beweisen konnten ${ }^{317}$, und ernannte im Oktober des Jahres Hasso von Uchtenhagen zum Hauptmann bzw. Landvogt der Neumark ${ }^{318}$, setzte ihn jedoch bereits im April 1353 wieder ab, um mit Otto von Schlieben einem Nichtneumärker dieses Amt zu überlassen. ${ }^{319}$ Lange konnte der Römer die von Wedel von Ministerialenämtern in seinem Land

313 Vgl. Urkunde von 1345 September 26, Ausfertigung: BLHA Potsdam, Rep.23 A, Kurmärkische Stände, U I/38; Abschrift: SBB PK Berlin, Urkunden, Wippelsche Sammlung, A 29; Druck: CDB III 1, S. 24 f., Nr. 23.

314 Vgl. Gahlbeck: terra Transoderana (wie Anm. 10), S. 146-148.

315 Vgl. die Urkunden von 1348 [um Mitte Oktober], R 1348-1351 A, fol. 33, Nr. 38; CDB I 18, S. 122, Nr. 41 (zu 1349), von 1348 [Mitte Oktober-November 19], R 1348-1351 A, fol. 33 f., Nr. 39; CDB I 18, S. 126 f., Nr. 49 (zu 1350), von 1348 Oktober 27, R 1348-1351 A, fol. 29v, Nr. 20; CDB I 18, S. 120, Nr. 38; und von 1348 November 19, R 1348-1351 A, fol. 61vf., Nr. 141, ungedruckt.

316 Vgl. die Urkunden von 1349 Januar 3, R 1348-1351 A, fol. 31v, Nr. 30; CDB I 18, S. 19, Nr. 26, und von 1350 November 28, R 1348-1351 A, fol. 48v, Nr. 95, ungedruckt.

317 Vgl. die Urkunden von 1352 Februar 29, R 1352-1356 A, fol. 75, Nr. 12, und von 1352 März 4, R 1352-1356 A, fol. 73v, Nr. 4, beide ungedruckt.

318 Vgl. Urkunde von 1352 Oktober 7, R 1352-1356 A, fol. 79vf., Nr. 28, CDB I 18, S. 129 f., Nr. 54 (zu Juli 8). Aus den Bestimmungen der Urkunde geht hervor, dass dieses Amt im Prinzip gleichbedeutend mit dem eines Landvogts der Neumark war.

$319[. .$.$] das wir [...] dem festen manne Otten von Slywen, ritter, unserm lieben getruwen, lassen und$ bevolen haben [...] unsir voythie unsir lande öbir Oder, die der feste man Hasso von Wedel von 
jedoch nicht fernhalten. Bereits ein Jahr später ernannte er Hasso von Wedel-Uchtenhagen zum Hauptmann von Schivelbein, der das Kommando über 100 Mann haben sollte, während Otto von Schlieben 200 Mann befehligen sollte; auch sollten Otto von Schlieben und Hasso von Uchtenhagen alle Einkünfte aus der Hauptmannschaft im Verhältnis 2:1 untereinander aufteilen. ${ }^{320} \mathrm{Zu}$ diesem Zeitpunkt bekleidete Hans (Henning) von WedelSchivelbein das Amt des markgräflichen Kammermeisters. ${ }^{321}$ Im Oktober 1354 musste Ludwig der Römer Hasso von Wedel-Falkenburg zum Landvogt und Hauptmann der Neumark bestellen, dessen Bruder und Neffe Hans von Schivelbein und Hasso von Uchtenhagen ihm als Distriktsvögte und Hauptleute an die Seite gestellt wurden. ${ }^{322}$ Zugleich benannte der Markgraf einen Rat von acht Personen, der den Landvogt unterstützen sollte und ohne deren Rat der Wittelsbacher weder Gerichtsentscheidungen fällen noch sonstige Handlungen unternehmen durfte, die die inneren Angelegenheiten des Landes betrafen. ${ }^{323}$ Hasso von Falkenburg stieg schließlich im Mai 1355 zum Hofmeister Markgraf Ludwigs auf, dem dieser die Regentschaft über die ganze Mark Brandenburg in seiner Abwesenheit übertrug. ${ }^{324}$ In die Vogtei der meisten Distrikte der Neumark folgte 1360 Wedego von Wedel nach, der bis 1364 amtierte. Als dieser anlässlich des Machtübergangs von Ludwig dem Römer an Markgraf Otto VIII. im Oktober 1364 abgesetzt wurde und mit Nickel von Ertmannsdorf ein Landfremder als Vogt in der Neumark nachfolgte, kam es in der Folgezeit aufgrund eines Streites über die aus der Vogtei und den übrigen Ämtern im Landesdienst angefallenen Schulden des Markgrafen gegenüber den von Wedel und seiner Verleihung des Angefälles der Güter des Henning von Wedel, eines Sohnes von Heinrich Aneseel, an Nickel von Ertmannsdorf zu einem Zerwürfnis, in der ein größerer Teil der Familie, die den Wittelsbachern seit 40 Jahren treu gedient hatte, Otto VIII. die Gefolgschaft aufkündigte und in den Dienst König Kasimirs III. von Polen trat. ${ }^{325}$ Dieser Konflikt wirkte sich für beide Seiten nachteilig aus. Während der Markgraf 1368 gegen das von den von Wedel und anderen neumärkischen Rittern unterstützte königlich-polnische Heer eine Niederlage erlitt, wurde die Position der von Wedel durch den Abfall eines Teils ihrer Mitglieder von der Neumark mittelfristig entscheidend geschwächt. Zwar musste Markgraf Otto nach der Rückkehr der Abtrünnigen Hasso von Uchtenhagen um 1370/71 die Vogtei in der Neumark erneut einräumen und um die Jahreswende 1371/72 sogar ver-

Uchtenhagen, unsir lieber getruwer, von uns inne gehat hat. Urkunde von 1353 April 7, R 13521356 A, fol. 82vf., Nr. 41, ungedruckt.

320 Vgl. Urkunde von 1354 April 26, R 1352-1356 A, fol. 111 f., Nr. 138, CDB I 18, S. 226 f., Nr. 20.

321 Vgl. ebd. sowie Urkunde von 1354 Mai 30, R 1352-1356 A, fol. 110, Nr. 133, CDB I 18, S. 80 f., Nr. 31.

322 Vgl. die Urkunden von 1354 Oktober 7 und 8, R 1352-1356 A, fol. 108vf., Nr. 129, und fol. 106vff., Nr. 125; CDB I 18, S. 135 f., Nr. 163, 164.

$323[. .$.$] in nostros consiliarios, sine quorum consilio nullas causas vel negocia terminare in dicta terra$ et civitatibus volumus nec debemus, quam diu dictus Hasso noster advocatus et capitaneus existit. Urkunde von 1354 Oktober 7 (wie Anm. 322).

324 Vgl. Urkunde von 1355 Mai 19, R 1352-1356 A, fol. 115 f., Nr. 150, CDB III 1, S. 35 f., Nr. 37.

325 Vgl. Czacharowski: Społeczne i gospodarcze siły (wie Anm. 24), S. 50, 89-91, 172-175; Ders.: Adelsherrschaft (wie Anm. 24), Kap. II 7, S. 7 ff.; ders.: Die Neumark (wie Anm. 9), S. 155 f.; Gahlbeck: terra Transoderana (wie Anm. 10), S. 149 ff. 
pfänden $^{326}$, Kaiser Karl IV. hielt sie jedoch nach seiner Machtübernahme in der Neumark keines Amtes innerhalb der Neumark mehr für würdig. 1384 schließlich verkauften die von Wedel zu Schivelbein ihr dortiges Schloss an den Deutschen Orden, um ihre Schulden zu begleichen, und traten 1388 als Söldner in den Dienst des Ordens. ${ }^{327}$

Auf die Familien von Uchtenhagen, von Jagow und Mörner kann an dieser Stelle nur kursorisch eingegangen werden. Die von Uchtenhagen ${ }^{328}$ stammen aus der Altmark und leiten ihren Namen von dem an der Uchte gelegenen Dorf Uchtenhagen südöstlich von Osterburg her. Diesen Ortsnamen übertrugen sie auf die Dörfer Uchtenhagen im Barnim westlich der Stadt Bad Freienwalde sowie Uchtenhagen (Krzywnica) an der Krampehl im Kreis Saatzig westsüdwestlich der Stadt Freienwalde in Pommern. Die Parallelen in beiden Räumen sind unverkennbar. Die beiden gleichnamigen Städte sind wahrscheinlich Gründungen von Adligen, die sich als Edelfreie verstanden ${ }^{329}$, und wenn auch Freienwalde i.P. erst unter den von Wedel zur deutschen Rechtsstadt erhoben wurde, ist doch anzunehmen, dass die von Uchtenhagen an der Gründung dieses Ortes ebenso wie an der von Bad Freienwalde zumindest vorbereitend mitbeteiligt waren. ${ }^{330}$ Trotz der Herkunft aus der Altmark stammen die ältesten urkundlichen Belege für diese Familie aus Pommern. Im Jahr 1243 bezeugte Gerhard von Uchtenhagen die Verleihung des Magdeburger Rechts durch Herzog Barnim I. an die Stadt Stettin. ${ }^{331}$ Anscheinend gehörte er damals zur Ritterschaft am pommerschen Herzogshof und saß vermutlich mit den von Jagow zusammen auf der Burg Jagow im pommerschen Uckerland nordwestlich von Prenz-

326 Vgl. die Urkunde von 1371 April 12, CDB I 19, S. 254, Nr. 30, in der Hasso von Uchtenhagen als Vogt erwähnt wird, und die Verpfändungsurkunde von 1371 Dezember 31, R 1360-1373 B, fol. 136vf., Nr. 100, CDB I 18, S. 146 f., Nr. 82 (zu 1372 Dezember 31).

327 Vgl. die Urkunden von 1384 April 14, S. 236 f., Nr. 33, und von 1388 Oktober 19, CDB I 18, S. 151 ff., Nr. 87.

328 Zur Geschichte der von Uchtenhagen vgl. Johann Heinrich Zedler (Hg.): Johann Zedlers Grosses vollständiges Universallexicon aller Wissenschafften und Künste [künftig zit.: Zedlers Universallexicon]. 64 Bde., Leipzig 1732-1754, hier: Bd. 46, Sp. 848-849; Czacharowski: Społeczne i gospodarcze siły (wie Anm. 24), S. 78-80; Ders.: Adelsherrschaft (wie Anm. 24), Kap. II 6, S. 1-3.

329 Ich halte den Versuch der Deutung dieses Stadtnamens von Gerhard Schlimpert in BNB 5, S. 137 f., Nr. 92, der einen Zusammenhang mit einer Abgabenfreiheit für Rodungssiedlungen vermutet, nicht für zutreffend. Das Beiwort „Freien-“ weist hier eher auf eine Gründung des Ortes bzw. seinen Besitz durch Adlige hin, die ihren Status als Freie dokumentieren wollten. Ähnlich dürfte auch die Bildung der Ortsnamen Adamsdorf (Sulimierz, Adelsmanstorp), Gr. Ehrenberg (Przekolno, Herenberg) und Herrendorf (Chłopowo) in der Neumark zu erklären sein.

$330 \mathrm{Zu}$ Bad Freienwalde vgl.: HOL 6, S. 156 f. Rolf Barthel: [Artikel] Bad Freienwalde, in: Evamaria Engel/Lieselott Enders/Gerd Heinrich/Winfried Schich (Hgg.): Städtebuch Brandenburg und Berlin. Stuttgart-Berlin-Köln 2000, S. 10-13, hier: S. 10 (= Deutsches Städtebuch, Neubearbeitung, Bd. 2), S. 10-13, nimmt dagegen an, dass Bad Freienwalde von einem Ministerialen der Wettiner gegründet worden sei. - Zu Freienwalde i.P. vgl. Podehl: Burg und Herrschaft (wie Anm. 26), S. 670; Thomas Tippach (Bearb.) u.M.v. Roland Lesniak: [Artikel] Freienwalde i. Pomm., in: Peter Johanek/Franz-Joseph Post (Hgg.): Städtebuch Hinterpommern. Stuttgart 2003, S. $63-65$ (= Deutsches Städtebuch Neubearbeitung, Bd. 3,2).

331 Vgl. Urkunde von 1243 April 3, PUB 12, S. 496 ff., Nr. 417. Auch in einer zweiten Urkunde für Stettin vom selben Tag wird er unter den Zeugen genannt, vgl. ebd., S. 498, Nr. 418. 
lau. ${ }^{332}$ Wahrscheinlich war er auch der Gründer von Freienwalde i.P. und Uchtenhagen. Allerdings erfolgte die Gründung dieser beiden Siedlungen in einem Gebiet, das dem Bischof von Kammin unterstand ${ }^{333}$, so dass er möglicherweise sowohl Vasall Herzog Barnims als auch des Kamminer Bischofs war. Lieselott Enders zählt die von Uchtenhagen zu den deutschen Siedlungsunternehmern, die als bereits namhafte Ritter „,von Anfang an größere Rechte genossen und dem Landesherrn gegenüber unabhängiger auftreten

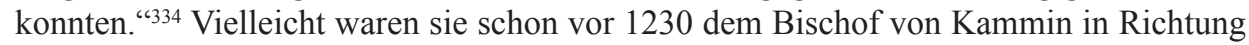
Oderberg gefolgt, stießen von dort weiter nach Süden vor und ließen sich schließlich im Gebiet am westlichen Ufer der Alten Oder nieder, wo sie Bad Freienwalde und Uchtenhagen gründeten. ${ }^{335}$ Vielleicht gelangten die von Uchtenhagen aber auch erst nach 1250 , als die Uckermark südlich der Welse an die Askanier fiel ${ }^{336}$, auf den Barnim und siedelten sich als Burgmannen der Askanier in Bad Freienwalde und dem dazugehörigen Burggut an, das sie Uchtenhagen nannten. In jedem Fall deuten die ersten Erwähnungen Arnolds (I.) von Uchtenhagen um 1300 darauf hin, dass die Familie um die Jahrhundertwende auf dem Barnim begütert war. Dieser Ritter gehörte zum Gefolge Markgraf Albrechts III. und testierte u.a. in Eberswalde. ${ }^{337}$ Ihren Besitz in Hinterpommern haben die von Uchtenhagen offenbar bereits in der zweiten Hälfte des 13. Jahrhunderts wieder aufgegeben und den von Wedel überlassen, die im dortigen Uchtenhagen einen ihrer Stammsitze einrichteten. ${ }^{338}$

332 Vgl. hierzu die Ausführungen zu den von Jagow weiter unten.

333 Diese Situation spiegelt sich im Wappen von Freienwalde wider, das in zwei Hälften gespalten ist und rechts einen Bischofsstab und links ein halbes Richtrad aufweist. Vgl. Tippach/Lesniak: Freienwalde i. Pomm. (wie Anm. 330), S. 64. Dieses Wappen hätte in dieser Form auch in der Zeit des Besitzes durch die von Uchtenhagen entstehen können, da die Familie das gleiche Wappen wie die von Wedel führte.

334 Lieselott Enders: Die Uckermark. Geschichte einer kurmärkischen Landschaft vom 12. bis zum 18. Jahrhundert. Weimar 1992, S. 57 (Veröffentlichungen des Brandenburgischen Landeshauptarchivs, 28).

335 Im Jahr 1233 stattete Bischof Konrad von Kammin das neu gegründete, von ihm „Gottesstatt“ ( $C i$ vitas Dei) genannte Prämonstratenserstift mit 100 Hufen in dem an Oderberg grenzenden Land Liepe aus, u. a. um dort seine Besitzansprüche und Diözesanhoheit in diesem Raum zu manifestieren: ut per claustrum adeo prenotatum termini nostre terre et dyocesis nostri episcopatus illesi declarentur. Urkunde von 1233 [Mai 23-Oktober 11], BLHA Potsdam, Rep. 10 B, Prämonstratenserkloster Gottesstadt, U 1; CDB I 13, S. 203, Nr. 2.

336 Vgl. den Vertrag von Hohenlandin von 1250, GStA PK, I. HA, Rep. 78a, Nr. 1, T.1, fol. 55 f., lit. z"'; PUB 12, S. 611 f., Nr. 512.

337 Vgl. Urkunden von 1300 März 17, KW, S. 476 f., Nr. 1781 (ausgestellt in Eberswalde), von 1310 Oktober 25, KW, S. 596, Nr. 2181 (ausgestellt vor Templin), und von 1311 (bzw. 1312) Dezember 27, KW, S. 624, Nr. 2285 (ausgestellt in Liebenwalde). - Der 1256 und 1259 erwähnte Herbert von Uchtenhagen wohnte offenbar noch in der Altmark. Sein plötzlicher Tod bewegte einen erkrankten Notar Markgraf Ottos III., der sich im Dominikanerkloster Seehausen/Altmark aufhielt und dort am 7. April 1259 davon erfuhr, zum sofortigen Eintritt in den Orden. Vgl. KW, S. 185, Nr. 795 (zu 1256 Juli 23) und S. 197, Nr. 837 (zu 1259 April 6-16). Bei dem zwischen 1270 und 1298 urkundlich belegten Johann von Uchtenhagen ist sowohl ein Wohnsitz in der Altmark als auch auf den Barnim möglich. Vgl. die Urkunden von 1270 August 4, KW, S. 242 f., Nr. 984, von 1272 Januar 21, KW, S. 252, Nr. 1017, und von 1298 Juli 2, KW, S. 456, Nr. 1708.

338 Vgl. Cramer: Die Herren von Wedel (wie Anm. 272), S. 76 f. 
Die nunmehr gänzlich märkische Familie hatte ihren Stammsitz vermutlich in Fürstenfelde (Boleszkowice), wo sie dem Kataster von 1337 zufolge mehrere Güter besaß. ${ }^{339}$ Mit der Bestallung Arnolds von Uchtenhagen zum Burghauptmann von Meseritz (Międzyrzecz) durch Markgraf Woldemar im Jahr $1316^{340}$ begann dann für sie eine Zeit, in der sich ihre Angehörigen den Markgrafen, Askaniern wie Wittelsbachern, an verschiedenen Orten der Mark Brandenburg in ihrer damaligen Ausdehnung als Burgmannen, Hauptleute und Vögte zur Verfügung stellten. Die Brüder Arnold (II.) und Henning von Uchtenhagen besaßen Zehden (wohl bis 1334/35) ${ }^{341}$, Schildberg (1334) ${ }^{342}$ und Zantoch $(1335)^{343}$, und zwar offenbar jeweils nacheinander und gemeinsam mit den von Jagow. 1341 erhielten sie die Genehmigung zum Bau einer Burg in Sonnenburg (Słońsk) südlich der Warthe. ${ }^{344}$ Sieben Jahre später verzichteten sie auf ihre Ansprüche auf Zantoch und hatten gemeinsam mit Johann von Wedel und Heinrich, Otto und Reineke Mörner die Vogtei in den Distrikten Königsberg, Soldin, Bärwalde, Schönfließ, Lippehne und Mohrin inne. ${ }^{345} \mathrm{Zu}$ Jahresbeginn 1349 wurden sie gemeinsam mit den von Mörner mit dem Städtchen Berneuchen belehnt, das sie mit einer Feste versehen durften. ${ }^{346}$ Henning von Uchtenhagen und Arnolds Söhnen Hans/Janus, Arnd und Heyne verschrieb Markgraf Ludwig der Ältere im Juni 1351 zur Begleichung seiner aus ihrem Dienst herrührenden Schulden Einkünfte aus Sellin (Zielin), Stolzenfelde, Bellin (Bielin), Rosenthal, Bärfelde (Kr. Königsberg), Gr. Mantel (Mętno), Altenkirchen (Łukowice), Kerkow und Falkenwalde (Wierzchlas), Dörfern in ihrem Vogteibezirk, nachdem er ihnen zuvor bereits Burg und Stadt Oderberg verpfändet hatte. ${ }^{347}$ Dort erhielten sie 1353 von Markgraf Ludwig dem Römer die Erlaubnis, die alte Burg abzubrechen und auf dem Werder in der Oder eine neue Burganlage zu bauen. ${ }^{348} \mathrm{Ihr}$ Vogteiamt in der Neumark mussten sie allerdings Ende 1352 aufgeben, als der Markgraf Ruleke von Liebenthal zum Vogt ernannte. ${ }^{349}$ Nach 1355 zogen sie sich aus der Neumark zurück. 1367 wurden sie als Inhaber von Sonnenburg zu den Rittern des Landes Sternberg (Torzym) gezählt. ${ }^{350}$ Auffällig ist, dass sie sich, obwohl

339 Bona illorum de Vchtenhagen cum opido Ffursteueld non dant precariam, ut dicunt, et habent 5 servicia. K 1337 B, fol. 111; LB/Gollmert, S. 16.

340 Vgl. die Urkunden von 1316 Juni 26, KW, S. 702 f., Nr. 2485-2487.

341 Vgl. Gahlbeck: Zisterzienser (wie Anm. 3), S. 372.

342 Vgl. Urkunde von 1334 März 5, R 1333-1348, fol. 2, Nr. 9; CDB I 18, S. 105, Nr. 9.

343 Vgl. Urkunde von 1335 September 20, R 1333-1339 L, fol. 26 f., Nr. 19; CDB I 18, S. 382, Nr. 18.

344 Vgl. Urkunde von 1341 Januar 2, R 1333-1348, fol. 18vf., Nr. 75; CDB I 18, S. 117, Nr. 31 u. CDB I 19, S. 131, Nr. 12.

345 Vgl. die Urkunden von 1348, R 1348-1351 A, fol. 48v, Nr. 14, von 1348 November 19, ebd., fol. 61vf., Nr. 141, und von 1348 November 20, ebd., fol. 28 f., Nr. 13, alle ungedruckt.

346 Vgl. Urkunde von 1349 Januar 6, R 1348-1351 A, fol. 33v, Nr. 40; CDB I 24, S. 47, Nr. 85.

347 Vgl. Urkunde von 1351 Juli 24, R 1348-1351 A, fol. 62vff., Nr. 144, ungedruckt.

348 Vgl. Urkunde von 1353 März 5 (Actum)/April 14 (Datum), R 1352-1356 A, fol. 89 f., Nr. 63; Druck: CDB I 12, S. 353, Nr. 5, fehlerhaft und mit falschem Datum zu 1353 Dezember 15.

349 Vgl. Urkunde von 1352 Dezember 2 (wie Anm. 192). Dazu vgl. die Ausführungen weiter oben.

350 Vgl. Urkunde von 1367 Dezember 24, Ausf. GStA PK Berlin, VII. HA (Urkunden), Abt. b (Haussachen der Markgrafen), Nr. 8; CDB I 20, S. 238 f., Nr. 74. Im Oktober 1355 verkauften Henning von Uchtenhagen und seine Neffen die Hälfte von Oderberg mit allem Zubehör, wozu u.a. die Hälfte der Zolleinnahmen zu Eberswalde-Neustadt und Hegermühle gehörten, für 600 Mark Branden- 
sie zu den führenden Geschlechtern in der Neumark gehörten - 1354 war Henning von Uchtenhagen Mitglied im neumärkischen Ältestenrat ${ }^{351}$ - , in der Neumark nördlich der Warthe an keinem der genannten Orte auf Dauer ansiedelten und sich um dauerhaften Besitz bemühten. Ihr Interesse richtete sich vor allem auf Besitzungen südlich der Warthe und westlich der Oder. Als Markgraf Ludwig der Römer den Sühnevertrag mit dem Bischof von Lebus von 17. Juni 1354 abschloss, hatte er offenbar den Plan, Sonnenburg zum Bischofssitz zu machen, und vereinbarte, dass der Bischof Lebus zurückgeben sollte, wenn es ihm, dem Markgrafen, bis zum 30. April 1356 gelinge, die von Uchtenhagen zum Verzicht auf die Burg in Sonnenburg und siebeneinhalb dazugehörige Dörfer zu bewegen. Der Versuch scheiterte jedoch, weil die von Uchtenhagen sich weigerten, diese Besitz aufzugeben. ${ }^{352}$ Unter den Luxemburgern zogen sie sich dann offensichtlich endgültig auf ihren Besitz auf dem Barnim zurück. ${ }^{353}$

Als Zweig der von Uchtenhagen oder zumindest als eng mit ihnen verwandt gilt die Familie von Jagow, die nicht nur das gleiche Wappen, sondern in der Askanierzeit im großen und ganzen auch die gleichen Vornamen führte. ${ }^{354}$ Auch die von Jagow werden zuerst in pommerschen Quellen erwähnt: Heinrich von Jagow war 1243 Zeuge in einer Urkunde der pommerschen Herzogin Marianne für das Zisterzienserinnenkloster in Stettin, Johann und Grening von Jagow in einem Dokument Herzog Barnims I. für das Sabinenkloster in Prenzlau. ${ }^{355}$ Nach Lieselott Enders geht der Name auf ihren Stammsitz im pommerschen Uckerland, die bedeutende slawische Burg Jagow nordwestlich von Prenzlau, zurück, nach der sich die Familie genannt habe. ${ }^{356}$ Wenn diese Annahme stimmt, so muss auch der in der Altmark ansässige Zweig diesen Namen angenommen haben. Die pommerschen Ritter waren vermutlich für Anlage des Dorfes Jagow (Jagów) im Land

burger Silber an die von Wedel. Vgl. Urkunde von 1355 Oktober 18, R 1352-1356 A, fol. 116vff., Nr. 155; CDB I 12, S. 354, Nr. 6. In neumärkischen Quellen ist Henning von Uchtenhagen (ohne seine Neffen) noch bis 1357 unter den Zeugen nachweisbar.

351 Vgl. Urkunde von 1354 Oktober 7 (wie Anm. 322).

352 Vgl. die beiden Urkunden von 1354 Juni 17, GStA PK Berlin, VII. HA, Allgemeine Urkundensammlung, Nr. 727 bzw. ebd., Urkunden, Abt. a (Mark als Reichsstand), Nr. 15 g.; CDB I 20, S. 224-230, Nr. 64, 65. Dazu vgl. Christian Gahlbeck/Ralf Gebuhr/Dirk Schumann: Sonnenburg (Słońsk). Johanniter-Ordensschloß, in: BKB, Bd. 2, S. 1148-1175, hier: S. 1149; Christian Gahlbeck: Die Rückkehr der Bischöfe nach Lebus im Jahr 1354. Wendepunkt in der Geschichte der Bischofsresidenz an der Oder, in: Klaus Neitmann/Heinz-Dieter Heimann (Hgg.): Spätmittelalterliche Residenzbildung in geistlichen Territorien Mittel- und Nordostdeutschlands. Berlin 2009, S. 295-323, hier: S. 315-319 (= Studien zur brandenburgischen und vergleichenden Landesgeschichte, Bd. 2).

353 Zu diesen Besitzungen dürfte mit ziemlicher Sicherheit auch das Dorf Sonnenburg südlich von Bad Freienwalde gehört haben, so dass hier mit einer Namensübertragung durch die von Uchtenhagen gerechnet werden kann, wenn auch derzeit nicht klar ist, in welche Richtung.

354 Vgl. Zeidlers Universallexicon (wie Anm. 328), Bd. 46, Sp. 848-849 (Artikel: von Uchtenhagen).

355 Vgl. die Urkunden von 1243 Januar 27, PUB 1², S. 492, Nr. 414, und von 1250 März 7, PUB $1^{2}$, S. 610 f., Nr. 511.

356 Vgl. Enders: Uckermark (wie Anm. 334), S. 54. Jagow war auch ein Propstei- bzw. Archidiakonatssitz des Bistums Kammin. Vgl. ebd., S. 72, 76, 90 f., 144. 
Bernstein verantwortlich, wo sie jedoch nicht auf Dauer sesshaft wurden. ${ }^{357}$ Durch den Vertrag von Hohenlandin ${ }^{358}$ gerieten Burg und Städtchen Jagow mit dem gesamten südlichen Uckerland in den Besitz der Askanier. Auf diese Weise wurden die dortigen von Jagow zu Vasallen der Markgrafen, weshalb sie nach 1250 aus den pommerschen Quellen verschwinden. In märkischen Urkunden lassen sich bis 1297 nur Belege für den altmärkischen Zweig finden: Arnold (I.) von Jagow ist für die Jahre 1267 bis 1284 im Gefolge der ottonischen Markgrafen bezeugt; er nahm 1280 als Vertreter des altmärkischen Adels an den Bedeverhandlungen mit den Askaniern teil. ${ }^{359}$ Johann (Henning) von Jagow bekleidete unter den johanneischen Markgrafen 1297 das Amt eines Vogtes von Rathenow. ${ }^{360}$ Als weitere Vertreter des altmärkischen Zweiges werden 1305 Arnold (II.) und zwischen 1319 und 1321 Matthias von Jagow genannt. ${ }^{361}$

In neumärkischen Quellen erscheinen die von Jagow erstmals im Jahr 1298: Bei der Gründung des Soldiner Kollegiatstifts durch Markgraf Albrecht III. weilte ein Beteko von Jagow unter den Zeugen. ${ }^{362}$ Ein Jahr später wurde Beteko zusammen mit seinem Bruder Herbert von Albrecht III. mit dem Städtchen Zehden belehnt. Wahrscheinlich rührte der Besitz des bei Zehden gelegenen Dorfes Wrechow (Orzechów), das Henning von Jagow 1337 zur Gänze besaß und von dem die Familie zur Leistung von 5 servicia verpflichtet war, von dieser Belehnung her. ${ }^{363}$ Unter Markgraf Woldemar engagierten sich die von Jagow ebenso wie die von Uchtenhagen im Gebiet der Kastellanei Meseritz, wo Beteko 1312/15 dem Zisterzienserkloster Semmritz Landbesitz in und um Blesen (Bledzew) zukommen ließ. ${ }^{364}$ Wohl erst der nächsten Generation gehörte Henning von Jagow an, der

357 Das Dorf ist erstmals im Kataster von 1337 quellenmäßig bezeugt. Vgl. K 1337 B, fol. 118; LB/ Gollmert, S. 27. Dort waren damals die von Billerbeck und Slamer begütert. - Da die Bischöfe von Kammin bis 1290 in Bernstein ebenfalls eine Propstei gegründet hatten, dessen Besitzumfang weitgehend unbekannt ist, muss damit gerechnet werden, dass zumindest Teile des Landes Bernstein nicht im herzoglichen, sondern im bischöflichen Auftrag von Adligen besiedelt wurden. Vgl. Gahlbeck: Oder-Drage-Raum (wie Anm. 43), S. 46 ff., 90; ders.: Zisterzienser (wie Anm. 3), S. 229 f.

358 Vgl. Urkunde von 1250 (wie Anm. 336).

359 Vgl. die Urkunden von 1267 November 18, KW S. 232, Nr. 947 (ohne Vornamen), von 1268 August 31, KW, S. 235, Nr. 957 (erster eindeutiger Beleg); von 1280 August 18, KW, S. 312 f., Nr. 1223 (Bedeverhandlungen), und von 1284 Juli 18, KW, S. 358, Nr. 1355 (letzter genau datierter Beleg).

360 Vgl. Urkunde von 1297 April 4, KW, S. 445, Nr. 1670.

361 Vgl. Urkunden von 1305 Januar 6, KW, S. 526, Nr. 1942, von 1319 Juli 11, KW, S. 792 f., Nr. 2708, von 1320 Mai 13, KW, S. 831, Nr. 2805, und von 1321 Dezember 21, KW, S. 876 f., Nr. 29042906. - Der im Verzeichnis der Kriegskosten des Wedego von Wedel von 1321 genannte Arnold von Jagow, der sich mit mehreren socii am Kriegszug in die Mark beteiligte, gehörte dagegen wahrscheinlich dem uckermärkischen Zweig der Familie an. Vgl. PUB 6, S. 81-85, Nr. 3560, hier: S. 82,83 .

362 Vgl. Urkunde von 1298 Juni 1, GStA PK Berlin, I. HA, Rep. 78a, Nr. 1, T. 2, fol. 92vff., Nr. 12; CDB I 18, S. 442 f., Nr. 3.

363 Vgl. Urkunde von 1299 August 10, GStA PK Berlin, I. HA, Rep. 21, Nr. 188 (Zehden), Vol. I, S. 3-4; CDB I 19, S. 67 f., Nr. 6.

364 Vgl. Urkunden von 1312 März 24, KW, S. 613 f., Nr. 2236, und von 1315 September 8, KW, S. 679 f., Nr. 2431. Es handelte sich nur um eine Schenkung, die Markgraf Woldemar als Vormund Markgraf Johanns 1312 vornahm und Johann V. 1315 in einer eigenen, wörtlich übereinstimmenden Urkunde nachvollzog. 
1334 unter Markgraf Ludwig dem Älteren Truchsess war und von diesem gemeinsam mit den Brüdern Matthias und Arnd von Uchtenhagen mit Schildberg belehnt wurde. ${ }^{365}$ Ein Jahr später erhielt er gemeinsam mit seinem Bruder Matthias, seinem Vetter Klaus und den von Uchtenhagen zu gesamter Hand die Burg Zantoch mit dem Dorf Zechow (Ciechów) und den Beden und dem Wagendienstgeld aus Sellin, Bärfelde, Heinersdorf (Chwalęcice) und Merzdorf (Gorzów-Małyszyn). ${ }^{366}$ Wahrscheinlich gaben die von Jagow Zantoch gemeinsam mit den von Uchtenhagen als Besitz auf, als diese 1341 Sonnenburg erhielten, und zogen sich anschließend aus der Neumark weitgehend zurück. Als letzter Inhaber von Besitzungen der Familie im Lande über der Oder ist Klaus von Jagow bezeugt, der bis zu seinem Tode (um 1347/48) die Dörfer Wrechow und Eulam (Ulim) im Warthebruch innehatte. ${ }^{367}$

Eng mit den von Uchtenhagen und von Jagow hing offenbar auch die Familie der Mörner $^{368}$ zusammen. Dieses Geschlecht verdankt seine große Bedeutung innerhalb des neumärkischen Adels im wesentlichen zwei Vertretern einer einzigen Generation, nämlich den Brüdern Dietrich und Otto Mörner, die am Hof der wittelsbachischen Markgrafen hohe Hofämter innehatten und so ihre Familie förderten. Die Herkunft der Mörner liegt im Dunkeln, ihr Name ist wahrscheinlich von der neumärkischen Stadt Mohrin abgeleitet, obwohl auch diese Adligen (vielleicht im Gefolge der von Uchtenhagen oder von Jagow) in die Neumark eingewandert sein dürften. Ihr erster namentlich bekannter Vertreter, Johann (Henning) Mörner, wird erstmals in der Gründungsurkunde Markgraf Albrechts III. für das Soldiner Kollegiatstift erwähnt. ${ }^{369}$ Stammsitz der Familie war das zwischen Zellin und Fürstenfelde (Boleszkowice) gelegene Dorf Klossow (Kłosów) am neumärkischen Rand des Oderbruchs. Dort besaßen die Mörner 1337 zehn dienstpflichtige Hufen. ${ }^{370}$ Sie wirkten hier offenbar als Lokatoren des Städtchens Zellin, das bereits in voraskanischer Zeit ein Verwaltungsmittelpunkt gewesen war, an dem die Bischöfe von Kammin ein Archidiakonat bzw. eine Propstei eingerichtet hatten, und erhielten die Güter in Klossow als Entschädigung für die mit der Gründung verbundenen Aufwendungen. ${ }^{371}$ Bereits um 1320

365 Vgl. Urkunde von 1334 März 5 (wie Anm. 342), K 1337 B, fol. 109v, LB/Gollmert, S. 13. Wrechow könnte in voraskanischer Zeit ein Burggut für die Burgmannen von Zehden gewesen sein. Allerdings lag die Zehdener Burg um 1300 bereits lange Zeit wüst, und ihre Stätte gehörte wahrscheinlich zur Gründungsausstattung des Zisterzienserinnenklosters Zehden. Vgl. Gahlbeck: Zisterzienser (wie Anm. 3), S. 222 f.

366 Vgl. Urkunde von 1335 September 20 (wie Anm. 343).

367 Vgl. Urkunde von 1348, R 1348-1351 A, fol. 48v, Nr. 14, ungedruckt. Zum Zeitpunkt der Ausstellung der Urkunde war Klaus von Jagow bereits verstorben. - Auf die Gründe, weshalb die von Jagow die Neumark verließen, kann hier nicht eingegangen werden. Es ist nicht auszuschließen, dass die Ursache hierfür bei ihren Besitzungen in der Uckermark bzw. der Altmark lagen, die von den Auseinandersetzungen um den falschen Woldemar wesentlich stärker als die Neumark betroffen waren.

368 Zur Familie Mörner vgl. Czacharowski: Społeczne i gospodarcze siły (wie Anm. 24), S. 66-71; ders.: Adelsherrschaft (wie Anm. 24), Kap. II 5, S. 1-4.

369 Vgl. Urkunde von 1298 Juni 1 (wie Anm. 362).

370 Vgl. K 1337 B, fol. 109; LB/Gollmert, S. 12.

371 Zu Zellin vgl. Wittlinger: Untersuchungen (wie Anm. 292), S. 97 f. Zum Kamminer Archidiakonat in Zellin vgl. Martin Wehrmann: Die Camminer Archidiakonate in der Neumark, in: SVGN 8 
müssen die Mörner eine reiche und angesehene Adelsfamilie gewesen sein, da Henning Mörner für Herzog Wartislaw IV. gegenüber mehreren pommerschen Städten als Bürge auftrat. ${ }^{372} 1347$ erwarben die Brüder Henning und Reineke Mörner von Henning und Bertram von Stegelitz das Städtchen Berneuchen. ${ }^{373}$

Den Aufstieg innerhalb des neumärkischen Adels verdanken die Mörner vor allem Dietrich Mörner, einem Geistlichen, der seit 1335 am Hof Markgraf Ludwigs des Älteren nachweisbar ist und schon bald zum Protonotar in der markgräflichen Kanzlei aufgestiegen war. Er gehörte als Kanoniker dem Kollegiatstift Soldin an, deren innerer Verwaltung er bis 1351 als Dekan vorstand. Von 1352 bis 1353 leitete er das Stift als Propst, bis er die Propstei in Bernau erhielt, die er bis 1366 innehatte. ${ }^{374}$ Seine Brüder Otto, Reineke und Heinrich, die sich vor allem im Krieg gegen den falschen Woldemar auszeichneten, erhielten im November 1348 zusammen mit Henning und Arnold von Uchtenhagen und Johann von Wedel die Distriktsvogtei Königsberg-Soldin-Schönfließ-Lippehne-Bärwalde-Mohrin. ${ }^{375} 1351$ trat an die Stelle Reinekes ihr Vetter Dietrich (Thilo). ${ }^{376}$ Insgesamt übten die Mörner die Vogtei bis zur Ernennung Rulekes von Liebenthal durch Markgraf Ludwig den Römer im Jahr 1352 aus. Otto Mörner wurde darüber hinaus zeitweilig die Münze in der Neumark übertragen, die er in Mohrin ansiedelte. ${ }^{377}$ Er gehörte seit 1354 dem neumärkischen Ältestenrat an und fungierte am Hof des Römers 1355 als Küchenmeister. ${ }^{378}$ Von 1369 bis 1373 wurde ihm das Hofrichteramt in der Neumark übertragen. ${ }^{379}$ Von Zellin und Klossow aus versuchten die Mörner, ihre Besitzungen sowohl in die Neumark hinein als auch über den Oderbruch hinweg auf den Barnim auszudehnen. Sie erlangten 1348 zunächst die Verleihung des Angefälles der Güter des Hincze Junge, auf das sie später zugunsten des Angefälles der Güter der Brüder Hermann und Nicolaus Witte verzichteten, die einen Landkomplex um die Burg Neuenhagen im Oderwinkel südlich von Oderberg sowie in Altenkirchen und Wittstock (Wysoka Wielkopolska) besaßen. ${ }^{380}$ 1349 belehnte Markgraf Ludwig der Ältere die Gebrüder Mörner mit den Dörfern Ort-

(1899), S. 1-10; Johannes Allendorf: Die Archidiakonate des Bistums Camin. Ein Beitrag zur Kirchengeschichte. Diss. Berlin 1927, S. 57.

372 Vgl. Urkunde von 1320 August 23, PUB 5, S. 534, Nr. 3398.

373 Vgl. Urkunde von 1347 Oktober 5, R 1333-1348 A, fol. 18, Nr. 116; CDB I 24, S. 41, Nr. 74.

374 Vgl. Christian Gahlbeck u.M.v. Blandine Wittkopp: Soldin (Myślibórz). Kollegiatstift, in: BKB, Bd. 2, S. 1123-1147, hier: S. 1127.

375 Vgl. Urkunde von 1348 November 19 (wie Anm. 315).

376 Vgl. Urkunde von 1351 August 9, R 1348-1351 A, fol. 66vff., Nr. 160, ungedruckt.

377 Vgl. die Urkunden von 1352 März 10, R 1352-1356 A, fol. 74vf., Nr. 10; CDB I 19, S. 24 f., Nr. 41, und von 1352 Oktober 5, R 1352-1356 A, fol. 78 ff., Nr. 26; CDB I 19, S. 77 f., Nr. 25.

378 Vgl. die Urkunden von 1354 Oktober 7 (wie Anm. 322), 1355 Mai 19 (wie Anm. 324) und von 1355 Oktober 16, R 1352-1356 A, fol. 122, Nr. 171, 172, beide ungedruckt.

379 Vgl. Urkunde von 1369 November 14, R 1360-1373 B, fol. 147 f., Nr. 71 (70); CDB I 18, S. 42 f., Nr. 73; Czacharowski: Społeczne i gospodarcze siły (wie Anm. 24), S. 70; ders.: Adelsherrschaft (wie Anm. 24), Kap. II 5, S. 1.

380 Vgl. die Urkunden von 1348 November 19, R 1348-1351 A, fol. 62 f., Nr. 142, ungedruckt; von 1350 Oktober 20 (wie Anm. 97), und [1350?] September 23, R 1348-1351 A, fol. 48 f., Nr. 92, CDB I 19, S. 18 f., Nr. 30. Hincze Junge war Bürger von Soldin und wurde 1341 mit dem Schulzenamt von Soldin belehnt. Zum Besitz Junges zählten Güter in Zollen, Wuthenow und Naulin. 
wig, Mädewitz (bei Wriezen) und Neutrebbin im Oderbruch und Kriescht (Krzeszyce) im Land Sternberg. Am Ende seiner Regierung in der Neumark verlieh er ihnen und ihren Vettern die gesamte Hand über diese Dörfer sowie über Klossow, Mohrin (More), Stolzendorf, Berneuchen und Oderberg. Darüber hinaus erhielten die Mörner von den Markgrafen 1350 das Haus des Juden Meyer in Berlin samt einer Synagoge und mehreren Hütten und spätestens 1354 das Dorf Rehberg bei Bernau. ${ }^{381}$ In Stolzendorf bei Mohrin errichteten Otto und Reineke Mörner unter Markgraf Otto VIII. zusammen mit Henning Plötze, Henning Güstebiese und einem Angehörigen der Elsholt die Burg Stolzenburg, wo sie dem Markgrafen als Burgmannen dienen sollten. Dieser wollte ihnen die gleichen Rechte verschaffen, wie sie die Burgmannen der Reichsburgen im hessischen Friedberg und Gelnhausen besaßen; da diese Rechte aber in der Neumark nicht bekannt waren, lehnten die Mörner und ihre Genossen die entsprechende Urkunde ab. ${ }^{382}$ Nach dem Tod Dietrichs und Ottos und dem Übergang der Mark an Kaiser Karl IV. büßten die Mörner ihre von den beiden Brüdern erworbene Stellung im neumärkischen Adel wieder ein; sie zogen sich auf ihre Güter im Oderbruch zurück und traten seitdem politisch kaum mehr in Erscheinung. ${ }^{383}$

\section{III}

Die Untersuchung der hier vorgestellten neun neumärkischen Adelsfamilien hat den Eindruck bestätigt, dass ihr Weg in die Neumark in fast allen Fällen über Pommern führte oder dort begann. Die von Brederlow, von Güntersberg, von Schöning, von Liebenow, von Wedel, von Uchtenhagen und von Jagow werden sämtlich vor ihrem Erscheinen in der Neumark in pommerschen Quellen genannt. Auch die Herkunft weiterer führender Adelsfamilien, der von Wulkow, Witte, Sydow, von der Osten ${ }^{384}$ und von der Marwitz, deren Schicksal hier nicht dargestellt werden konnte, weist in diese Richtung. Lediglich bei den von Liebenthal, die in den pommerschen Quellen bis 1345 nicht erwähnt werden und

381 Vgl. die Urkunden von 1350 Oktober 21, R 1348-1351 A, fol. 53v, Nr. 112, CDB I 19, S. 19, Nr. 31, und von 1354 Oktober 4, R 1352-1356 A, fol. 113vff., Nr. 147, ungedruckt. Außer Rehberg erhielten die Mörner 1354 noch dienstpflichtigen Besitz in Neuendorf bei Oderberg. Das Haus in Berlin sollte wahrscheinlich vor allem als Absteigequartier für Dietrich und Otto Mörner dienen. Czacharowski: Społeczne i gospodarcze siły (wie Anm. 24), S. 67, lokalisiert das Haus nicht in Berlin, sondern in Berlinchen.

382 Vgl. Urkunde von 1368 April 21, R 1360-1363 A, fol. 143 f., Nr. 61 (60), CDB I 19, S. 84, Nr. 35. Der Registereintrag in R 1360-1363 A und B trägt in der Überschrift den Zusatz Non est recepta.

383 Im Verzeichnis von 1402 werden als Vasallen, die dem Deutschen Orden huldigten, nur zwei Familienangehörige erwähnt, Erasmus Mörner sowie Henning Mörner aus dem Zehdenschen Winkel. Vgl. Urkunde von [1402 um und nach August 9], GStA PK Berlin, XX. HA, OBA 727.

384 Zur Familie von der Osten vgl. Otto Grotefend (Bearb.): Geschichte des Geschlechts v. d. Osten. Urkundenbuch. Im Auftrag des v. d. Ostenschen Familienverbandes bearbeitet, Bd. 1 (1200-1400). Leipzig 1914; Hans Wätjen: Von der Osten: ein pommersches Geschlecht im Wandel der Jahrhunderte. Eine geschichtliche Darstellung bis zur Gegenwart. Bonn 1960; Czacharowski: Społeczne i gospodarcze siły (wie Anm. 24), S. 71-78; ders.: Adelsherrschaft (wie Anm. 24), Kap. II 6, S. 1-10. 
deren Name auf den Barnim verweist, und bei den von Mörner, deren Herkunft im Dunkeln liegt, ist eine pommersche Vorgeschichte unsicher bzw. zweifelhaft. Verfolgt man den Weg der Adelsgeschlechter weiter zurück, so lässt sich dieser für die von Wedel in die Grafschaft Stormarn im heutigen Schleswig-Holstein, für die von Schöning, die von der Osten $^{385}$ und vielleicht für die von Liebenthal in den Braunschweiger Raum, für die von Liebenow nach Mitteldeutschland in das Gebiet um Merseburg und für die von Uchtenhagen und Jagow in die Altmark zurückverfolgen. Aus dem Havelland, dem Teltow, dem Land Lebus oder der Niederlausitz dagegen sind keine Geschlechter in die Neumark gekommen, die dort in eine führende Position gelangten. Die Namen der von Brederlow und von Mörner entstanden erst im Oder-Drage-Raum. Allerdings dürften auch diese beiden Familien als Einwanderer dorthin gekommen sein; es gibt keinerlei Hinweise dafür, dass sie einem autochthonen slawischen Adelsgeschlecht entstammten. Überhaupt sind keinerlei Anhaltspunkte überliefert, dass es in den slawisch besiedelten Gebieten zwischen Oder und Drage, Warthe und Pommern unmittelbar vor dem Einsetzen des hochmittelalterlichen Landesausbaus eine adlige slawische Führungsschicht gab. ${ }^{386}$

Die von Wedel und von Liebenow wurden sicher und die von Brederlow und Schöning sehr wahrscheinlich bereits in voraskanischer Zeit in der Neumark ansässig. Sie gehörten zu den Burgmannen der pommerschen Burgen in Kürtow (v. Wedel), Reetz (v. Liebenow, v. Wedel) und Lippehne (v. Brederlow, von Schöning), möglicherweise auch zu einer pommerschen Besatzung von Zehden (v. Brederlow) und Neu-Zantoch (v. Schöning). Auch die von Liebenthal können aufgrund ihrer 1303 und 1337 genannten Besitzungen Burgmannen gewesen sein. Ihre Güter in Bärfelde, Kr. Königsberg, Gr. Ehrenberg und Adamsdorf waren vermutlich Burggüter der Burgen Bärwalde, Bernstein und Lippehne. Die von Schöning und von Brederlow waren daneben offenbar auch Burgmannen der pommerschen Herzöge in Pyritz und die von Wedel auf Kremzow in Stargard, entweder ebenfalls als Vasallen der Herzöge oder aber als Vasallen der Bischöfe von Kammin, in deren Auftrag sie die Burg in Freienwalde i.P. und dazu als Burggut Uchtenhagen innehatten. Diese Aufgabe übernahmen die von Wedel von den von Uchtenhagen, die sich hier wohl um 1243 niedergelassen hatten, die Gegend dann aber um 1250 wieder verließen, als das Uckerland, wo sie mit den von Jagow auf Jagow saßen, durch den Vertrag von Hohenlandin an die Markgrafen fiel und sie zu Vasallen der Askanier wurden. Die von Uchtenhagen gelangten daher nicht über Uchtenhagen oder Freienwalde i.P. in die Neumark. Gleiches gilt für ihre Verwandten, die von Jagow, die vor 1250 möglicherweise

385 Vgl. Wätjen: Von der Osten (wie Anm. 384), S. 23 f.; Czacharowski: Społeczne i gospodarcze siły (wie Anm. 24), S. 71; ders.: Adelsherrschaft (wie Anm. 24), Kap. II 6, S. 1. Weitere Tätigkeitsgebiete der von der Osten waren Mecklenburg, Rügen, Pommern-Demmin und das Stift Kammin.

386 Eigentlich erwartet man die Existenz einer adligen slawischen Führungsschicht zumindest für den relativ stark besiedelten Raum Pyritz-Lippehne-Soldin, in der urkundlichen Überlieferung gibt es jedoch keinerlei Indizien dafür, anders als im pommerschen Land Bahn, wo eine solche Führungsschicht schriftlich bezeugt ist, die R. Benl als die „Bahner Erben“ bezeichnet hat. Vgl. Rudolf Benl: Die Gestaltung der Bodenrechtsverhältnisse in Pommern vom 12. bis zum 14. Jahrhundert. Köln, Wien 1986 (= Mitteldeutsche Forschungen, 93), hier: S. 64-71; Gahlbeck: Oder-Drage-Raum (wie Anm. 43), S 64-70. 
Burgmannen in Bernstein waren und als solche das Dorf Jagow im Land Bernstein innegehabt hatten. Für beide Familien lässt sich keine Kontinuität zwischen ihrer pommerschen Zeit (vor 1250) und ihrer Anwesenheit in der Neumark (ab ca. 1280) nachweisen; sie siedelten sich vielmehr von der Uckermark aus und erst unter den Askaniern als deren Vasallen dort an, und zwar konkret als Vasallen Markgraf Ottos V. und Markgraf Albrecht III. Allem Anschein nahm übernahmen die von Jagow mit Zehden und die von Uchtenhagen mit Fürstenfelde, das ursprünglich Chintz hieß, zwei alte zentrale pomoranische Burgorte, deren Burgen die Askanier nicht mehr benötigten, und wurden von ihnen mit der Aufgabe betraut, dort jeweils eine deutsche Rechtsstadt anzulegen, deren Lokatoren sie gewesen sein dürften. ${ }^{387}$ Den gleichen Auftrag erhielten die Mörner, die das zwischen diesen beiden Burgorten gelegene Zellin in eine deutsche Rechtsstadt umwandelten. Alle drei Orte wurden zu Mediatstädten und spielten unter den Städten der Neumark nur eine untergeordnete Rolle.

Unter den neun hier betrachteten führenden neumärkischen Adelsfamilien lassen sich also zwei verschiedene Gruppen ausmachen: die von Wedel, von Liebenow, von Brederlow und von Schöning und wahrscheinlich auch die von Liebenthal, die als Burgmannen und Siedlungsunternehmer unmittelbar von Pommern aus, als Vasallen Herzog Barnims I. oder der Bischöfe von Kammin, in die Neumark gelangten, und die von Uchtenhagen, von Jagow und Mörner, die als landesherrliche Lokatoren in der Neumark eingesetzt und an älteren pommerschen Burgorten angesiedelt wurden, wo sie an die Stelle der früheren pommerschen Burgmannen traten, ohne selbst die Funktion und den Rang von Burgmannen einzunehmen.

Lieselott Enders hat für die Besiedlung der Uckermark drei unterschiedliche Typen von Ortsgründern gefunden: „Erstens ranghöhere Ritter (nobiles, domini), die als Unternehmer im landesherrlichen Auftrag den Landesausbau überhaupt organisierten und dabei für sich selbst weitgehend unabhängige Herrschaften schufen, zweitens rangniedrigere Ministerialen, die im direkten landesherrlichen oder über den Siedlungsunternehmer vermittelten Auftrag ein oder mehrere Dörfer praktisch , anrichteten““, und drittens „Niederadlige und Bauern, die als Lokator im wörtlichen Sinne wirkten, indem sie das ihnen vom Grundherrn übertragene Land an die Nutzer verpachteten. “" ${ }^{388}$ Nach diesem Schema lassen sich die von Wedel, von Liebenow, von Brederlow, von Schöning und von Liebenthal eher dem ersten und die von Uchtenhagen, Jagow und Mörner eher dem zweiten Typus zuordnen. Allerdings müssen m. E. Enders' Definitionen für beide Typen modifiziert werden. Die von Enders behauptete Unabhängigkeit der ersten Gruppe reichte weder in der Mark noch in Pommern so weit, dass die Adligen von der Landesherrschaft

387 Diese Entwicklung war für die von Uchtenhagen, die sich vor 1250 als Edelfreie betrachteten und dies bei der Gründung ihrer Städte Bad Freienwalde und Freienwalde i.P. im Stadtnamen zum Ausdruck brachten, von einer gewissen historischen Ironie geprägt, gaben sie doch dem alten Burgort Chintz im Auftrag der Markgrafen den Namen Fürstenfelde, durch den der Besitz der Stadt durch die Landesfürsten manifestiert wurde!

388 Enders: Uckermark (wie Anm. 334), S. 57. Die dritte Gruppe kann an dieser Stelle vernachlässigt werden, da ihre Vertreter nicht zu den oberen $20 \%$ innerhalb des Adels gehörten. 
unabhängige Herrschaften einrichten konnten. Vielmehr unterlagen auch sie, wie Rudolf Benl vor allem in seiner Auseinandersetzung mit Johannes Schultze ${ }^{389}$ deutlich gezeigt hat, dem Lehnrecht und waren ebenso wie die Vertreter der zweiten Gruppe Vasallen ihrer Landesherren. ${ }^{390}$ Der Unterschied zur zweiten Gruppe bestand vor allem darin, dass die Mitglieder der ersten Gruppe als Fremde an den pommerschen Hof kamen und die Bedingungen, unter denen sie als Ritter und Siedlungsunternehmer in den Dienst des Herzogs oder des Bischofs traten, mehr oder minder frei aushandeln konnten. Es war ihre freie Entscheidung, sich an den herzoglichen Hof zu binden oder nicht; sie konnten ohne weiteres auch woandershin ziehen. Die zweite Gruppe, deren Vertreter ursprünglich wie die von Uchtenhagen und von Jagow zum ersten Typus gezählt und sich bereits als Siedlungsunternehmer betätigt hatten, stand, als die Askanier die südliche Uckermark übernahmen, vor der Entscheidung, sich entweder mit ihrem uckerländischen Besitz in die Lehnsabhängigkeit der Markgrafen zu begeben oder ihre Freiheit zu dem Preis zu behalten, ihre gerade erst gewonnenen Güter sowie ihre kostenträchtigen Investitionen in die von ihnen aufgesiedelte terra ersatzlos zu verlieren, um an anderer Stelle von vorne anzufangen. Diejenigen, die sich für das Vasallitätsverhältnis unter den Askaniern entschieden, waren als landsässig Gewordene an diese erheblich stärker gebunden als die aus der Fremde Gekommenen. Da sie aus der ersten Gruppe hervorgegangen waren, kamen sie aber immer noch als Unternehmer für größere Siedlungs- und Ausbauprojekte in Betracht, z. B. für die Anlage einer ganzen deutschrechtlichen Stadt oder für die Einrichtung des gesamten mit einer solchen Stadt verbundenen Weichbilds im Sinne des Landesausbaus. Auch konnten sie ebenso wie die Vertreter des ersten Typus als Burghauptleute für die Landessicherung des askanischen Herrschaftsgebiets sorgen. wie das Engagement der von Uchtenhagen, Jagow oder Mörner in Meseritz, Sonnenburg oder Zantoch zeigt. Von ihnen sind diejenigen Adligen zu unterscheiden, die je nach Vermögen von den adligen Siedlungs-Großunternehmern als Kleinunternehmer zur Aufsiedlung einzelner oder mehrerer Dörfer angeworben wurden und im übrigen auch militärisch zur Gefolgschaft, zu den socii oder mithelfern der Ritter-Unternehmer zählten, die ihre Hauptleute waren.

Um sich längerfristig im führenden Kreis des neumärkischen Adels bis 1350 zu etablieren, war in der Regel offenbar die Schlüsselposition ein Engagement als Burgmann (oder: Burghauptmann) in einer landesherrlichen Burg in Pommern (unter Einschluss des Uckerlandes), entweder unmittelbar wie im Falle der von Wedel, Liebenow, Brederlow, Schöning und Liebenthal, oder mittelbar, als Voraussetzung für die Übertragung größerer Aufgaben in der Landessicherung und im Landesausbau durch die Askanier, wie bei den von Uchtenhagen, Jagow und Mörner. ${ }^{391}$ Wer sich in diesen Funktionen bewährt hatte,

389 Vgl. Johannes Schultze: Proprietas und Hereditas östliche Elbe und Oder, in: Blätter für deutsche Landesgeschichte 104 (1968), S. 32-41.

390 Vgl. Benl: Bodenrechtsverhältnisse (wie Anm. 386), Kap. V, S. 202-349 und speziell S. 329-343.

391 Eine Ausnahme waren hier die von Güntersberg, die als Familie von ursprünglich bürgerlicher Herkunft erst 1284 in den Adelsstand erhoben wurden, als der Landesausbau in Pommern schon ein weit fortgeschrittenes Stadium erreicht hatte. Das Beispiel der von Güntersberg deutet an, dass es durchaus möglich war, auch nach der Zeit des hochmittelalterlichen Landesausbaus in den Kreis der führenden Adelsgeschlechter aufzusteigen. 
kam alsbald auch für höhere Aufgaben im Landesdienst in Frage. Daher lässt sich bei den meisten der hier behandelten Familien ein Aufstieg beobachten, bei dem die Generation der Söhne schon in jungen Jahren als Vögte einer terra tätig waren und entweder selbst in höherem Alter zu Oberhauptleuten wurden oder höhere Hofämter wie die des Marschalls, des Truchsess, des Mundschenks, des Küchen- oder Kammermeisters oder des Hofrichters oder (als höchstes Amt) das des Hofmeisters erhielten. Diese Ämter erforderten zum einen, wie bereits das Engagement als Siedlungsunternehmer, erhebliche finanzielle Mittel, zum andern erbrachten sie bedeutende Erträge, die es den Adligen irgendwann im Laufe der Zeit ermöglichten, größere Besitzkomplexe zu erwerben und schließlich zu Schlossgesessenen zu werden.

Für die Siedlungsgeschichte ergeben sich aus der Betrachtung der Herkunft der hier untersuchten Adelsfamilien und ihrer Wirkungsgebiete in der Neumark neue Aspekte. Die pommerschen Regionen, aus denen diese Familien kamen, waren das Uckerland um Prenzlau, das anschließende Gebiet um das Dreieck Penkun-Gartz-Stettin, der Pyritzer Weizacker, der ehemals zur terra Zehden zählende Raum Bärwalde-Königsberg und das Land Stargard. Es handelt sich um die Gebiete, die dem Zehntvertrag zwischen Herzog Barnim I. von Pommern und Bischof Konrad III. von Kammin von 1240 zufolge seit langem wüst lagen, deren Dörfer man gemeinsam neu ausbauen wollte. ${ }^{392}$ Innerhalb der Neumark spielte für die adlige Siedlung das von der terra Pyritz abgetrennte Land Lippehne, das nach Norden bis vor Pyritz, nach Süden bis vor Soldin reichte, eine Schlüsselrolle. Der Raum zwischen Lippehne und Soldin, dessen westlicher und östlicher Rand bis nach Schildberg, Berlinchen und Bernstein reichte, war, abgesehen von den Landschaften des Oder-, Warthe- und Netzebruchs, die in vorkolonialer Zeit am dichtesten besiedelte Landschaft der Neumark. ${ }^{393}$ Dieser Raum wurde zwischen 1248 und 1276 hauptsächlich im Auftrag der Kamminer Bischöfe Wilhelm und Hermann von Gleichen besiedelt, von denen der letztere das Land Lippehne 1276 an die Askanier verkaufte. ${ }^{394}$ Diese Bischöfe dürften daher wohl dafür verantwortlich sein, dass die von Brederlow, von Schöning und von Liebenthal sich als ihre Burgmannen in und um Lippehne ansiedelten. Auch die adlige Besiedlung der Gebiete in der hinteren Neumark scheint in weit höherem Maße von den Bischöfen von Kammin initiiert worden zu sein, als in der Literatur bisher wahrgenommen wurde. Für die weitere Erforschung der adligen Siedlung in der Neumark sollte die Rolle der Bischöfe daher gleichermaßen mitbetrachtet werden wie die der pommerschen Herzöge.

392 [...] villarum longo tempore desertarum, que in territoriis Ceden, Piriz, Princelaw, Pinkun et Stetin de novo exculte fuerint a colonis. Urkunde von 1240 April 24, PUB 12, S. 451 ff., Nr. 377.

393 Vgl. Gahlbeck: Zisterzienser (wie Anm. 3), S. 569-576 u. S. 1114 f., Kte. III.

394 Vgl. Urkunden von 1276 August 18 und August 30 (wie Anm. 69). 



\title{
Von Frankfurt an der Oder nach Landsberg an der Warthe Die Anfänge der markgräflichen Stadtgründungen in der Neumark unter Johann I. und Otto III.
}

\author{
Von WINFRIED SCHICH
}

Es ist gesicherter Stand der Forschung, daß die Markgrafen von Brandenburg im 13. Jahrhundert die Gründung von Städten als ein wesentliches Mittel zur Ausweitung und Festigung ihrer territorialen Herrschaft genutzt haben. ${ }^{1}$ Sie trugen damit dem Stand der städtischen Entwicklung im Raum westlich der Elbe Rechnung. Unter den Markgrafen, die die Städtegründungen in den von ihnen neu erworbenen Ländern gezielt einsetzten, ragen die beiden Brüder Johann I. und Otto III. heraus, die seit 1220, anfangs unter der Vormundschaft ihrer Mutter Mechthild, bis 1258 gemeinsam regierten und 1266 bzw. 1267 starben $^{2}$. Die Chronik der Markgrafen von Brandenburg (Chronica Marchionum Brandenburgensium), die um 1280 niedergeschrieben wurde, stellt als besonders bemerkenswerte Taten der Markgrafen folgendes heraus: Sie erwarben von dem Fürsten Barnim von Pommern die Länder Barnim, Teltow und viele andere, kauften das Uckerland bis zum Fluß Welse ..., bauten Berlin, Strausberg, Frankfurt, Angermünde, Stolpe, Liebenwalde, Stargard, Neubrandenburg und viele andere Orte, verwandelten Wüsteneien in Äcker und

1 Bei dem vorliegenden Text handelt es sich um die erweiterte und leicht veränderte Fassung des Vortrages, den ich am 3.10.2003 auf der Tagung „Adel, Städte und Landesherr in der Neumark“ im Haus Brandenburg in Fürstenwalde und erneut am 22.2.2005 in der Öffentlichen Wojewodschafts- und Stadtbibliothek in Landsberg an der Warthe (Wojewódzka i Miejska Biblioteka Publiczna w Gorzowie Wielkopolskim) gehalten habe. In dieser Form - einschließlich polnischer Übersetzung - wurde er bereits veröffentlicht unter dem Titel: Die markgräflichen Stadtgründungen in der Neumark: die Anfänge unter Johann I. und Otto III. (Lokacje miast margrabiów w Nowej Marchii: początki pod panowaniem Jana I i Ottona III), in: Nowa Marchia - prowincja zapomniana wspólne korzenie, Zestyty Naukowe 3, Gorzów Wlkp.2005, S. 103-123, 227-254. Ich danke Dr. Christian Gahlbeck, Berlin, für wertvolle Hinweise.

2 Hermann Krabbo: Die Stadtgründungen der Markgrafen Johann I. und Otto III. von Brandenburg (1220-1267), in: Archiv für Urkundenforschung 4 (1912), S. 255-290; - Johannes Schultze: Entstehung der Mark Brandenburg und ihrer Städte, in: ders.: Forschungen zur brandenburgischen und preußischen Geschichte. Ausgewählte Aufsätze, hg. v. Wilhelm Berges. Berlin 1964, S. 137-154 (=Veröffentlichungen der Historischen Kommission zu Berlin, 13; Erstdruck 1960); - Hans K. Schulze: Die Besiedlung der Mark Brandenburg im hohen und späten Mittelalter, in: Jahrbuch für die Geschichte Mittel- und Ostdeutschlands [künftig zitiert: JGMOD] 28 (1979), S. 42-178, hier S. 148-166; - Winfried Schich: Berlyn, Struzberch, Vrankenvorde... et alia loca plurima exstruxerunt. Zum Bau der Städte in der Mark Brandenburg im 13. Jahrhundert, in: Wilhelm Janssen/Margret Wensky (Hg.): Mitteleuropäisches Städtewesen in Mittelalter und Frühneuzeit. Edith Ennen gewidmet. Köln-Weimar-Wien 1999, S. 105-140. 
gewannen so Überfluß an allen Gütern. ${ }^{3}$ Es wird deutlich, daß über die Städte das Land wirtschaftlich erfaßt und ausgebaut wurde. Die markgräfliche Expansion richtete sich von dem ostelbischen Kernland Havelland aus vor allem in Richtung Nordosten und Osten. Die am weitesten im Norden und im Osten gelegenen unter den als Beispielen aufgeführten Städten waren Neubrandenburg und Frankfurt an der Oder. Wir wollen im folgenden zu klären versuchen, inwieweit die Politik der Städteförderung unter den beiden Markgrafen bereits über die Oder hinausgriff. Das einzige sichere Datum ist die Gründung von Landsberg an der Warthe (heute Gorzów Wielkopolski) im Jahre 1257. Diese Stadt wird daher einen wichtigen Platz in den folgenden Ausführungen einnehmen. Ihre Gründung wird eingeordnet in die Expansion der Markgrafen in das polnische Land Lebus, wozu der Ausbau der Oderstadt Frankfurt gehörte, der im folgenden ebenfalls behandelt wird. Im Gegensatz zu Frankfurt nennt der zitierte Chronist Landsberg nicht.

Frankfurt wurde, wie das erhaltene Privileg Markgraf Johanns von 1253 zeigt, mit Blick auf die weitere Expansion über die Oder gegründet oder richtiger: ausgebaut. ${ }^{4}$ Die Stadt entstand in zentraler Lage im Land Lebus, das sich auf beiden Seiten der Oder erstreckte und das die Markgrafen sowie der Erzbischof von Magdeburg von Polen erworben und kurz zuvor untereinander aufgeteilt hatten. ${ }^{5}$ Das Land Lebus selbst wird in der

3 Georg Sello (Hg.): Chronica Marchionum Brandenburgensium, in: Forschungen zur Brandenburgischen und Preußischen Geschichte 1 (1888), T. 1, S. 111-180, hier S. 121.

4 Adolph Friedrich Riedel (Hg.): Codex diplomaticus Brandenburgensis [künftig zitiert: CDB], Hauptteil I, Bd. 23. Berlin 1862, S. 1 Nr. 1; - Hermann Krabbo/Georg Winter (Bearb.): Regesten der Markgrafen von Brandenburg aus askanischem Hause. Berlin 1910/55 [künftig zitiert: KW], S. 176 f. Nr. 766.

5 KW, S. 175 Nr. 761; - vgl. Oskar Breitenbach: Das Land Lebus unter den Piasten. Fürstenwalde 1890, S. 84-105; - Paul van Nießen: Geschichte der Neumark im Zeitalter ihrer Entstehung und Besiedlung (Von den ältesten Zeiten bis zum Aussterben der Askanier). Landsberg a.W. 1905, S. 133-139, 145 f.; - Herbert Ludat: Bistum Lebus. Studien zur Gründungsfrage und zur Entstehung und Wirtschaftsgeschichte seiner schlesisch-polnischen Besitzungen. Weimar 1942, S. 298-306 (Exkurs II); - Johannes Schultze: Die Mark Brandenburg, Bd. 1. Berlin 1961, S. 149-151; - Karol Olejnik: Obrona polskiej granicy zachodniej. Okres rozbicia dzielnicowego i monarchii stanowego (1138-1385) [Die Verteidigung der polnischen Westgrenze. Die Periode der partikularen Zersplitterung und der ständischen Monarchie (1138-1385)]. Poznań 1970, S. 107-126; - Gerard Labuda: Zajęcie ziemi lubuskiej przez margrabiów brandenburskich w połowie XIII wieku [Die Inbesitznahme des Lebuser Landes durch die Brandenburger Markgrafen in der Mitte des 13. Jhs.], in: Śląski Kwartalnik Historyczny, Sobótka 28 (1973), S. 311-322; Wolfgang Podehl: Burg und Herrschaft in der Mark Brandenburg. Untersuchungen zur mittelalterlichen Verfassungsgeschichte unter besonderer Berücksichtigung von Altmark, Neumark und Havelland. Köln-Wien 1975, S. 309-313 (= Mitteldeutsche Forschungen, 76); - Jerzy Walachowicz: Geneza i ustrój polityczny Nowej Marchii do początków XIV wieku [Die Entstehung und die politische Verfassung der Neumark bis zum Anfang des 14. Jahrhunderts]. Warszawa/Poznań 1980, S. 10-36 (= Poznańskie Towarzystwo Przyjaciół Nauk, Prace Komisji Historycznej, 31); - Andrzej Wałkowski: Poglądy na sprawie utraty Lubusza w świetle badań dyplomatycznych nad umową z 1249 roku [Ansichten zur Frage des Verlustes von Lebus im Lichte diplomatischer Forschungen über den Vertrag von 1249], in: Nadwarciański Rocznik Historyczno-Archiwalny 1 (1994), S. 20-34; - Rolf Barthel: Die Besiedlungsgeschichte des Landes Lebus, in: Cornelia Willich: Die Ortsnamen des Landes Lebus. Weimar 1994, S. 9-50, hier S. 16-23 (= Brandenburgisches Namenbuch, 8); - Edward Rymar: Margrabowie brandenburscy z dynastii askańskiej wobec biskupstwa 
Chronik ebenfalls nicht genannt. Von Polen, genauer von Schlesien, aus wurden Stadt und Land Lebus als „Schlüssel des Landes“ (clavis terre) - so in der Vita der heiligen Hedwig - betrachtet; dieser ging durch die Expansion deutscher Fürsten verloren. ${ }^{6}$

Das politische, kirchliche und wirtschaftliche Zentrum des Landes bildete der gleichnamige Ort, der Burg, Bischofssitz und städtische Siedlung in sich vereinigte. Durch die Zollprivilegien Herzog Heinrichs des Bärtigen von Schlesien für die Zisterzienser in Leubus (Lubiąż) ist Lebus bereits seit 1211 als Handels- und Salzumschlagplatz bezeugt. ${ }^{7}$ In Urkunden von 1226 und 1249 wird Lebus als castrum und civitas, also als Burg und

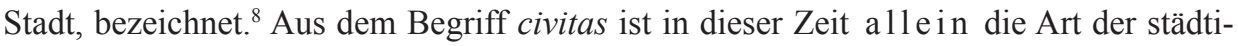
schen Qualität nicht sicher zu erkennen. Seit dem ausgehenden 12. Jahrhundert verbreitete sich zwar das Wort civitas mit dem Begriffsinhalt der „kommunalen Marktstadt“, für die die Volkssprachen ein neues Wort (deutsch stat, polnisch miasto) statt des alten burg/ gród benutzten, doch im 13. Jahrhundert konnte in Polen auch die stärker herrschaftlich gebundene Form der „Stadt“, die großräumige zentrale Funktionen erfüllte, noch als $c i$ vitas bezeichnet werden. Zum Bischofssitz gehörte nach Kirchenrecht ohnehin eine civitas, ganz gleich, ob sie noch unter dem allgemeinen polnischen Herzogsrecht stand oder ob es sich bereits um eine nach deutschem Recht neu strukturierte Marktstadt handelte. Im funktionalen Sinne war Lebus jedenfalls bereits vor der Mitte des 13. Jahrhunderts eine ,Stadt“. 9

lubuskiego (1250-1320) [Die brandenburgischen Markgrafen aus askanischem Geschlecht im Verhältnis zum Lebuser Bistum (1250-1320)], in: ders.: Studia i materiały z dziejów Nowej Marchii i Gorzowa. Szkice historyczne [Studien und Materialien zur Geschichte der Neumark und Landsbergs an der Warthe. Historische Skizzen]. Gorzów Wlkp. 1999, S. 41-70 (= Biblioteczka Nadwarciańskiego Rocznika Historyczno-Archiwalnego, 8); - Christian Gahlbeck: Historischtopographisches Inventar der Stadt Lebus, Berlin 1999 (masch., Exemplar im Brandenburgischen Landesamt für Denkmalpflege und Archäologischem Landesmuseum [BLDAM], Wünsdorf); Siegfried Griesa: Das Land Lebus in historischer Zeit, in: Frankfurter Jahrbuch 2000, S. 7-52; Edward Rymar: Klucz do ziem polskich. Der Schlüssel zu den polnischen Ländern. Gorzów Wlkp. 2007 ; - Monika Kilian-Buchmann: Frankfurt (Oder) im 13. und 14. Jahrhundert. Untersuchungen zur Bevölkerungsstruktur und Siedlungsentwicklung. Frankfurt (Oder) 2008, S. $43-51$ (Frankfurter Jahrbuch 2008/09); - Dietrich Kurze: Das Bistum Lebus zwischen Magdeburg und Gnesen, in: Jahrbuch für Berlin-Brandenburgische Kirchengeschichte 68 (2011), S. 17-49, hier S. 28-32.

6 Aleksander Semkowicz (Hg.): Vita sanctae Hedwigis, in: Monumenta Poloniae Historica, Bd. 4. Lwów 1884 (ND Warszawa 1961), S. 501-642, hier S. 571; - vgl. Rymar: Klucz (wie Anm. 5).

7 Schlesisches Urkundenbuch [künftig zitiert: SUB], Bd. 1, bearb. v. Heinrich Appelt. Wien-KölnGraz 1963/71, S. 89 f. Nr. 123.

8 SUB I, S. 195-197 Nr. 268; - SUB II, bearb. v. Winfried Irgang. Wien-Köln-Graz 1977, S. 232 f. Nr. 368; - vgl. Podehl (wie Anm. 5), S. 303-317, 711 f.; - Walter Kuhn: Die deutschrechtlichen Städte in Schlesien und Polen in der ersten Hälfte des 13. Jahrhunderts. Marburg 1968, S. 95 f. Kuhn schließt aus dem Begriff civitas auf eine 1226 bereits entwickelte Stadt im westlichen Sinne.

9 Zum archäologischen Befund: Uwe Fiedler: Castrum und civitas Lubus/Lebus, in: Christian Lübke (Hg.): Struktur und Wandel im Früh- und Hochmittelalter. Stuttgart 1998, S. 163-177 (= Forschungen zu Geschichte und Kultur des östlichen Mitteleuropa, 5); - Rainer Schulz: Die Burg Lebus, Kr. Seelow, in: Berlin und Umgebung. Stuttgart 1991, S. 219-225 (= Führer zu archäologischen Denkmälern in Deutschland, 23); - Blandine Wittkopp: Kirche unter dem Schloßberg. Ausgrabungen in der Pfarrkirche Lebus, Landkreis Märkisch-Oderland, in: Archäologie in Berlin und Brandenburg 2000. Stuttgart 2001, S. 120-122; - dies.: Adalbertskathedrale ermittelt. Baubegleitung 
Die neuartige Form der Stadt, die im Markt ihr Zentrum hatte, deren im Handel und Gewerbe tätige Bürger in einer lokalen Gemeinde zusammengeschlossen waren, die mit einem besonderen Recht ausgestattet war, wurde auch bereits in der schlesischen Zeit des Landes gefördert. Als Herzog Heinrich der Bärtige 1224 den Zisterziensern und Zisterzienserinnen von Leubus (Lubiąż) und Trebnitz (Trzebnica) im bisher dünn besiedelten westlichen Randgebiet des Landes Lebus jeweils 200 Hufen Land schenkte, um das Land durch Siedlung gegen die vordringenden deutschen Fürsten zu sichern, verlieh er ihnen zugleich das Recht, dort einen städtischen Marktort zu errichten. ${ }^{10}$ Die Zisterzienser gründeten die Stadt Lubes, die deutsches Recht (ius teutonicum) erhielt und 1232 erstmals als civitas genannt wird, bevor sie kurz darauf den Namen Müncheberg annahm. ${ }^{11}$

Vergleichbar ist die Situation im Land Küstrin (Kostrzyn) nördlich der Warthe und östlich der Oder. Das dünn besiedelte Gebiet war im frühen 13. Jahrhundert zwischen den Herzögen von Großpolen und Schlesien sowie denen von Pommern umstritten und wurde schließlich dem schlesischen Land Lebus angegliedert. ${ }^{12} 1232$ setzte Herzog Heinrich der Bärtige von Schlesien in Konkurrenz zu Herzog Władysław Odonic von Großpolen hier die Templer an. Diese erhielten im (Burg-)Bezirk von Küstrin (in confinio Cozsterine) die villa Quartschen (Chwarszczany) mit 1000 Hufen zwischen Warthe, Oder und Mietzel (Myśla), verbunden mit der Erlaubnis der Marktgründung zu deutschem Recht

auf dem Schloßberg in Lebus, Lkr. Märkisch-Oderland, in: Archäologie in Berlin und Brandenburg 2003. Stuttgart 2004, S. 123-125; - dies.: Die Lebuser Kathedralstandorte im Spiegel neuer archäologischer Untersuchungen, in: Doris Bulach/Matthias Hardt (Hg.): Zentrum und Peripherie in der Germania Slavica. Stuttgart 2008, S. 137-155 (= Forschungen zur Geschichte und Kultur des östlichen Mitteleuropa, 34); - Franz Schopper: Lebus: Burgberg, Stadt und Kirche, in: Frankfurt (Oder) und das Land Lebus. Stuttgart 2005, S. 165-169 (= Führer zu archäologischen Denkmälern in Deutschland, 45). - Vgl. auch Joachim Herrmann: Burgen im Oderbruch seit der Jahrtausendwende, in: Hans-Friedrich Kniehase (Hg.): Kulturlandschaft Oderbruch. Hydrologie und Siedlung einer Niederungslandschaft in Mittelalter und Neuzeit. Scharbeutz-Wetter (Ruhr) 2003, S. 275-291, hier S. 283 f. - Nicht benutzt werden konnte: Stanisław Kowalski: Miasta środkowego Nadodrza [Städte im mittleren Odergebiet]. Zielona Góra 1994.

10 SUB I, S. 178 f. Nr. 246. - Vgl. Winfried Schich: Das schlesische Kloster Leubus und die Gründung von Müncheberg und Münchehofe an der Westgrenze des Landes Lebus im zweiten Viertel des 13. Jahrhunderts, in: Franz J. Felten/Nikolas Jaspert (Hg.): Vita Religiosa im Mittelalter. Festschrift für Kaspar Elm zum 70. Geburtstag. Berlin 1999, S. 193-216 (mit weiterer Literatur), erneut in ders.: Wirtschaft und Kulturlandschaft, bearb. u. hg. v. Ralf Gebuhr u. Peter Neumeister. Berlin 2006, S. 105-125; - zum Landesausbau unter Herzog Heinrich: Benedykt Zientara: Heinrich der Bärtige und seine Zeit. Politik und Gesellschaft im mittelalterlichen Schlesien. Aus dem Polnischen übersetzt von Peter Oliver Loew. München 2002, S. 173-192 (= Schriften des Bundesinstituts für Kultur und Geschichte der Deutschen im östlichen Europa, 17) [poln. Orig.: Henryk Brodaty i jego czasy, Warszawa 1975].

11 SUB II, S. 9-12 Nr. 19-21, S. 15 Nr. 27, S. 179 Nr. 298.

12 Zientara (wie Anm. 10), S. 299-301; - Edward Rymar: Prawne podstawy ekspansji brandenburskiej na wcześniej pomorskie obszary księstwa wielkopolskiego (Nowej Marchii) [Die rechtlichen Grundlagen der brandenburgischen Expansion in den früher pommerschen Gebieten des großpolnischen Fürstentums (der Neumark)], in: ders.: Studia (wie Anm. 5), S. 7-40; - jetzt vor allem Christian Gahlbeck: Der Oder-Drage-Raum in voraskanischer Zeit. Großpolen, Schlesien und Pommern im Wettstreit um den Besitz der späteren Neumark, in: JGMOD 45 (1999), S. 1-97, bes. S. $25-30$. 
innerhalb der Grenzen dieser Hufen (foro infra terminos illorum habendo iure et more Teutonicali). ${ }^{13}$ Der Marktort entstand allem Anschein nach neben der Hauptburg Küstrin, nach der auch das umliegende Land benannt wurde. ${ }^{14} 1234$ verzichtete Herzog Barnim I. von Pommern auf alle Rechte im Land Küstrin (terra Custerin) zugunsten der Templer. ${ }^{15}$ Die Markgrafen Johann und Otto erwarben 1261 von den Templern den südlichen Teil des Landes mit dem opidum $;{ }^{16}$ dieses muß mit Küstrin gleichgesetzt werden. ${ }^{17}$

Der Begriff oppidum ist an sich im Mittelalter vieldeutig, doch in der Mark Brandenburg und in anderen Regionen wurden in dieser Zeit in der Regel kleinere Marktstädtchen so bezeichnet. ${ }^{18}$ Sie waren häufig, aber nicht in jedem Fall mit einer Burg (castrum)

13 Schenkung des Herzogs Władysław Odonic von 1232: Kodeks dyplomatyczny Wielkopolski (Codex diplomaticus Majoris Poloniae), Bd. 1, Poznań 1877, S. 124 Nr. 141;- dazu das Zehntprivileg des Bischofs Lorenz von Lebus, der eng mit Heinrich dem Bärtigen verbunden war, aus demselben Jahr: Winfried Irgang (Bearb.): Urkunden und Regesten zur Geschichte des Templerordens im Bereich des Bistums Cammin und der Kirchenprovinz Gnesen. Nach Vorlage von Helmut Lüpke neu bearbeitet. Köln-Wien 1987, S. 12 f. Nr. 6, S. 14 Nr. 8, S. 44 f. Nr. 44 (=Veröffentlichungen der Historischen Kommission für Pommern, IV, 10); - vgl. Helmut Lüpke: Untersuchungen zur Geschichte des Templerordens im Gebiet der nordostdeutschen Kolonisation. Bernburg 1933 (phil. Diss. Berlin), S. 16; ders.: Die Templerkommende Tempelhof. Ein Beitrag zur Geschichte des Templerordens in Ostdeutschland, in: Teltower Kreiskalender 30 (1933), S. 21-34, hier S. 27; - Gahlbeck: Oder-Drage-Raum (wie Anm. 12), S. 27 f., 50-57; - Christian Gahlbeck/Dirk Schumann: Quartschen (Chwarszczany), Kommende des Templer- bzw. Johanniterordens, in: HeinzDieter Heimann/Klaus Neitmann/Winfried Schich (Hg.): Brandenburgisches Klosterbuch. Handbuch der Klöster, Stifte und Kommenden bis zur Mitte des 16. Jahrhunderts, Teilbd. 1 u. 2. Berlin 2007, S. 991-1018, hier S. 991-993; - Maciej Przybył: Die Herzöge von Großpolen und Schlesien und die Templer im Raum an der mittleren Oder und unteren Warthe, in: Christian Gahlbeck/ Heinz-Dieter Heimann/Dirk Schumann (Hg.): Regionalität und Transfergeschichte. Ritterordenskommenden der Templer und Johanniter im nordöstlichen Deutschland und in Polen. Berlin 2014, S. 140-154 (= Studien zur brandenburgischen und vergleichenden Landesgeschichte, 9).

14 Wenn Gahlbecks Annahme (a. a.O., S. 30 f.) richtig ist, daß die Burg Küstrin selbst nicht zur Schenkung von 1232 gehörte, sondern erst 1241 von den Templern erworben wurde, dann muß die Gründung nach diesem Jahr angesetzt werden.

15 Pommersches Urkundenbuch, Bd. 1, neu bearb. v. Klaus Conrad. Köln-Wien 1970 [künftig zitiert: PUB I], S. 376 f. Nr. 309 (= Veröffentlichungen der Historischen Kommission für Pommern, II, 1); - Irgang: Urkunden (wie Anm. 13), S. 17 f. Nr. 12.

16 CDB II, 1. Berlin 1843, S. 70 Nr. 96; - KW, S. 207 Nr. 869; - Irgang: Urkunden (wie Anm. 13), S. 48 f. Nr. 48; - zur Datierung eher auf 1262: Edward Rymar: Datacja układy templariuszy z margrabiami brandenburskimi w sprawie komandorii chwarszczańskiej i myśliborskiej [Die Datierung der Übereinkunft der Templer mit den Brandenburger Markgrafen über die Kommenden Quartschen und Soldin], in: Nadwarciański Rocznik Historyczno-Archiwalny 8 (2002), S. 311-315.

17 Helmut Wittlinger: Untersuchungen zur Entstehung und Frühgeschichte der neumärkischen Städte. Landsberg (Warthe) 1932, S. 39-43 (= Die Neumark, Jahrbuch 8); - Hugo Rachel: Küstrin, in: Deutsches Städtebuch. Handbuch städtischer Geschichte, hg. v. Erich Keyser, Bd. 1. Nordostdeutschland. Stuttgart-Berlin 1939, S. 566-569; - Edwin Rozenkranz: Kostrzyn [Küstrin], in: Zdzisław Kaczmarczyk/Andrzej Wędzki (Hg.): Studia nad początkami i rozplanowaniem miast nad środkową Odrą i dolną Wartą (Województwo Zielonogórskie) [Studien zu den Anfängen und zum Grundriß der Städte an der mittleren Oder und unteren Warthe (Wojewodschaft Grünberg)], Bd. 1. Ziemia Lubuska, Nowa Marchia, Wielkopolska [Land Lebus, Neumark, Großpolen]. Zielona Góra 1967, S. 211-226, bes. S. 216 f.; - Heinz-K. Junk: Küstrin. Altenbeken 1989 (= Deutscher Städteatlas, Lfg. IV, Nr. 8).

18 Schich: Berlyn (wie Anm. 2), S. 130-132. 
räumlich verbunden. Sie besaßen ebenso wie die größeren, gewöhnlich civitas genannten Städte eine städtische Verfassung. Eine strenge Abgrenzung zwischen civitas und oppidum bestand nicht; die Termini konnten bei manch einem Ort wechseln, ohne daß eine Qualitätsveränderung vorlag.

$\mathrm{Ob}$ auch die Bischöfe von Lebus, die in dieser Zeit in enger Verbindung mit den Herzögen von Schlesien standen, die Gründung neuartiger Städte für den Ausbau ihrer Güter genutzt haben, kann nicht sicher nachgewiesen werden. Bemerkenswert ist aber, daß in der Urkunde von 1252, mit der sich der Erzbischof von Magdeburg mit dem Bischof von Lebus über die Zehntberechtigung einigte, unter den bischöflichen Orten die civitas forensis Osna (Drossen/Ośno Lubuskie) genannt wird, wogegen die übrigen als villa bezeichnet werden. ${ }^{19}$ Drossen war danach eine „Marktstadt“, das heißt weder eine civitas älterer Form, die wie Lebus im Anschluß an eine zentrale Burg (und an den Bischofssitz) entstanden war, noch ein forum älterer, also nichtstädtischer Art. Diese Stadt zeichnete sich im Gegensatz zu Lebus dadurch aus, daß sie im Markt ihren funktionalen und topographischen Mittelpunkt hatte. ${ }^{20}$ Ein altes Siedlungszentrum war Drossen allem Anschein nach nicht; eine Burg ist nicht nachgewiesen. Es ist nicht berechtigt, den Begriff civitas forensis auf forum zu verkürzen. ${ }^{21}$ Seine Anwendung auf einen Marktort, der unter polnischem Recht unabhängig von einem älteren Burgzentrum entstanden war, wäre ungewöhnlich. Es ist eher anzunehmen, daß civitas in Verbindung mit forensis eine deutschrechtliche Stadt bezeichnete. Man kann vermuten, daß es sich bei der Marktstadt Drossen um eine Gründung des Bischofs von Lebus innerhalb seines Besitzkomplexes handelte, die zu dem Landesausbau gehörte, den Herzog Heinrich der Bärtige $(† 1238)$ in seinem Herrschaftsbereich förderte. ${ }^{22}$

Mit den vorstehenden Ausführungen sollte gezeigt werden, daß in den ersten Jahren der eigenständigen Regierungstätigkeit der beiden markgräflichen Brüder Johann und Otto, die für ihre Städtepolitik gerühmt werden, also etwa um 1230, im Raum beiderseits der Oder und der Warthemündung die verschiedenen Herrschaftsträger die Gründung von neuartigen Marktorten bzw. Städten bereits eingeleitet hatten. Diese wurden aus den Bindungen des polnischen Herzogsrechtes herausgelöst und erhielten ein besonderes lokales Recht, wie es sich in deutschen Städten herausgebildet hatte. Es handelte sich gewiß noch um bescheidene städtische Formen, aber sie waren wirtschaftlich auf den Markt ausgerichtet und kommunal verfaßt. Eine ähnliche Gestalt hat man für die erste Anlage

19 CDB I, 20. Berlin 1861, S. 183 f. Nr. 10.

20 Die frühe Stadt ist in der Umgebung des Alten Marktes (Rynek Stary) zu suchen; vgl. Die Kunstdenkmäler des Kreises Weststernberg, bearb. v. Wilhelm Jung u. Willy Spatz. Berlin 1913, S. 22-30 mit Stadtplan von 1725 auf Tafel 2 (= Die Kunstdenkmäler der Provinz Brandenburg, VI, 3); Hugo Rachel: Drossen, in: Deutsches Städtebuch (wie Anm. 17), S. 524 f.; - vor allem Stanisław Kowalski: Średniowieczne Ośno Lubuskie - przyczynek do genezy i rozwój przestrzennego [Das mittelalterliche Drossen im Land Lebus - ein Beitrag zur Genese und zur räumlichen Entwicklung], in: Studia Zachodnie. Zielona Góra 1992, S. 37-46, bes. S. 41-43.

21 So van Nießen (wie Anm. 5), S. 143.

22 Andrzej Wędzki: Urbanisierungsprozesse im Land Lebus im Mittelalter, in: Frankfurter Beiträge zur Geschichte 4 (1977), S. 12-21, hier S. 18; - Alicja Karłowska-Kamzowa: Ośno [Drossen], in: Kaczmarczyk/Wędzki (wie Anm. 17), S. 251-269, hier S. 252-254; - Kuhn (wie Anm. 8), S. 94. 
von Frankfurt erschlossen, die in die Zeit der schlesischen Herzöge datiert wird, weil ein Markt bei der Nikolaikirche in dem markgräflichen Privileg für Frankfurt von 1253 als bereits bestehend erwähnt wird. ${ }^{23}$ In derselben Zeit mußten die schlesischen Zisterzienser, deren wirtschaftliche Aktivitäten auch auf den Oderhandel ausgerichtet waren, bereits die Expansion der nach Osten vordringenden Markgrafen in Rechnung stellen. 1230 gewährten ihnen diese nämlich für die Heringstransporte auf der Oder Zollfreiheit in ihrem (der Markgrafen) derzeitigen und zukünftigen Herrschaftsgebiet (per omnem nostrum districtum, quem nunc habemus et in futuro sumus dante domino habituri). ${ }^{24} \mathrm{Kurz}$ nachdem 1249 Herzog Bolesław von Schlesien einen Teil des Landes Lebus an den Erzbischof von Magdeburg abgetreten hatte, sicherten sich auch die Markgrafen einen Anteil an diesem Land. In der erwähnten Urkunde über den Vergleich zwischen dem Bischof von Lebus und dem Erzbischof von Magdeburg kündigte der letztere am 7. März 1252 bereits die kurz bevorstehende Teilung des Landes Lebus mit den Markgrafen an. ${ }^{25}$ Sie erfolgte bald darauf, und schon im Juli 1253 stellte Markgraf Johann I. die Urkunde für die zu bauende bzw. auszubauende civitas Frankfurt aus. ${ }^{26}$

Civitas meint hier die kommunal verfaßte Marktstadt. Mit ihr sollte das Land beiderseits der Oder im markgräflichen Teil ein neues Zentrum auf (im Sinne der Zeit) moderner wirtschaftlicher Grundlage erhalten, über das der Hauptstrom des Verkehrs in westöstlicher Richtung verlaufen und das zugleich das Land beiderseits des Flusses an den Nord-Süd-Fernhandel anschließen sollte, der traditionell noch zu einem erheblichen Teil auf dem Wasserweg abgewickelt wurde. Frankfurt bekam die gleiche Funktion für das Land Lebus beiderseits der Oder, wie die Doppelstadt Berlin-Cölln sie für die Landschaften Barnim und Teltow beiderseits der Spree bereits seit einiger Zeit wahrnahm. Frankfurt erhielt das Berliner Recht, der Bau einer Oderbrücke und einer Schwesterstadt auf

23 Friedrich Schilling: Die erste Einwanderung und Ansiedlung von Deutschen in Frankfurt a.d. Oder. Frankfurt a.d.O. 1926, S. 65-91 (= Frankfurter Abhandlungen zur Geschichte, 1); - Eckhard Müller-Mertens: Gründung und Entwicklung der Stadt Frankfurt an der Oder - Klassenkämpfe im 14./15. Jahrhundert, in: Frankfurter Beiträge zur Geschichte 1 (1976), S. 18-36; - Winfried Schich: Die Herausbildung der mittelalterlichen Stadt in der Mark Brandenburg. Der Wandel der Topographie, Wirtschaft und Verfassung im 12./13. Jahrhundert, in: Helmut Jäger (Hg.): Stadtkernforschung. Köln-Wien 1987, S. 213-243, hier S. 225-227 (mit weiterer Literatur) (= Städteforschung A, 27); - Monika Kilian/Ulrich Knefelkamp: Von der Kaufmannssiedlung zur Hansestadt - eine mittelalterliche Erfolgsgeschichte, in: Ulrich Knefelkamp/Siegfried Griesa (Hg.): Frankfurt an der Oder 1253-2003. Berlin 2003, S. 31-65; - Kilian-Bachmann (wie Anm. 5) S. 121-158.

24 SUB I, S. 233 f. Nr. 318.

25 CDB I, 20, S. 183 f. Nr. 10.

26 CDB I, 23. Berlin 1862, S. 1-3 Nr. 1 u. 2; - KW, Nr. 766; - Herbert Helbig/Lorenz Weinrich (Hg.): Urkunden und erzählende Quellen zur deutschen Ostsiedlung im Mittelalter, T. 1, 2.Aufl. Darmstadt 1975, S. 242-251 Nr. 60 (= Ausgewählte Quellen zur deutschen Geschichte des Mittelalters, 26a). - Auf das Verhältnis der beiden Urkunden zueinander, von denen die eine den echten Wortlaut in deutscher Übersetzung, die andere den vielleicht verfälschten lateinischen Text enthält, die den später veränderten Gegebenheiten Rechnung trug, kann hier nicht näher eingegangen werden; vgl. dazu Krabbo (wie Anm. 2), S. 273-290, bes. S. 283. Seit Schilling (wie Anm. 23), S. 19-64, werden im allgemeinen beide Urkunden für echt gehalten; so auch Kilian/Knefelkamp (wie Anm. 23) und Kilian-Bachmann (wie. Anm. 5), S. 113 f. 
dem Platz Zliwitz (Słubice) jenseits der Oder (trans Oderam) waren vorgesehen. Słubice wäre die erste askanische Stadtgründung östlich der Oder gewesen, wenn sie denn zustande gekommen wäre. Die mittelalterliche Stadtentwicklung konzentrierte sich aber auf das westliche Oderufer; am östlichen bestand lediglich ein Brückenkopf, aus dem die Frankfurter Dammvorstadt hervorging, die dann 1945 in Słubice umbenannt wurde. ${ }^{26 a}$ Die 60 Hufen, die 1253 für die Stadt Zliwitz vorgesehen waren, fielen an Frankfurt, das anfangs mit 124 Hufen (davon 104 für den Ackerbau) - einschließlich der inzwischen üblich gewordenen 4-Hufen-dos für die Pfarrkirche - ausgestattet worden war. Die Bürger erhielten - wie ebenfalls üblich - Zollfreiheit im Herrschaftsbereich des Stadtherrn und Steuerfreiheit für die Zeit des Neuaufbaues (hier für sieben Jahre). Nach dieser Frist fiel ein Drittel der Zinsen von Hausgrundstücken, Hufen und Verkaufsstätten ebenso wie von den Gerichtsgefällen an den Lokator, der das Amt des Schultheißen erhielt; zwei Drittel verblieben dem Markgrafen.

Wie ein „Paukenschlag“ erscheint im Land Lebus vor etwa 750 Jahren die neue große Bürgerstadt. Planung und Ausführung der Stadtanlage sind nur aus einem „Bündnis“ des Markgrafen mit den wirtschaftlich maßgeblichen Kräften zu erklären. Unter den Zeugen des Lokationsprivilegs für Frankfurt finden wir die Namen von Marsilius de Berlin und von Theodericus de Blumenberch. Marsilius war nachweislich Schultheiß von Berlin, Dietrich vielleicht von Blumberg. Letzterer trug jedenfalls seinen Zunamen sehr wahrscheinlich nach Blumberg, dem Städtchen auf dem Barnim, das von Berlin aus die erste Station in der Reihe der oppida auf dem kurz zuvor angelegten neuen Handelsweg durch die markgräfliche nova terra Barnim, das heißt durch das neu besiedelte Land Barnim, nach Oderberg bildete. ${ }^{27}$ Auf diesem Weg wurde - sicher zum großen Teil von Berlin aus organisiert - vor allem Getreide nach Stettin (Szczecin) exportiert und Fisch importiert. Beide Zeugen dürften von Berlin aus in beiden Richtungen, zuerst nach Norden und dann zusätzlich nach Osten, engagiert gewesen sein. Die Frankfurter erhielten - nach Ablauf der sieben Freijahre - das Recht der Berliner, so wie diese es von den Bürgern von Brandenburg übernommen hatten. Der Rat von Berlin schickte bald darauf Ausführungsbestimmungen über das in Berlin geltende Recht; ${ }^{28}$ sie zeigen die eindeutige Vorrangstellung der Kaufleute vor den handwerklich tätigen Bürgern.

Frankfurt war in seiner schlesischen Zeit in westlicher Richtung mit höchster Wahrscheinlichkeit vor allem nach Südwesten orientiert, das heißt auf die von Frankfurt am Main nach Osten führende Franken- oder Hohe Straße, die über Erfurt und Leipzig sowie in ihrem Hauptstrang weiter über Bautzen und Görlitz nach Breslau (Wrocław) verlief und letztlich auf Krakau (Kraków) zielte. Ein Nebenstrang führte von Leipzig aus nach

26a Siehe jetzt auch: Frankfurckie przedmieście Słubice na tle historii miasta. Słubice im Spiegel der Stadtgeschichte Frankfurts, in: Sebastian Preiss u.a.: Słubice. Historia - topografia - rozwój. Geschichte - Topografie - Entwicklung. Frankfurt (Oder) 2003, S. 23-132.

27 Winfried Schich: Oppida, Kirchenbauten und Fernhandelsstraße zwischen Berlin und Oderberg im 13. Jahrhundert, in: Franz J. Felten/Stephanie Irrgang/Kurt Wesoly (Hg.): Ein gefüllter Willkomm. Festschrift für Knut Schulz zum 65. Geburtstag. Aachen 2002, S. 143-171, hier S. 159 f. CDB I, 23, S. 3 Nr. 3. 
Frankfurt (Oder) über Torgau und Luckau, die (in wirtschaftlicher Hinsicht) Hauptstadt der Niederlausitz, wo sie die im Aufschwung begriffene Fernstraße von Magdeburg nach Schlesien kreuzte. ${ }^{29}$ Der Herkunftsname des Frankfurter Lokators Gottfried von Herzberg weist in dieselbe Richtung, denn Herzberg liegt an der genannten Straße zwischen Torgau und Luckau; die Straße in Richtung Luckau heißt dort noch heute „Frankfurter Straße“. Erst mit der Privilegierung von 1253 und dem anschließenden Ausbau der Stadt wurde Frankfurt stärker an die askanische Mittelmark mit ihrem Hauptort Berlin im Westen angeschlossen. Frankfurt sollte als neue zentrale Handelsstadt im östlichen Teil der erweiterten Mark Brandenburg dienen. Sie setzte auf einer neuen Grundlage die wirtschaftlichen Funktionen der alten Landesburg und des Bischofssitzes Lebus fort; dieser Ort befand sich 1253 ohnehin noch nicht in seiner Gesamtheit in markgräflicher Hand. Dies sind die Zusammenhänge und Hintergründe, die man für den Ausbau von Frankfurt aus den schriftlichen Quellen mit einem hohen Maß an Wahrscheinlichkeit erschließen kann.

Die Lokationsurkunde von 1253 sagt ausdrücklich, daß die civitas Frankfurt gebaut werden sollte (civitatem ... dedimus construendam). Bisher war in der Forschung unstrittig, daß bei diesem Ausbau der größere südliche Teil der mittelalterlichen Stadt mit der Marienkirche angelegt wurde. Zweifel wurden neuerdings geäußert, weil sich unterhalb der bisher ältesten erfaßbaren Basilika, deren Bau traditionell auf die Zeit unmittelbar nach 1253 datiert wird, Indizien für einen älteren Kirchenbau gefunden haben. ${ }^{30}$ Mit dem archäologischen Befund wird man sich eingehender beschäftigen müssen. Falls die Datierung des ersten Kirchenbaues in die Zeit vor 1253 gesichert sein sollte, so müßte der 1253 angesprochene „Bau“ der Stadt hier einen weiteren älteren Siedlungskern neben dem um St. Nikolai überformt haben.

Der Grundriß von Frankfurt zeigt eine planvolle und ausgesprochen städtische Form (Abb. 1). Drei Straßen sind parallel zum Oderufer geführt - ähnlich wie die drei parallelen Hauptstraßen in Berlin. Zusammen mit den Querstraßen begrenzen sie etwa gleich große Baublöcke mit den areae oder buwesteten (Baustätten) der Bürger. Die Querstraßen öffnen die Stadt mit dem Markt zum Ufer hin, wo sich der Hafen befand und der Umschlag zwischen Fluß- und Landverkehr erfolgte. Die überregionale Verkehrsverbindung in West-Ost-Richtung ist in die parallel zum Oderufer ausgerichtete Straßenführung eingeordnet. Die einzige Durchgangsstraße in Nord-Süd-Richtung ist die Richtstraße; auf ih-

29 Friedrich Bruns/Hugo Weczerka: Hansische Handelsstraßen. Textband. Weimar 1967, passim; Atlas. Köln-Graz 1962, Karten III, 15, $20-23$ (= Quellen und Darstellungen zur hansischen Geschichte, XIII, 1 u. 2).

30 Blandine Wittkopp: Wann wurde St. Marien gegründet? Zur Auswertung von Grabungen in der Stadtpfarrkirche Frankfurt (Oder), in: Archäologie in Berlin und Brandenburg 2001. Stuttgart 2002, S. 132 f.; - dies.: Marienkirche, in: Frankfurt (Oder) und das Land Lebus (wie Anm. 9), S. 101 f. Vgl. Andreas Cante: Baugeschichte, Ausstattung und Restaurierungen der Frankfurter Marienkirche im historischen Überblick, in: Ralf-Rüdiger Targiel (Hg.): Die Marienkirche zu Frankfurt (Oder). Frankfurt (Oder) 2005, S. 11-35, hier S. 11 f.; - Kilian-Buchmann (wie Anm. 5), S. 140-142. 


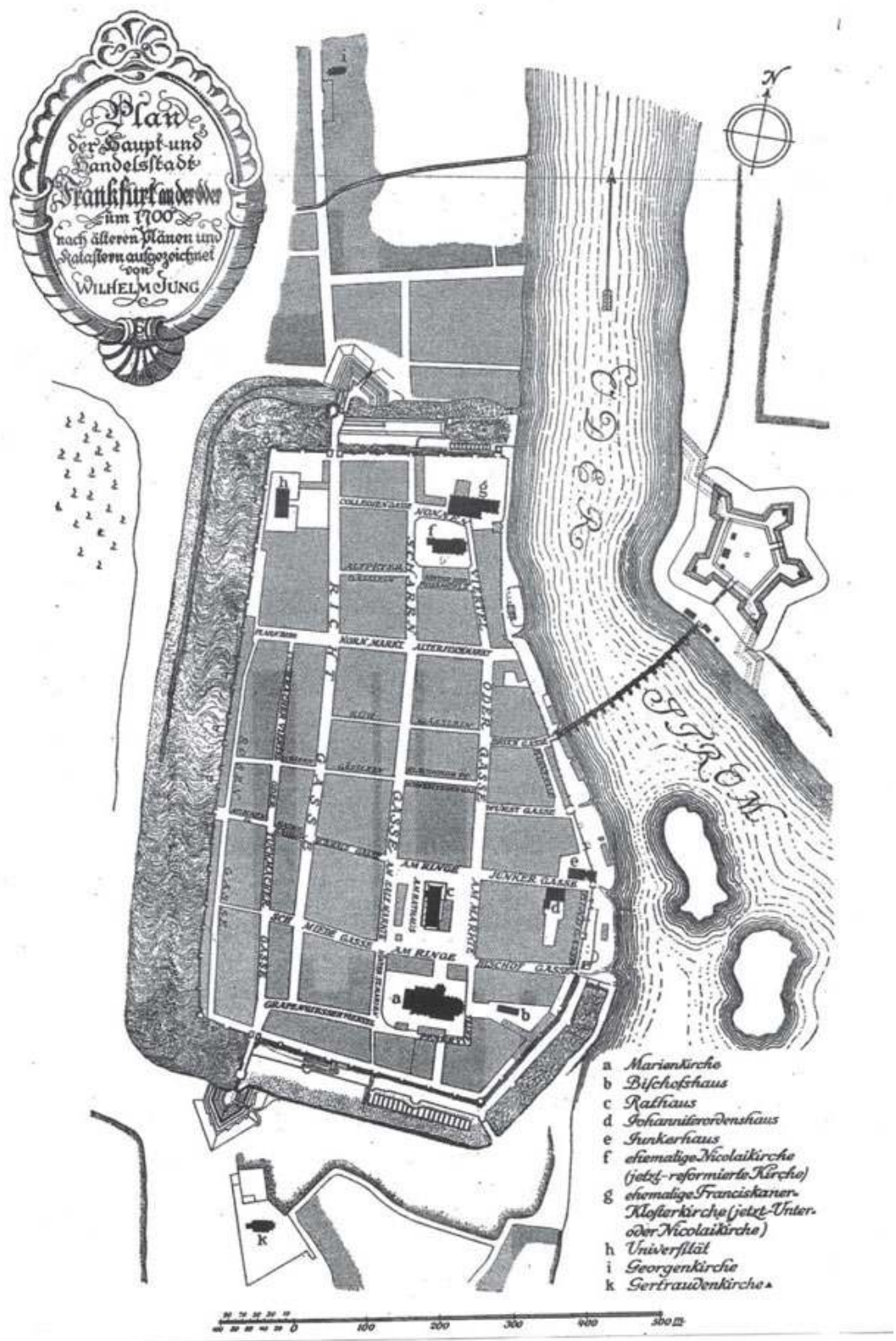

Abb. 1: Frankfurt an der Oder um 1700 nach älteren Plänen und Katastern aufgezeichnet von Wilhelm Jung. Aus: Die Kunstdenkmäler der Stadt Frankfurt a.O., bearb. v. Wilhelm Jung, Willy Spatz u. Friedrich Solger. Berlin 1912,

S. 5 Abb. 2 (= Die Kunstdenkmäler der Provinz Brandenburg, VI, 2). 
ren Namen kommen wir später zurück. Die Grundzüge dieser Anlage dürften in die Zeit kurz nach der Mitte des 13. Jahrhunderts zurückreichen. ${ }^{31}$

Ebenso wie bei den gleichzeitigen Lokationen von Posen (1253) und Krakau (1257) war in Frankfurt der Bau eines Kaufhauses auf dem Markt (teatrum in foro) vorgesehen. Während aber die polnischen Herzöge das Haus mit den Tuchläden auf eigene Kosten zu errichten versprachen, ${ }^{32}$ sollten in Frankfurt die Bürger den Bau des Kaufhauses, ebenso wie den der Oderbrücke, aus eigenen Mitteln finanzieren. Die Kaufleute waren an der Bindung des Gewandschnitts, das heißt des Tuchverkaufs en détail, an das Kaufhaus interessiert, um die Konkurrenz der lokalen Tuchproduzenten auszuschließen oder wenigstens zu begrenzen. Von den einzelnen Verkaufsstätten (stationes) im teatrum erhielten die Markgrafen einen Zins, ebenso wie von den Hausstätten und den Hufen und auch von den Mühlen an der Klinge, einem Nebenbach der Oder nördlich der Stadt. Zur neuen Stadt gehörte in dieser Zeit üblicherweise eine Wassermühle. Die Befestigung wird in der Urkunde nicht erwähnt. Es war hier vermutlich selbstverständlich, daß die Bürger sie selbst in ihre Hände nahmen; dies war schließlich in ihrem eigenen Interesse. Die Befestigung bestand in dieser Zeit üblicherweise aus Wall, Graben und Palisade, von denen Reste in verschiedenen brandenburgischen Städten in den letzten Jahren ergraben worden sind. ${ }^{33}$ Auf der Grundlage des archäologischen Befundes an der Südwestecke des mittelalterlichen Stadtkerns von Frankfurt (im Zuge der späteren Steinmauer) konnte die Rekonstruktion einer hölzernen Palisade mit einem Wehrgang auf einem Wall aus der Frühzeit der Stadtanlage versucht werden. ${ }^{34}$ Insgesamt gewinnt man aus dem Wortlaut der Urkunde von 1253 den Eindruck, daß einigermaßen kapitalkräftige Bürger für den Aufbau der Stadt schon bereit standen.

Östlich der Oder standen allem Anschein nach derartige Kräfte noch nicht in ausreichendem Maße zur Verfügung. Diesen Eindruck vermittelt jedenfalls ein Vergleich des Frankfurter Privilegs mit der vier Jahre später für (Neu-)Landsberg an der Warthe ausgestellten Urkunde. ${ }^{35}$ Markgraf Johann, der hier ebenso wie im Fall Frankfurt allein urkun-

31 Zum archäologischen Befund in Frankfurt siehe jetzt: Vera Kliemann: Die ur- und frühgeschichtliche Besiedlung des Stadtkreises Frankfurt (Oder), in: Frankfurter Jahrbuch 2000, S. 65-84, bes. S. 80 f.; - Kilian-Buchmann (wie Anm. 5), S.161-194 u. ö.; - zur weiteren räumlichen Entwicklung der Stadt: Dirk Bloch: Frankfurt (Oder). Stadtgeschichte im Kartenbild 1700 bis 2003. Berlin 2003.

32 Kodeks dyplomatyczny Wielkopolski (Codex diplomaticus Majoris Poloniae), Bd. 1. Poznań 1877, S. 285-287 Nr. 321; - Kodeks dyplomatyczny miasta Krakowa (Codex diplomaticus civitatis Cracoviensis). 1257-1506, hg. v. Franciszek Piekosiński, Bd. 1. Kraków 1879, S. 1-4 Nr. 1 (= Monumenta medii aevi historica res gestas Poloniae illustrantia, 5); - Helbig/Weinrich (wie Anm. 26), T. 2, Darmstadt 1970, S. 242-249 Nr. 62, S. 290-297 Nr. 77 (= Ausgewählte Quellen ..., 26b).

33 Jürgen Kunow (Hg.): Befestigungen brandenburgischer Städte in der archäologischen Überlieferung, Wünsdorf 2000 (= Arbeitsberichte zur Bodendenkmalpflege in Brandenburg, 5).

34 Christa Plate: Graben, Wall, Mauer, Tor und Turm. Die Stadtbefestigung im archäologischen Befund aus Untersuchungen im Land Brandenburg 1991-1998, in: Kunow (wie Anm. 33), S. 1-34, hier S. 18; - Nico Aten: Ein Wall mit Palisade: Ausgrabungen in der Altstadt von Frankfurt (Oder), in: Archäologie in Berlin und Brandenburg 1993-1994. Stuttgart 1997, S. 123-125.

$35 \mathrm{Zu}$ den Anfängen von Landsberg siehe Rudolf Eckert: Geschichte von Landsberg a.W. Stadt und Kreis. Landsberg a.W. 1890, T. 1, S. 15-19; - Die Kunstdenkmäler des Stadt- und Landkreises Landsberg (Warthe), bearb. v. Kurt Reißmann. Berlin 1937, S. 81-87 (= Die Kunstdenkmäler 
dete, beauftragte am 2. Juli 1257 seinen Getreuen Albert von Luge, seine freie Stadt Landisberch Novam zu errichten (construendi), und überließ ihm dafür wie üblich ein Drittel der Zinsen von Hausstätten, Hufen und Verkaufsständen auf dem Markt sowie von den Gerichtsgefällen und auch von den Mühlen, die innerhalb des Stadtgebietes (infra civitatis terminos et agrorum) am Kladow-Fließ (Kłodawa) gebaut werden sollten. ${ }^{36}$ Die Stadt wurde mit 104 Ackerhufen und 50 Hufen Weideland ausgestattet; der Zins war aber erst nach Ablauf von zehn Freijahren, gerechnet vom Martinstag (11. November) des Jahres 1257 an, zu entrichten. Danach erhielten die Bürger die Stadt zu Brandenburger Recht; Brandenburg an der Havel war der oberste Stadtrechtsvorort in der Mark. Bis zum nächsten Martinsfest, also innerhalb von wenig mehr als vier Monaten, - so sagte der Markgraf $\mathrm{zu}$ - werde er selbst die Stadt plancis et seris, also mit Planken und Querbalken, sichern, später dann plancis decentioribus atque fossis, das heißt mit besseren, passenderen Planken - vermutlich von der Art, wie sie für Frankfurt rekonstruiert worden sind - und mit Gräben befestigen. Es ist ein seltener Fall, daß in diesem Zeitraum die Art der Befestigung einer märkischen Stadt näher charakterisiert wird. Die Befestigung mit Planken auf einem Wall und mit vorgelagertem Graben war, wie erwähnt, in dieser Zeit noch die übliche. Näher beschrieben wurde sie hier wohl deswegen, weil den künftigen Bewohnern durch die provisorischen Befestigungsanlagen, deren Bau unter Leitung des Lokators vermutlich mit den ihm unterstellten militärischen Kräften und der ansässigen slawischen Bevölkerung durchgeführt wurde, rasch Sicherheit geboten werden sollte, bevor dann die Bürger bei den stärkeren Befestigungsanlagen selbst mit Hand anlegten. Ein Teil der ansässigen Bewohner wurde vermutlich in dem westlich der Stadt gelegenen Kietz angesiedelt und zu Diensten gegenüber der Herrschaft verpflichtet. ${ }^{37}$

der Provinz Brandenburg, VII, 3); - Fritz Buchholz: Landsberg (Warthe), in: Deutsches Städtebuch (wie Anm. 17), S. 572-576; - Grażyna Wróblewska: Gorzów [Landsberg], in: Kaczmarczyk/ Wędzki (wie Anm. 17), S. 173-198; - Andrzej Wędzki: Gorzów od czasów najdawnejszych do schyłku średniowiecza [Landsberg von den ältesten Zeiten bis zum Ende des Mittelalters], in: Joachim Benyskiewicz/Zygmunt Boras/Andrzej Wędzki: Dzieje Gorzowa [Geschichte Landsbergs], Bd. 1. Gorzów Wlkp. 1990, S. 13-77, hier S. 25-30; - Jerzy Walachowicz: Geneza (wie Anm. 5), S. 144-146; - ders.: Czy tylko sześć miast? Wokół askańskich lokacji miejskich trans Oderam [Warum nur sechs Städte? Zu den askanischen Stadtlokationen jenseits der Oder], in: Ewa Borkowska-Bagieńska/Henryk Olszewski (Hg.): Historia prawa - Historia kultury. Liber memorialis Vitoldo Maisel dedicatus. Poznań 1994, S. 75-85 (= Prace Wydziała Prawa i Administracji uniw. im. A. Mickiewicza w Poznaniu, 1).

36 CDB I, 18. Berlin 1859, S. 369 Nr. 1; - KW, S. 190 Nr. 813; - Ewa Syska: Die Urkunden der Stadt Landsberg an der Warthe (Gorzów Wielkopolski) aus der Askanier- und Wittelsbacherzeit 1257-1373, in: JGMOD 48 (2002), S. 29-116, hier S. 33-35 Nr. 1; - dies.: Dokumenty Gorzowa Wielkopolskiego (Landsbergu) z lat 1257-1373 [Die Urkunden von Gorzów Wielkopolski (Landsberg) aus den Jahren 1257-1373]. Gorzów Wlkp.-Poznań 2006, S. 11 f. Nr. 1. Bei den folgenden Verweisen auf Syska: Urkunden (wie Anm. 36) ist ebenfalls diese Neuerscheinung zu berücksichtigen.

37 Herbert Ludat: Die ostdeutschen Kietze. Mit einem Nachwort versehen. Hildesheim-Zürich-New York 1984, S. 52, 62 (Nachdruck der Ausgabe Bernburg 1936); - allgemein zu den Kietzen: Eberhard Bohm: Die Kietze als Problem der nichtstädtischen Herrschaftssiedlung in der Mark Brandenburg, in: Berichte zur deutschen Landeskunde 51 (1977), S. 41-59; - Jan M. Piskorski: Brandenburskie Kietze (chyże) - instytucja pochodzenia słowiańskiego czy „produkt“ władzy askańskiej? 
Abschließend erhielt der Lokator und künftige Schultheiß der Stadt zusätzlich 64 Hufen außerhalb der Grenzen der Stadt (extra civitatis terminos) zu Lehen. Es war also gleichzeitig mit der Stadt die Anlage eines Kirchdorfes in der Größe vorgesehen, wie sie für die sogenannte askanische Plansiedlung, vor allem in der Neumark, charakteristisch ist. ${ }^{38}$ In diesem Zusammenhang ist darauf hinzuweisen, daß die Stadt selbst mit der ackerbaulich nutzbaren Gemarkung von Anfang an ein - im weiteren Sinne gesprochen ackerbürgerliches Element erhielt. Damit sollte keineswegs in erster Linie die Nahrungsgrundlage der Stadt gesichert werden, sondern ihre Lebensfähigkeit insgesamt, und dazu gehörten Bau und Unterhalt der Befestigung. Dafür benötigte man möglichst viele Hände und vor allem auch Fuhrwerke, wie sie die Ackerbauern besaßen. Bei der Neuanlage wurde von Anfang an einkalkuliert, daß Bevölkerungszahl und Wirtschaftskraft einer allein auf den Markt ausgerichteten Siedlung für den Aufbau und Bestand dieser vergleichsweise großen civitas nicht ausreichten. Mit der um den Ackerbau erweiterten wirtschaftlichen Basis war es möglich, die Stadt mit einer größeren Zahl von wirtschaftlich aktiven Bewohnern zu füllen. Die engere Verknüpfung der Stadt mit der Landwirtschaft, über den Markt hinaus, konnte auf verschiedene Weise organisiert werden. Sie konnte in die städtische Gemarkung selbst einbezogen oder als eigenes Dorf in rechtlicher Verbindung mit der Stadt geordnet werden. Letzteres gilt für das Dorf des städtischen Schultheißen wie im Fall Landsberg ebenso wie für die Stadtdörfer, die später im Deutschordensstaat und in verschiedenen Teilen Polens angelegt wurden. ${ }^{39}$ Mit dem Aufbau des Schulzendorfes wurde der Vorsteher der städtischen Gemeinde unmittelbar in den Ausbau des Landes einbezogen.

Aus der Landsberger Lokationsurkunde kann man also schließen, daß mit der Stadtgründung gleichzeitig die Neusiedlung im ländlichen Bereich und die Umstrukturierung der vorhandenen Siedlungen mit Vermessung von Hufen und damit der Aufbau der terra Landsberg, wie sie dann später im Neumärkischen Landbuch von 1337 faßbar wird, ${ }^{40}$ eingeleitet oder eine bereits unter pommerscher Herrschaft begonnene Entwicklung, wie sie

[Die brandenburgischen Kietze - eine Institution slawischer Herkunft oder ein „Produkt“ askanischer Macht?], in: Przegląd Historyczny 79 (1988), T. 1, S. 301-329; - ders.: Die brandenburgischen Kietze - Eine Institution slawischen Ursprungs oder ein Produkt askanischer Herrschaft?, in: Bulach/Hardt (wie Anm. 9), S. 181-202. - Zur Lage des Kietzes an der Warthe westlich von Landsberg: Special-Carte des gantzen Warthe-Bruchs von 1765/66 (Geheimes Staatsarchiv PK, Berlin, Kart.A 531).

38 Schulze (wie Anm. 2), S. 127.

39 Wilhelm Krimpenfort: Der Grundbesitz der Landstädte des Herzogtums Preußen. Geschichte, Wirtschaft, Recht, Sozialordnung. Marburg 1979 (= Marburger Ostforschungen, 35); - Hans Jürgen Reimers: Die Stadtdörfer der mittelalterlichen Ostsiedlung in Polen. Marburg 1976 (=Wissenschaftliche Beiträge zur Geschichte und Landeskunde Ostmitteleuropas, 104); - Peter Erlen: Europäischer Landesausbau und mittelalterliche deutsche Ostsiedlung. Ein kultureller Vergleich zwischen Südwestfrankreich, den Niederlanden und dem Ordensland Preußen. Marburg 1992 (= Historische und landeskundliche Ostmitteleuropa-Studien, 9), S. 185-187.

40 Ludwig Gollmert (Hg.): Das Neumärkische Landbuch Markgraf Ludwig's des Aelteren vom Jahre 1337, Frankfurt a.O. 1862 (= Mitteilungen des Historisch-Statistischen Vereins zu Frankfurt a.O., 2), S. 20-22; - dazu die Karte in: Georg Wilhelm von Raumer: Die Neumark Brandenburg im Jahre 1337 oder Markgraf Ludwig's des Aelteren Neumärkisches Landbuch aus dieser Zeit. Berlin 
Christian Gahlbeck vermutet, ${ }^{41}$ fortgesetzt wurde. In diesem „Land“ lagen mehrere Dörfer mit 64 Hufen, darunter Heinersdorf (Chwalęcice) und Kladow (Kłodawa) nördlich der Stadt am Flüßchen Kladow (rzeka Kłodawa). Die Lage des Schulzendorfes ist an der Kladow - zwischen der Stadt und Heinersdorf - zu vermuten, weil der Lokator zusammen mit dem Dorf eine oder mehrere zusätzliche Mühlen für die Verarbeitung des wichtigsten agrarischen Produktes errichten durfte. Zusammen mit dem Getreideanbau wurde in dieser Zeit allgemein die Anlage von Wassermühlen vorangetrieben; sie erhielten ihren Standort häufig am Rand der Stadt und stärkten ebenfalls deren zentrale Funktionen. ${ }^{42}$ Das Dorf des Lokators dürfte später in die städtische Gemarkung einbezogen worden und wüst gefallen sein. Vielleicht ist es mit dem Dorf Legstorp gleichzusetzen, das 1347 bei der Stadt (prope civitatem) Landsberg lag ${ }^{43}$ und das danach nicht wieder genannt wird. Der Ortsname, vielleicht ursprünglich Lugestorp, könnte vom Zunamen des Lokators Albrecht von Luge abgeleitet worden sein. ${ }^{44}$ Die Lage von Legstorp ist unbekannt. Sie wird in der Regel im Gebiet der Zantocher Vorstadt in Richtung Zechow (Czechów) gesucht. ${ }^{45}$ Eher ist aber aus dem oben genannten Grund ein Platz auf der Grundmoränenplatte nahe dem Fließ Kladow nördlich der Stadt zwischen dieser und Heinersdorf zu vermuten, vielleicht in der Gegend der Hinteren Mühle. ${ }^{46}$

Der Wortlaut der Urkunde für Landsberg macht deutlich, daß hier eine Marktstadt in der Form einer bürgerlichen „Großburg“ gebaut werden sollte. Der gewählte Ortsname zeigt ebenfalls, daß diese als „Landesburg“ zur Erfassung des neu gewonnenen und bisher zur Kastellanei Zantoch (Zantok) gehörenden Gebietes nördlich der Warthe dienen

1837. - Vgl. jetzt Christian Gahlbeck: Das sogenannte Neumärkische Landbuch Markgraf Ludwigs des Älteren von 1337, in: JGMOD 50 (2004), S. 1-48, hier S. 18 f. und Karte auf S. 10 f.

41 Gahlbeck: Oder-Drage-Raum (wie Anm. 12), S. 69 f.

42 Winfried Schich: Der Beitrag der Landesarchäologie für die Landesgeschichte, in: Archäologisches Nachrichtenblatt 9 (2004), S. 152-165, hier S. 161 f. Zum Kladow-Fließ jetzt Edward Rymar: Nazwy wodne prawobrżeznej dolnej Warty między Santokiem i Kostrzynem [Gewässernamen am rechten Ufer der unteren Warthe zwischen Zantoch und Küstrin], in: Nadwarciański Rocznik Historyczno-Archiwalny 19 (2012), S. 23-77, hier S. 49-59.

43 CDB I, 18, S. 120 Nr. 37, S. 391 Nr. 33; - Christian Gahlbeck: Zisterzienser und Zisterzienserinnen in der Neumark. Berlin 2002, S. 549, 551 mit Anm. 27 (= Veröffentlichungen des Brandenburgischen Landeshauptarchivs, 47). - Nach freundlicher Mitteilung von Dr. Christian Gahlbeck, Berlin, handelt es sich bei den beiden von Riedel gedruckten Urkunden um Abschriften ein und derselben Urkunde von 1347, wobei die ältere den Ortsnamen in der Form Legstorp, die jüngere in der Variante Zulegstorp enthält. Die Form Legstorp ist vorzuziehen. Ich korrigiere danach meine in Anm. 1 zitierten Ausführungen „Die markgräflichen Stadtgründungen“, S. 236 f. Anm. 38, und danke Dr. Christian Gahlbeck für diesen Hinweis.

44 Ich folge hier dem Vorschlag von Dr. Christian Gahlbeck.

45 Eckert (wie Anm. 35), T. 2, S. 19; - Edward Rymar: Albert znany „z Luge“, zasadźca Gorzowa i jego rodzina [Albert genannt „,von Luge“, der Lokator von Landsberg, und seine Familie], in: Nadwarciański Rocznik Historyczno-Archiwalny 3 (1996), S. 211-213.

46 Auf einer Karte von 1787 ist bei ihr ein „Wüster Akker“ eingetragen; Geheimes Staatsarchiv PK, Berlin, Kart. E 407. - Vgl. auch Gahlbeck: Zisterzienser (wie Anm. 43). 
sollte. ${ }^{47}$ Gleichzeitig stellte er einen Bezug zur markgräflichen Stadt (Alt-)Landsberg im Barnim her. Die Masse der Neusiedler muß keineswegs aus dieser Stadt gekommen sein.

Es wird zu Recht häufig darauf hingewiesen, daß Neu-Landsberg gegen das polnische Zantoch gerichtet war und damit erneut gegen einen älteren Burg- und Hauptort, der sich noch nicht in askanischer Hand befand - ebenso wie zuvor in den Fällen Berlin und Köpenick sowie Frankfurt und Lebus. ${ }^{48}$ Man muß sich allerdings von der Vorstellung lösen, daß die Markgrafen und die mit ihnen ,verbündeten“ Kräfte einen völligen Neuanfang an einem bisher kaum genutzten Platz gemacht hätten. Im Fall Frankfurt war, wie erwähnt, vermutlich bereits in der schlesischen Zeit die verkehrsgünstige Lage des Ortes für die Neubildung einer städtischen Siedlung genutzt worden, und in dem von Landsberg deutet ebenfalls vieles darauf hin, daß der dortige Wartheübergang gegenüber der immer noch unbestrittenen Hauptburg Zantoch schon klar an Bedeutung gewonnen hatte, als die askanischen Markgrafen hier erschienen. Zantochs Lage war wohl in fortifikatorischer Hinsicht und für den Flußverkehr vorzüglich, ${ }^{49}$ weniger aber für den Landverkehr, der in dieser Zeit erheblich zunahm. Die allgemein steigende Bedeutung des Landverkehrs in diesem Raum wird schon aus den oben erwähnten Zollprivilegien für das Kloster Leubus deutlich. Die Zollfreiheit, die die Mönche 1211 für vier Schiffe pro Jahr auf der Oder erhielten, ließen sie sich gleichzeitig in 40 Wagenfuhren umrechnen..$^{50}$ Die Tatsache, daß die Gegend des späteren Landsberg schon in voraskanischer Zeit vergleichsweise dicht besiedelt war, wird aus der Karte der Verteilung der archäologischen Funde hinreichend deutlich. ${ }^{51}$ Dennoch reichte der Platz in seiner zentralörtlichen Funktion nicht an den Herrschaftsmittelpunkt Zantoch heran. Andernfalls wäre wohl auch der polnische Name des Ortes, der vorausgesetzt werden kann, aus der schriftlichen Überlieferung bekannt, und

47 Winfried Schich: Landsberg. Burg oder Stadt. Siedlungsgeschichtliche Bemerkungen zu einem in Mitteleuropa verbreiteten Ortsnamen, in: Jana Kubková u. a. (Hg.): Život v archeologii středověku. Das Leben in der Archäologie des Mittelalters. Festschrift für Miroslav Richter u. Zdeněk Smétanka. Praha 1997, S. 561-567, erneut in ders.: Wirtschaft (wie Anm. 10), S. 439-448.

48 Schultze: Entstehung (wie Anm. 2), S. 150 (Erstdruck 1960); - Podehl (wie Anm. 5), S. 701.

49 Wróblewska (wie Anm. 35), S. 177 f.; - Podehl (wie Anm. 5), bes. S. 291-302, 700-703; - vgl. auch Zofia Kurnatowska: Herrschaftszentren und Herrschaftsorganisation, in: Alfried Wieczorek/ Hans-Martin Hinz (Hg.): Europas Mitte um 1000, Bd. 1. Stuttgart 2000, S. 458-463, hier S. 458 f.

50 SUB I, S. 89 f. Nr. 123.

51 Armin Volkmann: Mittelalterliche Landeserschließungen und Siedlungsprozesse in der unteren Wartheregion (Woj. Zachodnio-Pomorskie, Lubuskie und Wielkopolskie bzw. ehemalige Neumark) (= Beiträge zur Ur- und Frühgeschichte Mitteleuropas, 44). Langenweißbach 2006, S. 37 f. Karten 4 u. 5 sowie S. 114; - ders.: Die Besiedlung der ehemaligen Neumark (Teilbereiche der Wojewodschaften Zachodnio-pomorskie, Lubuskie und Wielkopolskie) im Mittelalter anhand polnischer und deutscher archäologischer Forschungen, in: Nowa Marchia - prowincja zapomniana - wspólne korzenie, Zeszyty Naukowe 2. Gorzów Wlkp. 2005, S. 144-165; - Tadeusz Szczurek: Siedlungen auf dem Gebiet des heutigen Gorzów Wielkopolski vor dessen Gründung, in: Nowa Marchia ..., Zeszyty Naukowe 6. Gorzów Wlkp. 2006, S. 275-318. - Vgl. auch Wędzki (wie Anm. 35), S. 13-25; - Gahlbeck: Zisterzienser (wie Anm. 43), S. 496-498 Anm. 52, 548, 563-566 u. Kt.II,2 auf S. 1112 f.. 
es hätte 1945 kaum die Schwierigkeiten gegeben, einen passenden polnischen Namen für Landsberg zu finden. ${ }^{52}$

Einen ersten Hinweis auf eine gewisse Bedeutung des dortigen Wartheüberganges in einer schriftlichen Quelle findet man in der Urkunde des Zisterzienserklosters Paradies (Paradyż). Das Kloster war aus einer Schenkung des polnischen comes Bronisz um 1230, unterstützt vom großpolnischen Herzog, hervorgegangen. ${ }^{53}$ Nach einem langjährigen Prozeß, in dem der Orden die Gründung sorgfältig vorbereitet und nach allen Seiten gehörig abgesichert hatte, wurde 1236 ein Konvent aus dem askanischen Hauskloster Lehnin nach Paradies entsandt. Das Kloster richtete sich wie üblich mit der Gründung von Grangien und der Neugestaltung von Klosterdörfern in seiner Umgebung ein. ${ }^{54} 1252$ schenkte ihm dann ein Bogenschütze (sagittarius) Herzog Przemysławs von Großpolen das Gut (hereditas) oder Dorf (villa) Kernein (Karnin), dessen Nordgrenze das Wartheufer gegenüber dem späteren Landsberg bildete. Der Herzog erlaubte den Mönchen zusätzlich, die hereditas nach ihren Bedürfnissen umzugestalten, sie zu verkaufen, zu vertauschen oder auch in wertvollere Nutzung zu überführen (seu eciam in usus valenciores convertendi). ${ }^{55}$ Das Kloster richtete in der Wartheniederung einen befestigten Wirtschaftshof ein, der vor allem auf die Viehzucht ausgerichtet war, wie sein 1373 zuerst erscheinender Name „Kuhburg" (Krowi gród, heute Zakanale-Siedlce) zeigt, ${ }^{56}$ daneben das Klosterdorf Kernein, das vermutlich vorzugsweise für den Getreideanbau vorgesehen war (Abb. 2).

52 Jerzy Zysnarski: Legenda o Kobylej Górze [Die Legende von Kobyla Góra/Stutenberg], in: ders.: Czarowice z Kobylej Góry. Transgraniczna historia Gorzowa i inne szkice z przeszłości miasta. Gorzów 2000, S. 9-28; - Grzegorz Rossoliński: Umbenennungen in der Ziemia Lubuska nach 1945, in: Bernd Vogenbeck/Juliane Tomann/Magda Abraham-Drefenbach (Hg.): Terra Transoderana. Zwischen Neumark und Ziemia Lubuska. Berlin 2008, S. 59-68, hier S. 63.

53 Theodor Warminski: Urkundliche Geschichte des ehemaligen Cistercienser-Klosters zu Paradies. Meseritz 1886, S. 28-39; - Olgierd Borkowski: Powstanie i rozwój opactwa cysterskiego w Paradyżu-Gościkowie w XIII-XIV wieku [Entstehung und Entwicklung der Zisterzienserabtei Paradies-Gościkowo im 13.-14.Jh.], in: Rocznik Lubuski 14 (1986), S. 177-212 (mit umfassenden Literaturangaben); - Andrzej Marek Wyrwa: Szlak cysterski w Wielkopolsce [Der Zisterzienserweg in Großpolen]. Poznań 1996, S. 58-70; - Ryszard Hołownia/Krzysztof Kaczmarek: Paradyż (Gościkowo), in: Andrzej Marek Wyrwa/Jerzy Strzelczyk/Krzysztof Kaczmarek (Hg.): Monasticon Cisterciense Poloniae, Bd. 2. Poznań 1999, S. 285-289; - Joanna Karczewska (Hg.): Opactwo Cysterskie w Paradyżu. Jego rola w dziejach i kulturze pogranicza [Die Zisterzienserabtei in Paradies. Ihre Rolle in Geschichte und Kultur des Grenzlandes]. Zielona Góra 2004.

54 Winfried Schich: Ausstattung und Anlage des Klosters Lehnin und seiner Tochterklöster Paradies, Chorin und Himmelpfort im Vergleich, in: Karczewska (wie Anm. 53), S. 23-42, hier S. 28-37.

55 Kodeks dypl. Wielkopolski (wie Anm. 32), Bd. 1, S. 272 f. Nr. 306; - Gahlbeck: Zisterzienser (wie Anm. 43), S. 563.

56 Syska: Urkunden (wie Anm. 36), S. 114 Nr. 92. Mit dieser bislang unbekannten Urkunde ist der Name Kuhburg erheblich früher belegt, als dies vorher der Fall war. - Zum Hof vgl. Edward Rymar: Gorzów - Paradyż. Mnisi Dwór, Mnisi Most, Karnin i ... 12 talentów pieprzu [LandsbergParadies. Mönchshof, Mönchsbrücke, Kernein und ... 12 Pfund Pfeffer], in: Karczewska (wie Anm. 53), S. 55-62; - Christian Gahlbeck: Zur Frage der Wirtschaftsbeziehungen der Zisterzienser zu den Städten der Neumark, in: Winfried Schich (Hg.): Zisterziensische Wirtschaft und Kulturlandschaft. Berlin 1998, S. 99-139, bes. S. 124-126 (= Studien zur Geschichte, Kunst und Kultur der Zisterzienser, 3); - Winfried Schich: Höfe nichtbrandenburgischer Klöster und die Orte mit dem 


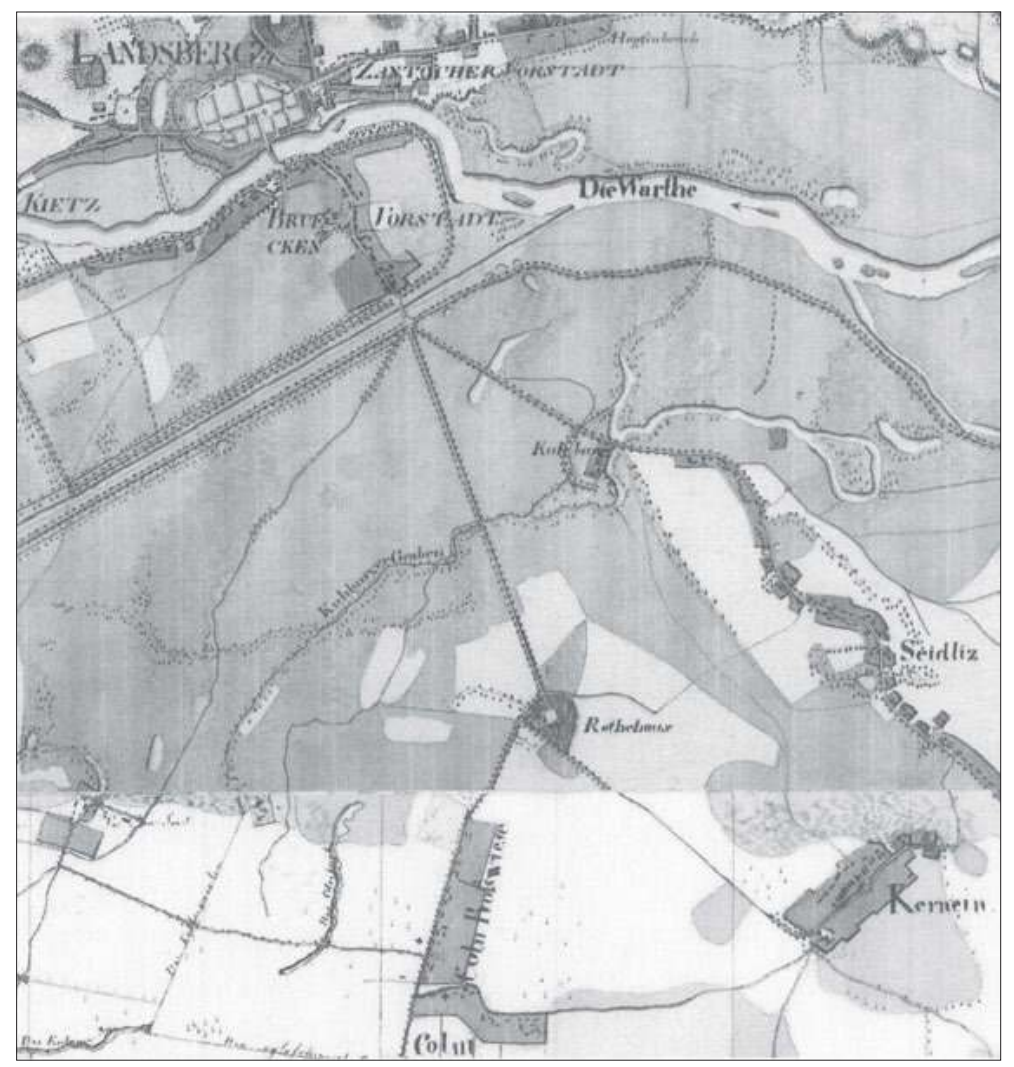

Abb. 2. Landsberg an der Warthe, die ehemalige Grangie Kuhburg und das Dorf Kernein. Aus: Urmeßtischblatt,

Nr. 1704 und 1776 von 1822 (Staatsbibliothek PK Berlin, Kart.N 729/1).

Man könnte den Eindruck gewinnen, daß die wirtschaftlich engagierten Zisterzienser eine völlig neue Handelsverbindung aufzubauen begannen - im eigenen Interesse und in dem der Markgrafen. Man könnte, wie vielfach üblich, den Vorgang mit der Schlagzeile „Zisterzienser bereiten den Markgrafen den Weg nach Osten“ versehen, aber dies wäre sachlich kaum angebracht. Es wurde schon an anderer Stelle darauf hingewiesen, daß die Zisterzienser mit ihren Zollprivilegien und mit ihrer Besitzpolitik nicht neue Wege eröffnet haben, sondern daß man umgekehrt aus den betreffenden Urkunden auf die zeitgenössischen Handelswege schließen kann, denen die Zisterzienser ihrerseits bei ihren wirt- 
schaftlichen Aktivitäten folgten. ${ }^{57}$ Die Erwerbung von Kernein durch das weiter südlich gelegene Kloster Paradies deutet darauf hin, daß der Fernverkehr bereits um 1250 auf den Platz des späteren Landsberg zielte. Wenn man zusätzlich berücksichtigt, daß das pommersche Kloster Kolbatz (Kołbacz) schon vorher das $10 \mathrm{~km}$ nordwestlich von Landsberg gelegene Gut Zanzin (Santocko) erhalten und Pommern auch eine Burg nördlich der Warthe (Neu-Zantoch) gegenüber Zantoch errichtet hatte, ${ }^{58}$ so wird man als Motiv für die Schenkung eher einen Zusammenhang mit dem Ringen zwischen Polen und Pommern um das Land an der unteren Warthe vermuten dürfen - und dies gewissermaßen am Vorabend des Vordringens der Markgrafen und der Gründung der Stadt durch Johann I. Dessen Expansion in diesen Raum ist bereits mit der Verabredung der Heirat seines Sohnes Konrad mit Constantia, der Tochter Herzog Przemysławs, zu fassen, die in das Jahr 1255 datiert wird und die der Herstellung des Friedens zwischen Polen und der Mark nach vorausgehenden kriegerischen Auseinandersetzungen dienen sollte. ${ }^{59}$ Die 1260 erfolgte Hochzeit in Zantoch brachte dem Askanier als Heiratsgut die Kastellanei Zantoch (noch ohne die Burg) ein. In der Zwischenzeit erfolgte die Gründung der Stadt Landsberg.

Die entscheidende Neuerung bestand 1257 darin, daß der Markgraf den hinsichtlich der Verkehrslage besser ausgestatteten Platz in dem Gebiet mit fruchtbaren Ackerböden zum neuen Landeszentrum ausbauen ließ und dies in der Form der kommunal verfaßten und gut befestigten Marktstadt. Zur Füllung der Großburg sollten die bürgerlichen Kräfte herangezogen werden, die sich im Handel, im Handwerk und im Ackerbau betätigten. Unter den Zeugen finden sich im Gegensatz zu Frankfurt aber noch allein markgräfliche Ritter (milites). Vermutlich wurde bald darauf der Bau des Dammes durch das Warthebruch in Angriff genommen; seine Existenz ist erst 1316 bezeugt. ${ }^{60}$

Der Beitrag der Markgrafen zum Aufbau der Stadt war im Fall Frankfurt deutlich geringer als in dem von Landsberg. Man mag schon in den Ortsnamen einen Hinweis auf die jeweils vorrangige Funktion finden: hier die Handelsstadt, dort die Landesburg. Hinweise auf eine besonders abgegrenzte Stadtburg liegen in Landsberg und Frankfurt - abgesehen von der Existenz jeweils eines Kietzes - nicht vor. Auch das Vorhandensein einer Burg in der Zeit vor der Stadtgründung ist in Landsberg nicht nachweisbar. Erst zur Zeit

57 Vgl. etwa Winfried Schich: Zum Problem des Einstiegs der Zisterzienser in den Handel im 12. Jahrhundert unter besonderer Berücksichtigung des Ordensstatutes De nundinis, in: Jerzy Strzelczyk (Hg.): Historia i kultura cystersów w dawnej Polsce i ich europejskie związki. Poznań 1987, S. 33-59 (= Uniwersytet im. Adama Mickiewicza w Poznaniu, Ser. Hist.,135), erneut in ders.: Wirtschaft (wie Anm. 10), S. 33-53; - ders.: Der frühe zisterziensische Handel und die Stadthöfe der fränkischen Zisterzienserklöster, in: Klaus Wollenberg (Hg.): In Tal und Einsamkeit. 725 Jahre Kloster Fürstenfeld. Die Zisterzienser im alten Bayern, Bd. 3: Kolloquium. Fürstenfeldbruck 1990, S. 121-143.

58 Edward Rymar: Cystersi na terytorium Nowej Marchii przed i w trakcie jej tworzenia oraz ich stosunki z margrabiami brandenburskimi z dynastii askańskiej [Die Zisterzienser in der Neumark vor und in der Zeit von deren Bildung sowie ihre Beziehungen zu den Markgrafen aus askanischem Geschlecht], in: Strzelczyk (wie Anm. 57), S. 193-210, hier S. 198 f. und Karte auf S. 209; - Gahlbeck: Zisterzienser (wie Anm. 43), S. 557 f.; - ders.: Oder-Drage-Raum (wie Anm. 12), S. 58 f.

59 KW, S. 183 Nr. 787, S. 203 Nr. 856. - Vgl. Rymar: Prawne podstawy (wie Anm. 12), S. 18 f.

60 CDB I, 18, S. 374 f. Nr. 8; - Syska: Urkunden (wie Anm. 36), S. 43 f. Nr. 10. 
der Ordensherrschaft bestand um 1450 in der Südostecke der Stadt ein Schloß; ${ }^{61}$ der Kietz lag dagegen westlich der Stadt. Die Kietze könnten auch mit einem herrschaftlichen Hof innerhalb der Stadt verbunden gewesen sein, wie er in anderen markgräflichen Städten der Zeit nachgewiesen ist. ${ }^{62}$

Zugespitzt kann man formulieren: In Frankfurt wurde der Handelsplatz mit einer Befestigung geschützt, in Landsberg die Burg mit wirtschaftlich aktiven Bewohnern gefüllt. Angemessener ist es, in beiden Fällen von der Vereinigung von Markt und Burg in einem neuartigen Siedlungskörper zu sprechen. Dabei konnte die gewerbliche Grundlage mehr oder weniger stark sein. In Frankfurt standen allem Anschein nach bereits genügend interessierte Fernhändler bereit, in Landsberg wurde ein landesherrlicher Stützpunkt auf einer anfangs deutlich schwächeren stadtwirtschaftlichen Grundlage errichtet. Die Stadtanlage ist im Vergleich mit Frankfurt kleiner ausgefallen. Zwischen der Richtstraße (heute ul. Sikorskiego) und einer Parallelstraße, der späteren Juden- bzw. Luisen- und der Schloßgasse (ul. Lużycka und Obotrycka), erhielten der Markt und die Stadtkirche ihren Platz. Mehrere kurze Straßen verbinden den städtischen Kern mit dem Flußufer, wo der Umschlag zwischen Land- und Flußverkehr stattfand. Dieser muß von Anfang an von großer Bedeutung gewesen sein, auch wenn die zweite markgräfliche Urkunde für Landsberg von 1257 mit der Verleihung des Rechtes der Niederlage in ihrer Echtheit zu Recht angezweifelt wird. ${ }^{63}$ Die Landsberger transportierten ihre Waren auf dem Wasserweg vom nördlichen, die Mönche von Paradies vom südlichen Ufer der Warthe aus - vor allem nach Stettin (Szczecin). Im rückwärtigen Teil der Stadt zieht sich parallel zur Stadtmauer die Baugasse (später Wollstraße bzw. ul. Poczta und Wełniany Rynek) hin. Hier fanden die Höfe derjenigen Bürger ihren Platz, deren wirtschaftliche Betätigung vorrangig auf den Ackerbau ausgerichtet war. Das Zentrum bildeten, neben der Pfarrkirche, die Richtstraße, die „Nebenrichtstraße“ - diesen Namen finden wir in Berlinchen (Barlinek) - und der Markt. ${ }^{64}$ Diese Elemente dürften von Anfang an geplant worden sein, im übrigen kann der erst erheblich später aufgezeichnete Stadtgrundriß (Abb. 3) das Ergebnis einer mehr oder weniger langen Entwicklung gewesen sein. Bereits mit dem Bau der Steinmauer kann es im Verlauf der Befestigungslinie zu einigen Veränderungen gekommen sein. 1321 erwirkte der Rat in diesem Zusammenhang eine Verlegung der Mühlen an der Kladow. ${ }^{65}$

61 Zur Frage der Burg vgl. Podehl (wie Anm. 5), S. 680; - Edward Rymar: Średniowieczny zamek (dwór) w Gorzowie [Das mittelalterliche Schloß (der Hof) in Landsberg], in: Nadwarciański Rocznik Historyczno-Archiwalny 6 (1999), T. 2, S. 137-141; - Gahlbeck: Zisterzienser (wie Anm. 43), S. 496-498 Anm. 52.

62 Eberhard Bohm: Teltow und Barnim. Untersuchungen zur Verfassungsgeschichte und Landesgliederung brandenburgischer Landschaften im Mittelalter. Köln-Wien 1978, S. 305-317 (= Mitteldeutsche Forschungen, 83).

63 CDB I, 18, S. 370 Nr. 2; - Syska: Urkunden (wie Anm. 36), S. 35 f. Nr. 2; - vgl. Edward Rymar: Gorzowskie prawo składu [Das Landsberger Niederlagsrecht], in: ders.: Studia (wie Anm. 5), S. 157-173.

64 Ed. Jobst Siedler: Märkischer Städtebau im Mittelalter. Beiträge zur Geschichte der Entstehung, Planung und baulichen Entwicklung der märkischen Städte. Berlin 1914, S. 37 Abb. 42, S. 58 Abb. 76.

65 Syska: Urkunden (wie Anm. 36), S. 49 Nr. 15. 


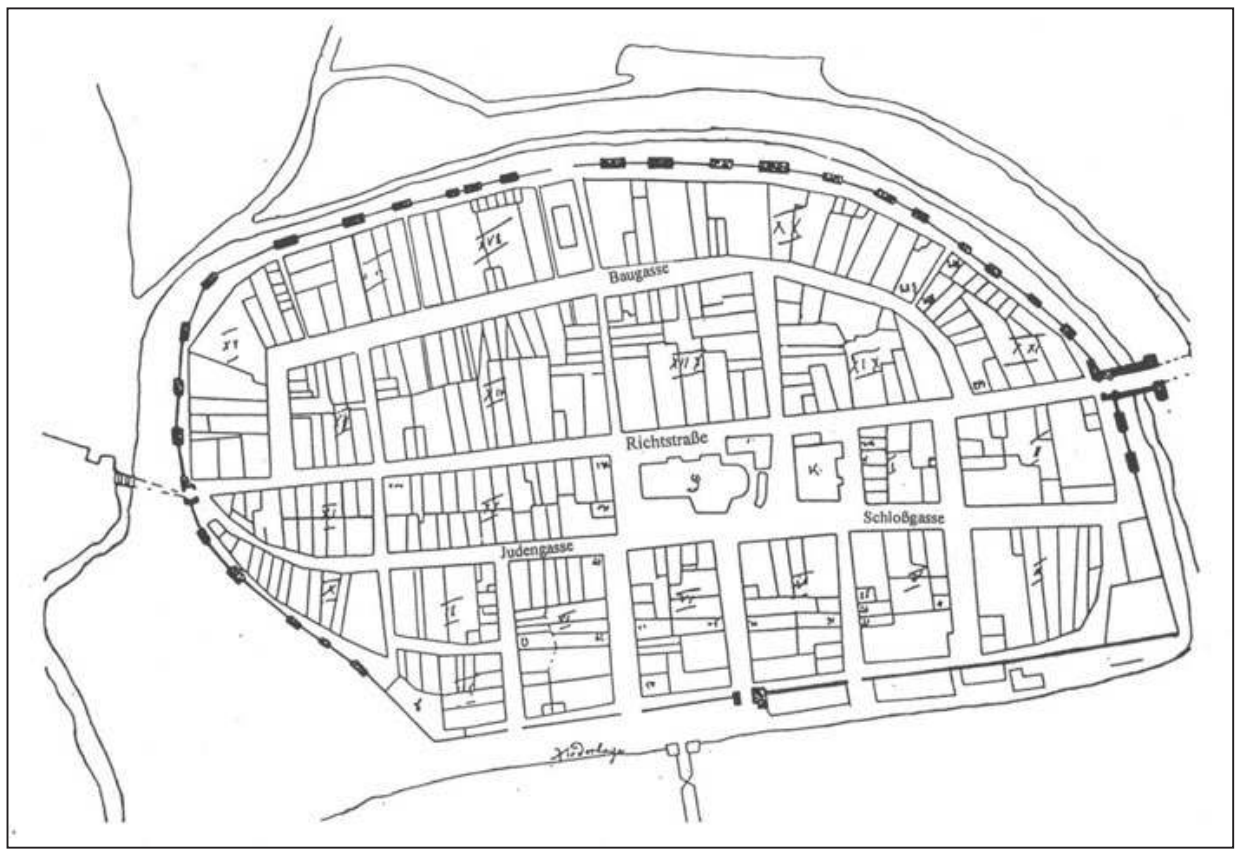

Abb. 3. Landsberg 1721. Aus: Die Kunstdenkmäler des Stadt- und Landkreises Landsberg (Warthe), bearb. v. Kurt Reißmann. Berlin 1937, S. 84 Abb. 52 (= Die Kunstdenkmäler der Provinz Brandenburg, VII, 3). Mit nachträglicher Hinzufügung der Straßennamen.

Im Planungsschema finden sich zwischen Frankfurt und Landsberg auch Parallelen. Neben der anfänglichen Wallbefestigung und der in etwa zentralen Lage des Marktes gilt dies für die Hauptdurchgangsstraße, die in beiden Fällen als Richtstraße bezeichnet wurde, und für die Öffnung durch Quergassen zum Flußufer. In Frankfurt wurde bei der Platzwahl für den neuen Markt vielleicht auf den im Norden bereits bestehenden Markt Rücksicht genommen.

Der Name der Richtstraße, der sich auch in anderen märkischen Städten jenseits der Oder für die Hauptstraße findet, hat nichts mit dem Gericht zu tun, sondern mit der „Richtung“. Es ist der gerade Weg oder die Straße, die die Richtung gibt bzw. nach der man sich richtet. ${ }^{65 a}$ Der Name hängt also zusammen mit der Richtschnur, und er ist vergleichbar mit dem Buchtitel „Richtsteig Landrechts“ des Sachsenspiegels aus dem 14. Jahrhundert; ${ }^{66}$

65a So jetzt auch Jerzy Zysnarski: Od Abdeckerei do Żwirowej, czyli klucz do toponomastyki Gorzowa [Von Abdeckerei bis Żwirowa oder Schlüssel zur Toponymie von Landsberg], in: Nadwarciański Rocznik Historyczno-Archiwalny 13 (2006), S. 31-70, hier S. 31 f.

66 Jacob und Wilhelm Grimm: Deutsches Wörterbuch, dtv-Ausgabe, Bd. 14, bearb. v. Moritz Heyne. München 1984, Sp.904 (= Bd. 8 der Orig.ausg. Leipzig 1893): Richtsteig = „ein weg nach dem man sich richtet", auch übertragen im Sinne von Richtschnur in der Gerichtsbarkeit. - Dazu vgl. auch 
dieser „Richtsteig“ diente gewissermaßen als Wegweiser für die Gerichtspraxis. Im 16. Jahrhundert konnte einer Landsberger Ratsordnung zufolge die Meile entweder „nach dem Richtsteige“, das heißt in gerader Richtung, oder ,nach gemeinen Straßen“ gemessen werden. ${ }^{67}$ Eine Richtstraße (richtstrate) wird bereits im 15. Jahrhundert in Wriezen, einer Stadt an der Oder am Ostrand des Barnim gegenüber der Neumark, genannt. ${ }^{68}$ Sie scheint ein Kennzeichen vieler Plananlagen des 13. Jahrhunderts in diesem Raum zu sein. Von ihr aus wurde offenbar die Stadt vermessen. Man darf schon wegen der Vermessung der Hufen annehmen, daß den Markgrafen hier geschulte Vermesser zur Verfügung standen, die sie auch für die Planung der Städte einsetzen konnten. ${ }^{69}$ Solche mensuratores sind im 13. Jahrhundert andernorts bezeugt. Das Land Stargard, das die Markgrafen Johann I. und Otto III. im Norden der Mark planmäßig mit Marktstädten und Hufendörfern ausbauten, galt bereits im Jahre 1270 in seiner Gesamtheit als vermessen (mensurati). ${ }^{70}$

Schließlich gehörte zu diesem Typ der Stadt die große Pfarrkirche, die die Bedeutung des Ortes schon beim Blick aus der Ferne zeigte. Dies gilt vor allem für die noch bestehende Marienkirche zu Landsberg. Sie war die erste große Backsteinkirche in der Neumark, die - so Jarosław Jarzewicz in seinem Werk über die gotische Architektur in der Neumark - die askanische Herrschaft dokumentieren sollte. ${ }^{71}$ Unmittelbar nach der Stadtgründung wurde wohl zunächst der Bau einer Feldsteinkirche begonnen, auf diesen folgte aber rasch der Bau der Backsteinkirche. Grundriß und Details der Backsteintechnik sowie

Dietlinde Munzel: Richtsteig, in: Handwörterbuch der deutschen Rechtsgeschichte, hg. v. Adalbert Erler u. Ekkehard Kaufmann unter philologischer Mitarbeit von Ruth Schmidt-Wiegand, Bd. 4. Berlin 1990, Sp. 1061-1063; - Ingeborg Buchholz-Johanek: Buch, Johann von, in: Lexikon des Mittelalters, Bd. 2. München-Zürich 1983, Sp.811.

67 Hans Bütow: Aus weiland Markgraf Johannsen Zeiten: Landesherrliche Verordnungen für die Neumark und Verfügungen des Landsberger Rates, in: Die Neumark, Mitteilungen 10 (1933), S. 41-54, hier S. 53 f. (um 1560). Vgl. auch Grimm (wie Anm. 66), Sp.907 unter „Richtweg“. Der Maßstock hieß bei den Zimmerleuten „Richtstock“ (ebenda, Sp.906).

68 CDB I, 12. Berlin 1857, S. 457 Nr. 61 zu 1473.

69 Vgl. Winfried Schich: Zur Größe der area in den Gründungsstädten im östlichen Mitteleuropa nach den Aussagen der schriftlichen Quellen, in: Stuart Jenks/Jürgen Sarnowsky/Marie-Luise Laudage (Hg.): Vera Lex Historiae. Studien zu mittelalterlichen Quellen. Festschrift für Dietrich Kurze zu seinem 65. Geburtstag. Köln-Wien-Weimar 1993, S. 81-115, bes. S. 88-92, erneut in ders.: Wirtschaft (wie Anm. 10), S. 379-406; - Schulze (wie Anm. 2), S. 127 f.

70 Mecklenburgisches Urkundenbuch, Bd. 2. Schwerin 1864, Nr. 1194; - KW, S. 243 Nr. 985. - Vgl. Winfried Schich: Der Ausbau des Landes Stargard unter der Herrschaft der Markgrafen von Brandenburg - die mittelalterlichen Grundlagen der Kulturlandschaft im östlichen Teil von Mecklenburg-Strelitz, in: Karola Stark (Hg.): Vom Anfang und Ende Mecklenburg-Strelitzer Geschichte. [Friedland] 2003, S. 11-44, bes. S. 17.

71 Jaroslaw Jarzewicz: Gotycka architektura Nowej Marchii. Budownictwo sakralne w okresie Askańczyków i Wittelsbachów [Die gotische Architektur der Neumark. Sakrale Baukunst im Zeitalter der Askanier und Wittelsbacher]. Poznań 2000, S. 57 f., 68, 86-94, 279-281 (= Poznańskie Towarzystwo Przyjaciół Nauk, Prace Komisji Historii Sztuki, 29). - In der Datierung etwas vorsichtiger (vielleicht erst nach 1275): ders.: Die Architektur der gotischen Kathedrale in Gorzów (Landsberg), in: Nowa Marchia - prowincja zapomniana - wspólne korzenie, Zeszyty Naukowe 3. Gorzów Wlkp. 2005, S. 205-225. - Vgl. jetzt Fritz Wochnik: Die Pfarrkirchen in Landsberg/Warthe (Gorzów Wlkp.) und in Drossen (Ośno Lubuskie), in: Jahrbuch für brandenburgische Landesgeschichte 62 (2011), S. 43-73, hier S. 45-47. 
bestimmte „Zitate“ weisen nach Jarzewicz auf das askanische Hauskloster Lehnin hin, dessen Tochterkloster Paradies als Vermittler dienen konnte; der Bau der Klosterkirche in Paradies wird auf die Jahre um und kurz nach der Mitte des 13. Jahrhunderts datiert. ${ }^{72}$ Es ist vorstellbar, daß Bauleute von dort nach Landsberg weitergezogen sind. Es scheint, daß die Zisterzienser, die südlich der Warthe ihre befestigte Grangie bauten, im Interesse ihres Besitzes und ihrer Handelsaktivitäten bald nach 1257 mit den Askaniern und ihrer Stadt in Verbindung getreten sind. Die Markgrafen umgekehrt zogen alle verfügbaren Kräfte zum Aufbau ihrer Städte heran. Mit der Landsberger Kirche wurde schließlich auch ein Propstei- bzw. Archidiakonatssitz verbunden, der seit 1297 bezeugt ist. ${ }^{73}$ Nach der Ausweitung des markgräflichen Herrschaftsgebietes östlich der Oder nach Norden erhielt innerhalb der Kirchenorganisation des pommerschen Bistums Kammin die Stadt Soldin (Myślibórz) die vorrangige zentralörtliche Funktion für die gesamte Neumark. Dem dortigen Archidiakonat war Landsberg als Ruralarchidiakonat untergeordnet, Markgraf Albrecht III. gründete in Soldin zusätzlich ein Kollegiatstift. ${ }^{74}$

Das Modell der Stadtanlage mit Richtstraße, Nebenrichtstraße und Marktplatz wurde bei weiteren Stadtgründungen in der Neumark vielfältig modifiziert. Auch bei den fast kreisrunden Stadtanlagen von Friedeberg (Strzelce Krajeńskie) und Soldin mit ihrem vermutlich nicht in die Gründungszeit zurückreichenden, sondern später neu angelegten Straßennetz bezeichnet die Richtstraße die Hauptstraße, von der wohl die Vermessung ausgegangen ist. ${ }^{75}$ Nach demselben Muster wurde zu einem nicht bekannten Zeitpunkt die anfängliche Anlage der Stadt Drossen ergänzt, und dies vielleicht ebenfalls unter markgräflicher Herrschaft. Die Entwicklung Drossens in der zweiten Hälfte des 13. Jahrhunderts ist mit den schriftlichen Quellen nicht zu erhellen. ${ }^{76}$ Die Stadt gehörte seit der Teilung des Landes 1252/53 zum markgräflichen Territorium. Unter den Orten, die die Markgrafen dem Bischof von Lebus 1317 bestätigten, findet sich Drossen nicht mehr. ${ }^{77}$ Vielleicht gelangten die Markgrafen 1354 nicht zum ersten Mal in den Besitz der Stadt, indem sie sie vom Bischof zu Lehen nahmen ${ }^{78}$. Drossen lag zwischen Frankfurt und Landsberg. Über Frankfurt war Drossen später mit dem mittelmärkischen Wirtschaftsraum zwischen der Havel (Spandau) und der Oder (Frankfurt, Wriezen, Freienwalde) verbunden, der in Berlin sein Zentrum hatte. Es fällt auf, daß im 14. Jahrhundert Drossen als

72 Jarzewicz: Gotycka architektura (wie Anm. 71), S. 25 f.; - ders.: Die Architektur, S. 207.

73 KW, S. 443 Nr. 1664; - Syska: Urkunden (wie Anm. 36), S. 39 Nr. 5 (zu 1297).

74 KW, Nr. 1645, 1700; - Willy Hoppe: Das neumärkische Stift Soldin, in: Friedrich Beck (Hg.): Heimatkunde und Landesgeschichte. Zum 65. Geburtstag von Rudolf Lehmann. Weimar 1958, S. 188-203. - Christian Gahlbeck: Soldin (Myślibórz), Kollegiatstift, in: Heimann/Neitmann/ Schich (Hg.): Brandenburgisches Klosterbuch (wie Anm. 13), S. 1123-1147, bes. S. 1124. - Vgl. jetzt auch Edward Rymar: Jurysdykcja kościelna na ziemiach pogranicza pomorsko-wielkopolskiego. Archidiakonaty nowomarchijskie (XIV-XVI w.) [Die kirchliche Gerichtsbarkeit in den Ländern des pommersch-großpolnischen Grenzgebiets. Die neumärkischen Archidiakonate (14.-16. Jh.)], in: Nadwarciański Rocznik Historyczno-Archiwalny 18 (2011), S. 45-68.

75 Die Grundrisse siehe in: Siedler (wie Anm. 64), S. 59 Abb. 77, S. 71 Abb. 99.

76 Vgl. Karłowska-Kamzowa (wie Anm. 22), S. 254-259. Siehe auch oben S. 188 mit Anm. 19-22.

$77 \quad$ KW, S. 718 Nr. 2527.

78 CDB I, 20, S. 226 Nr. 64, S. 229 Nr. 65. 
einzige Stadt aus dem Raum östlich der Oder zu den Städten gehörte, die zusammen mit Berlin und Cölln vom Landesherrn das Münzprägerecht erwarben. Drossen lag danach also im Berliner Münzbezirk. ${ }^{79}$ Es kann vermutet werden, daß diese Verbindung noch in das 13. Jahrhundert zurückreichte. Ein markgräflicher Einfluß auf den Ausbau Drossens ist durchaus wahrscheinlich, wenn man davon ausgeht, daß über diese Stadt eine Straßenverbindung vom Oderübergang Frankfurt zum Wartheübergang Landsberg hergestellt werden konnte.

Die Markgrafen hatten ihre Expansion östlich der Oder anfangs vorrangig auf das Land Lebus südlich der Warthe gerichtet. In diesen Zusammenhang gehörte vielleicht auch der Angriff auf die polnische Kastellaneiburg Bentschen (Zbąszyn) im Jahre 1251. ${ }^{80}$ Nach der Gründung von Landsberg bemühten sie sich um einen neuen Anschluß ihrer vorgeschobenen „Landesburg“ Landsberg durch das Land nördlich der Warthe an ihr Territorium westlich der Oder, genauer an Strausberg in dem seit etwa 1230 fast flächendeckend aufgesiedelten Barnim. ${ }^{81}$ Auf der Nordseite der Warthe lag der eingangs erwähnte Besitzkomplex der Templer. 1261 ließen sich die Markgrafen einen Teil des Landes Küstrin, und zwar den mit dem oppidum, offensichtlich dem Marktstädtchen, das die Templer inzwischen in Küstrin eingerichtet hatten, und mit fünf Dörfern an der Straße von Küstrin nach Landsberg abtreten, darunter Warnick (Warniki), Tamsel (Dąbroszyn) und Vietz (Vitnica), und bestätigten ihrerseits den restlichen Templerbesitz um den Hof Quartschen. ${ }^{82}$ Der Übergang über die Oder und der im Osten anschließende Marktort, dazu die weiteren Orte an der auf dem nördlichen Wartheufer verlaufenden Straße nach Landsberg waren seitdem in markgräflicher Hand. Die Markgrafen setzten bei der Expansion über die Oder nicht auf die Ritterorden, sondern eher auf ihre eigenen Ministerialen und bei den Städten vor allem auf die Bürger. Küstrin wurde aber nicht wie Frankfurt und Landsberg zur geschlossenen Bürgerstadt ausgebaut, sondern verkörperte weiterhin den Siedlungstyp, der sich aus herrschaftlicher Burg und kommunalem Städtchen zusammensetzte. ${ }^{83}$ Letzteres wurde stadtrechtlich an Strausberg gebunden. Eine Straßenverbindung von Strausberg zum Oderübergang bei Küstrin muß vorausgesetzt werden. Da eines der nordöstlich von Küstrin gegründeten Dörfer den Namen Blumberg trägt, darf man vielleicht damit rechnen, daß einer der an der Privilegierung von Frankfurt beteiligten Zeugen, der vermutbare Schultheiß Dietrich von Blumberg, auch am Ausbau des Landes Landsberg beteiligt war. ${ }^{84}$

Seit den 1260er Jahren besaßen die Markgrafen zwei Gebiete, die dann vor allem unter ihren Nachfolgern als Basis für die weitere Expansion in nordöstlicher Richtung die-

79 Paul Clauswitz (Hg.): Berlinisches Stadtbuch. Neue Ausgabe, Berlin 1883, S. 52-56.

80 Van Nießen (wie Anm. 5), S. 138; - Rymar: Prawne podstawy (wie Anm. 12), S. 18.

81 Bohm (wie Anm. 62), S. 193-202, bes. S. 200 - Vgl. Ellen Franke/Winfried Schich: Die Besiedlung des Barnim im 13. Jahrhundert auf der Grundlage verschiedener Quellengattungen, in: Felix Biermann/Günter Mangelsdorf (Hg.): Die bäuerliche Ostsiedlung des Mittelalters in Nordostdeutschland. Frankfurt a.M. 2005, S. 227-242 (= Greifswalder Mitteilungen, 7).

82 Wie Anm. 16.

83 Junk (wie Anm. 17). - Der Grundriß ist vermutlich durch den Festungsbau stark verändert worden.

84 Siehe oben mit Anm. 27. 
nen konnten: erstens den nordöstlichen Teil des Landes Lebus mit den beiden größeren Bürgerstädten Frankfurt und Landsberg als Brückenköpfen am jeweils wichtigsten Übergang über die Oder und die Warthe und zweitens das seit den 1230er Jahren ausgebaute neue Land (nova terra) Barnim mit den beiden Hauptorten Berlin und Strausberg. Von Strausberg aus verliefen in Richtung Osten die Straßen zur Oderniederung. ${ }^{85}$

Weitere Stadtgründungen der Markgrafen Johann I. und Otto III. sind im Land östlich der Oder nicht nachzuweisen. Mehrere später neumärkische Städte hatten in dieser Zeit bereits unter pommerscher Herrschaft wichtige Impulse erhalten (Abb. 4). Das erste sichere Datum für eine markgräfliche Stadtgründung besitzen wir erst wieder mit dem Lokationsprivileg für nova Berlyn, also für Berlinchen (Barlinek), das 1278 die Markgrafen Otto V. und Albrecht III., die Söhne Ottos III., erteilten. ${ }^{86}$

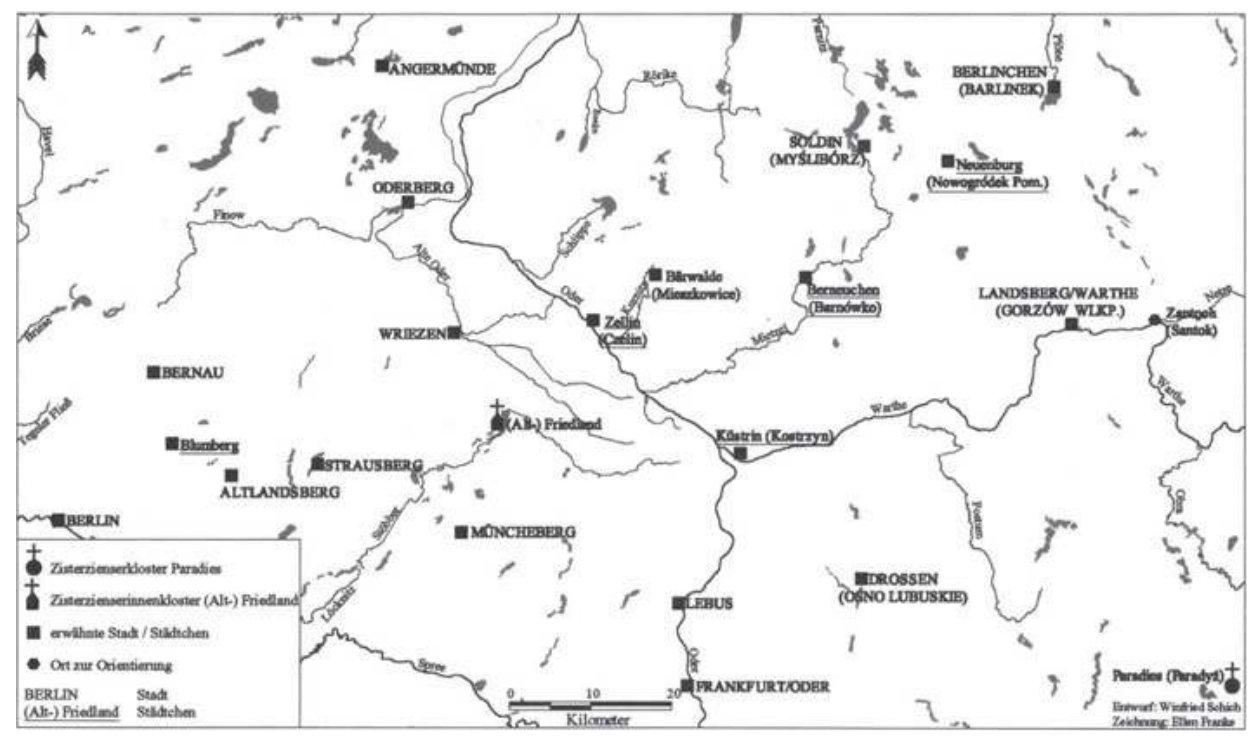

Abb. 4. Im Beitrag erwähnte Städte beiderseits der unteren Warthe und der mittleren Oder.

Vorher muß bereits die Stadt Soldin gegründet worden sein. 1261 hatten die Markgrafen Johann I. und Otto III. von den Templern nicht nur den Südteil des Landes Küstrin erhalten, sondern auch Hof und See (curiam et stagnum) Soldin zusammen mit $300 \mathrm{Hu}-$

85 Siehe die Karte von Gerd Heinrich: Handelsstraßen des Mittelalters. 1300-1375-1600. Berlin 1980 (= Historischer Handatlas von Brandenburg und Berlin, Nachträge 5).

86 CDB I, 18, S. 63 Nr. 4; - KW, S. 289 Nr. 1137; - vgl. Wittlinger (wie Anm. 17), S. 11-14; - Hugo Rachel: Berlinchen, in: Deutsches Städtebuch (wie Anm. 17), S. 500. - Zu den übrigen askanischen Stadtlokationen in der Neumark siehe auch Walachowicz: Czy tyłko sześć miast (wie Anm. 35). 
fen. ${ }^{87} \mathrm{Zu} 1271$ berichtet eine polnische Chronik, daß bei einem polnischen Angriff die gut befestigte Stadt Soldin (civitatem... Soldin bene munitam) und andere urbes et castra zerstört worden seien. ${ }^{88}$ Für den Neuaufbau erteilten die Markgrafen 1281 eine umfassende Schenkung und bestimmten unter anderem, daß alle neu zu gründenden und bereits gegründeten Städte und Dörfer (civitates vel ville) ihr Recht (iura sua) aus Soldin holen sollten. ${ }^{89}$ Diese Anordnung wurde offensichtlich zunächst nicht in die Tat umgesetzt. 1317 ordnete nämlich Markgraf Waldemar an, daß die Ratmannen und Bürger der Städte (civitates) Berlinchen (Barlinek), Neu-Landsberg (Gorzów), Küstrin (Kostrzyn), Zellin (Czelin), Bärwalde (Mieszkowice), Neu-Bernau (Berneuchen/Barnówko) und Neuenburg (Nowogródek Pomorski), die bisher die markgräfliche Stadt Strausberg im Barnim als ihren gerichtlichen Oberhof genutzt hatten, sich künftig an seine Stadt Soldin zu wenden hätten. ${ }^{90}$

Die Entstehungszeit der drei zuerst genannten Städte ist bekannt. Sie lag für Landsberg und Küstrin vor 1261, Berlinchen wurde erst 1278 gegründet. Die Anfänge der anderen vier Städte liegen völlig im Dunkeln. Abgesehen von Bärwalde handelte es sich um später ganz unbedeutende Städtchen, die die Bezeichnung civitas nicht mehr verdienten. ${ }^{91}$ Wer sie gegründet hat, bleibt unbekannt. Die Rechtsbeziehungen lassen an die Askanier denken, andererseits weist in dieser Gegend manches auf Aktivitäten von adligen Herren hin, und natürlich müssen auch die Herzöge von Pommern in Rechnung gestellt werden. ${ }^{92}$ Man darf aber annehmen, daß es die Markgrafen waren, die sie als Städte (civitates) privilegiert haben, um über sie - vielleicht zusammen mit einer bereits bestehenden Burg - das Land zu erfassen. Von den fünf civitates der Reihe von Zellin bis Neu-Berlin erhielten zwei, Berneuchen (Neu-Bernau) und Berlinchen (Neu-Berlin), ihren Namen von einer größeren markgräflichen Stadt im Barnim. Die anfängliche rechtliche Anbindung an Strausberg spricht im Fall des nahe Soldin gelegenen Neuenburg für eine Gründung vor 1281, dem Jahr der Privilegierung von Soldin als Rechtsvorort.

Im folgenden sollen einige Überlegungen über die Anfänge der genannten Städte zur Diskussion gestellt werden. Wir beginnen mit Zellin, das am Rand des Oderbruchs lag und von dem aus man zumindest zeitweise die Oder, wohl zunächst vor allem in

87 Wie Anm. 16; - zu diesem Besitz der Templer siehe Gahlbeck: Oder-Drage-Raum (wie Anm. 12), S. 37-39, 86 f.; - ders.: Soldin (Myślibórz), Kommende des Templerordens, in: Heimann/Neitmann/Schich (Hg.), Brandenburgisches Klosterbuch (wie Anm. 13), S. 1107-1110.

88 Kronika Boguchwała i Godysława Paska, bearb. v. Wacław Alexander Maciejowski, in: Pomniki dziejowe Polski (Monumenta Poloniae Historica), hg. v. August Bielowski, Bd. 2. Lwów 1872 (Nachdruck Warszawa 1961), S. 454-598, hier S. 596; - KW, S. 250 Nr. 1008. - Zu Soldin: Wittlinger (wie Anm. 17), S. 69-73; - Hermann Pieper: Zur Gründungsgeschichte der Stadt Soldin, in: Heimatkalender des Kreises Soldin 10 (1931), S. 85-95; - Hugo Rachel: Soldin, in: Deutsches Städtebuch (wie Anm. 17), S. 640-642; - Podehl (wie Anm. 5), S. 694; - Walachowicz: Czy tyłko sześć miast (wie Anm. 35), S. 84. - Pieper, S. 90 f., schlägt 1269/70 als Gründungszeit vor.

89 CDB I, 18, S. 440 f. Nr. 1; - KW, S. 323 Nr. 1256.

$90 \quad$ CDB I, 18, S. 445 Nr. 6; - KW, S. 757 Nr. 2617.

91 Wittlinger (wie Anm. 17), S. 80 f., 87 f., 97 f. - Neuenburg ist derart unbekannt, daß Walachowicz: Czy tyłko sześć miast (wie Anm. 35), S. 84, es irrtümlich mit Nörenberg/Ińsko gleichsetzt.

92 Dazu jetzt vor allem Gahlbeck: Oder-Drage-Raum (wie Anm. 12). 
Richtung Wriezen, überqueren konnte..$^{93} 1721$ wurde bei Zellin eine Fähre eingerichtet. ${ }^{94}$ Bei Niedrigwasser konnte man vermutlich den Fluß durch eine Furt überqueren. Noch während des Zweiten Weltkrieges wurde der Übergang von Militärtransporten genutzt.95 Im 14. Jahrhundert erscheint Zellin als Archidiakonatssitz des Bistums Kammin. ${ }^{96}$ Daraus kann man schließen, daß der Ort bereits im 13. Jahrhundert unter pommerscher Herrschaft eine zentrale Funktion wahrgenommen hat. Vielleicht kann man die - wohl um 1250 von den Markgrafen von Brandenburg veranlaßte - Gründung des Zisterzienserinnenklosters (Alt-)Friedland westlich der Oderniederung mit Blick auf Zellin erklären. ${ }^{97}$ Ein Vorstoß der Markgrafen über die Oderniederung nach Zellin in Richtung Bärwalde ist vorstellbar. In diesem Raum hatten Adlige bereits unter pommerscher Herrschaft die Besiedlung vorangetrieben. ${ }^{98}$ Der Name von Bärwalde wird auf die Siedlungstätigkeit der Ritterfamilie Behr zurückgeführt. ${ }^{99}$ Seit 1295 erscheint Bärwalde als markgräflicher Aufenthaltsort und seit 1298 als civitas. ${ }^{100}$ Von wem die Stadt gegründet wurde, ist nicht nachweisbar. Über Vermutungen kommt man hier ebenso wie bei den anderen, zuerst 1317 civitas genannten Orten vorläufig nicht hinaus.

Man könnte versucht sein, eine frühe Straße zu rekonstruieren, die von Bärwalde aus weiter über Berneuchen, das wegen seines Ortsnamens (Neu-Bernau) als markgräfliche Gründung vermutet wird, ${ }^{101}$ und über Neuenburg nach Berlinchen, eine nachweislich markgräfliche Gründung, führte. In dieser Richtung könnten die Markgrafen vorgerückt sein, bevor sie in den Besitz der späteren nördlichen Neumark mit ihren größeren Städten und den diese verbindenden Straßen gelangt sind. Doch für eine solche Verkehrsverbindung liegen keine Indizien vor. Zwischen Bärwalde und Berneuchen ist keine direkte Verbindung mit einem Übergang über das Pulver-Fließ zu erschließen. ${ }^{102}$ Geht man vom später erkennbar werdenden Straßennetz aus, so lagen Bärwalde, Berneuchen und Neuenburg

93 Wittlinger (wie Anm. 17), S. 97 f. - Zur Entwicklung des Oderbruchs siehe jetzt Kniehase (wie Anm. 9).

94 Johannes Schultze: Zellin, in: Handbuch der historischen Stätten Deutschlands, Bd. 10. Berlin und Brandenburg, hg. v. Gerd Heinrich, 3. überarb. u. erg. Aufl. Stuttgart 1995, S. 476 f. - Siehe auch Urmeßtischblatt Nr. 1699 von 1826 (Staatsbibliothek PK Berlin, Kart. N 729/I).

95 Wolfgang Kreft: Das östliche Mitteleuropa im historischen Luftbild. Marburg 2000, S. 238.

96 Wittlinger (wie Anm. 17), S. 98 mit Anm. 9; - Gahlbeck: Soldin (wie Anm. 74), S. 1124; - Rymar: Jurysdykcja (wie Anm. 74), S. 56 f.

97 Zu diesem Kloster siehe jetzt Matthias Friske/Christian Gahlbeck/Gregor Konrad Onasch/Blandine Wittkopp: Altfriedland, Zisterzienserinnen, in: Heimann/Neitmann/Schich (Hg.): Brandenburgisches Klosterbuch (wie Anm. 13), S. 72-88.

98 Gahlbeck: Oder-Drage-Raum (wie Anm. 12), S. 68-72.

99 Johannes Schultze: Bärwalde, in: Handbuch der hist. Stätten (wie Anm. 94), S. 421. - Vgl. jetzt Ewa Syska: Herb rycerski na pieczęci miejskiej, czyli o początkach Pełczyc i Mieszkowic [Ritterwappen auf dem Stadtsiegel, oder über die Anfänge von Bernstein und Bärwalde], in: Cognitioni gestorum. Studia z dziejów średniowiecza dedykowane Profesorowi Jerzemu Strzelczykowi, red. v. Dariusz A. Sikorski u. Andrzej M. Wyrwa. Poznań-Warszawa 2006, S. 385-393, jetzt in deutscher Übersetzung unten S. 223-233.

100 Wittlinger (wie Anm. 17), S. 8-10.

101 Johannes Schultze: Berneuchen, in: Handbuch der hist. Stätten (wie Anm. 94), S. 422 f.; - vgl. Wittlinger (wie Anm. 17), S. $80 \mathrm{f}$.

102 Siehe Topographische Karte 1:25 000, Nr. 3254 von 1893, berichtigt 1934. 
jeweils an einer von Küstrin oder von Landsberg an der Warthe nach Norden und damit nach Pommern führenden Straße. Dies gilt auch für Neuenburg, das ursprünglich an der Straße von Landsberg nach Pyritz lag. ${ }^{103}$ Erst 1353 wurde der Fuhrverkehr von Landsberg nach Pommern über Neuenburg zugunsten der Führung über Soldin verboten. ${ }^{104}$

Neuenburg wird erstmals 1298 in einer Grenzbeschreibung anläßlich der Gründung des Domstiftes Soldin genannt, ${ }^{105}$ als Stadt erst in der genannten Urkunde von 1317. Unmittelbar südlich des Ortes liegt, umgeben von einer feuchten Niederung, ein Burgwall, ${ }^{106}$ der nach den Keramikfunden ungefähr in den Zeitraum vom 10.-14. Jahrhundert datiert wird. ${ }^{107}$ Zusammen mit dem Ortsnamen der civitas läßt sich vermuten, daß Neuenburg um 1300 aus einer Burg und einem offenen Marktstädtchen bestand. ${ }^{108}$ Die Bezeichnung civitas in der Urkunde von 1317 weist allem Anschein nach vorrangig auf die kommunale Verfassung des Ortes hin. Manches brandenburgische Städtchen (oppidum), das in den Urkunden regelmäßig so und nicht als Stadt bezeichnet wird, führte ein Siegel mit der Umschrift civitas. ${ }^{109}$ Am Anfang stand im Fall Neuenburg vermutlich die Burg, neben ihr wurde (vor 1317) ein Marktstädtchen errichtet.

Van Nießen nimmt an, der Herzog von Pommern habe nach dem Verlust der Gebiete um Soldin und Landsberg Neuenburg als vorgeschobenen Posten und gewissermaßen als „neue Burg“ errichtet. ${ }^{110}$ Wegen der Größe der Feldmark (1337: 84 Hufen) hat man auch an die Templer als Gründer gedacht, ${ }^{111}$ zumal in der Nachbarschaft der Ortsname „Tempelhof" zu finden ist; ${ }^{112}$ bei diesem handelt es sich aber um den Namen eines im 19. Jahrhundert errichteten Vorwerkes. ${ }^{113}$ Helmut Wittlinger vermutet dagegen, daß die Askanier nach dem Erwerb von Soldin Neuenburg als dessen östlich vorgeschobenen Posten errichtet hätten. ${ }^{114}$ Entscheidend war für Neuenburg aber nicht die Straßenverbindung nach

103 Wittlinger (wie Anm. 17), Abb. 51 im Anhang; - Heinrich (wie Anm. 85).

104 CDB I, 18, S. 469 Nr. 44.

105 CDB I, 18, S. 442 Nr. 3.

106 Topographische Karte 1:25 000, Nr. 3056 von 1891, berichtigt 1934.

107 R. Rogosz: Nowogródek (Neuenburg), in: Materiały Zachodnio-Pomorskie 15 (1969), S. 544-547 (Fpl.1); - Gahlbeck: Zisterzienser (wie Anm. 43), S. 1035 Nr. 370.

$108 \mathrm{Zu}$ Neuenburg siehe Berthold Schulze: Besitz- und siedlungsgeschichtliche Statistik der brandenburgischen Ämter und Städte 1540-1800. Berlin 1935, S. 94 (=Einzelschriften der historischen Kommission für die Provinz Brandenburg und die Reichshauptstadt Berlin, 7); - ders.: Neue Siedlungen in Brandenburg 1500-1800. Berlin 1939, S. 107 (= Einzelschriften ..., 8); - Wittlinger (wie Anm. 17), S. 87 f.; - Podehl (wie Anm. 5), S. 684 f.; - Edward Rymar: Nowogródek Pomorski przed wiekami [Neuenburg vor Jahrhunderten], in: Nadwarciański Rocznik Historyczno-Archiwalny 5 (1998), S. 11-34.

109 Vgl. etwa Schich: Oppida (wie Anm. 27), S. 162 mit Anm. 101, S. 164 mit Anm. 110.

110 Van Nießen: Geschichte (wie Anm. 5), S. 138.

111 Vgl. Wittlinger (wie Anm. 17), S. 87.

112 Hermann Pieper: Zur Besiedlungs- und Ortsnamenkunde des Soldiner Kreises, in: Heimatkalender des Kreises Soldin 9 (1930), S. 71-83, hier S. 74; - Rymar: Nowogródek (wie Anm. 108), S. $15-17$.

113 Helmut Lüpke: Untersuchungen über den sagenhaft überlieferten oder fälschlich vermuteten Besitz der Tempelherren in Ostdeutschland, in: Jahrbuch für brandenburgische Kirchengeschichte 31 (1936), S. 29-97, hier S. 89 f.

114 Wittlinger (wie Anm. 17), S. 87. 
Soldin, sondern die Lage an der alten Straße, die den Wartheübergang Landsberg mit Pommern, vor allem mit Pyritz im fruchtbaren „Weizacker“, verband und die einige Kilometer an Soldin vorbei führte.

Es fällt auf, daß Neuenburg nahezu im Zentrum der terra Soldin von 1337 lag, wogegen der namengebende Hauptort sich im Nordwesten in einer ausgesprochen peripheren Lage befand. ${ }^{115}$ Es ist weiterhin bemerkenswert, daß sich gerade in der Umgebung von Neuenburg fruchtbare Geschiebemergelböden erstreckten. ${ }^{116}$ Nach der Klassifikation im frühen 18. Jahrhundert war Neuenburg in dieser Gegend mit den besten Böden ausgestattet. ${ }^{117}$ Wenn man von den Markgrafen als Gründern ausgeht, so läßt die vorstehend geschilderte Situation die Vermutung zu, daß diese die „neue Burg“ als ersten Stützpunkt in dem von Landsberg aus nächsten Gebiet mit fruchtbaren Böden in nördlicher Richtung, jenseits eines siedlungsungünstígen Streifens, angelegt haben und daß im Zusammenhang mit dem weiteren Ausbau des Landes ein Städtchen an die Burg angeschlossen wurde. Die Burg könnte nach der Zerstörung von Soldin 1271 als Stützpunkt gedient haben, von dem aus dann 1278 Neu-Berlin gegründet wurde.

Nach Johannes Schultze sind die Gründe für den Erwerb von Hof und See Soldin mit 300 Hufen durch die Markgrafen ,nicht so deutlich ersichtlich““. ${ }^{118}$ Wenn die vorstehenden Überlegungen richtig sind, so dürfte der Erwerb von Soldin zusammen mit der Gegend von Küstrin mit der beabsichtigten Expansion der Markgrafen nach Norden zu erklären sein. Im Mittelpunkt beider Erwerbungen stand dann Landsberg, das den östlichen Vorposten der Mark bildete. Die geschilderten Vorgänge reichten freilich zeitlich über den Tod der Markgrafen Johann und Otto (1266 bzw. 1267) hinaus. Die Söhne Ottos III., denen nach der 1266 erfolgten Landesteilung dieser Teil des - inzwischen auch im Nordwesten erweiterten - Landes jenseits der Oder zugefallen war, ${ }^{119}$ setzten die von diesen gewiesene Richtung fort. Otto V. und Albrecht III. gründeten 1278 Berlinchen (NeuBerlin). Otto hatte einer polnischen Chronik zufolge in der Zeit der Unmündigkeit seines Bruders bereits vor 1271 im Gebiet der einstigen polnischen Kastellanei Zantoch civitates et villas iure theutonico gegründet. ${ }^{120}$ Von diesen zerstörte Herzog Bolesław bei seinem Angriff 1271 vor allem die gut befestigte civitas Soldin. $\mathrm{Zu}$ den übrigen civitates kann auch das eine oder andere der genannten Städtchen gehört haben, das dieser oder ein anderer Markgraf von Brandenburg entweder selbst gegründet oder zusätzlich privilegiert und rechtlich an seine Stadt Strausberg gebunden hatte.

115 Vgl. die Karte in: Raumer (wie Anm. 40) im Anhang; - dazu die Karte in: Gahlbeck: Das Neumärkische Landbuch (wie Anm. 40), S. $10 \mathrm{f}$.

116 Wittlinger (wie Anm. 17), S. 87.

117 Paul Schwartz: Die Klassifikation von 1718/19. Ein Beitrag zur Familien- und Wirtschaftsgeschichte der neumärkischen Landgemeinden. Landsberg a.W. 1927, S. 72-87, besonders S. 84 (= Die Neumark, Jahrbuch, 4).

118 Schultze: Mark, Bd. 1 (wie Anm. 5), S. 159.

119 Berthold Schulze: Brandenburgische Landesteilungen 1258-1317. Berlin 1928, S. 17 f. (= Einzelschriften der Historischen Kommission für die Provinz Brandenburg und die Reichshauptstadt Berlin, 1).

120 Wie Anm. 88. 
Abschließend bleibt noch einmal zu betonen, daß die Markgrafen Johann und Otto ihre ersten Städte östlich der Oder mit den deutschen Neusiedlern nicht aus ,wilder Wurzel“", das heißt auf der grünen Wiese, gegründet haben. Sie knüpften vielmehr mit ihren Siedlungsaktivitäten an eine Entwicklung an, die bereits unter polnischer und pommerscher Herrschaft eingeleitet worden war. Die Expansion über die Oder zielte zunächst auf bereits vergleichsweise dicht besiedelte Gebiete. Entscheidend waren für die Markgrafen aber nicht die alten Herrschaftszentren, also die Burgorte, sondern diejenigen wirtschaftlichen Mittelpunkte, die nach „modernen“ Gesichtspunkten ausgebaut werden konnten. Hier setzten sie nach der Eroberung den Städtebau zur Sicherung und zum weiteren Ausbau des Landes ein. Dazu zogen sie bürgerliche Kräfte heran, die an der Ausweitung ihrer Handelsaktivitäten, vor allem am Getreideexport, interessiert waren. Zusätzliche Siedler konnten aus den älteren, bereits dicht besiedelten Ländern wie vor allem dem Barnim geholt werden. Handel und Gewerbe wurden in den privilegierten Marktstädten zusammengefaßt und deren Aufbau mit dem Ausbau der ländlichen Siedlung und des Ackerbaues in der Umgebung verknüpft. Dies bedeutete gleichzeitig, daß das Land an den städtischen Markt gebunden, seine Produktion auf ihn ausgerichtet wurde.

Die Stadt wurde also als zentraler Ort einer vorrangig auf den Getreideanbau ausgerichteten Agrarlandschaft geplant. Die ,moderne“ Stadt war aber nicht nur ein gewerblicher Marktort, sondern zugleich eine gut befestigte Siedlung, die die Funktion einer Burg übernehmen konnte. Mit der Hufenausstattung erhielt sie eigene Äcker für die Gewinnung des Grundnahrungsmittels Getreide, mit der Wassermühle das notwendige Instrument zum Mahlen desselben, mit den Bebauern der Hufen eine größere Zahl von Bewohnern sowie die nötigen Fuhrwerke zum Bau, zum Unterhalt und zur Verteidigung der Befestigungsanlagen. Zusätzlich wurde im Fall Landsberg über die Person des Stadtschultheißen ein Dorf enger mit der Stadt verbunden. Die feste wirtschaftliche wie rechtliche Verknüpfung des Ackerbaues mit der Marktstadt gab dieser eine breitere wirtschaftliche Grundlage, als sie die eingangs beschriebenen städtischen Marktorte besaßen, die vor der brandenburgischen Expansion gegründet worden waren.

Aus den schriftlichen Quellen und dem Stadtgrundriß läßt sich schließen, daß Johann I. und Otto III. in ihrem Herrschaftsgebiet östlich der Oder mit Landsberg die erste Stadt anlegen ließen, deren planmäßiger und rationaler Grundriss mit Straßen, Plätzen und Hofstätten vor allem auf die Bedürfnisse von Handel, Handwerk und Ackerbau ausgerichtet war. Nach diesem Vorbild wurden später weitere Städte in der Neumark errichtet. Die Markgrafen Johann und Otto haben eine entscheidende Grundlage für den weiteren Aufbau der brandenburgischen terra Transoderana unter ihren Nachfolgern geschaffen. Zu diesem gehörte dann die Erfassung des Landes über die Städte, wie sie im Neumärkischen Landbuch von 1337 deutlich wird ${ }^{121}$ und wie sie auch andere Fürsten im 13. Jahrhundert anstrebten und erreichten. In wirtschaftlicher Hinsicht findet er im 14. Jahrhundert in den umfangreichen Getreideexporten aus den neumärkischen Städten auf dem Wasserweg nach Stettin (Szczecin) seinen Ausdruck.

121 Wie Anm. 40. 



\title{
Die Stadt Königsberg (Neumark) als agrarisches Zentrum im späten Mittelalter
}

\author{
Von Felix Escher
}

Die Hauptfeststellung „Königsberg ist der Mittelpunkt eines agrarischen Gebietes“ ist bereits in den Titel des Beitrages eingeflossen. Um dies festzustellen, bedarf es freilich keiner besonders intensiven Recherche. Noch im 18. Jahrhundert war der Kreis Königsberg in der ansonsten zumeist mit geringen Böden ausgestatteten Neumark ,,sowohl in Ansehung des Umfangs und der Größe, als auch vornehmlich wegen der guten Viehzucht und der Fruchtbarkeit der Aecker der vorzüglichste in der Neumark". Zur Stadt wird ausdrücklich die Lage in einer ,angenehmen und fruchtbaren Gegend“" hervorgehoben.

Der Platz selbst hatte wohl bereits in slavischer Zeit eine Mittelpunktfunktion. Doch bleiben manche Fragen zur Entwicklung einer Befestigung im Stadtgebiet offen ${ }^{2}$. Fest steht das Vorhandensein eines ca. 3,3, Kilometer westlich der Stadt gelegenen Burgwalles, dessen Siedlungsabfolge freilich noch nicht ausreichend publiziert ist ${ }^{3}$. Ebenso kann hier nicht auf die Probleme der Lokalisierung des Landes Chinz und dessen Identifizierung mit der späteren terra Königsberg eingegangen werden ${ }^{4}$. Als Stadtherr des nun civitas genannten Ortes trat 1270 der Bischof von Brandenburg seine Rechte im Tausch an die Markgrafen von Brandenburg Johannes II. und Otto IV. $\mathrm{ab}^{5}$. Für den Bischof war es ein wenig günstiger Tausch, trotz der im Vorvertrag von $1267^{6}$ vereinbarten Gleichstellung beider Verhandlungspartner. Mit dem oppidum und dem Ländchen Löwenberg hatte er wesentlich geringeren Besitz er-

1 Zitat aus:F. G. Leonhardi: Erdbeschreibung der Preussischen Monarchie, Bd. 3,2 Abtheilung. Halle 1794, S. 451.

$2 \mathrm{Zu}$ den Anfängen nach der schriftlichen Überlieferung vgl. Hellmut Wittlinger: Untersuchungen zur Entstehung und Frühgeschichte der neumärkischen Städte (= Die Neumark 8 [1932], S. 33-39). Die Existenz einer Burg, die 1348 von den Bürgern erworben und zerstört wurde, nimmt Paul van Nießen: Geschichte der Neumark im Zeitalter ihrer Entstehung und Besiedlung (von den ältesten Zeiten bis zum Aussterben der Askanier). Landsberg 1905, S. 559, an. Für die frühere Existenz der Burg im Stadtgebiet, die bisher nicht eindeutig lokalisiert werden konnte, spricht das Vorhandensein eines ,echten“ Kietzes, vgl. dazu Bruno Krüger: Die Kietzsiedlungen im nördlichen Mitteleuropa. Beiträge der Archäologie zu ihrer Altersbestimmung und Wesensdeutung. Berlin 1962 (= Deutsche Akademie der Wissenschaften zu Berlin, Schriften der Sektion für Vor- und Frühgeschichte, 11), S. 127 f.

3 Tadeusz Nawrolski/Ryszard Rogosz: Odkrycia: Powiat Chojna, in: Materialy Zachodnio-Pomorski 16 (1970),S. 663-665.

4 Der Landschaftsname wird heute eher mit dem Gebiet um das spätere Fürstenfelde identifiziert, vgl. dazu die umfassende Studie von Christian Gahlbeck: Zisterzienser und Zisterzienserinnen in der Neumark. Berlin 2002, S. 103 (= Veröffentlichungen des Brandenburgischen Landeshauptarchivs, 47).

5 Hermann Krabbo, Georg Winter (Bearb.): Regesten der Markgrafen von Brandenburg aus askanischem Hause. Leipzig, Berlin 1910-1955 (künftig zitiert: KW), Nr. 986.

$6 \quad \mathrm{KW}, \mathrm{Nr} .948$. 
halten. Gewonnen hatten die Markgrafen. Sie geboten nun über die civitas Koningesberg und die Dörfer Bernickow/Barnkowo, Göllen, Mantel/Mętno (Groß- und Klein-Mantel), Rehdorf/Stoki, Raduhn/Raduń, Grabow/Grabowo, Kränig/Krajnik (Hoch- und Nieder-Kränig), Crimowe (Wüstung am Krimo-See), Peetzig/Piasek, (Nieder-)Saathen/Zaton Dolny und alle übrigen Besitzungen zum Land Königsberg, außer fünf slavischen Dörfern, die zuvor der brandenburgischen Kirche abgesprochen waren, und das Eigentum von 300 Hufen, die zur Hälfte (?) der Kirche gegeben werden sollten.

Gerade aus den Bestimmungen über die wohl noch nicht endgültig erschlossenen $300 \mathrm{Hu}-$ fen zeigt sich, dass auch noch in der zweiten Hälfte des 13. Jahrhunderts die Urbarmachung bzw. Umwandlung vorheriger Ackerflächen in ein verhuftes, mithin schoßpflichtiges Agrarland in diesem unmittelbar östlich der Oder befindlichen Raum nicht völlig beendet war. Für das am Rand weltlicher und kirchlicher Machtbereiche gelegene Gebiet ist es bis jetzt nicht überzeugend gelungen, den Vorgänger des Bischofs von Brandenburg als Stadtherrn und Gründer der hochmittelalterlichen deutschrechtlichen Stadt Königsberg festzustellen. War es der Herzog von Pommern, der auf Kosten des Markgrafen - oder auch des Bischofs von Lebus - den Bischof von Brandenburg in der Zeit des brandenburgischen Zehntstreites stärken wollte? War es der schlesische Herzog Heinrich der Bärtige, dessen Machtposition im Warthe-Oder-Raum in den 40er Jahren des 13. Jahrhunderts fragil wurde? ${ }^{7}$ Sollte es ein kleinerer slavischer Herrschaftsträger gewesen sein? Auch die frühe Zugehörigkeit Königsbergs zu dem nordöstlich der Stadt gelegenen umfangreichen Templerbesitz ist denkbar. Im Zusammenhang mit einer Grenzbeschreibung des Landes Bahn wird der Ort unter diesem Namen 1244 zuerst genannt, und 1282 wird dem Orden von den Markgrafen Otto und Konrad das Patronatsrecht über die Pfarrkirche geschenkt, das die Templer vielleicht schon in voraskanischer Zeit besessen hatten ${ }^{8}$. Wir können aus Mangel an Quellen nur Mutmaßungen anstellen. Deutlich ist, dass mit dem Beginn der askanischen Zeit nicht nur die civitas, die deutschrechtlich organisierte Stadt, sondern auch deren Mühlen ausdrücklich erwähnt wurden. Der 1244 genannte Name Konigkesberge ${ }^{9}$ gibt ebenfalls Rätsel auf. Ist der Ortsname übertragen worden? Wenn ja, von welchem Ort ist er übertragen? Nach welchem König ist er benannt? Ist der erste Teil des Namens eine deutsche Angleichung der früheren slawischen Bezeichnung der umgebenden Landschaft?

Die Burg könnte zum Sitz eines markgräflichen Vogtes geworden sein. Unter der wittelsbachischen Herrschaft (1337) werden im Neumärkischen Landbuch zur terra Königsberg 30 Dörfer (davon drei wüst) gezählt. Sie gehörte damit zu den umfangreichsten Vogteien des Landes östlich der Oder, nur die terra Friedeberg (33 Dörfer, davon acht wüst) zählte mehr

7 Gahlbeck (wie Anm. 4), S. 108, nimmt den Pommernherzog als Gründer an; zu Heinrich dem Bärtigen s. Benedykt Zientara: Henryk Brodaty i jego czasy (1973), dt.: Heinrich der Bärtige und seine Zeit. Politik und Gesellschaft im mittelalterlichen Schlesien. München 2002; als weiterer Herrschaftsträger käme auch der Herzog von Kalisch Wladistaw Odonicz in Frage.

8 Adolph Friedrich Riedel (Hg.): Codex Diplomaticus Brandenburgensis. Sammlung der Urkunden, Chroniken und sonstige Geschichtsquellen für die Geschichte der Mark Brandenburg, Hauptteile A-D, 41 Bde. Berlin 1838-1869, hier: Reihe A, Bd. 19 (künftig zitiert: CDB A 19), S. 174.

9 Nennung von 1244 in: Klaus Conrad (Hg.): Pommersches Urkundenbuch (künftig zitiert: PUB), Bd. I. Köln, Wien 1970, S. 338. 
Siedlungen ${ }^{10}$. In einer 1310 erfolgten Schenkung von Mühlengefällen der Familie Boytz an das Hospital \{domus) zum Heiligen Geist ${ }^{11}$ wird in einer Wegbeschreibung die nova civitas, die Neustadt, erwähnt. Folglich kann für Königsberg wie für viele andere Städte in Brandenburg, auch Berlin, von einer zumindest zweistufigen Entwicklung des Stadtraumes ausgegangen werden. Der ältere Kern könnte in der Nähe des 1347 zuerst erwähnten Kietzes ${ }^{12}$ zu lokalisieren sein. In der Nähe lag wohl auch - analog zu anderen Städten - die hochmittelalterliche Burg. Zur Neustadt wäre mithin das Gebiet des Marktes und der Marienkirche mit einem regelmäßigeren Grundriss zu rechnen. Zu vermuten ist, dass der ältere Kern zumindest zeitweise eine eigene Pfarrei besaß. 1408 bestätigte der Bischof von Kammin die Stiftung eines Nebenaltars in der Capella St. Nikolai innerhalb der Stadt ${ }^{13}$, die zu diesem Zeitpunkt keine Pfarrechte mehr besaß, aber noch existierte. Die Niklasstraße erinnert an diese früh zugunsten einer einzigen Stadtpfarrei aufgegebene (Pfarr-) Kirche. Das Nebeneinander der Marien- und Nikolaipfarren ist in ostelbischen, besonders brandenburgischen Städten häufig anzutreffen. Im 14. Jahrhundert bestanden neben den bereits genannten geistlichen Einrichtungen das in der Stadt 1290 gegründete Augustinerstift, an den Toren das St. GeorgSpital vor dem Bernickower Tor und ab 1409 St. Gertrauden, die spätere Johanniskirche vor dem Vierradener Tor. Noch später entstand eine Jerusalemskapelle ${ }^{14}$. Merkwürdig ist, dass sich trotz der wirtschaftlichen Kraft der Stadt kein Bettelorden angesiedelt hat. Darüber hinaus hatte Königsberg als Münzprägestätte überregionale Bedeutung ${ }^{15}$.

Unter den Zeugen der bereits erwähnten Urkunde von $1310^{16}$ finden wir die Ratsleute dieses Jahres (qui consules huius anni habebantur): Johannes von Prenzlau und Heydeke, Heyneke, Siegfried und Johannes von Stendal. Die Oberschicht der Stadt kam aus den führenden Handelsstädten der Alt- und Uckermark.

Ebenso dynamisch wie die Stadtentwicklung selbst war die der städtischen Feldmark. Diese hatte noch im Jahr 1850 einen Umfang von 14685 Morgen, mithin mehr als 3800 $\mathrm{ha}^{17}$, und gehörte damit zu den großen Stadtgemarkungen. Auch diese Stadtflur war nicht in einem Zug entstanden: Wie die dörflichen Feldmarken war das große Ackerland der Stadt Königsberg in Hufen aufgeteilt. Markgraf Woldemar übereignete 1319 den Hufenbesitzern der städtischen Hufen das Recht, den als Ertragsabgabe nach Lehnrecht ausgebenen Zins zu erwerben. ${ }^{18}$ Dies geschah im Falle eines von Peter von Schwanebeck gehaltenen Hufenzinses über eine Hufe umgehend. Der Rat der Stadt erwarb den gesamten Zins im April $1319^{19}$.

10 Ludwig Gollmert (Hg.): Das Neumärkische Landbuch Markgraf Ludwig's des Älteren vom Jahre 1337. Frankfurt a.O. 1862.

11 CDB A 19, S. 179.

12 Zur Lokalisierung des Kietzes s. Krüger (wie Anm. 2).

13 CDB A 19, S. $301 \mathrm{f}$.

14 Zu den spätmittelalterlichen kirchlichen Verhältnissen zusammenfassend: Hans Bütow: Zur Reformationsgeschichte der Stadt Königsberg Nm. Landsberg/Warthe 1943.

15 Die Münze ist 1350 bezeugt, CDB A 19, S. 218.

16 Vgl. Anm. 11.

17 Angaben nach: Erich Keyser (Hg.): Deutsches Städtebuch. Handbuch städtischer Geschichte, Bd. 1. Stuttgart, Berlin 1939, S. 562.

18 CDB A 19, S. 184.

19 CDB A 19, S. 183 f. 
Neben dem Ackerland waren schon zuvor Bruch- und Heideland, das Mantelbruch und die Heide nach Schwedt bereits 1271 als Besitz der Stadt bestätigt worden ${ }^{20}$. Die Seen Mantel (Manteler See), Jelant (Göllener See), Wubyser (Wubiser See) und Wustrow (Wustrow) konnten 1317 zusammen mit einer Regelung der Urbede aus dem markgräflichen in den Besitz der Stadt gebracht werden ${ }^{21}$. Damit reichte das städtische Gebiet bis nach Nahausen/ Nawodna, Uchtdorf/Lisie Pole, Göllen, Jädickendorf/Godków und Mantel bis zur Manteniz (Beke).

Nachdem die Brüder Heinrich, Henning, Heinrich und Albert von Sydow im Jahre 1348 für 100 Talente brandenburgischer Pfennige ihr Lehn, den See Crymo, die Fischerei der Mühle nahe dem Mühlendeich mit Ausnahme einiger Fischereirechte, z.B. dem auf die Brassen, der Stadt wiederkäuflich übertragen hatten ${ }^{22}$, überließen die genannten Brüder ebenfalls wiederkäuflich - die Rechte am See Crimow dem Königsberger Bürger Nikolaus Culebars $^{23}$. Erst 1413 verzichteten die Brüder Matthias und Wilke von Sydow endgültig auf ihre Ansprüche auf den Cremoln, die Mühlstätte und den Burgwall zugunsten des Rates von Königsberg ${ }^{24}$. Die Fischerei im Cremoln, dem Crimow-See, behalten sich die Brüder vor. Wie in vielen anderen Fällen dürfte die Feldmark zu der von Königsberg zugeschlagen und von der Stadt aus bearbeitet worden sein. Die Mühle wurde - aus Konkurrenzgründen? - nicht mehr genutzt. Die Ablösung stadtfremder Rechte in dem Gebiet war freilich noch nicht abgeschlossen: Noch 1364 verkauften die von Fiddichow Land zur Anlage eines Weges zum Crimow, verbunden mit der Verpflichtung, keine Verbauung an der Rörike vorzunehmen ${ }^{25}$.

Das kleine bei Schönfliess (Trzcińsko Zdrój) entspringende und bei Vierraden in die Oder entwässernde Flüßchen Rö(h)rike (Ruriza) war die Lebensader Königsbergs. 1292 war den Bürgern die freie und durch Mühlen und Verbauungen ungehinderte Schiffahrt auf der Rörike und der Oder nach Stettin sowie überall die Befreiung von Zoll und anderen Abgaben auf Handelswaren sowie von Ungeld, wohin sie sich auch wandten, in Landfahrzeugen wie auch in Kähnen \{ubicunque se diverterint cum eorum mercimonijs siue in Curribus sive in Navibus), von den Markgrafen Otto (IV.) und Konrad zugestanden worden ${ }^{26}$. In der gleichen Urkunde wurde auch die Freiheit vom Marktzoll verbrieft. Sie war damit die Grundlage der auf den Agrarexport über Stettin ausgerichteten Königsberger Wirtschaft. Der Rat ließ sich diese Bestimmungen im Wortlaut von den späteren Markgrafen immer wieder bestätigen, so 1354 durch Ludwig den Römer ${ }^{27}$. Der Handel blieb in der wittelsbachischen Zeit nicht unbegrenzt. 1336 gab Markgraf Ludwig den di dar sitten in user stat to Koningesberch, di darinnen borgher unde buren sin, das Recht, ,,allerlei Korn, Weizen, Gerste und Hafer, führen auf dem Wasser der Oder nieder gegen Stettin oder über Land, wie es ihnen

20 CDB A19, S. 173 f.

21 CDB A 19, S. 183.

22 CDB A 19, S. $210 \mathrm{f}$.

23 CDB A 19, S. 192.

24 CDB A 19, S. 314 f.

25 CDB A 19, S. 243.

26 KW, Nr. 1395; CDB A 24, S. 8.

27 CDB A 19, S. 231. 
am aller bequemsten ist ${ }^{628}$. Allerdings sollte der Handel, wenn der Scheffel Weizen mehr als 2 Schilling Brandenburgischer Pfennige, der Scheffel Roggen mehr als 18 Pfennige und die Scheffel Gerste und Hafer jeweils ein Schilling wert waren, unterbleiben und das Korn in schlechten, deshalb teuren Erntejahren im Land bleiben. Ob diese frühe Regelung in der Kornausfuhrpolitik gegriffen hat, bleibt fraglich. Ein weiteres, in den konkreten Bestimmungen noch weniger ausgeführtes Privileg Ludwig des Älteren von 1351 sicherte den Königsbergern den zollfreien Handel auf der Oder, Havel und Elbe sowie an den an den genannten Flüssen gelegenen Städten und Orten $\mathrm{zu}^{29}$.

Ebenso wie die Verkehrswege waren für den Handel geeignete Maßsysteme notwendig: Am gleichen Tag wie die Privilegierung mit den Mühlenrechten erhielten die „Ratsherren, Schöffen und die Stadt Königsberg“ das Recht, ,einen gestrichenen Scheffel“ bei Weizen, Roggen und Gerste zu verwenden; bei Hafer musste es ein ,gehäufter" Scheffel sein. Dies sollte in gleicher Weise wie in der Stadt Prenzlau geschehen ${ }^{30}$. Wie die uckermärkische Metropole, die ihr Getreide über die Ücker und das Stettiner Haff zur Odermetropole transportierte, wollte es auch die Konkurrenzstadt in der nordöstlichen Neumark halten. Kaiser Karl IV. gestattete von Tangermünde aus 1377 der Stadt Königsberg, den gehäuften Scheffel, den sie zuvor gebraucht hatten, zu streichen. Er sollte dabei allerdings so groß bleiben, wie er vorher gewesen war. Zu den in der gleichen Urkunde genannten Rechten gehörte der eines Jahrmarktes am Sonntag nach Martini. Ferner sollten Pferd und Harnisch der Bürger auch an die weibliche Erbfolge gehen ${ }^{31}$. Damit war das im sächsischen Landrecht vorgesehene männliche Erbrecht bei der Heergewäte aufgehoben. Die jeweiligen Zusammenhänge, in denen die allgemeine Privilegierung zugleich eine Erwähnung von Hohlmaßen gibt, unterstreichen deren Wichtigkeit für die städtische Entwicklung

Die Stadt und auch ihre Bürger expandierten über den engeren Stadtbereich hinaus. 1317 verlieh Markgraf Woldemar einem Bürger vier Hufen als Lehnsbesitz in Bernickow /Barnkowo $^{32}$. Die Gebrüder Heinrich und Bolle von Stendal wurden 1323 von Arnold von Sack im gleichen Ort mit ebenfalls vier Hufen belehnt ${ }^{33}$, und sie fungierten beim Verkauf von 22 Hufen mit dem Schulzenamt und dem Patronat an den Bürger Nikolaus Culebars im Jahr $1328^{34}$. Die Verkäufer waren Henning und Cuno von Fiddichow /Widuchowa. Als Bolle von Stendal starb, erhielten 1338 seine vier Söhne zu Lehnrecht 40 Hufen nebst dem oberen und niederen Gericht und dem Patronatsrecht sowie der Bede über weitere sechs Hufen in Zachow. Zudem wurden sie mit Anteilen an der Mühle in Lietzegöricke/Lysogorki und der Königsberger Münze belehnt ${ }^{35}$. Nikolaus Culebars und die von Stendal gehörten mithin zu den führenden Vertretern des Lehnbürgertums in Königsberg, ohne freilich allein auf die agrarischen Renten fixiert zu sein. Darüber hinaus zählten beide Familien auch zu den Wohltätern

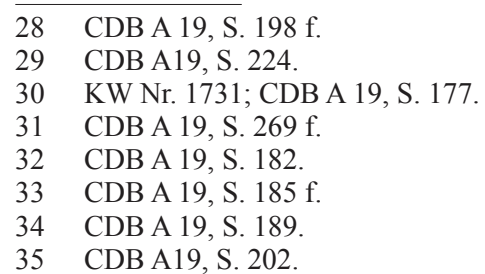


der Königsberger Kirchen. So stiftete Bolle von Stendal 1334 den Heilig-Kreuz-Altar in der Marienkirche ${ }^{36}$.

Das bereits zuvor mehrheitlich im Lehnsbesitz Königsberger Bürger stehende Dorf Bernickow wurde im Dezember 1349 durch Markgraf Ludwig dem Älteren als Dank für die Treue der Stadt Königsberg mit allen Rechten der Stadt übertragen ${ }^{37}$. Die Stadt hatte zuvor Pfänder des Markgrafen und des dänischen Königs Waldemar in Höhe von 300 Talenten Pfennigen ausgelöst, die nun mit markgräflichen Abgaben in der Neumark verrechnet werden sollten $^{38}$. König Waldemar Atterdag war ja im Bündnis mit den Wittelsbachern und den pommerschen Herzögen zur Abwehr der territorialen Expansion Karls IV. bis in die Mittelmark gelangt. Im Oktober 1348 hatte man in der Stadt die Zusicherung erhalten, dass die von der Stadt getätigten Kriegslieferungen ersetzt werden würden ${ }^{39}$. Königsberg scheint als wichtige Drehscheibe der Finanzierung dieses Feldzuges gedient zu haben. Ein später Reflex auf die Ereignisse und Transaktionen dieser Jahre könnte in dem Diplom des Markgrafen Otto V. aus dem Mai 1370 zu finden sein, der beurkundet, dass er „Kleinodien, Geräte und Gut“, die einst dem König von Dänemark gehört hätten und dem markgräflichen Vertrauensleuten und der Stadt Königsberg übergeben worden seien, in Empfang genommen habe ${ }^{40}$.

In der Zeit um 1350, als auch das große, die Hauptflüsse der Mark Brandenburg betreffende Zollprivileg ausgestellt wurde, stand der Rat auf dem Höhepunkt seiner Macht. Nun wandte man sich gegen die in der Stadt lebenden Juden. Die Königsberger Juden wurden entgegen den Zusicherungen des Markgrafen für die neumärkischen Juden von 1344 bzw. 1350 - im November 1350 ergriffen und ermordet. Der neumärkischen Vogt berichtet im Februar 1351 in einer im 19. Jahrhundert noch im Original im Königsberger Stadtarchiv vorliegenden Urkunde von der ex parte domini marchionis, consulibus eiusdem civitatis in adiutricium $^{41}$ geschehenen Tat. Der Verbrennung folgte der befehlsgemäße Einzug der Vermögen zugunsten des Markgrafen. Johannes Schultze vermutete für den Vorgang örtliche Voraussetzungen. Die starke Verschuldung des Markgrafen in der Stadt, die im Oktober des gleichen Jahres zur Verpfändung des Schwedter Oderzolls an den Königsberger Rat führte ${ }^{42}$, könnte Ursache gewesen sein, sich der nun lästig gewordenen jüdischen Konkurrenz im Handel zu entledigen. František Graus hat für diese im 14. Jahrhundert mehrfach auftretenden, örtlich begrenzten Vorkommnisse die moderne Bezeichnung „Pogrom“ gewählt. Kenn-

36 CDB A 19, S. 195.

37 CDB A 19, S. 217 f.

38 CDB A 19, S. 217.

39 CDB A 19, S. 212; zur allgemeinen Lage s. Roderich Schmidt: Brandenburg und Pommern in der Politik Kaiser Karls IV. Das Kräftespiel zwischen Wittelsbachern, Luxemburgern und Greifen, in: Ferdinand Seibt: Kaiser Karl IV. Staatsmann und Mäzen. München 1978, S. 203-208, bes. S. 205.

40 CDB A 19, S. 251 f. - Zu den brandenburgisch-dänischen Verbindungen, insbesondere auch den Beziehungen der Familie Wedel, die in der Zeugenreihe auftaucht, zu Dänemark in der ersten Hälfte des 14. Jahrhunderts, vgl. jetzt Benjamin Lassiwe: Drei brandenburgische Adlige im Norden. Zum Aufenthalt von Friedrich von Lochen, Gebhard von Bortfeld und Hasso von Wedel am Hof des dänischen Königs Waldemars IV., in: Jahrbuch für brandenburgische Landesgeschichte 56 (2005), S. 47-88.

41 CDB A 19, S. 223.

42 CDB A19, S. 224 f. 
zeichnend ist das Zusammenwirken der „Obrigkeit“, hier der an die städtische Oberschicht verschuldeten Wittelsbacher, mit dem Königsberger Rat aus materiellen Gründen. In der Regel führten diese Aktionen nicht zu Ausweisungen, sondern zu Ermordung der örtlichen Judenschaft ${ }^{43}$; dies geschah auch in Königsberg.

Königsberg mit seinem wirtschaftlichen Wohlstand wurde vor allem in der Zeit des Niederganges der Herrschaft der Wittelsbacher über Brandenburg zum Einfallstor der Feinde aus dem Norden in die Neumark. Am 24. August 1372 verstarb der junge Herzog Kasimir IV. von Pommern-Stettin während einer Belagerung der Stadt. Die Schlüsselposition der Stadt wurde auch später, nach der Verpfändung der Neumark an den Deutschen Orden (1402-1455), als Verhandlungsort zwischen Brandenburg und Pommern (1468) deutlich.

Zusammenfassend ist zu sagen: Parallel zu den Erwerbungen agrarischer Nutzflächen und Lehnsbesitz über agrarische Abgaben bemühte sich die städtische Führungsschicht bereits im 13. Jahrhundert, Besitz an den Mühlen im Stadtgebiet zu erwerben. Die geographische Lage am Rand einer pleistozänen Platte wie auch als agrarisches Zentrum hatte im Königsberger Gebiet, wo sich die Rörike in drei Arme teilte, zur Anlage einer größeren Zahl von Mühlen geführt. Zu den vier eindeutig zu bestimmenden Mühlstandorten, die auch noch in der Neuzeit existierten, kommen einige, zwei, vielleicht drei hinzu, die bereits im Mittelalter oder auch später aufgelassen wurden. Am Tage der Verleihung der Rechte über die Getreidemaße, dem 12. Oktober 1298, erhielten die Ratsherrn, Schöffen und die Stadt Königsberg von dem in der Stadt weilenden Markgrafen Otto (IV.) das Recht zur Errichtung städtischer Mühlen in der Stadt und ihrer Gemarkung ${ }^{44}$. Das landesherrliche Mühlenregal war an die Stadt übergegangen. Doch bestanden schon zuvor Mühlen wie die ab $1310^{45}$ schrittweise in den Besitz des Spitals und deshalb Heiliggeistmühle benannte Mühle. Verkäufer waren die Gebrüder Boyz. 1313 erwarb die Stadt gemeinsam mit dem Bürger Trutwin Besitzanteile an der Tormühle ebenfalls von den hier „Butz“ genannten Brüdern ${ }^{46}$. Markgraf Ludwig fügte 1324 einer Bestätigung der städtischen Rechte die Schenkung der -sonst nicht unter diesem Namen überlieferten „Galchmühle“ - mit dem Bemerken, „damit die Stadt beständig wachse“, hinzu ${ }^{47}$. Die Boyz verkauften in der ersten Hälfte des 14. Jahrhunderts ebenfalls ihre Anteile an der Schwedter Mühle. Die „Witwe-Anselms-Mühle“ ging schrittweise aus dem Besitz der von Plötz in den der Stadt und ihrer Bürger über. Sämtliche genannten Mühlen waren Kornmühlen. Die Gewandschneider, auch in Königsberg wohl zugleich Fernkaufleute und Tuchproduzenten, erhielten im Jahr 1400 das Grundstück, um eine eigene Walk-

43 František Graus: Pest, Geissler, Judenmorde. Das 14. Jahrhundert als Krisenzeit. Göttingen 1987, S. $381 \mathrm{ff}$.

44 KW, Nr. 1732; CDB A 19, S. 178.

45 Rodgero Prümers (Hg.): Pommersches Urkundenbuch, Bd. II. Stettin 1881, 247; CDB A 19, S. 177.

46 CDB A 19, S. 180.

47 CDB A 19, S. 186. - Robert Reiche: Bausteine zur Geschichte der Stadt Königsberg in der Neumark während des Mittelalters. Königsberg Nrn. 1898 (= Wissenschaftliche Beiträge zum Jahresbericht des Friedrich-Wilhelms-Gymnasium in Königsberg Nm). Er lokalisiert die Mühle mit der späteren Graupenmühle. 
mühle anlegen ${ }^{48}$. Ferner bestand am Schulzenteich oberhalb der großen Mühle eine weitere Mahlstätte.

Bereits dem Königsberger Gymnasialprofessor Reiche war aufgefallen, dass Besitzrechte an den Mühlen im ersten Jahrhundert ihres Bestehens bei drei Adelsfamilien, den Fiddichow, den Boytz und den Plötz, lagen ${ }^{49}$, und folgerte mit guten Gründen, dass dies auf Verhältnisse in der Gründungszeit der Stadt zurückgehen könnte. Spätestens seit den Untersuchungen Winfried Schichs ${ }^{50}$ sind die Zusammenhänge von städtischer Gründung und Anlage von Stauanlagen zum Mühlenbetrieb hinreichend deutlich geworden. Sämtliche Mühlen mit Ausnahme der Schloßmühle (Walkmühle der Gewandschneider) waren im Spätmittelalter in städtischem Besitz ${ }^{51}$. Die Auflagen beim Bau und Betrieb einer derartigen Mühle werden aus dem am 15. Juli 1358 ausgestellten Vertrag der Stadt mit dem Müller Heester, der die Große (Buten-) Mühle für 500 Talente Finkenaugen mit ihrer Zustimmung gekauft hatte, deutlich: Die Abgaben der Mühle an die Stadt beliefen sich auf 30 Wispel Roggen und 4 Wispel Braugerste ${ }^{52}$. Heester musste ferner die Verpflichtung eingehen, für die Bürger die einfache Metze zu mahlen, und durfte weder Geld noch Geschenk von ihnen fordern. Wenn er beide Mühlenarchen (das Mühlstauwerk und die Freiarche) erneuern wollte, sollte er das Holz für das Scharwerk auf eigene Kosten kaufen, das Heranfahren aber sollte durch die Stadt geschehen, die auch die Kosten für die dort zu errichtenden und unterhaltenen Brücken trug. Einen Aalfang durfte Heester selbst anlegen. Die Fischerei und Rohrernte auf dem Mühlenteich stand ihm, aber auch den Bürgern zur Hälfte zu. Das Mühlwasser sollte so wie jetzt gewährleistet sein, und bei einem etwaigen Brand oder Zerstörung der Mühle konnte die Pachtzahlung ausgesetzt werden. Bei einem Verkauf hatte die Stadt das Vorkaufsrecht. Mit dem Kauf der Mühlen im 14. Jahrhundert emanzipierte sich die Stadt nicht nur wirtschaftlich, sondern auch politisch von den Nachfahren der Gründer, ebenso wie es in der gleichen Zeit durch die Erwerbung des Schulzenamtes, der Gerichtsrechte und der Zerstörung der Burg (1348) geschah ${ }^{53}$.

Die städtische Herrschaft über Bernikow wurde durch die Adelsfamilie von Sack 1381 in Frage gestellt, und erst der neumärkische Landvogt Caspar von Donin konnte die v. Sack veranlassen, ihre Ansprüche aufzugeben ${ }^{54}$. Dem Lehnsbesitz eines Königsberger Bürgers folgte der von Markgraf Ludwig dem Römer 1359 an die Stadt übereignete Lehnsbesitz in Grabow $^{55}$. 1360/61 überließ Ludwig der Stadt für die ihm und seinem Heer geleistete Unterstützung den Hof (curia) in Reichenfelde/Garnowo und das Dorf Wentzschen, (Nieder-) Kränig/Krajnik Dolny mit allen Rechten, außer den Rechten die den v. Fiddichow gehörten ${ }^{56}$.

48 CDB, A 19, S. 289, wohl spätere Schloßmühle.

49 Reiche (wie Anm. 47), S. 111.

50 Winfried Schich: Die Havel als Wasserstraße im Mittelalter. Brücken, Dämme, Mühlen, Flutrinnen, in: Jahrbuch für brandenburgische Landesgeschichte 45 (1994), S. 31-55.

51 Reiche (wie Anm. 47), S. 109.

52 CDB A 19, S. $234 \mathrm{f}$.

53 Wie Anm. 52.

54 CDB A19, S. 274.

55 CDB A19, S. 237.

56 CDB A19, S. $238 \mathrm{ff}$. 
Es ist nicht allein auf die Quellenlage zurückzuführen, auch die negative Agrarkonjunktur dürfte dafür gesorgt haben, dass über längere Zeit keine Ausweitung des Lehnsbesitzes stattfand. Neben dem Verkauf einiger agrarischer Renten konnte 1451 die vogtliche Erlaubnis zum Ankaufeines Drittels des Ortes Schönrade/ Tuczno durch den Rat der Stadt erlangt werden $^{57} .1456$ konnte die Stadt in Hanseberg/Krzymöv die Lehnsbesitzungen der von Sydow ${ }^{58}$ und 1458 von den von der Marwitz das ganze Dorf Altenkirchen/ Lukowice erwerben ${ }^{59}$. Lehnsbesitzungen der Bürger werden für diese Zeit nur noch mittelbar, etwa durch ein in der städtischen Überlieferung festgehaltenes Legat eines Bürgers 1463 zugunsten der Pfarrkirche ${ }^{60}$, überliefert.

Die Lage der agrarischen Erzeuger hatte sich im späten 15. Jahrhundert sicher gebessert, doch noch nicht wieder stabilisiert. Indikator dafür sind wieder auftauchende Wüstungserscheinungen: 1499 belehnte der Kurfürst die Bürgermeister und Ratmannen zu Königsberg mit sieben besetzten und zwei unbesetzten sowie vier „kurzen“ Hufen, die teils besetzt, teils unbesetzt waren, sowie elf Hufen auf dem Feld zu Cremow ${ }^{61}$. Vorbesitzer waren wieder die von Sydow. Doch gehörten zu dieser Zeit nicht nur Adlige, die sich stückweise von ihrem Besitz trennen mussten, sondern auch wieder der Kurfürst selbst zu den Schuldnern der Stadt ${ }^{62}$. Bereits 1448 hatte der Vogt des Deutschen Ordens als Vertreter des zeitweiligen Landesherrn das Städtchen Mohrin/Moryn der Stadt Königsberg als Pfand übertragen ${ }^{63}$. Der Neubau der Marienkirche und des Rathauses entstanden zu dieser Zeit.

Die Hohenzollern stärkten die adligen Agrarproduzenten, die ihre und die Überschüsse ihrer Untertanen nun direkt an Exporteure in den Hafenstädten schicken konnten. Die städtischen Kaufleute wurden ausgeschaltet. Am Anfang des 16. Jahrhunderts kann der Königsberger Handel in Stettin nur noch indirekt, über das hier als Bankhaus fungierende führende Stettiner Handelshaus Loitz ${ }^{64}$, geführt werden. Die Loitz und der Rat wurden Partner, nicht mehr die einzelnen Kaufleute der $\operatorname{Stadt}^{65}$. Mit den vor allem in der Regierungszeit Kurfürst Joachims II. dem Adel übertragenen Rechten der Kornausfuhr dürften die Loitz auch auf diese Verbindung keinen Wert mehr gelegt haben. Die Bedeutung der Stadt als Handelszentrum im 14. Jahrhundert wurde nicht mehr erreicht. Königsberg versank wie viele andere märkische Städte schon lange vor den Zerstörungen des 30jährigen Krieges in die Bedeutungslosigkeit.

$57 \quad$ CDB A19, S. 375 f.

58 CDB A19, S. $383 \mathrm{f}$.

59 CDB A19, S. 387 f.

60 CDB A 19, S. 394 f.

61 CDB A19, S. 423.

62 1505: 550 Gulden CDB A19, S. 425.

63 CDB A19, S. 369 f.

64 Zum Stettin-Danziger Handelshaus Loitz und seinen brandenburgischen Beziehungen s. Hugo Rache1/Johannes Papritz/Paul Wallich: Berliner Großkaufleute und Kapitalisten, Bd. 1. Neuausgabe Berlin 1967.

65 Zum Beispiel im Vertrag von 1507: CDB A 19, S. 126 f. 



\title{
Ein Ritterwappen auf dem Stadtsiegel oder über die Anfänge von Bernstein (Pelczyce) und Bärwalde (Mieszkowice)"
}

\author{
Von EWA SySKA
}

Die Geschichte der Kolonisation der südlichen Gebiete des westpommerschen Herzogtums, die in der zweiten Hälfte des 13. Jahrhunderts unter brandenburgische Herrschaft kamen, ist immer noch wenig bekannt. Eine der wichtigsten Rollen hat in diesem Prozess die aus Westfalen stammende Familie Behr gespielt. Die Wanderung nach Osten begann höchstwahrscheinlich der im Jahr 1224 in der Grafschaft Lüchow erwähnte Lippold I. Behr ${ }^{1}$. Auf Spuren der Siedlungstätigkeit der Behrs stoßen wir im Raum von Greifswald bis Stolp ${ }^{2}$. Um die Mitte des 13. Jahrhunderts gelangte der aus der Gützkower Linie stammende Lippold I. Behr (erwähnt 1224-1225/1275)3 in den Besitz von Gütern an den südlichen Rändern des westpommerschen Herzogtums, auf dem Gebiet des Bernsteiner Landes, das er sich mit dem Bischof von Cammin teilte ${ }^{4}$. Im zweiten Viertel des 13. Jahrhunderts entstand an einem Ort, an dem sich einmal eine pommersche Burg befunden hatte, vermutlich auf seine Veranlassung ein Kastell, das zu Ehren des Geschlechts Berensteyn (dt. Bernstein, pol. Pełczyce) genannt wurde ${ }^{5}$. Um das Jahr 1275 übertrugen Lippold I., seine Frau Margarete und ihr Sohn Harnid (erwähnt 1240-1283) ${ }^{6}$ den Mönchen

* Dieser Aufsatz wurde in seiner polnischen Originalfassung unter dem Titel „Herb rycerski na pieczęci miejskiej, czyli o początkach Pełczyc i Mieszkowic", in: Dariusz A. Sikorski, Andrzej M. Wyrwa (Hg.): Cognitioni Gestorum. Studia z dziejów średniowiecza dedykowane Profesorowi Jerzemu Strzelczykowi. Poznań-Warszawa 2006, S. 385-393, veröffentlicht.

1 Georg Christian Friedrich Lisch: Urkunden und Forschungen zur Geschichte des Geschlechts Behr, Bd. 1-3. Schwerin 1861-1864 [künftig zit.: UBehr], 1, S. 10, 17 u. f., S. 31-40, 95; vgl. UBehr 2, S. 21-30; - Dariusz Wybranowski: Działalność rycerstwa biskupów kamieńskich za rządów Henryka von Wachholtza w świetle dokumentów z lat 1300-1317 [Ritterlicher Dienst für die Bischöfe von Kammin in der Amtszeit von Heinrich von Wachholtz im Lichte von Dokumenten der Jahre 1300-1317], in: Kopijnicy, szyprowie, tenutariusze. Gdańskie Studia z Dziejów Średniowiecza 8 (2002), S. 295-312, hier S. 273.

2 Eberhard Sauer: Der Adel während der Besiedlung Ostpommerns. Stettin 1939, S. 146-147; UBehr 1, S. 7.

3 UBehr 1, Nr. 7, S. 12 (4. Juli 1224); Nr. 8, S. 15 (1225); 1275 ?, vgl. unten Anm. 7; UBehr 2, S. 20 21: „Stammtafel der gützkowschen Familie Behr“".

4 Christian Gahlbeck: Der Oder-Drage-Raum in voraskanischer Zeit, in: Jahrbuch für die Geschichte Mittel- und Ostdeutschlands 45 (1999), S. 1-97, hier S. 90 u. 47.

5 UBehr 2, S. 26: „Es ist also urkundlich beglaubigt, dass Lippold I. Behr, wahrscheinlich im zweiten Viertheil des 13. Jahrhunderts, das Schloss Bernstein, vermutlich auf einem alten fürstlichen Burgwalle aus der Wendezeit, gründete und im Besitze des dazu gehörenden Landes Bernstein war“.

6 Klaus Conrad (Hg.): Pommersches Urkundenbuch, Bd. 1, 2. Auflage. Köln-Wien 1970; Rodego Prümers (Hg.): Pommersches Urkundenbuch, Bd. 2-3. Stettin 1885-1891; Georg Winter (Hg.): 
vom Orden von St. Viktor in Paris 20 Hufen in der Nähe der Dörfer Gottberg (Boguszyny) und Groß Ehrenberg (Przekolno), jedoch übernahmen die Bedachten das ihnen Verliehene nie ${ }^{7}$. In der Mitte der siebziger Jahre des 13. Jahrhunderts wurde der Platz Lippolds I. im Bernsteiner Land von seinen Söhnen Dietrich (erwähnt 1248-1290/1298) und Lippold II. (erwähnt 1237-1294/1298) eingenommen ${ }^{8}$. Ihnen wird die Erhebung Bern-

Pommersches Urkundenbuch, Bd. 4. Stettin 1902; Otto Heinemann (Hg.): Pommersches Urkundenbuch, Bd. 5-6. Stettin 1905-1907; Hans Friedrichs (Hg.): Pommersches Urkundenbuch, Bd. 7. Stettin 1934; Erwin Assmann (Hg.): Pommersches Urkundenbuch, Bd. 8. Köln 1961 (künftig zit. PUB); hier: Bd. 1, Nr. 377, S. (24. April 1240); -UBehr 1, Nr. 16, S. 28 (7. Oktober 1248); - Nr. 20, S. 38 (1249); - Nr. 27, S. 51 (31.Oktober 1249); - Nr. 28, S. 52 (31. Oktober 1249); - Nr. 36, S. 60 (20. April 1254); - Nr. 44, S. 71 (21. Januar 1261); - Nr. 47, S. 75 (28. Februar 1263); - Nr. 72 , S. 107 (25. September 1270); - Nr. 78, S. 114 (24. Juli 1272); - Nr. 82, S. 120 (6. Juli 1273); Nr. 84, S. 123-125 (13. Januar 1274); - PUB 2, Nr. 1012, S. 308 (24. Mai 1275); - Nr. 1018, S. $312-313$ (28. September 1275); - Nr. 1019, S. 313 (28. September 1275); - Nr. 1044, S. 333 (1276); - UBehr 1, Nr. 91, S. 134 (13. März 1276); - PUB 2, Nr. 1118, S. 392 (14. Dezember 1278); - UBehr 1, Nr. 104, S. 153 (1282); - PUB 2, Nr. 1257, S. 491 (13. März 1283).

$7 \quad$ PUB 1, Nr. 227b, S. (ca 1275 ?): Lippoldus miles dominus de Berensteyn et Margarita eius uxor et Herevedus eorum filius _ _ dilectis in Domino fratribus ordinis sancti Victoris — _ ob reverenciam gloriosorum matrium, sancti Victoris Marcelliensis et sancti Dyonisii archipiscopi, sanctique Thome Cantuariensis archipiscopi _ - viginti mansos iacentes in insula ac circa insulam inter villam Gotberga ex una parte et villam Herenberge ex altera contulimus. - Hermann Hoogeweg: Die Stifter und Klöster der Provinz Pommern, Bd. 2. Stettin 1924, S. 71-72. - Vgl. Rudolf Benl: Die Gestaltung der Bodenverhältnisse in Pommern vom 12. bis zum 14. Jahrhundert. Köln-Wien 1986 (= Mitteldeutsche Forschungen, 93), S. 329-343. Vgl. UBehr 2, S. 21-30.

8 Dietrich Behr: PUB 1, Nr. 477, S. 563 (1248, Fälschung); - Nr. 490, S. 585 (25. Mai 1249); Nr. 500, S. 597 (Oktober 1249); - PUB 2, Nr. 612, S. 24 (6. August 1255); - Nr. 737, S. 106 (17. Juni 1263); - Nr. 751, S. 115 (17. Mai 1264); - UBehr 1, Nr. 84, S. 123-125 (13. Januar 1274); PUB 2, Nr. 1097, S. 373 (5. Juni 1278); - Nr. 1146, S. 412 (10. November 1279); - Nr. 1206, S. 452 (6. Juli 1281). - - Lippold I. Behr: PUB 1, Nr. 346, S. 417 (12. November 1237); - UBehr 1, Nr. 12, S. 21 (26. Mai 1239); - PUB 1, Nr. 476, S. 560 (2. November 1248); - Nr. 478, S. 564 (November 1248): Lyppoldus dapifer noster; - Nr. 492, S. 588 (Juni 1249): dominus Lyppoldus dapifer noster; - Nr. 498, S. 595 (8. September 1249); - Nr. 499, S. 596 (Oktober 1249); - Nr. 514, S. 613 (14. Mai 1250): Lippoldus Ursus dapifer noster; - UBehr 1, Nr. 31, S. 54-55 (12. April 1251); - PUB 1, Nr. 538, S. 639 (13. Mai 1251); - UBehr 1, Nr. 37, S. 61 (5. August 1255); PUB 2, Nr. 751, S. 115 (17. Mai 1264); - Nr. 752, S. 116 (17. Mai 1264); - Nr. 757, S. 119 (26. Juni 1264); - Nr. 777, S. 132 (26. Mai 1265); - Nr. 876, S. 205 (12. Januar 1269); - Nr. 889, S. 217 (12. Juli 1269); - Nr. 977, S. 280 (11. Juni 1273); - UBehr 1, Nr. 84, S. 123-125 (13. Januar 1274); - PUB 2, Nr. 1018, S. 312 (28. September 1275); - Nr. 1044, S. 333 (1276); - Nr. 1186, S. 440 (1280); - Nr. 1235, S. 476 (Mai 1282); - Nr. 1257, S. 491 (13. März 1283); - Nr. 1294, S. 520 (21. Februar 1284); - Nr. 1361, S. 579 (24. November 1285); - PUB 3, Nr. 1479, S. 54 (18. November 1288); - Nr. 1553, S. 112 (22. Oktober 1290); - Nr. 1670, S. 195 (24. Februar 1294); - UBehr 1, Nr. 123, S. 184 (7. August 1284); - PUB 3, Nr. 1730, S. 246 (12. Juli 1295); gestorben vor 24. Mai 1298, vgl. PUB 3, Nr. 1847, S. $337-338$ (24. Mai 1298): Theodericus, Henricus, milites, Johannes, Hartidus et Bernardus, fratres dicti Ursi, filii Lippoldi Ursi — - a parte nostro dilecto Lippoldo Urso, felicissime recordationis. - - Dietrich I und Lippold I. sind nach Bernstein aus Pyritz (poln. Pyrzyce) angekommen, s. PUB 1, Nr. 476, S. (2. November 1248); vgl. auch UBehr 1, Nr. 101, S. 151 (16. April 1281): Insuper donavimus et appropriavimus sanctiminialibus antedictis [d.h. dem Zisterzienserinnenkloster Stettin] XVI marcas denariorum et proprietatem eorundem in moneta civitatis nostre Pyritz, quatuor, quas inantea habuerunt, et duodecim, quas Ursi ipsis pro quibusdam debitis resignaverunt. 
steins zum Rang einer Stadt zugeschrieben, die etwa um das Jahr 1275 erfolgte. ${ }^{9}$ Christian Gahlbeck vermutet, dass die Verleihung der Stadtrechte an Berlinchen (Barlinek) im Jahr 1278 eine unmittelbare Antwort der Markgrafen von Brandenburg auf die Gründung Bernsteins war ${ }^{10}$. Im Gebiet des Bernsteiner Landes gründeten die Behr vermutlich auch das Dorf Bärfelde (Bolewice), worauf vor allem sein deutscher Name hinweist ${ }^{11}$. Um 1279/80 übernahmen die Markgrafen von Brandenburg die Herrschaft im Bernsteiner Land, und die Behr waren als Untertanen der pommerschen Herrscher gezwungen, ihre Besitzungen zu verlassen. Die führende Stellung in der Region nahmen fortan die von Wedel ein ${ }^{12}$.

Die einzigen Spuren, die seit Jahrhunderten an die Verbindungen der Behr mit Bernstein erinnern, sind der Name der Stadt und ihr Wappen. Nach den Informationen, die Otto Hupp am Ende des 19. Jahrhunderts gab, stammte das älteste bekannte Siegel des Stadtrats von Bernstein vom Anfang des 16. Jahrhunderts (in seinem Feld befindet sich ein schreitender Bähr vor dem Hintergrund eines Eichbaums, der auf einem kleinen Hügel eingepflanzt ist. ${ }^{13}$. Schon in den sechziger Jahren des 18. Jahrhunderts bemerkte

$9 \quad$ UBehr 3, Nr. 446, S. 270 (17. März 1290): Alberti Marggraven tho Brandenborch Confirmation der Gerechtigkeit der Stadt Bernstein up hundert und XX huuen und anders, szo Diderick und Lippoldt Beren dartho gegeven; - Joachim Zdrenka: Dokument margrabiów brandenburskich dla Pełczyc (Bernstein) z roku 1298 [Eine Urkunde der Markgrafen von Brandenburg für Bernstein aus dem Jahr 1298], in: Studia Źródłoznawcze 32-33 (1990), S. 183-187, hier S. 185 (8. Juli 1298): Item sicut a novella plantatione dicte civitatis dominus Theod(oricus) et dominus Luppoldus Ursi vocati perpetuo dicte civitati contulerunt. - UBehr 2, S. 25: „Der Stammvater Lippold I. war also im Besitze des Schlosses und des Landes Bernstein. Seine Söhne Dietrich und Lippold II. gründeten neben der Burg die Stadt“. - Vgl. Helmut Wittlinger: Untersuchungen zur Entstehung und Frühgeschichte der neumärkischen Städte. Landsberg/Warthe 1932 (= Jahrbuch für die Geschichte der Neumark, 8), S. 14 f.; - Edward Rymar: Burzliwe dzieje Ziemi Pełczyckiej (do końca XV wieku) [Die turbulente Geschichte des Bernsteiner Landes (bis zum Ende des 15. Jahrhunderts)], in: Zeszyty Pyrzyckie 5 (1972/73), S. 139-175; - Grzegorz Jacek Brzustowicz: Pełczyce - Bernstein. Z przeszłości ziemi pełczyckiej [Pełczyce - Bernstein. Aus der Vergangenheit des Bernsteiner Landes]. Choszczno 2004, S. 20-21. - Vgl. UBehr 2, S. 23, 25-26.

10 Christian Gahlbeck: Zisterzienser und Zisterzienserinnen in der Neumark. Berlin 2002, S. 115 (= Veröffentlichungen des Brandenburgischen Landeshauptarchivs, 47): „Als Gegengründung zu Bernstein legten daraufhin die Markgrafen Otto V. und Albrecht III. am 25. Januar 1278 die Stadt Berlinchen zu deutschem Recht an“. - Vgl. Adolf Friedrich Riedel (Hg.): Codex diplomaticus Brandenburgensis Hauptteil I [A]. Bd. 1-25. Berlin 1838-1863; Hauptteil II [B]. Bd. 1-6. Berlin 1843-1858; Hauptteil III [C], Bd. 1-3. Berlin 1859-1861 [künftig zit.: CDB]; hier: A 18, S. 63, Nr. 4 (25. Januar 1278). - Ganz anderer Meinung ist Brzustowicz: Pełczyce-Bernstein (wie Anm. 9), S. 21.

11 UBehr 1, S. 23 u. 46; Gahlbeck: Der Oder-Drage-Raum (wie Anm. 4), S. 90.

12 Rymar: Burzliwe dzieje (wie Anm. 9), S. 148-149; - Wybranowski: Działalność rycerstwa (wie Anm. 1), S. 273; - Gahlbeck: Zisterzienser (wie Anm. 10), S. 983, Anm. 33. Vgl. unten Anm. 22. Zum Thema Burg Bernstein s. CDB A 18, S. 65-66, Nr. 7 (21. März 1290): cum loco castri - qui locus Borchwall vulgariter apellatur; - Rymar: Burzliwe dzieje (wie Anm. 9), S. 150.

13 Otto Hupp: Die Wappen und Siegel der deutschen Städte, Flecken und Dörfer. Bd. 1. Königreich Preußen. H. 1-2. Berlin 1894-1898, hier H. 1, S. 44: „Ein Siegel vom Anfang des 16. Jahrh. zeigt einen auf Steinen nach links gegen einen Baum schreitenden Bären (die Umschrift ist auf dem vorliegenden Abdruck undeutlich) $(32 \mathrm{~mm}$ )“. - Vgl. UBehr 1, S. 46: „Die Stadt führt allerdings in einem ältern Rathssiegel, welches wahrscheinlich aus der ersten Hälfte des 16. Jahrhunderts 
Friedrich Dreger, dass das Wappen Bernsteins auf die ersten Besitzer der Stadt, die Familie Behr, hinweise ${ }^{14}$. Zwar wurde fast hundert Jahre später diese Möglichkeit von G. C. Friedrich Lisch angezweifelt, aber nach der Auffindung von Urkunden, die die Verbindung der Behr mit Bernstein bestätigten, gab er Dreger recht ${ }^{15}$. Auch spätere Forscher hatten keine Zweifel an der Richtigkeit dieser Auffassung ${ }^{16}$. Umso mehr kann die jüngst von Wojciech Strzyżewski geäußerte Ansicht verwundern, der bestreitet, daß das Bild des Bären im Stadtwappen von dem Wappen der ersten Eigentümer der Stadt, ,,der Famile Bähr oder Beeren“, stammt, und meint: „Dieser Name erschien in keiner der ältesten Urkunden aus der Mark, und deshalb wurde das Wappenbild der Stadt [Bernstein, E.S.] nach dem Namen der Stadt und ihrer natürlichen Lage gebildet ${ }^{\text {"17 }}$. Diese falsche Auffassung rührt von einem offensichtlichen Versehen her, denn schließlich sind die meisten Urkunden, die die Familie Behr betreffen, von G. C. Friedrich Lisch oder im Pommerschen Urkundenbuch publiziert worden ${ }^{18}$. Außerdem gibt Strzyżewski aus unverständlichen Gründen den Namen des Geschlechts in der Form „Bähr“ oder „Beeren“ an, was vielleicht die Ursache der ganzen Verwirrung war ${ }^{19}$.

Um zur Etymologie des Wappens von Bernstein zurückzukehren, ist daran zu erinnern, daß sich im Nachlaß von Johann Carl Conrad Oelrichs Zeichnungen eines unpublizierten mittelalterlichen Stadtsiegels von Bernstein aus dem Jahr 1315 erhalten haben (Auf ihrer Grundlage wurde auch die Zeichnung angefertigt, die sich jetzt in der von Otto

stammt, einen Schild mit einem links schreitenden Bären“; - Brzustowicz: Pełczyce-Bernstein (wie Anm. 9), S. 23. Im Nachlaß Bekmann (Geheimes Staatsarchiv Preußischer Kulturbesitz, Berlin [künftig zit. GStA PK], Sign.: VI. HA NL Bekmann, VD, Nr. 5) befindet sich ein Lackabguss des unbekanntes Siegels des Bernsteiner Stadtrates aus dem 16/17. Jh., ø ca. 29-30 MM, im Siegelfelde, im Schilde ein linksschreitender Bär, Siegelumschrift: + S CIVI — — TE ВARИSTЕIИ.

14 Friedrich v. Dreger: Codex Pomeranie vicinarumque terrarum diplomaticus, oder Urkunden, so die Pommersch-Rügianisch- und Caminischen, auch die benachbarten Länder, Brandenburg, Mecklenburg, Preussen und Pohlen angehen, Bd. I. Berlin 1768. S. 282, s. unten Anm. 21.

15 UBehr 1, S. 46-47: „Wenn nun auch keine einzige Nachricht von einem Verhältnisse der Familie Behr zu der Stadt Bernstein redet, so ist es doch nach dem Namen und dem Siegel der Stadt nicht unwahrscheinlich, dass die Stadt von den Behr gegründet sei; sollte dies aber der Fall sein, so muss man annehmen, dass der Besitz durch die Behr dem v. wedelschen Besitze voraufgehe und ungefähr in die Mitte des Lebens des Ritters Heinrich Behr falle“. UBehr 2, S. 23.

16 Vgl. Rymar: Burzliwe dzieje (wie Anm. 9), S. 146; - Tadeusz Białecki: Herby miast Pomorza Zachodniego [Stadtwappen von Hinterpommern]. Szczecin 1991, S. 99; - Brzustowicz: PełczyceBernstein (wie Anm. 9), S. 24.

17 Wojciech Strzyżewski: Treści symboliczne herbów miejskich na Śląsku, Ziemi Lubuskiej i Pomorzu Zachodnim do końca XVIII wieku [Symbolische Inhalte von Stadtwappen aus Schlesien, dem Lebuser Land und Hinterpommern]. Zielona Góra 1999, S. 158, Anm. 70.

18 Vgl. oben Anm. 1.

19 Vgl. auch: CDB A 7, S. 5 f. (30. Mai 1312, Fälschung); vgl. Hermann Krabbo, Georg Winter: Regesten der Markgrafen von Brandenburg aus askanischem Hause. Leipzig-Berlin 1910-1955, Nr. 2249, S. 617; - CDB A 11, S. 209, Nr. 8 (25. Januar 1314). - Hans Spangenberg: Hof- und Zentralverwaltung der Mark Brandenburg im Mittelalter. Leipzig 1908, S. 74. - Vgl. auch UBehr 1, S. 24: „Die von Behren auf Gr. und Kl. Beeren bei Berlin waren in der Mark Brandenburg und in Sachsen angesessen. Sie führten: im blauen Schilde einen silbernen Schwan und auf dem Helme eine gekrönte, blau gekleidete «Jungfrau», welche Gerstenkörnlein aus der Hand streuet“. 


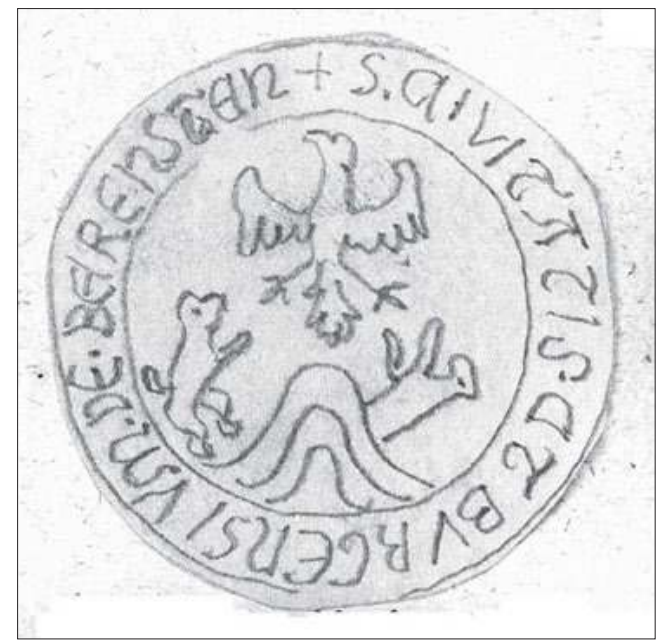

Zeichn. 1 Abzeichnung des großen Siegels von Bernstein (Geheimes Staatsarchiv

Preußischer Kulturbesitz Berlin, VIII. HA, Sammlungen I 9 [Hupp], Heft 24)

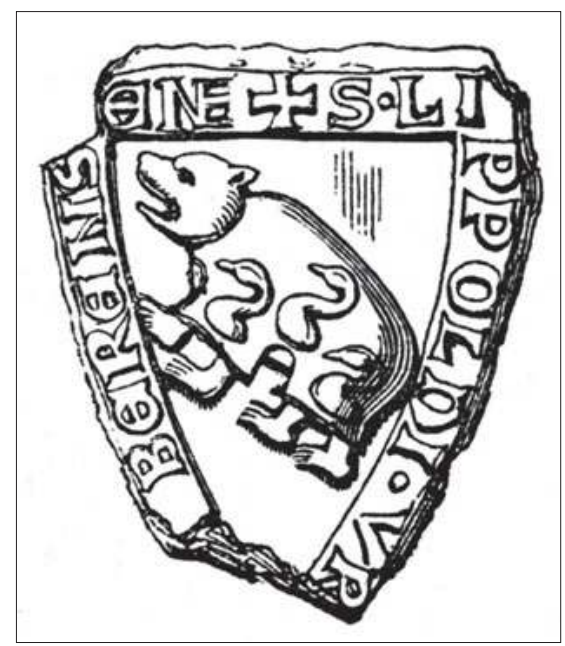

Zeichn. 2 Abzeichnung des Siegels von Lippold II. Behr von 1288 (G. A. Seyler, Geschichte der Heraldik, S. 271)

Hupp nachgelassenen Sammlung findet. $)^{20}$. Dieses Siegel zeigt auf beiden Seiten einer kleinen Erhebung zwei steigende Bären, über ihnen ein Adler; seine Randumschrift lautet: : + S. CIVITATIS. ET BVRGENSIVM. DE. BERENSTEN (Zeichn. 1). Obwohl dieses Siegel nur aus einer Zeichnung bekannt und nicht klar ist, an welchem Dokument es angebracht war ${ }^{21}$, lohnt es sich doch, einige genauere Angaben zu wagen, die seine Datierung eingrenzen können. Erstens: Die beiden steigenden Bären, die auf diesem Siegel sichtbar sind, symbolisieren die Gründer der Stadt, die Familie Behr, und spielen auf das Wappen des sich von Bernstein titulierenden Lippold II. an ${ }^{22}$ (Zeichn. 2). Zweitens:

20 Staatsbibliothek zu Berlin - Preußischer Kulturbesitz, Sammlung Oelrichs, Nr. 147/4, k. 4: „Sig. civitatis Berenstein in diploma. ... de anno 1315“; ebd., Nr. 147/4, k. 5; GStA PK, VIII. HA, Sammlungen I 9 (Hupp), Heft 24: „Aus Oelrichs Manuskript (Bibliothek v. Joachimsthalschen Gymnasium in Berlin) Oelrichsche Notiz: «Berg über dem selben von Märk. Adler, an jeder Seite aber ein Bär in die Höfe steigend. Die Bären stammen aus dem Geschlechte derer von Behr her, die diese Stadt fundiert und nach ihrem Namen genennet»".

21 Wahrscheinlich hing das genannte Siegel an der Urkunde vom 23. Februar 1315 (ed. CDB A 18, S. 74, Nr. 21), vgl. Gahlbeck: Zisterzienser (wie Anm. 10), S. 78-79 u. Anm. 77; - ders.: Bernstein (Pełczyce), in: Heinz-Dieter Heimann, Klaus Neitmann, Winfried Schich in Verbindung mit Martin Bauch, Ellen Franke, Christian Gahlbeck, Christian Popp, Peter Riedel (Hg.): Brandenburgisches Klosterbuch. Handbuch der Klöster, Stifte und Kommenden bis zur Mitte des 16. Jahrhunderts, Bd. 1. Berlin 2007, S. 196-197 (= Brandenburgische Historische Studien, 14).

22 Abriss: UBehr I, Taf. II, Nr. 6 und Gustav A. Seyler: Geschichte der Heraldik (Wappenwesen, Wappenkunst und Wappenwissenschaft). Nürnberg 1885-1889 (= G. A. Seyler: J. Siebmachers grosses und allgemeines Wappenbuch. Bd. A. Geschichte der Heraldik. Nürnberg 1890), S. 271, Siegelum- 
Bernstein muss noch ein älteres Siegel aus der Zeit der Gründung besessen haben (ohne den Adler der Markgrafen), das man sich bei der Herstellung des neuen Stempels zum Vorbild nahm. Drittens: Der Adler, der die Oberhoheit der Markgrafen von Brandenburg symbolisiert, kann an diesem Siegel erst um 1279/80 angebracht worden $\operatorname{sein}^{23}$. Viertens: Die am Rand sichtbare Inschrift ,,s civitatis et burgensium ..." weist auf ein hohes Alter dieses Siegels hin, denn die Form „,burgensium“ wurde am häufigsten von den Städten der Mark Brandenburg im 13. und 14. Jahrhundert gebraucht ${ }^{24}$. Und schließlich weist die Buchstabenform der Legende des Siegels, wie sie aus der Zeichnung in der Sammlung Otto Hupps bekannt ist, darauf hin, dass wir es hier mit einem Stempel zu tun haben, der an der Wende vom 13. zum 14. Jahrhundert entstanden ist ${ }^{25}$. Somit spricht alles dafür, dass das Typar des besagten Siegels in diesem Zeitraum entstand, sehr wahrscheinlich kurz nach der Übernahme der Herrschaft über die Stadt durch die Markgrafen von Brandenburg, d.h. um das Jahr 1279/80.

Noch am Ende des 19. Jahrhunderts vermutete der Erforscher der neumärkischen Geschichte Paul van Niessen, daß zu den Besitzungen der Familie Behr nicht nur Bernstein gehörte, sondern auch Bärwalde (Mieszkowice), das im 13. Jahrhundert am Rand des westpommerschen Fürstentums lag. Davon sollte vor allem das Wappen dieser Stadt zeugen ${ }^{26}$.

schrift: + S * LI | PPOLDI * VR[SI DE] BERENS | [T]ENE, vgl. UBehr 1, S. 54; ebenda, Nr. 107, S. 156-157 (13. März 1283); ebenda, Nr. 119, S. 178-179 (18. November 1288); vgl. UBehr 3, S. $45-46$.

23 Vgl. oben Anm. 12.

24 Z.B. Berlin: Friedrich A. Vossberg: Die Siegel der Mark Brandenburg, Lief. 2. Berlin 1887, Taf. C.2, Nr. 1 u. 2; - Angermünde: Hupp: Die Wappen (wie Anm. 13), H. 1, S. 30; - Beelitz: ebd., H. 1, S. 30; - Brandenburg: ebd., H. 1, S. 31; - Havelberg: ebd., H. 1, S. 32; - Kyritz: ebd., H. 1, S. 33; Perleberg: ebd., H. 1, S. 35; - Prenzlau: ebd., H. 1, S. 35; - Pritzwalk: ebd., H. 1, S. 35; - Schwedt/ Oder: ebd., H. 1, S. 38; - Spandau: ebd., H. 1, S. 38; - Templin: ebd., H. 1, S. 38; - Frankfurt/Oder: ebd., H. 1, S. 44; - Guben: ebd., H. 1, S. 45; Königsberg/Nm. [Chojna]: ebd., H. 1, S. 46; - Drossen [Krosno Odrzanskie]: ebd., H. 1, S. 46; - Soldin [Myślibórz]: ebd., H. 1, S. 48; - Sorau [Żary]: ebd., H. 1, S. 48; Woldenberg [Dobiegniew]: ebd., H. 1, S. 49; - Landsberg/Warthe [Gorzów Wielkopolski]: Ewa Syska: Pieczęcie Gorzowa Wielkopolskiego w średniowieczu [Die Siegel von Landsberg an der Warthe im Mittelalter], in: Nadwarciański Rocznik Historyczno-Archiwalny 10 (2003), S. 9-21, hier S. 12-13, 19; - Stendal: Gustav Winkel: Die Wappen und Siegel der Altmark und Prignitz. Magdeburg 1894, S. 11; - Salzwedel: ebd., S. 21; - Osterburg: ebd., S. 28; - Seehausen: ebd., S. 30; - Werben: ebd., S. 32. - Vgl. Marian Haisig: Studia nad legendą pieczęci miejskiej [Untersuchungen über die Legenden von Stadtsiegeln]. Wrocław 1953, S. 25-26; - Hermann Kownatzki: Sigillum burgensium - Sigillum civitatis. Ein Beitrag zur Entwicklung der Staatsauffassung im Mittelalter. Köln 1979.

25 Vgl. Barbara Trelińska: Gotyckie pismo epigraficzne w Polsce [Gotische Inschriftenschrift in Polen]. Lublin 1991, S. 27-44.

26 Paul v. Niessen: Neumärkische Studien, in: Forschungen zur Brandenburgischen und Preußischen Geschichte 2 (1889), S. 341-398, hier S. 362: „Bärwalde führt im Wappen denselben Bär wie das Geschlecht der Bere, damals auch häufig ursi genannt; die Sage läßt es von einem Bär gegründet sein“; - Gahlbeck: Zisterzienser (wie Anm. 10), S. 103. - Vgl. Georg Voß, Willy Hoppe: Bärwalde, in: Die Kunstdenkmäler des Kreises Königsberg. Berlin 1928, S. 372: „Möglich ist ..., daß sich Bärwalde ähnlich wie Berlin, dessen Name sprachlich mit dem Wort ,Bär' nichts zu tun hat, das an den Stadtnamen anklingende Wappentier erst später wählte und daß der 1319 zuerst, seitdem sehr oft bezeugten Form Bernwald die Bedeutung zukommt: gebrannter Wald, Rodung im Wald“. 


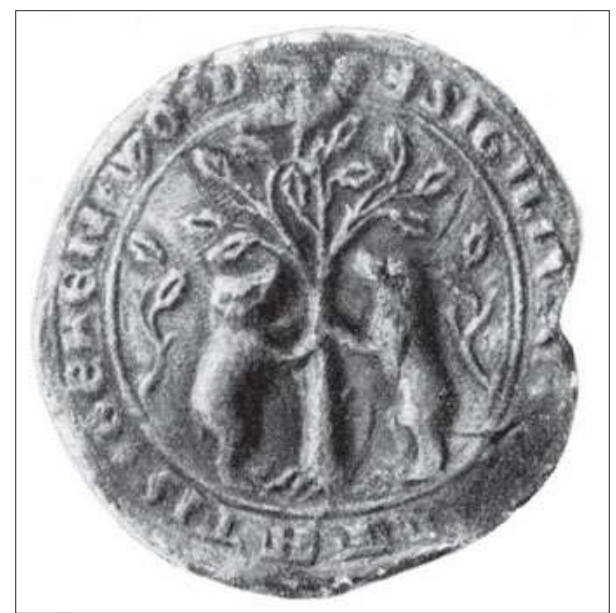

Abb. 1 Großes Siegel von Bärwalde (Mieszkowice) aus dem Jahr 1364 (fot. nach: Die Kunstdenkmäler, S. 372)

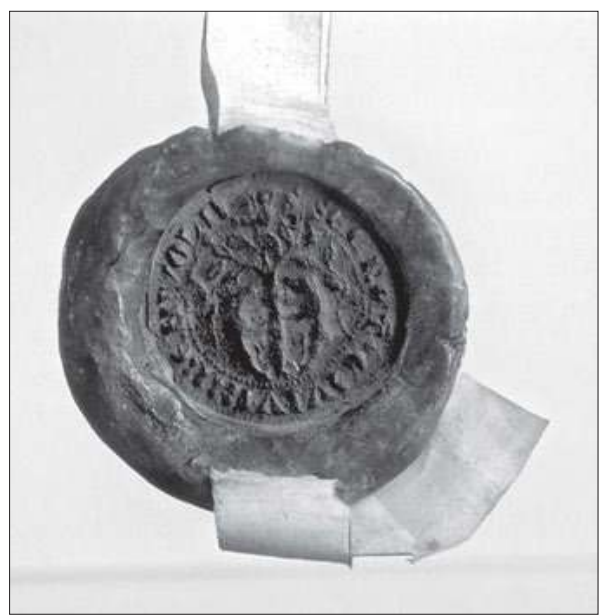

Abb. 2 Sekretsiegel von Bärwalde (Mieszkowice) aus dem Jahr 1506 (Orig. Brandenburgisches Landeshauptarchiv Potsdam,

Rep. 9B, Johanniterorden, U 393)

Sowohl auf dem großen Wappensiegel von Bärwalde ${ }^{27}$ (Abb. 1) wie auf seinem Sekretsiegel $^{28}$ (Abb. 2) sind zwei steigende Bären vorgestellt, dazwischen eine Eiche; über den Ästen des Baums sieht man einen Adler, das Symbol der Oberhoheit der Markgrafen von Brandenburg ${ }^{29}$. Jedoch nimmt man aus Mangel an Beweisen, die die Hypothese van Niessens bestätigen, an, dass das Wappen von Bärwalde nur den Namen der Stadt wiedergibt, verstanden als „Bärenwald“30. Dennoch müssen einige offensichtliche Tatsachen

27 Hupp: Die Wappen (wie Anm. 13), H. 1, S. 44. Siegelumschrift: + SIGILLVM * CIVITATIS * BEREN * WOLD. Der älteste bekannte Abdruck vom 25. Juni 1364 befindet sich heute in: Národní archiv v Praze, Sign. Archiv České koruny, Nr. 930 (Foto: Die Kunstdenkmäler des Kreises Königsberg [wie Anm. 26], S. 372, Fot. 335). - Vgl. auch: Winfried Schich: Redende mittelalterliche Städtesiegel vor allem brandenburgischer Städte, in: Jahrbuch für Brandenburgische Landesgeschichte 55 (2004), S. 9-30, hier S. 17 und Abb. 2, und Edward Rymar: Mieszkowice Średniowieczne, in: ders.: Z dawnych dziejów przyodrzańskiej Nowej Marchii. Chojna 2012, S. 79-94, hier S. 82.

28 Hupp: Die Wappen (wie Anm. 13), H. 1, S. 44; Orig.: Brandenburgisches Landeshauptarchiv, Potsdam, Rep. 9 B Johanniterorden Ballei Brandenburg, Urkunde Nr. 393 (28. Juni 1506). Siegelumschrift: S' SECRET'* CIVIV IN BERWOLD.

29 Das heutige Wappen von Mieszkowice (Bärwalde) zeigt einen Tannenbaum, beiderseits am Stamm ein aufgerichteter schwarzer Bär.

30 Marian Gumowski: Najstarsze pieczęcie miast polskich XIII i XIV wieku [Die ältesten Siegel polnischer Städte aus dem 13. und 14. Jahrhundert]. Toruń 1960, S. 147; - vgl. Emil Bahrfeldt: Das Münzwesen der Mark Brandenburg von den ältesten Zeiten bis zum Anfange der Regierung der Hohenzollern. Berlin 1889, Taf. XXVII, Nr. 44. In diesem Falle könnte es um ein Siegel an der Urkunde vom 5. Dezember 1323 gehen (vor 1945 im Stadtarchiv Frankfurt/Oder); s. PUB 6, Nr. 3730, S. 195-197: „Nach dem Originale im Stadtarchive zu Frankfurt a. O. (VIII, 2, 42). Von 
erwähnt werden. Der Name Bärwalde wird in den ältesten Quellen in der Form „Berenwalde/Berenwolde" verzeichnet und nahm erst in den Zeiten der Wittelsbacher die Form „Bernwald/Bernwolde“ $\mathrm{an}^{31}$. Zum Vergleich: In den ältesten Aufzeichnungen erscheint der Name Bernstein in der Form „Berensteyn/Berensten“ ${ }^{“ 32}$. Außerdem liegt bei Franzburg, auf den Gütern, die ehemals dem Rüganer Zweig der Behrs gehörten, ein Dorf mit fast identischem Namen, Behrenwalde ${ }^{33}$. Sowohl auf dem Siegel von Bärwalde als auch auf dem von Bernstein befindet sich das Bild des Adlers am Rand, auf der Linie der Umschrift, und macht den Eindruck, als sei es irgendwann zu dem schon früher existierenden Ganzen hinzugefügt worden ${ }^{34}$. Am Beispiel der ältesten Siegel Berlins sieht man genau, wie der Prozess der Entstehung eines ,sprechenden Siegels“ verlief. Auf dem ältesten bekannten Siegel der Stadt von 1253 war ein Adler vor dem Hintergrund eines Stadttors zu sehen ${ }^{35}$, doch vor dem Jahr 1280 erschien ein neues Typar, das zwei steigende Bären zeigt, die einem Schild mit dem brandenburgischen Adler den Rücken zuwenden. Seit dieser Zeit verwandte der Stadtrat von Berlin, der den Namen der Stadt mit dem deutschen Wort „Bär“ verband, ausschließlich Siegel mit dem Bild eines Bären ${ }^{36}$. So zeigt das

den an Pergamentstreifen hängenden Siegeln sind nur die von Soldin und Bärwalde vorhanden“. Vgl. Adolf Gurnik: Das Stadtarchiv zu Frankfurt a. d. Oder, in: Programme des Realgymnasiums Frankfurt a.d.O., T. 1. 1253-1373. Frankfurt a. d. O. 1895, S. 13.

31 CDB A 18, S. 69 f., Nr. 13 (30. August 1295): Berenwalde; - PUB 3, Nr. 1804, S. 306-307 (24. April 1297): Berenwolde; - CDB A 18, S. 442-443, Nr. 3 (1. Juni 1298): Berwalde; S. 373, Nr. 6 (16. September 1308): - Gerardo de Berenwolde; CDB A 19, S. 10, Nr. 15 (24. Februar 1317): Berenwolde; CDB A 18, S. 445, Nr. 6 (26. Dezember 1317): Berenwalde, vgl. Orig. Brandenburgisches Landeshauptarchiv Potsdam, Rep. 8 Soldin, U 1: Berenwolde; - CDB A 7, S. 85-86, Nr. 2 (12. August 1319): Berenwold; - CDB A 2, S. 459, Nr. 28 (12. August 1319): Berenwolde; - CDB A 13, S. 240, Nr. 54 (14. August 1319): Berenwalde; - CDB A 19, S. 184 f., Nr. 21 (24. April 1320): Berenwolde; S. 11, Nr. 16 (10. August 1320): Berenwolde; - CDB A 23, S. 19-21, Nr. 24 (5. Dezember 1323): Berenwalde; - CDB A 19, S. 187 f. (23. April 1325): Berenwolde, Bernwolde, Beerwolde; - Louis Gollmert: Das neumärkische Landbuch Markgraf Ludwig's des Aelteren vom Jahre 1337. Frankfurt a. O. 1862, S. 11 (1337): Bernwolde;-CDB A 18, S. 14-15, Nr. 17 (11. September 1338): Bernwald.

32 Z.B.: ca. 1275, vgl. oben Anm. 7; - CDB A 18, S. 212 f., Nr. 1 (13. Juli 1280): Berrenstein; - 17. März 1290: vgl. oben Anm. 9; - CDB A 18, S. 65 f., Nr. 7 (21. März 1290): Berensten; - S. 66 f., Nr. 9 (26. November 1290): Berensten; - S. 67 f., Nr. 10 (17. April 1291): Berensten; - S. 68, Nr. 11 (18. Juni 1292): Burnstein; - S. 69, Nr. 12 (27. Juni 1293): Bernsteyn; Hermann Krabbo: Ungedruckte Urkunden der Markgrafen von Brandenburg aus askanischem Hause. Erste Folge, in: Forschungen zur Brandenburgischen und Preußischen Geschichte 25 (1912), S. 1-27, hier S. 14, Nr. 11 (27. Mai 1295): Bernesten; - CDB A 18, S. 69 f., Nr. 13 (30. August 1295): Berendsten; S. 70, Nr. 14 (25. Juni 1296): Bernstein; - S. 70 f., Nr. 15 (2. Juli 1298): Berensten; - S. 71, Nr. 16 (2. August 1299): Berensten. - Vgl. oben Anm. 5 u. 22.

33 UBehr 1, S. 59; Nr. 122, S. 183 (24. Februar 1294): Berenwold; - UBehr 2, Nr. 249, S. 160-162 (22. Juni 1339): Thideke Bere van Berenwolde; - UBehr 3, Nr. 303, S. 50 (20. April 1376): Vicko Bere de Barenwolt; - Nr. 398, S. 186-187 (14. Februar 1415): Barenwolde; - Nr. 439, S. 259 (16. März 1425): Barenwolde.

34 Vgl. Hupp: Die Wappen (wie Anm. 13), H. 1, S. 44, s. oben Anm. 30.

35 Abriss: Friedrich A. Vossberg: Die Siegel (wie Anm. 24), Lief. 2, Taf. C. 2., Nr. 1; - Werner Vogel: Berlin und seine Wappen. Berlin-Frankfurt a.M. 1987, S. 14.

36 Heinz Machatschek: Als der Wappenbär geboren wurde. Aus der Geschichte der Berliner Wappen. Berlin 1987, S. 28 f.; - Schich: Redende mittelalterliche Städtesiegel (wie Anm. 27), S. 11. 


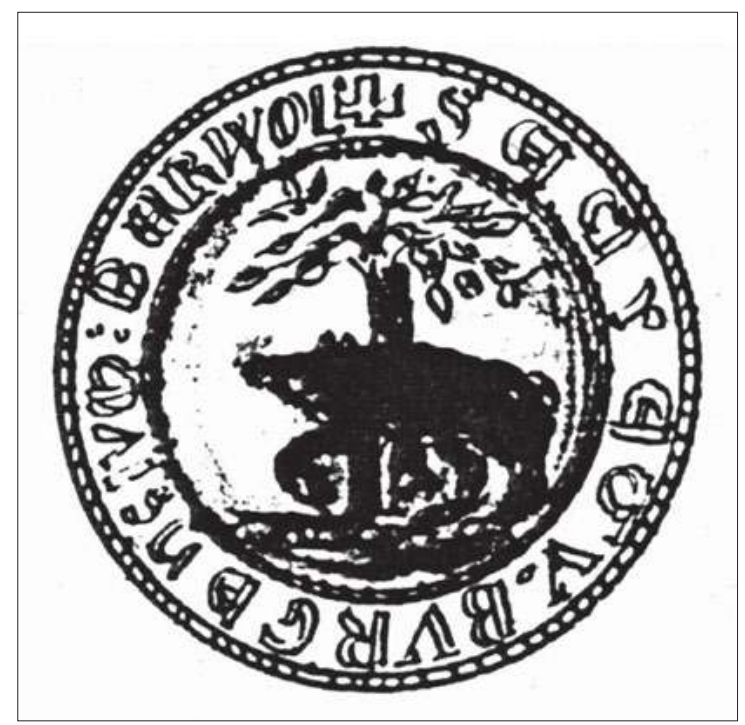

Zeichn. 3 Abzeichnung des Sekretsiegels von Bärwalde (Barwice) (Staatsbibliothek Preußischer Kulturbesitz Berlin, Oelrichs Sammlung II, K. 21, nr 145/1, 6v)

Beispiel dieses Siegels, dass das bedeutend ältere Motiv des Stadttores durch den „,sprechenden" Bären verdrängt wurde ${ }^{37}$. Mit einem solchen Phänomen haben wir es weder in Bernstein noch in Bärwalde zu tun.

Es lohnt auch, daran zu erinnern, dass im 14. Jahrhundert der Stadtrat von Bärwalde (Barwice) im Fürstentum Westpommern sich eines Siegels bediente, in dessen Feld vor dem Hintergrund einer Eiche ein schreitender Bär vorgestellt war (Zeichn. 3) ${ }^{38}$. Bis heute nimmt man an, daß dieses Siegel den Namen der Stadt umschreibt, wie ihn die deutschen Siedler verstanden, die das slawische Barwitz ${ }^{39}$ in Bärwalde umbenannten und ihr Ver-

37 Abriss: Vossberg: Die Siegel (wie Anm. 24), Lief. 2, Taf. C. 2., Nr. 2 (1280), Nr. 3 (1338), Nr. 4 (1488), vgl. Vogel: Berlin (wie Anm. 35), S. 14-16; - Schich: Redende mittelalterliche Städtesiegel (wie Anm. 27), S. 10 f. - Vgl. Siegel des Stadtrates von Berlinchen (Barlinek) [Nove/Nova Berlin]: CDB A 18, S. 63, Nr. 4 (25. Januar 1278); - S. 445, Nr. 6 (26. Dezember 1317); - S. 14 f., Nr. 17 (11. September 1338); - S. 78 f., Nr. 27 (26. September 1348); - S. 79, Nr. 28 (1. Januar 1349); S. 121, Nr. 39 (1. Januar 1349); - S. 80, Nr. 30 (30. September 1351)]; - vgl. auch Hupp: Die Wappen (wie Anm. 13), H. 1, S. 44, und oben Anm. 35.

38 Abriss: Staatsbibliothek zu Berlin - Preußischer Kulturbesitz, Sammlung Oelrichs II, K. 21, Nr. 145/1, 6v, Siegelumschrift: + SECRETV * BVRGENSIVM: BERWOL'; - vgl. GStA PK, VIII. HA, Sammlungen I 9 (Hupp), H. 14 (Abriss); - s. auch: Hupp: Die Wappen (wie Anm. 13), H. 2, S. 91; - vgl. oben Anm. 24.

39 Ignacy Zakrzewski: Kodeks dyplomatyczny Wielkopolski [Urkundenbuch von Großpolen]. Bd. I. Poznań 1877, Nr. 570 (19. November 1290): via que ducit de civitate Barwitz ad territorium, quod Crayen dicitur (1286/1290); - vgl. Stanisław Krzyżanowski: Dyplomy i kancelaryja Przemysława II [Urkunden und Kanzlei Przemysławs II.], in: Pamiętnik Wydziału Filologicznego i Filozoficzno- 
ständnis dieses Namens in das Stadtwappen übertrugen ${ }^{40}$. Allerdings gibt es in diesem Fall gewisse Hinweise, die auf Verbindungen der Behr mit Bärwalde hindeuten ${ }^{41}$. Um 1325-1329 besaßen Henning Behr (erwähnt 1288-1326) ${ }^{42}$ und danach sein Sohn Lippold (erwähnt 1318-1334) ${ }^{43}$ das Land Belgard [Białogard] ${ }^{44}$, zu dem Bärwalde gehörte. Interessant ist, dass die Vertreter der Bütower Linie, denen das Land Belgard gehörte, sich eines Wappens bedienten, das einen schreitenden Bären darstellt $t^{45}$. Stammte der Bär, der auf dem ältesten bekannten Wappen von Bärwalde sichtbar ist, aus dem Wappenbild der Behr von Belgard? Aus Mangel an anderen Quellenhinweisen ist diese Hypothese schwer zu verifizieren, aber der Umstand, daß im Dezember 1334 Lippold Behr als Zeuge in Angelegenheiten des nahen Landes Tempelburg [Czaplinek] ${ }^{46}$ erscheint, erlaubt es, eine Diskussion zu diesem Thema zu eröffnen.

Im Licht aller angeführten Beobachtungen ist festzustellen:

Auf den ältesten bekannten Siegeln von Bernstein (Pełczyce) und Bärwalde (Mieszkowice) sind Elemente zu erkennen, die aus dem Wappenbild der Familie Behr (Gützkower Linie) übernommen sind.

Historycznego Akademii Umiejętności 8 (1890), S. 122-193, hier S. 179, Nr. 122. - Vgl. Ferner Helmut Lüpke: Die pommersche terra Krayna und der Templerorden, in: Monatsblätter der Gesellschaft für pommersche Geschichte und Altertumskunde 46 (1932), Nr. 10, S. 141-146, hier S. 142; - ders.: Das Land Tempelburg. Eine historisch-geographische Untersuchung. in: Baltische Studien N.F. 35 (1933), S. 43-97, hier S. 46-47, 87-89.

40 Gumowski: Najstarsze pieczęcie (wie Anm. 30), S. 32; Marian Czerner: Herby miast województwa koszalińskiego [Stadtwappen der Wojewodschaft Koszalin (Köslin)]. Koszalin 1989, S. 37.

41 Diese Möglichkeit hat schon Georg Christian Friedrich Lisch vorgeschlagen, vgl. UBehr 1, S. 46.

42 Lippold Behr, Knappe: PUB 5, Nr. 3158, S. 361 (30. Dezember 1317); - UBehr 2, Nr. 194, S. 82-83 (23. April 1321): armiger; - UBehr 2, Nr. 202, S. 91-94 (15. August 1322); - Nr. 214, S. 108 (9. März 1326); - Nr. 220, S. 120 (16. Juli 1329); - Nr. 221, S. 121 -122 (19. November 1329); - PUB 7, Nr. 4598, S. 377 (3. Dezember 1330); - UBehr 2, Nr. 235, S. 141 (16. Oktober 1334); - Nr. 236, S. 143 (16. Oktober 1334); - Nr. 238, S. 147 (26. Dezember 1334); PUB 8, Nr. 5223, S. 383 (26. Dezember 1334); - Nr. 5224, S. 384 (26. Dezember 1334).

43 Lippold Behr, Knappe: PUB 5, Nr. 3158, S. 361 (30. Dezember 1317); - UBehr 2, Nr. 194, S. 81-84 (23. April 1321): armiger; - Nr. 202, S. 91-94 (15. August 1322); - Nr. 214, S. $108-109$ (9. März 1326); - Nr. 220, S. 120 (16. Juli 1329); - Nr. 221, S. 121-122 (19. November 1329); - PUB 7, Nr. 4598, S. 377 (3. Dezember 1330); - UBehr 2, Nr. 235, S. 141 (16. Oktober 1334); - Nr. 236, S. 142-143 (16. Oktober 1334); - Nr. 238, S. 147 (26. Dezember 1334); - PUB 8, Nr. 5223, S. 383 (26. Dezember 1334); - Nr. 5224, S. 384 (26. Dezember 1334).

44 Vgl. PUB 4, Nr. 2350, S. 267 (4. Mai 1307); - s. auch: Nr. 2170, S. 147 (15. Juli 1304); - vgl. UBehr 2, Nr. 211, S. 104 (29. November 1325): Hennyngus Bere cum Bellegarensi territoriis; PUB 7, Nr. 4535, S. 323 (6. Dezember 1329): nos Luppoldus Ber, dominus et heres de Belgarth; Wybranowski: Działalność rycerstwa (wie Anm. 1), S. 275.

45 Vgl. UBehr 2, Nr. 221, S. 104 (19. November 1329), Orig. GStA PK, XX. HA, Pergamenturkunden, Schiebl. 50, Nr. 63, an der Urkunde hingen drei Siegel der drei Söhne Hennings Behr, d.h. Heinrich, Henning und Lippold, s. Abrisse: UBehr 1, Taf. VI, Nr. 26-28. - Vgl. UBehr 2, S. 43; PUB 7, Nr. 4532, S. 320-321. - Das Siegel von Lippold Behr hing auch an einer Urkunde von 1329, vgl. PUB 7, Nr. 4535, S. 323 (6. Dezember 1329), Orig. GStA PK, XX. HA Pergamenturkunden, Schiebl. 50, Nr. 10.

46 Vgl. UBehr 2, Nr. 235, S. 141 (16. Oktober 1334); - PUB 8, Nr. 5224, S. 384 (26. Dezember 1334). 
Ein bislang unbekanntes Siegel des Stadtrats von Bernstein von der Wende vom 13. zum 14. Jahrhundert zeigt viele Analogien mit den ältesten bekannten Siegeln von Bärwalde (Mieszkowice), und nach der Hypothese, die vor über hundert Jahren von Paul van Niessen vorgebracht wurde, kann man vermuten, daß Bärwalde von der Familie Behr gegründet wurde.

Der schreitende Bär, der auf dem Wappen von Bärwalde (Barwitz) aus dem 14. Jahrhundert erscheint, deutet darauf hin, daß die Stadt für eine gewisse Zeit der Bütower Linie der Familie Behr, die im Belgarder Land herrschte (und mit einem Wappen siegelte, das einen schreitenden Bären vorstellt), gehört haben könnte. 



\title{
Die Städte und der Deutsche Orden in der Neumark und in Preußen
}

\author{
Von Roman CZAJA
}

\begin{abstract}
Die Frage nach dem Verhältnis des Deutschen Ordens zu den neumärkischen Städten wurde schon häufig in der älteren wie auch in der neueren Forschung aufgegriffen ${ }^{1}$. Besonders großes Interesse erweckte in der bisherigen Fachliteratur seine Städtepolitik in der Frühphase des Aufbaus seiner Landesherrschaft in der Neumark ${ }^{2}$. Es wurde häufig die Meinung geäußert, dass sie durch ein Streben nach einer Stärkung seiner Macht mit möglichst friedlichen Mitteln geprägt wurde. Der neue Landesherrn versuchte in der Neumark die städtischen Autonomie zu beschränken und die Städte nach dem preußischen Vorbild einem zentralisierten Machtsystem unterzuordnen: „Die Ordensherren brachten aus Preußen die Erfahrung mit, dass Städtefreiheit gefährlich sei“ ${ }^{3}$. Diese Auffassung erscheint im Lichte der neueren Forschungen zur städtischen Autonomie und zum ständischen Leben im Ordensland zu stark vereinfacht ${ }^{4}$. Der vorliegende Beitrag erhebt keinen Anspruch auf
\end{abstract}

1 Karl Heidenreich analysiert in seiner Monographie die neumärkische Städtepolitik des Deutschen Ordens in einem Zusammenhang mit dem Aufbau der Landesherrschaft und der Entwicklung der neumärkischen Stände, vgl. Karl Heidenreich: Der Deutsche Orden in der Neumark (1402-1455). Berlin 1932 (=Einzelschriften der Historischen Kommission für die Provinz Brandenburg und die Reichshauptstadt Berlin, 5); Paul Nießen: Geschichte der Stadt Dramburg. Dramburg 1897, S. 67 ff.; Antoni Czacharowski: Miasta Nowej Marchii w pierwszych latach panowania Zakonu Krzyżackiego [Die Städte der Neumark in den ersten Jahren der Herrschaft des Deutschen Ordens], in: Haiina Manikowska u.a. (Hg.): Aetas media aetas moderna. Studia ofiarowane profesorowi Henrykowi Samsonowiczowi w siedemdziesiątą rocznicę urodzin. Warszawa 2000, S. 175-181; vgl. zahlreiche Studien von Edward Rymar: Konflikt spoleczeństwa Nowej Marchii z Zakonem Krzyżackim w 1443 r. [Der Konflikt der Gesellschaft der Neumark mit dem Deutschen Orden im Jahre 1443], in: Przegląd Zachodniopomorski 5 (1990), S. 91-113; ders.: Przywilej wójta Nowej Marchii Baldwina Stala z 1408 r. dla soltysa gorzowskiego [Das Privileg des neumärkischen Vogtes Balduin Stal für das Landsberger Schulzenamt aus dem Jahre 1408], in: Nadwarciański Rocznik Historyczno-Archiwalny 6/2 (1999), S. 31-36; ders.: Polsko-czeska wyprawa zbrojna do Nowej Marchii w 1433 roku [Polnisch-böhmischer Feldzug in die Neumark in dem Jahre 1433], in: Przegląd Zachodniopomorski 37,1 (1993), S. 31-56; ders.: Nowa Marchia po wyprawie husyckiej w czasie wojny polsko-krzyżackiej w latach 1433-1435/36 [Die Neumark nach dem Hussiteneinfall während des Krieges zwischen Polen und dem Deutschen Orden in den Jahren 1433-1435/36], in: Przegląd Zachodniopomorski 38,4 (1994), S. 9-34; ders.: Administracja krzyżacka w Nowej Marchii 1384/1402-1454/1455 [Die Verwaltung des Deutschen Ordens in der Neumark 1384/1402-1454/1455], in: ders.: Studia i materiaty z dziejów Nowej Marchii i Gorzowa. Szkice historyczne. Gorzów Wlk. 1999, S. 99-134.

2 Czacharowski: Miasta (wie Anm. 1); Rymar: Przywilej wójta Nowej Marchii (wie Anm. 1).

3 Heidenreich (wie Anm. 1), S. 43.

4 Roman Czaja: Miasta pruskie a zakon krzyżacki. Studia nad stosunkami między miastem a władzą terytorialną w późnym średniowieczu [Die preußischen Städte und der Deutsche Orden. Eine Studie zu den Beziehungen zwischen Stadt und Landesherrschaft im späten Mittelalter]. Torun 1999; 
eine vollständige Darstellung der Beziehungen zwischen dem Orden und den Städten in Preußen und in der Neumark. Sein Ziel besteht vielmehr darin, die Voraussetzungen der neumärkischen Städtepolik vor den Verhältnissen zwischen der Stadt und dem Landesherrn in Preußen vorzustellen.

Mit Sicherheit verfügte der Deutsche Orden bis zum Ende des 13. Jahrhunderts gegenüber den Städten seines Territoriums in Preußen über umfangreiche Gerichts-, Verwaltungs- und Wirtschaftsrechte. Die dortigen Großstädte erlangten jedoch im Laufe des 14. Jahrhunderts die Unabhängigkeit des Gerichtswesens und der Gesetzgebung, das Recht auf die freie Wahl der städtischen Beamten und die Markthoheit. Bis zum Beginn des 15. Jahrhunderts bewahrte der Orden seine Befugnisse im Bereich der Mühlen- und Münzregalien. Die Ausweitung der städtischen Kompetenzen und die Beschränkung der landesherrlichen Rechte vollzogen sich auf zwei verschiedene Weisen. Gerichtsrechte und Marktregalien wurden den preußischen Städten vom Orden in Privilegien verliehen. Um dem Stadtherrn seinen Einfluß auf die Besetzung städtischer Ämter zu nehmen und um Gesetzgebungskompetenzen zu erlangen, gingen die Städte hingegen via facti vor, wobei sie sich bemühten, ihre Ansprüche mit Rechtsurteilen der Magdeburger Schöffen und dem Stadtrecht zu begründen ${ }^{5}$. Im Gegensatz zur Neumark, wo die Landesherren im 14. Jahrhundert ihren Städten aus Geldnot Ämter, Gerichtsrechte, Münzen, Zollstätten, Mühlen usw. verkauften oder verpfändeten, spielte Geld bei der Ausweitung der Selbstverwaltungsrechte der preußischen Großstädte keine größere Rolle 6 . Eine preußische Besonderheit war die Tatsache, dass der Landesherr bis zum 15. Jahrhundert bei seinen politischen und wirtschaftlichen Maßnahmen das Interesse der Großstädte und ihrer Führungsgruppen in einem viel größeren Ausmaß als das Interesse des Adels und der Kleinstädte berücksichtigte. Die preußischen Hansestädte brauchten zwar für ihre Beteiligung an den handelspolitischen Unternehmungen der Hanse die Zustimmung des Hochmeisters, aber das wirtschaftliche und politische Interesse der kaufmännischen Oberschicht erfuhr meistens dessen Unterstützung 7 . Die verfassungsrechtliche Autonomie der kleinen preußischen Städte entwickelte sich nicht über ein Anfangsstadium hinaus. Der Orden behielt

ders.: Preußische Hansestädte und der Deutsche Orden. Ein Beitrag zu den Beziehungen zwischen Stadt- und Landesherrschaft im späten Mittelalter, in: Hansische Geschichtsblätter 118 (2000), S. 57-76; Jürgen Sarnowsky: Die ständische Kritik am Deutschen Orden in der ersten Hälfte des 15. Jahrhunderts, in: Bernhart Jähnig u. Georg Michels (Hgg.): Das Preußenland als Forschungsaufgabe. Eine europäische Region in ihren geschichtlichen Bezügen. Festschrift für Udo Arnold zum 60. Geburtstag gewidmet von den Mitgliedern der Historischen Kommission für ost- und westpreuBische Landesforschung, Lüneburg 2000, S. 403-422.

5 Czaja: Preußische Hansestädte (wie Anm. 4), S. 64 ff .

6 Antoni Czacharowski: Społeczne i polityczne siły w walce o Nową Marchię w latach 1319-1373 [Soziale und politische Kräfte im Kampf um die Neumark in den Jahren 1319-1373], Toruń 1968, S. 17 n; ders.: Miasta (wie Anm. 2), S. 176.

7 Markian Pelech: Die Beisteuer der kleineren Städte an die Hansestädte des Deutschordenslandes Preußen im Jahre 1396, in: Preußenland 22 (1984), S. 9-16; Klaus Neitmann: Die Staatsverträge des Deutschen Ordens in Preußen 1230-1449. Studien zur Diplomatie eines spätmittelalterlichen deutschen Territorialstaates. Köln-Wien 1986, S. 51 ff. (= Neue Forschungen zur BrandenburgPreußischen Geschichte, 6). 
sich das Recht vor, die Hochgerichtsbarkeit und die Markthoheit wahrzunehmen wie auch Willküren und die Wahl der städtischen Amtsträger zu bestätigen. ${ }^{8}$ Die finanziellen Belastungen der preußischen Städte gegenüber dem Landesherrn waren sehr unterschiedlich. Er forderte von den ältesten Großstädten nur einen symbolischen Rekognitionszins (Kulm ca. 2 mr., Thorn und Elbing ca. 3 mr., Altstadt Königsberg $1 \mathrm{mr} .4$ sc.). Die jüngeren Städte zahlten jedoch einen Grundzins und Abgaben vom Marktregal. So hatten beispielsweise Kneiphof über 70 mr. und Rechtstadt Danzig 340 mr. Zinsen zu zahlen. Die kleineren Städte mußten Abgaben etwa von 10 bis über 100 Mark leisten. Die städtischen Zinse machten etwa 7,5\% (ca. 3500 mr.) der Gesamteinkommen des Ordens in Preußen aus ${ }^{9}$.

Als der Deutsche Orden 1402 die Neumark als Pfand in Besitz nahm, verfügten die dortigen Städte über eine relativ große verfassungsrechtliche Selbständigkeit und über einige landesherrliche Wirtschaftsrechte. In der Zeit der Wittelsbacher (1323-1373) hatten die Städte fast ausnahmslos die rechtliche und wirtschaftliche Nutzung der Mühlen erworben $^{10}$. Einige Stadträte hatten sich auch pfandweise oder käuflich von der landesherrschaftlichen Gerichtsbarkeit befreit (Königsberg, Arnswalde, Friedeberg, Landsberg, Neu-Berlin). Der Landesherr behielt bis 1402 von den landesherrlichen Zinsen und Abgaben aus den Städten die Orbede (insgesamt ca. 500 mr), einige Zölle und zwei Drittel der Einnahmen aus der höheren Gerichtsbarkeit in Woldenberg, Soldin, Bärwalde, Mohrin, Schönfließ, Küstrin, Tankow, vielleicht auch Lippehne ${ }^{11}$.

Nach der Übernahme der Neumark konzentrierte sich die Aufmerksamkeit des neuen Landesherrn auf die Bildung einer festen finanziellen Basis seiner Herrschaft. Seine wirtschaftliche Kraft in Preußen resultierte hauptsächlich aus dem großen Grundbesitz. In Pommerellen und im Kulmerland befanden sich in seiner Hand mindestens 50\% des Bodens und im „eigentlichen“ Preußen zwei Drittel ${ }^{12}$. Daher trat er seinen Untertanen in vie-

$8 \quad$ Henryk Samsonowicz: Kleinstädte im Deutschordensstaat Preußen, in: Udo Arnold (Hg.): Stadt und Orden. Das Verhältnis des Deutschen Ordens zu den Städten in Livland, Preussen und im Deutschen Reich Marburg 1993, S. 143-154 (= Quellen und Studien zur Geschichte des Deutschen Ordens, 44); Roman Czaja: Die Rolle der Kleinstädte im ständischen Leben des Ordenslandes Preußen, in: Wilfried Ebrecht u. a. (Hg.): Der weite Blick des Historikers. Einsichten in Kultur-, Landes- und Stadtgeschichte. Peter Johanek zum 65. Geburtstag, Köln-Weimar-Wien 2002, S. 399-407.

9 Jürgen Sarnowsky: Die Wirtschaftsführung des Deutschen Ordens in Preußen (1382-1454). KölnWeimar-Wien 1993, S. 213, Tab. 65 (= Veröffentlichungen aus den Archiven Preußischer Kulturbesitz, 34).

10 Herbert Helbig: Gesellschaft und Wirtschaft der Mark Brandenburg im Mittelalter Berlin 1973, S. 84 (= Veröffentlichungen der Historischen Kommission zu Berlin, 41).

11 Das Landbuch der Mark Brandenburg von 1375, hrsg. v. Johannes Schultze. Berlin 1940, S. 57; Czacharowski: Sily spoleczne (wie Anm. 6), S. 17; Edward Rymar: Elita miasta Chojna w średniowieczu [Die Elite der Stadt Königsberg/Neumark im Mittelalter], in: Przegląd Zachodniopomorski 13,3 (1998), S. 10.

12 Henryk Samsonowicz: Der Deutsche Orden als Wirtschaftsmacht des Ostseeraumes, in: Udo Arnold (Hg.): Zur Wirtschaftsentwicklung des Deutschen Ordens im Mittelalter. Marburg 1989, S. 105 (= Quellen und Studien zur Geschichte des Deutschen Ordens, 38); Bernhart Jähnig: Zur Wirtschaftsführung des Deutschen Ordens in Preußen vornehmlich vom 13. bis zum frühen 15. Jahrhundert, in: ebd., S. 118. 
len Fällen zugleich als Grund- und Landesherr entgegen ${ }^{13}$. In der Neumark hatte er keine großen Möglichkeiten, seinen Grundbesitz auszubauen. Die wirtschaftliche Basis seiner Macht in den neuerworbenen Gebieten konnten ähnlich wie in den anderen spätmittelalterlichen Territorien Regalien, hauptsächlich landesherrliche Zinse und Abgaben, sein ${ }^{14}$. Deswegen war die wichtigste Aufgabe der Ordensbehörden in der Neumark, die im 14. Jahrhundert verlorenen landesherrlichen Einnahmen aus dem Mühlenregal und aus dem Grundbesitz zurückzugewinnen ${ }^{15} .1400$ und 1401 investierte der Orden etwa $1000 \mathrm{mr}$. in den Ankauf von vier Mühlen und zwei Seen vor der Stadt Dramburg ${ }^{16}$. Balduin Stal, der Vogt der Neumark, stellte während der Verhandlungen in Arnswalde am 26. Februar 1403 seine Pläne in Bezug auf die Finanzverwaltung vor. Er bat die Städte um die Zustimmung, dass der Orden Mühlen, Zölle und Orbede einlöse und zurückgewinne. Dem Vorschlag des Landesherrn, die städtischen Mühlen anzukaufen, wurde von der Mehrheit der Städte zugestimmt. Nur die Räte von Arnswalde und Königsberg widersetzten sich dem Verkauf ihrer Mühlen. Den Widerstand des Arnswalder Rates versuchte der Hochmeister mit Hilfe eines Briefes an die vier Gewerke zu brechen. Es scheint jedoch, dass die Geldgeschenke für den Bürgermeister Kirsten Landsberg wirkungsvoller waren ${ }^{17}$. In den Jahren 1403 und 1404 kaufte der Orden die Mühlen nicht nur in Arnswalde, sondern auch in Friedeberg, Landsberg, Kallies, Woldenberg, Soldin, Mohrin, Bärwalde und Lippehne. 1406 verkaufte der Rat der Stadt Berlinchen noch zwei Mühlen dem Landesherrn ${ }^{18}$. In einem Brief vom 31. Januar 1405 schrieb der Hochmeister an die neumärkischen Stände: und als Ir wisset, Das Ir uns us allen Steten, usgenomen Konyngisperg, euwir Molen vorkouft habt mit aller herschaft und zugehorungen und zu allem Nutze ${ }^{19}$. Der Rat der Stadt Königsberg lehnte im Februar 1403 den ihm angebotenen Verkauf der städtischen Mühlen sehr entschieden ab, und der Ordensvogt konnte auch den Widerstand der Stadt nicht überwinden ${ }^{20}$. Die Wiedergewinnung des Mühlenregals war ein relativ erfolgreiches, aber zugleich sehr kostspieliges Unternehmen. In den Jahren 1403-1404 zahlte der Marienburger Tressler für den Ankauf der Mühlen etwa $5100 \mathrm{mr}^{21}$.

13 Sarnowsky: Wirtschaftsführung (wie Anm. 9), S. 184.

14 Ebd., S. 180.

15 Heidenreich (wie Anm. 1), S. 22.

16 Das Marienburger Tresslerbuch der Jahre 1399-1402, hrsg. v. Ernst Joachim. Königsberg 1896, S. 82, 84, 108; von Niessen: Geschichte Dramburg (wie Anm. 1), S. 71; Heidenreich (wie Anm. 1), S. 23.

17 Das Marienburger Tresslerbuch (wie Anm. 15), S. 135, 146, 201, 252; Heidenreich (wie Anm. 1), S. 23.

18 Edward Rymar: Mlyny i mlynarstwo w Nowej Marchii (XIII - pocz. XV wieku) [Mühlen und Mühlenwesen in der Neumark (13. - Anfang des 15. Jahrhunderts)], in: Zbigniew Czarnucha, Dariusz A. Rymar (Hgg.): Niebezpieczne drogi podejrzani mlynarze. Gorzów 2000, S. 104; Heidenreich (wie Anm. 1), S. 24.

19 Codex diplomaticus Brandenburgensis, hrsg. v. Adolph F. Riedel, 1. Hauptteil, Bd. 24. Berlin 1863, Nr. 183, S. 121.

20 Heidenreich (wie Anm. 1), S. 25.

21 Marienburger Tresslerbuch (wie Anm. 15), S. 222, 294. 
In den ersten Jahren seiner Herrschaft in der Neumark unternahm der Deutsche Orden keine größeren Eingriffe in die verfassungsrechtlichen Privilegien der Städte. Man kann nur vermuten, dass der Vogt Balduin Stal durch den Erwerb der Höfe oder Häuser in einigen Städten (Dramburg, Arnswalde und Landsberg) eine Grundlage für die Anwesenheit des Landesherrn innerhalb der Stadtmauern zu schaffen versuchte ${ }^{22}$. Der Orden strebte auch nach der Einlösung der verpfändeten städtischen Gerichte und der Orbede. 1403 kaufte der Vogt das niedere Gericht in der Stadt Dramburg vom Henning von Wedel zu Falkenburg ${ }^{23}$. 1404 wurde für etwa 130 mr. die Orbede von Schönfliess eingelöst ${ }^{24}$. $\mathrm{Zu}$ den Maßnahmen, die der Orden im Rahmen des Aufbaus seiner Herrschaftsstrukturen ergriff, gehörte auch das Fehdeverbot. Die neumärkischen Städte konnten vor 1402 ohne Genehmigung des Landesherrn Hilfsverträge mit anderen Städten abschließen und das Fehderecht als eine Form der Selbsthilfe verwenden ${ }^{25}$. Weil jedoch die Ordensverwaltung den hinreichenden militärischen Schutz dem Lande nicht gewähren konnte, fühlten sich die Städte durch das Fehdeverbot benachteiligt. 1404 schrieb der Vogt der Neumark Balduin Stal dem Komtur von Schlochau über eine Klage des Rates der Stadt Dramburg auf sein Verlangen nach dem Verzicht auf das selbständige Fehderecht in deren Streit mit dem pommerschen Geschlecht von Borcke: do ich irst tezu Dramburg qwam, do qwam der ganeze rat und clageden mir eren gebrechen, der do grocz were gewest, ee das land uns wurdin, und ny alzo groz verdrys und obirmut geschehen war, den als nu dy an uns kommen seyn, das machet, das sie dartzu nicht thun dorften an unsern willen und wytschap, und were in vor schade geschehen, so hatten sy io czwir alzo grossen schalen wyder getan, alz yn were geschehen ${ }^{26}$.

Die militärische Niederlage des Deutschen Ordens im Krieg gegen Polen und Litauen hatte auch den Zusammenbruch der finanziellen Grundlage seiner Macht zur Folge. Nach 1410 verfügte der Tressler in Marienburg über keine Mittel mehr, um die Politik der Wiedergewinnung der landesherrlichen Rechte in den Städten der Neumark fortzusetzen ${ }^{27}$. Es gibt sogar Hinweise darauf, dass einige in den Jahren 1402-1410 erworbenen Rechte wieder verpfändet wurden. Beispielsweise verlieh der Vogt in der Neumark 1421 das niedere Gericht in der Stadt Dramburg der Famlie von dem Borne ${ }^{28}$.

Es lässt sich vermuten, dass nach 1410 der Einfluß der Vögte auf die Städte geschwächt wurde. Ein Beweis dafür ist die selbständige Handlungsweise der Stadt Dramburg in der sog. Draheimer Fehde. Im Juni 1422 besetzten die Dramburger Bürger ei-

22 Heidenreich (wie Anm. 1), S. 26, 29; von Niessen: Geschichte Dramburg (wie Anm. 1), S. 72; Czacharowski: Miasta (wie Anm. 2), S. 179 f.

23 von Niessen: Geschichte Dramburg (wie Anm. 1), S. 77.

24 Marienburger Tresslerbuch (wie Anm. 15), S. 222.

25 Heidenreich (wie Anm. 1), S. 31.

26 Geheimes Staatsarchiv Preußischer Kulturbesitz, XX. Hauptabteilung, Ordensbriefarchiv (weiter zitiert: GStAPK, XX.HA, OBA), Nr. 733; vgl. Ernst Joachim, Walter Hubatsch (Hgg.): Regesta Historico-Diplomatica Ordinis S.Mariae Theutonicorum 1198-1525 (weiter zitiert: Regesta), T. 1, Göttingen 1948, Nr. 733.

27 Sarnowsky: Wirtschaftsführung (wie Anm. 9), S. 151; Heidenreich (wie Anm. 1), S. 29.

28 von Niessen: Geschichte Dramburg (wie Anm. 1), S. 83. 
genmächtig ohne Wissen des Landesherrn die Burg Draheim. Weil dieser Angriff dem Deutschen Orden Schwierigkeiten in seinen Beziehungen mit Polen verursachte, versuchten der Hochmeister und der Vogt einen Druck auf die Dramburger auszuüben, damit sie die Burg zurückgäben. Die Ermahnungen und Gespräche bewogen sie jedoch zu keinem Zugeständnis ${ }^{29}$. Der Vogt schrieb am 3. Mai 1423 an den Hochmeister: und sagete dem rade und den burgern euwer gnaden begher, das sy das slos weder sollin geben. ..., und gab in das vor als ich ernste und herteste muchte, daruff sy mir eyn kortz entwerte geben, weide in ewer gnade geld davor geben, so weiden sy euch das slos abtreten ${ }^{30}$. Der Hochmeister mußte also den Widerstand Dramburgs mit Gewalt niederschlagen. Zunächst wurde Draheim von Ordenstruppen erobert und dann die Stadt Dramburg zur Unterwerfung gezwungen. Die Bestrafung der Stadt für die eigenmächtige Handlung war relativ mild. Der Rat, der für den Ungehorsam verantwortlich war, wurde aus der Stadt verwie$\operatorname{sen}^{31}$.

Die Vertreter der neumärkischen Städte widersetzten sich auf den ständischen Versammlungen stärker als die Ritterschaft den Forderungen des Landesherrn. 1412 und 1446 leisteten sie Widerstand gegen die Einführung einer außerordentlichen Steuer. Sie spielten auch eine führende Rolle in den Verhandlungen der neumärkischen Stände mit dem Landesherrn, die ihrer dem neugewählten Hochmeister geleisteten Huldigung vorangingen $^{32}$. Ähnlich wie in Preußen wurden auch in der Neumark in den dreißiger Jahren des 15. Jahrhunderts die ständischen und städtischen Zusammenkünfte unabhängig von den Ordensbehörden einberufen ${ }^{33}$.

Eine bahnbrechende Bedeutung für die Beziehungen zwischen dem Landesherrn und den Städten hatte der Einfall der Hussiten 1433 und die Besetzung eines Teiles der Neumark durch pommersche und polnische Truppen 1433-1435. Die Verwüstung des Landes schwächte die wirtschaftliche Lage der neumärkischen Städte. Der Krieg offenbarte auch die militärische und wirtschaftliche Schwäche des Deutschen Ordens, der dem Lande die Sicherheit nicht gewährleisten konnte. In dieser Situation mussten sich die Städte und Ritterschaft selbst darum kümmern. Der Rat der Stadt Arnswalde hielt dem Vogt Heinrich Rabenstein während der Verhandlungen am 16. Juni 1433 eine Vernachlässigung der städtischen Befestigungen, Fehlen der Ausrüstung und auch Geldmangel für die Bezahlung der Söldner vor. Die Bürger widersetzten sich der gemeinsam mit den Ordenssöld-

29 Ebd., 84ff.

30 GStAPK, XX.HA, OBA, Nr. 4114.

31 von Niessen: Geschichte Dramburg (wie Anm. 1), S. 88 f.

32 Der neumärkische Vogt beschwert sich in einem Brief an den Hochmeister, dass ich das gancze jar swerlich gearbeit habe mit man und stete der nuwen mark und sunderlich mit eyn teils der steten und ir dorczy ny brengen künde mir gehorsam czu sein...;, GStAPK, XX.HA, OBA, Nr. 1679; vgl. auch Nr. 2035 (Widerstand der Stände gegen die Huldigung). Siehe den Beitrag von K. Neitmann in diesem Band.

33 Heidenreich (wie Anm. 1), S. 39, 43; Klaus Neitmann: Die „Hauptstädte“ des Ordenslandes PreuBen und ihre Versammlungstage. Zur politischen Organisation der preußischen Städte unter der Herrschaft des Deutschen Ordens, in: Zeitschrift für Historische Forschung 19,2 (1992), S. 135; Czaja: Preussische Hansestädte (wie Anm. 4), S. 72. 
nern geplanten Verteidigung der Stadt ${ }^{34}$. In dieser Situation zog sich der Vogt mit seinen Söldnertruppen aus ihr zurück. Der Rat öffnete die Tore dem pommerschen Herzog, und dann huldigte er dem polnischen König. Der Vogt klagte im September 1433 in den Briefen an den Hochmeister, dass die Ritterschaft und Städte die Verteidigung des Landes selbständig organisierten ${ }^{35}$. Am 11. November schlossen 39 Vertretern der Ritterfamilien ein Bündnis ab, um die Städte der Neumark in ihren Ansprüchen zu unterstützen: dat wi wollen und scholen bleiben by den ersamen steden der Nigemarke to Brandenborgk ${ }^{36}$. Man kann vermuten, dass dieses Bündnis die Ordensbehörde zu einer Unterstürzung des Wiederaufbaus der zerstörten Städte bewog. Am 30. November erteilte der Hochmeister den Städten Woldenberg, Friedeberg, Soldin, Lippehne und Bärwalde das Recht auf den Holzschlag im Ordenswald. Königsberg, Schönfliess und Landsberg wurden für einige Jahren von der Zahlung der Orbede befreit ${ }^{37}$. Nach dem Friedensvertrag von Brest 1435 erlangte der Orden die Herrschaft über Arnswalde zurück, zugleich verpflichtete er sich jedoch, keine Vergeltungsmassnahmen gegen die Stadt zu unternehmen ${ }^{38}$.

Eine neue Etappe der Städtepolitik in der Neumark fällt in die Zeit des Hochmeisters Konrad von Erlichshausen (1441-1449), der nach der Festigung der Ordensherrschaft in der Neumark und nach der Wiedererlangung seines Einflusses in den Städten strebte. Sein Ziel war es, hauptsächlich durch den Ausbau der Schlösser in den Städten die militärische Macht des Landesherrn zu stärken. Der rücksichtslose Ausführer dieses Vorhabens war der Vogt Georg von Egloffstein $(1441-1448)^{39}$. Seine Handlungsweise erweckte große Unzufriedenheit unter Ritterschaft und Städten. Darüber hinaus verschlechterten sich die Beziehungen zwischen dem Landesherrn und den Städten durch den Verdacht, dass einige von ihnen die Ansprüche des Kurfürsten von Brandenburg Friedrich II. auf die Neumark unterstützten. Nach dem Vertragsabschluß mit dem Kurfürsten (16. Oktober 1443) trat der Orden zum Angriff gegen die Opposition $\mathrm{an}^{40}$. In Arnswalde wurden Bürgermeister Krug und der Bürger Sagher hingerichtet. Der zweite Bürgermeister Janicke Soldyn und Hans

34 Andrzej Nowakowski: Nieudana próba poszerzenia granic Polski na Pomorzu w latach 1433-1435 [Ein mißlungener Versuch der Ausbreitung der Grenze Polens in Pommern in den Jahren 1433-1435], in: Przegląd Zachodniopomorski 5 , 3 (1990), S. 64 ff.; Rymar: Polsko- czeska wyprawa (wie Anm. 1), S. 51 f.; Karl Berg: Amswalde unter dem Deutschen Orden und den ersten Hohenzollern. Arnswalde 1923, S. 51.

35 Rymar: Nowa Marchia po wyprawie (wie Anm. 1), S. 15 f.

36 GStAPK, XX.HA, OBA, Nr. 6724.

37 Heidenreich (wie Anm. 1), S. 74; Rymar: Nowa Marchia po wyprawie (wie Anm. 1), S. 17.

38 Die Staatsverträge des Deutschen Ordens in Preussen im 15. Jahrhundert, Bd. I, hrsg. v. Erich Weise, Königsberg 1939, Nr. 180, S. 209 f.; Jan Wroniszewski: Dokument zrzeczenia się przez Wladyslawa III Choszczna na rzecz Krzyżaków z 20 maja 1436 roku [Die Urkunde des Verzichts durch Wladislaus III. auf Arnswalde zugunsten des Deutschen Ordens von 20. Mai 1436], in: Roman Czaja, Janusz Tandecki (Hgg.): Studia nad dziejami miast i mieszczaństwa w średniowieczu. Toruń 1996, S. 305-307.

39 Heidenreich (wie Anm. 1), S. 50; Erich Weise: Georg von Egloffstein (ca. 1409-1458) und die 1. Fortsetzung der Älteren Hochmeister-Chronik, in: Preussenland und Deutscher Orden. Würzburg 1958, S. 350 (Ostdeutsche Beiträge aus dem Göttinger Arbeitskreis, 9); Rymar: Konflikt (wie Anm. 1), S. 96.

40 Rymar: Konflikt (wie Anm. 1), S. 102. 
von der Buken wurden aus der Stadt verwiesen. In ihr sollte ein Schloss gebaut werden. Der gewaltsame Eingriff führte jedoch zu keiner Beruhigung der Situation ${ }^{41}$. 1445 empfahl der Vogt dem Hochmeister strenges Verfahren gegen Arnswalde ${ }^{42}$. In diesem Jahr erhielt die Stadt ein neues Privileg, in dem sich der Landesherr einen Teil des städtischen Grundbesitzes und die städtische Gerichtsbarkeit vorbehielt. Noch 1450 sind Auseinandersetzungen zwischen der Stadt und dem Hauptmann des Ordensschlosses belegt. Bei diesem Konflikt wurden wieder einige Bürger aus der Stadt verwiesen ${ }^{43}$.

1443 wurden neben Arnswalde auch Schivelbein und Landsberg bestraft. In Schivelbein griff der Vogt Walter Kirschkorb in die Zusammensetzung des Rates und des Gerichtes ein und beschränkte die verfassungsrechtliche Selbständigkeit der Stadt. Darüber hinaus musste sie 1000 mr. Finkenaugen als Strafe bezahlen ${ }^{44}$. In Landsberg baute der Deutsche Orden ein Schloss ${ }^{45}$. 1445-1446 hatte der Vogt auch einen Streit mit Königsberg, wo er auf dem Gelände des Augustinerklosters einen Hof errichtete ${ }^{46}$. Die harte Städtepolitik der vierziger Jahren brachte dem Orden keine Erfolge. Einerseits wurde das gespannte Verhältnis zwischen den Städten und dem Landesherrn noch verschärft. Auf der anderen Seite verschlechterten die Konflikte die wirtschaftliche Lage der Städte. Deswegen strebte der neue Vogt der Neumark Christoph Eglinger (2. November 1450-1455) nach der Verbesserung der Beziehungen zu ihnen. Ein Zeichen der neuen Politik war die Übergabe des Niedergerichtes an Arnswalde und Neulandsberg ${ }^{47}$.

Zusammenfassend soll darauf hingewiesen werden, dass der Deutsche Orden in der Neumark keine einheitliche Städtepolitik betrieb. In den Jahren 1402-1404 wurde sein Verhältnis zu den Städten hauptsächlich durch sein Bestreben bestimmt, die finanziellen Grundlagen seiner Herrschaft zu schaffen. In dieser Zeit unternahm der Vogt keine Eingriffe in deren verfassungsrechtlichen Verhältnisse. Erst in den vierziger Jahren versuchte der Orden, durch den Burgenausbau und die Beschränkung der verfassungsrechtlichen Selbständigkeit eine stärkere Kontrolle zu erreichen, was jedoch zu einem Konflikt mit dem neumärkischen Bürgertum führte. Dass „die Ordensherrschaft auf dem Lande überhaupt weniger fühlbar wurde als in den Städte, die die Last am stärksten empfanden“, wie Heidenreich urteilte ${ }^{48}$, scheint im Lichte der dargestellten Vorgänge nicht für die ganze Zeit der Herrschaft des Deutschen Ordens in der Neumark zuzutreffen. Es lassen sich auch einige Parallelen in den Verhältnissen zwischen den Städten in Preußen und in der Neumark feststellen wie die Erhaltung des Mühlenregals durch den Landesherrn und die wachsende politische (ständische) Aktivität der Städte in den dreißiger Jahren des 15. Jahrhunderts. Es gab auch deutliche Unterschiede. In der Neumark ergab sich

41 GStAPK, XX. HA, OBA, Nr. 6724; Berg (wie Anm. 34), S. 73 ff .; Rymar: Konflikt (wie Anm. 1), S. 103, bezeichnet Sagher irrtümlich als Ratmann.

42 GStAPK, XX.HA, OBA, Nr. 8831.

43 Rymar: Konflikt (wie Anm. 1), S. 109 f., 112; Heidenreich (wie Anm. 1), S. 43.

44 GStAPK, XX.HA, Pergamenturkunden, Nr. 2859; Heidenreich (wie Anm. 1), S. 76.

45 Rymar: Konflikt (wie Anm. 1), S. 103.

46 GStAPK, XX.HA, OBA 8855; Heidenreich (wie Anm. 1), S. 96.

47 Codex diplomaticus Brandenburgensis (wie Anm. 19), Nr. 213, S. 158.

48 Heidenreich (wie. Anm. 1), S. xx. 
der Konflikt zwischen dem Landesherrn und dem Bürgertum in den vierziger Jahren des 15. Jahrhunderts aus der Absicht des Ordens, die Herrschaft über die Städte zu festigen. In Preußen resultierte die Auseinandersetzung zwischen dem Deutschen Orden und den Städten (hauptsächlich den Großstädten) aus der Tatsache, dass deren Führungsgruppen nach vollständiger Unabhängigkeit und nach der Beteiligung an den inneren Angelegenheiten und der Außenpolitik des Landes strebten. Darüber hinaus bildete in Preußen der Adel gemeinsam mit den Bürgern die ständische Opposition. Dagegen hat sich diese $\mathrm{Zu}-$ sammenarbeit in der Neumark trotz einiger Ansätze in einem größeren Ausmaß nicht entwickelt. Deswegen war es möglich, die Autonomie der neustädtischen Städte im Sinne einer fürstlich-adligen Territorialpolitik zu brechen. 



\title{
Huldigung und Privilegienbestätigung Die Ausbildung der landständischen Verfassung der Neumark unter der Herrschaft des Deutschen Ordens und der frühen Hohenzollern
}

\author{
Von Klaus Neitmann
}

Das Aussterben des angestammten einheimischen Herrschergeschlechtes der Askanier stürzte bekanntlich die Mark Brandenburg in eine tiefe, weit über ein Jahrhundert andauernde Krise der Landesherrschaft ${ }^{1}$. Sie geriet als erledigtes Reichslehen in das Blickfeld und in die Auseinandersetzungen der spätmittelalterlichen Großdynastien des Deutschen Reiches, der Wittelsbacher und der Luxemburger ${ }^{2}$, und diente ihnen als willkommenes, aber im politischen Alltag eher vernachlässigtes Nebenland zur Vergrößerung ihrer Hausmacht. Ihre Übertragung an die Hohenzollern konsolidierte nicht kurzfristig, sondern erst in einem langfristigen, von Rückschlägen unterbrochenen Prozeß ihre inneren und äußeren Verhältnisse. Kein anderer Teil der Mark Brandenburg hat neben dem personellen und dynastischen Herrscherwechsel so folgenreich den territorialen Herrschaftswechsel erfahren wie die Neumark. Denn es reicht nicht aus, darauf hinzuweisen, daß sie von 1402 bis 1454 der Herrschaft des Deutschen Ordens und seines Hochmeisters in Preußen unterstand und damit für ein halbes Jahrhundert aus der Mark Brandenburg ausgegliedert war. Die entscheidenden Rechtsgrundlagen des jeweiligen Herrn änderten sich mehr als zweimal, insofern, als 1402 Markgraf Sigismund das Land dem Orden zunächst in der Form eines Kaufs auf Wiederkauf verpfändete und es ihm dann 1429 in sein uneingeschränktes Obereigentum übertrug. Umgekehrt kehrte die Neumark 1454 duch den Verkauf des Ordens mit dem Vorbehalt des Wiederkaufsrechtes nur vorläufig an Brandenburg zurück und wurde dessen unanfechtbarer Teil erst wieder 1517, als der Hochmeister zugunsten des Markgrafen auf alle Rechte und Gerechtigkeiten des Ordens endgültig und uneingeschränkt verzichtete.

All diese verschiedenartigen Wechsel berührten nachhaltig die Beziehungen des jeweiligen neuen Landesherrn zu seinem Land bzw. zu dessen Untertanen. Im Kern erwartete er von ihnen, daß sie ihm Gehorsam leisteten, und sie erwarteten von ihm, daß er ihre Rechte bewahrte. Damit rückten für die Beteiligten einerseits Huldigung, andererseits

1 Johannes Schultze: Die Mark Brandenburg, Bd. 2. Berlin 1961, 3. [unveränderte] Aufl. Berlin 2004. - Helmut Assing: Die Landesherrschaft der Askanier, Wittelsbacher und Luxemburger (Mitte des 12. bis Anfang des 15. Jahrhunderts), in: Ingo Materna, Wolfgang Ribbe (Hg.): Brandenburgische Geschichte. Berlin 1995, S. 85-168, hier S. 132-168. - Eindringliche verfassungsgeschichtliche Analyse: Walter Schlesinger: Zur Geschichte der Landesherrschaft in den Marken Brandenburg und Meißen während des 14. Jahrhunderts, in: Hans Patze (Hg.): Der deutsche Territorialstaat im 14. Jahrhundert, II. Sigmaringen 1971, S. 101-126 (= Vorträge und Forschungen, 14).

2 Peter Moraw: Von offener Verfassung zu gestalteter Verdichtung. Das Reich im späten Mittelalter. Berlin 1985, S. 211-259 (= Propyläen Geschichte Deutschlands, 3). 
Privilegienbestätigung in den Mittelpunkt der Aufmerksamkeit. Mit der Huldigung verpflichteten sich die Untertanen, ihrem Herrn treu und gehorsam zu sein, und mit der Privilegienbestätigung verpflichtete sich der Herr, die Gerechtigkeiten und Gewohnheiten seiner Untertanen unverbrüchlich zu beachten. Huldigung und Privilegienbestätigung, die so der Sache nach eng zusammengehörten und einander ergänzten, stellten sich im Falle eines Herrscher- und Herrschaftswechsels freilich nicht immer von selbst und reibungslos ein. Denn gerade die Forderung des Landesherrn nach Huldigung veranlaßte die Stände - wenn wir uns bereits für unseren Untersuchungszeitraum, das 15. Jahrhundert, dieses damals noch ungebräuchlichen Terminus bedienen wollen -, Ansprüche auf Bekräftigung und großzügige Erweiterung ihrer althergebrachten Privilegien zu erheben, und ließ die Lage eintreten, daß beide Seiten über die genaueren Inhalte der ständischen Rechte und Pflichten und über das genauere Ausmaß der ständischen Rat und Hilfe intensiv und kontrovers miteinander verhandelten. Man mag durchaus wie vor Jahrzehnten der Schweizer Historiker Werner Näf vom „Herrschaftsvertrag“ sprechen ${ }^{3}$, wenn Gegenstand der Erörterungen, im neumärkischen Falle zumindest in einer entscheidenden Situation, die grundsätzlicheren Bedingungen der Herrschaftsausübung und die präziseren Bedingungen der dem Landesherrn von den Ständen geschuldeten Leistungen waren. Denn es ist offensichtlich, daß die Privilegienbestätigung im Gegensatz zu ihrer äußeren Form, die die Urkunde als einen vom Landesherrn den Ständen gewährten Gunsterweis erscheinen ließ, in der Sache einer vertragsähnlichen Abmachung zwischen zwei Parteien mindestens nahekam. Wir werden im Folgenden die zahlreichen neumärkischen Herrscher- und Herrschaftswechsel des 15. Jahrhunderts durchgehen und sichten unter der Frage, in welcher Weise, mit welchen Zielen und mit welchen Ergebnissen sich dabei Landesherr und Landstände über Huldigung und Privilegienbestätigung auseinandersetzten und verständigten. Dabei wird zu klären sein, unter welchen politischen und rechtlichen Umständen die beiden Seiten die Thematik anpackten und in welchen Lagen sie sie mit größerem oder geringerem Nachdruck zur Durchsetzung ihrer Absichten aufgriffen. Die reichhaltige Überlieferung des spätmittelalterlichen Deutschordensarchivs ${ }^{4}$ für die erste Hälfte

3 Werner Näf: Herrschaftsverträge und Lehre vom Herrschaftsvertrag, in: Schweizer Beiträge zur Allgemeinen Geschichte 7 (1949), S. 26-52, bes. S. 30; - ders., Frühformen des „modernen Staates“ im Spätmittelalter, in: Historische Zeitschrift 171 (1951), S. 225-243, wiederholt in: Hanns Hubert Hofmann (Hg.): Die Entstehung des modernen souveränen Staates. Köln 1967, S. 101-114, bes. S. 113 (= Neue Wissenschaftliche Bibliothek). - Anschauliches und aussagekräftiges Beispiel für ständische Huldigungen und landesherrliche Privilegienbestätigungen in einem geistlichen Territorium, deren Entstehung und Entwicklung: Berent Schwineköper: Der Regierungsantritt der Magdeburger Erzbischöfe, in: Walter Schlesinger (Hg.): Festschrift für Friedrich von Zahn. Bd. I: Zur Geschichte und Volkskunde Mitteldeutschlands. Köln-Graz 1968, S. 182-238, hier S. 204-291, 235 f. (= Mitteldeutsche Forschungen, 50/I).

4 Geheimes Staatsarchiv Preußischer Kulturbesitz (im Folgenden abgekürzt: GStA PK), Berlin-Dahlem, XX. HA (Historisches Staatsarchiv Königsberg). Die größtenteils in der Kanzlei des Hochmeisters erwachsenen Archivalien sind, abgesehen von den Amtsbüchern, verzeichnet in: Regesta Historico-Diplomatica Ordinis S. Mariae Theutonicorum, bearb. v. Erich Joachim, hrsg. v. Walther Hubatsch, Pars I: Index Tabularii Ordinis S. Mariae Theutonicorum. Regesten zum Ordensbriefarchiv, Vol. 1-3; Pars II: Regesta Privilegiorum Ordinis S. Mariae Theutonicorum. Regesten der Pergament-Urkunden aus der Zeit des Deutschen Ordens; Register zu Pars I und zu Pars II. Göttin- 
des 15. Jahrhunderts erlaubt es, die Entstehung der ständischen Privilegien nicht nur auf Grund einer kritischen Analyse ihres Inhaltes zu beurteilen, sondern zumindest für einen maßgeblichen Einzelfall die Vor- und Nachgeschichte eingehend an Hand der vorliegenden ausführlichen Verhandlungsaufzeichnungen zu untersuchen. Die Privilegienbestätigung von 1430 werden wir in den Mittelpunkt unseres Beitrages rücken, weil sich an ihm die allgemeinen Probleme in den Beziehungen zwischen Landesherrn und neumärkischen Ständen im 15. Jahrhundert am eindringlichsten verdeutlichen lassen.

Einleitend sei zur Eingrenzung unseres Gegenstandes noch angemerkt, daß zu den hier behandelten ständischen Privilegien nur eine zahlenmäßig kleine, aber inhaltsreiche, wohl überhaupt die gewichtigste Gruppe von landesherrlichen Vergünstigungen gerechnet wird. Daß die Markgrafen von Brandenburg in der Neumark seit deren Erwerbung in der Mitte und in der zweiten Hälfte des 13. Jahrhunderts die Rechte und Pflichten von einzelnen Personen und Körperschaften, seien es Klöster verschiedenartiger Ordensgemeinschaften, seien es adlige Herren oder deren Familien, seien es Städte und deren Bürgerschaften, in Privilegien festgehalten haben, bedarf keiner näheren Erläuterung; die Gegebenheiten des Einzelfalles erfuhren hier eine genauere juristische Regelung. Eine Privilegierung der gesamten neumärkischen Stände, also sämtlicher Stände als Gruppe oder als Korporation ${ }^{5}$, ist vor dem Herrschaftsbeginn des Deutschen Ordens nur ausnahms- und ansatzweise erfolgt. Jedenfalls kennt die Forschung keine Urkunde aus der Zeit vor 1402, die ausdrücklich den lieben und getruwen rittern, knechten, burgermeister, rathmanen, burger, gebuwren und gemeynen sowohl uff dem lande als in steten derselben Nuwenmarke, sie sien geistlich ader wertlich, epthen, epthynnen und thumhern, welcherley weßens ader wirdikeit die sien, wie es 1430 heißen wird, als Empfängern zugedacht

gen 1948-1973 (im Folgenden zitiert: ROT). Die in den Regesta angegebenen Nummern zu den einzelnen Briefen im Ordensbriefarchiv sind identisch mit den gültigen Archivsignaturen. - Die die Neumark betreffenden Vorgänge aus dem Deutschordensarchiv sind (nicht ganz vollständig) regestiert in: Repertorium der im Kgl. Staatsarchive zu Königsberg i. Pr. befindlichen Urkunden zur Geschichte der Neumark, bearb. v. Erich Joachim u. hrsg. v. P[aul] van Niessen. Landsberg a. W. 1895 (= Schriften des Vereins für Geschichte der Neumark, 3) (im Folgenden zitiert: Repertorium).

5 Vgl. zur allgemeinen Einführung in den gegenwärtigen Forschungsstand zu den mittelalterlichen Ständen den Artikel von R. Mitsch: Stand, Stände, -lehre. I. Definition; Mittel- und Westeuropa, in: Lexikon des Mittelalters, Bd. 8. München 1996, Sp. 44-49. Mitsch unterscheidet zwischen Stand als Kategorie sozialer Ordnung und „Stand als Bezeichnung für gesellschaftlich-politische Großgruppen, die als Reichs- oder Landstände ... innerhalb eines politischen Systems ein im einzelnen abgestuftes Recht auf Teilhabe an Herrschaft beanspruchen.“(Sp. 45). „Als entscheidende Bedingungen für die Formierung der politischen Stände ... sind das unmittelbare Verhältnis zum König bzw. Landesherrn und eigene Herrschaftsrechte anzusehen. Die ständische Verfassung enwickelte sich auf der Grundlage der Verpflichtung der Vasallen zu Rat und Hilfe und dem in bestimmten Fällen legitimierten Widerstandsrecht der Lehnsleute gegen den Lehnsherrn. ... Von entscheidender Bedeutung für die Bildung der Landstände waren die finanziellen Forderungen der Landesherren, die bei der Einführung neuer Steuern der Zustimmung der Landschaften bedurften. Der in der Bezeichnung , dualistische Ständestaat' implizierte Antagonismus zwischen den Landesherren und den Ständen ist in bezug auf das ausgehende Mittelalter zu relativieren, da sich das Verhältnis zwischen den Fürsten und den Ständen vielfach eher durch Kooperation als durch ein dualistisches Gegeneinander auszeichnete“ (Sp. 48 f.). Diese Interpretation des (spät)mittelalterlichen Ständestaates soll im Folgenden am neumärkischen Beispiel des 15. Jahrhunderts näher überprüft werden. 
wäre. Aus der Zeit der wittelsbachischen Herrschaft in der Mark sind allerdings mehrere Urkunden überliefert, die die Markgrafen an die neumärkischen Städte insgesamt gerichtet haben; sie betrafen die Erhebung des Schosses oder die Klärung gerichtlicher Zuständigkeiten und gewährten in Fragen, in denen die neumärkischen Städte als Gruppe aufgetreten waren, ihnen allen dieselbe Gnade. Als Markgraf Ludwig der Ältere im Oktober 1338 von Adel und Städten der Mark Brandenburg einen Schoß zur Auslösung der Niederlausitz erhob, verpflichtete er sich gegenüber mehreren Empfängern bzw. Empfängergruppen in gleichlautenden Urkunden dazu, künftig nie wieder von seinem Land, abgesehen von drei Notfällen, eine derartige Steuer zu verlangen. Eine Ausfertigung, die dann im Stadtarchiv Königsberg/Neumark verwahrt wurde, stellte er für alle neumärkischen Städte aus: Dat gelove wy usen liven und getrawen ratmannen algemeyne over Oder van allen steden ${ }^{6}$. Die Ratmannen von Berlin und Cölln gelobten dann im Dezember 1338 den Adligen und den Bürgern der dreizehn Städte Königsberg, Mohrin, Bärwalde, Schönfließ, Soldin, Lippehne, Landsberg, Friedeberg, Berlinchen, Woldenberg, Arnswalde, Reetz und Dramburg, daß das Landschoß, das die Ratmannen von Königsberg von den Rittern und Knechten und von den städtischen Bürgern im Land ,über der Oder“ eingesammelt und ihnen übergeben hatten, ausschließlich zur Auslösung der Niederlausitz verwendet werden solle ${ }^{7}$. Da die Ritterschaft der Neumark somit zur Steuerleistung ebenso wie die Städte herangezogen wurde, wird sie sicherlich ebenfalls ein gleichlautendes markgräfliches Privileg erhalten haben; es werden mithin, sofern die Annahme zutrifft, zwei inhaltlich übereinstimmende landesherrliche Zusicherungen getrennt für beide Stände ausgefertigt worden sein. Im März 1344 versprach Ludwig der Ältere vom altmärkischen Calbe aus den Bürgern und Einwohnern der Städte Königsberg, Soldin, Arnswalde, Friedland, Woldenburg und aller anderen Städten ,jenseits der Oder“", daß sie sich für Rechtsfälle außerhalb der Mauern ihrer Stadt nur vor dem Richter ihres eigenen Wohnortes zu verantworten bräuchten ${ }^{8}$, somit Klage gegen sie vor ihrem heimischen Stadtgericht erhoben werden mußte. 20 Jahre später, im Juni 1364, gelobte Markgraf Otto der Faule in Soldin seinen Städten „diesseits der Oder“, alle Urkunden, die sie von Ludwig dem Älteren (1323-1351) und von Ludwig dem Römer (1351-1365) erhalten hätten, einzuhalten und sie in keinerlei Weise zu brechen'.

Die wenigen Beispiele bezeugen zumindest, daß die Gesamtheit der neumärkischen Städte von den Markgrafen privilegiert wurde, vermutlich auch in getrennter Beurkundung

$6 \quad$ Melle Klinkenborg (Hg.): Das neumärkische Ständearchiv. Strausberg o.J. [1925], S. 163 Nr. 1 (= Das Archiv der Brandenburgischen Provinzialverwaltung, 2); - Adolf Friedrich Riedel (Hg.): Codex diplomaticus Brandenburgensis, 41 Bde. Berlin 1838-1869, hier: Bd. I 19, S. 202 Nr. 50 (im Folgenden zitiert: CDB). - Weitere Ausfertigungen: CDB I 20, S. 209 Nr. 44 (Ausfertigung für Ritter und Knechte in der Vogtei Frankfurt und Ratmannen und Bürgerschaft der Stadt Frankfurt); CDB III 1, S. 16 Nr. 18 (dat gelowe wi unszen liven und getruwen rathmannen van allen steden; Abdruck ,nach Ausfertigungen in verschiedenen städtischen Archiven“). - Zum politischen Vorgang vgl. die kurze Darstellung bei Schultze: Mark Brandenburg, Bd. 2 (wie Anm. 1), S. 56.

$7 \quad$ CDB II 2, S. 140 f. Nr. 756.

8 Das neumärkische Ständearchiv (wie Anm. 6), S. 164 Nr. 2.

9 Ebd., S. 165 Nr. 3. 
die gesamte Ritterschaft. Die Dokumente des 15. Jahrhundert werden zeigen, daß die Initiative zu ihrer Ausfertigung von „Mannen und Städten“, also von der adligen Ritterschaft und von der städtischen Bürgerschaft, ausging, daß diese beiden Stände unbestritten im Vordergrund standen, wenn das Land dem Hochmeister und seinen Vertretern entgegentrat. Ein gemeinsam Ritterschaft und Städten der Neumark erteiltes Privileg liegt von den wittelsbachischen und luxemburgischen Markgrafen nicht vor, was insofern nicht überrascht, als die Neumark bzw. die neumärkischen Stände damals trotz spürbarer Eigenständigkeit politisch nur begrenzt selbständig innerhalb der gesamten Mark Brandenburg auftraten.

\section{I}

Als der ungarische König Sigismund (1387-1437), der jüngere Sohn Kaiser Karls IV., als Markgraf von Brandenburg (seit 1378) in seiner ewigen Geldverlegenheit Anfang des 15. Jahrhunderts die Neumark gegen den Meistbietenden zu veräußern beabsichtigte ${ }^{10}$, gelobte er am 21. März 1402 zu Prag allen Rittern, Knechten, Mannen und Städten in der Neumark, sie in ihren Rechten und Gnaden, die sie von seinem kaiserlichen Vater und von ihm selbst bekommen hätten, zu erhalten und zugleich dafür zu sorgen, daß jeder Herr, an den er sie verpfänden oder verweisen werde, ihre Rechte und Gnade in gleicher Weise wie er achten werde. Wenn der neue Herr in der Zukunft sie vergewaltige oder ihre Rechte verletze, werde der König sie bis zur Wiederherstellung des alten Rechtszustandes verteidigen, zunächst in Freundschaft und durch Verhandlungen, aber nötigenfalls auch mit gewalt und mit dem swerde ${ }^{11}$. Daß der Markgraf Ritterschaft und Städten der Neumark die ihnen in der Zeit der luxemburgischen Herrschaft seit 1373 gewährten Privilegien bestätigte, wurde durch die damals geplante Verpfändung des Landes und seinen bevorstehenden Übergang an einen neuen Herrn - den Deutschen Orden oder im Falle von dessen Weigerung das Königreich Polen - ausgelöst. Sigismund wollte einen eventuellen Widerstand der Stände gegen die beabsichtigte Veräußerung von vornherein ausschalten, indem er ihnen zusicherte, seinen Nachfolger auf die Einhaltung ihrer landesherrlichen Gnadenerweise zu verpflichten und darüber hinaus sogar im Falle von deren Übertretung auf friedlichem oder militärischem Wege zu ihren Gunsten gegen den landesherrlichen Rechtsbrecher einzuschreiten. Ihnen sollte durch sein weitreichendes Versprechen die

10 Grundlegende, unüberholte Darstellung zur Deutschordensherrschaft in der Neumark: Karl Heidenreich: Der Deutsche Orden in der Neumark (1402-1455). Berlin 1932, hier S. 3-14 (= Einzelschriften der Historischen Kommission für die Provinz Brandenburg und die Reichshauptstadt Berlin, 5). - Christian Krollmann: Politische Geschichte des Deutschen Ordens in Preußen. Königsberg i.Pr. 1932, S. 81 f. (= Ostdeutsche Landeskunde in Einzeldarstellungen). - Wegen der vielen aus den Quellen zusammengetragenen Einzelheiten immer noch unverzichtbar: Johannes Voigt: Geschichte Preußens, von den ältesten Zeiten bis zum Untergange der Herrschaft des Deutschen Ordens, Bd. 6. Königsberg 1834, Ndr. Hildesheim 1968, S. 231-238. Ferner: Ders., Die Erwerbung der Neumark. Ziel und Erfolg der Brandenburgischen Politik unter dem Kurfürsten Friedrich I. und Friedrich II. (1402-1457), Berlin 1863.

11 Das neumärkische Ständearchiv (wie Anm. 6), S. 165 f. Nr. 4 (nach der Urkundenausfertigung im Stadtarchiv Landsberg/Warthe). 
Furcht genommen werden, daß der Herrschaftswechsel ihre Rechtsstellung verschlechtern könnte, wenn der neue Herr sich nicht an die Zusagen seines Vorgängers gebunden fühlte ${ }^{12}$.

Als am 25. Juli 1402 Sigismunds Bevollmächtigter Stibor, der ehemalige Woiwode in Siebenbürgen, auf der Marienburg mit Hochmeister Konrad von Jungingen (1393-1407) handelseinig wurde und ihm die Neumark für 63.200 ungarische Gulden verpfändete ${ }^{13}$, wurde entsprechend dem königlichen Versprechen vom vorangegangenen März der Erwerber ausdrücklich auf die Einhaltung der ständische Rechte und Gewohnheiten verpflichtet, wie es denn allgemein bei Pfandgeschäften üblich war, daß der Pfandnehmer auf Verlangen des Pfandgebers die Beachtung der althergebrachten Privilegien seiner neuen Untertanen versprach ${ }^{14}$. Am selben 25. Juli bestätigte der Hochmeister Rittern, Knechten, Bürgermeistern, Ratleuten, Bürgern, Bauern und Gemeinen auf dem Lande und in den Städten in der Neumark, sie seien geistlich oder weltlich, nach vollzogenem Kauf und entsprechend ihrem Begehren alle Privilegien und Freiheiten, die ihnen vor Zeiten von Kaisern - d.h. von Kaiser Karl IV. als Markgraf von Brandenburg -, Kaisers Kindern d.h. von dessen Söhnen Sigismund und Johann von Görlitz als dem Kaiser nachfolgende Markgrafen von Brandenburg bzw. Herren der Neumark (Sigismund 1378-1388 und 1396-1402, Johann 1388-1396) -, Fürsten und Fürstinnen - d.h. von früheren Markgrafen von Brandenburg - verliehen worden waren. Er, der Hochmeister, werde die Privilegien und Freiheiten stets einhalten und ihnen in keiner Weise zuwiderhandeln und bestätige zugleich auch die im Land seit alters gepflogenen Gewohnheiten ${ }^{15}$. Konrads Urkunde ging über diejenige Sigismunds insofern hinaus, als sie alle (sozialen) Stände der städtischen und ländlichen Bevölkerung der Neumark, Adel, Bürger, Bauern und Gemeine, ansprach und die von allen früheren Landesherren - nicht nur von den luxemburgischen - erteilten Privilegien wie auch die im Territorien geltenden ungeschriebenen Gewohnheiten - und nicht nur die schriftlichen Pergamente - bekräftigte. Die Privilegienbestätigung glich damit sehr viel mehr dem üblichen Muster, nach dem im Falle eines Herr-

12 Das Haupt eines der führenden neumärkischen Adelsgeschlechter, Heinrich von Güntersberg, ließ sich noch am 18. April 1402 zu Prag von Sigismund seinen neumärkischen Besitz zwischen Netze und Drawe, so wie seine Vorfahren und er sie seit alters auf Grund markgräflicher Belehnungen innegehabt hätten und so wie er ihnen schon von Sigismunds Vater Karl IV. bekräftigt worden sei, bestätigen. CDB I 24, S. 108 Nr. 168. Auch wenn der Text den Anlaß der königlichen Beurkundung nicht zu erkennen gibt, wird sie von dem Wunsch Heinrichs ausgelöst worden sein, vor dem zu erwartenden Übergang der Neumark an den Deutschen Orden eine zusätzliche aktuelle Besitzbestätigung des bisherigen Landesherrn zum Nachweis der eigenen Rechte gegenüber dem künftigen Landesherrn zu erhalten.

13 Erich Weise (Hg.): Die Staatsverträge des Deutschen Ordens in Preußen im 15. Jahrhundert, Bd. I (1398-1437). Marburg 2. Aufl. 1970, S. 23 Nr. 15.

14 Klaus Neitmann: Die Pfandverträge des Deutschen Ordens in Preußen, in: Zeitschrift für Ostforschung 41 (1992), S. 1-67, hier S. 20-22.

15 Das neumärkische Ständearchiv (wie Anm. 6), S. 166 f. Nr. 5; CDB I 19, S. 291 Nr. 182 (beide Editionen nach der Urkundenausfertigung im Stadtarchiv Königsberg/Neumark); CDB II 3, S. 153 Nr. 1268 (nach späterer Abschrift der Joachimsthalschen Schulbibliothek). 
schaftswechsel die ständischen Rechte vom neuen Herrn anerkannt wurden, und kam dadurch den ständischen Erwartungen entgegen.

Ein Passus der vom königlichen Bevollmächtigten ausgestellte Verpfändungsurkunde sowie eine zusätzlich von ihm ausgefertigte Urkunde entbanden die gesamte Mannschaft der Neumark ihres ihrem bisherigen Landesherrn Sigismund geleisteten Treueides und verwies sie zur Huldigung an den Hochmeister - was Sigismund selbst in seiner eigenen Verkaufsurkunde vom 29. September 1402 in der Sache wiederholte, indem er die Neumärker an den Hochmeister und seinen Orden verwies und sie ihm gegenüber zur althergebrachten Dienst- und Steuerleistung aufforderte ${ }^{16}$. Die Stibor begleitenden Vertreter des neumärkischen Adels und der neumärkischen Städte huldigten wohl noch am 25. Juli ihrem neuen Herrn ${ }^{17}$, als Einleitung der umfassenderen Huldigung sämtlicher Stände des Landes. Denn noch am 25. Juli beauftragte der Hochmeister den Vogt zu Schivelbein Johann von Techwitz damit, zusammen mit Magister Nikolaus, dem Bürgermeister von Dirschau, die Neumark „einzunehmen“, d.h. die Huldigung bzw. Treueidleistung des Landes entgegenzunehmen ${ }^{18}$, wofür der Treßler ihn und seine Begleitung mit ansehnlichen Geldsummen versah ${ }^{19}$. Zwei Wochen später, am 9. August 1402, schworen und huldigten unter Berufung auf diese Entbindung und Verweisung zu Arnswalde sechs namentlich genannte neumärkische Ritter und Knechte namens aller Ritter, Knechte und Adligen der Neumark und die Bürgermeister und Ratmannen der fünf Städte Arnswalde, Friedeberg, Landsberg, Soldin und Königsberg namens aller Städte, alle zugleich im Namen aller städtischen und ländlichen Einwohner der Neumark dem Hochmeister und dem Orden und gelobten, von ihnen nie wieder zurückzutreten, ausgenommen den Fall, daß Hochmeister und Orden selbst sie von Huldigung und Eidesleistung wieder lossagen sollten. Die ritterschaftlichen und städtischen Vertreter bekannten in der von ihnen besiegelten Urkunde außerdem, daß der Hochmeister ihnen zwei Urkunden über seine Bestätigung ihrer Privilegien übergeben

16 Wie Anm. 13 und ebd., Nr. 17, § 1: Dorumbe wir alle gesworen und holdunge der manschaft der Nuwenmarke mit seiner czugehorunge vorgeschriben und alle ander undirsassen haben gewiset und wisen mechticlich an den vorbenumpten homeistir und seinen orden, im und seinen nachkomelingen czu thunde allirlei recht und dinst, geschos und steur, als sie uns und unsern vorfarn getan und gegeben haben.

17 Am 28. Juli 1402 schrieb der Hochmeister dem Herzog von Pommern-Stolp zur Abwehr von dessen Ansprüchen auf die Neumark, Stibor, usgesant mit etczlichen us de Nuwenmarke von des ganczen landes wegen und stete von König Sigismund, habe ihm, dem Hochmeister, die Neumark angeboten, er habe daraufhin die Neumark pfandweise in seinen Besitz übernommen, und die manne usgesant von dess ganczen landes wegen und steten uns geholdit haben. Johannes Voigt (Hg.): Codex Diplomaticus Prussicus. Urkunden-Sammlung zur ältern Geschichte Preussens aus dem Königl. Geheimen Archiv zu Königsberg nebst Regesten, Bd. 6. Königsberg 1861, Ndr. Osnabrück 1965, S. 142 Nr. 133 = CDB I 24, S. 109 f. Nr. 270.

18 Zur Deutung dieser Begrifflichkeit vgl. Klaus Neitmann: Der Hochmeister des Deutschen Ordens in Preußen - ein Residenzherrscher unterwegs. Untersuchungen zu den Hochmeisteritineraren im 14. und 15. Jahrhundert. Köln-Wien 1990, S. 16 f. (= Veröffentlichungen aus den Archiven Preußischer Kulturbesitz, 30).

19 [Erich] Joachim (Hg.): Das Marienburger Tresslerbuch der Jahre 1399-1409. Königsberg 1896, Ndr. Bremerhaven 1973, S. 177 f. 
habe ${ }^{20}$. Wie aus einem weiter unten ausführlich zu erörternden Fall einer hochmeisterlichen Privilegienbestätigung im Analogieschluß abzuleiten ist, wird Konrad von Jungingen jeweils eine eigene Urkunde für die Ritterschaft und für die Städte ausgestellt haben, ohne daß man der einst im Königsberger Stadtarchiv überlieferten (städtischen) Ausfertigung irgendwelche zwischen den beiden Versionen abweichenden Textpassagen ablesen könnte. Adel und Städte traten, wie den Formulierungen der Urkunde unmißverständlich zu entnehmen ist, dem Orden als eigene Gruppen entgegen, eine sie beide überwölbende Gemeinsamkeit entstand allenfalls dadurch, daß sie ihre Verpflichtungen zugleich auch im Namen aller Bewohner der Neumark bekundeten und damit zusammen für das gesamte Land zur Wahrung seiner Rechte gegenüber dem neuen Landesherrn handelten. Die genannten Adligen entstammten den angehensten und begütertsten Familien der Neumark: Der Ritter Heinrich von Güntersberg ${ }^{21}$ und die Knechte Hasso Wedel zu Neuwedel, Hans von Brederlow zu Dertzow, Klaus von Sanitz, Michael von Sydow und Konrad von der Marwitz werden aufgezählt. Die genannten Städte waren die damaligen neumärkischen Immediatstädte, sie hatten ihre unmittelbare Unterstellung unter den Landesherrn in den wechselhaften Zeiten des 14. Jahrhunderts bewahrt.

$\mathrm{Da}$ außer den namentlich aufgeführten Adligen und Städten wiederholt alle Adligen, alle Städte und alle Einwohner erwähnt und in die Zusagen ihrer Repräsentanten einbezogen wurden, war keine bloße Floskel, wie eine Aufstellung der Ordenskanzlei über die Huldigung des neumärkischen Adels zeigt ${ }^{22}$. Unter der Überschrift Disse nochgeschreben ritter und knechte haben geholdiget und gesworen in der Nuwenmargke werden insgesamt 161 Personen, darunter jeweils mehrere, mehrfach sechs, sieben oder gar neun Mitglieder der großen Geschlechter wie der Güntersberg, Wedel, Wolde, Borne, Sydow, Strauß, Marwitz, Schöning, Ellingen, Wreech, Brederlow, namentlich aufgezählt, die anscheinend zu unterschiedlichen Zeiten und an unterschiedlichen Orten nach dem 25. Juli 1402 den Ordensvertretern die Huldigung geleistet haben, wie aus der Gliederung der Liste abzuleiten ist. Nachdem der weitaus größere Teil der Personen aneinandergereiht ist, zieht der Schreiber eine (Zwischen)Summe: Summa $1^{c}$ und XIX erbar lewthe, fügt sogleich hinzu: Disse haben dornoch geholdet und läßt dann nach der Nennung zweier Gebrüder von Brederlow zu Dertzow vier kleine Gruppen aufeinander folgen: dis ist der Czedensche wynkel - umbe Lypenschen ryden - disse haben geholdet czum Arndswalde - Schybelbeyn geholdet. Die Überschriften deuten darauf hin, daß nach der ersten

20 Ediert: CDB II 3, S. 153 f. Nr. 1269 (nach der Edition in v. Ledeburs Archiv Bd. VI S. 83) bzw. schlechter - CDB I 24, S. 115 f. Nr. 177 (nach der Abschrift in Dickmanns Urkundensammlung). Ausfertigung: GStA PK, XX. HA, Pergamenturkunden, Schbl. 43 Nr. 8; danach die Neuedition unten im Quellenanhang, Nr. 1.

21 Heinrich von Güntersberg hatte am 26. Juli 1402 auf Geheiß des Hochmeisters vom Treßler 20 Mark empfangen (Tresslerbuch [wie Anm. 15], S. 177), war also offenkundig am 25. Juli auf der Marienburg anwesend gewesen, als die Urkunden über den Besitzübergang der Neumark ausgestellt wurden, hatte vermutlich als ständischer Vertreter an der Behandlung der ständischen Wünsche durch den Orden mitgewirkt. - Zur Stellung Heinrich von Güntersbergs in der Neumark vgl. Heidenreich (wie Anm. 10), S. 17 f.

22 GStA PK, XX. HA, Ordensbriefarchiv (im folgenden zitiert: OBA) 727; Regesten: Repertorium, S. 19 Nr. 92; ROT I/1/1, Nr. 727. 
umfassenden Huldigung, vielleicht der zu Arnswalde am 9. August 1402, in der Folgezeit an einzelnen neumärkischen Orten - Zehden, Lippehne, nochmals Arnswalde und Schivelbein - kleine Gruppen von Rittern und Knechten aus den jeweiligen umliegenden Kleinregionen ihre Eide abgelegt haben. Die Zusammenstellung verdeutlicht, daß die Huldigung nicht auf einzelne repräsentative Vertreter - die durch ihre Mitwirkung an der Verpflichtungsurkunde herausgehoben waren - beschränkt blieb, sondern daß der neue Landesherr auf die Einbeziehung der großen Masse des Adels - sicherlich ohne Anspruch auf unbedingte Vollständigkeit - großen Wert legte, um so dem Einzelnen seine Verpflichtung zu Treue und Gehorsam gegenüber Hochmeister und Orden nachdrücklich bewußt zu machen.

Wie man dem gesamten Vorgang ansieht, stehen Huldigung ${ }^{23}$ und Privilegienbestätigung in engstem Zusammenhang. Wenn der Landesherr wechselt - hier dadurch, daß das Territorium einer anderen Herrschaft pfandweise überlassen wird -, werden die Untertanen ihres alten Treueides entbunden und durch die anschließende neue Eidesleistung an den neuen Landesherrn gebunden; für ihn ist die Huldigung der Einwohner die maßgebliche Rechtsgrundlage für die Begründung seiner Herrschaft, genauer gesagt, für seine Forderung nach der von ihnen ihm zu leistenden Treue. Die Untertanen ihrerseits wollen durch den Herrschaftswechsel ihre Rechtslage zumindest nicht verschlechtert, wenn nicht verbessert sehen, sie wünschen sich daher die ausdrückliche schriftliche Bestätigung ihrer Privilegien. Der Hochmeister ging 1402 auf das gleichermaßen vom bisherigen königlichen Landesherrn und von den Ständen geäußerte Ansinnen ein, er akzeptierte, daß seine Privilegienbestätigung sachlich und zeitlich der allgemeinen ständischen Huldigung vorausging (auch wenn vielleicht seine Urkunden vom 25. Juli 1402 erst anläßlich der Huldigung am 9. August den Ständen übergeben wurden). Dabei bestätigte Konrad von Jungingen die ihnen von den vorhergehenden Landesherren erteilten schriftlichen Urkunden ebenso wie die im Lande seit alters bestehenden Gewohnheiten, allerdings in ganz allgemeiner Form, ohne irgendeine Konkretisierung der gültigen Rechte und Gewohnheiten, so daß im Konfliktfall von Urkundenaussteller und -empfängern nach einer klärenden gemeinsamen Auslegung gesucht werden mußte.

1402 gaben sich die Beteiligten jedenfalls mit der allgemeinen Privilegienbestätigung zufrieden, und ebenso 1407, als der nächste Herrschaftswechsel anstand, jetzt dadurch verursacht, daß im Orden nach dem Tode Konrads von Jungingen ein neuer Hochmeister, sein Neffe Ulrich von Jungingen (1407-1410), zum Ordensoberhaupt bestimmt worden war. Gut vier Monate nach seiner Wahl am 26. Juni 1407, am 29. Oktober desselben Jahres, bestätigte er den vor ihm erschienenen Mannen und Städten der Neumark entsprechend ihrer Bitte die Urkunde seines Vorgängers vom 25. Juli 1402, bestätigte, wie er in seiner Verlautbarung fortfuhr, Rittern, Knechten, Mannen, Städten, Bürgern, Bauern und der (All)Gemeinheit der Neumark die ihnen von früheren Landesherren ausgefertigten Urkunden, Privilegien, Rechte und Freiheiten, so wie sie ihnen bereits von seinem Vor-

23 Vgl. im allgemeinen: Th[eo] Kölzer: Art. Huldigung, in: Lexikon des Mittelalters, Bd. 5/1. München 1990, Sp. 184. - Zu den Huldigungen der neumärkischen Stände vgl. vorrangig die Darlegungen von Heidenreich (wie Anm. 10), S. 52-58. 
gänger bestätigt worden seien ${ }^{24}$. Ulrichs Urkunde von 1407 bezieht sich zwar, wie man sieht, ausdrücklich auf die Konrads von 1402, ohne sie jedoch wörtlich in Teilen oder gar in Gänze zu inserieren. Sie ist neu konzipiert worden und beruft sich dabei auch im Einklang mit der üblichen Beurkundungen eines Hochmeisters auf den Rat und Willen seiner Mitgebietiger, die in einer umfangreichen Zeugenreihe benannt werden: die fünf Großgebietiger, die Komture von Thorn und Graudenz, der Vogt der Neumark Balduin Stal sowie, ergänzend, der Kaplan, die beiden Kumpane und die beiden Schreiber des Hochmeisters.

Die schwere Tannenberger Niederlage von 1410 gegen die polnisch-litauische Union und ihre Folgen stürzten den preußischen Ordensstaat in langwierige politische und militärische Auseinandersetzungen, von denen auch die czwischen der Cron zu Polen und dem lande zu Pomeren gelegen(e) Neumark, wie ihre territorialpolitische Lage einmal ein Jahrhundert später in Urkunden des Hochmeisters Albrecht (von Brandenburg-Ansbach) und des Kurfürsten von Brandenburg beschrieben wurde ${ }^{25}$, nicht unberührt blieb. In den aufgeregten Zeiten waren ihre langen Grenzstrecken nach außen hin gegenüber feindseligen Nachbarn zu sichern, vornehmlich im Süden gegenüber dem Königreich Polen, dessen Ansprüche auf Grenzfestungen oder gar auf das gesamte Land abzielten, aber auch im Norden gegenüber den pommerschen Herzögen und ihrem Adel, deren Absichten und Maßnahmen den Landfrieden immer wieder in Frage stellten. Der neumärkische Ordensvogt als lokaler Vertreter des Hochmeisters zog daher die Städte und vor allem die Ritterschaft zu wiederholten Malen wegen der ständigen Grenzkonflikte und häufigen Fehden zu militärischen Dienstleistungen heran, suchte sie zu Aufgeboten gegen die drohenden Gegner an den Landesgrenzen wie im Lande selbst zu bewegen - weil er auf ihre Mithilfe zwingend angewiesen war: Allein mit seiner kleinen Dienerschar und ohne militärischen Beistand der Städte war er etwa gänzlich außerstande, alle Landstraßen gegen räuberische Überfälle pommerscher Adliger auf städtische Handelszüge zu sichern ${ }^{26}$. In unausweichlicher Konsequenz mußte er mit den Ständen über die auf den Heereszügen erst zu befürchtenden und dann eingetretenen Verluste und Schäden an Menschen, Tieren und Material, insbesondere an wertvollen Pferden, die leicht verletzt oder getötet werden konnten, verhandeln, um den in ihren Reihen aufgekommenen Unmut zu dämpfen. Hinzu kamen hochmeisterliche Steuerwünsche an die neumärkischen Stände. Sie wurden also seit dem Krieg von 1409/11 vom Orden in zuvor ungeahntem Ausmaß zu militärischen und finanziellen Dienstleistungen aufgefordert, und es konnte daher den Beobachter nicht

24 Das neumärkische Ständearchiv (wie Anm. 6), S. 167 f. Nr. 6; CDB I 19, S. 308 Nr. 204 (beide Editionen nach der Urkundenausfertigung im Stadtarchiv Königsberg/Neumark).

25 Erich Joachim: Die Politik des letzten Hochmeisters in Preußen Albrecht von Brandenburg, 1. Teil 1510-1517. Leipzig 1892, S. 311 Nr. 139 (= Publikationen aus den K. Preußischen Staatsarchiven, 50). - CDB II 6, S. 280 Nr. 2473.

26 GStA PK, XX. HA, OBA 1679, siehe unten Quellenanhang Nr. 2 [4]. - Zu den Bemühungen des Ordens um Eindämmung des Fehdewesens vgl. Heidenreich (wie Anm. 10), S. 30 f. - Für wertvolle Hinweise zum Militärwesen des 15. Jahrhunderts und zur Interpretation der Abschnitte über die militärischen Verpflichtungen in den Verhandlungen und Urkunden von 1430 (s.u.) danke ich Prof. Dr. Sven Ekdahl, Berlin, und Dr. Uwe Tresp, Potsdam. 
überraschen, daß die verschiedenen landesherrlichen Anträge rasch kontroverse Diskussionen über die Grundlagen der beiderseitigen Beziehungen, wie sie durch Huldigung und Privilegienbestätigung geschaffen worden waren, verursachten.

Ob die Stände im Frühjahr 1411 die Forderung des neuen Hochmeisters Heinrich von Plauen (1410-1413), des Nachfolgers des bei Tannenberg gefallenen Ulrich von Jungingen, nach ihrer Huldigung erfüllten oder nicht, bleibt mangels eindeutiger Quellenzeugnisse unklar. Heinrich ersuchte am 2. April 1411 Ritter und Knechte, Bürger und Gemeinden der Neumark, dem neuernannten Vogt Albrecht von der Duben (1411-1412), den er mit Heinrich von Güntersberg ins Land schickte, an seiner statt zu huldigen. Zugleich verlangte er von den Ständen, zur Bezahlung der Ordenssöldner Steuern und Geschoß zu entrichten, was sie noch im Frühjahr 1412 ablehnten. Ob wegen der Steuerverweigerung auch die Huldigungsforderung abgewiesen wurde, ist nicht ersichtlich ${ }^{27}$. Aber spätestens anläßlich des nächsten Hochmeisterwechsels brach die Grundsatzdebatte um die Herrschaftsgrundlage offen aus. Denn als im Januar 1414 Michael Küchmeister (1414-1422) nach dem Sturz Plauens das Hochmeisteramt übernahm, stieß sein Verlangen nach der ständischen Huldigung auf heftigen Widerspruch. Mannen und Städte lehnten sie im Februar 1414 gegenüber dem Vogt Sander Machwitz (1413-1420) ab: Sie hätten einst dem Orden gehuldigt und geschworen und stünden zu ihren daraus entspringenden Verpflichtungen, aber sie wollten Huldigung und Eidesleistung nicht mehr wiederholen. Die nachfolgende Klage enthüllte die Ursache ihres Widerspruchs. Konrad von Jungingen habe ihnen bei der Übernahme der Herrschaft gelobt und verbrieft, sie bei ihrer alten Gerechtigkeit zu belassen und diese nicht zu mindern, sondern lieber zu bessern (was eine sehr freie, wenn auch nicht völlig sinnwidrige Wiedergabe von Konrads Urkunde aus dem Jahr 1402 war). Diese Zusage werde ihnen nicht eingehalten, denn sie würden gefangengenommen, sie erlitten Schäden, die ihnen von den wechselnden Vögten, vom Vorgänger ebenso wie vom Nachfolger, nicht erstattet würden, so daß sie auf ihren Verlusten sitzen blieben und dadurch verdorben würden. Michael von Sydow jammerte zur beispielhaften Bekräftigung gegenüber dem Vogt darüber, daß der Orden ihm nicht die 450 Mark, die er zur Auslösung seines Sohnes aus dem Gefängnis habe aufwenden müssen, zurückerstattet habe. Die ständischen Opponenten verlangten vom Hochmeister die ausdrückliche Zusicherung, selbst ihnen ihren Schaden zu vergüten, sofern der Vogt sich ihnen wegen eines Ämterwechsels entziehe. Einige Kritiker gingen sogar noch weiter: Unter Berufung auf die Privilegienbestätigung Sigismunds von 1402 gedachten sie, sich bei ihm über die Verletzung ihrer Gerechtigkeiten durch den Orden zu beklagen ${ }^{28}$, war der König für sie auch während der Pfandschaft immer noch der Garant der ständischen Rechte, deren Verlet-

27 Markian Pelech: Der verlorene Ordensfoliant 5 (früher Hochmeister-Registrant II) des Hist. Staatsarchivs Königsberg, mit Regesten (nach Rudolf Philippi und Erich Joachim), in: Udo Arnold (Hg.): Beiträge zur Geschichte des Deutschen Ordens, Bd. 1. Marburg 1986, S. 123-180, hier S. 142 Nr. 20 (= Quellen und Studien zur Geschichte des Deutschen Ordens, 36 = Veröffentlichungen der Internationalen Historischen Kommission zur Erforschung des Deutschen Ordens, 1). - Heidenreich (wie Anm. 10), S. 48, 53 (Die hier von ihm behauptete ständische Ablehnung der Huldigung ist aus der von ihm angeführten Quelle, OBA 1679, nicht abzuleiten.). 
zung zu unterbinden er sich selbst urkundlich verpflichtet hatte. Die andauernden Querelen mit Polen nach Tannenberg hatten die Aufgebote und den damit eingehenden Schaden gegenüber den älteren Zeiten stark vermehrt, da der Orden, wie er schon in den Jahren nach 1402 bewiesen hatte und erst recht unter dem außenpolitischen Druck seit 1409 bekräftigen mußte, ein nachdrücklicheres Regiment im Lande zu führen gedachte als einst die weit entfernten luxemburgischen Markgrafen. Demgegenüber beklagten die Stände unter Berufung auf ihre Privilegienbestätigung von 1402 den Bruch ihrer althergebrachten Rechte und Gewohnheiten, auch wenn diese darin nicht präzisiert worden waren und damit unterschiedlichen Interpretationen offenstanden, und verwiesen insbesondere darauf, daß in der Zeit der raschen Wechsel im Vogtamt zwischen 1408 und 1414 die Nachfolger die Ritterschaft und Städten geschuldeten Verpflichtungen ihrer Vorgänger nicht anerkannt und beachtet hätten.

Die Hochmeister waren durchaus gewillt, ihren Beschwerden entgegenzukommen und ihre Verluste auszugleichen. Bereits Heinrich von Plauen hatte im Aufgebotsfalle mit der Mannschaft so verfahren wollen, als mans vor gehalden hat, uff das sie deste gutwilliger werden, wend wir yo kegen in thun wellen, als do mogelich ist und als man in vor getan hat. Damit war der neumärkische Vogt im Juli 1412 angewiesen worden, die Ritterschaft auf dem Kriegszug mit Kost und Futter zu versorgen und ihr den dabei erlittenen Schaden zu ersetzen ${ }^{29}$. Denn während des großen Krieges mit Polen-Litauen 1409/11 war genauso verfahren worden: Als sich neumärkische Adlige an dem Kriegszug nach Polen im August 1409 beteiligten, stellte der Orden, wie es in einem diesbezüglichen Bericht heißt, ihnen, als sie aus ihrem Haus ritten, all ihren Bedarf bereit und stand für ihren Schaden ein $^{30}$. Die Städte verlangten nun in diesem Punkt ihre Gleichstellung mit der Ritterschaft, sie lehnten es Anfang 1412 ab, mit ihr zusammen an der Befriedung der Straßen mitzuwirken, da sye nicht reiten wolden mitsampt den mannen, man stund in den vor schaden $^{31}$. Diese Forderung lehnte Michael Küchmeister ab, da die Städte auch früheren Herren dienstpflichtig gewesen seien; ohne urkundlichen Nachweis über die Erlassung der Dienstverpflichtung werde er diese nicht verändern. Im Hinblick auf die Schulden eines abgehenden Vogtes stellte er hingegen in Aussicht, einen Beauftragten zur Aufnahme der ausstehenden Forderungen zu entsenden und den Vogt zur Einhaltung sei-

29 GStA PK, XX. HA, OBA 1712, siehe unten Quellenanhang Nr. 3 [2].

30 GStA PK, XX. HA, OBA 1115 = Repertorium, S. 45 Nr. 238. - Die Zusage verdeckte freilich die grundsätzliche Frage, wer auf der Ordensseite die Aufwendungen tragen sollte, der neumärkische Vogt oder der Hochmeister. Die Vögte führten ihr finanzielles Unvermögen ins Spiel und baten den Hochmeister um Übernahme der Leistungen, und ihre fehlende Zahlungsfähigkeit und -bereitschaft bewog ebenfalls die Stände dazu, immer wieder den Einsatz des Hochmeisters für den Fall des Versagens des Vogtes zu verlangen. Im Juni 1410, also noch vor der Schlacht bei Tannenberg, berichtete der Vogt dem Hochmeister, er könne dem neumärkischen Adel auf einer bevorstehenden Zusammenkunft mangels Geld und sonstigen Mitteln keinen Schadenersatz versprechen. Wenn er wirklich aufgeboten werden solle, müsse ihm Zehrgeld entrichtet werden, und zwar, wie gemeint war, vom Hochmeister. Er, der Vogt, wolle den Adel dazu bewegen, daß der Hochmeister die Entschädigungsfrage entscheide. GStA PK, XX. HA, OBA 1300. - Den Hinweis auf diese beiden Quellen verdanke ich Prof. Dr. Sven Ekdahl, Berlin.

31 GStA PK, XX. HA, OBA 1679, siehe unten Quellenanhang Nr. 2 [4]. 
ner Verpflichtungen anzuweisen; er hielt es allerdings nicht für notwendig, darüber eine Verschreibung auszustellen. Die Quellen schweigen darüber, ob wegen seines teilweisen Entgegenkommens die Huldigung stattfand ${ }^{32}$. Es scheint ein unentschiedener, allerdings nicht auf konfrontative Zuspitzung angelegter Schwebezustand eingetreten zu sein. Die Stände lehnten die regelmäßige Wiederholung der Huldigung im Falle eines Hochmeisterwechsels solange ab, wie ihnen nicht ihre militärischen und finanziellen Ansprüche durch eine hochmeisterliche Urkunde ausdrücklich verbrieft worden waren, ohne damit die 1402 dem Orden geschworene Treue prinzipiell in Frage zu stellen. Und der Hochmeister kam zumindest den ritterschaftlichen Wünschen in der Praxis unter Bezugnahme auf althergebrachte Gewohnheiten entgegen, allerdings ohne sich durch die Gewährung eines Privilegs förmlich und stärker binden zu wollen. Es war aus der Sicht des Ordens nur folgerichtig, daß Paul von Rusdorf (1422-1441), als er im März 1422 die Nachfolge Michael Küchmeisters im Hochmeisteramt antrat, den neumärkischen Vogt bevollmächtigte, die Huldigung den neumärkischen Ständen und Untertanen zu erlassen ${ }^{33}$. Indem er von sich aus auf die Huldigung verzichtete, war ihnen die Gelegenheit zur erneuten Vorbringung ihrer Forderungen genommen, zugleich der bisherige modus vivendi ohne förmliche schriftliche Fixierung bekräftigt.

\section{II}

Schneller, als die Beteiligten damals vermutet haben werden, stellte sich für die Stände wieder ein günstiger Anlaß für die Durchsetzung ihrer Anliegen ein. Am 7. September 1429 übereignete Sigismund dem Orden gegen dessen militärische Hilfeleistung in Ungarn gegen die Türken endgültig und uneingeschränkt die Neumark, indem er auf sein Wiederkaufsrecht verzichtete. Dabei entließ er die neumärkischen Untertanen nochmals aus seinem Gehorsam und befahl ihnen, dem Hochmeister, seinen Gebietigern und dem Deutschen Orden zu huldigen ${ }^{34}$. Am folgenden Tag bevollmächtigte er Erzbischof Günther von Magdeburg, gemäß seiner vorhergegangenen Urkunde Hochmeister und Deutschem Orden die Neumark in aller Form zu übereignen, allen Einwohnern die Huldigung zu gebieten und sie aus den Eiden auf den König zu entlassen. Mit besonderer Urkunde vom selben Tag entband er seine einstigen neumärkischen Untertanen des ihm geleisteten Eides und trug ihnen auf, dem Orden auf Verlangen des von ihm dazu eingesetzten Magdeburger Erzbischofs zu huldigen ${ }^{35}$. Die neumärkischen Stände hatten gerade etliche Monate zuvor, im Januar 1429, in der ungelösten Huldigungsfrage wieder ihre Opposition

32 Heidenreich (wie Anm. 10), S. 53 f., nach dem seit 1945 verlorenen OF 8, S. 80-81; vgl. auch das Kurzregest zu diesem hochmeisterlichen Schreiben im Findbuch 66 des GStA PK, XX. HA, Bl. 10.

33 GStA PK, XX. HA, OBA 3780, ediert unten Quellenanhang, Nr. 5.

34 Staatsverträge I (wie Anm. 13), S. 181 Nr. 168. - Zu den politischen Zusammenhängen vgl. Krollmann (wie Anm. 10), S. 131 f. - Carl August Lückerath: Paul von Rusdorf. Hochmeister des Deutschen Ordens 1422-1441. Bad Godesberg 1969, S. 81-87 (= Quellen und Studien zur Geschichte des Deutschen Ordens, 15).

35 Staatsverträge I (wie Anm. 13), S. 182 Nr. 169. 
gegen den Orden bekundet, als Hochmeister Paul von Rusdorf anläßlich eines Wechsels im Vogtamt, des Überganges von Walter Kirschkorb (1422-1428) auf Nikolaus Nickeritz (1428-1430), Vorgänger wie Nachfolger gemeinsam damit beauftragte, Mannen und Städte um die Erneuerung der Huldigung zu ersuchen. Nickeritz stieß auf deutlichen Widerstand der Städte, sie widersetzten sich seiner Aufforderung, als er von jeder einzelnen von ihnen auf einem Umzug durch das Land die Huldigung einzuholen trachtete, und verlangten nach erfolgter Abstimmung in ihren Reihen, ihnen zur Beratung der Angelegenheit bis Ostern (27. März 1429) Zeit einzuräumen. In seinem Schreiben an den Hochmeister vom 22. Januar 1429 bemerkte Nickeritz, daß dem Vernehmen nach die Städte die Huldigung nicht leisten wollten, und empfahl daher Rusdorf, sich in der Angelegenheit mit den Brüdern Borchart und Eckart von Güntersberg, seinen - des Vogtes - Räten, zu beraten ${ }^{36}$.

Sigismunds Entschluß zur staatsrechtlichen Übereignung der Neumark an den Orden und seine diesbezüglichen Anweisungen lösten langsam und schrittweise einen Meinungswandel unter den neumärkischen Ständen aus. Zwar widerstrebten sie auch noch der Huldigung, als sie die königliche Aufforderung vom 7. September 1429 erhalten hatten, und wünschten sich von ihm eine ausdrückliche mündliche Anweisung. Sigismund ging auf ihre Bitte ein und bestellte am 17. März 1430 eine neumärkische Gesandtschaft von je vier Vertretern der Ritterschaft und der Mannschaft zu sich auf den bevorstehenden, zur Bekämpfung der böhmischen Hussiten angesetzten Reichstag zu Nürnberg nach Ostern, ließ aber keinen Zweifel daran, daß er nochmals ihre Entlassung aus der ihm geleisteten Huldigung und ihre Verweisung an Hochmeister und Orden bekräftigen werde ${ }^{37}$. Offensichtlich unter dem Eindruck dieses Schreibens lenkten die Neumärker ein. Jedenfalls konnte Anfang Mai 1430 Kirschkorb dem Hochmeister mitteilen, Mannen und Städte hätten sich zur Huldigung bereitgefunden, zwei ihrer Vertreter, der adlige Borchart von Güntersberg und der bürgerliche Arnswalder Bürgermeister Janike Soldin, würden demnächst den Hochmeister mit der Bitte aufsuchen, yn [d.h. Mannen und Städten] brifflich czu vorsegheln, sie czu losen evichlich by iren alden rechtikeiden. Damit war, wie sich in der Folge deutlich zeigten sollte, nicht bloß die Wiederholung der allgemeinen Privilegienbestätigung von 1402 gemeint, sondern es wurde eine Präzisierung und Konkretisierung der Verpflichtungen des Ordens, eine gegenüber 1402 inhaltlich erweiterte Privilegierung der Stände angestrebt.

Eine in diesem Sinne abgefaßte Urkunde des Hochmeisters vom 13. Juli $1430^{38}$ liegt - allerdings nur abschriftlich - im Ordensfolianten 95 des Deutschordensarchivs, also im Archiv des Urkundenausstellers, vor. Sie ist bislang der Forschung gänzlich unbekannt geblieben, wird etwa in der für unser Thema maßgeblichen Quellensammlung Joachims/ van Niessens und der grundlegenden Studie Heidenreichs überhaupt nicht erwähnt - weil

36 GStA PK, XX. HA, OBA 5037, ediert unten Quellenanhang, Nr. 6. - Zu der im Folgenden noch deutlicher hervortretenden Gruppe der Räte des Vogtes vgl. die gründliche Erörterung bei Heidenreich (wie Anm. 10), S. 65-83.

37 GStA PK, XX. HA, OBA 5311, ediert unten Quellenanhang, Nr. 7.

38 GStA PK, XX. HA, Ordensfoliant 95, fol. 180v-181v, ediert unten Quellenanhang, Nr. 9. 
kein Bearbeiter der neumärkischen Geschichte bislang darauf verfallen war, eine zentrale neumärkische Quelle in einem hochmeisterlichen Handfestenbuch mit fast ausschließlich Preußen betreffenden Güterverleihungen zu suchen ${ }^{39}$. In der Narratio bezieht sich der Hochmeister ausdrücklich auf das durch Sigismunds endgültige Übereignung der Neumark und seine Verweisung der Stände an den Orden ausgelöste doppelte Anliegen der Ritterschaft und Städte, die von seinem Vorgänger Konrad von Jungingen gewährten Artikel zu erneuern mit etlichen andern vorgegeben stucken, also sie einerseits zu bekräftigen und sie andererseits im Sinne der ständischen Forderungen zu ergänzen. Er kommt ihnen in der Weise entgegen, daß er zuerst unter wörtlicher Wiederaufnahme der entscheidenden Passagen von 1402 die vormals erteilten Privilegien ebenso wie die althergebrachten Gewohnheiten bestätigt. Mit der unmittelbar anschließenden Formulierung sunderlichen begnaden wir ... leitet er zu seinen auf die Streitpunkte der letzten beiden Jahrzehnte zurückgehenden Zugeständnisssen in einzelnen Sachverhalten über, vornehmlich zum wesentlichsten Gegenstand, den militärischen Diensten. Dabei unterscheidet er zwischen der Ritterschaft und den Städten. Wenn die Mannschaft von ihm selbst oder von seinem lokalen Vertreter zu Diensten aufgefordert wird, soll ihr der Vogt entsprechend dem bisherigen Verfahren ihre Versorgung bzw. Verpflegung vom Auszug aus dem eigenen Haus bis zur Rückkehr dorthin, also während der gesamten Dauer des militärischen Einsatzes, gewährleisten und für all ihren dabei erlittenen Schaden einstehen. Wenn ihr Schaden wegen seines durch eine schwere Niederlage verursachten großen Umfanges die Möglichkeiten des Vogtes zum Ersatz übersteigt, wird der Hochmeister selbst diesen übernehmen. Die Ritterschaft wird mit diesen Regelungen sehr großzügig behandelt, denn andernorts galten die kriegsherrlichen Verpflichtungen zur Versorgung und zum Schadenersatz vielfach nur für die Strecke vom Sammelplatz des Heeres oder erst von der Landesgrenze an und jeweils wieder zum Ausgangspunkt zurück. Die Städte werden demgegenüber schlechter behandelt, denn ihnen wird die Gleichstellung mit der Ritterschaft nur für ihren Dienst außerhalb der Landesgrenzen, nur nach wohl begründeter Beweisführung und nur nach

39 Zum angesprochenen Ordensfolianten 95, dessen Analyse den nachfolgenden überlieferungsgeschichtlichen Betrachtungen zugrunde gelegt ist, vgl. Klaus Neitmann: Zu den Handfestensammlungen des Deutschen Ordens. Eine Untersuchung des Ordensfolianten 95, in: Archiv für Diplomatik 36 (1990), S. 187-220. - Die beiden gleich zu behandelnden Privilegienbestätigungen für die neumärkischen Stände vom 13. Juli und 29. Dezember 1430 sind in ein zeitgenössisch so bezeichnetes „Handfestenbuch“ eingetragen, der Eintrag der zweiten Urkunde ist handfeste der Nuwen Marke überschrieben. Wenn heutzutage ständische Privilegierungen und Dienstgutverleihungen unter inhaltlichen Erwägungen unterschiedlichen Urkundengruppen zugeordnet werden, wird dabei die wesentliche Gemeinsamkeit übersehen, die der Ordenskanzlei die Eintragung in demselben Amtsbuchtyp hat selbstverständlich erscheinen lassen. Die Urkunden für einzelne Dienstgutinhaber wie für ganz ständische Gruppen betreffen jeweils die gegenseitigen Rechte und Pflichte der Parteien, im Mittelpunkt stehen die militärischen und finanziellen Leistungen, zu denen die Urkundenempfänger auf Grund ihres Besitzes gegenüber den Urkundenausstellern verpflichtet sind. Insofern weicht das ständische Privileg, wenn es die dem Orden von Ritterschaft und Städten der Neumark unter bestimmten Voraussetzungen geschuldeten militärischen und finanziellen Dienste beschreibt, nicht von dem Privileg für eine Einzelperson aus der Reihe der preußischen Ritter und Knechte ab, die ihr Gut mit einer bestimmten Hufen- oder Hakenzahl vor allem gegen die Zusicherung von Kriegsdiensten (und eher geringfügigen Geld- und Naturalienabgaben) erhalten. 
dem Urteil des Rates des neumärkischen Vogtes gewährt. Die Dienstpflicht innerhalb der Neumark haben sie demnach gänzlich auf eigene Kosten zu leisten, und die Versorgungsausgaben einer Dienstpflicht außerhalb der Neumark, etwa im Kriegsfalle in Polen oder in Pommern, werden materiell also nur nach einem Beweisverfahren des neumärkischen Rates, der sich aus ordensfreundlichen Adligen zusammensetzt, anerkannt. Zudem wird in ihrem Fall nicht an eine Schadenersatzleistung gedacht, wie sich zwar nicht aus dem undeutlichen Wortlaut der Urkunde, aber aus den gleich zu schildernden späteren Verhandlungen ergibt. Verglichen mit diesen Regelungen, fällt ein weiteres Zugeständnis des Hochmeisters erheblich weniger ins Gewicht. Wenn ein Neumärker seine alten Handfesten durch Feuer und andere Umstände verliert, sollen sie ihm unter Nachweis ihres Inhaltes und des alten Besitzes ohne Abgabe oder Geschenk erneuert werden, die Hochmeisterkanzlei darf sich also nicht durch überhöhte Gebühren bloße Privilegienerneuerungen abhandeln lassen.

Die Urkunde ist nur an der genannten Stelle abschriftlich überliefert, was den skeptischen Urkundenkritiker nach der Zuverlässigkeit der Überlieferung fragen läßt. Der vorliegende Text weist keinerlei Anzeichen einer bloßen Entwurfsfassung oder einer unvollständigen Abschrift auf. Auch die formelhaften Urkundenbestandteile, die in den Handfestenregistern öfter Kürzungen zum Opfer fallen, sind vollständig erhalten; so ist die Intitulatio ausgeschrieben, und die Urkunde ist mit einer langen, dem bedeutsamen Gegenstand angemessenen Zeugenreihe abgeschlossen, mit der Nennung der fünf Großgebietiger des Ordens, fünf weiterer Komture, des Kaplans, der beiden Kumpane und zweier Schreiber des Hochmeisters; der Kaplan steht an der Spitze der hochmeisterlichen Kanzlei. Die Handfesten sind fortlaufend in das Register von ständig wechselnden Schreibern eingetragen worden ${ }^{40}$, nicht immer gleichzeitig mit der Erstellung der Ausfertigung, aber allenfalls in geringem zeitlichem Abstand von weniger Wochen oder ausnahmsweise Monaten. Soweit einige erhaltene Ausfertigungen den genauen Textvergleich erlauben, sind die Abschriften im allgemeinen sehr zuverlässig; geringfügige Abweichungen mit Wortumstellungen, stilistischen Varianten oder verkürzten Zeugenreihen verändern nicht substantiell den Wortlaut der Ausfertigung. Unsere Textabschrift ist auch nicht im Gegensatz zu anderen Kopien des Handfestenbuches durchgestrichen, als Zeichen dafür, daß die Urkunde ihre Rechtsgültigkeit verloren hätte. Es gibt also, wie aus dem Überlieferungsort, dem in der hochmeisterlichen Kanzlei fortlaufend geführten Handfestenregister zu schließen ist, keinerlei begründete Zweifel an der Ausfertigung des neumärkischen Privilegienbriefes zu Thorn am 13. Juli 1430. Die Privilegienbestätigung scheint endgültig ein abgeschlossenes Kapitel zu sein, wenn man in einem Brief des neumärkischen Vogtes vom 31. Juli 1430 liest, der Hochmeister möge den versiegelten Brief mit einem Boten an Mannen und Städte der Neumark senden, uf das sie deste williger yo czur erbhuldinge musten werden ${ }^{41}$.

40 Vgl. hierzu und zu den folgenden Bemerkungen Neitmann: Handfestensammlungen (wie Anm. 38), S. 201-207.

41 GStA PK, XX. HA, OBA 5423 = Repertorium, S. 110 Nr. 645. 
Es scheint allerdings nur so, denn wir sind unbeabsichtigt mit dieser Schlußfolgerung in einer nur allzu oft übersehenen Untiefe der Urkundenkritik versunken. Wir brauchen in unserem Handfestenbuch nach dem Ende unserer Lektüre der Urkunde vom 13. Juli 1430 nur drei Blätter umzuschlagen, auf den Blättern 184r bis $185 \mathrm{r}$ finden wir eine weitere, handfeste der Nuwenmarke überschriebene Urkunde Pauls von Rusdorf für die neumärkischen Stände vom 29. Dezember $1430^{42}$, die der vorherigen verdächtig ähnelt. Der Text wiederholt in weiten Passagen die Juli-Urkunde, wie in der Edition der Petitdruck verdeutlicht, allermeist wortwörtlich, nur mit ganz geringfügig geänderten oder ergänzten Formulierungen. Der Petitdruck läßt sogleich die wesentlichen inhaltlichen Zusätze ins Auge springen. Die Bestimmung über die Neuausfertigung verlorener Handfesten, für die die Herrschaft unverändert auf Geschenk oder Gabe verzichtet, ist ergänzt durch eine Gebührenordnung der zuständigen Kanzlei: Für die Ausstellung von Handfesten und Briefen über Lehen und Güter soll der Schreiber des Vogtes den Rittern nicht mehr als 12 böhmische Groschen oder zwei Mark Finkenaugen abnehmen, für Briefe über das Leibgeding von Frauen nicht mehr als sechs Groschen oder eine Mark Finkenaugen. Völlig neu eingefügt wird ferner eine erbrechtliche Bestimmung zu einem den Adel über die Jahrhunderte hinweg berührenden Thema: Die Vererbung von Lehen zu gesamter Hand mit tatsächlicher Teilung unter den Erbberechtigten darf der Orden nicht in Frage stellen, er darf sie also nicht zu ihrer Einziehung und damit zur Ausweitung des landesherrlichen Besitzes nutzen. Wohl zwecks Klarstellung wird vermerkt, daß auch das Gesinde und die Pferde der adligen Mannen angemessene Verpflegung beanspruchen dürfen. Die referierten Zusätze und Veränderungen betreffen ausschließlich die Ritterschaft, denn im Gegensatz zur Juli-Urkunde hat der Hochmeister im Dezember die getrennte Privilegienbestätigung für Ritterschaft und Städte vorgesehen, wie der Nachtrag zur Urkundenabschrift belegt, wo es zunächst heißt: Eine Handfeste in gleichem Wortlaut ist den Städten der Neumark gegeben worden, unter alleinigem Zusatz des nachfolgenden, mit der Stelle der Einfügung genau markierten Artikels, welcher lautet: Um der Bitten der Gebietiger und der Ritterschaft willen gewährt der Hochmeister den neumärkischen Städten die Gnade, daß er oder seine Amtmannen im Falle des Aufgebotes erem reiszigem geczuge, also ihren Berittenen, gleich der Mannschaft außerhalb der Landesgrenzen Futter und Kosten gibt, jedoch ihnen für keinen Schaden einsteht. Was die Städte von unreisigem geczug, also an Fußvolk, mitführen, sollen sie selbst versorgen. Der Hochmeister unterscheidet demnach innerhalb des städtischen Aufgebotes nach der militärischen Leistungsfähigkeit: Reisige, also berittene Hauptleute und Wäppner aus dem begütertum Bürgertum, erhalten vom Orden die üblichen Zuwendungen, während die Ausgaben für die „Unreisigen“, das Fußvolk aus den Gewerken, das während eines Feldzuges nach Möglichkeit auf Wagen befördert wird, von den Städten selbst getragen werden müssen, und Schadenersatz wird ihnen grundsätzlich abgeschlagen. Wie die preußischen Kriege des 15. Jahrhunderts zeigten, war das Fußvolk in der Feldschlacht ziemlich nutzlos, hingegen gut einsetzbar bei Belagerungen und als Burgbesatzung.

42 GStA PK, XX. HA, Ordensfoliant 95, fol. 184r-185r, ediert unten Quellenanhang, Nr. 12A, $12 B$. 
Nach dem Vergleich der beiden Urkundentexte liegt die Schlußfolgerung nahe, daß die Stände sich mit den Bestimmungen der Juli-Urkunde nicht zufrieden gaben, sondern auf weitere Zugeständnisse des Hochmeisters drangen, allerdings mit unterschiedlichen Schwerpunkten seitens der Ritterschaft und der Städte. Erstere sahen ihre Forderungen im Bereich der militärischen Dienste erfüllt und wünschten noch Änderungen auf güterrechtlichem Felde, Verpflichtungen des Ordens zur Erstausstellung von Güterurkunden zu mäßigen Gebühren und insbesondere zur unverbrüchlichen Beachtung von Besitzungen zu gesamter Hand, damit der Orden Besitzteilungen der Adelsfamilien nicht zu eigenen Gunsten ausnutzte. Die Städte wollten sich hingegen mit ihrer minderen Berechtigung bei den militärischen Diensten nicht abfinden. Die diesbezügliche Verpflichtung des Ordens vom Juli wird nicht in ihrem Kern umgestoßen, sondern wird im Dezember eigentlich nur präzisiert und ergänzt, indem zwischen berittenen, versorgungsberechtigten „Reisigen“ und der „unreisigen“ übrigen Mannschaft, dem Fußvolk, ohne Ansprüche unterschieden wird. Damit kann man allenfalls von einem begrenzten Erfolg der Städte sprechen, denn trotz der von ihnen erreichten Verbesserung blieben sie gegenüber der Ritterschaft weiterhin deutlich „benachteiligt“: Der Orden gewährleistete der Ritterschaft Vollversorgung und Schadenersatz innerhalb und außerhalb des Landes - was von ihr offenkundig gegenüber dem vom Orden gelegentlich angebotenene Solddienst bevorzugt wurde -, während er den Städten Schadenersatz überhaupt nicht und Versorgung nur dem berittenen Teil ihres Aufgebotes außerhalb des Landes zugestand. Indem er seine Zusicherungen in dieser Weise gegenüber den beiden Gruppen differenzierte, urteilte er indirekt über deren unterschiedliche militärische Leistungsfähigkeit.

Für die Erkenntnis der Vorgänge ist man glücklicherweise nicht nur auf den Urkundenvergleich angewiesen, sondern dank der reichhaltigen Überlieferung des Ordensarchivs, die in vergleichbarer Weise der der Mark Brandenburg im 14. und 15. Jahrhundert abgeht, können die Verhandlungen zwischen dem Orden und den Ständen genau nachgezeichnet werden. Ein ausführliches Verhandlungsprotokoll des Ordens unterrichtet über den Verlauf der Gespräche vom 26. bis 28. November 1430 zu Soldin zwischen den Komturen zu Danzig und Tuchel, Walter Kirschkorb, dem erwähnten Vorvorgänger des amtierenden neumärkischen Vogtes Heinrich Rabenstein (1430-1435), und Jost von Hohenkirchen, vielleicht unter Einbeziehung des Komturs von Schlochau Johann von Pommersheim, und den Ständen um Erbhuldigung und Privilegienbestätigung und läßt mit der gelegentlichen wörtlichen Wiedergabe einzelner Redebeiträge die Argumentationsweisen der Parteien anschaulich deutlich werden ${ }^{43}$. Der Ablauf der Verhandlungen zeigt mit wünschenswerter Deutlichkeit, daß sich hier nicht zwei Seiten, die Landesherrschaft und die Stände, direkt und unversöhnlich gegenüberstanden, sondern daß die Frontlinien anders gezogen wurden. Weder waren die Stände eine homogene Einheit mit einheitlicher Auffassung, noch war ein ausgleichendes Element in den kontroversen

43 GStA PK, XX. HA, OBA 5535, ediert unten Quellenanhang, Nr. 11. - Vgl. auch die Darstellung des Verhandlungsablaufs bei Heidenreich (wie Anm. 10), S. 41 f., 54 f.; beachte auch seine Beobachtungen S. 36, 43 f., zu der für politische Frontbildungen wichtigen Unterscheidung innerhalb des Adels zwischen den „vornehmsten“ und den ,gemeinen“ Mannen. 
Debatten zwischen Orden und Ständen zu übersehen. Wie nach den Positionen, die die verschiedenen Parteien in den vorangegangenen beiden Jahrzehnten verfochten hatten, kaum anders zu erwarten gewesen war, ging der maßgebliche Widerstand gegen die Forderung nach der ständischen Huldigung von den Städten aus und drehte sich der Kampf in erster Linie um die Ordensleistungen für die militärischen Aufgebote. Die Heftigkeit der Debatte wurde sicherlich dadurch befördert, daß nach der staatsrechtlichen Verfügung Sigismunds eine Privilegienbestätigung ernsthaft anstand und seitens des Ordens kaum mehr zu vermeiden war und zugleich mit der geänderten Rechtsgrundlage der Ordensherrschaft, der Umwandlung der ablösbaren und damit zeitlich befristeten Pfandschaft in zeitlich unbefristetes, dauerhaftes Eigentum, eine „Erbhuldigung“ verlangt wurde, also die Anerkennung des jetzigen Hochmeisters und seiner Erben und Nachkommen als Landesherren.

Die preußischen Ordenskomture wurden bereits auf ihrer Fahrt vom pommerellischen Schlochau zum neumärkischen Tagungsort Soldin in Schivelbein und den anderen aufgesuchten Städten auf Opposition eingestimmt: Etliche Städte und Mannen würden sich, so lauteten die Gerüchte, der Huldigung widersetzen. In Soldin ließen sich die städtischen Ratmannen im Gegensatz zur Ritterschaft von den hochmeisterlichen Gesandten bzw. deren Boten erst mehrmals auffordern, bevor sie mit großer Verzögerung im Tagungslokal erschienen und damit die Eröffnung der Verhandlungen ermöglichten. Der nächste Seitenhieb gegen die Ordensvertreter folgte wenig später. Im Frühjahr, wohl im April, war wie schon erwähnt eine unter Leitung des Komturs von Schlochau Johann von Pommersheim stehende, aus zwei adligen Vertretern - darunter dem Rat des Vogtes Borchart von Güntersberg - und zwei Bürgern - einen Bürgermeister von Soldin, einen Ratmannen von Königsberg - bestehende Gesandtschaft an König Sigismund auf dessen Verlangen hin beschlossen, aber wegen der Unsicherheit über seinen deutschen Aufenthaltsort erst im Sommer, wohl im August abgeschickt worden, u.a. zur Erörterung über die Entbindung der Stände von den dem König geleisteten Eid $^{44}$. Die Städte suchten jetzt den Bericht über die Gesprächsergebnisse zu unterbinden, da ein städtisches Gesandtschaftsmitglied, der Königsberger Ratmann Hans Grünitz, in Soldin fehle und nur alle vier Gesandte zusammen aussagten sollten. Das vorgeschobene Argument bezweckte offenkundig, die anzunehmende königliche Ermahnung zur Huldigung an den Orden möglichst zu unterdrücken oder in ihrem Wert herabzusetzen.

Als Mannschaft und Städte über das Verlangen nach der Erbhuldigung berieten, suchten letztere erstere auf ihre Seite zu ziehen, zunächst nur mit mäßigem, schließlich mit gar keinem Erfolg. Denn nur ein Teil des Adels, die gemeynen manne von der ritterschafft, folgte überhaupt dem städtischen Wunsch nach einer internen Verständigung über die Verhandlungslinie gegenüber dem Orden, und als am folgenden Tag wiederum mit Verzögerung die Gespräche mit den Ordensvertreter wiederaufgenommen wurden, versagte sich auch dieser Teil der Ritterschaft der städtischen Position: die stete bleben alleyne ste-

44 OBA 5037 [4] (siehe unten Quellenanhang, Nr. 6), $5422=$ Repertorium, S. 110 Nr. 644, $5456=$ Repertorium, S. 111 Nr. 649. 
hen. Die Städte blieben in der Defensive, weil der bedeutendere Teil des Adels von vornherein sein Entgegenkommen gegenüber dem Orden signalisiert hatte. Des voiths rath und die vornemesten von der manschafft, die nicht in dem rathe woren, hatten sich schnell zur Huldigung bereitgefunden, sofern der Orden ihre Privilegien und Gerechtigkeiten bestätige und ihren den Ordensgesandten übergebenen Entwurf weiterer Artikel annehme. Die ,gemeinen Mannen“ schlossen sich nach den ergebnislosen Beratungen mit den Städten der Haltung der vornehmsten Adligen an, so daß, wie die Ordensvertreter feststellten, die manschafft alsampt bey uns bleyp. Nachdem die Komture die Ausstellung des hochmeisterlichen Privilegs zugesichert hatten, leistete die Ritterschaft die Erbhuldigung. Trotzdem beharrten die Städte zunächst noch auf ihrem Junktim; sie wollten erst huldigen, wenn fünf Artikel ihnen vom Hochmeister mit ewiger Gültigkeit verbrieft worden seien. Während drei von ihnen, die Bestätigung ihrer Gerechtigkeiten und Gewohnheiten, die freie Verwendung von Mühleneinnahmen, die gleichbleibende Höhe der Urbede, akzeptiert wurden, stießen zwei weitere auf entschlossenen Widerspruch der Komture. Die Städte forderten vom Orden, auf den Bau von Schlössern oder anderen Befestigungen in den Städten zu verzichten. Das Ansinnen, den eigenen befestigten Amtssitz innerhalb der Stadtmauern zur Wahrung und Durchsetzung der eigenen Macht aufzugeben, wiesen die Ordensvertreter kurz und knapp zurück mit der Bemerkung, es dünke ihnen nicht wol billich czu sein, das wir nicht unsir lande sulden bauwen, wo es uns und unsirm orden czu notcze und czu fromen komen mochte. Über diesen Punkt schweigt das spätere Privileg vom 29. Dezember gänzlich, der Hochmeister verschloß sich aus verständlichen Gründen dieser städtischen Zumutung vollkommen und war nicht gewillt, auf sein landesherrliches Burgenregal zu verzichten.

Lange Diskussionen entspannen sich über die militärischen Dienste, den eigentlichen Kernpunkt der städtischen Klagen, der bereits zuvor in vorbereitenden Erörterungen einzelner Städte behandelt worden war. So jammerte Landsberg, das seine Forderungen in einem förmlichen, besiegelten Schreiben zusammengefaßt hatte, über die Verluste an Leuten, Pferden und Harnisch und die dadurch erlittenen Schäden auf einem vom Vogt Jost Strupperger (1420-1422) befohlenen Zug außerhalb des Landes, es wünschte sich für solche Unternehmungen eine völlige Gleichstellung mit der Ritterschaft ${ }^{45}$. Auf den Soldiner Verhandlungen lautete die Position der gesamten Städtegruppe genauso: Sie verlangte, im Falle von auswärtigen Kriegszügen, also im Falle von Diensten für die Herrschaft, wie die Ritterschaft vom Orden Verpflegung mit Brot, also Lebensmittel für die Männer, und Futter für die Pferde sowie Schadenersatz zu erhalten. Nach den Beweisen für ihren Standpunkt befragt, wußten ihre Vertreter nicht mehr zu antworten, als das si es bie ern eyden behalden welden, das man en den artikel pflichtig sie czu halden. Die Nachfrage lautete: Habt er ouch edwas andirs me, domit ir dieselbige gerechtigkeit, als er sprechet, beweiszen mogt?, und sie erbrachte so den ausdrücklich eingestandenen Man-

45 GStA PK, XX. HA, OBA 5536 = Repertorium, S. 113 Nr. 660. - Zur Gruppe der landtagsfähigen Städte vgl. Heidenreich (wie Anm. 10), S. 36 f. - Auf einer Landsprache im Januar 1427 hatten die Stände gemeinschaftlich ihre Bereitschaft erklärt, einem landesherrlichen Aufgebot gegen die Hussiten zu folgen, sofern ihnen Zehrung und Schaden ersetzt würden. Ebd., S. 49. 
gel an urkundlichem Beweis, der offenkundig höheren Rang beanspruchen konnte bzw. verlangt wurde, wenn die Auslegung der bestehenden Gewohnheiten zwischen den Parteien strittig war. Die Komture wichen der direkten Konfrontation mit den Städten aus, indem sie die Entscheidung über die unterschiedlichen Standpunkte den (adligen) Räten des neumärkischen Vogtes überließen. Diese waren nicht darüber begeistert, so in die Zwickmühle zwischen die widerstreitenden Parteien versetzt zu werden, wend sprechen sie den stete abe und uns [sc. dem Orden] czu, so hetten sie der stete fintschaft, und sprechen sie uns abe und en czu, so hetten sie unsir ungnade. Aber sie entzogen sich der ihnen übertragenen Verantwortung nicht, sie unterbreiteten den Kompromißvorschlag, allem reysigem geczewge aus den Städten, also allen Berittenen des städtischen Aufgebotes, außerhalb des Landes Brot und Futter zu geben, nicht aber den andern, also dem anderen städtischen Troß ${ }^{46}$. Die Ordensvertreter stellten die Zustimmung des Hochmeisters zu dieser Formel in Aussicht, und nach nochmaliger Rücksprache mit ihren heimischen Gemeinden lenkten die städtischen Vertreter ein und erklärten ihre Bereitschaft zur Huldigung. Das Ergebnis war das bereits eingehend erörterte hochmeisterliche Privileg vom 29. Dezember 1430. Damit schien das Thema Privilegienbestätigung endlich abgeschlossen zu sein ...

Aber es schien wiederum nur so, denn erneut haben wir aus kopialer Urkundenüberlieferung und dazugehörigem Verhandlungsprotokoll eine vorschnelle Schlußfolgerung abgeleitet, anstatt uns von höchster diplomatischer Vorsicht leiten zu lassen. Der Text der Urkundenabschrift im Ordensfolianten 95 paßt zwar inhaltlich genau zu den voraufgegangenen Gesprächen und gibt zweifellos das vom Hochmeister akzeptierte Verhandlungsergebnis in jedem Punkt zutreffend wieder. Aber die korrekte Abschrift einer Urkundenausfertigung in einem Handfestenregister gibt keine Auskunft über einen für ihre Rechtsgültigkeit erheblichen, ja entscheidenden Umstand. Ob die Ausfertigung des hochmeisterlichen Privilegs dem Empfänger übergeben, ihm „,behändigt“ und von ihm angenommen worden ist, läßt sich unserem Registereintrag nicht entnehmen. Nach einem Bericht des neumärkischen Vogtes an den Hochmeister vom Mai $14322^{47}$ hatten die Städte das hochmeisterliche Privileg vom Dezember 1430 immer noch nicht angenommen und ihm nicht zugestimmt, und zwar wegen wegen des entscheidenden Streitpunktes, der Behandlung des städtischen Aufgebotes. Unverdrossen verlangten sie weiterhin, den Artikel über die Versorgung des reisigen Zuges mit Futter und Brot zu streichen zugunsten der Bestimmung, fuder und brot to gevende allen, dy geeschet werden tu folgende ut iuwem lande der Nigen marcken, reysich edder nicht. Auch nach dem verheerenden Hussiteneinfall 1433, von dem die Neumark stark betroffen war ${ }^{48}$, schleppte sich die Angelegenheit noch unge-

46 Es bleibt unerfindlich, warum Heidenreich (wie Anm. 10), S. 80, unter Anführung der eben zitierten Äußerung der Räte ihnen ,,eine bedenkliche Schwäche“ vorhält, wenn sie ,,aus dem Wunsche, es mit keiner Seite zu verderben, überhaupt nicht handelten“. Mit ihrer hübsch zugespitzten Bemerkung verwiesen die Räte auf die grundsätzliche Problematik ihrer Stellung, ohne sich damit ihrer Verantwortung entziehen zu wollen, und handelten anschließend ungesäumt, indem sie den gegenüberstehenden Parteien einen Vergleich anboten.

47 GStA PK, XX. HA, OBA 6083, ediert unten Quellenanhang, Nr. 13.

48 Vgl. Lückerath (wie Anm. 34), S. 148-154, bes. S. 148 f. 
klärt weiter hin, bis sie anscheinend unter dem Druck der ständischen Schadenersatzforderungen, die die Kriegsverluste verursacht hatten und die überhaupt durch die Kriegsfolgen wieder in den Mittelpunkt der Diskussion gerückt waren, endgültig geregelt wurde.

Als der Hochmeister nach den Klagen einer ständischen Gesandtschaft über die erlittenen Kriegsschäden seinen vertrauten Großkomtur Walter Kirschkorb in die Neumark schickte, stieß dessen Verteilung der mitgebrachten Schadenersatzgelder auf heftigen Widerspruch, weil sie nach gunst unde willen sunder mederade unde kantnysse manne unde stede erfolgt sei. Außerdem wiederholten die Stände ihre Beschwerde darüber, daß sie von ihrem Vogt keine Hilfe bekommen könnten, wenn sie aus Polen und Pommern gefangen genommen, beraubt und geplündert würden, und erbaten daher in solcher Situation den unmittelbaren hochmeisterlichen Eingriff. Auf Grund von Unklarheiten über den Kreis der Anspruchsberechtigten veranlaßte der Großkomtur Ritterschaft und Städte zur Rechtsfindung auf einer Landsprache: Beide Stände entschieden, daß jedermann, der unter Gefangenschaft oder sonstige Schädigung gelitten hatte, zu Recht Wiedergutmachung verlangen dürfe, gleichgültig, ob er während des Krieges namentlich zum Kriegszug aufgefordert oder auch ohne ausdrücklichen individuellen Befehl an ihm teilgenommen hatte. In der Erörterung all dieser Probleme des militärischen Schadenersatzes beklagten sich die Städte, wie sie zusammen mit der Ritterschaft dem Hochmeister im November 1434 schrieben $^{49}$, darüber, ihren bryff der erfhuldinge noch nicht erhalten zu haben, und baten um dessen gebührenfreie Aushändigung in der ihnen im November 1430 von den Gebietigern gelobten Form, da sie sonst ihre Steuern und Dienste nicht mehr wie bislang wegen ihres Konfliktes mit ihren Gewerken und Gemeinden entrichten könnten. Die städtische Darlegung kann wohl nicht anders gedeutet werden, als daß die Stadträte bis dahin trotz ihrer Zusage vom 30. November 1430 den Empfang des hochmeisterlichen Privilegs verweigert hatten, jetzt aber unter dem Druck ihrer Gewerke und der gesamten Bürgerschaft, die vielleicht wenigstens die vorliegenden Zugeständnisse des Landesherren in Bezug auf Schadenersatzleistungen gesichert wissen und diese zur Erleichterung ihrer Belastungen beanspruchen wollten, zum Einlenken bereit waren. Ob Paul von Rusdorf ihrem vom neumärkischen Vogt unterstützten Wunsch folgte, ist den Quellen des Ordensarchivs oder anderer heutiger archivalischer Bestände ausdrücklich nicht zu entnehmen. Die Ausfertigung seines Privilegs für die neumärkischen Städte vom 29. Dezember 1430 wurde jedenfalls bis 1945 im Stadtarchiv Königsberg/Neumark verwahrt und stimmte, wie die Editionen Riedels und Klinkenborgs beweisen, weitestgehend wörtlich und vollständig, von ganz geringfügigen, inhaltlich zu vernachlässigenden Unterschieden ${ }^{50} \mathrm{ab}-$ gesehen, mit der eben zitierten abschriftlichen Fassung im Handfestenregister des Hochmeisters überein. Danach ist zu vermuten, daß Paul von Rusdorf nach dem städtischen

49 GStA PK, XX. HA, OBA 6904, ediert unten Quellenanhang, Nr. 14.

50 Solche geringfügige Unterschiede zwischen der Ausfertigung und einer (wohl nach dem Entwurf angefertigten) Abschrift sind üblich und keineswegs verwunderlich; wie die Anmerkungen h), 1) und insbesondere n) (mit der sicherlich aus Versehen unterbliebenen Anführung des Obersten Marschalls in der Aufzählung der Großgebietiger in der Zeugenreihe) zeigen, hat die Ausfertigung an wenigen Stellen Versehen ihrer Abschrift korrigiert und bietet daher hier den besseren Text. 
Meinungswandel seine Urkunde den Empfängern endlich ausgehändigt und daß sie durch ihre Annahme endgültig Rechtskraft erlangt hat. Daß der später wiederholt so bezeichnete „Landbrief“ Rusdorfs allgemein anerkannte Gültigkeit gewonnen hat, geht eindeutig daraus hervor, daß sich die Parteien das ganze nachfolgende 15. Jahrhundert hindurch in Briefen und Urkunden ausdrücklich auf ihn bezogen und beriefen und seine Bestimmungen vollständig oder teilweise wiederholten und bekräftigten.

Nach der ersten „Erbhuldigung“ vom November 1430 - erst nach Sigismunds Verzicht von 1429 konnten die Beteiligten rechtlich unanfechtbar davon ausgehen, daß die Herrschaft über die Neumark auf unbegrenzte Dauer beim damaligen Hochmeister und seinen Nachfolgern und Erben liegen werde - ist das Rusdorfsche Privileg bis zum Ende der Ordensherrschaft 1454 trotz zweimaliger Wechsel im Hochmeisteramt durch keine andere Privilegienbestätigung ersetzt worden. Ob es 1441 von Rusdorfs Nachfolger Konrad von Erlichshausen (1441-1449) erneuert worden ist und/oder Gegenstand von Verhandlungen zwischen Ständen und Landesherrschaft war, bleibt mangels eindeutig verwertbarer Quellen im Dunkeln. Es ist nur die Eidesformel überliefert, mit der die Neumärker Hochmeister Konrad von Erlichshausen, dem an seiner Statt bevollmächtigten Vogt und dem ganzen Orden getreu und untertan zu sein, seinen Schaden abzuwehren und die einem rechten Herrn schuldige Treue zu leisten geloben und schwören sollten ${ }^{51}$. Der Text zeigt, daß es in der Neumark eine Debatte, die denen zwischen dem Orden und den preuBischen Ständen von 1441 und 1450 über den Wortlaut des Huldigungseides gliche oder auch nur ähnelte, nicht gegeben hat. Während die preußischen Stände die Verpflichtung auf die Ordenskorporation am liebsten beseitigt und sich nach dem ordensinternen Konflikt der späten 1430er Jahre nur noch dem Hochmeister verbunden hätten, bestand für die neumärkischen Stände kein Grund, die Reihung von Hochmeister, neumärkischem Vogt, der das Ordensoberhaupt ständig im Lande vertrat, und ganzem Orden, dem Hochmeister und Vogt entstammten, in Frage zu stellen; die preußische Verfassungsdiskussion, die

51 GStA PK, XX. HA, Ordensfoliant 18, S. 32, ediert unten Quellenanhang, Nr. 15. - Riedel druckt im CDB II 3, S. 154 f., den von den Wedels zu Neuwedel und Falkenburg sowie den Bewohnern von Arnswalde dem Hochmeister Paul von Rusdorf geleisteten Huldigungseid ab, ohne Aufhellung der Überlieferungslage und ohne Datierungsversuch. Die Eidesformel deckt sich teilweise mit der von 1441, teilweise erweitert sie sie um zusätzliche, die Verpflichtungen des Eidesleistenden noch stärker betonende Formulierungen; sie dürfte für die Huldigungen von 1431 und später gebraucht worden sein. In der folgenden Wiedergabe von Riedels Textabdruck sind die Übereinstimmungen mit der Formel für Konrad von Erlichshausen durch Unterstreichungen markiert: Ich gloube und swere dem erwirdigen hern hern Pauel von Ruszdorff, homeister Dewtsches ordens, meynem rechten erbherrn, allen seynen gebietigern, dortzu euwirn gantzen orden und euwirn nachkomelingen, auch euch here voithe der Newenmarke und kumpthur czu Slochow, in seyner stadt volmechtiget, getrewe, hold und gehorsam tzzu seinde, euwir beste zu beweisen, euwern schaden tzu wenden nach meynem hogsten vermogen, von euch nymmer zu tretende, es sie denne, das ich von euch adder euwern nachkomelingen mit hande und munde wurde verlassen und verweiset, als eyn itzclich undertenige fromer man pflichtig ist tzu thunde seynem rechten erbherren, als mir Goth helffe und die Heiligen. Zur politischen Lage der Neumark in der Regierungszeit Konrads von Erlichshausen vgl. die ausführliche Darstellung von Klaus Eberhard Murawski: Zwischen Tannenberg und Thorn. Die Geschichte des Deutschen Ordens unter dem Hochmeister Konrad von Erlichshausen 1441-1449. Göttingen 1953, S. 136-153 (= Göttinger Bausteine zur Geschichtswissenschaft, 10/11). 
von ganz anderen politischen und rechtlichen Voraussetzungen ausging, blieb für sie bedeutungs- und vorbildlos. Für den Herrschaftsübergang von Konrad zu Ludwig von Erlichshausen (1450-1467) 1450 liegen dann aussagekräftigere Zeugnisse als für den Herrschaftswechsel 1441 vor. Ritterschaft und Städte beklagten sich 1450 nicht mehr über die Bestimmungen des Landbriefes, sondern darüber, daß diese ihnen nicht eingehalten worden seien. Der neue Hochmeister Ludwig von Erlichshausen hatte Anfang November 1450 zwei Gebietiger, den neuen Vogt Christoph Eglinger (1450-1455) und den Komtur von Schlochau Johann Rabe, in die Neumark entsandt und sie bevollmächtigt, in seinem Namen und an seiner Statt von Ritterschaft, Städten und allen sonstigen Untertanen - genauer gesagt: von den edlen und gestrengen rittern, knechten, mannen und den vorsichtigen burgermeistern, rathmannen und den gemeynen unsir stete und sust gemeyniglichen allen unsern und unsirs odens undirsassen unsir Neuwenmarcke - die Huldigung zu empfangen, zu der sie nach alter guter Gewohnheit und Gebühr verpflichtet seien ${ }^{52}$. Die hochmeisterliche Forderung stieß auf den deutlich artikulierten Widerwillen der Stände. Sie verwiesen insbesondere darauf, daß ihnen entgegen dem Wortlaut des Landbriefes ihr Schaden, den sie oftmals durch Auslösung aus Gefängnishaft und Verlust von Pferden erlitten hätten, nicht erstattet worden sei, ebenso wenig wie die ihnen von den Vögten geschuldeten Beträge. Die alten Kritikpunkte, die bereits nach 1410 aufgetaucht waren, bestanden fort, weil zumindest nach der ständischen Darstellung der Orden die wiederholten, schließlich 1430 verbrieften Versprechungen mißachtet und übergangen hatte. So mußten die Ordensgebietiger in ihrem Bericht an den Hochmeister festellen, das dy lant und stete swer woren czur holdigunge ${ }^{53}$. Aus der Formulierung wird man aber wohl schließen dürfen, daß letztlich trotz der Bedenken Ritterschaft und Städte den hochmeisterlichen Vertretern gehuldigt haben ${ }^{54}$.

52 GStA PK, XX. HA, Ordensfoliant 17, S. 571 (Vollmacht der beiden Gesandten), ediert unten Quellenanhang, Nr. 16, und OBA 10418 (Instruktion der Gesandten), ediert unten Quellenanhang, Nr. 17.

53 GStA PK, XX. HA, OBA 10466, siehe unten Quellenanhang, Nr. 18 [6].

54 ROT I/1/2, Nr. 10483, erwähnt die Eidesformel der Neumark für Hochmeister Ludwig von Erlichshausen aus dem Jahr 1450; die betreffende Archivalieneinheit GStA PK, XX. HA, OBA 10483 (= Repertorium, S. 220 Nr. 1325), die sich heutzutage aus vier älteren ursprünglich selbständigen Archivalieneinheiten zusammensetzt, wie deren Altsignaturen zu entnehmen ist, enthält auch einen von Johannes Voigt angefertigten Regestenzettel: „Eidesformel, nach welcher die Neumark dem Hochmeister Ludwig von Erlichshausen die Huldigung leistet“. Aber unter den 25 Eidesformularen, die jetzt in OBA 10483 vereinigt sind (ohne daß noch die früheren Archivalieneinheiten, aus denen sie entnommen sind, erkennbar wären), ist keine eindeutig auf die Neumark zu beziehen; viele Textentwürfe lassen hingegen sichtbar werden, daß sie der Diskussion zwischen dem Orden und den preußischen Ständen um die genaue Formulierung des Huldigungseides entstammen. Man wird vermuten dürfen, daß die Neumärker 1450 dieselbe Eidesformel wie die von 1441 (siehe oben S. 267 mit Anm. 51) gebrauchten, da die verfassungsrechtlichen Voraussetzungen sich seitdem nicht geändert hatten. 
Wenige Jahre später bereitete der Aufstand des Preußischen Bundes und der Ausbruch des Krieges mit Polen der Ordensherrschaft in der Neumark ein rasches Ende ${ }^{55}$. Als der vom Hochmeister bevollmächtigte Landkomtur zu Sachsen Friedrich von Polenz am 22. Februar 1454 Kurfürst Friedrich II. von Brandenburg (1440-1470) das Land für 40.000 rheinische Gulden unter dem Vorbehalt des Wiederkaufsrechts verkaufte, räumte er ihm dabei auch die Befugnis ein, die Huldigung zu empfangen ${ }^{56}$. Ritterschaft und Städte huldigten dem Kurfürsten im März und April 1454 mit einer vorgegebenen Formel ${ }^{57}$. In diesem Zusammenhang bestätigte Friedrich II. am 7. und 8. April 1454 zu Landsberg die ständischen Privilegien in zwei gesonderten, getrennt für Ritterschaft und Städte ausgefertigten, von ihm besiegelten, aber Zeugenreihen ermangelnden Urkunden, in Anlehnung an den Landbrief von 1430 und unter seiner Verwendung, aber mit bezeichnenden Abwandlungen ${ }^{58}$. Beide Urkunden erwähnen übereinstimmend die von der Ritterschaft bzw. den Städten dem Kurfürsten geleistete „Pfandhuldigung“, die, wie hinzufügt wird,

55 Zum äußeren Ereignisablauf vgl. Schultze (wie Anm. 1), S. 76-80.

56 Erich Weise (Hg.): Die Staatsverträge des Deutschen Ordens in Preußen im 15. Jahrhundert, Bd. II (1438-1467). Marburg 1955, S. 113 Nr. 287.

57 Erwähnt in der Nachbemerkung zu Staatsverträge II (wie Anm. 56), S. 113 Nr. 287.

58 Gedruckt: Das neumärkische Ständearchiv (wie Anm. 6), S. 171 Nr. 8 (1454 April 7, ritterschaftliche Ausfertigung), S. 172 Nr. 9 (1454 April 8, städtische Ausfertigung). Die Urkundeneditionen werden von dem Herausgeber Klinkenborg mit den Kopfregesten „Kurfürst Friedrich II. bestätigt die Rechte der Neumärkischen Stände“ bzw. ,... die Recht der neumärkischen Städte“ eingeleitet, womit die unterschiedlichen Empfänger beider Diplome nicht zutreffend benannt sind. Die städtische Ausfertigung wird im Urkundenbestand des Stadtarchivs Landsberg/Warthe (heute im Staatsarchiv Gorzów Wlkp.) aufbewahrt; die ritterschaftliche Ausfertigung ist verlorengegangen, sie ist abgedruckt nach einer Registerüberlieferung des Ausstellers im GStA PK, I. HA Rep. 78 Kurmärkische Lehnskanzlei. - Die Abhängigkeiten der beiden Urkunden von Vorurkunden sind nicht in allen Einzelheiten von Klinkenborg korrekt wiedergegeben. In der städtischen Ausfertigung ist die Formulierung also haben wir angesehen leipliche zuneyggung (S. 171, Z. 13/14 v.u.) ebenfalls Rusdorfs Landbrief vom 29. Dezember 1430 entnommen, während infolge Änderung der sachlichen Verhältnisse die Formulierung unnser kantzler, unnser schreiber (S. 172, Z. 14/15 v.o.) neu hinzugefügt worden ist. Die Bestimmung von 1430 zur Übernahme von ritterschaftlichen Schadenersatzforderungen durch den Hochmeister anstelle des überanstrengten Vogtes ist 1454 wegen der anderen Verwaltungsstrukturen gänzlich gestrichen worden. Andere, belanglose Abweichungen können hier vernachlässigt werden. Daß die städtische Ausfertigung, wie Klinkenborg bemerkt, ,stärkere Anklänge an frühere Urkunden“ aufweise, ,ohne daß eine direkt als Vorurkunde gedient hätte“, kann ich nicht finden; auch hier hat der Landbrief Rusdorfs, wie der Vergleich zwischen seinem Abschnitt [2] und der ersten Hälfte der Dispositio von 1454 zeigt, als Vorlage gedient. Allerdings sind im Gegensatz zur ritterschaftlichen Ausfertigung die Festlegungen zum militärischen Aufgebot nicht wörtlich wiederholt, sondern der Kurfürst bestätigt pauschal die älteren Freiheiten und Gewohnheiten der Städte sowie besonders den ihnen vom Hochmeister übergebenen Landbrief und fügt mit teilweise übernommenen, teilweise neu formulierten und sachlich ergänzten Aussagen Bestimmungen über Privilegienerneuerungen hin (vgl. oben im Haupttext). - Eine in der Überlieferung des brandenburgischen Geheimen Rates befindliche, der Schrift nach aus dem 15. Jahrhundert stammende Abschrift des Rusdorfschen Landbriefes (GStA PK, I. HA, Rep. 42, Nr. 3) belegt, daß sich die kurfürstlichen Kanzlei 1454 oder bei einer späteren Privilegienerneuerung den Text des Privilegs von 1430 für ihre eigenen Zwecke gesichert hat. 
ihr Ende findet, wenn der Hochmeister die Pfandsumme zurückzahlt, denn dann wird der Kurfürst Prälaten, Herren, Mannen und Städte ihrer Eide entbinden und Schlösser und Städte dem Orden wieder einräumen. Für die Privilegienbestätigung der Ritterschaft übernahm Friedrich weitestgehend den Wortlaut des Rusdorfschen Privilegs, die geringfügigen Änderungen in der Dispositio ergeben sich zwangsläufig aus den neuen Herrschaftsverhältnissen und beeinträchtigen in keiner Weise den Umstand, daß die materiellen Regelungen von 1430 vollständig und unverändert bestätigt werden. Die Urkunde für die Städte ist in ihrem Wortlaut trotz einiger Übernahmen aus der Urkunde Rusdorfs stärker neu konzipiert worden. Der Kurfürst bestätigt Bürgermeistern, Ratmannen und allen Bürgern der neumärkischen Städte all ihre Freiheiten, Gerechtigkeiten und Gewohnheiten, und er sichert ihnen zu, alle ihre von früheren Herren einschließlich von Hochmeistern und deren Vögten ausgestellten Urkunden, insbesondere den den Städten gegebenen Landbrief, einzuhalten. Er will ihnen alle ihre zuvor innegehabten Lehen, Erben und Eigen belassen, so daß in Ergänzung zu 1430 der städtische Lehens- und Allodialbesitz ausdrücklich bestätigt wird. Und er will verlorengegangene Urkunden unter Nachweis ihres Gebrauches und ohne eine Gabe an die Herrschaft, aber gegen eine Schreibergebühr von 12 Groschen erneuern, so daß die Kanzleitaxe, die 1430 nur für die Ritterschaft festgelegt worden war, jetzt auch auf die Städte übertragen wird und ihre Begrenzung auch ihnen zugute kommt.

Im Jahre 1455 wurde die Abtretung der Neumark an Brandenburg juristisch vollendet und in diesem Zusammenhang auch wiederholt der ständischen Huldigung gedacht, damit alle Neumärker ausdrücklich ohne die Möglichkeit zur Benutzung eines rechtlichen Schlupfloches den Herrschaftswechsel für sich annahmen. Als Abgesandte des Hochmeisters am 14. Januar 1455 mit Friedrich II. dessen Zug nach Schivelbein und weiter nach Marienburg zur Vermittlung zwischen dem Deutschen Orden und seinen Feinden vereinbarten, beschlossen sie u.a., daß nach dessen Rückreise die Mannschaft in der Neumark an ihn zur Huldigung, sofern diese noch nicht geschehen sei, verwiesen werde ${ }^{59}$. Am 12. August 1455 dehnte der Hochmeister die Huldigung ausdrücklich auf Driesen und auf Vogtei und Stadt Schivelbein, die - außerhalb der neumärkischen Pfandschaft vom Orden erworben - besonderer Abmachungen bedurften, aus ${ }^{60}$. Als er selbst am 19. September 1455 zu Mewe die Abtretung der Neumark einschließlich der Schlösser Driesen und Schivelbein (nebst der Stadt Schivelbein) unter den im einzelnen beschriebenen Bedingungen beurkundete, wurden die Pflichten der Stände einbezogen. Die Stände und sonstige Untertanen sollten vom Orden entlassen und an den Kurfürsten und seine Erben als natürliche Erbherrschaft bis zum etwaigen Wiederkauf verwiesen werden, sobald der Kurfürst und seine drei Brüder innerhalb eines halben Jahres ihre Ratifikationsurkunden dem Hochmeister ausgehändigt hätten. Falls der Orden die Neumark wiederkaufe, waren

59 Staatsverträge II (wie Anm. 56), S. 182 Nr. 332, § 7. - Vgl. ferner die dementsprechende Werbung eines kurfürstlichen Gesandten an den Hochmeister vom 17. Juni 1455, Repertorium (wie Anm. 4), S. 250 Nr. 1509.

60 Staatsverträge II (wie Anm. 56), Nachbemerkung zu Nr. 332, S. 183. 
die Stände gehalten, ihm erneut die Erbhuldigung zu leisten ${ }^{61}$. Ludwig von Erlichshausen wartete jedoch die brandenburgische Ratifikationsurkunde zur Ausstellung seiner Entlassungsurkunde gar nicht ab, noch am selben Tage entband er die Stände und alle Untertanen der Neumark von Eid und Erbhuldigung und verwies sie an Kurfürst Friedrich II. von Brandenburg und seine Erben als nunmehrige Erbherrschaft, der sie die Erbhuldigung zu leisten hätten ${ }^{62}$. Friedrich achtete sorgsam auf die umfassende, vollständige Verweisung der Stände an die neue Herrschaft. Am 16. Oktober 1455 bat er den Hochmeister wieder um Vollmacht wegen Entlassung aller Vasallen der Neumark, ob noch irgen keine man oder undersassen in der Neuwen Margk noch nicht gehuldet hetten. Er begründete sein Gesuch zwei Tage später mit den Schwierigkeiten bei der Übergabe von Driesen, so daß der Hochmeister am 21. Oktober seinen Kommissaren entsprechende Vollmachten gewährte und schließlich noch am 17. September 1456 eine besondere endgültige Entlassung für Driesen und Schievelbein verfügte ${ }^{63}$. Genauso wie die hochmeisterliche Kanzlei 1402/03, so war auch die kurfürstliche Kanzlei 1454/55 darum bemüht, die huldigenden Neumärker zur Gewinnung einer Übersicht über die neumärkischen Verhältnisse, insbesondere die Personalverhältnisse namentlich zu erfassen; eine überlieferte Liste, die bislang allerdings nur unzureichend und fehlerhaft ediert worden ist, nennt fast 70 erbarn man in der Nuwenmarck uber Oder, die gehuldiget haben ${ }^{64}$.

Es scheint so, als ob den Ständen die kurfürstlichen Privilegienbestätigungen von 1454, die im Rahmen einer raschen Besitznahme ausgestellt worden waren, auf Dauer nicht ausgereicht hätten und von ihnen zur unverbrüchlichen Sicherung ihrer althergebrachten Rechte als formal unzureichend erachtet worden seien. Denn am 31. Mai 1461 legten die Stände dem Kurfürsten zu Soldin Rusdorfs Privileg vor und baten ihn um dessen Bestätigung. Friedrich II. kam ihrem Gesuch nach, indem er die Vorlage vollständig inserierte, sie befestigte und ihre ewige Einhaltung ohne Abschwächung oder „Kränkung“ zusicherte. Seine jetzige Urkunde war mit einer langen Zeugenreihe von angesehenen und hochrangigen 22 Personen, die vom Kanzler, Bischof Friedrich Sesselmann von Lebus, Bischof Dietrich Stechow von Brandenburg, Graf Friedrich von Orlamünde, Graf Gottfried von Hohenlohe, Graf Jakob von Lindow-Ruppin über die Herren von Zossen, Sonnewalde, Schenkendorf bis zum Obermarschalk, Kammermeister, den Landvögten in der Uckermark und zu Cölln sowie zum adligen Hofgesinde reichte, versehen. Zugleich war an die Urkunde das große Siegel des Kurfürsten gehängt. Zeugenreihe und Besiegelung geben der Privilegienbestätigung von 1461 verglichen mit der von 1454 einen repräsentativeren Rang, ohne die Inhalt substantiell irgendwie zu verändern. Darin mag der ständische Antrieb zu ihrer Ausfertigung gelegen haben. Umgekehrt benutzte der Kurfürst die Narratio dazu, die kurmärkische bzw. hohenzollernsche Interpretation der neumärkischen

61 Ebd., S. 183 Nr. 333, §§ 3, 6.

62 Ebd., S. 184 Nr. 334.

63 Ebd., Nachbemerkung zu Nr. 334, S. 185.

64 CDB I 24, S. 161 Nr. 217; vgl. die kurze Beschreibung bei Christian Gahlbeck: Zisterzienser und Zisterzienserinnen in der Neumark. Berlin 2002, S. 894 mit Anm. 1 (dort der archivalische Quellennachweis) (= Veröffentlichungen des Brandenbugischen Landeshauptarchivs, 47). 
Abtrennung von der Mark Brandenburg, auf der die hohenzollernschen Revindikationsforderungen beruht hatten, darzulegen und damit gewissermaßen gegenüber den Empfängern rechtsverbindlich zu erklären. Nachdem die Neumark erblich zum Kurfürstentum bzw. zur Markgrafschaft Brandenburg gehört habe und durch etliche weise semliche iare an den Dewtschen orden gekomen was, sei sie wegen der Zuneigung und Treue ihrer Prälaten, Herren, Mannen und Städte zu ihm, Kurfürsten Friedrich II., und mit Willen und Zustimmung des Hochmeisters Ludwig von Erlichshausen und seiner Gebietiger erblichen widder an uns und unser herschaft, die marggrafschaft zcu Branburg, heymkomen. In vergangenen Zeiten sei den Ständen von Hochmeister Paul von Rusdorf, dem sie zu dem male zustunden und verpflicht waren, ein Landbrief gegeben worden, den zu bestätigen die Stände ihn als iren rechten naturlichen erbherren gebeten hätten ${ }^{65}$. Die erbliche, somit dauerhafte Zugehörigkeit der Neumark zur Markgrafschaft Brandenburg wird herausgestrichen, die Unterstellung unter die Ordensherrschaft zwar nicht gerade als rechtswidrig hingestellt - was die kurfürstliche Bestätigung eines hochmeisterlichen Privilegs für die neumärkischen Stände rechtlich zumindest zweifelhaft gemacht hätte -, aber doch mit nebulösen Wortwendungen ohne klare Beschreibung der damalige Rechtsgrundlage des Ordens bedacht. Die hohenzollernsche Herrschaft über die Neumark gründet sich jedenfalls in der Eigendarstellung auf den kurfürstlichen Erbanspruch auf einen Teil der Mark Brandenburg, die genaue Rechtsgrundlage der „Wiedergewinnung“ der Neumark 1454, die Pfandschaft bzw. der Kauf auf Wiederkauf, die einschränkende Pfandhuldigung und die mögliche Entbindung der Stände aus der brandenburgischen Huldigung werden gar nicht mehr erwähnt. Die Pfandherrschaft wurde so nach außen hin, gegenüber den Ständen zugunsten der Erbherrschaft unterdrückt - der Weg in die weitere staatsrechtliche Zukunft der Neumark war vorgezeichnet.

Freilich stellte Friedrich II. das Rückkaufrecht des Ordens grundsätzlich selbst dann nicht in Zweifel, als das dem Orden verbliebene (Rest-)Preußen durch den II. Thorner Frieden von 1466 der Schutzherrschaft des Königs von Polen unterstellt war und der Kurfürst daher mit der Gefahr rechnete, der Hochmeister könne einmal in einem künftigen Konflikt mit Brandenburg seine Anrechte auf die Neumark dem König von Polen abtreten und das Land könne dann von diesem beansprucht werden. Friedrich wies in einer internen Instruktion für seine Nachfolger darauf hin, daß nach den Abmachungen allein der Orden zum Wiederkauf berechtigt sei; auf diese Bestimmung solle man sich nötigenfalls stützen, damit die Neumark by deutschen landen unnd dem heilgen romischen reich und by dem wirdigen kurfurstenthumb der marg zu Brandburg, der es by ansetzung der kure ingeleibet ist, blibe und nicht in undeutsch gezunge gebracht wurde ${ }^{66}$.

65 Das neumärkische Ständearchiv (wie Anm. 6), S. 174 f. Nr. 10; CDB I 24, S. 181 f. Nr. 236. Beide Editionen beruhten auf der Urkundenausfertigung im Stadtarchiv Königsberg/Neumark, was vermuten läßt, daß es sich um die städtische Ausfertigung handelte und die zu vermutende ritterschaftliche wegen fehlenden sicheren Aufbewahrungsortes verloren gegangen ist.

66 Das Neumärkische Ständearchiv (wie Anm. 6), S. 3 f., Zitat S. 4. - Daß Schultze (wie Anm. 1), S. 80, dem Kurfürsten auf Grund des zitierten Zeugnisses ,die tiefe Sorge ... um die Erhaltung des Deutschtums im Osten“ zuspricht und ihn ,als deutsche[n] Grenzwächter gegenüber dem Polenreich“ sieht, zeugt zwar in dieser Ausdrucksweise vom Nationalitäten- und Grenzkampf der Zwi- 
Nachdem Markgraf Albrecht Achilles (1470-1486) im April 1470 die Nachfolge seines abgedankten Bruders Friedrich II. angetreten hatte ${ }^{67}$, reiste er von seinen fränkischen Landen nicht sogleich in die Mark, sondern beauftragte Mitte Mai die von ihm bestellten Statthalter, seinen Sohn, Markgraf Johann - den späteren Kurfürsten Johann Cicero -, und mehrere vertraute Ratgeber, die Huldigung der Märker zu fordern und einzuholen und ihnen, wenn sie erfolgt sei, ihre Freiheiten zu bestätigen. Die Formel des Huldigungseides fügte er ihren Instruktionen bei: Wir huldigen, globen und sweren dem Markgrafen Albrecht zu Brandenburg etc. ein rechte erbhuldigung, als unserm rechten, naturlichen erbherrn, getreu, holt, gewertig und gehorsam ze sein, iren fromen zu werben und iren schaden zu wenden und alles das zu thon, das wir in als unsern rechten, naturlichen erbherrn zu thund pflichtig sind ${ }^{68}$. Es ist nun bezeichnend für die innere politische Gliederung der Mark Brandenburg, daß die Verhandlungen der Statthalter mit den Ständen über die Huldigung und die anschließende Huldigung selbst getrennt für Alt- und Mittelmark einerseits, die Neumark andererseits stattfanden. Das gesonderte politische Schicksal der Neumark, also ihre über ein halbes Jahrhundert andauernde Trennung von Alt- und Mittelmark führte dazu, daß die Neumärker anläßlich des ersten Herrscherwechsels nach der Wiedervereinigung allein und nicht zusammen mit den Alt- und Mittelmärkern die landesherrlichen Abgesandten im eigenen Lande empfingen, dort mit ihnen die Huldigung erörterten und ihnen leisteten. Nachdem Anfang Juni 1470 die Stände aus der Mittelmark, der Uckermark, dem Land Sternberg, aus der Altmark und der Prignitz auf einem Landtag zu Berlin gegen Erfüllung billiger Wünsche die Huldigung in Aussicht gestellt hatten, wenn Albrecht im Lande erscheine ${ }^{69}$, traten gänzlich unabhängig von ihnen Prälaten, Ritterschaft, Mannschaft und Städte der Neumark am 15. Juli 1470 zu Soldin zur Abstimmung ihres Verhaltens gegenüber dem neuen Herrn zusammen. Prälaten, Ritter und Mannen einerseits, die Städte andererseits versprachen sich gegenseitig ein gemeinsames Auftreten in den anstehenden politischen Angelegenheiten, nämlich in Bezug auf die Huldigung, den Lehnsempfang, die Steuerforderungen und die Verfolgung von Friedensbrechern ${ }^{70}$.

schenkriegszeit, aber die Äußerungen Friedrichs II. (vgl. weitere, ebd., S. 80 mit Anm. 73, zitierte) belegen, wie gegenüber manchen „,a-nationalen“ Interpretationsansätzen unserer eigenen Gegenwart festzuhalten ist, sein politisches Selbstbewußtsein als Angehöriger der „deutschen Nation“, der nicht „,deutsche Lande“ der Herrschaft anderer Nationen unterstellt sehen mochte.

67 Vgl. zu den Umständen des Regierungsantritts und der Huldigung Schultze (wie Anm. 1), S. 109 f., $113-117$.

68 Felix Priebatsch (Hg.): Politische Correspondenz des Kurfürsten Albrecht Achilles, Bd. 1: 1470-1474. Leipzig 1894, Nr. S. 121 Nr. 40, S. 125 Nr. 44, S. 128 Nr. 51, S. 131 Nr. 52 (daraus das Zitat) (= Publikationen aus den k. Preußischen Staatsarchiven, 59). - Zu den Vorgängen um die Huldigung 1470 vgl. auch die kurze Darstellung Priebatschs in der Einleitung seiner Edition, S. $14-16$.

69 Ebd., S. 136 Nr. 55.

70 CDB III 1, S. 535 Nr. 382. Vgl. auch: Heinz-Dieter Heimann, Klaus Neitmann, Winfried Schich u. a. (Hg.): Brandenburgisches Klosterbuch. Handbuch der Klöster, Stifte und Kommenden bis zur Mitte des 16. Jahrhunderts, Bd. 1. Berlin-Brandenburg 2007, S. 628 (Beteiligung des Zisterzienserklosters Himmelstädt am Bund der neumärkischen Stände) (= Brandenburgische Historische Studien, 14). 
Das nach der kurfürstlichen Instruktion zu erwartende konziliante Auftreten der kurfürstlichen Vertreter, an der Spitze Markgraf Johann, hat offensichtlich auf dem neumärkischen Ständetag am 29./30. Juli 1470 in Soldin schärfere Kontroversen verhindert und eine rasche Einigung ermöglicht. Während die Städte nur in allgemeiner Form landesherrliche Hilfe und Beistand erbaten, beklagte der Adel wieder einmal seine in den friedlosen Zeiten entstandenen Verluste und mahnte den Ersatz seiner Kriegsschäden - seiner verbrannten Häuser und seiner Kriegsgefangenschaften - an: die edelleut haben vil schadens erlitten, ganz außgeprant, gefangen in gefencknus verzert, den schaden bitten sie alle. Aber die Wiederholung der Privilegienbestätigung Friedrichs II. reichte nach einigen Debatten zur Besänftigung der oppositionellen Wortführer aus: nach vil reden, zwitrachten und anfellen, wann das land an vil orten vast durch die kriegslouft beschedigt ist, haben wir das land am montag nach Jacobi [1470 Juli 30] eingenomen, d.h. 100 Edelleute huldigten sogleich auf dem Tag Markgraf Johann anstatt des abwesenden Kurfürsten. Die kurfürstlichen Räte rechneten außerdem im Land noch mit 300 Edelleuten, die von ihren Abgesandten zu geeigneten Orten bestellt und dort die Huldigung leisten sollten. Die Städte sagten auf dem Tag zu, den mit Beglaubigungsschreiben ausgestatteten landesherrlichen Vertretern zu huldigen, wenn diese in ihren Mauern erschienen und sie dazu aufforderten. Markgraf Johann nahm noch am 30. Juni die Huldigung in Soldin auf einem offenen Platz und am folgenden Tag die in Küstrin entgegen und entsandte bevollmächtigte Räte in die anderen Städte zum selben Zweck ${ }^{71}$. Die landesherrliche Bestätigung der ständischen Privilegien wurde im Namen des Kurfürsten Albrecht zu Soldin am 30. Juli ausgefertigt ${ }^{72}$. In ihrer Dispositio griff sie weitgehend auf die städtische Privilegienbestätigung vom 8. April 1454 zurück, benutzte also die Formulierungen, die die Freiheiten, Gerechtigkeiten und Gewohnheiten von Prälaten, Ritterschaft und Städten sowie die von den Hochmeistern und ihren Vögten gegebenen Briefe, darunter den hochmeisterlichen Landbrief, und die von Friedrich einzeln oder allgemein ausgestellte Briefe ohne nähere Beschreibung einzelner konkreter Bestimmungen bestätigten - übrigens unter Verzicht auf den Passus über die Schreibergebühr anläßlich von Privilegienerneuerungen. Die überlieferte Ausfertigung liegt im Stadtarchiv Landsberg, ist also wohl das für die Städte bestimmte Exemplar. Der Wortlaut spricht dafür, daß die Ritterschaft keine inhaltlich abweichende Ausfertigung erhalten hat; darauf deutet hin, daß der dem lande gegebene hochmeisterliche Landbrief berührt wird, während die Vorurkunde an dieser Stelle von den den steten gegebenen Landbrief sprach. Ein wörtlich gleichlautendes zweites Exemplar mag die Ritterschaft vom Markgrafen erhalten haben. Als Kurfürst Albrecht zum ersten Mal als neuer Landesherr im Anfang November 1471 persönlich in der Mark erschien, zog er anschließend zur Entgegennahme der Huldigung von Berlin über die Altmark und die Prignitz in die Uckermark, verzichtete aber auf den Besuch der Neumark, da Markgraf Johann dort schon im Vorjahr die Huldigung erhalten hatte ${ }^{73}$.

71 Politische Correspondenz Albrechts (wie Anm. 68), S. 157 Nr. 75, hier S. 160 f.

72 Das neumärkische Ständearchiv (wie Anm. 6), S. 175 Nr. 11.

73 Politische Correspondenz Albrechts (wie Anm. 68), S. 296 Nr. 259. 
Unter Albrechts Nachfolger, seinem Sohn Johann Cicero (1486-1499), erlebte der Landbrief noch einmal eine stärkere, ausdrückliche Wiederbelebung. Am 6. September 1491 bestätigte der Kurfürst zu Cölln an der Spree die Privilegien der neumärkischen Stände in der Weise, daß er unverändert die Urkunde Friedrichs II. vom 31. Mai 1461 mit deren Insertion des Landbriefes Rusdorfs wiederholte. Ebenso wie 1461 wurde 1491 die Privilegienbestätigung formvollendet und repräsentativ gestaltet, wiederum mit einer langen Zeugenreihe von 14 Personen, darunter den Bischöfen von Havelberg und Lebus, dem Herrenmeister der Ballei Brandenburg des Johanniterordens, Graf Johann von Lindow-Ruppin und den höchsten Hofbeamten, versehen und mit dem großen kurfürstlichen Siegel ausgestattet ${ }^{74}$. Damit reißt die Nachwirkung des hochmeisterlichen Privilegs von $1430 \mathrm{ab}$. Im zweiten Jahrzehnt des 16. Jahrhunderts war die Ordenszugehörigkeit der Neumark im Bewußtsein der handelnden Politiker bereits so sehr in eine weit entfernte Vergangenheit entrückt, daß der streng verfassungsrechtlich betrachtet allein auf die Pfandschaft gegründete brandenburgische Besitz des Landes längst als unumstößlich galt. Als Hochmeister Albrecht von Brandenburg (1511-1525) 1516 für seine Kriegspläne gegen Polen Kurfürst Joachim I. von Brandenburg (1499-1535) zu einem Darlehen bewegen und den erbetenen Betrag auf die Pfandsumme der Neumark aufschlagen wollte, mußte er feststellen, daß sein drohender Hinweis auf das Auflösungsrecht des Ordens in Berlin nicht mehr verfing. Die Neumark sei, erwiderte der Kurfürst kühl, „dem Hause Brandenburg so zugetan, daß sie hinfort nicht mehr zur Ablösung gelangen könne ${ }^{675}$. Ein Jahr später beharrte er unnachgiebig auf seinem Anspruch: Die Newmargk betreffendt, hilten sich sein gnaden wol vorsorgt. Solts och anders furgenomen werden, must heis raws gehen .... Albrecht erreichte schließlich 1517, daß Joachim I. ihm und seinem Kriegsvolk gegen seinen endgültigen und uneingeschränkten Verzicht auf alle Rechte, Gerechtigkeiten und Obrigkeit des Ordens an der Neumark das freie Durchzugsrecht durch die Mark zugestand und militärische Hilfe versprach ${ }^{76}$. Der neumärkischen Stände gedachte Albrechts Urkunde mit seiner implizit enthaltenen Aufgabe des Wiederkaufsrechtes nur ganz beiläufig mit der historischen Reminiszenz in der Narratio, daß der hochmeisterliche Vorgänger 1454 seine neumärkischen Untertanen an den Markgrafen von Brandenburg verwiesen habe ${ }^{77}$. Obwohl die Situation von 1517, staatsrechtlich geurteilt, vollkommen der von 1429 entsprach, dachte damals keine Partei daran, im Rahmen der unwiderruflichen Rückkehr der Neumark an Brandenburg die neumärkischen Stände erneut zur Huldigung vor dem Kurfürsten aufzufordern oder gar eine erneute landesherrliche Bestätigung ihrer Privilegien zu planen. Über 60 Jahre nach dem Ende der Ordensherrschaft war die Zugehörigkeit der Neumark zu Brandenburg so fest und unverrückbar verankert, daß es

74 Das neumärkische Ständearchiv (wie Anm. 6), S. 176 Nr. 12.

75 Joachim (wie Anm. 25), S. 37, 118 f., 273 Nr. 109 (daraus das Zitat).

76 Ebd., S. 148-151, 310 Nr. 138 (daraus das Zitat). - Zum politischen Hintergrund der kurfürstlichen Haltung vgl. Schultze (wie Anm. 1), S. 216 f.

77 CDB II 6, S. 280 Nr. 2473 (nach Original); CDB I 24, S. 230 Nr. 299 (nach älterer Edition). Joachims Gegenurkunde: Joachim: Die Politik des letzten Hochmeisters (wie Anm. 20), S. 311 Nr. 139. 
einer wiederholten ausdrücklichen rechtlichen Anerkennung der hohenzollernschen Obrigkeit durch die Stände gerade aus kurfürstlicher Sicht nicht mehr bedurfte.

Die ständischen Privilegien der späteren Hohenzollern des 16. und 17. Jahrhunderts knüpfen nicht mehr an die älteren Dokumente ihrer Vorgänger an, sondern bedeuten einen völligen Neuanfang mit ganz anderen inhaltlichen Schwerpunkten und unter Beachtung anderer formaler Beurkundungsregeln. Inhalt und Formen des 16. Jahrhunderts seien hier nur durch den Hinweis auf zwei landesherrliche Privilegien zugunsten der neumärkischen Stände angedeutet. 1553 einigte sich Markgraf Hans von Küstrin auf dem Landtag zu Soldin mit den Prelaten, Graffen, Ritterschaft, erbarn Manschafften und Stetten als gemeiner unserer Landschafft in unsern Furstenthumben und Landen der Newen Marke, Landes zu Sternberg, Schlesien und Lausitz über das juristische Verfahren in Appellationsangelegenheiten und stellte damit den Instanzenzug und die Rechtswege zur Erlangung und Sicherung von Recht und Gerechtigkeit auf eine neue Grundlage. Von der vertragsähnlichen Vereinbarung wurden zwei Ausfertigungen auf Pergament niedergeschrieben, sie wurden sowohl von Markgraf Hans, der eingangs allein aus Aussteller erscheint, als auch von 35 gewählten und bevollmächtigten Vertreter der „Stände“ besiegelt und unterschrieben, die eine Ausfertigung behielt die „Landschaft“ für sich, die andere stellte sie dem Markgrafen $\mathrm{zu}^{78}$. Nach dem Tode des Markgrafen Hans bestätigte sein Neffe und Nachfolger, Kurfürst Johann Georg, auf dem Landtag zu Küstrin 1572 Prälaten und Ritterschaft der Neumark ihre Freiheiten, Privilegien und Gewohnheiten und traf mit ihnen in einer Vielzahl von Paragraphen Abmachungen über die Tilgung der landesherrlichen Schulden, die adligen Gutwirtschaften und deren Abgaben und Ansprüche auf bäuerliche Dienstleistungen und mancherlei andere wirtschaftliche Angelegenheiten. Der Kurfürst ließ den Landtagsabschied vierfeltig umbschreiben, mit seinem und den Siegeln von vier bevollmächtigten Vertretern der Prälaten und Ritterschaft versehen und unterschrieb zusammen mit zwei Prälaten (aus dem Johanniterorden) ${ }^{79}$. Ohne hier noch in eine detaillierte Analyse eintreten zu wollen und zu können, belegen allein diese skizzenhaften Verweise auf zwei markgräflich/kurfürstliche Privilegien zugunsten der neumärkischen Stände, daß sich die Gegenstände der landesherrlich-ständischen Verhandlungen und der in Privilegien festgehaltenen Verhandlungsergebnisse und die Art und Weise von deren schriftlicher Fixierung und Dokumentierung erheblich gewandelt hatten. Die militärischen Dienste von Ritterschaft und Städten, die die Verhandlungen des 15. Jahrhunderts bestimmt hatten, waren unter dem Eindruck ruhigerer Zeitverhältnisse im Bewußtsein der Beteiligten gänzlich zurückgetreten und bestimmten nicht mehr ihr Verhältnis zum Landesherrn.

78 Das neumärkische Ständearchiv (wie Anm. 6), S. 178 Nr. 13.

79 Ebd., S. 182 Nr. 14. 
Vergegenwärtigen wir uns zum Abschluß noch einmal den zurückgelegten Weg vom Anfang bis zum Ende des 15. Jahrhunderts, von 1402 bis 1491, indem wir aus unseren Einzelbeobachtungen in fünf Punkten - unter Konzentration auf die Phase der Deutschordensherrschaft - einige wesentliche Schlußfolgerungen für die Deutung des landesherrlich-ständischen Verhältnisses in der Neumark ${ }^{80}$ - und vielleicht darüber hinaus - ziehen.

1. Ständische Huldigung und landesherrliche Privilegienbestätigung gehörten, wie die einzelnen Beispiele eindeutig gezeigt haben, untrennbar zusammen. Wer das eine Thema ansprach, mußte gewärtig sein, daß in der Reaktion das andere Thema erwähnt wurde. Denn es galt: Die Privilegienbestätigung setzte die Huldigung voraus - wie aber auch genauso umgekehrt: Die Huldigung bedingte die Privilegienbestätigung. Die Reihenfolge der beiden Rechtsakte verursachte keine erkennbaren Reibereien zwischen den beiden Seiten. In ihnen war offenkundig die Überzeugung fest verankert, daß der stufenweise Übergang vom alten auf den neuen Herrn rechtlich erst vollendet war, wenn sowohl die Stände gehuldigt als auch der Landesfürst ihre Privilegien erneuert hatte. Eine Einigung über den künftigen ständisch-landesherrlichen modus vivendi anläßlich eines Herrschaftswechsels wurde schließlich in allen betrachteten Fällen gefunden, auch wenn die Stände mehrfach beklagten, daß ihnen die vorliegenden Verbriefungen entweder inhaltlich nicht ausreichten und der Ergänzung bedürften oder daß sie ihnen nicht eingehalten würden und umfassend beachtet werden müssten. Entweder gelang es, die Gegensätze in grundsätzlicher, überzeugender Weise durch einen letztlich allseits angenommenen Kompromiß wie 1430 auszugleichen, oder sie wurden oberflächlich und dilatorisch behandelt, unter Berufung auf frühere Zusagen vorerst zugedeckt und auf spätere Zeiten verschoben wie 1414, ohne die Differenzen zur ausweglosen Konfrontation zu steigern. Beiden Parteien war bewußt, daß sie unter normalen Umständen aneinander gebunden waren und miteinander leben mußten. Die ständische Inanspruchnahme des Widerstandsrechtes und die Aufkündigung des ständischen Gehorsams wie in Preußen 1454 ist doch als ganz außergewöhnlicher und außerordentlich seltener Fall einzustufen.

Die Huldigung der Stände war in Worte gefaßt in dem Eid, den sie ihrem Landesherrn leisteten. Dessen Formel rief in der Neumark weder in der Ordens- noch in der Hohenzollernzeit nennenswerte Debatten hervor: Sie beinhaltete, wie die Fassung von 1441 verdeutlicht, die Treueerklärung des einzelnen Untertanen gegenüber dem Hochmeister, gegenüber seinem Bevollmächtigten im Land, dem Vogt, und gegenüber dem ganzen Orden.

80 Die knappen, aber pointierten Darlegungen von Gerd Heinrich: Die ,Freien Herren“ und das Land. Markgrafenherrschaft und landständische Einflußnahme in Brandenburg während des Spätmittelalters, in: Die Anfänge der ständischen Vertretungen in Preußen und seinen Nachbarländern, hrsg. v. Hartmut Boockmann unter Mitarbeit v. Elisabeth Müller-Luckner. München 1992, S. 137-150 (= Schriften des Historischen Kollegs, Kolloquien 16), zeigen, daß die ständische Problematik in der Neumark trotz aller Gemeinsamkeiten mit der übrigen Mark einige Eigenheiten aufweist und einer detaillierten besonderen Behandlung wert ist. 
Die Neumärker anerkannten somit vorbehaltlos die Bindung an das Ordensoberhaupt, seinen beauftragten Amtmann und die Ordenskorporation, weil sie alle drei immer als Einheit erlebt und empfunden hatten. Die preußischen Stände hingegen unterschieden im Zeichen des Ständekampfes zwischen Hochmeister und Ordensgemeinschaft, sie suchten sich 1441 und 1450 immer stärker mit ihrem Eid nur noch ersterem, der als Fürst verstanden wurde, zu verpflichten und nicht mehr letzterer, weil sie hatten erfahren müssen, daß sie aus der in sich zerstrittenen Korporation zu entgegengesetzten Treuebekundungen aufgefordert worden waren. Die eigentlichen Kontroversen wurden in der Neumark über den Inhalt der Privilegienbestätigung ausgefochten. Im allgemeinen knüpfte die fragliche Urkunde des Landesherrn an die Vorurkunde seines Vorgängers an, übernahm deren Wortlaut vollständig oder weitgehend unverändert, ergänzte oder korrigierte allenfalls in geringfügigeren Punkten. Und in der Dispositio wurde zunächst ausschließlich oder vorrangig festgehalten, daß der Landesherr sich zur Beachtung der ständischen Rechte und Gewohnheiten verstand, ohne diese präzise und konkret darzustellen. Die Stände legten durchaus Wert darauf, in ihrer Rechts- und Verfassungslage grundsätzlich und umfassend bestätigt zu werden, ohne von vornherein auf einem Katalog von speziellen Gerechtigkeiten zu bestehen und ohne sich auf schriftliche Festlegungen zu Einzelpunkten zu beschränken, wie schon der ständige Bezug auf die Gewohnheiten zeigt. Andererseits legten es politische Erfahrungen und politische Ziele nahe, auf der Aufnahme von besonderen Rechten oder Pflichten zu bestehen, in Punkten, auf die die eine oder beide Seiten größten Nachdruck legten, die ihnen in erster Linie am Herzen lagen oder die unter ihnen ganz umstritten waren. Im Konfliktfall zeigte sich die Landesherrschaft von einer allein eidlich untermauerten Behauptung einer angeblichen ständischen Gerechtigkeit wenig beeindruckt, sie verlangte stattdessen deren urkundlichen Nachweis, der nur durch den Bezug auf die bestehenden Rechte und Gewohnheiten nicht zu erbringen war. Ob eher und mehr die bloße Wiederholung von Vorurkunden und die Anrufung der althergebrachten Zustände dominierten oder ob umgekehrt die genaue Ausarbeitung und Vereinbarung ausgewählter gewichtiger Sachverhalte in den Vordergrund trat, war von der jeweiligen politischen Lage abhängig. Der Reiz und der Erkenntnisgewinn unseres Themas offenbaren sich daher am ehesten durch die Analyse von Einzelfällen über einen langen Zeitraum hinweg.

2. Huldigungen und Privilegienbestätigungen wurden immer ausgelöst durch einen Herrschaftswechsel, durch einen noch bevorstehenden ebenso wie durch einen schon vollzogenen Herrschaftswechsel. Dieser Begriff ist vor dem konkurrierenden des Herrscherwechsels zu bevorzugen, weil er umfassender die in der Praxis auftretenden drei verschiedenartigen Fälle abdeckt. Der erste Fall bestand darin, daß im Territorium nach dem Tode oder dem Rücktritt des bisherigen Herrschers kraft Erb- oder Wahlrechts sein Nachfolger die Herrschaft antrat, ein neuer Hochmeister von der Ordenskorporation gewählt wurde bzw. ein Sohn oder Bruder des vorherigen Markgrafen erblich nachfolgte. Klare erb- oder wahlrechtliche Regelungen verminderten zwar die Angriffsflächen und Erfolgschancen der Stände, hinderten sie aber keinesfalls daran, Forderungen in größerer oder geringerer Zahl und von größerem oder geringerem Gewicht zu erheben. Der gesamte Vorgang beruhte auf der Voraussetzung, daß ihr Treueid immer einer bestimmten Person, 
dem regierenden Herrn oder Fürsten, galt und mit dessen Tod oder Rücktritt erlosch; er war nicht auf einen abstrakten Staat oder gar Staatsverfassung bezogen. Infolgedessen war er notwendigerweise zu erneuern, wenn ein anderer Mann an die Stelle der bisherigen Bezugsperson nachgerückt war. Ein wenig komplexer gestaltete sich die Lage, wenn die Landschaft die territoriale Zugehörigkeit tauschte, wenn mithin die Neumark zwischen der Mark Brandenburg und dem Deutschen Orden hin und her geschoben wurde, einem anderen Fürsten und seinem Territorium eingeschränkt oder uneingeschränkt zugewiesen wurde. Dann waren zunächst die Untertanen von ihrem bisherigen Herrn des ihm geleisteten Treueides zu entbinden und von ihm an den neuen Herrn zu verweisen, die zwingende Bedingung dafür, daß dieser von ihnen für sich einen neuen Treueid verlangte und dabei ihnen ihre Rechte bekräftigte. Der neumärkische Territorialwechsel beanspruchte dabei 1402 und 1454 einiges Geschick der beteiligten Landesherren zur Ermöglichung eines reibungslosen Überganges, rief aber keine lauten ständischen Proteste hervor, etwa wegen ihrer Abtrennung von der eigentlich laut Goldener Bulle unteilbaren Mark Brandenburg. Der dritte Fall ist für unsere Thematik besonders aussagekräftig, die Änderung der verfassungsrechtlichen oder legitimatorischen Grundlage der Herrschaft, also die Ersetzung einer zeitlich befristeten und sachlich beschränkten Pfandherrschaft durch eine zeitlich und sachlich unbegrenzte Erbherrschaft, anders formuliert aus ständischer Sicht: die Ersetzung einer Pfandhuldigung durch eine Erbhuldigung, aus landesherrlicher Sicht: der endgültige Ausschluß einer Rückerwerbung des vormaligen Besitzers. Es war diese Verfassungslage, die die Neumärker 1430 dazu nutzten, die bislang schwebenden prinzipiellen Probleme ihres Rechte- und Pflichtenkanons gegenüber ihrem Landesherrn nachdrücklich aufzugreifen und durch eine neue Privilegierung mit zusätzlichen schriftlichen Vereinbarungen zu lösen.

Im Hinblick auf die zahlreichen Herrscher- und Herrschaftswechsel in der Mark Brandenburg des 14. Jahrhunderts hat Walter Schlesinger gemeint, daß „das Band zwischen Landesherrn und Landesbewohnern, zwischen Herrn und Holden durch den immer wiederholten Herrschaftswechsel sich immer mehr lockerte ...", in zugespitzter Form lautet sein Urteil: „Man hat nicht den Eindruck, daß die Pflichten, die mit einer Huldigung eingegangen wurden, noch von jemandem ernst genommen worden sind“"81. Seiner Einschätzung soll hier nicht im Kern widersprochen, aber doch die Beobachtung ihr zur Seite gestellt werden, daß die Beteiligten, die Landesherren ebenso wie die Stände, offensichtlich immer größten Wert darauf legten, ja, wohl legen mußten, einen Herrschaftswechsel mit Huldigung und Privilegienbestätigung zu vollziehen. Ohne daß die Stände ihrem neuen Herrn huldigten, ohne daß er ihnen ihre Gerechtigkeiten und Gewohnheiten bestätigte, war eine ausreichende Legitimationsgrundlage nicht geschaffen, konnte der berechtigte landesherrliche Anspruch auf Gehorsam bezweifelt und verneint werden, so daß auf beide Vorgänge keinesfalls verzichtet wurde, auch wenn sich die politische Lage innerhalb kurzer Zeit wieder völlig gewandelt und zu anderen Landesherren geführt hatte.

81 Schlesinger (wie Anm. 1), S. 116 f. 
3. Die neumärkischen Ereignisse in Zusammenhang mit Huldigung und Privilegienbestätigung werfen einiges Licht auf das in der Geschichtswissenschaft wiederholt und kontrovers diskutierte Thema des sog. dualistischen Ständestaates. Der in der älteren Forschung, wie sie etwa von Fritz Hartung in seiner Deutschen Verfassungsgeschichte vom 15. Jahrhundert bis zur Gegenwart klassisch formuliert worden war ${ }^{82}$, stark betonte Dualismus von Landesherrschaft und Ständen ist von jüngeren Historikergenerationen zugunsten der nachhaltig hervorgehobenen Kooperation beider Seiten zumindest relativiert oder gar grundsätzlich in Zweifel gezogen worden ${ }^{83}$. Wenn wir unser Urteil auf die Neumark des 15. Jahrhunderts gründen, liegen sowohl die Berechtigung als auch die Schranken des Dualismus-Modells auf der Hand. Einerseits ist nicht zu übersehen, daß Herrschaft und Stände sich auf einer gemeinsamen Rechtsgrundlage gegenüberstanden, daß sie auf dieser wie zwei selbständige Parteien miteinander verhandelten und dabei von gleich zu gleich um einen Ausgleich miteinander rangen. Andererseits verfehlt die Vorstellung eines starren Gegensatzes zweier Seiten die historische Wirklichkeit in erheblichem Maße. Die neumärkischen Stände waren, wie zunächst aus den Vorgängen abzuleiten ist, kein einheitlicher Block, es setzten sich nicht Vertreter der Stände, sondern Angehörige der Mannschaft bzw. Ritterschaft sowie der Städte mit den Vertretern der Landesherrschaft auseinander. Die politische vorrangige Frage lautete immer wieder, ob Mannschaft und Städte sich auf eine übereinstimmende Linie gegenüber der Herrschaft verständigten oder ob eine der beiden Seiten dieser mehr zuneigte und eher zu einem Übereinkommen bereit war, so daß man von einer Dreieckskonstellation zu sprechen geneigt ist. Das hochmeisterliche Privileg von 1430, das zentrale Dokument unseres Beitrages, verdankt seine Entstehung und seinen Inhalt der Konstellation, daß die Mannschaft wegen der ausreichenden Berücksichtigung ihrer Interessen das Privilegienangebot des Ordens annahm und sich damit von den Städten trennte. Nichts kennzeichnet mehr das Nebeneinander von zwei eigenständigen ständischen Gruppen als die ständige Ausfertigung von zwei gesonderten Privilegien für die Ritterschaft und die Städte. Daß Adel und Bürgertum in sich ebenfalls nicht von vornherein immer einheitlicher Auffassung waren und nicht einheitlich auftraten, braucht hier nicht weiter vertieft zu werden.

Dann offenbaren gerade die Verhandlungen von 1430, daß zwischen der Herrschaft und den beiden ständischen Gruppen ein Gremium stand, das nicht eindeutig einer Seite zuzuordnen war, eben weil es seinem Wesen nach zur Vermittlung bestimmt war: der Rat des neumärkischen Vogtes. Die Räte dienten dem Landesherrn, waren von ihm ausge-

82 Fritz Hartung: Deutsche Verfassungsgeschichte vom 15. Jahrhundert bis zur Gegenwart. Stuttgart 9. Aufl. 1969, S. 82-92, bes. S. 89-91. - Heidenreich (wie Anm. 10) folgt in seinen grundsätzlichen Interpretationen uneingeschränkt dem Modell eines Dualismus von Ständen und Landesherrschaft, zeigt aber eher unbeabsichtigt dessen Grenzen durch seine konkreten Schilderungen der Verhältnisse.

83 Vgl. die Erörterung der jüngeren Forschungsdebatte mit jeweils eigenen eigenständigen Ansätzen bei Ulrich Lange: Der ständestaatliche Dualismus - Bemerkungen zu einem Problem der deutschen Verfassungsgeschichte, in: Blätter für deutsche Landesgeschichte 117 (1981), S. 311-333, u. Peter Moraw: Zu Stand und Perspektiven der Ständeforschung im spätmittelalterlichen Reich, in: Die Anfänge (wie Anm. 80), S. 1-33. 
wählt und waren ihm verpflichtet, aber sie entstammten dem neumärkischen Adel, zählten zu seinen sehr angesehenen und begüterten Angehörigen, und waren daher durch ihre soziale Herkunft und durch ihr amtliches Vertrauensverhältnis in die Lage versetzt, in einem Konflikt zwischen Ständen und Herrschaft auszugleichen. Im Falle der dramatischen Zuspitzung drohten sie zwar zwischen beiden Seiten zerrieben zu werden, wie sie 1430 so schön ausdrückten, aber sie brachten letztlich das damalige Kompromiß zustande. In vergleichender Betrachtung ist es aufschlußreich, daß dieses Modell, das 1430 in der Neumark seine Bewährungsprobe bestand, in Preußen nicht funktionierte, obwohl es die Hochmeister Heinrich von Plauen und Paul von Rusdorf 1412 und 1432 zu institutionalisieren suchten: Sie erklärten sich nämlich bereit, sich an den Rat einer von ihnen ausgewählten Gruppe von bürgerschaftlichen und ritterschaftlichen Angehörigen zu binden. Aber die großen Städte und die Ritterschaften lehnten das neue Verfassungselement ab, weil sie - nicht zu Unrecht - befürchten mußten, daß dadurch ihre eigenen Mitspracherechte beschnitten und die letzte Entscheidung in ein unter maßgeblich hochmeisterlichem Einfluß stehendes, weniger an den Ständen orientiertes Organ verlagert würde. Die politischen Differenzen zwischen den neumärkischen Ständen und dem Orden waren nicht so scharf ausgeprägt wie in zunehmendem Maße nach 1410 in Preußen, so daß ein landesherrlicher Rat einen Ausgleich zu befördern vermochte, auch wenn erheblichere inhaltlichen Differenzen auftraten.

An dieser Stelle soll noch vermerkt werden, daß die Geistlichkeit der Neumark, also ihre geistlichen Institutionen mit grundherrschaftlichem Eigentum wie die Zisterzienserklöster, das Domkapitel zu Soldin und der Johanniterorden, für unsere Thematik keine nennenswerte Rolle spielten, ja, daß sie in ihr nahezu überhaupt nicht vorkamen. Es waren immer wieder und fast ausschließlich die Ritterschaft und die Städte, die mit den Ordensvertretern auf den Landtagen verhandelten, die mit ihnen über Huldigung und Privilegiengewährung debattierten, und es waren, genau besehen, Ritterschaft und Städte, deren Rechte die Landesherren bestätigten. Die ersten hochmeisterlichen Privilegienkonfirmationen erwähnten die neumärkischen Prälaten ausdrücklich gar nicht, erst Paul von Rusdorf fügte den von seinen Vorgängern angesprochenen Ritter und Knechten, Bürgermeistern, Ratmannen, Bürgern, Bauern und Gemeinen auf dem Lande und in den Städten noch die Äbte, Äbtissinnen und Domherren an, die er alle im Besitz ihrer Freiheiten und Gerechtigkeiten bekräftigte. Sein schmaler Zusatz vermag aber nicht darüber hinwegzutäuschen, daß die einzelnen konkreten Bestimmungen seines Generalprivilegs nur Ritterschaft und Städte betrafen. In gleicher und ähnlicher Weise führten die späteren landesherrlichen Privilegien die Prälaten neben Ritterschaft und Städten auf, bestätigten ihnen allen pauschal ihre Gerechtigkeiten, aber die ständige Bezugnahme auf den Landbrief Pauls von Rusdorf bedeutete, daß die Belange der beiden weltlichen Stände im Vordergrund standen. Christian Gahlbeck hebt hervor, daß die Generalkonfirmationen, die die einzelnen Klöster im 13. und 14. Jahrhundert über ihre Rechte und Besitzungen von den Landesherrn erhalten hatten, im 15. Jahrhundert abgelöst bzw. ersetzt worden seien durch deren allgemeine Konfirmationsurkunden für die Landstände, und sieht die Ursa- 
che in dem zunehmenden Territorialbewußtsein der neumärkischen Stände ${ }^{84}$. Seine ansprechende Deutung erklärt freilich nicht den von ihm ebenfalls behandelten Sachverhalt, daß die Prälaten zumindest in der Ordenszeit auf den Landtagen nicht erschienen und nicht an den Erörterungen über die Generalkonfirmationen für die Stände beteiligt waren $^{85}$. Die Ursache dürfte in den dort vorrangig auf der Tagesordnung stehenden Materien zu suchen sein, zu denen die geistlichen Einrichtungen keinen substantiellen Beitrag zu leisten vermochten.

4. Denn unter den Gegenständen, die in die neumärkischen Verhandlungen zwischen Herrschaft und Ständen eingebracht wurden und die deren Ergebnis in Gestalt der Privilegien bestimmten, ragte in der Ordenszeit mit langer Nachwirkung in der frühen Hohenzollernzeit konkurrenzlos der Militärdienst hervor, also die Frage nach Art und Ausmaß der ständischen Heeresfolge und der dazugehörigen landesherrlichen Leistungen. Es bestand für ein ständisches Aufgebot ein Unterschied zwischen einem Einsatz innerhalb oder außerhalb der Neumark, ähnlich wie etwa in Preußen für die kulmerländische Ritterschaft auf Grund der Kulmer Handfeste von 1233 (und ihrer Erneuerung von 1251), nach der sie zum Landwehrdienst nur innerhalb der Grenzen der Kulmerlandes, bis zur Weichsel und deren beiden Nebenflüsse Ossa und Drewenz, verpflichtet war und gegen ihren Willen nicht zum Kriegseinsatz an anderen Orten entboten werden durfte. Die preußische Kriegsgeschichte des 15. Jahrhundert zeigt die nachhaltige und folgenreiche Wirkung dieser von den Begünstigten sorgsam bewahrten Privilegierung, indem sie den Deutschen Orden zwang, auf den Einsatz der kulmerländischen Ritterschaft außerhalb des Kulmerlandes von vornherein zu verzichten oder deren Finanzierungslasten in Kauf zu nehmen oder an die Freiwilligkeit zu appellieren ${ }^{86}$.

Die Behandlung der neumärkischen Städte orientierte sich 1430 am Einsatz ihres Aufgebotes diesseits oder jenseits der Landesgrenzen: Innerhalb der Neumark waren die Städte zu seiner Unterhaltung auf eigene Kosten verpflichtet, außerhalb der Neumark durften sie für einen Teil, für die berittene Truppe, Versorgung beanspruchen. Der Mannschaft waren hingegen inner- wie außerhalb des eigenen Landes Verpflegung ihrer Einheiten und Schadenersatz für die von ihnen erlittenen Verluste, vornehmlich die Ersetzung der verletzten oder getöteten Pferde und die Lösung aus der Kriegsgefangenschaft, zugesichert, wobei der Urkundentext offen läßt, ob sie über die Landwehr hinaus zum Kriegsdienst jen-

84 Gahlbeck (wie Anm. 64), S. 767-796, bes. S. 793-796.

85 Ebd., S. 894-901. Ob Friedrich II. 1454 tatsächlich mit der Einladung der Zisterzienserklöster zum damaligen Landtag eine dauerhafte Neuerung einführte (so Gahlbeck ebd., S. 897), erscheint mir sehr zweifelhaft. Denn 1454 mußte der Kurfürst zum Zwecke seiner allgemein anerkannten Herrschaftsübernahme größten Wert darauf legen, daß alle Stände, auch die Prälaten, ihm huldigten. Ansonsten vermag Gahlbeck als einzigen konkreten Beleg für die Teilnahme der Prälaten an den ständischen Versammlungen nur die oben erwähnte Zusammenkunft von 1470 anzuführen.

86 Guido Kisch: Die Kulmer Handfeste. Text, rechtshistorische und textkritische Untersuchungen nebst Studien zur Kulmer Handfeste. Sigmaringen 1978, S. 120 f. (§ 17) (=Forschungen und Quellen zur Rechts- und Sozialgeschichte des Deutschordenslandes, 2). - Sven Ekdahl: Über die Kriegsdienste der Freien im Kulmerland zu Anfang des 15. Jahrhunderts, in: Preußenland 2 (1964), S. 1-14, bes. S. 2 f., 7-10; - ders.: Der Krieg zwischen dem Deutschen Orden und Polen-Litauen im Jahre 1422, in: Zeitschrift für Ostforschung 13 (1964), S. 614-651, hier S. 632 f. 
seits der Grenzen verpflichtet waren; sonstige Verhandlungen sprechen dafür, daß dieser nur auf Freiwilligkeit beruhte. Die neumärkischen Städte verlangten in all diesen Punkten uneingeschränkte Gleichrangigkeit mit der Ritterschaft. Die Hochmeister billigten mit ihrer Privilegierung die traditionellen Ansprüche des Adels, gegenüber denjenigen der Städte verstanden sie sich nur zu deren teilweiser Berücksichtigung, womit sie indirekt zum Ausdruck brachten, daß sie die militärischen Dienste des Adels für höherwertig als die der Städte erachteten. Allen wiederholt vorgetragenen Wünschen der Städte zum Trotz hielten sie daran fest, sie in ihrem Kern, der Gleichstellung mit der Ritterschaft, abzuweisen.

Während die allgemeinen Überblicksdarstellungen zum spätmittelalterlichen Ständestaat in den finanziellen Anforderungen des Landesherrn, in seinem Verlangen nach Steuererhebungen den wesentlichen Ansatz zum Ausbau der ständischen Mitsprache betonen, spielte dieser Gesichtspunkt in der Neumark zwar wiederholt eine gewichtige Rolle ${ }^{87}$, aber in entscheidendem Maße vermochte er die Beziehungen zwischen Herrschaft und Ständen nicht zu bestimmen oder gar zu lenken. Wie beispielsweise der Wunschkatalog der Städte von 1430 zeigte, hätten sie gerne in das angestrebte landesherrliche Privileg auch Verzichte des Hochmeisters im Bereich seiner Regalien, des Mühlen- und Burgenregals, aufgenommen, aber nichts davon konnte von ihnen durchgesetzt werden. Die anderen Gesichtspunkte kamen jedoch gegen die Militärfrage nicht auf, wie man dem Ergebnis der Privilegienverhandlungen von 1430 abliest. Der Vorrang des Militärdienstes ist aus der außenpolitischen Lage des Landes fast über das ganze Jahrhundert hinweg zu erklären, aus den zahlreichen kleineren und größeren Fehden und Kriegen, die nahezu von allen Nachbarn drohten, vornehmlich von Polen und von Pommern, die immer wieder die äußere Sicherheit der Neumärker in Frage stellten und beeinträchtigten und die einen dauerhaften Landfrieden verhinderten. Die ständig von außen, von mißgünstigen Nachbarn drohenden Gefahren und deren wiederholt vorkommende kriegerische Angriffe und Einfälle, die dadurch hervorgerufenen Anforderungen an das Heeresaufgebot der Neumark bestimmte nachhaltig die Verfassung des Landes, sowohl die des Landesherrn und seiner Amtsleute als auch die der Stände und ihrer Gruppen und folgerichtig die zentralen Gegenstände der beiderseitigen Diskussionen und Verhandlungen. Unter solchen politischen Gegebenheiten war der Orden mit seinem schwachen Personalbestand in der Neumark unausweichlich auf die militärische Unterstützung der Stände angewiesen, in erster Linie auf die offenkundig als leistungsfähiger eingeschätzte der Ritterschaft, wenn er die Fehden eindämmen, die Feinde überwinden und den Landfrieden sichern wollte. Für Kämpfe und Schlachten wurde vorrangig „Reisige“, berittene Kämpfer, benötigt, und sie entstammten in erster Linie dem Adel, weniger dem Bürgertum.

5. Für die Formierung der neumärkischen Stände und die Ausbildung einer landständischen Verfassung in der Neumark wird man der Zeit der Ordensherrschaft im allgemeinen und den Verhandlungen um Huldigung und Privilegienbestätigung im besonderen erhebliches Gewicht zusprechen dürfen. Von 1402 bis 1454 war die Neumark, auch wenn sie de iure dem Hochmeister unterstand und der preußischen Ordensherrschaft an-

Vgl. im einzelnen Heidenreich (wie Anm. 10), S. 45-52. 
gegliedert war, de facto wegen ihrer von Preußen gänzlich abweichenden, eigenständigen Verfassungsordnung ein eigenes Territorium. Auch wenn die neumärkischen Ritter und Städte vereinzelt schon im 14. Jahrhundert von den wittelsbachischen Markgrafen von Brandenburg gesondert und gruppenweise privilegiert worden waren, führte doch erst ihre völlige Abtrennung von Alt- und Mittelmark und deren Ständen dazu, daß sie sich insgesamt oder zumindest jede Gruppe für sich um die Regulierung ihres Verhältnisses zu dem neuen Landesherrn bemühen mußte. Auf Landtagen, die zwar nicht regelmäßig, aber doch in größerer Anzahl einberufen wurden, kamen die ständischen Vertreter zur Erörterung der brennenden politischen Angelegenheiten mit dem Vogt und sonstigen Vertretern des Ordens zusammen. Nach 1410 stellte sich rasch heraus, daß die Berufung auf die althergebrachten Rechte und Gewohnheiten auf Grund ihrer mangelnden schriftlichen Fixierung unter den außenpolitischen Gefährdungen nicht ausreichten, den ständischen Wünschen im vorrangigen Bereich des militärischen Aufgebotes gebührenden Nachdruck zu verleihen. Die Herrschaftswechsel gaben dann den äußeren Anstoß dazu, daß die Stände in ihrer Gesamtheit oder ihre beiden maßgebliche Zweige, Ritterschaft und Städte, allgemeine, also sie alle betreffende und begünstigende Privilegierungen verlangten, wenn sie sich alle zur angemahnten Huldigung bereiterklären sollten. Die Debatten drehten sich dabei nicht darum, daß einzelne Adlige oder einzelne Städte sich neue Rechte verleihen lassen wollten, sondern Ritterschaft und Städte als Gruppe(n) erwarteten ein an sie alle gerichtetes und für sie alle geltendes landesherrliches Privileg. Aus der 1430 wiederholt ausgesprochenen Bekräftigung vormaliger, seit alters bestehender Gewohnheiten ist abzuleiten, daß ältere Traditionen nur in begrenztem Maße um neue Gesichtspunkte erweitert wurden, hingegen der Akzent seitens der Stände auf die ausdrückliche schriftliche Fixierung ihrer präzisierten Rechte und damit auf deren urkundliche Anerkennung seitens der Landesherrschaft gelegt wurde.

Die Verhandlungen des 15. Jahrhunderts zeigten dabei das geringe Ausmaß ständischer Institutionalisierung. Bezeichnenderweise wurden, um dafür nur ein einziges archivgeschichtliches Detail anzuführen, die hier behandelten landesherrlichen Privilegien für die Gesamtheit der neumärkischen Stände nicht an einer einzigen Stelle im Sinne eines zentralen ständischen Urkundenarchivs zusammengefaßt und verwahrt. Die eindeutig nur für die Ritterschaft ausgestellten Urkunden sind überhaupt nur durch Abschriften im landesherrlichen Ausstellerarchiv überliefert. Die für beide Stände oder nur für die Städte ausgestellten Urkunden wurden entweder Königsberg oder Landsberg - mit deutlichem Übergewicht Königsbergs - zur Deponierung anvertraut. Erst landesherrliche Privilegien des 16. Jahrhunderts sind in ein ständisches Urkundenarchiv eingegangen ${ }^{88}$, und wenn man das publizierte Findbuch der Aktenüberlieferung der neumärkischen Stände mit den dortigen Laufzeitangaben betrachtet ${ }^{89}$, muss man schlussfolgern, daß eine eigene

88 Vgl. die archivalischen Nachweise zu den fraglichen Urkunden in Klinkenborgs Edition der landesherrlichen Privilegien und Reverse, Das neumärkische Ständearchiv (wie Anm. 6), S. 162 ff.

89 Neumärkische Stände (Rep. 23 B), bearb. v. Margot Beck u. eingeleitet v. Wolfgang Neugebauer. Frankfurt am Main u.a. 2000 (= Quellen, Findbücher und Inventare des Brandenburgischen Landeshauptarchivs, 9). - Der darin enthaltene Beitrag von Wolfgang Neugebauer: Die neumärkischen 
Aktenregistratur wohl kaum vor der Mitte des 17. Jahrhunderts eingerichtet worden ist. Der Gedanke an eine eigenständige ständische Verwaltung einschließlich eines dazugehörigen Archivs lag also im 15. Jahrhundert noch jenseits der damaligen Vorstellungswelt, gewichtige Urkunden wie die hier erörterten wurden einem angesehenen Mitglied der Stände zur Archivierung überlassen. Die Formen der innerständischen Willensbildung sind zwar mangels aussagekräftiger Quellen kaum zu erkennen. Aber die Urkunden bezeugen, daß einzelne Adlige und einzelne Städte namens der gesamten Ritterschaft und der gesamten Städtegruppe und somit verbindlich für sie handelten, was einen ausreichenden Grad an politischer Selbstorganisation verrät. Und wenn 1470 vielleicht nur ein Viertel des neumärkischen Adels zum angesetzten Landtag mit dem Markgrafen zur Erörterung und Festlegung der Modalitäten von Huldigung und Privilegienbestätigung erschien, gab den Ausschlag, daß die Anwesenden offenkundig von allen Seiten, von ihren Standesgenossen ebenso wie von der Landesherrschaft, als handlungs- und abschlußberechtigt angesehen wurden und daß die dort getroffenen Absprachen, die Verpflichtung zur ständischen Huldigung und die Ausstellung des landesherrlichen Privilegs, auch alle Abwesenden einbezogen, sie ebenso verpflichteten wie begünstigten. Die Auseinandersetzungen um die auf das Militärwesen konzentrierten Inhalte einer landesherrlichen Privilegierung der Stände, die auf ihren Höhepunkten wegen bevorstehender Huldigungen geführt wurden, schufen im neumärkischen 15. Jahrhundert die ersten wesentlichen Elemente einer fixierten landständischen Verfassung.

\section{Q u e l l e n a n h a n g}

Editionsrichtlinien: Wörtliche Übernahmen aus einer herangezogenen Vorurkunde werden im Petitdruck wiedergegeben; dabei ausgelassene einzelne Worte der Vorurkunde werden durch * gekennzeichnet. - Inhaltlich belanglose Schreiberkorrekturen bleiben im philologischen Apparat unberücksichtigt. - Aus drucktechnischen Gründen sind Vokale, die in den Vorlagen einem anderen Vokal übergeschrieben sind, hier im Druck diesen nachgestellt. - Im Falle von durch mechanische Beschädigungen entstandenen Textverlusten ist die geschätzte Zahl der ausgefallen Buchstaben durch eine entsprechende Punktezahl angedeutet. - Den jetzt gültigen Signaturen des Ordensbriefarchivs, den in den ROT verzeichneten laufenden Nummern des Bestandes, ist wegen der Zitierung in der älteren Literatur die bis Ende des 19. Jahrhunderts gebrauchte Altsignatur (,olim “), bestehend aus der römischen Numerierung der Schiebladen und der laufenden arabischen Numerierung der einzelnen darin enthaltenen Schriftstücke, hinzugefügt. - Zur besseren Orientierung des Lesers sind die Schreiben bzw. Urkunden nach Möglichkeit in einzelne durchgezählte inhaltliche Abschnitte gegliedert worden.

Stände im Lichte ihrer Tätigkeit, S. XVII-LXXIX, ist grundlegend für die frühneuzeitliche Geschichte der neumärkischen Stände und schildert, wie sie sich seit dem 16. Jahrhundert, auf den hier beschriebenen spätmittelalterlichen Voraussetzungen aufbauend, institutionell verfestigten und ihre Tätigkeitsfelder ausweiteten. 
1. Der Ritter Heinrich von Güntersberg, die Knechte Hasso von Wedel zu Neuwedel, Hans von Brederlow d.A. zu Dertzow, Klaus von Sanitz, Michael von Sydow und Konrad von der Marwitz namens aller Adligen der Neumark sowie die Städte Arnswalde, Friedeberg, Landsberg, Soldin und Königsberg namens aller Städte und namens aller Einwohner der Neumark bekennen, daß sie, nachdem der Bevollmächtigte König Sigismunds von Ungarn, der ehemalige Woiwode zu Siebenbürgen Stibor, sie ihrer jenem geleisteten Eide entbunden und sie an Hochmeister Konrad von Jungingen und seinen Orden verwiesen hatte, diesen namens aller Adligen, Städte und Einwohner der Neumark gehuldigt und geschworen haben, von ihnen niemals zu treten. Der Hochmeister hat den Rittern und Knechten bzw. den Städten der Neumark in zwei Urkunden alle ihre Privilegien und Freiheiten unschädlich dem Verkaufsbrief über das Land bestätigt. $\quad$ Arnswalde, $1402 \mathrm{Au}$ gust 9 .

GStA PK, XX. HA, Pergamenturkunden, Schl. 43 Nr. 8. - Ausfertigung, Pergament. Zehn wohlerhaltene Siegel, ein Siegel (Nr. 6, das Siegel des Konrad von der Marwitz) $a b$, aber Rest des Pergamentstreifens vorhanden; die Siegler auf den Pergamentstreifen namentlich bezeichnet (in der Reihenfolge des Betrachters von links nach rechts): Guntersberg. - Hasse. - Alde Hans. - Claws Sancz. - Michil Sydow. - (Siegel ab, Rest des Pergamentstreifens). - Arnswalde. - Ffredeberg. - Landisberg. - Soldyn. - Kongisberg. Rückvermerke: (zeitgenössisch:) R[egistrata]. - Eyne [übergeschrieben über gestrichen: Dis ist die] bekennunge der holdigunge unde der eyde der us der Nuwenmarke, beide der edlingen und der burger, och wy dy Newe Marke an den orden kommen ist. - AT. - (Spätere Vermerke:). - 3. - 1402. - No.8.

Druck: CDB II 3, S. 153 f. Nr. 1269 (nach L.v. Ledebur's Archiv Bd. VI, S. 83, mit zahlreichen kleinen Lesefehlern und wenigen Wortauslassungen) bzw. CDB I 24 (nach der Abschrift in Dickmanns Urkundensammlung, mit noch schlechterer Textwiedergabe).

Reg.: ROT II, S. 172 Nr. 1478. - Karl Kletke: Regesta Historiae Neomarchicae. Die Urkunden zur Geschichte der Neumark und des Landes Sternberg, 2. Abteilung. Berlin 1868, S. 3 f. (= Märkische Forschungen, 12 [im folgenden zitiert: Kletke: Regesta]).

Wir Heynrich von Guntersberg, ritter, Hasse von Wedel, der do wont tzu Nuwen Wedel, alde Hans von Brederlow, der do wont tzu Derczow, Claws von Sancze, Michil von Sydow und Conrodt von der Marwitz, knechte, im namen aller ritthere, knechte und edlynge der Nuwen Marke und dortzu wir burgermeistere, ratmanne und gemeyne desser nachgeschrebin stete Arnswalde, Ffredeberg, Landisperg, Soldyn und Konyngisperg im namen aller stete und nemlich im namen aller inwo ${ }^{\mathrm{e}}$ er der vorgeschrebin Nuwen Marke, beyde uff dem lande und ouch in steten uff dissit der Oder, bekennen offentlich mit craft desses briffes allen kegenwortigen und czukumftigen, als der herre Stybor, vormals woywoda tzu Sybbenbu'rgen, mit vullermacht unsers allergnedigisten herren hern Sigmundes, kongis tzu Ungern, die vorgeschrebin Nuwe Marke mit aller erer tzubehorunge recht und redlich vorkoufft hatte dem erwirdigen gheystlichin herren hern Conrodt von Jungingen, des ordens der bruedere des spyptales sente Marien des Dutschen huses von Jerusalem 
homeistere, und synem gantzen orden ${ }^{90}$ und noch dem, als her uns frey und los saytte alle der eyde, huldunge und verphlichtunge, die wir dem vorgenanten unserm allergnedigisten herren hern Sy ${ }^{\mathrm{e}}$ gismundo, konge tzu Ungern, adir ymande anders in synem namen gethan hatten, und her uns vulmechtichlich hatte gewist an den egenanten herren homeister und synen orden ${ }^{91}$, so haben gesworn und gehuldet beyde wir obingeschrebin und gemeynlich alle manne, ritther, knechte und edlynge und dortzu alle stete, rad und gemeyne der vorgeschreben Nuwen Marke mit gutem willen und wolbedachten mu'te dem egenanten unserm gnedigen herren homeister Dutsches ordens tzu Prusen und synem orden und gelo ${ }^{e}$ ben im namen aller manne, ritther, knechte und edlynge und im namen aller stete, burgermeistere, ratmanne, gemeyne und inwonere der vorgeschreben $\mathrm{Nu}^{\mathrm{e}}$ wen Marke in guten true ${ }^{\mathrm{e}} \mathrm{wen}$ und eren ane allerleye argelist, von ihm und synen orden nymmerme tzu treten ewiglich, is wer denne, das uns unser herre homeister und syn orde verwiste mit hande und mit munde mit gutem willen und wohlbedochten mu'te und uns ledig saytte der huldunge und swerunge, die wir im haben gethan und synem orden. Vortme so bekenne wir offentlich mit dissem briffe im namen aller manne, ritther, knechte und edlynge und im namen aller stete und inwo ${ }^{\mathrm{e}}$ ner der obingeschrebin Nuwen Marke, das unser herre homeister vorgenant $\mathrm{czwy}^{\mathrm{e}}$ ne briffe deme lande, ritthern, knechten und steten der Nuwen Marke gegeben hat, in den her bestetiget alle unser privilegia und vrygheiten, gegeben von keysern, keysers kindern, fursten und herren, rechten herren desselbin landes ${ }^{92}$; dieselben czwyne briffe, alzo gegeben von unserm gnedigen herren homeister, sullen unschedelichen syn allen articulen des houptbriffes obir den kouff desselben landes, der gegeben ist von dem aldirluchsten unserm gnedigisten herren hern Sygismundo, konge tzu Ungern ${ }^{93}$. Czu merer sicherheit, das wir die vorgeschrebene unser huldunge stete und veste wellen halden, hab wir obingeschrebene ritther, knechte und stete im namen aller anderen, beyde edlynge, burgern, gebur, gemeyne adir welcherleye sie synt, in der Nuwen Mark gesessen uff deme lande und in den steten, unser ingesegel an dessen briff lassen hangen, der gegeben ist czu Arnswalde an deme abunde sancti Laurencii im vierczenhu[n]derstem und anderm yore.

2. Vogt der Neumark [Albrecht von der Duben] an Hochmeister [Heinrich von Plauen]: [1] Will zu dem Verhandlungstag mit [Heinrich] Grunenberg und [Hans] Qweis am 10. April alle Mannen und Städte der Neumark nach Landsberg entbieten; [2] hofft nach der Zusammenkunft mit den Städten und einem Teil der Mannschaft zu Landsberg am 24. März, daß sie Leib und Gut für den Orden einsetzen werden; [3] will das Land der Neumark auf dem Tag [am 10. April] dazu auffordern, zum Hochmeister zu reiten, sofern dort die Bede nicht bewilligt wird; [4] bedarf zur Befriedung der Straßen der Hilfe der Städte,

90 Urkunde Stibors vom 25. Juli 1402, siehe Staatsverträge I (wie Anm. 13), S. 23 Nr. 15 (oben Anm. 13).

91 Vgl. ebd. den Hinweis auf die zweite Urkunde Stibors vom selben Tag.

92 Die Urkunde Konrads von Jungingen vom 25. Juli 1402, Das neumärkische Ständearchiv (wie Anm. 6), S. 166 f. Nr. 5 (oben Anm. 15).

93 Siehe Anm. 90. 
für die sie Schadenersatz verlangen, hofft aber nach dem vergangenen Tag, zusammen mit Mannen und Städten der Neumark die Räubereien der Mannen der Herzöge [Bogislaw VIII.] von Pommern[-Stolp] und [Swantibor III. von Pommern-]Stettin, besonders diejenigen des Hans und Henning von Cremsaw, zu unterbinden; [5] hat den Städten der Neumark auf der Zusammenkunft zu Soldin am 25. November [1411] erlaubt, einen Landfrieden mit den benachbarten Fürsten und ihren Städten abzuschließen, ohne daß jedoch der Herzog [Bogislaw VIII.] von Pommern[-Stolp] sich anschließend dazu bereitgefunden hätte. Hermsdorf, [14]12 März 30.

GStA PK, XX. HA, OBA 1679 (ol. XIII 108). - Ausfertigung, Papier, Spuren des briefschließenden Siegels.

Außenadresse: Dem erwirdigem homeister Duczes ordens mit aller erw[ir]dikeit - $\mathrm{d}(\mathrm{en}-$ tur). - Inhaltsvermerk: Voyt der Nuwen Marke de pecunia ordini debita cum litteris eorum excusacionis $[\ldots \ldots \ldots]^{\mathrm{a}}$.

Reg.: ROT I/1/1, S. 101 Nr. 1679. - Repertorium, S. 54 Nr. 286a. - Kletke: Regesta, S. $59 \mathrm{f}$. (falsch datiert).

Meynen willigen undertonigen gehorzam. Erwirdiger und liber, genediger her meyster, [1] ewern briff, mir gesant, hab ich wol vornomen, in dem ewer genad schribet als von dem tage, den der marschalk ${ }^{94}$ gemacht hat mit Grunberg und Qweis ${ }^{95}$ etc. Thu ich ewern genaden czu wissen, das ich uff denselben tag als den nehsten suntag noch Ostern ${ }^{96}$ czusammen vorboth habe alle man und sthete der Nuwen Marke ken Landisberg. So hoffe ich, das ich dorczu nemen wil von man und steten, dye uns in den sachen nutcze und wol beqweme werden, noch ewer begerung, wenth ich, ab Goth wil, in den und in andern sachen das beste thun wil noch allen meynen vormogen; und wy ich den von dem tag entscheide, das wil ich ewern genaden an sumen vorschreiben. [2] Auch, genediger liber her meyster, ewer genad geruch czu wissen, das ich dis gancze jar gar swerlich gearbeit habe mit man und steten der Nuwen Marke und sunderlich mit eyn teils der steten und ir dorczu ny brengen kunde, mir gehorzam czu sein bis uff den tag als am donerstag noch Judica ${ }^{97}$; do hat ich stet und eyn teil der man besammen czu Landisberg. Nu danke ich Goth und hoffe, das ichs dorczu gebrocht habe mit guethen und unguethen, das syes meynen noch meynem rath czu halden und czu thun und leip und guth bey ewern genaden und dem orden czu czu setczen. [3] Auch als ewer genad schribet, wye ir dye lanth der Nuwen Marke vorboth hatte und sye nicht komen mochten dorch der ko ${ }^{\mathrm{e}} \mathrm{rcze}$ der czit und dorch unfredes wegen; doran sich ewer genad nicht g[e]ruche ${ }^{\mathrm{b})} \mathrm{zu}$ keren, sunder wenth ich den $\operatorname{tag}^{98}$ mit in halde, so wil ich sye czu ewern genaden heysen reithen, und uff welichen tag,

94 Oberster Marschall Michael Küchmeister (1411-1414).

95 Die Söldner Heinrich Grunenberg und Hans Qweis beanspruchten Sold vom Orden, nach Auffassung des Hochmeisters zu Unrecht. Vgl. die Quellennachweise bei Pelech (wie Anm. 27), S. 165 Nr. 95 mit Anm. 56.

96 [1412] April 10.

97 [1412] März 24.

98 D.i. der eingangs genannte Tag am 10. April 1412. 
das wil ich ewern genaden vorschreiben. Weres adir sache, das sye czu rathe worden, das sye dye bethe wolden geben, so wolde ich das understeen, das sye czu ewern genadn nicht dorfften reiten. [4] Sunder um der strose befredung geruch ewer genad czu wissen, das ich dorczu alleyn nicht gethun mochte sunder der stete hulffe, der ich nicht en hat, und sye nicht reiten wolden mitsampt den mannen, man stund in den vor schaden. Und wenth ich mit meynen dinern halden lis uff eynen hald ader uff czweyn, gelichwol nomen dye ro ber uff anderen strosen. Das geschit uns us des herczogens lanth von Pomern ${ }^{99}$ und seynen mannen und auch en teils von des herczoges man von Stethyn ${ }^{100}$ und sunderlich von Hanus und Hennig von Cremsaw, das ich nu, ab Got wil, noch dem egen(anten) tage vorgangen ${ }^{101}$ wol understeen wil mit hulfe und rath der man und stete der Nuwen Marke. [5] Auch geruchet czu wissen, als ich man und stete der Nuwen Marke bey mir hat czum Soldin den montag vor Katherine vorgangen ${ }^{102}$, do bothen mich dye stete der Nuwen Marke, in czu dirlauben eynen landfrid uffczunemen mit dem umgessenen fo ${ }^{\mathrm{e}}$ rsten und der forste steten. Das hat ich in dirlaubet und vorbriffet, sulchen lantfred mit in uffczunemen unschedlichen unser herschafft, das nymant understanden hat wenth der herczog von Pomern ${ }^{103}$, wenth mir genczlichen czu wissen worden ist von en teils der stethe der Nuwen Marke, wye das der herczog von Pomern czu seynen stethen sulde gesprochen haben: „Was landisfrede sal ich ufnemen? Ap ich den lantfrede uffneme, so muste ich in doch korczlichen uffsagen". Noch semlichen sachen hat sich ewer genad wol czu richten. Geben czu Hermansdorff am mitwoch in der marterwoch ${ }^{\mathrm{c})}$ anno XII․

Voigth der Nuwen Marke.

a) unleserlich. - b) Loch im Papier. - c) in der marterwoch zu Beginn der neuen Zeile wiederholt.

3. Hochmeister [Heinrich von Plauen] an Vogt der Neumark [Albrecht von der Duben]: [1] fordert dazu auf, die Häuser Driesen und Zantoch bestmöglich zu bestellen, auch wenn er, der Hochmeister, wegen des laufenden Verhandlungstag [in Ofen] nicht an einen polnischen Angriff glaubt; [2] ermahnt dazu, die [neumärkische] Mannschaft im Falle ihres Aufgebotes und bezüglich ihres Verlangens nach Kost, Futter und Schadenersatz entsprechend bisheriger Gewohnheit zu behandeln; [3] bittet, sich unter Verzicht auf 100 Spießen Söldner mit den Kräften der Neumark bis zur Rückkehr oder Nachricht der Ordensgesandten [aus Ofen] mit den Kräften der Neumark zu behelfen; [4] lehnt die Erstattung der angeblich vom Vogt ausgegebenen 300 Schock ab und hält zur Selbsthilfe bis zur Rückkehr der Gesandten an; [5] weist an, nötigenfalls die polnische Einnahme des Hauses Zantoch mit den Johannitern zu verhindern und eine eventuelle Beschädigung der

99 Herzog Bogislaw VIII. von Pommern-Stolp.

100 Herzog Swantibor III. von Pommern-Stettin.

101 D.i. der zuvor genannte Tag vom 24. März 1412.

102 [1411] November 23.

103 Herzog Bogislaw VIII. von Pommern-Stolp. 
Neumark oder der Häuser Driesen und Zantoch sogleich und unmittelbar den Ordensgesandten in Ungarn zu melden. $\quad$ Marienburg, [1412]104 Juli 26.

GStA PK, XX. HA, OBA 1712 (ol. XIII 111). - Konzept zweier Schreiber, Papier.

Vermerk: Copia littere magistri generalis ad advocatum de $\mathrm{No}[\mathrm{va}]^{\mathrm{a})}$ Marchia cum littera Heinrici de Junthersberg. In Ma[rienburg] ${ }^{\text {a) }}$ data III feria post Jacobi.

Reg.: ROT I/1/1, S. 103 Nr. 1712. - Repertorium, S. 54 Nr. 287.

Homeister Dutsches ordens.

Ersamer lieber her voith. [1] Euwirn brif uns gesand, der gegeben ist czu Hermansdorff am tage Marie Magdalene ${ }^{105}$, haben wir wol vornomen, und als ir darynne schreybet von der besammelunge der Polan und das sie meynen, das hus Drisden czu belegen adir ${ }^{\text {b) San- }}$ tok $^{\text {b) }}$ etc. Lieber her voith, wiewol wir glauben, das sich die Polan czurichten und besammeln, so hoffe wir doch nicht, das sie das thun adir euch sust beschedigen bynnen deßem tage ${ }^{106}$. Idoch so sihet yo gewarnet mit euwirn lande und bestellet die ${ }^{\text {c) }}$ huserc), als ir beste konnet und $\mathrm{mo}^{\mathrm{e}}$ get, das nicht vorwarlosunge doran geschee, wend uns grosse macht an den $^{\text {d) }}$ husern ${ }^{\text {d) }}$ leyt. [2] Ouch, als ir schreybet, ap is czu dingen queme, das denne die manschaft nicht worde reiten, man gebe in denne koste und futer und stunde in vor den schaden etc. Lieber her voith, wir bitten euch, das ir dieselbe manschaft fleisseclichen anleget, das sie das beste bie uns thun, und haldets so mit in, als mans vor gehalden hat, uff das sie deste gutwilliger werden, wend wir yo kegen in thun wellen, was do mogelich ist und als man in vor getan hat. [3] Als ir ouch schreybet von den 100 spissen, ap ir die uff solt soldet ufnemen adir wie irs domete halden suldet etc. Lieber her voith, wir bitten euch, das irs mit den 100 spissen besteen lasset und ${ }^{\text {e) }}$ behelfet euch, ap is euch not thun wirt, mit der Nuwen Marke, als ir beste konnet und moget ${ }^{\mathrm{e}}$, bis das unsire sendeboten wedir heymkomen $\operatorname{adir}^{f)}$ das wir botschaft von in haben ${ }^{\text {f107. }}$. Wie wir denne irkennen, das sich die ding machen wellen, dornoch so wellen wir euch ouch schreiben. [4] Vortme als ir schreybet von den 300 schoken $^{\mathrm{g}}$ [?], die ir hettet vorczeret bynnen deme krige ${ }^{108}$ und in den tagen vorczeret $^{\mathrm{h}}$, und bittet, euch mit gelde czu bedenken. Lieber her voith, als ir leczten [bie] uns woret ${ }^{\mathrm{i})}, \mathrm{do}^{\mathrm{j})}$ hulfen wir euch obir unser vormogen, so das ir meynet, das ir euch wol behelfen weldet, bis das euwere renthe gefile. Ouch wissen wir keynen krig, den ir gehalden habet, sundir den tag, den habet ${ }^{\mathrm{k})}$ ir ouch gehalden ${ }^{\mathrm{k}}$ an unsern willen ${ }^{\mathrm{l}}$. Was ir do vorczeret habet, so haben euwere vorfare ouch wol tage gehalden und haben sich dach ${ }^{\mathrm{k})}$ behulfen ${ }^{\mathrm{m}}$. Wir bitten euch, lieber her voith, das ir noch das beste thut bie allen dingen,

104 Das Jahr 1412 ergibt sich aus der wiederholten Bezugnahme auf die Ordensgesandten in Ungarn.

105 Hermsdorf, [1412] Juli 22.

106 Die Ende Mai 1412 in Ofen (Ungarn) begonnenen Schiedsgerichtsverhandlungen zwischen Vertretern des Deutschen Ordens und Polen-Litauens um die Bestimmungen des I. Thorner Friedens von 1411 endeten am 24. August 1412 mit dem von dem Schiedsrichter König Sigismund verkündeten Schiedsspruch.

107 Die Gesandten des Deutschen Ordens auf dem Verhandlungstag in Ofen unter Leitung des Obersten Marschalls Michael Küchmeister (vgl. die vorhergehende Anm.).

108 Krieg zwischen dem Deutschen Orden und Polen 1409-1411. 
und behelfet euch, als ir beste moget, bis das unsere sendeboten wedir czu lande komen; so wellen wir abir vort doruff gedenken, wie wir nu [?] thun, und euch dovon ${ }^{\mathrm{n})}$ ein guttig antwort $^{\text {n) }}$ schreyben.

[5] Ouch, lieber her voith, bitten wir euch, ap ir derkentet, das die Polan das hus Santok belegen welden ${ }^{\circ}$ adir sust dornoch stunden, so bestellets yo mit den Johannis [?] herren, das das hus die ${ }^{p)}$ Polan nicht ${ }^{\text {r) }}$ yngewynnen, wend ys der Nuwen Marke czumole schedelich were und ${ }^{\text {s) }}$ unserm lande ${ }^{\text {s) }}$, wie die Polan das hus ynne hetten. Gescheges ouch, das die Polan deme lande der Nuwen Marke adir den husern Drisden und Santok eingerley schaden adir ungemach czuczogen, das schreybet von stat an ane alles sumen unsern sendeboten ken Ungern, ee danne ir is uns schreybet, wend is czu lang were, so irs von ersten uns schrebet und wir ys denne vort sulden schreiben.

a) wegen rechten Randes nicht weiter ausgeschrieben. - b)-b) von der zweiten Hand auf dem rechten Rand mit Verweiszeichen nachgetragen. - c)-c) von der zweiten Hand übergeschrieben über gestrichen: das hus. $-d$ )-d) von der zweiten Hand den übergeschrieben über gestrichen demeselben sowie husern korrigiert aus huse. -e)-e) von der zweiten Hand auf dem linken Rand mit Verweiszeichen nachgetragen. -f)-f) von der zweiten Hand interlinear mit Verweiszeichen nachgetragen. - g) von der zweiten Hand übergeschrieben über gestrichen: marken. - h) folgt gestrichen: hevet. - i) folgt gestrichen: do habet ir uns eins sulchen nicht underrichtet, und weneten, das wir alle ding mit euch geslichtet hetten. Ouch so woret ir yo nicht bynnen deme krige in der Nuwen Marke, sunder Engelhard, euwir vorfar [Engelhard Kassau, Vogt 1410 November - 1411 Anfang April]. Ir wisset ouch selben und habets wol derkant, das wir keyn gelt nichten haben, das wir euch gesenden mogen noch euch domete czu hulffe komen; und dorumme, lieber her voith, habet ir etwas bynnen deßen tagen vorczeret, wir hoffen yo, das ir ein sulchs selben wol usrichtet und beczalet. - j) ab hier schreibt nur noch die zweite Hand. - k) übergeschrieben. - l)-l) folgt gestrichen: habet gehalden. - m) folgt gestrichen: Ir habet ouch unserm gebrechen. - n)-n) übergeschrieben über gestrichen: das denne. - o) folgt gestrichen: so bestellets yo mit den. - p) übergeschrieben über gestrichen: den. - r) folgt gestrichen: in derk. -s)-s) auf dem linken Rand mit Verweiszeichen nachgetragen.

\section{Vogt der Neumark Sander Machwitz an Hochmeister [Michael Küchmeister]:}

[1] Die neumärkischen Mannen und Städte wollen nicht erneut huldigen und schwören, da ihnen entgegen der Zusicherung des Hochmeisters [Konrad von Jungingen] ihre alten Gerechtigkeiten nicht eingehalten werden; sie würden gefangengenommen, Schaden erleiden und dadurch ins Verderben geraten. Sie wollen unter Berufung auf ein [Privileg] des Königs [Sigismund] von Ungarn über den Orden klagen. Die neumärkischen Unterhändler mit dem Hochmeister sind sich auf ihrer nachfolgenden Zusammenkunft zu Dramburg einig geworden, wie sie sich der Huldigung erwehren wollen. Michael von Sydow klagt darüber, daß die 450 Mark für die Auslösung seines Sohnes ihm nicht erstattet werden. [2] Der Vogt sendet dem Hochmeister die Antwort des Burggrafen [Friedrich VI.] von Nürnberg wegen der Leute von Bärwalde. [3] Er hat den Bischof von Lebus um eine Verhandlung in Küstrin am 4. März wegen der dortigen Leute gebeten. [4] Die 
neumärkischen Mannen wünschen vom Hochmeister zu erfahren, ob ihre Schäden von ihm beglichen werden, wenn sie nicht vom neuen Vogt wegen des Amtswechsels erstattet werden; der Vogt legt ihr diesbezügliches Schreiben an den Hochmeister bei. Soldin, [14]14 März 3.

GStA PK, XX. HA, OBA 2035 (ol. XIII 188). - Ausfertigung, Papier, briefschließendes Siegel. - Von zwei Händen geschrieben. - Textverluste sind wegen Löcher im Papier, wegen des abgerissenen unteren Randes und wegen Fleckens auf dem Papier entstanden. Außenadresse: Dem erwerdigen home[ister Dutsches] ordens mit aller werdich[eit] - d(entur).

Reg.: ROT I/1/1, S. 126 Nr. 2035. - Repertorium, S. 63 Nr. 342.- Kletke: Regesta, S. 65 f.

Minen willigen undertenigen gehorsam mit aller behechlikeit in allen gecziiten. Erwirdiger, lyber, gnediger her meister, [1] alz euwer gnade ir beful von der huldunge wegen, ufczunemen von euwer gnade wegen und denselbigen ingebet [ingebot?] an dy anderen czu brengen, dy do waren czu Hamerstein by euwern gnaden von den mannen und stethe ${ }^{109}$; thu ich euwern gnaden $\mathrm{czu}^{\circ}$ wissen, daz mirs domyd geet an dem eyn wege alz an dem anderen. Sy sprechen, sy haben eyns gehuldiget und gesworen dem orden ${ }^{110}$, dar wellen sy by thun alz bydderve luthe und der eren recht ist, und ober daz wellen zy mee nicht huldigen adder sweren; und sprechen ouch, wy in der meister, der sy irst ufnam, dem zy gehuldiget und gesworen haben, in geloubet und vorbryfet hoth, zy czu losen by irer alden rechtikeit, dy nicht czu mynren, zunder lyber czu bessern ${ }^{111}$, dez in doch nicht gehalden wirt. Sy werden gefangen, zy nemen schaden, by dem eyn voithe vor, by dem anderen hyndennoch, dy czien iren wech; der eyn gypt in zo vele alz der andere, also daz zy jo ym schaden blyben und werdens vortorben; und leechen mirs und machen mirs zo wunderlich mit irem schaden und anderen tyngen, daz ich schier nicht en weis, wor ich us adder in zal ader wes bu ${ }^{\circ}$ gynnen. Mir hoth eyn bidderve man gesaet, w $[\ldots \ldots \ldots \ldots . . .$. vom koninge von Ungarn, dy ich habe horen lesen, sy by irer rechtikeit czu losen [........ nicht wedderferet und geschiet ${ }^{112}$, zo wellen sy eyn uf machen $\mathrm{u}[\ldots \ldots$ konin]ge von Ungern und willen clagen aber euch und unsern orden. Ouch thu ich [euwern gnaden czu wissen?], alz ich von euwern gnaden schiit czu Hamersteyn und ich wedder ken Dramburg [qwam, erfur?] ich in warheit, wy dyselbigen, dy do waren geweset by euwern gna-

109 Hochmeister Michael Küchmeister weilte nach seiner Wahl am 9. Januar 1414 zunächst in der Marienburg (bis Januar 21), ist dann Januar 25 in Danzig, Februar 13 in Thorn, Februar 15 in Graudenz und Februar 24 wieder in Marienburg nachweisbar, von wo aus er sogleich zu einer Reise in das Niederland um Königsberg aufbrach; vgl. Neitmann: Hochmeister (wie Anm. 18), S. 85 f. Die Belege deuten darauf hin, daß er Mitte Februar 1414 das Kulmerland und Pommerellen zur Entgegennahme der Huldigung durchzogen hat; während dieses Umrittes könnte er ca. Februar 20 in Hammerstein die Vertreter der neumärkischen Stände getroffen haben.

110 Vgl. oben Quellenanhang, Nr. 1 (Urkunde von 1402 August 9), siehe oben S. 286 f.

111 Vgl. Das neumärkische Ständearchiv (wie Anm. 6), S. 166 Nr. 5 (1402 Juli 25); siehe oben S. 250 f.

112 Es wird wohl Bezug genommen auf die Urkunde König Sigismunds von Ungarn vom 21. März 1402, in der er die neumärkischen Privilegien bestätigte und sich auch im Falle der Verpfändung der Neumark für ihre Einhaltung einzusetzen versprach; siehe oben Anm. 11. 
den von man[nen und ste]ten, czusament gyngen in eyn kamer und gossen dar gy glochke und wurdens eyn, wy zy sich der huldunge weren wolden, alz is mir nu von euwer gnade wegen wedderfaren ist. Ouch zo hoth zunderlichen Michil von Sidow gesprochen, daz man im nicht dy 450 marken weddergybt, dy her vor sines sones gefenknisse hoth musen geben, dy sullen dem orden schaden 4.500 marcen, dar euwern gnaden steit uf czu gedenken. [2] Ouch, gnediger her meister, sende ich euwern gnaden daz entwert von dem burggraffen von Norenberg ${ }^{113}$ uf euwern bryf, im gesant von der Bernwaldischen wegen, den euwer gnade wol wirt vornemen etc. [3] Ouch hoth mir zunderlich der bischoff von Labus ${ }^{114}$ geschreben alz von der Costrynischen wegen. So hab ich im wedder geschreben und gebethen, daz her zich welde odmudigen, jegen mir czu kamen ken Costryn uf ${ }^{\text {b) }}$ den suntag Reminiscere ${ }^{\mathrm{b}) 115}$ adder syne gewaldigen dar senden, dy aller sache von [s]ynentwegen mechtik weren; zo hoffede ich czu Gothe, daz wir alle dynk welden gutlichen heenleggen und fruntlichen alle zachen czu eynem ganczen ende dirscheiden, [a]ls nu euwer gnade ouch dovon geschreben hatthe. Ouch ${ }^{\mathrm{c}}$ werdens euwer gnade wol vor[nemen?] in dyssem ingeschlossen bryfe. [4] Sunderlichen, gnediger her meister, thu ich euwern gnaden [cz] u wissen, wy daz mich dy man in der Marke vorgeleet haben alz von eyns bryfes wegen, den [..] en sy von euwern gnaden bugerende, ap sy schaden untfyngen by mir adder by eym andern [voi]the und der abegynge, wy is qweme und ire schaden in nich[t] weddergeleet wurde, ap sy den schaden by euwern gnaden solden fynden adder wy sy is darumme halden sullen etc. Des haben sy eyn bryf losen schreiben und haben mich gebethen, den mit mynem bryfe euwern gnaden czu senden, dez ich in nicht weygern adder vorsagen kunde. Waz sy haben euwern gnaden geschreben, ist mir unwissentlich. Waz euwer gnade guthis hy by thun will, mogen euwer gnade uf gedenken. Gegeben czu Soldyn am sunnabende vor Reminiscere anno XIIII'.

Sander Machwitcz, voith der Nuwen Marke.

a) unterer Rand des Papiers ausgerissen. - b)-b) von der zweiten Hand auf dem linken Rand nachgetragen. - c) ab hier schreibt die zweite Hand.

5. Hochmeister [Paul von Rusdorf] an Vogt der Neumark [Walter Kirschkorb]: übersendet zwei vom ehemaligen Hochmeister [Michael Küchmeister] und von ihm selbst ausgestellte Vollmachten, in denen Mannen, Städte und Untertanen der Neumark ihrer Huldigung erlassen werden. Marienburg, 1422 Juni 24 [Auszug].

GStA PK, XX. HA, OBA 3780 (ol. XIII 177). - Konzept, Papier. - Textverluste wegen Löcher im Papier.

Edition bzw. Reg.: Toeppen, Ständetage I, S. 392 Nr. 310 (Teildruck). - Prokuratorenberichte III, Nr. 120 (Reg. unter Außerachtlassung der hier abgedruckten Textstelle).

113 Burggraf Friedrich VI. von Nürnberg, seit 1411 Verweser der Mark Brandenburg, 1415/17 Markgraf und Kurfürst.

114 Bischof Johann Borsnitz von Lebus (1397-1420).

115 [1414] März 4. 
Dem voithe der Nuwen Marke.

Her voith ${ }^{\text {a) }}$, hirbey werden euch geentwert czwene offene brife, eynen von ${ }^{\text {b) }}$ unsers alden homeisters und den andern von unsers selbens wegen, in den ir werdet gemechtiget, manne, stete und [un]dirsassen der Nuwen Marke irer holdungen czu irlassen und denne die wedir von $[\ldots \ldots \ldots \ldots \ldots \ldots . . . . . . . m e n$, als ir das alles wol befynden werdet und gelernet

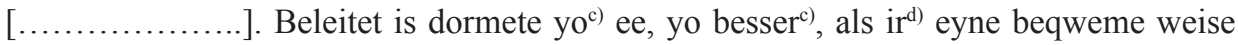
dorczu $[\ldots . . . . . .$.$] ussynnen werdet. [Folgen andere Gegenstände].$

a) folgt gestrichen: bey dessem beweisere senden wir eu [?]. - b) übergeschrieben. c)-c) interlinear nachgetragen. - d) folgt gestrichen: wol.

6. V[ogt der Neumark Nikolaus Nickeritz] an Hochmeister [Paul von Rusdorf]: [1] hat mit dem Komtur zu Danzig [Walter Kirschkorb] entsprechend dem hochmeisterlichen Befehl Mannen und Städte der Neumark um Erneuerung der Huldigung ersucht, die Städte haben ihn jedoch zwecks ihrer Beratung um Aufschub bis Ostern [März 27] gebeten und wollen dem Vernehmen nach die Huldigung verweigern. [2] Da die Brüder Borchard und Eckart von Güntersberg am 20. Februar in ihrem Dorf Woltersdorf bei Schlochau weilen, wird er, der Vogt, sie bitten, die diesbezüglichen Geschäfte entweder dem Hochmeister persönlich, sofern er in die Nähe kommt, oder dem Komtur zu Danzig zur Weiterleitung an den Hochmeister mitzuteilen. [3] Über den Streit zwischen den von Uchtenhagen und den von Brederlow um die dem verstorbenen Hans von Brederlow zu Dertzow zugehörigen Lehngüter hat er einen Verhandlungstag zu Königsberg [Neumark] mit dem auf den beiliegenden Zettel dargelegten Ergebnis ausgerichtet. [4] Er wird gemäß hochmeisterlichem Befehl auf den Schutz des Hauses Driesen sorgfältig achten. Arnswalde, [14]29 Januar 22.

GStA PK, XX. HA, OBA 5037 (ol. XIVa 57). - Ausfertigung, Papier, Spuren des briefschließenden Siegels. - Textverluste wegen Löcher im Papier.

Außenadresse: Dem erwerdighen homeister $\mathrm{Du}^{\mathrm{o}}$ thschs ordens mit allir erwerdikeit ane alles sumen, sunderge maght daran liet. - Beförderungsvermerke: Gegangen vom Elbinge am sonnobende vor purificacionis Marie ${ }^{116}$ noch mittage hora secunda. - Gekomen unde gegangen von der Balge am sontage dornoch ${ }^{117}$ vor mittag hora IX ${ }^{\mathrm{a}}$. - Gekomen unde gegangen von Brandenburg am sontage noch mittage hora secunda. - Gekomen unde gegangen von Konig[sberg] am sontage vor purificacionis Marie hora VIa vor mitternacht. - Gekomen czu Waldow am montage vor purificacionis Marie ${ }^{118}$ im XXIX $^{\text {ten }}$ jore $^{119} .-$ Inhaltsvermerk [?]: Voyth ${ }^{\text {a) }}$ [de]r Neuwen Mark.

Reg.: ROT I/1/1, S. 314 Nr. 5037. - Repertorium, S. 105 Nr. 609.

116 [1429] Januar 29.

117 [1429] Januar 30.

118 [1429] Januar 31.

119 Der Brief wurde, wie die Beförderungsvermerke zeigen, - vermutlich von Marienburg aus - über Elbing, Balga, Brandenburg und Königsberg dem damals auf einem Umzug durch das sog. Hinterland, d.h. das (nord)östliche Ostpreußen befindlichem Hochmeister nachgesandt und erreichte ihn 
Willighen undertenighen ghehorsam mit aller beheghlikeit euwern erwerdighen gnaden in allen ghecziithen. Erwerdiger, gnediger, lieber hern meister, [1] so denne euwer gnade dem kumpthur czu Danczik ${ }^{120}$ und mich inghegebin hatthe und befolen, als von weghen der vornuwunghe der huldunghe czu reden und vorczubrenghen euwern mannen und stethen der Nuwen $\mathrm{Ma}[\mathrm{rke}]$, daz wir beqwemichligh an sie ghebracht haben euwer gnade wille und begherunghe daryne yn vorghelehet, als daz der kumpthur von Danczik euwern gnaden wol hot underrichtet. Gnediger her meister, ich hatthe ghehoffet, zy zolden billigh euwern begher daran vorfullet haben, daz doch nicht gheschein ist. Ich waz uf der fart und czogh umme yn dy stethe und wolde dy huldunghe uffghenomen habin; hatten sie sich voreynt und schreben mir ire briffe, dar ich in io entwert uff schrep, und baden umme tagh bys uff dy Ostern ${ }^{121}$ dorin czu ghebin, uff daz sie sich mitenander egentlik berothen und besprechen muchten, daz noch also steit, und zetczen sich $n u^{\circ}$ doweder und meynen, als ich vorneme, dy huldunghe nicht czu thunde. [2] Wor $n u^{\circ}$ euwer gnade daz von hoth und wie daz herkumpt, kan ich euwern gnaden itczunt nicht vorscreben; sunder dy euwern Borchard und Egghard brudere von Gunttersbergh dy werden in iren gheschefthen czyhen, und uff Reminiscere negeste in der faste ${ }^{122}$ werden sie sien czu Walterstorff by Slochow in irem dorffe ${ }^{123}$, dar yn sunderghe macht an lyet, daz sie langhe vorczoghen haben; dy ich under deme werde bitthen und bekummern, wen euwer gnade denne uff der nehede were, daz sie vorbat czu euwern gnaden ritthen, dy dingh und gheschefthe anrichten $^{124}$, wy zie sich haben, daz daz yn grunt[lic]h kunt ist und wissentlich. Ap zie nu czu euwern gna[den] nicht muchten komen czu der cziet, [zo] werde ich sie anlanghe, daz sie dyselbighen sachen dem [k]umpthur von Danczik antraghen, der euwern [g]naden klerligh dovon usrichtunghe wirt thun; hir mag[h] euwer gnade uff budocht sien. [3] Nemlich, gnediger her meister, zo sien etczwelke czwydrechte czuschen $\mathrm{d}[\mathrm{en}]$ euwern in der Nuwen Marke als czwuschen den Uchtenhaghen und den Brederlo von zemlichen leheenguthen weghen, daz Hanse von Brederlo czu Dertczowe seliger ghedechtnisse hatthe czughehort, daz dem kumpthur von Danczik egentlich wissentlich ist, wy sich dy dingh $\mathrm{nu}^{\mathrm{o}}$ haben; darumme sie nuwelich vor mich eynen tage haben ghehalden czu Koningesbergh und sien also dovon ghescheiden, als nu ${ }^{\circ}$ disse ingheslossen czedel ${ }^{125}$ uswiset, dar euwer gnade ouch wol magh uff bedocht sien, wy man in den gheschefthen beqwemlich muchte faen, daz kein gheczenke in euwern landen dovon untstunde ${ }^{\mathrm{b})}$. [4] Ouch, gnediger her meister, scribet euwer gnaden von weghen $\mathrm{d}[\mathrm{es}]$ huses czu Drisen, daz in sorghfaldiger huthe czu habin, daz ich mynen hoghsten flies $[\ldots . . . . . .$.$] wil nach mynem hochsten$

in Waldau (östlich von Königsberg). Zum hochmeisterlichen Itinerar vgl. Lückerath (wie Anm. 34), S. 215.

120 Walter Kirschkorb, Komtur von Danzig 1428-1434, zuvor, von 1422-1428 Dezember 27, Vogt der Neumark, der unmittelbare Vorgänger von Nickeritz.

121 [1429] März 27.

122 [1429] Februar 20.

123 Woltersdorf, Kreis Schlochau (1914).

124 Hochmeister Paul von Rusdorf ist am 1. und 2. März 1429 in Danzig, am 12. März in Schlochau nachweisbar. Lückerath (wie Anm. 34), S. 215.

125 Der Zettel liegt bei, hier nicht abgedruckt.. 
vormoghen. Gegeben to Arnswalde ame daghe Vincencii [under mi]ns amptes ingesegel anno XXIXo.

$\mathrm{V}[\text { oigt der Nuwen Marke }]^{\mathrm{c})}$.

a) davor Loch im Papier; ob und wieviel Text vor dem Wort dadurch verlorengegangen ist, läßt sich nicht feststellen. - b) folgt gestrichen: doch so hab ich yn frede ghebothen zu halden czu beider cziet by lybe und by guthe. - c) rechte untere Ecke des Papierblattes ausgerissen, Umfang der Ergänzung unklar.

7. Sigmund, Römischer König und König zu Ungarn und Böhmen, an Mannschaft und Städte der Neumark: hat vernommen, daß sie sich der Huldigung, die dem Hochmeister und dem Orden zu Preußen zu leisten er ihnen nach Zueignung des Landes an diese geschrieben hatte, widersetzen und seine diesbezügliche mündliche Anweisung erwarten. Daher befiehlt er ihnen, mit je vier Angehörigen der Mannschaft und der Städte auf dem von ihm und den Kurfürsten, Fürsten, Herren und Städten zur Bekämpfung der [hussitischen] Ketzer zu Nürnberg angesetzten Tag nach Ostern (April 16) zu erscheinen, damit sie dort von ihm ihre Entlassung aus der ihm geleisteten Huldigung empfangen. Tirnau, [1430] März 17.

GStA PK, XX. HA, OBA 5311 (ol. XIIIa 147). - Ausfertigung, Papier, Spuren des briefschließenden Siegels. - Außenvermerk: Item das ist der dritte briff an mannen, steten der Newemargen. - Ebd. eine zeitgenössische Abschrift.

Reg.: ROT I/1/1, S. 332 Nr. 5311. - Altmann II, Nr. 6752. - Kletke: Regesta, S. 102.

Wir Sigmund, von Gotes gnaden Romischer kunig, zu allen czeiten merer des reichs und zu Hungern, zu Beheim, Dalmacien, Croacien etc. kunig, embieten den strengen und vesten rittern, knechten und mannen und den fuersichtigen burgermeistern, reten und burgern gemeinlich der stet des landes der Newenmark, unßern lieben getruen, unser gnad und alles guet. Lieben getruen, als wir dasselb land der Newenmark mit allen seinen zugeho ${ }^{\mathrm{e}}$ rungen, rechten und herlichkeiten, nichts ußgenomen, das unser vetterlich erb gewezt ist, dem erwirdigen hoemeister und dem orden zu Preussen, unsem lieben andechtigen, als sie dann das vormals von uns in pfandweiß, als ir brieff, die sy von uns doruber haben, clerlichen usweisen ${ }^{126}$, ynne gehabt haben, Got und unser lieben frawen zu lob und zu eren gnediclichen gegeben und zugeeygent haben, als dann unser kuniglich maiestatbrief, in doruber gegeben, das clerlichen usweisen ${ }^{127}$, und als wir euch dann sunderlich ouch geschriben und gebeten haben, das ir dem egen(anten) hoemeister und dem orden nach laut unser brieff huldung tu ${ }^{\mathrm{e}}$ n soltet ${ }^{128}$; also haben wir vernommen, wie ir euch soliche huldung $\mathrm{zu}$ tuen widersetzet und meynt, das nit anders dann uff unser muntliche empfehlnuß zu tuen, das wir ouch willig zu tuen sein. Und sinddemmal wir ytzund uf mit-

126 Urkunde Sigismunds vom 29. September 1402, Staatsverträge I, S. 24 Nr. 17 (oben Anm. 16).

127 Urkunde Sigismunds vom 7. September 1429, Staatsverträge I, S. 181 Nr. 168 (oben Anm. 34).

128 Urkunde Sigismunds vom selben Tag, erwähnt ebd., S. 181 Nr. 169 (oben Anm. 35). 
vasten $^{129} \mathrm{zu} \mathrm{Nu} \mathrm{e}^{\mathrm{e}}$ remberg uf eynem gemeinen tag, den wir und unsere kurfursten, fursten, hern und stete, den ketzern zu widersteen, gesatzt haben, sein werden, dorumb so ist unser meynung, bevelhen und heissen euch ouch ernstlich und vesticlich mit disem brieff, das ir vyer von der mannschaft und vyer von den steten mit voller macht zu uns gen $\mathrm{Nu}^{\mathrm{e}-}$ remberg oder wo wir dann in deutschen landen sein werden nach Ostern ${ }^{130}$ sendet, solich empfelhnu ${ }^{\mathrm{e}} ß$ muntlich von uns zu ho ${ }^{\mathrm{e}}$ ren und ufzunemen habt, und tu't dorynn nit anders bey unsern hulden. Geben zu Tyrnaw am freytag vor dem suntag Oculi in der vasten, unserer reiche des Hungerischen etc. im XLIII, des Romischen im XX und des Bohemischen im X jaren.

Ad mandatum d[omini] regis Caspar Sligk ${ }^{131}$.

8. Komtur zu Danzig [Walter Kirschkorb] an Hochmeister [Paul von Rusdorf]:

[1] Nach den in der Mark umlaufenden Gerüchten sollen die Kurfürsten und der Römische König [Sigismund] jetzt oder demnächst in Nürnberg zusammenkommen, wohin sich auch Herzog Kasimir [VI.] von [Pommern-]Stettin derzeit begibt. [2] Die [neumärkischen] Mannen und Städte haben sich zur Huldigung bereiterklärt und werden Borchard von Güntersberg und den Bürgermeister zu Arnswalde Janike Zoldin zum Hochmeister mit der Bitte um schriftliche Bestätigung ihrer alten Gerechtigkeiten entsenden. [3] AuBerdem werden sie Borchart von Güntersberg, Klaus Strucz, den Bürgermeister zu Soldin Welsow und den Ratmann zu Königsberg Hans Grunitcz zum Römischen König [Sigismund] schicken, also zur Verringerung der Zehrungskosten nur vier statt der vom König gewünschten acht Personen. [4] Der Komtur wird morgen heimwärts [nach Danzig] ziehen.

[Zettel:] Borchart [von Güntersberg] und Janike Soldin wollen vom 13. bis zum 17. Mai über Landeck, Schlochau, [Preußisch] Stargard zum Hochmeister auf die Marienburg ziehen. Soldin, [14]30 Mai 4.

GStA PK, XX. HA, OBA 5361 (ol. IV 104). - Ausfertigung, Papier, Spuren des briefschließenden Siegels.

Außenadresse: Dem erwerdigen homeister Duthschs ordens mit aller erwerdikeit tag unde nacht ane alles sumen, zunderge grosse magh daran liet. - Beförderungsvermerke: Gegangen vom Soldin am fritage na crucis ${ }^{132}$ gar $\mathrm{ffru}^{\circ}$. - Gegangen vom Arnswolde am fridage na crucis hora $4^{\text {ta }}$ post meridiem. - Gegangen von Schivelbin am fritage nach crucis hora III ${ }^{\mathrm{a}}$ vor mittage. - Empfängervermerke: Kump[tur] von den Danczk usz der Nuwen Marken. - Responsio est facta etc.

Reg.: ROT I/1/1, S. 335 Nr. 5361. - Repertorium, S. 110 Nr. 640.

129 [1430] März 26.

130 [1430] April 16.

131 Kaspar Schlick, damals Vizekanzler König Sigismunds.

132 [1430] Mai 5. 
Mynen willighen, undertenigen ghehorsam euwern gnaden mit aller behechlikeit czuvor. Erwerdiger, gnediger, lieber hern meister, [1] wol zold ich euwern gnaden cziithunghe scribin als von den gheschefthin der korforsthen etc., doch kan ich von hern adder andern waraftighin eghentligh nicht derfaren, wie sich die dingh derloufen. Die rede geen hie in der Marken, daz die korforsten lichte itczunt edder gar uff eyn korcz czu Norenberge uff die cziit, ouch unser here Romescher koninge mit yn dar czuzamen werden kamen, unde herczoge Kasemir von Stetin itczunt uff dem weghe ist, doheen ken Norenberge czu czihen; daz ist luthbar unde enket. [2] Sunderlich von der gheschefthe weghin der huldunge, gnediger hern meister, habin sich die euwern man unde stethe willichlich yngegebin, darumme Borchart von Gunttersberge, Janike Zoldin, borgermeister czu Arnswolde, euwer gnaden werdin suchen kortczlich brifflich unde muntlich vorczubrenghen unde bugerlighen bitthende, yn brifflich czu vorsegheln, sie czu losen evichlich by iren alden rechtikeiden. Bynnen achtagen werden sie uscziheen, unde uff welche cziet sie by euwern gnaden werdin sien, wil ich von Slochow daz euwern gnaden wol vorscribin, daz euwer gnade io uff der nehede sie unde uff die cziit etczwelche ghebitiger by euch moget ghehabin. [3] Nemlighin zo habin sie noch des voythes ${ }^{133}$ unde mynem rothe disse 4, Borcharde von Gunttersberge, Claws Strucz, Welsowen, borgermeister czu Soldin, Hans Grunitczen, rotman czu Koningesberge, irkorn, darnehest czu czihen czu unserm hern Romischin koninge, wor sie den moghin ghehabin; disse 4 uns dunkin und konen [?] irkennen, daz sie euwern gnaden unde unserm orden nutcze und gar beqweme darczu sien. Wol sulde irer 8 sien noch uswisunghe unde begerunghe unsers hern Romeschin koninges unde noch luthe syns briffes ${ }^{134}$. Nu umme ringer czerunge willen, daz yn lichte czu sweer wurdin, werden sie mid [?] die 4 senden. [4] Ouch werd ich als morghin, daz ist der fritage noch crucis, von hynnen cziheen heymwart. Gegeben czu Soldin am dunrestage nach invencionis sancte crucis under myns amptes ingesegel anno $\mathrm{XXX}^{\circ}$.

Kumpthur czu Danczik.

Zettel: Gnediger hern meister, noch dem datum disses briffes zyen sie als Borchard und Janike Soldin czu rothe ghewordin, daz sie bys sunnavent negestkamen vort aver achtage ${ }^{135}$ up dy nacht werden ligghen czu Landecke, darna uff den suntage ${ }^{136}$ czu Slochow, den mantage ${ }^{137}$ uff der vrue, den dinstage ${ }^{138}$ czu Stargard, den mitwoche czu Marienburgh $^{139}$. Ap euwer gnade nicht uf der nehede were, mu $^{\circ}$ chte euwer gnade bestellen czu Stargard edder en keghen scribin, wor sie czu euwern gnaden sullen kamen.

133 Vogt der Neumark Nikolaus Nickeritz.

134 Sigismunds Schreiben vom 17. März 1430 an Ritterschaft und Städte der Neumark, siehe Quellenanhang, Nr. 7.

135 [1430] Mai 13.

136 [1430] Mai 14.

137 [1430] Mai 15.

138 [1430] Mai 16.

139 [1430] Mai 17. 
9. Hochmeister Paul von Rusdorf bekennt, [1] daß ihn Mannen und Städte der Neumark, nachdem König Sigismund ihr Land dem Deutschen Orden übereignet hatte, gebeten haben, ihnen die von Hochmeister Konrad von Jungingen gegebenen Artikel mit weiteren Stücken zu erneuern. [2] Daher bestätigt der Hochmeister ihre Privilegien, Rechte und alterhergebrachten Gewohnheiten. [3.a] Der Ordensvogt wird der Mannschaft, wenn der Hochmeister oder er sie zum Dienst auffordert, Unterhalt für den Auszug aus ihren Häusern und die Rückkehr dorthin gewähren und für allen Schaden einstehen. Wenn der Vogt wegen ihrer schweren Niederlage den Schaden selbst nicht zu ersetzen vermag, wird der Hochmeister diese Verpflichtung übernehmen. [3.b] Wenn die Städte zu Diensten auBerhalb der Landesgrenzen in einem anderen Land aufgefordert werden, werden sie bis zur Rückkehr in ihr Land wie die Mannschaft behandelt, jedoch nach redlichem Beweis und nach Erkenntnis des neumärkischen Rates. [4] Der Hochmeister wird den Neumärkern verlorengegangene Urkunden und Handfesten ohne Gabe an die Herrschaft erneuern [5] und gelobt, alle vorstehenden Artikel den Mannen, Städten und Einwohnern der Neumark unverbrüchlich zu halten. Thorn, 1430 Juli 13.

GStA PK, XX. HA, Ordensfoliant 95, fol. 180v-181v. - Gleichzeitige Abschrift. - Wörtliche Übernahmen aus der Vorurkunde Hochmeister Konrads von Jungingen von 1402 Juli 25 sind im Petitdruck wiedergegeben, dabei sind Auslassungen aus der Vorlage durch* gekennzeichnet. - Überschrift: Vorschreibunge der manschafft, steten, inwonern der Nuwenmarke, als sie der Ro[mische] ko[ning] dem orden hat vorschreben und voreigenth,

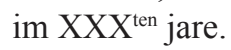

Wir bruder Pauwel von Rusdorff, des ordens sente Marien des Dewtschen huwsses von Iherusalem homeister, thun kunth und offembar bekennen allen, den desse schrifte werden vorbracht, [1] das sint der czeith der allerdurchluchtste furste, unsir allirgnedigster herre, herre Segemunde, Romischer, Hungirscher und Behmischer etc. koning, von sunderlichen gnaden uns und unsirm orden hat gegeben und voreigent das land, die Nuwemarke benumpt, und die mechtiglich an unsirn orden geweißet mit alle irer czubehorunge unde inwonern, gleichs als seyne gnade dy gehabt hat und die brieffe, dorobir von seynir koninglichen maiestat gegeben, das clar ussweisen ${ }^{140}$, so haben uns manne unde stete, dorynne wesende, demutiglichen angelegen, das wir semeliche articulos, die von dem erwirdigen seligen gedechtnisses bruder Conrad von Iungingen, uff die czeit homeister, als dieselbe Nuwemarke erst an unsirn orden qwam, [sien vorschreben] ${ }^{\text {a) }}{ }^{141}$, en geruchten zu vornuwen mit etlichen andern vorgegeben stucken etc. Des so haben wir angesehn ire so lipliche, gunstige czuneigunge unde rechtfertige truwe, die sie czu unsirm orden haben, unde mit reyffem, wolbedachtem unsirer gebietigere rathe sien wir en des gerne gefollig unde begeren wissentlich czu sien allen, die dessen brieff sehn adir horen lesen, [2] das wir den vorgedachten unsirn lieben getruwen * rittern, knechten, burgermeistern, rathmannen,

140 Staatsverträge des Deutschen Ordens, Bd. 1 (wie Anm. 13), Nr. 168.

141 Ebd., Nr. 15-16. 
burgern, gebuwern unde gemeynen sowohl uff deme lande als in den steten derselben Nuwenmarke, sie seyn geistlich adir wertlich, epten, eptischynnen unde thumherren, welcherley wirdikeith adir wesens die sien, mildeclich mit crafft dessis brieffes bestetigen unde beweren alle ire privilegia, gerechtikeiten unde freiheiten, die en in vorczeiten vorlehnet sien und gegeben von keyßern, keysers kindern, fursten unde furstynnen rechter herschafft des ebenumpten landes, dorczu alle lobeliche und redeliche gewonheiten, von alders gehalden doselbist im lande. [3.a.] Sunderlichen begnaden wir die manschafft des ebenumpten landes mit eym sulchen, ap wir adir unsirs ordens voith doselbist sie czu unsirn dinsten heischten adir lissen heischen, so sal unsirs ordens voith derselben Nuwenmarke en notdurfft geben us iren huwßern und wedir dorin unde vor allen schaden stehn, als vormols unsirs ordens voithe getan haben. Geschege abir, do Got vor sey, der manschafft semeliche swere nedirloge unde sulcher grosser schade, das unsirs ordens voith doselbist des czu swach were unde nicht vormochte ussczurichten, so wellen wir mitsampt unsirn nochkomelingen sulchen schaden selbir richten. [3.b] Wurden ouch unsire lieben getruwen der stete in der Nuwemarke geheischen czu unsirn dinsten und so die bussen unsirn landen grenitczen in eyn andere landt bracht wurden, so sal man en phlichtig sien czu thuen gleichs unsirn mannen so lange, bis das sie in unsire landt wedirkomen, doch mit sulcher underscheiden, ap man en des noch redelicher beweisunge wirt phlichtig sien unde noch irkentnisse unsirs rathes derselben Nuwemarke. [4] Vorturben ouch imandes der Nuwenmarke seyne alden brieffe unde hantfesten adir fuwers halben adir ouch sust in anderer weise czunichte wurden, semlichen alsam wellen wir ire hantfesten, die en also abegingen, ane gift unde goben der hirschafft gerne vornuwen, wenne wir mit redelichkeit unde worheith underweiset werden, wie die alden gelautet haben unde ouch in der weise, wie sie ire gutere in besitczunge von alders gehabt haben bis uff die czeit, als sie der vornuwunge sien begerende. [5] Alle die obengeschrebenen stucke unde artikel unde eynen iclichen besunder vor sich glowben wir bruder Pauwel, homeister vorgedocht, unsirn lieben unde getruwen mannen, steten unde inwonern der Nuwemarken vor uns, unsire nochkomelinge und unsirn gantczen orden stete, feste, heil unde unvorrucket czu halden czu ewigen czeiten. Unde des czu grossir sicherheith haben wir unsirs ordens groste ingesegel mit rechter wissenschaft lassen anhengen dessem brieffe, der gegeben ist uff unsirm huwße Thorun an sente Margarethe, der heiligen jungfrauwen, tage in den joren unsirs Herren tuwsuntvierhundert unde im dreissigsten jare. Des sien geczuwge unsire lieben in Gote brudere unde gebietigere Erasmus Fischborn, groskompthur, Henrich Holth, obirster marschalke, Conradt Beldirsheym, obirster spitaler und czum Elbinge, Merten Kempnather, obirster trappier und czu Cristburg kompthure, Herman Gans, treßler, Lodwig von Landzee, czu Thorun, Jost Hoenkircher, czum Tuchel, Walter Kirskorp, czu Dantczke, Johan Pomersheym, czu Slochow, Vincencius Wirczpurger, czur Golube kompthure, her Nicklos, unsir caplan, Rutcher von Schonenwert, Wetczil von Wladicheym, unsire compan, Lucas unde Martin, unsire schreibere, und vil ander glowbenwirdige.

a) die in der Abschrift dieser Urkunde und der ihr in diesem Passus folgenden Nachurkunde von 1430 Dezember 29 (Quellenanhang Nr. 11.A.B) fehlenden Worte sind ergänzt 
nach dem Text der Ausfertigung der letzteren Urkunde, vgl. die Edition in: Das neumärkische Ständearchiv, S. 169.

10. Hochmeister [Paul von Rusdorf] an den Ordensmeister zu Livland [Zisse von Rutenberg]:

hat den Komtur von Schlochau [Johann von Pommersheim] mit etlichen Mannen und Städten der Neumark zum Römischen König [Sigismund] wegen der Befreiung von ihrem Eid und um anderer Sachen willen, besonders wegen der Sorge vor der Feindschaft der Polen und der Ketzer [Hussiten], entsandt. Marienburg, 1430 September 5 [Auszug].

GStA PK, XX. HA, OBA 5456 (ol. XVII 175). - Konzept, Papier.

Reg.: ROT I/1/1, S. 341 Nr. 5456. - Repertorium, S. 111 Nr. 649.

Teildruck mit Reg.: Liv-, Est- und Curländisches Urkundenbuch, Bd. 8: 1429 Mai-1435, bearb. v. Hermann Hildebrand, Riga, Moskau 1884, S. 177 Nr. 305.

[...] Ouch wisset, das wir den kompthur von Slochow ${ }^{142}$ mit etlichin mannen und ouch der stete der Nuwen Marke gesant haben czum hern Ro[mischen] ko[ning] als von der freysagunge ires eydes und sost ouch umb mancherlich vaste vil sachen, die uns vor augen halden, undir den wir keyns so sere besorgen, als das die Polner mitsampt den ketczern eynen mutwillen werden czuczihen unserm orden. Dis schreiben wir euch umb eyn sulchs, ap uns sulche not wurde entstehen, do Got vor sey, das ir ouch gewarnet seyt uns czu helfen. [...]

11. Bericht [des Komturs zu Schlochau Johann von Pommersheim ?] zu den Verhandlungen der Bevollmächtigten des Hochmeisters [Paul von Rusdorf], der Komture zu Danzig [Walter Kirschkorb] und Tuchel [Jost von Hohenkirchen], mit der Mannschaft und den Städten der Neumark in Soldin vom 27.-30. November [1430] über die Bedingungen der ständischen Erbhuldigung für den Hochmeister:

[1] Die vom Hochmeister mit der Entgegennahme der ständischen Huldigung beauftragten Komture fordern auf ihrer Anreise den Vogt der Neumark [Nikolaus Nickeritz] auf, seinen Rat nach Soldin zu bestellen und die Räte aller neumärkischen Städte und die Mannschaft kurzfristig zu sich zu entbieten. [2] Verhandlung zu Soldin am 27. November: Auf die Forderung der Komture nach der Erbhuldigung erklären sich der Rat des Vogtes und die vornehmsten Mannen zu ihrer Leistung bereit, sofern ihnen ihre Privilegien und die übergegebenen Artikel bewilligt werden, während die Städte nach Beratung mit den gemeinen Mannen um Aufschub bis zum folgenden Tag bitten und nach Fürsprache des Rates erhalten. [3] Verhandlung am 28. November: Entgegen der städtischen Bitte leistet die gesamte Mannschaft die Erbhuldigung unter der Bedingung, daß der Hochmeister ihr eine Verschreibung über ihre Gerechtigkeiten ausfertigt, während daraufhin die

142 Johann von Pommersheim, Komtur zu Schlochau 1425-1431. 
Städte als Voraussetzung ihrer Erbhuldigung die folgenden fünf Forderungen aufstellen: [3.a] Bestätigung der alten Gewohnheiten und Freiheiten, Unterlassung des Baues von Schlössern und anderen Befestigungen des Ordens in den Städten, Erlaubnis zu städtischen Ankäufen mit Mühlengeldern, Verzicht auf Erhöhung der Urbede, gleiche Behandlung des städtischen und ritterschaftlichen Aufgebotes mit Zusicherung von Unterhalt und Schadenersatz; die Komture lehnen die zweite Forderung ab, die letzte verweisen sie an den Rat des Vogtes. [3.b] Der Rat schlägt vor, den Städten zuzugestehen, daß ihr reisiger Zug und sonst niemand vom Orden mit Brot und Futter im Falle von Aufgeboten außerhalb des Landes ausgestattet wird. Die städtischen Vertreter erhalten zur Beratung des Vorschlages Aufschub bis zum übernächsten Tag. [4] Verhandlung am 30. November: Die Städte nehmen den angebotenen Artikel an und erklären sich zur Erbhuldigung bereit, wenn die Ordensvertreter zu ihnen kommen. O.O., [1430 kurz nach November 30].

GStA PK, XX. HA, OBA 5535 (ol. XIII 126), 1 Bogen Papier von 31,5 cm x 43,5 cm, zuerst längs und dann quer gefaltet, S. 1-4 beschrieben, Direktschrift, S. 4 zeitgenössische Inhaltsvermerke von anderer Hand: Omagium Noue Marchie. - Omagium Noue Marchie. Und sost von eyner sache von Ottenhagen unde etc. in der Newen Marke. - Inhaltsvermerke des 16. Jhs.: Nuo. 446. Von erbhuldunge der Neuwen Marcke dem ordenn etc. - Undt wie das zugangen.

Reg.: ROT I/1/1, S. 346 Nr. 5535. - Kletke: Regesta, S. 104 f.

In desser nochgeschreben weisze haben wir empfangen die erbholde vom gantczen lande und steten der Nuwen Margke.

[1] Czum ersten dem voithe der Nuwen Margke schrebe wir ${ }^{143}$ von Czipplow ${ }^{144}$ und ouch von Slochow, das wir sampth mit dem kumpthur von Danczgke ${ }^{145}$ und Tuchel ${ }^{146}$ in die Margke, die erbholde von dem lande und steten von unsirs homeisters weigen uffczunemende, gesand und komen wurden. Item ouch schrebe wir em doselbist, das her uff eynen nemlichen tag vor sich vorbote seynen rath czu Szoldyn; wen wir dohyn qwemen, das wir sie alsampth do finden mochten. Item dorczu ouch schrebe wir em, das her uff eynen kortczen tag dornoch vor sich vorbotte doselbist hyn die rathe aller stete der Nuwen Margke und dorczu des gantczen landes al die gemeyne manschafft, czu horende die gescheffte von uns, dorumbe wir von unsirm homeister czu en gesand weren. Also czoge wir vort uss dem lande.

143 Der Berichterstatter nennt sich nirgendwo selbst. Vielleicht ist es der Komtur von Schlochau Johann von Pommersheim: In vorhergehenden Zeiten waren an den Verhandlungen mit den neumärkischen Ständen neben dem neumärkischen Vogt Komture aus den benachbarten pommerellischen Ordenskomtureien beteiligt. Johann von Pommersheim leitete im Sommer 1430 die mit ständischen Vertretern besetzte Gesandtschaft an König Sigismund, so daß es wohl nicht zufällig ist, daß der Berichterstatter selbst die ständischen Gesandtschaftsmitglieder zur Referierung ihres Gespräches mit dem König aufforderte.

144 Zipplau, Kreis Danziger Höhe (1914).

145 Walter Kirschkorb, Komtur von Danzig 1428-1434.

146 Jost von Hohenkirchen, Komtur von Tuchel 1423-1431. 
Item do wir ken Schybelbeyn qwomen, do wart uns vorgebracht, wy edtliche stete und edliche von der manschafft sich mit der holdunge wedir uns setczen welden, und dieselbige cziethunge hatten wir vortan bis ken Soldyn in allen steten.

Item am sontage vor Andree ${ }^{147}$ qwomen wir ken Szoldyn.

[2] Item am montage dornoch ${ }^{148}$ huben wir an unsir gescheffte, dorinne wir ussgesand woren, und haben vor uns vorbotet die manschafft, die do von staden an vor uns qwam, sundir den steten czu dryn adir czu vier molen boten santen, so das si es gantcz lang vorczogen, e denne si vor uns komen wolden. Do sie do qwomen, do sagten wir en unsirs homeisters grus und gunst, als sich das geboret.

Item dornach hysse wir dem kumpthur von Danczgke, dem lande, steten und vor en allen czu vorczellen, umbe wes willen her von unsirm homeister czuvorn her in die Margke gesandt was und was her wedir unsirm homeister brachte czu antwerdte ${ }^{149}$.

Item dornoch begernten wir von Guntersberge und von den andern, die mit em czum Romisschen konige geczogen woren ${ }^{150}$, das sie vor uns und vor in allen offenbarlich sagten, was sie dem hern Romisschen konige vom lande und der stete weigen hatten vorgebracht und was sie wedir von em vor eyn antwerdt ingebracht hatten.

Item so was eyner do nicht von Koningsberge, Hans Grunitcz genant, der mit Guntersberge ouch czum Romisschen konige von der sachen weigen gewest was. An den hilden sich die stete und wolden nicht gonnen den andern dreyn, die vor uns woren, das si es ussprechen und gesagt hetten, wy es en do dirgangen was, bis das der vierde ouch dorczu qweme. Item do begernten wir doch von denselben dreyn, das si es vor allen uns sagten, als sie toten.

Item dornoch goben wir dem lande den machtbrieff. Do sie en hatten geleszen, do antwerdten sie uns sprechende, das si dem brieff gantcz wol gelowbten und uns ouch sust wol ane den brieff gelowbt hatten, und goben uns den brieff wedir.

Item dornoch forderten wir von en die erbholde. Des gyngen sie alsampt als die manschafft und stete in ein gespreche.

Item des qwomen sie sampt vor uns wedir. Des voiths rath und die vornemesten von der manschafft, die nicht in dem rathe woren, andwerthen uns, welden wir sie bie der gerechtigkeit erer privilegien und bie den artikelen lassen, der wir eyne usschrifft haben, die sie uns vor goben, so welden sie gerne thun, was sie sulden.

Item von den steten wart uns keyn antwerdt gegeben czu der czieth, dornoch wir uns richten mochten.

Item do gyngen die stete in eyn besundirlich gespreche und czogen czu en die gemeynen manne von der ritterschafft und lissen von en stehen des voiths rath, dorczu ouch die manschafft, die bey den steten nicht blieben wolde.

Item des qwomen die stete mit der manschafft wedir, die sie bey en hatten, und boten uns umbe frist bis in den andern tag. Do wolden wir des nicht thun. Do bothen sie uns wol czu

147 [1430] November 26.

148 [1430] November 27.

149 Vgl. oben Quellenanhang, Nr. 8.

150 Vgl. oben Quellenanhang Nr. 8 [4]. 
dreyn molen, gliechwol wolden wir en nicht vrist geben. Do vilen sie mit groszen beten an des voiths rath bittende, das sie welden en von uns frist bitten bis in den andern tag. Wywol der rath das ungerne dach thate, so boten sie gliechwol vor sie, so das wir umbe des rathes willen en vorczog goben. Das geschach alsampth am montage.

[3] Item wir goben en frist bis in den dinstag ${ }^{151}$, das sie alsampt czu szeben des morgens wedir czu uns qwemen. Die manschafft qwam, sundir die stete vorczogens bis ken czehen, e denne sie wedir qwomen.

Item do sie qwomen, do gyngen die stete in ein gespreche und menten, das die manschafft sulde bey en blieben, die am andern tage dovor bie en gewest und gestanden hatte. Das geschach aber nicht, sundir die stete bleben alleyne stehen, und die manschafft alsampt bey uns bleyp.

Item do voreyneten wir uns mit der manschafft, und sie belowbten uns erer gerechtigkeit und vorschriebunge, die en unsir homeister thun wil, als wir en gelobt han, und tothen uns doruff die erbholdunge.

Item dornoch begernten wir die erbholde von den steten; doruff sie uns antwerthen, wen en desse nachgeschreben artikel und stucke vorschreben weren, so welden sye thun die erbholde.

[3.a] Dis sient die artikel der stete, als hie nochfolget, die sie uns in sulcher gestalt vorgebracht han.

Der erste artikel ist:

Gnedigen hern, dis ist euwir erbarn manne und stete der Nuwen Margke eyntrechtiger beger, das er eynem iclichen manne lasset und gonnet ere alden gewonheiten, rechtigkeit, besitczunge, herschafft, fryheithen und eigentschafft, do sie methe begobet und begnadiget sien von keyszern, keyszirs kyndern, fursten, furstynnen, das sie fredeclich besessen han und dar sie methe an euch gekomen sien noch lawthe erer furstiglichen brieffen, doruff gegeben und vorsegelt, is sie an molen, molensteden, an steten, dorffern, holczungen, wassern, weszen, weiden, acker, gerichte hogste und nedirste, an orbede, mosze und wichte adir welcherley das sie.

Doruff antwerthen wir en, das sie wol genczlich dobie sulden blieben und gelassen werden, als wir der manschafft czuvor ouch gelobt hatten, die uns das wol getrauwthen, das wir en brieffe von unsirm homeister dorobir schigken welden.

Der ander artikel:

Das wir nicht sulden die stete vorbauwen mit slossern adir mit anderen bevestungen.

Doruff antwerthen wir, nicht wol billich czu sien, das wir nicht unsir lande sulden bauwen, wo es uns und unsirm orden czu notcze und czu fromen komen mochte.

Der drytte artikel ist:

Al was die stete mit erem molengelde mogen kowffen, das man en das bestetigen, gonnen und vorbrieffen sulde ane eynigerley gift und gobe und en czuvor eigende, also als unsir gnediger her homeister czu Prwsszen en das vorbriefft und gelobt hat.

$151 \quad[1430]$ November 28. 
Doruff sproche wir, das der hobtbrieff, den wir dem lande von unsirm homeister schigken welden, wol bestetigen und bie rechte behalden sal alle andere brieffe, die unsir homeister en czuvor gegeben hat.

Der vierde artikel:

Die stete gemeynclich clagen, das sie werden besweret in bereythunge erer orbede forder, denne sie von alders sien gewonet und dorinne befunden, wendt sie nach eyntracht der herschafft und der lande das schog grosschen haben vornughet und vorgulden mit sechs marg fynkenoughen bie unsirs hern Walters Kyrsskowffs gecziethen, kumpthur czu Danczgke.

Doruff antwerthen wir, das sie sullen gelassen werden bie inhaldunge erer brieffe und privilegien, als die inhalden; dornoch sal der voith von en nemen.

Der fumffte artikel:

Wenne die stete uss dem lande Nuwen Margke nochczufolgen geheyssen werden, so sal man en stehen vor schaden und sulde sie gliech den erbarn mannen vorczeren mit futer und brote und ouch uffrichten den erbarn mannen und steten eren schaden, den sie itczundt in der hern dinste empfangen han.

Doruff antwerthe wir, das der rath des voiths das wol dirkennen sulde, in des dirkenntnisse und czu redelicher beweisunge is sulde stehen blieben, dorczu unsir homeister und ouch sie gelassen han.

Desse vorgeschreben artikel begern sie von unsirm homeister czu vorbrieffende, von des ordens weigen ewigclich czu haldende.

[3.b] Item am dinstage nach essens qwomen wir wedir uff dem hoffe czusampde und lissen des voiths rath szitczen gheen, czu vorhoren die beweisunge von den steten uff den fumfften artikel, der hie vorgeschreben ist. Des frogete wir die stete in kegenwertigkeit des rathes, womethe si es welden beweiszen, das man en denselben artikel [a]lso ${ }^{\text {a) }}$ pflichtig czu thunde were; doruff sie sich besprochen.

Item do antwerthen sie uns, das si es bie eren eyden behalden welden, das man en den artikel pflichtig sie czu halden.

Item do sprochen wir: „Habt er ouch edwas andirs me, domit ir dieselbige gerechtigkeit, als er sprechet, beweiszen mogt?" Do sprochen sie, das sie keyne andir beweisunge dorobir hetten.

Item do sproche wir czu des voiths rathe: „Lieben getruwen, noch unsir antwerdt und ouch nach erer beweisunge wellen wirs gerne in dem artikel von unsirs homeisters weigen bie euch blieben. Wie irs nach redelicher dirkentnisse ussprecht, das sal unsir wille sien".

Item sprochen sie, das sie das nicht wol also czu en nemen mochten, [w]endt ${ }^{\text {a) }}$ sprechen sie den steten abe und uns czu, so hetten sie der stete fintschafft, und sprechen sie uns abe und en czu, so hetten sie unsir ungnade.

Item undir dem qwam der rath czu uns sprechende, were is unsir wille, das man allem reysigem geczewge von den steten bawssen landes brot und futter gebe und nicht den andern, wenne sie uss dem lande geheisschen werden, was do denne von en reysiges geczewge were, das man den also tete, das welden sie den steten gerne vorbrengen und 
dirmanen dorinne, was sie dorbie thun welden etc. Das tate der rath dorumbe, das den artikel nicht dorfften ussprechen.

Item sprochen wir, das wir dorbie nicht ane unsirn homeister thun welden, und frogeten die stete, welden sie den artikel uff unsirs homeisters gnaden genczlich szetczen, so das sie ouch bie seyner gnade gnuszam blieben sulden, ane forder wedirrede und also, das sie den artikel ouch hirnachmols nymmer czu vor andirweythen gedencken sulden, so welden wir ken unsirm homeister dorinne helfen, als wir beste mochten.

Item do boten sie uns, das wir en gonnen welden, das sie wedir czurucke in die stete czihen mochten. Sie welden den gemeynen aller stete die sachen und menungen vorbrengen, was en dorczu guth tochte gethon, uff das sie ane ere volbort nicht thun dorfften umbe vordechtnisse willen, und offtes den die gemeyne hirnochmols wedir den rath haben mochte. Des gunden wir en wedir czurucke czu czihen und das sie uns eyn antwerdt am nesten donrstage dornach ${ }^{152}$ selbist wedir brechten und geben, als sie toten etc.

[4] Item do sie wedir qwomen, do antwerdten sie uns, das sie welden in dem artikel bie unsirs homeisters gnade blieben. Undir vil andir rede so goben sie sich die erbholde czu thun, wen wir czu en in die stete qwemen, als sie gethon haben. Und umbe des willen sien sie mit uns hir ins landt gekomen.

a) Loch im Papier.

12. A. Hochmeister Paul von Rusdorf bekennt, [1] daß ihn Mannen und Städte der Neumark, nachdem König Sigismund ihr Land dem Deutschen Orden übereignet hatte, gebeten haben, ihnen die von Hochmeister Konrad von Jungingen gegebenen Artikel mit weiteren Stücken zu erneuern. [2] Daher bestätigt der Hochmeister ihre Privilegien, Rechte und althergebrachten Gewohnheiten. [3] Der Ordensvogt wird der Mannschaft, wenn der Hochmeister oder er sie zum Dienst auffordert, samt Gesinde und Pferden Unterhalt für den Auszug aus ihren Häusern und die Rückehr dorthin gewähren und für allen Schaden einstehen. Wenn der Vogt im Fall einer schweren Niederlage ihr den Schaden selbst nicht zu ersetzen vermag, wird der Hochmeister diese Verpflichtung übernehmen. [4] Brüder oder Vettern dürfen von ihren Eltern ererbte Lehngüter zu gesamter Hand ohne Nachteil für ihr Gesamthandrecht aufteilen. [5.a] Der Hochmeister wird den Neumärkern verlorengegangene Urkunden und Handfesten ohne Gabe an die Herrschaft erneuern. [5.b] Der Schreiber des Vogtes wird von der Mannschaft für die Ausfertigung einer Handfeste oder Urkunde über Lehen und Güter 12 böhmische Groschen bzw. 2 Mark Finkenaugen und über weibliches Leibgeding 6 Groschen bzw. 1 Mark Finkenaugen nehmen. [6] Der Hochmeister gelobt, alle vorstehenden Artikel den Mannen, Städten und Einwohnern der Neumark unverbrüchlich zu halten. Marienburg, 143[0] Dezember 29. [Ausfertigung für die Mannschaft der Neumark]

$152[1430]$ November 30. 
12.B. Hochmeister Paul von Rusdorf bekennt [usw. wie Nr. 11.A., unter Hinzufügung eines neuen Artikels nach 5.b]:

[6] Die Amtleute des Ordens werden den Städten, wenn der Hochmeister oder sie selbst zum Dienst auffordern, für ihren reisigen Zug wie der Mannschaft außerhalb der Landesgrenzen Futter und Kost gewähren, ohne daß der Orden für irgendeinen Schaden einsteht. [7] Der Hochmeister gelobt [usw. wie Nr. 11.A.]. Marienburg, 143[0] Dezember 29. [Ausfertigung für die Städte der Neumark]

A Stadtarchiv Königsberg/Neumark, Urkunden, Nr. 194 (seit 1945 verschollen). - Ausfertigung (für die Städte der Neumark), Pergament, anhängendes Siegel.

B GStA PK, XX. HA, Ordensfoliant 95, fol. 184r-185r. - Gleichzeitige Abschrift. Überschrift: Handfeste der Nuwenmarke.

Druck: CDB A 24, S. 140 (in Unkenntnis des in der hochmeisterlichen Kanzlei gebräuchlichen Weihnachtsstils irrtümlich auf 1431 Dezember 28 datiert). - Das neumärkische Ständearchiv, S. 168 Nr. 7 (beide Editionen nach A, ohne Identifizierung als für die Städte bestimmte Ausfertigung).

Die folgende Edition folgt B. Wörtliche Übernahmen aus der Vorurkunde Pauls von Rusdorf von 1430 Juli 13 sind im Petitdruck wiedergegeben, dabei sind Auslassungen aus der Vorlage mit* gekennzeichnet. Die Ergänzungen gegenüber dieser Vorurkunde sind oben im Kopfregest durch Unterstreichung verdeutlichtt. Die geringfügigen wörtlichen Abweichungen von A sind (unter Zugrundelegung der Edition Klinkenborgs) angemerkt, orthographische Unterschiede und kleine Wortumstellungen außer Betracht gelassen.

Reg.: Kletke: Regesta, S. 106 (falsch datiert).

Wir bruder Pauwel von Rusdorff etc. ${ }^{\text {a) }}$ thun kunth und offembar bekennen allen, den desse schriffte werden vorbracht, [1] das sind der czeit der allerduchluchtste furste, unsir allirgnedigster herre, herre Segemund, Romischer, Hungerischer und Behmischer etc. koning, von sunderlichin gnaden uns und unsirm orden hat gegeben und voreygent das land, die Nuwemarke benumpt, und die mechtiglich an unsirn orden geweißet hat czu ewigen czeiten mit alle erer czubehorunge und inwonern, geleichs also siene gnade die ${ }^{\text {b) }}$ gehabt hat und die briffe, dorobir von siener koniglichin maiestad gegeben, das clerlich ${ }^{c}$ ußweißen, so haben uns manne und stete, dorynne wessende, demuttiglichin angelegen, das wir semliche articulos, die von deme erwirdigen seligen gedechtnissis bruder Conrad von Jungingen, uff die czeit homeister, als dieselbe Nuwemarke erst an unsirn orden qwam, [sien vorschreben], en geruchten czu vornugen mit edlichen andern vorgegeben stucken etc. Des so haben wir angesehen ire so lieplieche, gunstige czuneigunge und rechtfertige truwe, die sie $\mathrm{czu}^{\mathrm{d})}$ unsirm orden haben, und mit reyffen, wolbedochten unsir gebietiger rathe sien wir en des gerne gefollig und begeren wissentlich czu sien allen, die dessen briffe sehen, horen ader leßen, [2] das wir den vorbedochten unsir lieben und getruwen rittern, knechten, burgermeister, rathmanen, burgern, gebuwren und gemeynen sowol uff dem lande als in ${ }^{*}$ ) steten derselben Nuwenmarke, sie sien geistlich ader wertlich, epthen, epthynnen und $^{\mathrm{f}}$ thumhern, welcherley weßens ader wirdikeit die sien, mildeclich mit crafft desses briffes bestetigen und $^{\mathrm{f}}$ beweren alle ire privilegia, gerechtikeithen und 
freyheiten, die en in vorczeiten vorlehnet sien und gegeben von keyßern, keyßers kindern, fursten und furstynnen rechter herschafft des obenbenumpten landes, dorczu ouch alle lobeliche und redliche gewonheiten, von alders gehalden doselbist im lande. [3] Sunderlichin begnaden wir die manschafft des ebenumpten ${ }^{\mathrm{g}}$ landes mit eym sulchen, ap wir ader unsirs ordens voith doselbis sie czu unsirm dinste ader geschefte heischten ader liesse heischen, so sal unsirs ordens voith derselben Nuwenmarke en, erem gesinde und pferden redliche notdorfft geben uff der reißen uss eren huwssern und wedir dorin und vorbas vor allen schaden stehen, als man von alders vormols gethan hot. Geschege *, do Got vor sie, der mansschafft semeliche swere nedirlage und sulcher grosser schade, das unsirs ordens voith doselbis des czu swach were und nicht vormochte ußczurichten, so wellen wir mitsampt unsirn nochkomelingen sulchen schaden selbir richten. [4] Geschege is ouch, das bruder ader fetter mit lehen von eren eldern beerbet weren in samender hand, ap sich die teilten ader voneynander sosten, das sal en kegen uns und unsirn nochkomelingen an erer gesamender hand und rechtikeit unschedelich sien, als wir das gefunden haben und vor gewest ist. [5.a] Vorturben ouch ymandes der Nuwenmarke siene alden brieffe und handfesten ader fures halben ader ouch sust in ander weiße czunichte wurden, semeliche alsam wellen wir ere handfesten, die in also abegingen, und ${ }^{\text {h) }}$ sust ere lehen ligen ane gifft und gobe der herschaft gerne vornugen, wenn wir mit redlichkeit und worheid undirweißet werden, wie die alden geluwt haben, und ouch in der weiße, wie ${ }^{f)}$ sie ere gutere in besitczunge von alders gehabt haben bis uff die czeith, als sie der vornuwunge sien begerende. [5.b] Ouch thun wir unsirn lieben getruwen ${ }^{\mathrm{i})}$ der manschafft die gnade, das unsirs voithes schreibere doselbis im lande von hantfesten, brieffen uff lehen ader gut $t^{\mathrm{j})}$ nicht mee nehmen sullen von ymande denne 12 Behmische groschen ader czwu marg vinkenougen und vor eynen briff obir frauwen liepgedinge nicht mee sullen nemen denne sechs grosschen ader eyne marg vinkougen. [6] Alle * obengeschreben stucke und artikel und eynen iclichin besunder vor sich geloben wir bruder Pauwel, homeister vorgedocht, unsirn lieben * getruwen mannen und steten und inwonern der Nuwenmarke vor uns, unsir nochkomelinge und unsirn gantczen orden stete, feste, heil und unvorrucket ${ }^{\mathrm{k})} \mathrm{czu}_{\mathrm{c}}$ halden czu ewigen czeiten. * Des czu grosser sicherheid haben wir unsirs ordens groste ingesegel lassen ${ }^{1)}$ anhengen * dessem briffe, der gegeben ist uff unsirm huwße Mariemburg am fritage noch dem heiligen Cristage $\mathrm{im}^{\mathrm{m})} \mathrm{XIIII}^{\mathrm{c}}$ und XXXI ${ }^{\text {ten }}$ jore $^{\mathrm{m})}$. Geczug sien die ersamen geistlichen unsirs ordens lieben brudere und gebietigere, bruder ${ }^{\text {f) }}$ Johan Broel, groskompthur ${ }^{\text {n) }}$, Conrad von Beldirsheym, obirster spitteler und czum Elbinge, Merten Kempnather, obirster trappier und czu Cristpurg kompthur, Heinrich von Plauwen, treßler, Jost Struperger, czur Balge, Jost Hoenkircher, czum Tuchol, und ${ }^{\mathrm{f})}$ Walter Kirskorp, czu Danczke kumpthur, her Nicklos, unsir cappellan, Ruther von Schonewert und ${ }^{\text {f) }}$ Wetczel von Wladicheym, unsir compan, Lucas und Martinus, unsir schreiber, und vil andir truwirdige ${ }^{\mathrm{o}}$.

In geleichem lute von wort czu worte ist eyne hantfeste vorlegen und gegeben den steten der Nuwenmarke, czugesatczt alleyne desser nedengeschreben artikel, der folgen sal deme artikel, der uff des schreibers gebo ${ }^{\mathrm{e}}$ re luwtet und sich also anhebet: Ouch thun wir unsirn lieben getruwen der manschafft die gnade, das unsirs ordens voiths schreibere etc., und also vort an aber in gleichem luwte bis czum ende des obengeschreben briffes: 
Sunderlichen umb unser gebietiger, unser lieben getruwen der ritterschafft der Nuwenmarke bete und der stete dinste willen, die sie bisher gethan haben und noch thun sullen in czukomftigen czeiten, begnaden wir unser lieben getruwen die stete derselben $\mathrm{Nu}-$ wenmarke mit eym sulchen, wen sie von uns ader unsers ordens amptluten geheischet werden, wie stark sie denne mit reiszigem geczuge folgen, denselben luwten mit erem reiszigem geczuge wir ader unsers ordens amptmann geleich unser lieben getruwen der manschaft buwssen unser lande grenitczen futtir und koste wellen geben, idoch also bescheidentlich, das wir ader unser orden en vor keynen schaden stehn sullen. Was abir die stete von unreisigem geczuge haben, den sollen sie selber alle notdorfft besorgen etc.

a) homeister des ordens der bruder des hospitals sente Marien des Dewtchen huwsses von Jerusalem $A$. - b) sie $A$. - c) clar $A$. - d) an $A$. - e) den $A$. - f) fehlt $A$. - g) oberbenumpten $A$. - h) umme $A$. - i) und getruwen $A$. - j) ander gutt $A$. - k) davor unterpunktet: unvorseret (ebenso $A .-l$ ) mit rechter wissenschaft lassen $A .-m$ ) - $m$ ) in den jaren unsirs herren tuwsend vierhundert und danach im eynunddreisigistem jare $A$. - n) folgt Heinrich Holt, obirster marschalk $A$. - o) gloubewirdige $A$.

13. Vogt der Neumark [Heinrich Rabenstein] an Hochmeister [Paul von Rusdorf]:

Die neumärkischen Städte verlangen, daß in die zuletzt ausgefertigte hochmeisterliche Urkunde die Zusicherung von Futter und Brot für das gesamte städtische Aufgebot eingefügt wird, so daß der Vogt wegen dieser und anderer Forderungen eine Landsprache festgelegt hat. Dramburg, 1432 Mai 10. [Auszug]

GStA PK, XX. HA, OBA 6083 (ol. XIIIa 25). - Ausfertigung, Papier, briefschließendes Siegel. - Außenadresse: Deme erwerdigen homeister Du'tsches ordens mit allir erwerdicheit, dach und nacht ane alles sume $-\mathrm{d}($ entur).

Reg.: ROT I/1/1, S. 378 Nr. 6083. - Repertorium, S. 120 Nr. 705.

[...] Sundergin, gnediger, leve her homeister, den briff, den iuwe gnade den steden der Nigen Marcken heft nu $u^{\mathrm{e}}$ lest gegeven, willen sy nach siner inholdinge in etliker mate nicht upnemen ofte belevin, sundergin in deme sy meynen, dar $u^{e} t$ tu hebbende den artikel als fuder ${ }^{\text {a) }}$ und brod tu gevende ${ }^{\text {a) }}$, dy mit reyszegem tuge folgen ${ }^{153}$, und meynen, in dy stede tu settende fuder ${ }^{b)}$ und brod to gevende ${ }^{\text {b) }}$ allen, dy geeschet werden tu folgende ut iuwem lande der Nigen Marcken, reysich edder nicht, und ok etlike andere schelingen und rechticheit, $\mathrm{dy}^{\mathrm{e}} \mathrm{sy}^{\mathrm{e}}$ meinen willen hebben tu holdende; darumme ik en doch nach rode unsir manne in der Marcke einen dach tu der negisten landsproke hebbe gelecht, da ${ }^{\mathrm{e}} \mathrm{r}$ ik en van iuwer gnade wegen nach iuwer manne dirkantnisße des rechten wil behelpen. Da ${ }^{\mathrm{e}} \mathrm{rup}$ so hebben sy ${ }^{\mathrm{e}}$ my dinste noch orbede tu dissir ti ${ }^{\mathrm{e}} \mathrm{d}$ nicht geweigerd. [...]

Voged der Nigen Marcke.

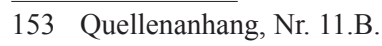


a)-a) übergeschrieben über gestrichen: vor schaden stande. - b)-b) übergeschrieben über gestrichen: vor schaden tu stande.

14. Mannschaft und Städte der Neumark an Hochmeister Paul von Rusdorf: Entsprechend der hochmeisterlichen Ankündigung hat Walter Kirschkorb das mitgebrachte Geld zur Ersetzung der durch den Einfall der Polen und Böhmen entstandenen Schäden nach Gunst, aber ohne Rat von Mannen und Städten verteilt, woraus große Zwietracht entstanden ist. Auf Anregung Kirschkorbs haben die Aussteller auf einer Landsprache für Recht erkannt, daß jedermann, der im vergangenen offenbaren Krieg des Hochmeisters gefangen genommen worden ist oder Schäden erlitten hat, gleichgültig, ob er namentlich zum Heereszug aufgefordert war oder nicht, Wiedergutmachung beanspruchen darf. Da den Städten noch ihre Erbhuldigungsurkunde fehlt, bitten die Aussteller darum, daß der Hochmeister sie ihnen ohne Abgabe zuschickt in der Form, wie die Gebietiger es ihnen in der Erbhuldigung zugesagt haben, denn ansonsten können sie ihre Urbede und Dienste nicht wie bisher leisten, da sie darum mit ihren Gewerken und Gemeinden in großer Zwietracht stehen. O.O., 1434 November 19.

GStA PK, XX. HA, OBA 6904 (ol. XIII/a 1). - Ausfertigung, Papier, Spuren zweier briefschließender Siegel. - Außenadresse: Deme erwerdigen, grotmechtigen hern ern Pawel van Rusdorff, meistere Dutsches ordens, erem huldigen, gunstigen unde gnedigen hern, med groter andacht unde gantczer werdicheid.

Reg.: ROT I/1/2, S. xxx Nr. 6904. - Repertorium, S. 134 Nr. 792. - Kletke: Regesta, S. 121.

Underdanicheit med wilgem dinste in rechtem horsam, was wy gudes vormogen. Erwerdighe, grotmechtige, gnedige here, alze wy in ghewerve by iw hadden $\mathrm{Cu}^{\mathrm{e}}$ rde unde Clawese, vedderen, ghenad dy Strutcze, darthu Botervelde unde Blediken umme den schaden unde inval der Polen unde der Beymen ${ }^{154}$, an uns, Gode gheclaget, vullenbracht unde bewesen, so hebben sy uns weder ingebracht, dat uns iwe gnade wolde zenden eynen bydiger, thu bezynde unde weder thu legghende allen schaden nach derkantnysse unde rade der manne unde stede der Nyen Marke in redeliker mathe. Des is wol by uns gewest unse huldige here hern Walter Kirskorff ${ }^{155}$ unde sodane ghelt, alze he brochte, den schaden thu $v^{e}$ rbutende, ghedeylet unde geven, nach gunst unde willen sunder mederade unde kantnisse manne unde stede, dar gro ${ }^{\mathrm{e}}$ affgunst unde twydracht is ave ghekomen: thu ${ }^{\mathrm{e}} \mathrm{n}$ irsten male in deme, dat etlike iwer gnaden erbarn manne alrede darumme den landen hebben untczeght, dat wy hebben undernomen unde en gheleyde zeght zo langhe, dat uns iwer gnade gutlike antworde darup weder moge komen. Vortmer werde wy ghevanghen, gherovet unde gheschyndet ut deme lande Polen, Pomeren und Stettin unde doch an unseme gunstigen heren, den voghede, neyne untsettinghe konen hebben efte ghewerven

154 Die Neumark und Pommerellen hatten im Sommer 1433 unter dem Einfall der verbündeten Polen und böhmischen Hussiten und ihre Verwüstungen nach dem Ausbruch des Krieges zwischen Polen und dem Deutschen Orden schwer zu leiden.

155 Walter Kirschkorb: bis April 1434 Komtur von Danzig, ab Mai 1434 Großkomtur. 
nochte enghe hulpe krigen unde vruchten zere, dat den landen vele mer grotes schaden daraff moghe untstan, id sy denne, dat iwer gnaden grotmechticheid medsampt der bydiger rade dar anders vor ghedenket. Ok alze unser huldige here hern Walter Kirskorff up uns zettede thu rechte, eft men denghenen, dy schadaftich sint gheworden in deme krige edder ghevanghen unde doch by namen nicht sint geeschet efte heiten riden; darup hebbe wy manne unde stede vorben(ant) thuzamende west in eyner lantsprake unde zegghen vor eyn recht, sundertid iwer gnaden grotmechticheid eynen standen openbaren krigh heft gehat, wy darover is gegrepen efte schadaftich gheworden, he sy geeschet efte nicht, den schal men em legheren unde benemen thu eyme gantczen ende. Were ok ymant, dy enghe vanghen hedde gegrepen, he were darthu geeschet in deme krige efte nicht, der he nicht hedde gheantwordet der herschap, dat schal men by demesulven vynden unde sick daran vorhalen. Sundergen ok schelet iwen armen steden noch ere bryff der erfhuldinge unde is en nicht geworden. Hirumme bidde wy allensampt demudich med flite, gy en den willen schicken unde gheven sunder engerleie gift unde gave in aller mathe, alze en dy bydigere in der erfhuldinge hebben ghelovet ${ }^{156}$, anders konen sy ere orbode unde dinst nicht geven efte dun, alze sy wente her ghedan, wente sy zitten med eren werken und meynheiden darumme in groter swarheid unde twydracht; des iwer grotmechticheid gnedichlike antworde, alze gy med rade der bydigere unser aller nod unde der lande beste darinne derkennen unde kysen. Screven under Peter Wreghes unde der stad Landisberghe ingesegel, der wy uns alle med guder eyndracht unde vulbort hirinne ghebruken na Godes bort $\mathrm{M}^{\circ} \mathrm{CCCC}^{\circ} \mathrm{XXXIIII}^{\circ}$ jare am dage Elyzabeth vidve.

Manne unde stede der Nyen Marke med gantczer eyndracht.

15. Formel des Huldigungseides der Neumärker gegenüber Hochmeister Konrad von Erlichshausen. [14]41.

GStA PK, XX. HA, Ordensfoliant 18, fol. 32v. - Gleichzeitige Abschrift, Papier.

Druck (ohne Überschrift und Schlußformel): Murawski, Zwischen Tannenberg (wie Anm.xx), S. 425, Anm. 124.

Disser nachgeschreben eyt ist der eith, den die $\mathrm{us}^{\text {a) }}$ der Neuwen Marke haben gesworen her Conradt von Erlichshuwsen, homeister Deutsches ordens, im XLI ${ }^{\text {ten }}$ jare.

Ich gelobe und swere, dem erwerdigen heren Conradt von Erlichshuwsen, meynem rechten heren, homeister Deutsches ordens, euch heren voithe, an seyner stadt gemechtiget, und darczu euwerm ganczen orden getruw und undertanig zcu seyn, euwern schaden zcu wenden und zcu weren und euch dovor czu warnen ${ }^{\text {b) }}$ nach meynem vormogen und alle andere stucke in truwen zcu thun, die eyn iczlicher undertaniger und man noch seynem wesen von rechte pflichtig ist zcu thuen seynem rechten heren, als mir Got helffe und die heiligen.

156 Gemeint sind die Verhandlungen der Gebietiger mit Ritterschaft und Städten Ende November 1430 und ihre Zusicherungen über die hochmeisterliche Privilegierung der Städte, siehe oben Quellenanhang, Nr. 11. 
a) Vorlage: uns. - b) Vorlage: warnan.

16. Hochmeister Ludwig von Erlichshausen bevollmächtigt Christof Eglinger, Vogt der Neumark, und Johann Rabe, Komtur zu Schlochau, dazu, nach dem Tode des Hochmeisters Konrad von Erlichshausen und nach seiner, Ludwigs, Wahl zum Hochmeister in seinem Namen von Ritterschaft, Städten und allen sonstigen Untertanen des Ordens in der Neumark gemäß deren Pflicht die Huldigung zu empfangen, und fordert alle und jeden einzelnen Betroffenen dazu auf, Vogt und Komtur an seiner Statt die Huldigung wie gewönlich zu leisten. Marienburg, 1450 November 2.

GStA PK, XX. HA, Ordensfoliant 17, S. 571. - Gleichzeitige Abschrift, Papier. - Überschrift: Machtbriff, dem voithe der Neuwenmarken und den komptur czu Slochaw, die holdigung czu empfoen, metegegeben.

Reg.: ROT I/1/2, S. 678 Nr. 10419.

Wir bru[der] Lud[wig] von Erlich[shuwsen], ho[meister] Deu[tsches] or[dens], entpieten den edlen und gestrengen rittern, knechten, mannen und den vorsichtigen burgermeistern, rathmannen und den gemeynen unsir stete und sust gemeyniglichen allen unsern und unsirs ordens undirsassen unsir Neuwemarcke, welchirley adels, wirdigheith, wesens adir statums die seyn, unsir und unsirs ordens lieben getruwen, heyl in den heren, luwter liebe, gunst und allis gut. Lieben getruwen, nachdem ir wol vornomen habt, das der erwirdige bruder Con[rad] von Erlich[shuwsen], unsirs ordens homeister etwan, eyns naturlichen todes abgegangen ist ${ }^{157}$ und wir czu der wirdicheit unsirs ordens homeisterschafft mit eyntrechtigem allir gebitiger rate, willen und volbort noch schickunge des almechtigen Gotis irwelt und gekoren seyn ${ }^{158}$, als ir des ouch, czweifeln wir nicht, durch den ersamen unde geistlichen bruder Hansen van Tobeneck, alden voith unsir Neuwenmarcken ${ }^{159}$, wol und volkomlich $\mathrm{mo}^{\mathrm{e}} \mathrm{gt}$ undirrichtet seyn, und wenne ir uns denne euwir holdigung zcu thun pflichtig seyt, so haben wir die ersamen und geistlichen unsirs ordens brudere alse Cristoffern Eglinger, voith unsir Neuwenmarcken, und Johan Raben, komptur czu Slochaw $^{160}$, disse beweisere, nach rate unsir gebitiger darczu gefertiget und gemechtiget und volmechtigen sie ouch in crafft diß brieffs, so das sie die holdigung in unsirm namen van euch allen gemeynigleichen addir eynen itczlichen besundern, wie sich das treffen und gebo ${ }^{\mathrm{e}}$ ren werde, uffnemen und empfahn mogen und sollen. Und dorumbe bitten unde begeren wir van euch allen gemeynlichen und van eynem itczlichen besundern mit fleissiger irmanung, das ir den obgenanthen unsirs ordens voith und komptur und an unsir stat euwir holdigung thut und uns also durch sie holdiget, als das gewonlich ist, holdiget und

157 Hochmeister Konrad von Erlichshausen war am 7. November 1449 verstorben.

158 Konrads Neffe Ludwig von Erlichshausen war am 21. März 1450 vom Großen Kapitel des Ordens zum neuen Hochmeister gewählt worden.

159 Hans Thobenecker, Vogt der Neumark seit 1448, wurde am 2. November 1450 in seinem Amt von Christof Eglinger abgelöst.

160 Johann Rabe, Komtur zu Schlochau (1450-1454). 
euch darynne so gutwillig beweiset, als wir und alle unsir gebitiger euch des gentczlichen wol czugetruwen und als ir billiche dancksagungen davor begeret zcu haben. Des zcu orkund und merer sicherheit haben wir unsir segil angehangen lassen dissem brieffe, der geben ist uff unserm hwß Marienburg am tage allir selen im XIIII ${ }^{\mathrm{c} \text { ten }}$ und $\mathrm{L}^{\text {ten }}$ jare.

17. [Hochmeister Ludwig von Erlichshausen] instruiert den neuen Vogt der Neumark Christoph Eglinger und den Komtur zu Schlochau Johann Rabe für die Verhandlungen mit Mannschaft und Städten der Neumark:

[1] Sie sollen eingangs die Gnade des Hochmeisters und den Gruß der Gebietiger entbieten, [2] die Stände zum Gehorsam gegenüber dem neuen Vogt ermahnen sowie sie auf Grund ihrer Vollmacht zur Huldigung gegenüber dem neuen Hochmeister auffordern. [3] Nach der Huldigung soll die Mannschaft um Steinfuhren zum Haus Landsberg gebeten [4] sowie das Land dazu bewogen werden, zum Schutz vor nachbarlichen Überfällen von einer oder zwei Hufen einen Scheffel Hafer in Schivelbein, Dramburg, Landsberg und anderen Grenzorten bereitzustellen. [5] Auf Klagen der Mannschaft und Städte über den ehemaligen Vogt Georg von Egloffstein sollen Vogt und Komtur das Bedauern des Hochmeisters sowie für künftige rechtlicher Bedrängnisse dessen guten Willen ausdrücken. [6] Strittige Sachen sollen der Vogt und der Komtur zusammen mit dem Rat entscheiden oder an den Hochmeister mit der Ankündigung seiner gebührenden Antwort verweisen. [7] Wenn der Herzog [Joachim der Jüngere] von [Pommern-]Stettin sie wegen eines Bündnisses mit dem Hochmeister anspricht, sollen sie von ihm eine schriftliche Äußerung erbitten und die diesbezügliche Antwort des Hochmeisters und seiner Gebietiger zusichern. [8] Zu allen vorstehenden Punkten soll der Komtur dem Hochmeister Bericht erstatten. [9] Wenn der Abt von Marienwalde den Vogt um Bestätigung seiner Privilegien ersucht, soll dieser notariell beglaubigte Abschriften dem Hochmeister zur Konfirmation zusenden. o.O., [14]50 November 2.

GStA PK, XX. HA, OBA 10418 (ol. XIII 34). - 1 Bogen Folio, S. 1-3 beschrieben, Papier, Direktschrift, zwei Hände.

Reg.: ROT I/1/2, S. xxx, Nr. 10418. - Repertorium, S. 219 Nr. 1322. - Kletke: Regesta, S. $198 f$.

Bevelung, dem neuwen voithte der Neuwen Marcken, Cristoffer Eglinger, und John Raben, dem kompthur czu Slochaw, in die Neuwe Marcke metegegeben am tage allir selen im $L^{\text {en }}$ jare.

[1] Czum ersten, so sie in die Neuwe Marcke czu der manschafft und steten komen, so sullen sie en sagen des hern homeisters genade und alles gutist und der gebitiger frundschafft und grus.

[2] Darnach solle der voith en lassen lesen des hern homeisters brieff, dadurch em das ampt bevolen ist ${ }^{161}$, dabey sie der kompthur sulle dirmanen, das sie den neuwen voith

161 GStA PK, Ordensfoliant 17, S. 570. 
uffnemen vor eynen voith der Neuwen Marcken und dem gehorsam seyn in des hern homeisters stat.

Und so sie sich darczu dirbitten, so homeisters, dem Got genade ${ }^{162}$, disser kegenwertiger homeister czu eynem homeister ist gekoren $^{163}$, deme sie nach alder gutten gewonheit und gebo ${ }^{\mathrm{e}}$ re pflichtig seyn zcu holdigen. So hat der herre homeister sie beyde ußgeschicket und gemechtiget, die holdigung an seyner stat zcu empfoen nach luwte des machtbrieffs en metegegeben ${ }^{164}$, daruff sie den machtbrieff so ${ }^{\mathrm{e}}$ llen lassen leßen und, so der geleßen ist, die holdigung daruff fordern nach alder gewonheit.

[3] Wenn denn die holdigung getan ist, das sie denn die manschafft bitten, das eyn iczlicher dem hern homeister mit eyner fuhre grundsteyn czu dem huwse Landisberg wellen seyn behulffen und dahen antwurten lassen.

[4] Vorbaß sollen sie mit den landen also reden, syndemmale die umbgelegenen lande gancz arm seyn und manichirley kryge itczund in vylen landen seyn, so mu ${ }^{\mathrm{e}}$ sse men sich obirfalles und gedranges besorgen. Und darumb begert der here homeister, das sie jo van iczlicher hube adir jo czum wenigsten van czwen huben eynen scheffel haber als zcu Schivelbeyn, Dramburg, Landsberg und wo es su'st an den grenitczen not wurde seyn uffschutten wellen lassen, uff das, ap die lande obirfallen und gedranget wurden, daß men des denn czur not gebruwchen $\mathrm{mo}^{\mathrm{e}}$ chte.

[5] Item ap die manschafft addir stete adir su'st imands ichts vorbrengen wu'rde van beswerungen adir ungewo ${ }^{e}$ nlichen gerichten, die en durch unnsers ordens voith etwan Jorge Egloffsteyn ${ }^{165}$ gescheen weren, darczu sollen sie antwurten, were itchts gescheen, das were dem homeister nicht zcu willen und hort es ouch ungerne; und ap imands furbas czu unrechte gedranget wurde, das der homeister dach nicht getruwet, so das an den homeister wurde gebracht, her wurde dabey thun, was gebo ${ }^{\mathrm{e}}$ lich were.

[6] Und was sachen der voith und der kompthur czu Slochaw mit den reten der Neuwen Marcke adir su $\mathrm{e}^{\mathrm{e}} \mathrm{st}$ endscheiden $\mathrm{mo}^{\mathrm{e}} \mathrm{gen}$, die sollen sie endscheiden. Was sie adir nicht endscheiden konnen und davon grosse clage ist, so ${ }^{\mathrm{e}}$ lle der kompthur sprechen, her welles gerne an den homeister und an die gebitiger brengen und das beste darynne bewerben, und her getruwe, der homeister werde sich darynne also beweisen, als das geborlich werde seyn.

[7] Item ap der herre herczog von Stetyn den voith der Neuwen Marcken und den kompthur von Slochaw in egener personen adir durch seyne botschafft besuechen und en, das her sich mit dem hern homeister und seynem orden vorbynden welde ammutten wurde ${ }^{166}$, so so ${ }^{\mathrm{e}}$ llen sie daruff also antwurten, sie haben wol vornomen, das der abt vom Marien-

162 Siehe Anm. 155.

163 Siehe Anm. 156.

164 Vollmacht vom 2. November 1450, siehe oben Quellenanhang, Nr. 16.

165 Georg von Egloffstein, Vogt der Neumark 1441-1448.

$166 \mathrm{Zu}$ den mehrjährigen Verhandlungen zwischen dem Orden und Herzog Joachim dem Jüngeren von Pommern-Stettin vgl. Staatsverträge II (wie Anm. 56), S. 91 f.; Murawski (wie Anm. 51), S. $148-151$. 
walde eyn solchs ouch an den hern homeister gebracht habe. Ouch ist wol furmals handelunge davon gewesen, sunder es ist nichts darynne beslossen. Were nu dem herren herczogen etwas darynne zcu synne, so mo ge her seyne meynunge in schrifften ussetczen und en antwerten lassen; sie weldens gerne an den homeister und seyne gebitiger brengen, der em denn seyns und seyner gebitiger willens meynunge wol widder werde verstehen lassen.

[8] Item uff alle disse obengeschrebene sachen solle der kompthur czu Slochaw dem hern homeister antwurt brengen.

[9] Item ${ }^{\text {a) }}$ so der abt von Marienwalde den voith der Neuwen Marke wirt anlangen von der bestetigunge irer privilegien durch den herren homeister, so sal der voith eynen tag und stad dorczu legen und sal sich uff denselben tag warnen eyns offenbaren schreibers, etlicher gelarter und ouch wissender bruder des ordens und leygen, die sich doruff vorstehen, und sal mitsampt en besehen die segil und brieffe, ap sie rechtfertig und ane gebrechen seyn, und welche die her an schriften und ouch an segeln rechtfertig fyndet, die sal her lassen copieren ader abeschreiben und in den abeschriften sich den notarien lassen underschreiben mit seynem czeichen in sulcher weiße ader dergeleichen:

Copia collacionata cum originali per me N. auctoritate imperiali publicum notarium signoque meo consignata.

Sulche abeschrifte alßo vorwart sal der voith senden dem herren homeister, der sie denn noch behage wirt confirmiren.

a) Hier setzt die zweite Schreiberhand ein.

18. Vogt der Neumark [Christof Eglinger] an Hochmeister [Ludwig von Erlichshausen]: [1] Die Streitigkeiten in der Neumark wird der Komtur zu Schlochau [Johann Rabe] dem Hochmeister schriftlich und mündlich berichten. [2] Der Vogt bedarf der gefreiten Güter der Gustebiesen zur Unterhaltung des Hauses Landsberg, bittet den Hochmeister darum, städtische Urbeden sowie Pachten, die Georg von Egloffstein, Vogt zu Schönsee, [Hans] Thobenecker, Vogt zu Schivelbein, und der Burggraf zu Driesen verpfändet haben, wieder auszulösen [3] sowie zu entscheiden, ob er Heidehafer und Mühlenpacht dem Vogt zu Schivelbein abfordern soll. [4] Er bittet darum, den Ordensherrn Georg von Eickstädt von Schlochau nach Landsberg zu versetzen [5] sowie ihn mit Leuten oder Geld gegen einen befürchteten Überfall Herzog Heinrichs [von Mecklenburg] auf die Neumark zu unterstützen. [6] Land und Städte widerstrebten der Huldigung wegen des mangelhaften Schadenersatzes und der unbeglichenen Schulden der Vögte. [7] Er befürwortet für das Haus Küstrin die baldige Vollendung des Grabens. [8] Baupferde und andere Pferde des Hauptmanns sind von Teile Doberko und seinen Miträubern Heinrich Hondorf, Nickel Waldow und zwei Knechten gestohlen und in das Land der Bibersteine getrieben worden. Woldenberg, 1450 Dezember 17.

GStA PK, OBA 10466 (ol. LXXVII Nr. 75). - Ausfertigung, Papier, Spuren des briefschließenden Siegels (Bl. 1), mit Anlage (Gedechtnisße) (Bl. 2-3), Papier, Bl. 2r-3r beschrie- 
ben, Direktschrift, von anderer Hand als Bl. 1 beschrieben. - Außenadresse: Deme gar ernwerdighen hoemeistere Dutzsches ordens myt aller ernwerdikeit.

Meynen willigen $[\mathrm{u}]$ ndertanigen ${ }^{\text {a) }}$ gehorsam mit allem fleißigen gutin vermoge zcuvore. Ernwerdiger und gnediger lieber her hoemeister, [1] als ich dann van ewer gnaden gescheiden byn, das ich ewern gnaden vorscreiben solde allen gebruch und schelunge in der Nuwen Marke; des wille ewer gnade wissen, wie das der kumpthur zcu Slochow ${ }^{167}$ das alles in scrifften hod und ewern gnaden der sachen gelegenheit muntlichen anrichten und wol vorczellen werd. [2] Vorbaß, gnediger, lieber her hoemeister, bitte ich ewer gnade als meynen gnedigen herrn und obirsten, das ir mit den gebietigern darvo ${ }^{\mathrm{e}} \mathrm{r}$ seyt, das der Gustebysen gutere yo gefreyet werden. Anders werd ewer gnade und unser orden darumme mit denselbygen und ouch andern gutern zcu großem schaden komen. Ouch wen die gutere nicht gefreyet worden, so kunde ich das huß zcu Lansberg nicht halden ader eynem howptmanne keyne notrofft darczu besorgen und geben, dann ich sust zcu weynich und zcu gerynge an der uffborynge und czynseren habe, das ich mich mitte enthalden mag. Ouch hod ern Jurgen vam Egloffstein, voith czu Schonensehe, vorsetzcet 24 Rynsche gulden an der orbare zcu Konigesberge, die mir ouch jerlichen abegehen, die sie mußen geben eynem burgere zcu Frankenfort; das ewer gnade ouch mit den gebietigern darvo ${ }^{\mathrm{e}} \mathrm{sy}^{\mathrm{e}}$, das die muchten abegeloset werden. Ouch hod Tobenecker, voith zcu Schyvelbein $^{168}$, uffgehaven de pacht van Sammentin bey Arnswalde, nemlich 38 Rynsche gulden, und 15 gulden pacht van Dalow, de nu vellich ist geweset uff Martini negestvorgangen $^{169}$. Ouch hott de borggraffe zcu Dryßen uffgehaven de orbare zcu Arnswalde, nemlich 20 gute mark. Darumme bitte ich, ewer gnade wille Tobeneckere screiben und ouch ern Kaldenborne, das se mir de pacht und orbare wedderkeren und geben. [3] Ouch hod der voith zcu Schyvelbein den heydehabern, die uff dissen herbest ist vellig geweset, wol die helffte uff $[\ldots . .$.$] dert ^{\mathrm{b})}$ und $^{\mathrm{c})}$ ouch etzliche molenpacht, nachdeme als er entsatzet ist worde[n. Ap $]^{\text {b) }}$ ich ene ouch darumb manen sal, das setze ich zcu ewern gnaden, dann ich nichtes daranne $\mathrm{t}[\mathrm{u}] \mathrm{n}^{\mathrm{b})}$ will sunder ewer gnaden wissen und wille. [4] Ouch als ich van ewern gnaden gescheiden byn $\mathrm{u}[..] \mathrm{d}[. .]^{\mathrm{b})}$ herrn unses ordens hiruß zcu senden; so bitte ich ewer gnade, das ir heruß senden willet er[n Ju]rgen ${ }^{\text {b) }}$ Eykstadt, der itczundt zcu Slochow ist, die ouch vo ${ }^{\mathrm{e}} \mathrm{r}$ in der Marke geweset ist, den ich haben und setzen wolde ken Lansperg und keynen herrn hiruß ken Arnswalde senden, und es darmitte losset anstehen biß uff den herbest, dann ich selbst meyn meyste leger aldar habin wil mit meynen dynren, uff das ich destu baß ußkomen moge, und hoffe es, ab God wil, also zcu bestellen, das ewern gnaden und unserm orden keyn schade darvan entstehen sulle. [5] Ouch, gnediger her homeister, byn ich warafftig gewarndt, wie das hertzoge Hynrik ${ }^{170}$ und syne anwaldigen die Nuwen Marke obirvallen wil, sobalde de Oder bestanden ist. Hirumme mag ewer gnade mit den gebietigern darvo ${ }^{\mathrm{e}} \mathrm{r}$ gedencke, das mir ewer gnade hulffe darczu doh ${ }^{\mathrm{d})}$ mit lewten

167 Johann Rabe, Komtur zu Schlochau 1450-1454.

168 Hans Thobenecker, Vogt der Neumark 1448-1450, Vogt zu Schivelbein 1450-1455.

169 [1450] November 10.

170 Herzog Heinrich der Ältere (der Fette) von Mecklenburg (1436-1477). 
edder mit gelde, dann ich zcu swach zcu dem obirfalle byn mit der Marke, als ich gewarnt byn. Wil ewer gnade sunder schade bleiben, so mag ewer gnade darvo ${ }^{\mathrm{e}} \mathrm{r}$ wol gedencken. Gegeben zcu Waldenborg am dunretaghe vor sandt Thomeß tage anno Domini etc. $\mathrm{L}^{\circ}$. Voith der Nuwen Marke.

Gedechtnisße ken unserm homeister.

[6] Item das dy lant und stete swer woren czur holdigunge dorumme, das er schade, den sy genomen haben von der nederloghe, von her Jorgen ${ }^{171}$ und ouch sust, das sy gefachen an gefenkenisße und an pherden schaden genomen haben, das yn allewege geloubt were, uffczurichten noch lawte eres lantbrives, der in gegeben ist in der ersten erbholdunghe, und ouch sust von den schulden, dy en dy voythe scholdigk bleben.

[7] Item von des hawses wegen Kostrin, das der grabe ee io besser her ummer muchte komen, wen merkeliche lewte ingehem dovon gereth haben, das is fele lewten in den oughen leith, und wol menen, wen is alsampth gereth is, daz wirs nicht lange behalden, und wol not were, in grosser hut czu halden.

[8] Item von der bawpherde wegen, dy do genomen seyn und gestolen bey nachte und ouch des houbtmannes pherde, das hat geton Teile Doberko, der seynen vater wonende hot under dem hern margrafen von Brandeborg ${ }^{172}$ und hot das unvorwart seyner eren geton, wen her ment czu unserm orden schulde czu haben, und man im keyns phlege ist, das denne dur rechte vorczeiten sal dirkant seyn. Ouch so ist mete gewest Hinrich Hondorff, der seynen vater hot wonen under deme von Bebersteyn, der kert sich weder an seynen vater noch an seyne frunde. Ouch so ist mete gewest Nickel Waldaw, der mit eyme pherde phleeth czu reiten, und czwene knechte, dy sint Tylen Doberkows gewesen, genant Claus Peile, der ander Sleicher, und treben dy pherde in daz von Bebersteyns lant ${ }^{173}$, der do bey seynen gantczen fleiß hot geton, und andere gutte frunde, dy deme howptmanne czugehoren, bestalten umme semliche pherde, so das dyselbigen dybe mit den pherden rathen nach der Alden Marke. Alzo balde is der herre margrafe dirfur, gap her von stunt seynen offen briff des houptmans dinern und ouch sust hulfe tathe, so das im 14 pherde von den bawpherden weder wurden, so das der houptman hoft czu den andern wol rath steeth, sunder des houp[t]mans pherde seyn noch des meiste tel weg, und der bawpherde sint noch $4 \mathrm{au}$, so is er czwe gestorben.

Item so hette her gerne 12 pherde, alz her mit unserm homeister gereth hot, und das dy herauß wurden geschikket 14 taghe noch Weynachten.

a) Buchstabe abgescharbt. - b) Loch im Papier. - c) davor gestrichen: und ouch das how. - d) übergeschrieben über gestrichen: tun.

171 Georg von Egloffstein, Vogt der Neumark (1441-1448).

172 Markgraf Friedrich II. von Brandenburg (1440-1470).

173 Die Bibersteine waren Inhaber der damals im Markgraftum Niederlausitz gelegenen Herrschaft Beeskow-Storkow. 



\title{
Die Vögte des Deutschen Ordens in der Neumark und ihr Verhältnis zu Preußen
}

\author{
Von BERNHART JäHNIG
}

Der Deutsche Orden gliederte seine Landesherrschaft ${ }^{1}$ in Preußen in ein Netz verfassungsrechtlich gleichartiger Bezirke, die als Komtureien bezeichnet wurden. Deren Verwaltung wurde von einem Komtur und dessen Konvent wahrgenommen, der je nach Größe des Komtureibezirks aus einer unterschiedlich großen Zahl von Ordensbrüdern bestand. Dies gilt nicht nur für die Zeit des Aufbaus im 13. Jahrhundert, sondern wurde auch nach dem Erwerb von Pommerellen im Jahre 1308/09 durchgeführt, als nacheinander die Komtureien Danzig, Dirschau, Schwetz, Schlochau und Tuchel eingerichtet wurden. Aus zweierlei Gründen hat der Orden jedoch nicht mehr uneingeschränkt neue Komtureien eingerichtet. Zum einen standen ihm nicht mehr unbegrenzt Ritterbrüder zur Verfügung, um die neuen Konvente personell angemessen auszustatten. War in den Jahren 1270-1305 die Anzahl der kulmerländischen Komtureien deutlich vermehrt worden, wurde nach 1325 ein Teil der kleinen Konvente des Kulmer Landes wieder abgezogen, um deren Brüder an den neuen Orten einsetzen zu können. Die betroffenen kulmerländischen Komtureien wurden dabei in Vogteien umgewandelt ${ }^{2}$, die nur noch von einem Vogt mit einem meist jüngeren Ritterbruder als Kumpan und einem Priesterbruder verwaltet wurden, jedoch der Ordensleitung unmittelbar unterstellt blieben. Selbst die bedeutend größere pommerellische Komturei Dirschau wurden nach wenigen Jahren in eine solche Vogtei umgewandelt. Zum anderen wurde die Verwaltung des Ordenslandes, nachdem die Ordensleitung in die Marienburg eingezogen war, stärker zentralisiert. Dazu gehörte vermutlich unter Hochmeister Werner von Orseln die Einrichtung der hochmeisterlichen Kammer und der Treßlerkasse. In diese zinsten die selbständigen Vogteien, während die Komtureien ihre Einnahmen für die Unterhaltung ihres Konvents benötigten ${ }^{3}$.

1 Grundlegende Beobachtungen bei Bernhart Jähnig: Verfassung und Verwaltung des Deutschen Ordens und seiner Herrschaft in Livland. Berlin, Münster 2011 (=Schriften der Baltischen Historischen Kommission, 16).

2 Vgl. Reinhard Wenskus: Das Ordensland Preußen als Territorialstaat des 14. Jahrhunderts, zuerst 1970, neu in: Ders.: Ausgewählte Aufsätze zum frühen und preußischen Mittelalter. Sigmaringen 1986, S. 317-352, hier S. 329, 332 f.

3 Vgl. Arthur Sielmann: Die Verwaltung des Haupthauses Marienburg in der Zeit um 1400, in: Zeitschrift des Westpreußischen Geschichtsvereins 61 (1921), S. 1-101, hier S. 41-43, 88-93; zur hochmeisterlichen Kammer auch Klaus Militzer: Die Entstehung der Deutschordensballeien im Deutschen Reich. Marburg 21981, S. 138 ff. (= Quellen und Studien zur Geschichte des Deutschen Ordens, 16); Simon Helms: Luther von Braunschweig. Marburg 2009, S. 46-49 (= Quellen und Studien zur Geschichte des Deutschen Ordens, 67). 
Als der Deutsche Orden gegen Ende des 14. und zu Beginn des 15. Jahrhunderts noch einmal die Gelegenheit hatte, sein Gebiet wenigstens für eine begrenzte Zeit zu vergrößern, verzichtete er von vornherein auf die Neugründung von Komtureien und richtete sogleich Vogteien ein. So entstanden

- 1384 in Hinterpommern die Vogtei Schivelbein, als diese Herrschaft von dem hochverschuldeten Hans von Wedel erworben wurde ${ }^{4}$,

- 1398 nach erfolgreichem Kampf gegen die Vitalienbrüder für ein Jahrzehnt die Vogtei Gotland ${ }^{5}$,

- ebenfalls 1398 nach dem Vertrag von Sallinwerder mit Großfürst Witowt von Litauen auch für etwa ein Jahrzehnt die Vogtei Samaiten ${ }^{6}$

- und schließlich als letzte Gründung 1402 im Anschluß an eine Verpfändung durch den brandenburgischen Markgrafen Siegmund, der zugleich König von Ungarn war, die Vogtei Neumark ${ }^{7}$, die sich räumlich an die Vogtei Schivelbein anschloß.

Diese Nachbarschaft ist es gewesen, die dazu führte, daß die Vogtei Neumark während ihres Bestehens von einem guten halben Jahrhundert für die längste Zeit (1402-1441, 1448-1450) zusammen mit Schivelbein von demselben Vogt verwaltet wurde. Daß die Ordensleitung die Neumark und Schivelbein weitgehend als eine Verwaltungseinheit ansah, ist auch daran zu erkennen, daß im Großen Ämterbuch des Ordens, in dem die Amtswechsel der Komture und selbständigen Vögte protokollarisch festgehalten wurden, Schivelbein nach 1402 keine eigene Rubrik mehr hat, sondern zusammen mit den neumärkischen Häusern und Höfen aufgeführt wird ${ }^{8}$. Soldin galt zwar, bevor Markgraf Johann (Hans) 1535 Küstrin als Residenz ausbauen ließ, als Hauptort der Neumark ${ }^{9}$. Da jedoch der Vogt als Gebietiger des Deutschen Ordens für die Neumark zur Erledigung seiner Verwaltungsgeschäfte keinen Konvent hatte, wurde auch keine Konventsburg benötigt. Den Ausstellungsorten seiner dienstlichen Schreiben nach zu urteilen, hat er an

4 Geheimes Staatsarchiv Preußischer Kulturbesitz, XX. HA Historisches Staatsarchiv Königsberg [künftig: StA Kbg.], Schiebl. 46 Nr. 31 f., Schiebl. 95 Nr. 77.

5 Vgl. Friedrich Benninghoven: Die Gotlandfeldzüge des Deutschern Ordens 1398-1408, in: Zeitschrift für Ostforschung 13 (1964), S. 421-477.

6 Erich Weise (Hg.): Die Staatsverträge des Deutschen Ordens in Preußen im 15. Jahrhundert, Bd. 1. Marburg 21970, Nr. 2 § 4; zum Vertrag vgl. Klaus Neitmann: Die Staatsverträge des Deutschen Ordens in Preußen 1230-1449. Köln, Wien 1986, S. 150-153 (= Neue Forschungen zur brandenburgpreußischen Geschichte, 6), zur politischen Lage Wilhelm Nöbel: Das Problem der Einrichtung der Ordensvogtei Samaiten, in: Zeitschrift für Ostforschung 17 (1968), S. 692-697.

$7 \quad$ StA Kbg., Schiebl. 43 Nr. 3, 4 u. 8; vgl. Johannes Voigt: Die Erwerbung der Neumark. Ziel und Erfolg der Brandenburgischen Politik unter den Kurfürsten Friedrich I. und Friedrich II. 1402-1457. Berlin 1863; Karl Heidenreich: Der Deutsche Orden in der Neumark (1402-1455). Berlin 1932, S. 3-14 (= Einzelschriften der Historischen Kommission für die Provinz Brandenburg und die Reichshauptstadt Berlin, 5).

8 Walther Ziesemer (Hg.): Das Große Ämterbuch des Deutschen Ordens. Danzig 1921, Ndr. Wiesbaden 1968, S. 672-674 (Schivelbein 1385, 1386, 1389, 1402), 765-774 (Neumark 1408, 1410, 1413, 1428, 1430, 1441, Küstrin 1443).

9 Gerd Heinrich: Berlin und Brandenburg. Stuttgart ${ }^{3} 1995$, S. 415 (= Handbuch der historischen Stätten Deutschlands, 10). 
wechselnden Orten zwischen Küstrin und Schivelbein seine Amtsgeschäfte geführt. Im folgenden werden die Vögte der Neumark vorgestellt, indem ihre Laufbahnen ${ }^{10}$ skizziert und ihre Amtszeiten in der Neumark charakterisiert werden, um dann anschließend zu versuchen, einen Anhalt für deren Stellung in der Gesamtheit der preußischen Deutschordensgebietiger zu gewinnen ${ }^{11}$.

Der erste Vogt, dem die Neumark von der Ordensleitung gleich 1402 übertragen wurde, war Balduin Stael von Holstein ${ }^{12}$. Er steht hinsichtlich seiner diplomatischen Behandlung des neumärkischen Adels in einem guten Ruf. Die Lage der Neumark ähnelte im Blick auf die Sozialstruktur derjenigen, der sich im 14. Jahrhundert der livländische Ordenszweig ausgesetzt sah, als er das durch den Hochmeister vom dänischen König angekaufte Nordestland mit einer starken Ritterschaft seiner Landesverwaltung einzugliedern hatte. Balduin Stael von Holstein kam aus einer adeligen Familie, die auch in der Grafschaft Mark ansässig war, die außerdem in allen größeren niederrheinischen Territorien vertreten war. Er selbst war in der hochmeisterlichen Kammerballei Koblenz für zwei Jahre Komtur des Haupthauses gewesen, ehe er 1399 nach Preußen kam. Ob er mit einem Balduin Stol identisch ist, der bereits 1394 und dann 1400/1402 in der Komturei Balga tätig war, ist nicht sicher zu sagen. 1402 übernahm er jedenfalls Schivelbein mit der Neumark und verwaltete die neue bzw. erheblich vergrößerte Vogtei sechs Jahre lang. Warum er 1408 abgelöst wurde, ist nicht erkennbar, denn er übernahm zunächst innerhalb der Komturei des preußischen Haupthauses Marienburg die Vogtei Grebin für ein Jahr, ehe er Ende 1409 Komtur von Strasburg an der Drewenz wurde. Einen möglichen weiteren Aufstieg verhinderte sein Tod auf dem Schlachtfeld bei Tannenberg am 15. Juli 1410.

Neuer Vogt der Neumark wurde im August 1408 Arnold von Baden ${ }^{13}$. Er entstammte einer aus der zähringischen Ministerialität hervorgegangenen Ritterfamilie. Er war 1401-1408 Unterer und Oberer Kumpan der Hochmeister Konrad und Ulrich von Jungingen. Inhaber dieser Ämter sollten für höhere Aufgaben ausgebildet und getestet werden. 1407 war Arnold von Baden für sieben Monate auch Vogt von Gotland, der an der Abwicklung dieses kostspieligen Unternehmens mitwirkte. Anschließend blieb

10 Das älteste Verzeichnis preußischer Ordensamtsträger stammt von Johannes Voigt: Namen-Codex der Deutschen Ordens-Beamten. Königsberg 1843, Ndr. Niederwalluf 1971; neuerer Forschungsstand bei Bernhart Jähnig: Dostojnicy zakonu krzyżackiego w Prusach [Die Würdenträger des Deutschen Ordens in Preußen], in: Roman Czaja, Andrzej Radzimiński (Hgg.): Zakonu krzyżacki w Prusach i Inflantach. Toruń 2013, S. 279-329. Die hier zu findenden Angaben sind grundsätzlich zu vergleichen, soweit nicht das Große Ämterbuch (wie Anm. 7) weiterführende Auskünfte gibt.

11 Vorausgegangen ist eine ähnliche Untersuchung für die Komture von Thorn. Bernhart Jähnig: Zur Stellung des Komturs von Thorn unter den Deutschordens-Gebietigern in Preußen, in: Beiträge zur Geschichte Westpreußens 7 (1981), S. 99-144. Zur Rangfolge der preußischen Deutschordensgebietiger vgl. ders.: Hat Kaiser Karl IV. im Jahre 1355 mit Hochmeister Winrich von Kniprode verhandelt, in: Blätter für deutsche Landesgeschichte 116 (1980), S. 77-119.

12 Vgl. Hans Limburg: Die Hochmeister des Deutschen Ordens und die Ballei Koblenz. Bad Godesberg 1969, S. 49 (= Quellen und Studien zur Geschichte des Deutschen Ordens, 8); Lutz Fenske, Klaus Militzer (Hgg.): Ritterbrüder im livländischen Zweig des Deutschen Ordens. Köln u.a. 1993, Nr. 827 S. 611 (= Quellen und Studien zur baltischen Geschichte, 12).

13 Vgl. Julius Kindler v. Knobloch: Oberbadisches Geschlechterbuch 1. Heidelberg 1898, S. 28; Bernhard Schmid, in: Altpreußische Biographie 1. Königsberg 1941, S. 26. 
er nur anderthalb Jahre Vogt der Neumark. Im April 1410 wurde er bei einer größeren Gebietigerwandlung - als also eine Mehrzahl von Gebietigern in ihren Ämtern ausgetauscht wurde - Komtur von Schlochau. Auch seine Laufbahn wurde durch den Großen Krieg des Jahres 1410 abgebrochen.

Im Zuge der Gebietigerwandlung im April 1410 wurde der spätere Hochmeister Michael Küchmeister ${ }^{14}$ Vogt der Neumark. Er entstammte einer obersächsisch-schlesischen Ritterfamilie. Er war 1396-1402 Pfleger von Rastenburg in der Komturei Balga, übernahm 1402 das Königsberger Großschäfferamt und war damit für den Bernsteinhandel verantwortlich, ehe er 1404 die Vogtei Schamaiten übernahm. Dieses Amt verlor er infolge des Aufstandes der Schamaiten im August 1409. Als Vogt der Neumark nahm er nicht an der Schlacht bei Tannenberg teil, geriet aber im Herbst 1410 in polnische Kriegsgefangenschaft. Nach der Entlassung aus dieser wurde er etwa Februar/März 1411 als Oberster Marschall einer der Großgebietiger unter Heinrich von Plauen. Als dieser Hochmeister allzu selbständig gegen den Rat der Mehrzahl der Gebietiger im Herbst 1413 ein Präventivkrieg gegen Polen einleitete, gelang es Michael Küchmeister, den Hochmeister absetzen zu lassen. Im Januar 1414 wurde er zum Nachfolger gewählt. Seine unglückliche Regierungszeit führte schließlich dazu, daß er im März 1422 resignierte, also zurücktrat. Er verwaltete noch acht Monate lang die Komturei Mewe und ist bald darauf gestorben.

Während der Gefangenschaft von Michael Küchmeister wurde dieser nur wenige Wochen lang von dem späteren Treßler Boemund Brendel vertreten. Offiziell neuer Vogt der Neumark wurde im November 1410 Engelhart Kirsau oder Kassau. Über seine Herkunft ist bisher nichts bekannt geworden. Später gab es eine Familie dieses Namens in Pommerellen. Engelhart ist bisher auch nicht in einem anderen Ordensamt vor der Übernahme der Neumark nachzuweisen. Die Vogtei hat er nur ein halbes Jahr lang, bis April 1411, versehen. Als im Juni 1415 die Komturei Birglau bei Thorn aufgelöst wurde, war er deren letzter Komtur, 1416 war er Komtur im ebenfalls kulmerländischen Schönsee, im Jahr 1418 war er eine kurze Zeit lang Hauskomtur von Balga, seit 1419 ist er in der Komturei Marienburg zu finden, zunächst als Vogt von Leske, 1422 als Fischmeister von Scharfau. Das war im ganzen eine wenig erfolgreiche Laufbahn, in deren Verlauf ihm nur kleinere Ämter übertragen wurden.

Neuer Vogt der Neumark wurde im April 1411 der böhmische Landadelige Albrecht von der Dube ${ }^{15}$. Er war 1394-1402 Landkomtur der dem Hochmeister unmittelbar unterstehenden Ballei Böhmen gewesen. Wohl wegen zweifelhafter Amtsführung wurde er nach Preußen geholt. Bevor er Vogt der Neumark wurde, hat er in Preußen kein anderes

14 Vgl. Wilhelm Nöbel: Michael Küchmeister. Hochmeister des Deutschen Ordens 1414-1422. Bad Godesberg 1969 (= Quellen und Studien zur Geschichte des Deutschen Ordens, 5); Bernhart Jähnig: Michael Küchmeister, in: Udo Arnold (Hg.): Die Hochmeister des Deutschen Ordens 1190-1994. Marburg 1998, S. 119-122 (= Quellen und Studien zur Geschichte des Deutschen Ordens, 40).

15 Wiederholt genannt in Josef Hemmerle: Die Deutschordens-Ballei Böhmen in ihren Rechnungsbüchern 1382-1411. Bonn, Bad Godesberg 1967 (= Quellen und Studien zur Geschichte des Deutschen Ordens, 22). 
Amt bekommen. In der Neumark blieb er anderthalb Jahre, ehe er im November 1412 als Vogt von Brattian ins Kulmer Land gesetzt wurde. 1414 ist er schließlich nach Böhmen zurückgegangen, wo er wieder das Landkomturamt übernahm und auch noch 1436 in diesem nachweisbar ist. Er war wohl die schillerndste Figur im Neumärker Vogtsamt.

Neuer Vogt der Neumark wurde im November 1412 Heinrich Hauer oder Hoyer von Mandern ${ }^{16}$, der aus Waldeck kam und einer landgräflich thüringischen Ministerialenfamilie entstammte. Er begegnet zunächst 1411 in Marienburger Hausämtern, ehe er für gut ein Jahr die Vogtei Brattian übernahm. Von dort ging er in die Neumark, wo er jedoch nicht viel länger als ein halbes Jahr blieb. 1417 finden wir ihn wieder in der Komturei Marienburg, wo er zunächst zwei Jahre lang als Hauskomtur eine für den inneren Dienstbetrieb wichtige Stelle innehatte, ehe er für drei Jahr Stuhm als Vogt übernahm. Selbständiger wurde seine Aufgabe als Vogt des großen Gebietes Dirschau westlich der Weichsel, und zwar 1422-1424. Schließlich wurde er Vogt des Hochstiftes Samland ${ }^{17}$. Damit hatte er die weltliche Verwaltung von dessen Bischof zu leiten. Nach 1429 kommt er in den Quellen nicht mehr vor. Obwohl Heinrich Hauer keine Komtursstelle hatte einnehmen können, hatte er doch einige verantwortungsvollere Aufgaben wahrzunehmen.

Vom Juni 1413 bis Oktober 1420 hat Sander von Machwitz über sieben Jahre lang die Neumark verwaltet. Sonst ist von ihm nichts bekannt. Vielleicht entstammte er der vogtländischen Familie von Machwitz oder war ein Verwandter des pommerellischen Landadeligen Otto von Machwitz, der nach 1454 als Ordensfeind hervortrat ${ }^{18}$. Es ist bisher auch keine Überlieferung bekannt geworden, ob er vorher oder hinterher ein Amt im Deutschen Orden in Preußen ausgeübt hat.

Anders sieht es beim Nachfolge Jost von Strupperg ${ }^{19}$ aus, der von Oktober 1420 bis Juni 1422 Vogt der Neumark gewesen ist. Er stammte aus einer Ritterfamilie der bayerischen Oberpfalz. Wir finden ihn seit 1410 in der Komturei Christburg, nämlich zuerst als Kumpan des Komturs, dann als Hauskomtur und schließlich 1415-1418 als Komtur, wobei zu erwähnen ist, daß gerade in diesen Jahren das Großgebietigeramt des Obersten Trapiers von Christburg getrennt war. 1418-1420 war der Strupperger Vogt von Brattian, bevor er in die Neumark ging, wo er etwas länger als anderthalb Jahre blieb. Dann wurde er zum ersten Mal Großgebietiger als Treßler und hatte zwei Jahre lang die Kasse des Hochmeisters zu führen. Anschließend ging er in den Nordosten und wurde sechs Jahre lang Komtur von Balga, eine der bedeutendsten Komtureien des Ordenslandes. Im Juli

16 Zur Herkunft vgl. Dieter Wojtecki: Studien zur Personengeschichte des Deutschen Ordens im 13. Jahrhundert. Wiesbaden 1971, S. 40 Anm. 210 (= Quellen und Studien zur Geschichte des östlichen Europa, 3); Ritterbrüder (wie Anm. 12), Nr. 572 S. 437.

17 Vgl. Heinz Schlegelberger: Studien über die Verwaltungsorganisation des Bistums Samland im Mittelalter. Phil. Diss. Königsberg 1922, Ndr. hg. v. Radosław Biskup, in: Ders., Mario Glauert (Hgg.): Die Domkapitel des Deutschen Ordens in Preußen und Livland. Münster 2004, S. 134 (=Zeitschrift für die Geschichte und Altertumskunde Ermlands, Beiheft 17), zu den Verwaltungsaufgaben S. 103-108.

18 Vgl. Werner Paravicini: Zeitenwende. Edelleute aus dem Ordensland Preußen und Livland im Westeuropa des 15. Jahrhunderts, in: Reich, Regionen und Europa in Mittelalter und Neuzeit. Festschrift für Peter Moraw. Berlin 2000, S. 426 f. (Historische Forschungen, 67).

19 Vgl. Karl H. Lampe, in: Altpreußische Biographie 2. Marburg 1967, S. 712. 
1431 stieg er als Oberster Marschall in den Rang eines Großgebietigers auf. Dann zog er sich aus der großen Politik zurück und hat kleinere Ämter zumeist in der Komturei Königsberg wahrgenommen. Als Pfleger von Ossek hat er allerdings 1437/38 die Visitation der preußischen Ordenshäuser durchgeführt, deren Ergebnis in dem bekannten Großen Zinsbuch überliefert ist ${ }^{20}$, das eine der bedeutendsten Quellen zur preußischen Verwaltungs- und Wirtschaftsgeschichte ist. Zuletzt ist der Strupperger 1440 für einige Wochen als Komtur von Tuchel in einem kleinen Amt in Pommerellen zu finden.

Der nächste Vogt der Neumark war Walther von Kirskorf ${ }^{21}$ aus der Grafschaft Kleve. Er war ein Bruder des livländischen Meisters Frank Kirskorf. Walther begegnet uns zuerst im Juni 1422 als Vogt der Neumark, wo er über sechs Jahre blieb, ehe er Komtur von Danzig wurde. Auch dort weilte er sechs Jahre und stieg dann zu den Großgebietigern auf. Zunächst war er von Mai 1434 bis Januar 1436 Großkomtur und damit Vertreter des Hochmeisters, von September 1436 bis Oktober 1438 war er Oberster Trapier und Komtur von Christburg. In den unruhigen Zeiten des Hochmeisters Paul von Rusdorf ${ }^{22}$, als das Proporzdenken im Zuge des sogenannten Zungenstreits die Ämtervergabe beeinflußte, blieb er als Rheinländer zunächst ohne erkennbares Amt, ehe er im April 1440 in die Neumark zurückkehrte. Ein Jahr später wurde die Vogtei geteilt, Walther von Kirskorf behielt Schivelbein offenbar als Alterssitz, bis er dort im Oktober 1448 starb.

Nach der ersten neumärkischen Amtszeit von Walther von Kirskorf wurde Nikolaus von Nickeritz sein Nachfolger. Dieser stammte aus einer meißnischen Ritterfamilie. Er begegnet zunächst im Kulmer Land, und zwar 1423 als Vogt von Roggenhausen. Spätestens im Dezember 1426 war er Komtur von Strasburg. Zwei Jahre später, im Dezember 1428, übernahm er das wichtige Amt des Vogtes der Neumark. Nach weniger als zwei Jahren zog er im September 1430 als Vogt nach Dirschau weiter. Sein letztes Gebietigeramt übte er von Juli 1431 bis Dezember 1433 als Komtur von Schlochau aus. Danach ist er im Konvent von Elbing zu finden, und zwar als Unterspittler. Im Unterschied zum Obersten Spittler hatte er die tatsächliche Aufsicht über das Elbinger Heilig-Geist-Spital wahrzunehmen ${ }^{23}$. Das nach wie vor hohe Ansehen dieses ehemaligen Neumärker Vogtes zeigt sich darin, daß er 1441/42 von der Ordensleitung als Visitator nach Livland geschickt wurde und auch später in den Elbinger Konventslisten vorn zu finden ist ${ }^{24}$.

20 Edition: Peter G. Thielen (Hg.): Das Große Zinsbuch des Deutschen Ritterordens (1414-1438). Marburg 1958.

21 Vgl. Ritterbrüder (wie Anm. 12), Nr. 491 S. 380.

22 Vgl. Carl August Lückerath: Paul von Rusdorf. Hochmeister des Deutschen Ordens 1422-1441. Bad Godesberg 1969 (= Quellen und Studien zur Geschichte des Deutschen Ordens, 15).

23 Zu dieser Aufgabe vgl. Wieslaw Długokęcki: Abriß der Geschichte der Spitäler und des Spitalwesens von Elbing vom 13. bis 17. Jahrhundert, in: Bernhart Jähnig (Hg.): 75 Jahre Historische Kommission für ost- und westpreußische Landesforschung. Lüneburg 1999, S. 312 f. (= Tagungsberichte der Historischen Kommission für ost- und westpreußische Landesforschung, 13).

24 Belege in: Marian Biskup, Irena Janosz-Biskupowa (Hgg.), Udo Arnold (Red.): Visitationen im Deutschen Orden im Mittelalter, 1-3. Marburg 2002-2008, Bd. 1, S. 98, 163, 169 f., 184 f., 250, Bd. 2, S. 154 (= Quellen und Studien zur Geschichte des Deutschen Ordens, 50/1-3). Er war nicht, wie die Herausgeber der Visitationsakten wiederholt schreiben, Oberster Spittler und damit Kom- 
Nachfolger wurde eine offenbar sehr streitbare und ehrgeizige Persönlichkeit, nämlich der aus dem Vogtland stammende Heinrich von Rabenstein ${ }^{25}$. Im Orden finden wir ihn sogleich von September 1430 bis März 1435 als Vogt der Neumark. Von dort ging er als Komtur in das benachbarte Schlochau weiter, wo er über zwei Jahre blieb, ehe er 1437-1438 in Thorn Komtur und damit der nach den Großgebietigern ranghöchste Komtur wurde. Er wurde dann sogar Oberster Marschall von März 1438 für zwei Jahre. Als er sich dort nicht mehr halten konnte, versuchte er in die Komturei Thorn zurückzukehren. Als dieser Versuch am dortigen Konvent scheiterte, gelang es ihm, wenigstens für einige Monate als Oberster Spittler und Komtur von Elbing in der Nähe des Hochmeisters zu bleiben. Im Juni 1441 mußte er sich dann mit dem deutlich kleineren Amt eines Komturs von Tuchel begnügen, 1451 wurde er Komtur von Strasburg bis zum Beginn des Dreizehnjährigen Krieges 1454. Bekannt ist noch, daß er 1456 in Kriegsgefangenschaft geriet, aus der er 1457 befreit wurde. Ein Amt hat er nicht mehr übernommen.

Ebenfalls aus einer vogtländischen Adelsfamilie, die schon seit dem 13. Jahrhundert zahlreiche Ordensbrüder gestellt hat, stammte Hans (Johannes) von Dobeneck ${ }^{26}$. Er hatte zwei Amtszeiten als Vogt der Neumark. Vorher hatte er sein erstes kleines Amt 1432 in Neidenburg, das als Pflegeamt zur Komturei Osterode gehörte. 1434/35 war er einige Monate lang Komtur von Nessau, ehe der Orden dieses kleine Gebiet gegenüber Thorn endgültig im Brester Frieden an Polen abtreten mußte. Im April 1435 begann er als Rabensteins Nachfolger seine erste Zeit als neumärkischer Vogt, die 31/2 Jahre dauerte. Danach verwaltete er von 1438 bis 1442 die verbundenen Ämter der Vogtei Leipe und der Komturei Schönsee im Kulmer Land. Zu einem unbekannten Zeitpunkt übernahm er die Vogtei Dirschau, aus der er 1446 ausschied. Nach dem Tode von Walther von Kirskorf als Vogt von Schivelbein im Oktober 1448 wurde unter Hans von Dobeneck Schivelbein für zwei Jahre wieder mit der Neumark vereinigt. Als im November 1450 erneut eine Teilung erfolgte, behielt er Schivelbein. Dies war vermutlich als Alterssitz gedacht.

Nach des Dobeneckers erster Neumärker Zeit folgte Hans von Stockheim als Vogt der Neumark. Es gibt vorwiegend im norddeutschen Raum eine Vielzahl von Adelsfamilien, die sich nach Stockheim oder Stöckheim nannten. Während für den livländischen Ordensbruder Dietrich von Stöckheim in der Mitte des 14. Jahrhunderts eine Zugehörigkeit zu der aus der Hildesheimer Ministerialität kommenden Familie wahrscheinlich gemacht werden konnte, ist für verschiedene in Preußen tätige Ordensbrüder eine Verwandtschaft nicht nachzuweisen. Hans (Johann) von Stockheim ${ }^{27}$ ist für meistens nur kürzere Zeitab-

tur von Elbing, denn dieses Amt hatte zu jener Zeit bereits der spätere Hochmeister Heinrich Reuß von Plauen übernommen.

25 Vgl. Jähnig: Thorn (wie Anm. 11), S. 143.

26 Alban Freiherr von Dobeneck: Geschichte der Familie von Dobeneck. Berlin 1906. Besondere Bedeutung erlangte der spätere pomesanische Bischof Hiob von Dobeneck; vgl. Kurt Forstreuter, in: Neue Deutsche Biographie 4. Berlin 1959, S. 4 f.; Mario Glauert: Die Einsetzung Hiob von Dobenecks zum Bischof von Pomesanien 1501/1502, in: Preußische Landesgeschichte. Festschrift für Bernhart Jähnig zum 60. Geburtstag. Marburg 2001, S. 161-174.

27 Ausführliche Erörterung der genealogische Problematik durch Lutz Fenske in: Ritterbrüder (wie Anm. 12), Nr. 846. Hier werden auf S. 628 Hans und Johann im Anschluß an das Amtsinhaber- 
schnitte in einer größeren Zahl von Ämtern nachzuweisen, die jedoch kaum den zeitweilig in ihn gesetzten Hoffnungen des Hochmeisters Paul von Rusdorf entsprochen haben dürften. 1424 ist er als Hauskomtur in Danzig zu finden. In den Jahren von 1425 bis 1427 war er als Unterer und Oberer Hochmeisterkumpan offenbar nicht sehr erfolgreich, denn anschließend ist er 1428 und 1430 nur in den Stellungen eines Pflegers in Tapiau und Ortelsburg anzutreffen. Erst in der nicht allzu bedeutenden pommerellischen Komturei Tuchel erreichte er für die Jahre 1431-1437 Gebietigerrang. Von dort ging er im November 1438 als Vogt in die Neumark. Er blieb aber nur ein knappes Jahr, denn schon im Oktober 1439 übernahm er wie einige vor ihm die Vogtei Brattian für eine unbekannt lange Zeit. Seine angesehenste Stelle hatte er von 1441 bis 1444 als Komtur von Schlochau inne.

Sein unmittelbarer Nachfolger als Vogt der Neumark wurde - wie bereits ausgeführt Walther von Kirskorf in seiner zweiten gesamtneumärkischen Zeit. Nachdem Schivelbein als Alterssitz für ihn eingerichtet worden war, wurde die restliche Vogtei Neumark im Juni 1441 Georg von Egloffstein übertragen. Dieser entstammte einer bekannten fränkischen Adelsfamilie, die dem Orden, vor allem im Reich, bedeutende Ritterbrüder gestellt hatte ${ }^{28}$. Von Georg von Egloffstein ist nichts bekannt aus der Zeit, bevor er Vogt der Neumark wurde. Er blieb dort bis November 1448, ehe auch er die Verwaltung der verbundenen Ämter der Vogtei Leipe und der Komturei Schönsee bis zum Beginn des Dreizehnjährigen Krieges übernahm. In der Wissenschaft bekannt geworden ist er als der Ritterbruder der von Hochmeister Ludwig von Erlichshausen 1451/52 veranlaßten Visitation der deutschmeisterlichen Ordensprovinzen und ihrer Häuser und Brüder und weil sich die Niederschriften über diese Visitationsreise bis heute erhalten haben ${ }^{29}$. Dies zeigt einmal mehr, daß das mit großer Vollmacht ausgestattete Amt eines Visitators auch einem Gebietiger übertragen werden konnte, der kein Komtursamt innehatte.

Letzter Vogt der Neumark wurde im November 1450 Christoph von Eglingen. Er stammte aus einer im westlichen Bayern (nordöstlich Ulm) ansässigen Adelsfamilie. Es ist bekannt, daß er vor seiner Neumärker Zeit 1437 dem Christburger Konvent angehört hatte. 1446-1448 war er Oberer Hochmeisterkumpan unter Konrad von Erlichshausen.

verzeichnis bei Peter Gerrit Thielen: Die Verwaltung des Ordensstaates Preußen vornehmlich im 15. Jahrhundert. Köln, Graz 1965 als zwei Personen gesehen, obwohl die Ämter in eine Reihe passen. Die im Marienburger Ämterbuch (Danzig 1916, S. 155 u. 158) zu 1445 aufgeführten Pferde aus dem Besitz eines offenbar kurz vorher gestorbenen Stockheim dürften dem Waldmeister von Bönhoff Johann von Stockheim (1441-1442) gehört haben.

28 Vgl. Bernhart Jähnig: Junge Edelleute am Hof des Hochmeisters in Marienburg um 1400, zuerst 2002, aktualisiert in: Ders.: Vorträge und Forschungen zur Geschichte des Preußenlandes und des Deutschen Ordens im Mittelalter. Münster 2011, S. 216-218 (= Quellen und Darstellungen zur Geschichte Westpreußens, 34).

29 Edition: Visitationen (wie Anm. 22) 2, Nr. 148 f., 175. Die von Erich Weise: Georg von Egloffstein (ca. 1409-1458) und die 1. Fortsetzung der Älteren Hochmeisterchronik, in: Preußenland und Deutscher Orden. Festschrift für Kurt Forstreuter. Würzburg 1958, S. 344-373 (= Ostdeutsche Beiträge aus dem Göttinger Arbeitskreis, 9), vorgetragene Meinung, Georg sei Verfasser einer Fortsetzung der Älteren Hochmeisterchronik, wird wegen mehrerer Gründe als unwahrscheinlich angezweifelt von Hartmut Boockmann: Die Geschichtsschreibung des Deutschen Ordens, in: Hans Patze (Hg.): Geschichtsschreibung und Geschichtsverständnis im späten Mittelalter. Sigmaringen 1987, S. 464 (= Vorträge und Forschungen, 31). 
Offenbar hat er gewisse Fähigkeiten entwickelt, so daß ihn der neue Hochmeister Ludwig von Erlichshausen in die Neumark schickte, wo er in den letzten Jahren vor Kriegsbeginn die durch das Land ins Reich führenden Wege zu sichern hatte. Während des Krieges, als die Neumark wieder im Besitz der Brandenburger Kurfürsten und Markgrafen war und die westlichen Gebiete des Preußenlandes längst verloren waren, ist er 1465 als Hauptmann zu Rastenburg zu finden, wo er auch gestorben ist.

Versuchen wir einen Überblick über die Gesamtheit der Neumärker Vögte zu gewinnen. Dabei fragen wir zunächst nach der sozialen und geographischen Herkunft. Von 1402 bis 1455 haben 15 Ritterbrüder des Deutschen Ordens das Amt eines Vogts der Neumark innegehabt. Von zweien wissen wir nichts über ihre Herkunft, und es hat sich auch kein Anhalt für eine Vermutung ergeben. Alle übrigen entstammen niederadeligen Familien. Das ist nicht sehr überraschend, weil im 15. Jahrhundert hochadelige und bürgerliche Ritterbrüder insgesamt keine Rolle mehr im Orden gespielt haben. Letztere kamen in dieser Zeit höchstens als Graumäntler vor, die niemals Gebietigerämter wahrgenommen haben, vielmehr wurden ihnen die weniger angesehenen Hausämter in den Konventen übertragen ${ }^{30}$.

Hinsichtlich der geographischen Herkunft der neumärkischen Vögte gliedern wir diese nach den deutschen Großlandschaften. Neben den beiden Unbekannten fällt ein Böhme etwas aus dem Rahmen des gewohnten Bildes. Es ist jedoch nicht ungewöhnlich, daß Ritterbrüder aus den Kammerballeien nach Preußen geholt wurden, was auch unter den Neumärker Vögten vereinzelt vorkommt. Von den verbleibenden zwölf Ritterbrüdern kommen drei aus dem niederdeutschen, fünf aus dem mitteldeutschen und vier aus dem oberdeutschen Raum. Angesichts der kleinen Gesamtzahl dürfen die Zahlenverhältnisse nicht überinterpretiert werden. Doch als Tendenz sind sie zu gebrauchen, zumal der berühmte ,Zungenstreit ${ }^{31}$ in den Spätjahren des Hochmeisters Paul von Rusdorf voll in unseren Zeitraum fällt. Eine vor über drei Jahrzehnten erstellte Karte der Herkunft der preußischen Ordensgebietiger, die allerdings nicht mit letzter Sorgfalt erarbeitet worden ist, ermöglicht auf der Grundlage der damals ermittelten Herkunftsorte der Ordensritter Verhältniszahlen und Entwicklungstendenzen zu beobachten ${ }^{32}$. Danach kam im 15. Jahrhundert etwa die Hälfte der Ordensgebietiger ganz Preußens aus den drei oberdeutschen Landschaften Schwaben, Franken und Bayern. Unter den Vögten der Neumark war es nur ein Drittel, nämlich vier aus Südbaden, Mittelfranken, Oberpfalz und Westbayern. Die Mitteldeutschen, die für ganz Preußen im 13. Jahrhundert eine Mehrheit hatten, sind

30 Vgl. Bernhart Jähnig: Der Danziger Deutschordenskonvent in der Mitte des 15. Jahrhunderts, zuerst 1985, aktualisiert in: Ders.: Vorträge (wie Anm. 28), bes. S. 263-267.

31 Vgl. Sophie Meyer: Paul von Russdorf und die Konvente von Königsberg, Balga und Brandenburg, in: Altpreußische Monatsschrift 46 (1909), S. 363-417, 543-591; zuletzt Simon Helms: Der Aufstand der Deutschordenskonvente Königsberg, Balga und Brandenburg (1440), ein landsmannschaftlich motivierter Konflikt?, in: Mrągowskie Studia Humanistyczne 4-5 ([2002/2003] 2004), S. 14-28.

32 Ernst Weichbrodt (Bearb.): Gebietiger des Deutschen Ordens in Preußen nach ihrer Herkunft, in: Hans Mortensen u.a. (Hgg.): Historisch-geographischer Atlas des Preußenlandes, Lfg. 1. Wiesbaden 1967 (1968); zur Interpretation dieser Karte vgl. Jähnig: Danzig (wie Anm. 30), bes. S. 263 f. 
unter den Vögten der Neumark mit fünf vertreten, nämlich zwei aus dem Vogtland und je einer aus Waldeck bzw. Thüringen, Obersachsen (Meißen) und Schlesien. Sie waren aber auch andernorts im Preußen des 15. Jahrhunderts stark vertreten, besonders in Elbing um 1440/50. Auffälliger sind in der Neumark die drei Niederdeutschen, denn aus dieser Großlandschaft sind im Unterschied zum livländischen Ordenszweig in Preußen zu allen Zeiträumen nur wenige Ordensbrüder zu finden. Die drei Vögte aus der westfälischen Grafschaft Mark, aus Kleve und aus einer nicht näher bestimmbaren Landschaft wirken angesichts der kleinen Zahl der neumärkischen Gebietiger hinsichtlich ihrer landschaftlichen Herkunft überrepräsentiert.

Die Vögte der Neumark haben ihr Amt unterschiedlich lange ausgeübt. Die Amtsdauer schwankt zwischen fünf Monaten bei Engelhart Kirssau und 71/2 Jahren bei Georg von Egloffstein. Als Besonderheit ist zu beachten, daß zwei Vögte jeweils zweimal innerhalb ihrer Laufbahn das neumärkische Vogtamt innehatten, nämlich Walther von Kirskorf und Hans von Dobeneck. Veranschlagen wir deren Amtszeiten jeweils einzeln, dann haben wir 17 Amtszeiten bei 15 Personen. Die durchschnittliche Amtszeit liegt bei drei Jahren und einem Monat. Schauen wir nur auf die 15 Personen, beträgt der Durchschnitt 31/2 Jahre. Die Ordensstatuten sahen vor, daß auf den jährlichen General- oder Provinzialkapiteln die Gebietiger Rechenschaft abzulegen hatten, damit sie, wenn ihre Amtsführung nicht zufriedenstellend beurteilt wurde, ausgewechselt werden konnten. Es gab aber auch andere Gründe zu einer ,wandelunge der Gebietiger“, wie sie etwa der Chronist Johann von Posilge in seiner Chronik der Lande Preußen knapp beschreibt ${ }^{33}$. Das kann hier nicht bei allen Vögten untersucht werden, einzelnes wurde bei den Laufbahnskizzen schon angedeutet. Auffällig ist, daß die kürzesten Amtszeiten von weit unter einem Jahr in die Zeit des Großen Krieges 1409-1411 und in die Jahre danach fallen. Hier machte sich der Verlust an qualifizierten Kandidaten infolge der zahlreichen Todesfälle in der Schlacht bei Tannenberg bemerkbar ${ }^{34}$. Eine gewisse Konsolidierung der Personalverhältnisse zeigt sich jedoch schon nach wenigen Jahren, denn nach 1413 beginnen in der Vogtei Neumark Amtszeiten von mehr als vier Jahren. Kürzere Amtszeiten sind nur noch dann eingetreten, wenn der betroffene Ordensritter in ein höherrangiges Amt aufgestiegen ist.

Wenden wir uns nun der Frage zu, welche Bedeutung das Amt eines Vogts der Neumark in den Laufbahnen der 15 Ordensritter gehabt haben könnte, die dieses Amt innehatten. Bei fünf Vögten ist nicht überliefert, ob sie vorher im Orden ein anderes Amt versehen haben. Da die erste Hälfte des 15. Jahrhunderts die dichteste Quellenüberlieferung des Ordensarchivs aufweist, ist es erlaubt zu unterstellen, daß diese fünf vorher kein gleichwertiges oder gar höheres Amt innehatten. Für insgesamt sieben Ordensritter war die Berufung zum Vogt der Neumark ein Aufstieg. Zwei Vögte kamen zwar aus einem

33 Vgl. Bernhart Jähnig: Innenpolitik und Verwaltung des Deutschen Ordens in Johann von Posilges Chronik des Landes Preußen, in: Vom vielfachen Schriftsinn im Mittelalter. Festschrift für Dietrich Schmidtke. Hamburg 2005, S. 205-236.

34 Dazu vgl. Berhart Jähning: Eine Korporation in Personalnöten. Die Bedeutung des Schlachtentods von 203 Deutschordensbrüdern am 15. Juli 1410, in: Miscellanea Historico-Archivistica 19 (Warszawa 2012), S. 119-132. 
niedrigeren Amt, waren aber schon vorher Komtur gewesen. Drei Vögte hatten diesen Rang schon andernorts vorher bekleidet. Für vier Vögte war der Weg in die Neumark ein Abstieg, wobei jedoch einschränkend zu sagen ist, daß es sich in drei Fällen vorher nur um kleinere Komtureien gehandelt hat.

Acht Mal ist ein Vogt der Neumark in ein höheres Amt aufgestiegen, davon nur drei in eine kleinere Komturei, die anderen fünf in bedeutendere Gebietigerämter. Drei Vögte stiegen erst auf, nachdem sie noch eine andere Vogtei durchlaufen hatten. Ein weiterer Vogt mußte vor dem Aufstieg zeitweilig mit einem niedrigeren Amt vorliebnehmen. In mehr als zwei Dritteln der Fälle sind die Vögte der Neumark aufgestiegen. Drei Vögte blieben auch andernorts im gleichen Rang, während zwei an Rang verloren haben, von denen Sander von Machwitz nach siebenjähriger Amtszeit ganz aus den Quellen verschwindet. Der Grund kann auch in einem Todesfall liegen. Es ist auch kein anderer Vogt der Neumark im Amt gestorben.

Während wir bisher das „Vorher“ und „Nachher“ der neumärkischen Vögte isoliert betrachtet haben, soll dies nun für die einzelnen Personen in einer Zusammenschau erfolgen, um die Stellung der Vogtei in den einzelnen Laufbahnen zu bestimmen. Die Amtszeiten der beiden Vögte, die zweimal in der Neumark gewesen sind, werden jeweils gesondert berücksichtigt. Es zeigt sich, daß fünf Vögte aus einem niedrigeren Amt kamen und in ein höheres weitergingen, sechs kamen aus einem höheren Amt und gelangten auch wieder in ein höheres Amt. Ein Vogt kam aus einer anderen Vogtei und wurde dann Komtur. Nur zwei Vögte waren aus niedrigeren Ämtern gekommen und wurden auch in solche weiterversetzt. Zwei andere Vögte, die ein solches Amt schon vorher innehatten, blieben es auch danach. Ein früherer Komtur blieb nach der Neumark im Vogtsrang. Auch bei dieser Zusammenschau zeigt sich, daß in mehr als zwei Dritteln der Fälle der Weg nach der Neumark in die Ränge von Komturen oder sogar Großgebietigern führte. Wenn unter den vorhin vorgestellten Vögten als Beispiel einer aufsteigenden Laufbahn sich der spätere Hochmeister Michael Küchmeister besonders anzubieten scheint, ist einschränkend zu sagen, daß sein Aufstieg zum Großgebietiger wesentlich dadurch erleichtert wurde, daß mutmaßliche Konkurrenten auf dem Schlachtfeld bei Tannenberg geblieben waren. Nachdem sich die Personalverhältnisse einige Jahre nach Tannenberg beruhigt hatten, sind Jost von Strupperg, Walther von Kirskorf und Heinrich von Rabenstein unter unterschiedlichen Umständen zu Großgebietigern aufgestiegen. Nikolaus von Nickeritz erreichte zwar nicht mehr diesen Rang, erhielt aber als Visitator außerordentliche Vollmachten für eine zeitlich begrenzte Aufgabe ebenso wie nach ihm Georg von Egloffstein.

Aus alledem folgt, daß das Amt des Vogts der Neumark aus den eingangs genannten Gründen keine Komturei werden konnte. Die Inhaber dieses Amtes gehörten noch nicht zu den eigentlichen Gebietigern. Vielmehr hatten sie den Hochmeistern, die niemals persönlich die Neumark aufgesucht haben, besonders häufig zu berichten und von der Marienburg Weisungen entgegenzunehmen. Diese Vögte hatten jedoch die Aussicht, in den Rang von Gebietigern aufzusteigen. Denn anders als bei den kulmerländischen Vogteien des 14. Jahrhunderts, die auch der Ordensleitung unmittelbar unterstanden, war die Vogtei Neumark mehrheitlich eine Station in aufsteigenden Gebietigerlaufbahnen. Dazu paßt auch, daß seit der Küchmeisterzeit die durchschnittliche Amtsdauer wieder eine normale 
Länge erreicht hatte, wie sie das Große Ämterbuch für die Blütezeit im späten 14. Jahrhundert ausweist. Die Neumark war auch kein Alterssitz für älter gewordene Gebietiger, dazu wurde lediglich Schivelbein in der Spätzeit von der gemeinsamen Verwaltung abgezweigt. Zusammenfassend läßt sich feststellen, daß die große geopolitische Bedeutung der Neumark für den Orden in Preußen sich in der Personalpolitik der Ordensleitung widerspiegelt. 


\title{
Festungsbau und Herrschaftspraxis. Die Umstrukturierung des neumärkischen Territoriums durch Markgraf Johann von Küstrin im 16. Jahrhundert ${ }^{1}$
}

\author{
Von RaLF Gebuhr
}

Nachdem Kurfürst Joachim I. im Juli 1535 gestorben war, wurde mit ihm letztmalig ein Fürst im Zisterzienserkloster Lehnin, der von den Askaniern gestifteten Begräbnisstätte brandenburgischer Markgrafen, zu Grabe getragen. ${ }^{2}$ Sein Sohn und Nachfolger Joachim II. hob im Zuge der Reformation das Kloster 1542 auf und ließ einige Jahre darauf die Särge seines Vaters und seines Großvaters Johann Cicero in den Dom nach Cölln an der Spree überführen, dem künftig wichtigen Gedächtnisort der Hohenzollerndynastie. Das heraufdämmernde konfessionelle Zeitalter zeigte sich bereits in neuen Konturen der Erinnerungslandschaft.

Daher hat die Überlegung einiges für sich, dass auch konfessionspolitische Gründe eine Rolle gespielt haben, ${ }^{3}$ als der treu zu Papst und Habsburgern stehende Joachim I. im Oktober 1534 verfügte, dass das Land geteilt werden solle, falls seine Söhne aber ie nicht beieinander sich im regiment vertragen mochten. ${ }^{4}$ In diesem Falle sollte Markgraf Johann die Neumark uber Oder, darzu das land zu Sterneberg, soweit sich das erstreckt, zusampt dem furstenthumb Crossen, Zulch, Sommerfeld und dem lendichen Bobersberg erhalten. Hinzu kam auch die herschaft Cotbus und Peitz, nichts ausgenommen. ${ }^{5}$ Die Gebiete, in denen diesem Testament folgend Johann 1535 seine eigenständige Herrschaft antrat, bildeten weitgehend ein geschlossenes Territorium. „Exterritorial“ blieb lediglich

1 Der diesem Aufsatz zugrundeliegende Vortrag „Soldin und Küstrin. Zur Entscheidung des Markgrafen Johann für einen neuen Zentralort [Myślibórz i Kostrzyn - decyzja margrabiego Jana w sprawie nowej miejscowości centralnej/nowej siedziby]“, gehalten im Dezember 2004 in Landsberg an der Warthe (Gorzów Wielkopolski), wurde als Vortragsmanuskript gedruckt in der Dokumentation: Nowa Marchia - prowincja zapomniana - wspólne korzenie [Die Neumark - eine vergessene Provinz - die gemeinsamen Wurzeln]. Materialy z sesji naukowych organizowanych przez Wojewódzką i Miejską Bibliotekę Publiczną w Gorzowie Wlkp. z Stiftung Brandenburg w Fürstenwalde od września 2004 r. do lutego 2005 r. (Zeszyty naukowe/Wojewódzka i Miejska Biblioteka Publiczna, 3), Gorzów Wlkp. 2005, S. 67-76 (191-200).

2 Zu Lehnin vgl. Stefan Warnatsch: Art. „Lehnin. Zisterzienser“, in: Heinz-Dieter Heimann, Klaus Neitmann, Winfried Schich u.a. (Hgg.): Brandenburgisches Klosterbuch. Handbuch der Klöster, Stifte und Kommenden bis zur Mitte des 16. Jahrhunderts. Berlin-Brandenburg 2007, S. 764-803.

3 Wolfgang Neugebauer: Die Hohenzollern, Bd. 1. Anfänge, Landesstaat und monarchische Autokratie bis 1740. Stuttgart 1996, S. 82 (= Urban-Taschenbücher 573).

4 So die „,väterliche Disposition Kurfürst Joachims I.“ vom 22. Oktober 1534 (Hermann von Caemmerer [Hg.]: Die Testamente der Kurfürsten von Brandenburg und der beiden ersten Könige von Preußen. München, Leipzig 1915, Nr. 8, hier S. 58 [= Veröffentlichungen des Vereins für Geschichte der Mark Brandenburg [16]]).

Ebd., S. 59. 


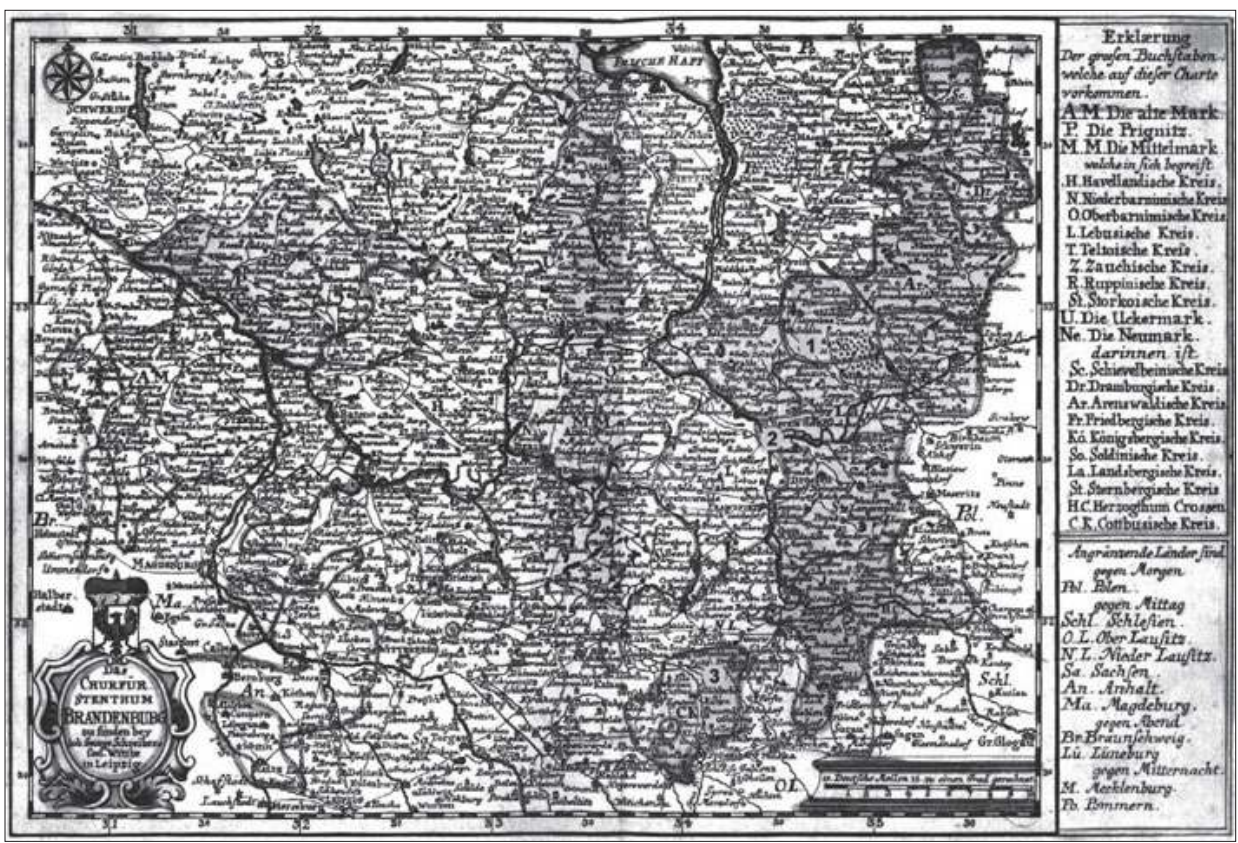

Abb. 1: Das neumärkische Territorium (dunkel unterlegt) auf der Brandenburgkarte J. G. Schreibers von 1749 (bearbeitet). 1: Soldin, 2: Küstrin, 3: Peitz.

die Niederlausitzer Herrschaft Cottbus und Peitz. Zur Residenz wählte er sich, völlig abweichend von den traditionellen zentralörtlichen Strukturen des neumärkischen Raumes, das am Zusammenfluss von Warthe und Oder und direkt an der Grenze zum mittelmärkischen Territorium seines Bruders Joachim II. gelegene Städtchen Küstrin (heute Kostrzyn nad Odrą, Woiwodschaft Lebus) (Abb. 1).

Nur eine Generation lang, bis 1571, wurde die neumärkische Stadt als Sitz eines Fürsten genutzt. Als Residenz ist der Ort heute wenig beachtet. Im gewichtigen Nachschlagewerk „Höfe und Residenzen im spätmittelalterlichen Reich““, ${ }^{6}$ dessen erster Band auf über 1600 Seiten in einer Vielzahl von Artikeln das Werden von Residenz- und Zentralorten im „Reich nördlich der Alpen“ mit den Niederlanden, Lothringen, der Eidgenossenschaft sowie den böhmischen und schlesischen Fürstentümern darlegt, ${ }^{7}$ sucht man das Stichwort „Küstrin“ vergebens. Dies muss zunächst nicht weiter verwundern, denn konzeptionel-

6 Werner Paravicini (Hg.): Höfe und Residenzen im spätmittelalterlichen Reich. Ein dynastisch-topographisches Handbuch. Bearbeitet von Jan Hirschbiegel und Jörg Wettlaufer. Sigmaringen 2003 (= Residenzenforschung, 15).

7 Vgl. Materialien zum Werk „Fürstliche Höfe und Residenzen im Spätmittelalterlichen Reich. Ein dynastisch-topographisches Handbuch“. Kiel 1999, S. 8 (= Mitteilungen der Residenzen-Kommission der Akademie der Wissenschaften zu Göttingen, Sonderheft 3). 
ler Ausgangspunkt des Kompendiums war auf der Grundlage der Arbeiten von J. Ficker, K.-F. Krieger und G. Engelbert ${ }^{8}$ die Reichsmatrikel von 1521, in denen das neumärkische Fürstentum des Markgrafen Johann von Küstrin selbstverständlich nicht verzeichnet war.

Jedoch kann die Stellung des Markgrafen als Reichsfürst nach den maßgeblichen Arbeiten kaum in Frage stehen. Lediglich die ebenfalls durch die testamentarische Verfügung des Kurfürsten Joachim I. zum neumärkischen Herrschaftsgebiet geschlagenen Herrschaften Cottbus und Peitz sowie Crossen und Züllichau waren Lehen der Krone Böhmen. Der neumärkische Kernraum hätte ohne weiteres den Kriterien der ResidenzenKommission bei der Erfassung reichsfürstlicher Residenzen genügt. Die Auslassung von Küstrin und Neumark in dem wichtigen Nachschlagewerk erstaunt auch darum, weil Residenzen wie beispielsweise das durchaus vergleichbare Zerbst, das gewiss nicht unter die spätmittelalterlichen Residenzen des Reiches gezählt werden kann und erst ab 1603 für knapp zweihundert Jahre Residenz eines selbständigen Fürstentums war, einen eigenen Artikel erhielten. ${ }^{9}$ Zerbst jedoch, und hiermit sollen die Überlegungen zur Schaffung neuer zentralörtlicher Strukturen im neumärkischen Territorium einsetzen, hatte der Residenz des Markgrafen von Küstrin vor allem eines voraus: eine Vergangenheit. Hier gab es nicht nur traditionelle landesherrliche Rechte, sondern ebensolche des Reiches, der Erzbischöfe von Magdeburg und der Bischöfe von Brandenburg. Seit 1308 erscheint Zerbst wiederholt als Ausstellungsort askanischer Urkunden, bereits im 13. Jahrhundert ist ein Kollegiatstift nachweisbar. Damit genügt Zerbst den von Klaus Neitmann herausgearbeiteten wichtigen mentalen Voraussetzungen, um eine „richtige“ Residenz zu werden. ${ }^{10}$ Küstrin hat nichts dergleichen aufzuweisen.

Aus dieser Perspektive ist zwar die Entscheidung berechtigt, Küstrin nicht unter die spätmittelalterlichen Residenzen des Reiches zu rechnen, es macht jedoch den Fall des Markgrafen und die strukturelle Neuordnung seines Territoriums in der ersten Hälfte des 16. Jahrhunderts für eine eingehendere Untersuchung um so interessanter. Die vorgefundene zentralörtliche Struktur des neumärkischen Raumes war beim Regierungsantritt des Hans von Küstrin eine völlig andere als die von diesem Fürsten bei seinem Tod hinterlassene. Hier schuf ein Renaissanceherrscher Neues, abweichend von vorgefundenen Strukturen. Vergleichbare durchgreifende raumplanerische Impulse können in nennenswerter Zahl erst einige Generationen später angetroffen werden: unter den Herrschern des Barock.

8 Julius Ficker: Vom Reichsfürstenstande. Forschungen zur Geschichte der Reichsverfassung zunächst im 12. und 13. Jahrhundert, 2 Bde., Bd. 2 bearb. und hg. von Paul Puntschart. Innsbruck 1861-1923 (Nachdr. Aalen 1961); Günther Engelbert: Die Erhebung in den Reichsfürstenstand bis zum Ausgang des Mittelalters. Diss. Marburg 1948; Karl-Friedrich Krieger: Die Lehnshoheit der deutschen Könige im Spätmittelalter (ca. 1200-1437). Aalen 1979 (= Untersuchungen zur deutschen Staats- und Rechtsgeschichte N.F., 23).

9 Ralf Gebuhr: Art. „Zerbst“”, in: Paravicini (wie Anm. 6), Bd. 1, S. 655-657.

10 Klaus Neitmann: Was ist eine Residenz? Methodische Überlegungen zur Erforschung der spätmittelalterlichen Residenzbildung, in: Peter Johanek (Hg.): Vorträge und Forschungen zur Residenzenfrage. Sigmaringen 1990, S. 11-43 (= Residenzenforschung, 1). 


\section{Eingriffe: Festungsbau in Küstrin}

Stadt und Umfeld von Küstrin wurden beim Ausbau zur Residenz offenbar weitgehend neu gestaltet. Die letzte umfangreiche Untersuchung des frühneuzeitlichen Festungswesens unter den Hohenzollern in Brandenburg und Franken resümiert mit Recht: „Der Festungsbau, der [ab etwa 1537, R.G.] rund fünfzig Jahre nicht mehr zur Ruhe kommen sollte, veränderte die Struktur der Stadt und ihres Umlandes vollkommen."11 Zunächst wurde mit der Verlegung der Oderbrücke die Verkehrsanbindung der Stadt grundlegend verändert. Schon zu 1536, also lange vor dem eigentlichen Baubeginn der Befestigungsanlagen zu Martini 1537, konnte D. Burger erste Belege über Beschwerden von Fuhrleuten ausmachen, welche die neue Verkehrsführung betrafen. Vergleichbar sind diese verkehrstechnischen Veränderungen mit dem zweiten Festungsbau des Hans von Küstrin in der bei Cottbus in der Niederlausitz gelegenen Stadt Peitz. Hier wurde der Verkehr, völlig abweichend vom Bild der mittelalterlichen Siedlung, zunächst ein Stück um die neuen Befestigungswerke der Stadt herumgeführt, um dann im Ort am Markt rechtwinklig abzubiegen (Abb. 2). Wenn in Küstrin der Standort der Kirche bereits ein mittelalterlicher ist

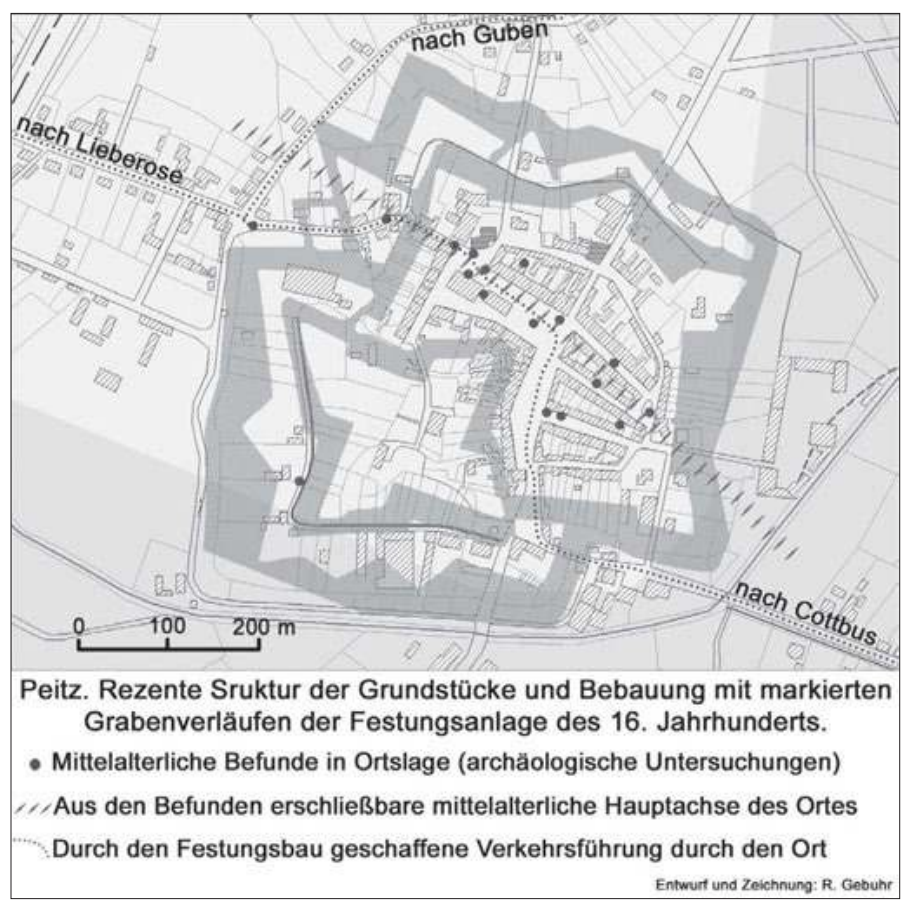

Abb. 2

11 Daniel Burger: Die Landesfestungen der Hohenzollern in Franken und Brandenburg im Zeitalter der Renaissance. München 2000, S. 206 (= Schriftenreihe zur Bayerischen Landesgeschichte, 128). 


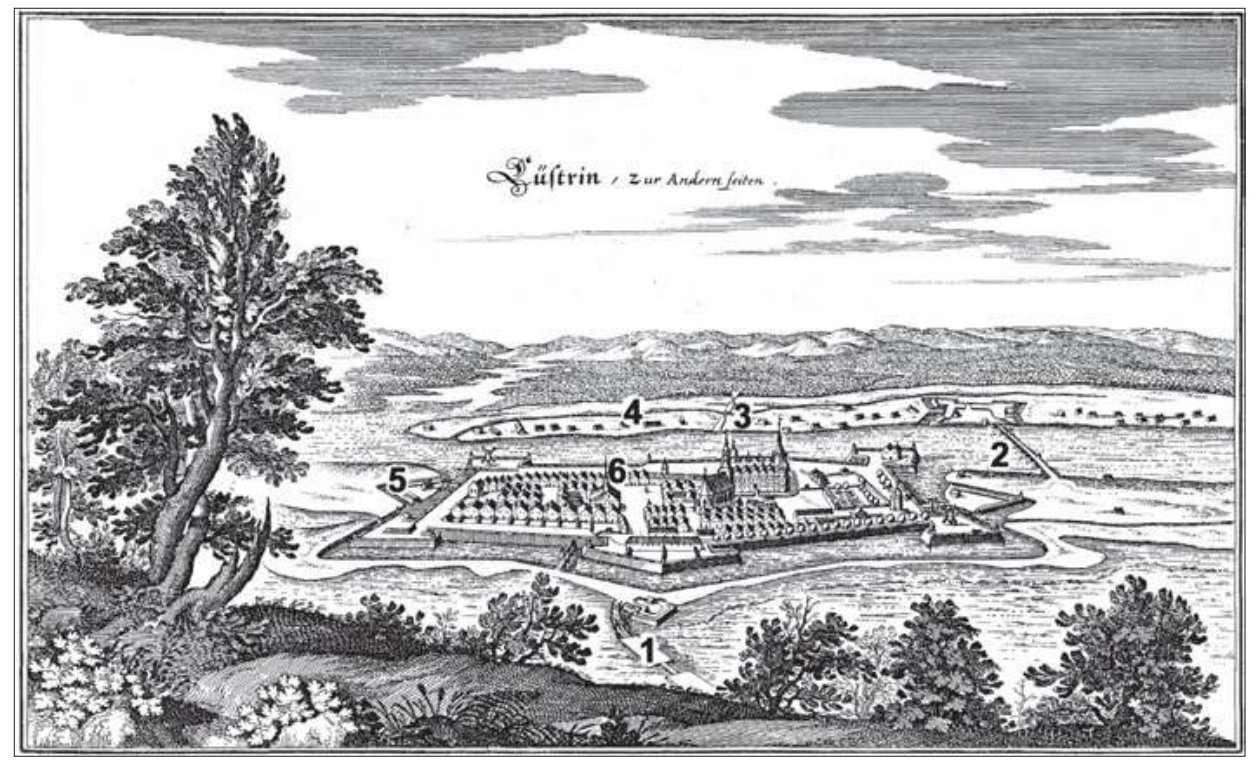

Abb. 3: Küstrin vom Osten (Merian 1652, nach S. 42, bearbeitet), im Hintergrund die „Seelower Höhen “. 1: Damm durch die Wartheniederung, 2: Brücke zur Stadt seit dem Ausbau zur Festung, 3: Zufahrt zur mittelalterlichen Oderbrücke, 4: Kietz nach der Verlegung,

5: In älterer Literatur vermutete Lage des mittelalterlichen Kietzes, 6: Wahrscheinliche Lage des mittelalterlichen Kietzes als zeilenförmige Ufersiedlung neben der Burg.

und hier der alte Marktplatz der Burgsiedlung Küstrin lag - wofür einiges spricht, doch gibt es hierzu noch keine hinreichende Untersuchung -, wurde in Küstrin ebenso wie in Peitz ein neuer Zusammenhang von Markt und Durchgangsverkehr geschaffen. In beiden Fällen musste der Markt in einer neuen Weise passiert werden, im Fall von Peitz gar über zwei Seiten.

Eine weitere offensichtliche Veränderung betrifft die Lage der Dienstsiedlung der alten Burg von Küstrin, des 1397 erwähnten Kietzes, ${ }^{12}$ der mit dem Festungsbau auf eine der Stadt gegenüberliegende Oderinsel verlegt wurde. In der Festung erinnern die Namen der „Kietzer Straße“, des „Kietzer Tores“ sowie der vor dem Tor liegenden „Kietzer Wiesen“ an den ehemals rechtlich eigenständigen Siedlungsteil. Ob der Name „Kietzerwiesen“ unmittelbar den Standort der alten Kietzsiedlung angibt, wie unter anderem auch D. Burger vermutet, ${ }^{13}$ ist fraglich. Der Name lässt eher auf ein zum Kietz gehöriges Flur-

12 Adolph Friedrich Riedel (Hg.): Codex diplomaticus Brandenburgensis. Sammlung der Urkunden, Chroniken und sonstigen Geschichtsquellen für die Geschichte der Mark Brandenburg und ihrer Regenten. Berlin 1838-1869 (im Folgenden abgekürzt: CDB), hier: Bd. I 19, S. 36.

13 Vgl. Burger (wie Anm. 11), Karte S. 209. 
stück schließen, während die ursprüngliche Kietzsiedlung im Bereich der Häuserzeile am Ufer zwischen Schloss und Kietzer Tor zu suchen sein dürfte (Abb. 3).

Auch wenn ohne archäologische Forschung in diesem Punkt nur begründete Vermutungen geäußert werden können, beeindruckt der Umfang an Neukonditionierungen der Ortsanlage Küstrins. Die durch kunsthistorische Forschungen wiederholt untersuchten gewichtigen Beispiele für Neuplanungen von Renaissanceresidenzen sind jüngeren Datums. In Sabbioneta etwa, der neu errichteten Residenz des Fürsten Gonzaga-Colonna in Norditalien, sind erste Bauarbeiten an den Befestigungsanlagen 1554 fassbar, ${ }^{14}$ achtzehn Jahre nach den ersten Planungs- und Bauarbeiten in Küstrin. Die erste umfassende Neuanlage einer Planstadt mit Residenz nördlich der Alpen war das 1599 durch Herzog Friedrich I. von Württemberg gegründete und durch Heinrich Schickardt geplante und gebaute Freudenstadt. ${ }^{15}$ Freilich sind die umfassenden siedlungsplanerischen Eingriffe in eine bestehende Struktur wie in Küstrin und Sabbioneta nicht ohne weiteres mit einer geometrischen Neuanlage wie Freudenstadt vergleichbar. Doch steht hier der Beginn einer Kontinuität zur Debatte: Die Frage nach möglicherweise neuen Formen des Umgangs eines Renaissanceherrschers mit den Lebensweisen und -gewohnheiten seiner „Landeskinder“, mit der Zurichtung ihrer Sinne auf eine ,staatliche“ Perspektive. ${ }^{16}$

Weitere landschaftliche Veränderungen um die neugeschaffene Residenz Küstrin betreffen Eingriffe in die hydrologische Situation im und um den Ort. Zunächst entstanden wassertechnische Einrichtungen für die zum Festungsbetrieb nötigen Mühlen. Hierfür wurde eigens ein in die Festungsanlagen der nördlichen Bastion integrierter Kanal angelegt. ${ }^{17}$ Welche Aufgabe die Schaffung einer regelmäßigen Wasserzufuhr für den stabilen Mühlenbetrieb in der durch zahlreiche Inseln und kleine Wasserarme geprägten flachen Niederung darstellte, lässt die durch D. Burger auf der Grundlage einer umfassenden Sichtung des kartographischen Materials erstellte Rekonstruktion des topographischen Umfeldes der Festung erahnen (Abb. 4). ${ }^{18}$ Das Umfeld musste reguliert werden, für Festungsgräben und Mühlen wurden eine Stauanlage sowie ein neuer Mühlgraben angelegt und für den Verkehr der neue „Kurze Damm“ geschaffen. Die Anstrengungen, des Wassers Herr zu werden, spricht auch aus der kurzen Mitteilung über Küstrin in der „Topographia Germaniae“ des Matthäus Merian: Der Markgraf habe den Festungsbau 1537 begonnen, heißt es dort; „Sie ist erst von Erden auffgebauet worden/weil aber die erdene Wercke/wegen des grossen Gewässers/so alda Jährlich in die neun Monat zu verharren/

14 Vgl. Gerrit Confurius: Sabbioneta oder die schöne Kunst der Stadtgründung. München 1984; Susanne Grötz: Sabbioneta. Die Selbstinszenierung eines Herrschers. Marburg an der Lahn 1993 (= Studien zur Kunst- und Kulturgeschichte, 10), und Gisela Heinrich: Sabbioneta - eine Residenzstadt der Renaissance. Realität und Imagination. Weimar 1999.

15 Vgl. Manfred Eimer: Geschichte der Stadt Freudenstadt. Freudenstadt 1937.

16 Vgl. zum Forschungsproblem Heinz Schilling (Hg.): Institutionen, Instrumente und Akteure sozialer Kontrolle und Disziplinierung im frühneuzeitlichen Europa (Institutions, Instruments and Agents of Social Control and Discipline in Early Modern Europe). Frankfurt am Main 1999 (= Ius commune, Sonderhefte. Studien zur europäischen Rechtsgeschichte, 127).

17 Vgl. die Rekonstruktionszeichnung der Anlage bei der Bastion „Königin“ durch Burger (wie Anm. 11), S. 227.

18 Ebd., S. 209. 


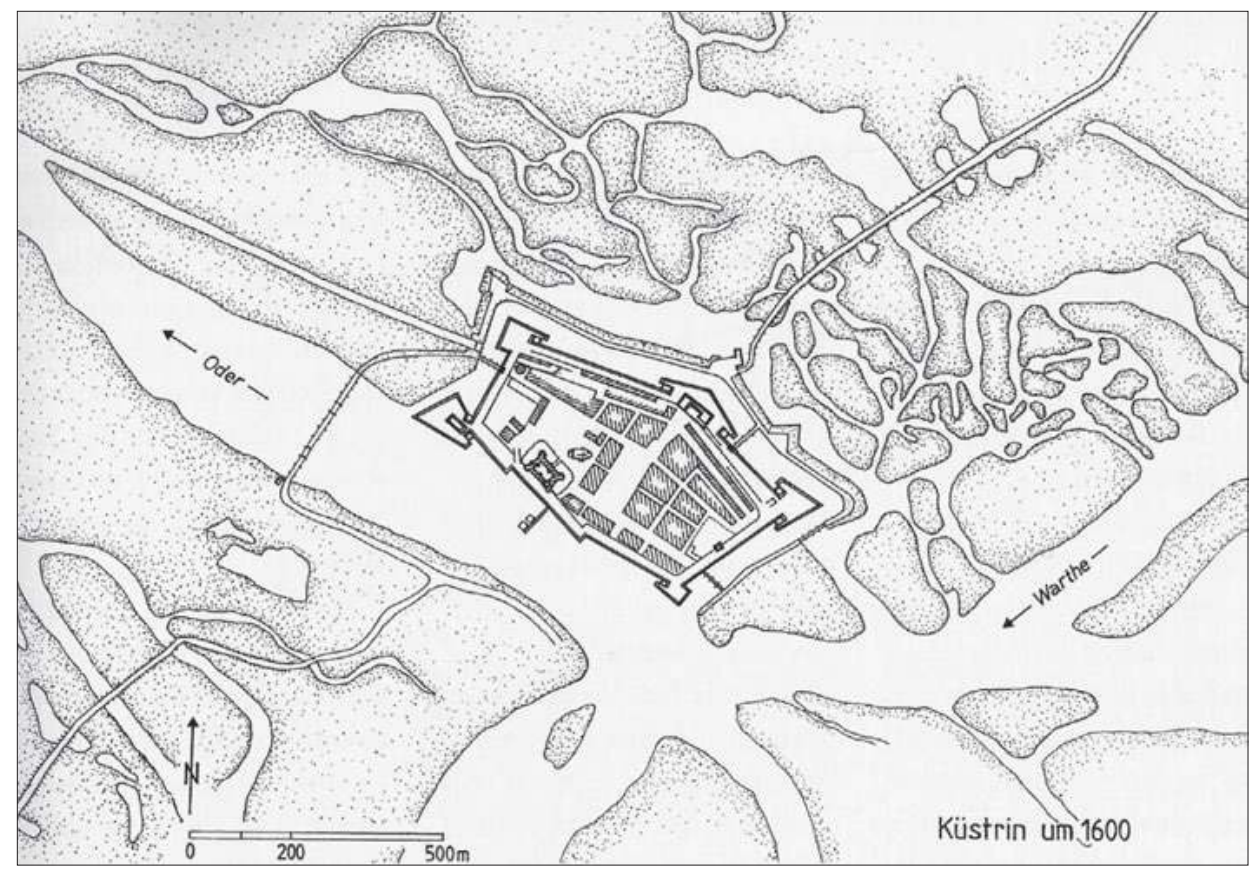

Abb. 4: Rekonstruktion der Gewässersituation an der Oder-WartheMündung um 1600 durch D. Burger (2000, S. 209, modifiziert).

und nur im Sommer zu fallen/ja auch offt im Sommer/ehe man sichs versiehet zu ergiessen pflegt/grossen Schaden erlitten/hat er entlich alles von aussen mit Mauersteinen mauren lassen ..." "19

Wenngleich zu den konkreten Zusammenhängen von Wasser- und Festungsbau in Küstrin noch Forschungsbedarf besteht, so ist doch die Tatsache umfangreicher wassertechnischer Bauten seit der ersten Hälfte des 16. Jahrhunderts im Gebiet polnischdeutscher Kontakte auffällig. In der jüngsten Forschung wurde wiederholt darauf hingewiesen, dass um 1500 auf den wichtigen Baustellen deutscher Fürstentümer polnische Spezialisten anzutreffen sind, die im Zusammenhang mit Befestigungsarbeiten mit der Fertigung wassertechnischer Anlagen betraut waren. ${ }^{20}$ Dies war beispielsweise in Allstedt beim Brunnenbau der Fall, in Duderstadt an der Stadtbefestigung, in Halle beim Bau der

19 Matthaeus Merian, Martin Zeiller: Topographia Germaniae. Topographia Electoratus Brandenburgici et Ducatus Pomeraniae etc. das ist Beschreibung der vornembsten und bekantisten Stätte und Plätz in den hochlöblichsten Churfürstenthum und March Brandenburg ... Kassel 1965 (Faksimile der Erstausgabe von 1652), S. 45.

20 Vgl. zum folgenden Elmar Brohl: Polnische Einflüsse auf den frühen Festungsbau in Mitteldeutschland um 1500, in: Heiko Laß (Hg.): Von der Burg zum Schloß. Landesherrlicher und adeliger Profanbau in Thüringen im 15. und 16. Jahrhundert. Bucha bei Jena 2001, S. 117-132. 
Moritzburg unmittelbar am Flusslauf der Saale, in Marburg und Wildeck beim Teichbau, in Sömmerda und Ziegenhain beim Grabenbau. Die Reihe der von E. Brohl festgestellten Belege kann noch um den Fall des Jagdschlosses „Fröhliche Wiederkunft“ ergänzt werden, das sich der sächsische Kurfürst Johann Friedrich der Großmütige um 1550 in seinem Jagdrevier bei Wolfersdorf einige Kilometer südlich von Jena errichten ließ. Mit dem Bau der dazugehörigen Teichanlage war ebenfalls ein polnischer Spezialist betraut, dessen Anwesenheit gut dokumentiert ist, weil er 1548 mit dem Baumeister des Kurfürsten, Nickel Gromann, in Streit geriet und seine Arbeiter entließ. ${ }^{21}$ Solche Belege fehlen bislang für Küstrin. Doch verdient der Umstand, dass Techniker aus Polen mit speziellem Können im Wasserbau an der Errichtung von Befestigungs- und Repräsentationsbauten beteiligt waren, auch darum größere Aufmerksamkeit, weil sich die Forschung häufig in erster Linie auf die italienischen Ingenieure konzentriert, die ab der zweiten Hälfte des 16. Jahrhunderts den europäischen Markt für Spezialkräfte im Festungsbau beherrschten.

\section{Konfessionspolitik}

Im politischen Wirken des Markgrafen Johann („Hans“) von Küstrin dürfte der bald nach seinem Regierungsantritt vollzogene Konfessionswechsel der folgenreichste Schritt gewesen sein. Darin ging er seinem Bruder, Kurfürst Joachim II., der sich 1539 in der Spandauer Nicolaikirche erstmals öffentlich das Abendmahl in beiderlei Gestalt reichen ließ, offenbar noch voran. Schon als Kind hatte er in hochdramatischer Weise tiefe konfessionelle Risse in seiner eigenen Familie spüren müssen. ${ }^{22}$ Seine Mutter Elisabeth, die 1485 geborene Tochter des Königs Johann von Dänemark, seit 1502 mit dem Kurfürsten Joachim I. von Brandenburg verheiratet, war durch ihren Bruder, König Christian II. von Dänemark, schon früh für Martin Luther und seine Lehre begeistert worden, während ihr Mann, der Bruder des Magdeburger und Mainzer Erzbischofs und Kardinals Albrecht von Brandenburg, zu den entschiedensten Gegnern der Reformation gehörte. Elisabeth nutzte die Abwesenheit ihres Gatten um die Osterzeit 1527, um sich von einem aus Wittenberg entsandten Prediger das Abendmahl in beiderlei Gestalt reichen zu lassen. Es kam zu schweren Auseinandersetzungen mit ihrem Mann, der sich bei Geistlichen ein Gutachten darüber einholen ließ, ob er seine Frau zum Tode verurteilen oder sich von ihr scheiden lassen solle. Nachdem diese vom Inhalt des Gutachtens erfahren hatte, dass der Kurfürst berechtigt und verpflichtet sei, seine Gemahlin lebenslang einzusperren, floh

21 Carl August Hugo Burkhardt: Die Gefangenschaft Johann Friedrichs des Großmüthigen und das Jagdschloß zur »Fröhlichen Wiederkunft«. Weimar 1863, S. 21, Anm. 4. Zum Überblick vgl. Hans Patze: Art. „Fröhliche Wiederkunft“, in: Ders. (Hg.): Handbuch der historischen Stätten Deutschlands, Bd. 9. Thüringen. Stuttgart 1989, S. 128 (= Kröners Taschenausgabe, 313). Bereits aus kaiserlicher Gefangenschaft, in die er nach der Niederlage im Schmalkaldischen Krieg 1547 geraten war, hatte der Kurfürst Anweisungen zum Bau des Jagdschlosses gegeben, das 1551 fertiggestellt war.

22 Zum Folgenden vgl. Friedrich Wilhelm Bautz: Art. „Elisabeth, Kurfürstin von Brandenburg“, in: Biographisch-bibliographisches Kirchenlexikon, Bd. 1. Hamm (Westf.) 1990, Sp. 1493-1494. 
sie im März 1528 zu ihrem Onkel, dem Kurfürsten Johann von Sachsen. Tiefe politische Verwicklungen waren die Folge; unter anderem versuchte Joachim I. auf dem Reichstag zu Augsburg, mit Hilfe des Kaisers die Rückkehr seiner Gemahlin zu erzwingen. Elisabeth blieb auch nach dem Tod ihres Mannes im Jahre 1535 in Sachsen und kehrte erst nach dem Konfessionswechsel ihrer Söhne nach Brandenburg zurück, wo sie 1555 auf ihrem Witwensitz Spandau verstarb.

Dieser Konfessionswechsel war den Brüdern Joachim und Johann durch ihren Vater nicht leicht gemacht worden, denn er hatte seine Söhne frühzeitig mit Prinzessinnen aus altgläubigen Fürstenhäusern verlobt und sie geschickt in altgläubige Bündnissysteme eingeflochten. ${ }^{23}$ Nachdem Johann 1535 seinen Teil des väterlichen Erbes in der Neumark angetreten und die dortigen Stände ihm im Herbst desselben Jahres gehuldigt hatten, setzte er sich mit Luther in Verbindung und führte in seinem Land mit unmittelbarer Unterstützung der Wittenberger die Reformation ein. Schon bei der Huldigung tauchten offenbar Probleme auf, von denen der märkische Chronist Andreas Angelus (1561-1598) berichtet: Als aber die Mönche im Augustiner Closter zu Königsberg vernommen/das gedachter Marggraff Hans von jugend auff der Bäpstischen Abgötterey feind gewesen/und gedacht/ es würde uber ihnen außgehen/sind sie aus dem Closter entlauffen/und haben das beste/ so sie haben im Closter unnd in ihrem Dorffe Reichenfeld bekommen können/mit sich hinweg genommen. ${ }^{24}$

Durch geschickte Winkelzüge löste sich Hans aus dem altgläubigen „Hallischen Bund" und trat dem Schmalkaldischen bei. Trotzdem finden wir den schon von Jugend auf an Kriegszüge gewöhnten Fürsten im Schmalkaldischen Krieg auf der Seite des Moritz von Sachsen und damit in der kaiserlichen Partei. Das hinderte ihn nicht, während der Belagerung von Magdeburg durch Moritz der protestantischen Stadt durch Truppen beizustehen und kurz darauf wieder auf Moritz' Seite gegen den Kaiser zu kämpfen. Hinter all diesen Wechseln, die nur zum kleinen Teil angeführt sind, dürfte nicht nur rationales Kalkül gesteckt zu haben. So scheint bei seiner Entscheidung, sich lange vor dem Beginn des Schmalkaldischen Krieges von diesem Bund zu lösen, schlichte Parteinahme für seinen Schwiegervater Heinrich den Jüngeren von Braunschweig gegen den Landgrafen Philipp von Hessen zu stecken. Es bleibt dennoch festzuhalten, dass der Fürst sein kleines Territorium außerordentlich geschickt durch die wilden und häufig undurchschaubaren Fährnisse seiner Zeit steuerte. Den dabei gezeigten Weitblick haben offenbar schon Zeitgenossen bewundert, als sie ihn mit Beinamen wie „,der Weise und Ernste“ belegten. ${ }^{25}$

23 Vgl. zum Folgenden Theodor Hirsch: Art. „Johann von Brandenburg-Küstrin“, in: Allgemeine deutsche Biographie. Auf Veranlassung ... Seiner Majestät des Königs von Bayern Maximilian II. hg. durch die Historische Commission bei der Königlichen Akademie der Wissenschaften, Bd. 14. Leipzig 1881, S. 156-165; Ludwig Mollwo: Markgraf Hans von Küstrin. Hildesheim und Leipzig 1926, und Johannes Schultze: Art. „Johann (Markgraf von Brandenburg-Küstrin; 1513 bis 1571)“, in: Neue deutsche Biographie. Hg. von der Historischen Kommission bei der Bayerischen Akademie der Wissenschaften, Bd. 10. Berlin 1974, S. 476 f.

24 Andreas Angelus: Annales Marchiae Brandenburgicae. Frankfurt an der Oder 1598, S. 324.

25 Ebd., S. 280 zum 3. August 1513: ... Marggraff Johannes von Brandenburg/mit dem zunamen der Weise und Ernste ... in Tangermünde geboren. 
Die landschaftshistorische Seite im Wirken dieses geschickten Fürsten galt der Neuschaffung seiner Residenz und damit der inneren Neugestaltung seines Landes. Die Geschichte der frühesten Stufe befestigungstechnischer Technologieimporte aus Italien im niederdeutschen Raum ist mit seiner Persönlichkeit verbunden. Während sein FreundFeind Moritz von Sachsen seine Residenz Dresden seit Mitte der vierziger Jahre mit modernen pentagonalen Bastionen befestigte, ${ }^{26}$ gestaltete sich Hans in Küstrin eine völlig neue Residenz. Dies ist wichtig zu betonen, weil der offensichtlich erste Einsatz dieser innovativen Bauformen nördlich der Alpen seit dem Jahr 1538 in Gestalt der Bastionen hinter der Nürnberger Burg erfolgte. ${ }^{27}$ Wann jedoch der Markgraf genau die italienische Technik kennenlernte und pentagonale Bastionen erstmals in Küstrin zur Ausführung brachte, ist noch nicht hinreichend geklärt. Gleich mit dem Beginn der Bauarbeiten im Jahre 1537 war es sicher noch nicht der Fall. D. Burger geht davon aus, dass Markgraf Johann während seiner Teilnahme an der Belagerung von Metz 1552-53 den Entschluss zu einer Neukonzeption der Küstriner Anlagen gefasst hat. ${ }^{28}$ Allerdings muss hier auch berücksichtigt werden, dass Hans von Küstrin mit Moritz von Sachsen als seinem territorialen Nachbarn nicht selten Kontakt pflegte und die Befestigungsarbeiten in Dresden sicher kannte, die dieser seit 1545 in Dresden durchführen ließ. ${ }^{29}$

26 Zur Befestigung Dresdens und Moritz von Sachsen vgl. Eva Papke: Festung Dresden. Aus der Geschichte der Dresdner Stadtbefestigung. Dresden 1997.

27 Zur Frühgeschichte des Festungsbaus mit pentagonalen Bastionen vgl. John Rigby Hale: The Development of the Bastion, 1440-1534, in: Ders. u.a. (Hg.): Europe in the late Middle Ages. London 1965, S. 466-494; zur Rezeption der Bauten nördlich der Alpen vgl. Thomas Biller: Der bastionäre Befestigungsbau des 16. Jahrhunderts und sein Weg nach Deutschland, in: Ders.: Die Wülzburg. Architekturgeschichte einer Renaissancefestung. München, Berlin 1996, S. 1-62. Die bei Ulrich Schütte: Wandlungen in der Stadtbefestigungstechnik seit dem frühen 16. Jahrhundert, in: Stadt Burg - Festung. Stadtbefestigung von der Antike bis ins 19. Jahrhundert. Internationale Tagung Glurns 23. bis 25. Juni 1994. Innsbruck 1994, S. 167-201, hier S. 171 Anm. 12 (= Veröffentlichungen des Innsbrucker Stadtarchivs, NF 21), genannten früheren Daten für die Rezeption italienischer Formen nördlich der Alpen (z.B. Küstrin ab 1537) sind nach den Forschungen von Biller und Burger zu revidieren. Zum Bau der Bastion in Nürnberg vgl. Heinz-Joachim Neubauer: Der Bau der großen Bastei hinter der Veste 1538-1545. Ein Beitrag zur Geschichte der Nürnberger Stadtbefestigung und zu den Auseinandersetzungen des reichsstädtischen Rates mit Markgraf Georg dem Frommen von Brandenburg-Ansbach, in: Mitteilungen des Vereins für Geschichte der Stadt Nürnberg 69 (1982), S. 196-263. Wichtige neue Ergebnisse zur Geschichte des frühen Festungsbaus in Mitteleuropa haben die archäologisch-historischen Untersuchungen der Wiener Festungsanlagen ergeben (vgl. Stadtarchäologie Wien. Heike Krause et al.: Mauern um Wien. Die Stadtbefestigung von 1529 bis 1857. 2., überarbeitete und erweiterte Auflage Wien 2014 [=Wien archäologisch, 6]).

28 Burger (wie Anm. 11), S. 212.

29 Vgl. Simon Issleib: Hans von Küstrin und Moritz von Sachsen, in: Neues Archiv für Sächsische Geschichte und Altertumskunde 23 (1902), S. 1-63, hier S. 51: Hans schrieb u.a. am 4. Okt. 1551, als er aus Torgau kommend Richtung Cottbus reiste, einen Brief aus Sonnewalde an Moritz. 


\section{Raumpolitik: Zwischen Soldin und Küstrin}

Auf welcher Grundlage hat der Markgraf seine Entscheidungen zur Umstrukturierung seines Territoriums gefällt? Wie sah die Struktur der Landschaft aus, die er vorfand?

Um den Prozess herrschaftlicher Generierung einer ,neuen Landschaft“ in der brandenburgischen Neumark durch den Markgrafen Hans beurteilen zu können, ist eine Analyse der zentralörtlichen Struktur dieses Raumes vor seinem Herrschaftsantritt zumindest im Grundriss notwendig. ${ }^{30}$ Einen Zentralort von altem Herkommen wie in Brandenburg oder in Mecklenburg hat es offenbar in dem Gebiet, welches später „Neumark“ hieß, nicht gegeben. Bei der Betrachtung des Aufbaues kirchlicher Strukturen fällt allerdings sogleich Soldin (heute Myślibórz, Woiwodschaft Westpommern) ins Auge (Abb. 5). Das so wichtige Indiz eines Kollegiatstiftes ist in der Neumark allein in Soldin gegeben. ${ }^{31}$ In diesem Ort besaßen die Dominikaner ihre einzige Niederlassung in der Neumark. In seiner ältesten überlieferten Urkunde erhält der offenbar einige Jahrzehnte zuvor gegründete Ort im Jahre 1281 nach Zerstörungen durch polnische Krieger neue Privilegien, in denen

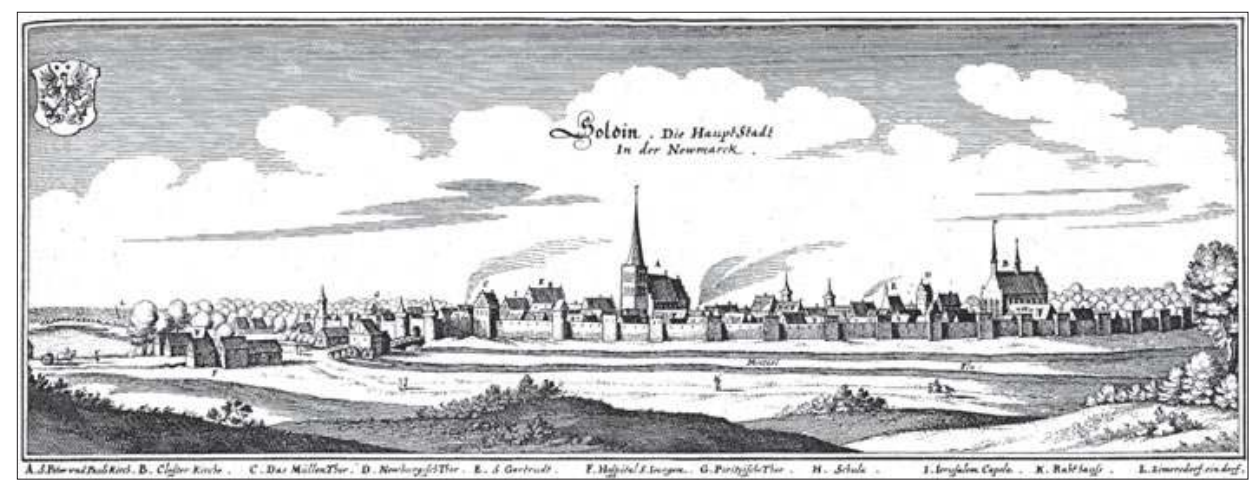

Abb. 5: Noch der „Merian“ von 1652 vermerkt Soldin als „Hauptstadt in der Neumark“ (Merian 1652, nach S. 92).

30 Als historisch-politischen Überblick vgl. Johannes Schultze: Art. „Die Neumark“, in: Gerd Heinrich (Hg.): Handbuch der historischen Stätten Deutschlands, Bd. 10. Brandenburg. Stuttgart 1985, S. 411-419 (= Kröners Taschenausgabe 311).

31 Das Stift wurde durch Markgraf Albrecht III. 1298 gegründet. Zur Stiftsgeschichte vgl. Willy Hoppe: Das neumärkische Stift Soldin, in: Friedrich Beck (Hg.): Heimatkunde und Landesgeschichte. Zum 65. Geburtstag von Rudolf Lehmann. Weimar 1958 (= Veröffentlichungen des Brandenburgischen Landeshauptarchivs, 2), und Christian Gahlbeck: Art. „Soldin (Myślibórz). Kollegiatstift", in: Brandenburgisches Klosterbuch (wie Anm. 2), S. 1123-1147. 
die Markgrafen unter anderem festlegen, dass sowohl die schon bestehenden Dörfer und Städte als auch die noch zu errichtenden ihr Recht in Soldin holen sollen. ${ }^{32}$

Das wirtschaftliche Wachstum der Stadt muss beträchtlich gewesen sein, wofür die dem Landesherren zu entrichtenden Abgaben ein wichtiges Indiz darstellen. Das durch Kaiser Karl IV. nach seiner Regierungsübernahme in der Mark in Auftrag gegebene Landbuch, welches dem Herrscher einen Überblick über seine Einkünfte gestatten sollte, verzeichnet in der Neumark folgende Einkünfte aus den Städten (De civitatibus trans Oderam): ${ }^{33}$ An der Spitze steht Soldin (Soldyn) mit dreiundsiebzig Mark Silber, die dem Landesherren jährlich zu entrichten sind. Sehr finanzstark sind auch Königsberg und Arnswalde, die jeweils sechzig marcas argenti entrichten müssen. Das solide Mittelfeld teilen sich Dramburg (Drahenburg) mit vierzig, Schönfließ (Schowenflicz) mit siebenunddreißig sowie Morin (Moryn) und Bärwalde (Beerwalde) mit jeweils dreißig Mark. Am unteren Ende der Liste stehen Lippehne (Lyppene) und Berlinchen (Berlin Nova) mit jeweils fünfundzwanzig Mark sowie Oderberg mit nur vierzehn Mark, die dem Herrscher jährlich zustehen. Das Ende der Liste nimmt Küstrin ein, zu dem gar keine Angaben gemacht werden. Der Vergleich mit den landesherrlichen Einkünften in anderen brandenburgischen Städten zeigt, welche Siedlungen sich mit dem Ort in der Neumark messen können. Natürlich belegt die Handelsstadt Frankfurt an der Oder mit 200 Mark den Spitzenplatz, ${ }^{34}$ ebenso wie die Doppelstadt Berlin/Cölln mit 150 Mark. ${ }^{35}$ Stendal, der überragend bedeutende Ort der Altmark - auch hier gab es (seit 1188) ein Kanonikerstift - zahlt mit 80 Mark Silber nur wenig mehr als Soldin. ${ }^{36}$ Potsdam hat nur 3 Mark, 3 Schock und 24 Groschen zu zahlen. ${ }^{37}$

32 Hermann Krabbo, Georg Winter (Bearbb.): Regesten der Markgrafen von Brandenburg aus askanischem Hause. Leipzig/Berlin 1910-1955, Nr. 1008 (zu 1271) und Nr. 1256 (zu 1281) (=Veröffentlichungen des Vereins für Geschichte der Mark Brandenburg [8]). Zur frühen Geschichte Soldins vgl. Hermann Pieper: Zur Gründungsgeschichte der Stadt Soldin, in: Heimatkalender des Kreises Soldin 10 (1931), S. 85-95; Helmut Wittlinger: Untersuchungen zur Entstehung und Frühgeschichte der neumärkischen Städte, in: Die Neumark 8 (1932), S. 69-71, und Hugo Rachel: Art. „Soldin“, in: Erich Keyser (Hg.): Deutsches Städtebuch. Handbuch städtischer Geschichte, Bd. 1. Nordostdeutschland. Stuttgart, Berlin 1939, S. 640-642.

33 Johannes Schultze (Hg.): Das Landbuch der Mark Brandenburg von 1375. Berlin 1940, S. 56 f. (= Veröffentlichungen der Historischen Kommission für die Provinz Brandenburg und die Hauptstadt Berlin 8,2).

34 Ebd., S. 50.

35 Ebd., S. 52.

36 Ebd., S. 54. Zum Kollegiatstift Stendal vgl. Christian Popp: Das Domstift St. Nikolai zu Stendal. Zur Geschichte des altmärkischen Kollegiatstifts von der Gründung 1188 bis zur Auflösung 1551. Diss. Berlin 2005, und ders.: Art. „Stendal. Kollegiatstift“, in: Brandenburgisches Klosterbuch (wie Anm. 2), S. 1197-1213.

37 J. Schultze gibt (Landbuch [wie Anm. 33], S. 462) eine Darstellung des Wertes der Steuerleistungen. Da die „Mark“ ein Edelmetallgewicht für Silber darstellt, aus dem Pfennige gemünzt werden konnten, ist ein Überblick relativ gut möglich. Eine Mark Silber zu 233,8 g ergibt 240 Pfennige $(1$ marca argenti $=4$ Goldgulden $=68$ Groschen $)$; dabei gilt: „Die Mark Silber wird in den Urkunden als Mark Brandenburgischen oder Stendalischen Gewichts bezeichnet." (ebd., Anm. 2). Vier Mark wären also nach heutigen Gewichtseinheiten etwa ein Kilogramm Silber. Natürlich ist es 
Analoge Bilder mit nur geringfügigen Abweichungen ergeben sich, wenn man die Aufgebotslisten neumärkischer Städte anlässlich verschiedener kriegerischer Auseinandersetzungen vergleicht. Immer steht Soldin unter den wirtschaftlich und militärisch starken Orten, Küstrin im Gegensatz hierzu unter den schwachen. Bezeichnend ist beispielsweise das Aufgebot neumärkischer Städte anlässlich des Zuges nach Wien, um den Angriff der osmanischen Truppen im Jahre 1529 abzuwehren: Soldin stellte 23 Mann nach Arnswalde mit 38, Königsberg mit 34, Landsberg mit 28 und Friedeberg 27 Mann. Es folgten Schönfließ mit 16 Kriegern, Schievelbein mit 15, Bärwalde mit 13 und Dramburg mit 10 Kriegsknechten. Am unteren Ende der Liste finden sich Küstrin mit 9, Woldenberg mit 8 sowie Morin, Berlinchen und Lippehne mit jeweils 5 Knechten. ${ }^{38}$

Für diese bedeutende wirtschaftliche Kraft Soldins dürften weitere Privilegien eine Rolle gespielt haben - so die 1352 und auch 1353 getroffene Verfügung Ludwigs des Römers, dass Fernverkehr seinen Weg über diesen Ort zu nehmen habe. ${ }^{39}$ Bezeichnend für die Macht der Stadt ist eine Urkunde aus dem Jahre 1349, in der die wittelsbachischen Fürsten die Stadt nicht etwa für ihre Parteinahme auf Seiten des falschen Woldemar und die bei dieser Gelegenheit zerstörte landesherrliche Burg bei der Stadt zur Rechenschaft zogen, sondern ihr anlässlich der Versöhnung weitere Privilegien einräumten. Die Markgrafen versprachen, auf den Bau einer neuen Burg zu verzichten, einen Vogt nur mit Erlaubnis einzusetzen und keine fremden Söldner auf das Gebiet der Stadt zu führen. ${ }^{40}$

In dieser Zeit dürfte die Stadt bereits einen imposanten Anblick geboten haben. Neben den Gebäuden der bereits erwähnten kirchlichen Institutionen besaß sie eine Befestigung mit drei Toren und 49 Türmen und Weichhäusern. ${ }^{41}$ Für permanente Ausbauarbeiten an der Befestigung sprechen die ehemals vorhandenen Außentore und die seit 1725 eingeebnete dreifache Wall-Graben-Anlage. Analog zu Berlin besaß die Stadt - und das ist für die hier zu behandelnde Frage nicht unwichtig - einen markgräflichen Wohnhof im Westen der Stadt, also dort, wo der Fürst, vom Kernraum seiner Herrschaft herkommend, in die Stadt einritt. In Soldin fanden nicht nur 1466 die Verhandlungen zwischen Brandenburg und Pommern statt, die Stadt wurde darüber hinaus Versammlungsort der Landstände. Im Dominikanerkloster von Soldin schlossen sich Prälaten, Ritterschaft und die Städte der Neumark 1470 zu einem Schutz- und Trutzbündnis zusammen und versprachen sich gegenseitige Hilfe in allen ehrlichen Sachen; Ritterschaft und Städte wollten in Sachen Huldigung, Ziese, Landschäden und Unpflichten der Herrschaften zusammenhalten und einträchtig handeln. Man sicherte sich gegenseitigen Beistand gegen Räuber und

schwierig, zur historischen Kaufkraft dieser Geldwerte genauere Angaben zu machen. Zudem bestehen zwischen einzelnen Orten und Landschaften mitunter erhebliche Schwankungen.

38 Werner Reinhold: Chronik der Stadt Soldin, von der ältesten bis auf die neueste Zeit nach sämmtlichen gedruckten und ungedruckten Quellen, namentlich nach den Urkunden und Dokumenten des Soldiner Rathsarchiws, bearbeitet und mit Beifügung des Urkunden und Dokumente herausgegeben von Dr. Werner Reinhold, Verfasser der Chronik Rostock's, Anklam's, Treuenbrietzen's, Prenzlau's, Spremberg's, Birnbaum's ..., Soldin 1846, S. 76.

39 CDB (wie Anm. 18), Bd. I 18, S. 467.

40 Ebd., S. $457 \mathrm{f}$.

41 Vgl. auch zu Folgendem Rachel (wie Anm. 32), S. 641. 
Friedensbrecher sowie die Verfolgung der eigenen Rechte auf gemeinsame Kosten und Gefahr zu. ${ }^{42}$ In all diesen Fragen wären also, analog zu Berlin/Cölln, in Soldin wichtige Voraussetzungen zum Ausbau einer Residenz gegeben gewesen. Warum hat sich Hans jedoch anders als seine Vorfahren entschieden, die knapp einhundert Jahre zuvor mit dem Schlossbau in Berlin/Cölln begannen und damit Weichen der Residenzkultur stellten, die bis in das zwanzigste Jahrhundert wirksam blieben?

Die zeitlich nahestehenden Quellen machen eher technisch-taktische Gründe für die Entscheidung verantwortlich. Bei Merian heißt es: Als nun Marggraf Hans zu Brandenburg auß den Kriegen/darinn er dem Kayser und Könige von Hispanien Carolo V. gedienet/kommen/hat er bey sich gedacht wieviel in Kriegszeit an den Strömen gelegen/wie Sie Freund und Feind zu seinem Vortheil gebrauchen könne/und derhalben die Vestung Anno 1537. an/und den Kietz über die Oder geleget ". ${ }^{43}$ G. Berg verweist in seiner Untersuchung zur Geschichte des Markgrafen Johann auf die kurz nach 1700 entstandene Chronik des Johann Christoph Bekmann (1641-1717). Dort heißt es, dass für den Festungsbau ursprünglich Königsberg ausersehen gewesen sei, dann aber Küstrin wegen seiner Lage am Zusammenfluss von Oder und Warthe und inmitten von Sümpfen durch Hans gewählt worden sei, der die sehr bequeme und zur Defension des Landes höchst nützliche Situation erkannte und die Stadt und den Kietz zusammengezogen und stracks Anno 1537 einige Werke von Erde aufwerfen lassen habe. ${ }^{44} \mathrm{G}$. Berg fasst zusammen: ,Von dieser Zeit an [bereits 1536 - R.G.] nahm Johann dauernd seinen Wohnsitz in Cüstrin und machte es zu seiner Residenz. Was ihn dazu bestimmt hat, gerade diese Stadt, die damals eine der unbedeutendsten der Neumark war, anstatt Soldin, der alten Hauptstadt des Landes, zu seinem Hoflager zu erwählen, hat er selbst nirgends ausgesprochen. Wahrscheinlich war es die günstige Lage der Stadt; einmal wurde sie von Oder und Warthe, auf denen damals ein äußerst lebhafter Verkehr herrschte, berührt; dann lag sie auch etwa in der Mitte zwischen der nördlichen und der südlichen Grenze seines Fürstentums. “45

Soweit scheint der Markgraf nur allgemeinen Kriterien gefolgt zu sein, die C. Haase in seiner Überblicksdarstellung zur „Mittelalterlichen Stadt als Festung“ mit den Worten zusammenfasste: „Grenzlage und Schutzlage waren die Kriterien, nach denen man die Plätze aussuchte, die modern befestigt werden sollten. ${ }^{" 46}$ Bei der Beurteilung dieser Ansichten aus dem 17. und 18. Jahrhundert muss allerdings berücksichtigt werden, dass aus ihnen auch die Perspektive eines militärisch planenden Fürsten jüngerer Zeit spricht. Es wird nicht beachtet, dass die Handlungen des Markgrafen Johann durchweg Pionierleistungen waren und diese Zweckrichtung, einem Fürsten der folgenden Jahrhunderte si-

42 Das Bündnis wurde am 20. Juli desselben Jahres in Soldin bestätigt durch Albrecht Achilles. Vgl. Richard Bieling: Kloster und Klosterkirche Soldin, in: Heimatkalender des Kreises Soldin (Neumark) 6 (1927), S. 39-46, hier S. 42.

43 Merian (wie Anm. 19), S. 45.

44 Gustav Berg: Beiträge zur Geschichte des Markgrafen Johann von Cüstrin. Landsberg an der Warthe 1903, S. 101 f. (= Schriften des Vereins für Geschichte der Neumark, 14).

45 Ebd., S. 15.

46 Carl Haase: Die mittelalterliche Stadt als Festung. Wehrpolitisch-militärische Einflußbedingungen im Werdegang der mittelalterlichen Städte, in: Studium Generale 16 (1963), S. 379-390. 
cher selbstverständlich, bei ihm nicht vorausgesetzt werden darf. Es müssen also weitere Gründe gesucht werden. Hierbei fällt zuerst der Umfang fürstlichen Besitzes in Küstrin ins Auge, der durch Säkularisationen von Besitz des Deutschen Ordens, in dessen Händen sich Küstrin lange Zeit befunden hatte, anzuwachsen versprach. Hier konnte der Landesherr auch ökonomische Grundlagen für eine eigenständige Politik finden. Doch spricht gegen eine solche Annahme als einziges Kriterium, dass auf der Seite seines Bruders Joachim II. zunächst an einen Ausbau von Zossen gedacht war, das über den einkommensstärksten Burgbezirk der Mittelmark verfügte. Davon war aber schließlich zugunsten Spandaus abgerückt worden. ${ }^{47}$

Ein dritter Grund dürfte in der starken Soldiner Bürgerschaft zu sehen sein, die bereits benannt wurde. Es ist sehr wahrscheinlich, dass für den Fürsten das Gedenken an die jahrelangen Auseinandersetzungen seines Vorfahren Friedrich II. mit der Bürgerschaft von Berlin und Cölln eine Rolle spielte, die schließlich im „Berliner Unwillen“ gipfelten. In dessen Verlauf kam es nicht nur zur Zerstörung der Schlossbaustelle in Cölln, sondern auch zu tumultartigen Auseinandersetzungen um das „Hohe Haus“ und zur Vernichtung von Urkunden in der dortigen Kanzlei. ${ }^{48}$ Im Endeffekt unterlag hier die Bürgerschaft, und der 1443 am Spreeufer begonnene Berliner Schlossbau der Hohenzollern wurde als repräsentatives Symbol fürstlicher Macht fertiggestellt. ${ }^{49}$ E. Müller-Mertens wertete in seinem Beitrag zur „Geschichte Berlins“, die Wirkung sei erster „,durchschlagender Erfolg gegenüber der städtischen Autonomie. Das macht den Berliner Unwillen zu einem gravierenden Ereignis von nationalgeschichtlicher Bedeutung in den Kämpfen zwischen Fürstengewalt und Städtebürgertum im 15. Jahrhundert. Die Berliner Vorgänge gaben ein Signal zu einem allgemeinen Vorgehen deutscher Fürsten gegen ihre Städte. “'50

Obgleich Markgraf Johann Auseinandersetzungen, wo es ihm angebracht schien, keineswegs aus dem Wege ging, ${ }^{51}$ scheint es in diesem Fall plausibel, dass er als klug kalku-

47 Zur Diskussion um die Standortwahl für eine mittelmärkische Festung vgl. Burger (wie Anm. 11), S. 289-292.

48 Zu den städtepolitischen Implikationen dieser Auseinandersetzungen vgl. Ekkhard Müller-Mertens: Zur Städtepolitik der ersten märkischen Hohenzollern und zum Berliner Unwillen, in: Zeitschrift für Geschichtswissenschaft 4 (1956), S. 525-546. Die sozialen Dimensionen bis in die höchsten Kreise des städtischen Patriziats werden sichtbar bei Peter Neumeister: Persönlichkeiten des „Berliner Unwillens“ 1447/1448. Die Familie Reiche, in: Berlin in Geschichte und Gegenwart. Jahrbuch des Landesarchivs Berlin 1994, S. 41-59.

49 Vgl. Wolfgang Ribbe (Hg.): Schloß und Schloßbezirk in der Mitte Berlins. Das Zentrum der Stadt als politischer und gesellschaftlicher Ort. Berlin 2005 (= Publikationen der Historischen Kommission zu Berlin).

50 Ekkhard Müller-Mertens: Die Entstehung Berlins. Die mittelalterliche Stadt. In: Laurenz Demps u. a. (Hg.): Geschichte Berlins von den Anfängen bis 1945. Berlin 1987, S. 49-154. Vgl. in diesem Sinne auch Knut Schulz: Vom Herrschaftsantritt der Hohenzollern bis zum Ausbruch des Dreißigjährigen Krieges, in: Wolfgang Ribbe (Hg.): Geschichte Berlins, Bd. 1. Von der Frühgeschichte bis zur Industrialisierung. München 1987, S. 249-340, hier S. 262-273, und Winfried Schich: Anlage und Funktion des Schlosses und des Schloßbezirkes in Mittelalter und Renaissance, in: Ribbe (wie Anm. 49), S. 25-44.

51 Dies zeigen deutlich die Ereignisse um den Ausbau von Peitz zur Festung, die den Eindruck einer politischen Provokation gegen den Habsburger Ferdinand (1503-1564, 1526 König von Böh- 
lierender Fürst keine Zeit für langwierige Konfrontationen aufbringen wollte. Wie bereits erwähnt, erschien er schon seinen Zeitgenossen als der „Weise und Ernste“. Bemerkenswert ist ein Hinweis in den Ausführungen Merians, dass bei der Auswahl von Küstrin das leichtere Spiel mit der Bürgerschaft eine Rolle gespielt haben kann. In der „Topographia Germaniae" heißt es: Es ligt sonsten Cüstrin gar eben: hat einen herzlichen grossen Platz zur Musterung/hüpsche Häuser in der Statt/und ein feines Volck. Wie dann die Burgerschafft wol abgericht ist/und/neben den Soldaten/die Wachen versehen thut. ${ }^{52}$

Bei all dem ist ferner auffällig, dass der Markgraf zwar administrative Funktionen in seinem Land neu festlegte, dies aber für wirtschaftliche Vorortfunktionen nicht in gleichem Maße gilt. An einer guten wirtschaftlichen Situation Soldins war ihm offenbar sehr gelegen, denn der Ort wurde in dieser Beziehung auch weiterhin gefördert. Als es 1539 zu einem großen Brand kam, reagierte der Fürst mit umfassenden Erleichterungen für die Bürger, wie es neun Jahre zuvor sein Vater bei gleicher Gelegenheit ebenfalls getan hatte. In gewisser Weise blieb dem Ort sogar eine bedeutende Hauptstadtfunktion im Sinne der Produktion von „Bedeutung“ für andere Kommunen erhalten: Markgraf Hans ließ 1540 in allen neumärkischen Städten Soldinsches Maß und Gewicht gelten. ${ }^{53}$ Auffällig ist jedoch auch in diesem Zusammenhang, dass der Herrscher nach dem Brand im Jahre 1539 auch in Soldin die Gelegenheit für eine räumliche Neuordnung der Stadt ergriff: „Nach diesem großen Brande gab Markgraf Hans selbst an, wie die Straßen und der Markt sollten gezogen werden. “54

Der planerische Zugriff des Landesfürsten auf die Stadtgestalt bei der alten neumärkischen Hauptstadt um das Jahr 1540 erfolgte noch einige Jahre vor dem Auftauchen des bastionierten Festungsbaues italienischer Manier im norddeutschen Raum, wie er sich im sächsischen Nachbarland des neumärkischen Herrschers ab 1545 zeigte. ${ }^{55}$ Die als Agenten dieser Bauformen wirkenden vermessungstechnisch geschulten Ingenieure italienischer Herkunft dürften also zu diesem Zeitpunkt noch nicht zur Verfügung gestanden haben, ihr Wirken setzte im brandenburgischen Raum erst in der zweiten Jahrhunderthälfte ein, ${ }^{56}$ zeitigte aber im Laufe der Neuzeit als wichtige technologische Basis herrschaftlicher Interessen an baulicher Repräsentation allenthalben sichtbare Ergebnisse. ${ }^{57}$ „Das Pla-

men, 1558 Kaiser), Lehnsherr der Herrschaft Cottbus und Peitz, tragen (vgl. Burger [wie Anm. 11], S. 256-258).

52 Merian (wie Anm. 19), S. 45.

53 Reinhold (wie Anm. 38), S. 78.

54 Ebd. In diesem Sinne führt auch Rachel (wie Anm. 32), S. 641 aus, Soldins ,... außerordentlich regelmäßiger Grundriß ..." sei kein Zeugnis der mittelalterlichen Stadtgründung, da die Stadt nach dem ,... Brand von 1539 auf Grund eines Planes des Markgrafen Johann neu erbaut wurde“.

55 Papke (wie Anm. 26).

56 Vgl. Burger (wie Anm. 11).

57 An dieser Stelle sei auf die geschulten Festungsingenieure Johann Balthasar Neumann (1687-1753) und Johann Gregor Memhardt (1607-1678) verwiesen, die in Würzburg und Berlin wirkten. Bezeichnenderweise ist es auch die Gestalt eines vermessungstechnisch geschulten „Hauptmanns“, der in Goethes „Wahlverwandtschaften“ die Anlage eines herrschaftlichen Parks organisiert. Der Einfluss italienischer, niederländischer und französischer Festungsingenieure auf Landschaftsplanung und Schlossbau wird in der Forschung zwar selten übersehen, ist aber bislang noch nicht Ge- 
nerische ist eines der Elemente, die für die frühneuzeitliche Stadt charakteristisch sind“, resümierte K. Gerteis diesen Zug neuzeitlicher Städtegeschichte, um im gleichen Zuge auf ältere Wurzeln zu verweisen, die besonders östlich der Elbe wirksam waren: „Planstädte hat es allerdings auch schon im Mittelalter gegeben. Beispiele liefern die Kolonialstädte im Osten, die im Zuge der deutschen mittelalterlichen Ostbewegung entstanden. " 58 In diesem Sinne dürfte in den raumpolitischen Herrschaftsakten Johanns neben der perspektivisch sehr wirkungsvollen „Geometrisierung“ noch ein hohes Maß an traditionellen Vorstellungen wirksam gewesen sein.

\section{Geleitpolitik}

Weniger die Suche nach abstrakten geometrisch-raumplanerischen Grundprinzipien im Denken des Herrschers als die Betrachtung wirtschaftspolitischer Zusammenhänge lenkt die Aufmerksamkeit auf einen weiteren - möglicherweise entscheidenden - Punkt für die zentralörtliche Neustrukturierung der Landschaft: Die Lage Küstrins im mitteleuropäischen Verkehrsnetz. Ebenso wie die 1560 begonnene Festung in Spandau (die heutige „Zitadelle“) liegt Küstrin am Zusammenfluß zweier großer schiffbarer Flüsse. Es war mit erheblichen logistischen Aufgaben verbunden, die mit den Festungen verbundene Artillerietechnik zu transportieren. Dies war auf dem Wasserwege in der Regel besser

genstand einer systematischen Untersuchung geworden. Henning Eichberg: Festung, Zentralmacht und Sozialgeometrie. Kriegsingenieurwesen des 17. Jahrhunderts in den Herzogtümern Bremen und Verden. Köln 1989, problematisiert zwar den Zusammenhang von Festungstechnik und vordergründig ,zivilen“ Kulturtechniken, doch bleibt der Zugriff der Studie auf das technikhistorische Feld „Festung“ letztlich verkürzt; vgl. Ralf Gebuhr: Festung und Repräsentation. Zur Sozialgeometrie-These von Henning Eichberg, in: Torsten Meyer, Marcus Popplow (Hgg.): Technik, Arbeit und Umwelt in der Geschichte. Günter Bayerl zum 60. Geburtstag. Münster 2006, S. 181-200.

58 Klaus Gerteis, Klaus: Die deutschen Städte in der frühen Neuzeit. Zur Vorgeschichte der „bürgerlichen Welt". Darmstadt 1986, S. 41 f. In der weiteren Entwicklung tritt nach K. Gerteis hierzu noch „der Wille, die Stadt in ein Ganzes zusammenzufügen“ und aus Stadt und Schloss ein „Gesamtkunstwerk" zu bilden. Hieraus entfalte sich letztendlich der spezifische Typ frühneuzeitlicher Planund Idealstädte, wie er bei Albrecht Dürer und Heinrich Schickhardts Plan für Freudenstadt begegnet (ebd., S. 27). Grundsätzlich bleibt das ,augenfälligste Merkmal der deutschen Städte zwischen Mittelalter und Industrieller Revolution [...] der enge Zusammenhang ihrer Entwicklung mit dem Ausbau des frühmodernen institutionellen Flächenstaates.“ (ebd., S. 176.). Ähnlich Herbert Knittler: Die europäische Stadt in der frühen Neuzeit. Institutionen, Strukturen, Entwicklungen. Wien 2000, S. 56 (= Querschnitte 4): „Hinter der neuzeitlichen Stadtgründung stehen Planungsvorgänge, die sich eine Anpassung der Stadtform an rationale Funktionen zum Ziele machen." Von hier aus schließt sich H. Knittler der These von H. Eichberg (wie Anm. 57) an, dass ,geometrische Muster“ zum „Grundprinzip“ werden, weil sie „Symmetrie und Ordnung im Sinne ästhetischer und gesellschaftlicher Wertvorstellungen“ verkörpern (ebd.). U. Schütte sieht die Frage einer grundlegenden geometrischen Konfiguration der Gesellschaft, hinter der soziale und politische Zusammenhänge letztlich zu Randfaktoren werden, skeptisch (Ulrich Schütte: Das Schloß als Wehranlage. Befestigte Schloßbauten der frühen Neuzeit im alten Reich. Darmstadt 1994, S. 297 f.). Vgl. hierzu auch Ralf Gebuhr: Rez. „Ulrich Schütte: Das Schloß als Wehranlage. Befestigte Schloßbauten der frühen Neuzeit im alten Reich. Darmstadt 1994“, in: Zeitschrift für Geschichtswissenschaft 44 (1996), S. 359-361, und ders.: Festung (wie Anm. 57). 
zu bewältigen als auf dem Landwege. Eine bemerkenswerte Parallele bietet der Fall des Transportes von Sandsteinsäulen für das Rathaus in Frankfurt (Oder) am Beginn des 17. Jahrhunderts, wo man sich nach eingehender Kalkulation für den Wasserweg von Pirna in die Mark entschied..$^{59}$

Immense Bedeutung hatte in der Zeit um 1500 der Handel mit Rinderherden vom Osten her. Die Agrarkrise des späten Mittelalters war ein wichtiger Grund, warum es insgesamt zu einer neuen Ausrichtung der Agrarwirtschaft mit stark zunehmendem Fleischverbrauch kam. ${ }^{60}$ Damit stellte die Kontrolle von Landwegen im Zuge des immens anschwellenden Ochsenhandels von Osten her in Richtung der Umschlagplätze Berlin, Zerbst und Buttstädt (Abb. 6) eine lukrative potentielle Einnahmequelle dar. In der Kontrolle von Landwegen nahm eine regelrechte Zollpolitik des Markgrafen ihren Ausgang, auf die für die Zeit um 1500 auch an anderer Stelle Hinweise gefunden wurden. Die Untersuchung der Wirtschafts- und Baupolitik im kursächsischen Amt Belzig zeigte, dass die Einnahmen des Amtes aus den Dörfern im Laufe des 15. Jahrhunderts deutlich sanken. Trotzdem leistete man sich umfangreiche Bauarbeiten an der Burg. Dies war möglich, da das Amt seine Einnahmen an „Geleitstellen“ steigerte, also den Handelsverkehr abschöpfte. ${ }^{61}$

Ebenso verfuhr Hans von Küstrin. L. Mollwo verweist auf eine ganze Reihe von Belegen, aus denen deutlich wird, dass der Markgraf eine umfassende Zollpolitik betrieb. Eingang ins Land wurde nur noch über große und leicht zu kontrollierende Straßen erlaubt, an denen die Zölle erhoben werden konnten. ${ }^{62}$ Wesentlich ist, dass man verschiedene Zölle, die vorher nur einmal in der Mark erhoben wurden, nun zusätzlich verlangte. Der reisende Händler musste zweimal zahlen: einmal in Kurbandenburg bei Joachim II. und einmal in der Neumark bei Hans von Küstrin. Auf diese Weise profitierten der Küstriner und der Reppener Zoll von Frankfurt an der Oder (das ja nicht zum Gebiet des Hans von Küstrin gehörte). In Küstrin wurde neues Brückengeld für Rindvieh, Schafe und

59 Otto Stiehl: Das Rathaus zu Frankfurt an der Oder, in: Zeitschrift für Geschichte der Architektur 4 (1911), H. 5/6, S. 99-123, hier, S. 116 ff.

60 Wilhelm Abel: Agrarkrisen und Agrarkonjunktur. Eine Geschichte der Land- und Ernährungswirtschaft Mitteleuropas seit dem hohen Mittelalter. 3. neubearbeitete und erweiterte Aufl. Hamburg, Berlin 1978; Ekkehard Westermann: Register von Ochsen- und Schweinekauf des Kasseler und Marburger Hofes in Dänemark, Hannover, Greven, Lipling, Buttstädt, Zerbst und Berlin von 1508-1618, in: Scripta Mercaturae 1/2 (1973), S. 53-86; Friedrich-Wilhelm Henning: Der Ochsenhandel aus den Gebieten nördlich der Karpaten im 16. Jahrhundert, in: ebd., S. 23-52; Wolfgang von Stromer: Wildwest in Europa. Der transkontinentale Ochsenhandel in der frühen Neuzeit, in: Kultur und Technik 2 (1979), S. 36-43; Christina Dalhede: Zum europäischen Ochsenhandel: Das Beispiel Augsburg 1560 und 1578. St. Katharinen 1992.

61 Ralf Gebuhr: Fehde, Krieg und Wüstung. Bemerkungen zum Einfluss singulärer Ereignisse auf das spätmittelalterliche Wüstungsgeschehen im Amt Belzig, in: Felix Biermann, Günter Mangelsdorf (Hgg.): Die bäuerliche Ostsiedlung des Mittelalters in Nordostdeutschland. Untersuchungen zum Landesausbau des 12. bis 14. Jahrhunderts im ländlichen Raum. Beiträge einer interdisziplinären Tagung des Lehrstuhls für Ur- und Frühgeschichte der Universität Greifswald, 16. und 17. April 2004. Frankfurt am Main 2005, S. 391-397 (= Greifswalder Mitteilungen, 7).

Mollwo (wie Anm. 23), S. 126 ff. 


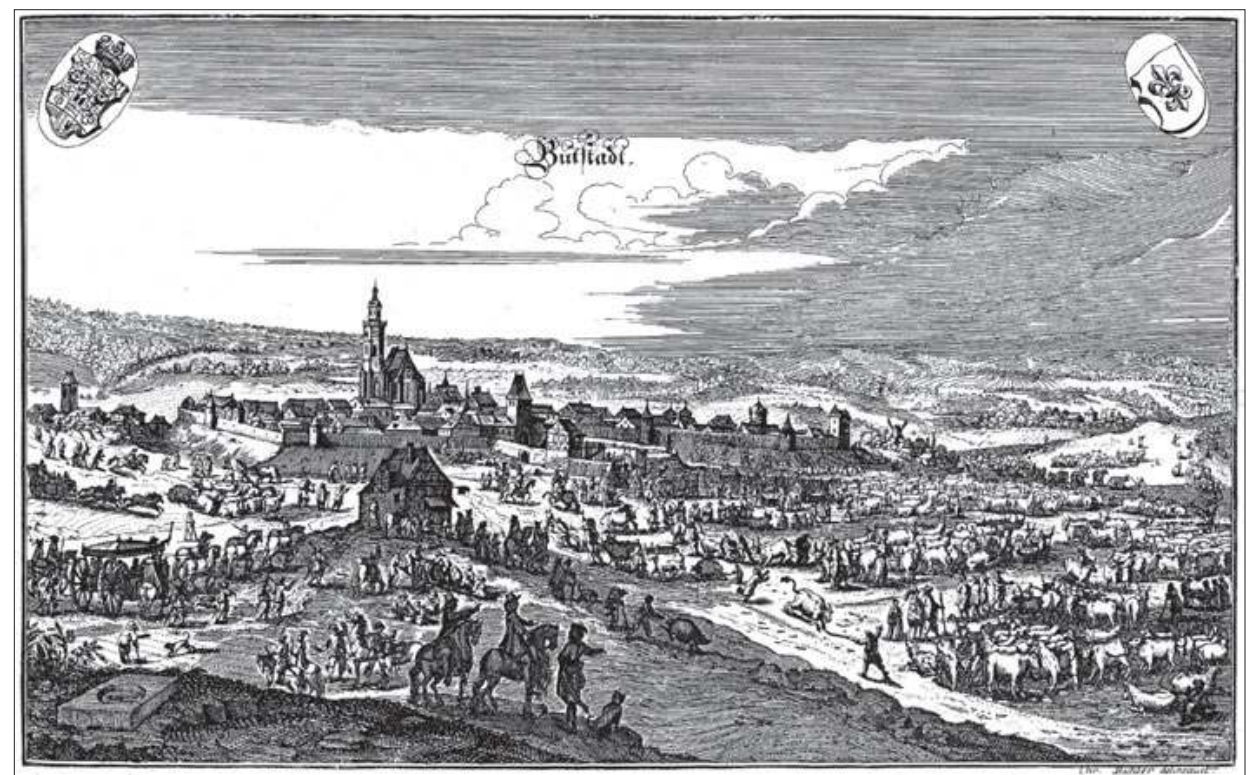

Abb. 6: Viehhandel dominierte über Jahrhunderte die Erscheinung von Buttstädt in Thüringen (Merian 1650, nach S. 30).

Schweine erhoben. ${ }^{63}$ Natürlich protestierte die Stadt, und auch Kurfürst Joachim, der Bruder Johanns, intervenierte, zeitweise wurde in diesen Auseinandersetzungen die Straße Landsberg-Krossen gesperrt. Doch letztlich setzte sich Johann durch.

Zwar wurden die Aktenbestände der Neumärkischen Amtskammer, die seit dem 16. Jahrhundert die Aufsicht über die Zollgefälle der Neumark und damit auch über den Küstriner Zoll hatte, bei der Beschießung Küstrins im Siebenjährigen Krieg vernichtet, doch wird man im Prozess der frühneuzeitlichen Territorialisierung staatlicher Macht die Umformung der Verkehrsverhältnisse keineswegs außer Acht lassen dürfen. In der Herrschaftstätigkeit des Markgrafen Hans dürften der Zugriff auf den Verkehr (,Zollpolitik“) und der Zugriff auf die Bürger die zwei zentralen Elemente für die Veränderung der inneren Struktur der Neumark gewesen sein. 



\title{
Zwischen Resistenz und Anpassung: Die neumärkische Adelsgesellschaft von der Mitte des 16. bis zum frühen 18. Jahrhundert
}

\author{
Von Frank GösE
}

Die Beobachtung, dass die frühneuzeitliche neumärkische Adelsgesellschaft eher im „Windschatten“ der Geschichte gestanden hat, besitzt nicht nur aus der Perspektive der heutigen Forschung eine gewisse Berechtigung. Es scheinen hier Kontinuitäten vorzuliegen, die sich auch mit den zeitgenössischen Wahrnehmungen der frühneuzeitlichen brandenburgischen Geschichte decken. Grund genug also, sich den ländlichen Herrenschichten dieser „vergessenen“ brandenburgischen Teillandschaft zuzuwenden. Im Folgenden kann natürlich nicht erschöpfend auf die frühneuzeitliche Entwicklung der neumärkischen Adelsgesellschaft eingegangen werden. Dem steht eine ohnehin recht ambivalente Forschungslage entgegen ${ }^{1}$. Vielmehr soll versucht werden, einige Grundzüge der neumärkischen Adelsgeschichte zwischen der Mitte des 16. und dem frühen 18. Jahrhundert vorzustellen. Dabei gilt es, aus plausiblen Gründen sowohl Quellen landesherrlicher Provenienz als auch die ständische Überlieferung in die Untersuchung einzubeziehen. Methodisch sinnvoll erscheint es ferner, bei dieser Betrachtung gelegentlich die Entwicklung in den kurmärkischen Landschaften im Blick zu behalten. Dies geschieht nicht nur aus komparativen Erwägungen heraus, sondern auch deshalb, weil das Verhältnis zwischen der neu- und kurmärkischen Adelsgesellschaft stets von gegenseitigen Wahrnehmungs- und Mobilitätsprozessen charakterisiert war.

Zunächst zur räumlichen Lage der Neumark ${ }^{2}$, die - so unsere These - bei der Erklärung der mentalen Disposition der Adelsgesellschaft nicht unberücksichtigt bleiben darf. Residenzferne und Abgeschiedenheit bildeten die hervorstechendsten Merkmale dieser brandenburgischen Teillandschaft. Die breite Oderniederung trennte die Siedlungsge-

1 Es bleibt zu hoffen, dass sich für die neumärkische Stände- und damit auch Adelsgeschichte durch die Neuverzeichnung des vergleichsweise gut überlieferten Ständearchivs neue Impulse entwickeln werden. Vgl. hierzu den sowohl bilanzierenden als auch auf Forschungsdesiderata hinweisenden Beitrag von Wolfgang Neugebauer: Die neumärkischen Stände im Lichte ihrer Tätigkeit, in: Margot Beck (Bearb.) u. Wolfgang Neugebauer (Einleitung): Neumärkische Stände (Rep. 23 B). Frankfurt a.M. 2000, S. XVII-LXXVI (= Quellen, Findbücher und Inventare des Brandenburgischen Landeshauptarchivs, Bd. 9). Des Weiteren sei verwiesen auf den von Christian Gahlbeck erarbeiteten Archivführer zur Geschichte Ostbrandenburgs bis 1945. München 2007. - Recht gut erscheint der Forschungsstand auch zur Adelsgeschichte des letzten Drittels des 18. Jahrhunderts, nicht zuletzt auf Grund der Forschungen zum Retablissement. Vgl. Hans Moegelin: Das Retablissement des adligen Grundbesitzes in der Neumark durch Friedrich den Großen, in: Forschungen zur Brandenburgischen und Preußischen Geschichte 46 (1934), S. 28-69 u. 233-274.

2 Verstanden hier im weiteren Sinne, denn bis weit in das 18. Jahrhundert wurde mitunter nur das Gebiet nördlich von Warthe und Netze zur „Neumark“ gezählt. 
biete des ucker- und neumärkischen Adels scharf voneinander. Im Vergleich zu den in der gesamten Frühen Neuzeit zu beobachtenden wechselseitigen Mobilitätsvorgängen zwischen den kleinräumigen brandenburgischen Adelslandschaften blieben solche Prozesse zwischen den kur- und neumärkischen Gebieten eher gering. Zum östlichen Nachbarn Polen wirkte die Grenze als Konfessions- und Sprachbarriere, obgleich es in den Lebensläufen neumärkischer Adelsfamilien davon nicht wenige Ausnahmen gab: Der 1640 geborene Sebastian (der Jüngere) v. Troschke erwarb seine Bildung nicht nur in der heimatlichen Neumark, sondern auch im polnischen Sirakowo, nicht zuletzt „um - was damals unbedingt nötig“" schien - ,polnisch zu lernen““3. Später wurde er Landesältester des Kreises Züllichau. Auch aus den Reihen der in den neumärkisch-hinterpommerischpolnischen Grenzlandschaften beheimateten Familie von der Goltz hatten nicht wenige Angehörige auch in polnischen Diensten gestanden; ein Geschlechtszweig war ohnehin in Polen angesessen ${ }^{4}$.

Der - zumindest für gängige Periodisierungen der Frühneuzeit - etwas eigenartig erscheinende zeitliche Rahmen (1535-1740) für unsere Betrachtungen verlangt vielleicht nach einer kurzen Erklärung: Sowohl am Beginn als auch am Ende des hier untersuchten Zeitraumes sah sich die neumärkische Ritterschaft markanten Herrscherpersönlichkeiten gegenübergestellt: Nach der 1535 erfolgten Landesteilung schuf Markgraf Johann (Hans von Küstrin), der etwa dem von G. Oestreich beschriebenen, ein ausgeprägtes ,persönliches Regiment“ führenden Fürstentypus entsprach, ein für damalige Verhältnisse recht effizient arbeitendes Verwaltungssystem. Dies konnte nicht ohne Wirkungen für die Stellung der Stände und damit eben auch des neumärkischen Adels bleiben. Der Regierungsstil des Küstriners hatte den Anspruch des Fürsten auf seine quasi souveräne Stellung unmissverständlich zum Ausdruck gebracht. 200 Jahre später war es der später als „Soldatenkönig“ etikettierte Friedrich Wilhelm I., der mit seinen durchgreifenden Reformen den schon seit längerem wirkenden Monarchisierungs- und Zentralisierungsprozess mit all seinen Implikationen für das fürstlich-ständische Verhältnis zu einem vorläufigen Abschluss gebracht hatte - ein Vorgang, der zwangsläufig auch dem neumärkischen Adel eine Palette an Zumutungen und Anpassungszwängen abverlangt hatte.

\section{$I$.}

Wenden wir uns zunächst der Stellung des neumärkischen Adels während der Regierungszeit des Markgrafen Hans von Küstrin zu. Das in der älteren Forschung vermittelte Bild lässt auf eine Herrschaftspraxis schließen, die der Ritterschaft nur einen geringen Partizipationsspielraum beließ. Zumeist ungefragt hätte sie demnach die - vor allem finanziellen - Zumutungen ihres Landesherrn hinnehmen müssen. Dem kam entgegen, dass Hans nach der bewährten Devise „divide et impera“ in der Regel das Zusammentreten

3 Paul v. Troschke: Das Geschlecht derer von Troschke. Görlitz 1911, S. 39.

4 Nachrichten über die Familie der Grafen und Freiherren von der Goltz, 2. Abtlg. Neustadt a.d. Aisch 1960, S. 28. 
eines Plenarlandtages vermied, vielmehr verhandelte er mit den Repräsentanten einzelner Kreise bzw. einem Ausschuss der Ritterschaft. Zudem versuchte der Markgraf über die im Vergleich zu den Landreitern mit größerer Autorität ausgestatteten Amtshauptleute auch auf die ritterschaftlichen Kreise Einfluss zu gewinnen, zumal diese zumeist aus dem einheimischen Adel ausgewählt wurden ${ }^{5}$. Auf Grund ihrer gleichzeitigen Einbindung in den fürstlichen Rat konnten sie ,ein gewisses Bindeglied zwischen Regierung und Adel bilden“"6. Wenn man sich ausschließlich die fürstliche Perspektive zu eigen macht, könnte man angesichts der für seine Zeit beeindruckenden Reformtätigkeit des neumärkischen Markgrafen zu dem naheliegenden Schluss kommen, dass sich die Oberstände nur auf eine Statistenrolle zu beschränken gehabt hätten ${ }^{7}$. Ein Blick in die ständische Überlieferung korrigiert jedoch diesen Eindruck.

Die erhaltenen Akten lassen den Regierungsalltag dieses Fürsten gegenüber ,seinem“ Adel nicht als so durchgreifend-reglementierend erscheinen, wie es ein tradiertes Bild suggerieren mag. Natürlich wurden die Reformen durch die neumärkische Ritterschaft als etwas „Neues“, bis dahin relativ Unbekanntes wahrgenommen. Die Neumark war schließlich recht unvermittelt aus einem Nebenland zu einem eigenständigen Staatswesen mit eigener Residenz, Hof und Landesverwaltung geworden. Aber die Zumutungen, die der Markgraf seinen Ständen abverlangte, hielten sich in den Grenzen dessen, was auch in anderen vergleichbaren Territorien Usus war. Mit dem in Küstrin angesiedelten Hof, den in ihm aufgehenden Rat, der Kanzlei (besonders mit dem dort für die Adelsfamilien bedeutsamen Lehnsregister!), dem für die landesherrlichen Einnahmen zuständigen Rentbzw. Kammermeister, der Regierung und dem Kammergericht wurden nicht nur die institutionellen und personellen Grundlagen einer effizienteren Herrschaftspraxis geschaffen, sondern auch für den neumärkischen Adel Bezugspunkte gebildet, denen er sich schwerlich entziehen konnte.

Vergessen wurde unter dem Blickwinkel des häufig überzeichneten ,ständischen Dualismus“, dass auch der Adel stets ein gewisses Interesse an einer starken Landesherrschaft bekundet hatte. Das über Brandenburg hinaus Aufsehen erregende Vorgehen Hans’ von Küstrin gegen die Borckes darf nicht als repräsentativ für seine Adelspolitik überinterpretiert werden ${ }^{8}$. Vielmehr wird er damit auch partiell die Interessenlage eines Teils der neumärkischen Adelsgesellschaft getroffen haben, die schon häufig des Borckes hochmütiges, zudringliches Wesen moniert hatte'. Und dass auch die Durchsetzungsfähigkeit

$5 \quad$ Schon im Landtagsabschied von 1539 kamen diese Beschwerden zur Sprache. Vgl. Brandenburgisches Landeshauptarchiv, Potsdam [im Folgenden abgekürzt: BLHA], Rep. 23 B Nr. 1017, unpag.

6 Hans Mollwo: Markgraf Hans von Küstrin. Hildesheim/Leipzig 1926, S. 93 u. 380 f.

7 Auch Johannes Schultze folgerte aus der von ihm sehr hoch veranschlagten fürstlichen Machtposition, dass die politische Bedeutung der neumärkischen Stände „stark gesunken“ sei. Johannes Schultze: Die Mark Brandenburg, Bd. 4. Berlin 1968, S. 120.

8 Vgl. Paul von Nießen: Markgraf Johann und die Familie Borcke. Ein Beitrag zur Charakteristik des Fürsten und seiner Politik, in: Schriften des Vereins für die Geschichte der Neumark 25 (1910), S. 23-46; Mollwo (wie Anm. 6), S. 392 ff.

9 Geheimes Staatsarchiv Preußischer Kulturbesitz Berlin-Dahlem [im Folgenden abgekürzt: GStAPK], I. HA. Rep. 4 Nr. 23, unpag. 
dieses Fürsten an seine Grenzen stoßen konnte, belegen die Konflikte mit jenen Adelsfamilien, die sich in den Grenzlandschaften der Neumark ein recht hohes Maß an Eigenständigkeit bewahrt hatten ${ }^{10}$. Somit dürfte dem relativierenden Urteil eines die Rigidität des Regierungshandelns des Markgrafen ansonsten recht hoch veranschlagenden älteren Forschers durchaus zuzustimmen sein, wonach die neumärkischen Adligen - auch mit Blick auf die im Zeichen der Agrarkonjunktur stehende wirtschaftliche Entwicklung $^{11}-$,,im ganzen ... recht zufrieden mit ihrer Lage“ gewesen seien ${ }^{12}$. Zudem war dem neumärkischen Markgrafen die bewährte Taktik, einzelne Angehörige der einflussreichen Adelsfamilien enger an sich zu binden, nicht fremd. So sollen Caspar und Matthias von Waldow ,in nahen Beziehungen“ zum Markgrafen gestanden haben; ersterer fungierte in dem regional bedeutenden Amt des Landeshauptmanns des Landes Sternberg ${ }^{13}$.

Solche Bindungen konnten auch im Zusammenhang der Kirchenpolitik des Markgrafen geknüpft werden. Es ist bekannt, dass neben den Landesherren auch der Adel in den Territorien, in denen die Reformation eingeführt wurde, von Säkularisationsgewinnen profitieren konnte ${ }^{14}$. Hans von Küstrin bedachte mehrere Adlige mit säkularisiertem Klostergut; so etwa erhielt Hans v. Bornstedt das Kloster Friedland zur Wohnung, und Joachim v. Benckendorff wurde mit den Gütern des Klosters Arnswalde zu Berg bedacht ${ }^{15}$. Entgegenkommen gegenüber den - mitunter regional divergierenden - ständischen Interessen bewies der Markgraf, als er den Fortbestand der sächsischen Rechtstradition in den Weichbildern Cottbus, Sommerfeldt und Züllichau garantierte ${ }^{16}$.

Gegen eine zu polarisierende Sichtweise auf das adlig-landesherrliche Verhältnis wäre ferner einzuwenden, dass die zahlreichen Feldzüge Hans'von Küstrin durchaus die Bindungen zwischen Fürst und Adel enger gestalten konnten. Der neumärkische Markgraf gehörte bekanntlich zu den politisch und militärisch aktivsten Reichsfürsten während der hochbrisanten Jahre des Schmalkaldischen Krieges und der Fürstenverschwörung gegen Kaiser Karl V., auch wenn der Kriegslärm nur verhalten an das Ohr der Neumärker gedrungen war. Ein Solidarisierungseffekt war jedenfalls kaum zu übersehen, und die neumärkische Ritterschaft ertrug unter diesen Umständen so manche Belastung eher ohne Murren als in friedlicheren Zeiten ${ }^{17}$. Das Konfessionsmotiv band den Adel, der sich in

10 Vgl. hierzu exemplarisch: Paul von Nießen: Die Fehde des Jesse gegen Schivelbein und der Markgraf Hans, in: Schriften des Vereins für die Geschichte der Neumark 22 (1908), S. 133-138.

11 Belege für die gute wirtschaftlich-finanzielle Lage bei Willy Spatz/ Willy Hoppe: Die Geschichte derer von Waldow. Berlin 1927, S. 49; Georg Schmidt: Die Familie von dem Borne. Merseburg 1887.

12 Mollwo (wie Anm. 6), S. 391.

13 Spatz/ Hoppe (wie Anm. 11), S. 45.

14 Vgl. hierzu übergreifend Volker Press: Adel, Reich und Reformation, in: Wolfgang J. Mommsen (Hg.): Stadtbürgertum und Adel in der Reformation. Studien zur Sozialgeschichte der Reformation in England und Deutschland. Stuttgart 1979, S. 330-383.

15 Adolph Friedrich Riedel (Hg.): Codex Diplomaticus Brandenburgensis [im Folgenden abgekürzt: CDB] A 18, S. 366.

16 BLHA, Rep. 23 B Nr. 1017, unpag.

17 Allerdings konnte es Meinungsverschiedenheiten darüber geben, ob ein Vasall verpflichtet war, an einem Feldzug seines Fürsten teilzunehmen, der ihn weit außerhalb des eigenen Landes führte. Auf 
seiner überwältigenden Mehrheit dem lutherischen Glauben zugewandt hatte, noch enger an seinen Landesherrn, der sich z.B. in der Interimsfrage als unbeugsam erwiesen hatte, deshalb aber zugleich in eine gefährliche außenpolitische Lage geraten war. Sein aktives Engagement war hingegen nur möglich, weil er im Gegensatz zu anderen Fürsten noch in recht großem Umfang auf die im Lehnswesen verankerte Gestellungspflicht seines Adels bauen konnte. Regelmäßige Musterungen wurden durch Hans durchgeführt, so dass die Kriegstüchtigkeit der Mehrheit der Ritterschaft gewährleistet war. Im Ernstfalle konnte er „auf einen festen Stamm von mindestens 700 Reitern rechnen“"18. Man weiß sowohl aus brandenburgischen ${ }^{19}$ als auch spanischen Quellen ${ }^{20}$, dass der neumärkische Markgraf als „Pensionär“ auf der Gehaltsliste des spanischen Königs stand und sich im Bedarfsfall verpflichtete, für Philipp II. Truppen auszuheben. Diese Alternative eines auswärtigen Kriegsdienstes blieb für die neumärkische Ritterschaft auch nach der Regierungszeit Hans' von Küstrin bestehen und wurde angesichts der für die brandenburgischen Lande selbst insgesamt friedlichen Zeitläufte durch eine nicht geringe Zahl neumärkischer Adliger gewählt. So dienten z.B. aus den Familien v. Löben, v. Waldow oder v. Schöning mehrere Angehörige als Söldner in den französischen Religionskriegen des ausgehenden 16. Jahrhunderts. ${ }^{21}$ Doch zumeist wird man das genaue Schicksal der in fremden Heeren dienenden Adligen kaum mit Sicherheit verifizieren können; in den Familiengeschichten begnügte man sich in solchen Fällen mit lapidaren Bemerkungen wie ,unbekannt“ bzw. ,außer Landes“.

Diese im Vergleich etwa zur Kurmark starke Einbindung der neumärkischen Ritterschaft in Kriegsdienste vermag vielleicht eine Erklärung für den überraschenden Befund vermitteln, wonach einige Jahrzehnte später unter den Offizieren der entstehenden brandenburgisch-preußischen Armee ein recht hoher Anteil von Neumärkern vertreten war. ${ }^{22}$ Kontinuitätslinien scheinen sich hier vom zweiten Drittel des 16. Jahrhunderts über die Zeit des Dreißigjährigen Krieges, die nachweislich der familiengeschichtlichen Überlieferung ohnehin durch eine hohe Zugehörigkeit neumärkischer Adliger zu den verschiedenen Söldnerheeren charakterisiert war, bis in die Formierungsphase des Miles perpetuus ergeben zu haben.

Nicht unbedeutend erscheint für die Analyse des fürstlich-adligen Verhältnisses, aber auch der Binnenstruktur der neumärkischen Ritterschaft die Frage, wer die neumärkische

diese durch D. v. d. Osten vertretene Position entgegnete Markgraf Johann, dass ein vasall seinem Herrn nicht allein beistendigk, sondern auch ausserhalb landes behülfflich sein solle. GStAPK, I. HA. Rep. 22 Nr. 223, unpag.

18 Mollwo (wie Anm. 6), S. 427.

19 Vgl. dazu die Akte GStAPK, I. HA, Rep. 16, Nr. 24, Fasz. 3.

20 Friedrich Edelmayer: Söldner und Pensionäre. Das Netzwerk Philipps II. im Heiligen Römischen Reich. München 2002, S. $208 \mathrm{ff}$.

21 Mit Hans V., Valentin und Adam v. Schöning (auf Hohen-Lübbichow) kämpften drei Brüder nahezu gleichzeitig auf dem französischen Kriegsschauplatz. Vgl. Hans u. Kurd v. Schöning: Geschichtliche Nachrichten von dem Geschlechte von Schöning und dessen Gütern. Berlin 1830, S. 53.

22 Vgl. Peter-Michael Hahn: Aristokratisierung und Professionalisierung. Der Aufstieg der Obristen zu einer militärischen und höfischen Elite in Brandenburg-Preußen von 1650-1725, in: Forschungen zur Brandenburgischen und Preußischen Geschichte N. F. 1 (1991), S. 161-208, hier S. 194. 
Adelsgesellschaft auf den ständischen Versammlungen repräsentierte. Aus den nicht allzu reichlich vorliegenden Quellen wird ersichtlich, dass es zwar in den meisten Fällen die in den jeweiligen neumärkischen Teillandschaften begüterten Familien waren, aus deren Mitte die Repräsentanten der Oberstände kamen. Die folgende Tabelle setzt die in den Quellen genannten auf dem „Landtag“ des Jahres 1557 anwesenden Adligen in Beziehung zu den in der Lehnpferderolle aufgeführten Besitzgrößen:

Vertreter der Ritterschaft auf dem neumärkischen Landtag im Juli $1557^{23}$ :

\begin{tabular}{|l|l|c|}
\hline Name & Ort (Kreis) & $\begin{array}{l}\text { Besitzgröße (Lehnpferde } \\
\text { nach Register 1565) }\end{array}$ \\
\hline Matthias v. Waldow & Bernstein (Arnswalde) & 8 \\
\hline v. d. Osten & Schildberg (Königsberg) & 5 \\
\hline Joachim v. Wedel & (Dramburg) & 2 \\
\hline Balzer v. Kumeise & Berneuchen (Landsberg) & 2 \\
\hline Jakob v. Horker & Glasow (Soldin) & 2 \\
\hline
\end{tabular}

Im Falle des Kreises Dramburg fällt jedoch das Fehlen des dort einflussreichsten Geschlechts, derer v. Güntersberg, auf. Diese hatten mit 15 Lehnpferden die absolute Spitzenstellung in diesem Kreis inne. Es ist davon auszugehen, dass die anderen Rittergutsbesitzer dieses Kreises wohl kein sonderliches Interesse bekundeten, denen v. Güntersberg, die ihrerseits auch wieder über Aftervasallen verfügten, die Vertretung der kreisständischen Interessen zu übertragen.

Ansonsten wurde jedoch das Bild, auch für die Zeit nach 1571, durch eine Konstellation bestimmt, nach der Angehörige der begütertsten Familien ihre Kreise repräsentierten. Für eine im Jahre 1599 stattfindende Zusammenkunft ist die Anwesenheit von 16 Adligen aus den in ihren Kreisen führenden Familien ${ }^{24}$ ebenso bezeugt, wie auch die Mehrheit der im Spätherbst 1614 in Küstrin anwesenden Ständevertreter (wichtige Zusammenkunft im Zusammenhang mit den veränderten Konfessionsverhältnissen) aus den begüterten Geschlechtern (z.B. v. Rothenburg, v. Löben u. v. Knobelsdorff im Kreis Krossen; v. Wedel u. v. Waldow im Kreis Arnswalde) entstammte ${ }^{25}$. Aus diesen Familien hatte Markgraf Hans im übrigen auch die überwiegende Mehrheit der für die Verwaltung der neumärkischen Teillandschaften wichtigen Landeshauptleute rekrutiert, was zugleich auch als ein Beleg dafür angesehen werden kann, dass dieser auf seine landesherrliche Autorität so insistierende Fürst das Indigenat weitgehend unangetastet ließ ${ }^{26}$.

Die „Nähe“ dieser politisch einflussreichen Geschlechter zur Landesherrschaft dokumentiert sich nicht zuletzt auch in finanziellen Transaktionen. Es mag verwundern, dass der auf Grund seiner gerade im Vergleich zu seinem kurfürstlichen Bruder um eine spar-

23 Erarbeitet nach: GStAPK, I. HA, Rep. 42 Nr. 18a B, B1. 7 und Carl v. Eickstedt: Beiträge zu einem neueren Landbuch der Marken Brandenburg. Magdeburg 1840, S. 38-47.

24 GStAPK, I. HA, Rep. 42 Nr. 18a D, Bl. 44.

25 Ebenda, Nr. 18d, Bl. 2

26 Mollwo (wie Anm. 6), S. 381. 
same Haushaltsführung bemühte neumärkische Markgraf finanzielle Anleihen beim Adel seines Fürstentums aufnahm. In seinen beiden Testamenten von 1546 und 1560 sind diese Außenstände detailliert aufgelistet: Im Falle seines Ablebens wären demnach an Hans v. Minckwitz 3000 Gulden, dem Landeshauptmann von Driesen, Hans v. Zabeltitz 2000 G. und dem Verweser des „Herzogtums Krossen“, Hans v. Knobelsdorff 1000 G. auszuzahlen. Im Testament von 1560 kamen mit dem Marschall Joachim v. Seggerde (3000 G.), dem Sohn des Cottbusser Hauptmanns Barthold v. Mandelslow (2813 G.) und dem Beeskower Hauptmann Anselm v. Zeischwitz (2000 G.) noch weitere Amtsträger hinzu ${ }^{27}$. Zwar waren diese Summen im Vergleich zu den exorbitanten Außenständen seines kurfürstlichen Bruders gering; der Befund belegt indes, dass auch im Verhältnis zwischen dem neumärkischen Markgrafen und ,seinem“ Adel jene Mechanismen und Kausalitäten griffen, die allenthalben das fürstlich-ständische Verhältnis im 16. Jahrhundert prägten.

Diese, das ältere Interpretament einer eher adelsfeindlichen Haltung des Markgrafen relativierenden Beobachtungen erklären vielleicht auch, dass der neumärkischen Ritterschaft ihr alter Landesherr schon bald nach dem Herrscherwechsel von 1571 in einem etwas verklärten Licht erschien. Dahinter wird man zugleich die Absicht vermuten müssen, die milde Regierungspraxis Hans 'von Küstrin den Anforderungen unter seinem Nachfolger gegenüberzustellen: Schon im ersten Regierungsjahr des neuen Landesherrn, Kurfürst Johann Georgs, führten die neumärkischen Oberstände Klage über den Modus der Haferlieferungen an die landesherrlichen Behörden. Sie verbanden ihre Beschwerde mit dem maliziösen Hinweis darauf, wenn S. f. Gn., Markgraf Hans länger gelebet, dieselben würden unsere unterthanen bitt gehört und sie mit diesen Lasten verschonet haben ${ }^{28}$. Ein ähnliches Motiv wurde 1578 angeschlagen, als die neumärkische Ritterschaft monierte, dass sie von den kurfürstlichen Zöllnern und Landreitern ungefragt mit der Türckensteuer beschwerlich belegt wurde, während unter Markgraf Hans dieselben ohne der Landschaft ... bewilligung nichts angeordnet worden $\mathrm{se}^{29}$.

Zunehmend gewann jedoch nach 1571 ein Thema in den ständischen Gravamina die Oberhand, das mit der peripheren Lage der Neumark in Verbindung stand. Die Repräsentanten der neumärkischen Stände hatten nicht geringe Probleme, sich in der wieder vereinten Mark zurechtzufinden. Sie bildeten nunmehr nur noch einen Teil eines gesamtständischen Corpus. Sicherlich hatte es der kleine Küstriner Hof nicht mit der Residenz in Berlin-Cölln aufnehmen können, gleichwohl ging den neumärkischen Oberständen nach 1571 ein Orientierungspunkt z. B. für Karriereoptionen verloren. Da wirkungsvolle personelle Netzwerke einen langfristigen Vorlauf, manchmal über Generationen hinweg benötigten, konnten auch die neumärkischen Adelsfamilien diesen Verlust nicht so ohne weiteres kompensieren. Nur sehr wenigen aus ihren Reihen gelang es, eine engere und dauerhafte politische Bindung zum Kurfürsten zu etablieren, wie etwa Hans (V.) v. Schö-

27 CDB A 24, S. 250 ff. u. $267 \mathrm{ff}$.

28 GStAPK, I. HA, Rep. 42 Nr. 20a, unpag.

29 Ebenda. 
ning, der den Kurfürsten Johann Sigismund 1609 nach Preußen begleitete und sich seitdem recht enger Beziehungen zur Dynastie erfreute ${ }^{30}$.

Die ständischen Suppliken der Jahrzehnte nach 1571 künden von diesen Anpassungsproblemen: In den 1593 vorgebrachten Gravamina der neumärkischen Ritterschaft wurde z.B. darüber geklagt, dass das Konsistorium zu weit abgelegen sei, so dass denen von Adell, von den Pfarrern und Cüstern in ihren jure patronaty viel eintragk geschehe. Deshalb bitte man darum, dass bei der Küstriner Regierung ein Consistorium gehalten und Geistliche Sachen dar möchten entschieden werden. In eine ähnliche Richtung zielte eine Supplik zur Gerichtspraxis: Da Brandenburg [gemeint ist der Schöffenstuhl in Brandenburg (Havel) - F.G.] weit abgelegen sei, bitte man darum, das die Von Adell peinliche Urthell holen möchten wo Sie wollen ${ }^{31}$.

Die Oberstände trachteten offenbar danach, die durch die 36jährige Separierung eingetretenen Strukturen zu konservieren. Beachtet werden muss, dass während dieser Jahrzehnte der Staatsbildungsprozess beträchtliche Fortschritte gemacht hatte und die brandenburgische Verwaltung und das Kirchenwesen bedeutenden Veränderungen unterzogen worden war $^{32}$. In diesem Sinne wären auch die zumeist recht hohen Teilnehmerzahlen auf den Landtagsverhandlungen jener Zeit zu erklären: Auf dem 1599 in Küstrin stattfindenden Landtag versammelten sich z.B. 116 neumärkische Adlige ${ }^{33}$. Natürlich fehlen auch in den neumärkischen Quellen nicht jene, uns aus der kurmärkischen Geschichte hinlänglich bekannten Klagen über ein fehlendes Interesse der Stände an ihren Zusammenkünften; dies setzte sich allerdings als Grundzug erst nach den Verwerfungen des Dreißigjährigen Krieges in der zweiten Hälfte des 17. Jahrhunderts durch ${ }^{34}$.

Vor allem galt es, sich innerhalb des Gesamtstaates gegenüber den anderen märkischen Teillandschaften zu behaupten. Konkurrenz bestimmte eher das Verhältnis der kleinräumigen Adelsgesellschaften zueinander als das auch vorhandene Gefühl, einem gemeinsamen Corpus anzugehören ${ }^{35}$. Die dreieinhalb Jahrzehnte währende Separierung hatte nicht nur eine gewisse Entfremdung der neumärkischen Ritterschaft zur BerlinCöllner Residenz mit sich gebracht, sondern auch zu Distanzierungen gegenüber den Ständen der kurmärkischen Teillandschaften geführt. Einer Forderung nach Reduzierung der Bauerndienste für den Bau der Festung Küstrin begegnete man z.B. mit der Begrün-

30 Schöning (wie Anm. 21), S. 54.

31 GStAPK, I. HA, Rep. 42 Nr. 18a B, Bl. 47 f.

32 Vgl. hierzu nur Wolfgang Neugebauer: Residenzenpraxis und Politik in Kurbrandenburg im 16. Jahrhundert, in: Jahrbuch für brandenburgische Landesgeschichte 51 (2000), S. 124-138.

33 GStAPK, I. HA, Rep. 42 Nr. 18a B, Bl. 17 ff. Ins Auge fällt aber das Fehlen derer v. Borcke!

34 Allenfalls kann auch schon zuvor ein Sich-Entziehen vor anstehenden unangenehmen Entscheidungen beobachtet werden. Auf dem in Landsberg abgehaltenen Landtag von 1610, auf dem u.a. die wachsenden Anforderungen der Landesdefension beraten werden sollten, wurde das fast gänzliche Ausbleiben der Krossener Oberstände moniert. GStAPK, I. HA, Rep. 42 Nr. 18c, unpag.

35 Vgl. hierzu jüngst, auch mit Blick auf das 16. Jahrhundert: Frank Göse: Zwischen regionaler Konkurrenz und ständischer Solidarität. Adel und Städte der Mark Brandenburg in der zweiten Hälfte des 17. Jahrhunderts, in: Michael Kaiser/Michael Rohrschneider (Hg.): Membra unius capitis. Studien zu Herrschaftsauffassungen und Regierungspraxis in Kurbrandenburg (1640-1688), Berlin 2005, S. 53-76 (= Forschungen zur Brandenburgischen und Preußischen Geschichte, Beiheft 7). 
dung, dass die Mittelmärker nicht zu diesem Unternehmen herangezogen werden würden. Die neumärkischen Stände vermittelten den Kurfürsten gegenüber den - auch für ihr Selbstverständnis aufschlussreichen - Eindruck, dass sie die meisten Lasten zu übernehmen hätten ${ }^{36}$. Im Juli 1650 artikulierten sie ihre Befürchtung, dass es ihnen ergehe, wie im October vorigen Jahres, dass sie nehmlich die Last allein und von den Ständen jenseit der Oder ohne Beysprung und Satisfaction gelassen werden möchten ${ }^{37}$.

Es erscheint nachvollziehbar, dass insbesondere die auf dem neumärkischen Territorium spürbaren Drangsale des Dreißigjährigen Krieges Folgen für das Verhältnis der neumärkischen Kreise untereinander haben mussten. Solidaritätsbekundungen der neumärkischen Stände für die durch die unmittelbaren Kriegswirkungen bedrängten Kreise waren durchaus vorhanden und belegen damit auch ein gewisses Zusammengehörigkeitsgefühl der neumärkischen Teillandschaften. Unerschöpflich war es indes nicht. Angesichts der besonderen Heimsuchung des Landsberger Kreises infolge Plünderung und Brandschatzung hätten die drei anderen sogenannten „Vorderkreise“ (Soldin, Königsberg und Arnswalde) im Jahre 1634 als deren Mitglieder Condolentz und affection nicht unterlassen und den Ausgeplünderten für mehrere Jahre Kontributionsfreiheit gewährt. Zwei Jahre später aber, als die anderen Kreise solche merckliche Plünderung und unersetzlichen ruin ausgestanden und erlitten, zogen sie dieses Zugeständnis zurück ${ }^{38}$.

Die distanzierte Haltung gegenüber den kurmärkischen Standesgenossen verwundert insofern, als man beim Durchmustern der ständischen Gravamina durchaus auf eine gemeinsame Interessenlage des Adels dies- und jenseits der Oder stößt. Sowohl in solchen für die landadligen Lebenswelten bedeutsamen Themenbereichen wie dem Zollwesen, der Jagdgerechtigkeit, dem Lehnswesen, der Versorgung von Witwen und unverheirateten Töchtern als auch zu dem weit gespannten Bereich der ländlichen Sozialordnung gingen die Vorstöße und Rückzugsgefechte der Stände in eine ähnliche Richtung ${ }^{39}$. Dennoch muss nachweislich der archivalischen Überlieferung davon ausgegangen werden, „dass ein durch Konkurrenz geprägtes Verhalten im internen Verhältnis der Stände überwogen hatte ${ }^{640}$. Eine gern gewählte Taktik der neumärkischen Vertreter bestand darin, bei Beschlussfassungen der gesamtbrandenburgischen Stände in vermeintlicher Bescheidenheit zurückzutreten und abzuwarten. Sie wollten, so formulierten z.B. die Repräsentanten der ostbrandenburgischen Stände im Dezember 1614 als Vertreter der Neumark, als dem geringsten Theill solcher lande nicht dem Votum der Überoderschen Stände vorgreifen ${ }^{41}$.

Bei der Erklärung der noch lange nach 1571 auf Eigenständigkeit bedachten Haltung der neumärkischen Oberstände sollte nicht unbeachtet bleiben, dass die Alternative ei-

36 So etwa in der Akte GStAPK, I. HA, Rep. 45 Nr. 14, unpag.

37 GStAPK, I. HA, Rep. 42 Nr. 46, unpag.

38 BLHA, Rep. 4B Nr. 459, Bl. 4.

39 Vgl. zu den ständischen Verhandlungen der Jahre 1571 bis 1596 in der Neumark: GStAPK I. HA Rep. 42 Nr. 18a B; für die kurmärkischen Verhältnisse vgl. v. a. die partiell auch die neumärkischen Verhältnisse einbeziehende Studie von Hellmuth Croon: Die kurmärkischen Landstände 1571-1616. Berlin 1938.

40 Göse: Zwischen regionaler Konkurrenz (wie Anm. 35), S. 74.

41 GStAPK I. HA, Rep. 42 Nr. 18d, Bl. 47. 
ner abermaligen Separierung der Neumark durchaus im Bereich des Möglichen lag. Das Testament des Kurfürsten Johann Georg von 1596 sah vor, dass dessen Sohn aus dritter Ehe, Markgraf Christian, die Neumark erhalten sollte. Die Stände schienen dieser Option recht aufgeschlossen gegenübergestanden zu haben. Erst mit der durch den Geraer Hausvertrag und den Onolzbacher Vergleich beendeten „Teilungskrise“ ist diese Möglichkeit einer erneuten eigenstaatlichen Existenz der Neumark beseitigt worden ${ }^{42}$.

Auch ein Blick auf das Heiratsverhalten der neumärkischen Ritterschaft bestätigt die gering entwickelten Bindungen zwischen der kur- und neumärkischen Adelsgesellschaft. Die Orientierung der Heiratsverbindungen, zumindest der Mehrheit der neumärkischen Adelsfamilien, blieb nach innen gerichtet ${ }^{43}$. Allenfalls können über das Durchschnittsmaß hinausgehende Eheverbindungen in das benachbarte Pommern rekonstruiert werden. Diese recht engen Heiratskreise der neumärkischen Adelsgeschlechter blieben im übrigen im gesamten, hier interessierenden Untersuchungszeitraum erhalten ${ }^{44}$.

Den bei der Betrachtung des Heiratsverhaltens deutlich gewordenen recht engen Bindungen zwischen der neumärkischen und hinterpommerschen Adelsgesellschaft hatte auch die Landesherrschaft bei ihrem Bemühen, die Bindungen zu ,ihrem“ Adel enger zu gestalten, Rechnung zu tragen. Die Orientierung auf rechtsverbindliche Modalitäten bei grenzüberschreitenden Verbindungen, so z.B. im Zusammenhang der nicht selten vorkommenden Erbfälle, zeigte sich z.B. in entsprechenden Unterlagen über die sich in der ersten Hälfte des 17. Jahrhunderts verändernden Bestimmungen des pommerschen Adelsrechts, die bei der neumärkischen Regierung gesammelt wurden ${ }^{45}$. Nach der Eingliederung Hinterpommerns in den brandenburgisch-preußischen Gesamtstaat verfügte die Landesherrschaft nunmehr auch über Möglichkeiten, bestimmten Wünschen der neumärkischen Oberstände zu entsprechen. So wurde in dem kurfürstlichen Revers für die neumärkische Ritterschaft von 1653 auf eine Kritik reagiert, wonach zwar Kinder von Untertanen hinterpommerscher Rittergutsbesitzer, die in die Dienste neumärkischer Adliger gegangen waren, zurückgebracht werden mussten - umgekehrt galt dies aber bislang nicht $^{46}$. Schon einige Jahrzehnte zuvor sah sich Kurfürst Johann Georg mit Vorhaltungen neumärkischer Adliger konfrontiert, dass bei fehlgeschlagenen Kreditgeschäften, in die märkische und pommersche Bürgen involviert waren, man die gantze Summa von den Märkischen Bürgen allein fordern wollen ${ }^{47}$.

42 Wolfgang Neugebauer: Die Hohenzollern, Bd. 1: Anfänge, Landesstaat und monarchische Autokratie bis 1740. Stuttgart, Berlin, Köln 1996, S. 99.

43 Vgl. hierzu das bei Gustav Adalbert von Mülverstedt: Sammlung von Ehestiftungen und Leibgedingsbriefen ritterschaftlicher Geschlechter der Provinz Sachsen, Brandenburg, Pommern und Preußen. Magdeburg 1863, gesammelte Material.

44 Frank Göse: Zur Geschichte des neumärkischen Adels im 17./18. Jahrhundert. Ein Beitrag zum Problem des ständischen Regionalismus, in: Forschungen zur Brandenburgischen und Preußischen Geschichte N.F. 7 (1997), S. 1-47, hier S. 41 f.

45 BLHA, Rep. 4B Nr. 440.

46 Revers des Kurfürsten für die neumärkische Ritterschaft, Küstrin, 19.08. 1653, in: M. Klinkenborg (Hg.): Das Brandenburgische Provinzialarchiv, Bd. 2: Die Neumark. Strausberg 1925, S. 298.

47 BLHA, Rep. 23 B Nr. 1017, unpag. 
Um auf die eingangs aufgeworfene Fragestellung der inneren Struktur der neumärkischen Ritterschaft zurückzukommen, sei an die gelegentlich vertretene Auffassung erinnert, dass man es beim brandenburgischen Adel mit einem weitgehend in sich ,homogenen Niederadel“" zu tun habe ${ }^{48}$ - einer Interpretation, die jedoch Missverständnisse hervorrufen kann. Sicher ist es richtig, dass es etwa im Vergleich zur ostpreußischen Adelslandschaft oder gar den durch einen in sich differenzierten Adel geprägten süd- und westdeutschen Territorien in der brandenburgischen Ritterschaft keine scharfen juristischen Abstufungen gab; dennoch dürfen die hier zu beobachtenden Differenzierungen nicht übersehen werden. Damit sprechen wir nicht nur die bekannte Unterteilung in ,beschlossene“ und „unbeschlossene“ Geschlechter an, wenngleich sich hier gewisse Zusammenhänge zwischen Besitzumfang, also wirtschaftlicher Stärke und der Frequentierung an landesherrlichen und ständischen Ämtern, also politischem Einfluss ableiten lassen. Zudem erscheinen die in der Literatur und den Quellen gegebenen Zuordnungen neumärkischer Adelsfamilien zu den „Schlossgesessenen“ widersprüchlich ${ }^{49}$. Ohnehin wird man hier von keiner allzu großen Konstanz auszugehen haben. Als etwa die v. Blücher 1577 das vormals denen v. d. Osten gehörende halbe Rittergut Plate kauften, wurden sie als „Schloßgesessene“ bezeichnet ${ }^{50}$. Auch die zuweilen als Merkmal für die Zugehörigkeit zu schlossgesessenen Geschlechtern genannte Verfügungsgewalt über Aftervasallen hält dem Quellenbefund nicht stand, zumal es als umstritten erscheint, ob Aftervasallen überhaupt eine Landtagsberechtigung besaßen ${ }^{51}$.

Der in einigen neumärkischen Geschlechtern anzutreffende Anspruch der Höherrangigkeit beruhte mitunter auf fragilen Annahmen. Noch der Rechtsgelehrte Benjamin Leube zählte z.B. die v. Wedel in seinem zu Beginn des 17. Jahrhunderts erschienenen Werk „Catalogus Comitum, Baronum et Toparcharum“ wegen ihrer überragenden Machtstellung im Mittelalter zu den „Baronen und Dynasten“. Dagegen reagierte der Kurfürst Friedrich Wilhelm recht schroff auf eine solche Anmaßung der Wedels. Irritiert ließ er im Mai 1669 bei der neumärkischen Regierung anfragen, wieso sich Gustav Wilhelm v. Wedel in einer Supplik an ihn als Baron tituliere, da Wir keinem Unserer Unterthanen verstatten, dass er ohne Unseren Consens und gnädigem Belieben sich andere Titel anmaßen dörffe ${ }^{52}$. Der daraufhin um eine Bestätigung seines fragwürdigen Titels angesprochene v. Wedel berief sich auf ein kaiserliches Diplom, das er aber niemals vorgezeigt hatte.

48 Gerhard Dilcher: Der alteuropäische Adel - ein verfassungsgeschichtlicher Typus?, in: Hans-Ulrich Wehler (Hg.): Europäischer Adel 1750-1950. Göttingen 1990, S. 57-86, hier S. 84.

49 Vgl. dazu Göse: Zur Geschichte (wie Anm. 44), S. 8 mit Anm. 29.

50 Arnim Freiherr von der Osten: Nachrichten über Herkunft, Verzweigung und Wappen Derer von der Osten und von der Osten, genannt Sacken. Berlin 1893, S. 29.

51 Mollwo (wie Anm. 6), 383.

52 GStAPK, I. HA, Rep. 22 Nr. 372, unpag. 


\section{II.}

Brandenburg gehörte bekanntlich zu jenen Reichsterritorien, die am stärksten durch die unmittelbaren Wirkungen des Dreißigjährigen Krieges getroffen wurden ${ }^{53}$. Die allenthalben zu beklagende „Destabilisierung der sozialen und politischen Ordnung“ musste zwangsläufig auch gravierende Auswirkungen auf den Adel dieses Territoriums haben ${ }^{54}$. Die inneren Strukturen der Adelsgesellschaften wurde in den folgenden Jahrzehnten durch demographische Einbrüche, Besitzwechsel sowie einen enormen Anpassungsdruck an die neuen wirtschaftlichen Rahmenbedingungen nachhaltig verändert. Es handelte sich dabei um Verlusterfahrungen, die auch den bis dahin führenden Geschlechtern wie denen v. Wedel, v. Güntersberg, v. Uchtenhagen oder v. Borcke nicht erspart blieben ${ }^{55}$. Erschwerend für die Bemühungen um die Krisenbewältigung und den Wiederaufbau trat hinzu, dass die zweite Hälfte des 17. Jahrhunderts durch einen Rückgang und anschließend stagnierende Entwicklungen der Getreidepreise charakterisiert war. Somit muss für die nordostdeutschen Territorien von einer recht langen Rekuperationsphase ausgegangen werden, die etwa bis in die 1720er Jahre währte.

Diese Krisenerfahrungen finden ihre Konkretion auf der Ebene der Adelsfamilien. Der neumärkische Zweig des Geschlechts derer v. Troschke stand am Ende des Dreißigjährigen Krieges vor dem Ruin, obwohl in seinen Reihen ein höfischer Amtsträger zu finden war. Doch selbst als der bei der Kurfürstinwitwe als Hofmarschall in Diensten stehende Asmus v. Troschke 1647 starb, ,war nicht einmal soviel Geld da, dass er standesgemäß begraben werden konnte ${ }^{656}$.

Zugleich stand die zweite Hälfte des 17. Jahrhunderts bekanntlich im Zeichen einer Verschärfung der Abhängigkeitsverhältnisse der bäuerlichen Hintersassen. So wie für seine kurmärkischen Standesgenossen zahlreich belegt, bemühte sich auch der neumärkische Adel, über die Einziehung von Bauernland und die Erhöhung der Frondienste die wirtschaftliche Basis der Gutsherrschaft zu verstärken. Der infolge der starken landesherrlichen Stellung noch im 16. Jahrhundert erkennbare Rückstand des neumärkischen Adels im Ausbau der gutsherrschaftlichen Position hatte sich zu seinen kurmärkischen Standesgenossen schon bis zum Dreißigjährigen Krieg verringert. Der Landtagsrezess von 1653 gab, gleichwohl er in seiner zäsurbildenden Bedeutung nicht überschätzt werden sollte, hierfür den allgemeinen rechtlichen Rahmen ${ }^{57}$. Folgt man dem bekannten West-Ost-Ge-

53 Vgl. Günther Franz: Der Dreißigjährige Krieg und das deutsche Volk. Jena 1941, S. 19-29.

54 Volker Press: Soziale Folgen des Dreißigjährigen Krieges, in: Winfried Schulze (Hg.): Ständische Gesellschaft und soziale Mobilität. München 1988, S. 239-268, hier S. 242.

55 Vgl. hierzu mit zahlreichen Belegen, auch zur neumärkischen Adelsgeschichte: Frank Göse: Rittergut - Garnison - Residenz. Studien zur Sozialstruktur und politischen Wirksamkeit des brandenburgischen Adels 1648-1763. Berlin 2005, S. 35-134 (= Veröffentlichungen des Brandenburgischen Landeshauptarchivs, Bd. 51).

56 Die Kurfürstinwitwe setzte sich dafür ein, dass das noch erhaltene Gold- und Silbergeschmeide nicht an die Gläubiger, sondern an die Witwe und die Kinder gehen sollte. Troschke (wie Anm. 3), S. 36 .

57 Vgl. Klinkenborg (wie Anm. 46), S. 290-306. 
fälle, gehörte die Neumark neben der Uckermark und Hinterpommern nunmehr zu den Landschaften der brandenburgisch-preußischen Monarchie mit einer hohen Dienstbelastung der Untertanen ${ }^{58}$. Diese juristische Verschärfung der Abhängigkeitsverhältnisse ging einher mit den Bemühungen der neumärkischen Ritterschaft, auf Kosten der Städte Handelsvorteile zu erlangen. Das Privileg, auf Ritterland gewonnenes Getreide zollfrei auszuführen, wurde stillschweigend auch auf das auf Bauernland geerntete ausgeweitet. Und nicht wenige Adlige dehnten ,ihr Recht für sich Bier ziesefrei zu brauen, auch auf die von ihnen aufgekauften Bauernhufen aus ${ }^{\text {“59 }}$. Einen langen Atem bewies der neumärkische Adel auch bei der Wahrung seiner Steuerfreiheit. Alle Versuche der Landesherrschaft, auf indirektem Wege den Adel z.B. zur Zahlung der Akzise stärker hinzuziehen, scheiterten - selbst ein sich so autokratisch gebärdender Monarch wie Friedrich Wilhelm I. musste hier den kürzeren ziehen ${ }^{60}$.

Trotz des Ausbaus ihrer privilegierten Stellung blieb die allgemeine wirtschaftliche Lage für die übergroße Mehrheit der neumärkischen Ritterschaft in den dem Dreißigjährigen Krieg folgenden Jahrzehnten desolat. Die meisten neumärkischen Rittergüter hatten einen Wert zwischen 10000 und 20000 Rtl.; der kurmärkische Adel verfügte dagegen mehrheitlich über Besitzungen zwischen 20000 und 50000 Rtl. ${ }^{61}$.

Lediglich einige in militärischen Diensten stehende Adlige bewiesen mehr Fortune, ihr Einkommen zur Sanierung bzw. Erweiterung ihres Landbesitzes zu verwenden. Hier wird man vor allem jene Militärs zu beachten haben, denen es während des Dreißigjährigen Krieges oder in dem sich anschließend formierenden brandenburgisch-preußischen Heer gelang, Vermögen zu erwerben. Hierzu war aber ein mehrjähriger Dienst erforderlich; angesichts der zunächst nur kurzzeitig aufgestellten Regimenter hielt sich der finanzielle Gewinn in Grenzen. So vermochte etwa Sebastian v. Troschke, der als Hauptmann in der brandenburgischen Armee diente, die Familienbesitzungen im Kreis Sternberg zu retten und dafür zu sorgen, ,dass nicht ein Fußbreit Troschkescher Besitz in fremde Hände kam“662. Dagegen konnten die aus neumärkischen Adelsfamilien hervorgehenden, auf regionaler Ebene wirksamen Amtsträger kaum in entscheidendem Maße ökonomische Vorteile aus ihren Chargen ziehen. Die angespannte finanzielle Situation ließ Kur-

58 Vgl. hierzu übergreifend und mit komparativem Ansatz: Michael North: Die Entstehung der Gutswirtschaft im südlichen Ostseeraum, in: Zeitschrift für historische Forschung 26 (1999), S. 43-59; Hartmut Harnisch: Probleme einer Periodisierung und regionalen Typisierung der Gutsherrschaft im mitteleuropäischen Raum, in: Jahrbuch für Geschichte des Feudalismus 10 (1986), S. 251-274. Auf die „Ostmitteleuropäischen Strukturzusammenhänge“ der Gutsherrschaft in Ostbrandenburg verweist Wolfgang Neugebauer: Der Adel in Preußen im 18. Jahrhundert, in: Ronald G. Asch (Hg.), Der europäische Adel im Ancien Régime. Von der Krise der ständigen Monarchie zur Revolution (1600-1789), Köln/Weimar/Wien 2001, S. 49-76, hier S. 52.

59 Paul Schwartz: Die Neumark während des Dreißigjährigen Krieges, 2. Teil. Landsberg a. d. Warthe 1902, S. 149.

60 Vgl. hierzu jüngst: Neugebauer: Die neumärkischen Stände (wie Anm. 1), S. LIV.

61 Vgl. hierzu ausführlich: Göse: Zur Geschichte (wie Anm. 44), S. 12-24.

62 Troschke (wie Anm. 3), S. 36. 
fürst Friedrich Wilhelm einen strikten Sparkurs einschlagen, der für einen nicht geringen Teil der neumärkischen Amtsträgerschaft erhebliche Gehaltseinbußen mit sich brachte ${ }^{63}$.

Nun mag man vielleicht relativierend einwenden, dass die sich im Verlauf des Jahrhunderts beträchtlich ausweitende Berlin-Potsdamer Hof- und Residenzgesellschaft eine ganze Reihe von neuen, auch recht gut bezahlten Chargen geschaffen hatte. Allerdings konnte der neumärkische Adel hiervon nur in geringem Maße profitieren. Die sich im 17. Jahrhundert bekanntlich stark vergrößernde Hohenzollernmonarchie hatte aus naheliegenden Gründen auch die Adelsgesellschaften der neu hinzugekommenenen Territorien angemessen bei der Besetzung führender Positionen am Hof und in der Zentralverwaltung zu berücksichtigen. Zwangsläufig musste dies dazu führen, dass der relative Anteil des brandenburgischen Adels innerhalb der Berlin-Potsdamer Residenzgesellschaft zurückging. Nach den Erhebungen von P. Bahl kamen nur 15 der insgesamt 343 während der Regierungszeit des Großen Kurfürsten am Berlin-Potsdamer Hof wirksamen Amtsträger aus der Neumark, darunter befanden sich 12 Adlige. Wenn man indes bedenkt, dass die Mark Brandenburg mit insgesamt 121 Personen innerhalb der Amtsträgerschaft immer noch die größte Gruppe darstellte, wird das Gefälle zwischen der Kur- und Neumark allzu offensichtlich ${ }^{64}$. Es konnte zwangsläufig nicht folgenlos geblieben sein, dass die unzureichende Integration der ostbrandenburgischen Adelsgesellschaft in den größer gewordenen Gesamtstaat, die nicht nur auf die zeitweilige Selbständigkeit der Neumark im 16. Jahrhundert zurückgeführt werden kann, auch in jenen Jahrzehnten virulent blieb, in denen der Zentralisierungs- und Bürokratisierungsprozess zügig vorangetrieben wurde.

Demzufolge kann es nicht verwundern, dass die sich nicht mit einem Leben auf dem Rittergut begnügenden neumärkischen Adligen sich auch in andere Richtungen orientierten. Hier wird man auf längere Traditionen zu sehen haben, die etwa auf die recht engen Verbindungen zwischen der neumärkischen und hinterpommerschen Adelsgesellschaft hindeuten und darüber hinaus nicht wenige neumärkische Adlige in die Dienste der am Kampf um das Dominium Maris Baltici beteiligten Staaten geführt hatten. So ist etwa nachweislich des prosopographischen Materials bei denen v. Wedel eine gewisse Affinität für einen Eintritt in die Dienste der schwedischen Krone auszumachen. Allein in der Reetz-Nörenberger Linie standen im 17. Jahrhundert fünf Angehörige in schwedischen Militärdiensten $^{65}$. Und 20\% der eine Militärkarriere durchlaufenden Mitglieder des Geschlechts der v. d. Osten hatten zwischen 1680 und 1750 unter der dänischen Fahne gedient $^{66}$. Allzu groß wird die Gesamtzahl der in auswärtige Dienste tretenden neumärkischen Adligen indes nicht gewesen sein, denn für solch einen Schritt bedurfte es schon

63 Vgl. Paul Schwartz: Der Beamtenabbau nach dem Dreißigjährigen Kriege, in: Die Neumark. Mitteilungen des Vereins für Geschichte der Neumark 1 (1924), Nr. 4, S. 49-58.

64 Peter Bahl: Der Hof des Großen Kurfürsten. Studien zur höheren Amtsträgerschaft BrandenburgPreußens. Köln, Weimar, Wien 2001, S. 146 (= Veröffentlichungen aus den Archiven Preußischer Kulturbesitz, Beiheft 8).

65 Vgl. Max v. Wedel (Bearb.): Gesamtmatrikel des Schloßgesessenen Geschlechts der Grafen und Herren von Wedel. Berlin 1905.

66 Hans Wätjen: Von der Osten. Ein pommersches Geschlecht im Wandel der Jahrhunderte. Braunschweig 1960, S. 110. 
eines gewissen „Startkapitals“ und der zumindest anfänglichen Unterstützung des Familienverbandes.

Damit wird die Aufmerksamkeit nunmehr auf eine weitere Alternative des neumärkischen Adels gelenkt, sich den neuen Herausforderungen anzupassen: den Militärdienst in der brandenburgisch-preußischen Armee. Doch handelte es sich hierbei um einen nur allmählich greifenden Prozess. Zwar versuchte der brandenburgische Kurfürst in wachsendem Maße, den einheimischen Adel im Lande zu halten ${ }^{67}$, und der stetig wachsende Miles Perpetuus bietet dafür sicher eine zunächst plausibel erscheinende Erklärung. Als z.B. der Rittmeister Hans Christoph v. Strauß seinen Landesherrn im März 1670 gebeten hatte, ihm mangels hiesiger Einsatzmöglichkeiten den Weggang in auswärtige Dienste zu gestatten, ordnete der Kurfürst an, dass er sich alhir bis zu vorfallendem avancement sich bei hofe aufhalten, und die tafel alda haben solle ${ }^{68}$.

Allerdings darf man sich nicht zu der Annahme verleiten lassen, dass jetzt neumärkische Adlige en masse in das Heer strömten, was für sie zugleich eine Alternative zur wirtschaftlich angespannten Situation auf den Rittergütern dargestellt hätte. Vielmehr war die Heeresgeschichte bis zum ausgehenden 17. Jahrhundert durch schwankende Truppenstärken charakterisiert. In der Regel wurde ein großer Teil der Regimenter nach Beendigung der Feldzüge wieder aufgelöst. Der eben präsentierte Fall des v. Strauß verdeutlicht exemplarisch, dass nicht permanent genügend Offiziersstellen vorhanden waren. Selbst für die eine Militärkarriere ins Auge fassenden neumärkischen Adligen reichten die zur Verfügung stehenden Stellen nicht aus. Nur 60 der in einer älteren Aufstellung erfassten ca. 700 Offiziere und Fähnriche der zwischen 1648 und 1670 errichteten Regimenter stammten aus Adelsgeschlechtern, die in der Mark Brandenburg ansässig waren; davon können 23 mit hoher Wahrscheinlichkeit der Neumark zugeordnet werden ${ }^{69}$. Eine starke Konzentration von Neumärkern war sowohl im Offiziers- wie Mannschaftsbestand in dem 1645 gebildeten (24.) Regiment zu Pferde unter Oberst Georg Ehrentreich von Burgsdorff anzutreffen. Dies belegt zugleich, dass auch im Zeitalter der Stehenden Heere die kleinräumige Adelslandschaft vorerst noch ihre Bedeutung für die Militärorganisation behielt. So orientierte eine am 14. Juni 1661 vom brandenburgischen Generalkriegskommissar Claus Ernst v. Platen erarbeitete Verfügung auf eine Einteilung der in der Mark Brandenburg zu bildenden Kompanien nach dem Regionalprinzip. An die Spitze dieser aus den Lehndienstaufgeboten zu bildenden Einheiten sollten Offiziere aus den in den jeweiligen Teillandschaften beheimateten Adelsfamilien gestellt werden. So sah die Planung z.B. vor, dass die Obristwachtmeister v. Krusemark und v. d. Knesebeck die altmärkischen, Alex-

67 Insgesamt handelte es sich dabei um 12 Edikte. Vgl. Friedrich Freiherr v. Schroetter: Die brandenburgisch-preußische Heeresverfassung unter dem Großen Kurfürsten. Leipzig 1892, S. 117

68 GStAPK, I.HA Rep. 22 Nr. 313, unpag.

69 Ermittelt nach Gustav Adalbert von Mülverstedt: Die brandenburgische Kriegsmacht unter dem Großen Kurfürsten. Magdeburg 1888, S. 632-710. 
ander Joachim v. Platen die prignitzschen sowie die Offiziere v. Moerner, v. Osten und v. Sydow die neumärkischen Kompanien anzuführen hätten ${ }^{70}$.

Bedacht werden müssen bei der Erörterung dieses Problemkreises auch Veränderungen innerhalb des Lehenssystems. Die alte Gestellungspflicht, der - wir erinnern uns der neumärkische Adel noch in der zweiten Hälfte des 16. Jahrhunderts in vergleichsweise großem Umfange nachgekommen war, geriet zunehmend außer Übung. Laut einer Aufzeichnung des Arnswaldischen Kreiskommissars v. Beneckendorff seien im Jahre 1635 die Lehnpferde zum letzten mahl in natura aufgebracht und gemustert worden; danach wurden die Verpflichtungen nur mit Geld abgegolten ${ }^{71}$. 1672, zu Beginn des Holländischen Krieges, musste der brandenburgische Kurfürst gegenüber den neumärkischen Ständen Befürchtungen ausräumen, er werde das adlige Lehnsaufgebot zu Kriegsdiensten außerhalb der Landesgrenzen nutzen. Dies wäre dero gnädigster Intention gantz zuwider. Er habe den adligen Ständevertretern die auswärtige Gefahr ... nur darum fürstellen lassen, damit die Gelder soviel eilfertiger aufgebracht werden ${ }^{72}$. Zum anderen kamen angesichts der desolaten Situation vieler Rittergüter in den von einer lange anhaltenden Agrardepression geprägten Jahrzehnten nicht wenige Adlige in eine ähnliche Lage wie der auf Kutzdorf ansässige Friedrich Christoph v. Schönbeck. Konfrontiert mit der Forderung, ein Lehnpferd zu stellen, konnte er die zuständigen Beamten der Küstriner Amtskammer im Februar 1666 bewegen, sich beim kurfürstlichen Geheimen Rat für eine Befreiung einzusetzen. Diese mussten gegenüber dem Geheimen Rat bekennen, dass es diesen guten Cavalier woll schwer fallen würde, wan Er iezo Ein Pferdt, da Er ohne das nur 2 schlechte geringe Pferdt hat, womit Er seinen AckerBaur bestellen muss, davon hingeben und aufbringen sollte ${ }^{73}$.

Diese Beispiele geben zugleich Veranlassung, unsere Aufmerksamkeit auf die Veränderungen im neumärkischen Lehnssystem zu lenken. Schließlich wurde in den in jüngerer Zeit erschienenen Studien zur brandenburgischen Adelsgeschichte auf die große Bedeutung des Lehenssystems auch für die frühneuzeitlichen Jahrhunderte hingewiesen ${ }^{74}$. Bereits in den letzten Kriegsjahren, die mit dem Beginn der Regierung des Großen Kurfürsten zusammenfielen, setzte sich allenthalben die Tendenz durch, die adligen Rittergutsbesitzer stärker an ihre Pflichten als Vasallen zu erinnern. Der Kurfürst mahnte im Juli 1645 die für Lehnsangelegenheiten zuständige neumärkische Regierung in Küstrin wegen des Ausbleibens einiger Vasallen bei der Huldigung. Von diesen seien unverzüglich die fehlenden Angaben beizubringen und das ausstehende Lehngeld einzuschicken. Ab-

70 Vgl. Otto Meinardus (Bearb.): Protokolle und Relationen des Brandenburgischen Geheimen Rates, Bd. 6. Leipzig 1917, S. 384.

71 BLHA, Rep. 23 B, Nr. 224, unpag.

72 Ebenda.

73 GStAPK, I. HA, Rep. 24 GG 1, Fasz. 4, B1. 17.

74 Vgl. Peter-Michael Hahn: Fürstliche Territorialhoheit und lokale Adelsgewalt. Die Durchdringung des ländlichen Raumes zwischen Elbe und Aller. Berlin, New York 1989, S. 327; Göse: Rittergut (wie Anm. 55), S. 110 ff.; sowie jüngst Dirk H. Müller: Adliges Eigentumsrecht und Landesverfassung. Die Auseinandersetzungen um die eigentumsrechtlichen Privilegien des Adels im 18. und 19. Jahrhundert am Beispiel Brandenburgs und Pommerns. Berlin 2011. 
schließend forderte der Kurfürst die neumärkischen Amtsträger auf, stärker als bisher auf die Lehnsdisziplin zu achten. Er habe nämlich den Eindruck gewonnen, als achteten die leute der lehnbrieffe ... gar wenig ${ }^{75}$. Durch die kurfürstlichen Behörden wurden die Lehnsangelegenheiten zum anderen als ein geeignetes Mittel angesehen, die Autorität der Landesherrschaft gegenüber den Oberständen in Erinnerung zu rufen. Zugriffsmöglichkeiten ergaben sich für die landesherrliche Verwaltung vor allem deshalb, weil viele Adelsfamilien versäumt hatten, um einen Consens ihrer Lehen nachzusuchen bzw. diese zu ,muten“. Es erscheint nur aus der zeitlichen Distanz verwunderlich, warum ein so scheinbar archaisch anmutendes Prozedere für die Disziplinierung des Adels favorisiert wurde. Das Lehenssystem eignete sich vor allem deshalb für diesen Zweck, weil die landesherrliche Politik hier eine Organisationsstruktur innerhalb der Adelsgesellschaft, die in besonderem Maße auf Traditionalität und Konsens beruhte, allmählich instrumentalisieren konnte. Die Kurfürsten verstanden es, die Handhabung des Lehnrechtes geschickt in ihre Adelspolitik einzubinden, die mit der Erweisung von Gnaden und der Androhung von Sanktionen operierte. Nur zwei Beispiele seien dafür an dieser Stelle präsentiert.

Der - im übrigen selbst aus der Neumark stammende - Wirkliche Geheime Rat Johann Friedrich Freiherr v. Löben versuchte einen neumärkischen Rittergutsbesitzer vor einer Lehnstrafe zu bewahren. Er trug in der am 31. Januar 1659 im Geheimen Rat stattfindenden Sitzung den Fall des Hans Christoph v. Grünberg vor. Dieser aus dem Kreis Cottbus stammende Adlige bat, weil er wegen Armut die Lehen wegen seines Bruders Güter zu muten nicht gehabt, dass ihm solches nicht präjudiciren und ihm verziehen werden solle $^{76}$. Dagegen konnten Angehörige des Geschlechts v. Wedel auf geringere Nachsicht hoffen. Nachweislich der für 1684 vorliegenden Specification über Lehnstrafen wurden einige Lehnstücke dieser Familie eingezogen ${ }^{77}$. Es erscheint allerdings nicht verwunderlich, dass die lehnsrechtlichen Instrumente durch den Kurfürsten genutzt wurden, um auf solche Adelsfamilien stärkeren Druck auszuüben, die sich auf anderen Feldern der landesherrlichen Politik unbotmäßig gezeigt hatten. Schon im Zusammenhang einer Erbauseinandersetzung hatten sich die von Wedel in den 1660er Jahren gegenüber der Regierung in Küstrin als die in dieser Angelegenheit entscheidende juristische Instanz als sehr widerspenstig erwiesen. Von daher überraschte die kurfürstliche Entscheidung nicht, dass Curt Dietrich v. Wedel die Lehnstrafe von 37 Rtl. nicht erlassen wurde; ausdrücklich wurde darin sein Ungehorsam moniert ${ }^{78}$.

Vor diesem Hintergrund wird verständlich, dass auch die neumärkische Ritterschaft die in den ersten Regierungsjahren König Friedrich Wilhelms I. in Angriff genommene Lehnsallodifikation als Herausforderung betrachtete ${ }^{79}$. Der Adel befürchtete, dass die Ab-

75 GStAPK, I. HA, Rep. 22 Nr. 372, unpag.

76 Protokolle und Relationen (wie Anm. 70), Bd. 6, S. 55.

77 Eickstedt (wie Anm. 23), S. 442.

78 GStAPK, I. HA, Rep. 22 Nr. 372, unpag.

79 Vgl. dazu neben der älteren Studie von Victor Loewe: Die Allodifikation der Lehen unter Friedrich Wilhelm I., in: Forschungen zur Brandenburgischen und Preußischen Geschichte 11(1898), S. 341-374, in jüngerer Zeit Dirk H. Müller: Die Umwandlung der märkischen Rittergüter in lehns- 
lösung des Lehnswesens zu einer Erosion des Zusammenhalts innerhalb des Geschlechtsverbandes führen würde. Das Lehnssystem habe bislang - so die verbreitete Argumentationslinie der Ritterschaft - den ohnehin latent bestehenden Trend der Erbteilungen und der Verschleuderung von Familienbesitz durch einzelne Geschlechtsangehörige zumindest aufgehalten. In einer im Februar 1717 ungewöhnlich gut besuchten Kreisversammlung der Oberstände des zur Neumark zählenden Kreises Krossen erinnerten die Rittergutsbesitzer z.B. mit Nachdruck daran, dass die Lehngüter nicht schlechterdings und alleinig denen Possesoribus, sondern der ganzen Familie oder wenigstens den Agnatis und Gesamthändern gehörten, welche diese mit vielen Kosten erhielten ${ }^{80}$. Schwer abfinden konnten sich allerdings die Adelsfamilien mit der Entrichtung des nun regelmäßig aufzubringenden Lehnpferdegeldes, die man als eklatanten Eingriff in die Steuerfreiheit des Adels interpretierte. Dies sei ein Versto $\beta$ gegen hergebrachte adlige freiheiten, ließ sich z.B. die Arnswaldische Ritterschaft vernehmen ${ }^{81}$. Insbesondere die Vertreter jener Adelslandschaften, die nur über einen geringen wirtschaftlich-finanziellen Rückhalt verfügten, machten auf die unzumutbaren Belastungen aufmerksam, sollte die bisherige Lehnpferdeeinteilung zur Grundlage der neuen Besteuerung genutzt werden. In ihrem Memorial klagten die Oberstände der ostbrandenburgischen Landschaften, dass viele nur ein Rittergütchen von 4 bis 6000 Rtlt. Wert [hätten], worauf ein halbes oder auch wohl ein ganzes Lehnpferd haftet, welches aber mit Schulden und oneribus dergestalt beschweret, dass sie davon auch den allerschlechtesten Unterhalt nicht zulänglich haben, geschweige dann noch einen so hohen jährlichen Canonem entrichten können. Mehr als 20 Rtl. könne man sich nicht zumuten ${ }^{82}$.

Dennoch sollte man sich - ähnlich wie dies am Beispiel des Markgrafen Hans von Küstrin vorgeführt wurde - davor bewahren, die gewiss nicht wenige Zumutungen für die neumärkische Ritterschaft enthaltende Politik dieses Königs überzuinterpretieren. Der Soldatenkönig war kein „Adelsfeind“"83! Auch dieser Monarch hatte Rücksichten auf die Interessenlage der Adelsgesellschaften seines Staates zu nehmen, was sich nicht zuletzt im Zusammenhang der Lehnsreform bestätigen sollte. Er gestand den neumärkischen Oberständen Konzessionen zu, die auf einer Anerkennung ihrer Eigenständigkeit hinausliefen. Die Führung des für die Taxierungen und Kreditbelastungen der Rittergüter eingerichteten Landbuches lag fortan in der Verwaltung der neumärkischen Stände ${ }^{84}$. Ebenso

rechtlich verfaßtes Familieneigentum unter Friedrich Wilhelm I., in: Jahrbuch für die Geschichte Mittel- und Ostdeutschlands 46 (2001), S. 171-203; Göse: Rittergut (wie Anm. 55), S. 181-211. BLHA, Rep. 23 B Nr. 157, unpag.

81 GStAPK, I. HA, Rep. 66 Nr. 19, Bl. 106.

82 BLHA, Rep. 23 B Nr. 954, B1. 17.

83 Zur Adelspolitik Friedrich Wilhelms I. vgl. neben der klassischen Studie von Gerd Heinrich: Der Adel in Brandenburg-Preußen, in: Hellmut Rössler (Hg.): Deutscher Adel 1555-1740. Darmstadt 1965, S. 259-314; Frank Göse: Das Verhältnis Friedrich Wilhelms I. zum Adel, in: Friedrich Beck/ Julius H. Schoeps (Hg.), Der ,Soldatenkönig“ Friedrich Wilhelm I. und seine Zeit. Potsdam 2003, S. 99-138 (= Brandenburgische Historische Studien, Bd. 12).

84 Vgl. Neugebauer, Die neumärkischen Stände (wie Anm. 1), S. LVIII. 
finden sich in den Quellen Belege dafür, dass der König durchaus ein Gespür für die mitunter angespannte Lage des neumärkischen Adels hatte ${ }^{85}$.

Dass der König auf die Mitwirkung der Stände gerade auch bei der Umsetzung dieser Reform angewiesen war, belegen die nicht geringen Probleme, die bei der Einführung des nun regelmäßig zu erhebenden Lehnskanons entstanden waren. Damit werden zugleich wieder einmal die strukturellen Grenzen ,,absolutistischer“" Verwaltungspraxis vorgeführt. Es kostete offenbar große Mühe, eine halbwegs zuverlässige Specification der auf den einzelnen Familien bzw. Rittergütern liegenden Lehnpferde zu erstellen. Ein Vergleich der vorliegenden Listen offenbarte zum Teil beträchtliche Unstimmigkeiten. In der Neumark betrug diese Differenz 46 Lehnpferde, was einem Geldwert von 1840 Rtl entsprach ${ }^{86}$.

Diese notwendigen Relativierungen der Durchsetzungskraft der Landesherrschaft erscheinen jedoch plausibel, wenn man die Aufmerksamkeit auf die Amtsträgerschaft richtet. Die in der Neumark wirkenden und in übergroßer Mehrheit aus dem einheimischen Adel hervorgehenden Amtsträger verstanden sich noch lange Zeit primär als Interessenvertreter ihrer Mitstände - diese Beobachtung ist auch auf jene Chargen (Kreiskommissare, Landräte) auszuweiten, denen traditionell ein großer Anteil an der landesherrlichen Durchdringung der Teillandschaften zugemessen wurde ${ }^{87}$. Wie weit die Unterstützung adliger Interessen durch die regionalen Amtsträger gehen konnte, zeigte die Verhaltensweise neumärkischer Landräte bei der Einziehung einer während des Spanischen Erbfolgekrieges erhobenen Kopfsteuer, bei der sie „die im Felde stehenden Adligen gezielt übersehen" hatten. ${ }^{88}$

Die vorgebrachten Belege können dahingehend gedeutet werden, dass die neumärkischen Oberstände versuchten, sich dem Integrationsprozess zwar nicht zu entziehen, wohl aber einen entsprechenden Gegendruck zu entfalten, um ein gewisses Maß an Eigenständigkeit zu erhalten. Auch die Landesherrschaft hatte dies zu berücksichtigen. Anerkennend nahm sie den offensichtlich größeren Zusammenhalt der neumärkischen Stände wahr ${ }^{89}$. Die Küstriner Regierung erinnerte im Dezember 1684 daran, dass der Kurfürst die in der Neumark bewährte Praxis der gegenseitigen Unterstützung im Notfalle als das beste Mittel das Land zu conserviren und demselben die unumgängliche onera publica leicht zu

85 So wies der König die neumärkische Regierung am 31. März 1729 an, im Interesse der Witwe v. Rohwedel dafür zu sorgen, dass der Pächter W. Völcker das Gut Krantzien (Kr. Arnswalde) ohne ferners Einwenden räumen und an die Rohwedelschen Kinder wieder abtrethen müsse. GStAPK, I. HA, Rep. 96 B Nr. 1, B1. 89.

86 BLHA, Rep. 23 B Nr. 224.

87 Vgl. Otto Hintze: Der Commissarius und seine Bedeutung in der allgemeinen Verwaltungsgeschichte, in: ders.: Staat und Verfassung. Gesammelte Abhandlungen zur allgemeinen Verfassungsgeschichte, hrsg. v. Gerhard Oestreich. Göttingen 1970, S. 242-274; auf der Grundlage archivalischer Quellen: Göse: Zur Geschichte (wie Anm. 44), S. 26 ff.

88 Neugebauer, Die neumärkischen Stände (wie Anm. 1), S. XLIII.

89 Hierfür nur ein Beispiel: Maria Eleonore v. Billerbeck bat im März 1713 den neuen König um Pardon für ihren mit Landesverweisung bestraften Gatten Hans Georg. Dabei erhielt sie die Unterstützung der sämtlichen Ritterschaft der Neumark, Sternberg und incorporierten Kreise, was natürlich einen entsprechenden Eindruck beim Monarchen hinterließ. GStAPK I. HA, Rep. 22 Nr. 18, Fasz. 1, B1. 2. 
machen gelobet habe und dieselbe oftmahls denen Ständen jenseit der Oder und Elbe zum Beyspiel vorstellen lassen ${ }^{90}$. Die zwar nicht auf offenen Widerstand, wohl aber auf subtile Resistenz hinauslaufende Haltung der neumärkischen Oberstände stellte eine Konstellation dar, mit der sich auch die Landesherren abzufinden hatten. Es handelte sich dabei um Erfahrungen, die auch in die bekannten differenzierten Bewertungen des „Soldatenkönigs“ zum Adel der Landesteile seines Staatswesens eingeflossen sein mögen. Zur neumärkischen Ritterschaft bemerkte er in der Instruktion für meinen Nachfolger von 1722 lakonisch: Klagen würden sie zwar stetig[lich], aber man müsse darauf keine Reflexion machen, den [n] sie seindt meisten ohne fundame[n]t, es ist aber so Ihre Landesgewohnheit ${ }^{91}$.

\section{III.}

Abschließend soll unser Blick noch einmal auf die im beginnenden 18. Jahrhundert einsetzenden Strukturveränderungen innerhalb des neumärkischen Adels gerichtet werden, wohl wissend, dass diese eine nicht zu unterschätzende Relevanz gegenüber der in dieser Studie behandelten zentralen Problemstellung aufweisen. Wir haben dabei vornehmlich die wachsende Einbindung der neumärkischen Ritterschaft in den Militärdienst im Blick. Faßt man die im jeweiligen Stichjahr im aktiven Dienst stehenden Rittergutsbesitzer mit den bereits schon wieder verabschiedeten Offizieren zusammen, dann stieg dieser Anteil von 36\% (1718) auf 46\% (1751) $)^{92}$. Bei der Suche nach den Auswirkungen dieser Entwicklung hat man in mehrere Richtungen zu schauen.

Auch wenn jüngst in Kritik an der älteren Forschung die Bedeutung des Miles Perpetuus für die Integration der Landesteile der brandenburgisch-preußischen Monarchie zurückhaltender eingeschätzt wurde ${ }^{93}$, spricht doch einiges dafür, die durch den Militärdienst spürbar belebten Mobilitätsvorgänge innerhalb des neumärkischen Adels recht hoch zu veranschlagen. Es lag bekanntlich in der landesherrlichen Intention, eine regionale Durchmischung des Offizierskorps zu erreichen. Betrachtet man die für das Jahr 1718 zuzuordnende Gesamtzahl von 68 aus neumärkischem Adel stammenden Offiziere und setzt diese Zahl mit jenen 14 Offizieren (also 20,5\%) ins Verhältnis, die auch in neumärkischen Garnisonsorten dienten, dann war der König seinem Ziel schon recht nahe gekommen. Der größte Teil der Offiziere stand dennoch außerhalb der eigenen Teillandschaft in Garnison, also in der Kurmark und Magdeburg (17), in Preußen (14), Hinterpommern (10) oder in den westlichen Landesteilen (13 $)^{94}$. Der Einwand, dass es sich dabei angesichts des häufi-

90 BLHA, Rep. 4B Nr. 459, unpag.

91 Zitiert nach: Richard Dietrich (Bearb.): Die Politischen Testamente der Hohenzollern. Köln, Wien 1986, S. $229 \mathrm{ff}$.

92 Göse: Rittergut (wie Anm. 55), Tabellen 49, 50, S. 490 f.

93 Jürgen Luh: Heer und Herrschaft. Zur Rolle der Armee im Integrationsprozess der kurbrandenburgischen Territorien, in: Kaiser/Rohrschneider (Hg.): Membra unius capitis (wie Anm. 35), S. 235-245.

94 Frank Göse: Zwischen Garnison und Rittergut. Aspekte der Verknüpfung von Militärgeschichte und Adelsforschung am Beispiel Brandenburg-Preußens, in: Ralf Pröve (Hg.): Klio in Uniform? Prob- 
gen Wechsels der Garnisonsorte nur um kurzzeitige Aufenthalte gehandelt hatte, die keine längerfristigen Bindungen bewirkten, soll nicht völlig in Abrede gestellt werden. Zieht man jedoch die Entwicklung des Heiratsverhaltens der im Militärdienst stehenden neumärkischen Adligen hinzu, deuten sich offenbar längerfristige Bindungen in die anderen Territorien der Monarchie an. Demnach weitete sich der Heiratskreis der adligen Militärs von der Mitte des 17. bis zum Ende des 18. Jahrhunderts immer weiter aus ${ }^{95}$.

Auch innerhalb der neumärkischen Adelsgesellschaft können im Zusammenhang mit der Einbindung in den Militärdienst Mobilitätsvorgänge beobachtet werden. So eröffneten sich für eine Reihe von neumärkischen Rittergutsbesitzern Möglichkeiten für einen mitunter regen Güterhandel ${ }^{96}$ und finanzielle Transaktionen, über die sie sonst nicht verfügt hätten. Gerade in solchen kleinräumigen Adelslandschaften, in denen kleine Güter dominierten und in denen demzufolge der finanzielle Spielraum der Besitzer gering war, konnte dies von Bedeutung sein: Im Kreis Friedeberg kamen z.B. 40\% aller Kreditaufnahmen von Offizieren; in Königsberg lag dieser Anteil bei 26\% ${ }^{97}$.

Andererseits bildete der Militärdienst in unteren Rängen aber ein Zuschussgeschäft. Der im Regiment Dönhoff dienende Leutnant Curt Heinrich v. Brederlow schilderte der neumärkischen Regierung im Juni 1722 seinen Fall. Das Rittergut Granow (Kr. Arnswalde), bestehend aus 6 Ritterhufen, war schon zu dem Zeitpunkt der Übernahme durch den v. Brederlow sehr verschuldet, vor allem durch die Abfindung der Stiefmutter und die Auszahlung von Heiratsgeld an seine drei Schwestern. Und weil ich gleich sehr jung ein Soldate geworden, so habe ich in meinem Soldatenstande auch zu meiner nöthigen Ausgabe Geld gebrauchet, dergestalt, dass ich anitzo 3100 Rtl. darauf schuldig bin. Seine Kreditoren drängten jetzt, da er mündig geworden, häfftig in Mich und wollen absolut ihre Zahlung haben, so dass er sich zur wiederkäuflichen Veräußerung des Gutes an seinen Regimentskameraden, einen Leutnant v. Dessow, entschlossen habe ${ }^{98}$.

\section{IV.}

Versuchen wir am Ende unserer Betrachtungen ein Resümee zu ziehen. Gefragt war nach langfristigen Veränderungen in der neumärkischen Adelsgesellschaft zwischen der Mitte des 16. und dem frühen 18. Jahrhundert im Spannungsfeld zwischen Resistenz und

leme und Perspektiven einer modernen Militärgeschichte der Frühen Neuzeit. Köln, Weimar, Wien 1997, S. 109-142, hier S. 125.

95 Vgl. das quantitative Material in: Göse: Rittergut (wie Anm. 55), S. 250.

96 Ein Ende des 17. Jahrhunderts an den Obristen v. Bornstedt verliehenes Vorwerk im Amt Driesen ging danach an den Obristen v. Schönebeck und von diesem an einen Obristen v. Mehlen. 1726 bewarb sich der Oberst v. Papstein um diesen Besitz, nachdem er zuvor schon das sich in der Nähe befindende Rittergut Geilenfelde erhalten hatte. Vgl. GStAPK, I. HA, Rep. 22 Nr. 236, Bl. 3.

97 Diese Werte korrelieren mit den Anteilen von Offizieren in den kleinräumigen Adelsgesellschaften: in Friedeberg 36\% (1718) bzw. 33\% (1751, mit ehemaligen Offizieren sogar 46\%) und im Kr. Königsberg 43\% (1718) bzw. 20\% (1751, mit ehemaligen Offizieren sogar 53\%) Vgl. Göse: Rittergut (wie Anm. 55), Tabellen 49, 50 u. 57, S. 490 f. u. 498. 
Anpassung. Erwartungsgemäß konnte es im Lichte der aus verschiedenen Wirkungsbereichen gewonnenen Belege keine eindeutige Zuordnung zu einem der beiden Pole geben. Die Herausforderungen, die die ostbrandenburgische Ritterschaft zu bewältigen hatte, lagen auf verschiedenen Ebenen.

1. Die wirtschaftlichen Grundlagen blieben für die neumärkischen Adelsfamilien im gesamten Untersuchungszeitraum eher bescheiden. Daran änderten auch kurze konjunkturelle Phasen, wie etwa um 1700, nichts grundlegend. Der Abstand zu den kurmärkischen Teillandschaften, das West-Ost-Gefälle blieb virulent. Andererseits hielten sich aber auch die internen Veränderungen in der Struktur der ostbrandenburgischen Adelsgesellschaft in Grenzen. Im Gegensatz zur Kurmark, die sich allmählich zur „Zentralprovinz" des sich formierenden brandenburgisch-preußischen Staates entwickelte, blieb die neumärkische Ritterschaft von solchen tiefgreifenden Wandlungen der Besitzverhältnisse wie im Umfeld der Ausprägung der Berlin-Potsdamer Residenzgesellschaft verschont.

2. Zugleich verfügten die neumärkischen Oberstände über geringere Partizipationsmöglichkeiten, um im politischen Zentrum der Monarchie für eigene Interessen wirksam zu werden. Das personelle Netzwerk zwischen einer Amtsträgerschaft, die gute Kontakte zur Führungsgruppe am Hof unterhalten konnte, und der ostbrandenburgischen Adelsgesellschaft erschien nicht so eng geflochten wie in der Kurmark. Die neumärkischen Adelsfamilien hatten es nach der 1571 beendeten Eigenstaatlichkeit der Neumark nicht vermocht, den mit dem Küstriner Hof wegfallenden politischen Bezugspunkt durch eine stärkere Hinwendung zur Berliner Residenz zu kompensieren.

3. Die im Vergleich zur Kurmark zu beobachtende gewisse Eigenständigkeit der Neumark stellte jedoch auch für die Landesherrschaft ein Problem dar. Dieser Landesteil entzog sich länger und erfolgreicher als die residenznahen Landschaften dem durch Zentralisierungs- und Bürokratisierungstendenzen geprägten Staatsbildungsprozess. Die Kreiskommissare und Landräte verstanden sich ebenso wie die in der Küstriner Regierung wirkenden Amtsträger eher als Vertreter ihrer Mitstände als in der Rolle als Sachwalter der landesherrlichen Interessen. Tiefgreifendere innerstrukturelle Veränderungen im neumärkischen Adel erfolgten vor allem durch die Einbindung in das Stehende Heer.

4. Alles in allem kann die Neumark jenem Typ einer Adelslandschaft zugeordnet werden, der zwar durch Residenzferne mit all den daraus erwachsenden Implikationen charakterisiert war, dennoch aber über ein nicht gering zu veranschlagendes Anpassungspotential verfügte, um auf Veränderungen angemessen reagieren zu können. Angesichts der Erfahrungen mit solchen Herrscherpersönlichkeiten wie Markgraf Hans von Küstrin oder König Friedrich Wilhelm I. waren - mitunter auch subtile - Formen von Anpassung und Resistenz gefragt. Man wird überhaupt im Lichte der Adelspolitik dieser Herrscher erneut auf die Überlegung hingeführt, dass das Verhältnis zwischen Fürstenmacht und Ständetum nicht als Nullsummenspiel zu interpretieren ist. Die in den Quellen aufscheinende Realität entzieht sich allzu polarisierenden Bewertungen. 


\title{
Handel und Gewerbe der Neumark in friderizianischer Zeit Entwicklungsprozesse, Standorte, soziale Träger
}

\author{
Von Rolf Straubel
}

\section{Fabrikation und Handel}

Die Neumark gehörte in der zweiten Hälfte des 18. Jahrhunderts zu den Provinzen, die der Monarchie zu ihrer meist positiven Handelsbilanz verhalfen. Sie stellte damit gleichsam das Gegenstück zur benachbarten Kurmark und damit zu dem Landesteil dar, der im Verkehr mit dem Ausland in der Regel ein starkes Defizit hatte' ${ }^{1}$. Die neumärkischen Verhältnisse glichen in mehrfacher Hinsicht denen in Schlesien und hoben sich andererseits stark von den Gegebenheiten in Pommern ab. Wie in Schlesien spielte in der Neumark das Transitgeschäft nur eine untergeordnete Rolle, dafür gingen hier wie da die in der Provinz erzeugten Gewerbezeugnisse zu mehr als 80 Prozent ins Ausland, in der Kurmark und in Magdeburg pendelte der Anteil dagegen um die Marke von 50 Prozent. Und im Unterschied zu Pommern wiederum gehörte die Neumark zu den Regionen, die maßgeblich zum Aufstieg Preußens in den Kreis der großen europäischen Gewerbe- bzw. Wirtschaftsstaaten beitrugen ${ }^{2}$. Vor diesem Hintergrund erscheint es durchaus sinnvoll, sich etwas näher mit dem Handel und dem neumärkischen Exportgewerbe zu beschäftigen.

1 Siehe zur Kurmark die Angaben bei Friedrich Wilhelm Bratring: Statístisch-topographische Beschreibung der gesammten Mark Brandenburg. 3 Bde. Berlin 1804-1809, hier in Bd. 1, S. 158-180 Angaben über den Handel der Kurmark.

2 Zuletzt hierzu Rolf Straubel: Die Handelsstädte Königsberg und Memel in friderizianischer Zeit. Ein Beitrag zur Geschichte des ost- und gesamtpreußischen „Commerciums“ sowie seiner sozialen Träger (1763-1805/15). Berlin 2003 (= Bibliothek der Brandenburgischen u. Preuß. Geschichte, 10). Aufschlüsse liefen u. a. die Tabellen über Handel d. Provinzen im Anhang, S. 677 f. 
Das neumärkische Ein- und Ausfuhrgeschäft ${ }^{3}$

\begin{tabular}{|l|c|c|c|c|c|c|c|}
\hline \multirow{2}{*}{ Etatsjahr } & \multicolumn{2}{|c|}{ Export } & \multicolumn{2}{c|}{ Import } & \multicolumn{2}{c|}{ Transit } & \multirow{2}{*}{ Gesamt } \\
\cline { 2 - 8 } & Ausland & Inland & Ausland & Inland & f. eigene & $\begin{array}{c}\text { f. fremde } \\
\text { Rechng. }\end{array}$ & \\
\hline 1752 & \multicolumn{2}{|c|}{ zs. 1024880} & \multicolumn{2}{|c|}{ zs. 564429} & \multicolumn{2}{|c|}{ o.A. } & 1589309 \\
\hline 1753 & \multicolumn{2}{|c|}{ Zs. 1208013} & \multicolumn{2}{|c|}{ zS. 494377} & \multicolumn{2}{c|}{ o.A. } & 1702390 \\
\hline $1764 / 65$ & 392404 & $(960916)$ & 233500 & $(253542)$ & 113129 & $(1327588)$ & \\
\hline $1782 / 83$ & 788762 & 585978 & 225856 & 893359 & $253021 *$ & $602189 *$ & 3349165 \\
\hline $1784 / 85$ & 340847 & 678466 & 220328 & 401052 & 533249 & 86238 & 2173942 \\
\hline $1785 / 86$ & 591684 & 1266110 & 436439 & 606052 & 176521 & 103825 & 3180631 \\
\hline $1787 / 88$ & 516802 & 1462718 & 291403 & 605399 & 126390 & 235606 & 3238318 \\
\hline $1788 / 89$ & 586968 & 1304841 & 469440 & 702010 & 149672 & 253052 & 3465983 \\
\hline $1800 / 01$ & 586968 & o.A. & 391221 & 834321 & 252808 & 229580 & 2654768 \\
\hline $1803 / 04$ & 923903 & o.A. & 441604 & 1117866 & o.A. & 263317 & 2746690 \\
\hline
\end{tabular}

Ungeachtet aller statistisch bedingten Mängel lassen sich aus obiger Tabelle sowie anderen Erhebungen zumindest einige Trends feststellen. Zum einen nahm der Handel der Neumark mit anderen Provinzen der Monarchie wie mit dem Ausland in der zweiten Hälfte des 18. Jahrhunderts mehr oder weniger kontinuierlich zu, Einbrüche mußten lediglich infolge von Kriegswirren oder territorialen Veränderungen verzeichnet werden. Zweitens erwirtschaftete die Provinz in der Regel einen Handelsüberschuß, und zwar sowohl im Verkehr mit der Fremde wie mit den anderen Landesteilen. Diese Entwicklung scheint für das Einfuhrgeschäft mit der Zerschlagung des polnischen Staates in den frühen neunziger Jahren offenbar ein Ende gefunden zu haben, weil jetzt Produkte aus dem Nachbarland als preußische deklariert wurden und die Balance zuungunsten der Neumark veränderten. Andererseits blieb aufgrund des starken Wollwarenexportes die Bilanz mit dem Ausland nach wie vor positiv.

Hervorzuheben ist sodann, daß nach Ausweis der überlieferten Ein- und Ausfuhrlisten aus den letzten drei Jahrzehnten des 18. Jahrhunderts die Neumark trotz ihres starkes Wollgewerbes in kaum geringerem Maße ein wichtiger Produzent bzw. Lieferant von

3 Alle Angaben in Talern. Die Daten beruhen auf: Geheimes Staatsarchiv Preußischer Kulturbesitz (im folgenden GStA), I. HA, Rep. 96, Tit. 421 F (für 1752 und 1753), Brandenburg-Preußisches Hausarchiv (weiter als BPH), Rep. 47, Tit. E III, Nr. 40 (für 1764/65, diese Erhebungen basieren jedoch auf anderen Kriterien, daher können nur die Werte für den Handel mit dem Ausland für den Vergleich benutzt werden), BPH, Rep. 47, Tit. E III, Nr. 54 (für 1782/83, 1784/85); I, Rep. 96, Tit. 421 Y (für 1785/86), I, Rep. 96, Tit. 224 K, vol. II (f. 1787/88), vol. III (für 1788/89). Für das Jahr 1782/83 beziehen sich die Transitangaben * auf die Durchfuhr in andere preußische Provinzen und ins Ausland (dies die zweite Rubrik). 1803/04 nach GStA, II. HA, Akzisedep., A, Tit. XLIII, Sect. 6, Nr. 2, vol. II. 1800/01 nach Bratring: Beschreibung (wie Anm. 1), T. 2, S. 68 f., hier auf Seite 66 auch der wichtige Hinweis auf die Unvollständigkeit der Statistiken für die Jahrhundertwende, hier für 1800/01 und 1803/04, weil bei den Akziseämtern keine Erhebungen über den Handel, über den Export in anderen Provinzen der Monarchie geführt wurden! - Die benutzten Akten sind nur z.T. paginiert, bei den Statistiken wird auf die Nennung der Seitenzahl verzichtet. Bei den Beständen wird bei der ersten Erwähnung auf die Hauptabteilung (HA.) verwiesen, dann nur noch die römische Zahle genannt. 
Getreide, Vieh und Holz für die Residenzstädte Berlin und Potsdam gewesen ist, ein Geschäft, für das ihre grenznahe Lage zu Polen von großem Nutzen war. Angeblich sollen die Neumärker nämlich auch für die eigene Konsumtion billiges Getreide gekauft, dafür einen Teil des in der Region erzeugten Korns westlich der Oder verkauft haben. Zudem stammte ein Teil des exportieren Schlachtviehs aus dem Russischen, von wo es als Jungvieh bezogen und in der Provinz nur gemästet worden war ${ }^{4}$. Dennoch sind die überlieferten Daten für diese Sparten bemerkenswert.

So wurden aus der Neumark im Jahr 1787/88 Getreide, Vieh, Holz und Tabak im Wert von rund 675000 Talern in andere preußische Provinzen ausgeführt, vornehmlich aber nach Frankfurt/O. sowie in die beiden Residenzstädte ${ }^{5}$. Gemessen am Gesamtvolumen dieser Sparte des Inlandsgeschäftes hätte sein Anteil bei immerhin 46 Prozent gelegen. Die Ausfuhr von Wollwaren und Leinwand, die im Unterschied zu jenen Lebensmitteln aber hauptsächlich in die Fremde gingen, soll damals einen Betrag von etwa 630000 Talern erreicht haben, lag also hinter jener Sparte zurück. Unter Einbeziehung von Wolle hätte jenes Geschäft sogar um fast 200000 Taler über diesem gelegen. Ähnliche Proportionen hatte es im Etatsjahr 1785/86 gegeben. Damals erreichte die Ausfuhr von Getreide und Vieh allein einen Betrag von 515000 Talern, für Textilfabrikate wurde dagegen eine Summe von rund 600000 genannt. War jenes Geschäft in hohem Maße von solchen Faktoren wie Witterung und Ernte abhängig, so unterlag der Wollwarenexport den ständigen Nachfrageschwankungen auf den Außenmärkten. Dafür mag die Statistik für 1782/83 stehen. In jenem Jahr überschritt die Ausfuhr neumärkischer Wollstoffe aufgrund des anhaltenden Konfliktes der Seemächte knapp die Marke von einer Million Talern, von denen Artikel für mehr als 750/m Talern tatsächlich in die Fremde gingen, weitere Tuche für ca. 240/m verblieben dagegen in der Monarchie. Umgekehrt verließen die Provinz Getreide für gerade 18000 und Vieh für 43000 Taler, so daß diese Sparte eben einen Anteil von sieben Prozent an jener erreichte ${ }^{6}$. Ähnlich waren die Gegebenheiten dann 1803/04. Einer Ausfuhr von Getreide von kaum 6000 und von Holz für 45000 Talern stand allein eine solche von Wolltuchen für knapp 770000 Talern gegenüber ${ }^{7}$. Eher normal dürfte offenbar aber ein annäherndes Gleichgewicht zwischen beiden Branchen gewesen sein, unnormal die Dominanz der einen oder der anderen.

Generell ist die wirtschaftliche Potenz dieser territorial kleinen Provinz erstaunlich. So machten bereits in den achtziger Jahren Beamte des V. Departements des Generaldirektoriums darauf aufmerksam, daß das ungleich größere Pommern nicht nur beim Export von Fabrikaten hinter der Neumark zurückblieb, Grund genug, um wirtschaftliche Förderprogramme für den Landesteil an der Ostsee aufzulegen, war daran gedacht, Pommern zu einem ähnlich starken Exportgewerbe wie der Neumark zu verhelfen. Anteil an der Blüte der Neumark hatte die Nähe zu Polen, bezog es von hier doch billiges Getreide, Vieh und nicht zuletzt Wolle. Besonders für Züllichau ist das dokumentiert. Damit wies

4 Siehe dazu Bratring: Beschreibung (wie Anm. 1), Bd. 3, S. 66 f.

5 GStA, I, Rep. 96, Tit. 224 K, vol. II.

6 GStA, BPH, Rep. 47, Tit. E III, Nr. 54, fol. 32 f.

7 GStA, II, Akzisedep., A, Tit. XLIII, Sect. 6, Nr. 2, vol. II, fol. 306 f. 
die Neumark ähnlich günstige Standortfaktoren wie Schlesien auf. Beispielhaft verwiesen sei in diesem Zusammenhang auf die Ordre vom 4.12.1766, mit der die grenznahen neumärkischen Städte Züllichau, Zielenzig, Friedeberg, Neuwedell und Callies die Erlaubnis bekamen, polnisches Korn für ihre eigene Konsumtion, d.h. hauptsächlich für ihre Wollfabrikanten, einzuführen, sofern die Erzeugung in der Region ungenügend war ${ }^{8}$. Am gleichen Tage wurden aber auch die zuständigen Akziseämter angewiesen, Maßnahmen gegen einen Mißbrauch dieser Erlaubnis zu treffen. Polen diente somit nicht nur als Bezugsquelle für billiges Magazingetreide, sondern es bildete durch seine Lieferungen von Korn, Schlachtvieh, Wolle, Rohleder und anderen Materialien gleichsam eine wichtige Voraussetzung dafür, die Konkurrenzfähigkeit der schlesischen, kur- und neumärkischen Textilfabrikanten auf den Außenmärkten zu behaupten. Andererseits war der benachbarte Staat auch ein wichtiger Absatzmarkt für preußische Gewerbeerzeugnisse, ein Grund dafür, warum sich ostpreußische Kaufleute in den neunziger Jahren gegen seine Zerschlagung und insbesondere gegen die Annexion polnischer Gebiete durch das Zarenreich aussprachen. Infolgedessen lehnte Friedrich II. im Januar 1774 einen Antrag des Küstriner Kammerpräsidenten C.C.H. von Logau ab, den neumärkischen Wollfabrikanten eine Exportbonifikation zu gewähren ${ }^{9}$. Nach Ansicht des Königs würden die Tuchmacher bereits den Vorteil der benachbarten Messen in Frankfurt genießen und hätten in Polen einen gesicherten vorzüglichen Absatz. Drei Monate später kritisierte der Monarch einen Bericht der neumärkischen Kammer, die die hohen Wollpreise mit einem Viehsterben in der Provinz begründet hatte, und meinte, die billigen Wollimporte aus Polen würden diese Verluste mehr als kompensieren. Im Interesse eines ungestörten Verkehrs mit dem Nachbarstaat lehnte er eben damals auch ein Transitverbot für polnische Wolle ab.

Gemessen an der absoluten Webstuhlzahl und am Produktionsausstoß stand das wollverarbeitende Gewerbe der Neumark zwar merklich hinter dem schlesischen zurück, werden jedoch Bevölkerung und Größe beider Provinzen berücksichtigt, stellt sich das Verhältnis etwas anders dar. So war um 1800 die Zahl der schlesischen Tuchmacher etwa doppelt so hoch wie die der neumärkischen, bei der Bevölkerung übertraf Schlesien den Nachbarn indes um das Achtfache. Wie bereits K. Kaufhold festgestellt hat, konzentrierte sich die Tuchherstellung in einer Handvoll neumärkischer Klein- und Mittelstädte, von denen die meisten weniger als 5000 Einwohner hatten ${ }^{10}$. Solche kleinstädtischen Gewerbezentren waren unter anderem Callies, Drossen, Cottbus, Neudamm, Reppen und Zielenzig. Für die Jahre 1756, 1761 und 1797 überlieferte Erhebungen zeigen, daß das Potential des neumärkischen Wollgewerbes im letzten Drittel des 18. Jahrhunderts weiter wuchs, wobei der für $1761 \mathrm{zu}$ verzeichnende Einbruch dem Siebenjährigen Krieg geschuldet war.

8 GStA, I, Rep. 96 B, Nr. 69, S. 334 f.

9 GStA, I, Rep. 96 B, Nr. 73, S. 35.

10 Karl Heinrich Kaufhold: Das Gewerbe in Preußen um 1800. Göttingen 1978, S. 120 f., besonders S. 125 (= Göttinger Beiträge zur Wirtschafts- und Sozialgeschichte, 2). Danach entfielen in der Neumark knapp 40\% des Wollgewerbes auf Städte mit weniger als 5000 Einwohnern, in der Kurmark waren es dagegen gerade $17 \%$. 
Entwicklungstendenzen im neumärkischen Wollgewerbe ${ }^{11}$

\begin{tabular}{|l|r|r|r|}
\hline Stichjahr & 1756 & 1761 & 1797 \\
\hline städtische Einwohnerzahl & 63871 & 46947 & 75732 \\
\hline davon Tuchmachermeister & 1923 & 1696 & 2323 \\
\hline Anstieg, Rückgang, in\% & 100,0 & 88,2 & 120,8 \\
\hline Zahl Tuchmachergesellen & 289 & 176 & 880 \\
\hline Anstieg, Rückgang, in\% & 100,0 & 60,9 & 304,5 \\
\hline Tuchproduktion, in Stück & 45696 & 36842 & 70925 \\
\hline Anstieg, Rückgang, in\% & 100,0 & 80,6 & 155,2 \\
\hline Zeugproduktion, in Stück & 1725 & 627 & 6753 \\
\hline Anstieg, Rückgang, in\% & 100,0 & 36,4 & 391,5 \\
\hline
\end{tabular}

Während sich zwischen 1756 und 1797 die Zahl der zünftigen Tuchmacher gerade um ein Fünftel erhöhte, stieg im gleichen Zeitraum die Zahl der Gesellen um nahezu das Dreifache. Dieser Befund kann unzweifelhaft als Indiz für eine Zunahme der Verlagsverhältnisse gewertet werden. In einem Bericht der Küstriner Kammer von 1784 hieß es denn auch, christliche und jüdische Verleger drückten die Tuchmacher in Hinterstädten wie Callies und Neuwedell und seien mitverantwortlich für deren Verarmung ${ }^{12}$. Zwar mußte auch zur Jahrhundertwende die Mehrzahl der Meister noch ohne »Hilfskräfte« auskommen, andererseits entstanden v.a. in den Städten mit einer besonders hohen Webstuhldichte zunehmend größere Betriebe, in denen Gesellen wie verarmte »Fabricanten « arbeiteten. Getragen wurde dieser Konzentrationsprozeß sowohl von Meister-Verlegern als auch von Kaufleuten. Indikatoren eines anhaltenden Wachstums waren ferner die $\mathrm{Zu}-$ nahme der verarbeiteten Wollmenge wie der Produktionsausstoß. So erhöhte sich zwischen 1740 und 1801 der Wollverbrauch um mehr als 70 Prozent (von rund 105000 auf 174000 kleine Stein) ${ }^{13}$. Wurden 1756 gerade 46000 Stück Tuche hergestellt, waren es 179771 000, was ein Wachstum um 55 Prozent bedeutete. Dagegen erhöhte sich die städtische Einwohnerzahl in dem genannten Zeitraum nur um etwa 12000 Köpfe (von 63871 auf 75 732), was auf eine gewerbliche Verdichtung verweist.

\section{Handels- und Gewerbezentren der Provinz}

In der Neumark waren vor allem diejenigen Städte in den überregionalen Warenverkehr eingebunden, in denen Tuche und Leinwand für den Export hergestellt wurden. Dazu ge-

11 Die Angaben beruhen auf: GStA, II. HA, Neumark, Materien, Historische Tabellen, Nr. 12, vol. XXIII. 1781 gab es 1711 Tuchmacherstühle (gesamtes Wollgewerbe 1847 Stühle), fertigten 6067 »Fabricanten« Wollwaren für 672270 Taler an, von denen Artikel für 272860 ins Ausland gingen: II. HA, Fabr.dep., Tit. XCV, Nr. 5, fol. 13.

12 GStA, II, Fabr.dep., Tit. XCV, Nr. 5, fol. 47 f.

13 Diese Zahlen nach Bratring: Beschreibung (wie Anm. 1), Bd. 3, S. 58. 
hörten Landsberg/Warthe, Callies, Reppen, Driesen, Cottbus, Zielenzig und Züllichau ${ }^{14}$. Sofern diese Orte an wichtigen Verkehrsrouten lagen - das traf für Landsberg, Reppen und Driesen zu -, profitierten sie dazu noch vom Durchgangsverkehr von und nach Polen, Schlesien und Ostpreußen. In einigen Fällen mag auch der Absatz von Material- und »Fabrique«waren auf das platte Land sowie der Handel mit Wolle oder Getreide von Bedeutung gewesen sein. Für die meisten Orte traf jedoch die vom Akziserat Chemnitz auf seiner neumärkischen Departementsvisite 1798 gemachte Bemerkung zu: Der Tuchhandel ist hier in Crossen so wie in den mehresten Städten meines Departements weit bedeutender, als der Material Handel ${ }^{15}$.

Und dieser Tuchhandel wiederum lag wie etwa in Peitz in den Händen einiger weniger Kaufleute, bei denen es sich z. T. um Aufsteiger der ersten oder zweiten Generation aus dem Handwerk handelte. Auch die Kehrseite des Prozesses sah in den meisten Städten gleich aus: Die Mehrzahl der Tuchmacher war verarmt und wurde von den Händlern verlegt. Andererseits gebührte den Kaufleuten das Verdienst, durch den Besuch von in- und ausländischen Messen oder Reisen in die entsprechenden Länder Geschäftsbeziehungen angeknüpft und neue Absatzmärkte erschlossen zu haben. Dazu zählte der Zielenziger »Commissionär« Graeber, der 1798 Lieferungen nach Rußland hatte. Landsberger »Commercianten « setzten in den siebziger Jahren Tuche aus den neumärkischen Hinterstädten über Konitz nach Polen und über Königsberg nach Litauen ab.

Daß dabei die Verhältnisse von Ort zu Ort mitunter sehr verschieden waren, zeigt Crossen. Im Unterschied zu Peitz und Züllichau arbeiteten die Tuchmacher hier vornehmlich für eigene Rechnung, was ihre Exportchancen aber nicht beeinträchtigte. Denn von ihren Fabrikaten ging ungefähr ein Drittel nach Sachsen, Mecklenburg und Schweden ${ }^{16}$. Sie gehörten offenbar wie ihre Zunftgenossen aus Strausberg, Beeskow, Storkow und Brandenburg - die Gewerke aus diesen Städten erscheinen in den Frankfurter Meßregistern - zu denjenigen, die Mitmeister auswählten und auf Messen und Jahrmärkte schickten, um dort für den Warenvertrieb zu sorgen. Diese Delegierung einzelner »Fabricanten« erscheint als ein wichtiges Instrument beim Aufbau von Verlagsbeziehungen. Da die Zünfte zu unterschiedlichen Zeiten darangingen, sich Außenmärkte zu erschließen, war dieser Prozeß hier bereits weiter fortgeschritten als dort.

Auf den Zusammenhang von Export und gewerblicher Prosperität machte der zuständige Beamte Ende 1799 bei seiner Schilderung der Verhältnisse in Driesen aufmerksam, wobei er allerdings auch die Risiken nicht verschwieg, die mit einer starken Ausfuhr verbunden waren. In einem Bericht vom Vorjahr war die Rede davon gewesen, daß die $» F a b-$ ricanten« aus Cottbus, Peitz, Reppen, Drossen und Zielenzig auf den letzten beiden Messen in Leipzig und Frankfurt/O. kaum Käufer für ihre Tuche gefunden hätten, weshalb sie Preisnachlässe gewähren und die Waren kreditieren mußten. Infolgedessen fehlte es den ärmeren Tuchmachern jetzt an Geld zur Bestreitung des Lebensunterhaltes wie zur

14 Dies läßt sich u.a. aus den Angaben erschließen in: GStA, II, Neumark, Materien, Historische Tabellen, Nr. 12, vol. XXIII.

15 GStA, II, Fabr.dep., Tit. XCV, Nr. 7, fol. 4 RS.

16 Ebda., fol. $4 \mathrm{f}$. 
Fortsetzung ihres Metiers. Da die Meister in Driesen keine Messen besuchten und sich auf den Binnenmarkt beschränkten, seien sie von jenem Einbruch verschont geblieben. Andererseits setze ihre einseitige Marktorientierung der Ausweitung des Gewerbes enge Grenzen $^{17}$.

Aus den Akziseregistern, den Manufakturtabellen, zeitgenössischen Beschreibungen und den Kontributionsverzeichnissen läßt sich ähnlich wie für Pommern, Schlesien, die Kurmark und Magdeburg der Platz bestimmen, den die einzelne Stadt im Wirtschaftsgefüge der Provinz einnahm; außerdem sind Rückschlüsse auf die Stellung der Kaufleute möglich. Bei der Ende 1813 ausgeschriebenen Anleihe entfiel auf die Neumark ein Betrag von 130000 Talern, von denen 101200 tatsächlich aufgebracht wurden. Insgesamt neun Städte zahlten eine Summe von 50250 Talern, der Rest lastete auf den Kreisen. Wie in Pommern und im Unterschied zu früheren Umlagen steuerte nur noch eine Handvoll Städte, unter denen es zudem bemerkenswerte Unterschiede hinsichtlich ihrer finanziellen Leistungsfähigkeit gab. Aus dem Kreis der Steuerzahler ragten wiederum die Kaufleute heraus, auf die bei der Ausschreibung der Anleihe auch in erster Linie orientiert worden war. In Abhängigkeit von der Wirtschaftsstruktur der Kommunen entfielen auf die Handeltreibenden zwischen einem Drittel und 90 Prozent der Steuerbeträge.

Wirtschafts- und Steuerkraft neumärkischer Städte ${ }^{18}$

\begin{tabular}{|l|c|c|c|c|c|c|}
\hline Ort & $\begin{array}{c}\text { Zahl d. } \\
\text { Zivilbev. }\end{array}$ & $\begin{array}{c}\text { Zahl d. } \\
\text { Tuchmacher }\end{array}$ & $\begin{array}{c}\text { Akziseauf- } \\
\text { kommen in T. }\end{array}$ & Rang & Kontribution & Rang \\
\hline Driesen & 2086 & 79 & 16711 & 4. & 4300 & 4. \\
\hline Crossen & 3192 & 55 & 38622 & 2. & 7800 & 3. \\
\hline Landsberg & 5599 & 26 & 39192 & 1. & 11750 & 2. \\
\hline Zielenzig & 2877 & 261 & 9426 & 5. & 2050 & 7. \\
\hline Züllichau & 5395 & 255 & 21723 & 3. & 14650 & 1. \\
\hline Soldin & 2714 & 55 & 8704 & 8. & 2850 & 6. \\
\hline Drossen & 2622 & 155 & 9049 & 7. & 2100 & 7. \\
\hline Königsberg & 3068 & 5 & 14687 & 5. & 3750 & 5. \\
\hline Reppen & 2170 & 212 & 4729 & - & & - \\
\hline Sommerfeld & 1662 & 91 & 5871 & - & & - \\
\hline
\end{tabular}

Bemerkenswert ist zunächst, daß von der Veranlagung bei weitem nicht alle neumärkischen Textilgewerbezentren erfaßt wurden. So fanden etwa Reppen, Falkenburg und Sommerfeld keine Berücksichtigung. Andere wie Neudamm wurden zwar veranlagt, hier zahlte aber der Kaufmann Jahn den gesamten Beitrag des Ortes (1/m T.). Trotz ähnlich

17 Ebda., fol. 8 f., fol. 15.

18 Die Akzisebeträge nach Leopold Krug: Betrachtungen über den Nationalreichtum des preußischen Staates und über den Wohlstand seiner Bewohner. 2 Theile. Berlin 1805, T. 2, S. 91-116; die übrigen Angaben nach GStA, II, Neumark, Materien, Historische Tabellen, Nr. 12, vol. XXIII und GStA, I. HA, Rep. 151 I A, Nr. 2 663. Da der Rang, den die einzelnen Städte bei Akzise- und Steueraufkommen einnahmen, nur leicht schwankte, ist zu vermuten, daß wie bei diversen Kontributionsausschreibungen in der Kurmark Bevölkerungszahl und Akziseertrag wichtige Erhebungskriterien waren. 
hoher Webstuhldichte müssen die Möglichkeiten zur Vermögensbildung folglich unterschiedlich gewesen sein. D.h. weder gelang Zunftmitgliedern in jedem kleinstädtischen Textilgewerbezentrum der Aufstieg zum Meister-Verleger, noch hatte jeder Tuchhändler Anteil an dem lukrativen Exportgeschäft. In die gleiche Richtung zielen die Hinweise auf die wirtschaftlichen Verflechtungen zwischen den einzelnen Städten, beschränkten sich wohlhabende Kaufleute doch keineswegs auf den Verlag der Tuchmacher im eigenen Ort. Angemerkt sei ferner, daß es ähnlich wie in Pommern z. T. beachtliche Unterschiede zwischen Bevölkerungszahl, Akziseaufkommen und Steuerveranlagung gab, was auf Unterschiede in der Wirtschaftsstruktur schließen läßt.

Wie aus den in obiger Tabelle aufgeführten Zahlen für Zielenzig und Soldin hervorgeht, kann aus einer hohen Webstuhldichte weder unmittelbar auf das Akzise- noch auf das direkte Steueraufkommen geschlossen werden. Das zeigen insbesondere die Angaben für Reppen und Sommerfeld. Obwohl in beiden Orten ungleich mehr Tuchmacher für den Export tätig waren, blieben sie doch merklich hinter dem Akziseertrag von Soldin zurück. Und Zielenzig brachte trotz einer viel höheren Webstuhldichte nur wenig mehr indirekte Steuern auf als Soldin. Da die Bevölkerung der beiden letztgenannten Städte etwa gleich groß war, müssen folglich andere Faktoren die Divergenz bewirkt haben. $\mathrm{Zu}$ denken ist dabei in erster Linie an die Herstellung von Bier und Branntwein sowie an den Ackerbau, der in vielen preußischen Kleinstädten noch eine große Bedeutung besaß. Auch die Tatsache, ob die Stadt eine Garnison beherbergte, ist ins Kalkül zu ziehen.

Weitere Angaben scheinen diese Vermutung zu bestätigen. So wurden 1797 in Soldin etwa doppelt soviele Braustellen und Branntweinblasen gezählt wie in Zielenzig. Dazu kam ein unterschiedlich großer Krugverlag. Stand dort ein Regiment in Quartier, so gab es hier kein Militär. Ferner beschäftigte sich die städtische Bevölkerung offenbar in unterschiedlicher Weise mit Ackerbau und Viehzucht. In Soldin gehörten der Kämmerei nämlich 236 Hufen Acker, in Zielenzig aber nur 60. Und schließlich machen auch die Angaben im Feuerversicherungskataster auf Divergenzen aufmerksam. Für den Tuchmacherort waren hier 86 825, für Soldin aber 254938 Taler eingetragen ${ }^{19}$.

Wie bei der Gegenüberstellung der Städte Burg und Neuruppin andernorts bereits gezeigt worden ist, war es jeweils ein ganzes Bündel von Faktoren, durch die die Lage der Bevölkerung beeinflußt wurde. Dazu gehörten die Betriebsformen im exportorientierten Gewerbe, die Marktorientierung, die verkehrsgeographische Lage und die handwerklichkommerziellen Traditionen. Außerdem konnte am Beispiel von Burg - hier gehörten der Kämmerei ebenfalls ausgedehnte Acker- und Wiesenflächen - nachgewiesen werden, welch hohen Stellenwert die nebengewerbliche Tätigkeit hatte. Häufig ermöglichte gerade die geschickte Verbindung von Ackerbau und Tuchherstellung, von Bierproduktion und Viehzucht die Anhäufung größerer Vermögen. Während in Neuruppin zur Jahrhundertwende im exportorientierten Gewerbe offenbar noch der selbständige Meisterbetrieb

19 GStA, II, Neumark, Materien, Historische Tabellen, Nr. 12, vol. XXIII. Bei Bratring: Beschreibung (wie Anm. 1), Bd. 3, S. 130 f. (Soldin) und S. 269 (Zielenzig) finden sich für die Bier- und Branntweinherstellung aber etwas andere Angaben. Danach war dieser Erwerbszweig in Zielenzig größer als in Soldin. 
vorherrschte, die »Fabricanten« infolge der Lieferungen für das Berliner Lagerhaus keine Veranlassung sahen, Meß-Plätze zu besuchen, wurden in Burg andere Wege beschritten. Hier entstanden damals etliche kleingewerbliche Verlage, reisten die Meister-Verleger nach Frankfurt/Oder, Braunschweig und Leipzig, womit sie eine wichtige Voraussetzung für die Prosperität des örtlichen Textilgewerbes schufen ${ }^{20}$.

In Driesen wurden neun Personen veranlagt, wobei die zu zahlenden Beträge zwischen 100 und 1500 Talern schwankten. Kaum zufällig entfiel auf die Firma Treppmachers Erben die größte Summe (1 500 T.). Diese war 1765 etabliert worden und soll in den folgenden Jahrzehnten bedeutende Geschäfte mit Wein und Materialwaren gemacht haben. Vorteilhaft für die Großhandlung wirkte sich die Lage der Stadt an der Netze sowie an der früheren Grenze nach Polen aus ${ }^{21}$. Dazu kamen noch zwei weitere Umstände. Driesen gehörte neben Memel, Tilsit, Königsberg, Elbing, Bromberg, Stettin und Breslau zu denjenigen privilegierten preußischen Städten, die aufgrund des Zolltarifs vom 24.5.1775 allein zum Handel mit Polen berechtigt waren ${ }^{22}$. Günstig zu Buche schlug ferner, daß seit 1772 die Poststraße von Berlin nach Königsberg/Pr. ebenso über Driesen führte wie jene von Posen nach Stettin. Und schließlich erhöhte sich durch den Bau des Bromberger Kanals der Schiffsverkehr auf der Netze, damit aber auch der Warenaustausch zwischen Stettin und Zentralpolen erheblich. Folglich schätzte die Küstriner Kammer im Frühjahr 1784 die Lage in Driesen und Friedeberg im Unterschied zu anderen Hinterstädten wie Dramburg, Falkenberg und Schievelbein als gut ein, geschuldet dem reziproken Verkehr und der recht starken Bevölkerung ${ }^{23}$.

\section{Namhafte Kaufleute und Fabrikanten}

Der aus Posen stammende Treppmacher, der angeblich von Finanzrat F.B. von Brenckenhoff 1763 zur Übersiedlung in die Neumark veranlaßt worden war, errichtete mit einem Betriebskapital von 100000 Talern die Großhandlung in Driesen ${ }^{24}$. Sein Etablissement soll ihm 20000 Taler gekostet haben. Mitentscheidend für seinen wirtschaftlichen Er-

20 Vgl. Rolf Straubel: Kaufleute und Manufakturunternehmer. Eine empirische Untersuchung über die sozialen Träger von Handel und Großgewerbe in den mittleren preußischen Provinzen (1763 bis 1815). Stuttgart 1995, S. 315-317 (= Beiheft 122 d. VSWG). - Brigitte Meier: Neuruppin 1700 bis 1830. Sozialgeschichte einer Kurmärkischen Handwerker- und Garnisonstadt. Berlin 1993, hat S. 74 f. auf das Wachstum des Textilgewerbes hingewiesen, aus Mangel an entsprechenden Quellen konnte sie - abgesehen von allgemeinen Aussagen - die innergewerbliche Differenzierung jedoch nicht aufzeigen.

21 Bratring: Beschreibung (wie Anm. 1), Bd. 3, S. 175. Hier wird ausdrücklich diese Großhandlung aufgeführt und betont, daß Driesen von allen Städten der Hinterkreise aufgrund seiner günstigen Lage den meisten Verkehr habe.

22 So die Angaben bei Adolf Reckling: Geschichte der Stadt Driesen, in: Archiv der Brandenburgia 4 (1898), S. 37; dazu auch GStA, I, Rep. 96 B, Nr. 146.

23 GStA, II, Fabr.dep., Tit. XCV, Nr. 5, fol. 55 f.

24 Bei diesem handelte es sich offenkundig um Johann Gottlob Treppmacher, 1799 als Geh. Kommerzienrat gestorben. 
folg waren seine polnischen Handelsverbindungen, die er bereits in Posen geknüpft hatte, eine mehrjährige Akzise- und Zollfreiheit sowie das ihm gewährte Privileg. Letzteres verschaffte ihm die gleichen Vergünstigungen, wie sie die Stettiner Kaufleute besaßen, was v.a. auf zollpolitische Vorteile bei der seewärtigen Ein- und Ausfuhr hinauslief und Treppmacher gegenüber seinen Konkurrenten aus den Provinzialstädten begünstigte. Darüber hinaus traf er 1769 ein Arrangement mit der Akzise und verzichtete auf den Detailhandel. Ein Ende 1771 von der Steuerverwaltung unternommener Versuch, seine Handlung hinsichtlich der Akzise auf den gleichen Fuß wie die kleinen Städte zu stellen, scheiterte zunächst. Der Großkaufmann handelte vorwiegend mit polnischem Holz und ließ im Gegenzug über Stettin seewärts fremde Waren kommen, bestimmt für den polnischen Markt, kleinere Partien gingen auch nach Schweden. Eingeführt wurden in erster Linie Kolonialwaren, vornehmlich Wein. Pro Jahr soll er Waren für 60000 Taler allein aus Stettin bezogen haben. Dazu kamen noch heimische Artikel. So hatte sich Treppmacher jenes vorteilhafte Privileg mit dem Versprechen erkauft, jährlich für 6000 Taler inländische Manufakturwaren in Polen abzusetzen. Daß seine Vorrechte sehr einträglich gewesen sein müssen, erhellt u.a. aus der Eingabe des Kaufmanns Jantzen, der sich 1767 in Driesen etabliert hatte und Mitte 1772 um ein gleiches Privileg wie sein Konkurrent Treppmacher bat. Auch er wollte die Prärogativen der Stettiner Kaufleute für den Handel über See genießen, wurde zunächst jedoch am 20.6. d.J. abgewiesen ${ }^{25}$. Jantzen soll mit seinem Vermögen aus Hamburg in die Neumark gekommen sein, angeblich ebenfalls schon 1763, und erwirkte später doch noch ein ähnliches Privileg wie Treppmacher ${ }^{26}$.

Anfang 1771 machte Treppmacher in einem Immediatgesuch darauf aufmerksam, 200000 Taler für polnisches Holz verauslagt zu haben ${ }^{27}$. Stimmt diese Angabe, dann hätte zu diesem Zeitpunkt ein großer Teil des Stettiner Holzgeschäftes in seiner Hand gelegen. Allerdings ist die Zahl mit Vorsicht zu betrachten, da seine Supplik darauf abzielte, von dem neuen Impost für Holz in Höhe von 50 Prozent, wodurch diese Sparte den Kaufleuten entzogen und der kürzlich errichteten Nutzholzhandlung zugespielt werden sollte, befreit zu werden ${ }^{28}$. Sein Vorstoß war anscheinend nicht ohne Erfolg, blieb diese Sparte doch eine tragende Säule der Firma. Wenn er von der neuen Abgabe teilweise oder ganz befreit wurde, einen eindeutigen Beleg hierfür gibt es nicht, dann bedeutete dies ein $\mathrm{Zu}$ geständnis der Behörden an die Besonderheiten des Holzgeschäftes ${ }^{29}$. An anderer Stelle ist im Falle von Memel nämlich darauf hingewiesen worden, welch hoher Stellenwert einzelnen Personen, hier etwa Peter Pott d.Ä., Rudowski, Johann Simpson, aufgrund ih-

25 GStA, I, Rep. 96 B, Nr. 139, fol. 353. Möglichweise gehörte Jantzen zu denjenigen Polen, die von Treppmacher zur Übersiedlung nach Driesen bewogen worden sind. Laut einer anderen Notiz hatte sich Jantzen, aus Hamburg kommend, ebenfalls schon 1763 in der Neumark etabliert.

26 Dazu GStA, I, Rep. 96 B, Nr. 146, teilpaginiert, hier beider Supplik von Dez. 1775.

27 GStA, I, Rep. 96 B, Nr. 138, fol. 121, fol. 669.

28 Siehe dazu Bernhard Rosenmöller: Schulenburg-Kehnert unter Friedrich dem Großen. Berlin 1914, S. 229-230 (= Preußische Staatsmänner, 1).

29 Lt. Rosenmöller: Schulenburg (wie Anm. 28), S. 236, mußten Particuliers für polnisches Holz, das über die Oder und Stettin verschifft wurde, tatsächlich 50\% Zoll zahlen, auch im Handelsvertrag mit Polen von 1775 wurde diese Abgabe fixiert. 
rer geschäftlichen Beziehungen zu polnischen Lieferanten für den Flor des Holzhandels zukam. Aber auch derartige Großkaufleute mußten gelegentlich Niederlagen hinnehmen. Als etwa der Driesener Kommerzienrat im Herbst 1774 darum bat, für eine Sendung von 1000 Stück Eichen aus Westpreußen, die er von einem polnischen Grafen erhandelt hatte, von jenem 50prozentigen Zoll befreit zu werden, lehnte das Friedrich II. am 31.10. d.J. rundweg $a b^{30}$. Hatten für diesen doch die Geschäfte der Nutzholz-Administration Vorrang vor dem Gewinn eines Particuliers.

Im Dezember 1775 wurden Treppmacher und Jantzen im Kabinett vorstellig und beklagten sich über das Vorgehen der General-Akzise-Administration, die beiden ihre beneficien streitig machen wollte. Sie verwiesen auf den neuen Akzisetarif vom 24.5.1775, der der Stadt Driesen gleich Bromberg, Stettin und Breslau gewisse Erleichterungen für ihren Handel mit Polen gewährte. Dazu gehörte u.a. der Transit von fremdem Zucker, der hier im Unterschied zu anderen Grenzorten nur mit zwei Pfennig pro Pfund verzollt wurde. Jetzt verlangte die Zollverwaltung von den Driesener Großhändlern jedoch entgegen dem Neuen Tarif einen Groschen je Pfund und damit sechsmal so viel, wie die Breslauer Kaufleute zu erlegen hatten, wodurch sie ihre Konkurrenzfähigkeit verlieren würden $^{31}$. Bisherige Interventionen bei der Regie, ihnen ihre Prärogativen zu belassen, seien vergeblich gewesen. Offenbar erkannte Friedrich II. die Berechtigung ihrer Beschwerde an, forderte er doch eine Auskunft der Regie über die Klage. Dann hieß es am 21.12.1775 ausdrücklich, was den Leuten versprochen worden sei, muß auch gehalten werden. Welchen Umfang das Transitgeschäft mit Zucker nach Polen in den siebziger und achtziger Jahren gehabt hat, ist jüngst für Elbing dokumentiert worden ${ }^{32}$. Auch 1776 wurde der Kommerzienrat wieder mindestens dreimal im Kabinett vorstellig und kritisierte die Steuerverwaltung. In den frühen siebziger Jahren dürfte er damit etwa sechs bis zehn Immediatgesuche eingereicht haben. Dies zeugt zum einen von dem erheblichen Gewicht, den seine Handlung für Driesen und die Neumark besaß, eine Bedeutung, die Friedrich II. bei seinen Entscheidungen durchaus berücksichtigte. Andererseits lassen sich aus den Eingaben die veränderten Konstellationen nach der Inbesitznahme von Westpreußen wie die Bestrebungen der Regieverwaltung ablesen, im Interesse möglichst hoher Einnahmen scheinbar antiquierte Vorrechte abzubauen. Und dazu gehörten nicht zuletzt die Privilegien Treppmachers und Jantzens für ihren lukrativen Zwischenhandel mit Polen.

So versuchte die Regie Anfang 1776 den Driesener Großhandlungen außer dem neuen polnischen Zwischenzoll von zwei Prozent für Sendungen in das Nachbarland auch noch den vierprozentigen Zoll für den Oderkurs aufzuerlegen ${ }^{33}$. Da die Stettiner Kaufleute von letzterem befreit waren, sah Treppmacher in dem Versuch der Regie einen unzulässigen Eingriff in sein Privileg. Mit Nachdruck wies er deshalb in seiner Bittschrift darauf hin, durch die Erlegung jener vier Prozent mit den Stettinern nicht mehr konkurrieren zu können. Er bat Friedrich II. darum, in seinem Handlungsprivileg geschützt zu werden, im ge-

30 GStA, I, Rep. 96 B, Nr. 144, fol. 319.

31 GStA, I, Rep. 96 B, Nr. 146, teilpaginiert.

32 Straubel: Königsberg und Memel (wie Anm. 2), S. 243 f.

33 GStA, I, Rep. 96 B, Nr. 147, fol. 105. 
genteiligen Falle müßte er seinen beträchtlichen Handel in Driesen einstellen. Diese Bitte wiederholte er binnen kurzer Zeit noch zweimal, erreichte aber lediglich, daß der König ein Gutachten der Zollverwaltung anforderte, letztlich aber abgewiesen wurde und eine Entkräftung seines Privilegs hinnehmen mußte ${ }^{34}$. Auch eine koordinierte Aktion gemeinsam mit Jantzen im Juli 1777 bewirkte kein Einlenken von Regie und Kabinett. Beide Kaufleute hatten damals noch einmal darauf verwiesen, daß ihr polnischer Handel bei der Erlegung des vierprozentigen Oderzolls gegenüber der Stettiner Konkurrenz nicht bestehen könne ${ }^{35}$. Bliebe es bei der jetzigen Praxis, müßten ihr Ruin und wirtschaftliche Nachteile für die Stadt Driesen befürchtet werden. Friedrich II. schrieb beide Gesuche seinem Minister F.C. von Goerne zu, scheint damit aber nur auf Zeit gespielt zu haben. Am 17.5.1780 wurden die beiden Großhändler dann definitiv mit ihrem Gesuch um die zollpolitische Gleichstellung mit den Stettinern abgewiesen. Fortan mußten sie, nach dem sie der eigenen Angabe zufolge zwölf Jahre davon dispensiert waren, gleich den anderen neumärkischen Kaufleuten die sog. Provinzialzölle zahlen, und zwar ausdrücklich auch für ihre seewärts eingebrachten und für den Export nach Polen bestimmten Güter ${ }^{36}$. Friedrich II. beantwortete damit zwei Immediatsuppliken vom Frühjahr 1780 und beendete hiermit die nahezu fünfjährige Diskussion. Treppmacher wußte sich nach der Inbesitznahme von Westpreußen und den damit verbundenen Modifikationen in der Zollpolitik offenbar keinen anderen Rat, als Rückendeckung im Kabinett zu suchen. Seine wirtschaftliche Lage war derart prekär, daß er selbst die Gefahr auf sich nahm, durch das häufige Supplizieren den Unmut des Königs auf sich zu ziehen. Letztlich wurde er ein »Opfer" der Regie, die zwecks besserer Kontrolle der Warenströme den Zwischenhandel nach Polen v.a. über Stettin, Breslau und Elbing zum Nachteil von Driesen und Bromberg lenken wollte ${ }^{37}$. Für Driesen blieb der Flor des Kolonialwaren- und Holzgeschäftes mit Polen somit nicht mehr als eine Episode, geschuldet den günstigen Konstellationen, die sich in den ersten zwei Jahrzehnten nach dem Siebenjährigen Krieg ergeben hatten.

Um 1806 war die von Treppmacher gegründete Firma, an der zahlreiche Bürger der Stadt mit mehr oder weniger großen Einlagen beteiligt waren, noch im Stettiner Holzgeschäft tätig. Weitere für diese Handlung überlieferte Zahlen dokumentieren den hohen wirtschaftlichen Rang, den sie zeitweilig besessen hat. Danach soll der Firmengründer bei seinem Tod Aktiva von rund 500000 Talern hinterlassen haben, eine für eine

34 Der Kommerzienrat wurde im Juni 1777 noch einmal im Kabinett vorstellig und bat darum, ihm gleich den Stettiner Kaufleuten die vier Prozent Zoll auf dem Oderkurs zu erlassen. Ihm ging am 15.6. der Bescheid zu, er würde mit jenen $4 \%$ nicht mehr als andere Kaufleute geben, habe also keinen Grund zur Klage. Dieses Votum bedeutete faktisch den Verlust der bisherigen Gleichstellung mit den Stettinern und die Suspendierung des früher gewährten Privileges. Damit sah sich Treppmacher auf die gleiche Stufe gesetzt mit den Kaufleuten der pommerschen und neumärkischen Provinzialstädte: GStA, I, Rep. 96 B, Nr. 149, unpaginiert.

35 GStA, I, Rep. 96 B, Nr. 150, fol. 25 f.

36 GStA, I, Rep. 96 B, Nr. 154, fol. 392, 448.

37 GStA, I, Rep. 96 B, Nr. 147, fol. 361. Im Juni 1776 wies Treppmacher besonders auf eine Zurücksetzung von Driesen und Bromberg hin, wodurch die im Mai 1775 beiden Orten gewährten Vorrechte, insbesondere die Gleichbehandlung mit Stettin, Breslau etc., z.T. wieder zurückgenommen wurden. 
Provinzialstadt überaus respektable Summe. Infolge von Kontinentalsperre, Kontributionsleistungen und hohen Kriegsverlusten machte die Handlung 1817 Bankrott, wobei die Passiva jetzt auf 800000 Taler beziffert wurden ${ }^{38}$.

Ob die Firma auch mit Tuchen gehandelt hat, geht aus den Akten nicht hervor. Im gegenteiligen Falle dürfte sie eine der wenigen neumärkischen Handlungen gewesen sein, die nicht durch den Export von Wollwaren zu Ansehen und Wohlstand gekommen ist. Ihr Aufstieg hätte dann eine gewisse Analogie zu dem einiger Frankfurter Materialisten aufgewiesen ${ }^{39}$. Offenbar bestanden in Posen in der Mitte des 18. Jahrhunderts relativ gute Möglichkeiten zur Kapitalakkumulation. Denn neben Treppmacher wird in den neunziger Jahren in den Akten wiederholt der wohlhabende Bankier Kluge genannt, der neumärkische und südpreußische Tuchmacher in großem Stil verlegte und später ausgedehnte Ländereien erwarb. Sicher gab es auch unter den Driesener »Fabricanten« einige Meister-Verleger, nähere Informationen über sie liegen jedoch nicht vor. Einen größeren Betrag brachte 1813 in dem neumärkischen Ort noch die Firma Abraham Jacobs Söhne mit 1000 Talern auf, die 1816 bei der Bilanzierung der städtischen Kriegsschulden neben Treppmachers Erben die höchsten Forderungen anmeldete. Unter den erfaßten neun Personen waren sieben Kaufleute. Der Anteil der Stadt am neumärkischen Steueraufkommen betrug 4,3 Prozent ${ }^{40}$. Crossen hatte 7800 Taler oder 7,7 Prozent der Gesamtsumme aufzubringen. Veranlagt wurden 16 Personen, von denen etwa jede zweite aus den Reihen der Handeltreibenden kam. Die höchsten Beträge mit 1500 und zweimal 1000 Talern zahlten drei jüdische Kaufleute.

\section{Steuern als Indikator unterschiedlicher Wirtschaftsstrukturen}

Auf den direkten Zusammenhang zwischen Steuerkraft einerseits und Exportgewerbe bzw. Tuchhandel andererseits verweisen die Zahlen für Landsberg/W. und Züllichau. Sie dokumentieren einmal mehr, daß am Ende des 18. Jahrhunderts außerhalb der großen Handelszentren Kapitalbildung in erster Linie durch die Verbindung von Fabrikation und Warenvertrieb möglich war. Denn obwohl Landsberg eine um etwa 700 Köpfe stärkere Bevölkerung hatte als Züllichau, brachte der Tuchmacherort einen höheren Anleihebetrag auf.

38 Reckling: Driesen (wie Anm. 22), S. 49. Das Geschäft fiel 1798 an die Nichte Treppmachers, die auch das ein ziemlich typischer Fall - mit dem Disponenten der Handlung namens Dietrich verheiratet war.

39 Siehe zu Frankfurt zuletzt Rolf Straubel: Frankfurt (Oder) und Potsdam am Ende des Alten Reiches. Studien zur städtischen Wirtschafts- und Sozialstruktur. Potsdam 1995. S. 53 f. (= Quellen zur Geschichte u. Kultur Brandenburg-Preußens, 2). 
Landsberg und Züllichau im Vergleich $(1813)^{41}$

\begin{tabular}{|l|r|r|}
\hline Ort & $\begin{array}{c}\text { Landsberg/ } \\
\text { Warthe }\end{array}$ & Züllichau \\
\hline Zivilbevölkerung & 6144 & 5402 \\
\hline Webstuhlzahl & 109 & 316 \\
\hline Webstuhldichte & 17,7 & 58,5 \\
\hline Akzisebetrag & 39192 & 21723 \\
\hline Akzisebetrag je Kopf & 6,4 & 4,0 \\
\hline Kontribution 1813 & 11750 & 14650 \\
\hline Steuer je Kopf & 1,9 & 2,7 \\
\hline ges. Zunftmeister & 501 & 569 \\
\hline Anteil Mstr. an d. Bevölk. & 8,2 & 10,5 \\
\hline Gesellen und Jungen & 475 & 550 \\
\hline Anteil Ges. an d. Bevölk. & 7,7 & 10,2 \\
\hline
\end{tabular}

Freilich geht aus den Daten auch hervor, daß aus der Konzentration des Textilgewerbes nicht automatisch auf einen höheren Wohlstand der städtischen Bevölkerung geschlossen werden kann. Häufig verhielt es sich sogar umgekehrt, gehörte die überwiegende Mehrzahl der Weber doch zu den einkommensschwachen Bürgern. Am Beispiel der NebenResidenz Potsdam, des nach Berlin wichtigsten Standortes des großgewerblichen Sektors in der Kurmark, ist das konkret nachgewiesen worden ${ }^{42}$. Das höhere Akziseaufkommen Landsbergs resultierte aus der günstigen verkehrsgeographischen Lage, aus der die dortigen Handwerker, genannt seien nur Brauer und Brenner sowie die Ackerbürger, Nutzen zogen. Daneben spielte aber auch das Wollgewerbe im gesamten 18. Jahrhundert noch eine größere Rolle, wenngleich es mit dem Züllichaus nicht konkurrieren konnte. So wird für 1709 die Zahl der Tuchmachermeister mit rund 100 angegeben. Ihre Fabrikate gingen per Achse nach Magdeburg, Leipzig und Naumburg/S. sowie nach Stettin und Danzig.

Zwischen 1710 und 1720 soll die jährliche Tuchausfuhr 3000 Stück betragen haben. Von Bedeutung für die städtische Wirtschaft waren ferner die dreimal im Jahr stattfindenden Wollmärkte. In Landsberg verkauft wurde Wolle aus Polen, Pommern und der Mark. Die Einkäufer kamen aus Züllichau, Grünberg, Glogau, Breslau und Görlitz. In den achtziger Jahren wurden durchschnittlich 28000 Zentner Wolle verkauft $\mathrm{t}^{43}$. Im vorangehenden Dezennium soll der Tuchhandel ebenfalls noch geblüht haben, kauften Landsberger »Commercianten« Tuche aus Hinterstädten wie Callies und Neuwedell und vertrieben

41 Die Zahlen basieren: Zivilbevölkerung (1802) und Akzisebetrag (1798) auf Krug: Nationalreichtum (wie Anm. 18), T. 2, S. 63 und 91/92; die Webstuhlzahlen auf Bratring: Beschreibung (wie Anm. 1), Bd. 3, S. 327 (Züllichau) und S. 147 (Landsberg) sowie die Steuern nach GStA, I, Rep. 151 I A, Nr. 2 663. Die Webstuhldichte bezieht sich auf je 1000 Einwohner, Akzise- und Steuerbetrag dagegen auf die einzelne Person. Für 1798 sind für Züllichau 357 Webstühle ausgewiesen; offenbar beruht die Differenz zwischen beiden Angaben auf einem Erhebungsfehler, da in den Quellen von einer Prospertität des Textilgewerbes die Rede ist und nicht von einem Einbruch!

42 Straubel: Frankfurt (wie Anm. 39) S. 36-43.

43 August Engelien, Friedrich Henning: Geschichte der Stadt Landsberg an der Warthe. 2 Teile. Landsberg 1857, T. 2, S. 162 f., 211. 
diese über die Konitzer Jahrmärkte nach Polen, über Königsberg nach Litauen. Nach der Anlage von Tuch»fabriquen« in Großpolen und der Einführung eines Importzolls für fremde Tuche in Rußland habe der Verkehr um 1782/84 jedoch gestockt ${ }^{44}$. Sicher besaß das Wollwarengeschäft auch um 1800 noch eine gewisse Bedeutung, ein weiterer Grund für die recht hohe Veranlagung von Landsberg. Wenn in Züllichau dennoch bei der Anleihe eine höherer Summe aufgebracht wurde, dann hing das mit der Existenz einer Handvoll begüterter Kaufleute und Meister-Verleger zusammen, die aus der Arbeit abhängiger »Fabricanten« und aus dem Tuchhandel großen Nutzen zogen.

D.h. im Falle dieser beiden Städte gibt es eine Kluft zwischen Akziseaufkommen und Kontributionsbeitrag, welche als Gradmesser unterschiedlicher Erscheinungen angesehen werden muß. Während die indirekte Steuer scheinbar ausgeglichene wirtschaftliche und soziale Verhältnisse widerspiegelt, läßt die direkte starke Differenzierungen hinsichtlich Einkommen und Vermögen vermuten. In den meisten kurmärkischen, magdeburgischen und halberstädtischen Kommunen gab es einen unmittelbaren Zusammenhang zwischen Akzise- und direktem Steueraufkommen. Allerdings hat der Vergleich zwischen Potsdam und Frankfurt gezeigt, daß von der Bevölkerungszahl nicht automatisch auf die Höhe des Akzisebetrages, von diesem nicht unmittelbar auf die Kontributionssumme geschlossen werden kann. In Analogie zu den genannten kurmärkischen Städten ist für die beiden neumärkischen ebenfalls zu vermuten, daß die Divergenz mit der unterschiedlichen Wirtschaftsstruktur zusammenhing. Standen sich dort eine Gewerbe- und eine Handelsstadt gegenüber, so hier offenbar eine kleinere Beamtenstadt mit Nahmarktfunktion (Landsberg) und ein in den überregionalen Handel eingebundenes Textilgewerbezentrum ${ }^{45}$. Daß Landsberg noch um 1800 zu den wohlhabenderen neumärkischen Städten gehörte, zeigen auch die Angaben über die Kämmereieinnahmen und der Immobilienwert laut Feuerversicherungskataster. Hier wie da lagen die Summen 1797 jeweils etwa doppelt so hoch wie in Züllichau (17 686, 646 745; 6091 u. 318390 Taler ${ }^{46}$.

$\mathrm{Zu}$ den vermögenderen Bürgern Züllichaus gehörten Müllers Erben (1 000 T.), Besitzer der 1786 gegründeten feinen Tuch»fabrique«. Im Jahr 1800 liefen in diesem Betrieb 24 Webstühle, sollen Waren im Wert von rund 80000 Talern hergestellt worden sein, von denen etwa die Hälfte nach Rußland, Hamburg und über die Messen in Leipzig und Braunschweig exportiert wurde ${ }^{47}$. Bereits zwei Jahre zuvor hatte Akziserat Chemnitz bei seiner Visite die Manufaktur gewürdigt: Die Müllersche Fabrique excellirt unter allen durch ihren Umfang, durch die Ordnung, die darinn herrscht, und durch die Güte und

44 GStA, II, Fabr.dep., Tit. XCV, Nr. 5, fol. 52 RS.

45 Es ist aber hervorzuheben, daß bei anderen Anleihen Landsberg höhere Beträge steuerte als Züllichau.

46 GStA, II, Neumark, Materien, Historische Tabellen, Nr. 12, vol. XXIII. Die Zahlen beziehen sich auf das Jahr 1797. Auch beim Servis lag Landsberg mit 4479 Talern vor Züllichau mit 3786 Talern.

47 Bratring: Beschreibung (wie Anm. 1), Bd. 3, S. 327 bzw. August Splittgerber: Geschichte der Stadt und des Kreises Züllichau. Züllichau 1927, S. 58 f. Die zuletzt genannte Arbeit ist aber für die hier untersuchte Problematik ohne große Relevanz, nicht zuletzt deshalb, weil der Vf. seine Angaben über die wirtschaftliche Entwicklung, die nur am Rande gestreift wird, der Arbeit von Bratring entnommen hat! 
Feinheit der Waaren, die sie liefert, am mehresten ${ }^{48}$. In jenem Jahr stellten die 255 Tuchmacher des Ortes insgesamt 9197 Stück Ware her, von denen zwei Drittel exportiert wurden. Der Wert aller in Züllichau gefertigten Stuhlwaren soll 357245 Taler betragen haben. Der Beamte konstatierte folglich eine Prosperität der »Fabriquen«, von der die ganze Stadt profitierte ${ }^{49}$.

Auch bei den übrigen 1813 erfaßten Steuerzahlern mit Beträgen ab 1000 Talern dürfte es sich vornehmlich um Tuchhändler und aufgestiegene Meister gehandelt haben. Ein Schönfärber (500 T.) steht für die Möglichkeiten zur Kapitalakkumulation, die sich dieser Berufsgruppe ebenso wie Tuchscherern und anderen Spezialisten in Textilgewerbezentren boten. Daß tatsächlich in Teilen der Kur- und Neumark sowie von Niederschlesien zahlreiche Tuchmacher durch den direkten Absatz ihrer sowie von Mitmeistern aufgekauften Fabrikaten versucht haben, die herkömmliche Form der Produktionsorganisation auf eine höhere Stufe zu stellen, erhellt aus einer Verfügung des Generaldirektoriums von 1791. Danach beschwerten sich renommierte Tuchhändler seit einiger Zeit darüber, daß aus den benachbarten Städten viele »Fabricanten« die Frankfurter Messen besuchen und ihre Tuche in kleinen Partien verkaufen würden. Um rasch zu Geld zu kommen, verschleuderten sie ihre Waren, was sich nachteilig auf das allgemeine Preisniveau auswirkte. Die großen Tuchhändler forderten deshalb, den einzelnen Meistern den Messebesuch zu untersagen. Ihr Antrag wurde vom Generaldirektorium, das zuvor Gutachten verschiedener Provinzialbehörden eingeholt hatte, verworfen. Die Behörde verwies auf das Generalprivileg der Tuchmacher, wonach jedem Zunftmitglied der Messebesuch freistehe, sofern er mindestens zwölf Stück eigener Fabrikate mit sich führe. In einem Zirkular an die Kammern vom 26.10.1791 wurde diese Vorschrift noch einmal in Erinnerung gerufen ${ }^{50}$.

Einige wenige Quellenbelege stützen die Behauptung über die innergewerbliche Differenzierung bei den Züllichauer Tuchmachern sowie über die exponierte Rolle einiger mit dem Wollgewerbe verbundener Berufsgruppen, die besonders gute Aufstiegschancen besaßen. Hierzu gehörten wie in Burg, Calbe, Salzwedel die Färber und Tuchscherer. Gleich ihren Gildegenossen in anderen neumärkischen und schlesischen Städten beschränkten sich die Züllichauer Tuchhändler nicht auf den Vertrieb der im Ort erzeugten Fabrikate, sondern erwarben solche auch in benachbarten Kommunen. Zudem zogen sie Nutzen aus der Grenzlage und kauften wohlfeile Tuche im polnischen Karge. Bereits in den frühen fünfziger Jahren schwelte deshalb ein Streit zwischen dem Züllichauer Tuchmachergewerk und den Tuchhändlern. Während die »Fabricanten« den kostengünstigen

48 GStA, II, Fabr.dep., Tit. XCV, Nr. 7, fol. 4 RSf. Damals liefen in ihr 23 Stühle, sollen 357 Arbeiter (inkl. Spinner) Waren für 50463 Taler hergestellt haben.

49 Lt. GStA, II, Neumark, Städte-Sachen, Züllichau, Nr. 3, soll es im Jahr 1754 in der Stadt 430 Tuchmachermeister gegeben haben und damit 44 weniger als 1732; die Zahl der Gesellen habe um 127 abgenommen. Von dem Niedergang Züllichaus profitierten die benachbarten Orte, so etwa das polnische Karge.

50 GStA, II, Gen.dep., Tit. XXXVIII, Nr. 31. Vgl. dazu auch die Bemerkungen von Fritz Schmidt: Die Entwicklung der Cottbuser Tuchindustrie. Cottbus 1928, S. 134. Danach war den Fabricanten bereits mit Kabinettsorder vom 22.4.1770 verboten worden, mit einzelnen Stücken Tuch zur Messe zu ziehen. 
Ankauf fremder Tuche mitverantwortlich für den Nahrungsverfall der Stadt machten und behaupteten, minderwertige Produkte aus dem Polnischen würden als Züllichauer deklariert und im Ausland vertrieben, erklärten die Kaufleute, sie seien zur Komplettierung ihres Sortimentes zu einem solchen Schritt gezwungen.

1754 wurden die wechselseitigen Klagen durch die neumärkische Kammer untersucht und dabei festgestellt, daß zwischen 1747 und 1753 insgesamt 2953 Stück Tuche aus Karge eingeführt worden seien ${ }^{51}$. Obwohl das nur eine geringe Quantität und deshalb kaum angetan war, dem Züllichauer Gewerk großen Schaden zuzufügen, schlug sich die Kammer dennoch auf die Seite der Meister und drang auf ein gänzliches Verbot oder zumindest auf eine Heraufsetzung des Einfuhrzolls. Selbst der Hinweis der Kaufleute, daß die polnischen Tuche hier appretiert und gefärbt worden seien, konnte die Behörde nicht zu einem Meinungsumschwung bewegen. Andererseits sprach sich letztere für die Beibehaltung der freien Getreideeinfuhr aus Polen aus, da die städtischen Professionisten aus diesem Handel Nutzen zögen. Sie gestand zugleich ein, daß in Karge die Lebenshaltungskosten ungleich geringer seien als hier.

1754 gab es in Züllichau 430 Tuchmachermeister und 74 Gesellen sowie 20 Tuchscherer mit acht Gesellen, das waren 44 Tuchmacher und 127 Gesellen weniger als 1732. Teils durch den Siebenjährigen Krieg bedingt, teils aber auch aufgrund der wachsenden Konkurrenz benachbarter polnischer, neumärkischer und schlesischer Orte ging im Verlaufe der folgenden Jahrzehnte die Zahl der Gewerksmeister drastisch zurück. Bereits 1765 wurden nur noch 396 Tuchmacher und 50 Gesellen gezählt, für 1791 werden 233 Woll»fabricanten« und 16 Tuchscherer genannt. 1797 waren es dann 255 Tuchmachermeister mit 199 Gesellen. Treffen diese Angaben zu, dann wäre das Gewerk zwischen 1732 und 1797 um die Hälfte geschrumpft. Ob die Webstuhlzahl in ähnlicher Weise zurückging wie die Meisterzahl, ist nicht bekannt. 1798 wurden insgesamt 357 gezählt ${ }^{52}$.

Die Zahlen über das Produktionsvolumen lassen es allerdings geraten erscheinen, nicht einfach von einem Niedergangsprozeß zu sprechen. So sollen jene $396 \mathrm{im}$ Jahr 1765 registrierten Meister 17224 Stein Wolle zu 6406 Tuchen verarbeitet haben. 1797 wurden von ungleich weniger Gewerksmitgliedern aber 9197 Stück Tuche hergestellt, wofür sie 26814 Stein Wolle (1798) benötigten ${ }^{53}$. Anscheinend ging in Züllichau in der zweiten Hälfte des 18. Jahrhunderts die Zahl der Meister im Zuge einer innergewerblichen Differenzierung um nahezu die Hälfte zurück, andererseits erhöhte sich jedoch die der Gesellen (1754 74, 1797: 199) sowie der Produktionsausstoß. Wie in anderen Textilgewerbezentren verdingten sich verarmte »Fabricanten« als Gesellen, verzichteten angehende Professionisten aufgrund der ungünstigen Aussichten darauf, das Meisterrecht zu gewinnen.

Eine Erklärung der vier großen Tuchhandlungen aus dem Jahre 1790 verweist in eben diese Richtung, gaben deren Inhaber doch an, insgesamt 40000 Taler als Vorschüsse

51 GStA, II, Neumark, Städte-Sachen, Züllichau, Nr. 3, unpaginiert.

52 Die Zahlen u. a. nach Bratring: Beschreibung (wie Ann. 1), T. 2, S. 326 f.

531765 nach: GStA, II, Neumark, Historische Tabellen, Nr. 1 b, die Zahlen für 1797/98 nach Nr. 12, vol. XXIII bzw. II, Fabr.dep., Tit. XCV, Nr. 7. 
ausgegeben haben, wobei auf die Harrersche Firma allein 16800 entfielen $^{54}$. An dem Verlagsgeschäft beteiligt waren aber auch etliche der insgesamt 14 Tuchscherer, bezifferte einer dieser seine Darlehen doch auf 9400 Taler. Einer Erhebung des Steuerrates zufolge soll ein Tuchscherer zusammen mit zwei Gesellen in der Lage gewesen sein, jährlich 1000 Stück Tuche zu appretieren. Triebe er neben seiner Profession noch Tuchhandel, könne er pro Jahr einen Reingewinn von 632 Talern erzielen. Ein Tuchscherer bezifferte damals seine Bezüge allein aus der Müllerschen Handlung auf 1800 Taler. Dennoch muß für das Züllichauer Wollgewerbe ein Einbruch konstatiert werden, der angesichts gesteigerter Auslandsnachfrage erst in den neunziger Jahren gestoppt werden konnte. Als Hauptgründe müssen die von einer Untersuchungskommission bereits vor dem Siebenjährigen Krieg benannten Faktoren angesehen werden: zunehmende Konkurrenz der Tuchmacher aus dem polnischen Karge, hohe Lebenshaltungskosten und Einschränkung des ehedem freien Getreide- und Salzhandels mit dem benachbarten Polen, was sich nachteilig für das ganze Züllichauer Handwerk ausgewirkt habe.

Eine gegenläufige Entwicklung vollzog sich zwischen 1750 und 1800 dagegen in Zielenzig, Callies, Cottbus, Drossen und Reppen, in Orten, die eventuell von der Stagnation in Züllichau profitierten. Denn in ihnen verzeichnete das Textilgewerbe z. T. erhebliche Zuwächse. Verarbeiteten 1765 in Callies 79 Tuchmachermeister und 18 Gesellen 1523 Stein Wolle zu 1349 Tuchen, gab es 1797 hier 160 Meister und 10 Gesellen, deren Produktionsquantum bei 5668 Stück lag. In Cottbus verdoppelte sich im gleichen Zeitraum die Zahl der Meister (von 107 auf 214), die der Gesellen wuchs um das Sieben- und der Produktionsausstoß um das Vierfache (von 2387 Stück Tuchen auf 9873$)^{55}$. In Drossen und Reppen stieg die Tuchfabrikation jeweils um etwa ein Drittel, wohingegen es in Zielenzig nahezu eine Verdoppelung gab (von 142 auf 261 Meister, von 4405 Tuchen auf 9 288) ${ }^{56}$. Vornehmlich aufgrund der Entwicklung in diesen Städten wuchs das neumärkische Textilgewerbe nach dem Siebenjährigen Krieg noch erheblich an. Die Zahl der Tuchmacher stieg von 1894 (1765) auf 2323 (1797), das Produktionsvolumen sogar von 32533 Tuchen auf 70925 an. Demgegenüber blieb die Fertigung von Wollzeugen zweitrangig (2 160 und 6753 Stück) ${ }^{57}$.

1789/90 lag ein großer Teil des Züllichauer Tuchhandels in der Hand von vier ortsansässigen Firmen ${ }^{58}$. In diesem Metier betätigten sich außerdem noch einige wohlhabende Gewerksmeister. Als damals der Tuchscherer Christian Ludwig Schmuncke eine Konzession zum Tuchgroßhandel beantragte, stieß sein Gesuch auf den heftigen Widerstand der etablierten Kaufleute. Der Bittsteller, der sich auf eine einschlägige Passage des Zunft-

54 Diese und die folgenden Angaben nach GStA, II, Neumark, Städte-Sachen, Züllichau, Nr. 18.

55 So auch die Zahlen bei Schmidt: Tuchindustrie (wie Anm. 50), S. 141, hier Angaben zu Tuchmachern und Produktion.

56 GStA, II, Neumark, Materien, Historische Tabellen, Nr. 1 b, und Nr. 12, vol. XXIII.

57 Dazu u. a. GStA, II, Neumark, Historische Tabellen, Nr. 1 b, fol. 1 f. (hier die Zahlen für 1765), Nr. 6 b, fol. 78 f., Nr. 12, vol. XXIII (Zahlen für 1797).

58 Die folgenden Angaben nach GStA, II, Neumark, Städte-Sachen, Züllichau, Privilegien, Nr. 18, unpaginiert. 
privilegs von 1735 berief, bezifferte sein Vermögen auf wenigstens 12000 Taler $^{59}$. Nach Erhalt der Konzession wollte Schmuncke Züllichauer Tuchmacher verlegen, ihre Rohwaren selbst appretieren und diese auf in- und ausländischen Messen vertreiben. Zur Unterstützung seines Antrages verwies er darauf, daß in Orten wie Luckenwalde, Grünberg und Reppen ebenfalls Tuchscherer mit Tuchen handelten. Obwohl der Magistrat - pikanterweise war einer der Bürgermeister mit einem der opponierenden Kaufleute verwandt - das Gesuch verwarf, erhielt Schmuncke nach langwierigen Verhandlungen die Konzession. Im Verlaufe der folgenden beiden Jahre will er nach eigener Angabe Tuche im Wert von mehr als 55000 Talern im Ausland abgesetzt haben. Sein dabei eingesetztes Eigenkapital soll 15000 Taler betragen haben. Zwar wurde die Konzession des Tuchscherers 1791 kurzzeitig eingezogen, nach dem Amtsantritt C.A. (von) Struensees erhielt er sie dann jedoch zurück.

Von Interesse ist noch ein von den kaufmännischen Opponenten damals vorgebrachter Einwand. Letztere behaupteten nämlich, viele schlesische und neumärkische Fabrikationsorte stünden deshalb gegenüber Züllichau zurück, weil der Tuchhandel dort nicht durch gelernte Kaufleute betrieben werde. Folglich muß der Warenvertrieb in jenen Nachbarstädten vornehmlich in den Händen von wohlhabenden Meistern gelegen haben. Andererseits verstanden sich »Fabricanten « durchaus auf die Einrichtung eines gewinnbringenden Tuchhandels, was von Zunftgenossen in Burg, Brandenburg, Salzwedel unter Beweis gestellt worden ist ${ }^{60}$. Mit ihrer Bemerkung suchten die Züllichauer Kaufleute v.a. das Eindringen eines unerwünschten Konkurrenten zu verhindern. Sie gaben nämlich an, Schmuncke sei ihrer Profession unkundig und schade daher durch ungerechtfertigte Preise dem Tuchhandel. Da sich Steuerrat und neumärkische Kammer von der Ausweitung der Konkurrenz im Tuchhandel Vorteile für die »Fabricanten« versprachen, votierten sie für eine Konzession.

Den Recherchen des Steuerrates zufolge kauften die vier Züllichauer Handlungen auch größere Tuchpartien in anderen neumärkischen und schlesischen Städten auf. Die Behörden gestanden den Kaufleuten außerdem zu, für einen vermehrten Debit am Ort erzeugter Waren beigetragen zu haben. Allerdings sei dieses Wachstum nicht von Vorteil für die zahlreichen armen Gewerksmeister gewesen, sondern bewirkte in erster Linie verbesserte Vermögensumstände der »Commercianten«. In einem Bericht heißt es sogar, die von den Kaufleuten verlegten »Fabricanten« gehörten zu den ärmsten der Stadt. 1791 sollen von den 233 Züllichauer Tuchmachern nur noch 56 ausschließlich für eigene Rechnung und weitere 24 zum Teil für sich, teils mit Beihilfe des Wollmagazins gearbeitet haben. Die Mehrzahl (153 od. 65,7\%) werde hingegen von den Kaufleuten verlegt. Diese Angaben sprechen für eine starke Differenzierung der Meister und einen ausgeprägten Verarmungsproze $\beta^{61}$.

59 GStA, II, Neumark, Städte-Sachen, Züllichau, Nr. 18.

60 Straubel: Kaufleute u. Manufakturunternehmer (wie Anm. 20), S. 270-277.

61 Diese Angaben finden sich in dem Bericht der Küstriner Kammer vom 15.11.1791: GStA, II, Neumark, Städte-Sachen, Züllichau, Privilegien, Nr. 18. 
Relativ bescheiden waren die Kontributionssummen, die die Städte Soldin (2 850 Taler), Drossen (2 100), Zielenzig (2 050) und Königsberg (3 750) im Herbst 1813 aufbrachten. Aber auch in ihnen gab es einzelne Kaufleute mit einem beträchtlichen Vermögen, so Dehms in Zielenzig (1 000 T.). Hinter Züllichau, Landsberg und Crossen, die zusammen ein Drittel des gesamten neumärkischen Steuerbeitrages aufbrachten, blieben die anderen Kommunen indes merklich zurück. Teilweise beachtliche Summen wurden daneben von den in den einzelnen Kreisen lebenden vermögenderen Gutsbesitzern, Pächtern und Domänenbeamten aufgebracht.

Während 1807 alle neumärkischen Städte (zs. 35) veranlagt wurden, steuerten 1813 nur noch neun. Einige der anderen waren offenbar aufgrund der früher erbrachten Leistungen sowie der wirtschaftlichen Stagnation nicht mehr in der Lage, nennenswerte Beiträge aufzubringen. Bei den dritten hatte es politisch-territoriale Veränderungen gegeben (so bei Cottbus, seit 1807 in sächsischem Besitz). Jene Verschiebung erhellt besonders aus der unterschiedlichen Einstufung von Küstrin und Züllichau. Während der Tuchmacherort 1807 nur einen durchschnittlichen Beitrag zahlte, entfiel auf ihn wenige Jahre später die weitaus größte Summe, was ursächlich mit seiner Wirtschaftsstruktur zusammenhing ${ }^{62}$. Die Landeshauptstadt erhob sich 1807 ebenfalls nicht über die anderen Kommunen, später wurde sie aufgrund der französischen Besetzung (bis 1814) nicht mehr erfaßt. Zwar gab es am Sitz der Provinzialbehörden einige mehr oder weniger vermögende Beamte, dafür existierte aber weder ein nennenswertes Exportgewerbe noch ein überregionaler Handel ${ }^{63}$. Diese beiden Grundsäulen der städtischen Wirtschaft waren auch im neumärkischen Königsberg nur schwach entfaltet, das sich 1807 hinsichtlich von Servisund Steuerbetrag durchaus mit Züllichau messen konnte. Sein prozentualer Anteil an der Anleihe von 1813 lag infolgedessen nur geringfügig über dem früheren. Damit hob sich Königsberg nunmehr jedoch von dem Tuchmacherort ab. Der Blick auf Landsberg einerseits und Driesen sowie Crossen andererseits läßt ebenfalls Verschiebungen erkennen. Wenngleich der bevölkerungsreichste neumärkische Ort 1813 immerhin den zweithöchsten Steuerbeitrag aufbrachte, war sein Abstand gegenüber den anderen beiden Städten doch merklich geringer geworden. Deren stärkere Belastung hing in erster Linie mit einer begrenzten Prosperität des örtlichen Handels zusammen, denn weder Driesen noch Crossen verfügten über ein potentes Tuchgewerbe.

Ähnlich wie in Pommern sollten die »vornehmen« Handlungen der wichtigeren neumärkischen Städte Mitte 1813 den auf die Provinz ausgeschriebenen Beitrag von 42 800 Talern für die Ausrüstung der Landwehr vorfinanzieren. Die Verteilung der Summe zeigt die finanzielle Leistungskraft der Kaufleute der einzelnen Orte, wie sie sich in den Augen der Behörden darstellte. Unangefochten an der Spitze stand Landsberg mit einem

62 Die Zahlen für 1807 nach GStA, I, Rep. 151 I A, Nr. 2661.

63 Die gewerblichen Strukturen sind aus der neumärkischen Fabriquen-Tabelle für 1802 ablesbar: GStA, II, Fabr.dep., Tit. XCV, Nr. 1, fol. 3 f. In Küstrin liefen gerade knapp 50 Webstühle, gab es keinen großgewerblichen Betrieb. Ähnlich waren die Verhältnisse in Königsberg (ca. 36 Stühle). Mit etwa 100 Webstühlen hatte das Landsberger Textilgewerbe zwar ein recht ansehnliches Volumen, mit dem von Cottbus, Zielenzig, Züllichau konnte es jedoch nicht konkurrieren. 
Beitrag von 12000 Talern (od. 28\%), gefolgt von Züllichau mit 6800 (od. 16\%) und Driesen 6000 (od. 14\%). Dahinter rangierten Bernstein und Callies mit je 5000 Talern (od. 12\%). Die jüdischen Kaufleute in den Kleinstädten Soldin, Lippehne, Königsberg und Berlinchen sollten zusammen 8000 Taler (od. 19\%) aufbringen ${ }^{64}$. Also auch bei dieser Umlage wurden in erster Linie die größeren und überregionalen Handelsplätze (Landsberg, Driesen) sowie die Textilgewerbezentren herangezogen. Denn nur in diesen gab es finanzkräftige Kaufleute, welche die Zwangsanleihe finanzieren sollten.

64 GStA, I, Rep. 151 I A, Nr. 2 660. Diese Umlage unterschied sich folglich von der wenige Monate später vorgenommenen, was sich v.a. bei der Besteuerung von Landsberg und Züllichau zeigt. Hauptursache hierfür war jene Vorfinanzierung. Da die Textilfabricanten ihr Kapital für die Aufrechterhaltung der Produktion benötigten, sollten in erster Linie die Kolonialwarenhändler die geforderten Gelder vorstrecken. 



\title{
Inschriften in der Neumark
}

\author{
VON JOACHIM ZDRENKA
}

\section{Definition}

Die Behauptung, dass die Inschriften historische Quellen ersten Ranges sind, gilt nicht nur für eine an anderen Quellen arme Zeit wie die griechische und römische Antike, deren Inschriften seit dem 19. Jahrhundert in umfangreichen Corpora ediert werden, sondern auch ebenso für das Mittelalter und die frühe Neuzeit. Für diese beiden Epochen bieten die auf einst vermeintlich dauerhaften Materialien wie Stein, Holz, Metall, Textilien, Leder und Glas angebrachten Inschriften eine wesentliche Ergänzung der handschriftlichen und gedruckten Überlieferung. Ihre Mehrzahl zeichnet sich durch einen hohen Grad an Öffentlichkeit aus, der Konzeption und Ausführung der Texte bestimmt hat. Dies gilt vor allem für Inschriften auf Grabdenkmälern, Bauinschriften an öffentlichen Gebäuden, Inschriften an Bürgerhäusern, Stiftungsinschriften auf kirchlichen Ausstattungsgegenständen sowie Beischriften zu bildlichen Darstellungen. Somit haben die Inschriften zu allen Zeiten eine wichtige Rolle im Leben der Menschen gespielt und werden sie auch weiterhin spielen. Vor allem halten sie die Erinnerung an Verstorbene wach, erklären und deuten bildliche Darstellungen, weisen den Weg, nennen die Entstehungszeit von Bauwerken und ihrer Ausstattung, und sie bewahren die Namen von Stiftern, Künstlern und Eigentümern. Auf dieser Weise sind sie vielfach eng mit dem Ereignis, das sie überliefern, verbunden. Denn ein Grabdenkmal wird in der Regel direkt nach dem Tod eines Menschen hergestellt, ein Kunstwerk wird im Zuge seiner Entstehung signiert, Glockeninschriften werden beim Guss der Glocke angebracht. Inschriften vermitteln also - anders als rückschauend aufgezeichnete Chroniken - ein unmittelbares und authentisches Bild historischer Geschehnisse. Oft stehen sie in enger inhaltlicher Beziehung zu ihrem Inschriftenträger, und häufig bestimmt erst dieser die eigentliche Aussage der Inschrift wie z. B. bei den in der Ich-Form von sich selbst erzählenden Glocken und Geschützen (durch das Feuer bin ich geflossen).

Nicht nur für die Antike bieten die Inschriften eine wesentliche Ergänzung zu der geschriebenen und gedruckten urkundlichen und chronikalischen Überlieferung. Viele Personen des Mittelalters und der frühen Neuzeit sind uns nur deshalb bekannt, weil sich ihr Grabdenkmal mit einer im günstigsten Fall ausführlichen biographischen Inschrift erhalten hat. Eine große Zahl von Kunstwerken kann man nur aufgrund der auf ihnen angebrachten Jahreszahlen und Künstlersignaturen exakt datieren oder einem bestimmten Meister zuweisen. Die Mehrzahl der Inschriften unterscheidet sich von der auf Pergament oder Papier geschriebenen und gedruckten Überlieferung nicht nur durch ihre größere Dauerhaftigkeit, sondern auch durch einen ganz anderen Grad an Öffentlichkeit. Alle Inschriften, die noch an Ort und Stelle vorhanden sind, die nicht beschädigt oder abgetra- 
gen wurden, sind jedem des Lesens kundigen Betrachter in ihrer originalen Form und am ursprünglichen Ort präsent. Diese spezifische Art der Öffentlichkeit hat auch ihre Gestalt vielfältig bestimmt. Zum einen sind sie oft in besonders schönen Buchstaben ausgeführt, wie die zahlreichen schmückenden Hausinschriften auf den Fachwerkhäusern zeigen. Zum anderen boten sie ihrem Auftraggeber die Möglichkeit, sich nach außen in der Form zu präsentieren, wie er sich oder seine Familie darstellen wollte. So haben viele Hausbesitzer im 16. Jahrhundert ihre protestantische Gesinnung dokumentiert, indem sie Gottes Wort bleibt ewig (Jesaja 40,8), einen der Kernsprüche der Reformation, als Inschrift an ihre Häuser setzen ließen ${ }^{1}$.

Der Grad der Öffentlichkeit reicht jedoch allein nicht aus, um einen Text als Inschrift zu definieren. Viele Inschriften wie etwa diejenigen auf Glocken oder die Sterbevermerke auf Bleitafeln, die den Verstorbenen mit ins Grab gegeben wurden, entfalteten keine öffentliche Wirkung, sondern existierten vielmehr im Verborgenen. Deshalb hat die deutsche Epigraphik die pragmatische Definition des Begriffs ,Inschriften“ von Rudolf M. Kloss übernommen. Seiner Meinung nach sind Inschriften Beschriftungen verschiedener Materialien - wie Stein, Holz, Metall, Leder, Stoff, Email, Glas, Mosaik usw. -, die von Kräften und mit Methoden hergestellt sind, die nicht dem Schreibschul- und Kanzleibetrieb angehören ${ }^{2}$. Diese Definition hat sich in der Praxis bewährt und musste nur in einigen Details ergänzt bzw. korrigiert werden. Im Widerspruch zu Kloss werden nämlich mittlerweile auch solche Texte als Inschriften betrachtet, die mit der Feder auf Pergament oder Papier ausgeführt wurden, durch ihren Öffentlichkeitsgrad aber den Charakter von Inschriften innehaben, etwa Texte auf Pergamentblättern, die auf Holztafeln aufgezogen und in Kirchen und Rathäusern ausgehängt wurden. Hinsichtlich ihrer Funktion und Wirkungsabsicht weisen sie gegenüber Inschriften keine Unterschiede auf. Eine Ausnahme bilden hingegen Schriftzüge auf Münzen, Petschaften und Waffen, die generell nicht als Inschriften betrachtet und deshalb der Numismatik, Siegel- und Waffenkunde überlassen werden. Jedoch sind hier kleine Ausnahmen zulässig; z.B. wird die Inschrift auf einem Richtschwert aufgenommen, weil sie unmittelbar mit der örtlichen Geschichte verbunden ist.

Das bloße Abschreiben eines Inschriftentextes würde in vielen Fällen bedeuten, die Aussagekraft der Quelle zu reduzieren. Ziel einer Inschriftensammlung ist daher neben der originalgetreuen Abschrift des Textes die Bewahrung des Überlieferungszusammenhangs. Nur so kann gewährleistet werden, dass das gesamte Bedeutungsspektrum erfasst wird. Entsprechend der Unterschiedlichkeit von Inschriften und Inschriftenträgern sind hierfür differenzierte Fragestellungen notwendig, die selbst für einschlägig Vorgebildete oft nur schwer zu überblicken sind ${ }^{3}$.

$1 \quad$ Sabine Wehking/Christine Wulf: Leitfaden für die Arbeit mit historischen Inschriften. Bausteine zur Heimat- und Regionalgeschichte. Melle 1997, S. 9 f. (= Veröffentlichungen des Niedersächsischen Heimatbundes, Bd. 10).

2 Rudolf M. Kloos: Einführung in die Epigraphik des Mittelalters und der frühen Neuzeit. Darmstadt 1980, S. 2.

3 Wehking/Wulf (wie Anm. 1), S. 10 f. 


\section{Edition}

Bei der Inschriftenedition steht die genaue Wiedergabe der zum Teil schwer zu entziffernden Texte unter Auflösung ihrer Abkürzungen im Mittelpunkt. Damit verbunden ist die Dokumentation der kunstgeschichtlich oftmals bedeutenden Inschriftenträger. Knappe Beschreibungen der Objekte, die auch die darauf angebrachten Wappen und Verzierungen einbeziehen, ergänzen die reine Textedition und vermitteln den zum Verständnis notwendigen Zusammenhang zwischen Text, Inschriftenträger und Standort. Lateinische und andere fremdsprachige Texte werden zusätzlich übersetzt. Auf den Editionstext folgt ein Kommentar, in dem gegebenenfalls bestimmte die Inschrift oder den Inschriftenträger betreffende Fragen erörtert werden. Die Einleitung erschließt dem Benutzer die Inschriften aus unterschiedlichen Perspektiven: Sie bindet die epigraphischen Denkmäler in die Geschichte des betreffenden Gebietes ein, charakterisiert den Bestand und gibt eine zusammenfassende Auswertung der Beobachtungen zur Inschriften-Paläographie. Ausgewählte Abbildungen ergänzen Edition und Kommentar. Zahlreiche Register, die nach verschiedenen Gesichtspunkten angelegt sind, machen das edierte Material für historische, kunstgeschichtliche, philologische und volkskundliche Forschungen verfügbar. Mit der Edition wird reichhaltiges Material vor allem für verschiedene historische Fragestellungen bereitgestellt. Die einzelnen Texte, insbesondere die Grabinschriften, überliefern eine große Zahl von personengeschichtlichen und für die Regional- und Landesgeschichte wertvollen Daten. Außerdem spiegeln die inschriftlichen Quellen vielfältige geistesgeschichtliche und Frömmigkeitsprozesse wieder. Dazu gehören beispielsweise die im Laufe der Jahrhunderte sich wandelnden Vorstellungen von Tod, Jenseits und Auferstehung, die in den Grabinschriften ihren Niederschlag gefunden haben, die Entwicklung der Volkssprache zu einem - neben dem Latein - auch für repräsentative Zwecke geeigneten Ausdrucksmittel sowie die Verdrängung mundartlicher durch schriftliche Formen. Zahlreiche Inschriften erlauben aufgrund ihres Inhalts eine Datierung ihrer Träger, auf denen sie angebracht sind. Eine wesentliche Aufgabe der Edition ist ferner die Bereitstellung von Material für eine Inschriften-Paläographie des Mittelalters und der frühen Neuzeit, mit deren Hilfe Datierungen anhand der Buchstabenformen vorgenommen werden können. Damit lassen sich in vielen Fällen zeitlich ansonsten nicht näher bestimmbare Stücke einordnen und die von der Kunstgeschichte vorgenommenen stilkritischen Datierungen der Objekte erhärten oder ergänzen ${ }^{4}$.

Ein Musterbogen für die Bearbeitung und Auswertung einer Inschrift sollte folgende Rubriken enthalten: 1. Laufende Nummer, 2. Ort und genauer Standort, 3. Gegenstand, 4. Datierung, 5. Maße, 6. Material, gegenwärtiger Zustand, 7. Schriftart, 8. Schriftbesonderheiten, 9. Beschreibung des Inschriftenträgers und 10. Transkription der Inschrift 5 . Beim Punkt 3 (Gegenstand) ist der Inschriftenträger präzise zu bezeichnen. So können auf ein Grabdenkmal angesichts der bestehenden Formenvielfalt sehr verschiedene Begriffe

4 Vgl. die Werbebroschüre des Dr. Ludwig Reichert Verlages aus Wiesbaden „Die Deutschen Inschriften“, Wiesbaden 1998, S. 4.

5 Wehking/Wulf (wie Anm. 1), S. 31. 
wie Grabplatte, Grabstelle, Grabstein, Sarkophag, Epitaph, Totenschild und Mordwange bzw. Sühnestein angewandt werden. Auch bei Goldschmiedearbeiten und Einrichtungsgegenständen aus dem kirchlichen Bereich ist in besonderem Maße zu differenzieren ${ }^{6}$. Die Datierung der Inschrift und des Inschriftenträgers (Punkt 4) ist außerordentlich wichtig. In den meisten Fällen gibt schon der Text selbst eine präzise Auskunft über das Jahr der Anfertigung. Allerdings muss hier behutsam vorgegangen werden, denn in manchen Fällen ist zu unterscheiden zwischen Datierungen, die sich auf die Herstellung eines Inschriftenträgers beziehen, und solchen, die auf einen anderen Vorgang verweisen, etwa auf die Stiftung von Kirchengerät oder bei einem Grabdenkmal auf den Tod eines Menschen. In den zuletzt genannten Fällen kann zwischen der Entstehung des Inschriftenträgers und dem in der Inschrift genannten Datum ein größerer Zeitraum liegen. Ebenso kann eine alte Inschrift eines zerstörten oder beschädigten Inschriftenträgers auf ein als Ersatz angefertigtes Stück aus jüngerer Zeit übernommen worden sein. Dieser Fall kommt oft auf Kelchen und Abendmahlskannen vor, wenn beispielsweise ein mittelalterlicher Knauf (lat. nodus) mit seiner Inschrift an einem neuzeitlichen Kelch angebracht wurde. Große Schwierigkeiten bereitet die Datierung von Grabdenkmälern für Ehepaare, deren Sterbedaten weit auseinander liegen. Auch besteht die Möglichkeit, dass eine Person trotz der entsprechenden Ankündigung einer Grabschrift an einen anderen Ort bestattet wurde. Selbst mit Fälschungen ist zu rechnen, wenn etwa Inschriften angefertigt wurden, um vermeintliche Rechtsansprüche zu dokumentieren. Noch mehr Probleme bereiten nicht datierte Inschriften. In diesem Fall bieten aber die Texte neben den Schrift- und Buchstabenformen viele Indizien zu ihrer Datierung. Zur Eingrenzung des Entstehungszeitraumes helfen auch nichtinschriftliche Kriterien, etwa kunsthistorische Indizien oder archivalische Nachrichten zur Anfertigung des Inschriftenträgers oder der Entstehung seines baulichen Umfeldes. Archivalische Quellen können besonders bei personenbezogenen Inschriften wichtige Anhaltspunkte zur Entstehungszeit bieten. Durch die Ermittlung der Lebensdaten einer genannten Person kann der Entstehungszeitraum der Inschrift mit Terminus post und ante quem ermittelt werden. Bei Goldschmiedearbeiten und Gegenständen aus Zinn helfen die Meistermarken oder städtische Beschauzeichen ${ }^{7}$. Auch die Schriftbesonderheiten sind zu vermerken, ob etwa eine Inschrift erhaben ausgehauen oder eingehauen ist, Buchstaben spiegelverkehrt oder auf dem Kopf stehend ausgeführt oder ob Versalien verwendet wurden. Ebenso ist zu verzeichnen, wenn sie einzelne durch ihre Größe oder Gestaltung hervorgehobene Buchstaben am Wortanfang und im Wortinneren aufweist. In diesem Fall besteht die Möglichkeit, dass im Text verschlüsselte römische Zahlzeichen verborgen sind. Generell sind auffällige Merkmale an den Buchstaben zu notieren. In die-

$6 \quad$ Zum Beispiel: Reallexikon zur deutschen Kunstgeschichte. Stuttgart 1937 ff.; - Lexikon der Kunst. Neubearbeitung, Bd. 1-7. Leipzig 1996; - Lexikon des Mittelalters, Bd. 1-10. München 1980-1999, oder die Arbeit von Adolf Reinle: Die Ausstattung deutscher Kirchen im Mittelalter. Darmstadt 1988.

7 Marc Rosenberg: Goldschmiede Merkzeichen, Bd. 1-4. Frankfurt a.M. 1922-1928 und Erwin Hintze: Die deutschen Zinngießer und ihre Marken, Bd. 1-7. Aalen 1964 (Ndr. der Ausgabe 1921-1923) sowie mehrere Regionalarbeiten. 
sem Zusammenhang empfiehlt es sich, die jetzt üblichen Begriffe zu verwenden, wie sie in dem Band „Deutsche Inschriften. Terminologie zur Schriftbeschreibung“ (Wiesbaden 1998) ausführlich erläutert werden.

Die letzte Etappe bei der Bearbeitung einer Inschrift ist ihre Transkription mit allen Fehlern, Kürzungszeichen, Ligaturen, hochgestellten und überschriebenen Buchstaben, Interpunktionszeichen und Worttrennern. Zur Lesung der Inschriften von abgetretenen oder verwitterten Steinen hilft unter anderem eine gute Schwarzweißfotographie, die später auch für den Abbildungsteil verwendet werden kann. Eine gute Aufnahme erleichtert nicht nur die Arbeit am Schreibtisch, sondern erspart auch umständliche Beschreibungen vor Ort und ermöglicht eine Überprüfung der am Objekt vorgenommenen Lesungen.

Die Erschließung von kopialer Inschriftenüberlieferung aus Chroniken, älteren Sammlungen, Archivmaterialien oder Leichenpredigten hängt von der Art der jeweiligen Vorlage ab. Die Vielfalt der Kopien bringt viele Probleme mit sich, die von Fall zu Fall gelöst werden müssen. Der Weg einer kopialen Inschrift von der Transkription zur Edition stellt einen Sonderfall dar, der hier nicht näher erörtert werden kann.

\section{Verwaltungsgeschichte der brandenburgischen Gebiete östlich der Oder}

Die deutschen Inschriften sollen grundsätzlich nach geographisch-historischen Regionen bearbeitet werden. Da diese unterschiedlich groß sind und verschiedenen politischen $\mathrm{Zu}-$ gehörigkeiten und administrative Veränderungen unterlegen sind, ist es nicht immer möglich, diese Regel anzuwenden. Deswegen hat man für das deutsche Inschriftenwerk beschlossen, sich an die aktuellen Verwaltungskreise zu halten. Schwieriger wird es mit den historischen Ländern oder Regionen, die jetzt durch eine Staatsgrenze geteilt sind wie die frühere preußische Provinz Brandenburg. Wie sieht es mit den Inschriften auf ihren Gebieten östlich der Oder aus?

Die Region östlich der Oder und nördlich der unteren Warthe wurde etwa 1250 von den Markgrafen von Brandenburg erworben und seit 1266 als terra trans Oderam, 1290 als nova terra ultra Oderam und seit etwa 1400 als nova marca bezeichnet. 1402 wurde die Neumark von König Sigismund als Markgraf von Brandenburg an den Deutschen Orden verkauft. Sie bestand damals aus den Ämtern Königsberg (Chojna), Landsberg an der Warthe (Gorzów Wielkopolski), Soldin (Myslibórz), Friedeberg (Strzelce Krajeńskie), Driesen (Drezdenko), Zantoch (Santok), Arnswalde (Choszczno), Kallies (Kalisz Pomorski), Dramburg (Drawsko Pomorskie), Schivelbein (Świdwin) und Alt Draheim (Stare Drawsko). Während des 13jährigen Krieges zwischen dem Deutschen Orden und Polen erwarb Markgraf Friedrich II. von Brandenburg 1455 dieses Gebiet zurück. In Folge des Glogauer Erbfolgestreites 1482 gewann sein Nachfolger Albrecht Achilles große Teile des Herzogtums Crossen südlich der Warthe und gliederte sie in die Neumark ein: Crossen an der Oder (Krossno Odrzańskie), Züllichau (Sulechów), Sommerfeld (Lubsko) und Bobersberg (Bobrowice). 
Nach der Teilung der Mark Brandenburg bildete die Neumark von 1535 bis 1571 unter Markgraf Johann I. von Küstrin ein eigenes Herrschaftsgebiet. Sein 220 Quadratmeilen umfassendes Territorium bestand aus der eigentlichen Neumark nördlich der Warte mit den Kreisen (Ämtern) Soldin, Königsberg, Landsberg an der Warthe, Friedeberg, Arnswalde, Dramburg, Schivelbein, aus dem 30 Quadratmeilen großen Herzogtum Crossen mit Crossen und Sternberg (Torzym) sowie aus den 1455 brandenburgisch gewordenen Herrschaften Cottbus und Peitz in der Niederlausitz. 1696 wurde das Land Schwiebus (Świebodzin) zugekauft. Im Jahre 1815 kam die Neumark ohne Dramburg, Schivelbein und einen Teil Alt Draheims (Stare Drawsko), die an Pommern fielen, zur neugeschaffenen preußischen Provinz Brandenburg. Die Kreise Meseritz (Międzyrzecz) und Schwerin an der Warthe (Skwierzyna) (seit 1887) wurden dem Regierungsbezirk Posen der Provinz Posen zugeordnet ${ }^{8}$.

Nach dem Versailler Vertrag vom 28. Juni 1919 fielen aus dem Regierungsbezirk Posen Teile der Grenzkreise Birnbaum (Międzychód), Bomst (Babimost), Fraustadt (Wschowa), Krotoschin (Krotoszyn), Lissa (Leszno), Meseritz und Rawitsch (Rawicz) an Polen. Die Reste der Kreise Krotoschin, Lissa und Rawitsch wurden in den niederschlesischen Regierungsbezirk Breslau (Wrocław) eingegliedert, die übrigen Restkreise kamen an die neu gegründete Provinz Grenzmark Posen-Westpreußen: Schwerin an der Warthe (zusammengelegt mit Resten des Kreises Birnbaum), Bomst, Fraustadt und Meseritz. Zur Provinz gehörten weiterhin die Landkreise Deutsch Krone (Wałcz), Flatow (Złotów), der Netzekreis (powiat notecki) - der aus den Restkreisen Filehne (Wieleń), Czarnikau (Czarnkowo) und Kolmar (Chodzież) gebildet wurde -, Schlochau (Człuchów) und Schneidemühl-Stadt (Piła-Miasto). Im Zuge der Auflösung der Provinz Grenzmark Posen-Westpreußen und ihrer Eingliederung als Regierungsbezirk in die Provinz Pommern am 1. Oktober 1938 fiel der Kreis Fraustadt an die Provinz Schlesien, der aufgelöste Kreis Bomst mit Südteil an den Kreis Grünberg (Zielona Góra)/Provinz Schlesien, der Nordteil an den Kreis Züllichau-Schwiebus (Sulechów-Świebodzin)/Provinz Brandenburg. Die Landkreise Meseritz und Schwerin kamen ebenfalls an Brandenburg (Regierungsbezirk Frankfurt/Oder). Ende 1938 bestand der Regierungsbezirk Schneidemühl aus den Kreisen Arnswalde, Deutsch Krone, Dramburg, Flatow, Friedeberg in der Neumark, Netzekreis (mit Sitz in Schönlanke/Trzcianka), Neustettin (Szczecinek), Schlochau und Schneidemühl-Stadt ${ }^{9}$. Die Provinz Brandenburg östlich der Oder bestand dann bis 1945 aus dem Stadtkreis Landsberg an der Warthe (Gorzów Wielkopolski) und neun Landkreisen: Crossen an der Oder, Königsberg in der Neumark (Chojna), Landsberg an der Warthe, Meseritz, Oststernberg (Wschodni Torzym) mit Sitz in Zielenzig (Sulęcin), Schwerin

8 Grundriß zur deutschen Verwaltungsgeschichte 1815-1945. Reihe A: Preußen, Bd. 2, Teil I: Provinz (Großherzogtum) Posen, Teil II: Provinz Grenzmark Posen-Westpreußen. Marburg 1975, S. $22-26$.

9 Ebd., S. 111-113. 
an der Warthe, Soldin, Weststernberg (Zachodni Torzym) mit Sitz in Reppen (Rzepin) und Züllichau-Schwiebus ${ }^{10}$.

Seit 1945 gehört dieses Gebiet der Republik Polen an. Dessen verschiedene Verwaltungsteilungen in den nachfolgenden Jahrzehnten haben für das Projekt „Erfassung und Edition von Inschriften im westlichen Teil Polens (ehemals deutsche Gebiete)“ keine Bedeutung und werden nicht weiter verfolgt. Nach dem aktuellen Verwaltungsstand liegt das zu bearbeitende Gebiet in drei Wojewodschaften: lubuskie, wielkopolskie und zachodniopomorskie. Kirchlich ist es drei Diözesen unterstellt: gorzowsko-zielonogórska, poznańska und szczecińska.

\section{Bearbeitungszustand}

Der wissenschaftliche Bearbeitungsstand der Kunstdenkmäler aus den besprochenen Gebieten resultiert aus den dortigen politischen und verwaltungsrechtlichen Verhältnissen. Leider hat man bisher den Inschriften keine große Aufmerksamkeit geschenkt. Sie wurden nicht flächendeckend wissenschaftlich bearbeitet und ediert. Insofern ist festzustellen, dass die Wissenschaft mit dem Verlust der einzelnen Inschriftenträger durch Umwelteinflüsse (Z.B. greift der saure Regen die Steine chemisch an, so dass die Oberfläche abbröckelt und damit die Inschriften beschädigt oder gar völlig zerstört werden.), durch verständnislose Bautätigkeiten, Kriege, Brände, Plünderungen, geringe Widerstandsfähigkeit des Materials (Holz, Textilien) und durch potenzielle Wiederverwertbarkeit (Stein, Marmor, Kupfer, Edelmetalle) den Inhalt der Inschriften für immer verloren hat. Angesichts der Tatsache, dass nicht alle Inschriftenträger dauerhaft für künftige Generationen geschützt und bewahrt werden können, muss man wenigstens den heutigen Zustand dokumentarisch festhalten, denn paradoxerweise muss nun der vergängliche Beschreibstoff Papier bewahren, was einst auf vermeintlich dauerhaften Materialien für ewige Zeiten angebracht worden ist.

Abgesehen von verschiedenen kleinen Arbeiten und Beiträgen, die nur eine Auswahl von Inschriften boten und nicht deren flächendeckende Bearbeitung verfolgten, fanden sie die meiste Aufmerksamkeit in den für die einzelnen preußischen Provinzen eingerichteten Reihen „Die Bau- und Kunstdenkmäler“. Ihre Aufgabe war es, die wertvollsten Bau- und Kunstdenkmäler aufzunehmen, kurz zu beschreiben und kunsthistorisch zu bewerten. Bei den Objekten mit Inschriften spielten diese nur eine Nebenrolle. Weil die Bearbeitungsrichtlinien nicht vorsahen, alle ihre Texte wiederzugeben, hing es immer von dem jeweiligen Bearbeiter ab, welche er abgeschrieben und veröffentlicht hat. Vor allem hat man versucht, den Text der ältesten und wertvollsten Inschriften zu publizieren. Jedoch mindern die Auswahl, die Fehlerquote beim Lesen und die mangelhafte paläographische Auswertung erheblich den Wert der hier veröffentlichen Inschriften. Da seit diesen Pub-

10 Amtliches Gemeindeverzeichnis für das Großdeutsche Reich auf Grund der Volkszählung 1939, 2. Auflage. Berlin 1944, S. 57-69. 
likationen viele Inschriftenträger inzwischen verlorengegangen sind, stellen die nur dort publizierten Texte den einzigen Nachweis dar. Leider konnte man die geplanten Reihen, die Ende des 19. Jahrhunderts angefangen wurden, bis zum Zweiten Weltkrieg nicht zum Abschluss bringen. Deshalb stehen der Wissenschaft nur einzelne Bände für Teilregionen ohne flächendeckende Erfassung des gesamten jeweiligen Untersuchungsgebietes zur Verfügung. Von 1907 bis 1941 wurden „Die Kunstdenkmäler der Provinz Brandenburg“ in jeweils einen Kreis beinhaltenden Teilen, die zu insgesamt sieben Bänden zusammengefasst werden sollten, vom Brandenburgischen Provinzialverband herausgegeben ${ }^{11}$, darunter Teil 6 des Bandes 5 „Kreis Sorau und Stadt Forst“"12, Teil 3 „Kreis Weststemberg“ und Teil 6 „Kreis Crossen“ ${ }^{“ 13}$ des Bandes 6 sowie der Teil 1 des 7 Bandes „Kreis Königsberg in der Neumark“14 1937 wurde noch der Band „Die Kunstdenkmäler des Stadt- und Landkreises Landsberg (Warthe)“"veröffentlicht. ${ }^{15}$

In der DDR wurden 1978-1987 die Bau- und Kunstdenkmäler nach den Bezirken Potsdam, Frankfurt an der Oder (mit den Landkreisen Angermünde, Eberswalde, Bernau, Bad Freienwalde, Strausberg, Seelow, Fürstenwalde, Beeskow, Eisenhüttenstadt und den Stadtkreisen Schwedt, Frankfurt/Oder, Eisenhüttenstadt) sowie der zweiteilige Band für die Hauptstadt Berlin neu bearbeitet ${ }^{16}$. Das jenseits der Oder gelegene Gebiet wurde aus politischen Gründen ausgelassen. Nach der Wiedervereinigung hat sich in dieser Hinsicht nichts geändert. Für die Denkmäler des wiedererstandenen Landes Brandenburg wurde die neue Serie „Denkmaltopographie Bundesrepublik Deutschland. Denkmale in Brandenburg" gegründet, die im Auftrag des Ministeriums für Wissenschaft, Forschung und Kultur des Landes Brandenburg vom Brandenburgischen Landesamt für Denkmalpflege herausgegeben wird. 1994-2000 wurden 6 Bände in 7 Teilen veröffentlicht ${ }^{17}$. Die Bear-

11 Bd. 1: Teil 1: Westprignitz. Berlin 1909; - Teil 2: Ostprignitz. Berlin 1907; - Teil 3: Kreis Ruppin. Berlin 1914; - Bd. 2, Teil 1: Westhavelland. Berlin 1912; - Teil 3: Stadt und Dom Brandenburg. Berlin 1912; - Bd. 3: Teil 1: Kreis Prenzlau. Berlin 1921; - Teil 2: Kreis Templin. Berlin 1937 ;Teil 3: Kreis Angermünde. Berlin 1934; - Bd. 4: Teil 1: Kreis Teltow. Berlin 1941; - Bd. 5: Teil 1: Kreis Luckau. Berlin 1917; - Teil 3: Stadt- und Landkreis Cottbus, Berlin 1938; - Bd. 6: Teil 1: Kreis Lebus. Berlin 1909; - Teil 2: Stadt Frankfurt a. O., Berlin 1912.

12 Berlin 1939.

13 Berlin 1913, 1921.

14 Berlin 1928.

15 Bearbeitet von Kurt Reißmann. Berlin 1937.

16 Die Bau- und Kunstdenkmale in der DDR. Bezirk Potsdam, hrsg. vom Institut für Denkmalpflege der DDR, bearb. von der Abteilung Bestandsforschung Horst Drescher, Joachim Fait, Ingrid Kompa, Helmut Spielmann, Redaktion von Heinrich Trost. Berlin 1978; - Die Bau- und Kunstdenkmale in der DDR. Bezirk Frankfurt/Oder, hrsg. vom Institut für Denkmalpflege der DDR, bearb. von der Abteilung Forschung Heinrich Trost, Beate Becker, Horst Büttner, Ilse Schröder u. Christa Stepansky. Berlin 1980; - Die Bau- und Kunstdenkmale in der DDR. Hauptstadt Berlin, Bd. 1-2, hrsg. vom Institut für Denkmalpflege der DDR, Redaktion von Heinrich Trost. Berlin 1983-1987.

17 Bd. 1: Stadt Brandenburg an der Havel:Teil 1, bearb. von Marcus Cante. Worms am Rhein 1994; Teil 2, bearb. von Marie-Luise Buchinger. 1995; - Bd. 2: Teil 1: Cottbus, bearb. von Irmgard Ackermann, Marcus Cante, Antje Mues. 2001; - Bd. 5: Teil 1: Stadt Eberswalde, bearb. von Ilona Rohowski. 1997; - Bd. 7: Teil 1: Stadt Herzberg/Elster und die Ämter Falkenberg/Uebigau, Herzberg, Schlieben und Schönewalde, bearb. von Sybille Grämlich u. Irmelin Küttner. 1998; - Bd. 13: 
beitung des ehemaligen brandenburgischen Territoriums östlich der Oder ist nicht vorgesehen, obwohl sie für die deutsch-polnische Zusammenarbeit ein dankbares Feld wäre.

Ein Teil des Materials für das im Titel erwähnte Vorhaben ist in „Bau- und Kunstdenkmälern“" anderer preußischer Provinzen publiziert. In dem für den Regierungsbezirk Posen vorgesehenen „,Verzeichnis der Kunstdenkmäler der Provinz Posen III. Die Landkreise des Regierungsbezirks Posen“ veröffentlichte Julius Kohte „Die Kunstdenkmäler der Landkreise des Regierungsbezirks Posen“"18, darunter in der zweiten Lieferung die Kunstdenkmäler der Kreise Birnbaum, Schwerin, Meseritz, Bombst, Schmiegel (Smigiel) und Kosten (Koscian). Für die südliche Nachbargebiete wurde von Hans Lutsch in den Jahren 1886-1903 die Reihe für die Provinz Schlesien veröffentlicht, die ein mit der brandenburgischen Reihe vergleichbares Material beinhaltet ${ }^{19}$. In der Reihe der „Bauund Kunstdenkmäler der Provinz Pommern, Teil III: Die Baudenkmäler des Regierungsbezirks Köslin“ ist für das neumärkische Inschriftenvorhaben der Band III, Teil 1 „Die Kreise Schivelbein, Dramburg, Neustettin, Bublitz (Bobolice) und Rummelsburg (Miastko)“"von Bedeutung ${ }^{20}$.

\section{Projekt „Inschriften der Neumark“}

Um die Inschriften als Quelle für historische, kunsthistorische, sprachliche, schriftkundliche, sozialtopographische und weitere Untersuchungen zu einem bestimmten historischen

Teil 1: Stadt Neuruppin, bearb. von Matthias Metzler. 1996; - Bd. 17: Teil 1: Stadt Jüterborg mit Kloster Zinna und Gemeinde Niedergörsdorf, bearb. von Marie-Luise Buchinger u. Marcus Cante. 2000.

18 Bd. 1: Verzeichnis der Kunstdenkmäler der Provinz Posen. Politische, Kulturgeschichtliche und Kunstgeschichtliche Entwicklung des Landes v. Julius Kohte und Adolf Warschauer. Berlin 1898; - Bd. 2: Die Kunstdenkmäler des Stadtkreises Posen, bearb. v. Julius Kohte. Berlin 1896; - Bd. 3: Lief. 1: Posen-Ost u. -West, Obornik, Samter, Grätz und Neutomischel. Berlin 1895; - Lief. 2. Berlin 1895; Lief. 3: Die Kreise Fraustadt, Lissa, Rawitsch und Gostyn; - Lief. 4: Die Kreise Schrimm, Schroda, Wreschen, Jarotschin, Pleschken, Krotoschin, Koschmin, Adelnau, Ostrowo, Schildberg und Kempen. Berlin 1896; - Bd. 4: Die Kunstdenkmäler des Regierungsbezirks Bromberg, bearb. v. Julius Kohte. Berlin 1897.

19 Bd. 1: Die Stadt Breslau. Breslau 1886; - Bd. 2: Die Kunstdenkmäler des Regierungs-Bezirks Breslau. Breslau 1887-1889; - Bd. 3: Die Kunstdenkmäler des Regierungs-Bezirks Liegnitz. Breslau 1891; - Bd. 4: Die Kunstdenkmäler des Regierungs-Bezirks Oppeln. Verzeichnis der Kunstdenkmäler der Provinz Schlesien. Breslau 1894; - Bd. 5: Register zum Verzeichnissen der Kunstdenkmäler Schlesiens. Breslau 1903; - Bd. 6: Denkmäler-Karten. Breslau 1902. - In der Zwischenkriegszeit und nach dem Zweiten Weltkrieg wurden noch veröffentlicht: Die Kunstdenkmäler der Provinz Niederschlesien. Bd. 1: Die Stadt Breslau in drei Teilen. Breslau 1930-1934; - Josef von Golitschek u. Hans Lutsch: Schlesiens Kunstdenkmäler, Bildband. Gütersloh 1985; - Hans Lutsch: Schlesiens Kunstdenkmäler, Textband. Gütersloh 1986.; - Die Bau- und Kunstdenkmäler Schlesiens, Bd. 1: Regierungsbezirk Breslau, Teil 1: des Kreises Namslau. Breslau 1939; - Bd. 2: Regierungsbezirk Oppeln, Teil 2: des Stadtkreises Oppeln. Breslau 1939; - Bau- und Kunstdenkmäler des Deutschen Ostens, Reihe C Schlesien, Bd. 1: Die Bau- und Kunstdenkmäler des Landkreises Breslau, v. Kurt Degen. Frankfurt am Main 1965. Stettin 1934. 
Territorium bzw. Landschaft in einem abgegrenzten Zeitraum ausschöpfen zu können, muss die Bearbeitung des gesamten Gebietes erfolgen. Erst dann lassen sich sichere Rückschlüsse ziehen und wissenschaftliche Auswertungen des vollständigen Spektrums vornehmen. Zurzeit laufen zwei solche Vorhaben, zum einen für die historische brandenburgische Neumark und zum anderen für die polnische Wojewodschaft Lubuskie.

Das polnische Projekt, das von der Epigraphischen Arbeitstätte (Pracownia Epigraficzna) an der Universität in Zielona Góra durchgeführt wird, sieht vor, die Inschriften aus der gesamten heutigen Wojewodschaft Lubuskie zu erfassen, zu bearbeiten und zu edieren. Es ist geplant, in zwölf Bänden das Material zu veröffentlichen. Für den letzten Band sind Ergänzungen und Korrekturen zu den vorhergehenden Bänden beabsichtigt. Bis jetzt sind sechs Bände in der Reihe Corpus Inscriptionum Poloniae als Band X mit dem Untertitel Inskrypcje województwa lubuskiego pod redakcją Joachima Zdrenki [Inschriften der Wojewodschaft Lubuskie unter der Redaktion von Joachim Zdrenka] erschienen:

Heft 1: Inskrypcj e powiatu międzyrzeckiego do 1815 roku [Inschriften des Kreises Meseritz bis 1815], bearb. von Marceli Tureczek, Toruń 2006 mit 339 Katalognummern;

Heft 2: Powiat Wschowski [Kreis Fraustadt], bearb. von Adam Górski und Paweł Karp, Toruń 2006 mit 371 Katalognummern;

Heft 3: Powiat Świebodziński [Kreis Schwiebus], bearb. von Marceli Tureczek, Toruń 2009 mit 222 Katalognummern.

Heft 4: Powiat Nowosolski: Lapidaria w Bytomiu Odrzańskim i Koźuchowie [Kreis Neusalz: Alte Friedhöfe in Beuthen/Oder und Freystadt], bearb. von Adam Górski, Toruń 2009 mit 249 Katalognummern;

Heft 5: Powiat Zielonogórski [Kreis Grünberg], bearb. von Adam Górski und Pawel Karp, Torun 2012 mit 269 Katalognummern;

Heft 6: Powiat Nowosolski [Kreis Neusalz], bearb. von Adam Górski, Toruń 2013 mit 152 Katalognummern.

In diesen Bänden sind somit 1602 Objekte als Inschriftenträger erfasst, bearbeitet und veröffentlicht.

Das zweite Projekt Die Inschriften der Neumark, das auf Grund der Initiative und unter Leitung des Brandenburgischen Landeshauptarchivs in Potsdam betrieben wird und dessen Materialien von Joachim Zdrenka bearbeitet werden, will die Inschriften aus der historischen brandenburgischen Neumark erfassen, bearbeiten und veröffentlichen. Der erste Band dieser Reihe, die Inschriften des Stadt- und Landkreises Landsberg, liegt druckreif vor und soll im Jahr 2015 herausgegeben werden. Weitere Kreise, nämlich Crossen a. O., Weststemberg (Słubice) und Königsberg/Nm., sind in Angriff genommen worden. Für dieses Projekt werden grundsätzlich entsprechend dem Zeitraum, aus dem die zu untersuchenden Inschriften stammen, die frühneuzeitlichen Grenzen des eigenständigen Territoriums Neumark zugrunde gelegt, genauer gesagt, seine letzten Verwaltungsgrenzen von 1815. Damit werden elf Landkreise und ein Stadtkreis in der Untersuchung 
berücksichtigt: Landsberg a. d. Warthe (Stadt- und Landkreis), Soldin, Königsberg, Friedeberg, Arnswalde, Crossen, Sternberg, Schwiebus, Dramburg, Schivelbein und Alt-Draheim.

Die meisten Objekte stammen aus der Zeit nach der Reformation: ca. 10\% aus dem 16. Jahrhundert, ca. $40 \%$ aus dem 17. Jahrhundert und ca. $48 \%$ aus dem 18. Jahrhundert. Inschriften aus dem 15. Jh. werden nicht mehr als $2 \%$ ausmachen. Objekte aus dem 13./14. Jahrhundert sind nicht mehr vorhanden, wobei allerdings manche Inschriftentexte aus dieser Zeit durch die Fachliteratur überliefert sind. Voruntersuchungen haben ergeben, dass im Vergleich mit den in den „Bau- und Kunstdenkmälern der Provinz Brandenburg“ erwähnten Objekten ca. $70 \%$ der Inschriftenträger bis heute erhalten geblieben sind. Der Zustand der Objekte - vor allen derjenigen, die im Freien stehen - hat sich wesentlich verschlechtert, so dass manche Texte nur noch der Fachliteratur zu entnehmen sind. Die meisten Inschriftenobjekte (ca. 90\%) finden sich in Kirchen (Glocken, Kelche, Monstranzen, Leuchter, Oblatendosen, Kreuze, Bildnisse, Taufen, Grabplatten, Epitaphien, Glasmalereien). Insgesamt werden in den elf Landkreisen und dem einem Stadtkreis ca. 1900 Inschriftenträger zu untersuchen sein. Ca. 60\% der aufzunehmenden Inschriftentexte gehören zur Kategorie der einfachen Texte wie z.B. Kreuztituli, Datierungen, Besitzvermerke, die keines ausführlichen Kommentares benötigen. Die größte Arbeit werden die Inschriften auf den Grabplatten, Epitaphien, Glocken und Sargbildnisse beanspruchen.

Im Rahmen guter nachbarschaftlicher Zusammenarbeit werden die in dem deutschen und dem polnischen Projekt sich überschneidenden Kreise in beiden Publikationsreihen der jeweiligen Sprache publiziert werden. 



\title{
Das Haus Brandenburg Geschichte und Wirksamkeit
}

\author{
Von WeRner VogeL
}

Die Brandenburgische Landesversammlung faßte bereits 1990 den Beschluß, ein „Haus Brandenburg“" als Zentrum für die Geschichte und Kultur der ganzen Mark Brandenburg zu errichten und bekräftigte ihn 1995. Der Schwerpunkt der Darstellung sollte allerdings auf den einstmals brandenburgischen, östlich von Oder und Neiße gelegenen Gebieten der Neumark, der östlichen Niederlausitz und der Grenzmark Posen-Westpreußen liegen. Vorgesehen hierfür war das Schloß Rosengarten in Frankfurt an der Oder, das dank seiner Lage eine vorzügliche Verbindung nach Polen geboten hätte. Während sich dieser Plan zerschlug, gelang es der Landsmannschaft Berlin-Mark Brandenburg mit einer großartigen Spendenaktion, die sie unter ihrem Vorsitzenden Werner Bader und ihrem Geschäftsführer Günter Kirbach durchgeführt hatte, die Mittel zum Erwerb eines Grundstücks in Fürstenwalde, Parkallee 14, aufzubringen. Nachdem Magistrat und Stadtverordnetenversammlung von Fürstenwalde den Plan gebilligt hatten, wurde 1998/99 ein Fertighaus von der Firma Okal errichtet. An der Grundsteinlegung im Dezember 1998 nahmen Werner Bader, der Kurator der Stiftung Brandenburg Dieter Lonchant und der stellvertretende Bürgermeister von Fürstenwalde Ullrich Hengst teil. Bereits am 25. Juli 1999 wurde unter Teilnahme von Irmgard Büchsenschütz, der Witwe des bekannten märkischen Lieddichters Gustav Büchsenschütz, des Fürstenwalder Bürgermeisters Manfred Reim, des CDU-Oppositionsführers Jörg Schönbohm und des Ministerpräsidenten des Landes Brandenburg, Dr. Manfred Stolpe, als Festredner die Einweihung von „Haus Brandenburg“ gefeiert, an der auch polnische Vertreter, u.a. Zbigniew Czarnuch aus Vietz (Witnica), teilnahmen. Die Stadt Fürstenwalde besaß bereits enge partnerschaftliche Beziehungen zur neumärkischen Stadt Arnswalde (Choszno). Später wurde mit finanzieller Unterstützung des Ministerpräsidenten über dem Eingang das alte brandenburgische Wappen angebracht. Die Einweihung des Hauses Brandenburg fand nicht nur in der Fürstenwalder Presse Beachtung, sondern auch in Berliner und Potsdamer Tageszeitungen.

„Haus Brandenburg“ sollte als Begegnungsstätte der Heimatvertriebenen dienen, aber auch für versöhnliche Gespräche mit den heute polnischen Bewohnern des historischen Ostbrandenburg bereitstehen. Deshalb wurde im Obergeschoß eine Reihe von Zimmern eingerichtet, die für die Übernachtung von Besuchern des Hauses und seiner Bibliothek zur Verfügung stehen sollten. Als erste Großaktion war die Bibliothek der Stiftung Brandenburg aus Stuttgart nach Fürstenwalde überführt und hier vom Bibliothekar Christian Assenbaum eingerichtet worden. Zukünftig fanden die Sitzungen der Landsmannschaft und der Stiftung Brandenburg im Haus Brandenburg statt. 
Mit Schenkungsvertrag vom 19. Februar 2002 übereignete die Landsmannschaft ihr Haus an die von ihr 1974 im Land Baden-Württemberg gegründete Stiftung Brandenburg. Diese hatte die ihr zufließenden Mittel bisher zur Förderung von Publikationen zur Geschichte Ostbrandenburgs, für die Errichtung von Denkmälern in Polen etc. verwandt. Ihr Kurator Dietrich Handt (2000-2005) wirkte nunmehr gleichzeitig als Geschäftsführer des Hauses Brandenburg, da für die eigentlich erforderliche Anstellung eines Vollzeitbeschäftigten keine Mittel zur Verfügung standen. Er wurde unterstützt vom Stiftungsrat, dessen Vorsitzende Ingeborg Schellhaas ist. Zu seinen Mitgliedern gehörte seinerzeit auch ein Vertreter der Regierung des Landes Baden-Württemberg, Ministerialdirektor Dr. Freudenberg von der Vertretung des Landes in Berlin. Das Land Baden-Württemberg beteiligte sich noch bis Ende 2006 an der Finanzierung der Stiftung, zog sich dann aber aus dem Stiftungsrat zurück. Im Dezember 2007 erhielt die Stiftung Brandenburg von der Stiftungsbehörde des Landes Brandenburg die Genehmigung für eine neue Satzung und die Sitzverlegung von Stuttgart nach Fürstenwalde. Dem Antrag auf Entlassung aus dem Stiftungsverband des Landes Baden-Württemberg wurde vom dortigen Innenministerium entsprochen, so daß die Stiftung seit Anfang 2008 der Aufsicht des Landes Brandenburg untersteht.

Kurator und Stiftungsrat beschlossen 2002 die Beibehaltung des Namens „Haus Brandenburg“, obwohl dessen Aufgaben gemäß § 96 Bundesvertriebenengesetz neu definiert wurden. Künftig sollte es zum wissenschaftlich orientierten Dokumentationszentrum für Geschichte, Kultur und Wirtschaft Ostbrandenburgs ausgebaut werden, freilich unter Berücksichtigung gesamtbrandenburgischer Aspekte. Unter diesem Gesichtspunkt wurden die ursprünglichen Besucherzimmer allmählich für die Bedürfnisse der Bibliothek hergerichtet und genutzt. Deren Bestand wurde speziell auf die Neumark bzw. Ostbrandenburg ausgerichtet. Unter der Leitung von Maria Petzoldt wuchs die Bibliothek auf zur Zeit rund 15.000 Bände an. Die Benutzung durch deutsche und ausländische Besucher ist recht intensiv. Da aufgrund der begrenzten Finanzmittel nur eine Halbtagskraft möglich ist, wird auf vorherige Anmeldung von Benutzern Wert gelegt. Die Bibliothekarin bereitet dann allerdings auch die Materialauswahl für das genannte Thema vor. Außerdem werden von ihr sehr viele telefonische und schriftliche Anfragen bearbeitet. Während die Bibliotheksbenutzung im Allgemeinen kostenlos ist, müssen die Anfertigung von Reproduktionen (Kopien) und zeitaufwendige Recherchen bezahlt werden. Von der Zufriedenheit mit den erbrachten Leistungen zeugen weltweite Dankesbriefe und Spenden.

Eine geschätzte Besonderheit des Hauses ist das Archiv. Neben den Nachlässen ehemaliger Ostbrandenburger enthält es eine umfangreiche Dokumentensammlung, die nach geographischen Gesichtspunkten geordnet und in Stehordnern eingestellt ist. Sie enthält Urkunden, Drucksachen, Zeitungsausschnitte und handschriftliche Erinnerungen. Zum Bestand gehören weiterhin eine umfangreiche Kartensammlung, Dias, Videos und Tondokumente sowie eine Bildersammlung, die Fotografien, Gemälde und Grafiken enthält. Sie bilden ein vorzügliches Anschauungsmaterial des historischen Ostbrandenburg. Rund 10000 alte Ansichtspostkarten wurden von Matlen Horn in einer Datenbank erfaßt und sind damit vor Ort leicht zugänglich. Ziel des Hauses Brandenburg ist die Erfassung des Materials aller ostbrandenburgischen Heimatkreise und Heimatstuben. Besonders 
hervorgehoben seien unter den bereits im Haus befindlichen Beständen die der Kreise Soldin, Ost- und Weststernberg, deren Erschließung und datenbankmäßige Erfassung durch Werkverträge mit Gerhard Weiduschat zügig erledigt werden konnten, so daß dadurch die Benutzung ermöglicht und erleichtert ist. Mit anderen Heimatkreisen bestehen bereits intensive Gespräche und Vereinbarungen. Damit wird für die wissenschaftliche Erforschung der Neumark eine wertvolle Grundlage geschaffen, die die umfangreichen Bestände im Brandenburgischen Landeshauptarchiv in Potsdam und dem Geheimen Staatsarchiv Preußischer Kulturbesitz in Berlin-Dahlem ergänzt.

Das historische Ostbrandenburg umfaßt räumlich etwa ein Drittel der ehemaligen preußischen Provinz vor 1945 mit rund 750.000 deutschen Einwohnern. Seine historische Erforschung und Darstellung ist daher für die Kenntnis der einstigen Provinz Brandenburg, aber auch der gesamtdeutschen Geschichte überaus wichtig, zumal die Kenntnis dieses Raumes sehr beschränkt und ihre Weitergabe durch das Aussterben der Erlebnisgeneration gefährdet ist. Um die wünschenswerte Veranschaulichung dieser Landschaft zu ermöglichen, wurde im Erdgeschoß ein Museum eingerichtet, das von der Angestellten Matlen Horn betreut wird, die als Ganztagskraft zugleich für die ganztägige Zugänglichkeit des Hauses sorgt und als Sekretärin des Kurators tätig ist. Im Museum werden Trachten, Modellbauten (z.B. von Schloß und Festung Küstrin, der Kirche in Drossen und des Stadtzentrums von Unruhstadt), Porzellane mit neumärkischen Bildern, Gegenstände des täglichen Gebrauchs, Plastiken und Bilder sowie Landkarten und Publikationen zur Geschichte Ostbrandenburgs gezeigt. Eine Besonderheit bildet darunter die Dr. Günther Meinhardt-Stiftung mit brandenburgischen Münzen, Medaillen und Papiergeld, letzteres aus der Notzeit nach dem I. Weltkrieg. Das Papiergeld ist sehr individuell und bildhaft gestaltet. Da die räumlichen Möglichkeiten für die Präsentation des musealen Materials begrenzt sind, ein großer Teil davon daher magaziniert ist, werden die Einzelstücke öfter im Jahr gewechselt, so daß Besucher neben vertrauten Objekten auch immer wieder Neuigkeiten zu sehen bekommen. Dies gilt besonders für Ausstellungen anläßlich der Langen Nacht der Museen in Fürstenwalde und Umgebung, die alljährlich im Frühjahr angeboten wird. Außerdem werden auch selbständige Ausstellungen geboten wie etwa eine mit Originalwerken des Malers Ernst Henseler, der 1852 in Wepritz bei Landsberg an der Warthe geboren wurde, später in Berlin als Professor lehrte und für seine Tätigkeit an der Technischen Hochschule zum Ehrensenator ernannt wurde, in Berlin 1940 verstarb. Seine Bilder zeigen bedeutende Persönlichkeiten des 19. und 20. Jahrhunderts (u.a. Hoffmann von Fallersleben, den Schöpfer des Deutschlandliedes, und Reichskanzler Otto von Bismarck), speziell aber die Landschaft und die Menschen des Warthebruches.

Die gesamte Arbeit der Stiftung Brandenburg wird seit Ende 2002 unterstützt durch einen Wissenschaftlichen Beirat, der ein- bis zweimal jährlich tagt. Seine wertvolle Beratung wird leider in der Umsetzung der wissenschaftlichen Planungen und Absichten durch die unzulängliche finanzielle Situation der Stiftung beeinträchtigt. Zu deren Verbesserung, aber auch zur ideellen Förderung des Hauses Brandenburg hat sich ebenfalls 2002 ein „Haus Brandenburg-Freundeskreis“ gebildet, dessen Vorsitzender der in München lebende Hasso Freiherr von Senden ist, während seine Stellvertreter Lothar Hoffrichter für Fürstenwalde und Karlheinz Lau für Berlin sind. Freundeskreis und Stiftung 
bemühen sich, die Kenntnis vom historischen Ostbrandenburg zu verbreiten und zu vertiefen durch Führungen und Vortragsveranstaltungen, darunter bis jetzt (September 2013) 34 Märkische Gesprächsforen, im Haus Brandenburg. Sie sind stets gut besucht und enden jeweils mit anregender Diskussion. Über das politische Verhältnis zwischen Brandenburg und Polen berichteten u. a. Dr. Manfred Stolpe, der Minister des Inneren des Landes Brandenburg Jörg Schönbohm und die Ministerin für Wissenschaft, Forschung und Kultur Prof. Dr. Johanna Wanka. Über Probleme der gegenseitigen deutsch-polnischen Verständigung und Versöhnung sprachen Dr. Hanna Nogossek, die Leiterin des Deutschen Kulturforums östliches Europa in Potsdam, und Direktor Dr. Krzysztof Wojciechowski vom Collegium Polonicum an der Europa-Universität Viadrina in Slubice (Vorstadt Frankfurt/Oder). Fachorientierte Vorträge zur ostbrandenburgischen Geschichte bzw. zu regionalen neumärkischen Aspekten hielten etwa Dr. Reinhard Schmook über das Land Lebus beiderseits der Oder, Ingeborg Schellhaas über die neumärkische Stadtentwicklung am Beispiel von Lippehne (Lipiany), Prof. Dr. Edward Rymar zur Entstehung von Lebus und Dr. Martin A. Völker über den Künstler Ernst Henseler. Gemeinsam mit dem Brandenburgischen Landeshauptarchiv wurde 2003 eine Tagung für ostbrandenburgische Heimatforscher und Ortschronisten veranstaltet. 2003/2004 fand eine zweiteilige gemeinsame Tagung mit dem Brandenburgischen Landeshauptarchiv und der Historischen Kommission zu Berlin über Adel, Städte und Landesherren in der mittelalterlichen und frühneuzeitlichen Neumark statt.

Als besonderes, aber wesentliches Arbeitsgebiet von Stiftung und Haus Brandenburg ist das Bemühen um Verständigung und Versöhnung mit unseren polnischen Nachbarn zu nennen. Immer stärker wird dabei deutlich der Wunsch der polnischen Einwohner, über die deutsche Vergangenheit ihrer neuen Heimat informiert zu werden. Die neumärkischen Mitglieder des Stiftungsrates leisten hierbei eine wichtige vermittelnde Arbeit mit regelmäßigen Besuchen in ihrer alten Heimat. Sowohl zu den polnischen Bewohnern wie zu den öffentlichen Stellen und Einrichtungen in Polen werden dabei wertvolle Verbindungen geknüpft. Seitens der Kuratoren der Stiftung Brandenburg wurden darüber hinaus entsprechende Beziehungen zu Landsberg an der Warthe (Gorzów Wielkopolski), Zielenzig (Sulecin), Züllichau (Sulechow) und Grünberg (Zielona Góra) aufgebaut. So konnte von Grünberg eine Ausstellung über die Auswanderung Ostbrandenburger seit 1837 nach Australien übernommen werden, in Zielenzig und Züllichau konnten auf Tagungen deutsche Teilnehmer über das Haus Brandenburg und über historische Ereignisse sprechen. Mit der Wojewodschaftsbibliothek in Landsberg finden gemeinsame Vortragsveranstaltungen unter dem Titel „Die Neumark - eine vergessene Provinz“ statt, in denen abwechselnd deutsche und polnische Wissenschaftler zu Fachfragen sprechen. Alle diese Veranstaltungen werden stets sehr gut von einem interessierten Publikum besucht. Die Beiträge werden in einer zweisprachigen Schriftenreihe publiziert. Mit den Behörden in Zielenzig und Züllichau konnte darüber hinaus die weitere Zusammenarbeit vereinbart werden. Gruppen der Deutsch-Polnischen Gesellschaft und polnische Schülergruppen wurden über das Haus informiert und durch das Museum geführt.

In diesem weitgefaßten Rahmen bemüht sich das Haus Brandenburg, gleichsam als Dokumentationszentrum für Kultur und Geschichte der Neumark bzw. Ostbrandenburgs 
zu wirken, dessen rund 800jährige deutsche Vergangenheit zu überliefern, wissenschaftlich zu erforschen und verständlich darzubieten. Wichtig ist uns dabei, das Zusammenwirken mit Polen auszubauen und zur Versöhnung mit der heute dort lebenden polnischen Bevölkerung beizutragen. Von polnischer Seite wird stets das Interesse an einer Zusammenarbeit mit Stiftung und Haus Brandenburg nachdrücklich betont. Damit leisten Stiftung und Haus Brandenburg einen wertvollen Beitrag zur Aussöhnung zwischen beiden Völkern. Dies geschieht sowohl im Geiste unserer Satzung als auch im Sinne der brandenburgischen Landesregierung und fördert zugleich den Tourismus. 


Die Neumark, die vom 13. Jahrhundert bis 1945 brandenburgischen Gebiete östlich der Oder und beiderseits der unteren Warthe, liefert ein überzeugendes Beispiel für „Regionalismus und ständisches Wesen als einem Grundthema europäischer Geschichte" (Dietrich Gerhard). Keine andere brandenburgische Landschaft hat ihre Eigenart so scharf und so deutlich ausgeprägt. Ihre beiden bestimmenden Stände, Adel und Städte, haben sich allen zentralisierenden Bestrebungen ihres Landesherrn zum Trotz mit ihrem Geschick und Selbstbehauptungswillen und aus der jahrhundertelangen Erfahrung relativer Eigenständigkeit die Eigentümlichkeiten ihrer abgegrenzten überschaubaren Lebenswelt in gleichbleibenden oder gewandelten Formen zu behaupten vermocht. Die einzelnen Untersuchungen des Bandes kreisen darum, wie die Neumärker in freundschaftlichem Zusammenwirken ebenso wie in kontroverser Auseinandersetzung mit der kurfürstlichen Zentrale in Berlin, zwischen den Polen von „Resistenz“ und „Anpassung“ (Frank Göse) ihr eigenes Land und sein Verfassungsgefüge in politischer, sozialer und wirtschaftlicher Hinsicht auszugestalten trachteten. 